

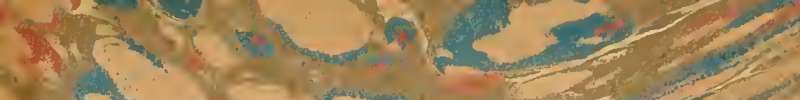

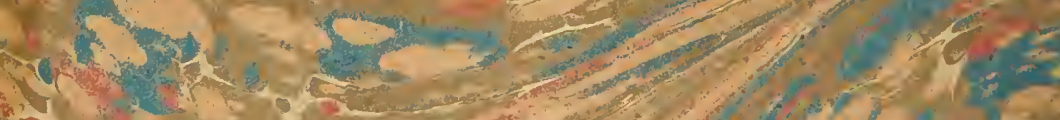

P.

\section{C.}

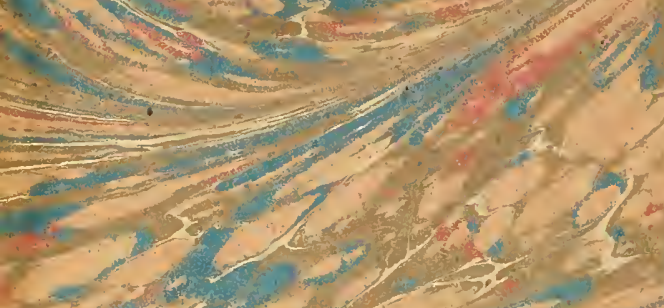

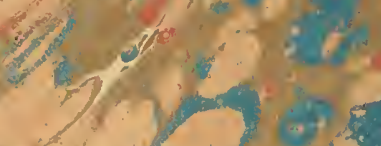

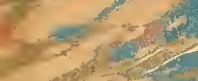

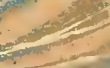

tate

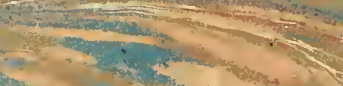

3
+5

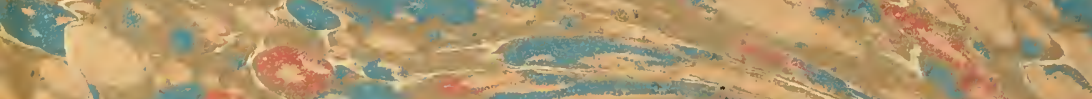

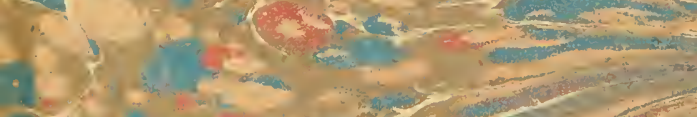

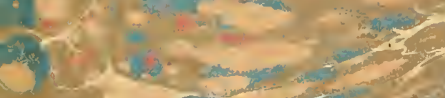

(1)

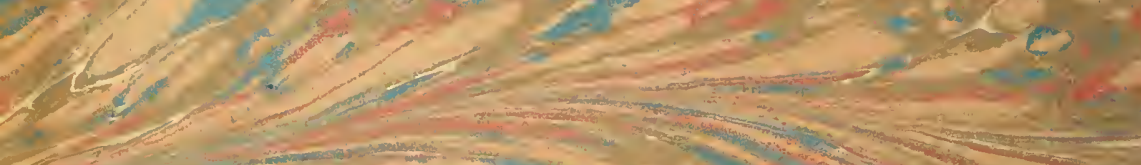

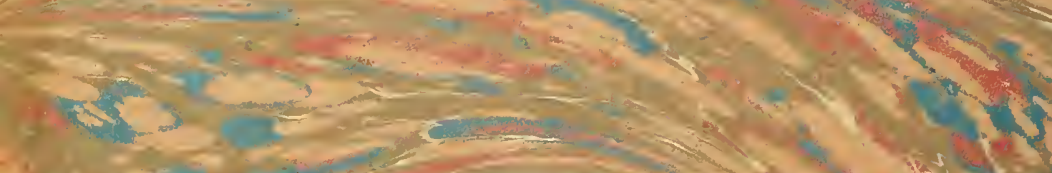
(1)

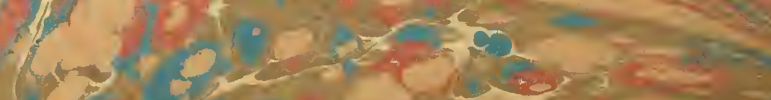

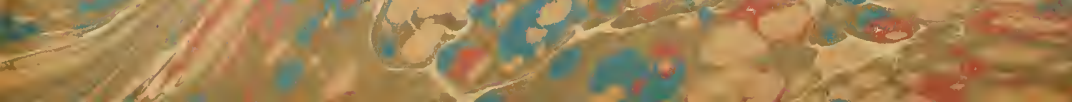




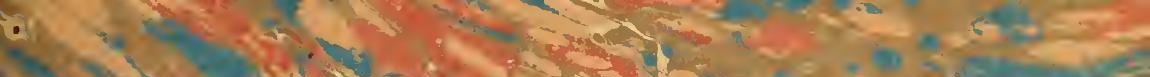

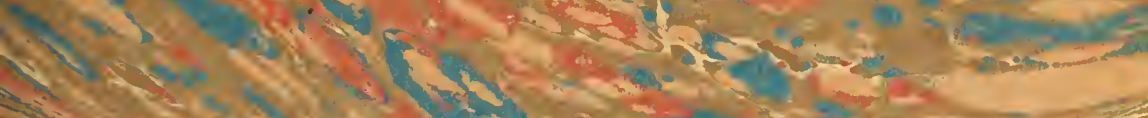

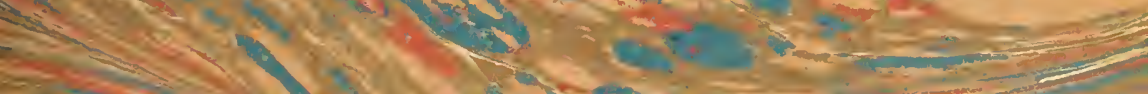

$3+2$

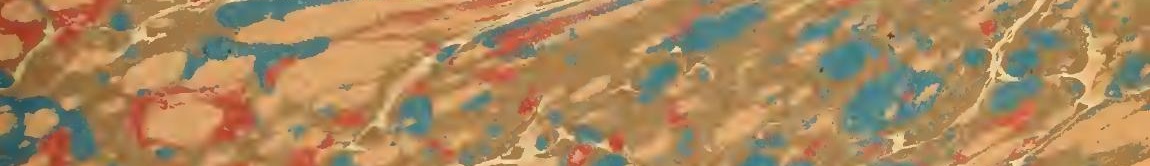
3.20 $-2,0020$

\section{3}

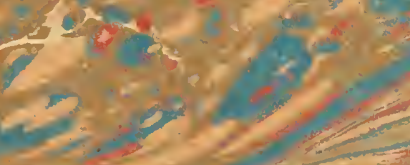

\section{$=\frac{1}{20}$}

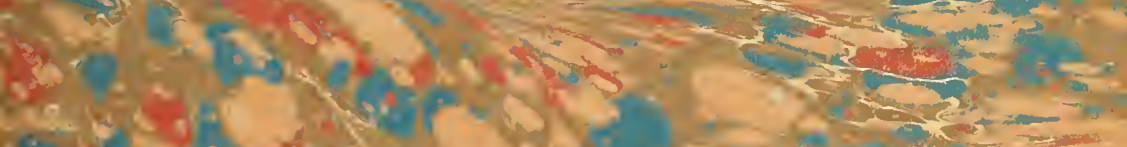
9. $10.005-2=$

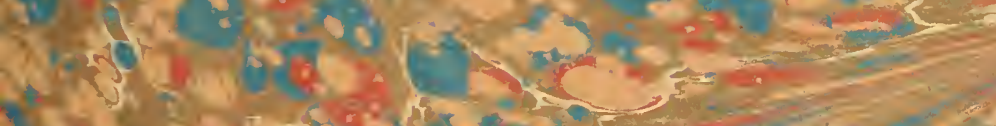
Wh $10=03$

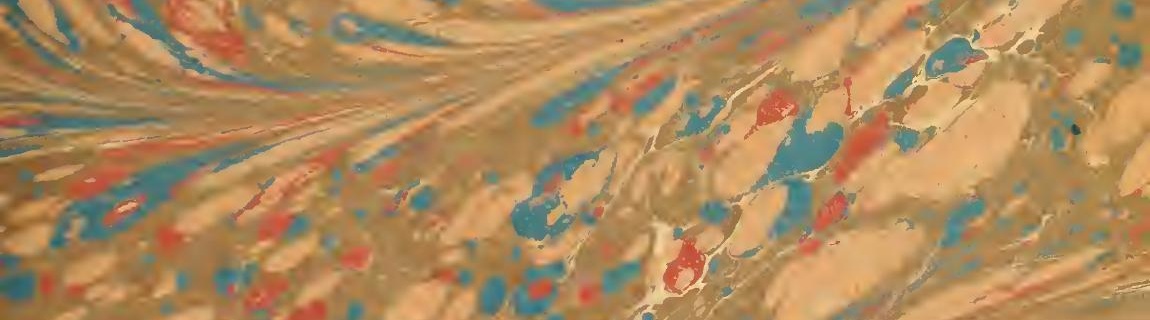
$x^{2}+3,20^{3}, 10$

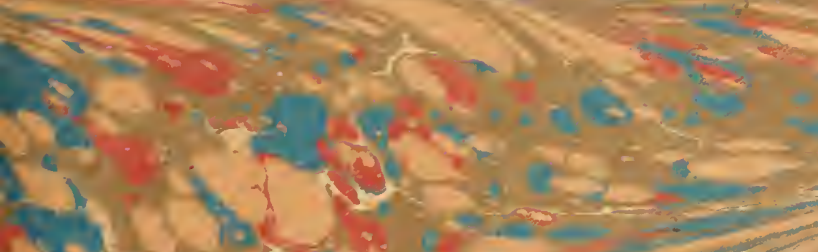
$4 y^{2}+2=$

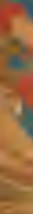

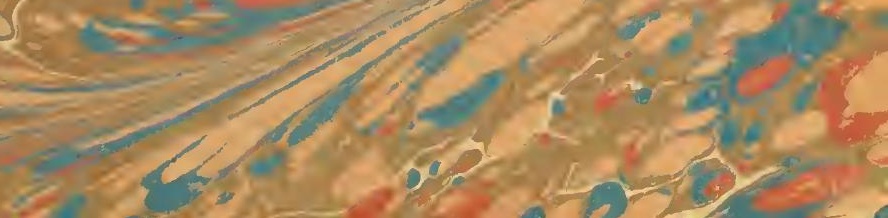

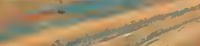
-

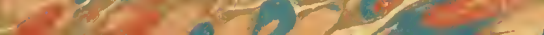







\title{
A NEW
}

\section{GEOGRAPHICAL, HISTORICAL,}

\author{
AND
}

\section{COMMERCIAL GRAMMAR:}

\author{
AND PRESENT STATE OF THE
}

\section{SEVERAL KINGDOMS OF THE WORLD.}

\author{
CONTAINING,
}

1. The Figures, Motions, and Distances of the|| 7. Observations on the Changes that have beed Planets, according to the Newtonian System, ant where abserved upon the Face of Nature, and the latest Observations.

2. A general View of the Earth, considered as a Planet; with several useful Geographical Defi. nitions anil Problems.

3. The grand Divisions of the Globe into tand and Water, Continents, and Islands.

4. The Situation and Extent of Empires, King. doms, States, Provinces, and Colonies.

5. Their Climate, Air. Soil, Vegetable Productions, Metals. Minerals, Natural Curiosities, Seas, Rivers, Bays, Capes, Promontories, and Lakes.

6: The Birds and Beasts peculiar to each Country. since the most early Periods of History.

8. The History and origin of Nations, their Forms of Government, Religion, Laws, Revenúes, Taxes, Naval and Mdilitary Strength, Orders of Knighthood, \&c.

9. The Genius, Manners, Customs, and Habits of the People.

10. 'J heir Language. Learning, Arts, Sciences, Ma. nufactures, and Commerce.

11. The Chief Cities, Structures, Rdins, and Artificial Curiosities.

12. The Longitude, Latitude, Bearings, and Diss tances of principal places from London.

TO WHICH ARE ADDED,

1. A GEOGRAPHICAL INDEX, WITH THE NAMES OF PLACES ALPHABETICALLY

ARRANGED. 2. A CHRONOLOGICAL TÁBLE OF RFMARKABLE EVENTS, FROM THE CREATION TO THE PRESENT TIME. 3. A LIST OF MEN OF LEARNING AND SCIENCE.

\section{BY WILLIAM GUTHRIE, ESQ.}

THE ASTRONOMICAL PART BY JAMES FERGUSON, F. R. S;

TO WHICH HAVE BEEN ADDED

THE LATE DISCOVERIES OF DR. HERSCHEL, AND OTHER EMINENT ASTRONOMEKS:

ILLUSTRATED WITH TWENTY.EIGHT CORRECT MAPS;

THE SECOND AMERICAN EDITION IMPROVED.

IN TWO VOLUMES..... VOL, I;

\section{- PHILADELPHIA :}

PUBLISHFD BT JOHNSON \& WARNER, AND FOR SALE AT THELR BODK STORE IN PHILADELPHIA, AND RICHMOND VIRGINIA, 


\section{DISTRICT OF PENNSYLVANIA, TO WIT :}

BE IT REMEMBERED, That on the seventeenth Gay of June, in the thirty-ninth year of the Independence of the United States of America, A. D. one thousand eight hundred and fifteen, Jон нsоN \& WAR -

(L.S.) NER, of the said district, have deposited in this office the Title of a Book, the right whereof they claim as Proprietors in the words following, to wit :

"A new Geographical, Historical, and Commercial Grammar, and present " state of the several Kingdoms of the World-containing, 1. The Figures,

"Motions, and Distances of the Planets, according to the Newtonian "System and the latest observations. 2. A general View of the Earth, "considered as a Planet; with several useful Geographical Definitions " and Problems. 3. The grand Divisions of the Globe into Land and "Water, Continents and Islands. 4. The situation and extent of Empires, " Kingdoms, States, Provinces and Colonies. 5. Their Climate, Air, Soil, "Vegetable Productions, Metals, Minerals, Natural Curiosities, Seas, " Rivers, Bays, Capes, Promontories, and Lakes. 6. The Birds and Beasts " peculiar to each Country. 7. Observations on the Changes that have "been any where observed upon the Face of Nature since the most as early periods of History. 8. The History and Origin of Nations, their "Forms of Government, Religion, Laws, Revenucs, Taxes, Naval and "Military strength, Order's of Kinighthood, \&c. 9. The Genius, Manners, "Customs, and Habits, of the People. 10. Their Language, Learning, Arts, "Sciences, Manufactures, and Commerce. 11. The Chief Cities, Structures, " Ruins, and Artificial Curiosities. 12. The Longitude, Latitude, bearings "s and distances of principal places from London. To which are added, 1. A

"Geographical Index, with the names of places, alphabetically arranged.

"2. A Chronological Table of remarkable Events, from the Creation to the

"present Time. 3. A List of Men of Learning and Science. By William

"Guthrie, Esq. The Astronomical part by James Ferguson, F. R. S. To

"which have been added the late discoveries of Dr. Herschel, and other emi.

" nent Astronomers. Illustrated with twenty-eight correct Maps. The Se-

"cond American Edition improved. In two Volumes-Vol. 1."

In Conformity to the Act of the Congress of the United States, intituled, "An Act for the Encouragement of Learning, by securing the Copies of Maps, Charts, and Books, to the Authors and Proprietors of such Copies, during the Times therein mentioned."-And also to the Act, entitled, "An Act supplementary to an Act, entitled, "An Act for the Encouragement of Learning, by securing the Copies of Maps, Charts, and Books, to the Authors and Propietors of such Copies during the Times therein mentioned," and extending the Benefits thereof to the Arts of designing, engraving, and etching historical and othel Prints."

D. CALDWELL, Clerk of the District of Pennsylvaniz 


\section{ADVERTISEMENT.}

THE distinguished approbation which the public have shown to this work, as is evident from the many editions through which it has passed, from the rapidity of the sale of very large impressions, and from the increasing demand which continues to be made for it, affords, it may be presumed, a proof sufficiently satisfactory of its utility and excellence.

In this edition, however, very considerable improvements, and a variety of alterations and additions, have been made, of ,which it will be necessary to give some account.

In the first place, a regular and uniform arrangement has been given to the several articles or heads which compose the descriptions of each country, with the addition of such as were found necessary to complete this uniformity. Some alterations liave likewise been made in the arrangement of the several countries and kingdoms, which, except in one or two instances, where a somewhat abrupt transition was unavoidable, are treated of accord. ing to their contignity of situation; an order which appears at once more natural and more adapted to a geographical work, than an arrangement derived from their supposed political importance, by which the reader is suddenly transported from Prussia to Spain; from Spain to Turkey in Europe; and from 'Turkey in Europe to Holland.

New tables have been given of the divisions of seve. ral countries, as of the provinces of Sweden and the go. vernments of Russia. To the enumeration of the coun. ties of England and Scotland are added the number of 
inhabitants in each, according to the returns under the late population act. A table is also given of the departments of France, including those into which the countries violently annexed to her territory were divided, with the extent in square miles and population of each, as published by the French government. General views are added of the dominions, revenues, and forces of the Austrian and Prussian monarchies in their present state, with additional separate descriptions of several countries apa pertaiuing to them; as Gallicia ${ }_{2}$ or Austrian Poland, Silesia, and Nioravia.

Nor have our improvements of this kind been confined to Europe : the account of Hindoostan, its divisions, \&c. has received a new arrangement, and been carefully revised, with a variety of alterations and additions. New and separate descriptions have likewise been given of the countries of Chinese 'Tartary, 'Tibet, Independent Tartary and Asiatic Russia; as also of the settlement of the Cape of Good Hope.

In the two last editions of this work, many important corrections and additions were made from the latest voyages and travels; among which may be enumerated sir Greorge Staunton's account of the royage and embassy of lord Macartney to China; the embassies to 'Tibet and Ava, of captain Turner and major Symes; the travels, of Mr. Park in Africa, with the geographical illustrations of his journey by that judlicious geographer major Rennell; those of Mr. Browne in Egypt and Dar-Fur; and the voyages of the unfortunate French navigator $\mathbf{M}$. de la Perouse, and captain Vancouver. In the present edition we have availed ourselves of the travels of $\mathrm{Mr}_{\text {. }}$. Barrow in Sonthern Africa, and those of Mr. Hornemann, into the interior of the same continent; of those of Mr. Acerbi in Sweden and to the North Cape in Lapland; of those of Mr. Clarke in Russia ; and of those of Mackenzie, Ellicot, Michaud, Heriott, Lewis and Clarke, and Pike, in North America.

As this work is historical as well as geographical, the 
pexpetual changes of states and human affairs, especially those produced by the late revolutions which have conrulsed Europe, have rendered some considerable additions and alterations necessary in the historical part. Such have been made in this edition, and the history of each country is brought down to the present time; the stupendous exertious and rapid conquests of France, first as a republic, and afterwards under Bonaparte; the sulden reverses which followed the late campaign in Russia: the invasion of France by the allied armies; the expulsion of Bonaparte and the restoration of the Bourbons, have been faithfully detailed. To these events another revolution as sudden and unexpected as any which precerled it, has followed. The French army has again placed Bonaparte at the head of the government. The allied nations who expelled him before, have declared their intention of supporting the Bourbons. Europe is therefore upon the eve of engaging in a new contest, the result of which must be left for a future edition.

In publishing this second American edition of Guthrie's Geography, no reasonable care or expeuse has been spared to reuler it the most perfect that has yet appeared. Particular attention has been given to that part of it, which relates to the United States; various errors respecting our country that occur in the best European systems have been correcter; and in order to exhibit a more accurate view of its present physical, commercial, and political state, a considerable number of inportant additions are supplied. 'To gentlemen of Jiterary eminence, in the various sections of the United states, the editors are indebted for numerous contributions. The articles on the state of Lousiana and Missouri territory are from the pen of H. M. Brackenridge, Esq. author of the "-Views of Lonisiana," a work of great literary excellence. 'The article on the 'Loology of North Ameyica, is, for its extent, by far the most accurate which 
has ever appeared. The modesty of its author forbids a personal acknowledgment which the editors would have the highest satisfaction in making.

Still they are sensible that numerous errors and inaccuracies are to be found in the body of the work. Scarce a month passes in which we do not hear of some important political change among the nations of Europe. Ancient kingdoms are annihilated or curtailed to insignificance; new ones are formed, or those which were formerly small are extended to powerful empires. In America the daily presses can scarcely keep pace with the daily improvements of the country. Our information respecting the countries of Asia and Africa is still involved in considerable obscurity. The unfounded jealousies of some nations, and the absolute ignorance of others, prevent our receiving any knowledge, except from the transcient and unsatisfactory observations of travellers; who, far from being assisted by the natives, in their inquiries, are frequently purposely misinformed.' The editors are however persuaded, that the public will do them the justice to allow these volumes to contain a considerable proportion of new, important, and valuable information.

JUNE, 1815. 


\title{
CONTENTS OF VOLUME I.
}

\section{INTRODUCTION.}

\author{
PART I. \\ Of Astronomical Geography.
}

OF the Figure and Motion of the Earth, . . . Page 1

Different Systems of the Universe . . . . . 2

The Copernican System $\quad . \quad$. $\quad . \quad$. .3

Table of the Diameters, Periods, \&c. of the several Planets in the Solar System . . . . . . . . 5

Comets . . . . . . . . . $i b$.

Fixed Stars . . . . . . . . . . 6

Doctrine of the Sphere $\quad$. . . . . . 9

Description and Use of the Terrestrial Globe . . . 10

Problems performed by the Globe . . . . . 15

Geographical Observations . . . . . . 20

Natural Divisions of the Earth . . . . . . 22

Figure and Dimensions of the Earth . . . . . 23

Winds and Tides . . . . . . . . 24

Construction and Use of Maps . . . . . . 26

PART II.

Of the Origin of Nations, Laws, Government, and Commerce 28

PART III.

Of the Origin and Progress of Religion

EUROPE.

Extent, Boundaries

C.. .0 .057$

Grand Divisions . . . . . . . 58

Denmark . . . . . . . . . 59

Iceland . . . . . . . . . . 73

Ferro Islands . . . . . . . . . 78

Norway

Sweden

Lapland 
CONTENTS OF VOLUME 1.

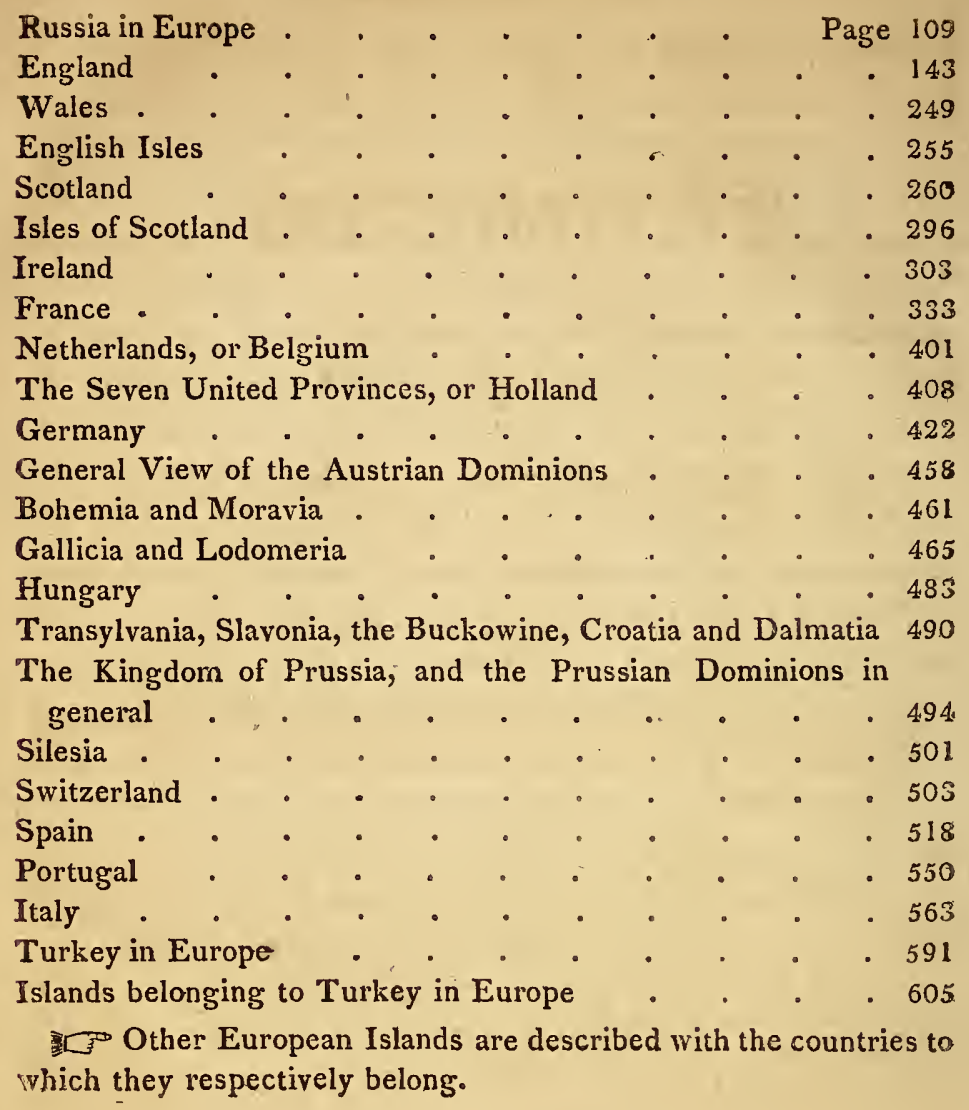




\title{
INTRODUCTION.
}

\author{
PART I.
}

\section{OF AS'TRONOMICAL GEOGRAPHY.}

\section{SECT. I.}

OF THE FIGURE AND MOTION OF THE EARTH, THE DIFFERENT SYSTEMS OF THE UNIVERSE, THE PLANETS, COMETS, AND FIXED STARS.

T

HE science of GEOGRAPHX, in the more extensive signification of the word, is so intimately connected with that of ASTRONOMY, that it will be necessary to begin this work with a summary view of the system of the world, and a brief account of the order and revolutions of the heavenly bodies. But first we shall premise a few observations on the figure and motion of the earth.

The earth was long considered as an extensive plain of unknown thickness, beneath which was the abode of the spirits of the dead.... the regions of Elisium and Tartarus. The heavens, in which the sun, moon, and stars appeared to move daily from east to west, vere conceived to be at no $\mathrm{s}$ reat distance from it, and to be only designed for its use and ornament. More attentive observation, however, soon showed that the earth was of a globular figure. Thus, when a ship sails on the sea, the tops of the masts first become visible at a distance; the setting sun may be distinctly seen from the top of a hill when it appears to those below to have sunk beneath the horizon; and the shadow of the earth in a lunar eclipse is of a circular figure. But it is needless to insist on these proofs, since the frequent voyages of different navigators round the rvorld, from the time of MIagelhaens, or Magellan, whose ship first circumnavigated the globe between the years 1519 and 1522 , he himself being killed at the Ladrone islands, to that of the repeated voyages of captain Cook, have demonstrated the figure of the earth to be globular beyond the possibility of a doubt.

The spherical figure of the earth being admitted, its motion became much more probable from the very nature of its form; and besides, a very strong, and in fact unanswerable, argument for that inotion was derived from considering, that if the earth did not move round the sun, not only the sun, but all the planets and stars,

Vot. I. 
must move round the earth. Now as astronomers, by calculations founded on the principles of geometry, are able to ascertain very nearly the distances of the heavenly bodies from the earth and from each other, it appeared that if we conceived the heavenly bodies to move round the earth, we must suppose them endowed with a motion or velocity so immense as to exceed all conception; whereas all the appearances in nature may be as well explained by imagining the earth to move round the sun in the space of a year, and to turn on its own axis once in twenty-four hours.

The earth, therefore, in the space of twenty-four hours, moves from west to east, while the inhabitants on the surface of it, like men on the deck of a ship, who are insensible of their own motion, and think that the banks move from them in a contrary direction, will conceive that the sun and stars move from east to west in the same time of twenty-four hours in which they, along with the earth, move from west to east. This daily or diurnal motion of the earth, being once clearly conceived, will enable us easily to form an idea of its annual or yearly motion round the sun. For, as that luminary seems to have a diurnal motion round our earth, which is really occasioned by the daily motion of the earth round its own axis, so, in the course of a year, he seems to have an annual motion in the heavens, and to rise and set in different points of them; which is really occasioned by the annual motion of the earth in its orbit or path round the sun, which it completes in the space of a year. Now, as to the first of these motions we owe the difference of day and night, so to the second we are indebted for the difference in the length of the days and nights, and in the seasons of the year.

Different systems of The Universe.... Thales, the Milesian, who, about 600 year's before Christ, first taught astronomy in Greece, had made a sufficient progress in this science to calculate eclipses, or interpositions of the moon between the earth and the sun, or of the earth between the sun and the moon. Pythagoras, a native of Samos, flourished about fifty years after Thales, and was, no doubt, equally well acquainted with the motion of the heavenly bodies. He conceived an idea, which there is no reason to believe had ever been suggested before, namely, that the earth itself was in motion, and that the sun was at rest. He found that it was impossible, in any other way, to explain consistently the heavenly motions. His system, hotvever, was so extremely opposite to all the prejudices of sense and opinion, that it never made great progress, nor. was ever widely diffused in the ancient world. The philosopher's of antiquity, despairing of being able to overcome ignorance by reason, endeavoured to adapt the one to the other, and in some measure to reconcile them. Ptolemy, an Egyptian philosopher, who flourished 138 years before Christ, supposed with the vulgar, that the earth as fixed immovably in the centre of the universe, and that the seven planets, considering the moon as one of the primaries, were placed near to it. Above them he placed the firmament of fixed stars, then the crystalline orbs, then the primum moblle, and, last of all, the colum empyreum, or heaven of heavens. All these vast orbs he imagined to move round the earth once in tiventy-four hours, and also to perform other revolutions round it, in certain stated and periodical times. To account for these motions, he was obliged to conceive a number of circles, called eccentrics: and epicycles, crossing and interfering with each other. This sys- 
tem vas universally maintained by the peripatetic philosophers, who were the most considerable sect in Europe, from the time of Ptolemy to the revival of learning in the sixteenth century.

At length, Copernicus, a native of Poland, a bold and original genius, adopted the Pythagorean or true system of the universe, and published it to the world in the year 1543. This doctrine had remained so long in obscurity, that the restorer of it was considered as the inventor, and the system obtained the name of the Coperniean Philosophy, though only revived by that great man.

But Europe was still immersed in ignorance, and Copernicus had many opponents. Tycho Brahe in particular, a noble Dane, sensible of the defects of the Ptolemaic system, but unwilling to acknowledge the motion of the earth, endeavoured, about the year 1586, to establish a new system of his own, which was still more perplexed and embarrassed than that of Ptolemy. It allows a monthly motion to the moon round the earth, as the centre of its orbit; and makes the sun to be the centre of the orbits of Mercury, Venus, Mars, Jupiter, and Saturn. The sun, however, with all the planets, is supposed to be whirled round the earth in a year, and even once in the twenty-four hours. This system, notwithstanding its absurdity met with many adrocates. Longomontanus, and other's, so far refined upon it, as to admit the diurnal motion of the earth, though they insisted that it had no annual motion.

About this time, after a darkness of many ages, the first dawn of Jearning and taste began to appear in Europe. Learned men in different countries began to cultivate astronomy. Galileo, a Florentine, about the year 1610, introduccd the use of telescopes, which afforded new arguments in support of the motion of the earth, and confirmed the old ones. The fury and bigotry of the clergy, indeed, had almost stifled the science in its infancy; and Galileo was obliged to renounce the Copernican system, as a damnable heresy. The happy reformation in religion, however, placed a great part of Eu. jope beyond the reach of the papal thunder. It taught mankind that the Scriptures were not given for explaining systems of natural philosophy, but for a much nobler purpose...to render us just, virtuous, and humane; that instead of opposing the word of God, which in speaking of natural things, suits itself to the prejudices of weak mortals, we employed our faculties in a manner highly agreeable to cur Maker, in tracing the nature of his works, which, the more they are considered, afford us the greater reason to admire his florious attributes of power, wisdom, and goodness. From this time, therefore, noble discoveries were made in all the branches of astronomy. Not only the motions of the heavenly bodies were clearly explained, but the general law of nature, according to which they moved, was discovered and illustrated by the immortal Newton. This law is called Gravity, or Attraction, and is the same by which any body falls to the ground, when disengaged from what supported it. It has been demonstrated, that this same law, which keeps the sea in its channel, and the various bodies which cover the surface of this carth from flying off into the air, operates throughout the universe, retains the planets in their orbits, and preserves the whole fabric of nature from confusion and disorder.

The Copernican system.... In the solar system of Copernicus, as confirmed and demonstrated from geometrical principles by the illustrious sir Isaac Newton, the sun is placed in the centre, and 
round him revolve the seven planets, the names of which are, bc: ginning with the nearest to the sun, Mercury, Venus, the Earth, Mars, Jupiter, Saturn, and the Georgium Sidus. The last of these was first discovered by Dr. Herschel with his telescope of great size and power, 40 feet in length, and $4 \frac{1}{2}$ in diameter, in the year 1781. For this discovery he received from the Royal Society the lhonorary recompense of sir Godfrey Copley's medal. Though the Georgium Sidus was not till then known as a planet, there are many reasons to suppose it had been seen before, but had been considered as a fixed star. But from the steadiness of its light, from its diameter being increased by high magnifying powers, and from the change he had observed in its situation, Dr. Herschel first concluded it was a comet; but in a little time he, with others, determined that it was a planet, from its vicinity to the ecliptic, the direction of its motion, and its being stationary in the time and in such circumstances as correspond with similar appearances in other planets. When the moon is absent, it may be seen by the naked eye ; and the discovery of six satellites attending it confers upon it a dignity, and raises it to a conspicuous situation among the great bodies of our solar system.*

The magnitudes, annual periods; and mean distances from the sun, of the several planets, are given in the table subjoined. Their relative distances may likewise be thus stated in a manner more compendious and easy to be remembered. If the distance of the earth from the sun be supposed to be divided into ten parts, the distance of Mercury will be four such parts, that of Venus seven, that of Mars fifteen, that of Jupiter fity-two, that of Saturn ninetyfive, and that of the Georgium Sidus one hundred and ninety.

Besides these seven planets, there are eighteen others which move round four of these in the same manner as they do round the sun. Of these our Earth has one, called the Moon; Jupiter has four; Saturn seven, two of these having been lately discovered by Dr. Herschel ; and the Georgium Sidus six, discovered, as well as the planet itself, by the same excellent astronomer. These are called moons, from their resemblance to our moon; and sometimes secondary planets, because they seem to be attendants of the Earth, Jupiter, Saturn, and the Georgium Sidus, about which they move, and which are called frimary.

The orbits described by the planets are not exact circles, but ellipsis or ovals : hence the same planet is not always at the same distance from the sun; and the distance which is exactly between the greatest and least distance is called the mean distance.

* Another new planet was discovered nn the 1st of January 1801, by M. Piazzi, astronomer-royal at Palermo in Cicily, who called it Ferdinandea, in honour of his Sicilian majesty. It is aiso called Ceres, or Ceres Ferdinandea. It has its orbit between those of Mars and Jupiter. According to the latest observations, its period is four year's 222 days. Its distance from the sun is to that of the earth as 267 to:100, consequently above 250 millions of miles. It is not visible to the naked eye; and so small, that glasses of a very high magnifying power will not show it with a distinctly-defined diameter : Dr. Herschel has however estimated its diameter at 160 English miles.

Another planet has also been discovered by Dr. Olbers of Hamburgh : it is likewise situated between Mar's and Jupiter. It has been named Pallas. Its distance from the sun is to that of the earth as 280 to 100 , or: nearly $2 \% 0$ millions of miles. It is extremely small; its diameter being estimated by Dr. Herschel at only 110 miles. 
In the following table the inclinations of the axis of the planets to their orbits are given; and the meaning of this term it may be necessary to explain. IVe have already said that tire annual motion of the earth occasions the diversity of seasons : but this would not happen were the axis of the earth exactly parallel to, or in a line with, the axis of its orbit; because then the same parts of the earth would be turned towards the sun in every diurnal revolution; which would deprive mankind of the grateful vicissitudes of the seasons arising from the difference in length of the days and nights produced by this inclination of the axis. The axis of several others of the planets are in like manner inclined to the planes of their orbits, and the angle of their inclination is given in the following table.

\section{A TABLE OF THE DIAMETERS, PERIODS, Sc. OF THE SEVERAL PLANETS IN THE SOLAR SYSTEM.}

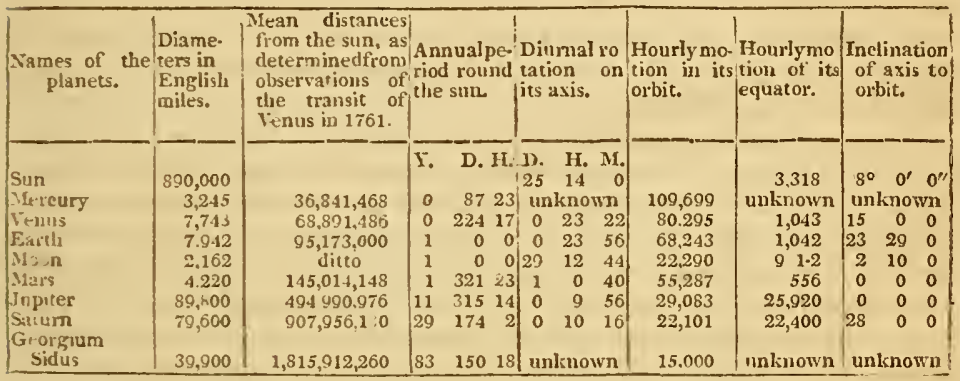

Comets.-Besides the primary and secondary planets already enumerated, there are other bodies which revolve round the sun, and, consequently, make a part of the solar system. These are caller Comets, and appear occasionally in every part of the hearens. Descending from the far distant parts of the system with great rapidity, they surprise us with the singular appearance of a train, or tail, which accompanies them; become visible to us in the lower parts of their orbits; and, after a short stay, go off again to vast distances, and disappear. Though some of the ancients had more just notions of them, yet the opinion having prevailed, that they were only meteors generated in the air, like to those we see in it every night, and in a few moments vanishing, no care was taken to observe or record their phænomena accurately till of late. Hence this part of astronomy is very imperfect. The general doctrine is, that they are solid compact bodies, like other planets, and regulated by the same laws of gravity, so as to describe equal areas in proportional times by radii drawn to the common centre. They move about the sun in very eccentric ellipsis, and are of much greater density than the earth; for some of them are heated in every period to such a degree as would vitrify or dissipate any substance known to us. Sir Isaac Newton computed the heat of the comet that appeared in the year 1680 , when nearest the sun, to be 2000 times hotter than red-isot iron, and that, being thus lieated, it must retain its heat till it comes round again, although its period should be more than 20,000 years; and it is computed to be only 575. The number of comets is very much greater than that of the 
planets which move in the vicinity of the sun. From the reports. of historians, as well as from the observations of late years, it has been ascertained that more than 4.50 were seen previous to the year I771; and when the attention of astronomers was called to this object by the expectation of the return of the comet of 1759 , no few. er than seven were observed in the course of seven years. From this circumstance, and the probability that all the comets recorded in ancient authors were of considerable apparent magnitude, while the smaller were overlooked, it is reasonable to conclude, that the number of comets considerably exceeds any estimation that might be made from the observations we now possess. But the number of those whose orbits are settled with sufficient accuracy to ascer tain their identity when they may appear again, is no more than fifty-nine, reckoning as late as the year 1771. The orbits of most of these are inclined to the plane of the ecliptic in large angles, and the greater number of them approached nearer to the sun than to the earth. Their motions in the heavens are not all in the order of the signs, or direct, like those of the planets; but the zumber whose motion is retrogade is nearly equal to that of those whose motion is direct. All which have been observed, however, have moved through the athereal regions and the orbits of the planets, without suffering the least sensible resistance in their motions; which sufficiently proves that the planets do not move in solid orbs. Of all the comets, the periods of three only are known with any degree of certainty, being found to return at intervals of 75,129 , and 575 years; and of these, that which appeared in 1680 is the most remarkable. This comet, at its greatest distance, is about 11,200 millions of miles from the sun, while its least distance from the centre of the sun is about 490,000 miles; being less than one third palt of the sun's semi-diameter from his surface. In that part of its orbit which is nearest the sun, it flies with the amazing velocity of 880,000 miles in an hour; and the sun, as seen from it, appears 100 degrees in breadth, consequently 4,0,000 times as large as he appears to us. The astonishing distance that this comet runs out into empty space naturally suggests to our imagination the vast distance between our sun and the nearest of the fixed stars, of whose attractions all the comets must keep clear, to return periodically and go round the sun.

THE FIXED STARS....Having thus brielly surveyed the solar system, which, though great in itself, is small in comparison with the immensity of the universe, we next proceed to the contemplation of those other vast bodies called the Fixed Stars. These are distinguished by the naked eye from the planets, by being less bright and luminous, and by continually exhibiting that appearance which we call the twinkling of the stars. This arises from their being so extremely small, that the interposition of the least body, of which there are many constantly floating in the air, deprives us of the sight of them; when the interposed body changes its place, we again see the star; and this succession, being perpetual, occasions the twinkling. But a more remarkable property of the fixed stars, and that from which they have obtained their name, is their never changing their situation with regard to each other, as the planets, from what we have already said, must evidently be always changing theirs. The stars which are nearest to us seem largest, and are therefore called stars of the first magnitude. Those of the secone 
nagnitude appear less, being at a greater distance; and so pro. ceeding on to the sixth magnitude, which includes all the fixed stars that are visible without a telescope.

The first observers of the heavens, in the early ages of the world, divided the stars into different assemblages or constellations, each of which they supposed to represent the image of some animal or other terrestrial object. These constellations have, in general, preserved the names which were given them by the ancients, by whom they were reckoned twenty-one northern, and twelve southern; but the moderns have increased the number of the northern to thirty-six, and that of the suuthern to thirty-two. Besides these, there are the twelve signs or constellations of the Zodiac, as it is called from the Greek word. ¿wor, an animal; because almost all these signs represent some anima!.

As to the number of the fixed stars, though, in a clear winter's night without moonshine, they seem to be innumerable (which is owing to their strong sparkling, and our looking at them in a confused manner) yet when the whole firmament is divided into constellations, the number that can at any lime be seen with the naked eye is not above a thousand. Since the invention of telescopes, indeed, the number of the fixed stars has been justly considered as immense; because, the greater perfection we arrive at in our glasses, the more stars always appear to us. Mr. Flamsteed, late loyal astronomer at Greenwich, has given us a catalogue of about 3000 stars. These are called telescopic stars, from their being invisible without the assistance of the telescope. Dr. Herschel, to whose ingenuity and assiduity the astronomical world is so much indebted, has evinced what great discoveries may be made by improvements in the instruments of observation. "In passing rapidly orer the heavens with his new telescope, says M. de Lalande, "the universe increased under his eye; 44,000 stars, seen in the space of a few degrees, seemed to indicate that there were seventy-five millions in the heavens." But what are all these, when compared to those that fill the whole expanse, the boundless fields of æther? Indeed the immensity of the universe must contain such numbers as would exceed the utmost stretch of the human imagination; for who can say how far the universe extends, or point out those limits where the Creator "stayed his rapid wheels," or where he "fixed the golden compasses?"

The immense distance of the fixed stars from our earth, and from each other, is, of all considcrations, the most proper for raising our ideas of the works of God. For, notwithstanding the great extent: of the earth's orbit or path (which is at least 190 millions of miles in diameter) round the sun, the distance of a fixed star is not sensibly affected by it; so that the star does not appear to be any nearer to us when the earth is in that part of its orbit nearest the star, than it: seemed to be when the earth was at the most distant part of it, or 190 millions of miles farther removed from the same star. "The star nearest us, and consequently the largest in appearance, is the dogstar, or Sirius. Modern discoveries make it probable, that each of those fixed stars is a sun, having planets and comets revolving round it, as our sun has the earth and other planets revolving round him. Now the dog-star appears 27,000 times less than the sun: and, as the distance of the stars must be greater in proportion as they seem less, mathematicians have computer the distance of Sirius from us to 
be two billians and two hundred thousand millions of miles. A ray of light, therefore, though its motion is so quick as to be commonly thought instantaneous, takes up more time in travelling fron the stars to us than we do in making a West-India voyage. A sound, which next to light, is considered as the quickest body we are acquainted with, would not arrive to us from thence in 50,000 years. And a cannon ball, flying at the rate of 480 miles an hour, would not reach us in 700,000 years.

The stars, being at such immense distances from the sun, cannot possibly receive from him so strong a light as they seem to have, nor any brightness sufficient to make them visible to us. For the sun's rays must be so scattered and dissipated before they reach such remote objects, that they can never be transmitted back to our eyes, so as to render those objects visible by reflection. The stars, therefore, shine with their own native and unborrowed lustre, as the sun does; and since each particular star, as well as the sun, is confined to a particular portion of space, it is evident that the stars are of the same nature with the sun.

It is far from probable that the Almighty, who always acts with infinite wisdom, and does nothing in vain, should create so many glorious suns, fit for so many important purposes, and place them at such distances from each other, without proper objects near enough to be benefited by their influences. Whoever imagines that they were created only to give a faint glimmering light to the inhabitants of this globe, must have a very superficial knowledge of astronomy,* and a mean opinion of the divine wisdom; since, by an infinitely less exertion of creating power, the Deity could have given our earth much more light by one single additional moon.

Instead then of one sun and one world only, in the universe, as the unskilful in astronomy imagine, that science discovers to us such an inconceivable number of suns, systems, and worlds, dispersed through boundless space, that if our sun, with all the planets, moons, and comets belonging to it, were annihilated, they would be no more missed by an eye that could take in the whole creation, than a grain of sand from the sea-shore; the space they possess being comparatively so small, that it would scarcely be a sensible blank in the universe, although the Georgium Sidus, the outermost of our planets, revolves about the sun in an orbit of 10,830 millions of miles in circumference, and some of our comets make excursions upwards of ten thousand millions of miles beyond the orbit of the Georgium Sidus; and yet, at that amazing distance, they are incomparably nearer to the sun than to any of the stars, as is evident from their keeping clear of the attracting power of all the stars, and returning periodically, by virtue of the sun's attraction.

From what we know of our own system, it may be reasonably concluded that all the rest are with equal wisdom contrived, situated, and provided with accommolations for rational inhabitants. For although there is an almost infinite variety in the parts of the creation which we have opportunities of examining, yet there is a general analogy running througl and connecting all the parts into one scheme, one design, one whole.

* Especially since there are many stars which are not visible without the assistance of a good telescope; and therefore, instead of giving light to this world, can only be seen by a few astronomers. 
Since the fixed stars are prodigious spheres of fire, like our sun, and at inconceiveable distances from each other as well as from us, it is reasonable to conclude they are made for the same purposes that the sun is; each to bestow light, heat, and vegetation, on a certain number of inhabited planets, retained by gravitation, within the sphere of its activity.

What a sublime idea does this suggest to the human imagination, limited as are its powers, of the works of the Creator! 'Thousands and thousancis of suns, multiplied without end, and ranged all around us, at immense distances from each other, attended by ten thousand times ten thousand worlds, all in rapid motion, yet calm, regular, and har'monious, invariably keeping the paths prescribed them ; and these worlds pcopled with myriads of intclligent beings, formed for endless progression in perfection and felicity.

If so much power, wisclom, goodness, and magnificence, be displayed in the material creation, which is the least considerable part of the universe, how great, how wise, how good must HE be, who made and governs the whole!

\section{SEC'T. II.}

\section{OF THE DOCTRINE OF THE SPHERE.}

Having, in the foregoing section, treated of the UNIVERSE in general, in which the earth has been considered as a planet, we now proceed to the doctrine of the SPHERE. In treating this subject we shall consider the earth as at rest, and the heavenly bodies as performing their revolutions around it. This method cannot lead the reader into any mistake, since we have previously explained the true system of the universe, from which it appears, that it is the real motion of the earth which occasions the affarent motion of the hearenly bodies. It is besides attended with this advantage, that it perfectly agrees with the information of our senses. The imagiration tierefore is not put on the stretch; the idea is easy and familiar; and in delivering the elements of science, this object canusot be too much attended to.

N. B. In order more clearly to comprehend what follows, the reader may occasionally turn his eye to the annexed plate of the Artificial or Armillary Sphere.

The ancients obscrved, that all the stars turned (in appearance) round the earth, froin east to west, in twenty-four hours; that the eircles which they described in those revolutions were parallel to each other, but not of the same magnitude; those passing over the micllc of the earth being the largest, while the rest diminished in proportion to their distance from it. They also observed, that there were two points in the heavens which always preserved the same situation. These points they termed celestial poles, because the leavens seemed to turn round them. In order to imitate these motions, they invented what is called the Artificial or Armillary Sphere, through the ccntre of which passes an Axis, whose extremitics are fixed to the immovable points called Poles. They farther observed, that, on the 20th of March and 23d of September", the circle described by the sun was at an equal distance from brots:

VOL. $\mathrm{P}$, 
the poles. This circle, therefore, must divide the earth into two equal parts, and on this account was called the Equator or Equaller. It was also called the Equinoctial Line, because the sun, when moving in it, makes the days and nights of equal lengrth all over the world. Having also observed, that from the 21 st of June to the $22 \mathrm{~d}$ of Decentber the sun advanced every day towards a certain point, and, having arrived there, returned towards that from which he had set out, from the 22d of December to the 21 st of June, they fixed these froints, which they called Solstices, because the direct motion of the sun was stopped at them; and represented the bounds of the sun's motion by two circles, which they named Tropics, because the sun no sooner arrived there, than he turned back. Astronomers, observing the motion of the sun, found its quantity at a mean rate, to be nearly a degree (or the 360 th part) of a great circle in the heavens, every twenty-four hours. This great circle is called the Ecliptic, and it, passes through certain constellations, distinguished by the names of animals, in a zone or belt, called the Zodiac, within which the moon and all the planets are constantly found. It touches the tropic of Cancer on one side, and that of Capricorn on the other, and cuts the equator obliquely, at an angle of twenty-three degrees twenty-nine minutes, the sun's greatest declination. To express this motion, they supposed two points in the heavens, equally distant from and parallel to this circle, which they called the Poles of the zodiac, which turning with the heavens, by means of their axis, describe the two holar circles. In the artificial sphere, the equinoctial, the two tropics, and two po. lar circles, are cut at right angles by two other circles called Colures, which serve to mark the points of the solstices, equinoxes, and poles of the zodiac. The ancients also observed that, when the sun was in any point of his course all the people inhabiting directly north and south, as far as the poles, have noon at the same lime. This gave occasion to imagine a circle passing through the poles of the world, which they called a Meridian and which is immovable in the artificial sphere, as well as the Horizon, which is another circle representing the bounds betwixt the two hemispheres, or half spheres, viz. that which is above and that which is below it.

\section{SEO'IT. TIL.}

\section{DESCRIPTION AND USE OF THE TERRESTRIAL GLOBE.}

The Terrestrial GLOEE is a representation of the surface of the earth, on an artificial globe or ball on which the several countries and places are laid down according to their relative situations, and to which the circles of the sphere before described are transferred.

AxIs AND POLES OF THE EARTH....The axis of the earth is that imaginary line passing through its centre, on which it is supposed to turn round once in twenty-four hours. The extreme points of this line are called the Poles of the earth, one in the north and the other in the south, which are exactly under the two points of the heavens called the North and South Poles.

CIRCLES OF THE GLOBE.... These are commonty divided into the greater and less. A great circle is that whose plane passes through the centre of the earth, and divides it into two equal parts or hemis $\phi$ 
pheres. A less circle is that which, being parallel to a greater, cannot pass through the centre of the earth, nor divide it into two equal parts. The greater circles are six in number, the less only four.

Equator...The first great circle is the Equator, or Equinoctial; by navigators called the Line. The poles of this circle are the same with those of the world. It passes through the east and west points of the earth, and divides it into the northern and somthern hemispheres. It is divided into 360 degrees, the use of which will soon appear.

HoRIZON... This grcat circle is represented by a broad circular piece of wood encompassing the globe, and dividing it into the upper and lower henispheres. Geographers distinguish the horizon into the sensible and rational. The first is that which bounds the utmost prospect of our sight, when we view the heavens around us, a/parently touching the earth or sea. This circle determines the rising or setting of the sun ancl stars, in any particular place; for when they begin to appear above the eastern edge, we say they rise; and when they go beneath the western, we say they are set. It ap. pear's that each place has its own sensible horizon. The other horizon, called the rational, encompasses the globe exactly in the mid. dle. Its poles (that is, two points in its axes, eacin ninety degrees distant from its plane as those of all circles are) are called the Zenith and Nadir; the former exactly above our heads, and the latter directly under our feet. The broad wooden circle which represents it on the globe, has several circles dirawn upon it; of these the innermost is that exhibiting the number of degrees of the twelve signs of the zodiac, viz. thirty to each sign. Next to this are the names of these signs together with the days of the month. Besides these, there is a circle representing the thirty-two rhumbs, or points of the mariners compass.

Meridian,...This circle is represented by the brass rings on which the globe hangs and turns. It is divided into 360 degrees, and cuts the equator at right angles; so that, counting from the equator each way to the poles of the world, it contains four times ninety degrees, and divides the earth into the eastern and western hemispheres. This circle is called the meridian, because, when the sun comes to the south part of it, it is then meridies or mid-day and then the sun has its greatest altitude for that day, which is therefore called its meridian altitude. Now, as the sun is never in its meridian altitude at two places east or west of one another at the same time, each of these places must have its own meridian. There are commonly marked on the globe twenty-four mericians, one through every fifteen degrees of the equator.

Zodrac... The Zodiac is a broad circle, which cuts the equator obliquely; in which the twelve signs above mentioned are repre. sentcd. In the middle of this circle is supposed another, called the Ecliptic, from which the sun never deviates in his annul course, and in which he advances thirty degrees every month. The twelve signs are,
1. Aries
2. Taurus

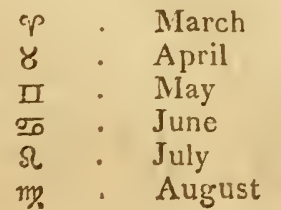
7. Libra
8. Scorpio
9. Saģittarius
$\simeq$. September
3. Gemini
$m$. October
4. Cancer
10. Capricornus vo
11. Aquarius
1 . November
5. Leo
12. Pisces
vi. December
6. Virgo
August
* February 
Colures... If we imagine two great circles both passing through the poies of the world, and one of them through the equinoctial points Aries and Libra, and the other through the solstitial points: Cancer and Capricorn, these are called the Colures; the one the Equinoctial, the other the Solstitial Colure. These are all the great circles.

Tropics....If we suppose two circles drawn parallel to the equinoctial, at twenty-three degrees thirty minutes distance from it, measured on the brazen meridian, the one towards the north, the other towards the south, these are called Tropics, from the Greek word rponn, a turning, because the sun appears, when in them, to turn backwards from his former course. The one is called the Tropic of Cancer, the other of Capricorn, because they pass through the first points of these sigus.

Polar circles.... If two other circles are supposed to be drawn at the like distance of twenty-three degrees thirty minutes, reckoned on the meridian from the polar points, these are called the Polar Circles. The northern is called the Arctic, because the north pole is near the constellation of the Bear, in Greek apxzos; the southern, the Antarctic, because opposite the former. And these are the four less circles.

Zones.... After the four less circles we have mentioned were known, it was observed that the earth, by means of them, might be divided into five portions, and consequently that the places on its surface might be distinguished according as they lay in one or other of these portions, which are called Zones, from the Greek word $\zeta \omega v n, w h i c h$ signifies a girdle ; being broad spaces, like swathes, sirding the earth about.

The torrid zone is that portion of the earth between the tropics, and called by the ancients torrid, because they conceived, that being continually exposed to the perpendicular or direct rays of the sun, it was rendered uninhabitable, and contained nothing but parched and sandy deserts. This notion, however, has long since been refuted. It is found that the long nights, great dews, regular rains and breezes, which prevail almost throughout the torrid zone, render the earth not only habitable, but so fruitful, that in many places they have two harvests in a year; all sorts of spices and drugs are almost solely produced there; and it furnishes the most perfect metals, precious stones, and pearls. In short, the countries of Africa, Asia, and America, which lie under this zone, are in all respects the most fertile and luxuriant upon earth.

The two temperate zones are comprised between the tropics and polar circles. They are called temperate, because, meeting the rays of the sun obliquely, they enjoy a moderate degree of heat.

The two frigid zones lie between the polar circles and the poles, or rather are enclosed within the polar circles. They are called the frigid or frozen, because most part of the year it is extremely cold there, and every thing is frozen so long as the sun is under the horizon, or but a little above it. However, these zones are not quite uninhabitable, though much less fit for living in than the torid.

None of all these zones have been fully explored by the Europeans. Our knowledge of the southern temperate zone is very imperfect; we know little of the northern frigid zone, and still less of the southern frigid zone. The northern temperate and torrid zones are those we are best acquainted with. 
Cermates....Besides the division of the earth into hemispheres and zones, geographers have also divided it into climates, which are zarrower zones, each included between two parallels of latitude, at such a distance from each other, that the Icngth of the longest day under that nearest the pole is increased by half an hour. As the length of the day under the equator is always twelve hours, and that of the longest day under the polar circles twenty-four hours, it is evident that there must be twenty-four of these climates betwecn the equator and either pole. With in the polar circles, where the longest day is always more than twenty-four hours long, the climates are reckoned by the increase of the day by months, till we reach the pole, where the whole year consists only of six months day and six months night. Of thesc climates, therefore, there will be six, making the whole number on each side the equator thirty.

We here insert a table of climates, which will show the length of the longest day in most of the principal places in the world.

\section{TABLE OF CLIMATES.}

\begin{tabular}{|c|c|c|c|c|c|c|c|}
\hline$\stackrel{2}{=}$ & \multicolumn{2}{|c|}{$\begin{array}{l}\text { Lat. } \\
\text { D. M. }\end{array}$} & \multicolumn{2}{|c|}{$\begin{array}{l}\text { Breadth } \\
\text { D. M. }\end{array}$} & \multicolumn{2}{|c|}{$\begin{array}{l}\text { Lon. Da. } \\
\text { H. M. }\end{array}$} & $\begin{array}{l}\text { Names of Countries and remarkable Places, situated in every Climate } \\
\text { north of the Equator. }\end{array}$ \\
\hline 1 & 8 & 25 & 8 & 25 & 12 & 30 & $\begin{array}{l}\text { 1. Within the first Climate lie the Gold and Silver Coasts in Africa; } \\
\text { Malacta in the East Indies; Cayenne and Surinam in Terra Fir. } \\
\text { ma, South America. }\end{array}$ \\
\hline 2 & 16 & 25 & 8 & 0 & 13 & 0 & $\begin{array}{l}\text { 2. Here lie Abyssinia in Afrieq; Siam, Madras. and Pondicherry, } \\
\text { in the East. Indies; Straits of Darien, between North and South } \\
\text { America; Tobago, the Granades, St. Vincent, and Barbadoes, in } \\
\text { the West.Indies. }\end{array}$ \\
\hline 3. & 23 & 50 & 7 & 25 & 13 & 30 & $\begin{array}{l}\text { 3. Contains Mecea in Arabia ; Bon,bay, part of Bengal, in the East. } \\
\text { Indies; Carton, in China; Mexico, Bay of Campeachy, in North } \\
\text { America; Janaica, Hispaniola, St. Christopher's, Antigua, Marti- } \\
\text { uico, and Guadaloupe, in the West-Indies. }\end{array}$ \\
\hline 4 & 30 & '20 & 6 & 30 & 14 & 0 & $\begin{array}{l}\text { 4. Egspt, and the Canary Islards in Africa; Delhi, capital of the } \\
\text { Mognil Empire, in Asia; Gulf of Mexieo. and East Florida, in } \\
\text { Nortl America; the Havann:, in the West-Indies. }\end{array}$ \\
\hline 5 & 36 & 28 & 6 & 8 & 14 & 30 & $\begin{array}{l}\text { 5. Gibraltar in Spain ; part of the Mediterranean Sea ; the Barbary } \\
\text { const, in Afriea ; Jerusalem; Ispalıan, capital of Persia; Nankin, } \\
\text { in China; California, New Mexico, West Florida, Georgia, snd the } \\
\text { Carolinas, in North America. }\end{array}$ \\
\hline 6 & 41 & 22 & 4 & 54 & 15 & 0 & 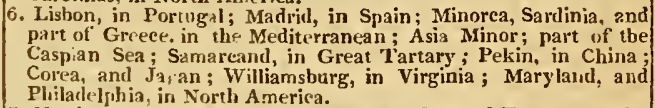 \\
\hline 7 & 45 & 29 & 4 & 7 & 15 & 30 & $\begin{array}{l}\text { 7. Northern provine s of Spain; snuthern ditto of France; Turin, } \\
\text { Genoa, and Rome, in Italy; Constantinople, and the Black Sea, } \\
\text { in Turkey, the Caspian Sea, and part of Tartary; New York, } \\
\text { Boston, in New England, North America. }\end{array}$ \\
\hline 8 & 49 & 1 & 3 & 32 & 16 & 0 & $\begin{array}{l}\text { 8. Paris; Vienna capital of Germany; Nova Scotia, Newfoundland, } \\
\text { and Canada, in North America. }\end{array}$ \\
\hline 9 & 52 & 0 & 2 & 59 & 16 & 30 & $\begin{array}{l}\text { 9. London. Flanders, Prague, Dresten ; Cracow, in Poland; south- } \\
\text { ern provinces of Russia; part of Tartary; north part of New. } \\
\text { folndland. }\end{array}$ \\
\hline i0 & 54 & 27 & 2 & 27 & 17 & 0 & $\begin{array}{l}\text { 10. Diblin. York, Hollund, Hanover, and Ta } \\
\text { land; Labrador, and New South Wales, in }\end{array}$ \\
\hline 11 & 56 & 37 & 2 & 10 & 1 & 30 & 11. Edin \\
\hline 12 & 58 & 29 & 1 & 5 & 1 & 0 & 12. \\
\hline 13 & 59 & 58 & 1 & 29 & 18 & 30 & 13. Ork \\
\hline 14 & 61 & 18 & 1 & 20 & 19 & 0 & 14. $\mathrm{B}$ \\
\hline 15 & 62 & 25 & 1 & 7 & 19 & 30 & 15. Hud \\
\hline 16 & 63 & 22 & & 57 & 20 & 0 & d the south part of West Greenland. \\
\hline 17 & 64 & 6 & & 44 & 20 & 30 & 17. D \\
\hline 18! & 64 & 49 & & 43 & 21 & 0 & 18. $P$ \\
\hline 79 & 65 & 21 & & $\begin{array}{l}32 \\
26\end{array}$ & $\begin{array}{l}21 \\
22\end{array}$ & $\begin{array}{r}30 \\
0\end{array}$ & Sea, Russia. \\
\hline $\begin{array}{l}20 ! \\
21 !\end{array}$ & $\begin{array}{l}65 \\
66\end{array}$ & $\begin{array}{r}47 \\
6\end{array}$ & & $\begin{array}{l}26 \\
19\end{array}$ & $\begin{array}{l}22 \\
22\end{array}$ & $\begin{array}{r}0 \\
30\end{array}$ & 20. H \\
\hline 22 & 65 & 20 & & 14 & 23 & $\begin{array}{r}30 \\
0\end{array}$ & 22. Ne \\
\hline 23 & 66 & 28 & & 8 & 23 & 30 & 23. Davis's Straits, in ditto. \\
\hline 24 & 66 & 31 & & 3 & 24 & & 24. Samoieda. \\
\hline 25 & 67 & 21 & & & & & \\
\hline 26 & 69 & 48 & & & & & 26. W \\
\hline 27 & 73 & 37 & & & & & 27. $\mathrm{Ze}$ \\
\hline 28 & 78 & 30 & & & ths. & & 28, $\mathrm{Ze}$ \\
\hline 29 & 84 & 5 & & & & & 29. Spitzbergen, or Eas \\
\hline & 90 & 0 & & & & & \\
\hline
\end{tabular}


QUADRANT OF ALTITUDE...In order to facilitate the performance of several problems, such as finding the altitude of the sun, measuring the distance and bearings of places, \&c. globes are provided with a pliant narrow plate of brass, divided into ninety degrees, which screws on the brass meridian, and turns every way. This plate is called the Quadrant of Altitude.

Hour circle.... This is a small brass circle, fixed under the bra. zen meridian, divided into twenty-four hours, and having an index moveable round the axis of the globe.

LATrTUDE.... The latitude of any place is its distance from the equator towards either pole, reckoned in degrees of the general meridian, and is northern or southern according as the place lies to the north or south of the equator. No place can have more thar ninety degrees of latitude, because the poles, where the reckoning of the latitude terminates, are at that distance from the equator.

If circles be supposed drawn parallel to the equator through every degree, or every subdivision of a degree of latitude, these circles are called Parallels of Latitude.

Longitude... The longitude of a place is its distance from the first meridian, in degrees of a circle passing through it parallel to the equator, and is reckoned either east or west. 'The first meridian is an imaginary semicircle drawn through any particular place from pole to pole. The situation of the first meridian, or the place from which the longitude is taken, is arbitrary, and has been fixed differently at different times and in different countries. Formerly the meridian of Ferro, the most westerly of the Canary Islands, was made, in general, the first meridian; probably, because the ancient geographers considered it as the most westerly point of the habitable globe; but at present the English astronomers usually reckon from the meridian of London, or rather that which passes through the observatory at Greenwich; the French from that of Paris, \&x. No place can have more than 180 degrees of longitude, because the circumference of the globe being 360 degrees, no place can be remote from another above half that distance; but formerly the French and other foreign geographers, in conformity with an ordonnance of Lewis XIII, reckoned their longitude from Ferro, only to the east, from the 1 st to the 360 th degree, or quite round the globe. The degrees of longitude are not equal, like those of latitude, but diminish in proportion as the meridians incline, or their distance contracts as they approach the pole. Thus in sixty degrees of latitude a degree of longitude is but half the length of a degree on the equator. The number of miles contained in a degree of longitude in each parallel of latitude is given in the following table. 
A TABLE ...SHOWING THE NUMBER OF ENGLISH MILES CONTAINED IN A DEGREE OF LONGITUDE, IN EACH PARALLEL OF LA. TITUDE FROII THE EQUATOR.

\begin{tabular}{|c|c|c|c|c|c|c|c|c|}
\hline $\begin{array}{l}\text { Degrees } \\
\text { of } \\
\text { Latitude. }\end{array}$ & Miles. & $\begin{array}{c}\text { 100th } \\
\text { Parts of } \\
\text { a Mile. }\end{array}$ & $\begin{array}{c}\text { Degrees } \\
\text { of } \\
\text { Latitude }\end{array}$ & Mriles. & $\begin{array}{l}100^{+h} \\
\text { Parts of } \\
\text { a Mlile. }\end{array}$ & $\begin{array}{l}\text { Degrees } \\
\text { of } \\
\text { Latitude }\end{array}$ & Miles. & $\begin{array}{l}\text { 100th } \\
\text { Parts of } \\
\text { a Mile. }\end{array}$ \\
\hline $0^{\circ}$ & 69 & 20 & 30 & 59 & 92 & 60 & 34 & 60 \\
\hline 1 & 69 & 19 & 11 & 59 & 32 & 61 & 33 & 55 \\
\hline 2 & 69 & 16 & 32 & 58 & 69 & 62 & 32 & 49 \\
\hline 3 & 69 & 10 & 33 & 58 & 04 & 63 & 31 & 42 \\
\hline 4 & 69 & 05 & 34 & 57 & 37 & 64 & 30 & 33 \\
\hline 5 & 68 & 95 & 35 & 56 & 69 & 65 & 29 & 24 \\
\hline 6 & 68 & 82 & 36 & 55 & 98 & 66 & 28 & 15 \\
\hline 7 & 68 & 68 & 37 & 55 & 26 & 67 & 27 & 04 \\
\hline 8 & 68 & 52 & 38 & 54 & 53 & 68 & 25 & 92 \\
\hline 9 & 68 & 55 & 39 & 53 & 78 & 69 & 24 & 80 \\
\hline 1) & 68 & 14 & 40 & 53 & 01 & 70 & 23 & 67 \\
\hline 11 & 67 & 93 & 41 & 52 & 2.3 & 71 & 22 & 53 \\
\hline 12 & 67 & 69 & 42 & 51 & 42 & 72 & 21 & 38 \\
\hline 13 & 67 & 43 & 43 & 50 & 61 & 73 & 20 & 23 \\
\hline 14 & 67 & 14 & 44 & 49 & 78 & 74 & 19 & 07 \\
\hline 15 & 66 & 84 & 45 & $43^{-}$ & 93 & 75 & 17 & 91 \\
\hline 16 & 66 & 52 & 46 & 48 & 07 & 76 & 15 & 74 \\
\hline 17 & 66 & 17 & $4 \pi$ & 47 & 19 & 77 & 15 & 57 \\
\hline 18 & 65 & 81 & 48 & 46 & 30 & 78 & 14 & 39 \\
\hline 19 & 65 & 43 & 49 & 45 & 40 & 79 & $1^{3}$ & 20 \\
\hline 20 & 65 & 03 & 50 & 44 & 48 & 80 & 12 & 62 \\
\hline 21 & 64 & 60 & 51 & 43 & 55 & 81 & 10 & 82 \\
\hline 22 & 64 & 16 & 52 & 42 & 60 & $8 ?$ & 09 & 63 \\
\hline 23 & 63 & 70 & 53 & 4.1 & 64 & 8.3 & 08 & 43 \\
\hline 24 & 63 & 22 & 54 & 40 & 67 & 84 & 07 & 23 \\
\hline 25 & 62 & 72 & 55 & 39 & 69 & 85 & 06 & 03 \\
\hline 26 & 62 & 20 & 56 & 38 & 69 & 86 & 04 & 83 \\
\hline 27 & 61 & 66 & 57 & 37 & 69 & 87 & 0,3 & 62 \\
\hline 28 & 61 & 10 & 58 & 36 & 67 & 88 & 02 & 41 \\
\hline 29 & 60 & 52 & 59 & 3.5 & 64 & 89 & 01 & 20 \\
\hline
\end{tabular}

\section{PROBLEMS PERFORMED BY THE GLOBE.}

\section{Proвlem 1. To Rectify the Globe.}

The globe being set upon a true plane, raise the pole according to the given latitude; then fix the quadrant of altitude in the zenith; and if there be any mariner's compass upon the peciestal, let the globe be so situated that the brazen meridian may stand due south and north, according to tivi two exiremities of the needle, allowing for its variation.

\section{PRов. 2. To find the Longitude and Latitude of any Place.}

Bring the given place to the brazen meridian, and the degree it is under is the latitude; then observe the degree of the equator under the same meridian, and you will have the longitude.

Pros. 3. The Longitude and Lati:urle of any Place being given, to find that Place on the Globe.

Bring the degree of longitude to the brazen meridian; find upon the same meridian the degree of latitude, whether south or north, and the point exactly under that degree is the place desired. 
Proв. 4. The Latitude of any Place being given, to find all those Places that have the same Latitude.

(a) РRов. 2. The globe being rectified (a) according to the latitude of the given place, and that place being brought to the brazen meridian, niake a mark exactly above the same, and turning the globe round, all those places passing uncler the said mark have the same latitude with the given place.

\section{Prob. 5. Trvo Places being given on the Globe, to find the Distance between them.}

If the places are under the same meridian, that is, have the same longitude, their difference of latitude, reckoning $69 \frac{1}{2}$ miles to a degree, will give the distance.

If they have the same latitude, but differ in longitude, their distance may be found by their difference of longitude, reckoning the number of miles in a degree of longitude in their common parallel of latitude, according to the table given above.

If they differ both in latitude and longitude, lay the graduated edge of the quadrant of altitude over both the places, and the number of degrees intercepted between them will give their distance from each other, reckoning every degree to be $69 \frac{1}{2}$ English miles.

\section{Pros. 6. To find the Sun's Place in the Eclintic at any Time.}

The month and day being given, look for the same upon the wooden horizon; and over-against the day you, will find the sign and degree in which the sun is at that time; which sign and degree being noted in the ecliptic, the same is the sun's place, or nearly, at the time desired.

Pвов. 7. The Month and Day being given, as also the farticular T'ime of that Day, to find those Places of the Globe to wohich the

Sun is in the Meridian at that Time.

The pole being elevated according to the latitude of the place where you are, bring the said place to the brazen meridian, and setting the index of the horary circle at the hour of the day, in the given place, or where you are, turn the globe till the index points at the upper figure of XII; which done, fix the globe in that situation, and observe what places are exactly under the upper hemisphere of the brazen meridian; for those are the places desired.

Proв. 8. To know the Length of the Day and Night in any Place of the Earth at any Time.

(a) Рнов. 2.

(b) Рвов. 6.

Elevate the pole $(a)$ according to the latitude of the given place; find the sun's. place in the ecliptic (b) at that time; which being brought to the east side of the horizon, set the index of the horary circle at noon, or the upper figure of XII : and turning the globe till the aforesaid place of the ecliptic touch the western side of the horizon, look upon the horary circle; and where the index points, reckon the number of hours to the upper figure of XII; for that is the length of the day; the complement of which to 24 hours is the length of the night. 
Prob. 9. T'o know by the Globe what o' Clock it is in any Part of the World at any Time, provided you know the Hour of the Day quhere you are at the same Time.

Bring the place in which you are to the brazen meridian, the pole being raised $(c)$ according to its

(c) Рrob. 3. latitude, and set the index of the horary circle to the hour of the day at that time. Then bring the desired place to the brizen meridian, and the index will point out the hour at that place.

Prob. 10. A Place being given in the Torrid Zone, to find the two Days of the Year in which the Sun shall be vertical to the same.

Bring the given place to the brazen meridian, and mark what degree of latitude is exactly above it. Move the globe round, and observe the two points of the ecliptic that pass through the said degree of latitude. Find upon the wooden horizon (or by proper tables of the sun's annual motion) on what days he passes through the aforesaid points of the ecliptic; for those are the days required, in which the sun is vertical to the given place.

Proв. 11. The Month and the Day being givers, to find by the Globe those Places of the Northern Frigid Zone, where the Sun begins then to shine constantly rithout setting; as also those Places of the Southern Frigid Zone, zithere he then begins to be totally absent.

The day given (which must be always one of those either be. tween the verual equinox and the summer solstice, or between the autumnal equinox and the winter solstice) find $(d)$ the sun's place in the ecliptic, and, marking the same, (d) Prob. 6. bring it to the brazen meridian, and reckon the like number of de. grees from the north pole towards the equator, as there is between the equator and the sun's place in the ecliptic, making a mark where the reckoning ends. Then turn the globe round, and all the places passing under the said mark are those in which the sun be. gins to shine constantly without setting, upon the given day. For solution of the latter part of the problem, set off the same dis. tance from the south pole upon the brazen meridian towards the equator, as was in the former case set off from the north; then marking as before, and turning the globe round, all places passing under the mark are those where the sun begins his total disappearance from the given day.

Prob. 12. A Place being given in either of the Frigid Zones, to find by the Globe what number of Days the Sun constantly shines ufion the said Place, and what Days he is absent, as also the first and last Day of his Afnearance.

Bring the given place to the brazen meridian, and observing its latitude (a) elevate the globe accordingly; count the same number of degrees upon the meridian

(a) РRов. 2. from each side of the equator as the pize is distant from the pole $;$ and making marks where the reckonings end, turn the globe, and carefully observe what two degrees of the ecliptic pass exactly under the two points marked on the meridian; first for the northem

VOI. I. 
arch of the circle, namely, that comprehended between the two degrees marked, which, being reduced to time, will give the number of days that the sun constantly shines above the horizon of the given place; and the opposite arch of the said circle will, in like manner, give the number of days in which he is totally absent, and also will point out which days those are. And in the interval he daily will rise and set:

Prов. 13. The Month and Day being given, to find those Places on the Globe, to which the Sun, when on the Meridian, shall be vertical on that Day.

(b) Рвов. 6. The sun's place in the ecliptic being found (b) make a small mark exactly above the sun's place. Then turn the globe; and those places which have the sun vertical in the meridian, will successively pass under the said mark.

Рвов. 14. The Month and Day being given, to find ufon what Point of the Comflass the Sun then rises and sets in any Place.

Elevate the pole according to the latitude of the place, and, finding the sun's place in the ecliptic at the given time, bring the same to the eastern side of the horizon, and it will show the point of the compass upon which he then rises. By turning the globe till his place coincicies with the western side of the horizon, you may also see upon that circle the exact point of his setting.

Prob. 15. To know by the Globe the Length of the longest and shortest Days and Nights in any Part of the World.

Elevate the pole according to the latitude of the given place, and bring the first degree of Cancer, if in the northern, or Capricorn, if in the southern hemisphere, to the eastern side of the how rizon. Then, setting the index of the horary circle at noon, turn the globe about till the sign of Cancer touches the western side of the horizon, and observe upon the horary circle the number of hours between the index and the upper figure of XId, reckoning them according to the motion of the index; for that is the length of the longest day, the complement of which to 24 hours is the extent of the shortest night. The shortest day and-longest night are only the reverse of the former.

Рвов. 16. The Hour of the Day being given at any Place, to find those Places of the Earth where it is either Noon or Midnight, or any other harticular Hour, at the same time.

Bring the given place to the brazen meridian, and set the index of the horary circle at the hour of the day in that place. Then turn the globe till the index points at the upper figure of XII, and observe what places arc exactly under the upper senicircle of the brazen meridian; for in them it is midday at the time given. Which done, turn the globe- till the index points at the lower figure of XII, and whatever places are then in the lower semicircle of the meridian, in them it is midnight at the given time. After the same manner we may find those places that have any other 
particular hour at the time given, by moving the globe till the index points at the hour clesired, and observing the places that are then under the brazen meridian.

Proв. 17. The Day and Hour being given, to find by the Globe that harticular Place of the Earth to which the sun is rertical at that Time.

The sun's place in the ecliptic (a) being found, and brought to the brazen meridian, make a mark above the same; then $(b)$ find those places of the earth in whose meridian the sun is at that instant,

(a) Proв. 6.

(b) Prob. 16. and bring them to the brazen meridian; which done, observe that part of the earth which falls exactly under the aforesaid mark in the brazen meridian; for that is the particular place to which the sun is rertical at that time.

Pвов. 18. The Day and Hour at any Place being given, to find all those Places wihere the Sun is then rising, or setting, or in the Meridian; consequently all those Places which are enlightened at that Time, and those wuhich have Truilight, or dark Night.

This problem cannot be solved by any globe fitted up in the common way, with the hour-circle fixed upon the brass meridian, unless the sun be on or near either of the tropics on the given day. But by a globe fitted up with the hour-circle on its surface below the meridian, it may be solved for any day in the year, according to the following method.

Having found the place to which the sun is vertical at the given hour, if the place be in the northern hemisphere, elevate the north pole as many degrees above the horizon as are equal to the latitude of that place : if the place be in the southern hemisphere, elevate the south pole accordingly, and bring the said place to the brazen meridian. Then, all those places which are in the western semicircle of the horizon, have the sun rising to them at that time, and those in the eastern semicircle have it setting: to those under the upper semicircle of the brass meridian it is noon; and to those under the lower semicircle it is midnight. All those places which are above the horizon are enlightened by the sun, and have the sun just as many degrees above them as they themselves are above the horizon; and this height may be known, by fixing the quadrant of altitude on the brazen meridian over the place to which the sun is vertical; and then laying it over any other place, observing what number of degrees on the quadrant are intercepted between the said place and the horizon. In all those places that are 18 degrees below the western semicircle of the horizon, the morning twilight is just beginning; in all those places that are 18 degrees below the eastern semicircle of the horizon, the evening twilight is ending; and all those places that are lower than 18 degrees, have dark night.

If any place be brought to the upper semicircle of the brazen meridian, and the hour index be set to the upper figure of XII, or noon, and then the globe be turned round eastward on its axis; when the place comes to the western semicircle of the horizon, the index will show the time of the sun's rising at that place; and when the 
same place comes to the eastern semicircle of the horizon, the index will show the time of the sun's setting.

To those places which do not go under the horizon, the sun sets not on that day: and to those which do not come above it, the sun does not rise.

Prob. 19. The Month and Day being given, with the Place of the Moon in the Zodiac, and her true Latitude, to find the exact Hour when she will rise and set, together with her Southing, or Coming to the Meridian of the Place.

The moon's place in the Zodiac may be found by an ordinary almanack; and her latitude, which is her distance from the ecliptic, by applying the semicircle of position to her place in the zodiac. For the solution of the problem, elevate the pole $(a)$ (a) Proв. 2 . sun's place in the ecliptic at the time being $(b)$ found, and marked, as also the moon's place at the same time, (b) Pros. 6. bring the sun's place to the brazen meridian, and set the index of the horary circle at noon; then turn the globe till the moon's place successively meet with the eastern and western side of the horizon, as also the brazen meridian; and the index will point at those various times the particular hours of her rising, setting, and southing.

\section{GEOGRAPHICAL OBSERVATIONS.}

1. The latitude of any place is equal to the elevation of the pole above the horizon of that place, and the elevation of the equator is equal to the complement of the latitude, that is, to what the latiqude wants of 90 degrees.

2. Those places which lie on the equator have no latitude, it being there that the latitude begins; and those places which lie on the first meridian have no longitude, it being there that the longitude begins. Consequently, that particular place of the earth where the first meridian intersects the equator has neither longitude nor latitude.

3. All places of the earth equally enjoy the benefit of the sun, in respect of time, and are equally deprived of it.

4. All places upon the equator have their days and nights equally long, that is, 12 hours each at all times of the year. For although the sun declines alternateiy from the equator towards the north and towards the south, yet as the horizon of the equator cuts all the paraliels of latitude and declination in halves, the sun must always continue above the horizon for one half a diurnal revolution about the earth, and for the other half below it.

5. In all places of the earth between the equator and poles, the days and nights are equally long, viz. 12 hours each, when the sun is in the equinoctial: for", in all the elevations of the pole short of 90 degrees (which is the greatest) one half of the equator or equinoctial will be above the hovizon, and the other half below it.

6. The days and nights are never of an equal length at any place between the equator and polar circles, but when the sun enters the signs $\checkmark$ Aries and $=2$ Libra. For in every other part of the ecliptic, the circle of the sun's daily motion is divided into two unequal parts by the horizon. 
7. The nearer any place is to the equator, the less is the difference between the length of the days and nights in that place; and the more remote, the contrary: the circles which the sun describes in the heavens every 24 , hours being cut more nearly equal in the former case, and more unequal in the latter.

8. In all places lying upon any given parallel of latitude, however long or short the day and night, be at any one of those places at any time of the year, it is then of the same length at all the rest; for in turning the globe round its axis (when rectified according to the sun's declination) all those places will keep equally long above and below the horizon.

9. The sun is vertical twice a-year to every place between the tropics; to those under the tropics, once a-ycar, but never any where else. For there can be no place between the tropics, but that there will be two points in the ecliptic whose declination from the equator is equal to the latitude of that place; and there is but one puint of the ecliptic which has a declination equal to the latitude of places on the tropic which that point of the ecliptic touches; and as the sun never goes without the tropics, he can never be vertical to any place that lies rithout them.

10. In all places lying exactly uuder the polar circles, the sun, when he is in the nearer tropic, continues 24 hours above the horizon without setting, because no part of that tropic is below their horizon. And when the sun is in the farther tropic, he is for the same length of time without rising, because no part of that tropic is below their horizon. But at all other times of the year, he rises and sets there as in other places; because all the circles that can be drawn parallel to the equator, between the'tropics, are more or less cut by the horizon, as they are farther from, or nearer to, that tropic which is all above the horizon; and when the sun is not in either of the tropics, his diurnal course must be in one or other of those circles.

11. To all places in the northern hemisphere, from the equator to the polar circle, the longest day and shortest night is when the sun is in the northern tropic; and the shortest day and longest night is when the sun is in the southern tropic; because no circle of the sun's daily motion is so much above the horizon, and so little below it, as the northern tropic; and uone so little above it, and so much below it, as the southeri. In the southern hemisphere, the contrary takes place.

12. In all places between the polar circles and poles, the sun appears for some number of days (or tather diurnal revolutions) without setting, and at the opposite time of the year without rising; because some part of the ecliptic never sets in the former case, and as mush of the opposite part nevel rises in the latter. find the nearer unto, or the more remote from, the pole, these places are, the longer or shorter is the sun's continuing presence or absence.

13. If a ship set out from any port, and sail round the earth eastward to the same port again, let her perform her voyage in what time she will, the people in that ship, in reckoning their time, will gain one complete day at their return, or count one day more than those who reside at the same port; because, by going contrary to the sun's diurnal motion, and being forwarder every evening than they were in the morning, their horizon will get so much the sooner above the setting sun, than if they had remained for a 
whole day at any particular place. And thus, by cutting off from the length of every day a part proportionable to their own motion, they will gain a complete day at their return, without gaining one moment of absolute time. If they sail westward, they will reckon one day less than the people do who reside at the same port; because, by gradually following the apparent diurnal motion of the sun, they will keep him each particular day so much longer above the horizon as answers to that day's course ; and thereby cut off a whole day in reckoning, at their return, without losing ane moment of absolute time.

Hence, if two ships should set out at the same time from any port, and sail round the globe, one eastward and the other westward, so as to meet at the same port on any day whatever, they will differ two days in reckoning the time, at their return. If they sail twice round the earth; they will differ four days; it thrice, then six, \& c.

\section{OF THE NATURAL DIVISIONS OF THE EARTH.}

The constituent parts of the Earth are two, the land and water. The parts of the land are continents, islands, peninsulas, isthmuses, promontories, capes, coasts, mountains, \&c. This land is divided into two great continents (besides the islands) viz. the eastern and zucstern continent. The eastern is subdivided into three parts, viz. Europe, on the north-west; Asia on the north-east; and Africa (which is joined to Asia by the isthmus of Suez, 60 miles over) on the south. The western continent consists of North and South America, joined by the isthmus of Darien, nearly 70 miles broad.

A continent is a large portion of land, containing several countries or kingdoms; without any entire separation of its parts by water, as Europe. An island is a smaller part of land, quite surrounded by water, as Great Britain. A heninsula is a tract of land, everywhere surrounded by water, except at one narrow neck, by which it joins the neighbouring continent, as the Morea in Greece; and that neck of land which so joins it is called an isthmus; as the isthmus of Suez, which joins Africa to Asia, and the isthmus of Darien, which joins North and South America. A promontory is a hill, or point of land, stretching itself into the sea, the end of which is called a cane, as the cape of Good Hope. A coast or shore is that part of a country which borders on the sea-side. Mountains, vallies, woods, deserts, plains, \&c. need no description. The most remarkable are taken notice of, and described, in the body of this work.

The parts of the water are oceans, seas, lakes, straits, gulfs, bays, or creeks, rivers, \&c. The waters are divided into three extensive oceans (besides lesser seas, which are only branches of these) viz. the Atlantic, the Pacific, and the Indian Ocean. The Atlantic or Western Ocean divides the eastern and western continents, and is 3000 miles wide. The Pacific divides America from Asia, and is 10,000 miles over. The Indian Ocean lies between the East Indies and Africa, being 3000 miles wide.

An ocean is a vast collection of water, without any entire separa. tion of its parts by land; as the Atlantic ocean. A sea is a smaller collection of water, which communicates with the ocean, confined by the land; as the Mediterranean and the Red Sea. A lake is a large collection of water, entirely surrounded by land; as the lake of Geneva, and the lakes in Canada. A strait is a narrow part of 
the sea, confined or lying between two shores, and opening a passage out of one sea into another, as the strait of Gibraltar, or that of Magellan. This is sometimes called a sound, as the strait into the Baltic. A gulf is a part of the sea running up into the land, and surrounded by it except at the passage by which it communicates with the sea or ocean. If a gulf be very large, it is called an inland sca, as the Mediterranean; if is do not go far into the land, it is called a bay, as the bay of Biscay; if it be very small, a creek, haven, station, or road for ships, as Milford Haven. Rivers, canals, brooks, \&c. need no description; for these lesser divisions of water, like those of land, are to be met with in most countries, and every one has a clear idea of what is meant by them. But in order to strengthen the remembrance of the great parts of the land and water we have described, it may be proper to observe that there is a strong analogy or resemblance between them. The description of a continent resembles that of an ocean; an island encompassed with water resembles a lake encompassed with land. A peninsula of land is like a gulf or inland sea. A promontory or cape of land is like a bay or creek of the sea; and an isthmus, whereby two lands are joined, resembles a strait, which unites one sea to another.

\section{OF THE TRUE FIGURE AND DIMENSIONS OF THE EARTH.}

Though we have hitherto spoken of the earth as a spherical or globular body, it is necessary to observe that it is not a perfect sphere. Its true figure was the subject of great disputes between the philosophers of the last age, among whom sir Isaac Newton, and Cassini, a celebrated French astronomer, were the leaders of two different parties. Sir Isaac showed, from mathematical prineiples, that the earth must be an oblate spheroid, or that it was flatted at the poles and jutted out towards the equator, so that a. line drawn through the centre of the earth, and passing through the poles, would not be so long as a line drawn through the same centre, and passing through the east and west points. The Frencls mathematician asserted precisely the reverse, that is, that its diameter was lengthened towards the poles. In order to decicle this question, the king of France, in 1736 , sent ont some able mathematicians to Lapland, to measure the length of a degree of latitude at the polar circle, and likewise others to Peru, to make the same admeasurement near the equator. Their observations confirmed the opinion of sir Isaac Newton beyond dispute, and proved that the earth is flatter towards the poles than towards the equator. The nature of sir Isaac's reasoning may be in some mensure elucidated by the simple experiment of fixing a ball of soft clay on a spindle, and whirling it round, for we shall find that it will jut out or project towards the middle, and flatten towards the poles. Sir Isaac, from his theory, had determined that the polar diameter of the eartls must be to the equatorial as 229 to 230 , nr about 55 miles shorter. Maupertuis, and the other French mathematicians who went to Lapland, decluced, from their mensuration of a degree, that the equatorial diameter is 7942 miles, and the polar 7852 miles; so that the former exceeds the latter by 90 miles.

According to these calculations, the circumfcrence of the earth under the equator will be 24,951 miles, which multiplied by the di- 
ameter will gife $198,160,842$ the number of square miles (sixty-nine and a half to a degree) in the spherical surface of the earth; and this number multiplied by one sixth of the diameter will give $524,541,748,774$, the number of cubic miles in its solid contents.

We here subjoin a table exhibiting the superficial contents in square miles, sixty to a degree, of the seas aud unknown parts of the world, of the habitable earth, the four quarters or continents; likewise of the great empires, and principal islands, placed as they are subordinate to each other in magnitude.

\section{TABLE.}

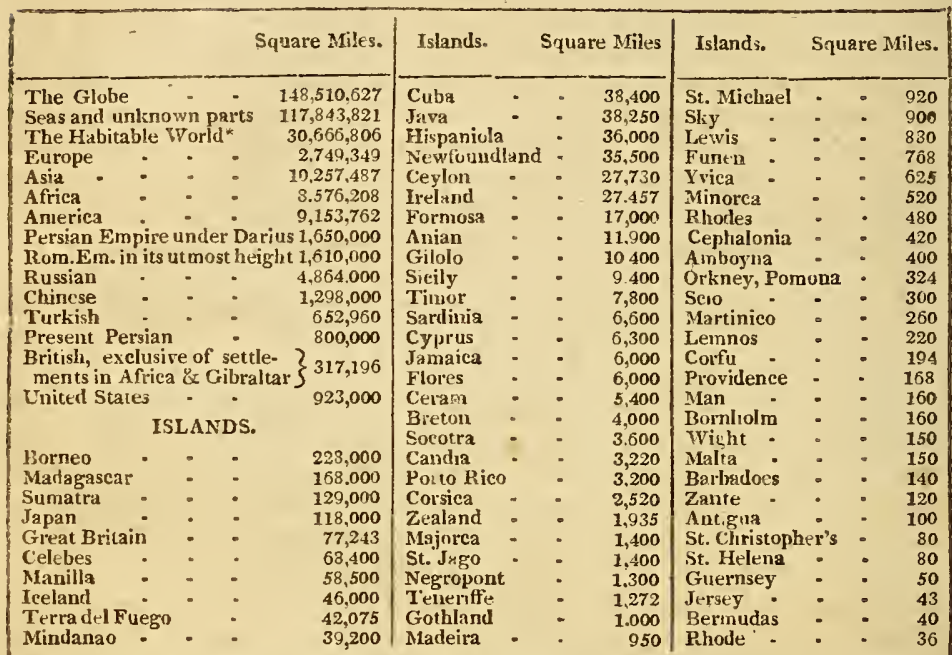

To these islands may be added the following. which have lately been discovered, or more fully explored. The exact dimensions of them are not ascertained; but tbey way be arranged in the following order, accurding to their magnitude, beginning at the largest, which is supposed to be nearly equal in size to the whole continent of Europe:

New Holland,
New Guinea,
New Zealand,
New Caledonia,
New Hebrides,
Otaherte, or I Ing George's Island,

* The number of inhabitants computed at? present to be in the known world, ac a medi. um, taken from the best calculations, are
about 700 millions.
Friendly Islands,

Sand wich Islands,

Navigator's Islands,

Marquesas,

Easter, or Davis's Island.

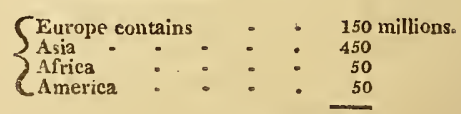

Total 700

Before we conclude this introductory part of our work, it will be proper to give a brief explanation of the nature and cause of winds and tides.

WINDS....The earth on which we live is every where surrounded by a fine invisibie fluid, which extends to several miles above its surface, and is called Air. It is found by experiments, that a small quantity of air is capable of being expanded, so as to fill a very large space, or to be compressed into a much smaller compass than it occupied before. The general cause of the expansion of the air is heat; that of its compression cold. Hence, if any part of the air 
ur atmosphere receive a greater degree of cold or heat than it had before, its parts will be put in motion, and expanded or compressed. But when air is put in motion, we call it wind in general, and a breeze, gale, or storm, according to the quickness or velocity of that motion. Winds, therefore, which are commonly considered as things extremely variable and uncertain clepend on a general cause, and act with more or less uniformity in proportion as the action of this cause is more or less constant. It is found, by observations made at sea, that, from thirty degrees north latitude to thirty de grees south, there is a constant east wind throughout the year blowing on the Atlantic and Pacific oceans, and called the Trade Wind. This is occasioned by the action of the sun, which, in moving from east to west, heats, and consequently expands, the air immediately under him; by which means a stream or tide of air always accompanies him in his course, and occasions a perpetual east-wind within these limits. This general cause, however, is modified by a numa ber of particulars, the explication of which would be too tedious and complicated for our present plan.

The winds called the Tropical Winds, which blow from some particular point of the compass without much variation, are of three kinds; 1. The General Trade Winds, which extend to nearly thirty cegrees of latitude on each side of the equator in the Atlantic, Ethio. pic, and Pacific seas. 2. The Monsoons, or shifting trade winds, which biow six months in one dircction, and the other six months in the opposite. These arc mostly in the Indian or Eastern Ocean, and do not extend above two hundred leagues from the land. Their change is at the vernal and autumnal equinoxes, and is accompanied with terrible storms of thunder, lightning, and rain. 3. The Sea and Land Breezes, which are another kind of periodical winds, that blow from the land from midnight to midday, and from the sea from about noon till midnight; these, however, do not extend above two or three leagues from shore. Near the coast of Guinea in Africa, the wind blows neariy always from the west, south-west, or south. On the coast of Peru in south America, the wind blows constantly from the south-west. Beyond the latitude of thirty north and south, the winds, as we daily perceirc in Great Britain, are more variable, shough they blow oftner from the west than any other point. Between the fourth and tenth degrees of north latitude, and between the longitude of Cape V $\mathrm{T}$ erd and that of the easternmost of the Cape Verd Islands, there is a tract of sea condemned to perpetual calms, attended with terrible thunder and lightning, and such rains, that this sea has acquired the name of the Rains.

Tides.... By the Tides is meant that regular motion of the sea according to which it ebbs and flows twice in twenty-four hours. The immortal sir Isaac Newton was the first who satisfactorily explained the cause and nature of the tides by his great principle of attraction, in consequence of which all bodies mutually draw or attract each other, in proportion to their masses and distance. By the action of this power, those parts of the sea which are immediately below the moon must be drawn towards it; and, consequently, wherever the moon is nearly vertical the sea will be raised, which occasions the flowing of the tide there. A similar cause produces the flowing of the tide likewise in those places where the moon is in the nadir, and which must be diametrically opposite to the former; for, in the hemisplicre farthest from the moon, the parts in the nadir,

Vor. I. 
being less attracted by her than the other parts which are noarer to her, gravitate less towards the earth's centre, and consequently must. be higher than the rest. Those parts of the earth, on the contrary, where the moon appears on the horizon, or ninety degrees distant: from the zenith and nadir, will have low water; for, as the waters in the zenith and nadir rise at the same time, the waters in their neighbourhood will press towards those places, to maintain the equilibrium; and to supply the place with these, others will move the same way, and so on to the places ninety degrees distant from the zenitl and nadir, where the water will be lowest. By combining this doctrine with the diurnal motion of the earth above explained, we shall be sensible of tine reason why the tides ebb and flow twice in a lunar day, or about twenty-four hours fifty minutes.

The tides are higher than ordinary twice every month, that is, about the times of new and full moon, and are called Spring Tides: for at these times the actions of both the sun and moon are united, and draw in the same straight line; and consequently the sea must be more elevated. At the conjunction, or when the sun and moon are on the same side of the earth, they both conspire to raise the waters in the zenith, and consequently in the nadir; and at the opposition, or when the earth is between the sun and moon, while one occasions high water in the zenith and nadir, the other does the same. The tides are less than ordinary twice every month, about the first and lant quarters of the moon, and are called Neap Tides: for in those quarters, the sun raises the waters where the moon depresses them, and depresses where the moon raises them; so that the tides are only occasioned by the difference by which the action of the moon, which is nearest us, prevails over that of the sun. These effects would be produced uniformly, were the whole surface of the earth covered with water; but since there are a multitude of islands and continents which interrupt the natural course of the water, a variety of appearances are to be met with in different places, which cannot be explained without considering the situation of the shores, straits, and other objects that have a share in causing them.

CuRrents.... There are frequently streams or currents in the ocean, which set ships a great way beyond their intended course. There is a current between Florida and the Bahama,islands, which always runs from south to north. A current runs constantly from the Atlantic, through the Strait of Gibraltar, into the Mediterranean. A current sets out of the Baltic Sea, through the Sound or strait between Sweden and Denmark, into the British channel, so that there are no tides in the Baltic. About small islands and heacl-lands in the middle of the ocean, the tides rise very little; but in some bays, and about the mouths of rivers, they rise from 12 to 50 feet.

\section{CONSTRUCTION AND USE OF MAPS.}

$M_{\Lambda P S} \ldots \Lambda$ map is a representation of the earth, or a part of it. A map of the world is a delineation in perspective of the globe, as it would appear to an eye placed in a particular point. The circles bounding such a map represent the brass meridian, and the curve lines running across at every ten degrees show the latitude north or south of the equator. The top and bottom are the north and 
south poles; and the curve lines uniting them are other meridians passing through every tenth degree of the equator, and showing the longitude east or west from the first meridian. The straight line intersecting these meridians, and passing through the centre, is the eatuator, or equinoctial; at proper distances from which, on each side, are curve lines representing the tropics and polar circles.

Maps and charts, especially the latter, are sometimes drawn on what is called Mercator's Projection, which is particularly of use to navigators. In these the meridians and parallels are straight lines, and the former equidistant from each other. The degrees of longitude in every parallel are the same, while the degrees of latitude are all unequal, being lengthened towards the poles. We have annexed a Chart of the TVorld on this projection.

In maps of particular countries, the top is generaliy considered as the north, the botiom as the south; and the east is consequentIy on the right hand, and the west on the left. Where this rule is not followed, a flower-de-luce is usually placed on some part of the map, pointing towards the north, by which the other points may be easily known. From the top to the bottom of the map are drawn meridians, or lines of longitude; and from side to side parallels of latitude. The outermost of the meridians and parallels are marked with degrees of latitude and longitude, by means of which, and the scale of miles commonly placed in the corner of the map, the situation, distance, \&c. of places may be found 'Thus, to find the distance of two places, suppose London and Paris, by the map, we have only to measure the space between them with the compasses, and to apply this distance to the scale of miles, which shows that 3ondon is 210 miles distant from Paris. If the places lie directly north or south, east or west, from each other, we have only to observe the degrees on the meridians and parallels; and by turning: these into miles, we obtain the distance without measuring. River's are described in maps by black lines, and are wider towards the mouth than towards the head or spring. Mountains are sketched on maps as on a picture. Forests and woods are represented by a kind of shrub; bogs and morasses by shades; sands and shallows are described by small dots; and roads usually by double lines. Near harbours, the depth of the water is expressed by figures de. noting fathoms.

LENGTII OF MILES IN DIFFERENT COUNTRIES....There is scarce. lya greater variety in any thing than in this sort of measure: not only those of separate countries differ, as the French from the English, but those of the same country vary in the different provinces from each other, and from the standard. Thus the common Eng lish mile differs from the statute mile : and the French have three sorts of leagues. We shall here give the miles of several countries, compared with the English by Dr. Halley.

The English statute mile consists of 5280 feet, 1760 yards, or 8 furlongs

The Russian verst is little more than $\frac{3}{4}$ of a mile English.

The Scotch and Irish mile is about $1 \frac{1}{4}$ English.

The Dutch, Spanish, and Polish, is about $3 \frac{1}{2}$ English.

The German is more than 4 English.

The Swedish, Danish, and Hungarian, is from 5 to 6 English.

The French common league is near 3 English; and

The English marine league is 3 English miles. 


\section{PART II.}

\section{OF THE ORIGIN OF NATIONS, LAWS, GOVERNMENT, AND COMMERCE.}

Having, in the following work, mentioned the ancient names of countries, and even sometimes in speaking of those countries carzied our researches beyond modern times, it was thought necessa$x y$, in order to prepare the reader for entering upon the particular history of each country we describe, to present him with a general view of the history of mankind, from the first ages of the world to the reformation in religion during the 16th century. An account of the most interesting and important events which have happened among mankind, with the causes that have produced, and the effects which have followed from them, is certainly of great importance in itself, and indispensably requisite to the understanding of the present state of commerce, government, arts, and manners, in any particular country : it may be called commercial and political greography, and, undoubtedly, constitutes the most useful branch of that science.

The great event of the creation of the world, before which there was neither matter nor form of any thing, is placed, according to the best chronologers, in the year before Christ 4004, and in the 710 th year of what is called the Julian period, which has been adopted by some chronologers and historians, but is of little real service. The sacred records have fully determined the question, that the world was not eternal, and also ascertained the time of its creation with great precision.**

It appears in general, from the first chapters in Genesis, that the world, before the flood, was extremely populous; that mankind had made considerable improvement in the arts, and were become extremely vicious, both in their sentiments and manners. Their wickedness gave occasion to a memorable catastrophe, by which B. C. the whole human race, except Noal and his family, were B. C. swept from the face of the earth. The deluge took place in 2348. the 1656th year of the world, and produced a very considerable change in the soil and atmosphere of this globe, rendering them less friendly to the frame and texture of the human body. Hence the abridgement of the life of man, and that formidabic irain of diseases which has ever since made such havock in the world. The memory of the three sons of Noah, the first founders of nations, was long preserved among their several descendants. Japhet continued famous among the western nations, under the celebrated name of Iapetus; the Hebrews paid an equal veneration to Shem, who was the founder of their race; and, among the Egyptians, Ham was long revered as a divinity, under the name

* The Samaritan copy of the Pentateuch (or five books) of Moses, makes the antediluvian period only 1307 years, 349 short of the Hebrew Bible com. putation; and the Septuagint copy stretches it to 2262 years, which is 606 years exceeding it; but the Hebrew chronology is generally acknowledged to be of superior authority. 
of Jupiter Hammon. It appears that hunting was the principal occupation some centuries after the deluge. The world teemed with wild beasts; and the great heroism of those imes consisted in destroying them. Hence Nimrod obtained immortal renown; and, by the admiration which his courage and dexterity unirersally excited, was enabled to found at Babylon the first monarchy whose origin is particularly mentioned in

B. Co 224.7 history. Not long after the foundation of Nineveh was laid by Asa sur; and in Egypt the four governments of Thebes, Theri, Memphis, and Tanis, began to assume some appearance of form and regularity. That these events should have happened so soon after the deluge, whatever surprise it may have occasioned to the learned some centuries ago, need not in the smallest degree excite the wonder of the present age. We have seen, from many instances, the powerful effects of the principles of population, and how speedily mankind increase, when the generative faculty lies under no restraint. The kingdoms of Mexico and Peru were incomparably more extensive than those of Babylon, Nineveh, and Egypt, during that early age; and yet these kingdoms are not supposed to have existed four centuries before the cliscovery of America by Columbus. As mankind continued to multiply on the earth, and to separate from each other, the tradition concerning the true God was cblitcrated or obscured. This occasioned the calling of Abraham to be the father of a chosen people. From this

B. C. 1921. period the history of ancient nations begins to dawn.

Mankind had not long been united into societies before they began to oppress and destroy each other. Chedorlaomer, king of the Elamites, or Persians, was already become a robber and a conquer. or. His force, however, could not have been very great, since, in one of his expeditions, Abraham, assisted only by his household, set upon him in his retreat, and, after a fierce engagement, reco. vered all the spoil that had been taken. Abraham was soon obliged by a famine to leave Canaan, the country where God had commanded him to settle, and to go into Egypt. This journey gives nccasion to Moses to mention some particulars respecting the Egyptians, which eviclently discover the characteristics of an im. proved and powerful nation. The court of the Egyptian monarch is described in the most brilliant colours. He was surrounded by a crowd of courtiers, solely occupied in gratifying his passions. The particular governments into which that country was divided were now united under one powerful prince; and Ham, who lec the colony into Egypt, became the founder of a mighty empire. TVe are not, however, to imagine, that all the laws which tool place in Egypt, and which have been so justly admired for their wisclom, werc the worl: of that early arge. Diodorus Siculus, a Greek writer, mentions many successive princes who laboured for their establishment and perfection. But in the time of Jacob, two centuries after, the first principles of civil orde: and regular government seem to have been tolerably understood among the Egyptians. The country was divided into several districts or se. parate departments; councils composed of experienced and select persons were established for the management of public affairs; granaries for preserving corn were erected; and, in fine, the Egyptians in that age enjoyed a commerce far from inconsiderable. It is from the Egyptians that many of the arts, both of clegance and 
utility, have been handed down in an uninterrupted chain to the modern nations of Europe. The Egyptians communicated their arts to the Greeks; the Greeks taught the Romans many improvements both in the arts of peace and war; and to the Romans the present inhabitants of Europe are indebted for their civilization and refinement. The kingdoms of Babylon and Nineveh remained se. parate for several centuries; but we scarcely know even the names of the kings who governed them, except that of Ninus, the successor of Assur, who, fired with the spirit of conquest, extended the bounds of his kingdom, added Babylon to his dominions, and laid the foundation of that monarchy, which, raised to its meridian splendour by his enterprising successor Semiramis, and distinguished by the name of the Assyrian empire, ruled Asia for many ages.

Javan, son of Japhet, and grandson of Noah, was the stock from whoin all the people known by the name of Greeks are descended. Javan established himself in the islands on the western coast of Asia Minor, from whence it was impossible that some wanderers should not pass over into Europe. The kingdom of Sicyon, near Corinth, founded by the Pelasgi, is generally supposed to have commenced in the year before Christ 2090. To these first inhabitants succeeded a colony from Egypt, who, about 2000 years beforc the Christian æra, penetrated into Greece, and, under the name of Titans, endeavoured to establish monarchy in that country, and to introduce into it the laws and civil polity of the Egyptians. But the empire of the Titans was soon dissolved; and the Greeks, who seem to have been at this time as rude and barbarous as any people in the world, again fell back into their lawless and savage manner of life. Several colunies, however, soon after passed over from Asia into Greece, and, by remaining in that country, produced a more B. C. considerable alteration in the manner of its inhabitants. The I850. most ancient of these were the colonies of Inachus and Ozyges; of whom the former settled in Argos, and the latter in Attica. We know very little of Ogygges or his successors. Those of Inachus endeavoureci to unite the dispersed and wandering Grecks; and their endearours for this purpose were not altogether unsuccessful.

But the history of the Israelites is the only one with which we are much acquainted during those ages. The train of extraordinary events which occasioned the settling of Jacob and his family in that part of Egypt of which Tanis was the capital are universally B. C. known. That patriarch died, according to the Hebrew clroB. C. nology, only 1689 years before Christ, and in the year of the 1689. world 2515 . This is a remarkable æra with respect to the nations of heathen antiquity, and concludes that period of time which the Greeks considered as altogether unknown, and which they have greatly disfigured by their fauulous narrations. Let us examine, then, what we can learn from the sacred writings, with respect to the arts, manners, and laws, of ancient nations.

It is a common error among writers on this subject, to consider all the nations of antiquity as being then alike in these respects. They find some nations extremely rude and barbarous, and hence they conclude that all were in the same situation. They discover others acquainted with many arts, and hence they infer the wisdom. of the first ages. There appears, however, to have been as much differcnce between the inlabitants of the ancient world, with regard 
to arts and refinement, as between the civilized kingdoms of modern Europe and the Indians of America, or the Negroes on the coast of Africa. Noah was undoubtedly acquainted with all the science and aris of the antediluvian world : these he would communicate to his children, and they again would hand them down to their posterity. Those-nations, therefore, who settled nearest the original seat of mankind, and who had the best opportunities to avail themselves of the knowledge which their great ancestor was possessed of, early formed themselves into regular societies, and made consicerable improvements in the arts which are most subservient to human life. Agriculture appears to have been known in the first ages of the world. Noah cultivated the vine; in the time of Jacob the fig-tree and the aimond were well known in the land of Canaan; and the instruments of husbandry, long before the discovery of them in Grcece, are often mentioned in the sacred writings. It is scorcely to be supposed that the ancient cities, both in Asia and Egypt (whose foundation, as we have already mentioned, ascends to the remo:est antiquity) could have been built, unless the culture of the ground had been practised at that time. Nations who live by hunting or pasturage only, lead a wandering life, and seldom fix their residence in cities. Commerce naturally foliors agriculture : and though we cannot trace the steps by which it vas introduced among the ancient nations, we may, from detached passages in sacred writ, ascertain the progress which had been male in it during the patriarchal times. We know, from the history of civil society, that the commercial intercourse between men must be pretty considerable, before the metals come to be considered as the medium of trade; and yet this was the case even in the days of Abraham. It appears, however, from the relations which establish this fact, that the use of money had not been of ancient date; it had no mark to ascertain its weight or fineness; and in a contract for a burying-place, in exchange for which Abraham gave silver, the metal was rreighed in the presence of all the people. As commerce improved, and bargains of this sort became more common, this practice was laid aside, and the quantity of silver was ascertain. ed by a particular mark, which saved the trouble of weighing it. But this does not appear to have taken place till the time of Jacob, grandson of Abraham. The refilah, of which we read in his time, was a piece of money, stamped with the figure of a lamb, and of a precise and stated value. The history of Joseph shows that commerce between different nations was then regularly carried on. The Ishmaëlites and Midianites, who bought him of his brethren, were travelling merchants, rcsembling the modern caravans, who carried spices, perfumes, and other rich commodities, from their own country into Egypt. Job, who, according to the best writers, was a native of Arabia Felix, and also a contemporary with Jacob, speaks of the roads of Thema and Saba, i.e. of the caravans which set out from those cities of Arabia. If we reflect that the com= modities of that country were rather the luxuries than the necessaries of life, we shall have reason to conclude that the countries into which they were sent for sale, and particularly Egypt, were considerably improved in arts and refinement.

That branch of the posterity of Noah who settled on the coasts of Palestine, were the first people of the world among whom navigation was made subservient to commerce : they were distinguished by a 
word which in the Hebrew tongue signifies merchants, and are the same nation afterwards known to the Greeks by the name of Phœnicians. Inhabiting a barren and ungrateful soil, they applied themselves to improve their situation by cultivating the arts. Commerce was their principal pursuit: and with all the writers of payan antiquity, they pass for the inventors of whatever tended to its advancement. At the time of Abraham they were regarded as a powerful nation : their maritime commerce is mentioned by Jacob in his last words to his children; and according to Herodotus, the Phonicians had by this time navigated the coasts of Greece, and carried of the daughter of Inachus.

The arts of agricuiture, commerce, and navigation, suppose the Knowledge of several others : astronomy, for instance, or a knowledge of the situation and revolutions of the heavenly bodies, is necessary both to agriculture and navigation; that of working metals, to commerce; and so of other arts. In fact we find, that before the death of Jacob, several nations were so well acquainted with the revolutions of the moon, as to measure by them the duration of their year. It had been a custom among all the nations of antiquity, as well as the Jews, to divide time into portions of a week, or seven days : this undoubted!y arose from the tradition with regard to the origin of the world. It was natural for those nations who led a pastoral life, or who lived under a serene sky, to observe that the various appearances of the moon were completed nearly in four weeks : hence the division of a month. Those people, again, who lived by agriculture, and were become acquainted with the division of the month, would naturally remark that twelve of these brought back the same temperature of the air, or the same seasons: hence the origin of what is called the lunar year, which has every where taken place in the infancy of science. This, together with the observation of the fixed stars, which, as we learn from the book of Job, must have been very ancient, naturally prepared the way for the discovery of the solar year, which at that time would be thought an immense improvement in astronomy. But, with regard to those branches of knowledge which we have mentioned, it is to be remembered that they were peculiar to the Egyptians, and a few nations of Asia. Europe offers a gloomy spectacle during this period. Even the inhabitants of Greece, who in later ages became the patterns of politeness and of every elegant art, where then a savage race of men, traversing the woods and wilds, inhabiting the rocks and caverns, a wretched prey to wild animals, and sometimes to each other. Those descendants of Noah who had removed to a great distance from the plains of Shinar, lost all connexion with the civilized part of mankind. Their posterity became still more ignorant; and the human mind was at length sunk into an abyss of misery and wretchedness.

We might naturally expect, that, from the death of Jacob, and as we advance forward in time, the history of the great empires of Egypt and Assyria would emerge from their obscurity. This, how B. C. ever, is far from being the case ; we only obtain a glimpse of B. C. them, and they disappear entirely for many ages. After the 1965. reign of Ninyas, who succeeded Semiramis and Ninus on the Assyrian throne, we find an astonishing blank in the history of that empire for no less than eight hundred years. The silence of ancient history on this'subject is commonly attributed to the soft- 
ness and effeminacy of the successors of Ninus, whose lives afforded no events worthy of narration. Wars and commotions are the great thenes of the historian, while the gentle and happy reigns of wise princes, pass unobserved and unrecorded. Sesostris, a prince of wonderful abilities, is supposed to have succeeded Ameophis, who was swallowed up in the Red Sea about the year before Christ 1892. By his assicluity and attention, the civil and military establishments of the Egyptians received very considerable improvements. Egypt, in the time of Sesostris and his immediate successors, was, in all probability, the most powerful kingdom upon earth, and is estimated to have contained 27 millions of inhabitants. Jut ancient history often excites, without gratifying, our curiosity; for, from the reign of Sesostris to that of Bucchoris, in the year before Christ 1781, we have little knowledge of even the names of the intermediate princes. Egypt, however, continued to pour forth her colonies into distant nations. Athens, that seat of learn. ing and poiteness, that school for all who aspired to wisdom,

owed its foundation to Cecrops, who landed in Greece with an B. C. Egyptian colony, and endeavoured to civilize the rough man- 1556. ners of the original inhabitants. From the institutions which Cccrops established among the Athenians, it is easy to infer in what a condition they must have lived before his arrival. The laws of marriage, which few nations are so barbarous as to be altogether unacquainted with, were not known in Greece. Mankind, like the beasts of the field, were propagated by accidental connexions, and with little knowledge of those to whom they owed their B. C. birth. Cranaüs, who succeeded Cecrops in the kingdom of 1506. Attica, pursued the same beneficial plan, and endeavoured, by wise institutions, to bridle the keen passions of a rude people.

Whilst these princes used their endeavours for civilizing this corner of Greece, the other kingdoms into which this country, by the natural boundaries of rocks, mountains, and rivers, was divided, and which had been already peopled by colonies from Egypt and the East, began to assume some appearance of form and regularity. Amphictyon conceived the idea of uniting in one B. C. confederacy the several independent kingdoms of Greece, and 1496. thereby delivering them from those intestine divisions which must render them a prey to each other, or to the first enemy who might think proper to invacle them. This plan he communicated to the kings or leaders in the different territories, and by his eloquence and address engaged twelve cities to unite together for their common preservation. Two deputies from each of those cities assembled twice a-year at Thermopylæ, and formed what, after the name of its founder, was called the Amphictyonic Council. In this assembly, whatever related to the greneral interest of the confederacy was discussed and finally determined. Amphictyon likewise, sensible that those political connexions are the most lasting which are strengthened by religion, committed to the Amphictyons the care of the Temple at Delphi, and of the riches which, from the dedications of those who consulted the oracle, had been amassed in it. This assembly was the great spring of action in Greece, while that country preserved its independence; and, by the union which it inspired among the Greeks, enabled them to defend their liberties against all the force of the Persian empire. Consiclering the circumstances of the age in which it was instituted, the Amphic. 
Eyonic council is, perhaps, the most remarkable political establish ment which ever took place among mankind.

In the year before Christ 1322, the Isthmian games were instituted at Corinth; and in 1303 the famous Olympic ganes by Pclops; which games, together with the Pythian and Nemæan, have been renclered immortal by the genius of Pindar.

The Greek statcs, formerly unconnected with each other, except by mutual inroads and hostilities, soon began to act with concert, and to undertake distant expeditions for the greneral interest of the confederacy.

The first of these was the famous expedition of the Argonauts, in which all Greece appears to have taken part.

B.C. The object of the Argonäuts was to open the commerce of 1263. the Euxine Sea, and to establish colonies in the adjacent country of Colchis. The ship Argo, which was the admiral of the flect, is the only one particularly named; though we learn from Homer, and other ancient writers, that several vessels were employed in that expedition. The feet was long tossed about on different coasts; but at length arrived at Fin, the capital of Colchis, after performing a voyage, which, considering the mean condition of the naval art during that age, was not less important than the circumB. C. navigation of the earth by our modern discoverers. During B. C. the interval between this voyage and the war against Troy, 1184. which was undertaken to recover the fair Helena, a queen of Sparta, who had been carried off by Paris, son of the Trojan king, the Greeks must have made a wonderful progress in arts, in power, and opulence. No less than 1200 vessels were employed in this expedition, each of which, at a medium, contained upwards of one hundred men. These vessels, however, were but half-decked; and it does not appear that iron entered at all into their construction. If we add to these circumstances, that the Greeks had not the use of the saw, an instrument so recessary to the carpentery a mociern must form but a mean notion of the strength or elegance of this fleet.

Having thus considered the state of Greece as a whole, let us exan mine the circumstances of the particular countries into which it was divided. There appears originally to have been a remarkable resemblance, as to their political situation, between the different kingdoms of Greece. They were governed each by a king, or rather by a chieftain, who was their leader in time of war, their judge in time of peacc, and who presided in the administration of their religious ceremonies. This prince, however, was far from being absolute. In each society there were a number of other leaders, whose influence over their particular clans or tribes was not less consiclerable than that of the king over his immediate followers. These captains were often at war with each other, and sometimes with their sovereign; and, each particular state was, in miniature, what the whole country had been before the time of Amphictyon. Theseus, king of Attica, about the year B. C. 1234, had, by his exploits, acquired great reputation for valour and ability. He saw the inconveniences to which this country, from being divided into twelve districts, was exposed; and he conceived, that, by means of the influence which his personal character, united to the royal authority with which he was invested, had universally procured him, te might be able to remove them. For this purpose he endeavour- 
ed to mantain and even to increase his popularity among the peasants and artisans; he detached, as much as possible, the diffurent tribes from the leaders who commanded them; he abolished the courts which had been established in different parts of Attica, and appointed one council-hail common to all the Athenians. Theseus, however, did not trust solely to the force of political regulations. He called to his aid all the power of religious prejudices. By establishing common rites of religion to be performed in Athens, and by inviting thither strangers from all quarters, by the prospect of protection and privileges, he raised that city from an inconsiderable village to a powerful metropolis. The splendor of Athens and of Theseus now totally eclipsed that of the other villages and their particular leaders. All the power of the state was in one city, and under one sovereign. The petty chieftains, who had formerly occasioned so much confusion, being now divested of all influence and consideration, became humble and submissive; and Attica remained under the peaceable government of a monarch.

This is a rude sketch of the origin of the first monarchy of which we have a distinct account, and may, without much variation, be applied to the other states of Greece. This country, however, was not destined to continue long under the government of kings. A new infuence arose, which in a short time proved too powerful both for the king and the nobles. Theseus had divided the Athenians into three distinct classes...the nobles, the artisans, and the husbandmen. In order to abridge the exorbitant power of the nobles, he had bestowed many privileges on the two other ranks of citizens. This plan of politics was followed by his successors; and the lower ranks of the Athenians, partly from the countenance of their sovereign, and partly from the progress of arts and manufactures which gave them an opportunity of acquiring property, be came considerable and independent. These circumstances were attended with a remarkable effect. Upon the death of Codrus, a prince of great merit, in the year before Christ 1070, the Athenians, become weary of the regal authority under pretence that they could find no one worthy of filling the throne of that monarch, who had devoted himself to death for the safety of his people, abolished the regal power, and proclaimed that none but Jupiter should be king of Athens.

The government of Thebes, another of the Grecian states; much about the same time, assumed the republican form. Near a century before the Trojan war, Cadmus, with a colony from Phœnicia, had founded this city, which from that time had been governed by kings. But the last sovereign being overcome in single combat by a neighbouring prince, the Thebans abolished the regal power. Till the days, however, of Pelopidas and Epaminondas (a period of seven hundred years) the Thebans performed nothing worthy of the republican spirit. Other cities of Greece, after the example of Thebes and Athens, erected themselves into republics. But the revolutions of Athens and Sparta, two rival states, which, by means of the superiority they acrjuired, gave the tone to the manners, genius, and politics of the Greeks, deserve our particular attention. The Athenians, by abolishB. C. 1070. ing the name of king, on the death of Codrus, did not entirely subvert the regal authority: they established a perpetual magis. trate, who, undel the name of Archon, was invested with almost 
the same powers which their kings had enjoyed; but after that office had continued three hundred and thirty-one years in the family of Codrus, they endeavoured to lessen its dignity, not by abridg ing its power, but by shortening its duration. The first period asB. C. signed for the continuance of the archonship in the same 684. person, was three years. Afterwards, still more to reduce the power of their archons, it was determined that nine annual magistrates should be appointed under this title. These magistrates were not only chosen by the people, but accountable to them for their conduct at the expiration of their office. These alterations were too violent not to be attended with some dangerous consequences. The Athenians, intoxicated with their freedom, broke out into the most unruly licentiousness. No written laws had been as yet enacted in Athens; and it was hardly possible that the ancient customs of the country, which wcre naturally supposed to be in part abolished by the successive changes in the government, should sufficiently restrain the tumultuous spirits of the Athenians in the first paroxysm of their independence. The wiser part of the state, therefore, who began to prefir any system of government to their present anarchy and confusion, were induced to cast their eyes on Draco, a man of an austere but virtuous disposition, as the fittest person for composing a system of law to bridle the furinus and unruly multitude. Draco undertook the office about the year 628 , but executed it with so much rigour, that, in the words of an ancient historian, "His laws were written with blood, and not with ink." Death was the indiscriminate punishment of every offence; and the code of Draco proved to be a remedy worse than the disease. Affairs again fell into confusion, which continued till those laws were reformed in the time of Solon, about the year before Christ 594. The wisdom, virtue, and amiable manners of Solon recommended bim to the most important of all offices, the giving laws to a free people. This employment was assigned him by the unanimous voice of his country; but he long deliberated whether he should undertake it. At length, however, motives of public utility overcame all considerations of private ease, safety, and reputation. The first step of his legislation was to abolish all the laws of Draco, excepting those relative to murder. The punishment of this crime could not be too great; but to consider other offences as equally criminal, was confounding all notions of right and wrong, and rendering the law ineffectual by its severity. Solon next proceeded to new-model the political law. He seems to have thought, that a perfect republic, in which each citizen should have an equal political importance, was a system of government, beautiful indeed in theory, but not reducible to practice. He diviced the citizens therefore into four classes, according to the wealth which they possessed; and the poorest class he rendered altogether incapable of any public office. They had a voice, how ever, in the general council of the nation, in which all matters of principal concern were determined in the last resort. But lest this assembly, which was composed of all the citizens, should, in the words of Plutarch, like a ship with too many sails, be exposed to the gusts of folly, tumult, and disorder, he provided for its safety by the twro anchors of the Senate and Areopagus. The first of these courts consisted of four hundred persons, a hundred from each tribe of the Athenians, who prepared all important bills that 
came before the assembly of the people; the second, though but a court of justice, gained a prodigious ascendency in the republic, by the wisdom and gravity of its members, who were not chosen but after the strictest scrutiny and the most scrious deliberation.

Such was the system of government established by Solon, which, the nearer we examine it, will the more excite our admiration. Upon the same plan most of the other ancient republics were established. To insist on all of therr, therefore, would neither be entertaining nor instructive. But the government of Sparta, or Lacedremon, had something in it so peculiar, that the great outlines of it at least ought not to be here omitted. The country, of which Sparta afterwards became the capital, was, like the othel states of Greece, originally divided into several petty principalities, of which each was under the jurisdiction of its own immediate chieftain. Lelex is said to have been the first ling, about the year before Christ 1516. At length, the two brothers, Eurysthenes and Procles, obtaining possession of this country, became conjunct in the royalty; and, what is extremely singular, their

B. C. 1102. posterity, in a direct line, continued to rule conjunctly for nine is undred years, ending with Cleomenes, anno 220 betore the Christi:tn æra. The Spartan government, bowever, did not take that singular form which renders it so remarkable, until the ime of Lycurgus, the celebrited legislator. The plan of 884. policy devised by L.ycurgus agreed with that already clescribed, in comprehending a senate and assembly of the people, and, in general, all those establishments which are deemed most requisite for the security of political independence. It differed from that of Athens, and indeed from all other governments, in having two kings, whose office was hereditary, though their power was suffieiently circumscribed by proper checks and restraints. But the sreat characteristic of the Spartan constitution arose from this, that, in all his laws, Lycurgus had at least as much respect to war as to political liberty. With this view, all sorts of luxury, all arts of elegance or entertainment, every thing, in finc, which had the smallest tendency to soften the minds of the Spartans, was absolutely proscribed. They were forbidlen the use of money; they lived at public tables on the coarsest fare; the younger were taught to pay the utmost reverence to the more advanced in years; and all ranks capable of bearing arms were daily accustomed to the most painful exercises. To the Spartans, alone, war was a relaxation rather than a hardship; and they behaved in it with a spirit, of which scarcely any but a Spartan could even form a conception.

In order to see the effect of these principles, and to connect unler one point of view the history of the different quarters of the globe, we must now cast our eyes on Asia, and observe the events which happened in those great empires of which we have so long lost sight. TVe have already mentioned in what obscurity the history of Egypt is involved, until the reign of Bocchoris. From this period to the dissolution of their government by Cambyses of Persia, in the year before Christ 524, the Egyptians are more celebrated for the wisdom of their laws and political institutions, than for the power of their arms. Several of these seem to have been dictated by the true spirit of civil wisdom, and were admirably calculated for preserving order and good 
government in an extensive kingdom. The great empire of Assy. ria, likewise, which had so long disappeared, becomes again an ob. ject of attention, and affords the first instance we meet with in history, of a kingdom which fell asunder by its own weight, and the effeminate weakness of its sovereigns. Sardanapalus, the last em. peror of Assyria, neglecting the adninistration of affairs, and shutting himself up in his palace with his women and eunuchs, fell into contempt with his subjects. The governors of his provinces, to whom, like a weak and indolent prince, he had entirely committed the command of his armies, did not fail to seize this opportunity of raising their own fortune on the ruins of their master's power. Arbaces, governor of Media, and Belesis, governor of Babylon, conspired argainst their sovereign, and having set fire to his capital (in which Sardanapalus perished) divided between them his extensive dominions. These two kingdoms, sometirnes united under one prince, and sometimes governed each by a particular sovereign, maintained the chief sway in Asia for many years. Phul revived the kingdom of Assyria; and Sholmaneser, orie of his successors, put an end to the kinglom of Israel, and carried the ten tribes captive into Assyria and Media. Nebuchadnezzar, king of Babylon, also in the year before Christ 587, overturned the kingdom of Judah, which had continued in the family of David from B. C. the year 1055, and conquered all the countries round him, 538. But in the year 538, Cyrus the Great took Babylon, and reduced this quarter of the world under the Persian yoke. The manners of this people, brave, hardy, and inclependent, as well as the government of Cyrus in all its various depurtments, are elegantly described by Xenophon, a Grecian philosopher and historian. The xra of Cyrus is in one respect extremely remarkable, besides that in it the Jews were delivered from their captivity, because with it the history of the great nations of antiquity, which has hitherto engaged our attention, may be said to terminate. Let us consider, then, the genius of the Assyrians, Babylonians, and Egyptians, in arts and sciences; and, if possible, discover what progress they had made in those acquirements which are most subservient to the interests of society.

The taste for the great and magnificent seems to have been the prevailing character of those nations; and they principally displayed it in their works of architecture. There are no vestiges, however, now remaining, which confirm the testimony of ancient writer's with regard to the great works that adorned Babylon and $\mathrm{Ni}$ neveh : neither is it clearly determined in what year they were begun or finished. There are three pyramids, stupendous fabrics, still remaining in Egypt, at some leagues distance from Cairo, and about nine miles from the Nile, which are supposed to have been the burying-places of the ancient Egyptian kings. The largest is five hundred feet in height, and each side of the base six hundred and ninety-three feet in leagth. The apex is thirteen feet square. The second covers as much ground as the first, but is forty feet lower. It was a superstition among the Egyptians, derived from the earliest times, that even after death the soul continued in the body as long as it remained uncorrupted. Hence proceeded the custom of embalming. The pyramids were erected with the same view. In them the bodies of the Egyptian kings, it has been supposed, were deposited. From what we read of the walls of Baby " 
Ion, the temple of Belus, and other works of the East, and from what travellers have recorded of the pyramids, it appears that they were really superb and magnificent structures, but totally void of elegance. The arts in which those nations, next 10 architecture, chiefly excelled, were sculpture and embroidery. As to the sciences, they principally bestowed their attention on sstronomy. It does not appear, nowever, that they had made yreat progress in explaining the causes of the phxnomena of the universe, or indeed in any species of raional and sound philosophy; as a proof of which it may be suficient to observe, that, according to the testimony ui sacred and profane writers, the absurd reveries of magic and astrology, whicis always decrease in proportion to the advancement of true science, were in high esteem among them during the latest period of their government. The countries which they occupied were extremely fruitful, and without much labour afforded all the necessaries, and even luxuries, of life. They had long inhabited great cities. 'These circumstances had tainted their manners with effeminacy and corrupion, and rendered them an easy prey to the Persians, a nation just emerging from barbarism, and, of consequence, brave and warlike.

The history of Persia, after the reign of Cyrus, who died in the year before Christ 529, offers little, considered in itself, that merits our regard; but, when combined with that of Greece, it becomes particuiarly interesting. The monarchs who succeeded Cyrus ̧ave ań opportunity to the Greeks to exercise those virtues which the freedom of their government had created and confirmed. Sparta remained under the influence of the institutions of Lycurgus: Athens had just recovered from the tyranny of the Pisistratidæ, a family who had trampled on the laws of Solon, and usurped the supreme power. Such was their situation, when Darius (at the instigation of Hippias, who had been expelled from Athens, and on account of the Athenians burning the city of Sardis) sent forth his numcrous armies against Greece.

B. C. 504. But the Persians were no longer those invincible soldiers who, under Cyrus, had conquered Asia. Their minds were enervated by luxury and servitude. Athens, on the contrary, teemed with great men, aninated by the late recovery of their freedom.

Miltiades, in the plains of Marathon, with ten thousand Athenians, overcame the Persian army of a hundred thousand foot and ten thousand cavalry. His countrymen Themistocles and Aristides, the first celebrated for his abilities, the second for his virtue, gained the next honours to the general. It does not fali within our plan to mention the events of this war, which, as the roblest monuments of the triumph of virtue over force, of courage over numbers, of liberty over servitude, deserve to be read at. length in ancient writers.

Xerxes, the son of Darius, came in person into Greece, with an immense army, which, according to Herodotus, amounted to two millions and one hundred thousand men. This account has been justly considered, by some ingenious modern wriB. C. 4.80 . ters, as incredible. The truth cannot now be ascertained; but that the army of Xerxes was extremely numerous, is the more probable, from the great extent of his empire, and from the absurd practice of the eastern nations, of encumbering their camp with a superfuous multitude. Whatever the numbers of his army were, he 
was every where defeated, by sea and land, and escaped to Asia in a fishing-boat. Such was the spirii of the Greeks, and so well did they know, that, "wanting virtue, life is pain and woe ; that wanting liberty, even virtue mourns, and looks around for happiness in vain." But, though the Persian war concluded gloriously for the Greeks, it is in a great measure to this war that the subsequent misfortunes of that nation are to be attributed. It was not the battles in which they suffered the loss of so many brave men, but those in which they acquired the spoils of Persia; it was not their enduring so many hardships in the course of the war, but their connexions with the Persians after the conclusion of it; which subverted the Grecian establishments, and ruined the most virtuous confederacy that ever existed upon earth. The Greeks became haughty after their victories. Delivered from the common enemy, they began to quarrel among themselves; and their quarrels were increased by Persian gold, of which they had acquired enough to B. C. make them desirous of more. Hence proceeded the famous 431. Peloponnesian war, in which the Athenians and Lacedæ. 431. monians acted as principals, and drew after them the other states of Greece. They continued to weaken themselves by these intestine divisions, till Philip, king of Macedon (a country till this time little known, but which, by the active and crafty genius of that prince, became important and powerful) rendered himself the absoB. C. lute master of Greece, by the battle of Chæronea. But this 3. C. conquest is one of the first we meet with in history, which 338. did not depend on the event of a battle. Philip had laid his scheme so deeply, and by bribery, promises, and intrigues, gained over such a number of considerable persons in the several states of Greece to his interest, that another day would have put in his possession what Chæronea had denied him. The Greeks had lost that virtue which was the basis of their confederacy. Their popular governments served only to give a sanction to their licentiousness and corruption. The principal orators in most of their states were bribed in the service of Philip, and all the eloquence of a Demosthenes, assisted by truth and virtue, was unequal to the mean but more seductive arts of his opponents, who, by flattering the people, used the surest method of gaining their affections.

Philip had proposed to extend the boundaries of his empire beyond the narrow limits of Greece. But he did not long survive the battle of Chæronea. Upon his decease his son Alexander was chosen general against the Persians, by all the Grecian states, B. C. except the Athenians and Thebans. These made a feeble 334. effort for expiring liberty; but they were obliged to yield to 334. superior force. Secure on the side of Greece, Alexander set out on his Persian expedition, at the head of thirty thousand foot, and five thousand horse. The success of this army in conquering the whole force of Darius in three great battles, in overruming and subduing, not only the countries then known to the Greeks, but many parts of India, whose very names had never before reached an European ear, has been described by many authors, both ancient B. C and modern, and constitutes a singular part of the history of 323. the world. Soon after this rapid career of victory and suc323. cess, Alexander died at Babylon. His captains, after sacrificing all his family to their ambition, divided among them his do. minions. 
During the period which elapsed between the reign of Cyrus and that of Alexander, the arts were carried to the highest perfection. Though the eastern nations had raised magnificent and stupendous structures, the Greelss were the first people in the world, who, in their works of architecture, added beauty to magnificence, and elegance to grandeur. The temples of Jupiter Oiympius and of the Ephesian Diana were the first monuments of good taste. They were erected by the Grecian colonies who settled in Asia Minor before the reign of Cyrus. Phidias, the Athenian, who died in the year B. C. 432 , is the first sculptor whose works have been immortal. Zeuxis, Parrhasius, and Timanthus, during the same age, first discovered the power of the pencil, and all the magic of painting. Composition, in all its various branches, reached a degree of perfection in the Greek language, of which a modern reader can scarcely form an idea. After Hesiod and Homer, who flourished 1000 years before the Christian $x$ ra, the tragic poets, Eschylus, Sophocles, and Euripides, were the first considerable improvers of poetry. Herodotus grave simplicity and elegance to prosaic writing. Isocrates gave it cadence and harmony; but it was left to Thucydides and Demosthenes to discover the full force of the Greek tongue. It was not, however, in the finer arts alone that the Grecks excelled. Every species of philosophy was cultivated among them with the utmost success. Not to mention the divine Socrates, the virtues of whose life, and the excellence of whose philosophy, justly entitled him to a very high degree of veneration; his three disciples, Plato, Aristotle, and Zenophon, may, for strength of reasoning, justness of sentiment, and propriety of expression, be considered as the equals of the best writers of any age or country. Experience, indeed, in a long course of years, has taught us many secrets in nature, with which those philosophers were unacquainted, and which no strength of genius could divine. But whatever some vain empirics in learning may pretend, the most learned and ingenious men, both in France and England, have acknowledged the superiority of the Greek philosophers, and have reckoned themselves happy in catching their turn of thinking and manner of expression. The Greeks were not less distinguished for their active than for their speculative talents. It would be endless to recount the names of their famous statesmen and warriors; and it is impossible to mention a few without cloing injustice to a greater number. War was first reduced to a science by the Greeks. Their soldiers fought from an affection to their country and an ardour for glory, and not from a dread of their superiors. We have seen the effects of this military virtue in their wars against the Persians; the cause of it was the wise laws which Amphictyon, Solon, and Lycurgus, had established in Greece. But we must now leave this nation, whose history, both civil and philosophical, is as important as their territory was inconsiderable, and turn our attention to the Roman affairs, which are still more interesting, both on their own account, and from the relation in which they stand to those of modern Europe.

The character of Romulus, the founder of the Roman state, when we view him as a leacler of a few lawless and wandering banditti, is an object of extreme insignificance. But when we consider him as the founder of an empire as extensive as the world, and whose progress and decline have occasioned the two B. C. 753. greatest revolutions that ever happened in Europe, we cannot but

Vol. I. 
be interested in his conduct. He possessed great military abilities and a wide fieid for the display of these was afforded by the political state of Italy, divided into a number of small but independent dis. tricts. Romulus was continually embrolled with one or other of his neighbours; and war was the only employment by which he and his companions expected, not only to agrandise themselves, but even to subsist. In the conduct of his wars with the neighbouring people, we may observe an adherence to the same maxims by which the Romans afterwards became masters of the world. Instead of destroying the nations he had subjected, he united them to the Roman state; Whereby Rome acquired a new accession of strength from every war she undertook, and became powerful and populous from that very circumstance which ruins and depopulates other kingdoms. If the enemies with whom he contended had, by means of the art or arms they employed, any considerable advantage, Romulus immediately adopted that practice, or the use of that weapon, and improved the military system of the Romans by the united experience of all their enemies. Of both these maxims we have an example in the war with the Sabines. Romulus, having conquered that nation, not only united them to tlie Romans, but, finding their buckler preferable to the Roman, instantly threw aside the latter, and made use of the Sabine buckler in fighting against other states. Romulus, though principally attached to war, did not altogether neglect the civil polity of his infant kingdom. He instituted what was called the Senate, a court originally composed of a bundred persons dis tinguished for their wisdom and experience. He enacted laws for the administration of justice, and for bridling the fierce and unruly passions of his followers; and, after a long reign spent in promoting B. C. the civil and military interests of his country, was according 717. to the most probable conjecture, privately assassinated by instituted. some of the members of that senate which he himself had

The successors of Romulus were all very extraordinary personages. Numa, who came next after him, established the religious ceremonies of the Romans, and inspired them with that veneration for an oath, which was ever after the soul of their military discipline. Tullus Hostilius, Ancus Martius, Tarquinius Priscus, and Servius 'Tullus, laboured, each during his reign, for the greatness of Rome. But Tarquinius Superbus, the seventh and last king, having obtained the crown by the execrable murder of his father-in-law Servius, continued to support it by the most cruel and infamous tyranny. 'This, together with the insolence of his son Sextus Tarquinius, who, by dishonouring Lucretia, a Roman lady, affronted the whole nation, 33. C. occasioned the expulsion of the Tarquin family, and with it 509. the dissolution of the regal government. As the Romans, however, were continually engaged in war, they found it necessary to have some officer invested with supreme authority, who might conduct them to the field, and regulate their military enterprises. In the room of the kings, therefore, they appointed two annual inagistrates, called consuls, who, without creating the same jealousy, succeeded to all the powers of their former sovereigns. This revolution was very favourable to the Roman power and grandeur. The consuls, who enjoyed but a temporary power, were desirous of signalising their reign by some great action; each vied with those who had gone before him, and the Romans were daily led cut against 
some new enemy. When we add to this, that people naturally war like, were inspired to deeds of valour by every considcration which could excite them....that the citizens of Rome were all soldiers, and fought for their lands, their children, and their liberties.... we shall not be surprised that they should, in the course of some centuries, extend their power over all Italy.

The Romans, now secure at home, and finding no enemy to contend with in Italy, turned their eyes abroad, and met with a powerful rival in the Carthaginians. This state had been founded or enlarged on the coast of the Mediterranean in Africa, some time before Rome, by a colony of Phœnicians, anno B. C. 869 ; and, according to the practice of their mother-country, they had cultivated commerce and naval greatness.

Carthage, in this design, had proved wonderfully successful. She commanded both sides of the Mediterranean. Besides that of Africa, which she almost entirely possessed, she liad extended herself on the Spanish side through the Straits. Thus mistress of the sea and of commerce, she had seized on the islands of Corsica and Sardinia. Sicily had difficulty to defend itself; and the Romans were too nearly threatened, not to take up arms. Hence a B. C. succession of hostilities between these rival states, known in 264 .

history by the name of Punic wars in which the Carthaginians, with all their wealth and power, were an unequal match for the Romans. Carthage was a powerful republic when Rome was an inconsiderable state; but she was now become corrupt and effeminate, while Rome was in the vigour of her political constitution. Car thage employed mercenaries to carry on her wars; Rome, as we have already mentioned, was composed of soldiers. The first war with Carthage lasted twenty-three years, and taught the Romans the art of fighting on the sea, with which they had hitherto been unacquainted. A Carthaginian vessel was wrecked on their coast; they used it for a model; in three months fitted out a fleet; and the consul Duilius, who fought their first naval B. C. battle, was victorious. The behaviour of Regulus, the Roman general, may give us an idea of the spirit which then animated this people. Being taken prisoner in Africa, he was sent back on his parole to negotiate a change of prisoners. He maintained in the senate the propriety of that law which cut off from those who suffered themselves to be taken, all hopes of being saved; and returned to certain death.

Neither was Carthage, though corrupted, deficient in great men. Of all the enemies the Romans ever had to contend with, Hannibal, the Carthaginian, was the most inflexible and dangerous. His father, Hamilcar, had imbibed an extreme hatred argainst the Romans; and having settled the intestine troubles of his country, he took an early opportunity to inspire his son, though but nine years old, with his own sentiments. For this purpose he ordered a solemn sacrifice to be offered to Jupiter, and, leading his son to the altar, asked him whether he was willing to attend him in his expe. dition against the Romans. The courageous boy not only consented to go, but conjured his father, by the gods piesent, to form him to victory, and teach him the art of conquering. "That I will joyfully do," replied Hamilcar, "and with all the care of a father who loves you, if you will swear upon the altar to be an eternal enemy to the Romans." Hannibal readily complied; and the solemnity of 
the ceremony, and the sacredness of the oath, made such an ita pression on his mind, as nothing afterwards could ever efface. Be. ing appointed general at twenty-five years of age, he crosses the B. C. Ebro, the Pyrenées, and the Alps, and unexpectedly rushes 218. Uown upon Italy. The loss of four battles threatens the fall of Rome. Sicily sides with the conqueror. Hieronymus, king of Syracuse, declares against the Romans, and almost all Italy abandons them. In this extremity, Rome owed its preservation to three great men. Fabius Maximus, despising popular clamour, and the military ardour of his countrymen, declines coming to an engagement. 'The strength of Rome has time to recover. Marcellus raises the siege of Nola, takes Syracuse, and revives the B. C. drooping spirits of his troops. 'The young Scipio, at the age 210. of four-and-twenty, flies into Spain, where both his father and uncle had lost their lives, attacks New Carthage, and carries it at the first assault. Upon his arrival in Africa, kings submit to him, Carthage trembles in her turn, and sees her armies defeated. B. C. Hannibal, sixteen years victorious, is in vain called home to B. C. defend his country. Carthage is rendered tributary, gives 201. hostages, and engages never to enter on a war, but with the consent of the Roman people.

At this time the world was divided, as it were into two parts; in the one fought the Romans and Carthaginians; the other was agitated by those quarrels which had lasted since the death of Alexander the Great; and of which the scene of action was Greece, Egypt, and the East. The states of Greece had once more disengaged themselves from a foreign yolse. They were divided into tirree confederacies, the $\mathbb{E}$ tolians, Achæans, and Beotians. Each of these was an association of free cities, which had assemblies and magistrates in common. The $\mathbb{R}$ tolians were the most considerable of them all. The kings of Macedon maintained that superiority which, in ancient times, when the balance of power was little attended to, a great prince naturally possessed over his less power. ful neighbours. Philip, the monarch who then reigned in Macedon, had rendered himself odious to the Greeks by some unpopular and tyrannical measures; the $\mathbb{E}$ tolians were most irritated; and, hearing the fame of the Roman arms, called them into Greece, and overcame Philip by their assistance. The victory, however, chiefly redounded to the advantage of the Romans. The Macedonian gar-risons were obliged to evacuate Greece; the cities were all declared free; but Philip became a tributary to the Romans, and the states of Greece became their dependents. The Etolians, discovering their first error, endeavoured to remedy it by another still more dangerous to themselves, and more advantageous to the $R_{0}$ mans. As they had called the Romans into Greece to defend them against king Philip, they now called in Antiochus, king of Syria, to defend them against the Romans. The famous Hannibal, too, had recourse to the same prince, who was at this time the most power. ful monarch in the East, and the successor to the dominions of Alexander in Asia. But Antiochus did not follow his advice so much as that of the $\mathbb{E}$ tolians; for, instead of renewing the war in Italy, where Hannibal, from experience, knew the Romans to be most vulnerable, he landed in Greece with a small body of troops, and, being overcome without difficulty, fled over into Asia. In this war the Romans made use of Philip for conquering Antiochus, as 
they had before done of the Etolians for conquering Philip. They now pursued Antiochus, the last object of their resentment, into Asia, and, having vanquished him by sea and land, compelled hin to submit to a disgraceful treaty.

In these conquests the Romans still allowed the ancient inhabitants to possess their territory. They did not even change the form of governnent. The conquered nations became the allies of the Roman people; which denomination, however, under a specious name, concealed a condition very servile, and inferred that they should submit to whaterer was required of them. When we reflect on those easy conquests, we have reason to be astonished at the resistance which the Romans met with from Mithridates, king: of Pontus, for the space of twenty-six years. But this monarch had great resources. His kingdom, bordering on the inaccessible - mountains of Caucasus, abounded in a race of men whose minds ${ }^{\circ}$ were not enervated with pleasure, and whose bodies were firm and vigorous; and he gare the Romans more trouble than even Hannibal.

The different states of Greece and Asia, who now began to feel the weight of their yoke, but had not the spirit to shake it off, were transported at finding a prince who dared to show himself an enemy to the Romans, and cheerfully submitted to his protection. Mithridates, however, was at last compelled to yield to the superior fortune of the Romans. Vanquished successively by Sylia and Lucullus, he was at length subdued by Pompey, and stripped of his dominions and his life, in the year before Christ 63. In Africa, the Roman arms met with equal success. Marius, in conquering Jugurtha, gave security to the republic in that quarter. Even the barbarous nations beyond the Alps began to feel the weight of the Roman arms. Gallia Narbonensis had been reduced B. C. into a province. The Cimbri, Teutones, and the other northern nations of Europe, broke into this part of the empire. The same Marius, whose name was so terrible in Africa, then made the north of Europe to tremble. The barbarians retired to their wilds and deserts, less formidable than the Roman le-

B. C. 102. gions. But while Rome conquered the world, there subsisted an incessant war within her walls. This war had continued from the first period of the government. Rome, after the expulsion of her kings, enjoyed but a partial liberty. The descendants of the senators, who were distinguished by the name of Patricians, were invested with so many odious privileges, that the people felt their de. pendence, and became determined to shake it off. A thousand disputes on the subject arose between them and the patricians, which always terminated in favour of liberty.

These disputes, while the Romans preserved their virtue, were not attended with any sanguinary consequences. The patricians, who loved their country, cheerfully resigned some of their privileges to satisfy the people; and the people, on the other hand, though they obtained laws by which they might be admitted to enjoy the first offices of the state, and though they had the power of nomination, always named patricians. But when the Romans, by the conquest of foreign nations, became acquainted with all their Juxuries and refinements.... when they became tainted with the effeminacy and corruption of the eastern courts, and sported with every thing. just and honourable in orcler to obtain them....the state, torn 
by the factions between its members, and without virtue on either side to keep it together, became a prey to its own children. Hence the sanguinary seditions of the Gracchi, which paved the way for an inextinguishable hatred between the nobles and commons, and made it easy for any turbulent demagogue to put them in action against each other. The love of their country was now no more than a specious name: the better sort were too wealthy and effeminate to subrnit to the rigours of military discipline; and the soldiers, composed of the dregs of the republic, were no longer citizens. They had little respect for any but their commander; under his banner they fought, and conquered, and plundered; and for him they were ready to die. He might command them to embrue their hands in the blood of their country. They who knew no country but the camp, and no authority but that of their general, were ever ready to obey him. The multiplicity of the Roman conquests, however, which required their keeping on foot several armies at the same time, retarded the subversion of the republic. These armies were so many checks upon each other. Had it not been for the soldiers of Sylla, Rome would have surrendered its liberty to the army of Marius.

Julius Cæsar at length appears. By subduing the Gauls, he gainB. C. ed his country the most useful conquest it ever made. Pom48. pey, his only rival, is overcome in the plains of Pharsalia. Cæsar is victorious almost at the same time all over the world; in Egypt, in Asia, in Mauritania, in Spain, in Gaul, and in Britain : conqueror on all sides, he is acknowledged master at Rome, and B. C. in the whole empire. Brutus and Cassius attempt to give 48. Rome her liberty by stabbing him in the senate-house. But though they thereby deliver the Romans from the tyranny of Julius, the republic cloes not obtain its freedom. It falls under the B.C. dominion of Mark Antony; young Cæsar Octavianus, ne31. phew to Julius Cæsar, wrests it from him by the sea-fight at Actium; and there is no Brutus or Cassius to put an end to his life. Those friends of liberty had killed themselves in despair; and Octavius, under the name of Augustus, and title of emperor, remains the undisturbed master of the empire. During these civil commotions, the Romans still preserved the glory of their arms amongst distant nations; and while it was unknown who should be master of Rome, the Romans were, without dispute, the masters of the world. Their military discipline and valour abolished all the remains of the Carthaginian, the Persian, the Greek, the Assyrian, and Macedonian glory; they were now only a name. No sooner, therefore, was Octavius established on the throne, than ambassadors from all quarters of the known world crowd to make their submissions. Ethiopia sues for peace; the Parthians, who had been a most formidable enemy, court his friendship; India seeks B. C. his alliance; Pannonia acinowledges him; Germany dreads

7. him; and the Weser receives his laws. Victorious by sea and land, he shuts the temple of Janus. The whole earth lives in peace under his power; and Jesus Christ comes into the world four years before the common æra.

Haring thus traced the progress of the Roman government while it remained a republic, our plan obliges us to say a few words with regard to the arts, sciences, and manners of that people. During the first ages of the republic, the Romans lived in a total neglects 
or rather contempt, of all the elegant improvements of life. War, politics, and agriculture, were the only arts they studied, because they were the only arts they esteemed. But upon the downfal of Carthage, the Romans, having no enemy to dread from abroad, began to taste the sweets of security, and to cultivate the arts. Their progress, however, was not gradual, as in the other countries we have described. The conquest of Greece at once put them in possession of every thing most rare, curious or elegant. Asia, which was the next victim, offered all its stores; and the Romans, from the most simple people, speedily became acquainted with the arts, the luxuries, and refinements of the whole earth. Eloquence they had always cultivated as the high road to eminence and preferment. The orations of Cicero are inferior only to those of Demosthenes. In poetry, Virgil yields only to Homer, whose verse, like the prose of Demosthenes, may be considered as inimitable. Horace, however, in his Satires and Epistles, had no model among the Greeks, and stands to this day unrivalled in that species of writing. In history, the Romans can boast of Livy, who possesses all the natural ease of Herodotus, and is more descriptive, more eloquent, and sentimental. Tacitus, incleed, did not flourish in the Augustan age; but his works do himself the greatest honour, while they disgrace his country and human nature, whose corruption and vices he paints in the most striking colours. In philosophy, if we except the works of Cicero, and the system of the Greek philosopher Epicurus, described in the nervous poetry of Lucretius, the Romans, during the time of the republic, made not the least attempt. In tragedy they never produced any thing excellent; and Terence, though remarkable for purity of style, wants that vis comica, or lively vein of humour, that distinguishes the writings of the comic poets of Greece, and those of our immortal Shakspeare.

We now return to our history, and are arrived at an æra which presents us with a set of monsters, under the name of emperors, whose acts, a few excepted, disgrace human nature. They did not, indeed, abolish the forms of the Roman republic, though they extinguished its liberties; and while they were practising the most unwarrantable cruelties upon their subjects, they themselves were the slaves of their soldiers They made the world tremble, while they in their turn trembled at the army. Rome, from the time of Augustus, became the most despotic empire that ever subsisted in Europe; and the court of its emperors exhibited the most odious scenes of that caprice, cruelty, and corruption, which universally prevail under a despotic government. When it is said that the Roman republic conquered the world, it is only meant of the civilised part of it, chiefly Greece,' Carthage, and Asia. A more difficult task still remained for the emperors....to subdue the barbarous nations of Europe...the Germans, the Gauls, the Britons, and even the remote people of Scotland; for though these countries had been discovered, they were not effectually subdued by the Roman generals. These nations, though rude and ignorant, were brave and independent. It was rather from the superiority of their discipline, than of their courage, that the Romans gained any advantage over them. The Roman wars with the Germans are described by Tacitus; and from his accounts, though a Roman, it is easy to discover with what bravery they fought, and with what reluctance they submitted to a foreign yoke. From the 
obstinate resistance of the Germans, we may judge of the difficul. ties the Romans met with in subduing the other nations of Europe. The contests were bloody; the countries of Europe were successively laid waste; number's of the inhabitants perished in the field, many were carried into slavery, and bat a feeble remnant submitted to the Roman powcr. This situation of affairs was extremely unfavourable to the happiness of mankind. The barbarous nations, incleed, from their intercourse with the Romans, acquired some taste for the arts, sciences, language, and manners of their new masters. These, however, were but miserable consolations for the loss of liberty, for being deprived of the use of arms, for being overawed by mercenary soldiers, kept in pay to restrain them, and for being delivered over to rapacious governors, who plundered them without mercy.

The Roman empire, now stretched out to such an extent, had lost its spring and force. It contained within itself the seeds of dissolution; and the violent irruptions of the Goths, Vandals, Huns, and other barbarians, hastened its destruction. These fierce tribes, who came to take vengeance on the empire, either inhabited the various parts of Germany which had never been subdued by the Romans, or were scattered over the vast countries of the north of Europe, and the north-west of Asia, which are now inhabited by the Danes, the Swedes, the Poles, the subjects of the Russian empire, and the Tartars. They were drawn from their native country by that restlessness which actuates the minds of barbarians, and niakes them rove from home in quest of plunder or new settlements. The first invaders met with a powerful resistance from the superior discipline of the Roman legions; but this, instead of daunting men of a strong and impetuous temper, only roused them to vengeance. They returned to their companions, acquaint. ed them with the unknown conveniences and luxuries that abounded in countries better cultivated, or blessed with a milder climate, than their own; they acquainted them with the battles they had fought, or the friends they had lost ; and warmed them with resentment against their opponents. Great bodies of armed men (says an elegant historian, in describing this scene of desolation) with their wives and children, and slaves, and flocks, issued forth, like regular colonies, in quest of new settlements. New adventurers followed them. The lands which they deserted were occupied by more remote tribes of barbarians. These in their turnpushed forward into more fertile countries; and, like a torrent continually increasing, rolled on, and swept every thing before them. Wherever the barbarians marched, their route was marked with blood. They ravaged or destroyed all around them. They made no distinction between what was sacred and what was profane. They respected no age, or sex, or rank. If a man were called to fix upon the period in the history of the world, during which the condition of the human race wa's the most calamitous and afflicted, he would, without hesitation, name that which elapsed from the death of 'Theodosius the Great, A. D. 395 , to the establishment of the Lombards in Italy, $\mathbf{\Lambda}$. D. 571 . The contemporary authors, who beheld that scene of desolation, labour and are at a loss for expressions to describe the horrors of it. The scourge of God, the destroyer of nations, are the dreadful epithets by which they distinguish the most noted of the bar. barous leaders. 
Constantine, who was emperor at the beginning of the fourth century, and who had embraced Christianity, transferred the seat of empire from Rome to Constantinople. The western and eastern provinces were in consequence separated from 328. each other, and governed by different sovereighs. The withdrawing the Roman legions from the Rhine and the Danube to the east, threw down the western barriers of the empire, and laid it open to the invaders.

Rome (now known by the name of the Western Empire, in contradistinction to Constantinople, which, from its situation, was call. ed the Eastern Ensire) weakened by this division, became a prey to the barbarous nations. Its ancient glory, vainly deemed immortal, was effaced; and Odloacer, a barbarian chieftain, was seated on the throne of the Cæsars. These irruptions

A D. 476 . into the empire were gradual and successive. The immense fabric of the Roman empire was the work of many ages; and several centuries were employed in demolishing it. The ancient military discipline of the Romans was so efficacious, that the remains of it, which descended to their successors, must have rendered them superior to their enemies, had it not been for the vices of their emperors, and the universal corruption of manners among the people. Satiated with the luxuries of the known world, the emperors were at a loss to find new provocatives. The most distant regions were explored, the ingenuity of mankind was exercised, and the tribute of provinces expended upon one favourite dish. The tyranny and the unirersal depravation of manners that prevailed under the emperors, or, as they are called, Cæsars, could only be equalled? by the barbarity of those nations of which the enpire at length became the prey.

Towards the close of the sixth century, the Saxons, a German. nation, were masters of the southern and more fertile provinces of Britain; the Franks, another tribe of Germans, of Gaul ; the Goths; of Spain; the Goths and Lombards, of Italy and the adjacent pro. vinces. Scarcely any restige of the Roman policy, jurisprudence, arts, or litcrature, remained. New forms of government, new laws, new manners, new dresses, new languages, and new names of men and countries, were every where introduced.

From this period till the 15th century, Europe exhibited a pic. ture of most melancholy Gothic barbarity. Literature, science, taste, were words scarcely in use during these ages. Persons of the highest rank, and in the most eminent stations, could not read or write. Many of the clergy did not understand the Breviary, which they were obliged daily to recite; some of them could scarcely read it. The human mind, neglected, uncultivated, and depressed, sunk into the most profound ignorance. The superio: genius of Charlemagne, who, in the beginning of the ninth cen tury, governcd France and Germany, with part of Italy.... and Alfred the Great in England, during the latter part of the same century..., enrleavoured to dispel this darkness, and give their subjects a short glimpse of light. But the ignorance of the age was too powerful for their efforts and institutions. The darkness returned, and even increased; so that a still greater degree of ignorance and barbarism prevailed throughout Europe.

A tew clivision of property gradually introduced a new species ff government, formerly unknown; which singular institution is

VOS. I. 
now distinguished by the name of the Feudal System. The king or general, who led the barbarians to conquest, parcelled out the lands of the vanquished among his chief officers, binding those on whom they were bcstowed to follow his standard with a number of men, and to bear arms in his defence. The chief officers imitatcd the example of the sovereign, and, in distributing portions of their lands among their dcpendents, annexcd the same condition to the grant; a system admirably calculated for defence against a forcign enemy, but which degencrated into an engine of oppression .

The usurpation of the nobles became unbounded and intolerable. They reduced the great body of the people into a state of actual servitude, and deprived them of the natural and most unalienable rights of humanity. They were slaves fixed to the soil which they cultivated, and together with it were transferred from one proprietor to another, by sale or by conveyance. Every offended baron or chieftain buckled on his armour, and sought redress at the hear of his vassals. His adversaries met him in like hostile array. The kindred and dependents of the aggressor, as well as the defender, wcre involved in the quarrel. They had not even the liberty of remaining neuter.

The monarchs of Europe perceived the incroachments of their nobles with impaticnce. In order to create some power that might counterbalance those potent vassals, who, while they enslaved the people, controlled or gave laws to the crown, a plan was adopted of conferring new privileges on tonns. These privileges abolished all marks of servitude; and the inhabitants of towns were formed into coiporations, or bodies politic, to be governed by a council and magistrates of their own nomination.

The acquisition of liberty soon produced a happy change in the condition of mankind. A spirit of industry revivesl ; commerce became an object of attention, and began to flourish.

Various causes contributed to revive this spirit of commerce, and to rcnew the intercourse between different nations. Constantinople, the capital of the Eastcrn or Greck empire, had escaped the ravages of the Goths and Vandals, who overthrew that of the West. In this city somc remains of litcrature and science were prescrved : this, too, for many ages, was the great emporium of A. D. trade ; and the crusades which were begun by the Cinristian 1096. powers of Europe with a view to drive the Saracens from 1096. Jerusalem, having opened a communication between Europe and the East, Constantinoplc was the general place of rendezvous for the Christian armies, in their way to Palestine, or on their return from thence. Though the object of these expeditions was conquest and not commcrce, and though the issue of them proved unfortunate, their commercial effects were both beneficial and permanent.

Soon after the close of the holy war, the marincr's compass was inA. D. vented, which facilitated the communication betwcen remote 1302. nations. The Italian states, particularly those of Venice 1302. and Genoa, began to establish a regular commerce with the East and the ports of Egypt, and drew from thencc all the rich productions of India. These commodities they disposed of to great advantage among the other nations of Europe, who began to acquirc some taste for elegance, unknown to their predecessors, or despised by them. During the 12 th and 1 th centuries the com 
merce of Europe was almost entirely in the hands of the Italians, more commonly known in those ages by the name of Lombarcls. Companies or societies of Lombard merchants settled in every diflerent kingdom; they became the carriers, the manufacturers, and the bankers of Europe. One of these companies setled in London; and thence the name of Lombard-street was derived.

While the Italians in the soulh of Europe cultivated trade with such industry and success, the commercial spirit awakened in the north towards the middle of the 1 sth century. As the Danes, Swedes, and other nations around the Baltic, were at that time extremely barbarous, and infested that sea with their piracies, the cities of Lubec and Hamburgh, soon after they had begुun to open some trade with the Italians, entered into a league of mutual de. fence. They derived such advantages from this union, that other towns acceded to their confederacy; and, in a short time, eighty of the most considerable cities, scattered through those large countries of Germany and Flanders which stretch from the bottom of the Baltic to Cologne on the Rhine, joined in an alliance, called the Hanseatic League, which became so formidable, that its friendship was courted and its enmity dreaded by the greatest monarchs. The members of this powerful association formed the first sys. tematic plan of commerce known in the middle ages, and conclucted it by common laws enacted in their general assemblies. They supplied the rest of Europe with naval stores, and selected different towis, the most eminent of which was Bruges in Flanders where they established staples, in which their commerce was regularly carried on. Thither the Lombards brought the productions of Iridia, together with the manufactures of Italy, and exchanged them for the more bulky but not less useful commodities of the north.

As Bruges became the centre of communication between the Lombards and Hanseatic merchants, the Flemings traded with both in that city to such extent as well as advantage, as diffused among them a general habit of industry, which long rendered Flanders and the adjacent provinces the most opulent, the most populous, and best cultivated countries in Europe.

Struck with the flourishing state of these provinces, of which he discovered the true cause, Edward III. of England endea youred to excite a spirit of industry among his own subjects, who, blind to the advantages of their situation, and

A. D. ignorant of the source from wich opulence was destined to flow into their country, totally neglected commerce, and did not even attempt those manufactures, the materials of which they furnished to foreignel's. By alluring Fleinish artisans to settle in his dominions, as well as by many wise laws for the encouragement and regulation of trade, he gave a beginning to the woollen manufacture of England, and first turned the active and enterprising genius of his people towards those arts which hare raised the English to the first rank amon's commercial nations.

The Christian princes, alarmed at the progress of their inveterate enemies the Turks, endeavoured to gain the friendship and assistance of the khans of Tartary. The Christian embassies were managed chiefly by monks, an active and enterprising set of men, who, impelled by zeal, and undaunted by difficulties and dan= ger, penetrated to the remote courts of those infidels. The English philosopher, Roger Bacon, was so industrious as to collect from 
their relations and traditions many particulars of the Tartars, which are to be found in Purchas's Pilgrim, and other books of travels. The first regular traveller of the monkish kind, who committed his discoveries to writing, was John du Plant Carpin, who, with some of his brethren, about the year 124.6, carried a letter from pope Innocent to the great khan of Tartary, in favour of the Christian subjects in that prince's extensive dominions. Soon after this, a spirit of travelling into Tartary and India became general : and it would be no difficult task to prove that many Europeans, about the end of the fourteenth century, served in the armies of Timur, or Tamerlane, one of the greatest princes of Tartary, whose conquests reached to the remotest corners of India; and that they introduced into Europe the use of gunpowder and artillery; the discovery made by a German chemist being only partial and accidental.

After the death of 'Tinur, who, jealous of the rising power' of the Turks, had checked their progress, the Christian adventurers, upon their return, magnifying the vast riches of the East-Indies, inspired their countrymen with a spirit of adventure and discovery, and were the first who suggested the practicability of a passage thither by sea. The Portuguese had been A. D. 1405. always fumous for their application to maritime affairs; and to their discovery of the Cape of Good Hope, Great Britain is at this day indebted for her Indian commerce.

The first adventurers contented themselves with short voyages, creeping along the coast of Africa, discovering cape after cape; but hy making a gradual progress southward, they, in the year 1497, at length discovered and doubled the extreme cape of that continent, which opened a passage by sea to the Eastern Ocean, ancl all those countries known by the names of India, China, and Japan.

While the Portuguese were intent upon a passage to India by the east, Columbus, a native of Genoa, conceived a project of sailing thicher by the west. His proposal being condemned by his countrymen as chimerical and absurd, he laid his scheme successively before the courts of France, England, and Portugal, where he had no better success. Such repeated disappointments would have broken the spirit of any man but Columbus. The expedition required expense, and he had nothing to defray it. Spain was now his only resource; and there, after eight years attendance, he at length succeeded, through the interest of queen Isabella. This princess was prevailed upon to patronise him by the representation of Juan Perez, guardian of the monastery of Rabida. He was a man of considerable learning, and of some credit with queen Isabella; and being warmly attached to Columbus, from his personal acquaintance with him, and knowledge of his merit, he had entered into an accurate examination of that great man's project, in conjunction with a physician settled in his neighbourhood, who was eminent for his skill in mathematical knowledge. This investigation completely satisfied them of the solidity of the principles on which Columbus founded his opinion, and of the probability of success in executing the plan which he proposed. Perez, therefore, so strongly recommended it to queen Isabella, that she warmly entered in to the scheme, and even generously offered, to the honour of her sex, to pledge her own jewels, in order to raise as much mo: 
ney as might be required in making preparations for the voyage. But Santangel, another friend and patron of Columbus, immediately cngaged to advance the sum that was requisite, that the queen might not be reduced to the necessity of having recourse to that expedient.

Columbus now set sail, anno 1492, with a fleet of three ships, upon one of the most adventurous attempts ever undertaken by man, and in the fate of which the inhabitants of two worlds were interested. In this voyage he had a thousand difficulties to contend with; and his sailor's, who were often discontented, at length began to insist upon his return, threatening, in case of refusal, to throw him overboard; but the firmness of the commander, and the discorery of land after a passage of 33 days, put an end to the commo. tion. From the appearance of the natives, he found to his surprise that this could not be the Indies he was in quest of, and that he had accidentally discovered a new world; of which the reader will find a more circumstantial account in that part of the following work which treats of America.

Europe now began to emerge out of that darkness in which she had been sunk since the subversion of the Roman empire. These discoveries, from which such wealth was destined to flow to the A. D. commercial nations of Europe, were accompanied and suc14.40. ceeded by others of unspeakable benefit to mankind. The invention of printing, the revival of learning, arts, and sciences, and, lastly, the lappy reformation in religion, all distinguish the 15 th and 16 th centuries as the first æra of modern history. It was in these ages that the powers of Europe were formed into one great political system, in which each took a station, wherein it has since remained, with less variation than could have been expected after the shocks occasioned by so many internal revolutions, and so many foreign wars, of which we shall give some account, in the history of each particular state, in the following work.

\section{PAR'T III.}

\section{OF THE ORIGIN AND PROGRESS OF RELIGION.}

DEITY is an awful object, and has ever roused the attention of mankind; but they, beirig incapable of elevating their ideas to all the sublimity of his perfections, have too often brought down his herfections to the level of their own ideas. This is more particu. larly true with regard to those nations whose religion had no other foundation but the natural feelings, and more often the irregular passions of the human heart, and who had received no light from heaven respecting this important object. In deducing the history of religion, therefore, we must make the same distinction which we have hitherto observed in tracing the progress of arts, sciences, and civilization among mankind. We must separate what is human from what is divine; what had its origin from particular revelations from what is the effect of general laws, and of the unassisto ed operations of the human mind. 
Agreeably to this distinction, we find, that, in the first ages of the world, the religioa of the eastern nations was pure and luminous. It arose from a divine source, and was not then disfigured by human fancies or caprice. In time, however, these began to have their influence; the ray of tradition was obscured; and among those tribes which separated at the greatest distance, and in the smallest numbers, from the more improved societies of men, it was altogether obliterated.

In this situation a particular people were selected by God himself to be the depositaries of his law and worship; but the rest of mankind were left to form hypotheses upon these subjects, which were more or less perfect, according to an infinity of circumstances which cannot properly be reduced under any general heads.

The most common religion of antiquity...that which prevailed the longest and extended the ridest....Was Polyturism, or the doctrine of a plurality of gods. The rage of system, the ambition of reducing all the phrnomena of the moral world to a few general principles, has occasioned many imperfect accounts, both of the origin and nature of this species of worship. For, witiout entering into a minute detail, it is impossible to give an adequate idea of the subject: and what is said upon it in general nuust always be liable to many exceptions.

One thing, however, may be observed, that the polytheism of the ancients seems neither to have been the fruit of philosophical speculations, nor of disfigured traciitions concerning the nature of the Divinity. It seems to have arisen during the rudest ages of society, while the rational powers were feeble, and while mankind were under the tyranny of imagination and passion. It was built, therefore, solely upon sentiment. As each tribe of men had their heroes, so likewise they had their gods. Those heroes who led them forth to combat, who presided in their councils, whose image was engraven on their fancy, whose exploits were imprinted on their memory, even after death enjoyed an existence in the imagination of their followers. The force of blood, of friendship, of affection, among rude nations, is what we cannot easily conceive : but the power of imagination over the senses is what all men have in some degree experienced. Combine these two causes, and it will not appear strange that the image of departed heroes should have been seen by their companions animating the battle, taking vengeance on their enemies, and executing, in a word, the same functions which they performed when alive. An appearance so unnatural would not excite terror among men unacquainted with evil spirits, and who had not learned to fear any thing but their enemies. On the contrary, it confirmed their courage, flattered their vanity; and the testimony of those who had seen it, supported by the extreme credulity and romantic cast of those who had not, gained an universal assent among all the members of their society. A small degree of reflection, however, would be sufficient to convince them, that, as their own heroes existed after death, the same might also be the case with those of their enemies. Two orders of gods, therefore, would be established....the propitious and the hostile; the gods who were to be loved, and those who were to be feared. But time, which effaces the impressions of traditions, and the frequent invasions by which the nations of antiquity were ravaged, desolated, or transplanted, made them lose the names and confound 
she characters of those two orders of divinities, and form various systems of religion, which, though warped by a thousand particular circumstances, gave no small indications of their first texture and original materials. For, in gcneral, the gods of the ancients gave abundant proof of human intirmity. They were subject to all the passions of men; they partook even of their partial affections; and, in many instances, discovered their preference of one race or nation to all others. They did not eat and drink the same substances with men; but they lived on nectar and ambrosia: they had a particular plcasure in smelling the steam of the sacrifices; and they made love with an ardour unknown in northern climates. The ritcs by which they were warshipped naturally resulted from their character. The most enlightened among the Greeks entertained nearly the same notions of gods and religion as those that are to be met with in the poems of Hesiod and Homer; and Anaxagoras, who flourishcd 430 years before Christ, was the first, even in Greece, that publicly announced the existence of one Creator and Governor of the universe.

It must be observed, however, that the religion of the ancients was not much connected either with their private behaviour, or with their political arrangements. If we cxcept a few fanatical societies, whose principles do not fall within our plan, the greater part of mankind were extremely tolerant in their principles. They had thcir own gods, who watched over them; their neighbours, they imagined, also had thcirs: and there was room enough in the universe for both to live together in good fellowship, without interfering or jostling with cach other.

The introduction of Christianity, by inculcating the unity of God, by announcing the purity of his character, and by explaining the service he requires of men, produced a total alteration in the religions sentiments and belief of the civilized part of mankind, among: whom it rapidly made its way by the sublimity of its doctrine and prccepts. It required not the aid of human power; it sustained itself by the truth and wisclom by which it was characterised : but in time it became corrupted by the ambition of the clergy, and the introduction of worldly maxims, of maxims very inconsistent with the precepts of its divine author.

The nianagement of whatever relatcd to the church being naturally conferred on those who had established it, first occasioned the elevation and then the domination of the clergy, and the exorbitant claims of the bishop of Rome over all the mcmbers of the Christian world. It is impossible to describe within our narrow limits all the concomitant causes, some of which wcre extremely delicate, by which this species of universal monarchy was established. The bishops of Rome, by being removed from the controul of the Roman emperors, then residling in Constantinople; by borrowing, with little variation, the religious ceremonies and rites established among the heathen world, and otherwise working on the credulous minds of the barbarians by whom that empire began to be dismembered; and by availing themselves of every circumstance which fortune threw in thcir way, slowly erected the fabric of their anticlyristian power, at first an object of veneration, and afterwards of terror, to all temporal princes. The causes of its happy dissolution are more palpable, and operated with greater activity. The most efficacious were the invention of printing, the rapir improve- 
ment of arts, government, and commerce, which, after many ages of barbarity, made their way into Europe. The scandalous lives of those who called themselves the "ministers of Jesus Christ," their ignorance and tyranny, the desire natural to sovereigns of delivering themselves from a foreign yoke, the opportunity of applying to national objects the immense wealth which had been diverted to the service of the church in every kingdom of Europe, conspired with the ardour of the first reformers, and hastened the progress of the reformation. The unreasonableness of the claims of the church of Rome was demonstrated; many of her doctrines were proved to be equally unscriptural and irrational; and some of her absurd mummeries and superstitions were exposed both by argument and ridicule. The services of the reformers in this respect give them a just claim to our veneration; but, involved as they had themselves been in the darkness of superstition, it was not to be expected that they should be able wholly to free themselves from errors: they still retained an attachment to some absurd doctrines, and preserved too much of the intolerant spirit of the church from which they had separated themselves. With all their defects, tiney are entitled to our admiration and esteem; and the reformation, begun by Luther in Fermany, in the year 1517, and which took place in England, A. D. 1534, was an event highly favourable to the civil as well as to the religious rights of mankind.

We shall now proceed to the principal part of our work, beginning with Europt. 


\section{EUPOPE.}

EUROPE, though the least extensive quarter of the globe (containing, according to Zimmermann,* 2,627,574 square miles, whereầs the nabitable parts of the world, in the other quarters, are estimated at $27,987,457$ square miles) is, in many respects, that which most deserves our attention. Here the human mind has made the greatest progress towards improvement; and here the arts, whether of utility or ornament, the science both military and civil, have been carried to the greatest perfection. If we except the earliest ages of the world, it is in Europe, that we find the greatest variety of character, government, and manners; and from its history we derive the greatest number of facts and memorials, either for our entertainment or instruction.

Geography discovers to us two circumstances with regard to Europe, which perhaps have had a considerable tendency in giving it the superiority over the rest of the world; first, the happy temperature of its climate, no part of it lying within the torrid zone ; and, secondly, the great variety of its surface. The effect of a moderate climate, both on plants and animals, is well known from experience. The immense number of mountains, rivers, seas, \&c. which divide the different countries of Europe from each 'other, is likewise extremely commodious for its inhabitants. These natural boundaries check the progress of conquest or despotism, which has always been so rapid in the extensive plains of Africa and the East. The seas and rivers facilitate the intercourse and commerce between the different nations; and even the barren rocks and mountains are more favourable for exciting human industry and invention, than the natural unsolicited luxuriancy of more fertile soils. There is no part of Europe so diversified in its surface, so interrupted by natural boundaries or divisions, as Greece; and we have seen that it was there the human mind began to know and to avail itself of its strength : and that many of the arts, subservient to utility or pleasure, were invented, or at least greatly improved.

The Christian religion is established throughout every part of Europe, except Turkey; but from the various capacities of the humarn mind, and the different lights in which speculative opinions are apt to appear, when viewed by persons of different educations and passions, that religion is divided into a number of different sects, but which may be comprehended under three general denominations ; first, the Greek Church; second, popery; and, thild, Protestantism; which last is again divided into Lutheranism and Calvinism, so called from Luther and Calvin, the distinguished reformers of the sixteenth century.

The languages of Europe are derived from the five following : the Greek, Latin, Gothic (the parent of the Teutonic, or old German) the Celtic, and Slavonic. 


\section{GRAND DIVISIONS OF EUROPE.}

Europe is situated between the 10th degree west and 65 th degres east longitude from London, and between the 36 th and $72 \mathrm{~d}$ degree of north latitude. It is bounded on the north by the Frozen Ocean; on the east, by Asia; on the south, by the Mediterranean Sea, which divides it from Africa; and on the west, by the Atlantic Ocean, which separates it from America; being 3000 miles long, from Cape St. Vincent in the west, to the mouth of the river Oby in the north-east; and 2500 broad from north to south, from the North Cape in Lapland, to Cape Caglia, or Matapan, in the Morea, the most southern promontory in Europe. It contains the following kingdoms and states:

\begin{tabular}{|c|c|c|c|c|c|c|}
\hline Iringdoms \& States. & 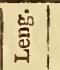 & 悹 & Chief Cities. & $\begin{array}{l}\text { Distances \& } \\
\text { Bearing from } \\
\text { Lundon. }\end{array}$ & $\begin{array}{l}\text { Difference of } \\
\text { Time fiom } \\
\text { London. }\end{array}$ & Religions. \\
\hline$\left\{\begin{array}{l}\text { England }:: \\
\text { Scotland } \\
\text { Ireland }::\end{array}\right.$ & $\begin{array}{l}380 \\
270 \\
285\end{array}$ & $\begin{array}{l}300 \\
160 \\
160\end{array}$ & $\begin{array}{l}\text { London : : } \\
\text { Edinburgh : } \\
\text { Dublin : }\end{array}$ & $\begin{array}{l}\text { Miles. } \\
400 \text { … } \\
270 \text { N. W. }\end{array}$ & $\mid \begin{array}{ccc}\text { H. M. } & \\
0 & 12 & \text { aft. } \\
0 & 26 & \text { aft. }\end{array}$ & $\begin{array}{l}\text { Calvinists, Luth. \&ce. } \\
\text { Calvinists, \&c. } \\
\text { Calvinists \& R. Cath. }\end{array}$ \\
\hline $\begin{array}{l}\text { Norway } \\
\text { Denmark }\end{array}$ & $\begin{array}{r}1100 \\
240\end{array}$ & $\begin{array}{l}150 \\
180\end{array}$ & $\begin{array}{l}\text { Bergen - - } \\
\text { Copenhagen }\end{array}$ & $540 \mathrm{~N}$. & $\mid \begin{array}{lll}0 & 24 & \text { bef: } \\
0 & 50 & \text { bef. }\end{array}$ & $\begin{array}{l}\text { Lutherans. } \\
\text { Intherans. }\end{array}$ \\
\hline Sweden - . & 800 & 500 & Stockholm & 750 N. E. & 110 bef. & Lutherans. \\
\hline Russia $\cdot \cdot$ : & 15001 & 1100 & Petersburg & 1140 N. E. & 24 bef. & Greek Church. \\
\hline King of Prussia Dom. & 606 & 350 & Berlin : • & $540 \mathrm{E}$. & o 49 bef. I & Lutherans and Calvin. \\
\hline Germany : - & 609 & 500 & Vienna - - & $600 \mathrm{E.}$ & $1 \quad 5$ bef. & R. Cath. Luth. and Cal. \\
\hline Bohemia . . . & 200 & 150 & Prague. . & $600 \mathrm{E}$. & 14 bef. & Roman Catholies \\
\hline $\left.\begin{array}{l}\text { Holland or } \\
\text { Batavian Repub. }\end{array}\right\}$ & 150 & 100 & Ainsterdam. & $180 \mathrm{E}$ & lo 18 bef. & Calvinists. \\
\hline France $\cdot \cdot \cdot$ & 650 & 560 & Paris . & 260 S. E. & o 9 bef. & Roman Catholics. \\
\hline Spain . . . - & 700 & 500 & Madrid . & $800 \mathrm{~S}$. & $\begin{array}{lll}0 & 17 & \text { aft. }\end{array}$ & Roman Catholics. \\
\hline Portugal . - - - & 300 & 100 & Lisbon & $850 \mathrm{~S} . \mathrm{W}$. & f 38 aft. & Roman Catholics. \\
\hline Switzerland - . - & 220 & 130 & Bern, Coire, ¿ce, & 420 S. E. & 028 bef. & Calvinists and R. Cath. \\
\hline Italian Republic . & 180 & 90 & Milan . - & 550 S. E. & o 37 bef: & Roman Catholics. \\
\hline $\begin{array}{l}\text { Tuscany or Kingdom, } \\
\text { of Etruria }\end{array}$ & 120 & 90 & F'lorence & 690 S. F. & $0 \quad 44$ bef. & Roman Catholies. \\
\hline State of the Church & 240 & 120 & Rome - . & 820 S. E. & $0 \quad 50$ bef. & Roman Catholics. \\
\hline Laples : . . & 280 & 120 & Naples - - & 910 S. E. & $\begin{array}{lll}0 & 57 & \text { bef. }\end{array}$ & Roman Catholics. \\
\hline Turkey in Europe & 890 & 680 & Constuntinople & 1320 S.E. & $l_{1} \quad 56$ bef. & Mahoms. \& G. Church \\
\hline
\end{tabular}

TXCLUSIVE OF THE BRITISH ISLES BEFORE MENTIONED, EUROPE CONTAINS THE FOLLOWING PRINCIPAL ISLANDS.

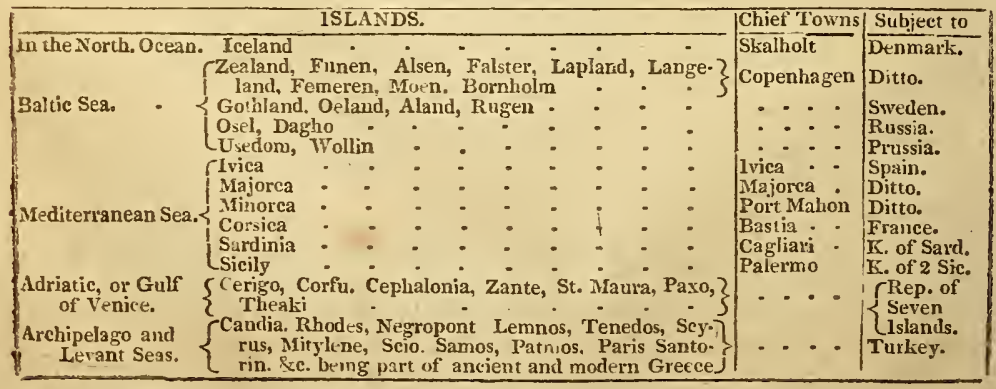

- Italy likewise contains several smaller states; as the Republics of Genoa, Iucca, and San Marino. 


\section{DENMARK.}

THE dominions of his Danish majesty, in Europe, consist of Den: mark Proper, or the peninsula of Jutland and the islands in the Baltic; the duchy of Holstein in Germany ; the islands of Iceland; and $\mathrm{Da}$ nish Lapland or Finmark. The dimensions and chief towns of these countries are given in the following table.

\begin{tabular}{|c|c|c|c|c|c|c|c|c|c|c|c|c|c|}
\hline \multirow[b]{2}{*}{ Jutland } & \multirow[b]{2}{*}{ - } & \multirow[b]{2}{*}{ - } & \multirow[b]{2}{*}{$\cdot$} & \multirow[b]{2}{*}{ - } & \multirow{2}{*}{$\begin{array}{l}\text { Square } \\
\text { Miles. } \\
6.866\end{array}$} & \multirow{2}{*}{$\frac{\text { ప్ }}{155}$} & \multirow{2}{*}{ 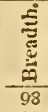 } & \multicolumn{6}{|c|}{ Chief Towns. } \\
\hline & & & & & & & & Viborg & - & - & - & - & - \\
\hline Sleswick & - & - & - & - & 2,640 & 70 & 63 & Sleswick. & - & - & - & - & - \\
\hline Holstein & - & - & - & - & 2,768 & 90 & 50 & Gluckstadt. & SN. & atitı & e. 5 & 41. & \\
\hline Zealand & - & - & - & - & 2,112 & 60 & 60 & Copenhagen. & 1. $\left\{\begin{array}{l}\mathbf{E}_{0} \\
.\end{array}\right.$ & ong & & 12.35 & \\
\hline Funen & - & - & - & - & 1,376 & 40 & 30 & Odense. & & & & & \\
\hline Falster & - & - & - & - & 150 & 23 & 12 & Nyteliobing. & $\cdot$ & - & - & - & - \\
\hline Lapland & - & - & - & - & 240 & 32 & 12 & Niskow. & • & $\bullet$ & - & $\bullet$ & - \\
\hline Langeland & & - & - & - & 70 & 30 & 3 & Rudkioping. & • & - & - & - & - \\
\hline Femeren & - & - & - & - & 50 & 14 & 5 & Burg. & - & - & - & - & - \\
\hline Alsen & - & - & - & - & 54 & 15 & 6 & Sunderborge & - & - & - & - & - \\
\hline Moen & - & - & - & - & 40 & 14 & 5 & Stege. & - & - & - & - & - \\
\hline Bornholm & - & - & - & - & 160 & 20 & 12 & Ronne & - & - & - & $\bullet$ & - \\
\hline Iceland & - & - & - & - & 43,264 & 350 & 240 & Skaiholt & - & - & - & - & - \\
\hline Norway & & - & - & - & 112,000 & 910 & 170 & Bergen. & - & - & - & - & - \\
\hline Danish Lapl & land & & . & - & 28,000 & 280 & 170 & Wardhuys & - & - & - & - & - \\
\hline
\end{tabular}

DENIIARK PROPER, OR THE PENINSULA OF JU ILAND, INCLUDING THE ISLANDS IN THE BALTIC.

Miles.

EXTENT AND SITUATION,

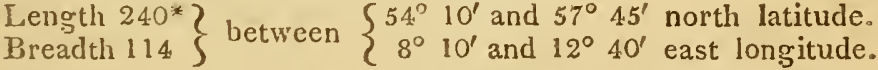

Containing 12,896 square miles, with 84 inhabitants to each.

NAME... The name of Denmark is derived by Saxo Grammaticus from Dan, the first founder, according to him, of the Danish monarchy; and Mark, a boundary or country. But this etymology is probably fabulous; all we know with certainty is, that the inhabitants of this part of Scandinavia were known by the name of Danes in the sixth century.

Boundaries AND Divisions.... Denmark is divided on the north from Norway by the Scaggerac Sea, and from Sweden on the east by the Sound; it is bounded on the south by Germany and the Baltic; and the German Sea divides it from Great Britain on the west.

Denmark proper is divided into two parts; the peninsula of Jutland, anciently called Chersonesus Cimbrica, and the islands at the entrance of the Baltic mentioned in the table. It is remarkable, that, though all these together constitute the kingdom of Denmark, yet not any one of them is separately called by that name. Copenhagen, the metropolis, is in the island of Zealand.

The Danish peninsula was formerly denominated Jutland, and divided into two parts.....North Jutland and South Jutland. The former

* These dimensions are those of the peninsula of Jutland only, where longest and broadest, in which sense they are always to be understood in this work. Jut. land, for ins' ance, is 114 miles in breadth where broadest; though in some parts it is not more than 30 . 


\section{DENMARK:}

of these is now called simply Jutland, and the latter Sleswick. Jut: land is divided into nine syssels or districts, and Sleswick into fifteen counties.

- Denmark Proper is likewise divided into six dioceses, or jurisdic. tions, of the following dimensions :

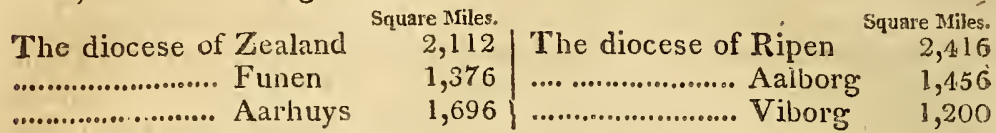

Mountains, lakes, rivens, canals....The interior of the broad nortiner" part of Denmark. Proper contains some hills of a bleak and wild aspect, but none entitled to the name of mountains. There are many small, but no large lakes. The smali streams which intersect the-tountry are numerous, but only two seem to deserve notice as rivers; the Guden, which receives the waters of forty rivulets, and runs a winding course of an hundred miles before it falls into the Categat; and the Eydar, the ancient boundary between Denmark and the German duchy of Holstein.

In the northern part of Jutland, an extensive creek of the sea, called Lymfiord, penetrates from the Categat through an extent of above seventy miles, to within two or three miles of the German Ocean : it is navigable, and contains numerous small islands.

A canal, called the Canal of Kiel, a considerable town in the north of Holstein, has been made, at the expense of nearly eight hundred thousand pounds, to open a communication between the Baltic and the river Eyclar, which flows into the German Sea It is above twenty miles in length, and is navigable by vessels of 120 tons. It was finish ed in 1785 .

Minerals....Some fuller's-earth, alum, and vitriol, found in Jutland, and porcelain clay obtained in the island of Bornholm, seem to constitute the whole of the mineral productions of Denmark Proper.

Climate, soil, and STATE of agriculture... The climate of Zealand and the south of Jutland is more temperate, on account of the vapours from the surrounding sea, than it is in nany more southerly parts of Europe. In the northern parts of Denmark, the winters are very severe, and spring and autumn are seasons scarcely known, on account of the sudden transitions from cold to heat, and from heat to cold. The entrance of the Baltic in winter is generally so obstructed with ice, as to be innavigable, and sometimes so frozen, as to be crossed by sledges and loaded carriages.

The soil of Zealand, Funen, and the south of Jutland, is fertiles and the agriculture of the two latter is compared by Mr. Marshal to that of England; but in the northern parts, the country is less cultivated. Zealand is for the most part a sandy soil, but fertile in grain and pasturage, and agreeably variegated with woods and lakes.

The greatest parts of the lands in Denmark and Holstein are fiefs. The ancient nobility, by grants which they extorted at different times from the crown, gained such power over the farmers, and those who resided upon their estates, that at length they reduced them to a state of extreme slavery, so that they were bought and sold with their lands, and were esteemed the property of their lords. Many of the noble land-holders of Sleswick and Holstein have the power of life and death. The situation of the farmers has, indeed, been made somewhat more agreeable by some modern edicts; but they are still, if such an cxpression may be allowed, chained to their farms, and are 
Iisposed of at the will of their lords. The late count Bernstorff, however, set a truly noble example by the emancipation of his tenants; and the prince-royal, in whom the administration of the government is now vested, has also had the magnanimity and true policy to give liberty to all the peasants of the crown.

VEGETABLE PRODUCTIONS, ANMALS....Jutland contains woods of oak, fir, beech, birch, and other trees. Denmark and Holstein produce corn in such abundance, as often to be able to export in one year to the value of above $100,000 \%$; they also produce rape-seed, liops, and flax. The horses of Denmark and Holstein are an excellent breed, both for the saddle and the carriagre. Besides great numbers of black-cattie, of which about 80,000 head are generally exported annually, they have hogs, slieep, and game. The sea-coasts abound with various kinds of fish.

Curiositifs, xatural axd artificial....Denmark Proper affords fewer of these than the other parts of his Danish majesty's dominions, if we except the contents of the Royal Museum at Copenhagen, which consists of a numerous collection of both. Here are préserved two famous antique drinking ressels, the one of gold, the other of silver, and both of the form of liunting horns. That of gold is about two feet nine inches long, weigls 102 ounccs, contains two English pints and a half, and was found in the diocese of Ripen, in 1639. The other, of silver, weighs about four pounds, and is called the OIdenburg Horn, because, as tradition affirms, it was presented to Otho, the first duke of Oldenburg, by a ghost. This museum contains a fine collection of paintings, and another of coins, as also a great number of astronomical, optical, and mathematical instruments.

Population....By an actual enumeration made in 1759 , of his $\mathrm{Da}$ nish majesty's subjects in his dominions of Denmark, Norway, Holstein; the islands in the Baltic, and the counties of Oldenburg and Delmenhorst in Vestphalia, they were said to amount to $2,444,000$ souls, exclusive of the Icelanders and Greenlanders. The most accurate account of the population is that made under the direction of the famous Struensee, in 1769, by which

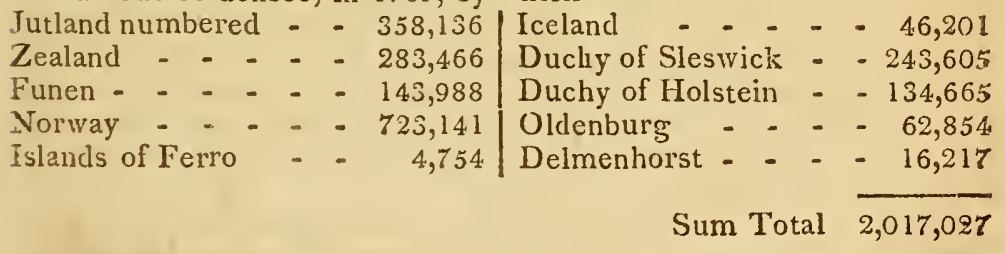

Since this estimate was taken, the counties of Oldenburg and Delmenhorst have been exchanged for the remainder of Holstein; and the population of the Danish dominions in Europe is thus given in Bœtticher's tablcs:

The diocese of Zealand 345,740 The duchy of Sleswick 251,230

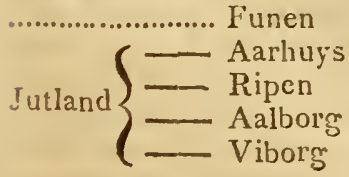

151,512

125,282

83,186

71,242

53,488

Holstein

311,758

The kingdom of Norway 700,000

The Ferro islands

5,000

Iceland

50,000

Sum Total $\overline{2,148,4.38}$

The population of Denmark Proper, or Jutland, Sleswick, and the 
islands of the Baltic, cxclusive of Holstein, will therefore amount to $1,081,680$.

National character and MaNners....The ancient inhabitants of Denmark possessed a degree of courage which approached even to ferocity : their national character in this respect, however, is much changed; but with their former ferocious habits, they have also laid aside in a great measure their ancient simplicity and innocence. Though not a very enterprising, they are a brave and humane people. They value themselves extremely upon those titles and privileges, which they derive from the crown; and are extremely fond of pomp and show. They endeavour to imitate the French in their manners, dress, and even in their gallantry; though they are naturally the very contrast of that nation. The Danes, like other northern nations, are given to intemperance in drinking, and convivial entertainments; but their nobility, who begin now to visit the other courts of Europe, are refining from their ancient national habits and vices.

Crties, chief towns, edifices....Copenhagen, which is situate on the island of Zealand, was originally a settlement of sailors, and first founded by some wandering fishermen in the twelfth century, but is now the metropolis, and makes a magnificent appearance at a distance. It is very strong, and defended by four royal castles or forts. It contains ten parish churches, besides nine others belonging to the Calvinists and other religious sects, and some hospitals. Copenhagen is adorned by several public and private palaces, as threy are called. Its streets are 186 in number, the houses about 4,000 and its inhabitants amount to 100,000 . The houses in the principal streets are built of brick, and those in the lanes chiefly of timber. The harbour is spacious, and is formed by a large canal flowing through the city, which admits only one ship to enter at a time; but the harbour is capable of containing 500. Several of the streets have canals and quays for ships to lie close to the houses; and the naval arsenal is said to exceed that of Venice. The road for shipping begins about two miles from the town, and is defended by 90 pieces of cannon, as well as the difficulty of the navigation. Yet, notwithstanding all these advantages, there is little appearance of industry or trade in this city; and Copenhagen, though one of the finest ports in the world, cannot boast of its commerce. The police of Copenhagen is extremely regular, and people may walk through the whole city at midnight with great safety. Indeed, it is usually almost as quiet here at eleven o'clock at night as in a country village.

About twenty English miles from Copenhagen, is a noble palace belonging to his Danish majesty, called Fredericsburg. It is a very large building, moated round with a triple ditch, and calculated, like most of the ancient residences of princes, for defence against an enemy. It was built by Christian IV, and, according to the architecture of the times, partakes of the Greek and Gothic styles. In the front of the grand quadrangle appear Tuscan and Doric pillars; and on the summit of the building are spires and turrets. Some of the rooms are very splendid, though furnished in the antique taste. The Innights ${ }^{\prime}$ hall is of great length. The tapestry represents the wars of Denmark, and the ceiling is a most minute and laboured performance in sculpture. The chimney-piece was once entirely covered with plates of silver, richly ornamented; but the Swedes, who have often landed here, and even besieged the capital, tore them all away, and vifted the palace, notwithstanding its triple moat and formidable ap. 
pearance. The royal palace of Christiansburg, one of the most commucious and most sumpluously furnished in Europe, was destroyed by tire on the 26th of February, 1794. About two miles firom Elsineur is a small royai palace, flat roofed, with twelve windows in front, said to be built on the place formerly occupied by the palace of Hamlet's father. In an adjoining garden is shewn the very spot where, ace corcing to tradition, that prince was poisoned.

Odensee is the capital of the island of Funen. It is situated on a river which runs into a large bay about a mile below the town. It contains a cathedral and three churches: here is also a royal palace. The number of inhabitants is about 5,000. It has been said that the Danish language is spoken here in its greatest purity.

Sleswick, the capital of the duchy of that name, is the largest town in the Danish peninsula. It is a long, irregular, but handsome town, containing between five and six thousand inhabitants.

Elsineur, or Helsingoer, is well built, contains 5,000 inhabitants, and with respect to commerce is only exceeded by Copenhagen itself. It is situate on the eastern coast of the island of Zealand, is strongly fortified on the land side, and towards the sea defended by a strong fort. Here all ressels pay a toll, and, in passing, lower their topsails.

Maxufactures and commerce... The manufactures of Denmark are not very numerous or important. In the royal manufactures, as they are called, at Copenhagen, a late intelligent traveller tells us 400 looms are employed in fabricating all sorts of woollen cloth, from the finest to that for the use of the soldiery. Other manufactures have also been encouraged by the crown, and by the patriotism of count Roncellen.

Denmark is extremely well situate for commerce; her harbours are well calculated for the reception of ships of all burdens, and her mariner's are very expert in the navigation of the different parts of the ocean. The dominions of his Danish majesty also supply a great variety of timber and other materials for ship-building; and some of his provinces afford many natural productions for exportation. Among: these, beside fir and other timber, are black-cattle, horses, butter, stock-fish, tallow, hides, train-oil, tar, pitch, and iron. To these we may add furs; but the exportation of oats is forbidden. The imports are, salt, wine, brandy, and silk, from France, Portugal, and Italy. The Danes have great intercourse with England, and thence import: broad-cloths, and all other articles manufactured in the great trading: towns of England.

Civil constitution, GOVERNMENT.... The ancient constitution of Denmark was originally much the same with that of other Gothic governments. The king came to the throne by election; and, in conjunction with the senate, where he presided, was invested with the executive power. He likewise commanded the army, and decided finally all the disputes which arose between his subjects. The legis. lative power, together with the right of election of the king, was verted in the states, who were composed, first, of the order of nobility, and secondly, of that of the citizens and farmers. After the introduction of the Christian religion, the clergy were also admitted, not only to be an order of the states, but to have seats likewise in the senate. These orders had their respective rights and privileges, and were independent of each other The crown had also its prerogatives, and a certain fined revenue arising out of lands which vere appro. 
priated to its support. This constitution had many evident acivantages : but, unfortunately, the balance of this government was never properly adjusted; so that the nobles very soon assumed a dictatorial power, and greatly oppressed the people, as the national assemblies were not regularly held to redress their grievances; and when the Roman Catholic clergy came to have a share in the civil government, they far surpassed the nobility in pride and ambition. The representatires of the people had neither power, credit, nor talents, to counteract the efforts of the other two orders, who forced the crown to give up its prerogatives, and to oppress and tyrannise over the people. Christian the Second, by endeavouring in an imprudent manner to stem the torrent of their oppression, lost his crown and his liberty; but Christian the Third, by uniting with the nobles and the senate, destroyed the power of the clergy, though the oppression of the common people by the nobility still remained. At length, in the reign of Frederic the Third, when the nation had been exhausted by a war with Sweden, the people, exasperated by the arrogance and oppressions of the nobility, who claimed as their privilege an exemption from all taxes, determined to rencler the king despotic to free themselves from their tyranny. In consequence of this resolution in a meeting of the states, deputies from the clergy and the commons were appointed to make the king a solemn tender of their liberties and services. The monarch accepted their offer, promising them relief and protection: the nobility, taken by surprise, were obliged to submit; and, on the 10th of January, 1661, the three orders of nobility, clergy, and people, signed each a separate act, by which they consented that the crown should be hereditary in the royal family, as well in the female as in the male line, and invested the king with absolute power, giving him the right to regulate the succession, and the resency, in case of a minority. This renunciation of their right, subscribed by the first nobility, is still preserved as a precious relic among the archives of the royal family.

After this extraordinary revolution in the government, the king of Denmark deprired the nobility of many of the privileges which they had before enjoyed; but he took no method to relieve those poor people who had been the instruments of investing him with the sovereign power, but left them in the same state of slavery in which they were before, and in which they have remained to the present age.

Laws.... The Iing unites in his person all the rights of sovereign power; but in affairs of importance he for the most part decides in his council, the members of which are named and displaced at his will. In this council, the laws are proposed, discussed, and receive the sanction of the royal authority, and all great changes or establisnments are proposed, and approved or rejected, by the king. Here likewise, or in the cabinet, he grants privileges, and decicles upon the explication of laws, their extension, or restriction, and upon all the most important affairs of state.

The supreme court of judicature for the kinglom of Denmark is holden in the royal palace of Copenhagen, of which the king is the nominal president. What are called the German provinces have likewise their supreme tribunal; which, for the duchy of.Holstein, is holden at Gluckstadt; and for the duchy of Sleswick, in the town of that nanie.

In this kingdom, as in many others, the king is supposed to bo 
present to administer justice in his supreme court; and therefore, the kings of Denmark not only preside nominally in the sovereign court of justice, but they have a throne erected in it, towards which the lawyers always address their discourses in pleading, as do the judges in delivering their opinion. Every year the king is present at the opening of this court, and often gives the judges such instructions as he thinks proper. The decision of these judges is final in all civil actions; but no criminal sentence of a capital nature can be carried into execution till it is signed by the king.

There are many excellent regulations for the administration of jus . tice in Denmark : but, notwithstanding this, it is so far from being: distributed in an equal and impartial manner, that a poor man can scarcely ever obtain justice in that country against one of the nobility, or against one who is favoured by the court. If the laws are so clearly in favour of the former, that the judges are ashamed to decide against them, the latter, through the favour of the minister, obtains an order from the king to stop all proceedings, or a dispensation from observ. ing particular laws; and there the matter ends.' The code of laws at present established in Denmark was published by Christian V: it is founded upon the code of Valdemar, and is nearly the same with that in use in Norway. These laws are very just and clear; and, if they were impartially carried into execution, would be productive of many beneficial consequences to the people. But as the king can alter and dispense with the laws as he pleases, and support his ministers and favourites in any acts of violence and injustice, the people of Denmark are subject to great tyranny and oppression, and have abundant reason to regret the tameness and servility with which their liberties were, in 1660, surrendered into the hands of their monarchs.

From that period, the peasants, till 1787, had been in a-situation little better than the brute creation; they scarcely could be said to possess any locomotive power, since they had no liberty to leave one estate, and to settle on another, without purchasing permission from their mastel's; and if they chanced to move without that permission, they were claimed as stray cattle. Such was the state of those wretched beings, who, at best, only rnight be said to vegetate. These chains of feudal slavery were then broken, through the interest of his royal highness the prince and heir-apparent to the crown; and the prisoners, for such they certainly might be called, were declared free. Notwithstanding the remonstrances, which were made against this by the landed gentry, were very numerous, yet, after a minute examination of the whole, an edict was issued which restored the peasants to their long-lost liberty. A number of grievances, under which the peasantry laboured, were likewise abolished at the same time.

Revenues....His Danish majesty's revenues have three sources: the taxes he levies upon his own subjects; the duties paid by fortigners; and his own demesue lands, including confiscations. The taxes consist of those on land and houses, the poll-tax, stamp-duties, taxes on salt and tobacco, and various other imposts. The tolls paid by strangers arise chiefly from foreign ships that pass through the Sound in to the Baltic, through the narrow strait of half a mile between Schonen and the island of Zealand. 'These tolls are in proportion to the size of the ship, and value of the cargo exhibited in the bilis of lading. This tax, which forms a considerable part of his Danish majesty's revenue, has more than once thrown the northern parts of Vol, I, 
Europe into a flame. It has been oiten disputed by the English and Dutch, being notining more originally than a voluntary contribution of the merchants towards the expenses of the light-houses on the coast; and the Swedes, who command the opposite side of the pass, for some time refused to pay it; but in the treaty of 1720 , between Sweden and Denmark, under the guarantee of his Britannic majesty George I, the Swedes ayreed to pay the same rates as are paid by the subjects of Great Britain and the Netherlands. The first treaty relative to it was by the emperor Charles V, on behalf of his subjects in the Low Countries. The toll is paid at Elsineur, a town situated on the Sound, at the entrance of the Baltic Sea, and about 18 miles distant from Copenhagen. The whole revenue of Denmark, including what is received at Elsineur, amounts at present to about $\$ 7,000,000$ yearly.

By a list of the revenue taken in 1730, it then only amounted to English money $454,700 l$. The expenses of the state amount annuallyto above $1,050,000 l$; and it is burdened with a debt of $2,600,000$.

Army AND NAyY.... The present military force of Denmark consists of 4:0,000 men, of this force about 10,000 is cavalry, and 30,000 infantry. Besides the regular troops, there is a national militia, called Landvaern; including all the male inhabitants between 36 and 45 years of age. These are called into service upon particular emergencies only. They amount to about 60,000 men. The fleet of Denmark, according to the official gazette of the 15th of October, 1803 , consisted of 19 ships of the line; of which were 1 of $90 ; 2$ of $80 ; 12$ of 74 ; and 4 of 64 guns ; 15 frigates, 8 brigs, and 13 gunboats. An order was issued some time since to increase the number of frigates to 30 , and constantly to keep up that number. This fleet is generally stationed at Copenhagen, where are the dock-yards, storehouses, and all the materials necessary for the use of the marine. There are 26,000 registered seamen, who cannot quit the kingdom without leave, nor serve on board a merchantman without permission from the admiralty : 4000 of these are kept in constant pay, and employed in the dock-yards : their pay, however, scarcely amounts to nine shillings per month; but they have a sort of uniform, with some provisions and lodging allowed for themselves and families. Part of the Danish fleet was destroyed at the bombardment of Copenhagen in 1801, and the remainder has been since captured by the English, to prevent its falling into the hands of the French. See more of this in the history of England.

ROYAL TITLES, ORDERS OF KNIGTHOOD....The kings of Denmark in their public acts take the title of " $\mathrm{king}$ of Denmark and of the Goths and Vandals, duke of Sleswick and Holstein, Stormar and Ditmarsch, count of Oldenburg and Delmenhorst." The orders of Innighthood are two: that of the Elephant, and that of Danebrog. The former was instituted by Christian I, in the year 1478, and is deemed the most honourable; its badge is an elephant surmounted with a castle, set in diamonds, and suspended to a sky-blue watered ribbon, worn, like the George in England, over the right shoulder : the number of its members, besides the sovereign, are thirty ; and the knights of it are addressed by the title of Excellency. The badges of the Danebrog order, which is said to have been instituted in the year 1219, and after being long obsolete was revived in 1671 by Christian $\mathbf{V}$, consist of a white ribbon with red edges, worn scarf-wise over the right shoulder; from which depends a small cross of diamonds, and 
an embroidered star on the breast of the coat, surrounded with the motto Pietate et Justitia. The badge is a cross pattee enamelled white, on the centre the letter $\mathrm{C}$ and $5 \mathrm{crowned}$ with a regal crown, and this motto: Restitutor. The number of knights is not limited; and they are very numerous.

RELIGION....The religion of Denmark is the Lutheran. The king dom is divided into six clioceses : Zealand, Funen, Viborg, Aarhuys, Ailborg, and Ripen; besides two in Iceland. There is no archbishop; but the bishop of Zealand is metropolitan in Denmark, as the bishop of Agrerhuys is in Norway. The annual revenue of the bishopric of $\mathrm{Zealand}$ is about $1000 l$. a year, that of Funen, $750 l$. the others are from $400 l$. to 600 . The bishops have no temporal power, nor more authority over the inferior clergy than is neressary for the maintenar.ce of good order in the church.

Literaturf... The Danes in general have made no great figure in literature; though astronomy and medicine are highly indebted to their Tycho Brahe, Borrichius, and the Bartholines: and the Round Tower and Christian's Haven display the mechanical genius of a Longomontanus. They begin now, however, to make some promising attempts in history, poetry, and the rlrama. But it appears that literature has received very little cncouragement in Denmark; which may be considered as the principal cause of its being so little cultivated by the Danes. Yet the names of Langebek, Suhm, and Holberg, have acquired some degree of deserved celebrity; and the travels of Niebuhr are distinguished for intelligent research and ac curate information.

Universities... Therc are two universities in Denmark; one at Copenhagen, and the other at Kiel in Holstein. The former has funds to the amount, it is said, of 300,000 rix-dollars, for the gnatuitous support of 328 students.

EDUCATION.... The education of the poor, has lately been a subject of attention to the government. The country has been divided into school districts, none of which is so large as to subject the children to inconvenience in attending, on account of the clistance. Government provide suitable teachers; and all parents are obliged to send their children to school after the age of seven years.

LANGU A GE.... The language of Denmark is a dialect of the Teutonic; but German and French are spoken at court; and the nobility have lately made great advances in the English, which is now publicly taught at Copenhagen as a necessary part of education. A company of English comedians occasionally visit that capital, where they find tolerable encouragement. The Lord's Prayer, in Danish, is as follows:

Vor fudor som er $i$ himmelin; heiligt vorde. dit naffn; tilkomme dic ryke; vorde din villie flaa jorden somi himmelin; sif os $i$ das vort daglige brod; og forlad os vor skyld som vi forlade vore skyldener; og leed os icke $i$ fristrelse, men frels os fra ont; thi reget er dit, os kraft os hergled i evighed. Amen.

ANTriqutres.... The antiquities of Denmark consist only of some rude remains of the temples and cemeteries of the ancient Celtic and Gothic inhabitants of the country. In several parts of the Danish dominions are found circles of upright stones; disposed in a manner similar to those of Stanehenge. There are also, on some rocks, Runic inscriptions, which are so ancient they can no longer be ex- 
plained with certainty ; but they are supposed to record some remark: able events.

History.... The most ancient inhabitants of Denmark, of whom: we have any account were the Cimbri, the Danish peninsula being calied by the ancients Chersonesus Cimbrica, or the peninsula of the Cimbri. After the conquest of the country by the Goths, we find the possessors of it formidable to their neighbours, by their piracies and sanguinary depredations, in the fifth century, under the name of Jutes or Vitx, and Angles; and in the sixth, under that of Danes. But the history of Denmark is fabulous and uncertain, till the tenth century. Harold Blaatand, who succeeded his father Gormo in 945, was the first Christian king of Denmark. He was followed by his son Swein, who invaded and laid waste England; and dying in 1014 , was succeeded by his son Canute the Great.

Under Canute the Great, Denmark may be said to have been in its zenith of giory, as far as extent of dominion can give sanction to the expression. Few very interesting events in Denmark preceded the year 1387, when Margaret, daughter of Waldemar III, who had married Hakon king of Norway, but was then a widow, mounted the throne ; and, partly by her address, and partly by hereditary right, formed the union of Calmar, anno 1397, by which she was acknowledged sovereign of Sweden, Denmark, and Norway. She held her dignity with such firmness and courage, that she was justly styled the Semiramis of the North. Her successors being destitute of her great qualifications, the union of Calmar, by which the three kingdoms werc in future to be under one sovereign, lost its effect; but Norway still continued annexed to Denmark. In the ycar 14.48, the crown of Denmark fell to Christian, count of Oldenburg, from whom the present royal family of Denmark is descended.

In 1515, Christian II, a tyrannical and sanguinary prince, ascended the throne of Denmark, and married the sister of the emperor Charles V. Being driven out of Sweden for his atrocious cruelties, the Danes rebelled against him likewise; and he fled, with his wife and children, into the Netherlands. Frederic, duke of Holstein, was unanimously. called to the throne, on the deposition of his cruel nephew. He embraced the opinions of Luther; and about the year 1536, the protestant religion was established in Denmark by that wise and politic prince Christian III.

Christian IV, of Denmark, in 1629, was chosen for the head of the protestant league formed against the house of Austria; but, though brave in his own person, he was in danger of losing his dominions; when he was succeeded in that command by Gustavus Adolphus king of Sweden. The Dutch having obliged Christian, who died in 1648 , to lower the duties of the Sound, his son Frederic III, consented to accept of an annuity of 150,000 florins for the whole. The Dutch, after this, persuaded him to declare war against Charles Gustavus king of Sweden; which had almost cost him his crown. In 1657, Charles stormed the fortress of Fredericstadt ; and in the succeeding vinter marched his army over the ice to the island of Funen, where he surprised the Danish troops, took Odensee and Nyburg, and marchcd ovcr the Great Belt to besiege Copenhagen itself. Cromwell, who then governed England under the title of Protector, interposed; and Frederic defended his capital with great magnanimity till the peace of Roschild, by which Frederic ceded the provinces of Hochland, Bleckingen, and Schonen, the island of Boinholm, and Bahus and 
Drontheim in Norway, to the Swedes. Frederic sought to elude these severe terms : but Charles took Cronenburg, and once more besieged Copenhagen by sea and land. The steady intrepid conduct of Frederic, under these misfortunes, endeared him to his subjects; and the citizens of Copenhagen made an admirable defence, till a Du.ch fleet arrived in the Baltic, and beat the Swedish fleet. The fortune of war was now entirely changed in favour of Frederic, who showed on every occasion great abilities, boih civil and military; and, having forced Charles to raise the siege of Copenhagen, might have carried the war into Sweden, had not the English fleet, under Montague, appeared in the Baltic. This enabled Charles to besiege Copenhagen a third time; but France and England offering their mediation, a peace was concluded in that capital, by which the island of Bornholm was restored to the Danes; but the island of Rugen, and the provinces of Bleckingen, Hochland, and Schonen, remained with the Swedes.

Though this peace did not restore to Denmark all she had lost, yet the magnanimous behaviour of Frederic, under the most imminent dangers, and his attention to the safety of his subjects, even preferably to his own, greatly endeared him in their eyes; and he at length became absolute, in the manner already related. Frederic was succeed. ed, in 1670 , by his son Christian V, who obliged the duke of Holstein Gottorp to renounce all the advantages he had gained by the treaty of Roschild. He then recovered a number of places in Schonen : but his army was defeated in the bloody battle of Lunden, by Charles XI, of Sweden. This defeat did not put an end to the war, which Christian obstinately continued, till he was defeated entirely a: the battle of Landscroon : and having almost exhausted his dominions in military operations, and being in a manner abandoned by all his allies, he was forced to sign a treaty, on the terms prescribed by France, in 1679 . Christian afterwards became the ally and subsidiary of Lewis XIV, and died in 1690 . He was succeeded by Frederic IV, who, like his predecessors, maintained his pretensions upon Holstein, and probably must have become master of that duchy, had not the English and Dutch fleets raised the siege of Tonningen, while the young king of Sweden, Charles XII, who was then no more than sixteen years of age, landed within eight miles of Copenhagen, to assist his brotherin-law the duke of Holstein. Charles probably woinld have made himself master of Copenhagen, had not his Danish majesty agreed to the peace of Travendahl, which was entirely in the duke's favour. By another treaty concluded with the States-General, Charles obliged himself to furnish a body of troops, who were to be paid by the con: federates, and afterwards took a very active part against the French in the wars of queen Anne.

Notwithstanding this peace, Frecleric was perpetually engaged in wars with the Swedes; and while Charles XII, was an exile at Bender, he made a descent upon Swedish Pomerania, and another, in the year 1712, upon Bremen, and took the city of Stade. His troops, however, were totally defeated by the Swedes at Gadesbuch, and his favourite city of Altona was laid in ashes. Frederic revenged himself by seizing great part of Ducal Holstein, and forcing the Swedish general, count Steinbock, to surrender himself prisoner, with all his troops.

- In the year 1716, the successes of Frederic were so great, by taking Tonningen and Stralsund, by driving the Swedes out of Norway, and reducing. Wismar in Pomerania, that his allies began to suspect he was aiming at she sovereignty of all Scandinavia. Upon the seturn of 
Charles of Sweden from his exile, he renewed the war against Den= mark with the most implacable violence; but, on the deatin of that prince, who was killed at the siege of Fredericshall, Frederic durst not refuse the offer of his Britannic majesty's mediation between him and the crown of Sweden: in consequence of which a peace was concluded at Stockholm, which left him in possession of the duchy of Sleswick. Frederic died in the year 1730, after having, two years before, seen his capital reduced to ashes by an accidental fire. His son and successor, Christian Frederic, or Christian VI, made the best use of his power, and the advantages with which he mounted the throne, by cultivating peace with all his neighbours, and promoting the happiness of his subjects, whom he eased of many oppressive taxes.

In 1734, Christian sent 6000 men to the assistance of the emperor, during the dispute of the succession to the crown of Poland. Though he was pacific, yet he was jealous of his rights, especially over Hamburgh. He obliged the Hamburgers to call in the mediation of Prussia, to abolish their bank, to admit the coin of Denmark as current, and to pay him a million of silver marks. In 1738 he had a dispute with his Britannic majesty about the little lordship of Steinhorst, which had been mortgaged to the latter by a duke of Holstein-Larenburgh, and which Christian said belonged to him. Some blood was spilt during the contest, which, however, ended in a treaty, by which his Britannic majesty agreed to pay Christian a subsidy of 70,000 . sterling a year, on condition of keeping in readiness 7000 troops for the protection of Hanover. This was a gainful bargain for Denmarls. Two year's after, he seized some Dutch ships, for trading without his leave to Iceland; but the difference was made up by the mediation of Sweden. Christian died in 1746 , with the character of being the father of his people.

His son and successor, Frederic $V$, had, in 1743 , married the princess Louisa, daughter to his Britannic majesty George II. He improved upon his father's plan for the happiness of his people, and took no concern, except that of a mediator, in the German war. It was by his intervention that the treaty of Closter-Seven was concluded between his rojal highness the late duke of Cumberland and the French general Richelieu. Upon the death of his first queen, who was mother to his present Danish majesty, he married a daughter of the duke of Brunswic-Wolfenbuttle; and died in 1766 .

His son, Christian VII, married his present Britannic majesty's youngest sister, the princess Carolina-Matilda. 'This alliance, though it wore at first a very promising appearance, had a very unfortunate termination. In the month of January, 1772 , by the intrigues, or at least the active agency of the queen-dowager, mother-in-law to the present king, Matilcia was charged with an illicit commerce with count Struensee, the minister and favourite of the king; and with being engaged with him, his brother, and count Brandt, in a conspiracy to deprive her husband and sovereign of his crown. She was in consequence arrested, and confined in the castle of Cronenburg. Her son, the prince-royal, who had entered into the fifth year of his age, was put under the care of a lady of quality, who was appointed governess, under the superintendency of the queen-dowager. Struensee and Brandt were seized, put in irons, and very rigorously treated in prison: they both underwent long and frequent examinations, and at length received sentence of death. "They were beheaced on 
the 2sth of April, having their right hands previously cut off; but many of their friends and adherents were afterwards set at liberty. Struensee at first absolutely denied having any criminal intercourse with the queen; but this he afterwards confessed: and though he is said by some to have been induced to do this only by the fear of torture, the proofs of his guilt in this respect were esteemed notorius, and his confessions full and explicit. In May, his Britannic majesty sent a small squadron of ships to convey the queen Matilda to Germany, and appointed the city of Zell, in his electoral dominions, for the place of her future residence. She died there of a malignant fever, on the 10 th of May, 1775, aged 23 years and 10 months.

In 1780 , his Danish majesty acceded to the armed neutrality proposed by the empress of Russia. He appears at present to have such a debility of understanding as to disqualify him for the proper management of public affairs. On the 16 th of April, 1784, another court revolution took place. The queen-dowager's friends were remored, a new council formed under the auspices of the prince-royal, some of the former old members restored to the cabinet; and every instrument must now be sirned by the king, and countersigned by the printe-royal.

The conduct of this prince exhibits that consistency of behaviour which enables him to pursue, with unremitting zeal, the prudent and. benevolent measures which he has planned for the benefit of his grateful country. The restoration of the peasantry to their long-lost liberty, and the abolition of many grievances under which they laboured, have already been mentioned. To these may be added the exertions he makes for the general diffusion of knowledge; the patronage he affords to societies of learning, arts, and science; the excellent measures he has adopted for the suppression of beggars, with whom the country was overrun, and the encouragement of industry, by the most extensive inquiries into the state of the poor throughout the kingdom; the wise regulations he has introduced into the corn trade, equally beneficial to the landed interest and to the poor; and the judicious laws, which under his influence have been made to encourage foreigners to settle in Iceland. The princess of Hesse-Cassel, his consort, is said to possess the most amiable dispositions and goodness of heart.

Count Schimmelmann, minister of state, finances, and commerce, has the merit of projecting the abolition of the slave-trade among: the subjects of Denmark. By his plan, which was approved by the king on the 22d of February, 1792, and is to be gradual, all trade in negroes was to cease on the part of the Danish subjects in 1803. The disinterestedness of this minister, who possesses large estates in the Danish West-India islands, recommends his exertions to greater praise. The above ordinance does not seem to have caused any discontent in Denmark among the. West.India merchants, and it is not thought it will cause any in the islands.

A scheme for defraying the national debt has been suggested and followed, by which a considerable reduction of it has been effected.

Denmark, from the beginning of the French revolution, formally rejected every solicitation to join the coalition of potentates against France.

In 1801, the Danish government acceded to the confederacy formed by the northern powers against the naval superiority of Creat 
Britain, under the title of a Convention of Neutrality. But this league was quickly dissolved by the appearance of an English fleet in the Baltic under the command of the gallant admiral Nelson, who, in the battle of the $2 \mathrm{~d}$ of April of the same year, forced the line of defence formed by the Danish fleet before Copenhagen, and compelled the Danes to agree to a cessation of arms to preserve their capital. In this short war the Danes lost their islands in the West-Indies, and their settlement of Tranquebar on the coast of Coromandel, whicls were conquered by the British arms. But the dispute between England and the northern powers being soon after amicably adjusted by a treaty, their foreign possessions have since been all restored to them; and taken a second time, after the renewal of hostilities between Great Britain and Denmark.

Christian VII, reigning king of Denmark, L. L.D. and F.R.S. was born January 29, 1749; in 1766 he was married to the princess Carolina-Matilda of England; and his issue.... l, Frederic, princeroyal of Dennark, born January 28, 1768, and married July 31, 1790, to the princess Mary-Sophia-Frederica of Hesse-Cassel. 2, LouisaAugusta, princess-royal, born July 7, 1771, and married May 27, 1786, to Frederic, prince of Sleswick-Holstein, by whom she has issue.

Brothers and sisters to the king.... , Sophia Magdalene, born July 3, 1746 ; married to the late king of Sweden, Gustavus III....2, Wilhelmina, born July 10, 1747; married Sept. 1, 1764, William, the present prince of Hesse-Cassel....3, Louisa, born Jan. 30, 1750 ; married Aug. 30, 1766, Charles, brother to the prince of Hesse-Cassel.... 4, Frederic, born Oct. 28, 1753. 


\section{ICHLAND.}

\section{EXTENT AIND SITUATION.}

Miles.

$\left.\begin{array}{l}\text { Length } 300 \\ \text { lieadth } 280\end{array}\right\}$ between $\left\{\begin{array}{l}63^{\circ} \text { and } 67^{\circ} \text { north latitude. } \\ 16^{\circ} \text { and } 25^{\circ} \text { west longitude. }\end{array}\right.$

Dontuining 43,000 square miles, with somewhat more than one inhabitant to each.

NaME.... Iceland evidently derives its name from the great masses of ire which float in the ocean that surround its shores.

Mountaiso, VolcaNoEs, LAkEs, Rivers... The mountains of Iceland range generally from the south-east to the north-west. The jincipal summits, covered with perpetual snow, are called Xokuls; and of these, Snxfials, which projects orer the sea in the south-west part of the island, is esteemed the loftiest : its height is computed at: above 6800 feet. Almost all the Icelandic mountains either are, or appear to have been, rolcanic. Of these, Heckla is most known to forcigners. This mountain is situated in the souchern part of the island, about four miles from the sea-coast, and is divided into three points at the top, the highest of which is that in the middle, which is computed to be above 5000 feet higher than the sea. This mountain has frequently sent forth flames, and a torrent of burning matter. Its cruptions were particularly dreadful in 1693, when they occasioned terrible devastations, the ashes being thrown all round the island to the distance of 180 English miles. An eruption of Mount Heckla happenerl in 1766. It began on the 5 th of April, and continued to the ith of September following. Flames proceeded from the mountain, in December, 1771 , and 1772 ; but no streams of lava.

But the greatest of the eruptions of Iceland, and in fact the most tremenclous of any recorded in history, was that in 1783, which, we are assured by the abbé Spallanzani, * who cites the authority of $\mathrm{Mr}$. Pennant, extended ninety-four miles in length, and fifty in breadth, dried up twelve rivers, and overwhelmed not only all the villages it found in its way, but likewise many hills. The perpendicular height of the sides of this current was from eighty to a hundred feet, so that the entire surface of the country was in a state of fluidity, and formed a lake of fire, resembling a mass of melted metal.

"In June, 1783," says the abbe Ordinaire, in his Natural History of Volcanoes, "it was feared that this island (Iceland) would fall to pieces; and it was even reported for some days that it had been swallowed up, so dreadfu! anit multiplied were the convulsions produced by its rolcanoes and inter al nires. A thick sulphureous smoke rendered the island absolutely invisible to mariners at sea, while the people on shore were all in danger of being suffocated by it. The fogs, which about that time spread over all liurope, was considered as an effect of these exhalations. Frightful hollow roarings proceeded from the bottom of the sea. From Mount Shapton Gluver, a seventh volcano in the island, there poured a terrific torrent of fire, which flowed for six weeks. It ran a distance of sixty miles to the sea; its

\footnotetext{
* See Spallanzani's Travels in the Two Sicilies, yol. it.
}

VOI. I. 
breadth was nearly tweive miles; and in its course it dried up the ri. ver Slaptaga, which in some places is thirty, and in others six-and thirty, feet deep."

In the month of April, of the same year, a volcanic island arose out of the sea, to the south of Iceland, which threw out fire from two of its eminences, and continued to increase in size for some time, but at length disappeared.

Of the lakes of Iceland, that called Thingvalla Vatu, in the southwest, said to be about forty miles in circuit, and Mv Vatu, in the opposite part of the island, appear to be the principal. The chief rivers are the Skalfanda, the Oxarfird, and the Brua, which flow from south to north.

Mrnerals, fossils.... No mines are worked in Iceland, though large pieces of silver, copper, and iron ore, have heen found on the surface of the ground. The principal minerals are sulphur, pumice, zeolite, calcedony, and malachite, or copper stalactites. The substance called surturbrand is a remarkable fossil: it is evidently wood, not quite yetrified, but indurated, which drops asunder as soon as exposed to the air. It is found at a great depth, and indicates trees to have been once much more plentiful in the island than they are at present.

Cimmate, sorl... The temperature of the air in Iceland, in its ordinary state, is moderate: the cold of winter is not rigorous; but the weather in summer is subject to great inequalities; and violent tem pests, accompanied sometimes with piercing cold, frequently destroy the fruits of the earth. The soil is tolerably fruitful in grass but differs according to different situations, being in some places sandy, and in others a stiff clay.

VEgETABLES, ANMALS....In so rude a climate as that of this country, no species of corn can be cultivated with advantage ; and agriculture is hardly known, except in the manuring of some pasture grounds, and the planting of a few potatoes, turnips, and cabbages, that may be found in five or six smail gardens.

Though there are indubitable proofs that Iceland formerly produced great quantities of timber, there are now vely few trees to be found on the whole island, and those of a very stinted growth.

Iceland has no wiid quadruperds, except rats, wild cats, and white and brown foxes. The horses are small, but'stout and serviceable. Birds are extremely numerous; there are several kinds of falcons, swans, and eiderducks, which furnish the inhabitants with eggs, and a very valuable down.

NATURAL CURIositres....Among the curiosities of Iceland none are more worky of attention than the hot spouting-water springs with which this island abounds. Some of these throw up columns of water, of several feet in thickness, to the height, as many affirm, of several hundred feet. They are of an unequal degree of heat. From some the vater flows gently, as from other springs, and it is then called a bath : from others boiling water spouts with great noise, and it is then called a kettle. Though the degree of heat is unequal, yet Dr. Van Troil says that he does not remember ever to have observed it under 188 of Fahrenheit's thermometer. At Geyser, Rœynum, and Laugarvatt. he found it at 212 (the boiling heat) and in the last place, in the ground, in a small hot current of water, at 213 degrees. It is very common for soine of the spouting-springs to cease, and others to rise up in their stead. Frequent earthquakes, and subterranean noises, heard at the time, cause great terror to the people who live 
In the neighbourhood. In several of these hot springs the inhabitants who live near them boil their victuals, only by hanging a pot, into which the flesh is put in cold water, in the water of the spring.

The largest of all the spouting-springs in Iceland is called Geyser. It is about two days' journey from Heckla, and not far from Skalholt. In approaching towards it, a loud roaring noise is heard, like the rushing of a torrent precipitating itself from stupendous rocks. The water here spouts sevelal times a-day, but always by starts, and after certain intervals. Some traveller's have affirmed that it spouts to the height of sixty fathoms. The water is thrown up much higher at some times than at others: when Dr. Van Troil was there, the utmost height to which it mounted was computed to be 92 feet.

Basaltine pillars are likewise very common in Iceland, which are supposed to have been produced by subterraneous fires. They have generally from three to seven sides, and are from four to seven feet in thickness, and from twelve to sixteen yards in length, without any horizontal divisions. In some places they are only seen here and there among the lava in the mountains; but in other's they extend two or three miles in length, without interruption.

Iceland contains great numbers of yawning fissures of the earth, and prodigious caverns, formed by volcanic explosions. The largest of these, as yet described, is that of Surthellar, which is above 5000 feet, or about an English mile, in length; above 50 feet high, and 35 feet broad. At Almengaia, near the water of Tingalla, is a fissure of a great but unmeasured length, from north to south, and 105 feet wide. Its western side, or wall, is above 107 fcet high, but its eastern only 45 feet.

Immense masses of ice, are every year, the cause of great damage to this country, and affect the climate of it. They arrive commonly with a N. WV. or N. N. WV. wind from Greenland. 'The field ice is of two or three fathons thickness, is separated by the winds, and less dreaded than the rock or mountain ice, which is often seen fifty and more feet above water, and is, at least, nine times the depth below water. These prodigious masses of ice are frequently left in shoal water, fixed as it were, to the ground; and in that state remain many months, nay, it is said even year's, undissolved, chilling all the ambient part of the atmosphere for many miles round. When many such lofty and bulky masses of ice are floating together, the wood that is often drifted along between them is so much chafed, and pressed with so much violence together, that it is said it sometimes takes fire; which circumstance has occasioned fabulous accounts of the ice being in flames. A number of bears arrive yearly with the ice, which commit sreat ravages, particularly among the sheep; they are, however, commonly soon destroyed, for the government allows a premium of ten dollars each, for killing them, besides the price of the skins, which are purchased for the king, and not allowed to be sold to any other person.

Populatrox... The number of inhabitants in Iceland is computed to be about 60,000 . The country was formerly much more populous, but it has frequently been ravaged by contagious diseases. The plague, in the oeginning of the fifteenth century, destroyed many thousands of the inhabitants, and almost depopulated the island; and in the years 1707 and 1708 , the small pox carried off 16,000 persons. Iceland has, also repeatedly suffered extreme by famines, the consequence of severe winters in that inclement climate. 
INHABITANTS, MANNERS, CUSTOMS....The Icelanders in general aye middle-sized, and well made, though not very strong. They are an honest, well-intentioned people, moderately industrious, and are very faithful and obliging. Thert is seldom heard of among them. They are much inclined to hospitality, and exercise it as far as their poverty will permit. Their chief employment is attending to fishing and the care of their cattle. On the coasts, the men employ their time in fish ing both winter and summer; and the women prepare the fish, and sew and spin. The men also prepare leather, work at several mechanic trades, and some few work in gold and silver. They likew ise manufacture a coarse kind of cloth, which they call rvadmal. Théy have an uncommonly strong attachment to their native country, and think themselves no where else so happy. $\Lambda \mathrm{n}$ Icelander, ther fore, seldom settles in Copenhagen, though the most advantageous conditions should be offered him. Their dispositions are serious, and they are much inclined to religion. They never pass a river, or any other dangerous place, without previously taking off their hats, and imploring the divine protection; and they are always thanktul for theip preservation when they have passed the danger. The dress of the Icelanders is not elegant or ornamental, but is neat, cleanly, and suited to the climate. On their fiugers the women wear several yold, silver, or brass rings. The poorer women dress in the coar.e cloth called ruadmal, and always wear black; those who are in better circumstances wear broar-cloth, with silver ornaments, gilt. The houses of the Icclanders are generally bad: in some places they are built of drift wood, and in others they are raised of lava, with moss stuffed between the lava. Their roofs are covered with sods laid over rafters, or sometimes over ribs of whales, which are both more durable and less expensive than wood. They have not even a chimney in their kitchens, but only lay their fuel on the hearth, between three stones, and the smoke issues from a square hole in the roof. Their food principally consists of dried fish, sour butter, which they consider as a great dainty, milk mixed with water and whey, and a little meat. Bread is so scarce among them, that there is hardly any peasant who eats it above three or four months in the year.

TOWNS, TRADE, REVENUE....There are no towns, or even villages properly so called, in any part of this island, the inhabitants only twelling in scparate farms, which sometimes contain several distinct habitations. The thrce or four houses of the Icelandic company at each of the twenty-two ports or harbours, are, however, dignified with the name of towns, though they are only trading places. The only manufacture of Iceland is the coarse cloth called wadmal. The commerce of the island is monopolised by a Danish company, which pays the king of Denmark 6,000 dollars yearly for that privilege. This company sends annually betwcen 24 and 30 vessels with corn, bread, wine, brandy, salt, linen, and other articies; and exports dried fish, salted meat, butter, tallow, train oil, the coarse cloth called wadmal, raw-wool, skins, and eiderciown; of which latter nealy 2,000 lbs. weight is annually exported.

As Iccland afforls no incitement for avarice or ambition, the inhabitants depend entirely on the protection of Denmark, which derives from the country a revenue of about 30,000 , crowns a year.

Goverament, LAws.... The government of Iceland, after it became subject to Norway and Denmark, was at first regulated by a marine officer who was sent there e'very year to inspect the state of the island: 
but the court of Denmark now appoints a governor, styled the stiftsamfamann, who constantly resides there, at a place called Bessestæder, in the south-west part of the island, and who appoints his own amptmann, or deputy. Each of the 18 syssels or districts, into which Icelaud is divided, has a magistrate called a sysselman, who acts as a justice of the peace, and before whom actions are usually commenced; bu. tisey may be carried by appeal to the courts of two superior judges, and the ${ }_{2} \mathrm{Ce}$ to the supreme court of judicature at Copenhagen. Justice is, in general, administered according to the Danish laws; but sometimes, likewise, according to the old Icelandic ordinances. Men convicted ut capital crimes are put to death by beheading or hanging: but if a woisan is condemned to die, she is sewed up in a sack and thrown into the sea.

ReLiglox.... The inhabitants of Iceland were converted to Christianity about lie year 1000; and in 1551, Lutheranism, which is still the religion of the country, was estabiished. The island is divided into two divieses, skalholi and Hoolum; of which the former contains 127 parisies, and the latter 62 . The yearly revenue of these bishoprics is about $200 l$. each. All the ministers are native Icelanders, and are said by Van Troil to receive a yearly salary of four or five hundred rix-duliars trom the king of Denmark, exclusive of what they obtain from them congregations. According to $M i$. Coxe, some have not more uban uree or four pounds annually.

LiteraturE.... From the introduction of the Christian religion into Iccland, till the year 1264, when this island became subject to Norway, it was one of the few countries in Europe, and the only one in the North, in which the sciences were cuitivated and held in esteem. But this period of time seems to have produced more learned men in Iceland than ais other period since. It appears from their ancient chronicles, that trey had consicierable kwowledge in morality, philosophy, natural history, and astronomy. Most of their works were written in the 11 th, $12 \mathrm{th}, 13 \mathrm{th}$, and $14 \mathrm{th}$ centuries; and some of them have been printed. Mr. Banks, now Sir Joseph Banks, presented one hundred and sixtytwo Icelandish maruscripts to the British Museum. That gentleman visited Iceland in 1772, accompanied by Dr. Solander, Dr. Van Troil, and Dr. Lind. Dr. Van Troil, who published an account of their voyage, observes, that he found more knowledge among the lower class in Iceland than is to be met with in most other places, ; that many of them could repeat the works of some of their poets by heart; and that a peasant was seldom to be found, who, besides being well instructed in the principles of religion, was not also acquainted with the history of his country; which proceeds from the frequent reading of their traditional histories, that being one of their principal amusements.

LANGUAGE.... The Icelandic is a very ancient dialect of the Gothic, and has been preserved so pure that any Icelander can understand the most ancient chronicles of his country. The Lord's Prayer in Icelandic is as follows :

Fader vor som est $i$ Himulum; I Halsad warde thit nama. Til. komme thitt Rikie. Skie thitt vilie so som i himmalam so ogh ho Jordanne. Wort dachlicha Brodh gif os i dagh Ogh forlat os nora Skuldar, so som ghh vi forlate them os Skildighe are Ogh inled os it:kie i Frestalsan. Jian frels os ifra ondo. Amen. 
Antreuities...In Iceland are found circles of upright stones, and stones laid on each other, in a manner similar, though on a smaller scale, to Stonehenge in England. They arê there called domings, or circles of judgment. There likewise still exists a bath built by Snorro, the celebrated Icelandic historian, in the thirteenth century.

History....A Norwegian colony under the conduct of two chiefs; named Ingulfr and Leifr, settled in Iceland in the ninth century. Other colonies soon followed, consisting principally of emigrants who fled from the tyranny of Harold Harfagre, king of Norway. These formed separate independent communities which, in time, united into one commonwealth under a supreme elective magistrate. In consequencé, however, of internal dissensions, and the arbitrary conduct of some ambitious citizens, the Icelandic republic in the year 1264 submitted, under certain conditions, to Hakan king of Norway; and afterwards became, with that country, a part of the dominions of the crown of Denmark, to which it still remains subject.

\section{THE FARO OR FERRO ISLANDS,}

So called from their lying in a cluster, and the inhabitants ferrying from one island to another. They are about 25 in number, though only 17 are said to be inhabited, and lie between 61 and $63 \mathrm{deg}$ N. lat. and 6 and $7 \mathrm{deg}$. W. long. from London. The space of this cluster extends about 70 miles in length and 40 in breadth, 300 miles to the westward of Norway ; having Shetland and the Orkneys on the south-east, and Greenland and Iceland upon the north and north-west. Strome, the largest island of this group, is twenty-four miles long and eight broad. The trade and income of the inhabitants, who may be about 4.000 of 5000 , add little or nothing to the revenues of Denmark. 


\title{
NORWAY.
}

\author{
EXTENT AND SITUATION.
}

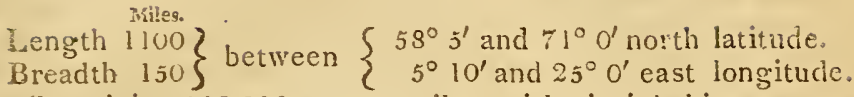

Containing 112,000 square miles, with six inhabitants to each.

NAME.... Norway signifies the Northern Way or country. It was anciently called Norrike, or the Northern Kingdon.

BouxdARIES AND DIVIsions.... Norway is bounded on the south by the entrance into the Baltic; on the west and north by the Northern Ocean; and on the east it is divided from Sweden by a long chain of mountains called at different parts by different names, as, Dofrefeld, Fillefeld, Runfeld, and Dounfeld.

This extensive country is divided into the four governments, or dioceses, of Aggerhuus, or Christiania, Christiansand, Bergen, and Drontheim; the latter is again subdivided into the two provinces of Nordland, and Finmark, or Danish Lapland.

Mountains, LAKEs, livers.... Norway is one of the most mountainous countries in the world; a chain of unequal mountains runs through it from south to north, to pass orie of which, called the Ardanger, a man must travel about seventy English miles; and to pass others, upwards of fifty. Dofrefeld is the highest of these mountains. The rivers and cataracts which intersect those dreadful precipices, and that are passable only by slight tottering wooden bridges, render travelling in this country very terrible and dangerous; though the government is at the expense of providing, at different stages, houses accommodated with fire, light, and kitchen furniture. Detached from this vast chain, other immense mountains present themselves all over Norway; some of them with reservoirs of water on the top, and the whole forming a most stupendous landscape. The caverns that are to be met with in these mountains are more wonderful than those, perhaps, in any other part of the world, though less liable to observation. One of them, called Dolsteen, was in 1750 visited by two clergymen, who reported, that they proceeded in it till they heard the sea dashing orer their heads; that the passage was as wide and as high as an ordinary church, the sides perpendicular, and the roof vaulted; that they descended a flight of ratural stairs; but when they arrived at another, they clurst not venture to proceed, but returned; and that they consumed two candles going and returning. In a mountain in Nordland, called Torg. Hallen, whose summit has been fancifully imagined to resemble the figure of a giant with a hat on his head, there is a vast pervious aperture a hundred yards high, and above two thousand in length, along which a road runs.

The lakes of Norway are extremely numerous; the largest of them is the Mioss, about. sixty miles in length, but of no great breadth except towards the centre, where it is from tweive to fiftecn miles. It has in it an island nearly ten miles in circumference. 'The lalie of Pands Sion, near the Mioss, is almost fifty niles iong, but scarcely more than two broad. The lake of Fxmund is thirty-five miles long and eight broad; and that of Ojeren, formed by the river Glom, 
twenty-three miles long. Some of these lakes contain floating islands sixty or eighty feet in diameter, formed by the cohesion of roots of trees and shrubs; and which, though torn from the main land, bear herbage and trees.

The principal rivers of Norway are the Glom, or Glonien, called likew ise the Stor Elve, or Great River, which from its source anong the mountains on the borders of Siveden, to the bay of Swinesund, where it falls into the sea, runs above three hundred English miles, and the Dramme, which flows into the bay of Christiania after having received the Beina and other streams. There are many other" smaller rivers.

Metals, minerals....Gold has been found in Norway, and some ducats were coined of it in 1645. The silver mincs of Konigsbers, about forty miles from Christiania, are reputed the richest in Europe. There are other silver mines in different parts of the country; and a mass of native silver, the produce of some of these, which is deposited in the royal cabinet of Copenhagen, weighs 409 marks, being worth 3000 rix-dollars, or $600 l$. The copper mines of Roraas are extremely productive, and afford a consicierable revenuc. But the iron mines near Arendahl are, perhaps, the most profitable.

Norway produccs abundance of marble, quicksilver, sulphur, salt, coal, vitriol, and alum : mines of cobalt have likewise been discovered within these few years at Fossum.

Climate, solu, vegetable productions....The climate of Norway varies according to the latitude, and the position with respect to the sea. At Bergen the winter is moderate, and the sea not frozen. The eastern parts of Norway are commonly covered with snow; and the cold generally sets in about the middle of Octobcr, and continues, with intense severity, to the middle of April ; the waters being all that time frozen to a considerable thickness. But evcn frost and snow have their conveniences, as they facilitate the conveyance of goods by land. In the more northern parts of this country, the cold is extremely intense. In summer, the inhabitants can read and write at midnight by the light of the sky; and in the most northerly parts, about midsummer, the sun is continully in view. In those parts, however, in the middle of winter, there is only a faint glimmering of light at noon for about an hour and a half, owing to the reflection of the sun's rays on the mountains. Nature, notwithstanding, has been so kind to the Norwegians, that, in th.e midst of their darkness, the sky is so serene, and the moon and the aurora borealis so bright, that they carry on their fishery, and work at their several trades in the open air.

The air of Norway, in general, is extremely pure, and many of the natives live to a very great age.

The soil and climate of Norway, are not very favourable to agriculcure, and no parts of that country yield sufficient corn for interior consumption; but though it is deficient in arable land, it is rich in pasture, and produces much cattle; and a patriotic society has so much encouraged agriculture, that within these fifty year's estates have risen nearly one-third in value.

The principal vegetable production of Norway is wood. The extensive forests of this country consist of fir, pine, oak, elm, ash, yew, birch, beech, and alder trees. The fir of Norway is in high estimation, being firmer, more compact, and less liable to rot, than that of most other countries. The sums received from foreign nations for 
timber are very great; one-tenth of which is paid to the king of Denmark, and forms no inconsiderable part of his revenue.

ANimalso... The horses, and in general the other cattle of Norway, are strail, but strong, hardy, and active. The wild animals are the elk, the rein-deer, the hare, the rabbit, the bear, the wolf, the lynx, the tox, the glutton, the leming, the ermine, the marten, and the bearer. The elk is a tall ash-coloured animal, its shape partaking at once of the horse and the stag; it is harmless, and in the winter social; and the flesu of it tastes like venison. The rein.deer is a species of stag; but we shall have occasion to mention it more particulariy hereafter. The hares are small, and are said to live upon snice in the winter time, and to change their colour from brown to white. The Norwegian bears are strong and sagacious. The Norwegian wolves, though fierce, are shy even of a cow or goat, unless impelled by hunger: the natives are dexterous in diggring traps for them, in which they are taken or killed. The lynx, by some called the goupes, is smaller than a wolf, but as dangerous; they are of the cat kind, and have claws like tigers; they dig under ground, and often undermine sheep-folds, where they make dreadful havoc. The skin of the lynx is beautiful and valuable, as is that of the black fox. White and red foxes are likewise found in Norway, and partake of the nature of that wily animal in other countries; they have a parti. cular way of drawing crabs ashore, by dipping their tails into the water, which the crab lays hold of.

The glutton, otherwise called the ervan, or vielfras, resembles a turnspit dog, with a long body, thick legs, sharp claws and teeth; his fur, which is variegated, is so valuable that he is shot with blunt arrows, to preserve the skin unhurt: he is bold, and extremely ravenous.

The ermine is a little creature, remarkable for its shyness and cleanliness; and its fur forms a principal part even of royal magnificence.

The leming, or Norwegian mouse, is a singular creature, of a reddish colour, and about five inches in length. 'Vast multitudes of these animals sometimes proceed from the mountains towards the sea, devouring every production of the soil, and spreading desolation like the locust. When they have consumed every eatable, it is said they at last prey on each other.

No country produces a greater variety of birds than Norway, especially water-fowl. The auks, which breed on the rocks, frequently appear in such numerous flocks that they darken the air, and the noise they make with their wings resembles a storm. Various kinds of wild ducks and pigeons are also found here. The Norwegian cock of the wood is a noble bird : he is of a black or dark gray colour, with an eye resembling a pheasant; and is said to be the largest of all eatable birds. Eagles of different species breed among the mountains and rocks of Norway, some of which are of a prodigious size and strength, and will seize lambs and kids; and it is said, have been known to carry off a child of two years old. The sea eagles sonretimes clart on large fishes with such force, that, being unable to extricate their talons, they are dragged into the water and drowned. The bird-men of Norway display remarkable agility and address in mounting the steepest rocks, and bringing away the young birds and their esss : the latter" of which are nutritive food, and are parboiled io vinegar.

Vol. I. 
The seas and lakes of Norway are extremely productive of most Finds of fish which are found on the sea-coasts of Europe. Stock-fish innumeráble are dried upon the rocks without salting. The haacmoren is a species of shark, ten fathoms in length, and its liver yields three casks of train-oil. The tuella-fiynder is an excessively large turbut, which has been known to cover a man who has fallen overboard, to keep him from rising. The season for herring-fish is announced to the fishermen by the spouting of water from the whales while following the herring shoals. The coast of Norway may be said to be the native country of herrings. Innumerable shoals come from under the ice, near the north pole, and, about the latitude of Iceland, divide themselyes into three bodies. One of these supplies the Western Isles and coasts of Scotland; another directs its course round the eastern part of Great Britain, down the Channel, and the third enters the Baltic through the Sound. They form great part of the food of the common people; and the cod, ling, kabeliau, and torsk fishes follow them, to feed upon their spawn, and are taken in prodigious numbers, in 50 or 60 fathoms water: these, especially their roes, and the oil extracted from their livers, are exported and sold to great acvantage; and above 150,000 people are maintained by the herring and other fishing on the coast of Norway. The sea-devil is about six feet in length, and is so called from its monstrous appearance and voracity. The sea-scorpion is likewise of a hideous form, its head being larger than its whole body, which is about four feet in length ; and its bite is said to be poisonous.*

Natural curiosities.... The dreadful vortes or whirlpool of Maelstrom, or Moskoestrom, is the most remarkable of the natural

* It may be proper to give !ere some account of those tremendous monsters of the Norwcrian seas, the sea-serpent and the kraken, since they have been describ. eci by Pontoppidan, and other writers of some repute, though it is not probable that either of them ever had existence. A sea-snake, or serpent of the ocean, it is sail, was shot in 1756 , by the master of a ship : its head resembled that of a horse; the mouth was large and black, as were the eyes; a white mane hung from its neck; it flonted on the surface of the water, and held its head at least two feet out of the sea. Between the head and neck were seven or eight folds, which were very thick; and the length of this snake was more than a hundred yards.... some say, fachoms. They are said to have a remarkable aversion to the smell of castor; for which reason ship, boat, and bark masters provide themselves with quantitics of that drug, to prevent being overset ; the serpent's of factory nerves being remarkably exquisite. The particulars retated of this animal, however incredible, have been attested upon oath. Egede (a very reputable author) says, that on the sixth day of July, 17.34. a large and frightful sea-nonster, raised itself so high out of the water", that its head reached above the main-top mast of the ship; that it had a long sha:p snout, broad paws, and spouted water like $a$ whale; and that the body seemed to be covered with scales; the skin was uneven and wrinkled, and the ' lowrer part was formed like a snuke. The boty of 1 his monster is said to be as thick as a hogshead; his skin variegated like a tortoise-shell; and his excrement, which floats on the surfuce of the water, to be corrosive, and blister the hands of the sea men if they handled it.

The kraken is said to be a mile and a half in circumference; and that when part of it appears above the water, it resembles a number of small islands and sandbanks on which fishes sport, ind se:l-weeds grow. Upon his farther emerging, a number of pellucid antenne, each about the height, form, and size of" a moderate mast, appear ; by the action and re-action of which he gathers his food, consisting of small fishes. When he sinks, which he does gradually, a dangerous swell of the sea succeeds, and a kind of whiriponl is naturally formed in the water. In 1680, we are told, a young kraken perishod among the rocks and cliffs of the parish of Alstahong; and his cleath was attended with such a strench, that the channcl where, he died was impa-suble. 
curiosities of Norway. It is caused by a furious current which runs among the Loffoden isles, particularly between the island of Moskoe and the point of Moskoenas, where its violence is greatest, flowing? contrary to the motion of the tide, in a kind of circular stream, Twice in twenty-four hours, at the turn of ebb and ticle, the current ceases, and the water is calm during almost an hour, after which it gradually increases, till it becomes tremendous, and roars witl a noise unequalled by the loudest cataracts. It is heard at the distance of many leagues, and forms a vortex of great extent and depth, so violent, that if a ship comes near it, it is immediately drawn irresistibly into the whirl, and there disappear's, being absorberl and carried down to the bottom in a moment, where it is dashed to pieces against the rocks; and when the water becomes again still, rises in scattered fragments, scarcely to be known for the parts of a ship. In the time of its greatest violence, the danger of its influence is said to extend to the distance of eight, or even twelve English miles from its centre. Whales, and other animals which liappen to be caught by this dreadful whirlpool, are said to show themselves sensible of their approaching clestruction by their hideous bellowings, and desperate but ineffectual struggles to escape.

Populatros....In 1809 the population of Norway was estimated, by Hassel, to amount to about 912,000 . By the census of 1802, it amounted to 910.074 .

National character, Manners.... The Norwegians in general are strong, robust, and brave; but quick in resenting real or supposed injuries. The women are handsome and courteous; and the Norwegian modes of living greatly resemble those of the Saxon ancestors of the present English. Every inhabitant is an artisan, and supplies his fanily in all its necessaries with his own manufactures; so that in Norway there are few who are by profession hatters, slioemakers, tailors, tanners, weaver's, carpenters, smiths or joiners. They often mix with oat-meal the bark of the fir, made into a kind of flour; and they are reduced to very extraordinary shifts for supplying the place of bread or farinaceons food. 'The middling. Norwegians lead that kind of life which we may say is furnished with plenty; but they are neither fond of luxury, nor do they dread penury : and this mildle state prolongs their lives surprisingly. "Though their dress is in many respects accommodated to their climate, yet, by custom, instead of guarding against the inclemency of the weather; they outbrave it; for they expose themselves to cold, without any covering upon their breasts or necks. A Norwegian of a hundred years of age, is not accounted past his labour; and, in 1733, four couples were married, and danced before his Danish majesty, at Fredericshall, whose ages when joined, exceeded 800 years.

CITIES, CHIEF Towss....Christiania is accounted the capital of Norway, because it is the seat of the supreme court of justice. It is situate about thirty English miles from the. sea, in a large and plea. sant valley, and is the hardsomest town in the country. It contains about 9000 inhabitants. Bergen is much the largest and most commercial town in Norway, containing nearly 20,000 inhabitants. It is principally built of wood, and has suffered by repeated fires; during one of which, in 177 l, the flames, it is said, were visible, or at least their reflection in the clouds, in the isles of Shetland. Drontheim, the capital of the diocese or province of the same name, contains about 8000 inhabitants. 
Commerce...The exports of Norway are timber, hemp, fias, iar, $_{3}$ furpentine, fish, tallow, copper, iron, hides, and the skins of bears, lynxes, and foxes. The annual export of deal alone, is reckoned at $175,000 l$. and that of iron at $70,000 l$. They export annually 80,000 raw hides, and 1000 manufactured. The whole exports of Norway, in 1768 , were stated at above $1,700,000 l$. sterling; and the imports at: less than $1,240,000 l$. which seems to indicate a considerable balance in favour of the country.

Government, LAws....Norway is governed by its own laws, contained in a particular code called the Norway Law, compiled by Griffelfield, by order of Christian V, the great legislator of his country. By this law, the palladium of Norway, the peasants are free, a few only excepted, on certain noble estates near Fredericstadt. The laws are administered by provincial courts and officers. The governor is president of the supreme court at Christiania.

REVENUE, ARMY, NAVY....Denmark derived from Norway a revenue of about $300,000 l$. per annum. The Norwegians maintain an army of 32,000 infantry, and 10,000 cavalry; besides these, they have a regular militia, amounting to 40,000 men, they can also supply about 14,000 excellent seamen.

Religion....The religion of Norway, like that of Denmark, is Lutheranism. The country is divided into four dioceses, or provinces, mentioned above, each of which has its bishop; but the see of Christiania has precedence. The annual revenue of each is $400 l$. excepting the bishop of Christiansand, who has $600 l$.

LiteratuRE, LANGUAGE.... In the principal town of each diocese there is a seminary called a Latin school; and at Bergen one named Frederic College. The language of Norway is the Danish, with a mixture of Swedish words, and Swedish pronunciation, among the inhabitants of the eastern parts bordering on Sweden; but the gentry, and inhabitants of the principal towns, we are told by Wilse, a native of Norway, speak purer Danish than is usual even in Copenhagen.

History....The first inhabitants of Norway were probably tribes of the Finnish race, the ancestors of the modern Laplanders. These were conquered and driven out by the Goths. Norway, till about the latter end of the ninth century, was divided into ten or twelve small states, under their several chiefs, which were then united into one nation by Harold Harfagre, who subdued the other petty princes, and rendered himself sovereign of the whole country. From that time Norway remained a distinct and independent kingdom, except that twice in the tenth and eleventh centuries it was subjected, for a short time, to Denmark; and in the thirteenth united likewise, for a time, with Sweden. At length, by the marriage of Hagen king of Norway with Margaret of Denmark, and the succession of their son Olaf, in 13s0, it became annexed to the dominions of the crown of Denmark, with which it remained united till 1813, when it was ceder? by treaty to the crown of Sweden. 


\title{
SWEDEN.
}

\author{
EXTENT AND SITUATION.
}

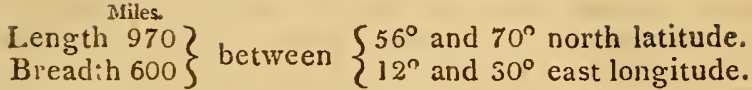

Containing 210,000 square miles with 14 inhabitants to each.

NAME....Sweden is called, in the present language of the country, Swea-rike, or the kingdom of Swea; an appellation of great antiquity, and probably derived from the ancient Suiones, who appear to have inhabited this part of Scandinavia.

Boundaries AND DIVIsIons.... Sweden is bounded on the south by the entrance of the Baltic sea; on the west by the mountains of Norway; on the North by Danish Lapland, or Finmark; and on the east by Russia. The whole kinglom is divided into five general parts: 1, Sweden Proper. 2, Gothland. 3, Nordland. 4, Swedish Lapland. 5, Finland. These are again subdivided into the following provinces:

Sweden Proper.

Upland, - - -

Sudermanland, - -

Nerike, - - -

Westermanland, - -

Dalecarlia, ,

Gothland.

$\left\{\begin{array}{l}\text { East-Gothland, } \\ \text { Smalland, or Smoland, - } \\ \text { Island of Oeland, } \\ \text { Island of Gothland, }\end{array}\right.$
$\left\{\begin{array}{l}\text { West-Gothland, - } \\ \text { Wermeland, - } \\ \text { Dalsland, - } \\ \text { Bohnslehn, - }\end{array}\right.$
$\left\{\begin{array}{l}\text { Hochland, - } \\ \text { Schonen, - } \\ \text { Blekingen. - }\end{array}\right.$

Nordland.

Gestrikeland,

Helsingland,

Medelpad,

Jemtland, -
Chief Towns.

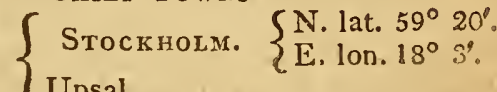

Upsal.

Nikioping.

Ocrebro.

Westeroes.

$\{$ Fahlun:

$\{$ Hedemora.

Norkiœping.

Calmar.

Borgholm.

Wesby.

Gottenburg. $\left\{\begin{array}{l}\text { N. lat. } 57^{\circ} 42^{\prime} \\ \text { E. lon. } 11^{\circ} 38^{\prime}\end{array}\right.$

Carlstadt.

Amal.

Kongshall,

Halmstadt.

Lund.

Carlscrona.

Gefle.

Hadwikshall.

Sundswall.

Karlstrom. 
Nordiand.

Herjedaien,

Angermanland,

TVest-Bothnia, - .

Swedish Lapland.

Asele Lapmark, -
Umea Lapmark, -
Pitea Lapmark, -
Lulea Lapmark, -
Tornea Lapmark, -
Kimi Lapmark, -

Finland.

East-Bothnia,

Finland Proper, - -

Tavastland,
Chief Towns.

Linonedall.

Hoernosand.

$\left\{\begin{array}{l}\text { Umea. } \\ \text { Torneo. } \\ \text { Pitea. }\end{array}\left\{\begin{array}{l}\text { N. lat. } 65^{\circ} 50^{\prime} \\ \text { E. lon. } 24^{\circ} 12^{\prime}\end{array}\right.\right.$

There are no towns in these dis. tricts, and the inhabitants often change their places of abode.

Sinedish part of Savolax. $\begin{array}{lll}\text { Island of Aeland, - } & \text { Castleholm. } \\ \text { Nyland, } & \text { - } & \text { Helsingfors. }\end{array}$

Swedish part of Knopio Kare-7 len, or Carelia, as far as the
river Kymene,

$\left\{\begin{array}{l}\text { Uleaborg. } \\ \text { Wasa. }\end{array}\right.$ (Nystadt) Abo. $\left\{\begin{array}{l}\text { N. lat. } 60^{\circ} 27^{\circ} \\ \text { E. lon. } 22^{\circ} 17^{\circ}\end{array}\right.$

Tavastchus. 
try, and the province of Dalecarlia in particular. Besides pine, bircli, popist, Hountain-ash, and fir, abound in them. In these forests conflagruibons are remarkably frequent, which consume or scorch all the trets sometimes $10 r$ an exteht of several miles. These are to be attributt, in part, to the carelessness of the peasants, who kindle fires in the woois without extinguishing them; and in part to the privilege allowed the pcasants to make use of the timber thus damaged in the crown forcsts, without paying the usual tax on it.

LAKES, RIVER5, CANALS... The lates of Siveden are very numerous. The largest of them is the IVenner, which is about 100 English miles long, and between 50 and 60 broad. It contains several islands, and receives 24 river's. The IVeter is about the same length, but of unequal breadth, being from only 6 to 26 miles broad. It is reported to be 200 fathoms deep, contains two islands, and receives about 40 small streams. The Mreiar is about 70 miles in length and 30 in breadth. It contains a prodignous number of smali islands; these are reckoned to be 1290; several of which are tinree or four miles in extent, and extremely fertile. At Stockholm this lake conmunicatcs with the Baltic, by two rapid currents, one of which is called the northern and the other the southern stream. The Hielnuar washes Sudermanland and Nerike: it is about 40 miles in length, and 20 in breadth, and communicates with the Malar. In Finland, the lake Pejend is about 80 miles long and 15 broad. There are also a great number of smaller lakes in this couniry.

Tlie principal river of Sweden is the Dahl, which rises in the mountains that separate Sweden from Norway, and, after a course of about 260 miles, falls into the Gulph of Bothnia, alsout 10 miles to the east of $\mathrm{G} \in \mathrm{fle}$. Near its mouth is a celebrated cataract, scarcely inferior to that of the Rhine at Shaffhausen. The breadth of the river thete is about a quarter of a mile, anst the perpendicular height of the fall between 30 and 40 feet. The rirers Gotha and Motala are the outlets of the lakes IVenner and Weter. The principal rivers of Finland are the Ulea, the Kano, and the Kymene, which flows into the Gulph of Finland, and constitutes the boundary of the Swedish part of Carelia.

Inland navigation has not been entirely unattended to in Sweden. The canal of Trolhætta, lately completed, has been wrought with great labour, assisted by the powerful force of gunpowder, through the midst of rocks. Its onject was to open a communication between the North Sea and the Lake W Wenner, by forming a new channel where the Gotha is rendered innavigable by cataracts. The length of this canal, in which there are nine locks, is nearly three miles, the width 36 feet, and the deph in some places above 50. "It is not easy," says a late judicious traveller, "for any one to form an iclea of the difficulties that were to be surmounted in the formation of this wonderful canal, unless he were an eve-witness. It was undertaken and begun by Charles XII ; formed part of a grand plan meditated by Gustavus Vasa, and attempted by some of his successors, for joining the Baltic with the North Sea, by means of a communication cut through the kingdom. If a canal should be extended by the lake of Wenner, by Oerebro, to the lake of Hiclmar, the Swedes may then, by a conjunction of this lake with that of Mrlar through the sluices of Arboga, transport all kinds of merchandise in the same vessel from Gothenburg to Stockholm. Thus a passage would be opened between the Nortl Sea and the Baltic; and, amoig other advantages, the duties of the Sound would be avoided. The canal of Trolhatta may justly be consiclered as, in some re- 
spects, characteristical of the Swedish nation, for it represents them as they are, prone to the conception of grand enterprises, and disting uish ed by mechanical invention. As a work of art, and of bold and persevering design, it is not too much to say that it is the first in the world; even the duke of Bridgewater's canal in England, and that of Languedoc in France, not excepted." **

Metals, minerals.... The mines of silver, copper, lead, and iron, in Sweden, constitute the principal wealth of the country. In the year 1738, a gold mine was likewise discovered near Adelfors, in the province of Smoland; but from the year 1741 to 174.7 it produced only 2,389 gold ducats, each valued at $9 s$. $4 . d$. sterling; and at present will not defray the expence of working. The silver mines, though greatly reduced in value, are more profitable; but by far the most valuable are the mines of copper and iron, though these are much less productive than they were formerly. The copper mines near Fahlun, in Dalecarlia, have been worked for nearly 1000 years : they are sunk to the depth of 1080 feet, and employ 1200 workmen. The copper is found, not in veins, but in great masses. The iton mines near Danemora, in Smoland, are accounted to produce the best iroll in the world. The metal is sometimes found in vast masses, of which the most remarkable is the hill of Taberg, in Smoland, which is one immense lump of iron ore, above 400 feet high, and three English miles in circuit. The iron mines in Sweden, together with the smelting houses and furnaces, are said to employ nearly 26,000 workmen.

Sweden likewise produces porphyry, rock-crystal, cobalt, antimony, zinc, and molybdena. Coal mines have been discovered within these few years in the province of Smoland.

Climate, soll, agriculture... The winter in every part of Sweden is extremely severe. The largest lakes, and the whole Gulf of Bothnia, is frozen over, and a kind of high road is made over the latter for sledges to pass into Finland. The southern parts have a sonewhat milder temperature than the northern. The spring continues only for a week or two, when the heat of summer becomes extreme, from the great length of the days, and the reflexion of the sun's rays from the rocks and mountains; so that in some of the northern provinces the harvest is sown and reaped in the space of seven or eight weeks. Frequent winds purify the atmosphere, the salubrity of which is evinced by numerous instances of longevity. The soil is in general very indifferent, but in some vallies, surprisingly fertile. The Swedes, till of late years, had not industry sufficient to remedy the one or improve the other. The peasants now follow the agriculture of France and Ergland, and raise almost as much grain as is requisite for the consumption of the country. Even Finland produces rich pasturage, and considerable crops of different kinds of grain.

The cultivation of tobacco has succeeded very well throughout the whole country. It grows in the greatest quantities near Stockholm and Abo; and perhaps Sweden at present does not require any importation of this commodity from foreign countries, except to have it somewhat superior in quality to that of its own growth.

Vegetables, animals.... The pine and the fir are the principal forest trees of Sweden; the birch grows in all the provinces; but it 
has been remarked that no beeches grow to the north of East-Gothland, and no oaks beyond Upland.

Whea rye, barley, oats, peas, and beans, are cultivated with success in Sweden; and though beyond Gefle and Biorneburg fruit-trees are rarely to be met with, common cherries, gooseberries, strawberries, raspberries, currants, and several sorts of pear's and apples, ripen in the open air in several of the provinces; and melons, by artificial culture, are brought to great perfection in dry seasons. Among the pears which ripen in Sweden, the principal is the bergamot; and amolig the apples, that of Astracan, which has a niost agreeable taste.

The wild animals of Sweden, are wolves, bears, beavers, elks, rein. deer, wild-cats, foxes, hares, and squirrels. In winter the foxes and squirrels become grey, and the hares as white as snow. 'The horses and oxen, and the cattle in general, are small, but hardy. Various kinds of birds are found here, particularly two singular species of falcons. The rivers and lakes abound in fish; and several species of them, pikes and sallmon in particular, are pickled and exported. The train-oil of the seals taken in the Gulf of Finland, is likewise a considerable article of exportation.

Natural curiosities.... The natural curiosities of Sweden con. sist in its cataracts, and the scenery of its forests and lakes. About 50 miles from Gottenburg are the famous cataracts of Trolhætta, formed by the river Gotha, which issues from the lake of Wenter, and being united after several breaks, falls with its whole and undivided stream into so deep a bed of water that large masts, and other peices of timber, precipitated down it, disappear for a very considerable time before they rise again to the surface. There is another ca. taract, on the river Dahl, about ten miles to the east of Gefle, esteemed little inferior to that of the Rhine at Schaffhausen, the breadth of the river being nearly a quarter of a mile, and the fall being between 30 and 40 feet. The effect is likewise greatly highten. ed by the surrounding scenery.

Populatron.... The number of inhabitants in Sweden is probably more correctly ascertained than in most other countries of Europe, the states in 1741 having erected an institution called the Commission of Register; the office of which was to collect and compare all the registers of marriages, births, and deaths, in Sweden. According to the tables constructed from these registers, the number of inhabitants amounted in 1751 to $2,229,661$; in 1772 , to $2,584,261$; and as from the same authority it appears that the population, in the space of 30 years ending in 1781 , had increased by more than 500,000 souls. The loss of Finland and Pomerania reduced the population to 2,353,355 souls. The addition of Norway has increased it again to $3,265,000$. In Bœtticher's tables the population of Sweden is given at $2,977,345$, of which number Finland contains 624,000.

National CHARACTER, MANNERs, customs....The Swedes are in general tall, well-formed, and capable of enduring the greatest fatigues. They are grave in their deportment, industrious, sincere, brave, and hospitable. The upper classes initate closely the manners of the French, the fashions of which nation have long been followed by the ladies, few of whom adopted the national dress which the late king endeavoured to introduce in 1777 . This was worn, however, by many of the men, and consisted, for them, of a close coat, very wide breeches, a girdle, a round hat, and a cloak. The women were to wear a black robe, with puffed gause sleeves, a coloured sash, and

Vox. I. 
zibbons. The Swedes in general, wear short dresses, and of a blue or black colour. Veils are much used by the women of all classes; even the fenale peasants, while at work in the fields, cover their: beads with black crape. Tinere is no country in the world where the women do so much work as in Sweden; they manage the plough, thrash out the grain, row on the water, serve the bricislayers, carry burdens, and do all the common drudgeries of husbandry.

CITIES, CHIEF TOWNS, EDIFICES....An uutusually small proportion of tine population of Sweden, or not nore than a tenth part, is collected in towns, the number of which is estimated at 104. Of these, 24. are staple-towns, where the merchants are allowed to import and export commodities in their own ships. Those towns which have no foreign commerce are called land-towns; and the third class are termed mine-towns, as belonging to the mine districts.

Stockholm is a staple-town, and the capital of the kingdom. It stands upon seven small rocliy islancis, besides two peninsulas, and is built upon piles. It strongly impresses a stranger with its singular and romantic scenery. A variety of contrasted and enchanting views are formed by numberless rocks of granite, rising boldly from the surface of the water, partly bare and craggy, partly dotted with houses, or feathered with wood. The harbour, which is spacious and convenient, though dificult of access, is an inlet of the Baltic : the water is clear as crystal, and of such a depth that ships of the largest burden can approach the quay, which is of considerable breadth, and lined with spacious buildings and warehouses. At the extremity of the harbour several streets rise one above another, in the form of ar amphitheatre; and the palice, a magnificent building, crowns the summit. Jowards the sea, about two or three miles from the town, the harbour is contracted into a narrow strait, and, winding among high rocks, disappears from the sight; the prospect is terminated by distant hills, overspread with forests. It is far beyond the power of words, or of the pencil, to delineate these singular views. The central island, from which the city derives its name, and the Ritterholm, are the handsomest parts of the town.

Excepting in the suburbs, where the houses are of rood, painted red, the $\mathrm{generality}$ of the buildings are of sione, or brick stuccoed white. The royal palace, which stands in the centre of Stockholm, and upon the highest spot of ground, was begun by Charles XI. It is a large quadrangular stone edifice, and the style of architecture is both elegant and magnificent.*

The number of housekeepers who pay taxes are 60,000. This city is furnished with all the exterior marks of magnificence, and erections for manufactures and commerce that are common to other great European cities; particularly a national bank, the capital of which is 450,000l. sterling.

Upsal, or Upsala, formerly the metropolis of Sweden, and the royal residence, is the chief town of the province of Upland, and is famous for its university and its cathedral, the finest church in Sweden, built in imitation of the church of Notre Dame at Paris. It is a small but very neat town, divided into two almost equal parts by a small river named Sala; and the streets are drawn at right angles from a central kind of square. A few of the houses are built with brick, and stuccoed, but the generality, as in most of the towns of Siveden, are of wood painted red. It contains, exclusively of the students, only about 3000 inhabitants.

* Coxe, vol. ii. p. 327, 328. 
Gathenburg, the second city of Sweden in magnitude, stands partly on the ridges of rocks, and partly in a plain, and is divided from these situations into the upper and lower town. The latter is entirely level, intersected by several canals, in the manner of the Dutch towns, and its houses are a!l constructed upon piles. The upper part hangs on the declivities; and rows of buildings rise one above another like the seats of an amphitheatre. The whole is regularly fortified; and its circumference is nearly three miles, exclusive of the suburbs, called Haga, which lie towards the harbour. The number of inhabitants is about 25,000 .

Carlscrona, the station of the royal navy in Siveden, has a harbour capable of containing 100 ships of the line. Its inhabitants are about 12,000 .

Manufactures and commerce... The manufactures of Siveden are neither numerous nor flourishing. Even the manufacturing of iron was introcluced into Siveden so late as the 16 th century, for till that time they sold their own crude ore to the Hanse-towns, and bought it: back again manufactured into utensils. About the middle of the 17 th century, by the assistance of the Dutch and Flemings, they began some manufactures of 'glass, starch, tin, woollens, silk, soap, and leather. They have now some of sail-cloth, cotton, linen, fustian, and other stuffs; as also of alum and brimstorie. In 1785 , it was computed that those of sail-cloth, wool, silk, and cotton, employed above 14,000 hancls. Vast quantities of copper are now wrought in Sweclen. They have also founderies for cannon, forges for anchors and Ere-arms, armouries, wire and flatting mills, mills also for fulling, and for boring and stamping : they likewise build many ships for sale.

The cxports of Siveden principally consist of the native productions of the country; as iron, the staple commodity, of which 400,000 shippounds are annually exported; copper; timber, the export of which produces a revenue of $315,000 l$. annually; pitch, tar, herrings, and fishbil. The imports are, rye and oiher kinds of grain, flax, hemp, tobacco, sugar, coffee, silk, and wines. In the year 1782 the exports of Sweden amounted to $1,368,830 l$. and the imports to $1,008,392 l$. leaving a balance in favour of the country of about $360,000 \%$.

Governaest... The government of Sweden has undergone many changes. The Swedes, like the Danes, were originally free, and during the course of many centuries the crown was elective; but after various revolutions, Charles XII, who was killed in 1718 , became despotic. He was succeeded by his sister Ulrica, who consented to the abolition of despotism, and restored the states to their former liberties; and they, in return, associated her husband, the landgrave of Hesse. Cassel, with her in the government. A new model of the constitution was then drawn up, by which the royal power was brought perhaps zoo low; for the king of Sweclen could scarcely be called by that name, being limited in every exercise of government. ihe senate had even a power of imposing upon the king a sub-committee of their number, who were to attend upon his person, and to be a check upon all his proceedings, down to the very management of his family.

But in August, 1772, the whole system of the Swedish government: was totaliy changed by the late king, in the most unexpected manner. The circumstances which attended this extraordinary revolution will be fourd in our history of Sweden. By that event the Sivedes, instead of having the particular defects of their constitution rectified, found their king invested with a degree of authority little inferior to that of 
the most despotic princes of Europe. By the form of government then introduced, the king may assemble and dissolve the states whenever he pleases : he has the sole disposal of the army, the navy, finances, and all employments civil and military; and though he cannot openly claim a power of imposing taxes on all occasions, yet such as then subsisted were rendered perpetual; and, in case of invasion or pressing necessity, he may impose some taxes till the states can be assembled; but of this necessity he is to be the judge, and the meeting of the states depends wholly upon his will and pleasure; and when thiy are assembled, they are to deliberate upon nothing but what the king thinks proper to lay before them. It is easy to perceive, that a government thus constituted can be little removed trom one of the most despotic kind. Yet, in order to amuse the nation with some slight àppearances of a legai and limited government in the new system, which consists of fifty-seven articles, a senate is appointed, consisting of seventeen members, comprehending the great officers of the crown and the governor of Pomerania; and they are required to give their advice in all the affairs of the state, whenever the king shall demand it. In that case if the questions agitated are of great importance, and the advice of the senators should be contrary to the opinion of the king, and they unanimous therein, the king, it is said, shall follow their advice. But this, it may be observed, is a circumstance that can hardly ever happen, since it is scarcely possible that all the members of a senate, consisting chiefly of officers of the crown, shonld? give their opinions against the kitg, and in every other case the king is to hear their opinions, and then to act as he thinks proper. There are some other apparent restraints of the regal power in this system of government; but they are in reality very inconsiderable. It is said, indeed, that the king cannot establish any new law, nor abolish any old one, without the knowledge and consent of the states: but the king of Sweden, according to the present constitution, is invested with so much authority, power, and infuence, that it is hardly to be expected that any person will venture to make an opposition to whatever he shall propose.

LAws....Sweden is not governed by the Roman or civil law, but by its own code, founded on the ancient Swedish lavs, and published with the sanction of the states in 1736. It was again revised, and such alterations aciopted as were suggested by the late king, and published in a new edition in 1781. There are four superior courts, as also in. ferior tribunals in the principal towns.' A kind of assizes is likewise held twice in the year by county-judges. Trials are had by a sort of jury of twelve persons, who, when they all agree, may decicle against the opinion of the judge; but in general they are implicitly guided by his dictates.

The common methods of execution in Sweden are beheading and hanging. For murder, the hand of the criminal is first chopped oft, and he is then beheaded and quartered. Women, after beheading; instead of being quartered, are burned. No capital punishment is inflicted without the sentence being confirmed by the king. Every prisoner is at liberty to petition the king, within a month after the trial. The petition either complains of unjust condemnation, and in such a case demands a revisal of the sentence; or else prays for pardon, or a mitigation of punishment. Malefactors are never put to death except for very attrocious crimes, such as murder, house-breaking, rob. bery upon the highway, or repeated thefts. Other crimes, many of 
which in some countries are considered as capital, are chiefly punished by whipping, condemnation to live upon bread and water, imprisonment and hard labour, either for life or a stated time, according to the nature of the crime. Criminals were tortured to extort confession, till the reign of the late king: but in 1773 his Swedish majesty abolished this cruel and absurd practice.

Revenue....The revenue, of Sweden, arising from the rents of crownlands, capitation taxes, customs, and various other articles, amounts to about $1,450,000 l$. The annual expenditure generally rather exceeds the revenue, and the debt of the crown amounted some years ago to $7,000,000 l$. Sweden, until lately, laboured under a very great scarcity of specie, the country being overwhelmed with papermoney; but this inconvenience has been in some degree remedied by a coinage of silver.

ARMY AND NAVT....No country in the world has produced greater heroes, or braver troops, than the Swedes; and yet they cannot be said to maintain a standing army, as their forces principally consist of a regulated militia. The cavalry is clothed, armed, and maintained, by a rate raised upon the nobility and gentry, according to their estates; and the infantry by the peasants. Each province is obliged to find its proportion of soldiers, according to the number of farms it contains. Every farm of 60 or $70 l$. per annum is charged with a foot soldier, furnishing him with diet, lodging, and ordinary clothes, and about $20 s$. a year in money; or else a little wooden house is built him by the farmer, who allow's him hay and pasturage for a cow, and ploughs and sows land enough to supply him with bread. When embodied, they are subject to military law, but otherwise to the civil law of the country. It may therefore literally be said that every Swedish soldier has a property in the country he defends. In 1791 the standing regiments amounted to 13,500 infantry and 1,000 cavalry; and the national troops to 22,500 infantry, 7,000 cavalry, and 3,500 dragoons.* In 1808 the regular troops were 18,425, and the national 34,614. In 1813 the Crown Prince had a regular army of 30,000 men in the field. Swe. den formerly could have fitted out 4.0 ships of the line; at present she has not more than 25 , and 10 or 15 frigates.

ROYAL TITLE, ORDERS OF KNIGHTHOOD.... The king takes the title of King of Sweden and of the Goths and Vandals; Grand-cluke of Finland, Hereditary Lord of Norway; Duke of Sleswick, Stormarn, and Ditmarsen; Count of Oldenburg and Delmenhorst.

The orders of knighthood are that of the Seraphim, or blue ribbon; of the Sword, or yellow ribbon; of the Polar Star, or black ribbon; and of Vasa, or the green ribbon. The order of the Sword is bestowed for military merit; and that of the Polar Star for ciril services.

RELIGION....Christianity was introduced into Sweden in the ninth century, and Lutheranism established by Gustavus Vasa. The na. tional church is governed by the archbishop of Upsal and thirteen bishops. The bishoprics are those of Linkœping, Skara, Stregnæs, IVesteros, Vexjœ, Abo, Lund, Borgo, Gotheburg, Calmar, Carlstadt, Hernæsand, and Gothland. The Swedes, were till of late years, very intolerent to those of other religious professions, and extremely severe laws were in force against the catholic priests. But they have now greatly relaxed fiom this bigotry: various sects are tolerated in Sweden, and Jews were permitted to settle there, and open synagogues 
at Stockholm, Gotheburg, Carlscrona, and Norkikeping, in 1778. In 1781 the catholics were likewise permitted to profess their religion publicly. Swedes who abandon their religion are, however, punish. able by banishment and the loss of their civil privileges.

LiTERATURE.... In natural history, chemistry, and metallurgy, several natives of Sweden have attained to particular eminences; and in these departments of science the names of the great Linnæus, professor Bergman, Wallerius, Quist, Klingenstierna, and Thunberg, are especially conspicuous. The Swedes have also not neglected the culture of the politer arts, and literature of almost every lind.

UnIversitres....There are three universities in Sweden; those of Upsal, Lund, and Abo. Of these, the principal is that of Upsal. This university contains about 500 students; that of Lund has about 300 ; and that of Abo nearly as many. There are, likewise, twelve seminaries for the education of youth, called gymnasia.' In every large town there is also a school, maintained at the expence of the crown, in which boys generally continue till the age of eleven, when they are sent to the gymnasia, and thence, at sixteen, to one of the universities. The university of Upsal has a library containing about 40,000 volumes. There are in Sweden twelve literary academies, most of which publi $h$ memoirs of their transactions.

LANGUAGE....The language of Sweden has a considerable resemblance to the Danish and Icelandic, and, like them, is derived from the ancient Gothic. The Lord's Prayer in Swedish is as follows.

Fader suar som ast $i$ himlom; helgat rearde tit namn; tilkomme tit rike; ske tin wilje, sasom $i$ himmelcn sa ock pa jordene; gif oss i dag wart dagelige brod; och forlat oss ware skulder, sasom ock wi forlatom them oss skyldige aro; och inled oss icke i frestelse, utan frels oss ifran ondo; ty riket ar tit, och machten, och herligheten i crigighet. Amen.

Antrquities.... Sweden contains numerous ranges of stones, similar in some degree, though not comparable in dimensions, to those of Stonehenge. There are also great numbers of small mounts or tumuli, like the barrows of Britain, and ancient monuments inscribed with Runic characters. Near Upsal is the morasten, or stone, on which the king used to be enthroned, as the Scottish monarchs anciently were at Scone.

History....The history of this kingdom, and indeed of all the northern nations, even during the first ages of Christianity, is confused and uninteresting, and often doubtful ; but sufficiently replete with murders, massacres, and ravages. That of Sweden is void of consistency till about the middle of the fourteenth century, when it assumes a more regular appearance. At this time, however, the government of the Swedes was far from being clearly ascertained or uniformly administered. The crown was elective; though in this election the rights of blood were not altogether disregarded. The great lords possessed the most considerable part of the wealth of the kingdom, which consisted chiefly in land; commerce being unknown or neglected, and even agriculture itself in a very rude and imperfect state. The clergy, particularly those of a dignified rank, from the great respect paid to their character among the inhabitants of the No:th, had acquired an immense influence in all public affairs, and obtained possession of the lands that had been left unoccupied by the nobility. 'These two ranks of men, enjoying all the property of the state, formed a council, called the Senate, which deliberated on all public affairs. This system of government was extremely unfavour- 
able to the national prosperity. The Swedes perished in the dissensions between their prelates and lay-barons, or between those and their sorereign; they were drained of the little riches they possessed, to suppoit the indolent pomp of a few magnificent bishops; and, what was still more tatal, the unlucky situation of their internal affairs exposed them to the inroads and oppression of a foreign enemy. These were the Danes, who, by their neighbouriood and power, were always able to avail themselves of the dissensions of Sweden; and to subject under a foreign yoke a country weakened and exhausted by its domes. tic broils. In this deplorable situation Sweden remained for more than two centuries; sometimes under a nominal subjection to its own priuces, sometimes united to the kingdom of Denmark, and in either case equally oppressed and insulted.

Magnus Lidislaus, crowned in 1276 , seems to have been the first king of Sweden who pursued a regular system to increase his authority. He was one of the ablest princes who ever sat on the Swedish throne. By his art and address he prevailed upon the convention of estates to make very extraordinary grants to him for the suppor of his royal dignity. The augmentation of the revenues of the crown was naturally followed by a proportionable increase of the regal power : and whilst, by the steady and vigorous exertion of this power, Magnus humbled the haughty spirit of the nobles, and created in the rest of the nation a respect for the royal dignity, with which they appear before to have been but little acquainted, he at the same time, by employing his authority in many respects for the public good, reconciled his subjects to acts of power which in former monarchs they would have opposed with the utmost violence. The successors of Magnus did not maintain their authority with equal ability; and several commotions and revolutions followed, which threw the nation into great confusion.

In the $y+a r 1387$, Margaret daughter of Valdemar king of Denmark, and widow of Huguin, king of Norway, reigned in both these kingdoms. That princess, to the ordinary ambition of her sex, added a penetration and enlargement of minci, which rendered her capable of conducting the greatest and most complicated designs. She has been called the Semiramis of the North, because, like Semiramis, she found means to reduce by arms, or by intrigue, an immense extent of territory ; and becanie queen of Denmark, Norway, and Sweden, being elected to the throve of the latter in 1564. She projected the union of Calmar, so famous in the North; by which these kingdoms were for the future to remain under one sovereign, elected by-each kingdom in its turn, and who should divide his residence between them all. Several revolutions ensued after the death of Margaret; and at length Christian II, the last king of Denmark, who, by virtue of the treaty of Calmar, was also king of Sweden, engaged in a scheme to render himself entirely absolute. The barbarous policy by which he attempted to effect this design proved the destruction of himself, and afforded an opportunity for changing the face of affairs in Sweden. In order to establish his authority in that lkingdom, he laid a plot for massacreing the principal nobility; and this horrid design was actually carried into execution, Nov. 8, 1520. Of all those who could oppose the despotic purposes of Christian, no one remained in Sweden but Gustavus Vasa, a young prince descended from the ancient kings of that country, and who had already signalised his arms against the lking of Denmark. An immense price was 
set upon his head. The Danish soldiers were sent in pursuit of him; but by his dexterity and address he eluded all their attempts, and escaped under the disguise of a peasant to the mountains of Dalecarlia. After undergoing innumerable dangers and fatigues, and working in the brass mines to prevent being discovered, he was betrayed by those in whom he reposed his confidence; but at length, surmounting a thousand obstacles, he engaged the savage, but warlike inhabitants of Dalecarlia to undertake his cause, and assist him to oppose and conquer his tyrannical oppressor. Sweden by his means again acquired independence. The ancient nobility were mostly destroyed; Gustavus was at the head of a victorious army, who admired his valour, and were attached to his person: he was created therefore, first, administrator, and afterwards king of Sweden, by universal consent, and with the shouts of the whole nation. His circumstances were much more favourable than those of any former prince who had possessed this dignity. The massacre of the nobles had freed him from those proud and haughty enemies, who had so long been the bane of all regular government in Sweden. The clergy, indeed were no less powerful than dangerous; but the opinions of Luther, which began at this time to prevail in the North, and the credit which they had acquired among the Swedes, gave him an opportunity of changing the religious system of that country; and the exercise of the Roman-catholic religion was prohibited in the year 1544, under the severest penalties. Instead of a Gothic aristocracy, the most turbulent of all governments, and, when empoisoned by religious tyranny, of all governments the most wretched, Sweden, in this manner, became a regular monarchy. Some favourable effects of this change were soon visible; arts and manufactures were established and improved ; navigation and commerce began to flourish; letters and civil improvements were introduced; and a kingdom, known only by name to the rest of Europe, began to be formidable by its arms, and to have a certain weight in all public treaties and deliberations.

Gustavus died in 1559, while his eldest son Eric was preparing to embark for England to marry queen Elizabeth.

Under Eric, who succeeded his father Gustavus Vasa, the titles of count and baron were introduced into Sweden, and made hereditary. Eric's miserable and causeless jealousy of his brothers forced them to take up arms; and the senate siding with them, he was deposed in 1566. His brother John succeeded him, and entered into a ruinous war with Russia. John attempted, by the advice of his queen, to reestablish the catholic religion in Sweden; but though he made strong efforts for that purpose, and even reconciled himself to the pope, he was opposed by his brother Charles, and the scheme proved ineffec-. tual. His son Sigismund was chosen king of Poland in 1587; upon which he endeavoured again to restore the Roman-catholic religion in his dominions; but he died in 1592 .

Charles, brother to John, was chosen administrator of Swe'den ; and being a strenuous protestant, his nephew Sigismund endeavoured to drive him from the administratorship, but without effect; till at last he and his family were excluded from the succession to the crown, which was conferred upon Charles in 1599. The reign of Charles, through the practices of Sigismund, who was a powerful prince, and at the head of a great party both in Sweden and Russia, was turbulent; which gave the Danes encouragement to invade Sweden. Theis conduct was checked by the great Gustavus Adolphus, heir- 
apparent to the crown of Sweden, though then a minor. Upon the death of his father, which happened in 1611 , he was declared of age by the states, though then only in his 18th year. Gustavus, soon after his accession, found himself, through the power and intrigues of the Poles, Russians, and Danes, engaged in a war with all his neighbours, under infinite disadvantages, all which he surmounted. He had nearly rendered himself sovereign of Russia. In 1617 he made a peace, under the mediation of James I, of England, by which he recovered Livonia, and four towns in the prefecture of Novgorod, with which he likewise received a sum of money.

The ideas of Gustarus began now to extend. He had seen much military service, and he was assisted by the counsels of La Gardie, one of the best generals and wisest statesmen of his age. His troops had become the best disciplined and most warlike in Europe. The princes of the house of Austria were, it is certain, early jealous of his enterprising spirit, and supported his ancient implacable enemy Sigismund, whom he defeated. In 1627, he formed the siege of Dantzick, in which he was unsuccessful; but the attempt, which was defented only by the sudden rise of the Vistula, added so much to - his military character, that the protestant princes placed him at the head of the confederacy for reducing the house of Austria. His life, from that the, was a continued chain of the most rapid and wonderful successes. After taking Riga, and overruning Livonia, he entered Poland, where he was victorious; and from thence, in 1630, he landed in Pomerania, clrove the Germans out of Mecklenburg, defeated the famous count Tilly, the Austrian general, who was till then thought invincible, and overran Franconia. Upon the defeat and cleath of Tilly, WVallenstein, another Austrian general of equal réputation, was appointed to the command against Gustavus, who was killed upon the plain of Lutzen in 1632, after gaining a victory, which, had he survived, would probably have put a period to the Austrian greatness.

The amazing abilities of Gustavus Adolphus, both in the cabinet and the field, never appeared so fully as after his death. He left behind him a set of generals trained by himself, who maintained the glory of the Swedish army with most astonishing valour and success. The names of duke Bernard, Bannicr, Torstenson, Wrangel, and others, and their great actions in war, will long live in the annals of Europe. It is uncertain what course Gustavus would have pursued, had his life been prolonged, and his successes continued; but there is the strongest reason to believe, that he had in view somewhat more than the relief of the protestants, and the restoration of the Palatine family. His chancellor Oxenstiern was as consummate a politician as he was a warrior; and during the minority of his daughter Christina, he managed the affairs of Sweden with such success, that she in a manner dictated the peace of Westphalia, in 1648 , which gave $a^{*}$ new system to the affairs of Europe.

Christina was but six years of age when her father was killed... Slie reccived a noble education; but her fine genius took an uncommo ro and indeed romantic turn. She invited to her court Descartes, "Sal-" masius, and other learned men, to whom she was not, however, extremely liberal. She expressed a value for Grotius; and she was an excellent judge of the polite arts, but illiberal and indelicate in the choice of her private favourites. She at the same time discharged all the duties of her high station; and though her generals were

Tor. I. 
bascly betrayed by France, she continued to support the honour of her crown. Being resolved not to marry, she resigned her crown to her cousin Charles Gustavus, son to the duke of Deux-Ponts, in 1654 .

Charles had great success against the Poles: he drove their king, John Casimir, into Silesia; and received from them an oath of allegiance, which, with their usual inconstancy, they broke. His progress upon the ice against Denniark has been already mentioned; and he died of a fever in 1660. His son and successor, Charles XI, was not five years of age at his father's death; and this rendered it necessary for his guardians to conclude a peace with their neighbours, by which the Swedes gave up the island of Bornholm, and Drontheim in Norray. All differences were accommodated at the same time with Russia and Holland; and Sweden continued to make a very respectable figure in the affairs of Europe. When Charles came to be of age, he received a subsidy from the French king, Lewis, XIV, but perceiving the liberties of Europe to be in clanger from that monarch's ambition, he entered into the alliance with England and Holo land. He afterwards joined with France against the house of Austria: but being defeated in Germany, at Felem Bellin, a powerful con: federacy was formed against him. The clector of Brandenburg made himself master of Swedish Pomerania; the bishop of Munster overran Bremen and Verden, and the Danes look Wismar, and several places in Schonen. They were afterwards beaten; and Charles, by the treaty of St. Germain, which followed that of Nimeguen in 1678, recovered all he had lost, except some places in Germany. He then married Ulrica Leonora, the king of Denmark's sister; but made a base use of the tranquillity he had regained, by employing his army to enslave his people. The states lost all their power; and Sweden was now reduced to the condition of Denmark. He ordered the brave Patkul, who was at the head of the Livonian deputies, to lose his head and his right hand, for the boldness of his remonstrance in favour of his countrymen; but he saved himself by flight; and Charles became so powerful, that the conferences for a general peace at Ryswick, 1697, were opened under his mediation.

Charles XI, died in 1697, and was succeeded by his minor son, the famous Charles XII. The history of no prince is better known than that of this hero. His fither's will had fixed the age of his majority to eighteen; but it was set aside for an earlier date by the management of count Piper, who becarne in consequence his first minister. Soon after his accession, the kings of Denmark and Poland, and the czar of Muscovy, formed a powerful confederacy against him, encouraged hy the mean opinion they had of his youth and abilities. He entered into a war with them all: and besieging Copenhagen, dictated the peace of Travendahl to his Danish majesty, by which the duke of Holstein was re-established in his dominions. The czar Peter was at that time ravaging Ingria, at the head of 80,000 men, and had besieged Narva. The armyof Charles did not exceed 20,000 mien; but such was his impatience, that he advanced at the head of 8000 , entirely routed the main body of the Russians, and raised the siege. Such were his successes, and so numerous his prisoners, that the Russians attributed his actions to nicromancy. Charles from thence marched into Saxony, where his warlike achievements equalled if they did not excel those of Gustavus Adolphus. He dethroned Agustus king of Poland; but stained all his latrels by putting the 
brave count Patkul to a death equally cruel and ignominious. He raised Stanislaus to the crown of Poland in 1705; and his name carried with it such terror, that he was courted by all the powers of Europe, and among others by the duke of Marlborough in the name of queen Anne, amidst the full career of her successes against France. His stubbornness and implacable disposition, however, were such, that he cannot be considered in a better light than that of an illustrious madman; for he lost, in the battle of Pultowa, 1709, which he fought in his march to dethrone the czar, more than all he had gained by his vic tories. His brave army was ruined, and he was forced to take refuge among the Turks at Bender. His actions there, in attempting to defend himself with 300 Swedes against 30,000 Turks, prove him to have been worse than frantic. The Turks found it, however, con. venient for their affairs to set him at liberty. But his misfortunes dici not cure his military madness; and after his return to his domirions, he prosecuted his revenge against Denmark, till he was killed by a cannon-shot, as it is generally said, at the siege of Fredericshall, in Norway, belonging to the Danes, in 1718, when he was not more than thirty-six years of age. It has been supposed that Charles was not in reality killed by a shot from the walls of Fredericshall, but that a pistol from one of those about him gave the decisive blow which put an end to the life of this celebrated monarch. This opinion is said to be very prevalent among the best informed persons in Sweden. And it appears that the Swedes were tired of a prince under whom they had lost their richest provinces, their bravest troops, and their national riches; and who yet, untamed by adversity, pursued an unsuccessful and pernicious war, nor would ever have consented to restore tranquillity to his country.

Charles XII, was succeeded by his sister, the princess Ulrica Eleanora, wife to the hereditary prince of Hesse. We have seen in what manner the Swedes recovered their liberties; and given some account of the capitulation signed by the queen and her husband. Their first care was to make peace with Great Britain, which the late king intended to have invaded. The Swedes then, to prevent far. ther losses by the progress of the Russian, the Danish, the Saxon, and other arms, made many and great sacrifices to obtain peace from those powers. The French, however, about the year 1738, formed a dangerous party in Sweden, under the name of the Hats, which not only disturbed the internal quict of the kingdom, but led it into a ruinous war with Russia. Their Swedish majesties having no children, it was necessary to settle the succession; especially as the duke of Holstein was descended from the queen's eldest sister, and was at the same time the presumptive heir to the empire of Russia. Four competitors appeared; the duke of Holstein-Gottorp, prince Frederic of Hesse-Cassel (nephew to the king) the prince of Denmark, and the duke of Deux-Points. The duke of Holstein would have carried the election, had he not emoraced the Greck religion, that he might mount the throne of Russia. The czarina interposed, and offered to restore all the conquests she had made from Sweden, excepting a small district in Finland, if the Sivedes would receive the duke of Holstein's uncle, the bishop of Lubeck, as their irereditary prince and successor to their crown. This was agreed to; and a peace was concluded at Abo, under the mediation of his Britannic majesty. This peace was so firmly adhered to by the czarina, that his Danish majesty thought proper to drop all his resentment, and forget the 
indignity done to his son. The successor of this prince, Aciolphus Frederic, married the princess Ulrica, sister to the king of Prussia, and entered into the possession of his new dignity in 1751 . He was a prince of a mild and gentle temper, but much harassed by the contending Swedish factions, and found his situation extreniely troublesome, in consequence of the restraints and opposition which he met with from the senate. He passed the greatest part of his reign very disagreeably, and was at length, through the intrigues of the queen, brought over to the French party. He died in February 177 I, and was succeeded by his son, Gustavus the Third, the late king, who possessed abilities greatly superior to those of his father.

Gustavus was about five and twenty years of age when he was proclaimed king of Sweden : his understanding had been much cultivated; he had an insinuating address, and a graceful and commanding elocution. He was at Paris at the time of his father's death, whence he wrote in the most gracious terms to the senate, repeatedly assuring them that he designed to govern according to the laws. In consequence of the death of his predecessor, an extraordinary diet was called to regulate the affairs of the government, and to settle the form of the coronation oatl. Some time after his arrival in Sweden, on the 28th of March, 1772, his majesty solemnly signed and swore to support the government of the lingdom as then established; to maintain the rights and liberties of the states, the liberty and security of all his subjects, and to reign with gentleness and equity according to the laws of the kingdom. But scarcely had he taken these solemn oaths, to rule according to the then established form of government, and accepted the crown upon these conditions, before he formed a plan to govern as he thought proper; regarding these oaths only as matters of ceremony. He made use of every art, the most profound dissimulation, and the utmost dexterity and address, in order to render this hazardous enterprise successful. On his first arrival at StockhoIm, he adopted every method which could increase his popularity. Three times a week he regularly gave audience to all who presented themselves. Neither rank, fortune, nor interest, were necessary to obtain access to him; it was sufficient to have been injured, and to have a legal cause of complaint to lay before him. He listened to the meanest of his subjects with affability, and entered into the minutest details that concerned them: he informed himself of their private affairs, and seemed to interest himself in their happiness. This conduct caused him to be considered as truly the father of his people, and the Swedes began to idolise him. At length, when he found his scheme ripe for execution, having taken the proper measures for bringing a considerable number of the officers and soldier's into his interest, on the 19th of August, 1772, he totaliy overturned the Swedish constitution of government. In less than an hour he made hiniself master of the whole military force of Stockholm; made all the members of the senate prisoners; and suffering no person to leave the city, that intelligence of these violent procecdings might not be carried to any other part of the kingdom, issued a proclamation for an assembly of the states to meet on the 21 st, which having accordingly met, he surrounded witis troops, and planted cannon, over which soldiers stood with lighted matches in their hands, facing the hall in which they were assembled. The king then, being seated on his throne, surrounded by his guards, and a numerous band of officers, after having addressed a speech to the states, ordered a secretary to read a new 
form of government, which he offered to the states for their accepm tance. As they were surrounded by an armed force, they thought proper to comply with what was recuired of them. The marshal of the diet, and the speakers of the other orders, signed the form of go. vernment; and the states took the oath to the king, which he dictated to them himself. He afterwarks gave them to understand, that he intended in six years time again to convene an assembly of the states. Thus was this great revolution completed without any bloodshed, in which the Swedes surrendered that constitution which their forefathers had bequeathed to them after the death of Charles the Twelfth, as a bulwark against any despotic attempt of their future monarchs.

The exorbitant power which Gustavus the Third had thus assumed, he exercised with some degree of moderation; and at an assembly of the states in 1786 , after many points were referred to them by the king, and debated with great freedom, he dismissed them with condescension and gentleness, at the same time remitting a tenth part of the subsidy which they had granted him.

On the 12th of July, 1788, hostilities commenced on the frontiers of Finland, between a body of Russian light troops and a detachment of the Swedes posted on the bridge of Pomalasund. After various engagements both by land and sea, in which Gustavus displayed the sreatest abilities, a peace, fixing the frontiers of Russia as they were before the war broke out, was signed at Werela, on the river $\mathrm{Ky}$ mene between the plenipotentiaries of the empress of Russia and the king of Sweden.

The reign of this king was terminated 'by a premature and tragic end. On the night of the 16 th of March, 1792, while at a masquerade in the opera-house at Stockholm, he was shot with a pistol, by an assassin named Ankersiroem, in consequence of a conspiracy among some of the discontented nobles; and having survived in great pain till the 29 th of that month, expired, in the 46 th year of his age and $22 \mathrm{~d}$ of his reign.

The prince-loyal, being fourteen years of age, was immediately proclaimed king, by the name of Gustavus Adolphus; and the duke of Sudermania, his uncle, and brother to the late king, in compliance with his majesty's will, was declared sole regent, and guardian of the young sovereign, till he should attain his majority, which was fixed at the age of eighteen, at which time he assumed the reins of government. Gustavus entered into the confederacy formed by the northern powers against England, by signing what was called the convention of neutrality. But the victory obtained by lord Nelson, in the battle of Copenhagen, and the sudden death of the emperor Paul of Russia, completely dissolved this coalition, and the relations between England and Sweden were again placed upon an amicable footing.

In 1807 , Sweden was the only nation on the continent which refus. ed to adopt the French commercial regulations. With a heavy national debt, a limited revenue, and a thin population, she became an object of enmity to all the surrounding nations. Early in the spring of 1807 , the emperor Alexander, without giving any notice to the Swedish government, sent a large army to take possession of Finland. Having overrun the greater part of the country, he then issued a declaration of war, which was followed by a similar declaration from the court of Denmark. Gustavus, collecting all his forces, sent a part of them to oppose the progress of the Russians, while 
with the remainder he made an attack upon Norway. In both itsstances his troops fought with the greatest bravery, but were finally overpowered. To the loss of Finland succeeded that of Pomerania. From these provinces almost all the grain consumed in Sweden had been derived, and the country was reduced to a state of starvation. Added to this, a dreadful plague broke out, and carried off numbers of the inhabitants. These successive misfortunes damped the courage of the soldiery, and raised among the peasants murmurs of discontent. Gustavus, however, persisted in prosecuting the war, evidently against the wish of the nation. A large part of the army refused to follow him, and raised the standard of rebellion. The king was about leaving the capital to endeavour to collect troops to suppress the insurrection, but was seized and imprisoned by the nobles, who placed the government in the hands of the duke of Sudermania, until the diet could be assembled. The diet met, deposed Gustavus, and called the duke of Sudermania to the throne. Thus the brave, the unfortunate, but the rash and inconsiderate Gustavus Adolphus, lost his crown by obstinately refusing to yield to imperious necessity.

The deposition of the king was followed in 1809 by the sudden death of the crown prince, the only son of Gustavus Adolphus. Suspicions were strongly entertained by many as to the cause of his death, which from several circumstances was thought not to have been a natural one; nor were there wanting those, who added this to the list of crimes of the then emperor of France. The government, however, declared that his death was natural. The king was without issue, and it became necessary that a successor to the crown should be nominated. The diet was assembled, and the French general Charles Jean Bernadotte, prince of Ponte Corvo, was named to them by the king as candidate, and elected with little opposition. In this choice the Swedish nation was influenced by a desire to conciliate the emperor Napoleon.

Bernadotte, from the moment of his election, seemed to forget the Frenchman in the Swede; and all his conduct evinced a wish to promote the interests of his adopted country. In 1812, an alliance was formed with England and Russia, to oppose the ambition of Bonaparte. In the spring of 1813 , the Swedish troops landed in Pomerania, and bore an active part in that important campaign, which broke to pieces the most powerful despotism of modern Europe.

Charles XIII, the present king of Sweden, was born Oct. 7, 1748, and was called to the throne in 1808 . He is without issue.

Charles Jean Bernadotte was born Jan. 26, 1763, and elected crown prince Aug. 18th, 1809.

Daughter of the late king, Sophia Wilhemina, born May 21st, 1801.

Queen dowager, Sophia Magdalena, daughter of Frederic V, king of Denmark, born July 3d, 174.6.

Brother of the king, Frederic Adolphus, duke of West-Gothland, born July 18 th, 1750 .

Sister of the king, Sophia Albertina, abbess of Quedlingburg, born Oct. 8,1753 . 


\section{LAPLAND.}

THOUGH Lapland has no peculiar government as a distinct nation, but is divided among the three great northern powers, Sweden, Denmark, and Russia, the peculiar character and manners of its inhabitants entitle it to be treated of in a distinct section; and as the largest and most cultivated part of it belongs to Sweden, it appears most proper to place the account of it after that of the country on which it is principally dependent.

Nane... The name of Lappes was given to the Laplanders by the Swedes, and is of uncertain derivation. Some say that it signifies exiles or fugitives, because they are of the race of the Fins driven out of their own country; other's, that it signifies sorcerers. The Laplanders call themselves Same, and their country Same-ednam; whence it has been conjectured that they are of the race of the Sarnoieds.

ExIENT AND DIVISIONS....Lapland, taking together the whole of Swedish, Danish, and Russian Lapland, extends from 64 to 71 degrees north latitude, and from 15 to 40 degrees west longitude, being in length about 600 miles, and in breadth 500 : it may contain about 120,000 square miles. The most southern part belongs to Sweden; the northern part appertains to Denmark, and is called Finmark. The distinction between the territory of the two countries, as agreed on by treaty in 1750 , is, according to $\mathrm{Mr}$. Acerbi, a late intelligent traveller into Lapland, that all that tract of country of which the rivers run into the Frozen Ocean shall belong to Denmark; and all that of which the rivers fall into the Gulf of Bothnia, shall be considered as Swedish Lapland. The eastern extremity of Lapland belongs to Russia, and makes a part of the government of Archangel.

The subdivisions of Swedish Lapland have already been given im the table of the Swedish provinces.

Mountains, Lakes, Rivers....Lapland contains many mountains, but none with which we are sufficiently acquainted to notice them particularly. The principal rivers are the Tornea, the Tana, and the Alten. The Tornea springs from the lake of the same name, and, after a course of 300 miles, falls into the Gulf of Bothnia. The Ta$\mathrm{na}$ and Alten fall into the Frozen Ocean. The Paes divides Russian Eapland from the part subject to Denmark. The lakes in Lapland are numerous; those of Hernasba-Staer, or the Great Lake, Tornea, Eulea, and Enara in Russian Lapland, are the chief.

Mrnerals, Metals...Lapland abounds in metals and minerals of every kind. Native gold has been found at Svappawara; copper, iron, lead, zinc, and plumbago, or black-lead, are found in various parts; and in the south of Swedish Lapland there are mines worked by the Swedes. Limestone, marble, gypsuin, rock-crystal, jasper, amethysts, and garnets, are also among the mineral productions of this country. Pearls of considerable value are said to be found in the rivers.

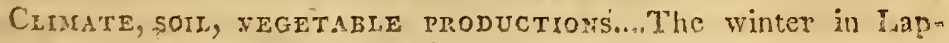


land, as may be expected in so northern a ciimate, is extremely severe. In the most nortlern parts the sun rcmains below the horizon from the 20th of November to the 10th of January; and from the beginning of September to the middle of March the whole country is covered with snow and ice; and in the depth of winter the lakes and rivers are generally frozen to the depth of two Danish ells and a half. In summer, on the other hand, the sun continues in like manner two months above the horizon; and the beat in the valiies and plains is excessive. Innumerable insects are produced, and the in habitants are infested with musquitoes to an intolerable degree. Mr. Acerbi, returning on the 20th of July from the North Cape, the most northern extremity of these regions, remarks in his Diary; "The sea was perfectly calm, and I do not remember having ever suffered greater heat in my life than in this journey."

With respect to the soil and vegetable productions of Lapland, the whole country is an immense wilderness, where agriculture is entirely unknown, except in a very few parts in the south, in which coria (principally rye and buckwheat) is cultivated. In the nortb, tracts of considerable extent are overgrown with moss, which is the principal food of the rein-deer. 'The trees are the fir, birch, larch, and small beech, which form vast but not very thick forests.

Anrmals.... The animals are nearly the same with those described in the account of Norway, excepting the rein-deer, which more peculiarly belongs to Lapland. This animal, the most useful, perhaps, of any in the creation, and which seems to have been provided by nature to recompense the Laplanders for the privation of the other comforts of life, resembles the stag, only it somewhat droops the head, and the horns project forward. In summer the rein-deer provide themsclves with leaves and grass, and in the winter they live upon moss; which they have a wonderful sagacity in finding, and, when found, scrape away the snow that covers it with their feet. The scantiness of their fare is inconceivable, as is the length of the journeys which they can perform without any other support. They fix the rein-deer to a kind of sledge, shaped like a small boat, in which the traveller, well secured from cold, is laced down; with the reins, which are fastened to the horis of the animal, in one hand, and a kind of bludgeon in the other, to keep the carriage clear of ice and snow. The deer, whose harnessing is very simple, sets out, and continues the journey with prodigious speed; and is so safe and tractable, that the driver is at little or no trouble in directing him. At night they look out for their own provender; and their milk often contributes to support their master. 'Their instinct in choosing their road, and directing their course, can only be accounted for by their being well acquainted with the country during the summer months when they live in the woods. Their flesh is well-tasted food, whether fresh or dricd; their stin forms excellent clothing both for the bed and the body; their millk and cheese are nutritive and pleasant; and their intestines and tenclons supply their masters with thread and cordage. When they run about wild in the fields, they may be shot at as other gane. But it is said, that if one be killed in a flock, the survivors will gore and trample him to pieces; therefore single stragglers are generally chosen. With all their excellent qualities, however, the rein-deer have their inconveniences. It is difficult in summer to keep them from straggling; they are sometimes buried in the snow; and they frequently grow restive, to the great danger of the driver and 
Bis carriage. Their surprising speed (for they are said to run at the: rate of 200 miles a-day) seems to be owing to their impatience to get rid of their incumbrance. None but a Laplander could bear the uneasy posture in which he is placed, when he is confined in one of these carriages or pulkhas; or would believe, that, by whispering the rein-deer in the ear, they know the place of their destination.

Population, inhabitants, Manners, customs....Lapland is very thinly peopled. Russian Lapland, according to Mr. Tooke, does not contain more than 1200 families, or about 6000 persons. The population of the whole of this extensive region is supposed to be not mole than 40,000 , or one person to about three square miles.

Both men and women are in general considerably shorter than more southern Europeans. Maupertuis measured a woman who was s,uckling her child, whose height did not exceed four feet two inches and about a half. The Laplander is of a swarthy and dark complexion; his hair is black and short, his mouth wide, and his cheeks hollow, with a chin somewhat long and pointed. The women are complaisant, chaste, often well made, and extremely nervous, which is also observable among the men, though more rarely.

Agriculture is not much attended to among the Laplanders. They are chiefly divided into Lapland fishers, and Lapland mountaineers. The former always make their habitations on the brink or in the neighbourhood of some lake, from which they draw their subsistence. The others seek their support upon the mountains and their environs, possessing herds of rein-deer more or less numerous, which they use according to the season, but go generally on foot. They are excellent and very industrious herdsmen, and are rich in comparison of the Lapland fishers. Some of them possess six hundred or a thousand rein-deer, and have often money and plate besides. They mark every rein-deer on the ears, and divide them into classes; so that they instantly perceive whether any one has strayed, though they cannot count to so great a number as that to which their stock often amounts. Those who possess but a small stock, give to every individual a proper name. The Lapland fishers, who are also called Laplanders of the Woods, because in summer they dwell upon the borders of the lakes, and in winter in the forests, live by fishing and hunting, and choose their situation by its convenience for either.

The greatest part of them, however, have some rein-deer. They are active and expert in the chase : and the introduction of fire-arms among them has almost entirely abolished the use of the bow and arrow. Besides looking after the rein-deer, the fishery, and the chase, the men employ themselves in the construction of their canoes, which are small, light, and compact. They also make sledges, to which they give the form of a canoe, harness for the rein-deer, cups, bowls, and various other utensils, which are sometimes neatly carved, and sometimes ornamented with bones, brass, or horn. The employment of the women consists in making nets for the fishery, in drying fish and meat, in milking the rein-deer, in making cheese, and tanning hides; but it is understood to be the business of the men tolook afo ter the kitchen, in which it is said the women never interfere.

'The Laplanders live in huts in the form of tents. A hut is from about twenty-five to thirty feet in diameter, and not much above six in height. They cover them, according to the season and the means of the possessor, some with briers, bark of birch, or linden; other's with turf, coarse cloth, or felt, or the old skins of rein.deer. The 
door is of felt, made like two curtains which open asunder." A little place surrounded with stones is made in the middle of the hut for the fire, over which a chain is suspended to hang the kettle upon. They are scarcely able to stand upright in their huts, but constantly sit upon their heels round the fire. At night they lie down quite naked; and, to separate the apartments, place upright sticks at small distances. They cover themselves with their clothes, or lie upon them. In winter they put their naked feet into a fur bag. Their household furniture consists of iron or copper kettles, wooden cups, bowls, spoons, and sometimes tin or even silver basons; to which may be added the implements of fishing and hunting. That they may not be obliged to carry such a number of things with them in their excursions, they build in the forests, at certain distances, little huts, made like pigeon houses, and placed upon the trunk of a tree, cut off at the height of about six feet from the root. In these elevated huts they keep their goods and provisions; and though they are never shut, yet they are never plundered. The rein-deer supply the Laplanders with the greatest part of their provisions : the chase and the fishery supply the rest. Their principal dishes are the flesh of the rein-deer, and puddings which they make of their blood, by putting it, either alone or mixed with wild berries, into the stomach of the animal from whence it was taken, in which they cook it for food. But the flesh of the bear is considered by them as their most delicate meat. They eat every kind of fish, even the sea-dog; as well as all kinds of wild animals, not exceping birds of prey and carnivorous animals. Their winter provisions consist chietly of flesh and fish dried in the open air, both of which they eat raw, without any sort of dressing. Their common drink is water, sometimes mixed with mnilk. They make also broths and fish-soups. Brandy is very scarce with them, but they are extremely fond of it. Whenever they are inclined to eat, the head of the family spreads a carpet on the ground; and the men and women squat round this mat, which is covered with dishes. Every Laplandcr always carries about him a knife, a spoon, and a little cup for drinking. Each has his portion separately given him, that no person may be injured; for they are great eaters. Before and after the meal they make a short prayer; and as soon as they save cionereating, each gives the other his hand.

In their dress the Laplanders use no kind of linen. The men wear close breeches, reaching down to their shoes, which are made of untanned skin, pointed, and turned up before; and in winter they put a little hay in them. Their doublet is made to fit their shape, and open at the breast. Over this they wear a close coat with narrow sleeves, the skirts of which reach down to the knees, and which is fastened round them by a leathern girdle, ornamented with plates of tin or brass. To this girdle they tie their knives, their instruments for making fire, their pipes, and the rest of their smoking apparatus. Their clothes are made of fur, of leather, or of cloth; the close coat, of cloth or leather, always bordererl with fur, or bindings of cloth of different colours. Their caps are edged with fur, pointed at top, and the four seams adorned with lists of a different colour from that of the cap. The women wear breeches, shoes, doublets, and close coats, in the same manner as the men; but their girdle, at which they carry likewise the implements for smoking tobacco, is commonly embroidered with brass wire. Their close coat has a colIar, which comes up somewhat higher than that of the men. Besides 
these, they wear handkerchiefs, and little aprons, made of painted cloth, riugs on their fingers, and ear-riugs, to which they sometimes hang chains of silver, which pass two or three times round the neck. They are often dressed in caps folded afer the manner of turbans. They wear also caps fitted to the shape of the head: and as they are much addicted to finery, they are all ornamented with the embroidery of brass wire, or at least with list of different colours.

A young man is not pernitted to marry till he be able to take and kill a rein-deer. When he is thus qualified, and has chosen a female to whom he wishes to make proposals, he communicates his desire to his own family, who then reparr in a body to the dwelling of the parents of the girl, laking with them a quantity of brandy to drink on the occasion, and a slight present for the young woman; for instance, a girdle ornamented with silver, a ring, or something of the like kind. When they come to the door of the hut in which she lives, the principal spokesman enters first, followed by the rest of the kindred, the suitor waiting without until he shall be invited to enter. As soon as they are come in, the orator fills uut a bumper of brandy, which he offer's to the girl's father, who, if he accept it, shows thereby that he approves of the match about to be moved for. The brandy is handed round, not only to the girl's father and mother, and her friends assembled together, but likewise to the intended bride; and in the course of this compotation, leave is obtained for the young man to forwarch his suit in his own person. The orator, then, in a set speech, makes a beginning; and in this stage of the courtship the lover is himself introduced, but takes his seat at a distance from the rest, placing himself near the door. "The parents of the girl at length signifying their full consent to the match, the suitur offers the maiden the present he has brought with him, and at the same time promises weddingclothes to the father and mother. If the parents, after having thus given their consent, depart from their word, it is an established law - amongst the Laplanders that all the expences incurred must be made good, even to the brandy drank at the first visit. The parties being thus betrothed, the young man is allowed to visit his mistress from time to time. On the day of the nuptials the bride appears dressed in her gala habit, with this difference, that whereas her head is close covered at other times, upon this occasion her hair is left tú flow loose upon her shoulders, and she wears a bandeau of different coloured stuffs, and sometimes a fillet. The nuptials are celebrated in a frugal manner, and without show. Such of the guests as are invited, and are of sufficient ability to do it, make the bride a present of money, rein-deer, or something towards a stock.*

The Laplanders, it is said, entertain an aversion to war; and it has never been found practicable to convert them into soldiers: but this is rather to be attributed to their habits of life, which disqualify them. for military discipline; as they will brave the fury of the tempestuous ocean with astonishing intrepidity, and skait without fear along the edges of tremendous precipices.

LANGUAGE.... The language of Lapland appear's to have an affinity to the Finnish, with an intermixture of some words evidently of Gothic origin, derived perhaps from their intercourse with the Danes and Swedes. Very different dialects, however, are spoken in differ. 
ent parts of the country. 'The Lord's Prayer in Laplandish is as follows :

Atki mijam juco lee almensisne. Aïs ziaddai tu Nam. Zqveigubatta tu Ryki Ziaddus tu Willio naukuchte almesne nau ei edna mannal. Wadde mijai udni mijan fart hafwen laibebm. Jah andagasloite mi jemijan suddoid naukuchte mije andagasloitebt kudi mije welgagas lien, Jah sissalaidi mijabni. Ale tocko kackzollebma hahast. Amen.

Religion.... The Laplanders have been induced, by the missionaries sent among them from Denmark and Norway, to profess Christianity; but this does not prevent them from sacrificing to the gods of their forefathers, and practising their ancient superstitions. The principal instrument of their magical rites, to which they are still addicted, is the Runic drum, which is a box of an oval shape, covered at one end with a skin, and furnished on the other with several strings and pieces of iron to rattle and make a noise; strange figures, intended to represent the heavenly bodies, beasts and birds, with many other characters, are drawn on the skin. The noaaid, or sorcerer, puts a ring upon his drum, and beats on if with his drumstick, which is made of the horn of the rein-deer, and according to the figure on which the vibration of the skin causes the ring to fall, he answers all questions concerning former or future events. At the same time he invokes the spirits to assist his drum; and in the course of this mummery falls into a fit, during which his soul is supposed to be with the spirits of the air, hearing their converse and learning the decrees of Heaven. Families in general possess such a drum, which the Laplander consults before he sets out on a journey, and which is his guide and director on all common occasions; but in affairs of greater moment he applies to the noaaids, or professed magicians, to consult it for him. These drums are preserved with great care and secrecy, and are hidden from sight cxcept at the time they are used. A woman dare not approach the place where one of these drums is concealed, much less durst she presume to touch it.

Trade....The Laplanders carry on a trade with the Swedes and Norwegians, by supplying them with the skins and furs of quadrupeds; such as ermines, sables, martens, squirrels; black, white, and variously coloured foxes; bears, lynxes, and wolves. In return they purchase meal, cloth, various utensils, spirituous liquors, and tobacco. The furs in which they traffic are of extreme fineness, and bear a high price, so that the balance of this trade is much in favour of the Iaplanders. 


\section{RUSSIA IN EUROPE.}

SITUATION AND EITENT OF RUSSIA IN EUROPE.

$\left.\begin{array}{ll}\text { Length } & \begin{array}{c}\text { Miles. } \\ 1960\end{array} \\ \text { Breadth } & 1850\end{array}\right\}$ between. $\left\{\begin{array}{l}44 \text { and } 72 \text { North latitude. } \\ 21 \text { and } 65 \text { East longitude. }\end{array}\right.$

Pussia in Europe contains 1,220,000 square miles, with 25 inhabitants to each.

SITUATION AND EXTENT OF THE WHOLE RUSSIAN EMPIRE.

$\left.\begin{array}{ll}\text { Length } & \begin{array}{l}\text { Miles. } \\ 6750\end{array} \\ \text { Breadth } & 2320\end{array}\right\}$ between $\left\{\begin{array}{l}\text { Degrees. } \\ 21 \text { and } 190 \text { E. or } 170 \mathrm{~W} . \text { longitude. } \\ 44 \text { and } 78 \text { North latitude. }\end{array}\right.$

The whole Russian empire contains 4,900,000 square miles, with less than 7 inhabitants to each.

NAmE....Russia derives its name from the Russi, or Rossi, a Slaronic tribe, who were the first known possessors of the country. It has very generally, however improperly, been denominated Muscovy, from Moscow, the capital, which takes its name from the river Moskva, on which it is situate.

Botndaries, Divisions....Russia in Europe is bounded on the north by the Frozen Ocean; on the east by the river Cara, the Uralian mountains, and the Volga; on the south by the Black Sea and Turkey; and on the west by Prussia, the Baltic Sea, and Sweden.

The whole Russian empire is divided into 50 governments.

GOVERNMENTS.

\begin{tabular}{|c|c|c|}
\hline Archangel & - & \\
\hline Bratzlau & - & \\
\hline Caucasia & - & \\
\hline Courland & - & \\
\hline
\end{tabular}

$\begin{array}{llll}\text { Ekaterinoslav } & - & \text { - } \\ \text { Irkutsk } & - & - & \text { - } \\ \text { Kaluga } & - & - & - \\ \text { Kagan } & - & - & - \\ \text { Kharkof } & - & - & - \\ \text { Kief - } & - & - & - \\ \text { Kolhyvane } & - & - & - \\ \text { Kostroma } & - & - & - \\ \text { Kursk } & - & - & - \\ \text { Mohilef } & - & - & \text { - } \\ \text { Mlinsk } & - & - & \text { - }\end{array}$

CHIEF TOWNS.

Archangel $\left\{\begin{array}{l}\text { N. lat. } 64.34 . \\ \text { E. lon. 38.55. }\end{array}\right.$

Bratzlau.

Astracan $\{$ N. lat. 4.21.

SN. lat. 56. 40 .

E. lon. 23. 50 .

SN. lat. 46.34.

E. lon. 32, 30 .

Ekaterinoslav.

S SN. lat.62. 1.

$\left\{\begin{array}{l}\text { Irkutsk } \quad\{\text { N.lon. 129.43. } \\ \text { E.lot. }\end{array}\right.$

Ochotsk.

Kaluga.

Kazan.

Kharkof.

Kief.

Tomsk.

Kostroma.

Kursk.

Mokilef.

Minski. 
GOVERNMENTS.

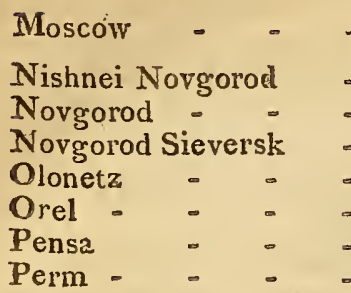

Petersburg -

Podolia - -

Polotzk - -

Pscove - -

Revel - -

Riazan - - .

Riga - - - -

Saratof - -

Simbirsk - - .

Slonim - - -

Smolensk - - -

Tambof - - -

Taurida - - -

Tobolsk - -

Tschernigof :-

Tula - - - -

Tver - - - .

Ufa - - .

Viætka - - -

Vilna - -

Vladimir - - .

Volhyna - - -

Vologda - - -

Voronetsch - -

Vorsnesensk - -

Vyborg - - -
CHIEF TOWNS.

Moscow $\left\{\begin{array}{l}\text { N. lat. 55. } 45 . \\ \text { E. lon. 37. } 4.6 .\end{array}\right.$

Nishnei Novgorod.

Novgorod.

Novgorod Sieversk.

Olonetz.

Orel.

Pensa.

Perm.

St. Petersburg $\left\{\begin{array}{l}\text { N. lat. 59. } 56 . \\ \text { E. lon. 30.19. }\end{array}\right.$

Kaminieck.

Polotzk.

Pscove.

Revel.

Riazan.

Riga $\left\{\begin{array}{l}\text { N. lat. 56. } 56 . \\ \text { E. lon. 23. } 58\end{array}\right.$

Saratof.

Simbirsk.

Slonim.

Smolensk

Tambof.

Caffa.

Tobolsk $\left\{\begin{array}{l}\text { N. lat. 58, } 12 . \\ \text { E. lon. 68. } 25 .\end{array}\right.$

Tschernigof.

Tula.

Tver.

Ufa.

$\left\{\begin{array}{l}\text { Orenburg } \\ \text { Viætka. }\end{array}\right\} \begin{aligned} & \text { N. lat. 51. } 46 . \\ & \text { E. lon. 55.5. }\end{aligned}$

Vilna.

Vladimir.

Lucko.

Vologda.

Voronetsch.

Vorsnesensk.

Vyborg.

Yaroslaf.

Mountains, Lakes, rivers, canals....Russia is in general a plain country, but between Petersburg and Moscow are the high grounds called the Valday Mountains, though the highest is only 4.00 yards above the level of Petersbury, or the sea. Between the lakes Ladoga and Onega is the chain of Olonetz, which runs in a direction almost due north for a great extent. The vast Uralian chain, which divides European from Asiatic Russia, extends from about the 50th to nearly the 67th degree of N. lat. or more than 1000 English miles. The Russians call this range Lemnoipoijas, the Girdle of the Earth. Ural also is a Tartarian word signifying a belt or girdle. These mountains are supposed to be the Montes Hyperboræi, or Riphæi, of the ancients. 
The principal lakes in European Russia are the Onega, in the government of Olonetz, about 150 miles in length by 30 in breadth; the lake Ladoga in the government of Vyborg, situate between the lake Onega and the Gulf of Finland, 180 miles in length by 70 in breadth, being one of the largest lakes in Europe ; the Peypus, which divides the governments of Petersburg and Riga, about 60 miles in length and So in breadth; the Ilmen, on which stands the city of Novgorod; and the Bielozersk, or White Lake, so called from its bottom being of white elay. The most considerable rivers are the Volga, or Wolga, running east and south, which, after traversing the greatest part of Russia, and winding a course of 3000 English miles, falls into the Caspian Sea. It is remarkable, that in all this long course there is not a single cataract to interrupt the navigation. As it approaches to its mouth it divides itself into a greater number of arms than any known river in the world, and discharges itself into the Caspian Sea by more than 70 mouths. By means of this noble river, the city of Moscow maintains a communication, not only with all the southern parts of Russia, but even with Persia, Georgia, Tartary, and other countries bordering on the Caspian Sea. The Don, or Tanais, divides the most eastern part of Russia from Asia, and, in its course towards the east, approaches so near the Volga, that the czar Peter I, had undertaken to form a communication between them by means of a canal : this grand project, however, was defeated by the irruption of the Tartars. This river, exclusive of its turnings and windings, discharges itself into the Palus Mæötis, or sea of Asoph, about four hundred miles from its rise. The Borysthenes, or Dnieper, which is likewise one of the largest rivers in Europe, runs through Lithuania, the country of the Zaporog Cossacs, and that of the Nagaisch Tartars, and falls into the Euxine, or Black Sea, at Kinburn, near Oczakow : it has thirteen cataracts within a small distance. To these may be added the Duna, or Dvina, which empties itself at Riga into the Baltic; the Dwina, which has its source near Ustiaga, and, dividing itself into two branches near Archangel, there falls in to the White Sea; and the Neva, which issues from the lake Ladoga, and falls into the Gulf of Finland below Petersburg.

Though the plan of Peter I, to unite the Volga and the Don by a canal, failed in the execution, a communication between Astracan and Petersburg is effected by the canal of Vishnei Voloshok, which unites the Twertza and the Shlina. The canal of Ladoga, which runs along the edge of that lake, joins the Voskof to the Neva, extending the length of 67 miles, and communicating with the canal of Vishnei Voloshok. Another canal is cut from Moscow to the river Don.

Metals, Minerals....The principal mines of the Russian empire are in Siberia, but there are some likewise in the European part, in the mountains of Olonetz, where a gold mine was discovered in 1739 ; but it yielded but 57 pounds of gold in the year, scarcely repaying the labour of working it.

Cimate, soil, Agriculture....The severity of the climate, in Russia, properly so called, is very great. Dr. John Glen King, who resided eleven years in Russia, observes, that the cold in St. Petersburg, by Fahrenheit's scale, is, during the months of December, January, and February, usually from 8 to 15 or 20 degrees below 0 ; that is from 40 to 52 degrees below the freezing point; though commonly, in the course of the winter, it is for a week or ten days some 
degrees lower. The same writer remarks, that it is very difficult for an inhabitant of our temperate climate to have any idea of a cold so great. It is such, that, when a person walks out in that severe weather, the cold makes the eyes water, and that water, freezing, hangs in little icicles on the eye-lashes. As the common peasants usually wear their beards, icicies are frequently seen hanging to their chins like a solid lump of ice. In some very severe winters, sparrows, though a hardy species of birds, have been seen quite numbed by the interse cold, and unable to fly : and drivers, when sitting on their loacled carriages, have sometimes been found frozen to death in that posture. When the thermometer has stood at 25 degrees below $O_{\bar{y}}$ boiling water thrown up into the air by an engine, so as to spread, has fallen down perfectly dry, formed into ice. A pint-bottle of common water was found by Dr. King frozen into a solid piece of ice in an hour and a quarter. A bottle of strong ale has also been frozen in an hour and a half; but in this substance there was about a tea-cup full in the middle unfrozen, which was as strong and inflammable as brandy or spirits of wine. But, notwithstanding the severity of the cold in Russia, the inhabitants have such various means and provisions to guard against it, that they suffer much less from it than might be expected. The houses of persons in tolerable circumstances are so well protected, both without doors and within, that they are seldom heard to complain of cold. The method of warming the houses in Russia, is by an oven constructed with several flues; and they can regulate the warmth in their apartments by a thermometer with great exactness, opening or shutting the flues to increase or diminish the heat. When the Russians go out, they are clothed so warmly, that they almost bid defiance to frost and snow; and it is observable that the wind is seldom violent in the winter; but when there is much wind, the cold is exceedingly piercing.

One advantage which the Russians derive from the severity of their climate, is the preserving of provisions by the frost. Good housewives, as soon as the frost sets in for the winter, about the end. of October kill their poultry, and keep them in tubs packed up with a layer of snow between them, and then take them out for use as occasion requires: by which means they save the nourishment of the animal for seizeral months. Veal frozen at Archangel, and brought to Petersburg, is esteemed the finest they have; nor can it be distinguished from what is fresh killed, being equally juicy. The markets in Petersburg are by this means supplied in winter with all manner of provisions, at a cheaper rate than would otherwise be possible; and it is not a little curious to see the vast stacks of whole hogs, sheep, fish, and other animals which are piled up in the markets for sale. The method of thawing frozen provisions in Russia is by immerging them in cold water; for when the operation of thawing them is effected by heat, it seems to occasion a violent fermentation, and. almost a sudden putrefaction : but when produced by cold water, the ice seems to be attracted out of the body, and forms a transparent incrustation round it. If a cabbage, which is thoroughly frozen, be thawed by cold water, it is as fresh as if just gathered out of the gar. den; but if it be thawed by fire or hot water, it becomes so rancid and strong that it cannot be eaten.

The quickness of vegetation in Russia is nearly the same as has been described in Sweden and Denmark. The snow is the natural manure of Russia, where grain grows in plenty, near Poland, and in 
the warmer provinces. The bulk of the people, however, are miserably fed; the soit, indeed, produces a rast number of mushrooms for their sulisistence. Peter the Great, and his successors down to the prescnt, time, have been at incredible pains to introduce agriculture into their dominions; and though the soil is not every where proper for corn, yet its yast fertility in some provinces may make grain as common in Russia as it is in the southern countries of Europe. The easy communication by means of rivers, which the inland parts of that enpire have with each other, facilitates the conveyance of those products of the earth which abound in one province, to another which may be deficient in them.

VEGETARLE PRODUCTIONS, ANiMALS...Russia contains numerous and crtensive forests of pine, fir, larch, mountain-ash, \&c. Wheat, oats, barley, rye, flax, hemp, and a variety of other vegetables, and fruits of different kinds, are produced in Russia, cspecially in the southern prorinces. The animals of the northem parts of Russia do not greatly differ from those of Denmark and Sweden, to the account of whicl we refer the reacler. The lynx, famous for its piercing eye, is a native of this empire; it nakes prey of every creature it can master, and is said to be produced chicfly in the fir-tree forests. Hyznas, bears, wolves, foxes, and other creatures already described, afford their furs for clothing the inhabitants; but the fur's of the black foxes and ermine are more valuable in Russia than elsewhere. The dromedary and camel were formerly almost the only beasts of burden known in many parts of Russia. The czar Peter encouraged a breed of large horses for war and carriages; but those employed in the ordinary purposes of life are but small; as are their cows and sheep.

Ve know of few or no birds in Russia that have not been already described. The same may be said of fishes, except that the Russians are better provided than their neighbours with sturgeon, cod, salmon, and beluga. The latter resembles a sturgeon, and is often called the large sturgeon; it is from twelve to fifteen feet in length, and weighs from 9 to 16 and 18 hundred weight; its flesh is white and delicious. Of the roe of the sturgeon and the beluga the Russians make the famous caviare, so much esteemed for its richness and ?avour.

Curiosities, Natural and Ahtificial....Among the natural curiosities of Russia, the thirteen cataracts of the Dnieper may be enumerated, as also may other cataracts in the government of Olonetz. The prodigious rocks of ice, of several miles in extent and surprising height, which float in the ocean to the north of Russia, may likewise be reckoned among the natural curiosities of this country ; as among the artificial may be commemorated the palace of ice which the empress Anne caused to be built on the bank of the Neva in 1740 . This edifice, constructed of huge quadrats of ice hewn in the manner of freestone, was 52 feet in length, 16 in breadth, and 20 in height; the walls were three feet thick. In the several apartments were tables, chairs, beds, and all kinds of household furniture, of ice. In front of the palace, besides pyramids and statues, stood six cannons, carrying balls of six pounds weight, and two mortars of ice. From one of the former, as a trial, an iron ball, with only a quąrter of a pound of powder, was fired. off : the ball went through a two-inch board at sixty paces from the mouth of the cannon, and the piece of ice-artillery, with its carriage, remained uninjured by the explosion. The illumination of the icepalace at night had an astonishingly grand effect.

Tor. I. 
In the cabinet of natural history at Petersburgh, is a rhinoceros, dug up on the banks of the river Valui, with his skin, and the hair upon it, perfect.

The Russians are extremely fond of the ringing of bells, which are always to be heard tinkling in every quarter. The great bell of Moscow weighs, according to Mr. Coxe, " 432,000 pounds, and exceeds in bigness every bell in the known world. Its size is so enormous," says that writer, "that I could scarcely have given credit to the account of its magnitude, if I had not examined it myself, and ascertained its dimensions with great exactness. Its height is 19 feet, its circumference at the bottom twenty-one yards eleven inches, its greatest thickness twenty three inches." It was cast in the reign of the empress Anne : but the beam on which it hung being burnt, it fell, and a large piece is broken out of it; so that it lately lay in a manner useless. Mr. Bruce in his Memoirs mentions a bell at Moscow, founded in the reign of the czar Boris, nineteen feet high, twenty-three in diameter, and two in thickness, and weighing 336,000 pounds.

Population.... The population of Russia has been variously represented by different writers. Some years since it was generally estimated at about twenty millions. Mr. Bœtticher, a German writer, in his statistical tables, gives the population of the European part at $20,882,986$, and that of the whole empire at 25 millions. Mr. Tooke, in his view of the Russian Empire, states that by the lists of the revision of the empire, drawn up in 1783, as he assures us, with the greatest care and accuracy of examination, there were in the 41 governments of which Russia then consisted, male inhabitants 12,838,529.

Supposing an equal number of females, the amount will be $25,677,000$ Allowing for the Cossacs and unnumbered tribes and classes $1,720,000$

We shall have for the whole population in $1783-\overline{27,397,000}$ To this number he adds, for the increase of inhabitants in 12 years, - - - - - - - $3,000,000$ And for the new acquisitions since 1783, or the nine new governments - - - - - - - 5,755,000

Consequently the population of the Russian empire in 1795

was at least - - - - - - - $\quad 36,152,000$

He afterwards deduces, from a table of the births, deaths and marriages in the eparchies of the Greek church throughout the Russian einpire, in the year 1799 , faithfully extracted from the general returns received by the synod, that the whole number of inhabitants must have then amounted, on a moderate estimate, to upwards of forty millions.

Prafessor Storch, in his "Historico-statistical Picture of the Rus. sian Empire at the end of the Eighteenth Century," likewise rates the population of the whole of the Russian dominions at 36 millions of souls. In 1808, according to the tables of Hassel, the population of the whole Russian empire amounted to $41,404,000$, and in 1811 it was calculated at $47,440,000$.

National character, manners, customs....The Russians, properly so called, are in general a personable people, hardy, vigorous, and patient of labour, especially in the field, to an incredible degree. Their complexions differ little from those of the English or Scots; but the women think that an addition of red heightens theirbeauty, and paint 
is said to be as necessary an article in the dress of a Russian lady as linen. Their eye-sight seems to be defective, occasioned, probably, by the snow, which for the greater part of the year is continually present to their eyes. Their officers and soldiers always possessed a large share of passive valor; and in several of the late wars have shown themselves as active as any troops in Europe. They are imnlicitly submissive to discipline, let it be ever so severe; endure extreme hardships with great patience; and can content themselves with rery hard fare.

Before the days of Peter the Great, the Russians were in general barbarous, ignorant, mean, and much addicted to drunkenness. Not only the common people, but many of the boyars, or nobles, lived in a continual state of idleness and intoxication"; and the most complete objects of misery and barbarity appeared in the streets, while the court. of Mloscow was the most splendid of any upon the globe. The czar and the grandees dressed after the most superb Asiatic manner; and their magnificence was astonishing. The earl of Carlisle, in the account of his embassy, says, that he could see nothing but gold and precious stones in the robes of the czar and his courtiers. Peter saw the bulk of his subjects, at his accession to the throne, little better than beasts of burden, destined to support the pomp of the court. He forced his great men to lay aside their long robes, and dress in the European manner; and even obliged the laity to cut off their beards. At present a French or Engilish gentleman may live as comfortably and. sociably in Russia as in most other parts of Europe. Their polite assemblies, since the accession of the late empress, have been put under proper regulations; and few of the ancient usages remain. It is, how ever, to be observed, that, notwithstanding the severities of Peter and the prudence of succeeding governments, drunkenness still continues among all ranks; nor are even priests or ladies ashamed of it on holidays.

The Russians ivere formerly noted for so strong an attachment to sheir native soil, that they seldom visited foreign countries. This, however, was only the consequence of their pride and ignorance; for Russian nobility, besides those who are in a public character, are now found at every court in Europe. Her late imperial majesty interested herself in the education of youns men of quality, in the knowledge of the vorld, and foreign services, particularly that of the British fleet.

It is said that the Russian ladies were formerly as submissive to their husbands in their families as the latter are to their superiors in the field; and that they thought themselves ill treated if they were not often reminded of their duty by the discipline of a whip, manufactured by themselves, which they presented to their husbands on the day of their marriage. Their nuptial ceremonies are peculiar to themselves; and formerly consisted of some very whinsical rites, many of which are now disused. When the parents have agreed upon a match, though the parties perhaps have never seen each other, the bride is critically examined by a certain number of females, who are to correct, if possible, any defect they find in her person. On her wedding day she is crowned with a garland of wormwood; and after the priest has tied the nuptial knot, his clerk or sexton throws a handful of hops upon her head, wishing she may prove as fruitful as that plant. She is then led home, with abundance of coarse and indeed indecent ceremonies, which are now wearing off eren 
amongst the lower ranks; and the barbarous treatment of wives by their husbands, which extended even to scourging or broiling them to death, is either guarded against by the laws of the country, or by particular stipulations in the marriage contract.

The nobility, and almost all the people of quality, dress after the German fashion; and the ladies, even in the remotest parts of the country, appear more modishly attired than would easily be imagined. The peasants, burghers, and most of the mercantile class, still adhere to the national dress. They let their beards grow, which are commonly long and bushy; their hair is cut and combed. They wear a short shirt without any sort of collar, and loose trousers, over which the shirt usually hangs, and is girt around the waist with a string. Over the shirt they wear a short breast-cloth, or vest, furnished with buttons, and a coat girt about with a sash that passes twice round the body. In winter the peasants are universally habited in a jacket made of sheep's hide, with the wool inwards; the covering for the head, is a square crowned red cap, with a circular edge of black wool round the rim, which is very becoming, and appears shadowing the eyes. On their feet they wear sandals made of the bark of the birch tree. Leg-wrappers are worn instead of stockings, especially by the lower class of people; these are tied about their feet and legs with packthread, so as to make them look very thick. 'The women wear a sarahian, or vest without sleeves, which is close about the neck, and sits tight to the body down to the hips: from the hips it spreads without gathers, and reaches down to the shoes. On the facing it is garnished with a thick row of little buttons, from the top to the very bottom : it is, however, girt with a sash, to which the bunch of keys is suspended. The girls in general wear their hair uncovered more than the women : the former plait it in three plaits, with ribbons and beads tied to the points of them. In some provinces they wear a band across the forehead bedizened with pearls and beads of various colours; in others they wear caps in the form of an upright crescent. In the vicinity of Moscow, and in several of the neighbouring governments, the cap has a stiff flap before, like a jockey-cap, and is decorated with pearls and various coloured stones. The dress of the female peasants of the Valdai consiets of a shift with full sleeves, and a short petticoat, with coloured stockings. Over this, in winter, they wear a pelisse of lamb's wool, as white as the snow around them, lined with cleth, and adorned with gold buttons and lace. Generally speaking, the traveller may pass over a vast extent of territory without noticing any change in the costume.

In great towns the funeral obsequies of people of rank are conducted in much the same manner as in other countries of Europe ; but the lower classes still retain some peculiar ceremonies. After the dead body is dressed, a priest is hired to pray for the soul, to purify the corpse with incense, and to sprinkle it with holy water while it remains above ground, which, among the better sort, it generally does for eight or ten days. When the body is carried to the grave, which is done with many gesticulations of sorrow, the priest produces a ticket, signed by their bishop and another clergyman, as the deceased's passport to heaven. This is put into the coffin, between the fingers of the corpse; after which the company return to the deceased's house, where they drown their sorrow in intoxication, which lasts, among the better sort, with a few intervals, forty days. During that time a priest every day recites prayers over the grave 
of the deceased; for though the Russians do not believe in purgatory, yet they imagine that their departed friend inay be assisted by prayer in his long journey to the place of his destination after this life.

At the new year is usually held a feast of the dead, on which every one visits the grave of his relations, lays some victuals upon it, and hears mass, in payment for which the priest gets the victuals. Profligates, such as have come to a miserable end, and all who have died without the sacrament were formerly thrown, without inhumation, into a hut for that purpose, and on the Thursday before Whitsuntide were buried by the clergy, who said masses for their souls, attended by the inhabitants of the place. At present greater indulgence is shown to these poor wretches.

The power of the Russians at imitation is said to be very great. Clarke says, the meanest Russian slave has been found adequate to the accomplishment of the most intricate and most delicate works of mechanism; to copy, with his single hand, what has demanded the joint labours of the best workmen in France or England. A barrenness of invention in matters of art, but great reading and correctness of imitation is a characteristic mark of nations with whom the arts are in their infancy.

The true manners of the people are not seen in Petersburg, nor even in Moscow, by entering the houses of the nobility only. The real Russian rises at an early hour, and breakfasts on a dram with black bread. His dinner at noon consists of the coarsest and most greasy viands, the scorbutick effects of which are counteracted by silted cucumbers, sour cabbage, the juice of his vaccinium, and his nectar quass. He sleeps always after eating, and goes early to his bed. The principal articles of diet are the same every where, grease and brandy. In their houses and persons they are remarkably filthy.

Cities, chinf towns, EDIFICEs....Petersburg, now the capital of Russia, is situate on both sides of the river Neva, between the lake of Ladoga and the bottom of the Gulf of Finland. In the year, 1703, this city consisted of a few small fishing huts, on a spot so waterish and swampy, that the ground was formed into nine islands, by which its principal quarters are still divided. Without entering into too minute a description of this wonderful city, it is sufficient to say that it extends about six miles every way, and contains every structure for magnificence, the improvements of the arts, revenue, navigation, war, commerce, and the like, that is to be found in the most celebrated cities in Europe.

As Petersburg is the emporium of Russia, the number of foreign ships trading to it in the summer time is extremely great. In winter 3000 one-horse sledges are employed for passengers in the streets. It is supposed that there are 170,000 inhabitants in this city; and it is ornamented with thirty-five great churches; for in it alnost every sect of the Christian religion is tolerated. It also contains five palaces, some of which are superb, particularly that which is called the New Summer Palace, near the Triumphal Port, which is ald elegant piece of architecture. There is likewise a foundling-hospital, assistant to the noble one at Moscow, where the mother may come to be delivered privately; after which she leaves the child to the state, as a parent more capable of promoting its welfare.

This magnificent city is defended on the side next the sea by the fortress of Cronstadt, which, considering the difficulty and danger of 
mavigating a large naval force through the Gulf of Finiand, is suffcient to guard it on that side from the attempts of any enemy. Petersburg is the capital of the province of Ingria, one of Peter the Great's conquests from the Swedes. In the neighbourhood of this city are numerous country-houses and gardens.

The city of Moscow, or Moskoa, formerly the capital of this great empire, stands on the river from which it takes its name. Though its streets are not regular, it presents a very picturesque appearance; for it contains such a number of gardens, groves, lawns, and streams, that it seems rather to be a cultivated country than a city. The ancient magnificence of this city would be incredible, were it not attested by the most unquestionable authors : but we are to make great allowances for the uncuitivated state of the arljacent provinces, which might have made it appear with a greater lustre in a traveller's eyes. Busching speaks of it as the largest city in Europe; but that can be only meant as to the ground it stands on, computed to be sixteen miles in circumference. It is generally admitted, that Moscow contains 1600 churches and convents, and forty-three palaces or squares. The merchant's exchlange, according to Busching, contains about 6000 fine shops, which display a vast parade of commerce, especially to and from China. No city exhibits a greater contrast than Moscow, of magnificence and meanness in building. The houses of the inhabitants in general are miserable timber booths; but their palaces, churches, convents, and other pubiic edifices, are spacious and lofty. The Kremlin, or grand imperial palace, is mentioned as one of the most superb structures in the world: it stands in the interior circle of the city, and contains the old imperial palace, pleasure-house, and stables, a victualling-house, the palace which formerly belonged to the patriarch, the cathedral, five convents, four parish-churches, the arsenal, with the public colleges, and other offices. All the churches in the Kremlin have beautiful spires, most of them gilt or covered with silver; the architecture is in the Gothic taste; but the insides of the churches are richly ornamented; and the pictures of the saints are decorated with gold, silver, and precious stones. The cathedral has nine towers, covered with copper, double gilt, and contains a silver branch with forty-eight lights, saicl to weigh 2800 pounds.

The most remarkable edifice as affording a striking monument of national manners, is the church of St. Basil, near the Kremlin. It is a complete specimen of the Tartar taste in building; and was erected by Ivan Basilovich the Second in 1538. To add to the singularity of its history, it was the workmanship of Italian architects. Its numerous and heavy cupolas, surmounted by gilded crucifixes, exhibit a striking contrast of colour and ornament. Pious individuals bequeath legacies towards the perpetual gilding or painting of this or that dome, according to their various fancies; so that it is likely to remain a splendid piece of patch-work for many generations.

The foundling hospital at Moscow is an excellent institution. It was founded by the late empress, and is supported by voluntary contributions, legacies, and other charitable endowments. It is an immense pile of building, of a quadrangular shape, and will contain 8000 foundlings. They are taken great care of, and at the age of fourteen have the liberty of choosing any trade; for which purpose there are different species of manufactures established in the hospital.

Moscow, when lord Carlisie was the English ambassador there, in 
the reign of Charles II, was twelve miles in compass, and the number of houses was computed at 40,000. According to Voltaire, when he wrote, it was twenty miles in circumference, and its inhabitants amounted to 500,000 . Mr. Coxe confirms the account of the circumference of this city, but thinks the estimate of its population much exaggerated: according to an account which was given to him by an English gentleman, which he received from a lieutcnant of the police, and which he says may be relied on, Moscow contains within the ramparts 250,000 souls, and in the adjacent villages 50,000. Trvo French travellers, who were there in 1792, say its population consists of from 300,000 to 328,000 souis, in summer; but in winter is increased to nearly 400,000 .

In 1812 this great city was almost totally destroyed by fire, lighted by its own inhabitants, to prevent its becoming a shelter to their invaders. The third day after the entrancc of the French troops, a violcnt wind arose, and the conflagration became general. In less than an hour, the whole extent of the capital for miles seemcd a sireet of flame. All the immense tract of land above the rivcr, which used to be covered with houses, was one sea of fire; and the sky was hidden by the tremendous volumes of smoke which rolled ovcr the city. After the flames were extinguished, Moscow was no longcr to be recognised. Nothing remained of this oncc magnificent city, but a vast plain covcred with ruins and smoking ashes! Every whcre the dilapidated strcets ivere choked up with human bodies, and the carcases of dead horses. Many of the streets have since becn rcbuilt upon the modern European plan, but the gaudy magnificcnce of Moscow is gone forever.

Archangel, situate at the mouth of the river Dwina, on the White Sea, was, before the time of Peter the Great, the only port by which Russia communicated with the rest of Europe. It is about three English miles in length, and one in breadth, built all of wood, excepting the exchange, which is of stone. Notwithstanding the decrease of the trade of Archangel since the building of Petersburg, it still exports a considerable quantity of merchandise.

Riga, a strong town, formerly the capital of Livonia, is, ncxt to Petersburg, the most commercial place in the Russian empire. It contains about 30,000 inhabitants. There is a floating wooden bridge over the Dvina 2600 feet long, and 40 broad, which, in winter, when the ice sets in, is removed, and in summer replaccd.

MARUFACTURES, COMMERCE... Great quantities of salt are manufactured in Russia, from mines, lakes and springs. The salt mines in the vicinity of the Tlek in the district of $U \mathrm{fa}$ produces $8,140,000$ pound annually. There are also large salt mines on the Vilni, in Irkutsk. The salt lakes are the Elion in Saratof, yielding annually 5,700,000 pound; those near Astracan; those in Kolhyran; the Fauridan; the Caucasian, and the Irkutskian. The richest salt springs are those of Solikamsk on the Kama, yielding annually 5,680,000 pound; and those of Starraya-Rura, on the Lovat.

The manufactures of isinglass, oil, and soap, are conducted in Russia with considerable activity and success. There are also manufactures of linen, silk, paper, and tobacco. Coarse cloths, carpets, and hats, are likewise made in Russia; and the lcather which takes its name from the country is a kind of staple commodity.

A pound is equal to $35,3.4$ American pounds. 
The productions and exports of Russia, in general, are many, and very valuable; viz. furs and peltry of various kinds, red leather, linen and thread, iron, copper, sail cloth, hemp and flax, pitch and tar, wax, honey, tallow, isinglass, linseed oil, pot-ash, soap, feathers, train-oil, hogs' bristles, musk, rhubarb, and other drugs, timber, and also raw silk from China and Persia. The Ukraine may be called the granary of the empire: the best corn, hemp, flax, honey, and wax, come from this fertile province, and 10,000 head of horned cattle are annually sent from its pastures into Silesia and Saxony.

The annual produce of the copper mines is about $7,350,000 \mathrm{lbs}$. Upwards of 5,000,000 dollars worth of iron is exported yearly. Timber and boards exported have been valued at $\$ 1,500,000$ per annum. The value of hemp exported in 1793 was $\$ 6,066,615$; flax $\$ 4,104,100$, with great quantities of hemp and flaxseed, and nearly $2,000,000$ gallons oil. The value of flax exported in 1802 amounted to nearly $\$ 6,000,000$. The exports of sail-cloth in the same year was estimated at $\$ 3,537,856$. In 1803 there were exported from the ports on the Baltic and Archangel 34,500 tons of tallow, worth upwards of $\$ 9,500,000$. The produce of neat cattle exported the same year was $\$ 3,118,571$.

Wheat, rye, barley and oats, tlie same year, exported to the amount: of $\$ 11,496,245$.

The balance of trade in favour of Russia, is said to amount to $\$ 5,000,000$ per annum.

Russia carries on a commerce over land, by caravans, to China, chiefly in furs: and they bring back from thence tea, silk, cotton, gold, Sxc. To Bochary, near the river Oxus in Tartary, Russia sends her own merchandise, in return for Indian silks, curled lamb-skins, and ready money; and also to the annual fare at Samarcand: she likewise tracles to Persia by Astracan, across the Caspian Sea, for raw and wrought silk. The late empress, in 1784, issued an edict, permitting all foreigners to carry on a free trade by sea and land with the several countries bordering on the Euxine, which have been lately annexed to the empire. The same privileges, religious and civil, are allowed to them in the ports of Cherson, Sebastopolis, and Theodosia (formerly Caffa) in the province of Taurida, as in Peters. burg.

Government.... The sovereign of the Russian empire is absolute and despotic in the fullest extent of those terms, and master of the lives and properties of all his subjects, who, though they are of the first nobility, or have been highly instrumental in promoting the welfare of the state, may, notwithstanding, for the most trifling offence, or even for no offence at all, be seized upon and sent to Siberia, or made to drudge for life upon the public works, and have all their goods confiscated, whenever the sovereign or his ministers shall think proper. Persons of any rank may be banished into Siberia, for the slightest political intrigue; and their possessions being confiscated, a whole family may at once be ruined by the insinuations of an artful courtier.

Laws.... The system of civil laws established in Russia is very imperfect, and in many instances barbarous and unjust; being an assemblage of laws and regulations drawn from most of the states of Europe, ill digested, and in many respects not at all adapted to the genius of the Russian nation. But the late empress made some attempts to reform the laws, and put them upon a better footing. The 
courts of justice were in general very corrupt, and those by whom it was adninistered extremely ignorant; but the judicious reyulations of Catharine II, fixed a certain salary to the office of judge, which before depended on the contributions of the unhappy clients; and this the poor were without hope or remedy. Many other improvements have been made in the legal code by the present emperor.

The Russians are remarkable for the severity and variety of their punishments, which are both inflicted and endured with a wonderful insensibility. - Peter the Great used to suspend the robbers upon the Volga, and other parts of his dominions, by iron hooks fired to their ribs, on gibbets, where they writhed themselves to death, hundreds at a time. The single and double knout have been inflicted upon iaclies as well as men of quality. Both of them are excruciating: but in the double knout the hands are bound behind the prisoner's back, and the cord being fixed to a pulley, lifts him from the ground, with the dislocation of both his shoulders; and then his back is in a manner scarified by the executioner with a hard thong cut from a wild ass's skin. This punishment has been so often fatal, that a surgeon generally attends the patient to pronounce the moment it should cease. It is not always the number of the strokes, but the method of applying them, which occasions the death of a criminal; for the execuioner can lill him in three or four strokes, by striking him upon the ribs; though persons are sometimes recovered, in a few weeks, who have received three hundred strokes moderately inflicted. The boring and cuttiug out of the tongue are likewise practised in Russia; and even the empress Elizabeth, though she prohibited capital punishments, was forced to give way to the supposed necessity of those tortures.

According to the strict letter of the law, there are no capital pu. nishments in Russia, except in the case of high treason: but there is much less humanity in this than has been supposed. For there are many felons who expire under the knout; and others die of fatigue in their journies to Siberia, and from the hardships they suffer in the mines; so that there is reason to believe that no fewer criminals suffer death in Pussia than in those countries where capital punishments are authorised by the laws.

Felons, after receiving the knout, and having their cheeks and forehead marked, are sometimes sentenced for life to the public works at Cronstadt, Vishnei Volotchok, and other places: but the common practice is to send them into Siberia, where they are condemned for life to the mines at Nershink. There are, upon an average, from 1600 to 2000 convicts at these mines. The greatest part are confined in barracks, excepting those who are married : the latter being perinitted to build huts near the mines, for themselves and families. The prohibition of the torture does honour to the late empless Catharine II.

Revenue... The revenue of Pussia arises from the capitation tax, or head-rnoney, the tax on the capital of merchants, the produce of the imperial domains, the customs, the stamp-duties, the tax on kabaks or public-lnouses, the salt-trade, the mines, the mint, and other raxes. It amounts, according to the latest and most authentic accounts, to about $\$ 60,000,000$.

When this sum is considered relatively, that is, according to the high value of money in that empire, compared to its low value in Great Britain, it will be found that the national revenue of Russia fas?

Vol. I. 
exceeds that of most other countries in Europe, and is amply suff.cient, not only to answer all the expenses of government, but also to afford considerable sums for the benefit and embellishment of the em. pire, though the late empress remitted many taxes, and abolished several monopolies. With the further increase of commerce, it will naturally keep equal pace.

According to Eœtticher, however, Russia has a national debt of nearly nine millions sterling, for the greater part of which inierest is paid at the rate of 8 per cent. The annual expenses of the'state, according to the same author, amount only to $5,600,000 l$.

ARMY AND NAVY ...The army is generally calculated to amount to from 400 to 450,000 men : according to Busching, it amounted, in 1772 , to above 600,000 ; and according to an estimate taken in 1784, it then anounted to 368,901 . Mr. Tooke, in his View of the Russian Empire, estimates the whole military force of Russia at 600,000 men, of whom, he says, we may reckon at least 500,000 effective soldiers in actual service.

The Russian armies are raised with little or no expense, and, while in their own country, subsist chiefly on provisions fur'nished them by the country people, according to their internal valuation. The pay of a soldier scarcely amounts to thirty shillings yearly; in garrison he receives only five rubles yearly. The pay of a sailor and a gunner is a ruble a month, and they are found with provisions when on shore.

The Russian navy in the harbours of Cronstadt, Revel, and Archangel, in the yaar 1792 , consisted of 50 ships of the line, of which 8 were of 110 guns, and the rest of 74 and $66 ; 27$ frigates of 28,32 , and 38 guns; 50 galleys, 300 gun-boats, 16 fire-ships, and other smaller vessels; besides a fleet in the Black Sea, consisting of 17 ships of the line, and a still greater number of frigates, corvettes, \&c. Twenty thousand sailors are kept in constant pay and service, either on board the ships or in the dock-yards. The harbour at Cronstadt, seven leargues from Petersburg, is defended on one side by a fort of four bastions, and on the other by a battery of 100 pieces of cannon. The canal and large basin will contain near 600 sail of ships.

ROYAL TITLR, NODILITY, ORDERS OF KNIGHTHOOD...The sovereign of Russia is called the Czar, or more properly Tzar, or if an empress Tzarina, a Slavonic word signifying king or sovereign. He takes the title in his ukases or royal decrees, and other public acts, of "Emperor and Autocrator of all the Russias." The term autocrator is a compound Greek word signifying self-vuler or sole ruler, and is employed to express the Russian word samoderjetz; but Mr. Tooke thinks that it does not come up to its meaning, which, perhaps, would be more truly exprcssed by "uncontrollable ruler." The fult title of the Russian monarchs is of considerable length, and enumerates a great number of the governnients of Russia, and the countries subject to their sway.

The distinctions of rank form a considerable part of the Russian constitution. The ancient nobility of Russia were divided into knezes or knazes, boyass, and vaivods. The knezes were sovereigns upon their own estates, till these were reduced by the czar: but they still retain the name. The boyars were nobility under the knezes; and the vaivods were governors of provinces. Those titles, how: ever, so often revived the ideas of their ancient power, that the late 
empresses introduced among their subjects the titles of counts and princes, and the other distinctions of nobility that are common to the rest of Europe.

The Russian orders of knighthood are six. The order of St. Andrew was instituted by Peter the Great in 1698, to animate his nobles and officers in his wars against the Turks. He chose $\mathrm{St}_{\text {. }}$ Andrew for his patron, because by tradition he was the founder of Christianity in the country. The knights are persons of the first rank in the empire. The order of St. Alexander Newski wis also instituted by Peter the Great, and confirmed by the empress Catharine I, in the year 1725. The order of St. Catharine was instituted by Peter the Great, in honour of his empress, for her assistance on the banks of the Pruth. The order of St. George, instituted by the empress Catharine II, in favour of the military officer's in her service. The order of St. Vlodimir was instituted October 3d, 1782, by the late empress, in favour of those who serve in a civil capacity. The order of St. Anne of Holstein, in memory of Anne, daughter of Peter the Great, was introduced into Russia by Peter III.

ReLigion.... The established religion of Russia is that of the Greek church, the tenets of which are by far too numerous and complicated to be discussed here: but the great article of faith by which that church has been so long separated from the Latin or Catholic church, is the doctrine that the Holy Spirit does not proceed from the Father and the Son, but from the Father only. They deny the pope's supremacy; and thongh they disclaim image-worship, they retain many idolatrous and superstitious customs. Their churches are full of pictures of saints, whom they consider as mediators. They observe a number of fasts and lents, so that they live half the year very abstemiously; an institution which is extremely convenient for the soil and climate. They have many peculiar notions with regard to the sacraments. They oblige their bishops, but not their priests, to celibacy. Peter the Great showed his profound knowledge in government in nothing more than in the reformation of his church. $\mathrm{He}$ broke the dangerous powers of the patriarch and the great clergy. He declared himself the head of the church, and preserved the subotclinations of metropolitans, archbishops, and bishops.' Their priests have no fixed income, but depend, for subsistence, upon the benevolence of their flocks and hearers. Peter, after establishing this great political reformation, left his clergy in full possession of all their idle ceremonies; nor did he cut off their beards : that impolitic attempt was reserved for the emperor Peter III, and greatly contributed to his fatal catastrophe. Before his time, an incredible number of both sexes were shut up in convents:' nor has it been found prudent, entirely to abolish those societies. The abuses of them, however, are in a great measure removed; for no male can become a monk till he is turned of thirty; and no female a nun till she is fifty; and even then not without permission of their superiors.

The conquered provinces, as already observed, retain the exercise of their own religion; but such is the extent of the Russian empire that many of its subjects are Mahometans, and more of them no better than Pagans, in Siberia and the uncultivated countries. Many illjudged attempts have been made to convert them by force, which have only tended to confirm them in their infidelity. On the banks of the river Sarpa, is a fourishing colony of Moravian brethren, to which the founders have given the name of Sarepta; the beginning of 
the settlement was in 1765 , with distinguished privileges from tho imperial court.

Literature... The Russians have hitherto made but an inconsideratide figtire in the republic of letters: but the great encouragement lately given by their sovereigns, in the institution of academies anc other literary societies, has produced sufficient proofs that they are no way deficient in intellectual abilities. The papers exhibited by then at their academical meetings have been favourably received all over Europe; especiaily those that relate to astronomy, the mathematics, and natural philosophy.

Universities....Three colleges were founded by Peter the Great at Moscow; one for classical learning and philosophy, the second for mathematics, and the third for navigation and astronomy; but they appear to have been neglected and suffered to fali to decay. The empiess Catharine II, also founded a university at Petersburg, and invited some of the most learned foreigners in every faculty, who are provided with grood salaries; and also a military academy, where the young nobility and oficers' sons are taught the art of war. It ought also to be ninetioned, to the honour of the same royal benefactress, that she founded a number of schools for the education of the lower classes of her subjects, throughout the best inhabited parts of the empire.

LANGUAGE...The Russian language is an improved dialect of the Slavonian, which, with its characters, is still in use in the offices of religion. The Russian alphabet has thirty-six letters, though some make the number amount to forty-one; but of these several are only notes of accent in pronunciation. They have a great resemblance in form to the Greek characters. The language is copious, expressive, anci requires great pliancy in the organs of utterance. The Pater Noster in Russian is as follows: Otshe nash, eje esi na nebesech; da soyatitsya imya troye da firiedet tzarstuye tvoye; da boodet volya troya, yako no nebese ee na zemle chleb nash nasooslinie dajd nam dnes; ee osiavecnam dolje nasha yakoje ee me ostavlyaem doljneckom nashim: ee ne vovede nas vo iskooshenie no eczbave nas ot loocavago; yako tvoc est $t z a r s i v o$, ee seela, ce slava, vo vekee vekov. Ameen.

Antrquities....Russia affords very few remains of anticuity : the catacombs or burying places near Kiow, which are a kind of subterranean labyrinths of considerable extent; and some brass idols of the pagan ancestors of the Russians, occasionally found in tombs, containing likewise weapons and ornaments; are perhaps all that can deserve notice.

History....We cannot, with the smallest degree of probability, carry our conjectures, with regard to the history of Russia, higher than the introciuction of Christianity, which happened about the tenth century, when the princess of this country, called Olga, is said to have been baptised at Constantinople, and refused the hand of the Greek emperor, John.Zimisces, in marriage. Photius, the famous Greek patriarch, sent priests to baptise the Russians, who were for some time subject to the see of Constantinop!e; but the Greek patriarchs afterwards resigned all their authority over the Russian church; and its bishops erected themselves into patriarchs, who were in a manner independent of the civil power. It is certain, that, till the year 1450 , the princes of Russia were but very little considered, being chiefly subjected by the Tartars. About this time John Basilides, or Ivan Vassillievitch, conquered the Tartars, and, among others, the 
duke of Great Novgorod, from whom he is said to have taken 300 cart loads of gold and silver. His prosperous reign of forty years gave a. new aspect to Russia.

His grandson, the famous John Basilowitz, or Vassillievitch II, having cleared his country of the intruding Tartars, subdued the kingdoms of Kasan and Astracan Tartary, in $\Lambda$ sia, and annexed them to the Russian dominions. By his cruelty, however, he obliged the, inhabitants of some of his finest provinces, particularly Livonia and Esthonia, to throw themselves under the protection of the Poles and Srredes. Before the time of this John II, the sovereign of Russia took the title of Velike Knez, "great prince," great lord, or great chief; which the Christian nations afterwards rendered by that of great duke. The title of Tzar, or, as we call it, Czar (a word which signifies king, or emperor) was added to that of the Russian sovereigns. Upon the death of John Basilowitz, the Russian succession was filled by a set of weak cruel princes; and their territories were torn in pieces by civil wars. In 1597, Boris Godonow assassinated Demetri, or Demetrius, the lawful heir, and usurped the throne. A young monk took the name of Demetrius, pretending to be that pririce who had escaped from his murderers; and with the assistance of the Poles, and a considerable party (which every tyrant has against him) he drove out the usurper and seized the crown himself. The imposture was discovered as soon as he came to the sovereignty, because the people were not pleased with him; and he was murdered. Three other false Demetriuses started up, one after another.

These impostures prove the despicable state of ignorance in which the Russians were immerged. The country became by turns a prey to the Poles and the Swedes, but was at length delivered by the good sense of the boyars, impelled by their despair, so late as the year 1613. The independency of Russia was then on the point of being extinguished. Uladislaus, son of Sigismund II, of Poland, had been declared czar; but the tyranny of the Poles was such, that it produc. ed a general rebellion of the Russians, who drove the Poles out of Moscow, where they had for some time defended themselves with unexampled courage. Phillaretes, archbishop of Rostow, whose wife was. descended from the ancient sovereigns of Russia, had been sent ambassador to Poland by Demetrius, one of the Russian tyrants, and there was detained prisoner, under pretence that his countrymen had rebelled against Uladislaus. The boyars met in a body; and such was their veneration for Philaretes, and his wife, whom the tyrant had shut up in a nunnery, that they elected their son Michael Feodorowitz, of the house of Romanoff, a youth of fifteen years of arge, to be their sovereign. The father being exchanged for some Polish prisoners, returned to Russia; and being created patriarch by his son, reigned in the right of Micliael with great prudence and success. He defeated the attempts of the Poles to replace Uladislaus upon the throne, and likewise the claim of a brother of Gustavus Adolphus. The claims of the Swedes and Poles upon Russia occasioned a war between those two nations, which gave Michael a kind of breatling-time; and he made use of it for the benefit of his subjects. He reigned thirty-three years; and by his wisclom, and the rnildness of his character, restored ease and tranquillity to his subjects.

Alexius succeeded his father Michael. He appears to have been a prince of great genius. He recovered Smolensko, Kiow, and the 
Ukraine but was unfortunate in his wars with the Swedes. When the grand-seignor, Mahomet IV, haughtily demanded some possessions from him in the Ukraine, his answer was, "that he scorned to submit to a Mahometan dog, and that his cimeter was as good as the grand-seignor's sabre." He promoted agriculture ; introduced into his empire arts and sciences, of which he was himself a lover; published a code of laws, some of which are still used in the administra. tion of justice; and greatly improved his army by establishing dis. cipline. This he effected chiefly by the aid of foreigners, most of whom were Scotch. He subdued a chief of the Don Cossacs, named Stenka Rasin, who endeavoured to make himself king of Astracan; and the rebel, with 12,000 of his adherents, were hanged on the high roads. He introduced linen and silk manufactures into his dominions; and, instead of putting to death or enslaving his Lithuanian, Polish, and Tartar prisoners, he sent them to people the banks of the Volga and the Kamma. Theodore succeeded his father Alexius in 1667. He reigned seven years; and having on his death-bed called his boyars around him, in the presence of his brother and sister, Ivan and Sophia, and of Peter, who was afterwards so celebrated, and who was his half-brother, he said to them, "Hear my last sentiments; they are dictated 'by my love for the state, and by 'my affection for my people. The bodily infirmities of Iran necessarily must affect his mental faculties; he is incapable of ruling an empire like that of Fyissia; he cannot take it amiss if I recommend to you to set him aside, and let your approbation fall on Peter, who, to a robust constitution, joins great strength of mind, and marks of a superior understancling." "But this wise destination extremely offended the princess Sophia, who was a woman of great ambition, and who, after the death of Theodore, found means to excite a violent serlition among the Strelitzes, who then formed the standing army of Russia. Their excesses surpassed all description; but Sophia, by her management, replaced her brother Ivan in his birth-right, and exercised the government herself with the greatest severity and inhumanity; for all the Russian grandees who were related to Peter, or whom she supposed to favour him, were put to cruel deaths. The instances given of her barbarous administration are shocking to humanity. At length, in 1682, the two princes, Ivan and Peter, were declared joint sovereigns, and their sister their associate co-regent. Her administration was bloody and tumultuous; nor durst she venture to check the fury of the Strelitzes, and other insurgents. Finding this debility in her own person, she intended to have married prince Basil Galitzin, who is said to have been a man of sense and spirit, and some learning. Being placed at the head of the army by Sophia, he marched into Crim Tartary; but Peter now was about 17 years of age, and asserted his right to the throne. Sophia and Ivan were then at Moscow; and upon Peter's publishing aloud that a conspiracy had been formed by his sister to murder him, he was joined by the Strelitzes, who defeated or destroyed Sophia's party, and forced herself to retire to a monastery. Galitzin's life was spared; but his great estate was confiscated, and the following curious sentence was pronounced as his punishment. "Thou art commanded by the most clement czar to repair to Karga, a town under the pole, and there to continue the remainder of thy days. His majesty, out of his extreme goodness, allows thee three pence per day for thy subsistence. This left Peter with no other competitor, in the year 1689 , than the mild and easy 
Iran; and upon his death, which happened in 1696, Peter reigned alone and cruelly provided for his own future security by the execution of above s000 Strelitzes.

Peter, though he had been but very indifferently educated through the jealousy of his sister, associated himself with the Germans and Dutch ; with the former for the salke of their manufactures, which he early introduced into his dominions; and with the latter for their skill in navigation, which he practised himself. His inclination for the arts was encouraged by his favourite Le Fort, a Piedmontese ; and general Gordon, a Scotchman, disciplined the czar's own regiment, consisting of 5000 foreigners; while Le Fort raised a regiment of 12,000, among whom he introduced the French and German exercises of arms, with a view of employing them in curbing the insolence of the Strelitzes. Peter, after this, began his travels, leaving his military affairs in the hands of Gordon. Fife set out as an attendant upon his own ambassadors; and his adventures in Holland and England, and other courts are too numerous, and too well known, to be inserted here. By working as a common ship-carpenter at Deptford and Saardam, he completed himself in ship-building and navigation; and through the excelient discipline introduced among his troops by the foreigners, he not only over-awed or crushed all civil insurrections, but all his enemies on this side of Asia; and at last he even exterminated, excepting two feeble regiments, the whole body of the Strelitzes. He rose gradually through every rank and service both by sea and land; and the many dcfeats which he received, especially that from Charles XII, at Narve, stimulated him to new exertions. The battles he lost rendered him at length a conqueror, by adding experience to his courage; and the generous friendship he showed to Augustus king of Poland, both before and after he was dethroned by the king of Sweden, redounds greatly to his honour. He had no regard for rank distinct from merit ; and he at last married Catharine, a young Lithuanian woman, who had been betrothed to a Swedish soldier; because, after a long cohabitation, he found her possessed of a soul formed to execute his plans and to assist his councils. Catharine was so much a stranger to her own country, that her husband afterwards discovered her brother, who scrved as a common soldier in his armies. But military and naval triumphs, which succeeded one another after the battle of Pultowa in 1709, with Charles XII, were not the chief glory of Peter's reign. He applied himself with equal as. siduity to the cultivation of commerce, arts, and sciences ; and made such acquisitions of dominion, that he may be said at the time of his death, which happened in 1725 , to have been the most powerful prince of his age, but more feared than beloved by his subjects.

Peter the Great was unfortunate in his eldest son, who in Russia is entitled the Czarowitz, and who, marrying without his consent, entered, as his father alleged, into some dangerous practices against his person and government; for which he was tried and condemned to death. Under a sovereign so despotic as Peter was, it is difficult to determine on the justice of the charge. It was undoubtedly his will that the young prince should be found guilty : and the very reading of the sentence appears to have been fatal to him. It is said, that, as soon as sentence of death was pronnunced upon the prince, in which were the following words, "The divine, ecclesiastical, civil, and military law, condemns to death, without mercy, all those whose attempts arainst their father and their sovercign are manifest," he fell into the 
most violent convulsions, from which it was with great difficulty that he regained a little interval of sense, during which he desired his father would come to see him; when he asked his pardon and soon after died. According to other accounts, he was secretly executed in prison, and marshal Weyde was the person who beheaded him. After this event, in 1724 , Peter ordered his wife Catharine to be crowned, with the same magnificent ceremonies as if she had been a Greek empress, and to be recognised as his successor; which she accordingly was, and mounted the Russian throne upon the decease of her husband. She died, after a glorious reign, in 1727, and was succeeded by Peter II, a minor, son to the czarowitz. Many domestic revolutions happened in Russia during the short reign of this prince; but none more remarkable than the disgrace and exile of prince Menzikoff, the favourite general in the two late reigns, and esteemed the richest subject in Europe. Peter II, died of the small pox, in 1750 .

Notwithstanding the despotism of Peter and his wife, the Russian senate and nobility, upon the death of Peter II, ventured to set aside the order of succession which they had established. The male issue of Peter was now extinguished; and the duke of Holstein, son to the eldest daugther, was, by the destination of the late empress, entitled to the crown; but the Russians, for political reasons, filled their throne with Anne, duchess of Courland, second daughter to Ivan, Peter's eldest brother, though her eldest sister, the dutchess of Mecklenburg, was alive. Her reign was extremely prosperous; and though she accepted the throne under limitations that some thought derogatory to her dignity, yet she broke them all, and asserted the prerogative of her ancestors. Upon her death in 1740 , John, the son of her niece the princess of Mecklenburg, by Anthony Ulric of Brunsivick Wolfenbuttle, was by her will entided to the succession; but being no more than two years old, Biron, who had been her favourite, and raised by her to the dutchy of Courland, was appointed to be administrator of the empire during his nonage. This destination was disagreeable to the princess of Mecklenburg and her husband, and unpopular among the Russians. Count Munich was employed by the princess of Mecklenburg to arrest Biron, who was tried, and conclemned to die, but was sent into exile to Siberia. The administration of the princess Anne of Mecklenburg and her husband was on many accounts, but particularly that of her German connexions, disagreeable, not only to the Russians, but to other powers of Europe; and notwithstanlling a prosperous war they carried on with the Swedes, the princess Elizabeth, daughter, by Catharine, to Peter the Great, formed such a party, that in one night's time she was declared and proclaimed empiess of the Russias; and the princess of Mecklenburg, her husband, and son, were marle prisoners.

The reign of Elizabeth may be said to have been more glorious than that of any of her predecessors, her father excepted. She abolish ed capital punishments, and introduced into all civil and military proceedings a moderation, till her time unknown in Russia; but at the same time she punished counts Munich and Osterman, who had the chief management of affairs during the late administration, with exile. She made peace with Sweden, and settled, as we have already seen, the succession to that crown, as well as to her own dominions, upon the most equitable foundation. Having gloriously finished a war with Sweden, she restored the natural order of succession in her own family, by declaring the duke of Holstein Gottorp, who was descended from 
hicr eldest sister, her heir. She gave him the title of grand-duke of Russia; and, soon after her accession to the tirrone, called him to her court, where he renounced the succession of the crown of Sweden, which undoubtedly was his right, embraced the Greek religion, and married a princess of Anhalt-Zerbst, the late empress Catharine II, by whom he had a son, the late emperor of Russia, Paul I.

Few princes have had a more uninterrupted career of glory than Elizabeth. She was completely victorious over the Swedes. Her alliance was courted by Great Britain, at the expense of a large subsidy ; but many political, and some private reasons, it is said, determined her to take part with the house of Austria against the king of Prussia in 1756. Fier arms alone gave a turn to the fortune of the war, which was in disfavour of Prussia, notwithstanding that monarch's amazing abilities both in the field and cabinet. Her success was such as portended the entire destruction of the Prussian power, which was, perhaps, saved only by her critical death, on January 5,1762 .

Elizabeth was succeeded by Peter III, grand-duke of Russia, and duke of Holstein, a prince whose conduct has been variously represented. He mounted the throne possessed of an enthusiastic admiration of his Prussian majesty's virtues; to whom he gave peace, and whose principles and practices he seems to have adopted as the rule of his future reign. He might have surmounted the effects even of those peculiarities, unpopular as they then were in Russia; but it is said that he aimed at reformation in his dominions, which even Peter the Great durst not attempt; and that he even ventured to cut off the beards of his clergy. It is also alleged that he had formed a resoluzion to destroy both the empress and her son, though they had been declared heirs to the imperial throne by the same authority which had. placed the crown upon his head: even the advocates of Peter III, acknowledge that he had resolved to shut up his wife and son in convent, to place his mistress upon the throne, and to change the order of succession. The execution of his designs was, however, prevented by an almost general conspiracy formed against him, in which the empress took a very active part; and this unfortunate prince scarcely knew an interval between the loss of his crown and his life, of which he was deprived, while under an ignominious confinement, in July 1762. His wife, the late Catharine II, was proclaimed empress.

The death of prince Ivan, son to the princess of Mecklenburg, was an act of state policy perfectly according with the means by which. Catharine ascended the throne. This young prince, as soon as he came into the world, was designed, though illegally, to wear the imperial crown of Russia, after the death of his great aunt, the empress Anne Ivannovna; but, on the advancement of the empress Elizabeth, he was condemned to lead an obscure life in the castle of Schlusselburg under a strong guard, who had particular orders, that, if any person or any armed force was employed in attempting to deliver him, they should kill him immediately. He lived quietly in his prison, when the empress Catharine II, mounted the throne; and as the revolution which deposed her husband Peter III, had occasioned a strong: ferment in the minds of the people, Catharine was apprehensive that some atte mpts might be made in favour of Ivan; she therefore doubled the guards of this unhappy prince, and particularly entrusted him to the care of two officers who were devoted to her interest. However, a lieutenant of infantry, who was born in the Ukraine, undertook, or at least pretended so, to deliver Ivan by force of arms, from the for-

Vox. I, 
tress of Schlusselburg; and under this pretence the prince was put to death, after an imprisonment of 23 years. The lieutenant who attempted to deliver him was arrested, and afterwards beheaded : but, notwithstanding this, it has been represented that he was a mere tool of the court, though he suffered for executing the instructions he received.

While this event excited the attention of the Russian nation, the Hames of civil war broke out with great violence in Poland; which was generally the case when the throne was vacant. And as the internal tranquillity of Poland was a capital object with Russia, the empress Catharine sent a body of troops into that country; and by her influence count Poniatowski was raised to the throne. She also interposed, in order to secure the rights which the treaty of Oliva had given to the Greek and Protestant subjects of Poland. But the umbrage which her imperial majesty's armies gave to the Roman-catholic Poles, by their residence in Poland, increased the rage of civil war in that country, and rendered it a scene of blood and confusion. The conduct of Russia with regard to Poland gave so much offence to the Ottoman court, that the grand-seignor sent Obreskoff, the Russian minister, to the prison of the Seven Towers, declared war against Russia, and marched a very numerous army to the confines of Russia and Poland. Hostilitics soon commenced between these rival and mighty empires. In the months of February and March, seventeen hundred and sixty-nine, Crim Gueray, khan of the Tartars, at the head of a great body of Tartars, supported by 10,000 spahis, having forced the Russian lines of communication, penetrated into the province of $\mathrm{New}$ Serva, where he committed great ravages, burning niany towns and villages, and carrying off some thousand families captive. In April following, the grand vizir, at the head of a great army, began his march from Constantinople, and proceeded towards the Danube. In the mean time. prince Galitzin, who commanded the Russian army on the banks of the Diniester, thought this a proper time to attempt something decisive, before the arrival of the great Turkish force in that quarter. Having accordingly crossed the Daiester with his whole army, he alvinced to Choczim, where he encamped in sight of a body of 30,000 Turks, commanded by Caraman Pasha, and intrenched under the cantion of the town. The prince, having made the necessary dispositions, attacked the Turks in their intrenchments early in the morning of the soth of Aprii, and, notwithstanding an obstinate defence, and a dreadful fire from the fortress, at length beat them out of their trenches. The Turks endeavoured to cover their retreat, by detaching a large body of cavalry to attack the right wing of the Russian army; but they met with such a warm reception from the artilery, that they soon retired in great disorder. General Stoffeln and prince Dolgorucki were then ordered to pursue the fugitives, at the head of eight battsilions; which they did so effectually, that they followed them into the suburbs of Choczim, and their pursuit was at length only stoppud by the palisadoes of the fortress.

On the 1 sth of July, a very obstinate battle was fought between a considerable Turkish arny, and the Russians under prince Galitzin, in the neighbourhood of Choczim, in which the Turks were defeated. The Russians immediately invested Choczim; but the garrison, being' numerous, made frequent sallies, and received great reinforcements from the grand-vizir's camp, who was now considerably advanced on this side of the Danube. Several actions ensued; and prince Galitzin was at length obliged to retreat, and repass the Dniester. It was com- 
puted that the siege of Choczim, and the actions consequent to it, cost: the Russians above 20,000 men.

In the management of this war, the grand vizir had acted with a desree of prudence, which it has been thought, would have proved latal to the designs of the Russians, if the same conduct had been atterwards pursued. But the army of the vizir was extremely licentious, and his caution gave offence to the Janissaries; so that, in consequence of their clamours, and the weakness of the counsels that prevailed in the seraglio, he at length became a sucrifice, and Moldovani Ali Pasha, a man of more courage than conduct, was appointed his succe.sor.

During these transactions, general Romalizow committed great devastations upon the Turks on the borders of Bender and Ouza kow, where he plundered and burnt several towns and villages, defeated a Turkish detachment, and carried off a great booty of cattle. The Tartars also committed great ravages in Foind, where they almost totally destroyed the palatinate of Bracklaw, besides doing mucin mischief in other places. In the beginning of September, the Russian army was again posted on the banks of the Dniester, and ef fectually defended the passage of that river against the Turks, whose whole army, under the command of the new vizir, was arrived on the opposite shore. Having laid three bridges over the Dniester, the Turkish army began to pass the river in the face of the enemy.

Prince Galizin having perceived this motion early in the morning of the 9 th of September, immediately attacked those troops that had crossed the river in the night, who consequently could neither choose their sround, nor have time to extend or form themselves properly where they were. Notwithstanding these extreme disadvantages, the engagement was very severe, and continued from seven in the morning till noon. The Turks fought with great obstinacy, but were at length totally defeated, and obliged to repass the river with great loss. and in the utmost confusion. It was computed, that about 60,000 Turks crossed the river before and during the time of the engage ment. Prince Galitzin cliarged at the head of five columns of infantry, with fixed bayonets, and destroyed the flower of the Turkish cavalry. It is said that the loss of the Turks in this battle amounted to 7000 men killed upon the spot, besides wounded and prisoners, and a great number who were drowned. Though the ill conduct of the vizir had greatly contributed to this misfortune, yet this did not prevent him from engaging in another operation of the same nature. He now laid but one bridge over the river, which he had the precau tion to cover with large batteries of cannon, and prepared to pass the whole army over. Accordingly, on the $17 \mathrm{th}$ of September, $8000 \mathrm{Ja}$ nissaries and 4000 regular cavalry, the flower of the whole Ottoman army, passed over with a large train of artillery, and the rest of the army were in motion to follow, when a sudden and extraordinary swell of the waters of the Duiester carried away and totally destroyed the bridge. The Russians lost no time in making use of this great and unexpected advantage. A most desperate engagement ensued, in which the slaughter of the Turks was prodigious. Not only the field of battle, but the river over which some few hundreds of Turks made their escape by swimming, was for several miles covered with dead bodies. The Russians took 64 pieces of cannon, and above 150 colours and horse-tails. The Turks immediately broke up their camp, and abandoned the strong fortress of Choczim, with all its stores and numerous altillery, and retired tumultuously towards the 
Danube. They were much exasperated at the ill conduct of their commander the vizir: and it was computed that the Turks lost 28,000 of the best and bravest of their troops, within little more than a fortnight; and 48,000 more abandoned the army, and totally deserted, in the tumultuous retreat to the Danube. Prince Galitzin placed a garrison of four regiments in the fortress of Choczim, and soon after resigned the command of the army to general count Romanzow, and returned to Petersburg covered with laurels.

The Russians continued to carry on the war with success; they overran the great province of Moldavia, and general Elemdt took possession of the capital, Jassy, without opposition. As the Grcek natives of this province had always secretly favoured the Russians, they now took this opportunity of their success and the absence of the Turks to declare themselves openly. The Greek inhabitants of Moldavia, and afterwards those of Wallachia, acknowledged the empress of Russia their sovereign, and took oaths of ficlelity to her. On the 18th of July, 1770, general Romanzow defeated a Turkish army near the river Larga: the Turks are said to have amounted to 80,009 men, and were commanded by the khan of the Crimea. On the second of August, the same Russian general obtained a still greater victory over another army of the Turks, commanded by a new grand vizir. This army was very numerous, but was totally defeated. It is said that above 7000 Turks were killed in the field of battle, and that the roads to the Danube were covered with dead bodies : a vast quantity of ammunition, 143 pieces of brass cannon, and some thoulsand carriages loaded with provisions, fell into the hands of the Russians.

But it was not only by land that the Russians carried on the war successfully against the Turks. The empress sent a considerable fleet of men of war, Russian built, into the Mediterranean, to act against the Turks on that side; and by means of this flect, under count Orloff, the Russians spread ruin and desolation through the open islands of the Archipelago, and the neighbouring defenceless coasts of Greece and Asia. The issue of this war was a peace, concluded on the 21 st of July, 1774, highly honourable and beneficial to the Russians, by which they obtained the liberty of a free navigation over the Black Sea, and a free trade with all the ports of the Ottoman empire.

Before the conclusion of the war with the Turks, a rebellion broke out in Russia, which gave much alarm to the court of Petersburg. A Cossac, whose name was Pugatscheff, assumed the name and character of the late unfortunate empcror, Peter III. He appeared in the kingdom of Kasan, and pretended that he made his escape, through an extraordinary interposition of Providence, from the murderers who were employed to assassinate him; and that the report of his death was only a fiction invented by the court. There is said to have been a striking resemblance in his person to that of the late emperor; which induced him to engage in this enterprise. As he possessed abilities and address, his followers soon became very numerous; and he at length found himself so powerful, his followers being armed and provided with artillery, that he stood several en"gagements with able Russian generals, at the head of large bodies of troops, and conmitted great ravages in the country. But being: at last totally defeated, and taken prisoner, he was brought to Mos= 
¿ô in an iron cage, and there beheaded and quartered on the 21 st of January, 1775.

Tne peace of 1774, was then indispensably necessary to the immediate preservation of the Turkish empire; but within so small a space of time as five years a new war was on the point of breaking out between the two empires, and was only prevented by a new treaty of pacification, which took place on the 2 lst of March, 1779. But the great source of discord still remained. The pretended independency of the Crimea afforded such an opening to Russia into the very heart of the Turkish empire, and such opportunities of interference, that it was scarcely possible that any lasting tranquillity could subsist between the two empires. A claim, made and insisted on by Russia, of establishing consuls in the three provinces of Moldavia, Wailachia, and Bessarabia, was exceedingly grievous to the Porte. After long disputes, the Turkish ministers, more from a sense of the disability of the state for war, than from pacific dispositions, found it necessary, towards the close of the year 1781 , to give up the point in debate with respect to the consuls. This concession, however mortifying, produced but a short-lived effect. New troubles were continually breaking forth. The emperor of Germany having avowed his determination of supporting all the claims of Russia as well as his own, all the parties prepared, with the utmost vigour, for the most determined hostility. The year 1783 accordingly exhibited the most formidable apparatus of war on the northern and eastern borders of Europe. However, in the midst of all these appearances of war, negociations for a peace continued to be carried on at Constantinople; which peace was at last signed, January 9 th, 1784 .

By this treaty Russia retained the full sovereignty of her new acquisitions, viz. the Crimea, the isle of Taman, and part of Cuban. As the recovery and restoration of every thing Greek was the predominant passion of the court of Petersburg, so the Crimea and its dependencies were in future to be known by the name of Taurida; particular places were likewise restored to their ancient appellations; and the celebrated port and city of Caffa resumed its long-forgotten name of Theodosia. Since this accession of dominion, new towns, with Greek or Russian names, are rising fast in the deserts, and are peopled mostly by colonies of Greeks and Armenians.

The year 1787 opened with the extraordinary spectacle of the journey of the empress of Russia to Cherson, where it seems to liave been her original intention to have been crowned with all possible magnificence, and under the splendid titles of empress of the East, liberator of Greece, and revivor of the series of Roman emperors, who formerly swayed the sceptre over that division of the globe. But this coronation, for reasons we are unable to assign, did not take place. The splendor of the route of the czarina surpasses whatever the imagination would spontaneously suggest. She was escorted by. an army. Pioneers preceded her march, whose business it was to render the road as even and pleasant as it could possibly be made. At the end of each day's journey she found a temporary palace erected for her reception, together with all the accommodations and luxuries that Petersburg could have afforded. In the list of her folJowers were the ambassadors of London, Versailles, and Vienna; and her own ambassador, as well as the envoy of the emperor to the court of Constantinople, were appointed to meet her at Cherson. The king of Poland met her in her journey; and the emperor, not satisfied 
with swelling her triumph at Cherson, appeared in that eapital cight days before her, and proceeded to a considerable cistance up the Drieper, to intercept her progress. Her route was through Kiow, where she remained three months, and was received under triumplial arches; and upon her arrival at Cherson, having thought proper to extend the walls of the city, she inscribed over one of the gates, "Through this gate lies the road to Byzantium." The czarina re. turned to Petersburgh by the way of Moscow.

Scarcely had the empress returned to her capital, before she was followed by the Turkish declaration of hostilities. The emperor of Germany joined her in declaring war against the Porte, which, instead of being disheartened at the formidableness of this confederacy, applied itself with redoubled ardour to prepare for resistance. The operations of the Russian forces were directerl against Choczim. and Oczakow. - In the former of these undertakings, they acted rather as auxiliaries to the emperor's general, the prince of Saxe Cobourg, who, from the last day of June to the 29th of September, 1788, continued a very powerful attack on Choczim, when it surrendered to the arms of the imperial forces. Oczakow, after an obstinate contest, in which the Russians at lengch became exposed to all the rigours of a winter campaign, was taken by storm on the 17 th of December following.

During the progress of these hostilities with the Porte, Russia found herself suddenly involved in a new and unexpected war. As a nation, Sweden had the greatest causes of resentment against Russia for past injury and loss, at the same time that she had every thing to dread from her present overgrown power and boundless ambition. Gustavus III, was therefore induced to meditate a project of hostilities against Russia, which commenced in Finland, a few days after the king's arrival in that province. The principal action of the campaign was the naval battle off Hoogland, in the Gulf of Finland. The engagement, which lasted five hours, was fought with considerable skill and obstinacy on both sides; but the victory was indecisive and claimed by both parties. At length, after several other engagements attended with various success, on the 14 th of August, 1790, a convention for a peace was signed between the courts of Russia and Sweden, and ratified in six days after.

At the close of the year 1790, the empress had the satisfaction to see her conquests no longer bounded by the coursc of the Danube. The capture of Ismail was the last important action. It was taken by storm on the 22d of December, 1790; but it is said that the siege and assault did not cost the Russians less than 10,000 men. The most shocking part of the transaction is, that the garrison (whose bravery merited, and would have received from a generous foe, the highest honours) were massacred in cold blood by the merciless Russians, to the amount of upwards of $30,000 \mathrm{men}$, by their own account. The place was given up to the unrestrained fury of the brutal soldiery ; and the most horrid outrages were perpetrated on the defenceless inhabitants.

England and Prussia, after a long and expensive armed negociation, at length assented to the demand of the empress, which was strengthened by the interference of Spain and Denmark, that Oczakow, and the territories between the rivers Bog and Dniester, should in full sovereignty belong to Russiz; that the river Dniester should for the future determine the frontiers of Russia and the Porte; that 
the two powers might erect on the shores of that river what fortresses they siould think proper; and that Russia should engage to grant a free navigation on the river Dniester.

The final treaty with the Turks was concluded at Jassy, the 9th of January, 1792. Catharine then applied herself to the improvement of Oczakow, and rendered it a place of great strength, importance, and commerce. At the same time she was not inattentive to European politics. When the coalition of sovereign powers was formed against France, Gustavus III, the late ling of Sweden, was to have conducted that expedition which was afterwards made against $F$ rance by the king of Prussia and the prince of Brunswick. Catharine, on this occasion, promised to assist him and the alliance with twelve thousand Russian troops, and an annual subsidy of three hundred. thousand rubles. She assured the pope that she would support him in the resumption of Avignon, and published a strong manifesto against the French revolution and the progress of the new principles of liberty; but the only active part she took against that revolution. was sending twelve ships of the line and eight frigates to join the English fleet, which were paid for by a subsidy, victualled and repaired in the British ports, and then returned home without rendering any effectual service. But her attention was principally directed to Poland, and the efforts which that people made in the cause of liberty. Whilst she amused the world with manifestoes against France, she beheld, with pleasure, the greatest powers of Europe wasting their strength and treasure; and, undisturbed by any foreign interference, made a second partition of Poland, thie circumstances of which the reader will find briefly narrated in our account of that unfortunate country.

By her intrigues, she in like manner annexed to the crown of Russia the fertile and populous country of Courland. She invited the duke of Courland to her court under the pretext that she wished to confer wlth him on some affairs of importance; and during his ab. sence the states of Courland assemblecl, and the nobles proposed to zenounce the sovereignty of Poland, and annex the country to the empire of Pussia. The principal members of the great council opposed this change; but the Russian general Pahlen appeared in the assembly, and his presence silenced all objections. The next day, March 18, 1795, an act was drawn up, by which Courland, Semigallia, and the circle of Pilten, were surrendered to the empress of Russia. The act was sent to Petersburg, and the submission of the states accepted by the empress. The duke of Courland was in no condition to refuse his acquiescence : he received very considerable presents from the empress, in compensation, and retired to live on some extensive estates he had purchased in Prussia.

But the acquisition, by intrigue and artifice, of countries incapable of resistance, was not sufficient to satisfy the ambition of Catharine. Incessantly anxious to extend her dominions, she turned her arms against Persia, under the pretext of defending Lolf Ali Khan, a clescendant of the race of the Sophis; but in reality to seize on the Persian provinces which border on the Caspian Sea. Her general Valerian Soubow penetrated, at the head of a numerous 'army, into the province of Daghestan, and laid siege to Derbent. Having carried a high tower which defended the place, he put all the garrison to the sword, and prepared to storm the city. The Persians, terrifiec? at the barbarous fury of the Russians, demanded quarter; and the 
keys of the city were delivered up to Soubow by the commandant, a. venerable old man, a hundred and twenty years of age, who had before surrendered Derbent to Peter I, at the beginning of the last century. Aga Mahmed was advancing to the relief of Derbent, when he learned that the place was already in the power of the Russians. Soubow drew out his army, and gave him battle; but victory declared. in favour of the Persians, who forced the Russians to retire into Derbent; in consequence of which defeat, a strong body of Russian troops were ordered to reinforce the army of Soubow.

These martial preparations, and plans of ambition, were, however, interrupted by her death. On the morning of the 9 th of November, 1796, she appeared very cheerful, and took her coffee as usual. Soon after she retired into the closet, where continuing unusually long, her attendants became alarmed, and at length opened the door, when they found her on the floor in a state of insensibility, with her feet against the door. Doctor Rogerson, her first physician, was immediately called, who bled her twice. At first she appeared rather to revive, but was unable to utter a word, and expired at ten o'clock at night.

Catharine II, in her youth had been handsome, and preserved in the close of life a graceful and majestic air. She was of a middle stature, well proportioned, and, as she carried her head very erect, appeared taller than she really was. Her forehead was open, her nose aqueline, her mouth well made, and her chin somewhat long, though not so as to have a disagreeable effect. her countenance did not want for ezpression; but she was too well practised in the courtly habits of dissimulation to sufferit to express what she wished to conceal.

With respect to her political character, she was undoubtedly a great sovereign. From the commencement of her reign she laboured, and with the greatest success, to increase the power and political consequence of her country. She encouraged learning and the arts, and made every exertion to extend, encourage, and enlarge the commerce of her subjects. She effected many and important regulations in the interior police, and particularly in the courts of justice. She abolished the torture, and adopted an excellent plan for the reformation of prisons. The new code of laws, for which she gave instructions, will contribute still more to mitigate the rigour of despotism. In the execution, indeed, of her plans for the aggrandisement of hel" empire, she appears to have acknowledged no right but power, no law but interest. Of her private life, her panegyrists, if prudent, will speak put little. They will dwell lightly on the means by which she mounted the throne. The only palliation of that conduct, which the most friendly ingenuity can suggest, will be derived from the frequent and bloody usurpations which, since the death of Peter the Great, had almost become the habit of the Russian court. But there are some acts, at the recital of which we should shudder, even if the scene were laid in Morocco. The mysterious fate of prince Ivan, in 1763, cannot be obliterated from history; the blood spilt in the longconceived scheme of expelling the Turks from Europe, and re-establishing the eastern empire in the person of a second Constantine, will not be expiated, in the estimation of humanity, by the gigantic magnificence of the project. Above all, the fate of Poland, the dissensions and civil wars industriously fomented in that unhappy kingdom, for a period of thirty years: the horrible massacres which attended its final subjugation, and the impious mockery of returning 
solemn thanks to heaven for the success of such atrocious crimes, will be a foul and indelible stain on the memory of Catharine.

She was succeeded by her son, Paul I, who in the beginning of his reign appeared to display a milder and more pacific disposition than that of his mother. Immediately on his accession to the throne, he ordered hostilities to cease between Russia and Persia; and a peace was soon after concluded between the two countries. He set at liberty the unfortunate Kosciusko, the general of the Polish patriots, with liberty either to reside in his dominions or retire to America, which latter country the general chose for his asylum, but whence he has since returned to Europe, and now resides in France. He behared with an honourable liberality towards the deposed king of Poland; and restored to their estates a great number of Polish emigrants and fugitives.

In the year 1799 , he, however, took a very active part in the waragainst France, and sent a powerful army, under the command of the celebrated general Suwarrow, which, co-operating with the Austrians, drove the French almost entirely out of Italy, entered S,witzerland, and threatened the interior of the republic. He, at the same time, sent a considerable force to act with the English army which had inraded Holland. But suddenly, with a capriciousness which from this time appeared to attend all his actions, he recalled his general, Stlwarrow, and his army from Switzerland, and appeared to have become more hostile to England than he had been to France. He seized all the British ships in his ports, detained upwards of 200 trading vessels in the harbour of Riga alone, and sending their cre rs up the country. From whatever cause proceeded his animosity against England; whether from perceiving, as has been supposed, that it was not the intention of the British ministry to give him possession. of Malta, of which he was eagerly desirous, or whether it was a consequence of his natupal extravagance and caprice, which in many instances bordered on phrenzy ; he entered into alliance with France, and excited a formidable confederacy of the maritime powers of the North against the naval interests of Great Britain, which was broker by the famous battle of Copenhagen. His frantic acts appear to have given great offence to many of the principal nobles. But on the $23 \mathrm{~d}$ of March 1800, he expired suddenly in the night, of an afrohlexy. Respecting the cause and manner of his death a cautious silence has been maintained in Russia, and it might not be proper to repeat the reports concerning it circulated in this country.

The day succeeding his decease, his eldest son, Alexander, was proclaimed emperor of all the Russias; and the new emperor soom after visited the senate, and issued several popular ukases; one in particular, reviving and confirming all the reculations of the empress Catharine for the encouragement of industry and commerce.

The conduct of Alexander, since his accession to the throne, has been characterised by a moderation, forming a strong contrast to the hasty violence of his predecessor. $\mathrm{He}_{\mathrm{e}}$ soon entered into a pacific accommodation with Great Britain, relinquished the claim on

- Particularly in the case of the extraordinary challenge which he inserted in the Petersburg gazette, proposing to the sovereigns of Europe to end the wars in which they had so long been engaged, by meeting lim, with their respective min r)isters, and engaging in single combat with himself and his minister. This chal. lenge, it has since appeared, was written under his directions by the celebrated Kíctzebue.

Vor. . 
Malta, and restored the English ships detained in the ports of Russia? He at the same time acted in conjunction with the first consul of France, in settling the indemnities allotted to the princes and states of the German empire, in which interference he probably had a view (patriotic with respect to his own subjects) to the extension of the inHuence and power of Russia.

He did not, however, continue long to act in concert with the ambitious ruler of France. The occupation of the northern provinces of Italy by the French troops was in violation of a secret convention between the two powers, and produced a remonstrance from count Malkou the Russian ambassador at the court of Paris. The remonstrance was not only disregarded, but the ambassador was so grossly insulted by Bonaparte at a public levee, that he immediately returned home. This treatment of his minister highly incensed Alexander, and the execution of the duke of Enghien, which soon followed, heightened his fears for the safety and inclependence of Europe.

On the 11 th of April, 1805, a treaty of concert between Great Britain and Russia was signed, and Austria was strongly solicited to join the league. The war which was now commenced was marked by want of concert and management on the part of the allies, and was consequently attended with defeat and disgrace. Prussia, Denmark, and the smaller German powers, were decidedly in the French interest. The court of Austria continued wavering, until compelled by the conduct of France either disgracefully to surrender her righis or to assert them in the field. She preferred the latter, and commenced hostilities by entering with a considerable force the Bavarian territory. The commander in chief, general Mack, was slow and indecisive in his movements, and by no means popular with the army. To this, and to the inadequacy of the Austrian forces, the disastrous commencement of the campaign may in a great measure be attribut cd. The Russians did not make their appearance till the beginning of November, when 70,000 men, under general Kutosoff, joined the Austrians on the banks of the Inn, but immediately retired upon the approach of the French army, which amounted to 110,000. Here a misunderstanding took place between the Russian and Austrian commanders, in consequence of which the latter withdrew his forces. Kutosofi, thus weakened, continued his retreat to Znaim ; but the rear of his army, under prince Bagration, was overtaken and attacked by the whole French force at Hollebrun. After a severe conflict they succeeded in cutting their way through the enemy, and effected a junction with the main army. On the 27 th of November, Kutosoff was reinforced by uniting with the second Russian division under general Buxhoven, and on the next day a column of the allies fell with great impetuosity on the advanced guard of Murat at Wischau, drove them from their post, and after a slight resistance made themselves masters of the town. On the same day the whole allied army encamped in the vicinity of Wischau. Bonaparte, improving by this slight reverse of fortune, pretended to retreat, and clrew the allies after him to Austerlitz. Here a severe engagement was fought on the $2 d$ of December, which terminated in the overthrow of the allied army. The emperor of Austria, completely disheartened, signed the humiliating treaty of Presburg, and the Russians returned home.

The emperor Alexander, however, by no means abandoned the idea of prosecuting the war, but made vigorous preparations for a fresh campaign. The important Austrian fortress of Cattaro, on the 
Adriatic, which was to have been delivered to the Frencl, was taken by a Russian force. Suddenly, however, a change took place in the policy of the Russian cabinet, and in violation of the treaty with Great Britain, a peace was concluded at Paris. Inmediately after this hostilities commenced between France and Prussia. The emperor of Russia now repented of the hasty measure, which he had adopted perhaps in a moment of despondency, at seeing himself left alone to struggle against the triumphant arms of France. Ready to embrace every opportunity which afforded the slightest probability of giving a check to the overgrown power of Napoleon, he concluded a treaty with Prussia. 'The Russian troops, however, were not brought into the field before the battle of Jena had decided the fate of their allies. A small army of 4.000 men, commanded by general Benningsen, then crossed the Vistula, but immediately upon ascertaining the great superiority of the enemy, they fell back upon their reinforcements, which were adrancing under Buxhoven. The command of the army was now given to general Kamenskoi, who advanced to Praga, where he was attacked and defeated. Another battle was fought on the 26th December in the vicinity of Pultusk. Both sides claimed the victory, but the Russians thought it prudent to retire. Peace between France and Prussia terminated the campaign.

The next spring Russia exerted herself to renew the contest. On the 25th of January, a battle was fought at Mohrungen, the beginning: of which was highly favourable to the Russian arms; but the French general Dupont arriving with considerable reinforcements, turned the fortune of the day, and Bonaparte was again victorious. Another and more severe engagement took place on the 7th and 8th of February at Eylau, and the Russians were once more driven from the field. On the 21 st of May Dantzic surrendered to the French. The Russian army, reinforced with 60,000 men, at the head of which was the emperor in person, accompanied by the archcluke Constantine, again advanced. They retook several important posts, and on the 5 th of June gained a considerable advantage over general Ney. But upon the approach of Bonaparte with his main army they retired towards Tilsit. After a number of minor engagements, in wbich the Russians suffered considerably, they were overtaken on the 14th at Friedland, by the French grand army. Here one of the warmest contested, battles was fought which modern Europe has witnessed. It raged without intermission from five in the morning till seven at night, when the Russian columns began to give way, and were finally driven from the field. In many of these engagements the French were double, and in all of them greatly superior, in point of numbers to the allies. The treaty of Tilsit was signed on the 7 th of July, 1807, and the French troops retired from the north to excite fresh tumults in the south of Europe.

While Russia was involved in a war with France, she was obliged to keep up a considerable force on the side of Turkey. In December, 1805, the Porte issued a declaration of war, and put her troops in motion. The Russians, anticipating the rupture, had already overrun the province of Moldavia and entered Wallachia, and before the close of the year they were masters of these two provinces, and also of Bessarabia. The Servians had also revolted and beaten the Turks in several engagements.

In the treaty of Tilsit, France guaranteed to Russia the possession of the Swedish territory in Finland; and the war which now com- 
menced between Russia and Sweden, evidently shewed the prependerance of French policy in the councils of the former. See SwEDEN.

This influence, however, had but a temporary existence; the good understanding between the two courts continuing little more than four years. The continental system, which France required Russia to adopt, destroyed the principal source of her income. It was the introduction of commerce which had made Russia of importance in the European compact, and deprived of commerce she must again sink into insignificance. Alexander was therefore compelled in silence to prepare for another rupture, in defence of rights, which no fattcries or commands of Napoleon could induce him to surrender. During the years 1810 and 1811 , the two powers were busily employed in preparing for the conflict; and in May, 1812, the Freneh armies, amounting to near $400,000 \mathrm{men}$, arrived on the banks of the Vistula. On the 16 th of June, Bonaparte took the command of his army; and on the $23 \mathrm{~d}$ crossed the Niemen, and commenced hostilities, by atw tacking a body of cossacs, stationed in Kovna, who were driven out with great slaughter. 'The Russian head quarters were at Wilna, towards which Napolcon advanced. On the 26 th the French light ca. valry were within nine leagues of Wilna, and the emperor Alexander gave orders for the immediate reunion of his army at Drissa behind the Dwina. The loss of the Russians in this movement was but trifling, and on the 9 th of July the different divisions were concentrated at Drissa, excepting the second army commanded by prince Bagration, and consisting of 60,000 men, who retreated by the way of Sloutzk towards Mohiloff. The enemy's column under marshal Oudinot having reached the neighbourhood of Dunabourg on the 18th, attacked the head of a bridge, where the Russians had constructed some works. Major-general Oulanoff received the charge and drove them back. The attack was renewed the next day, but with no better success, and Oudinot abandoning the attempt, marched towards Drouya, while the cavaliy under Murat took possession of Dissna. The whole of the Russian forces, including Bagration's army, amounted to 240,000 men, leaving the French a great superiority of numbers. On the 19 th of July, the Russian army under Barclay de Tolly, left Drissa, and on the 24th took a position in front of Vitepsk. Learning that Oudinot was marching towards Loutzen with a view of cutting off the cornmunication between Petersung and the imperial armies, Barclay de Tolly despatched general count Vigtenstein to oppose him. Vigtcnstein came up with the French at Yacobova, and after three days hard fighting, totally overthrew them. On the $22 \mathrm{~d}$, prince llagration arrived in the neighbourhood of Mohiloff, and understanding it to be in the possession of the enemy under marshals Davoust and Mortier, cletermined upon attacking it. The French defended themselves with spirit, and after a conflict of ten hours, $\mathrm{Ba}$ gration was compelled to retreat. On the 6th of August, he formed a junction with the left of the great army at Nadva. During this retreat his army had been reluced from 60,000 to 35,000 men. On the 16th of August, Bonaparie was at the head of his army before Smolensk. On the 17 th a severe engagement was fought between the tiro grand armies. The battle commenced early in the morning, and continued till after dark, when the Russians set fire to the city, and retired in excellent order towards Dorogobouche, where Bagration was encamped. The loss of lires in this engagement was upwards of 
10,000. Bonaparte lost no time in pursuing, and the rear of the Russian army under general Korff was intercepted by a French corps under Ney, Davoust, Murat and Junot. After a severe engagement, the French were obliged to retreat, and Korff joined the main army, About midnight on the 23d, Barclay de Tolly, having united with prince Bagration, arrived at Dorogobouche. On the 29th' of August prince Koutousoff arrived at head quarters from St. Petersburg, and took the commiand of the Russian army. He continued the retreat, and on the 1st of September the army halted in the vicinity of Borodino. Still as they proceeded they continued to destroy all kinds of provisions which could not be removed. The villages were burnt, the roads obstructed, and the bridges cut away. It was now necessary to dispute the passage of the enemy or to give np without a struggle the ancient capital of the empire. A battle was determined upon, and dispositions were made. About noon on the 5th the enemy appeared in great force, and commenced the battle by attacking the right wing of the army under Bagration. The position was lost and retaken four times, and at night remained in possession of the French. The 6 th was spent by both armies in preparing for a general engagement. By six o'clock on the morning of the 7 th the French renewed the attack. The battle soon became general. Upwards of 200,000 men, with two thousand pieces of canuon, were engaged in this sanguinary conflict. About nine the divisions of prince Bagration gave way, but upon being reinforced, again advanced, regairsed their position, and obliged the French to retreat in their turn. Night tcrminated the engagement. The killed amounted to near 80,000 men, besides 25,000 horses. The Russians lost several generals, among: whom were Bagration and Touchkoff. Bonaparte lost generals $\mathrm{Ca}$ lincourt and Montbrun. The victory was claimed by both parties, but the Russians maintained their position, and the French retreated from the field. The plan of retiring was still, however, continued, and Koutousoff, understanding the French had received considerable reinforcements, proceeded towards Moscow; and on the 14th of September the two opposing armies were encamped in the neighbourhood of that city. Koutousoff, not having been joined by his reinforcemcnts, found himself too weak to risk an engagement, and he therefore determined to sacrifice the capital for the safety of the empire. On the 15 th the French armies entered Moscow. Previous to abandoning the city, the Russians removed every thing that was valuable, and the French were astonished on entering it to find it enveloped in smoke and flame.

Bonaparte soon discovered that winter quarters for his troops were not to be found in Moscow. That city was surrounded by Russians, who destroyed every thing within his reach, and intercepted his supplies. After several ineffectual attempts at negociation he therefore cetermined to seek winter quarter's in the southern provinces. The little that remained of Moscow was again committed to the Rame;, and on the Ilth of October it was evacuated by the main army. Orders were given to blow up the Kremlin, but before they could be executed, that fortress was attacked and carried by a Pussian force. After several previous successes, of minor importance, general Vig. tenstein defeated St. Cyr at Polotzk on the 19th of October. On the 18th Murat was attacked by a clivision of the Russian army unde: general Benningsen, near Maloyarraslavitz, and driven from the field with considerable loss. Koutousoff was now no longer obliged to act 
on the defensive; he had received large reinforcements, while the numbers of the enemy were greatly diminished. The French army was in full retreat, and suffered excessively from cold and hunger. On the $2 \mathrm{~d}$ of November they were in considerable force at Wiagma, from.whence they were driven with great slaughter by general Miloradovitch. The frost commenced with unusual intensity, and the French troops were many of them destitute of cloathing. Their retreat became a disorderly flight, the severity of the weather clestroying more than the swords of their pursuers. On the 9th of November Bonaparte arrived at Smolensk. Between that place and Moscow he had lost 40,000 men. On the 13 th he cleparted for Krasnoy; and on the 15 th his rear evacuated Smolensk after reducing it to a heap of ruins. On the 17 th a division of upwards of 15,000 men under Davoust, was destroyed near Krasnoy by Miloradovitch. Bonaparte fled to Laidy. On the 17 th Ney's division was cut to pieces by the same forces. Immediately after, the rear of the French army, 11,000 strong, surrendered prisoners of war. When Bonaparte arrived at Orcha, with his army reduced to $40,000 \mathrm{men}$, he was informed that Victor had been defeated by Vigtenstein, and that Minsk was in the possession of admiral Tchitchagoff. On the 20th he left Orcha, and took the road to Borrisoff. On the 26th he was attacked on the shores of the Berezina by Vigtenstein. Five thousand of his men were killed, as many drowned, and 13,000 taken prisoners. Napoleon effected his escape by destroying the bridge after he had passed. On the 7 th of December he passed through Wina, and on the evening of the 10th arrived in disguise at Warsaw. On the 11 th the Russians entered Wilna. The Russian territories were now completely freed from their invaders. Of the 400,000 men which crossed the Niemen, not more than 25,000 returned.

The emperor Alexander pursued the career of victory. Sweden and Prussia joined in the common cause; nor was Austria the last to desert the standard of Napoleon. Most of the German states followed her example; and this formidable coalition, with Alexander at its head, supported by the treasures of Great Britain, was finally the means of hurling Bonaparte from his usurped throne, and placing the crown of France on the head of her legitimate sovereign.

Alcxander, the present emperor of all the Russias, was born December 23, 1777; married to the princess Louisa of Baden (bórn January 24, 1779) October 9, 1793.

Brothers and sisters to the emperor:

Constantine, born May 8, 1779 ; married to the princess of Saxe Cobourg: February 14, 1796.

Helena, boin December 24, 1784.

Maria, born February 15, 1786.

Catharine, born May 21, 1788.

Anne, born January 18, 1795.

Nicholas Paulovitsch, born June 2, 1796.

Michael Paulovitsch, born February 8, 1798.

Empress dowager, Maria Feodorowna (Sophia Dorothea Augusta) daughter of duke Frederick Eugenius of Wurtemberg, born October 25,1759 . 


\section{ENGLAND.}

EXTENT AND SITUATION.

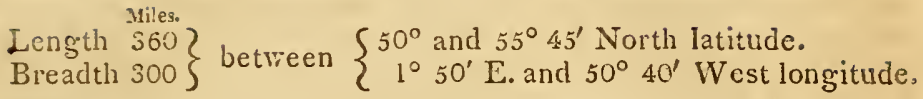

England and Wales contain 57,680 square miles, with 164 inhabitants to each.

NAME....Antiquaries are divided with regard to the etymology of the word England; some derive it from a Celtic word, signifying a level country, but the common etymology is doubtless the true one, according to which it originated from the Angles, a nation of the Cimbric Chersonesus, or modern Jutland, who conquered a consirlerable part of this island. In the time of the Romans, the whole island went by the name of Britannia. The word brit, according to Mr. Camden, signified painted or stained; the ancient inhabitants being famous for painting their bodies : other antiquaries, however, do not agree in this etymology. The western tract of England, which is aimost separated from the rest by the rivers Severn and Dee, is called Vales; a name which, according to some, is derived from a Celtic word, and signifies the land of strangers, because inhabited by the Belgic Gauls, who were driven thither by the Romans, and were strangers to the old natives.

BoUndaries....England is bounded on the north by that part of the island called Scotland; on the east by the German Ocean; on the west by St. George's Channel; and on the south by the English Channel, which parts it from France.

Divisions, ancient and modenn.... When the Romans provinciated England, they divided it into,

1. Britannia Prima, which contained the southern parts of the kingdom.

2. Britannia Secunda, containing the western parts, comprehending Wales. And,

3. Mlaxima Cæasariensis, which reached from the Trent as far northward as the wall of Severus, between Newcastle and Carlisle, and sometimes as far as that of Adrian in Scotland, between the Forth and Clyde.

4. Flavia Cæsariensis, which contained the midland counties.

When the Saxons invaded England, about the year 450, and when they were established, in the year 582, their chief leaders appropriated to themselves, after the manner of other northern conquerors, the countries which each had been the most instrumental in conquering; and the whole formed a heptarchy, or political confederacy consisting of seven kingloms. In time of war, a chief was chosen from the seven kings, by public consent; so that the Saxon heptarchy appears to have somewhat resenbled the constitution of Greece during the heroic ages. 
Xingdoms erected by the Saxons, usually styled the Saxon Heptarchy.

\section{KIINGDONS.}

1. Kent, founder by \{ IIengist in 475 , and $\{$ Kent ended in 823

2. South Saxons, founded by Ella in 491 , and ended in 600

3! East Angles, founded by Uffa in 575 , and ended in 793

4. IVest Saxons, founded by Cerdic in 512, and ended in 1060

5. Northumberland, founded by Ida in 574, and ended in 792

6. Last Saxons, founded by Erchewin in 527 , and ended in 746

$\therefore$ Mercia, founded by Cridda in 582 , and ended in 874
COUNTIES.

Sussex . . . . Chichester

Surry .... S Southwark

Norfolk

Suffolk . . . . Bury St.Edmunds

Cambridge, with . Cambridge

The Isle of Ely . . . E Ely

Cornwall . . . . Launceston

Devon . . . . Exeter

Dorset . . . . . Dorchester

Somerset . . . . Bath

Wilts . . . . Salisbury

Hants . . . . Winchester

Berks . . . . J Abingdon

Lancaster . . . . Lancaster

York . . . . . York

Durham . . . . Durham

Cumberland . . . Carlisle

Westmoreland . . Appleby

Northumberland \& Scotland, to the frith of Newcastle.

Edinburgh . . . .

Essex . . . .

Middlesex, and part of London

Hertford . $\cdot$.

The other part of Hertf. Hertford

Gloucester . . . . Glouceste:

Hereford . . . . Hereford

Worcester . . . . Wớrcester

Warwick . . . . Warwick

Leicester . . . . Leicestel

Rutland . . . . Oakham

Northampton . . . Northampton

Lincoln . . . . Lincoln

Huntingdon . . . Huntingdon

Bedford . . . . Bedford

Buckingham . . . Aylesbury

Oxford . . . Oxford

Stafford . . . . . Stafford

Derby . . . . Derby

Salop. . . . . Shrewsbury

Nottingham . . Nottingham

Lhester.... J Chester

It is the more necessary to preserve these divisions, as they account for difierent customs, and many very essential modes of inheritance, which to this day prevail in England, and which took their rise from different institutions uader the Sarons. Since the Norman 
invasion, England has been divided into counties, a certain number of which, excepting Middlesex and Cheshire, are comprehended in six circuits, or annual progresses of the judges, for administering justice to the subjects who are at a distance from the capital. The circuits are :

CIRCEITS.

COUNTIES.

Essex 226,437

Hertford 97,577

Kent 307,624

I.
IIome cir-
cuit .

Surry 269,043

Sussex 159,311

Bucks 107,4.44

Bedford 63,393

Huntingdon ? $37,568\}$

Norfolk cir- $\left.\begin{array}{c}\text { Cambridge } \\ 89,346\end{array}\right\}$ cuit . . Suffolk 210,431

III.

Oxford cir $\cdot\{$ Berks 109,215 cuit

\section{CHIEF TOWNS.}

Chelmsford, Colchester, Harwich, Malden, Saffion-Walden, Bocking, Braintree, and Stratford.

Hertford, St. Albans, Ware, Hitchin, Baldock, Bishop's-Stortford, Berkhamstead, Hempsted, and Barnet. Maidstone, Canterbury, Chatham, Rochester, Greenwich, Woolwich, Dover, Deal, Deptford, Feversham, Dartford, Romney, Sandwich, Sheerness, Tunbridge, Margate, Gravesend, and Milton.

Southwark, Kingston, Guildford, Croydon, Epsom, Richmond, Wandsworth, Battersea, Putney, Farnham, Godalmin, Bagshot, Egham, and Darking.

Chichester, Lewes, Rye, East Grin: stead, Hastings, Horsham, Midhurst, Shoreham, Arundel, Winchelsea, Battel, Brighthelmstone, and Petworth.

Aylesbury, Buckingham, High Wickham, Great Marlow, Stoney-Stratford, and Newport-Pagnel.

Bedford, Ampthill, Woodburn, Duno stable, Luton, and Biggleswadé.

Huntingdou, St. Ives, Kimbolton, Godmanchester, St. Neot's, Ramsey, and Yaxley.

Cambridge, Ely, Newmarlset, Royston, and Wisbech.

Bury, Ipswich, Sudbury, Leostoff, part of Newmarket, Aldborough, Bungay, Southwold, Brandon, Halesworth, Mildenhall, Beccles, Framlingham, Stowmarket, Wood. bridge, Lavenham, Hadley, Long Melford, Stratford and Easter. bergholt.

Norwich, Thetford, Lynn, Yara mouth.

Oxford, Banbury, Chipping-Norton; Henley, Burford, Whitney, Dorchester, Woodstock, and Thame. I Abingdon, Windsor, Reading, Wallingford, Newbury, Hungerford, Maidenhead, Farrington, Wantage, and Oakingham. 
CIRCUITS.

COUNTIES.

Gloucester ?

$250,809\}$

Worcester?

$139,333\}$

nued.

Monmouth ? $45,582\}$ xford cirHereford 89,191

Salop 167,639

Stafford 239,153<smiles>C=[Te]</smiles>

130,081 $\}$

Derby 161,142

Nottingham ?

Midland circuit .

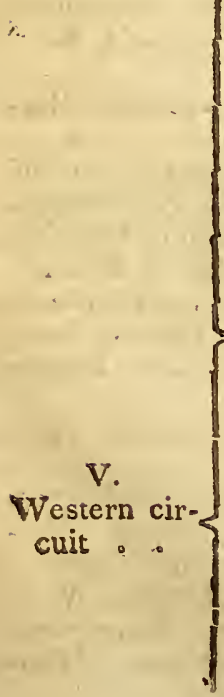

Lincoln 208,557

Rutland 16,356

Northampton?

131,757

Hants 219,656

Wilts 108,107
CHIEF TOWNS.

Gloucester, Tewkesbury, Ciren. cester, part of Bristol, Camden, Stow, Berkley, Dursley, Lechlade, Tetbury, Sudbury, Wotton, and Marshfield.

Worcester, Evesham, Droitwich, Bewdley, Stourbridge, Kidderminster, and Pershore.

Monmouth, Chepstow, Abergaven ny, Caerleon, and Newport.

Hereford, Leominster, Weobley, Ledbury; Kyneton, and Ross.

Shrewsbury, Ludlow, Bridgnorth, Wenlock, Bishop's Castle, Whitchurch, Oswestry, Wem, and Newport.

Stafford, Litchfield, Newcastle-un. der'-Line,Wolverhampton,Rugeley, Burton, Utoxeter, and Stone.

Warwick, Coventry, Birmingham; Stratford-upon-Avon, Tamworth, Aulcester, Nuneaton, and Ather. ton.

Leicester, Melton-Mowbray, Ashby-de-la-Zouch, Boswórth, and Harborough.

Derby, Chesterfield, Wirksworth, Ashbourne, Bakewell, Balsover, and Buxton.

Nottingham, Southwell, Newark, East and West Retford, Mansfield, :Tuxford, Worksop, and Blithe.

Lincoln, Stamford, Boston, Grantham, Croyland, Spalding, New. Sleaford, Great Grimsby, Gainsborough, Louth, and Horncastle.

'Oakham, and Uppingham.

Northampton, Peterborough, Daventry,Higham-Ferrers,Brackley, Oundle, Wellingboroug h, Thrapston, Towcester, Rockingham, Kettering, and Rothwell.

Vinchester, Southampton, Portsmouth, Andover, Basingstoke, Christchurch, Petersfield, Lymington, Ringwood, Rumsey, Alresford, and Newport, Yarmouth and Cowes, in the Isle of Wight.

Salisbury, Devizes, Marlborough, Malmsbury, Wilton, Chippenham, Calne, Cricklade, Trowbridge, Bradford, \& Warminster. 
COUNTIES.

Dorset 115,319

Somerset ?

$273,750\}$

V.

VVestern circuit conti-

Devon 343,001

\section{nued .}

\footnotetext{
.
} 
CIRCUITS. COUNTIES.

VI. Cumberland ?

Northern cir- $\{117,230\}$

cuit, conti-

nued.

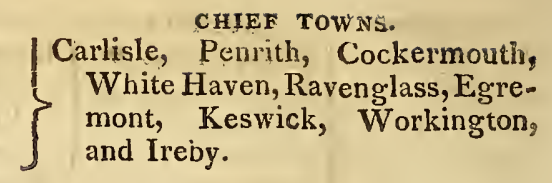

Middlesex is not comprehended in these circuits; nor Cheshire, which, being a county paiatine, enjoys municipal laws and privileges. The same may be said of Wales, which is divided into four circuits.

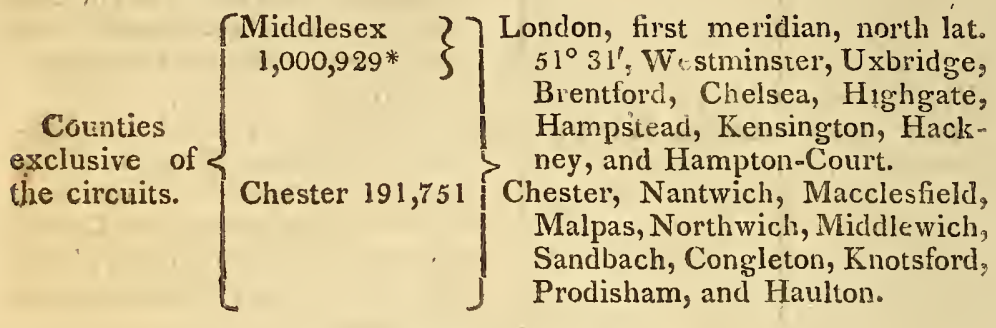

\section{CIRCUITS OF WAALES.}

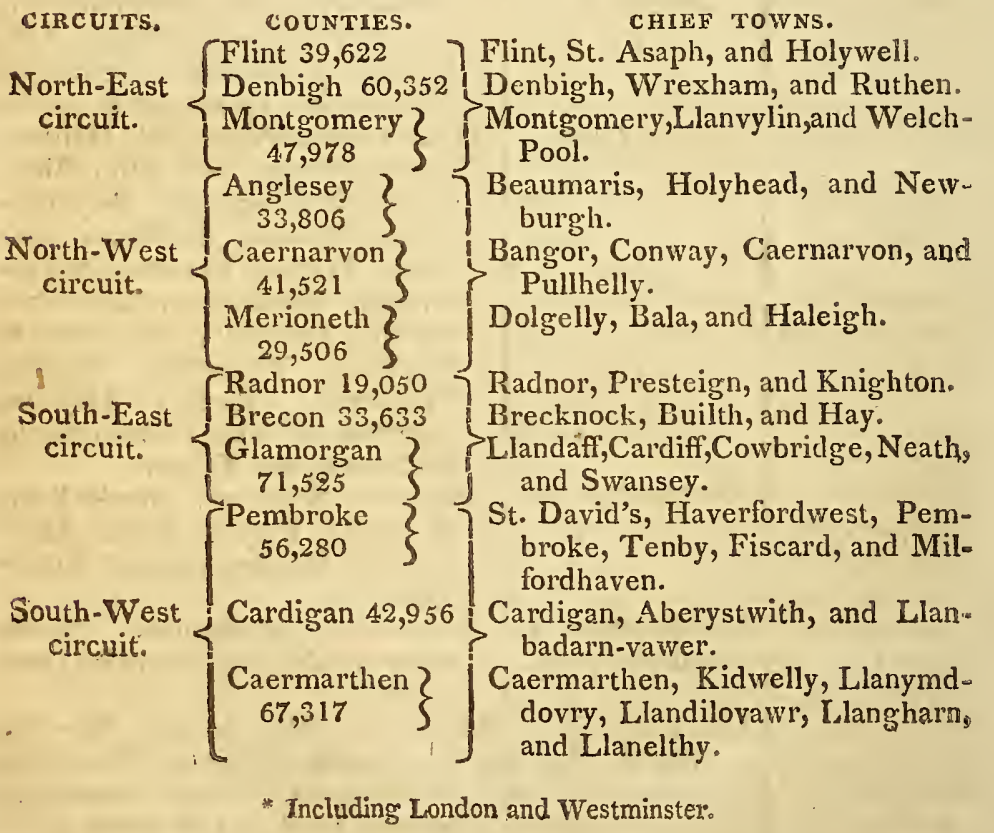


IN ENGLAND.

$\{0$ Counties, which send up to parliament .

25 Cities (Ely none, London four)

167 Boroughs, two each :

5 Boroughs (Abingdon, Banbury, Bewdley, Higham-Ferrers, and Monmouth) $\}$ one each

2 Universities

$s$ Cinque ports (Hastings, Dover, Sand-) wich, Romney, Hithe, and their three dependents, Rye, Winchelsea, and Seaford)

80 knights.

50 citizens. 334 burgesses.

5 burgesses.

4 representatives.

16 barons.

\section{ALES.}

12 Counties

12 Boroughs (Pembroke two, Merioneth? none) one each

\section{2 knights.}

12 burgesses.

\section{SCOTLAND.}

33 Shires . . . . . . . . 30 knights.

37 Cities and Boroughs . . . . . 15 burgesses.

\section{IRELAND.}

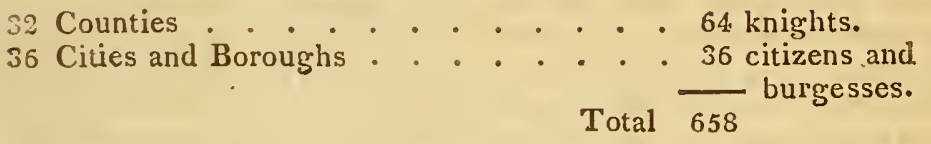

Besides the fifty-two counties into which England and Wales are divided, there are counties corporate, consisting of certain districts, to which the liberties and jurisdictions peculiar to a county have been granted by royal charter. Thus the city of London is a county distinct from Middlesex; the cities of York, Chester, Bristol, Exeter, Norwich, Worcester, and the towns of Kingston-upon-Hull and Newcastle-upon-Tyne, are counties of themselves, distinct from those in which they lie. The same may be said of Berwick -upon-Tweed, which lies in Scotland, and has within its jurisdiction a small territory of two miles on the north side of the river.

Under the name of a town, boroughs and cities are contained; for every borough or city is a town, though every town is not a borough or city. A borough is so called, because it sends up burgesses to parliament; and this makes the difference between a village or town, and a borough. Some boroughs are corporate, and some not corporate, and though decayed, as old Sarum, they still send burgesses to parliament. A city is a corporate borough, that has, or has had, a. bishop; for if the bishopric be dissolved, yet the city remains. 'To have suburbs, proves it to be a city. Some cities are also counties, as before mentioned.

FACE of THE COUNTRY.... No nation in the world can equal the cultivated parts of England in beautiful scenes. The variety of highlands and low-lands, the former gently swelling, and both of them forming the most luxuriant prospects, the corn and meadow grounds, the intermixtures of enclosures and plantation, the noble seats, com- 
fortable houses, cheerful villages, and well-stocked farms, often rising in the neighbourhood of populous towns and cities, decorated with the most vivid colours of nature, are objects of which an adequate idea cannot be conveyed by description. The most barren spots are not without their verdure. But nothing can give us a higher idea of the English industry, than observing that some of the pleasantest counties in the kingdom are naturally the most barren, but rendered fruitful by labour. Upon the whole, it may be safely affirm. ed, that no country in Europe equals England in the beauty of its prospects, or the opulence of its inhabitants.

Mountains....Though England is full of delightful rising grounds, and the most enchanting slopes, yet it contains few mountains. The principal are the Peak in Derbyshire, the Endle in Lancashire, the Wolds in Yorkshire, the Skiddaw and Saddle-back in Cumberland, the Cheviot-hills on the borders of Scotland, the Chiltern in Bucks, Malvern in Worcestershire, Cotswold in Gloucestershire, the Wrekin in Shropshire; with those of Plinlimmon and Snowdon in Wales. In general, however, Wales and the northern parts may be termed mountainous.

Forests.... The first Norman kings of England, partly for political purposes, that they might the more effectually enslave their new sub. jects, and partly from the wantonness of power, converted immense tracts of grounds into forests for bunting: and these were governed by laws peculiar to themselves: so that it was necessary, about the time of passing the Magna-Charta, to form a code of the forest-laws: and Justices in Eyre, so called from their sitting in the open air, were appointed to see them observed. By degrees those vast tracts were disforested : and the chief forests, properly so called, remaining out of no fewer than 69, are those of Windsor, New-Forest, the Forest of Dean, and Sherwood Forest. These forests produced formerly great quantities of excellent oak, elm, ash, and beach, besides walnut-trees, poplar, maple, and other kinds of wood. In ancient times England contained large woods, if not forests, of chesnut trees, which exceeded all other kinds of timber for the purposes of build. ing, as appears from many great houses still standing, in which the chesnut beams and roofs remain still fresh and undecayed, though some of them are above 600 years old.

LAKES....The lakes of England are few; though it is evident from history and antiquity, and indeed, in some places, from the face of the country, that meres and fens have been frequent in England, till drained and converted into arable land. The chief lakes remaining are Soham mere, Wittlesea mere, and Ramsey mere, in the isle of Ely, in Cambridgeshire. All these meres in a rainy season are overflowed, and form a lake of 4.0 or 50 miles in circumference. Winander mere lies in IVestmoreland: there are besides some small lakes in Cumberland, the chief of which is Derwent-water.

Rivers, springs, and mineral waters.... The rivers in England add greatly to its beauty as well as to its opulence. . The Thames, which, from the situation of the capital on its banks, naturally claims the first place among the rivers of England, rises on the confines of Gloucestershire, a little S. W. of Cirencester; and after receiving the many tributary streams of other rivers, it passes to Oxford, then by Abingdon, Wallingford, Reading, Marlow, and Windsor; from thence to Kingston, where formerly it met the tide, which, since the building of Westminster-bridge, is said to flow no higher than Rich- 
mond; whence it flows to London, and, after dividing the counties of Kent and Essex, widens in its progress, till it falls into the sea at the Nore, from which it is navigable for large ships to London-bridge.

The river Medway, which rises near Tunbridge, falls into the Thames at Sheerness, and is navigable for the largest ships as far as Chatham. The Severn, reckoned the second river for importance in England, and the first for rapidity, rises at Plinlinmon-hill in NorthIVales; becomes navigable at Welch-Pool ; runs east to Shrewsbury; then, turning south, visits Bridgnorth, Worcester, and Tewkesbury • where it receives the Upper Avon: after having passed Gloucester, it takes a south-west direction; is, near its mouth, increased by the TVye and Ustre, and discharges itself into the Bristol Channel, near King-road, where lie the great ships which cannot get up to Bristol. The Trent rises in the Moorlands of Staffordshire, and running southeast by Newcastle-under-Line, divides that county into two parts; then, turning north-east on the confines of Derbyshire, visits Nottinghan, running the whole length of that county to Lincolnshire, and being joined by the Ouse and several other rivers towards the mouth, obtains the name of the Humber, falling into the sea south-east of Hull.

The other principal rivers in England are the Ouse (a Gaëlic word signifying svater in general) which falls into the Humber after receiving the waters of many other rivers. Another Ouse rises in Bucks, and falls into the sea near Lynn in Norfolk. The Tyne runs from west to east through Northumberland, and falls into the German sea at Tinmouth, below Newcastle. The Tees runs from west to east, dividing Durham from Yorkshire, and falls into the German sea below Stockton. The Tweed runs from west to east, on the borders of Scotland, and falls into the German sea at Berwick. 'The Eden runs from south to north through WVestmoreland and Cumberland, and, passing by Carlisle, falls into Sol-way-Firth below that city. The lower Avon runs west through Wiltshire to Bath, and then, dividing Somersetshire from Gloucestershire, runs to Bristol, falling into the mouth of the Severn below that city. The Derwent runs from east to west through Cumberland, and passing by Cockermouth, falls into the Irish Sea a little below. 'The Ribble runs from east to west through Lancashire, and, passing by Preston, discharges itself into the Irish Sea. The Mersey runs from the south-east to the north-west through Cheshire, and then, dividing Cheshire from Lancashire, passes by Liverpool, and falls into the Irish Sea a little below that town. The Dee rises in Wales, and divides Flintshire from Cheshire, falling into the Irish channel below Chester.

The Champaign parts of England are generally supplied with excellent springs and fountains; though a discerning palate may perceive that they frequently contain some mineral impregnation. In some very high lands, the inhabitants are distressed for water, and supply themselves by trenches, or digging deep wells. 'The constitutions of the English, and the diseases to which they are liable, have rendered them extremely inquisitive after salubrious waters, for the pecovery and preservation of their health; so that England contains as many mineral wells, of known efficacy, as perhaps any country in the world. The most celebrated are the hot-baths of Bath and Bristol in Somersetshire, and of Buxton and Matlock in Derbyshire: The mineral waters of Tunbridge, Epsom, Cheltenham, Harrowgate, and Scarborough. Sca-vater is also much used for medical purposes; and 
so delicate are the tones of the English fibres, that the patients can perceive, both in drinking and bathing, a difference between the sea. water of one coast and that of another.

CANaLs.... Within the last fifty years a great number of canals have been cut in various parts of England, which have greatly contributed to the improvement of the country, and the facilitating of commercial intercourse between the trading towns. The first of these, in point of date, is the Sankey canal, the act of parliament for which was obtained in $\mathbf{1 7 5 5}$. It was cut to convey coals from the coal-pits at St. Helens to the river Mersey, and so to Liverpool, and is in length 12 miles.

But the canals of the late duke of Bridgewater, the great father of inland navigation in this country, are of much greater importance, both for the extent and the natural difficulties that were surmounted by the fertile genius of that extraordinary mechanic, Mr. Brindley. Of these great works, the first was begun in 1758, at Worsley-mill, about seven miles from Manchester, where a basin is cut containing a great body of water which serves as a reservoir to the navigation. The canal runs through a hill, by a subterranean passage large enough for the admission of long flat-bottomed boats towed by hand-rails on each side, near three quarters of a mile, to the duke's coal-works. There the passage divides into two channels, one of which goes 500 yards to the right, and the other as many to the left. In some pla. ces the passage is cut through solid rock, in others arched over with brick. Air-funnels, some of which are 37 yards perpendicular, are cut, at certain distances, through the rock to the top of the hill. At Bartonbridge, three miles from the basin, is an aqueduct, which, for upwards of 200 yards, conveys the canal across a valley and the navigable river Irwell. There are three arches over this river; the centre one 63 feet wide, and 38 feet high above the water, which will admit the largest barges to go through with masts and sails standing. The whole of the navigation is more than 29 miles: it falls 95 feet; and was finished in 5 years.

The Grand Trunk or Staffordshire canal was begun in 1766, under the direction of $\mathrm{Mr}$. Brindley, in order to form a communication between the Mersey and Trent, and in consequence between the Irish Sea and the German Ocean. It was completed in 1777, after the death of Mr. Brindley, who died in 1772, by his brother-in-law, Mr. Henshall. Its length is 22 miles; it is 29 feet broad at the top; 26 at the bottom, and five deep. It is carried over the river Dove by an aqueduct of 23 arches, and over the Trent by one of six. At the hill of Harecastle in Staffordshire, it is conveyed through a tunnel more than 70 yards below the surface of the ground, and 2880 yards in length. In the same neighbourhood there is another subterraneous passage of 350 yards, and at Preston on the Hill another 1241 yards in length. From the neighbourhood of Stafford a branch goes off from this canal, and joins the Severn near Bewdley: two other branches go, the one to Birmingham, and the other to Worcester.

The Braunston or Grand Junction canal (so called from its uniting: the inland navigation of the central counties) extends from the Thames at Brentford, to the Oxford canal at Braunston in Northamptonshire. A branch of it likewise goes from Uxbridge to Paddington; and a plan has been proposed, and considerable sums of money subscribed, for extending a cut from the latter place to the new WestIndia docks at Blackwall : but whether this design will be carried. into execution is as yet uncertain. 
A great number of other canals have been cut in various parts of the kingdom; as the Lancaster canal; the canal from Liverpool to Leeds, carried through an extent of 117 miles; the canal from Halifax to Manchester 51 miles; a canal from Basingstoke in Hampshire to the Thames at VVeybridge; another from Andover in the same county to the river near Southampton; and many others, which it would be tedious here only to enumerate.

Metals and minerals....Among the minerals, the tin mines of Cornwall deservedly take the lead. They were known to the Greeks and Phonicians, the latter especially, some ages before the Cirristian xra; and since the English have found a method of manufacturing their tin into plates and white iron, they are of immense advantage to the nation, their annual produce amounting nearly to the value of $200,000 l$. including what is conveyed to foreign markets. These tinworks are under peculiar regulations, by what are called the stannary laws; and the miners have parliaments and privileges of their own, which are in force at this time. Iron is found in plenty in England: the principal mines of it are in Coalbrook-dale, Shropshire; Dean's forest in Gloucestershire, and some parts of the north of England. I.ead is obtained in many parts of this island, particularly in Derbyshire, Yorkshire, Northumberland, and some counties in Wales. Near 20,000 tons of this metal are exported annually, notwithstanding great quantities are employed in different fabrications within the country. Of copper Cornwall is said to furnish the value of $200,000 \%$. annually, and the whole of the island to the amount of a million; the quantity exported having been estimated at above 1000 tons. The number of miners employed in Cornwall is said to amount to 100,000. There are no gold or silver mines in Britain; but particles of the former metal are found in the tin-mines of Cornwall, and some silver may be extracted from the ore of lead. Near Keswick in Cumberland is a rich mine of plumbago or black-lead, which the proprietors permit only to be opened once in six or seven years to prevent the markets from being overstocked. Zinc, in the form of lafis calaminaris, is found in Cornwall and Derbyshire. Devonshire, and other counties of England, produce nrarble; but the best kind, which resembles Egyptian granite, is excessively hard to work. Quarries of freestone are found in many places. Near Norwich in Cheshire are immense mines of rock-salt, which were discovered about the beginning of the last century. The quarries extend over many acres, and their crystal roof, supported by pillars, has a most beautiful appearance. The pit at Witton is of a circular form, 108 yards in diameter, and the roof is supported by 25 pillars, each containing: 294 solid yards of rock-salt. The annual produce of rock-salt at Northwich is estimated by Mr. Pennant at 65,000 tons. Cheshire like:wise produces alum. The fullers-earth found in Berkshire, and in some other counties, is of such consequence to the clothing trade, that its exportation is prohibited under severe penalties. Pit and sea coal is found in many counties of England; but the city of London, to encourage the nursery of seamen is chiefly supplied from the pits of Northumberland and the county of Durham. The cargoes are shipped at Newcastle and Sunderland. The exportation of coals to other countries is very considerable. The mines of Northumberland alone send every year upwards of 600,000 chaldron of coals to London, and 1500 vessels are employed in carrying them to that port along the castcrn coast of England.

YOI. I. 
Chimate, soll, And agriculture....England, from its insular situation and its proximity to the continent, is liable to a great uncertainty of weather; in consequence of which, the inhabitants, especially on several parts of the sea-coast, frequently suffer by agues and fevers. The air, in many places, is generally loaded with vapours wafted from the Atlantic Ocean by westerly winds; and the weather is so excessively capricious, and unfavourable to certain constitutions, that many of the inhabitants are induced to remove to a more regular climate for the restoration of their health. It cannot, however, be considered as in general insalubrious, as appears from the various instances of longevity which the country has afforded.

In consequence of the mutability of the climate, the seasons are very uncertain. Spring, sumnier, autumn, and winter, succeed each other; but in what month their different appearances will take place is very undetermined. The spring begins sometimes in February and sometimes in April. In May, the face of the country is often covered with hoar-frost instead of blossoms. "The beginning of June is sometimes as cold as the midlde of December; yet at other times the thermometer rises in that month as high as it does in Italy. Even August has its vicissitudes of heat and cold; and, upon an average, September, and next to it October, are the two most agreeable months in the year. The natives sometimes experience all the four seasons within the compass of one day; cold, temperate, hot, and mild weather. This inconstancy, however, is not attended with the effects that might be naturally apprehended. A fortnight, or at most three weeks, generally make up the difference with regard to the maturity of the fruits of the earth ; and it is hardly ever observed that the inhabitants suffer by a hot summer.

The soil of England and Wales differs in every county, not merely from the nature of the ground, though that must be admitted to occasion a very considerable alteration, but from the progress made in each in the cultivation of lands and gardens, the draining of marshes, and many other local improvements, which are here carried to a much greater degree of perfection than they are perhaps in any other part of the world, if we except China. In no country is agriculture better understood, or prosecuted with greater zeal for improvement and assiduity. Excellent institutions for the improvement of agriculture are now common in England; and their members print periodical accounts of their discoveries and experiments. The publications of the Bath Society upon the subject of agriculture are well known; and such has been the attention of the nation to this important object, that his present majesty has been pleased, August 31, 1793, by letters patent under the great seal, to constitute a byard for the encouragement of agriculture and internal improvement. The proper cultivation of the soil is an object so peculiarly interesting to the community at large, that those who most assiduously attend to it are perhaps to be accounted the most meritorious citizens of their country. The art of gardening is likewise cultivated with great success in several places in the vicinity of the metropolis: a single acre of land employed in the production of vegetables and fruits, will yield 120l. annually; the ordinary consumption of such commodities in the capital being computed at more than a million sterling.

VEGETABLES....England produces in abundance wheat, barley, rye, peas, beans, vetches, oats, and other grain. It is almost needless to 
mention, to the most uninformed reader, in what plenty the most excellent fruits, apples, pears, plums, cherries, peaches, apricots, nectarines, currants, gooseberries, raspberries, and other hortulan productions, grow here; and what quantities of cyder, perry, metheglin, and the like liquors, are made in some counties The cyder of Deron and Hcrefordshire, when kept. and made of proper apples, and in a particular minner, is often preferred, by judicious palates, to French white-wine. The natives of England have made the different fruits of the world their own, sometimes by simple culture, but often by hot-beds and other nueans of forcing nature. The English pine-apples are delicious, and now plentiful. The same may be said of other natives of the East and. West Indies, Persia, and Turkey. The English grapes are pleasing to the tasie, but their flavour is not exalted enough for making wine; and indeed wet weather injures the flavour of all the other fine fruits raised here. Our kitchen gardens abound with all sorts of greens, roots, and sallads, in perfection; such as artichokes, asparagus, cauliflowers, cabbages, colcworts, broccoli, peas, beans, kidncy-beans, spinage, beets, lettuce, celery, endive, turnips, carrots, potaloes, mushrooms, leeks, onions, and shallots.

IVoad for dyeing is cultivated in Bucks and Bedfordshire, as hemp and flax are in other counties. In nothing, however, have the English been more successful than in the cultivation of clover, cinquifoil, trefoil, saintfoin, lucern, and other meliorating grasses for the soil. It belongs to a botanist to recount the various kinds of useful and salutary herbs, shrubs, and roots, that grow in different parts of England. The soil of Kent, Essex, Surry, and Hampshire, is most favourable to the difficuit and tender culture of hops, which are now become a very considerable article of trade.

Axrmals... The English oxen are large and fat; but some prefer for the table the smaller breed of the Scotch and Welch cattle, after grazing in English pastures. The English horses are the best in the world, whether we regard their spirit, strength, swiftness, or docility. Incredible have been the pains taken, by all ranks, for improving the breed of this favourite and noble animal: and the success has been answerable; for they now unite all the qualities and beauties of Indian, Persian, Arabian, Spanish, and other foreign horses. The irresistible spirit and weight of the English cavalry render them superior to all others in war; and an English hunter will perform what would appear incredible in a fox or stag chase. Those which draw carriages in the streets of London are often particularly beautiful. The exportation of horses has of late become a considerable article of commerce. The breed of asses and mules begins likewise to be improved and encouraged in England.

The English sheep are of two kinds; those that are valuable for their fleece, and those that are proper for the table. The former are very large, and their fleeces constitute the original staple commodity of England. In some counties the inhabitants are as curious in their breed of rams as in those of their horses and dogs : and in Lincolnshire, particularly, it is no uncommon thing for one of these animals to sell for $50 l$. It must, however, be owned, that those large fat sheep are very rank eating. The late $\mathrm{Mr}$. Bakewell of Leicestershire was particularly famous for his improvements in the breed of sheep. Four or five hundred, and, according to some accounts, a thousand guineas have been given for the use of one of his rams for a single 
season. It is thought that in England twelve millions of fleeces are shorn annually; which, at a medium of $2 s$. a fleece, make $1,200,000 l$ 。 The other kind of sheep which are fed upon the downs, such as those of Banstead, Bagshot-heath, and Devonshire, where they have what the farmers call the short bite, is little, if at all, inferior in flavour and sweetness to venison.

The English mastiffs and bull-dogs are said to be the strongest and fiercest of the canine species in the world; but either from the change of soil, or feeding, they degencrate in foreign climates. James I, of England, by way of experiment, turned out two English bull-ciogs upon one of the fiercest lions in the Tower, and they soon conquered him. The mastiff, however, has all the courage of the buli-ciog, without its ferocity, and is particularly distinguished fo: his fidelity and docility. All the different species of dogs that abound in uther countries, for the field as well as domestic uses, are to be found in England.

What lıas been observed of the degeneracy of the English dogs i: for ign countr!es is applicable to the English game-cocks, which afford much barbarous diversion to our sportsmen. The courage of these birds is astonishing, and one of the true breed never leaves the pit airce without victory. The proprietors and feeders of this generous animal are likewise extremely curious as to his blood and pedigree.

Tame forls are much the same in England as in other countries; turkeys, peacocks, common pouitry, such as cocks, pullets, and capons, geese, swans, ducks, and tame pigeons. The wild sort are bustards, wild geese, wild ducks, teal, wigeon, plover, pheasants, partridges, woodcocks, grouse, quail, landrail, snipe, wood-pigeons, hawks of different kinds, kites, owls, herons, crows, rooks, ravens, magpies, jackdarvs and jays, blackbirds, thrushes, nightingales, goldfinches, linnets, larks, and a great variety of small birds; $\mathrm{Ca}$ nary-birds also breed in England. The wheat-ear is by many preferred to the ortolan, for the delicacy of its flesh and flavour, and is peculiar to England.

Few countries are better supplied than England with river and sea fish. Her rivers and ponds contain plenty of salmon, trout, ecls, pike, perch, smelts, carp, tench, barbel, gudgeons, roach, dace, gray mullet, bream, plaice, flounders, and cray-fish; besides a delicate lake-fish, called char, which is found in some fresh-water lakes of Wales and Cumberland, and, as some say, no where else. The seafish are cod, mackerel, liaddock, whiting, herrings, pilchard, skaite, soles. The john-dory, found towarc's the western coast, is reckoned a great delicacy, as is the red-mullet. Several other fish are found on the same coast. As to shell-fish, they are chiefly oysters, the propagation of which, upon their proper banks, requires a peculiar culture. Lobsters, crabs, shrimps, and escallops, one of the most delicious of shell-fishes, cockles, wilks, periwinkles, and muscles, with many other small shell-fish, abound in the English seas. The whales chiefly visit the northern coast; but great numbers of porpoises and seals appear in the channel.

With regard to repiiles, such as adders, vipers, snakes and worms; and insects, such as ants, grats, wasps, and flies, England nearly resembles the rest of Europe; and the difference, if any, becomes more proper for natural history than geography.

Natural curiositres....Among the natural curiosities of this com- 
try, those of Derbyshire appear to deserve the first place. Eilden hole, about four miles from Mam Tor, or the Mother Tower, which is superstitiously said to be continually mouldering away but never to diminish, is a chasm in the side of a mountain, nearly seven yards wide, and fourteen long, diminishing in extent within the rock; but of what depth is not known. A plummet once drew 884 yards of line after it, of which the last eighty were wet, without finding a bottom. The entrance of Poole's Hole, near Buxton, for several paces, is very low, but soon opens into a very lofty vault, like the inside of a Gothic cathedral. The height is certainly very great, yet much short of what some have asserted, who reckon it a quarter of a mile perpendicular ; though in length it exceeds that dimension : a current of water, which runs along the middle, adds, by its sounding stream, re-echoed on all sides, very much to the astonishment of all who visit this vast cavern. The drops of water which hang from the roof, and on the sides, have an amusing effect; for they not only reflect numberless rays from the candles carried by the guides, but as they are of a petrifying quality, they harden in several places into various forms, which, with the help of a strong imagination, may pass for lions, fonts, organs, and the like. The entrance into that stupendous cavern at Castleton, which is, from its hideousness named the Devil's Arse, is wide at first, and upwards of thirty feet perpendicular. Several cottagers dwell under it, who in a great measure subsist by guiding strangers into the cavern, which is crossed by four streams of water, and then is thought impassable. The vault, in several places, makes a beautiful appearance, being chequered with various coloured stones.

Other extraordinary caverns are found in the mountains of the north of England, as Yordas Cave, in the vale of Kingsdale in Yorkshire, which contains a subterraneous cascade. Wethercot Cave, not far from Ingleton, is divided by an arch of limestone, passing under which is seen a large cascade falling from a height of more than 20 yards. The length of this cave is about 60 yards, and the breadth 30 .

There are also, in various parts of England, many remarkable springs, of which some are impregnated either with salt, as that of Droitwich in Worcestershire; or sulphur, as the famous well of Wigan in Lancashire; or bituminous matter, as that at Pitcliford in Shropshire. Others have a petrifying quality, as that near Lutterworth in Leicestershire, and a dropping well in the West Riding of Yorkshire. And, finally, some ebb and flow, as those of the Peak in Derbyshire; and Laywell, near Torbay, whose waters rise and fall several times in an hour. To these we may add that remarkable fountain near Richard's Castle in Herefordshire, commonly called Bone-well, which is generally full of small bones, like those of frogs or fish, though often cleared out. At Ancliff, near Wigan in Lancashire, is the famous Burning Well; the water is cold, neither has it any smell; yet there is so strong a vapour of sulphur issuing out with the stream, that, upon applying a light to it, the top of the water is corered with a flame, like that of burning spirits, which last several hours, and emits so strong a heat that meat may be boiled over it. The fluid itself will not burn when taken out of the well**.

* 'This extraordinary heat has been found to proceed from a vein of coals, which has been since dug from under this well; at which time the uncommon warmth ceaser!. 


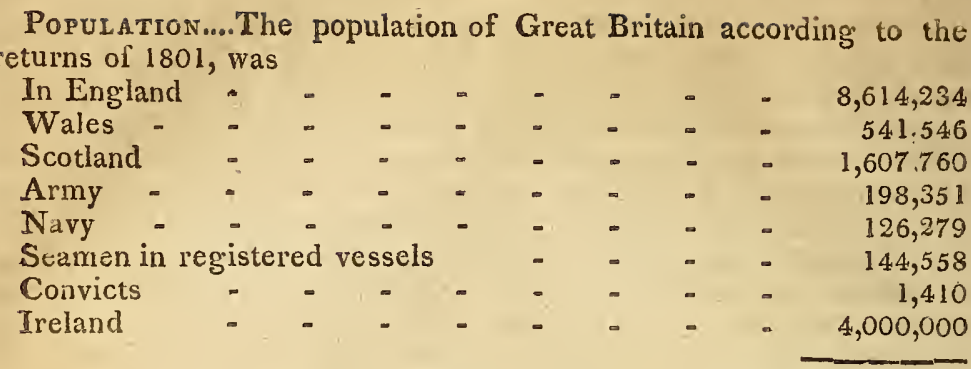

Total, 15,234,138

The population of the United Kingdom was estimated, in 1812, at $16,552,144$.

National CHARACTER, MANNERS, customs....Englishmen in their persons, are generally well-sized, regularly featured, commonly fair, rather thall otherwise, and florid in their complexions. The women, in their shape, features, and complexion, appear so graceful, and lovely, that England may be ternied the native country of female beauty. Butbeside the external graces so peculiar to the women in England, they are still more to be vaiued for their prudent behaviour, thorough cleanliness, and a tender affection for their husbands and children, and all the engaging duties of domestic life.

In their dispositions the English are rather grave and phlegmatic, but not without an occasional mixture of vivacity, as they are perhaps not inferior to any nation in true wit and genuine humour. They are remarkable for a nervous sensioility, which has been considered as one of the sources of those singularities which so strongly characterise the English nation. They sometimes magnify the slightest appearances into realities, and bring the most distant dangers immediately home to themselves; and yet, when real danger approaches, no people face it with greater resolution or constancy of mind. They are fond of clubs and convivial assocrations; and when these are kept within the bounds of temperance and moderation, they prove the best cure for those mental evils, which are so peculiar to the English, that foreigners have pronounced them to be national.

The English nobility and gentry of great fortunes now assimilate their manners to those of foreigners, with whom they cultivate a more frequent intercour'se than their forefathers did They do not now travel only as pupils, to bring home the vices of the countries they visit, under the tuition perhaps of a despicable pedant, or family dependant; but they travel for the purposes of society, and at the more advanced ages of life, when their judgments are mature, and their passions regulated. This has enlarged society in England, which foreigners now visit as commonly as Englishmen visited them, and the effects of the intercourse become daily more visible, especially as it is not now, as formerly, confined to one sex.

Such of the English noblemen and gentlemen as do not enter into the higher walks of life, affect what we call a snug rather than a splendid way of living. They study, and understand better than any people in the world, conveniency in their houses, gardens, equipages, and estates; and they spare no cost to purchase it. It has, however, been observed, that this turn renders them less communicative than they ought to be : but, on the other hand, the few connexions they form are sincere, cheerful, and indissoluble. The like habits descend 
pretty far into the lower ranks, and are often discernible among tradesmes. This iove of snugness and conveniency may be called the ruling passion of the English people, and is the ultimate end of all their application, labours, and fatigues. A good economist, with a brisk run of trade, is generally, when turned of fifty, in a condition to retire from business; that is, either to purchase an estate, or settle his money in the funds. He then commonly resides in a comtortable house in the country, often his native county, and expects to be treated on the footing of a gentleman; but his style of living is always judiciously suited to his circumstances.

The humanity of the English is manifested in the large subscriptions for public charities, raised by all degrees of both sexes. Poor and miserable objects are relieved in England with the greatest liberality. The very persons who contribute to those collections are at the same time assessed in proportion to their property for their parochial poor, who have a legal demand for their maintenance; and upwards of three millions sterling is said to be collected yearly in this country for charitable purposes. The institutions, however, of extra-parochial infirmaries, hospitals, and the like, are in some cases reprehensible. The vast sums bestowed in building them, the contracts made by their governors, and even the election of physicians, who thereby, qualified or unqualified, acquire credit, which is the same as profit, very often beget heats and cabals, which are very different from the purposes of disinterested charity (owing to the violent attachments and prepossessions of friends) and too often even to party considerations.

An Englishman of education and reading, is perhaps, the most accomplished gentleman in the world; he is, however, shy and reserved in his communications. This unamiable coldness is so far from being affected, that it is a part of his natural constitution. Living learning and genius often meet not with their suitable regard, even from the first-rate Englishmen; and it is not unusual for them to throw aside the best productions of literature, if they are not acquainted with the author. While the state distinction of Whig and Tory subsisted, the heads of each party affected to patronise men of literary abilities; but the pecuniary encouragements given them were but very moderate; and the very few who met with preferments in the state might have earned them by a competent knowledge of business, and that pliability which the dependents in office generally possess. We scarcely have an instance, even in the munificent reign of queen Anne, or of her predecessors, who owed so much to the press, of a man of genius, as such, being made easy in his circumstances. Mr. Addison had about $500 l$. a year of the public money to assist him in his travels; and Mr. Pope, though a Roman-catholic, was offered the like pension, by Mr. Craggs, the whig secretary of state, but did not accept of it; and it was remarked, that his tory friend and companion, the earl of Oxford, when sole minister, did nothing for him but bewail his misfortune in being a papist. Indeed, a few men of distinguished literary abilities, as well as some without, have of late received pensions from the crown; but, from the conduct of some of them, it should seem that state and party services have been expected in return.

The unevenness of the English in their conversation is very remarkable: sometimes it is delicate, sprightly, and replete with true wit; sometimes it is solid, ingenious, and argumentative; sometimes it is 
cold and phlegmatic, and borders upon disgust; and all in the same person. In many of their convivial meetings they are very noisy, and their wit is often offensive, while the loudest are the most ap. plauded. This is particularly apt to be the case in large companies; but, in smaller and more select parties, all the pleasures of rational conversation and agreeable society are enjoyed in England in a very high degree.

The courage of the English is cool and firm; if they have not that ardour of attack sometimes displayed by the French, they can support and defeat such an attack. Their soldiers will keep up their fire in the mouth of danger; but when they deliver il, it has a most dreadful effect upon their enemies; and in naval engagements they are unequalled. The English are not remarkable for invention, though they are for their improvements upon the inventions of others: and in the mechanical arts they excel all nations in the world. The intense application which an Englishman gives to a favourite study is incredible, and, as it were, absorbs all his other ideas. This is the cause of the numerous instances of mental absence that are to be found in the nation.

Stag and fox hunting, and horse-races, are sports of which many of the English are fond, even to infatuation. Somewhat, however, may be offered by way of apology for those diversions: the intense application which the English give to business, their sedentary lives, and luxurious diet, require exercise; and some think that their excellent breed of horses is increased and improved by those amusements. Next to horse-racing and hunting, cock-fighting, to the reproach of the nation, is a favourite diversion among the great as well as the vulgar. Miultitudes of both classes assemble round the pit at one of those matches, and enjoy the pangs and death of this generous animal; every spectator being concerned in a bet, sometimes of a high sum. The athletic diversion of cricket is still kept up in the southern and western parts of England, and is sometimes practised by people of the highest rank. Nany other pastimes are common in England, some of them of a very robust nature, such as cudgelling, wrestling, bowls, skittles, quoits, and prison-base ; not to mention duck-hunting, foot and ass races, dancing, puppet-shows, May-garlands, and, above all, ringing of bells, a species of music which the Engiish boast they have brought into an art. The barbarous diversions of boxing and prize-fighting, which were as frequent in England as the shows of gladiators in Rome, are now prohibited, though often practised; and all places of public diversions, excepting the royal theatres, are under regulations by act of parliament. Other diversions, which are common in other countries, such as tennis, fives, billiards, cards, swimming, angling, fowling, coursing, and the like, are familiar to the English. Two kinds, and those highly laudable, are perhaps peculiar to them; and these are rowing and sailing. The latter, if not introduced, was patronised and encouraged by his present inajesty's father, the late prince of Wales, and may be considered as a national improvement. The English are amazingly fond of skaiting, in which, however, they are not very expert; but they are adventurous in it, often to the danger and loss of their lives. The game acts have taken from the common people a great fund of diversion, though without answering the purposes of the rich; for the farmer and country people destroy the game in the nest, which they dare not kill with the gun. This monopoly of 
game, among so free a people as the English, has been considered in rarious lights.

In the diess of both sexes, before the present reign of George III, they followed the French; but that of the military officers partook. of the German, in compliment to his late majesty. The Engiish, at present, bid fair to be the dictators of dress to the French themselves, at least with regard to elegance, neatness, and richness of attire. People of quality and fortune, of both sexes, appear, on high occasions, in cloth of gold and silver, the ricliest brocades, satins, silks, and velvets, both flowered and plain : and it is to the honour of the court, that the foreign manufactures of ali these are discouraged. Some of these rich stuffs are said to be brought to as great perfection in England as they are in France, or any other nation. The quantitics of jewels that appear on public occasions are incredible, especially since the rast acquisitions of the English in the East-Indies. The same nobility, and persons of distinction, on ordinary 06 casions, dress like creditable citizens; that is, neat, clean, and plain, in the finest cloth and best of linen. 'The full dress of a clergyman consists of his gown, cassock, scarf, beaver-hat and rose, all of black; his undress is a dark-gray frock, and plain linen. The physicians, the furmality of whose dress, in large tic-perukes, and sworcls, was formerly remarkable, if not ridiculous, now dress like other gentlemen and men of business. The people of England love rather to be neat than fine in their apparel; but since the accession of his present majesty, the dresses at court, on particular occasions, are superb be. yond description. Few, even of the lowest tradesmen, on Sundays, carry about them less than 10l. in clothing, comprehending hat, stockings, shoes, and linen; and even many beggars in the streets appear decent in their cless. In short, none but the most abandoned of both sexes are otherwise; and the appearance of an artisan $\mathrm{m}$ manufacturer, in holiday limes, is commonly an indication of his industry and morals.

CITIES, ChIEF TOWNS, EDIFICES, PUBLIC AND pRIVATr....London, the metropolis of the British empire, and perhaps the most populous and wealthy city in the world, appears to have been founded between the reigns of Julius Cæsar and Nero; but by whom is uncertain; for we are told by Tacitus, that it was a place of great trade in Nero's time, and soon after became the capital of the island. It was first walled round, with hewn stones and British bricks, by Constantine the Great; and the walls formed an oblong square, in compass about three miles, with seven principal gates. The same emperor made it a bishop's see; for it appears that the bishops of London and York, and another English bishop, were at the council of Arles, in the year 514. He also established a mint in it, as is plain from some of his coins.

London, in the extensive sense of the name, including Westminster, Southwark, and part of Middlesex, is a city of surprising extent, of prodigious wealth, and of the most extensive trade. This city, when considered with all its advantages, is now what ancient Pome once was, the seat of liberty, the encourager of arts, and the admiration of the whole world. London is the centre of trade; it has an intimate connexion with all the counties in the kingdom; it is the grand mart of the nation, to which all parts send their commodities, from whence they are again sent back into every town in the Lution, and to every part of the world. From hence innumerable 
carriages by land and water are constantly employed; and from hence arises the circulation in the national body, which renders every part healthful, vigorous, and in a prosperous condition; a circulation that is equally beneficial to the head and the most clistant members. Merchants are here as rich as noblemen; witness their large and numerous roans to government: and there is no place in the world where the shops of tradesmen make such a noble and elegant appearance, or are better stocked,

It is situated on the banks of the Thames, a river which, though not the largest, is the richest and most commodious for commerce of any in the world; it being continually filled with fleets sailing to or from the most distant climates; and its banks, from London-bridge to Blackwall, are almost one continued great magazine of naval stores, containing three large wet docks, 32 dry docks, and 33 yards for the building of ships for the use of the merchants, besides the places al. lotted for the building of boats and lighters, and the king's yards, down the river, for the building of men of war. As this city is about 60 miles distant from the sea, it enjoys, by means of this noble river, all the benefits of navigation, without the danger of being surprised by foreign fleets, or of being annoyed by the moist vapours of the ocean. It rises regularly from the water-side, and, extending itself on both sides along its banks, reaches a prodigious length from east to west, in a kind of amplitheatre towards the north, and is continued for near 20 miles on all sides, in a succession of magnificent villas and populous villages, the country seats of gentlemen and tradesmen; whither the latter retire for the benefit of fresh air, and to relax their minds fiom the hurry of business. The regard paid by the legislature to the property of the subject has hitherto prevented any bounds being fixed for its extension.

The irregular form of this city makes it difficult to ascertain its extent. However, its length from east to west is generally allowed to be above seven miles, from Hyde-park Corner to Poplar : and its breadth in some places three, in others two, and in others, again, not much abore half a mile. Hence the circumference of the whole is almost 18 miles; or, according to a modern measurement, the extent of continued and still increasing buildings is 35 miles, 2 furlongs, and 39 roods. But it is much easier to form an idea of the large extent of a city so irregularly built, by the number of the people, amounting, by the returns under the census of 1810 , to $1,099,104$; and from the number of edifices devoted to the service of religion.

Of these, oesides St. Paul's cathedral, and the collegiate church at Westminster, here are 102 parish churches, and 69 chapels, of the established religion; 21 French protestant chapels; 11 chapels belonging to the Germans, Dutch, Danes, \&c.; 26 independent meetings; 34 presbyterian meetings; 20 baptist meetings; 19 popish chapels, and meeting-houses for the use of foreign ambassadors, and people of various sects; and three Jews synagogues. So that there are 305 places devoted to religious worship, in the compass of this vast pile of buikings, without reckoning the 21 out-parishes usually included in the bilis of mortality, and a great number of methodist tabernacles.

There are also in and near this city 100 alms-houses; about 20 hospitals and infirmaries; 3 colleges; 10 public prisons; 15 fleshmarkets; 1 market for live cattle ; 2 other markets more particularly for herbs; and 23 other markets for corn, coals, hay, \&c.; 15 inns 
of court; $s 7$ public squares, besides those within single buildings, as the Temple, \$xc.; 3 bridges; 49 halls for companies; 8 public schools, called fiee-schools; and 131 charity schools, which provide education for 5034 poor children; 207 inns; 44.7 taverns ; 551 coffeehouses; 5975 ale-houses; 1200 hackney-coaches; 400 ditto chairs; 7000 streets, lanes, courts, and alleys; and 130,000 dwelling-houses, containing, as has been already observed, upwards of $1,000,000$ inhabitants, who, according to calculations made so many years ago that they may be considered as low in the present enlarged state of this great city, consume annually, 101,000 black cattle; 710,000 sheep; 195,000 calves; 240,000 swine and pigs; 1,172,500 barrels of strong beer; 3000 tuns of foreign wines; and eleven millions of gallons of rum, brandy, and other distilled liquors; with 500,000 chaldrons of coals for fuel.

London-bridge was first built of stone in the reign of Henry II, about the year 1163 , by a tax laid upon wool, which, in the course of time, gave rise to the notion that it was built upon wool-packs : from that time it has undergone many alterations and improvements, particularly since the year 1756, when the houses were taken down, and the whole rendered more convenient and beautiful. The passage for carriages is 31 feet broad, and 7 feet on each side for foot passengers. It crosses the Thames where it is 915 feet broad, and has 10 arches of about 20 feet wide each; but the centre one is considerably larger.

IVestminster-bridge is reckoned one of the most complete and elegant structures of the kind known in the world. It is built entirely of stone, and extended over the river at a place where it is 1,223 feet broad; which is above 300 feet broader than at Londonbridge. On each sicle is a fine balustrade of stone, with places of shelter from the rain. The width of the bridge is 4.4 feet; having: on each side a fine foot-way for passengers. It consists of 14 piers, and 13 large and two small arches, all semicircular, that in the centre being 76 feet wide, and the rest decreasing four feet each from the other; so that the two least arches of the 13 great ones are each 52 feet. This magnificent structure was begun in 1738, and finished 1750 , at the expense of $389,000 \mathrm{l}$. defrayed by the parliament.

Blackfriars-bridge is not inferior to that of Westminster, either in magnificence or workmanship; but the situation of the ground on the two shores obliged the architect to employ elliptical arches: which, however, have a very fine effect; and many persons even prefcr it to Westminster bridge. This bridge was begun in 1760 , and finished in 1770, at the expense of $152,840 l$.

The cathedral of St. Paul is the most capacious, magnificent; and regular protestant church in the world. The length within is 500 feet; and its height, from the marble pavement to the cross on the top of the cupola, is 340 . It is built of Portland stone, according to the Greek and Roman orders, in the form of a cross, after the model of St. Peter's at Rome, to which, in some respects, it is superior. St. Paul's church is the principal work of sir Christopher Wren, and undoubtedly, the only work of the same magnitude that ever was completed by one man. He lived to a great age, and finished the building 37 years after he himself laid the first stone. It occupies six acres of ground, though the whole length of this church measures no more than the width of St. Peter's. The expense of build- 
ing, or rather rebuilding it, after the fire of London, was defrayed by a duty on coals, and is computed at a million sterling.

Westminster-abbey, or the collegiate church of Westminster, is a venerable pile of building in the Gothic taste. It was first built by Edward the Confessor: king Henry III, rebuilt it from the ground, and Henry VII, added a fine chapel to the cast end of it. This is the repository of the deceased British kings and nobility; and here are also monuments erected to the memory of many great and illus. trious personages, commanders by sea and land, philosophers, poets. \&c. In the reign of queen Anne, 4000 . a year, out of the coal duty, was granted by parliament for keeping it in repair.

The inside of the church of St. Stephen, Walbrook, is admired for its lightness and elegance, and does honour to the memory of sir Christopher Wren. The same may be said of the steeples of St. Mary's-le-Bow, and St. Bride's, which are supposed to be the mostcomplete in their kind of any in Europe. "The simplicity of the portico in Covent-garden is worthy the purest ages of ancient architecture. That of St. Martin's in the Fields would be noble and striking, could it be seen from a proper point of view. Several of the new churches are built in an elegant taste, and even some of the chapels have gracefulness and proportion to recommend them. The banqueting-house at Whitehall is but a very small part of a noble palace ciesigned by Inigo Jones, for the royal residence; and, as it now stands, under all iis disadvantages, its symmetry and ornaments are in the highest style and execution of architecture.

Westminster-hall, though on the outside it makes no very advantageous appearance, is a noble Gothic building, and is said to be the largest room in the world, the roof of which is not supported by pillars; it being 230 feet long, and 70 broad. The roof is the finest of its kind. Here are held the coronation-feasts of our kings and queens; also the courts of chancery, king's-bench, common-pleas, and exchequer.

The Monument, erected at the charge of the city, to perpetuate the memory of its being destroyed by fire, is worthy of notice. This column, which is of the Doric order, exceeds all the obelisks and pillars of the ancients, it being 202 feet high, with a stair-case in the middle to ascend to the balcony, whence there are other steps to the top, which is fashioned like an urn, with a flame issuing from it. On the base of the monument, next the street, the destruction of the city, and the relief given to the suffercrs by Charles II, and his brother, are emblematically represented in bas-relief. The north and south sides of the base have each a Latin inscription, the one describing its dreadful desolation, and the other its splendid resurrection; and on the east side is an inscription, stating when the pillar was begun and finished. The charge of erecting this monument, which was begun by sir Christopher Wren in 167l, and finished by him in 1677 , amounted to upwards of $13,000 l$.

The royal exchange is a large and noble building, and is said to have cost above 80,000 .

The terrace in the Adelphi is a very fine piece of architecture, and has laid open one of the finest prospects in the world.

We might here give a description of the Tower, Bank of England, the new Treasury, the Admiralty-office, and the Horse-guards at Whitehall, the Mansion-house, or house of the lord-mayor, the Custom-house, Excise-office, India-house, and a vast number of other 
public buildings; beside the magnificent edifices raised by our nobility; as lord Spencer's house, Marlborough-house, and Buckinghamhouse, in St. James's-park ; the earl of Chesterfield's house near hydepark; the duke of Devonshire's, and the late earl of Bath's in Piccadilly; the marquis of Lansdown's in Berkeley-square; Northumberland-house in the Strand; Montague-house (the British Museum*) in Bloomsbury; Cariton-house, the residence of his royal highness the prince of Wales, in Pall-Mall; Foley-house, and Burlington-house; with a number of others of the nobility and gentry: but these would be sufficient to fill a large volume.

This great and populous city is supplied with abundance of fresh water from the Thames and the New River, which is not only of inconceivable service to every family, but, by means of fire-plugs every where dispersed, the keys of which are deposited with the parishofficers, the city is in a great measure secured from the spreading of fire.

Before the conflagration in 1666, London (which, like most other great cities, had arisen from small beginnings) was totaliy inelegant, inconvenient, and unhealthy; which latter misfortune, without doubt, proceeded from the narrowness of the streets, and the unaccountable projections of the buildings, that confined the putrid air, and, joined with other circumstances, such as the want of water, rendered the city seldom free from pestilential contagion. The fire, which consumed the greatest part of the city, dreadful as it was to the inhabitants-at that time, was productive of consequences which made ample amends for the losses sustained by individuals : a new city arose on the ruins of the old; but, though more regular, open, convenient, and healthful than the former, yet it by no means had the character of magnificence or elegance, in many particulars; and it is ever to be lamented that the magnificent, elegant, and useful plan of the great sir Christopher Wren, was totally disregarded and sacrificed to the mean and selfish views of private property.

The plan of London, in its present state, will, in many instances, appear, to very moderate judges, to be as injudicious a disposition as can easily be conceived for a city of extensive commerce, on the border of so noble a river as the Thames. The wharfs and quays on its banks are extremely mean and inconvenient; and the want of regularity and uniformity in the streets of the city of London, and the mean avenues to many parts of it, are also circumstances that greatly lessen the grandeur of its appearance. Many of the churches, and other public buildings, are likewise thrust up in corners, in such a manner as might tempt foreigners to believe that they were designed to be concealed. The improvements of the city of London for some years past have however been very great; and the new streets, which are numerous, are spacious, and built with great regularity and elegance.

* Sir Hans Sloane, bart. (who died in 1753) may not improperly be called the founder of the British Museum; for its being established by parliament was only in consequence of his leaving, by will, his noble collection of natural history, his large library, and his numerous curiosities, which cost him 50,000l. to the use of the public, on conditions that the parliament would pay 20,000l. to his executors. To this collection were added the Cottonian library; the Harleian manuscripts, collected by the Oxford family, and purchased likewise by the parliament; and a collection of books given by the late major Edwards. His late majesty, in consideration of its great usefulness, was graciously pleased to add thereto the royal Libraries of books and manuscripts collected by the several kings of England. 
The roads leading to this great metropolis are not only lighted by lamps regularly placed on each side at short distances, but are rendered more secure by watchmen stationed within call of each other. Nothing can appear more brilliant than those lights, when viewed at a distance, especially where the roads run across ; and even the principal streets, such as Pall-Mall, New Bond-street, Oxford-strcet, \&c. convey an idea of elegance and magnificence.

Foreigners are surprised that the monarch of the richest nation in Europe, should be so indifferently lodged in his capital. The palace of St. James is commodious, but has the air of a convent; and that of Kensington, which was purchased from the Finch family by king William, is remarkable only for its gardens. Other houses, though belonging to the king, are far from deserving the name of royal.

Windsor-castle is the only fabric that merits the name of a royal palace in England; and that chiefly through its beautiful and commanding situation, which, with the form of its construction, rendered it, before the introduction of artillery, impregnable. Hampton-court was the favourite residence of king William. It is built in the Dutch taste, and has some good apartments, and, like Windsor, is near the Thames. Both these palaces have some good pictures; but nothing equal to the magnificent collection made by Charles I, and dissipated in the time of the civil wars. 'The cartoons of Raphael, which for design and expression, are reckoned the master-pieces of painting, have by his present majesty been removed from the gallery built for them at Hampton-court, to the Queen's palace, formerly Buckinghamhouse, in St. James's Park.

Next to the royal palaces, if not superior, in magnificence and expensive clecorations, are many private seats in the neighbourhood of London, and in every part of the kingdom, in which the amazing opulence of the English nation shines forth in its fullest point of view. In these also the princely fortunes of the nobility are made subservient to the finest classical taste; witness the seats of the marquis of Buckingham and earl Pembroke. At the seat of the latter, more remains of antiquity are to be found than are in the possession of, perhaps, any other subject.

The houses of the English nobility and gentry are peculiarly distinguished by the appropriate adaptation of their parts, the richness and elegance of their furniture, and the admirable preservation in which the whole is kept ; as well as by their hortulane and rural decorations, vistas, opening landscapes, temples; all the result of that enchanting art of imitating nature, and uniting beauty with magnificence.

York is a city of great antiquity, pleasantly situated on the river Ouse. It is surrounded with a good wall, through which are four gates and five posterns. Here are seventeen parish churches, and a very noble cathedral, or minster, it being one of the finest Gothic buildings in England. It extends in length 525 feet, and in breadth 110 feet. The nave, which is larger than any in Christendom, except that of St. Peter's church at Rome, is four feet and a half wider, and eleven feet higher, than that of St. Paul's cathedral at London. At the west end are two tower's, connected and supported by an arch which forms the west entrance, and is reckoned the largest Gothic arch in Europe. The windows are finely painted, and the front of the choir is adorned with statues of all the kings of England, from William the Norman to Henry VI, and there are thirty-two stalls, all of fine marble, with pillars, each consisting of one piece of alabaster. Here is 
also a very neat Gothic chapter-house. Near the cathedral is the Assembly-house, which is a noble structure, and which was designed by the late earl of Burlington. The city has a stone bridge of five arches over the river Ouse. It contains about sixteen thousand inhabitants.

Bristol is reckoned the second city in the British dominions, for trade, wealth, and the number of its inhabitants. It stands upon the north and south side of the river Avon; and the two parts of the city are connected by a stone bridge. The city is not well built; but, according to the late enumeration, contains 10,896 houses, and 63,645 inhabitants. Here is a cathedral and eighteen parish churches, besides seven or eight other places of worship. On the north side of a large square, called Queen's-square, which is adorned with rows of trees, and an equestrian statue of William the Third, there is a custom-house, with a quay half a mile in length, said to be one of the most commodious in England, for shipping and landing of merchants' goods. The Exchange, where the merchants and traders mect, is all of freestone, and is one of the best of its kind in Europe.

Lirerpool, situate at the mouth of the river Mersey, carries on an extensive traffic, and in population exceeds Bristol; containing, in $1801,77,653$ inhabitants. Its naturally advantageous situation has been considerably improved by art; particularly by the construction of three basins, or wet-docks, capable of containing near 4.00 ships of 500 tons in perfect security.

The city of Exeter was for some time the seat of the West-Saxon kings; and the walls, which at this time enclose it, were built by king Athelstan, who encompassed it also with a ditch. It is one of the first cities in England, as well on account of its buildings and wealth, as its extent, and the number of its inhabitants. It has six gates, and, including its suburbs, is more than two miles in circumference. There are sixteen parish churches, besides chapels, and fire large meeting-houses, within the walls of this city. The trade of Exeter, in serges, perpetuants, long-ells, druggets, kerseys, and other woollen goods, is very great. Ships come up to this city by means of sluices.

The city of Gloucester stands on a plcasant hill, with houses on every descent, and is a clean, well-built town, with the Severn on one side, a branch of which brings ships up to it. The cathedral here is an ancient and magnificent structure; and there are also five parish churches.

Litchfield stands in a valley, three miles south of the Trent, and is divided by a stream which runs into that river. The cathedral was founded in the year 1148: it was much damaged during the civil war, but was so completely repaired soon after the Restoration, that it is now one of the noblest Gothic structures in England. Litchfield is thought to be the most considerable city in the north-west of England, except Chester.

Chester is a large, populous, and wealthy city, with a noble bridge, that has a gate at each end, and twelve arches over the Dee, which falls into the sea. It has eleven parishes, and nine well-built churches. The streets are generally even and spacious, and, crossing one another in straight lines, meet in the centre. The walls were first erected by Edelfleda, a Mercian lady, in the year 908, and join on the south side of the city to the castle, from whence there is a pleasant walk round the city upon the walls, except where it is intercepted by some of 
the towers over the gates; and from thence there is a prospect of Flintshire, and the mountains of Wales.

Warwick is a town of great antiquity, and appears to have been of eminence even in the time of the Romans. It stands upon a rock of freestone, on the banks of the Avon: and a way is cut to it through the rocks, from each of the four cardinal points. The tawn is populous, and the streets are spacious and regular, and all meet in the centre of the town.

The city of Coventry is large and populous. It was formerly surrounded by a strong wall, and had twelve noble gates. It has a handsome town-house, and three parish churches, the steeple of one of which (St. Michael's) is esteemed a master-piece of architecture.

Salisbury is a large, neat, and well-built city, situated in a valley, and watered by the Upper Avon on the west and south, and by the Bourne on the east. The streets are.generally spacious, and built at right angles. The cathedral, which was finished in 1358, at the ex. pence of above 26,000l. is, for a Gothic building, the most elegant and legular in the kingdom. It is in the form of a lantern, with a beau= tiful spire of freestone in the middle, which is 4.10 feet high, being the tallest in England. The length of the church is 478 feet, the breadth is 76 feet, and the height of the vaulting 80 feet. The church has a cloister, which is 150 feet square, and of as fine workmanship as any in England. The chapter-house, which is an octagon, is 150 feet in circumference; and yet the roof bears all upon one small pillar in the centre, so much too weak, in appearance, for the support of such a prodigious weight, that the construction of this building is thought one of the greatest curiosities in England.

The city of Bath took its name from some natural hot baths, for the medicinal waters of which this place has been long celebrated, and much frequented. The seasons for drinking the Bath waters are the spring and autumn; the spling season begins with April, and ends with June; the autumn season begins with September, and lasts to December ; and some patients remain here all the winter. In the spring, this place is most frequented for health, and in the autumn for pleasure, when at least two thirds of the company, consisting chiefly of persons of rank and fortune, come to partake of the amusements of the place. In some seasons there have been no less than 8000 persons at Bath, besides its inhabitants. Some of the buildings lately erected here are extremely elegant, particularly Queen'ssquare, the North and South Parade, the Poyal Forum, the Circus, and Crescent

Nottingham is pleasantly situate on the ascent of a rock, overlooking the river Trent, which runs parallel with it about a mile to the south, and has been made navigable. It is one of the neatest places in England, and has a considerable trade.

Manchester, situate at the confluence of the rivers Irkand Irwell in Lancashire, though considered only as a village or market-town, exceeds in population every other town or city in England except the metropolis; the number of its inhabitants in 1801 being 84,020 . This it owes to its immense cotton manufactories, which, beside the townspeople, are said to give employment to fifty or sixty thousand per-s sons.

Birmingham in Warwickshire, and Sheffield in the southern part of Yorkshire, contain extensive manufactories of differen: kinds of hardware and cutlery; and both (the former especially) are in con- 
sequence extremely populous, the number of inhabitants being in the former, in 1801, 73,670, and in the latter 31,314 .

No nation in the world has such dock-yards, and all conveniences for construction and repairs of the royal navy, as Portsmouth, the most regular fortification in England, Plymouth (by far the best dockyard) Chatham, Woolwich, and Deptford. The Royal Hospital at Greenwich, for superannuated scamen, is scarcely exceeded by any royal palace, for its magnificence and expence.

CoMMERCE AND MA NUFACTURES....It is well known that commerce and manufactules have raised the English to be the first and most powerful people in the world. Historical reviews, on this head, would. be tedious. It is sufficient then to say, that it was not till the reign of Elizabeth that England began to feel her true weight in the scale of commerce. She planned some settlements in America, particularly Virginia, but left the expence attending them to be defrayed by her subjects; and indeed she was ton parsimonious to carry her own notions of trade into execution. James I, entered upon great and beneficial schemes for the English trade. The East-India company owes to him their success and existence; and British America saw her most flourishing colnnies rise under him and his family. The spirit of commerce went hand in hand with that of tiberty; and though the Stuarts were not friendly to the latter, yct, during the reigns of the princes of that family, the trade of the nation was greatly increas ed. It is not intended to follow commerce through all her fluctuations, but cnly to give a gene ral representation of the commercial interest of the nation.

The present system of English politics may properly be said to have taken rise in the reign of queen Elizabeth. At that time the protestant religion was establisined, which naturally allied us to the reformed states, and made all the popish powers cur enemies.

WVe began in the same reign to extend our trade, by which it ber came necessary for us also to watch the commercial progress of onr neighbours, and, if not to incommode and obstruct their traffic, to hinder then from impairing ours.

We then likewise settled colonies in America, which was become the great scene of European ambition; for, seeing with what treasures the Spaniards were annually enriched from Mexico and Peru, every nation imagined that an American conquest or plantation woulc. certainly fill the mother-country with gold and silver.

The discoveries of new regions, which were then every day made, the profit of remote traflic, and the necessity of long voyages, produced, in a few years, a great multiplication of shipping. The sea was considered as the wealthy element; and, by degrees, a new kind. of sovereignty arose, called naval dominion.

As the chief trade of Europe, so the chief maritime power, was at first in the hands of the Portuguese and Spaniards, who, by a com pact to which the consent of othe1 princes was not asked, had divided the newly-discorered countries between them: but the crown. of Portugal having fallen to the king of Spain, or being seized by him, he was master of the shipping of the two nations, with which he kept all the coasts of Europe in alarm, till the armada he had raised at a vast expence for the conquest of England was destroyed; which put a stop, and almost an end, to the naval power of the Spaniards.

At this time the Dutch, who were oppressed by the Spaniards, and feared yet greater evils than they felt, resolved no longer to endurs.

Vor. I. 
the insolence of their masters; they therefore revolted, and, after a struggle in which they were assisted by the money and forces of Elizabeth, erected an independent and powerful commonwealth.

When the inhabitants of the Low-Countries had formed their sys. tem of government, and some remission of the war gave them leisure to provide for their future prosperity, they easily perceived, that, as their territories were narrow, and their numbers small, they could preserve themselves only by that power which is the consequence of wealth; and that by a people, whose country produced only the necessaries of life, wealth was not to be acquired but from foreign dominions, and by transportation of the products of one country into another.

From this necessity, thus justly estimated, arose a plan of com. merce, which was for many years prosecuted with an industry and success perhaps never seen in the world before; and by which the poor tenants of mud.walled villages and impassable bogs, erected themselves into high and mighty states, who set the greatest monarchs at defiance, whose alliance was courted by the proudest, and whose power was dreaded by the fiercest nations. By the establishment of this state, there arose to England a new ally and a new rival.

When queen Elizabeth entered upon the government, the customs. produced only $36,000 l$. a year: at the Restoration, they were let to farm for $400,000 l$. and produced considerably above double that sum before the revolution. The people of London, before we had any plantations, and when our trade was inconsiderable, were computed at about 100,000; at the death of queen Elizabeth they were increased to 150,000 , and are now nearly six times that number. In those days we had not only naval stores, but ships, from our neighbours. Germany furnished us with all things made of metal, even to nails : wine, paper, linen, and a thousand other things, came from France. Portugal furnished us with sugars : all the produce of America was brought to us from Spain; and the Venetians and Genoese retailed to us the commodities of the East-Indies at their own price. The legal interest of money was twelve per cent. and the common price of our land ten or twelve years purchase. We may add, that our manufactures were few, and those but indifferent; the number of English merchants very small; and our shipping much inferior to what lately belonged to the American colonies.

Great Britain is, of all other countries, the most proper for trade; as well from its situation as an island, as from the freedom and excel lency of its constitution, and from its natural products and considerable manufactures. For exportation, our country produces many of the most substantial and necessary commodities; as butter, cheese, corn, cattle, wool, iron, lead, tin, copper, leather, copperas, pit-coal, alum, saffron, \&c. Our corn sometimes preserves other countries from starving. Our horses are the most serviceable in the world, and highly valued by all nations for their hardiness, beauty, and strength. With beef, mutton, pork, poultry, biscuit, we victual not only our own fleets, but many foreign vessels that come and go. Our iron we export manufactured in great guns, carcasses, boinbs, \&c. Prodigious and almost incredible is the value likewise of other goods from hence exported, viz. hops, flax, henip; hats, shoes, household-stuff, ale, beer, red-herrings, pilchards, salmon, oysters, liquorice, watches, ribands, toys, \&x. 
There is scarcely a manufacture in Europe but what is brought to §reat perfection in England. The woollen manutactures is the most considerable, and exceeds in goodness and quantity that of any other nation. Hardware is another principal article : locks, edge-tools, guns, swords, and other arms, are of superior excellence; household uten. sils of brass, iron, and pewter, also, are very great articles; and our clocks and watches are in great esteem.

Of the British commerce, that branch which we enjoyed exclusively, viz. the commerce with our colonies, was long regarded as the most advantageous. Yet, since the separation of the American States, from Great Britain, the trade, the industry, and manufactures of the latter hare continually increased. New markets have opened, the returns from which are more certain and less tedious than those from America. By supplying a greater variety of markets, the skill and ingenuity of our artisans have taken a wider range; the productions of their labour have been adapted to the wants, not of rising colonies, but of nations the most wealthy and the most refined; and our commercial system, no longer resting on the artificial basis of monopoly, has been rendered more solid as well as more liberal. The trade of England to the United States, in a variety of articles, is likewise very considerable.

The principal islands belonging to the English, in the West Indies, are Jamaica, Barbadoes, St. Christopher's, Grenada, Antigua, St, Vincent, Dominica, Anguilla, Nevis, Montserrat, the Bermudas or Somer's. Islands, and the Bahama or Lucayan Islands in the Atlantic Ocean; besides Trinidad, cecled to England by the late treaty of Aniens, and St. Lucia, recently taken from the French.

The English trade with their West-India Islands consists chiefly in sugars, rum, cotton, logwood, cocoa, coffee, pimento, ginger, indigo, materials for dyers, mahogany and manchineel planks, drugs and preserves. For these, the exports from England are Osnaburgs, a coarse kind of linen, with which the West-Indians now clothe their slaves; linen of all sorts, with broad-cloth and kerseys, for the planters, their overseers, and families; silks and stuffs for their ladies, and household servants; hats; red caps for their slaves of both sexes; stockings and shoes of all sorts; gloves and millinery ware, and perukes: laces for linen, woollen, and silks; strong beer, pale beer, pickles, candles, butter, and cheese ; iron-ware, as saws, files, axes, hatchets, chisels, adzes, hoes, mattocks, gouges, planes, augers, nails, lead, powder, and shot; brass and copper wares; toys, coals, and pantiles; cabinet wares, snuffs; and in general whatever is raised or manufactured in Great Britain; also negroes from Africa, and all sorts of Indian goods.

The trade of England to the East Indies constitutes one of the most stupendous political as well as commercial machines that is to be met with in history. The trade itself is exclusive, and lodged in a company which has a temporary monopoly of it, in consideration of money advanced to the government. This company exports to the East Indies all kinds of woollen manufacture, all sorts of hardware, lead, bullion, and quicksilver. Their imports consist of gold, diamonds, raw silks, drugs, tea, pepper, arrack, porcelain or Chinaware, salt-petre for home-consumption; and of wrought silks, muslins, calicoes, cottons, and all the woven manufactures of India, for exportalion to foreign countries.

To Turkey, England sends, in her own bottoms, woollen cloths, tin, 
lead, and iron, hardware, iron utensiis, clocks, watches, verdigris, spices, cochineal, and logwood. Stue imports from thence raw silks, carpets, skins, dyeing druys, cotton, fruits, medicinal drugs, cofiee, and some other articles. Formerly the balance of this trade was about 500,000l. annuaily, in favour of England. The English trade was atterwards diminshed through the practices of the French; but the Turkey trade at present is at a very low ebb with the French as well as the English.

Engiand exports to Italy woollen goods of various linds, peltry, leatner, lead, tin, fish, and East-India goods; and brings back raw and thrown silk, wines, oil, soap, olives, oranges, lemons, pomegranates, dried fruits, colours, anchovies, and other articles of luxury.

To Spain, England sends all kinds of woollen goods, leather, tin, lead, fish, corn, iron and brass manufactures, haberdashery wares, assortments of linen, from Germany and elsewhere, for the American colonies; and receives in return, wines, oils, dried fruits, oranges, lemons, olives, wool, indigo, cochineal, and other dyeing drugs, colours, gold and silver' coin.

Portugal formerly was, upon commercial accounts, the favourito ally of England, whose flects and armies have more than once saved her from destruction. England sends to this country almost the same kind of merchandises as to Spain, and receives in return vast quantities of wines, with oils, salt, dried and moist fruits, dyeing drugs, and gold coin.

The direct trade with France, Ifolland, and Flanders, has been interrupted by the late and present wars, though great quantities of English commodities still continue to be introduced into those countries through the ports of the north of Germany.

England sencls to the coast of Guinea sundry sorts of coarse woollen and linen, iron, penter, brass, and hardware nanufactures, lead, shot, swords, knives, fire-arnss, gunpowder, and glass manufactures. And, besidcs its drawing no money out of the kingdom, it lately supplied the American colonies with negro slaves, amounting in number. to above 100,000 annually. The other returns are in gold-dust, gum, dyeing and other drugrs, red-wood, guinea-grains, and ivory.

To Arabia, Persia, China, and other parts of Asia, England scnds much foreign silver coin and bullion, and sundry English manufactures, of woollen goods, and of lead, iron, and brass; and brings home from those remote regions, muslins and cottons of many various kinds, calicoes, raw and wrought silk, chintz, teas, porcelain, gold-clust, coffee, salt-petre, and many other drugs. And so great a quantity of those various merchandises is exported to foreign Euro. pean nations, as more than abundantly compensates for all the silver bullion which England carries out.

During the infancy of commerce to foreign parts, it was judged expedient to grant exclusive charters to particular bodies or corporations of men; hence the East-India, South-Sea, Hudson's-Bay, Turkey, Russia, and Royal-African companies; but the trade to Turkey, Russia, and Africa, is now laid open; though the merchant who proposes to trade thither must become a member of the company, be subject to their laws and regulations, and adrance a small sum at admission, for the purpose of supporting consuls, forts, \&c.

The prodigious extent of the trade of England, and its great and rapid increase of late years, will clearly appear from a comparative statement of the imports and exports, at different periods; the value 
of which, including foreign merchandise and manufactures, in the years undermentioned, was as follows :

\begin{tabular}{|c|c|c|c|c|c|}
\hline & Imports. & & & - & Exports. \\
\hline 1772 & $14,500,000 l$. & • & - & & $17,719,000 \mathrm{l}$. \\
\hline 1783 & $13,325,000 l$. & . & . & & $14,741,000 l$. \\
\hline 1792 & $19,029,000 l$. & . & . & . & $24,878,000 l$. \\
\hline 1797, & $21,450,000 l$. & . & 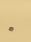 & 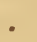 & $28,917,000 l$. \\
\hline 1801, & $58,680,000 l$. & . & . & . & $57,520,000 l$. \\
\hline 1809 & $46,138,179 l$. & . & - & - & $66,017,712 l$. \\
\hline
\end{tabular}

The number of registered ressels belonging to the British domirions, employed in trade in the year 1801, was 19,772 ; their tonnage $2,037,517$; and their number of men 143,987 .

As the quantity of circulating specie may in some measure indicate the extent of commerce, we may judge of the increase of the latter by comparing the sums which the three last monarchs found it necessary to coin. By George I, 8,725,921l. sterling were coined. In the long reign (thirty-three year's) of George II, 11,966,576l. sterling; and in the first twenty-four years of his present majesty's reign the sums coined amounted to $33,089,274 l$. sterling.

The English manufactures were a few years back estimated at the annual value of $63,500,000 l$. and supposed to employ $1,585,000$ people : of this sum, the woollen manufacture is stated to produce about $15,000,000 l$. the leather $10,000,000 l$. the iron, tin, and lead, 10,000,000 $l$. and the cotton $9,000,000 \mathrm{l}$. In 1809 the whole value of British maiufactures was estimated at $137,301,605 l$.

ConstituTION AND GOVERNMENT...Tacitus, in describing such a constitution as that of England, seems to think that, nowever beautiful it may be in theory, it will be found impracticable in the execution. Experience has proved this to be a mistake; for, by contrivances unknown to antiquity, the English constitution has existed for above 500 years. It must at the same time be admitted, that it has received, during that time, many amendments, and some interruptions; but its principles are the same with those described by the above-mentioned historian as belonging to the Germans and the other northern ancestors of the English nation, and which are very improperly blended under the name of Gothic.

All civil matters were proposed in a general assembly of the chief c,fficers and the people, till, by degrees, sheriffs and other civil officers were appointed. To Alfred we owe that master-piece of judicial policy, the subdivision of England into wapentakes and hundreds, and the subdivision of hundreds into tithings, names that still subsist in England; and overseers were chosen to direct them for the good of the whole. The sheriff was the judge of all civil and criminal matters within the county; and to him, after the introduction of Christianity, was added the bishop. In process of time, as business multiplied, itinerant and other judges were appointed; but, by the cariliest records, it appears that all civil matters were decided by 12 or 15 men, living in the neighbourhood of the place where the dispute lay; and here we have the origin of English jurics. It is ccrtain that they were in use among the carliest Saxon colcnics, thcir institution bcing ascribed by bishop Nicholson to Woden himself, their great legislator and leader. Hence we find traces of juries in the laws of all those nations which adopted the feudal system, as in Germany, 
France, and Italy; who had all of them a tribunal composed of twelve good men and true, equals or peers of the party litigant. In England we find actual mention made of them so early as the laws of king Ethelred, and that not as a new invention.

Before the introduction of Christianity, we know not whether the Saxols admitted of juries in criminal matters; but we are certain that there was no action so criminal as not to be compensated for by money.* A mulct was imposed, in proportion to the guilt, even if it tras murder of the king, upon the malefactor; and by paying it he purchased his pardon. Those barbarous usages seem to have ceased soun after the Saxons were converted to Christianity; and cases of felony and murder were then tried, even in the king's court, by a jury.

Royalty, among the Saxons, was not, strictly speaking, hereditary, though, in fact, it came to be rendered so through the affection which the people bore for the blood of their kings, and for preserving the regularity of government. Even estates and honours were not striclly hereditary, till they were made so by William the Norman.

In many respects, the first princes of the Norman line afterwards did all they could to efface from the minds of the people the remembrance of the Saxon constitution; but the attempt was to no purpose. The nobility, as well as the people, had their complaints against the crown; and, after much war and bloodshed, the famous charter of English liberties, so well known by the name of Magna Charta, was forcibly, in a manner, obtained from king John, and confirmed by his son Henry III, who succeeded to the crown in 1216 . It does not appear that, till this reign, and after a great deal of blood had been spilt, the commons of England were represented in parliament, or the great council of the nation; so entirely had the barons engrossed to themselves the disposal of property.

The precise year when the louse of commons was formed is not known: but we are certain there was one in the reign of Henry III, though we shall not enter into any disputes about their specific powers. We therefore now proceed to describe the constitution, as it stands at present.

In all states there is an absolute supreme power, to which the right of legislation belongs; and which, by the singular constitution of these kingdoms, is here vested in the king, lords, and commons.

OF TIE XING....The supreme executive power of Great Britain and Ireland is vested by our constitution in a single person, king or queen: for it is indifferent to which sex the crown descends; the person entitled to it, whether male or female, is immediately intrusted with all the ensigns, rights, and prerogatives of sovereign power.

The grand fundamental maxim, upon which the right of succession to the throne of these lingdoms depends, is, "that the crown, by common law and constitutional custom, is hereditary, and this in a manner peculiar to itself; but that the right of inheritance may, from time to time, be changed, or limited, by act of parliament : under which limitations the crown still continues hereditary."

The principal duties of the king are expressed in his oath at the coronation, which is administered by one of the archbishops or bish. ops of the realm, in the presence of all the people, who, on their

- Called by the Saxons Guelt; and thence the word guilty, in criminal trials̀. 
parts, do reciprocally take the oath of allegiance to the crown. This coronation oath is conceived in the following terms :

"The archbishof, or bishof, shall say, IVill you solemnly promise and swear to govern the people of this kingdom of England, and the dominions thereunto belonging, according to the statutes in parliament agreed on, and the laws and customs of the same? The king or queen shall say, I solemnly promise so to do.

"Archbishof or bisho/. Will you, to the utmost of your power, cause law and justice, in mercy, to be executed in all your judgments? King or queen, I will.

"Archbishof or bishof. Will you, to the utmost of your porver, maintain the laws of God, the true profession of the Gospel, and the protestant reformed religion established by the law? And will you preserve unto the bishops and clergy of this realm, and to the churches committed to their charge, all such rights and privileges as by the law do or shall appertain unto them, or any of them?. Kins or queen, All this I promise to do.

"After this, the king or queen, laying his or her hand ufion the holy Gosthel. shall say, The things which I have here before promised, I will perform and keep : so help me God! and then 'kiss the book."

This is the form of the coronation oath, as it is now prescribed by our laws : and we may observe, that, in the king's part in this original contract, are expressed all the duties that a monarch can owe to his people; viz. to govern according to law ; to execute judgment in mercy; and to maintain the established religion With respect to the latter of these three branches, we may further remark, that by the act of union, 5 Anne, c. 8 , two preceding statutes are recited and confirmed; the one of the parliament of Scotland, the other of the parliament of England; which enact, the former, that every ling at his accession shall take and subscribe an oath, to preserve the protestant religion, and presbyterian church government in Scotland: the latter, that at his coronation, he shall take and subscribe a similar oath, to preserve the settlement of the church of England within England, Ireland, Wales, and Berwick, and the territories thereunto belong * ing.

The king of Great Britain, notwithstanding the limitations of the power of the crown already mentioned, is the greatest monarch reigning over a free people. His person is sacred in the eye of the law, which makes it high treason so much as to imagine or intend his death; neither can he, in himself, be deemed guilty of any crime; the law taking no cognizance of his actions, but only in the persons of his ministers, if they infringe the laws of the land. As to his power, it is very great, though he has no right to extend his prerogative beyond the ancient limits or the boundaries prescribed by the constitution; he can make no new laws, nor raise any new taxes, nor act in opposition to any of the laws : but he can make war or peace; send and receive ambassadors; make treaties of league and commerce; levy armies, and fit out fleets, for the defence of his kingdom, the annoyance of his enemies, or the suppression of rebellions; grant commissions to his officers, both by sea and land, or revoke them at pleasure; dispose of all magazines, castles, \&c. summon the parliament to meet, and, when met, adjourn, prorogue, or dissolve it at pleasure; refuse his assent to any bill, though it has passed both houses; which, consequently, by such a refusal, has no more force than if it had never been moved : but this is a prerogative that the 
kings of Lingland have very seldom ventured to exercise. He pos. sesses the right of choosing his own council; of nominating all the great officers of state, of the household, and the church; and, in fine, is the fountain of honour, from whom all degrees of nobility and knighthood are derived. Such is the dignity and power of a king of Great Britain.

OF THE PARLIAMENT...Parliaments, or general councils, in some shape, are, as has been before observed, of as high antiquity as the Saxon government in this island, and coevai with the kingdom itself. Blackstone, in his valuable Commentaries, says, "It is generally agreed, that in the main the constitution of parliament, as it now stands, was marked out so long ago as the 17 th of king John, A. D. 1215 , in the Great Charter granted by that prince; wherein he promises to summon all archbishops, bishops, abbots, lords, and greater barons, personally : and all other tenants in chief under the crown, by the sheriffs and bailiffs, to meet at a certain place, with forty days notice, to assess aids and scutages when necessary. And this constitution hath subsisted, in fact, at least from the year 1266, 49 Henry III, there being still extant writs of that date to summon knights, ci. tizens, and burgesses to parliament."

The parliament is assembled by the king's writs, and its sitting must not be intermitted above three years. Its constituent parts are, the king, sitting there in his royal political capacity, and the three estates of the realm; the lords spiritual, the lords temporal, who sit. together with the king in one house, and the commons, who sit by themselves in another. The king and these three estates, together, form the great corporation or body politic of the kingdom, of which the king is said to be caput, principium, et finis : for, upon their com. ing together, the king meets them, either in person or by representation ; without which there can be no beginning of a parliament; and he also has alone the power of dissolving them.

It is highly necessary, for preseving the balance of the constitution, that the executive power should be a branch, though not the whole, of the legislature. The crown cannot begin of itself any alterations in the present established law; but it may approve or disapprove of the alterations suggested and consented to by the two houses. The legislative, therefore, cannot abridge the executive power of any rights which it now has by law, without its own consent; since the law must perpetually stand as it now does, unless all the powers will agree to alter it. And herein indeed consists the true excellence of the English government, that all the parts of it form a mutual check upon each other. In the legislature, the people are a check upon the nobility, and the nobility a check upon the people, by the mutual privilege of rejecting what the other has resolved: while the king is a check upon both; which preserves the executive power from encroachments.

The lords spiritual consist of two archbishops and twenty-four bishops, with four bishops from Ireland. The lords temporal consist of all the peers of the realm; the bishops not being in strictness held to be such, but merely lords of parliament. Some of the peers sit by descent, as do all ancient peers; some by creation, as do all the new-made ones; others, since the unions with Scotland and Ireland, by election, which is the case of the sixteen peers who represent the body' of the Scotch nobility, and the twenty-eight Irish peers who 
represent the Irish nobility. The number of peers is indefinite, and may be increased at will by the power of the crown.

The commons consist of all such men of any property in the kingdom as have not seats in the house of lords ; every one of whom has a voice in parliament, either personally, or by his representative.* The counties are represented by knights, elected by the proprietors of lands; the cities and boroughs are represented by citizens and burgesses, chosen by the mercantile part, or supposed trading inter. est, of the nation. The number of English representatives is 513 , of Scotch 45, and of Irish 100; in all 658. And every member, though chosen by one particular district, when elected and returned, serves for the whole realm. For the end of his going thither is not particular, but general ; not merely to serve his constituents, but also the commonwealth, and to advise his majesty, as appears from the writ of summons.

Some of the most important privileges of the members of either house are, privilege of speech, of person, of their domestics, and their lancls and goods.

The house of lords have-a right to be attended, and consequently are, by the judges of the courts of king's bench and common pleas, and such of the barolas of the exchequer as are of the degree of the coif, or have been made serjeants at law, as likewise by the masters of the court of chancery, for their advice in points of law, and for the greater dignity of their proceedings.

The speaker of the house of lords is generally the lord chancellor, or lord keeper of the great seal; which dignities are commonly vested in the same person.

Each peer has a right, by leave of the house, as being his own representative, when a vote passes contrary to his sentiments, to enter his dissent on the journals of the house, with the reasons of such dissent; which is usually styled his protest. Upon particular occasions, however, these protests have been so bold as to give offence to the majority of the house, and have therefore been expunged from their journals; but this has always been thought a vio lent measure.

The house of commons may be properly styled the grand inquest of Great Britain, empowered to inquire into all national grievances. The peculiar laws and customs of the house of commons relate principally to the raising of taxes, and the elections of members to serve in parliament. With regard to taxes, it is the ancient indisputable privilege and right of the house of commons, that all grants of subsidies, or parliamentary aids, do begin in their house, and are first bestowed by them; although their grants are not effectual, to all intents and purposes, until they have the assent of the other two branches of the legislature. The general reason given for this exclusive privilege of the house of commons is, that the supplies are raised upon the body of the people, and therefore it is proper that they alone should have the right of taxing themselves : and so reason-

* Tlis must be unclerstood with some limitation. Those who are possessed of land estates, though to the value of only $40 \mathrm{~s}$. per annum, have a right to vote for members of parliament; as have most of the members of corporations, boroughs, \&ic. But there are rery large trading towns, and populous places, which send no members to parliament; and of those towns which do send members, great num. ber's of the inhabitants have no votes. Many thousand persons of great personal rowerty have, therefore, no representatives.

YoL. I.

A a 
ably jealous are the commons of this privilege, that herein they will not suffer the other house to exert any power but that of rejecting; they will not permit the least alteration or amendment to be made by the lords in the mode of taxing the people by a money-bill. Under this appellation are included all bills by which money is directed to be raised upon the subject, for any purpose, or in any shape whatsoever, either for the exigencies of government, and collected from the kingdom in general, as the land-tax, or for private benefit, and collected in any particular district, as by turnpikes, parishrates, or in any other manner.

The method of making laws is much the same in both houses. In each house, the act of the majority binds the whole; and this majority is declared by rotes publicly and openly given; not privately, or by ballot. The latter method might, perhaps, be serviceable, to prevent intrigues and unconstitutional combinations; but it is impossible to be practised with us, at least in the house of commons, where every member's conduct is subject to the future censure of his constituents, and therefore should be openly submitted to their inspection.

The giving the royal assent to bills is a matter of great form. When the king is to pass bills in person, he appears on his throne in the house of peers, in his royal robes, with the crown on his head, and attended by his great officer's of state, and heralds. A seat on the right hand of the throne, where the princes of Scotland, when peers of England, formerly sat, is reserved for the prince of Wales. The other princes of the blood sit on the left hand of the king, and the chancellor on a close bench removed a little backwards. The viscounts and temporal barons, or lords, face the throne, on benches, or' wool-packs, covered with red cloth or baize. The bench of bishops runs along the house, to the bar on the right hand of the throne; as the dukes and earls do on the left. The chancellor and judges, on ordinary days, sit upon wool-packs, between the barons and the throne. The common opinion is, that the house sitting on wool is symbolical of wool being formerly the staple commodity of the kingdom. Many of the peers, on solemn occasions, appear in their parliamentary robes. None of the commons have any robes, excepting the speaker, who wears a long black silk gown; and when he appears before the king, it is trimmed with gold.

The royal assent may be given two ways; 1, In person. When the king sends for the house of commons to the house of peers, the speaker carries up the money bill or bills in his hand; and, in delivering them, he addresses his majesty in a solemn speech, in which he seldom fails to extol the generosity and loyalty of the commons, and to tell his majesty how necessary it is to be frugal of the public money. It is upon this occasion that the commons of Great Britain appear in their highest lustre. The titles of all bills that have passed both houses are read; and the king's answer is declared by the clerk of the parliament in Norman French. 2, By the statute 33 Henry VIII, c. 21, the ling may give his assent by letters patent under his great seal, signed with his hand, and notified, in his absence, to both houses assembled together in the high house, by commissioners consisting of certain peers named in the letters. And, when the bill has received the royal assent in either of these ways, it is then, and not before, a statute or act of parliament.

The king of England, besides his high court of parliament, has subordinate officers and ministers to assist him, and who are respon- 
sible for their advice and conduct. They are made by the king's nomination, without either patent or grant; and, on talking the requisite oaths, they become immediately privy-councillors during the life of the king that chooses them, but subject to removal at his pleasure.

The duty of a privy-councillor appears from the oath of office, which consists of seven articles. 1, To advise the king according to the best of his cunning and discretion. 2, To advise for the king's honour, and good of the public, without partiality through affection, love, need, doubt, or dread. 5, To keep the king's counsel secret. 4, To avoid corruption. 5, To help and strengthen the execution of what shall be there resolved. 6, To withstand all persons who would attempt the contrary. And, lastly, in general, 7, To observe, keep, and do all that a good and true councillor ought to do to his sovereign lord.

As no gorernment can be so complete as to be provided with laws that may answer every unforeseen emergency, the privy-council, in such cases, can supply the deficiency. Upon great and urgent occasions, such as that of a famine, or the dread of one, they can supersede the operation of the laws, if the parliament is not sitting; but this is considered as illegal, and an act of parliament must pass for the pardon and indemnification of those concerned.

There is one secretary of state for foreign affairs, and another for the home department. During the American war, there was a third secretary of state, whose office was revived in 1794, by the title of secretary for the war department.

The cabinet-council is a committee of the privy-council, consisting of a select number of ministers and noblemen, according to the king's opinion of their integrity and abilities, or attachment to the views of the court; but though its operations are powerful and extensive, a cabinet-council is not essential to the constitution of England.

This observation naturally leads us to mention the person who is so well known by the name of the first minister; a term unknown to the English constitution, though the office, in effect, is perhaps neces. sary. The constitution points out the lord high chancellor as minister; but the affairs of his own court give him sufficient employment. When the office of the first lord of the treasury is united with that of chancellor of the exchequer (offices which we shall explain hereafter) in the same person, he is considered as first minister. The truth is, his majesty may make any of his servants his first minister. But though it is no office, yet there is a responsibility annexed to the name and common repute, that renders it a post of difficulty and danger. We shall now take a short review of the nine great officers of the crown, who, by their posts, take place next to the princes of the royal family and the two primates.

The first is the lord high steward of England. This is an office very ancient, and formerly was hereditary, or at least for life : but now, and for centuries past, it is exercised only occasionally; that is, at a coronation, or to sit as a judge on a peer or peeress, when tried for a capital crime. In coronations, it is held, for that day only, by some nobleman of the first rank. In cases of trials, it is exercised generally by the lord chancellor, or lord keeper, whose commission as high steward ends with the trial, by breaking his white rod, the badge of his office.

The lord high chancellor presides in the court of chancery, to 
moderate the severities of the law in all cases in which the property of the subject is concerned; and he is to determine according to the dictates of equity and reason. He is an officer of the greatest weight and power of any now subsisting in the kingdom, and is superior in precedency to every temporal lord.

The post of lord high treasurer has of late been vested in a commission, consisting of nive persons, who are called lords of the treasury : but the first commissioner is supposed to possess the power of lord high treasurer. He has the management and charge of all the revenues of the crown kept in the exchequer; as also the letting of the leases of ail crown lands, and the gift of all places belonging to the customs in the several ports of the kingdom.

The lord president of the council was an officer formerly of $\mathrm{great}$ power, and hath precedence next after the lord chancellor and lord treasurer. His duty is to propose all the business transacted at the council-board, and to report to the king, when his majesty is not present, all its debates and proceedings.

The office of lord privy seal consists in his putting the king's seal to all charters, grants, and the like, which are signed by the king, in order to their passing the great seal.

The officer of lord great chamberlain of England is hereditary in the duke of Ancaster's family. He attends the king's person, on his coronation, to drcss him : he has likewise charge of the house of lords during the sitting of parliament; and of fitting up Westminster-hali for coronations, triais of peers, or impeachments.

The office of lord high constable has been disused since the attain. der and execution of Stafford, duke of Buckingham, in the year 1521, but is occasionally revived for a coronation.

The duke of Norfolk is hereditary earl marshal of England. Bcfore Englandi became so commercial a country as it has been for a hundred years past, this office reculuired great abilitics, learning, and knowledge of the English history, for its discharge. In war time he was judge of army causes, and decided according to the principles of the civil law. If the cause did not admit of such a decision, it was left to a personal combat, which was attended with a vast variety of ceremonies; the arrangement of which, even to the smallest trifle, fell within the marshal's province. 'To this day he or his deputy regulates all points of precedency according to the archives kept in the herald's office, which is entirely within his jurisdiction. He directs all solemn processions, coronations, proclamations, general mournings, and the like.

The officer of lord high admiral of England* is now likewise held by commission, and is equal in its importance to any of the preceding, especially since the increase of the Britisi naval power. The English admiralty is a board of direction as well as execution, and is in its proceedings independient of the crown itself. All trials upon life and death, in maritime affairs, are appointed and held under a commission immediately issuing from that board; and the members must sign even the death-warrants for execution. The board of admiralty regulates the whole naval force of the reaim, and names all its officers, or confirms them when named: so that its jurisdiction is very extensive.

- The last lord high admiral was George prince of Denmark and husband to gueen Anne. 
COURTS OF LAW AND LAWS.... The court of chancery, which is the court of equity, is next in dignity to the high court of parliament, and is designed to relieve the subject against fraucis, breaches of trust, and other oppressions, and to mitigate the rigour of the law. This court is always open.

The king's bench....So called either from the kings of England sometimes sitting there in person, or because all matters determinable by common law between the king and his subjects are here tried, except such affairs as properly belong to the court of exchequer. This court is, likewise, a kind of check upon all the inferior courts, their judges, and justices of the peace. Here preside four judges, the first of whom is styled lord chief justice of England.

The court of common pleas takes cognisance of ail pleas debatable, and civil actions depending between subject and subject; and in it, besides all real actions, fines and recoveries are transacted, and prohibitions are likewise issued out of it, as well as from the king's bench. The first judge of this court is styled lord chief justice of the common pleas, or common bench : beside whon there are likewise three other judges or justices of this court. None but serjeants at law are allowed to plead here.

The court of exchequer was instituted for managing the revenues of the crown, and has a power of judging both according to law and according to equity. In the proceedings according to law, the lord chief baron of the exchequer, and three other barons, preside as judges. But when this court proceeds according to equity, then the lord treasurer and the chancellor of the exchequer preside, assisted by the other barons.

For putting the laws effectually in execution, a high sheriff is annually appointed for every county (except Westmoreland and Middlesex) by the king; * whose office is both ministerial and juclicial. He is to execute the king's mandate, and all writs directed to him out of the king's courts of justice; to impannel juries; to bring causes and malefactors to trial; to see sentence, both in civil and criminal affairs, executed; and at the assize to attend the judges, and guard them all the time they are in his county. $\mathrm{He}$ is likewise to decide the elections of knights of the shire, of coroners and verderers : to judge of the qualifications of voters, and to return such as he shall determine to be duly elected. It is also part of his office to collect all public fines, distresses, amerciaments, into the exchequer, or where the king shall appoint, and to make such payments out of them as his majesty shall think proper.

As his office is judicial, he keeps a court called the county court, which is held by the sheriff, or his under-sheriffs, to hear and determine all civil causes in the county, under forty shillings.

Under the sheriff are various officers, as the under-sheriffs, clerks, stewards of courts, bailiffs (in London called serjeants) constables, jailers, beadles, \&c.

The next officer to the sheriff is the justice of neace, several of whom are commissioned for each county : and to them is intrusted the power of puiting great part of the statute law in execution, in

* Sherifis were formerly chosen by the inhabitants of the several counties. In some counties the sheriffs were formerly hereditary, and still continue in the county of Westmoreland. The city of London hath also the inheritance of the shrie. valty of Middlesex vested in their body by charter. 
relation to the highways, the poor, vagrants, treasons, felonies, riots, the preservation of the game, \&c. \&c.

The civil government of cities is a kind of small independent policy of itself; for every city hath, by charter from the king, a jurisdiction within itself, to judge in matters civil and criminal. They are constituted -with a mayor, aldermen, and burgesses, who, together, make the corporation of the city, and hold a court of judicature, where the mayor presides as judge.

The government of incorporated, boroughs is much after the same manner : in some there is a mayor, and in others two bailiffs.

The cinque-ports are five havens, formerly esteemed most important ones, that lie on the east part of England towards France, as Dover, Sandwich, Romney, Hastings, and Hythe, to which Winchelsea and Rye have been since added, with similar franchises in many respects. These cinque-ports were endowed with particuiar privileges by our ancient kings, upon condition that they should provide a certain number of ships, at their own charge, to serve in the wars for forty days, as often as they were wanted.

For the better government of villages, the lords of the soil or manor (who were formerly called barons) have generally a power to hold courts, called courts-leet and courts-baron, where their tenants are obliged to attend and receive justice. The business of courts-leet is chiefly to prevent and punish nuisances: and at courts-baron the conveyances and alienations of the copyhold tenants are enrolled, and they are admitted to their estates on descent or purchase.

A constable is a very ancient and respectable officer of the peace, under the English constitution. Every hundred has a high-constable, and every parish in that hundred a constable : and the latter are to attend the high constable upon proper occasions. They are assisted by another ancient officer called the tithingman, who formerly superintended the tenth part of an hundred, or ten free burghs, as they were called in the time of the Saxons, each free burgh consisting of ten families.

Besides these, there are courts of conscience in many parts of England, for the relief of the poor in the recovery of payment of small debts not exceeding five pounds.

The rights of individuals are so attentively guarded, that the sub. ject may, without the least danger, sue his sovereign, or those who act in his name, and under his authority : he may do this in open court, where the king may be cast, and be obliged to pay damages to his subject. The king cannot take away the liberty of the meanest individual, unless he has, by some illegal act of which he is accused or suspected upon oath, forfeited his right to liberty; or except when the state is in danger, and the representatives of the people think the public safety makes it necessary that he should have power of confining persons on such a suspicion of guilt; such as the case of a rebellion within the kingdom, when the legislature has sometimes thought proper to pass a temporary suspension of the Habeas-Corpus act. The king has a right to pardon; but neither he, nor the judges to whom he delegates his authority, can condemn a man as a criminal, except he be first found guilty by twelve men, who must be his peers or his equals. That the judges may not be influenced by the king or his ministers to misrepresent the case to the jury, they have their salaries for life, and not during the pleasure of their sorereign. Neither can the king take away or endanger the life of any 
subject, without trial, and the persons being first chargeable with a capital crime, as treason, murder, felony, or some other act injurious to society; nor can any subject be deprived of his liberty, for the highest crime, till some proof of his guilt be given upon oath before a magistrate; and he has then a right to insist upon his being brought, the first opportunity, to a fair trial, or to be restored to liberty on giving bail for his appearance. If a man is charged with a capital offence, he must not undergo the ignominy of being tried for his life till the eviciences of his guilt are laid before the grand jury of the town or county in which the fact is alleged to be committed, and not unless twelve of them agree to a bill of indictment against him. If they do this, he is to stand a second trial before twelve other men, whose opinion is definitive. By the 28 Edward III, it is enacted, that where either party is an alien born, the jury shall be one half aliens, and the other denizens, if required, for the more impartial trial; a privilege indulged to strangers in no other country in the world, but which is as ancient with us as the time of king Etheldred.* In some cases, the prisoner (who is always supposed innocent till there be sufficient proof of his guilt) is allowed a copy of the indictment, in order to assist him to make his defence. He is also furnished with the pannel, or list of the jury, who are his true and proper judges, that he may learn their characters, and discover whether they want abilities, or whether they are prejudiced against him. He may in open court peremptorily object to twenty of the number; $\dagger$ and to as many more as he can give reason for their not being admitted as his judges; till at last twelve unexceptionable men, the neighbours of the party accused, or living near the place where the supposed fact was committed, are approved of, who take the following oath, that they shall well and truly try, and true deliverance make between the king and the prisoner, whom they shall have in charge, according to the evidence. By challenging the jury, the prisoner prevents all possibility of bribery, or the influence of any superior power; by their living near the place where the fact was committed, they are supposed to be men who knew the prisoner's course of life, and the credit of the evidence. These only are the judges from whose sentence the prisoner is to expect life or death; and upon their integrity and understanding the lives of all that are brought in danger ultimately depend; and from their judgment there lies no appeal: they are therefore to be all of one nind, and, after they have fully heard the evidence, are to be confined, without meat, drink, or candle, till they are unanimous in acquitting or condemning the prisoner.

OF PUNISHMETS.... The law of England includes all capital crimes under high treason, petty treason, and felony. The first consists in plotting, conspiring, or raising up in arms against the sovereign, or in counterfeiting the coin. The traitor is punished by being drawn on a sledge to the place of execution, when, after being hanged upon a gallows for some minutes, the body is cut clown alive, the heart taken out and exposed to public view, and the entrails burnt; the head is then cut off; and the body quartered; after which it has been usual to fix the head on some conspicuous place. All the criminal's lands

* Statuta de Monticolis Walliz.

t The party may cliallenge thirty-five in case of treason. 
and goods are forfeited, his wife loses her dowry, and his children both their estates and nobility.

But though coining of money is adjudged high treason, the cris minal is only drawn upon a sledge to the place of execution, and there hanged.

Though the sentence passed upon all traitors is the same, yet, with respect to persons of quality, the punishment is generally altered to beheading : a scaffold is erected for that purpose, on which the criminal placing his head upon a block, it is struck off with an axe.*

The punishment for misprision of high treason; that is, for neglecting or concealing it ; is imprisonment for life; the forfeiture of all the offender's goods, and the profits arising from his lands.

Petty treason is when a child kills his father, a wife her husband, a clergyman his bishop, or a servant his master or mistress. This crime is punished by the offender's being drawn on a sledge to the place of execution, and there hanged upon a gallows till dead. Women guilty of this crime, or of high treason, were sentenced to be burnt alive; but this law has been lately repealed, and the punishment of burning abolished.

Felony includes murders, robberies, forging notes, bonds, deeds, \&xc. These are all punished by hanging: only murderers $\dagger$ are to be executed soon after sentence is passed, and then delivered to the surgeons in order to be publicly dissected. Persons guilty of robbery; when there are some alleviating circumstances, are generally condemned to hard labour upon the river, or traisported for a term of years, or for life, to Botany Bay.

Other crimes punished by the law's are,

Manslaughter, which is the unlawful killing of a person without pre= meditated malice, but with a present intent to kill ; as when two, who formerly meant no harm to each other, quarrel, and the one kills the other ; in this case the criminal is allowed the benefit of his clergy, for the first time, and only burnt in the hand.

Chance-medley is the accidental killing of a man without an evil in. tent; for which the offender is also to be burnt in the hand, unless the offender was doing an unlawful act; which last circumstance makes the punishment death.

Shoh-lifting, and receiving goods knowing them to be stolen, are punished with hard labour for a number of years, or burning in the hand.

Perjury is punished with the pillory and imprisonment.

Petty-larceny, or small theft, under the value of twelve-pence, is punished by whipping.

Libelling, using false weights and measures, and forestalling the market, are commonly punished with standing on the pillory.

For striking, so as to draw blood, in a king's court, the criminal is punished with losing his right hand.

For striking in Westminster-hall while the courts of justice are sitting, the punishment is imprisonment for life, and forfeiture of all the offenders estate.

- This is not to be considered as a different punishment, but as a remission of all the parts of the sentence mentioned before, excepting the article of beheading.

+ By a late act, murderers are to be executed within twenty-four hours after sentence is pronounced; but as Sunday is not reckoned a day, they are generally tried on a Saturday, so that they obtain a respite till Monday. 
Drunkards, vagabonds, and loose, idle, disorderly persons, are punished by being set in the stocks, or by paying a fine.

REVENUE...The ordinary expences of government were defrayed by means of taxes.

The annual taxes are 1, The land-tax,* or the ancient subsidy raised upon a new assessment. 2, The malt-tax, being an annual excise on malt, mum, cider, and perry.

The perpetual taxes are, 1, The customs, or tonnage and poundage of all merchandise exported or imported. 2, The excise duty, or inland imposition, on a great variety of commodities. 3, The salt duty. 4, The post-office, or duty for the carriage of letters. 5, The stamp duty on paper, parchment, \& c. 6 , The duty on houses and windows. 7, The duty on licences for hackney coaches and chairs. 8, The duty on offices and pensions.

The extraordinary grants are usually called by the synonymous names of aids, subsidies, and supplies, and are granted, as has been before hinted, by the commons of Great Britain in parliament assembled; who, when they have voted a supply to his majesty, and settled. the quantum of that supply, usually resolve themselves into what is called a committee of ways and means, to consider of the ways and. means of raising the supply so voted. And in this committee, every member (though it is looked upon as the peculiar province of the chancellor of the exchequer) may propose such scheme of taxation as he thinks will be least detrimental to the public. The resolutions of this committee (when approved by a vote of the house) are in general esteemed to be (as it were) final and conclusive. For though the supply cannot be actually raised upon the subject till directed by an act of the whole parliament, yet no moneyed man will scruple to advance to the government any quantity of ready cash, if the proposed terms be advantageous, on the credit of the bare vote of the house of commons, though no law be yet passed to establish it.

The gross receipt of the permanent revenue, after deducting the re-payment of over-entries, drawbacks, \&c. amounted, in the year ending the 5th of January 1804, according to a statement presented to the house of commons by Mr. Pitt, to 35,44:0,278l. besides the war taxes imposed in 1803 and 1804, amounting to nearly $13,000,000 \%$ The net revenue of Great Britain amounted

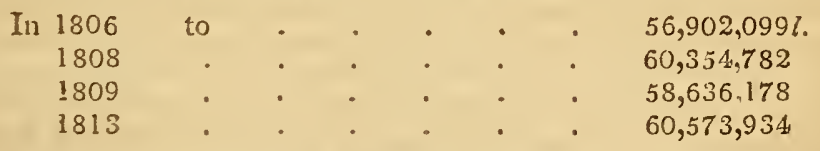

How these immense sums are appropriated is next to be considered. And this is, first and principally, to the payment of the interest of the national debt.

The total of all the sums borrowed, or the capital of the funcled debt of Great Britain, amounted, on the first of February, 1804, to $583,008,978 l$. of which $77,698,467 l$. had been purchased by the commissioners for the reduction of the national debt, and $21,147,1881$. had. been transferred to them on account of land-tax redeemed, leaving a funded debt unredeemed of $484,163,323 i$. The unfunded debt at the same time amounted to $16,305,607$, making the whole of the national

- This has lately been sold to the proprietors of the estates on which it is assessed, or other individuals, and thus rendered perpetual.

Vol, I. 
debt $500,468,930 l$. exclusive of $23,952,329 l$. on account of Ireland, and $7,042,805 l$. on account of the emperor of Germany.

To check, in some measure, the too rapid accumulation of a debt already so enormous, a part of the supplies for the years 1798 and 1799 were raised within the year. In 1798 a voluntary subscription was entered into for the service of government, which produced about a million and a half; and the taxes called the assessed taxes were trebled, and in some instances quadrupled, with allowance of relief in certain cases : these produced about five millions. In the year 1799 an act passed for levying a tenth of all income upwards of: $200 l$. per annum, with a tax, according to a certain scale, on all income from $200 l$. to $60 l$. per annum. The expected produce of this tax was estimated at ten millions, but amounted only to about six. In the year 1803 a similar tax was laid on all income arising from property, at the rate of five per cent. above $150 l$. per annum, and according to a certain scale below that sum to $60 l$.

The total sum to be raised for the expenditure of the year 1804, for the interest of the public debt, the civil list, the army, navy, pensions, bounties, extraordinary and secret services, Sc. amounted, according to the statement of the chancellor of the exchequer ( $\mathrm{Mr}$. Pitt) to the house of commons, to $71,498,431 l$; and the total of the ordinary revenue and extraordinary resources, including a lottery and a loan of fourteen millions, to 71,307,278l.

No permanent provision had ever been made for the progressive and certain payment of this immense debt, until 1786 ; when parliament had the wisdon and the firmness to pass an act for vesting unalienably, in commissioners, the sum of one million annually : in which act every possible precaution was taken that could be devised for preventing the surplus from being diverted, at any future time, and for carrying to the account of the commissioners, for the purpose of the act, the interest of such stock as should be purchased, and such temporary annuities as should fall in under the provisions of this act. O" the 5th of Jinuary, 1804, the commissioners had purchased $77,698,467 l$. of the capital of the debt.**

The cxpenses defrayed by the civil list are those that, in any shape, relate to civil government, as the expenses of the household, all salaries to officers of state, to the judges, and every one of the king's servants; the appointments to foreign ambassadors, the maintenance of the queen and royal family, the king's private expenses, or privypurse ; and other very numerous outgoings, as secret-service money, pensions, and other bounties. These, sometimes, have so far exceedcd the revenues appointed for that purpose, that application has been

* Dr. Price's calculation plainly. shows what this difference is: "One penny put out at our Saviour's birth, at 5 per cent. compound interest, would, in the year 1781, have increased to a greater sum than would be contained in $200.000,000$ of earths, all solid gold; but if put out to simple interest, it at the same time would have amounted to no more than sever shillings and sixpence. All governments that alienate funds destined for reimbursements, choose to improve money in the last rather than the first of these ways." He adds : "A million borrowed annually, for twenty years, will pay off, in this time, 55 millions 3 per cent. stock, if discharged at $60 l$. in money for every $100 \%$. stock; and in 40 years more, without any further aid from loans, 3.33 million (that is, 388 millions in all) would be paid off.

"The addition of nineteen years to this period would pay off 1000 millions.

"A surplus of half a million per annum, made up to a million by borrowing hralf a million every year for twenty years, would discharge the same sums in the same periods." 
made to parliament to discharge the debts contracted on the civil list, which is properly the whole of the king's revenue, in nis own distinct capacity; the rest being rather the revenue of the public, or its creditors, though cullected and distributed again in the name and by the officers of the crown.

Public companies....The company of the bank of England was in corporated by purliament, in the 5th and 6tin years of king William and queen Mary, by the name of the Governors and Company of the Bank of England.

This company is under the direction of a governor, deputy-governor, and twenty-four directors, who are annualiy elected by the general court of proprietors of bank-stork. Thirteen, or more, compose a court of directors for managing the affairs of the company. The qualification of a director is $2000 \mathrm{l}$; 年 a deputy-governor $3000 l$; and of a governor $4000 l$; $500 l$. bank-stock entitles the proprictor to vote at the general courts, provided he has been in possession of it six months.

EAst-Inda company...The first idea of this company was formed in queen Elizabeth's time; but it has since undergone great alterations. Its shares, or subscriptions, were originally only $50 l$. sterling, and its capital only 369,8911 . $5 \mathrm{~s}$; ; but in 1676 the shares were doubled, and consequently each became of $100 l$. value, and the capital $739,782 l .10 s . ;$ to which capital, if $963,639 l$. the profits of the compary to the year 1685 , be acided, the whole stock will be found to be $1,703,102 \%$. The losses sustained in wars with the Dutch, and the revolutions which had happened in the affairs of Hindostan, damped the ardour of the company; so that at the time of the revolution, when the war broke out with France, it was in a very indifferent situation. This was in a great measure owing to its having no parlia. mentary sanction; in consequence of which, its stock often sold for one half less than it was really worth; and it was resolved that a new company should be erected under the authority of parliament.

The old company, however, retained a great interest both in the parliament and nation; and the act being found in some respects defective, so violent a struggle between the two companies arose, that in the year 1702, they were united by an indenture tripartite.

A proprietor of stock to the amount of $1000 l$. whether man or wo. man, native or foreigner, has a right to be a manager, and to give a vote in the general council. ' $\Gamma$ wo thousand pounds is the qualification for a director. The directors are twenty-four in number, including the chairman and deputy-chairman, who may be re-elected in turn, six a year, for four years successively. The chairman has a salary of $200 i$. a year, and each of the directors $150 l$. The meetings or courts of directors are to be held at least once a week; but are commonly oftener, being summoned as occasion requires. Out of the body of directors are chosen several committees, who have the peculiar inspection of certain branches of the company's business.

The amazing territorial aequisitions of this company, computed to contain above 200,000 square miles, and thirty millions of people, must be necessarily attended with a proportionable increase of trade.*

* According to lists laid before the house of commons, the company employed 110 ships, and 8170 men.

Between India and Europe, in carrying cargoes to and from 70 ships and $7130 \mathrm{men}$.

lin the country trade, and from China.

6 packets

34 crabs 
From the report of the committee, in 1773 , appointed by parliament on Indian affairs, it appears that the India company, from the year 1708 to the year 1756 , for the space of forty-seven years and a half, divided the sum of $12,000 l$. or above $280,000 l$. per annum, which, on a capital of $3,190,000 l$. amounted to above eight and a half per cent. and that at the last-mentioned period it appeared, that, besides the above dividend, the capital stock of the company had been increased $180,000 l$.

The revenues of the countries ceded to the company by Tippoo Sultan, were stated in 1793 at $390,000 l$. and the future revenues of the British possessions in India were estimated at nearly 7,000,000l. leaving a net surplus, after deducting the interest on the debts in In dia, and the civil, military, and commercial charges, of 1,059,000l. per annum. The annual sales of India goods in Europe were estimated at nearly 5,000,000, which exceeds the prime cost and charges by $743,600 l$. and the net surplus on the whole of the revenues and trade of the East-India company, after paying 8 per cent. divided on the capital stock of $5.000,000 l$. is estimated at $1,239,24.1 l$. per annum.

In July, 1797, Mr. Dundas stated the total amount of the foreign revenues at $8,154,872 l$. and the charges upon them at $6,517,057 l$. leaving a net surpius of $1,637,815 l$. He at the same time stated the amount of the receipts and sales of the company at home, at $7,316,916 l$. Since that time the wealth and trade of the company have considerably increased.

South-SEa company.... This company was established under the reign of queen Anne, and incorporated under the title of "The Governor and Company of Merchants of Great Britain trading to the South Seas, and other Parts of America, and for encouraging the Fishery," \&c.

The company at first set out with good success; and the value of their stock for the first five years, had risen faster than that of any other company ; and his majesty, after purchasing 10,000l. stock, had coudescended to be their governor. Things were in this situation, when the South-Sea bubble was projected; the pretended design of which was, to raise a fund for carrying on a trade to the South-Sea, and purchasing annuities, \&c. paid to the other companies : and proposals were printed and distributed, showing the advantages of the design, and inviting persons into it. The sum necessary for carrying it on, together with the profits that were to arise from it, were divided into a certain number of shares, or subscriptions, to be purchased by persons disposed to adventure therein. And the better to carry on the deception, the directors engaged to make very large dividends, and actually declared that every $100 l$. original stock would yield $50 \%$. per annum; which occasioned so great a rise of their stock, that a share of $100 l$. was sold for upwards of $800 l$. This was in the month of July; but before the end of September it fell to $150 l$. by which multitudes were ruined, and such a scene of distress occasioned as is scarcely to be conceived. Most of the directors were severely fined, to the loss of nearly all their property; even those who had no share in the deception, because they ought, to have opposed and prevented it.

This company is under the direction of a governor, sub-governor, deputy-governor, and twenty-one directors; but no person is qualified to be governor, his majesty excepted, unless such governor has, in his own name and right, 5000l, in the trading stock; the sub-go- 
vernor is to have $4000 l$. the deputy-governor $3000 l$. and a director 2000 \% in the same stock. In every greneral court, every member having, in his own name and right, $500 l$. in trading stock, has one vote; if $2000 l$. two votes; if $3000 l$. three votes; and if $5000 l$. four votes.

The East-India company, the Bank of England, and the South-Sea company, are the only incorporated bodies to which the government is indebted, except the million bank, whose capital is only one million, constituted to purchase the reversion of the long exchequer orders.

Military and marine force of Great Britain.... The military state includes the whole of the soldiery, or such persons as are peculiarly appointed, among the rest of the peoplc, for the safeguard and defence of the realm.

The total number of troops on service in the year 1804, according to the statement of the secretary of war (Mr. Yorke) was 252,84: snen, consisting of 20,324 regular cavalry; 133,267 regular infantry, including officers and men; 87,652 militia; and 26,000 of the army of reserve: there was besides, of artillery, 11,202, malsing the total number of our actual force 267,243 men.

The British army in 1808, consisted of

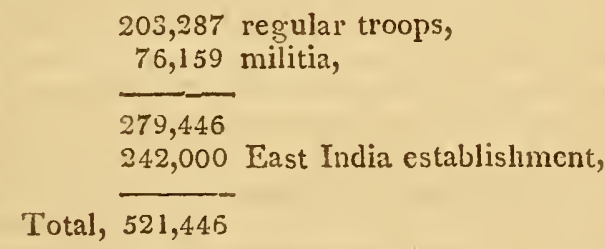

The complement of seamen, in time of peace, usually has amounted to 12 or 15,000 . In time of war, they formerly amounted to about s0,000 men; and after the commencement of the American war, to above 100,000, including marines. The vote of parliament for the service of the year 1798 and 1799 was for 120,000 seamen, including marines.

This navy is commonly divided into three squadrons, namely, the red, white, and blue, which arc so termed from the difference of their colours. Each squadron has its admiral : but the admiral of the red squadron has the principal command of the whole, and is styled viceadmiral of Great Britain. Subject to each admiral is also a vice and rear admiral. But the supreme command of our naval force is, next to the king, in the lords commissioners of the admiralty. Notwithstanding our favourable situation for a maritime power, it was not until the vast armament sent to subdue us by Spain in 1588, that the nation, by a vizorous effort, became fully sensible of its truc interest and natural strength, which it has since so happily cultivated.

At the beginning of the year 1800 , the British naval force consisted of 14.4 ships of the line, in commission, 22 fifty-gun ships, 200 frigates, and 292 other ships of war: in the whole, 658 ships; and, including receiving ships, ships in ordinary and building, 902 , of whicis 224. were of the line.

In 1813 the British naval force was as follows: 


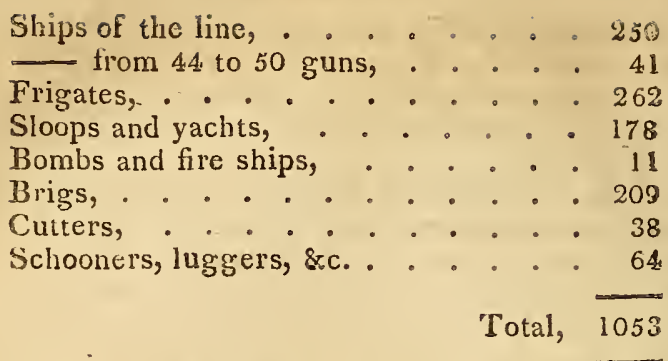

Of this number 549 vessels were in active service; the remainder is part refitting, or enuployed as guard, hospital, and prison ships.

There were in pay the same year 220 admirals, 824 caplains, 65l commanders, 3267 lieutenants.

Royal Titles AND ARMs.... The title of the king of England, since the union with Ireland, is, in Latin, Dei Gratia, Britanniarum, Rex, Fidei Defensor; and in English, By the Grace of Gocl, of Great Britain and Ireland King, Defender of the Faith. The designation of the kings of England was formerly his or her Grace, or Highness, till Henry VIII, to put himself on a footing with the emperor Charles $\mathrm{V}$, assumed that of Majesty; but the old designation was not abolished till towards the end of queen Elizabeth's reign. The title of Defender of the Faith, above mentioned, was given to Henry VIII, by the pope, on account of a book written by the king against Luther and the Reformation. Besides the titles already given, the king of Great Britain has others from his German dominions, as Elector of Hanover, Duke of Brunswick-Lunenburg, \&c.

The motto of Dieu et mon Droit, that is, God and my Right, is as old as the reign of Richard I, who assumed it to show his independency upon all earthly powers. It was afterwards revived by Edward III. when he laid claim to the crown of France. Almost every king of/England had a particular badge or cognisance; sometimes a white hart, sometimes a fetlock with a falcon, by which it is said Edward IV, alluded to the infidelity of one of his mistresses; and sometimes portcullis, which was that of the house of Lancaster, many of the princes of which were born in the castle of Beaufort. The white rose was the bearing of the house of York; and that of Lancaster, by way of contradistinction, adopted the red. The thistle, which is now part of the royal armorial bearings, belonged to Scotland, and was very significant when joined to its motto, Nemo me imfune' lacessit. "None shall provoke me unpunished."

The titles of the king's eldest son are, Prince of Wales, duke of Cornwall and Rothsay, earl of Chester, electoral prince of Brunswick and Lunenburg, earl of Carrick, baron of Renfrew, lord of the Isles, sreat-steward of Scotland, and captain-general of the artillery company.

ORDERS OF KNIGHTHOOD... The order of the Garter, the moset honourable of any in the world, was instituted by Edward III, January 19,1344 . It consists of the sovereign, who is always king or queen of England, of 25 companions, called knights of the garter, who wear a medal of St. George killing the dragon, supposed to be the tutelar saint of England, commonly enamelled on gold, suspended from a blue ribbon, which was formerly worn about their necks, but fince the latter end of James I, now crosses their bodies from their 
shoulder. The garter, which is of blue velvet, bordered with gold, buckled under the left knee, and gires the name to the order, was designed as an ensign of unity and combination; on it are embroidered the words, Honi soit qui mal y hense, "Evil to him who evil thinks."

Knights of the bath, so called from their bathing at the time of their creation, are supposed to have been instituted by Henry IV, about the year 1399: but the order seems to be more ancient. For many reigns they were created at the coronation of a king or queen, or on other solemn occasions. They wear a scarlet ribbon hanging from the left shoulder, with an enamelled medal, the badge of the order, a rose issuing from the dexter side of a sceptre, and a thistle from the sinister, between three imperial crowns placed within the motto, Tria juncta in unum, "Three joined in one." This order being discontinued, was revived by king George I, on the 8th of May, 1725 ; and the month following, eighteen noblemen, and as many commoners of the first rank, were installed knights of the order with great ceremony, at IVestminster, where the place of instalment is Henry VII's chapel. Their robes are splendid and showy, and the number of knights is undeterminate. The bishop of Rochester is perpetual dean of the order, which has likewise a register and other officers.

The origin of the English peerage, or nobility, has been already mentioned. Their titles, and order of dignity, are dukes, marquises, earls, viscounts, and lords or barons.

Baronets can scarcely be said to belong to an order, having no other badge than a bloody hand in a field argent, in theirarms. They are the only hereditary honour under the peerage, and would take place even of the knights of the garter, were it not that the latter are always privy-councillors: there being no intermediate honour between them and the parliamentary barons of England. They were instituted by James $\mathrm{I}$, about the year 1615. Their number was then two hundred, and each paid about $1000 \mathrm{l}$ on pretence of reducing and planting the province of Ulster in Ireland : but at present their number amounts to 700 .

A knight is a term used almost in every nation in Europe, and in general signifies a soldier serving on horseback : a rank of no mean estimation in ancient armies, and entitling the parties themselves to the appellation of Sir. Other knighthoods formerly took place in England; such as those of bannercts, bachelors, knights of the carpet, and the like; but they are now disused. Indeed, in the year 1773 , at a review of the royal navy at Portsmouth, the king conferred the honour of knights bannerets on two admirals and three captains. They have no particular badge on their garments, but their arms are painted on a banner placed in the frames of the supporters.

Peligron...The constitution of the church is episcopal, and it is governed by bishops, whose benefices were converted by the Norman conqueror into temporal baronies, in right of which every bishop has a seat and vote in the house of peers. The benefices of the inferior clergy are now freehold; but in many places their tithes are impropriated in favour of the laity. The economy of the church of England has been accused for the inequality of its livings; some of them extending from three hundred to fourteen hundred a year; and many, particulariy in Wales, being too small to maintain a clergyman, especially if he has arfamily, with any tolernble decency; but this seems not 
easily to be remedied, unless the dignified clergy would aclopt anch support the reforming scheme. The crown, as well as private persons, has done much towards the augmentation of poor livings.

The sovereigns of England, ever since the reign of Henry VIII, have been called, in public writs, the supreme heads of the church; but this title conveys no spiritual meaning, as it only denotes the regal power to prevent any ecclesiastical differences, or, in other words, to substitute the king in place of the pope before the Reformation, with regard to temporalities, and the internal economy of the church. The kings of England never intermeddle in ecclesiastical disputes, unless by preventing the convocation from sitting to agitate them, and are contented to give a sanction to the legal rights of the clergy.

To the church of England, under this description of the monarchical power over it, is governed by two archbishops, and twenty-four bishops, besides the bishop of Sodor and Man, who, not being possessed of an English barony, does not sit in the house of peers.* The two archbishops are those of Canterbuy and York, who are dignified with the address of Your Grace. The former is the first peer of the realm, as well as metropolitan of the English church. He takes precedence, next to the royal family, of all dukes and officers of state. He is enabled to hold ecclesiastical courts upon all affairs that were formerly cognisable in the court of Rome, when not repugnant to the law of God, or the king's prerogative. He has the privilege consequently of granting, in certain cases, licenses and dispensations, together with the probate of wills, when the party dying is worth upwards of five pounds. Besides his own diocese, he has under him the bishops of London, Winchester, Ely, Lincoln, Rochester, Litchfield and Coventry, Hereford, Worcester, Bath and Wells, Salisbury, Exeter, Chichester, Norwich, Gloucester, Oxford, Peterborough, Bristol; and, in Wales, St. David's, Landaff, St. Asaph, and Bangor.

* To the following list is subjoined the sum each see is charged in the king\% books, as also their estimated real value at present.

\section{ARCHEISHOPRICS.}

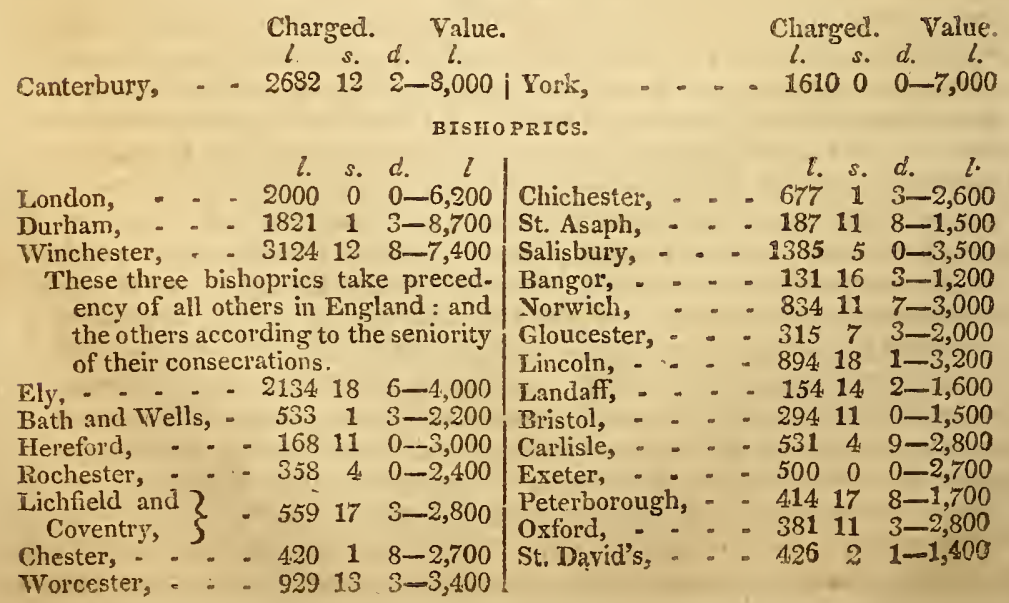


The archbishop of York takes place of all dukes not of the bloodroyal, and of all officers of state, the lord chancellor excepted. He has in his province, besides his own diocese, the bishoprics of Durham, Carlisle, Chester, and Sodor and Man.: In Northumberland, he has the power of a palatine, and jurisdiction in all criminal proceedings.

The bishops are addressed by the appellation of Your Lordship, styled "Rignt reverend Fathers in God," and take precedence of all temporal barons. They have all the privileges of peers; and the bishoprics of London, Winchester, Dutrtram, Salisbury, Ely, and Lincoln, require no additional revenuess to support their prelates in the rank of noblemen. English bishops are to examine and ordain priests and deacons, to consecrate churches and burying places, and to administer the rite of confirmation. Their jurisdiction relates to the probation of wills ; to grant administration of goods to such as die intestate ; to take care of perishable goods when no one will administer; to collate to benefices; to grant institutions to livings; to defend the liberties of the church; and to visit their own dioceses once in three year's.

The ecclesiastical government of England is, properly speaking, lodged in the convocation, which is a national representative body or synod, and answers pretty nearly to the ideas we have of a parlia-d ment; but it has not been permitted to sit for a time sufficient to enter into any discussions, since the reign of George I.

The bias which the clergy had towards popery in the reigns of Henry VIII, and Edward VI, and even so late as that of Elizabeth, occasioned an interposition of the civil power for a further reformation. Thence arose the furitans, so called from their maintaining a singular purity of life and manners. Many of them were worthy pious men, and some of them good patriots. Their clescendants are the modern presbyterians, who retain the same character, and have true principles of civil and religious liberty; but their theological sentiments have undergone a considerable change. Their doctrine, like that of the church of Scotland, was originally derived from the Geneva plan instituted by Calvin, and tended to an abolition of episcopacy, and to yesting the government of the church in a parity of presbyters. But the modern English presbyterians, in their ideas of church government, differ very little from the independents, or congregationalists, who are so called from holding the independency of congregational churches, without any respect to doctrine; and, in this sense, almost all the dissenters in England are now become indenen. dents. As to points of doctrine, the presbyterians are generally Arminians. Many of their ministers have greatly distinguished themselves by their learning and abilities; and some of their writings are held in ligh estimation by many of the clergy, and other mem. ber's of the established church. The same may be said of some of the independent and baptist ministers. The independents are generally Calvinists. The baptists do not believe that infants are proper subjects of baptism; and in the baptism of adults they practise immersion into water. 'They are divided into two classes, which are styled general baptists, and particular baptists. The general bapeists are Arminians, and the particular baptists are Calvinists.

The Methodists are a sect of a late institution; of which the late Mr. George IVhitfielrl and Mr. John Wesley are considered as the tounders. 'Ihey profess great fervour and devotion. Their teacher,

$$
\text { ToL. T. Th }
$$


Mr. Whitfield, thought that the form of ecclesiastical worship, and prayers, whether taken from a common-prayer book or poured forth extempore, were màtters of indifference : he therefore made use of both these methods. His foilowers are rigid observers of the doctrinal articles of the church of England, and profess themselves to be Calvinists. Mr. Whitfield died in the year 1770 ; but the places of worship, erected by him near London, are still frequented by persons of the same principles; and they profess a great respect for his memory. Mr. Wesley and his followers separated from Mr. Whitfield in consequence of their rejection of the Calvinistic cloctrine of predestination. He erected a very large place of public worship near Moorfields, and had under him a considerable number of subordinate preachers, who submitted to their leader very implicitly, propagated his opinions, and made proselytes throughout the kingdom with great industry. After a very long life, spent in the most strenuous endeavours to do good, and having been blest in reforming the morals of thousands of the lower ranks of society, be died in 1791 .

There are also a variety of subordinate sects (some of whom are from Scotland, particularly the Sandemanians) who have their separate followers, but very few at London and other places in England.

Of late years a sect called Swedenborgians has arisen, who derive their name from baron Swedenborg, a native of Sweden, whose reveries they have adopted. They resolve the scriptures almost entirely into allegory, and deal in a mysticism not easily explained.

The Quakers are a religious sect which took its rise about the middle of the 17 th century. They believe in the immediate influence of the Divine Spirit, and reject all forms in worship, even the sacraments of Baptism and the Lord's Supper. They declare against oaths and war, abiding literally by Christ's positive injunction, "Swear not at all." They disuse the names of the months and days of the week, as being given in honour of the false grods of the heathens; and the custum of speaking to a single person in the plural number, as having arisen from motives of adulation. They declare it their decided judgment that it is contrary to the Grospel to sue each other at law; and they enjoin all to end their differences by speedy and impartial arbitration according to rules laid down. If any refuse to adopt this mode, or, having adopted it, to submit to the award, it is the rule of the society that such be disowned.

It is well known that William Penn, one of this society, founded the province of Pennsylvania, and introduced therein a plan of civil and religious liberty, particularly of the latter, at that time unexampled. The government of the province was at first, and for many years, chiefly in the hands of the quakers; but as persons of other persuasions increased, and became partakers of power, they grew uneasy at the pacific plan of the quakers : and at length succeeding to establish such modes of defence for their country as did not accord with the principles of the latter, these gradually withdrew themselves from active employments of the state. For some time previous to the late revolution, few of them were found in any other station than that of private citizens; and, during its progress, their refusing to arm exposed them to much suffering, by distraints levied on them, in order to procure their quota in support of the war.

Many families in England still profess the Roman-catholic religion, and its exercise is under very mild and gentle restrictions. Though 
the penal laws against papists in England appear at first to be severe, yet they are either not executed, or with so much lenity that the Roman-catnolic feels himself under few hardships. The papists now seem to be convinced that a change of government, instead of bettering, would hurt their situation, because it would increase the jealousy of the legislature; which must undoubtedly expose them daily to greater burdens and heavier penalties. This sensible consideration has of late made the Roman-catholics to appear as dutiful and zealous subjects as any his majesty has. Scarcely any English papists, excepting those who were bred or had served abroad, were engaged in the rebellion of the year 1745 ; and though those at home were most carefully observed, few, or none of them, were found guilty of disloyal practices.

As England has been famous for the variety of its religious sects, so it has also for its Free-thinkers; but that term has been applied in very different senses. It has sometimes been used to denote op. posers of religion in general, and in particular of revealed religion; but it has also been applied to those who have been far from disbelieving Christianity, and who have only opposed some of those doctrines which are to be found in public creeds and formularies; but which they conceive to be no part of the original Christian sys tem. As to those who are truly deists or infidels, there is abundant reason to believe that this class of men is nuuch more numerous in some popish countries than in England. Nor does it appear that the writings of the deists against Christianity have been of any real disservice to it: on the contrary, they have caused the arguments in its favour to be used with greater force and clearness, and have been the means of producing such defences of it, as all the acuteness of modern infidelity has been unable to overthrow.

LITERATURE, AND THE ARTs....England may be considered the seat of learning and the Muses. Her great Alfred cultivated both, in the time of the Saxons, when barbarism and ignorance overspread the rest of Europe; nor has there, since his time, been wanting a continual succession of learned men, who have clistinguished themselves by their writings or studies. These are so numerous, that a bare catalogue of their names, down to this day, would form a moderate volume.

Even in the dark ages, England produced that prodigy of learning and natural philosophy, Roger Bacon, who was the forerunner in science to the great Bacon, lord Verulam, as the latter was to sir Isaac Newton. Among the curious works written by this illustrious man, we find treatises upon grammar, mathematics, physics, the flux and reflux of the British sea, optics, geography, astronomy, chronology, chemistry, logic, metaphysics, ethics, medicine, theology, philology, and upon the impediments of knowledge. As many of the English clergy had different sentiments in religious matters at the time of the Reformation, encouragement was given to learned foreigners to settle in England. Edward VI, during his short life, greatly encouraged these foreigners, and showed dispositions for cultivating the most useful parts of learning, had he lived. Learning, as well as liberty, suffered an almost total eclipse in England, during the bloody bigoted reign of queen Mary. Elizabeth, her sister, was herself a learned princess. She advanced many persons of consummate abilities to high ranks, both in church and state; but she seems 
to have considered their literary accomplishments as oniy secondary to their civil.

The encouragement of learned foreigners in England continued to the reign of James I, who was very munificent to Casaubon, and other foreign authors of distinction, even of different principles. The second Bacon, who has been already mentionel, was by him created viscount Verulam, and lord high chancellor of England. $\mathrm{He}$ was tikewise the patron of Camclen and other historians, as well asantiquaries, whose works are to this day standards in those studies.

His son Charles I, cultivated the polite arts, especially sculpture, painting, and architecture. He was the patron of Rubens, Vandyke, Inigo Jones, and other eminent artists; so that, had it not been for the civil wars, he would probably have converted his court and capital into a second Athens; and the collections he made for that purpose, considering his pecuniary difficulties, were astonishing. His favourite, the duke of Buckingham, imitated him in that respect, and laid out the vast sum of $400,000 l$. upon his cabinet of paintings and curiosities.

The earl of Arundel was another Mrenas of that age, and greatly; distinguished himself by his collection of antiquities, particularly his famous marble inscriptions, called the Arundelian marbles, now preserved ai Oxford. Charles and his court had little or no relish for poetry; but such was his generosity in encouraging genius and merit of every kind, that he increased the salary of his poet laureat, the famous Ben Jonson, from 100 marks to 100 pounds per annum, and a lierce of Spanish wire; which salary is continued to this day.

The public encouragement of learning and the arts suffered indeed an eclipse, during the time of the civil wars, and the succeeding interregnum. Many very learned men, however, found their situations under Cromwell, though he was no stranger to their political sentiments, so easy, that they followed their studies to the vast benefit of every branch of learning : and many works of great literary merit appeared even in those times of distraction. Usher, Walton, Willis, Harrington, Wilkins, and a prodigious number of other great names, were unmolested and even favoured by that usurper; and he would also have filled the universities with literary merit, could he have done it with any degree of safety to his government.

The reign of Charles II, was chiefly distinguished by the great proficiency made in natural knowledge, especially by the institution of the Royal Socicty. The king was a good judge of those studies; and, though irreligious himself, England never abounded more with learned and able divines than in his reign. He loved painting and poetry, but was far'more munificent to the former than the latter. The incomparable Paradise Lost, by Milton, was published in his reign, but was not read or attended to in proportion to its merit, though it was far from being disregarded so much as has been commonly apprehended. The reign of Charles II, notwithstanding the bad taste of his court in several of the polite arts, by some is reckoned the Augustan age in England, and is dignified with the names of Boyle, Halley, Hooke, Sydenham, Harvey, Temple, Tillotson, Barrow, Butler, Cowley, Waller, Dryden, Wycherley, and Otway. The pulpit assumed more majesty, a better style, and truer energy, than it had ever known before. Classic literature recovered many of its native graces ; and though England could not, under him, boast of a Jones and a Vandyke, yet sir Christopher Wren introduced a more 
general regularity than had ever been known before in architecture. Nor was sir Christopher IViren merely distinguished by his skill as an architect; his knowledge was very extensive; and his discoveries in philosophy, mechanics, \&rc. contributed much to the reputation of the newly established Royal Society. Some excellent English painters (for Lely and Kneller were foreigners) also flourished in this reign.

'That of James II, though he likewise had a taste for the fine arts, is chiefly distinguished in the province of literature by those compositions that were published by the English divines agaiust popery, and which, for strength of reasoning and depth of erudition, never were equalled in any age or country.

The names of Newton and Locke adorned the reign of William III, and he had a particular esteem for the latter, as he had also for Tillotson and Burnet.

The most uninformed readers are not unacquainted with the improvements which learning, and all the polite arts, received under the auspices of queen Anne, and which placed her court at least on a footing with that of Lewis XIV, in its most splendid days. Many of the great men who had figured in the reigns of the Stuarts and William, were still alive, and in the full exercise of their faculties, when a a new race sprang up in the republic of learning and the arts. Addison, Prior, Pope, Swift, lord Bolingbroke, lord Shaftesbury, Arbuthnot, Congreve, Steele, Rowe, and many other excellent writers both in verse and prose, need but to be mentioned to be admired.

The ministers of George I, were the patrons of erudition, and some of them were no mean proficients themselves. George II, was himself no Mrcenas; yet his reign yielded to none of the preceding, in the number of learned and ingenious men it produced. The bench of bishops was never known to be so well provided with able prelates as it was in the early years of his reign; a full proof that his nobility and ministers were judges of literary qualifications. In other departments of erudition, the favour of the public generally supplied the coldness of the court. In the present reign, a great progress has been made in the polite arts in England. The Royal Academy has been instituted, some very able artists have arisen, and the annual public exhibitions of painting and sculpture have been extremely favourable to the arts, by promoting a spirit of emulation, and exciting a greater attention to works of genius of this kind among the public in general. But, notwithstanding these favourable circumstances, the fine arts have been far from meeting with that public patronage to which they have so just a claim. Few of our public edifices are adorned with paintings or with statues. The sculptors meet with little employment; nor is the historical painter much patronised; though British artists of the present age liave proved that their genius for the fine arts is equal to that of any other nation.

Medicine and surgery, botany, anatomy, chemistry, and all the arts or studies for preserving life, have been carried to a great degree of perfection by the English. The same may be said of music, and theatrical exhibitions. Even agriculture is now reduced in England to a science, and that, too, without any public encouragement but such as is given by private noblemen and gentlemen, who associate themselves for that purpose.

Universities.... The two universities of Oxford and Cambridge have produced more learned men than any in Europe. Their magni- 
ficent buildings, which in splendor and architecture rival the most superb royal edifices, the rich endowments, the liberal ease and tranquillity enjoyed by those who inhabit them, surpass all the ideas which foreigners, who visit them, conceive of literary societies. So respectable are they in their foundations, that each university sends two members to the British parliament, and their chancellors and officers have a civil jurisdiction over their students, the better to secure their inclependency. Their colleges, in their revenues and buildings, exceed those of many other universities.

In Oxford there are twenty colleges and five halls : the former are very liberally endowed, but in the latter the students chiefly maintain themselves. This university is of great antiquity : it is supposed to have been a considerable place even in the time of the Romans; and Camden says, that "wise antiquity did, even in the British age, consecrate this place to the Muses." It is said to have been styled an university before the time of king Alfred; and the best historians admit, that this most excellent prince was only a restorer of learning here. Alfred built three colleges at Oxfurd; one for divinity, another for philosophy, and a third for grammar. The present colleges are, however, of a more recent date, none being older than the 1 sth century. The number of officers, fellows, and students, maintained at present by this university, is about 1000 ; and the number of such scholars as live at their own charge, msually about 2000.

The university of Cambridge consists of twelve colleges, and four halls; but though they are distinguished by different names, the privileges of the coileges and halls are in every respect the same. The number of fellows at this university is four hundred, that of scholars 666 , with 236 officers and servants of various kinds. All these are maintained on the foundation. They are not, however, all the students here: there are others called pensioners; the greater and the less. The greater pensioners are sons of the nobility, and of gentlemen of large fortunes, and are called fellow-commoners, because, though they are scholars, they dine with the fellows. The lesser pensioners dine with the scholars who are on the foundation, but live at their own expence. There are also a considerable number of poor scholars, called sizars, who wait upon the fellows and scholars, and pensioners of both rarks, by whom they are in a great degree maintained; but the number of pensioners and sizars cannot be ascertained with any accuracy, as it is in a state of perpetual fluctuation.

The senate-house at Cambridge is a most elegant edifice, executed entirely in the Corinthian order, and is said to have cost $16,000 l$. Trinity-college library is also a very magnificent structure; and in Corpus Christi college library is a valuals! collection of ancient manuscripts, which were preserved at the dissolution of the monasteries, and given to this college by archbishop Parker.

LANGUAGE... The English language is principally a compound of the Saxon and the French; the Saxon, however, predominates; and the words that are borrowed from the French, being radically Latin, are common to other nations, particularly the Spaniards and the Italians. A great number of words, especially scientific and technical terms, have been introduced from the Latin and Greek. A more minute account of this language would be superfluous to an English reader; but, relatively, it enjoys all the properties, without many of the defects, of other European languages. It is more energetic, 
raanly, and expressive, than either the French or the Italian; more copious than the Spanish, and more eloquent than the German, or the other northern tongues. It is, however, subject to some considerable provincialities in its accent, there being much difference in the pronunciation of the inhabitants of different counties : but this chiefly affects the lowest of the people; for, as to well-educated and wellbred persons, there is little difference in their pronunciation all over the kingdom. People of fortune and education in England, of both sexes, also commonly either speak or understand the French, and many of them the Italian and Spanish; but it has been observed that foreign nations have great difficulty in understanding the few English who talk Latin; which is perhaps the reason why that language is much disused in England, even by the learned professions.

Antrquerres.... The antiquities of England are either British, Roman, Saxon, Danish, or Anglo-Normannic; but these, excepting the Roman, throw no great light upon ancient history. The chief British antiquities are those circles of stones, particularly that called Stonehenge in Wiltshire, which have been attributed to the times of the Druids. Stonehenge is, by Inigo Jones, Dr. Stukeley, and others, described as a regular circular structure. The body of the work consists of two circles and two ovals, which are thus composed : the upright stones are placed at three feet and a half distance from eacl other, and joined at the top by over-thwart stones, with tenens fitted to the mortises in the uprights, for keeping them in their due position. Some of these stones are extremely large, measuring two yards. in breadth, one in thickness, and above seven in height; others are less in proportion. The uprights are wrought a little with a chisel, and sometimes tapered; but the transoms, or over-thwart stones, are quite plain. The outside circle is nearly one hundred and eighty feet in diameter, between which and the next circle there is a walk of 300 feet in circumference, which has a surprising and awful effect upon the beholders.

Monuments of the same kind as that of Stonehenge are to be met with in Cumberland, Oxfordshire, Cornwall, Devonshire, and: many other parts of England, as well as in Scotland and the northern isles.

The Roman antiquities in England consist chiefly of altars and monumental inscriptions, which instruct us as to the legionary stations of the Romans in Britain, and the names of some of their commanders. The Roman military ways give us the highest idea of the civil as well as military policy of those conquerors. Their vestiges are numerous: one is mentioned by Leland, as beginning at Dover, and passing through Kent to London, from thence to St. Alban's, Dunstable, Stratford, Towcester, Littleburn, St. Gilbert's Hill near Shrewsbury, then by Stratton, and so through the middle of Wales to Cardigan. The great Via Militaris, called Hermen-street, passed from London through Lincoln, where a branch of it, from Pontefract. to Doncaster, strikes out to the westward, passing through Tadcaster to York, and from thence to Aldby, where it again joined Hermenstreet. There would, however, be no end of describing the vestiges of the Roman roads in England, many of which serve as foundations to our present highways. The great earl of Arundcl, the celebrated. English antiquary, had formed a noble plan for describing those which pass through Sussex and Surrey towards London; but the civil war breaking out put an end to the undertaking. The remains of many 
Roman camps are discernible all over England ; one particularly, very little defaced, near Dorchester in Dorsetshire, where also is a Row man amphitheatre. Their situations are generally so well chosen, and their fortifications appear to have been so complete, that there is some reason to believe that they were the constant habitations of the Roman soldiers in England; though it is certain, from the baths and tessellated pavements, that have been found in different parts, that their chief officers or magistrates lived in towns or villas. Roman walls have likewise been found in England; and, perhaps, upon the borders of Wales, many remains of their fortifications and castles are blended with those of a later date. The private cabinets of no. blemen and gentlemen, as well as the public repositories, contain a vast number of Roman arms, coins, fibula, trinkets, and the like, which have been found in England; but the most amazing monument of the Roman power in England is the prætenture or wall of Severus, commonly called the Picts' wall, running through Northumberland and Cumberland; beginning at 'Tinmoutl, and ending at Solvay-Firth, being about eighty miles in length. 'The wall at first consisted only of stakes and turf, with a ditch; but Severus built it with stone forts and turrets at proper distances, so that each might have a speedy communication with the other; and it was attended all along by a deep ditch, or vallum, to the north, and a military highway to the south.

The Saxon antiquities in England consist cliefly in ecclesiastical edifices, and places of strength. At IVinchester is shown the round table of king Arthur, with the names of his knights. The antiquity of this table has been disputed by Camden and later writers, perhaps with reason; but if it be not British, it certainly is Saxon. The cathedral of Winchester served as the burying-place of several Saxor kings, whose bones were collected together by bishop Fox, in six large wooden chests. Many monuments of Saxon antiquity present themselves all over the kingdom, though they are often not to be discerned from the Normannic; and the British Museum contains several striking original specimens of their learning. Many Saxon charters, signed by the king and his nobles, with a plain cross instead of their names, are still to be met with. The writing is neat and legible, and was always performed by a clergyman, who affixed the name and quality of every donor, or witness, to his respective cross. The Danish erections in England are hardly discernible from the Saxon. 'The form of their camps is round, and they are generally built upon eminences; but their forts are square.

All England is full of Anglo. Normannic monuments, which we choose to call so, because, though the princes under whom they were raised were of Norman original, yet the expence was defrayed by English men with English money. Yorkminster, and Westminsterhall and abbey, are, perhaps, the finest specimens to be found in Europe of that Gothic manner which prevailed in building before the recovery of the Greek and Roman architecture. All the cathedrals and old churches in the kingdom are more or less in the same taste, if we except St. Paul's. It is uncertain whether the artificial exca = vations found in some parts of England are British, Saxon, or Norman. That under the old castle of Ryegate in Surrey is very remarkable, and seems to have been designed for secreting the cattle and effects of the natives, in times of war and invasion. It contains an oblong square hall, round which runs a bench, cut out of the same 
a och, for sitting upon; and tradition says that it was the room in which the barons of England met during the war's of king John. The rock itself is soft and very practicable; but it is hard to say where the excavation, which is continued in a square passage, about six feet high and four wide, terminates, because the work is fallen in, in some places.

Hrstory.... It is generally agreed that the first inhabitants of Britain were a tribe of the Gauls, or Celtæ, that settled on the opposite shore; a supposition founded upon the evident conformity in their language, manners, government, religion, and complexion.

The Britons, at the time of Cæasar's descent, 52 years $\mathbf{A}$. C. were governed in the time of war by a political confederacy, of which Cas. sibelan, whose territories lay in Hertfordshire and some of the adjacent counties, was the head; and this form of government continued among them for some time.

In their manner of life, as described by Cæsar and the best authors, they differed little from the rude inhabitants of the northern climates that have been already mentioned; but they certainly sowed corn, though perhaps they chiefly subsisted upon animal food and milk. Their clothing was skins; and their fortifications, beams of wood. 'They were incredibly dexterous in the management of their chariots; and they fought with lances, darts, and swords. Women sometimes led their armies to the field, and were recognised as sovereigns in their particular districts.

The Britons lived, during the long reign of Augustus Cæsar, rather as the allies than the tributaries of the Romans; but the communications between Rome and Great Britain being then extended, the emperor Claudius Casar, about forty-two years after the Birth of Christ, undertook an expedition in person, in which he geems to have been successful, against Britain. His conquests, however, were imperfect; Caractacus, and Boadicea, though a woman, made noble stands against the Romans. The formcr was taken prisoner, after a desperate battle, and carried to Rome, where his undaunted behaviour before Claudius gained him the admiration of the victors, and is celebrated in the histories of the times. Boadicea being oppressed in a manner that disgraces the Roman name, and clefeated, disdained to survive the liberties of her country. During the time the Romans remained in this island, they erected walls to protect the Britons from the invasions of the Caledonians, or Scots : and we are told that the Roman language, learning, and customs, became familiar in Britain. During the abode of the Romans in Britain, they introduced into it all the luxuries of Italy; and under them the South Britons were reduced to a state of great vassalage, while the genius of liberty retreated northwards, where the natives had made a brave resistance against these tyrants of the world. For though the Britons were unquestionably very brave, when incorporated with the Roman legions abroad, yet we know of no struggle they made in latter times, for their independency at home, notwithstanding the many favourable opportunities that presented themselves. The Roman emperors and generals, while in this island, assisted by the Britons, were frequently employed in repelling the attacks of the Caledonians: but they appear to have had no difficulty in maintaining their authority in the southern provinces.

Upon the mighty inundations of those barbarous nations, which, unser the names of Ginths and Vanclals, invaded the Roman empire witb

Vor.. 3.

D d 
infinite numbers, and with danger to Rome itself, the Roman legions were withdrawn out of Britain, with the flower of the British youth, for the defence of the capital and centre of the empire; and that they might leave the island with a good grace, they assisted the Britons in rebuilding with stone the wall of Severus between Newcastle and Carlisle, which they lined with forts and watch-lowers; and, having done this good office, took their last farewell of Briton about the year 448, after having been masters of the most fertile parts of it, if we reckon from the invasion of Julius Cæsar, near 500 years.

The Picts and Scots, finding the island finally deserted by the Roman legions, now regarded the whole as their prize, and attacked the wall of Severus with redoubled forces, ravaging all before them with a fury peculiar to northern nations in those ages, and which a remembrance of former injuries could not fail to inspire. The poor Britons, like a helpless family deprived of their parent and protector, already subdued by their own fears, had again recourse to Rome, and sent over their miserable epistle for relief (still upon record) which was addressed in these words: To Aëtius, thrice consul: The groans of the Britons; and after other lamentable complaints, said, That the barbarians drove them to the sea, and the sea back to the barbarians; and they had only the hard choice left of herishing by the sword or by the waves. But having no liopes given them by the Roman general of any succours from that side, they began to consider what other nation they might call over to their relief. Vortigern, chief of the Danmonii, in behalf of the Britons made an engagement with two Saxon chiefs, Hengist and Horsa, to protect them from the Scots and Picts. The Saxons readily accepted the invitation of the Britons; whom they relieved, by checking the progress of the Scots and Picts, and had the island of Thanet allowed them for their residence. But their own country was so populous and barren, and the fertile lands of Briton so agreeable and alluring, that in a very little time Hengist and Horsa began to meditate a settlement for themselves; and fresh supplies of their countrymen arriving daily, the Saxons soon became formidable to the Britons, whom, after a violent struggle of near 1,50 years, they subdued, or drove into Wales, where their lan. guage and their descendants still remain.

Literature at this time in England was so rude, that we know but little of its history. The Saxons were ignorant of letters; and public transactions among the Britons were recorded only by their bards and poets, a species of men whom they held in great veneration.

The Anglo-Saxons, during their heptarchy, were governed by priests and monks, and their bounty to the see of Rome was therefore unlimitcd. Ethelwald, king of Mercia, imposed an annual tax of a penny upon every house, which was afterwards known by the name of Peter'spince, because paid on the holiday St. Peter ad vincula, August first.

London was then a place of very considerable trade; and if we be. lieve the Sazon chronicles quoted by Tyrrel, Withred, king of Kent, paid at one time to Ina, king of Wessex, a sum in silver equal to $90,000 l$. sterling, in the year 694 ; and we read, in 709, of a Northumbrian prelate who was served in silver plate. It must however be owned, that the Saxon coins, which are generally of copper, are many of them illegible, and all of them mean.

In this state was the Saxon heptarchy in England, when, about the year 800 , most of the Anglo-Saxons, tired out with the tyranny of their petty kings, united in calling to the government of the heptarchy; 
Egbert, who was the eldest remaining branch of the race of Cerdic, one of the Saxon chiefs who first arrived in Britain. On the submis. sion of the Northumbrians in the year 327 , he became king of all England.

He changed the name of his kingdom into that of Engle-lond or England; but there is reason to believe that some part of England continued still to be governed by independent princes of the blood of Cerdic, though they paid perhaps a small tribute to Egbert, who died in the year 838 , at Winchester, his chief residence.

Egbert was succeeded by his son Ethelwolf, who divided his power with his eldest son Athelstan. By this time Eugland had become a scene of blood and ravages, through the renewal of the Danish invasions; and Ethelwolf, after some time bravely opposing them, retired in a fit of devotion to Rome, to which he carried with him his youngest son, afterwards the famous Alfred, the father of the English constitution.

Upon his death, after his return from Rome, he divided his dominions between two of his sons (Athelstan being then dead) Ethelbald and Ethelbert: but we know of no patrimony that was left to young Alfred. Ethelbert, who was the surviving son, left his kingdom, in 866 , to his-brother Ethelred; in whose time, notwithstanding the courage and conduct of Alfred, the Danes became masters of the sea-coast, and the finest counties in England. Ethelred being killed, 'his brother Alfred mounted the throne in 871 . He was one of the greatest princes, both in peace and war, mentioned in history. He fought seven. battles with the Danes with various success; and, when defeated, found resources that rendered him as formidable as before. He was, however, at one time reduced to a state of the greatest distress, being forced to live in the disguise of a cow herd: but still he maintained a secret correspondence with his brave friends, whom he collected together; and by their assistance gave the Danes many signal overthrows, till at last he recovered the kingdom of England, and obliged the Danes, who had settled in it, to swear obedience to his government : even part of IVales courted his protection; so that he was probably more powerful than any monarch that had ever reigned in England.

Among the other glories of Alfred's reign, was that of raising a maritime power in England, by which he secured her coasts from future invasions. He rebuilt the city of London, which had been burnt down by the Danes, and founded the university of Oxford about the year 895. He divided England into counties, hundreds, and tithings: or rather he revived those divisions, and the use of juries, which had fallen into disuse by the ravages of the Danes. Having been educated at Rome, he was not only a scholar, but an author ; and he tells us, that upon his accession to the throne he had scarcely a lay subject who could read English, or an ecclesiastic who understood Latin. He introduced stone and brick building into general use in palaces as well as churches; though it is certain that his subjects, for many years after his death, were fond of timber buildings. His encouragement of commerce and navigation may seem incredible to modern times; but he had merchants who traded in East-India jewels; and William of Malmsbury says, that some of their gems were reposited in the church of Sherborne in his time. He received from one October, about the year 890, a full discovery of the coast of Norway and Lapw land, as far as Russia; and he tells the king in his memorial, printed 
by Hakluyt, "that he sailed along the Norway coast, so far north ac commonly the whale-hunters used to travel." He invited numbers of learned men into his dominions, and found faithful and useful allies in the two Scotch kings, his contemporaries, Gregory and Donald, against the Danes. He is said to have fought no less than fiftysix pitched battles. He was inexorable against his corrupt judges, whom he used to hang up in the public highways, as a terror to evildoers. He died in the year 901 ; and his character is so completely amiable and heroic, that he is justly distinguished with the epithet of the Great.

Alfred was succeeded by his son Edward the Elder, under whom, though a brave prince, the Danes renewed their invasions. He died in the year 925 , and was succeeded by his eldest son Athelstan. This prince greatly encouraged commerce, and made a law, that every merchant who had made three voyages on his own account to the Mediterranean, should be considered as the equal of a thane or nobleman of the first rank. He caused the Scriptures to be translated into the Saxon tongue. He encouraged coinage; and we find by his laws, that archbishops, bishops, and even abbots, had then the privilege of coining money. He engaged in several wars with the Scots, in which he was generally successful, and died in 941. The reigns of his successors, Edmund, Edred, and Edwy, were weak and inglorious, they being either engaged in wars with the Danes, or disgraced by the influence of priests. Edgar, who mounted the throne about the year 959, revived the naval glory of England, and is said to have been rowed down the river Dee by eight kings, his vassals, he sitting at the helm; but, like his predecessors, he was the slave of priests, particularly St. Dunstan. His reign, however, was pacific and happy, though he was obliged to cede to the Scots all the territory to the north of the Tyne. He was succeeded in 975 , by his eldest son Edward, who was barbarously murdered by his step-mother, whose son Ethelred, by the aid of priests, mounted the throne in 978 . The English nation, at this time, was overrun with barbarians, and the Danes by degrees became possessed of the finest parts of the country, while their countrymen made sometimes dreadful descents in the western parts. To get rid of them, he agreed to pay them $30,000 \%$. which was levied by way of tax, and called Danegald, and was the first land-tax in England. In the year 1002, they had made such settlements in England, that Ethelred consented to a general massacre of them by the English ; but it is improbable that it was ever carried into execution. Some attempts of that kind were made in particular counties; but they served only to enrage the Danish king Swein, who, in 1013, drove Ethelred, his queen, and two sons, out of England into Normancly, a province of France, at that time governed by its own princes, styled the dukes of Normandy. Swein being killed was succeeded by his son Canute the Great : but Ethelred returning to England forced Canute to retire to Denmark, from whence he in vaded England with a vast army, and obliged Edmund Ironside (so called for his great bodily strength) Ethelred's son to divide with him the kingdom. Edmund being assassinated, Canute succeeded to the undivided kingdom; and dying in 1035, his son, Harold Harefoot, did nothing memorable; and his successor Hardicanute was so degenerate a prince, that the Danish royalty ended with him in England.

The family of Ethelred was now called to the throne; and Lidward, 
who is commonly called the Confessor, mounted it, though Edgar Atheling, by being descended from an elder branch, had the lineal right, and was alive. Upon the death of the Confessor, in the year 1066, Harold, son to Groodwin earl of Kent, mounted the throne of Eingland.

IVilliam duke of Normandy, though a bastard, was then in the unrivalled possession of that great duchy, and resolved to assert his right to the crown of England. For that purpose he invited the neighbouring princes, as well as his own vassals, to join hinı, and made liberal promises to his followers, of lands and honours in England, to induce them to assist him effectually. By these means he icollected 40,000 of the bravest and most regular troops in Europe ; and while Harold was embarrassed with fresh invasions by the Danes, William landed in England without opposition. Harold, returning from the north, encountered William at the place now called Battle, which took its name from that erent, near Hastings in Sussex, and a most bloody battle was fought between the two armies; but Harold being killed, the crown of England devolved upon IVilliam, in the year 1066.

The loss which both sides suffered at the battle of Hastings is uncertain, but William, with very little further dificulty, took posses. sion of the throne, and made a considerable alteration in the constitution of England, by converting lands into knights fecs, which are said to have amounted to 62,000 , and were held of the Norman and other great persons who had assisted him in his conquest, and who werc bound to attend him with their knights and their followers in his wars. He gave, for instance, to one of his barons the whole county of Chester, which he erected into a palatinate, and rendered by his grant almost independent of the crown; and here, according to some historians, we have the rise of the feudal law in England. William found it no easy matter to keep possession of his crown. Edgar Atheling, and his sister, the next Anglo-Saxon heirs, were affectionately received in Scotland, and many of the Saxon lords took arms, and formed conspiracies in England. He, however, surmounted all difficulties, especially after he had made a peace with Malcolm king of Scotland, who married Atheling's sister; but not without exercising horrible cruelties upon the Anglo-Saxons. He introduced the Norman laws and language. He built the stone square tower at London, commonly called the White Tower; bridled the country with forts, and disarmed the old inhabitants ; in short, he attempted every thing possible to obliterate every trace of the Anglo-Saxon constitution; though, at his coronation, he took the same oath that used to be taken by the ancient Saxon kings.

He caused a general survey of all the lands in England to be made, or rather to be completed (for it was begun in Edward the Confessor's time) and an account to be taken of the villains or servile tenants, slaves, and live-stock, upon each estate; all which were recorded in a book called Doomsday-book, which is now kept in the Exchequer. But the repose of this fortunate and victorious king was disturbed, in his old age, by the rebellion of his eldest son Robert, who had been appointed governor of Normandy, but assumed the government as sovereign of that province, in which he was favoured by the king of France. IVilliam, seeing a war inevitable, entered upon it with his usual vigour; and with incredible celerity transporting a brave English army, invacied France, where he was every where victorious; but died before he had finished the war, in the year 1087, the 
sixty-first year of his age, and twenty-first of his reign in England, and was buried in his own abbey at Caen in Normandy.

The succession to the crown of England was disputed between the Conqueror's sons Robert and William (commonly calied Rufus, from his being red-haired) and was carried in favour of the latter. He was a brave and intrepid prince, but no friend to the clergy, who have therefore been unfavourable to his memory. He was likewise hated by the Normans, who loved his eldest brother: and, consequently, he was engaged in perpetual wars with his brothers and rebellious sub. jects. He was accidentally killed, as he was hunting in New Forest in Hampshire, in the year 1100, and the forty-fourth year of his age.

This prince built Westminster-hall, and added several works to the tower, which he surrounded with a wall and a ditch. In the year 1100 happened that inundation of the sea, which overflowed great part of earl Goodwin's estate in Kent, and formed those shallows in the Downs, now called the Groodwin-Sands.

He was succeeded by his brother, Henry I, surnamed Beauclere on account of his learning, though his brother Robert was then returning from the Holy Land. His reign in a great measure restored the clergy to their influence in the state; and they formed, as it were, a separate body, dependent upon the pope, which afterwards created great convulsions in England. Henry, partly by force and partly by st.atagem, made himself master of his brother Robert's person, and duchy of Normandy; and, with the most ungenerous meanness, detained him a prisoner twenty-eight years, till the time of his death. He was afterwards engaged in a bloody but successful war with France; and, before his cleath, he settled the succession upon his daughter, the empress Matilda, widow to Henry IV, emperor of Germany, and her son Henry, by her second husband Geoffrey Plantagenet, earl of Anjou. Henry died of a surfeit, in the seventyeighth year of his age, in 1135 .

Notwitlistanding the late settlement of succession, the crown of England was claimed and seized by Stephen, earl of Blois, the son of Adela, fourth daughter to William the Conqueror. Matilda and her son were then abroad; however, she found a generous protector in her uncle David, king of Scotland; and a worthy subject in her natural brother Robert, earl of Gloucester, who headed her party until ther son grew up. A long and bloody war ensued, the clergy having absolved Stephen and all his friends from their guilt of breaking the act of succession : but at length the barons, who dreaded the power of the clergy, inclined towards Matilda; and Stephen, who depended chiefly on foreign mercenaries, having been abandoned by the clergy, was defeated and taken prisoner in 1141; and, being carried before Matilda, she scornfully upbraided him, and ordered him to be put in chains.

Matilda was proud and weak: the clergy were bold and ambitious; and, when joined with the nobility, who were factious and turbulent, were an over-match for the crown. They demanded to be governed by the Saxon laws, and finding Matilda refractory, they drove her out of England in 1142. Stephen, having been exchanged for the earl of Gloucester, who liad been taken prisoner likewise, upon obtaining his liberty, found that his clergy and nobility had in fact excluded him from the government, by building 1100 castles, where each owner lived as an independent prince. Stephen attempted to force them to declare his son Eustace lreir-apparent to the kingdom; and this 
exasperated the clergy so much, that they invited over young Henry of Anjou, who had been acknowledged duke of Normandy, and was son to the empress; and he accordingly landed in England with an army of foreigners.

This measure divided the clergy from the barons; who were apprehensive of a second conquest; and the earl of Arundel, witi the heads of the lay aristocracy, proposed an accommorlation, to which both parties agreed. Stephen, who about that time lost his son Eustace, was to retain the name and office of king; but Henry, who was in fact invested with the chief executive power, was acknowledged his successor. Though this accommodation was only precarious and imperfect, yet it was received by the English, who had suffered so much during the late civil wars, with great joy; and Stephen dying very opportunely, Henry mounted the throne, without a rival, in 1154.

Henry II, surnamed Plantagenet, was by far the greatest prince of his time. At his accession to the throne, he found the condition of the English boroughs greatly improved, by the privileges granted them in the struggles between their late kings and the nobility. Henry perceived the good policy of this, and still further extended the franchises of the boroughs, so that if a bondman or servant remained in a borough a year and a day, he was by such residence made free.

Henry like wise distinguished his reign by the conquest of Ireland; and by marrying Eleanor, the divorced queen of France, but the heiress of Guienne and Poitou, he became almost as porverful in France as the French king himself, and the greatest prince in Christendom.

Richard I, surnamed Cœur de Lion from his great courage, was the third but eldest surviving son of Henry II. He engaged in a most magnificent but ruinous crusade to the Holy Land, where he took Ascalon, and displayed his valour by many heroic acts. After several glorious but fruitless campaigns, he concluded a truce of three years with Saladin emperor of the Saracens; and in his return to England was treacherously surprised by the duke of Austria, who, in 1193 , sent him a prisoner to the emperor Henry VI. His ransom was fixed by the sordid emperor at 150,000 marks, about 300,000 pounds of our present money. On his return, he found his dominions in great disorder, through the practices of his brother John, whom, however, he pardoned; and by the invasions of the French, whom he repelled; but was slain while besieging the castle of Chalons, in the year 1199, the forty-second year of his age, and tenth of his reign.

The reign of his brother John, who succeeded him, is infamous in the English history. He is said to have put to death Arthur, the eldest son of his brother Geoffrey, who had the hereditary right to the crown. The young prince's mother, Constance, complained to Philip, the king of France; who, upon Jolın's non-appearance at his court as a vassal, deprived him of Normandy. John, notwithstanding, in his wars with the French, Scotch, and Irish, gave many proofs of personal valour; but became at last so apprehensive of a French invasion, that he rendered himself a tributary to the pope, and laid his crown and regalia at the foot of the legate Pandulph, who kept them for five days. The great barons resented his meanness, by taking arms : but he repeated his shameful submissions to the pope; and after experiencing various fortunes of war, John was at last brought so low, that the barons obliged him, in 1216 , to sign the great deed 
so well known by the name of Magna Charta. John had scarcely. signed it, when he retracted, and called upon the pope for protec. tion; on which the barons wihdrew their allegiance from John, and transferred it to Lewis, the eldest son of Philip Augustus, king of France. This gave offence to the pope; and the barons, being ap. prehensive of their country becoming a province to France, returned to their allegiance to John: but he was unable to protect them, till the pope refused to confirm the title of Lewis. John died in 1216, in the eighteenth year of his reign, and the forty-ninth of his age.

England was in a deplorable situation when the crown devolved upon Henry III, the late king's son, who was but nine years of age. The earl of Pembroke was chosen his guardian; and the pope taking part with the youns prince, the French were defeated and dri. ven out of the kingdom, and their king obliged to renounce all claims upon the crown of England. The regent, earl of Pembroke, who had thus retrieved the independency of his country, died in 1219 , and the regency devolved upon the bishop of Winchester. The king was of a feeble and pliable disposition, and had been persuaded to violate the Great Charter. Indeed he seemed always endeavouring to evade the privileges which he had been compelled to grant and confirm. An association of the barons was formed against him and his government; and a civil war commencing, Henry seemed to be abandoned by all but his Gascons and foreign mercenaries. His profusion brought him into great difficulties; and the famous Stephen Montfort, who had married his sister, and was made earl of Leicester, being chosen general of the association, the king and his two sons were defeated, and taken prisoners, at the battle of Lewes. A difference happening between Montfort and the earl of Gloucester, a nobleman of great authority, pince Edward, ilenry's eldest son, obtained his liberty; and assembling as many as he could of his father's subjects, who were jealous of Montfort, and veary of the tyranny of the barons, he gave battle to the rebels, whom he defeated at Evesham, August 4th, 1265, and killed Montfort. Prince Edward being afterwards engaged in a crusade, Henry, during his absence, died in 1272, the sixty-fourth year of his age, and the fifty-sixth of his reign, which was uncomfortable and inglorious.

Edward returning to England, on the news of his father's death, invited all who held of his crown in cafite to his coronation dinner, which consisted (that the reader may have some idea of the luxury of the times) of 278 bacon hogs, 450 hogs, 4.40 oxen, 430 sheep, 22,600 hens and capons, and 13 fat goats. (See Rymer's Fœdera.) Alexander III, king of Scolland, was at the solemnity; and on the occasion 500 horses were let loose, for those that could catch them to keep them.

Edward was a brave and politic prince. He reduced the Welsh to pay him tribute, and annexed that principality to his crown; and was the first who gave the title of Prince of Wales to his eldest son. He died in 1307, in the sixty-ninth year of his age, and thirty-fifth of his reign, while he was engaged in a new expedition against Scotland. He ordered his heart to be sent to the Holy Land, with 32,000 pounds for the maintenance of the Holy Sepulchre.

His son and successor, Edward II, showed early dispositions for encouraging favourites; but Gaveston, his chief minion, a Gascon, being banished by his father Edward, he mounted the throne with . vast advantages, both political and personal, all which he soon form 
Feited by his own imprudence. He recalled Gaveston, and loaded hims with honours, and married Isabella, daughter of the French king, who restored to him part of the territories which Edward I, had lost in France. The barons, however, obliged him once more to banish his farourite, and to confirm the Great Charter. Gaveston being beheaded by the barons, they fixed upon young Hugh Spencer as a spy upon the king; but he soon became his favourite. He, through his pride, avarice, and ambition, was banished, together with his father, whom he had procured to be made earl of Winchester. The queen, a furious ambicious woman, persuaded her husband to recal the Spencers, while the common people, from their hatred to the barons, joined the king's standard, and, after defeating them, restored him to the exercise of all his prerogatives. A cruel use was made of those suc. cesses; and many noble patriots, with their estates, fell victims to the queen's revenge; but at last she became enamoured with Roger Mortimer, who was her prisoner, and had been one of the most active of the anti-royalistlords. A breach between her and the Spencers soon followed; and going over to France with her lover, she found means to form such a party in England, that, returning with some French troops, she put the eldest Spencer to an ignominious death, made her husband prisoner, and forced him to abdicate his crown in favour of his son Edward III, then fifteen years of age. Nothing now but the death of Edward II, was wanting to complete her guilt; and he was most barbarously murdered in Berkley-castle, by ruffians, supposed to be employed by her and her paramour Mortimer, in the year 1327. In this reign the Knights Templars were suppressed.

Edward III, mounted the throne in 1327. He was then under the tuition of his mother, who cohabited with Mortimer; and they endearoured to keep possession of their power, by adopting many popular measures, and putting an end to all national differences with Scotland, for which Mortimer was created earl of March. Edward, young as he was, was soon sensible of their designs. He surprised them in person at the head of a few chosen friends in the castle of Not tingham. Mortimer was hanged as a traitor on the common gallows at Tyburn, and the queen shut up in confinement twenty-eight years, to her death. It was not long before Edward found means to quarm rel with David, king of Scotland, though he had married his sister. David was driven to France by Edward Baliol, who acted as Edo ward's tributary, king of Scotland, and general, and did the same ho: mage to Edward for Scotland as his father had done to Edward I. Soon after, upon the death of Charles the Fair, king of France, without issue, who had succeeded by virtue of the Salic law, which, the French pretended, cut off all female succession to that crown, Philip of Valois claimed it, as being the next heir male by succession; but he was opposed by Edward, as being the son of Isabella, who was sister to the three last-mentioned kings of France, and nirst in the female succession. The former was preferred; but the case being doubtful, Edword pursued his claim, and invaded France with a pow erful army.

The war, on the part of Edward, was a continued scene of success and victory. In 1340 he took the title of king of France, using it in all public acts, and quartered the arms of France with his own, adding this motto, Dieu et mon droit, "God and my right." At Cressy, August 26th, 1346, above 100,000 French were defeated, chiefly VOL. I. 
by the valour of the prince of Wales, who was but sixteen years of age, (his father being no more than thirty-four) though the English did not exceed 30,000. The loss of the French far exceeded the number of the English army, whose loss consisted of no more than three knights and one esquire, and about fifty private men. The batthe of Poictiers was fought in 1356, between the prince of Wales and the French king John, but with very superior advantage of number's on the part of the French, who were totally defeated, and their king and his favourite son $\mathrm{Philip}$ taken prisoners. It is thought that the number of French killed in this battle was double that of all the English army; but the modesty and politeness with which the prince treated his royal prisoner's formed the brightest wreath in his garland.

Edward's glories were not confined to France. Having left his queen Philippa, daughter to the earl of Hainault, regent of England, she had the good fortune to take prisoner David king of Scotland, who had ventured to invade England, about six weeks after the battle of Cressy was fought, and remained a prisoner eleven years. Thus Edward had the glory to see two crowned heads his captives at London. Both kings were afterwards ransomed; David for 100,000 marks, and John for three millions of gold crowns : but John returned to England, and clied at the palace of the Savoy. After the treaty of Bretigni, into which Edward III, is said to have been terrified by a dreadful storm, his fortunes declined. He had resigned his French dominions entirely to the prince of Wales; and he sunk in the esteem of his subjects at home, on account of his attachment to his mistress, Alice Pierce. The prince of Wales, commonly called the Black Prince, ${ }^{*}$ from his wearing black armour while he was making a glorious campaign in Spain, where he reinstated Peter the Cruel on the throne, was seized with a consumptive disorder, which carried him off in the year 1572. His father did not long survive him; for he died, clispirited and obscure, at Shene in Surry, in the year 1377, the sixty-fifth of his age, and fifty-first of his reign.

Richard II, son of the Black Prince, was only eleven years of age when he mounted the throne. The English arms were then unsuccessful both in France and Scotland. John of Gaunt's foreign connexions with the crowns of Portugal and Spain were of prejudice to England; and so many men were employed in unsuccessful wars, that the commons of England, like powder receiving a spark of fire, all at once flamed out into rebellion, under the conduct of Ball, a priest. Wat Tyler, Jack Straw, and others, the lowest of the people. The conduct of these insurgents was very violent; but it cannot be denied that the common people of England then laboured under many oppressions.

Richard was not then above sixteen; but he acted with great spirit and wisdom. He faced the storm of the insurgents, at the head of the Londoners, while Walworth the mayor, and Philpot an alderman, had the courage to put Tyler, the leader of the malcontents, to death, in the midst of his adberents. Richard then associated to himself a new set of favourites. His people and great lords again took up arms; and, being headed by the duke of Gloucester, the king's uncle,

- He was also the first in England that had the title of Duke, being created by his father duke of Cornwall ; and, ever since, the eldest son of the king of Eng. land is by birth duke of Cornwall. 
they forced Richard once more into terms : but being insincere in all his compliances, he was upon the point of becoming more despotic than any king in England ever had been, when he lost his crown and life by a sudden catastrophe.

A quarrel happened between the duke of Hereford, son to the duke of Lancaster, and the duke of Norfolk; and Richard banished them both, with particular acts of injustice to the former, who now became duke of Lancaster by his father's death. Richard carrying over a great army to quell a rebellion in Ireland, a strong party formed in England, the natural result of his tyranny, who offered the duke of Lancaster the crown. The duke landed from France at Ravenspur in Yorkshire, and was soon at the head of $60,000 \mathrm{men}$, all of them English. Richard hurried back to England, where, his troops refusing to tight, and his subjects, whom he had affected to despise, generally deserting him, he was made prisoner with no mole than twenty attendants; and being carried to London, was deposed in full parliament, upon a formal charge of tylanny and misconduct; and soon after is supposed to have been starved to death in prison, in the year 1399, the thirty-fourth of his age, and the twenty-third of his reign. He had no issue by either of his two marriages.

Henry the Fourth, son of John of Gaunt duke of Lancaster, fourtl son of Edward III, being settled on the throne of England, in prejudice to the elder branches of Edward III's family, the great nobility were in hopes that this glaring defect in his title would render him dependent upon them. At first some conspiracies were formed against him by the dukes of Surry and Exeter, the earls of Gloucester and Salisbury, and the ar'chbishop of York; but he crushed them by his activity and steadiness, and laid a plan for reducing their overgrown power. This was understood by the Percy family, the greatest in the north of England, who complained that Henry had deprived them of some Scotch prisoners, whom they had taken in battle; and a dangerous rebellion broke out under the old earl of Northumberland, and his son the famous Henry Percy, surnamed Hotspur; but it ended in the defeat of the rebels, chiefly by the valour of the prince of WVales. With equal good-fortune, Henry suppressed the insurrection of the Welch, under Owen Glendower; and by his prudent concessions to his parliament, to the commons paricularly, he at last overcame all opposition, while, to salve the defect of his title, the parliament entailed the crown upon him, and the heirs male of his body lawfully begotten, thereby shutting out all female succession. The young duke of Rothsay, heir to the crown of Scotland (afterwards James I, of that kingdom) falling a prisoner into Henry's hands about this time, was of infinite service to his government; and before his death, which happened in 1413 , in the forty-sixth year of his age, and thirteenth of his reign, he had the satisfaction to see his son and successor, the prince of Wales, disengage himself from many youthful follies, which till then had disgraced his conduct.

The English marine was now so greatly increased, that we find an English vessel of 200 tons in the Baltic, and many ot 1 er ships of equal burthen, carrying on a great trade all over Europe, but with the Hanse towns in particular.

At the accession of Henry V, in 1413, the Lollards, or the followers of VVickliffe, were excessively numerous; and sir John Old. castle, lord Cobham, having joined them, it was pretended that he 
had agreed to put himself at their head, with a design to overturn the government; but this appears to have been a groundless accusaw tion by the clergy, though he was put to death in consequence of it. His only real crime seems to have been the spirit with which he opposed the superstition of the age; and he was the first of the nobility who suffered on account of religion. Henry was about this time engaged in a contest with France, which he had many incitements for invading. He demanded a restitution of Normandy, and other provinces that had been taken from England in the preceding reigns; also the payment of certain arrears due for king John's rallsom since the reign of Edward III; and availing himself of the distracted state of that kingdom by the Orleans and Burgundy factions, he invaded it, first took Harfleur, and then defeated the French in the battle of Agincourt, which equalled those of Cressy and Poictiers in glory to the English, but exceeded them in its consequences, on account of the vast number of French princes of the blood, and other great noblemen, who were there killed. Henry who was as great a politician as a warrior, made such alliances, and divided the French among themselves so effectually, that he forced the queen of France, whose husband, Charles VI, was a lunatic, to agree to his marrying her daughter, the princess Catharine, to disinherit the dauphin, and to declare Henry regent of France during her husband's life, and him and his issue successors to the French monarchy, which must at this time have been exterminated, had not the Scots (though their king still continued Henry's captive) furnished the dauphin with vast supplies, and preserved to him the French crown. Henry, however, made a triumphal entry into Paris, where the dauphin was proscribed; and after receiving the fealty of the French nobility, he returned to England to levy a force that might crush the dauphin and his Scottish auxiliaries. He probably would have been successful, had he not died of a pleuritic disorder, in 14.42, the thirty-fourth year of his age, and the tenth of lis reign.

Henry VI, surnamed of Windsor, was no more than nine months old, when, in consequence of the treaty of Troyes, concluded by his father with the French court, he was proclaimed king of France as well as England. He was under the tuition of his two uncles, the dukes of Bedford and Gloucester, both of them princes of great accomplishments, virtues, and courage, but unable to preserve their brother's conquests. Upon the death of Charles VI, the affections of the French for his family revived in the person of his son and successor Charles VII. The duke of Bedford, who was regent of France, performed many glorious actions, and at last laid siege to Orleans, which, if taken, would have completed tie conquest of France. The siege was raised by the valour and good conduct of the Maid of Orleans, a phanomenon hardly to be paralleled in history, she being born of the lowest extraction, and bred a cow-lieeper, and some time a helper in stables in public inns. She must, notwithstanding, have possessed an anazing fund of sagacity, as well as valour. After an unparalleled train of heroic actions, and placing the crown upon her sovereign's hear', she was taken prisoner by the English in making a sally during the siege of Compiegne, who burnt her alive for a witch, at Rouel, May 50, 1431.

The death of the duke of Bedford, and the agreement of the duke of Burgुundy, the great ally of the English, with Charles VII, contributed to the entire ruin of the English interest in France, and the 
loss of all their fine provinces in that kingdom, notwithstanding the courage of Talbot the first earl of Shrewsbury, and their other officer's. The principal misfortune of England, at this time, was its disunion at home. The duke of Gloucesier lost his authority in the government; and the king married Margaret of Anjou, daughter to the needy king of Sicily, a woman of a high spirit, but an implacable disposition; while the cardinal of Winchester, who was the richest subject in England, if not in Europe, presided at the head of the treasury, and by his avarice ruined the interest of England, both at home and abroad. Next to the cardinal, the duke of York, who was lord lieutenant of Ireland, was the most powerful subject in England. He was descended by the mother's side from Lionel, an elder son of Edward III, and prior in claim to the reigning king, who was descended from John of Gaunt, Edward's youngest son : and he affected to keep up the distinction of a white rose ; that of the house of Lancaster being red. It is certain that he paid no regard to the parliamentary entail of the crown upon the reigning family; and he lost no opportunity of forming a party to assert his right; but acted at first with a most profound dissimulation. The inglorious management of the English affairs in France befriended him; and upon his arrival in England from Ireland, he found a strong party of the nobility his friends; but being considered as the fomenter of Cade's rebellion, he professed the most profound reverence to Henry.

The persons in high power and reputation in England, next to the duke of York, were the earl of Salisbury, and his son the earl of Warwick. The latter had the greatest land estate of any subject in England; and his vast abilities, joined to some virtues, rendered him equally popular. Both father and son were secretly on the side of York; and during a fit of illness of the king, that duke was made protector of the realm. Both sides now prepared for arms; and the king recovering, the queen with wonderful activity assembled an army ; but the royalists were defeated in the first battle of St. Alban's, and the king himself was taken prisoner. The duke of York was once more declared protector of the kingdom; but it was not long before the queen resumed all her influence in the government, and the king, though his weakness became every day more and more visible, recovered all his authority.

The duke of York upon this threw off the mask, and in 1459 openly claimed the crown; and the quecn was again defeated by the earl of Warwick, who was now called the king-maker. A parliament upon this being assembled, it was enacted that Henry should possess the throne for life, but that the duke of York should succeed him, to the exclusion of all Henry's issue. The queen, however, refused to agree to this-compromise. She retreated northwards; and the king being still a prisoner, she pleacled his cause so well, that, assembling a fresh army, she fought the battle of Wakefield, where the duke of York was defeated and slain, in 1460 .

It is remarkable that, though the duke of York and his party openly asserted his claim to the crown, they still professed allegiance to Henry; but the duke of York's son, afterwards Edward IV, prepared to revenge his father's death, and obtained several victories over the royalists. The queen however, advanced towards London; and defeating the earl of Warwick, in the second battle of St. Alban's, she deliv. ered her husband; but the disorders committed by her northern troops disgusted the Londoners so much, that she durst not enter 
London, where the duke of York was received, on the 28th of Feb. ruary 1461 , while the queen and her husband were obliged to retreat northwards. She soon raised another army, and fought the battle of 'Towton, the most bloody perhaps that ever happened in any civil war. After prodigies of valour had been performed on both sides, the victory remained with young king Edward, and near 40,000 men lay dead on the field of battle. Margaret and her husband were once more obliged to $\mathrm{Ay}$ to Scotland, where they net with generous protection.

Margaret, by the concessions she made to the Scots, soon raised a fresh army in Scotland, and the north of England, but met with defeat upon defeat, till at last her husband, the unfortunate Henry, was carried prisoner to London.

The duke of York, now Edward IV, being crowned on the 20th of June, fell in love with, and privately married, Elizabeth the widow of sir John Gray, though he had some time before sent the earl of War. wick to demand the king of France's sister in marriage, in which embassy he was successful, and nothing remained but the bringing over the princess into England. When the secret of Edward's marriage was known, the haughty earl, deeming himself affronted, returned to England inflamed with rage and indignation, and, from being Edward's best friend, became his most formidable enemy; and gaining over the duke of Clarence, Edward was made prisoner; but escaping from his confinement, the earl of Warwick, and the French king Iewis XI, declared for the restoration of Henry, who was replaced on the throne, and Edward narrowly escaped to Holland. Returning from thence, he advanced to London, under pretence of claim. ing his dukedom of York; but being received into the capital, he resumed the exercise of royal authority, made king Henry once more his prisoner, and defeated and killed Warwick in the battle of Barnet. A few days after he defeated a fresh army of Lancastrians, and made queen Margaret prisoner, together with her son prince Edward, whom Edward's brother, the duke of Gloucester, murdered in cold blood, as he is said (but with no great appearance of probability) to have done his father Henry VI, then a prisoner in the tower of London, a few days after, in the year 1471.

Edward, partly to amuse the public, and partly to supply the vast expences of his court, pretended sometimes to quarrel and sometimes to treat with France : but his irregularities brought him to his death, 1483 , in the twenty-third year of his reign, and forty-second of his age.

Notwithstanding the turbulence of the times, the trade and manufactures of England, particularly the woollen, increased during the reigns of Henry VI, and Edward IV. The invention of printing, which is generally supposed to have been imported into England by William Caxton, and which received some countenance from Edward, is the chief glory of his reign; but learning in general was then in a mean state in England.

Edward IV, left two sons by his queen, who had exercised her power with no great prudence, by having ennobled many of her obscure relations. Her eldest son, Edward V, was about thirteen; and his uncle, the duke of Gloucester, taking advantage of the queen's unpopularity among the nobility, found means to bastardise her issue, by act of parliament, under the scandalous pretext of a pre-contract between their father and another lady. The duke, at the same time, 
was declared guardian of the kingdom, and at last accepted the crown, which was offered him by the Londoners; having first put to death all the nobiiity and men of rank whom be thought to be well affected to the late king's family. Whether the king and his brother were murdered in the Tower, by his direction, is doubtful. Be this as it may, the English were prepossessed so strongly against Richard, as being the murderer of his nephews, that the earl of Richmond, who still remained in France, carried on a secret correspondence with the remains of Edward IV's friends; and by offering to marry his elciest daughter, he was encouraged to invade England at the head of about 2000 foreign troops; but they were soon joined by 7000 English and Welch. A battle between him and Richard, who was at the head of 15,000 men, ensued at Bosworth-field, in which Richard, after displaying astonishing acts of personal valour, was killed, having been first abandoned by a main division of his army, under lord Stanley and his brother, in the year 1485

Though the same act of bastardy affected the daughters as well as the sons of the late king, yet no disputes were raised upon the legitimacy of the princess Elizabeth, eldest daughter to Edward IV, and who, as had been before concerted, married Henry of Lancaster, earl of Richmond, thereby uniting both houses, which happily put an end to the long and bloody wars between the contending houses of York and Lancaster.

Henry, after encountering and surmounting many difficulties both in France and Ireland, was attacked in the possession of his throne by a young man, one Perkin IVarbeck, who pretended to be the duke of York, second son to Edward IV, and was acknowledged as such by the duchess of Burgundy, Edward's sister. Perkin, after various unfortunate adventures, fell into Henry's hands, and was shut up in the Tower of London, from whence he endeavoured to escape along with the innocent earl of Warwick; for which Perkin was banged, and the earl beheaded. In 1499, Henry's eldest son, Arthur prince of Wales, was married to the princess Catharine of Arragon, daughter to the king and queen of Spain; and he dying soon after, such was Henry's reluctance to refund her great dowry, 200,000 crowns of gold, that he consented to luer leing married again to his second son, then prince of WVales, on pretence that the first match had not been consummated. Soon after, Henry's eldest daughter, the princess Margaret, was sent with a most magnificent train to Scotland, where she was married to James IV. Henry, at the time of his cleath, which happened in 1509, the fifty-second year of his age, and twenty-fourth of his reign, was possessed of $1,800,000 l$. sterling, which is equivaleng to five millions at present. He was immoderately fond of replenishing his coffers, and often prevailed on his parliament to grant him subsidies for foreign alliances which he never intended to form.

Perhaps no prince ever entered with greater advantages on the exercise of royalty than Henry VIII. Young, vigorous, and rich, without any rival, he held the balance of power in Europe; but it is certain that he neglected those advantages in commerce with which his father became too lately acquainted. His vanity engaged him tor much in the affairs of the continent; and his flatterers encouraged him to make preparations for the conquest of all France. These projects led him into increclible expences. He became a candidate for ${ }^{\text {t }}$ the German empire, during its vacancy; but soon resigned his pre- 
tensions to Francis I, of France, and Charles of Austria, king of Spain, who was elected in 1519 .

Henry continued all this time the great enemy of the reformation and the champion of the popes and the Rumish church. He wrote a book against Luther, "Of the Seven Sacraments," about the year 1521, for "which the pope gave him the title of Defender of the Faith, which his successors retain to this day. But, about the year 1527 , he began to have some scruple with regard to the validity of his marriage with his brother's widow. It may be difficult to say at present how far he might be influenced by scruples of his conscience, or aversion to the queen, or the charms of the famous Anne Boleyn, maid of honour to the queen, whom he married before he had obtained from Rome the proper bulls of divorce from the pope. The difficulties he met with in this process ruined Wolsey, who died heartbroken, after being stripped of his immense power and possessions.

A variety of circumstances, it is well known, induced Henry at last to throw off all relation to, or dependence upon, the church of Rome, and to cause a reformation; in which, however, many of the Romish errors and superstitions were retained. Upon a slight suspicion of his queen's inconstancy, and after a mock trial, he cut off her head in the Tower, and put to death some of her nearest relations. The dissolution of the religious houses, and the immense wealth that came to Henry by seizing all the ecclesiastical property in his kingdom, enabled him to give full scope to his sanguinary disposition; so that the best and most innocent blood of England was shed on scaffolds, and seldom any long time passed without being marked with some illustrious victim of his tyranny.

His third wife was Jane Seymour, daugbter to a gentleman of for tune and family; but she died in bringing Edward VI, into the world. His fourth wife was Anne, sister to the duke of Cleves. He disliked her so much, that he soon obtained a divorce, though he suffered her to reside in England on a pension of $3000 l$. a year. His fifth wife was Catharine Howard, niece to the duke of Norfolk, whom he caused to be beheaded for anti-nuptial incontinency. His last wife was Catharine Par, in whose possession he died, after she had narrowly escaped being brought to the stake, for her religious opinions, which favoured the reformation. Henry's cruelty increased with his years, and was now exercised promiscuously on protestants and catholics. He put the brave earl of Surry to death, without a crime being proved against him; and his father, the duke of Norfolk, must have suffered. the next day, had he not been saved by the death of Henry himself, 1547 , in the 56 th year of his age, and the 38 th of his reign.

The state of England, during the reign of Henry VIII, is, by the means of printing, better known than that of his predecessors. His attention to the naval security of England was highly commendable ; and it is certain that he employed the unju iand arbitrary power he frequently assumed, in many respects, for the glory and interest of bis subjects: Without inquiring into his religious motives, it must be candidly confessed, that the partition he made of the property of the church among his courtiers and favourites, and thereby rescuing it from dead hands, undoubtedly promoted the present greatness of England. With regard to learning and the arts, Henry was a generous encourager of both.

In this reign the Bible was ordered to be printed in English. Wales was united and incorporated with England. Ireland was erect- 
et into a kingdom, and Henry took the title of king instead of lord of I'eland.

Edwa:d VI, was but nine years of age at the time of his father's reath; and after some disputes the regency was setiled in the person of his uncle the earl of Hertford, afterwards the protector, and duke of Somerset, a declared friend and.patron of the reformation, and an implacable enemy to the see of Rome.

The reformation, however, went on rapidly, through the zeal of Cranmer and others, some of them foreign divines. In some cases, particularly with regard to the princess MLary, they lost sight of that muderation which the reformers had before so strongly recommended ; and some cruel sanguinary executions, on account of religion, took place. Edward's youth excuses him from blame; and his charitable endowments, as Bridiwell and St. Thomas's hospitals, and also several schools which still exist and flourish, show the goodness of his beart. He died of a consumption in 1553, in the 16th year of his age, and the 7 th of his reign.

Edward, on his death-bed, from his zcal for religion, had made a very unconstitutional will; for he set aside his sister Mary from the succession, which was claimed by lady Jane Gray, daughter to the duchess of Suffolk, younger sister to Henry.VIII. This lady, though she had scarcely reached her 17 th year, was a prodigy of learning: and rirtue; but the bulk of the English nation recognised the claim of the princess Mary, and lady Jane was beheaded. Her husband, lord Guildford Dudley, son to the duke of Northumberland, also suffered in the same manner.

Mary being thus settled on the throne, suppressed an insurrection under IVyat, and proceeded like a female fury to re-establish popery, which she did all over Englanu. She recalled cardinal Pole from banishment, made him instrumental in her cruelties, and lighted up the flames of persecution, in which archbishop Cranmer, the bishops Ridley, Hooper, and Latimer, and many other illustrious confessors of the English reformed church, were consumed; not to mention a vast number of other sacrifices of both sexes, and all ranks, tha: suffered through eyedy quarter of the kingdom.

Mary now married Philip II, of Spain, who, like herself, was an unfeeling bigot to popery; and the chief praise of her reign is, that, by the marriage, articles, provision was made for the independency of the English crown. By the assistance of troops which she furnished to her husband, he. gained the important battle of St. Quintin : but that victory. was so ill improved, that the French, under the duke of Guise, soon after took Calais, the only place then remaining to the English in France, and which had been held ever since the reign of Edward III. This loss, which was chiefly owing to cardinal Pole's secret connexions with the Prench court, is said to have broken Mary's heart, who died in 1558, in the $42 \mathrm{~d}$ year. of her life, and 6th. of her reign.

Elizabeth, daughter to Henry VIII, by Anne Boleyn, mounted the throne under the most discouraging circumstances both at home and abroad. Popery was the established religion of England, her title to the crown, on account of the circumstances attending her mother's marriage and death, was disputed by Mary queen of Scots, grandchild to Henry VII's eldest daughter, and wife to the dauphin of France; and the only ally she had on the continent' was Philip king of Spain, who was the main support of the popish cause, both abrond and in

.Vor. I. 
England. Elizabeth was no more than 25 years of age at the time of her inauguration; but her sufferings under her bigoted sister, joined to the superiority of her genius, had taught her caution and policy; and she soon surmounted all difficulties.

In matters of religion she succeeded with surprising facility; for, in her first parliament in 1559 , the laws establishing popery were repealed, her supremacy was restored, and an act of uniformity passed soon after. And it is observed, that of 9400 beneficed clergymen in England, only about 120 refused to comply with the reformation. With regard to her title, she took advantage of the divided state of Scotland, and formed a party there, by which Mary, now become the vidow of Francis II, of France was obliged to renounce, or rather to suspend, her claim. Elizabeth, not contented with this, sent troops and money, which supported the Scottish malecontents, till Mary's unhappy marriage with lord Darnley, and then with Bothwell, the supposed murderer of the former, and her other misconduct and misfortunes, drove her to take refuge in Elizabeth's dominions, where she had often been promised a safe and honourable asylum. It is well Iknown how unfaithful Elizabeth was to this profession of friendship, and that she detained the unhappy prisoner eighteen years in England, then brought her to a mock trial, pretending that Mary aimed at the crown, and, without sufficient proof of her guilt, cut off her head; an action which greatly tarnished the glories of her reign.

The same Philip who had been the husband of her late sister, upon Elizabeth's accession to the throne, offered to marry her : but she dexterously avoided his addresses; and, by a train of skilful negotiations between her court and that of France, kept the balance of Europe so undetermined, that she had leisure to unite her people at home, and to establish an excellent internal policy in her dominions. She supported the protestants of France against their persecuting princes and the papists, and gave the dukes of Anjou and Alencon, brothers of the French king, the strongest assurances that one or other of them should be her husband; by which she kept that court, who dreaded Spain, at the same time in so good humour with her government, that it showed no resentment when she beheaded queen Mary.

When Philip was no longer to be imposed upon by the arts of Elizabeth, which had amused and baffled him in every quarter, he employec. the immense sums he drew from Peru and Mexico in equipping the most formidable armament that perhaps ever had been put to sea, and a numerous army of veterans, under the prince of Parma, the best general of that age, and procured a papal bull for absolving Elizabeth's subjects from their allegiance. The great size of the Spanish ships proved disadvantageous to them on the seas where they fought. The lord admiral Howard, and the brave sea-officers under him, engaged, beat, and chased the Spanish fleet for several days; and the waves and tempests finished the destruction which the English arms had begun, so that few of the Spanish ships recovered their ports.

Elizabeth had for some time supported the revolt of the Hollanders from Philip, and had sent them her favourite, the earl of Leicester, who acted as her viceroy and general in the Low Countries. Though Leicester behaved ill, yet her measures were so wise, that the Dutch established their independency; and then she sent forth her fleets under Drake, Raleigh, the earl of Cumberland, and other gallant naval officers, into the East and West Indies, whence they brought prodisious treasures, taken from the Spaniards, into England. 
Elizajeth in her old age grew distrustful, peevish, and jealous. Though she undoubtedly loved the earl of Essex, she teased him by her capriciousness into the madness of taking arms, and then cut off ${ }^{\prime}$ his head. She complained that she had been betrayed into this sanguinary measure ; and this occasioned a sinking of her spirits, which brought her to her grave in 1603, in the seventieth year of her age, and 45 th of her reign, having previously named her kinsman James VI, king of Scotland, and son to Mary, for her successor.

We can scarcely require a stronger proof that the English began to be tired of Elizabeth, than the joy testified by all ranks at the acces-. sion of her successor, notwithstanding the long inveterate animosities between the two kingdoms. James was far from being destitute of natural abilities for government; but he had received wrong impressions of the regal office, and too high an opinion of his own dignity, Itarning, and political talents It was his misfortune that he mounted the English throne under a full conviction that he was entitled to all the unconstitutional powers that had been occasionally exercised by Elizabeth and the house of Tudor, and which various causes had prevented the people from opposing with proper vigour. Neither did James make any allowance for the glories of Elizabeth, which, as 'has been observed, disguised her most arbitrary acts; and none for the free, liberal sentiments, which the improvement of knowledge and learning had diffused through England. James's first attempt of great consequence was to effect an union between England and Scotland; but though he failed in this through the aversion of the English to that measure, on account of his loading his Scottish courtiers with wealth and honours, he showed no violent resentment at the disappointment. It was an advantage to him at the beginning of his reign, that the courts of Rome and Spain were thought to be his enemies; and this opinion was increased by the discovery and defeat of the gunpowder treason.*

His pacific reign was a series of theological contests with ecclesiastical casuists, in which he proved himself more a theologian than a prince; and in 1617, he attempted to establish episcopacy in Scotland; but the zeal of the people baffled his design.

James was all this while perpetually jarring with his parliament, whom he could not persuade to furnish money equal to his demands; and at last he agreed that his son should marry the princess Henrietta Maria, sister to Lewis XIII, and daughter to Henry the Great of France. James died before the completion of this match ; and it is thought that, had he lived, he would bave discarded Buckingham. His death happened in 1625 , in the 59 th year of his age, after a reign over England of twenty-two years. James encouraged and employed that excellent painter sir Peter Paul Rubens, as well as Inigo Jones, who restored the pure taste of architecture in England; and in his reign poetical genius, though not much encouraged at court, shone with great lustre. Mr. Middleton also at this time projected the bringing water from Hertfordshire to London, and supplying the

- This was a scheme of the Roman-catholics to cut off at one blow the king; lords, and commons, at the meeting of parliament; when it was also expected that the queen and prince of Wales would be present. Notwithstanding this horrid crime, the bigoted catholics were so devoted to Garnet, a Jesuit, one of the conspirators, that they fancied miracles to be wrought by his blood, and in Spain he was considered as a martyr. 
city with it by means of pipes. This canal is still called the New River.

Charles I, was unfortunate in his marriage with the princess Henrietta Maria. She had' a high spirit, and despised whatever was incompatible with the prejudices of her arbitrary education. The spirit of the people had forced the late king into a rupture with Spain; and Charles early gave such indications of his partiality for Buckingham, and his own despotic temper, that the parliament was remiss in furuishing him with money for carrying on the war. Buckingham persuaded Charles to espouse the cause of the French Hugonots in their quarrel with that crown. They were, however, so ill supported, though Charles was sincere in his intentions to serve them, that Rochelle was reduced to extremity, by which the protestant interest received an irrecoverable blow in France. The blame of all the public miscarriages and disgraces was thrown by the almost unanimous voice both of the parliament and people upon the favourite; but he sheltered himself from their vengeance under the royal protection, till he was murdered by one Felton, a subaltern officer, as he was preparing to embark for the relief of Rochelle, which, soon after, surrendered to cardinal Richelieu.

The death of the duke of Buckingham did not deter Charles from his arbitrary proceedings, which the English patriots in that enlightened age justly considered as so many acts of tyranny. He, without authorityof parliament, laid arbitrary impositions upon trade, which were refused to be paid by many of the merchants and members of the house of commons. Some of them were imprisoned, and the judges were checked for admitting them to bail. The house of commons resented those proceedings by dratving up a protest, and denying admittance to the gentleman usher of the black rod; who came to adjourn them, till it was finished. This served only to widen the breach, and the king dissolved the parliament; after which he exhibited informations against nine of the most eminent member's, among whom was the great Mr. Selden, who was as much distinguished by his love of liberty as by his uncommon erudition. They objected to the jurisdiction of the court ; but their plea was overruled, and tley were sent to prison during the king's pleasure.

Every thing now operated towards the destruction of Charles. The commons would vote no supplies without some redress of the national grievances; upon which, Charles, presuming on what had been practised in reigns when the principles of liberty were imperfectly or not at all understood, levied money upon monopolies of salt, soap, and such necessaries, and other obsolete claims, particularly for knighthood; and raised yarious taxes without authority of parliament. Thus was the government rendered still more odious; and unfortus nately for Charles, he put his conscience into the hands of Laud, archbishop of Canterbury, who was as great a bigot as himself, both in church and state. Laud advised him to prosecute the puritans, and, in the year 1637, to introduce episcopacy into Scotland. The Scots upon this formed secret connexions with the discontentea English, and invaded England in August 1640, where Charles was so ill served by his officers and his army, that he was forced to agree to an inglorious peace with the Scots, who made themselves masters of New castle and Durham; and being now openly befriended by the house of commons, they obliged the king to comply with their demands.

Charles had made Wentworth, earl of Strafford, a man of great 
sbilities, president of the council of the North, and lord-lieutenant of Ireland: and he was generally believed to be the first minister of state. Strafiord had been a leading member of the opposition to the court; but he afterwards, in conjunction with Laud, exerted himself so vigorously in carrying the king's despotic schemes into execution, that he became an object of public detestation. As lord-president of the North, as lord-lieutenant of Ireland, and as a minister and privycounsellor in England, he behaved in a very arbitrary manner, and. was guilty of many acts of great injustice and oppression. He was, in consequence, at length, on the 22d of May 1641, brought to the block, though much against the inclinations of the king, who was in a manner forced by the parliament and people to sign the warrant for his execution. Archbishop Laud was also beheaded; but his execution did not take place till a considerable time after that of Strafford, the 10th of January, 345 . In the fourth year of his reign, Charles had passed the petition of right into a law, which was intended by the parliament as the future security of the liberty of the subject. It established particularly, "That no man hereafter be compelled to make or yield any gift, loan, benevolence, tax, or such like charge, without common consent by act of parliament ;" but he afterwards violated it in numerous instances, so that an universal discontent at his administration prevailed throughout the nation. A rebellion also broke out in Ireland, on October 23, 1641, where the protestants, without distinction of age, sex, or condition, to the amount of many thousands, were massacred by the papists; and great pains were taken to persuade the public that Charles secretly favoured them, out of hatred to his English subjects. The bishops werc expelled the house of peers, on account of their constantly opposing the designs and bills of the other house; and the leaders of the English house of commons still maintained a correspondence with the discontented Scots. Charles was ill enough advised to go in person to the house of commons, January 4, 1642, and there demand that lord Kimbolton, Mr. Pym, Mr. Hampden, Mr. Hollis, sir Arthur Haselrig, and Mr. Stroud, should be apprehended; but they had previously made their escape. This act of Charles was resented as high treason against his people; and the commons rejected all the offers of satisfaction he could make them.

Notwithstanding the many acts of tyranny and oppression, of which the ling and his ministers had been guilty, yet, when the civil war broke out, there were great numbers who repaired to the regal standard. Many of the nobility and gentry were much attached to the crown, and considered their own honours as connected with it; and a great part of the landed interest was joined to the royal party. The parliamerit, however, took upon thenselves the executive power, and were favoured by most of the trading towns and corporations; but its great resource lay in Loncion. The king's general was the earl of Lindsey, a brave but not an enterprising commander; but he had great dependence on his nephews, the princes Rupert and Maurice, sons to the elector Palatine, by his sister the princess Elizabeth. In the beginning of the war, the royal army had the ascendency; but in the progress of it, affairs took a very different turn. The earl of Essex was macle general under the parliament, and the first battle was fought at Edrgehill in Warwickshire, the 23d of October, 1642. Both parties claimed the victory, though the advantage lay with Charles; for the parliament was so much distressed, that they invited the Scots to 
come to their assistance, and they accordingly entered England anew: with about 20,000 horse and foot. Charles attempted to remove the parliament to Oxford, where many members of both houses met; but his enemies were still sitting at Westminsier, and contirued to carry on the war against him with great animosity. The independent party, which had scarcely before been thought of, began now to increase and to figure at Westminster. They were averse to the presbyterians, who till then had conducted the war against the king, nearly as much as to the royalists ; and such was their management, under the direction of the famous Oliver Cromwell, that a plan was formed for dismissing the earls of Essex and Manchester, and the heads of the presbyterians, from the parliament's service, on the suggestion that they were not for bringing the war to a speedy end, or not for reducing the king too low; and for introducing Fairfax, who was an excellent officer, but more manageable, though a presbyterian, and some independent officers. In the mean while the war went on with resentment and loss on both sides. Two battles were fought at Newbury, one on September 20th, 1643, and the other October $27 \mathrm{th}_{3}$ 1644 , in which the advantage inclined to the king He had likewise many other successes; and having defeated sir William Waller, he pursued the earl of Essex, who remained still in command, into Corn. wall, whence he was obliged to escape by sea; but his infantry sur. rendered themselves prisoners to the royalists, though his cavalry delivered themselves by their valour.

The first fatal blow the king's army received was at Marston-moor, Juiy 2d, 1644, where, through the imprudence of prince Rupert, the earl of Manchester defeated the royal army, of which 4000 were killed, and 1500 taken prisoners. This victory was owing chiefly to the courage and conduct of Cromwell; and though it might have been retrieved by the successes of Charles in the West, yet his whole conduct was a series of mistakes, till at last his affairs became irretrievable. It is true, many treaties of peace, particularly one at $\mathrm{Ux}$ bridge, were set on foot during the war ; and the heads of the presbyterian party, would have agreed to terms that very little bounded the king's prerogative. They were outwitted and overruled by the independents; who were assisted by the stiffness, insincerity, and unamiable behaviour of Charles himself. In short, the independents at last succeeded in persuading the members at Westminster that Charles was not to be trusted, whatever his concessions might be. From that moment the affairs of the royalists continually became more desperate; Charles successively lost all his towns and forts, and was defeated by Fairfax and Cromwell, at the decisive battle of Naseby, June 14, 164.5, owing partly, as usual, to the misconduct of prince Rupert. This battle was followed with fresh misfortunes to Charles, who retired to Oxford, the only place where he thought he could be safe.

The Scots were then besieging Newark, and no good understanding subsisted between them and the English parliamentarians; but the best and most loyal friends Charles had, thought it prudent to make their peace. In this melancholy situation of his affairs, he escaped in disguise from Oxford, and came to the Scotch army before Newark, on May 6, 1646, upon a promise of protection. The Scots, however, were so intimidated by the resolutions of the parliament at Westminster, that, in consideration of $400,000 \mathrm{l}$. of their arrcars being paid, they delivered the person of Charles into the hands 
of the parliament's commissioners, probably not suspecting the consequences.

The presbyterians were now more inclined than ever to make peace with the king; but they were no longer masters, being forced to receive iaws from the army and the independents. The army now avowed their intentions. They first by force took Charles out of the hands of the commissioners, June 4, 1647, and then, dreading that a treaty might still take place with the king, they implisoned $4 \mathrm{l}$ of the presbyterian members, voted the house of peers to be useless, and reduced that of the commons to 150 , most of them officers of the army. In the mean time, Charles, who unhappily promised himself relief from those dissensions, was carried from prison to prison, and sometimes cajoled by the indepcndents with hopes of deliverance, but al ways narrowly watched. Several treaties were begun, but miscarried; and he had been imprudent enough, after his effecting an escape, to put himself into the hands of colonel Hammond, the parliament's governor of the Isle of Wight. A fresh negociation was commenced, and almost finished, when the independents, dreading the general disposition of the people for peace, and strongly persuaded of the insincerity of the king, once more seized upon his person, brought him prisoner to London, carried him before a court of justice of their own erecting; and, after an extraordinary trial, his head was cut off, before his own palace at Whitehall, on the 30th of January, 1648-9, being the 49 th year of his age, and the 24th of his reign.

Charles is allowed to have had many virtues; and notwithstanding the errors of his government, his death was exceedingly lamented by great numbers; and many, who, in the course of the civil war, had been his great opponents in parliament, bccame converts to his cause, in which they lost their lives and fortunes.

By this time, Cromwell, who hated subordination to a parliament, had the address to procure himself to be declared commander-in-chief of the English army. Admiral Blake, and the other English admirals, carried the terror of the English name by sea to all quarters of the globe; and Cromwell, having now but little employment, began to be afraid that his services would be forgotten; for which reason he went, April 20, 1653, without any ceremony, with about 300 mus heteers, and dissolved the parliament, opprobriously driving all the members, about a hundred, out of their house. He next annihilated the council of state, with whom the executive power was lodged, and transferred the administration of government to about 140 persons, whom he summoned to Whitehall, on the 4th of July, 1653.

The war with Holland, in which the English were again victorious, still continued. Seven bloody engagements by sea were fought in little more than the compass of one year; and in the last, which was decisive in favour of England, the Dutch lost their brave admiral, Van Tromp. Cromwell all this time wished to be declared king; but he perceived that he must encounter unsurmountable difficulties from Fleetwood and his other friends, if he should persist in his resolution. He was, however, declared lord protector of the common. wealth of England; a title under which he exercised all the power that had been formerly annexed to the regal dignity. No king ever acted, either in England or Scotland, more despotically in some respects than he did; yet no tyrant ever had fewer real friends; and even those few threatened to oppose him, if he should take upon him 
the title of king. After a most uncomfortable usurpation of four yeara eight months and thirteen days, he died on the $3 \mathrm{~d}$ of September, 1658, in the 60th year of his age.

It is not to be denied that England acquired much more respect from foreign powers, between the death of Charles I, and that of Cromwell, than she had been treated with since the death of Elizabeth. In the year 1656, the charge of the public amounted to one million three hundred thousand pounds, of which a miliion went to the support of the navy and army, and the remainder to that of the civil government.

The fate of Richard Cromwell, who succeeded his father, Oliver, as protector, sufficiently proves the great difference there was between them, as to spirit and abilities, in the affairs of government. Richard was placed in his dignity by those who wanted to make him the tool of their own government; and he was soon after driven, without the least struggle or opposition, into obscurity. The restoration of Charles II, (who, with his mother and brothers, during the usurpation, had lived abroad on a very precarious subsistence) was effected by the general concurrence of the people, who seemed to have thought that neither peace nor protection were to be obtained, but by restoring the ancient constitution of the monarchy. General Monk, a man of military abilities, but of no principies, except such as served his ambition or interest, had the sagacity to observe this; and, after tem. porising in various shapes, being at the head of the army, he acted the principal part in restoring Charles II. For this he was created duke of Albemarle, confirmed in the command of the army, and loaded with honours and riches.

Charles II, being restored in 1650, in the first year of his reign seemed to have a real desire to promote his people's happiness. Upon his confirming the abolition of all the feudal tenures, he received from the parliament a gift of the excise for life; and in this act, coffee and tea are first mentioned. He knew and cultivated the true interests of his kingdom, till he was warped by. pleasure, and sunk in indolence, failings that had the same consequences as despotism itself. He appeared to interest himself in the sufferings of his citizens, when London was burnt down in 1666 ; but there were no bounds to his love of pleasure, which led him to the most extravagant expences. $\mathrm{He}$ has been severely censured for selling Dunkirk to the French king to supply his necessities, after he had squandered the immense sums zranted him by parliament. The price was about $250,000 l$ sterling. But even in this, his conduct was more defensible than in his secret connexions with France, which were of the most scandalous nature, utterly repurnant to the welfare of the kingdom, and such as must ever reflect infamy on his memory.

The first Dutcl war, which began in 1665, was carried on with great resolution and spirit under the duke of York; but, though Charles's misapplication of the public money, which had been granted for the war, the Dutch, while a treaty of peace was depending at Breda, found means to insult the royal navy of England, by sailing up the Medway as far as Chatham, and destroying several capital ships of war. Soon after this, a peace was concluded at Breda between Great Britain and the States-General, for the preservation of the Spanish Netherlands; and Sweden having acceded to the treaty, 1668, it was called the triple alliance.

In 1671, Charles was so ill advised as to seize upon the money of 
the bankers, which had been lent him at 81 . per cent. and to shut up the exchequer. This was an indefensible step; though Charles pretended to justify it by the necessity of his affairs, being then on the eve of a fresh war with Holland. This was declared in 1672, and had almost proved fatal to that republic; for in this war the English, fleet and army acted in conjunction with those of France. The duke of York conımanded the English fleet, and clisplayed great gallantry in that station. The duke of Monmouth, the eldest and favourite natural son of Charles, commanded 6000 English forces, who joined the French in the Low Countries; and all Holland must have fallen into the hands of the French, had it not been for the vanity of their monarch, Lewis XIV, who was in a hurry to enjoy his triumph in his capi:al, and some very unforeseen circumstances. All conficlence was now lost between Charles and his parliament, notwithstanding the glory which the English fleet obtained at sea against the Dutch. The popular clamour at last obliged Charles to give peace to that republic, in consideration of $200,000 l$. which was paid him.

Charles died, February $6 \mathrm{th}, 1645$, in the 55 th year of his age, and 25 th of his reign. He had married Catharine, infanta of Portugal, with whom he received a large fortune in ready money, besides the town and fortress of Tangier in Africa; but he left behind no lawful issue. The descendants of his natural sons and daughters are now amongst the most distinguished of the British nobility.

All the opposition which, during the late reign, had shaken the throne, seemed to have vanished at the accession of James II. The popular affection towards him was increased by the early declaration he made in favour of the church of England. The army and people supported him in crushing an ill-concerted rebellion of the duke of Monmouth, who pretended to be the lawful son of Charles II, and as such had assumed the title of king. That cluke being beheaded, July 15, 1685, and some hundreds of his follower's hanged, drawn, and quartered, in the west of England; exhibiting a scene of barbario ty scarcely ever known in this country, by the instrumentality of Jefferies and colonel Kirke; James desperately resolved to try how far the practice of the church of England would agree with her doctrine of non-resistance. The experiment failed him. He had recourse to the most offensive and at the same time most injudicious measure, to render popery the established religion of his dominions. He pretended to a power of dispensing with the known laws; he instituted an illegal ecclesiastical court; he openly received and admitted into his privy-council the pope's emissaries, and showed them more respect than was clue to the ministers of a sovereign prince. He sent an embassy to Rome, and received at his court the pope's nuncio. The abrupt en oachments he made upon both the civil and religious liberties of his people were disapproved of even by the pope himself, and all sober Roman-catholics. His sending to prison, and prosecuting for a libel, seven bishops, for presenting a petition against reading his rleclaration for liberty of conscience, and their acquittal upon a legal trial, alarmed his most loyal protestant subjects.

In this extremity, many great men in England and Scotland, thoug $h$ they wished well to James, applied for relief to William prince of Orange, in Holland, a prince of great abilities, and the inveterate enemy of Louis XIV, who then threatened Europe with chains. The prince of Orange was the nephew and son-in-law of James, having inarried the princess Mary, that king's eldest daughter. He, in coli:

Vos. I. 
sequence, embarked with a fleet of 500 sail for England, avowing it to be his design to restore the church and state to their true rights. Upon his arrival in England, he was joined not only by the Whigs, but by many whom James had considered as his best friends; and even his daughter, the princess Anne, and her husband, George prince of Denmark, left him, and joined the prince of Orange. James might still have reigned; but he was surrounded with French emissaries and ignorant Jesuits, who wished him not to reign rather than not to restore popery. They secretly persuaded him to send his queen, and son, real or pretended, then but six months old, to France, and to follow them in person, which he did; and thus, in 1688, ended his reign in England; which event in English history is termed the revolution.

William, notwithstanding the great service he had rendered to the nation, and the public benefits which took place under his auspices, particularly in the establishment of the bank of England, and the re. coining the silver money, met with so many mortifications from his parliament, that he actually resolved upon an abdication, and had drawn up a speech for that purpose, which he was prevailed upon to suppress. He long bore the affronts he met with, in hopes of being supported in his war with France; but at last, in 1697, he was forced to conclude the peace of Ryswick, with the French king, who acknowledged his title to the crown of England. William had lost his queen, December 28, 1694, but the government was continued in his person. After peace was restored, the commons obliged him to disband his army, all but an inconsilerable number, and to dismiss his favourite Dutch guards. Towards the end of his reign, his fears of seeing the whole Spanish monarchy in the possession of France at the death of the catholic king, Charles II, which was every day expected, led him into a very impolitic measure, which was the partition treaty with France, by which that monarchy was to be divided between the house of Bourbon and Austria. This treaty was highly resented by the parliament, and some of his ministry were impeached for advising it. It was thought William saw his error when it was too late. His ministers were acquitted from their impeachment; and the death of king James discovered the insincerity of the French court, which immediately proclaimed his son king of Great Britain.

This perfidy rendered William again popular in England. The two houses passed the bill of abjuration, and an address for a wa: with France. The last and most glorious act of William's reign was his passing the bill for settling the succession to the crown in the house of Hanover, on the 12th of June, 1701. His death was hastened by a fall from his horse, soon after he had renewed the grand alliance against France, on the 8th of March, 1702, in the 52d year of his age, and the 14th of his reign in England. The public debt, at the time of his death, amounted to the then unheard-of sum of $14,000,000$ l.

Anne, princess of Denmark, by virtue of the act of settlement, and being the next protestant heir to her father James II, succeeded to the throne. As she had been ill treated by the late king, it was thought she would have deviated from his measures; but the behaviour of the French in acknowledging the title of her brother, who has since been well known by the name of the Pretender, left her no choice ; and she resolved to fulfil all William's engagements with his 
allies, and to employ the earl of Marlborough, who had been imprisoned in the late reign on a suspicion of Jacobitism, and whose wife was her favourite, as her general. She could not have made a better choice of a general and statesman, for that earl excelled in both capacities. No sooner was he placed at the head of the English army abroad, than his genius and activity gave a new turn to the war, and he became as much the favourite of the Dutch as his wife was of the queen.

In the course of the war, several glorious victories were obtained by the earl, who was soon made duke of Marlborough. Those of Blenheim and Ramillies gave the first effectual checks to the French power. By that of Blenheim, in 1704, the empire of Germany was sared from immediate destruction. Though prince Eugene was that day joined in command with the duke, yet the glory of the day was confessedly owing to the latter. The French general Tallard was taken prisoner, and sent to England; and 20,000 French and Bavarians were killed, wounded, or drowned in the Danube, besides about 13,000 who were taken, and a proportionable number of cannon, artillery, and trophies of war. About the same time, the English admiral, sir George Rooke, reduced Gibraltar, which still remains in our possession. The battle of Ramillies, in 1706, was fought and gained under the duke of Marlborough alone. The loss of the enemy there has been variously reported; it is generally supposed to have been 8000 killed or wounded, and 6000 taken prisoners; but the consequences showed its importance.

After the battle of Ramillies, the states of Flanders assembled at Ghent, and recognised Charles for their sovereign, while the confeclerates took possession of Louvain, Brussels, Mechlin, Ghent, Oudenarde, Bruges, and Antwerp; and several other considerable places in Flanders and Brabant acknowledged the title of king Charles. The next great battle gained over the French was at Oudenarde, 1708, where they lost 3000 on the field, and about 7000 taken prisoners; and the year after, September 11, 1709, the allies forced the French lines at Malplaquet near Mons, after a bloody action, in which the French lost 15,000 men. These flattering successes of the English were balanced, however, by great misfortunes.

The queen had sent a very fine army to assist Charles III, in Spain, under the command of lord Galway; but in 1707, after he had been joined by the Portuguese, the English wcre defeated in the plains of Almanza, chiefly through the cowardice of their allies. Though some advantages were obtained at sea, yet that war in general was carried on to the detriment, if not the disgrace, of England. Prince George of Denmark, husband to the queen, was then lord high-admiral. At the same time England felt severely the scarcity of hands in carrying on her trade and manufactures.

As Lewis XIV professed a readiness for peace, and sued earnestly for it, the Whigs at last gave way to a treaty, and the conferences were held at Gertruydenburg, 1710. They were managed on the part of England by the duke of Marlborough and the lord Townshend, and by the marquis de Torcy for the French. But all the offers of the latter were rejected by the duke and his associates, as only designed to amuse and divide the allies; and the war was continued.

The unreasonable haughtiness of the English plenipotentiaries at Gertruydenburg (as some term it) and the then expected change of 
the ministry in England, saved France; and affairs from that day tduls a turn in its favour. Means were found to persuade the queen, who was faithfully attached to the church of England, that the war, in the end, if continued, must prove ruinous to her and her people, and that the Whigs were no friends to the national religion. The gencral cry of the deluded people was, that " the church was in danger," which, though groundless, had great effects. One Sacheverel, an ignorant, worthless preacher, had espoused the clamour in one of his sermons, with the ridiculous, impracticable doctrines of passive obedience and non-resistance. It was, as it were, agreed by both partics to try their strength in this man's cause. He was impeached by the commons, and found guiliy by the lords, who ventured to pass upon him only a very small censure. After this trial, the queen's affections were entirely alienated from the duchess of Marlborough, and the Whig administration. Her friends lost their places, which were supplied by Tories; and even the command of the army was taken from the duke of Marlborough, in 1712, and given to the duke of Ormond, who produced orders for a cessation of arms; but they were disregarded by the queen's allies in the British pay. And, indeed, the removal of the duke of Marlborough from the command of the army, while the war continued, was an act of the greatest imprudence, and excited the astonishment of all Europe. So numerous had been his successes; and so great his reputation, that his very name was almost equivalent to an army. But the honour and interest of the nation were sacrificed to private court intrigues, managed by Mrs. Masham, a relation of the duchess of Marlborough, who had supplanted her benefactress, and by Mr. Harley.

Conferences were opened for peace at Utrecht, in January, 1712, to which the queen and the French king sent plenipotentiaries; and the allies being defeated at Denain, they grew sensible they were no match for the French, now that they were abandoned by the English. A treaty was therefore concluded, by which it was agreed, that Philip should be established on the Spanish throne, but that he should renounce all clain to the crown of France; and the heirs to the Frencl monarchy in like manner renounce all right to the crown of Spain. It was stipulated likewise that the fortifications of Dunkirk should be demolished, and the harbour filled up.

The rest of the queen's life was rendered uneasy by the jarring of partics, and the contentions among her ministers. It has been conjectured that she was inclined to call her brother to the succession. The Whigs demanded a writ for the electoral prince of Hanover, as duke of Cambridge, to cume to England; and she was obliged hastily to ismiss her lord-treasurer, when she fell into a lethargic disorder, which carried hel off the first of August, 1714, in the fiftieth year of her age, and the thirteenth of her reign.

Anne had no strength of mind, by herself, to carry any important resolve into execution; and upon her death, the succession took place in terms of the act of settlement, and George I, elector of Hanover, son of the princess Soplin, grand daughter of James I, was proclaimed king of Great Britain, his mother, who would have been next in succession, having died but a few days before. He came over to England with strong prepossessions against the Tory ministry, most of whom he displaced. This did not make any great alteration to his prejedice in England; but many of the Scots, by the influence of the 
earl of Mar, and other chiefs, were driven into rebellion in 1715 , which was happily suppressed the beginning of the next year.

In 1718, a war commenced with Spain on account of the quadruple alliance that had been fornicd between Great Britain, France, Germany, and the States-General; and sir George Byng destroyed the Spanish fleet at Syracuse. But this war was soon ended by the Spaniards clelivering up Sarclinia and Sicily, the former to the duke of Savoy, and the latter to the emperor.

So fluctuating was the state of Europe at this time, that, in September 1725 , a new treaty was concluded at Hanover, between the kings of Great Britain, France, and Prussia, to counterbalance an alliance that had been formed between the courts of Vienna and Madrid. A squadron was sent to the Baltic, to prevent the Russians from attacking Sweden, another to the Mediterranean, and a third, under admiral Hosier, to the WVest Indies, to watch the Spanish plate fleets. This last was a fatal as well as an inglorious expedition. The admiral and most of his men perished by epidemical diseases, and the hulks of his ships rotted so as to render them unfit for service. The management of the Spaniards was little better. They lost nearly 10,000 men in the siege of Gibraltar, which they were obliged to raise.

A quarrel with the emperor was the most dangerous to Hanover of any that could happen; and though an opposition in the house of commons was formed by sir IVillian IVyndham and Mr. Pulteney, the parliament continued to be more and more lavish in granting money and subsidies for the protection of Hanover, to the kings of Denmark and Sweden, and the landgrave of Hesse-Cassel. Such was the state of affairs in Europe, when George I suddenly died on the 11th of June, 1727, at Osuaburg, in the sixty-eighth year of his age, and the thirteenth of his reign.

Sir Robert Walpole was considered as first minister of England when George I died; and some differences having happened between him and the prince of Wales, it was generally thought, upon the accession of the latter to the crown, that sir Robert would be displaced. 'That might have been the case, could another' person have becn found equally capable to manage the house of commons, and to gratify that predilection for Hanover which George II inherited from his father. No minister ever understood better the temper of the people of England, and none, perhaps, ever tried it more. 'He filled all places of power, trust, and profit, and almost the house of commons itself, with his own creatures; but peace was his clarling object, because he thought that war must be fatal to his power. During his long administration he never lost a question that he was in earnest to carry. The excise scheme was the first measure that gave a shock to his power : and even that he could have carried, had he not been afraid of the spirit of the people without doors, which might have either produced an insurrection, or endangered his interest in the next general election.

Queen Caroline, consort to George II, had been always a firm friend to the minister : but she died November 20th, 1737, when a variance subsisted between the king and his son, the prince of Wales. The latter complained, that through Walpole's influence he was deprived not only of the power but the provision to which his birth entitled him; and he put himself at the head of the opposition with so much firmness, that it was generally foreseen Walpole's power was drawing to a crisis. Admiral Yernon, who hated the minister 
was sent, in 1759 , with a squadron of six ships to the West Indies, where he took and demolished Porto Bello; but being a hot intractable man, he miscarried in his other attempts, especially that upon Carthagena, in which some thousands of British lives were wantonly thrown away. The opposition exulted in Vernon's success, and afterwards imputed his miscarriages to the minister's starving the war, by withholding the means for carrying it on. The general election approaching, so prevalent was the interest of the prince of Wales in England, and that of the duke of Argyle in Scotland, that a majority was returned to parliament who were no friends to the minister ; and, after a few trying divisions, he retired from the house; on the 9th of February, 1742, he was cleated earl of Oxford, and on the 11 th resigned all his employments.

George II bore the loss of his minister with the greatest equanimity, and even conferred titles of honour, and posts of distinction, upon the heads of the opposition. At the same time, the death of the emperor Charles VI, the danger of the pragmatic sanction (which meant the succession of his daughter to all the Austrian dominions) through the ambition of France, who had filled all Germany with her armies, and many other concurrent causes, induced George to take the leading part in a continental war. He was encouraged to this by lord Carteret, afterwards earl of Grenville, an able but headstrong minister, whom George had made his secretary of state, and indeed by the voice of the nation in general. George accordingly put himself at the head of his army, fought and gained the battle of Dettingen, June 16,1748; but would not suffer his general, the earl of Stair, to improve the blow, which was thought to proceed from tenderness for his electoral dominions.

Great Britain was then engaged in a very expensive war both against the French and Spaniards; and her enemies thought to avail themselves of the general discontent that had prevailed in England on account of Hanover. This naturally suggested to them the idea of applying to the Pretender, who resided at Rome; and he agreed that his eldest son Charles should repair to France; from whence he set sail, and narrowly escaped, with a few followers, in a frigate, to the western coasts of Scotland, between the islands of Mull and Sky, where he discovered himself, assembled his followers, and published a manifesto exciting the nation to a rebellion.

The government never so thoroughly experienced, as it did at that time, the benefit of the public debt for the support of the Revolution. The French and the Jacobite party (for such there was at that time in England) had laid a deep scheme of distressing the Bank; but common danger abolished all distinctions, and united them in the defence of one interest, which was private property. The merchants undertook, in their address to the king, to support it by receiving bank notes in payment. This seasonable measure saved public credit; but the defeat of the rebels by the duke of Cumberland at Culloden, in the year 1746 , did not restore tranquillity to Europe. Though the prince of Orange, son-in-law to his majesty George II, was, by the credit of his majesty, and the spirit of the people of the United Provinces, raised to be their stadtholder, the Dutch never could be brought to act heartily in the war. The allies were defeated at Val, near Maestricht, and the duke of Cumberland was in danger of being made prisoner. Bergen-op-Zoom was taken. The allies suffered other disgraces on the continent; and it now be. 
came the general opinion in England, that peace was necessary to save the duke and his ariny from total destruction:

The preliminaries for peace were signed in April 1748, and a definitive treaty was concluded at Aix-la-Chapelle in October; the basis of which was the restitution, on both sides, of all places taken during the war.

A new treaty of commerce was also signed at Madrid, between Great Britain and Spain.

In consequence of the encroachments of the French, who had built forts on our back settlements in America, and the dispositions they made for sending over vast bodies of véteran troops to support those encroachments, admiral Boscawen was ordered, in April 1755, to sail with eleven ships of the line, besides a frigate and two regiments, to the Banks of Newfoundland, where he came up with, and took two French men of war; the rest of their fleet escaping up the river St. Laurence, by the Straits of Belleisle. Orders were also issued for making general reprisals in Europe as well as in America; and that all the French ships, whether outward or homeward bound, should be stopped, and brought into British ports. These orders were so effectual, that, before the end of the ytar 1755 , above 500 of the richest French merchant ships, and above 8000 of their best sailors, were brought into the kingclom.

In July 1755 general Braddock, who had been injudiciously sent from England to attack the French, and reduce the forts on the Ohio, was defeated and killed, by falling into an ambuscade of the French and Indians near Furt du Quêne (now called Fort Pitt, or Pittsburg) but major-general Johnson defeated a body of French near Crown Point, of whom he killed about 1000.

In proportion as the spirits of the public were elevated by the formidable armaments which were prepared for carrying on the war, they were depressed by the intelligence that the French had landed 11,000 men in Minorca, to attack Fort St. Philip; that admiral Byng, who had been sent out with a squadron at least equal to that of the French, had been baffled, if not defeated, by their admiral Gallissoniere ; and that at last Minorca was surrendered by general Blakeney. The public outcry was such, that the king gave up Byng to public justice, and he was shot at Portsmouth for not doing all that was in his power against the enemy.

About this time Mr. Pitt was placed, as secretary of state, at the head of administration. The miscarriages in the Mediterranean had no consequence but the loss of Fort St. Philip, which was more than repaired by the vast success of the English privateers, both in Europe and America. The successes of the English in the Last Indies, under colonel Clive, are almost incredible. He defeated Suraja Dowla, nabob of Bengal, Bahar, and Orixa, and placerl Jaffier Ally Cawn in the ancient seat of the nabobs of those provinces. Suraja. Dowla, who was in the French interest, a few days after his being defeated, was taken by the new nabob, Jaffier Ally Cawn's son, and put to death. This event laid the foundation of the great extent of territory which the English now possess in the East Indies.

Mr. Pitt introduced into the cabinet a new system of operations against France, than which nothing could be better calculated to re store the spirits of his countrymen, and to alarm their enemies. Far from dreading an invasion, he planned an expedition for carrying the arms of England into France itself; and the descent was to be inade 
at Rochefort under general sir John Mordaunt, who was to command the land troops. Nothing could be more promising than the dispositions for this expedition. It sailed on the 8th of September 1757; but admiral Hawke brought both the sea and land forces back on the 6 th of October, to St. Helen's, without any attempt having been made to land on the coast of France.

The French having attacked the electorate of Hanover with a most powerful army, the English parliament voted large supplies of men and money in defence of the electoral dominions. The duke of Cumberland had been sent thither to command an army of observation, but was so powerfully pressed by a superior army, that he found himself obliged to lay down his arms; and the French, under the duke of Richelieu, took possession of that electorate and its capital. At this time, a scarcity, next to a famine, raged in England; and the Hessian troops, who, with the Hanoverians, had been sent to defend the kingdom from an invasion threatened by the French, remained still in England. So many difficulties concurring, in 1758 a treaty of mutual defence was agreed to between his majesty and the king of Prussia : in consequence of which, the parliament voted $670,000 l$. to his Prussian majesty; and also large sums, amounting in the whole to nearly two millions a year, for the payment of 50,000 of the troops of Hanover, Hesse-Cassel, Saxe-Gotha, Wolfenbuttle, and Buckeburg.

George II, with the consent of his Prussian majesty, declaring that the French had violated the convention concluded between them and the duke of Cumberland at Closterseven, ordered his Hanoverian subjects to resume their arms, under prince Ferdinand of Brunswick, a Prussian general, who instantly drove the French out of $\mathrm{Ha}$ nover : and the duke of Marlborough, after the English had repeatedly insulted the French coasts by destroying their stores and shipping at St. Malo and Cherbourg, marched into Germany, and joined prince Ferdinand with 12,000 British troops, which were afterwards increased to 25,000. The English every where performed wonders, and were every where victorious : but nothing decisive followed; and the enemy opened every campaign with advantage. Even the battle of Minden, the most glorious perhaps in the English annals, in which about 7000 English defeated 80,000 of the French regular troops, contributed nothing to the conclusion of the war, or towards weakening the French in Germany.

The English affairs this year proved equally fortunate in the East. Indies, where admiral Pococke gained considerable advantages over the French fleet; and general Lally, having besieged Madras, was obliged to raise the siege, and retire with precipitation, leaving behind him forty picces of cannon.

The year 1759 was introduced by the taking of the island of Goree, on the coast of Africa, by commodore Keppel. Three great expeditions had been planned for this year in America, and all of them proved successful. One of them was against the French islands in the West Indies, where Cruadaloupe was reduced. The second expedition was against Quebec, the capital of Canada. The command was given, by the minister's advice, to general Wolfe, a young officer of a truly military genius. Wolfe was opposed, with far superior force, by Montcalme, the best and most successful general the French had. Though the situation of the country which Wolfe was to attack, and the works the French threw up to prevent a descent of the Eng: 
Iisb, were deemed impregnable, yet Montcalme never relaxed in his vigilance. Wolfe's courage and perseveraince, however, surmounted incredible difficulties : he gained the heights of Aoraham, near Quebec, where he fought and defeated the French army; but was himself killed, as was Montcalme. General Monckton, who was next in command, being wounded, the completion of the French defeat, and the glory of reducing Quebec, was reserved for brigadier-general (afterwards lord viscount) Townshend.

General Amhurst, who was the first English general in command in America, conducted the third expedition. His orders were to reduce all Canada, and to join the army under general Wolfe on the banks of the river St. Lawrence. By the success of these expeditions the French empire in North America became subject to Great Britain.

The affairs of the French being now desperate, and their credit ruined, they resolved upon an attempt to retrieve all by an invasion of Great Britain : but on the 8th of August, 1759, admiral Boscawen attacked the Toulon squadron, commanded by M. de la Clue, near the straits of Gibraltar, took three ships of the line and burnt two. The rest of the fleet, consisting of seven ships of the line and three frigates, made their escape in the night; and on Nov. 20, sir Edward Hawke entirely defeated the Brest fleet, commanded by admiral Conflans; off the island of Dumet, in the bay of Biscay. After this engagement, the French gave over all thoughts of their invasion of Great Britain.

A negociation for peacc was accordingly entered upon, which proved abortive, as did many other projects for accommodation; buc on the 25th of October, 1760, George II died suddenly (from a rupture in the right ventricle of the heart) full of years and glory, in the 77 th year of his age, and 34th of his reign, and was succeeded by his grandson, now George III, eldest son to the late prince of Wales.

King George III ascended the throne witl great advantages. He ivas a native of England, in the bloom of youth, in his person tall and comely, and at the time of his accession, Great Britain was in the highest degree of power and prosperity, and the most salutary unanimity and harmony prevailed among the people. The first acts of his reign seemed also calculated to convince the public that the death of his predecessor should not relax the operations of the war. In 1761, the island of Belleisle, on the coast of France, surrendered to his majesty's ships and for'ces under commodore Keppel and general Hodgson; as did the important fortress of Pondicherry, in the East Indies, to colonel Coote and admiral Stevens. In 1762, the island of Martinico, hitherto deemed impregnable, with the islands of Grenada, St. Lucia, Grenadillas, St Vincent, and others of less note, were sub. dued by the British arms with inconceivable rapidity.

As his majesty could not espouse a Roman-catholic, he was pre. vented from intermarrying into any of the great families of Europe; he therefore chose a wife from the house of Mecklenburg Strelitz, the head of a small but sovereign state in the north-west of Germany; and the conduct of his excellent consort has constantly been such as most highly to justify his choice. She was conveyed to England in great pomp, and the nuptials were cclebrated on the very night of her arrival, viz. September 8, 1761; and on the $22 \mathrm{~d}$ of the samc month the ceremony of the coronation was performed with great magnificence in Westminster-abbey.

Vot. I.

II 
In the mean time, Mr. Pitt, who had conducted the war agains: France with such eminent ability, and who had received the best information of the hostile intentions and private intrigues of the court of Spain, proposed in council an immediate declaration of war against that kingdom. But he was overruled in the council, all the members of which declared themselves of a contrary opinion, excepting his brother-in-law, earl Temple. Mr. Pitt now found the decline of his influence; and it was supposed that the earl of Bute, who had a considerable share in directing the education of the king, had acquired an ascendency in the royal favour. Mr. Pitt, therefore, resigned the seals, and lord Temple also gave up the post which he held in the administration.

The war still continued to be carried on with vigour after the resignation of Mr. Pitt, and the plans were pursued that he had previously concerted. It was at length found indispensably necessary to engage in a war with Spain; the famous family compact among all the different branches of the Bourbon family being generally known; and accordingly war was deciared against that kingdom, on the 4th of January, 1762. A respectable armament was fitted out under admiral Pococke, having the earl of Albemarle on board to command the land forces; and the vitals of the Spanish monarchy were struck at by the reduction of the Havanna, the strongest and most important fort which his catholic majesty held in the West Indies, after a siege of two months and eight days. The loss of the Havanna, with the ships and treasures there taken from the Spaniards, was succeeded by the reduction of Manilla and the Philippine islands in the East. Indies, under general Draper and admiral Cornish, with the capture of the Trinidad, reckoned worth three million of dollars. To counteract those dreadful blows given to the family compact, the Frencls and Spaniards employed their last resource, which was to quarrel with and invade Portugal, which had been always under the peculiar protection of the British arms.

The negociations for peace were now resumed; and the enemy at: last offered such terms as the British ministry thought admissible and adequate on the occasion. The defection of the Russians from the confederacy against the king of Prussia, and his consequent successes, produced a cessation of arms in Germany, and in all other quarters; and on the 10th of February, 1765, the definitive treaty of peace between his Britannic majesty, the king of France, and the king of. Spain, was concluded at Paris, and acceded to by the king of Portugal : March 10, the ratifications were exchanged at Paris: the $22 \mathrm{~d}$, the peace was solemnly proclaimed at Westminster and London; and the treaty having on the $18 \mathrm{th}$ been laid before the parliament, it met the approbation of a majority of both houses.

In the mean time, the earl of Bute, who had been made-first lord of the treasury, resigned that office, and was succeeded by Mr. George Grenville; and under this gentleman's administration an act was passed, said to have been framed by him, which was productive of the most pernicious consequences 10 Great Britain; " an act for laying a stamp. duty in the British colonies of North America, which received the royal assent on the $22 \mathrm{~d}$ of March, 1765. Some other injudicious previous regulations had also been made, under pretence of preventing smuggling in America, but which in effect so cramped the trade of the colonies, as to be prejudicial both to them and the mother country. 
As soon as it was known in North America that the stamp act was passed, the whole continent was kindled into a flame; and when the act, printed by royal authority, reached the colonies, it was treated with every mark of indignation and contempt. Several acts of violence were likewise committed, with a view of preventing the operations of the stamp act.

These commotions in America occasioned so great an alarm in England, that the king thought proper to clismiss his ministers. The marquis of Rockingham was appainted first lord of the treasury; and some of his lordship's friends succeeded to the vacant places. In March, 1766, an act was passed for repealing the American stamp act. This was countenanced and supported by the new ministry; and Mr. Pitt, though not connected with them, yet spoke with great force in favour of the repeal.

The marquis of Rockingham, and his friends, continued in admis nistration but a short time, and in 1766 lord North became first lord of the treasury, and obtained a great ascendency in the councils of of the king.

In 1767 an act was passed, laying certain duties on paper, glass, tea, \&c. imported into America, to be paid by the colonies, for the purpose of raising a revenue to the government. About two years after, it was thought proper to repeal these duties, excepting that on tea; but as it was not the amount of the duties, but the right of the parliament of Great Britain to impose taxes in America, which was the subject of dispute, the repealing the other duties answered no purpose while that on tea remained; which accordingly became a fresh subject of contest between the mother country and colonies. The history of the American revolution comes more properly under the article UnITED STATES, to which we must refer.

The conduct of France towards Great Britain, in taking part with the revolted colonies, occasioned hostilities to be commenced between the two nations, though without any formal declaration of war on either side. On the 27 th of June, 1778, the Licorne and La Belle Poule, two French frigates, were taken by admiral Keppel. Orders were immediately issued by the French court for making reprisals on the ships of Great Britain; and on the 27 th of July a battle was fought off Brest between the English fleet, under the command of admiral Keppel, and the French fleet, under the command of count d'Orvilliers. The English fleet consisted of 30 ships of the line, and the French of 32 , besides frigates : they engaged for about three hours; but the action was not decisive, no ship being taken on either sicle, and the French fleet at length retreated into the harbour of Brest. Of the English 133 were killed in the action, and 373 wounded; and the loss of the French is supposed to have been very great.

In the East Indies also an engagement happened between some English ships of war, under the command of sir Edward Vernon, and some French ships under the command of Mons. de Tronjolly, on the 10th of August, in which the former obliged the latter to retire; and on the 17 th of October following, Pondicherry surrenclered to the arms of Great Britain. In the course of the same year, the island of St. Lucia, in the West Indies, was taken from the French; but the latter made themselves masters of Dominica, and the following year they obtained possession of the islands of St. Vincent and Grenada. At the close of the year 1779; several French ships of wax, and mer* 
chant ships, were taken in the West Indies, by a fleet under tho command of sir Hyde Parker.

By the intrigues of the French court, Spain was at length brought to engage with France in the war against England. One of the first enterprises in which the Spaniards engaged, was the siege of Gibraltar, which was defended by the garrison with great vigour. The naval force of Spain was also added to that of France, now become extremely formidable, and their combined fleets seemed for a time to ricle almost triumphant in the British Channel: So yreat were their armaments, that the nation was under no inconsiderable apprehensions of an invasion; but they did not venture to make an experiment of that kind, and, after parading for some time in the Channel, thought proper to retire to their own ports, without effecting any thing.

The middle of the year 1780 was distinguished by one of the most disgraceful exhibitions of religious bigotry that had ever appeared in this country; especially if it be considered as happening in an age in which the principles of toleration were well understood, and very prevalent. An act of parliament had been lately passed "for relieving his majesty's subjects, professing the Romish religion, from certain penalties and disabilities imposed upon them in the 11 th and 12 th years of the reign of king William III." The act at first seemed to give little offence to persons of any class in England; but in Scotland is excited much indignation, though it did not extend to that kingdom. Resolutions were formed to oppose any law for granting indulgences to papists in Scotland; and a Romish chapel was burned, and the houses of several papists demolished in the city of Edinburgh. The contagion of bigotry at length reached England; a number of persons assembled themselves together, with a view of promoting a petition to parliament, for a repeal of the late act in favour of the papists, and they assumed the title of the Protestant Association. It was then resclved, in order to give the more weight to their petition, that it should be attended by great numbers, of petizioners in person; and a public advertisement was issued for that pur. pose, signed by lord George Gordon.

Fifty thousand persons are supposed to have assembled with this view, on Friday the 2d of June, in St. George's Fields; from whence they proceeded, with blue cockades in their hats, to the house of commons, where their petition was presented by their president. In the course of the day several members of both houses of parliament were grossly insulted and ill-treated by the populace; and a mob assembled the same evening, by which the Sardinian chapel in Lincoln's-inn Fields, and another Romish chapel in Warwick-street, Golden-square, were entirely demolished. These riots continued for several days, during which time a number of public and private houses were destroyed, prisons broken open, and the most violent excesses committed.

But at length, as all property began to be insecure, an order was jssued, by the authority of the king in council, "for the military to act without waiting for directions from the civil magistrates, and to use force for dispersing the illegal and tumultuous assemblies of the people." The troops exerted themselves with diligence in the sup. pression of these alarming tumults, great numbers of the rioters were killed,' many were apprehended, who were afterwards tried and executed for felony,* and the metropolis was at length restored to order and tranquillity.

- Lord George Gordon was himself committed to the Tower, and tried for high treason, but acquitted. 
About the close of this year a war with Holland commenced, in consequence of the clandestine commerce carried on between the Dutch and the Americans; it was prosecuted with great vigour ; and that republic soon suffered a very severe blow in the loss of the island of St. Eustatius, which was taken by the English on the $2 \mathrm{~d}$ of February, 1781 .

On the 5th of August, the same year, an engagement was fought between an English squadron of ships of war, under the command of admiral Hyde Parker, and a Dutch squadron under the command of admiral Zoutman, off the Dogger Bank. Both the contending squadrons fought with great gallantry, and by both the victory was claimed.

The war continued to be prosecuted with various success; the French made themselves masters of the island of Tobago; and the Spaniards of Pensacola, and the whole province of West Florida, with little effectual resistance.

On the first of March, 1782, after repeated struggles in the house of commons, the house addressed the ling, requesting him to put a. stop to any further prosecution of the war against the American colonies. This was a most important event: it rendered a change of measures and of councils absolutely necessary, and diffused universal joy throughout the kingdom.

Peace every day became more desirable to the nation. A series of losses agitated the minds of the people. January 14th, 1782, the French took Nevis. On the 5th of February the island of Minorca surrendered to the Spaniards; and on the 13th of the same month the island of St. Christopher's was given up to the French. The valuable island of Jamaica would soon probably have shared the same fate, had not the British fleet, under admiral Rodney, fallen in with that of the French under the count de Grasse, in their way to join the Spanish fleet at St. Domingo. The van of the French was too far advanced to support the centre, and a signal victory was obtained. over them.

May 18, the Bahama islands surrendered to the Spaniards; but the credit of the British arms was well sustained at Gibraltar, under general Elliott, the governor; and the formidable attack, on the 13 th of September, with floating batteries of 212 brass cannon, 3xc. in ships from 1400 to 600 tons burthen, ended in clisappointment, and the destruction of all the ships and most of the assailants in them. The garrison was relieved by lord Howe in the month of October, who offered battle to the combined force of France and Spain, though twelve sail of the line inferior. The military operations after this were few, and of little consequence.

By the treaty of peace between Great Britain and France, the preliminaries of which were signed January 20, 1783, Great Britain ceded to France all her possessions before the war, the islands of Tobago, St. Lucia, St. Pierre, Miquelon, and Goree; with Pondicherry, Karical, Mahe, Chandernagore, and Surat, in the East Indies, which had been conquered from the F'rench during the war. France, on the other hand, restored to Great Britain the islands of Grenada, and the Grenadines, St. Christopher's, St. Vincent, Dominica, Nevis, and Montserat.

By the treaty with Spain, Great Britain gave up to that power East Florida, and also ceded West Florida and Minorca, which Spain had taken during the war. Spain agreed to restore the islands of 
Providence, and the Bahamas to Great Britain; but they had been retaken before the peace was signed,

By the treaty with Holland it was stipulated that Great Britain should restore ' $\Gamma$ rincomale in the island of Ceylon, but the French had already taken it; and that the Dutch should give up to England the town of Negapatnam and its dependencies.

In the treaty with the United States of America, the king of Great Britain acknowledged New Hampshire, Massachusetts Bay, Rhode Isiand and Providence Plantations, Connecticut, New York, New Jersey, Pennsylvania, Delaware, Maryland, Virginia, North Carolina, South Carolina, and Georgia, to be free, sovereign, and independent states; and for himself, his heirs and successors, relinquished all claims to the government, property, and territorial rights of the same, and every part thereof.

Thus a period was put to a most calamitous war, in which Great: Britain lost the best part of her American colonies, and many thousand valuable lives, and expended or squandered nearly 150 millions of money.

Whilst the ancient government of France was entirely overthrown, and a revolution, the most unexpected, was effected, it is difficult to imagine a picture of more complete serenity than England presented. This tranquillity, however, now appeared to be endangered by a dispute with Spain. Some English merchants having engaged in speculations in the fur trade, had established a factory at Nootka -Sound, on the north-west coast of America, after having taken possession of the country, in the name of the sovereign and crown of England. The Spaniards, ever jealous of settlements on that side of America, soon after sent some armed vessels from Mexico, seized all the ships on the coast, and obliged the English to abandon the settlement.

No sooner was this act of violence made known to the English government, than spirited remonstrances were made to the court of Spain, and a considerable armament prepared to enforce redress. The Spanish cabinet, however, thought it expedient to concede the point in dispute, and an amicable convention was signed at the Escurial, by the plenipotentiaries of the two nations, on the 28th of October, 1790.

The first disposition manifested by Great Britain to break with France regarded the navigation of the Scheldt, which the French had determined to open for the benefit of Antwerp and the Netherlands. This impediment, however, might perbaps have been removed, from the little disposition which was evinced by Holland to assert its right to the exclusive navigation, and from the readiness of the French to refer the whole affair to a negociation.

The next exception which was taken by the English ministry was to the decree of fraternity, which was offered by the French convention to the revolting subjects of any monarchical government, and which was justly considered as a direct affront to this country, and a plot against her peace.

The alien bill, which the French complained was an infraction of the commercial treaty, was the next cause of dispute; and this offence was augmented by the prohibition to export corn to France, while it was freely allowed to the powers at war with that country.

At length, towards the end of January, M. Chauvelin was officially informed by the English court, that his character and functions, so 
long suspended, had entirely terminated by the fatal death of the king of France; that he had 110 more any public character here, where his further residence was forbidden. Eight days were allowed for his departure; and this notification was published in the Gazette. M. Maret had been sent by the executive council of France with enlarged powers, as it was said, but arriving in England exactly at the period of M. Chauvelin's dismission, he thought it prudent immediately to return home.

Mr. secretary Dundas, on the 28th of January, presented to the house of commons a message from the king, in which his majesty expressed the necessity of making a further augmentation of his forces by sea and land, for maintaining the security and rights of his orvn dominions, for supporting his allies, and for opposing views of aggrandizement and ambition on the part of France. The question in relation to this subject was carried by a great majority in favour of ministers.

On the 25th of March, 1794, lord Grenville and count Woronzow signed a convention at London, on behalf of his Britannic majesty and the empress of Russia, in which their majesties agreed to employ their respective forces in carrying on the " just and necessary war" in which they were engaged against France; and they reciprocally promised not to lay down their arms but by common consent. Notwithstanding this solemn treaty, Catharine took no active part whatever in the war. Another treaty was concluded between his Britannic majesty and the king of Sardinia, signed at London tho 25th of April, by which Great Britain engaged to pay 200,000l. pir annum to the king of Sardinia, and three months in advance. A tria. ty was likewise concluded between his highness the prince of $\mathrm{H}$ esseCassel and his Britannic majesty; the former was to furnish 9000 men for the war, during three years; in return for which, England was to pay $100,000 l$. levy-money, and 56,000l. sterling per annun for six years.

On the first of June, 1794, the British fleet under the comnand of admiral lord Howe obtained a signal victory over that of the ryench, in which two ships were sunk, one burnt, and six brought into Portsmouth harbour.

On the 8th of December, a message from his majesty was brought down to the house of commons, signifying a disposition to etter into a negotiation with France, the government of that country having at length assumed such a form as to render a treaty with it practicable. Mr. Wickham, the British plenipotentiary to the Swiss Cintons, was appointed, in consequence, to make some overtures, through the medium of Mr. Barthelemi, the French envoy at Basle; bu this feeble s.ttempt at negotiation soon terminated without effect.

An apparently much more serious offer of this nature yas made the following year. About the latter end of the month of September, 1796, through the intervention of the Danish minister at Paris, a passport was applied for and obtained for a confidential person to be sent to Paris from the court of London, commissioned to discuss with the French government the means most proper for conducing to the reestablishment of peace. Lord Malmesbury was the person appointed by the British court to undertake this mission. His lordship accordingly repaired to Paris, where, he continued about two months. It was proposed, on the part of England, as the basis of the treaty, that France should restore the Netherlands to the cmpcror, and evacuate 
Italy ; in which case England engaged to restore all the conquests made on that power in the East and West Indies. The French directory replied, that they could not consent to proposals contrary to the constitution, to the laws, and to the treaties which bind the republic. Thus ended this negotiation.

The beginning of the year 1797, was distinguished by as extraordinary an event as perhaps ever occurred in this or any other war; the invasion of Great Britain by a force of 1200 men, without artillery, and almost without accoutrements. The alarm at first was general, and great, throughout the whole of Pembrokeshire, on the coast of which the landing was made : but-the men surrendered on the approach of a very inadequate force, and almost without resistance. On inquiry, it appeared that they consisted entirely of galley-slaves, and other criminals, from Brest; and the object was supposed to be at once to create an alarm on the British coast, and to rid the French republic of a number of desperate persons : but whatever the intentions of the enenay might be, they met, on the whole, with a complete disappointment ; for not only the expedition proved entirely fruitless, but, as two of the ships which disembarked the men were returning into Brest harbour, they were captured by the St. Fiorenzo and Nymph frigates.

On the third of March, government received intelligence of an important advantage obtained by the British fleet, under the command of sir John Jervis, over a Spanish fleet of much superior force, on the 14th of February, off Cape St. Vincent. The English admiral, by a successful mancuvre, separated the rear of the enemy's fleet from the main body, and captured two ships of 112 guns, one of 84 , anl one of 74 .

t.bout this time a serious mutiny took place in the British navy, the ailors demanding an increase of pay and redress of other grievance: The goverument thought proper to comply with their demand; and the wages were accordingly advanced; upon which the principal part of the mutineers declared themselves satisfied and submited. Some however raised new and extravagant complaints, and gorernment was obliged to resort to measures of severity before the spirt of insurrection could be quelled.

As if o erase this stain from the annals of the British navy, the fleet of aimiral Duncan, consisting principally of the ships which had been ungaged in this unhappy and disgraceful mutiny, sailed soon after to watch the motions of the Dutch fleet in the Texel, where it remained or some time blockaded, till, on its venturing out, an engagement ensued, in which the English fleet obtained a complete victory, taking the Dutch admiral De Winter, the vice-admiral, and nine ships.

In the cotrse of this year, another attempt was made by the British cabinet to neyotiate a treaty of peace with France. The preliminaries of a peace be:ween the French republic and the emperor of Germany, having been signed at Leoben, in the. month of April, by which the Netherlands were given up to France, the difficulty which had broken off the last nerotiation appeared to be in some measure removed, and applications were again made to the French government for pass. ports for a person who might enter into discussions relative to the basis of a future treaty. Lord Malmesbury was again appointed to this mission; but the French directory objected to his coming to Paris, and appointed Lisle for the place of the conference with com- 
missioners they sent thither for that purpose. What the Netherlands, however, had been in the former attempt to treat, the Cape of Good Hope and Ceylon proved in the preșent; and, after a stay of nearly three months, lord Malmesbury, not being able to declare himself empowered to consent to the surrender of all the conquests made from France or her allies, was abruptly ordered to depart, and, on the 20th of September, returned as before, not having effected the object of his mission.

In the following month the definitive treaty between the French republic and the emperor was concluded and ratified; and the French, having little other employment for their armies, began to talk loudly of an inmediate invasion of England. The directory assembled a large army along the coasts opposite to Great Britain, which they called the army of England : and a variety of idle reports were propagated relative to preparations said to be making in the ports of France; among others, that rafts of an enormous size and peculiar construction were building for the conveyance of troops. The British minister did not suffer these ridiculous exaggerations, nor even the evident absurdity and rashness of any attempt at an invasion of England, in the face of a fleet so decidedly superior to that of every enemy united, to produce an improper sccurity, but took such measures of precaution as were most proper for the general defence of the kingdom, and to guard the different parts of the country from the mischievous consequences of a sudden attack. But the threats of the cnemy were not even attempted to be carried into execution; and the directory soon after turned their views towards another quarter of the globe, by fitting out, at Toulon, a formidable expedition, which, about the latter end of May, sailed for Egypt, under the command of Bonaparte, probably with a view to prepare the way, by the conquest of that country, for an attack on the British settlements in India.

In the course of the preparations made for the invasion of England, a number of transports had been fitted out at Flushing, and some other of the ports of Holland, which were to come round by the canals to Dunkirk and Ostend, in order to avoid the British cruizers. An expedition was therefore fitted out in May 1798, under the command of captain Home Popham, and major-general Coote, which landed a body of troops at Ostend, who blcw up and entirely destroy. ed the sluice-gates and works of the canal at that place, and burnt several vessels that were intended for transports. Unfortunately, when the troops were ready to reimbark, the wind had changed, and the sea ran so high, that it was found to be impossible; and the enemy in the mean time collected round them in such force, that general. Coote, and those who had landed with him, amounting to nearly a thousand men, were obliged to surrentcr themselves prisoners.

Towards the latter end of this year, intelligence was received of the most brilliant victory ever gained at sea, even by the British navy, which has obtained such unequalled glory, on so many occasions, in the course of the present war. On the first of August, admiral sir Horatio Nelsom, who had been detached by earl St. Vincent in pursuit of the French fleet, which, as was mentioned above, sailed from Toulon in May, having received a reinforcement of ten sail of the line, arrived off the mouth of the Nile, where he found the enemy, and immediately made dispositions for an attack. The French fleet was at anchor in the bay of Aboukir. The admiral's ship car. ried a hundred and twenty guns, and above a thousand men; three

Vor. I. 
had eighty guns each, and nine had seventy-four. They were draw up near the shore in a strong and compact line of battle, fianked by four frigates and many gun-boats, and protected in the van by a battery planted in a small island. Their situation, therefore, was extremely advantageous for defence: but the great danger of an attack did not deter the British admiral from making the attempt. He was desirous to break the line of the French, and surround a part of the fleet, and he ably executed his purpose. At sun-set the engagement commenced; and both parties fought with the utmost fury. While the victory was yet undecided, the French admiral Brueys received two wounds, and? having changed his situation, was, soon after, deprived of life by a cannon shot. When the action had continued for two hours, two of the French ships were captured; a third struck soon after; and the whole van was in the power of the English, who eagerly proceeded to a completion of their victory. About nine at night, a fire was observed on board L'Orient, the French admiral's ship, which increased with great rapidity till about ten o'clock, when she blew up with a dreadful explosion. An awful pause and silence for about three minutes succeeded, when the wreck of the masts and yards, which had been carried to a vast height, fell down into the water, and on board the surrounding ships. After this awful scene, the engagement was prosecuted at intervals, till day-break; and only two of the French ships of the line, and two frigates, escaped capture or destruction. Nine sail of the line were taken, and one, besides L'Orient, was burned, her own captain setting fire to her. A frigate also was burned by her commander. Captain Hood, in the Zeaious, pursued the retiring vessels; but he was soon recalled by the admiral, as none of the ships covld support him in the chace.

This signal victory not only gave the British fleet the entire com. mand of the Mediterranean, but appeared to infuse fresh courage into all the powers on the continent to renew their exertions against Trance. The Turks deciared war with the republic, and the king of Naples attacked and took possession of Rome, then in the power of the French. But the reverse he afterwards experienced, and the other events of the campaign in Italy, will be related in our summary of the affairs of France.

About the same time that intelligence of this glorious victory was zeceived, sir John Borlase Warren defeated, off the coast of Ireland, a French squadron consisting of one ship of the line, the Hoche, and cight frigates, with troops and ammunition on board.

To complete the successes of the year, the fortress of Ciudadella and the island of Minorca, surrendered on the 15th of November to general Stuart and commodore Duckworth. This acquisition was made without the loss of a man.

In the beginning of May, 1799, a new war having taken place in India with Tippoo Saib, Seringapatam, his capital, was taken, and himself killed in the assault, by the British troops under the command of lieutenant-general Harris. Of the capture of this importan: place, and the consequent addition of the greater part of the Mysore country to the territory of the East India company, a further account will be found in our history of the British transactions and conquests in Hindostan.

In the month of August following, an expedition was fitted out in the West Indies under the command of lieutenant-general Trigge, and vice admiral lord Hugh Seymour, consisting of two ships of the 
bine, fire frigates, and several transports carrying stores and provisions: it arrived on the $16 \mathrm{ch}$ of that month off the mouth of the river Surinam : when the fort New Amsterdam, and the town of Paramaribo, the capital of the Dutch colony of Surinam, surrendered by capitulation to the British commanders without attempting resistance.

But the principal military operation undertaken by Great Britain, in this year, was the expedition fitted out to rescue Holland from the yoke of the French, in which about 30,000 British troops were employed, who were joined in Holland by 17,000 Russians, taken into the pay of England. The first division of this armument, under sir Ralph Abercrombie, sailed from Deal and Margate on the 13th of August for the Helder-point, at the mouth of the Texel ; but encountered such unfavourable and violent gales, that the troops could not effect a landing at the place of their destination till the morning of the 27 th. A hotly contested action then took place between the Britisla and the French and Dutch troops : but the valour of the former ultimately triumphed; and the enemy evacuated the batteries and works of the Helder, and seven Dutch men of war and thirteen Indiamen. surrendered to the fleet under admiral Mitchell, who immediately after stood down into the Texel, and offered battle to the Dutch fleet lying there, the whole of which, consisting of twelve ships of war, surrendered to the English admiral, the Dutch sailors refusing to fight, and compelling their officers to give up their ships for the service of the prince of Orange.

On the 13 th the duke of York arrived in Holland, with the second division, and took upon him the command of the army; and on the 19 th an engagement took place between the British and Russians and the French, in which the former failed in their attack, in consequence of the Russians suffering themselves to be thrown into disorder by their impetuosity and haste, which occasioned them to suffer severely, their loss amounting to $1500 \mathrm{men}$, and their general, who was taken prisoner. The army, however, soon recovered from the effects of this check, and on the $2 \mathrm{~d}$ of October, after a hard-fought battle of twelve hours, compelled the enemy to retreat, and took possession of the town of Alkmaar. But here the success of the expedition terminated. The enemy had received a reinforcement of about 6000 men, and occupied a strongly fortified position, which it would be necessary to carry before the army could advance; besides which, the state of the weather, the ruined condition of the roads, and the consequent total want of the supplies necessary for the army, presented such insurmountable difficulties, that in two days afterwards it was judged expedient to withdraw the troops from their advanced position: and as it now appeared that there could be no hope of success in any attempt to prosecute further the object of the expedition, the duke, in conjunction with vice-admiral Mitchell, concluded an armistice with general Brune, who commanded the French and Batavian armies, the principal conditions of which were, that eight thousand French and Batavian prisoners, taken before that campaign, should be restored to their respective countries; that the combined English and Russian army should evacuate the territory, coasts, islands, and internal navigation of the Datch republic, by the 30th of November 1799, without committing any devastation by inundations, cutting the dykes, or otherwise injuring the sources of navigation; and that the mounted batteries taken possession of at the Helder, or at other positions, should be restored in the state in which they were 
taken, or, in case of improvement, in the state in which they then were, together with all the Dutch artillery taken in them.

In the month of November, a new revolution took place in the government of France. The celebrated Bonaparte having returned from Egypt, displaced the directory, and assumed a kind of dictatorial power, under the title of First Consul, according to a new constitution which he procured to be framed and accepted. In order to induce the people to consent to this change, by which he was invested with the supreme authority, he promised them that he would take effectual measures to put an end to the miseries and destruction of war. In pursuance of this promise, on the very day on which he entered on his new dignity, he addressed a note immediately to the king of Great Britain, in which he expressed a wish to contribute effectually to a general pacification; and in a second note, afterwards transmitted by M. Talleyrand, to the English ministry, proposed "an immediate suspension of arms, and that plenipotentiaries on each side should zepair to Dunkirk, or any other town as advantageously situated, for the quickness of the respective communications, and who should apply themselves, without any delay, to effect the re-establishment of peace and a good understanding between the French republic and England." The British ministry, however, showed no disposition to accede to the overture, probably conceiving the new government $t_{a}$ of France not to have as yet acquired sufficient stability to be treated with, and encouraged, by the success which had attended the arms of the allies in the preceding campaign, to hope that they should be able still more effectually to humble and weaken France by a continuance of the war.

In the mean time a serious dispute had taken place between England and the northern powers, relative to the right of search of neutral ships, and some other demands of those powers, which were judged incompatible with the honour and interests of Great Britain. The emperor of Russia, so lately the determined foe of France, had now become her ally, and the enemy of England, and had incited and supported this coalition of the maritime powers of the north, against the naval superiority of Britain. To suppress this dangerous combination, before it had attained maturity, an armament was fitted out in the British ports, consisting of seventeen sail of the line, three frigates, and about twenty bomb-ketches and giun-brigs, under the command of sir Hyde Parker and lord Nelson. This fleet sailed from Yarmouth on the 12th of March, and triumphantly passed the Sound, which was deemed impossible, and reached the capital of Denmark. The Danes had made very formidable dispositions. Before the city was stationed an armed flotilla consisting of ships of the line, galleys, fire-ships, and gun-boats. These were flanked and supported by extensive batteries, on the two islands called the Crowns, the largest of which mounted from fifty to seventy pieces of cannon. The attack was made on the $2 \mathrm{~d}$ of April by a division of the English fleet unde. lord Nelson, consisting of twelve ships of the line and four frigates. After a very severe engagement, an end was put to the contest by lord Nelson spontaneously offering a cessation of arms. The Danes lost in the battle eighteen ships, among which were seven men of war of the line fitted up for that particular occasion. Lord Nelson had proceeded to approach Copenhagen, into which some bombs were thrown; but an attack on the city was prevented by a flag of truce, which was sent on board lord Nelson's ship, and an armis- 
tice was soon after concluded with sir Hyde Parker by the Danish court.

On the 19th of April the British fleet appeared off Carlscrona, and the admiral acquainted the governor that the court of Denmark, having concluded an armistice by which the unfortunate dispute with the court of St. James had been accommodated, he was directed to require an explicit answer from his Swedish majesty, relative to his intentions of adhering to or abandoning the hostile measures he had taken in conjunction with Russia. An official answer to this demand was communicated from the king of Swecten to sir Hyde Parker, intimating that his Swedish majesty would not fail to fulfil the engagements entered into with his allies; but that he would not refuse to listen to equitable proposals made by deputies furnished with proper authority to regulate the matters in dispute.

The termination of the contest, however, at that time, was, perhaps, not so much to be attributed either to the battle of Copenhagen, or to the victorious progress of the British fleet, as to the death of the emperor Paul of Russia, who on the 23d of March expired suddenly, and was succeeded by his son Alexander, who soon after his accession entered into negotiations for a pacific accommodation with England, in consequence of which a convention was at length signed at St. Petersburg, by which the principal claims of Great Britain were recognized and ratified.

By the dissolution of the confederacy of the northern powers, one of the great obstacles to the peace between Great Britain and the French Republic was happily removed; as was another, soon after, by the complete conquest of Egypt from the French, by general Hutchinson; general Abercromby, who originally had the command of that expedition, having unfortunately but gloriously fallen in the battle of Alexandria on the 21 st of March. The miluistry therefore entered seriously into negotiations for peace with the French government, the preliminaries of which were signed at London on the 1st of October 1801, between M. Otto on the part of the French republic, and lord Hawkesbury on the part of his Britannic majesty; and after further negotiations, the definitive treaty was signed at Amiens on the 27th of March 1802, by marquis Cornwallis on the part of England, and Joseph Bonaparte, the brother of the First Consul, on the part of the French republic.

By this treaty Great Britain agreed to restore all her conquests, the island of Trinidad, and the Dutch possessions in Ceylon, excepted. The Cape of Grood Hope was to remain a free port to all the-contracting parties, who were to enjoy the same advantages. The island of Malta was to be evacuated by the British troops and restored to the order of St. John of Jerusalem, but under the guarantee of the principal powers of Europe. Egypt was to be restored to the Ottoman Porte. The territory of Portugal was to be maintained in its integrity, and the French troops were to evacuate the territories of Rome and Naples. The republic of the Seven Islands was recognised by France, and the fishery of Newfoundland was established on its former footing.

But the restless and insatiable ambition of the French government did not suffer this treaty long to remain unviolated. It affected to treat England as compelled by necessity to conclude peace, and incapable of resisting the encroachments of France, unsupported by foreign allies. But the principal subject of dispute was the island of 
Malta, which England refused to evacuate without the guarantees for which she had stipulated in the treaty of Amiens. A length, after a protracted negotiation, in the course of which the First Consul expressed himself with equal petulence and insolence, descending even, in a conference with the English ambassador, lord Vhitworth, to the contemptible threat of invasion, a message from the throne was sent to the house of commons on the 16th of May 1803, stating, that the conduct of the French government had obliged his majesty to recalk his ambassador from Paris, and that the French ambassador had left London.

The threats of invasion again resorted to by France had the effect of uniting all classes in England. 300,000 volunteers were immediately embodied. In the course of this year St. Domingo, St. Lucie, and Tobago, were captured from the French; and the settlements of Berbice and Demerara from the Dutch. In the East Indies the British arms were also attended with success. During the years $1804-5$, England was obliged to be an almost silent spectator of the rapid increase of French power on the continent. The emperor of France compelled the Spaniards to take up arms against Great Britain, and on the plains of Germany defeated in numerous engagements the combined Austrian and Russian armies. On the ocean, however, the British arms were still triumphant. A squadron of six sail of the line, and some frigates, which had been blockaded for more than two years, had found means to elude the British force and put to sea; soon after the Toulon fleet of 11 ships of the line and two frigates pushed out to sea without being observed. They proceeded to $\mathrm{Ca}$ diz, where they were reinforced by six Spanish sail of the line, and then sailed for the West-Indies. Thither lord Nelson followed, and pursued them from island to island, but without being able to overtake them. After cruising upwards of a month among the West Indies, the French fleet returned to Europe, closely pursued by the Briish squadron. Though Nelson was unable to fall in with the enemy, who now amounted to twenty sail, they were met by sir Robert Calder's fleet, of fifteen sail of the line and two frigates, off Cape Finisterre. An action immediately commenced; it was supported with determined resolution for four hours; and finally concluded in favour of the English. The combined fleets arrived in a shattered condi sion at Ferrol, whence, after being reinforced, they sailed with $2 \%$ ships of the line for Cadiz. Here they receiverl another reinforcement, and on the 19th of October, with a fleet of 33 sail of the line, they again put to sea. On the 21 st they were overtaken by lord Nelson, near Cape Trafalgar. Both sides immediately prepared for action. About noon the dreadful contest commenced, and a little after twelve the battle became general. The combined fleets fought with determined gallantry, but the British fire was irresistible; and the issue was a complete and most brilliant victory. Nineteen ships of the line were captured. The victory, however, was considered as dearly purchased, for Nelson was among the slain.

After the death of Mr. Pitt, which soon followed, a change took place in the administration; the new members of which, considering the interests of the country as but little connected with the affairs of the continent, appeared not to be very solicitous for the success of their northern allies. The policy pursued by the ministry was, howcver, in opposition to the opinions of a large majority of the people; and the consequence was, that their administration was but a short 
one. But before a change of policy could be effectually adopted, the treaty of Tilsit had been signed, and all Europe, Sweden excepted, was arrayed in arms against Great Britain. The French government was now actively employed in fresh endeavours to create a naval force. The Danes had a considerable fleet, which it was evident must fall into the hands of one or the other of the belligerents. An armament of 30 sail of the line and 25,000 men was dispatched to the Belt, under the command of lord Cathcart and admiral Gambier. This force appeared before Copenhagen on the 14th of August, 1807, and demanded an inmediate surrender of the Danish fleet, promising to deliver it up again at the conclusion of the war. These proposals being rejected, the army landed without opposition on the morning of the $16 \mathrm{th}$, and on the evening of the $2 \mathrm{~d}$ of September the land bat teries and bomb and mortar vessels opened such a tremendous fire upon the city, that a general conflagration was thought to have taken place. On the night of the $3 d$ the fire was slackened; but on the 4th it was resumed with so much effect, that proposals for a truce were sent from the city. On the 3th the capitulation was signed, and the British troops entered the city. The Danish vessels being rigged with the utmost dispatch, the whole fleet was safe in the British ports before the end of October.

The war in the Spanish peninsula, which broke out this year, and in which the British took so active a part, forms a part of Spanish and Portuguese history. See Spain and Portugal. This war engaged the principal part of the resources of England and France till 1809, when hostilities commenced between France and Austria. A diversion was attempted in favour of the latter power, by landing a number of troops on the island of Walcheren, with a view of attacking the French fleet at Antwerp. They found the fleet, however, too strongly protected, and the expedition returned without effecting any thing. After the submission of Austria, Spain again became the onIy theatre of war. In 1810 the prince of Wales was appointed regent, the mental derangement of the king having rendered that measure necessary. The islands of Bourbon and Amboyna this year submitted to the British arms.

Early in 1812 hostilities commenced between France and Russia. A treaty was concluded with the latter power, and immense subsidies were made by Great Britain for the support of her armies. By this war the perseverance of England was at length crowned with success, and to her is principally to be attributed the happy revolution which has once more restored the ancient governments and balance of Europe. The particulars of the war will be found under the articles Russia, France, Austria, Prussia, \&c.

Peace was the immediate consequence of the restoration of the Bourbons to the throne of France. In the treaty signed at Paris on the 30th of May, 1814, England stipulates to restore to France all the colonies, fisheries, factories, and re-establishments of every kind, which France possessed on the 1st of Jan. 1792, in the scas and on the continents of America, Africa, and Asia, excepting the islands of Tobago and St. Lucia, and the Isle of France, and its dependencies, which the king of France cedes in full property and sovereignty to his Britannic majesty. 


\section{GENEALOGICAL LIST OF THE ROYAL FAMILX OF: GREAT BRITAIN.}

George-William-Frederick III, born June 4, 1738; proclaimed king of Great Britain, France, and Ireland, and elector of Hanover, October 26,1760; and married, September 8, 1761, to the princess Sophia-Charlotte, of Mecklenburg Strelitz, born May 16, 1744, crowned September 22, 1761, and now have issue:

1. George-Augustus-Frederick, prince of Wales, born August 12, 1762 ; married, April 8; 1795, to her highness the princess Caroline of Brunswick; has issue, Jan. 7, 1796, a princess.

2. Prince Frederick, born August 16,1763; elected bishop of Osnaburg, February 27, 1764; created duke of York and Albany, No. vember 7, 1784, K. G. and K. B. ; married, September 29, 1791 , Frederica-Charlotta-Ulrica-Catharina, princess royal of Prussia.

3. Prince William-Henry, born August 21,1765 ; created duke of Clarence, K. G. and K. T.

4. Charlotte-Augusta-Matilda, princess royal of England, born September 29, 1766 ; married, May 18, 1797, to his serene highness Frederick-William, hereditary prince of Wurtemberg Stuttgardt.

5. Prince Edward, born November 2, 1767 ; created duke of Kent, April, 1799.

6. Princess Augusta-Sophia, horn November 8, 1768.

7. Princess Elizabeth, born May 27, 1770.

8. Prince Ernest-Augustus, born June 5, 1771; created duke of Cumberland, April, 1799.

9. Prince Augustus-Frederic, born January 27, 1773 , created duke of Sussex, November 24, 1801.

10. Prince Adolphus-Frederic, born February 24, 1774, created duke of Cambridge, November 24, 1801.

11. Princess Mary, born April 25, 1776.

12. Princess Sophia, born November 3, 1777.

13. Princess Amelia, born August 7, 1783.

Issue of the late prince of Wales by the princess Augusta of SaxeGotha, now living :

1. Her royąl highness Augusta, born August 11, 1737; marrier? the hereditary prince (now duke) of Brunswick Lunenburg, January 16, 1764 .

2. His present majesty.

5. Prince William-Henry, duke of Gloucester, born Navember 25, 1743. 


\section{WALES.}

THOUGH this principality is politically included in England, ye as it has distinction in language and manners, we have, in conformity with common custom, assigned it a separate article.

\section{EXTENT AND SITUATION. \\ Miles.

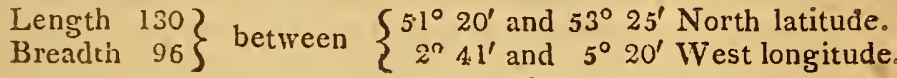

Wales contains 7011 square miles, with 77 inhabitants to each.

NArre...The Welch are supposed to be the descendants of the Cimbrian or Cymraig Gauls, who made a settlement in England about fourscore years before the first descent of Julius Cæsar, and thereby obtained the name of Gallies or Wallies (the $G$ and $W$ being promiscuously used by the ancient Britors) that is, Strangers. In the time of the Romans, Wales contained three nations, called the Demetæ, the Ordovices, and the Silures.

BoUNDARIES, DIVISIONS.... Wales was formerly of greater extent than it is at present, being bounded only by the Severn and the Dee; but after the Saxons had made themselves masters of all the plain country, the Welch, or ancient Britons, were shut up within mare narrow bounds, and obliged gradually to retreat westward. It does not, however, appear that the Saxons ever made any further conquests in their country than Monmouthshire and Herefordshire, which are now reckoned part of England. This country is divided into four circuits, comprehending twelve counties. See EnGLand.

Mountains, LAKes, Rivers....Wales abounds in mountains, especially in the northern part. Snowdon in Caernarvonshire, and Plinlimmon, which lies partly in Montgomery and partly in Cardiganshire, and forms a boundary of North Wales, are the principal. The height of Snowdon is 3568 feet above the level of the sea. The mountainous situation of the country greatly assisted the natives to make so noble and long a struggle against the Romans, Saxons, and Normans.

There are several lakes in Wales, though not remarkable for their size; as Llynn Tigid, or Pimple Mere; and Lynn Savedhan, or Brecknock Mere; the latter of which is.so full of fish, that the inha. bitants say two-thirds of it is water and the rest fish.

The principal rivers of Wales are the Severn, the Clwyd, the Wheeler, the Dee, the Elwy, and the Alen.

Metals, minerals.... Wales contain's many quarries of free-stone ard slate, several mines of lead, and abundance of coal-pits. The Parrys mountain in Anglesea is.a rich mine of copper, not found in

Voz. I. K l. 
veins, but in a prodigious heap, which is worked in the manner of a quarry. This valuable mine was discovered about thirty years ago.

Clrmare, sorl.... The seasons are nearly the same as in the northerin parts of England, and the air is sharp, but wholesome. The soil of IVales, especially towards the north, is mountainous, but contains rich vallies, which produce crops of wheat, rye, and other corn.

VEGETABLES, ANIMALS....In these, Wales differ's little from England. The horses are smaller, but can endure great fatigue; the black cattle are small likewise, but excellent beef; and their cows are remarkable for yielding large quantities of milk. Great numbers of goats feed on the mountains.

Natural currosities....Among the natural curiosities of this country, are the following: At a small village called Newton, in Glamorganshire, is a remarkable spring nigh the sea, which ebbs and flows contrary to the tide. In Merionethshire is Kader Idris, a mountain remarkable for its height, which affords variety of Alpine plants. In Flintshire is a famous well, known by the name of St. Wenefred's well, at which, according to the legendary tales of the common people, miraculous cures have been performed. The spring boils with vast impctuosity out of a rock, and is formed into a beautiful poly. gonal well, covered with a rich arch, supported by pillars, and the roof is most exquisitely carved in stone. Over the spring is also a chapel, a neat piece of Gothic architecture, but in a very ruinous state. King James II, paid a visit to the well of St. Wenefred in 1686 , and was rewarded for his piety by a present which was made him of the very shift in which his great grandmother, Mary Stuart, lost her head. The spring is supposed to be one of the finest in the British dominions, and is found to throw out about twenty-one tons of water in a minute. It never freezes, or scarcely varies in the quantity of water either in dry or rainy seasons; but in consequence of the latter ${ }^{\circ}$ it assumes a wheyish tingc. The small town adjoining to the well is known by the name of Holywell. In Caernarvonshire is the high mountain of Penmanmawr, across the edge of which the public road lies, and occasions no small terror to many travellers : from one hand the impending rocks seem every minute ready to crush them to pieces; and the great precipice below, which hangs over the sea, is so hideous, and till very lately (when a wall was raised on the side of the road) full of clanger, that one false step was of dismal consequence. Near Caermarthen is a fountain, which, like the sea, ebbs and flows twice in twenty-four hours.

There are a great number of pleasing prospects and picturesque views in Wales and this country is highly worthy the attention of the curious traveller.

POPUlation, INHADitants, maners, AND customs....The inhabitants of Wales, according to the returns under the late population act, amount to 541,546 . The Welch are, if possible, more jealous of their liberties than the English, and far more irascible: but their anger soon abates; and they are remarkable for their sincerity and fidelity. They are very fond of carrying back-their pedigrees to the most remote antiquity; but we have no criterion for the authenticity of their manuscripts, some of which they pretend to be coeval with the beginning of the Christian æra. It is however certain, that great part of their history, especially the ecclesiastical, is more ancient, and better attested, than that of the Anglo-Saxons. Wales was formerly famous for irs bards, and poets, particularly Thaliessin, who lived 
about the yeal 450, and whose works were certainly extant at the time of the Reformation, and clearly evincc that Geoffrey of Monmouth was not the inventor of the history which makes the present Welch the descendants of the ancient Trojans. This poetical genius seems to have influenced the ancient Welch with an enthusiasm for independency; for which reason Edward 1, is said to have made a general massacre of the bards; an inhumanity which was characteristical of that ambitious prince. The IVelch may be called an unmixed people, and are remarkable for still maintaining the ancient hospitality, and their strict adherence to ancient customs and manner's. This appears even among gentlemen of fortune, who in other countries commonly follow the stream of fashion. We are not however to imagine, that many of the nobility and gentry of Wales do not comply with the modes and manner of living in England and France. All the better sort of the Welch speak the English language, though numbers of them understand the Welch.

CITIES, TOWNS, EDIFICES.... Wales contains no cities or towns that are remarkable either for populousness or magnificence. Beaumaris is the chief town of Anglesey, ${ }^{*}$ and has a harbour for ships. Brecknock trades in clothing. Cardigan is a large populous town, and lies in the neighbourhood of lead and silver mines. Caermarthen has a large bridge, and is governed by a mayor, two sheriffs, and aldermen, who wear scarlet gowns and other ensigns of state. The other towns of Wales have nothing particular. It is, however, to be observed, that Wales, in ancient times, was a far more populous and wealthy country than it is at present; and though it contains no regular fortifications, yet many of its old castles are so strongly built, and so well sicuated, that they might be turned into strong forts at a small expence.

Commerce and MANUFActures... The IVelch are on an equality, as to their commerce and manufactures, with many of the western and northern counties of England. Their trade is mostly inland, or with England, into which they import numbers of black cattle. Milford haven, which is reckoned the finest harbour in Europe, lies in Pembrokeshire; but the Welch have hitherto reaped no great benefit from it, though of late considerable sums have been granted by parliament for its fortification. The town of Pembroke employs near 200 merchant ships, and its inhabitants carry on an extensive trade. In Brecknockshire are several woollen manufactures; and Wales in greneral carries on a great coal trade with England and Ireland.

Constitution AND Government... Wales was united and incorporated 'with England in the 27 th of Henry VIII, when by act of parliament, the government of it was modelled according to the English form; all laws, customs, and tenures, contrary to those of England, being abrogated, and the inhabitants admitted to a participation of all the English liberties and privileges, particularly that of sending members to parliament, viz. a knight for every shire, and a burgess for every shiretown, except Merioneth. By the 34 th and 35 th of the same reign, there were ordained four several circuits for the adminis. tration of justice in the said shires, each of which was to include three shires; so that the chief justice of Chester has under his jurisdiction

* The isle of Anglesey, which is the most western county of North Wales, is surrounded on all sides by the Irish Sea, except on the south-east, where it is di. vided from Briton by a narrow strait, called Menu, which in some places may be passed on foot at low water. The island is about 24 miles long, and 18 broad, anct contains 74 parishes. It was the ancient seat of the British Druids. 
the three several shires of Flint, Denbigh, and Montgomery. The shires of Caernarvon, Merioneth, and Anglesey, are under the justices of North Wales. Those of Caermarthen, Pembrokeshire, and Cardigan, have also their justices; as have likewise those of Radnor, Brecknock, and Glamorgan. By the 18th of queen Elizabeth, one other justice-assistant was ordained to the former justices; so that now every one of the said four circuits has two justices, viz. one chief justice, and a second justice assistant.

Revenues....The crown has a certain though small property in the product of the silver and lead mines; but it is said that the revenue accruing to the prince of Wales, from his principality, does not exceed 7 or $8000 l$. a year.

Arms...The arms of the prince of Wales differ from those of England only by the addition of a label of three points. His cap, or badge of ostrich feathers, was occasioned by a trophy of that kind, which Edward the Black Prince took from the king of Bohemia, when he was killed at the battle of Poitiers, and the motto is Ich dien, I serve. St. David, commonly called St. Taffy, is the tutelar saint of the Welch; and his badge is a leek, which is worn on his day, the lst of March.

ReLigion....The established religion in Wales is that of the church of England; but the common people in many places are so tenacious of their ancient customs, that they retain several of the Romish superstitions, and some ancient families among them are still Romancatholics. It is likewise said that Wales abounds with Romish priests in disguise. The principality also contains great numbers of protestant dissenters.

For Bishopricks. see England. In former times, Wales contained more bishopricks than it does now ; and about the time of the Norman invasion, the religious foundations there far exceeded the wealth of all the other parts of the principality.

Literature, LEARNing, and LEARNED MEN.... Wales was a seat of learning at a very early period; but it suffered much by the repeated massacres of the bards and clergy. Wickliffism took shelter in Wales, when it was persecuted in England. The Welch and Scotch dispute about the nativity of certain learned men, particularly four of the name of Gildas. Giraldus Cambrensis, whose history was published by Camden, was certainly a Welchman; and Leland mentions several learned men of the same country, who flourished before the Reformation. The discovery of the famous king Arthur's and his wife's burying-place was owing to some lines of Thaliessin, which were repeated before Henry II, of England by a Welch bard. Since the Reformation, Wales has produced several excellent antiquaries and divines. Among the latter were Hugh Broughton, and Hugh Holland, who was a Roman-catholic, and is mentioned-by Fuller in his Worthies. Among the former were several gentlemen of the name of Llhuyd, particularly the author of that invaluable work, the Archæologia. Rowland, the learned author of the Mona Antiqua, was likewise a IVelchman; as was that great statesman and prelate, the lord-keeper Williams, archbishop of York in the time of king Charles I. After all, it appears that the great merit of the Welch learning, in former times, lay in the knowledge of the antiquities, language, and history of their own country. Wales, notwithstanding all that Dr. Hicks and other antiquaries have said to the contrary, furnished the Anglo-Saxons with an alphabet. This is clearly de- 
monstrated by Mr. Llhuyd, in his Welch preface to his Archæologia, and is confirmed by various monumental inscriptions of undoubted authority. (See Rowland's Mona Antiqua.) The excelient history of Henry VIII, written by lord Herbert of Cherbury, may be adduced as another production of Welch literature.

LANGUAGE....The Welch have still preserved their ancient language, which is a dialect of the Celtic, though very different from the Erse or Irish. The Lord's prayer in Weich is as follows :

Ein Tad, yr hivn riyt yn y nefoedd, sancteiddier dy env : deued dy deyrnas; bydded dy ezuyllys ar y ddaear, megis y mae yn y nefoed: dyro in $i$ heddy w ein bara beunyddiol; a maddeu $i$ ni ein dyledion, fel y maddeusun ni i'n dyledivyr; ac nac arivain ni i brofedigaeth eithr grvared ni rhag drwg: canys eiddot ti yw'r deyrnas, a'r gallu, $a^{\prime} r$ sogoniant, yn oes oesoedd. Amen.

Avriquities.... Wales abounds in remains of antiquity. Several of its castles are stupendously large ; and in some, the remains of Roman architecture are plainly discernible. The architecture of others is doubtful; and some appear to be partly British and partly Roman. In Brecknockshire are some rude sculptures, upon a stone six feet high, called the Maiden-stone; but the remains of the Druidical institutions, and places of worship, are chiefly discernible in the Isle of Anglesey, the ancient Mona, mentioned by Tacitus, who describes it as being the chief seminary of the Druidical rites and religion. Caerphilly-castle in Glamorganshire is said to have been the largest in Great Britain, excepting VVindsor; and the remains of it show it to have been a most beautiful fabric. One half of a round tower has fallen quite down; but the other overhangs its basis more than nine feet, and is as great a curiosity as the leaning tower of Pisa in Italy.

History....The ancient history of Wales is uncertain, on account of the number of petty princes who governed it. That they were sovereign and independent, appears from the English history. It was formerly inhabited by three different tribes of Britons; the Silures, the Dimetæ, and the Ordovices. These people were nevel entirely subdued by the Romans, though part of their country, as appears from the ruins of castles, was bridled by garrisons. The Saxons, as has been already observed, conquered the counties of Monmouth and Hereford; but they never penetrated further, and the Welch remain an independent people, governed by their own princes and their own laws. About the year 870, Roderic, king of Wales, divided his dominions among his three sons; and the names of these divisions were, Dimetia, or South Wales; Povesia, or Powis land; and Venedotia, or North Wales. This division gave a mortal blow to the independency of Wales. About the year 1112, Henry I, of England planted a colony of Flemings on the frontiers of Wales, to serve as a barrier to England. The Welch made many brave attempts to maintain their liberties against the Norman kings of England. In 1237, the crown of England was first supplied with a pre. text for the future conquest of Wales; their old and infirm prince Llewellin, in order to be safe from the prosecutions of his undutiful son Gryffyn, having put himself under the protection of Henry III, to whom he did homage.

But no capitulation could satisfy the ambition of Edward I, who resolved to annex Wales to the crown of England; and L.lewellin, prince of Wales, disdaining the subjection to which old Liewellin 
had submitted, Edward raised an army at a prodigious expence, with which he penetrated as far as Flint, and, taking possession of the Isle of Anglesey, drove the Welch to the mountains of Snowdon, and obliged them to submit to pay a tribute. The Weich, however, made several efforts under young Llewellin; but at last, in 1282, he was killed in battle. He was succeeded by his brother David, the last independent prince of IVales, who falling into Edward's hands through treachery, was by him most barbarously and unjustly hanged; and Edward, from that time, pretended that Wales was annexed to his crown of England. It was about this time, probably, that Edward perpetrated the inhuman massacre of the Welch bards. Perceiving that this cruelty was not sufficient to complete his conquest, he sent his queen, in the year 1284, to be delivered in Caernarvon castle, that the Welch, having a prince born among themselves, might the more readily recognise his authority. This prince was the unhappy Edward II, and from him the title of prince of Wales has always since descended to the eldest sons of the Einglish kings. The history of Wales and England becomes now the same. It is proper, however, to observe, that the kings of Engiand have always found it their interest to soothe the Welch with particular marks of their regard. Their eldest sons not only held their titular dignity, but actually kept a court at Ludlow; and a regular council, with a president, was named by the crown, for the administration of all the affairs of the principality. This was thought so necessary a piece of policy, that when Henry VIII had no son, his daughter Mary was created princess of Wales. 


\section{ENGLISH ISLES.}

THE ISLE OF WVIGHT is situate opposite the coast of Hampshire, from which it is separated by a channel, varying in breadth from two to seven miles; it is considered as part of the county of Southampton, and is within the diocese of Winchester. Its greatest length, extending from east to west, measures nearly twenty-three miles; its breadth, from north to south, above thirteen. The air is in general healthy, particularly in the southern parts : the soil is various; but so great is its fertility, that it was many years ago computed, that more wheat was grown here in one year than could be consumed by the inhabitants in eight; and it is supposed that its present produce, under the great improvements of agriculture, and the additional quantity of land lately brought into tillage, has more than kept pace with the increase of population. A range of hills, which afford tine pasture for sheep, extends from east to west, through the middle of the island. The interior parts of the island, as well as its extremities, afford a great number of beautiful and picturesque prospects, not only in the pastoral but also in the great and romantic style. Of these beauties the gentlemen of the island have availed themselves, as well in the choice of situations for their houses, as in their other improvements. Domestic fowls and poultry are bred here in great numbers; the outward-bound ships and vessels at Spit-head, the Mother-bank, and Cowes, commonly furnishing themselves from this island.

Such is the purity of the air, the fertility of the soil, and the beauty and variety of the landscapes of this island, that it has been called the garden of England; it has some very fine gentlemen's seats; and it is often visited by parties of pleasure on account of its delightful scenes.

The island is clivided into thirty parishes; and, according to a very accurate calculation made in the year 1777 , the inhabitants then amounted to eighteen thousand and twenty-four, exclusive of the troops quartered there. Most of the farm-houses are built with stone, and even the cottages appear neat and comfortable, having each its little garden.

The town of Newport stands nearly in the centre of the island, of which it may be considered as the capital. The river Medina empties itself into the channel at Cowes harbour, distant about five miles, and, being navigable up to the quay, is very commodious for trade. The three principal streets of Newport extend from east to west, and are crossed at right angles by three others, all which are spacious, clean, and well paved.

Carisbrook castle, in the Isle of Wight, has been rendered remark able by the confinement of king Charles I, who taking refuge here, was detained a prisoner from November 1647 to September 1648. After the execution of the king, this castle was converted into $a$ 
place of confinement for his children; and his daughter, the princess Elizabeth, died in it. There are several other forts in this island, which were all erected about the 36 th year of the reign of Henry VIII, when many other forts and blockhouses were built in different parts of the coast of England.

In the English Channel are four islands subject to England : these are Jersey, Guernsey, Alderney, and Sark; which, though they lie much nearer to the coast of Normandy than to that of England, are within the diocese of Winchester. They lie in a cluster in Mount St. Michael's Bay, between Cape la Hogue in Normandy, and Cape Frebelle in Brittany. The computed distance between Jersey and Sark is four leagues; between that and Guernsey, seven leagues; and between the same and Alderney, nine leagues.

JERSEY, anciently C ESAREA, was known to the Romans, and lies farthest within the bay, in forty-nine degrees seven minutes north latitude, in the second degree twenty-six minutes west longitude, 18 miles west of Normandy, and 84 miles south of Portland. The north side is inaccessible through lofty cliffs; the south is almost level with the water; the higher land, in its midland part, is well planted, and abounds with orchards, from which is made an incredible quantity of excellent cider. The vallies are fruitful and well cultivated, and contain plenty of cattle and sheep. The inhabitants neglect tillage too much, being intent upon the culture of cider, the improvement of commerce, and particularly the manufacture of 'stockings. The honey in Jersey is remarkably fine; and the island is well supplied with fish and wild fowl of almost every kind, some of both being peculiar to the island, and very delicious.

The island is not above twelve miles in length, and is divided into twelve parishes. The air is so salubrious, that, in Camden's time, it was said there was here no business for a physician. The inhabitants are in number about 20,000. The capital town of St. Helier, or Hilary, which contains above 400 houses, has a good harbour and castle, and makes a handsume appearance. The property of this island belonged formerly to the Carterets, a Norman family, who have been always attached to the royal interest, and gave protection to Charles II, both when king and prince of Wales, at a time when no part of the British dominions durst recognise him. The language of the inhabitants is French, with which most of them intermingle English words. Knit stockings and caps form their staple commodity; but they carry on a considerable trade in fish with Newfoundland, and dispose of their cargoes in the Mediterranean. The governor is appointed by the crown of England, but the civil administration rests with a bailiff, assisted by twelve jurats. As this island is the principal remain of the duchy of Normandy depending on the kings of England, it preserves the old feudal forms; and particularly the assembly of states, which is, as it were, a miniature of the British parliament, as settled in the time of Edward I.

GUERNSEY is thirteen miles and a half from south-west to northeast, and twelve and a half where broadest, east and west. It is divided into ten parishes, which have only eight churches, four of the parishes being united, and Alderney and Sark, which are appendages of Guernsey, forming each a separate parish with its appropriate minister. Though this is naturally a finer island than that of Jersey, yet it is far less valuable; because it is not so well cultivated, nor is it so populous. It abounds in cider. The inhabitants speak French. 
Want of fuel is the greatest inconvenicucy that both islands labour under. The convention of the states cansists of a governor, coroners, jurats, clergy, and constables. The inhabitants carry on a considerable trade to Newfoundland and the Mediterranean. The staple inanufacture is knit stockings. The only harbour here is at St. Peter-le-port, which is guarded by two forts, one called the Old-Castle, and the other Castle-Cornet. Guernsey is likewise part of the ancient Norman patrimony.

ALDERNEY is about eight miles in compass, and is by much the nearest of all these islands to Normandy, from which it is separated. by a narrow strait, called the Race of Alderney, which is a dangerous passage in stormy weather, when the two currents meet; otherwise it is safe, and has depth of water for the largest ships. To the west lie a range of rocks extending near three leagues, called the Caskets, among which are several very dangerous whirlpools or ed. dies. The sons of king Henry I, were cast away and drowned here, passing to Normandy : here, likewise, the Victory man of war, commanded by admiral Balchen, was lost. This island is healthy, and the soil is remarkable for a fine breed of cows.

SARK is a small island depending upon Guernsey; the inhabitants are long-lived, and enjoy from nature all the conveniences of life; their number is about 300 . The inhabitants of the three last-mentioned islands, together, are thought to be about 20,000. The religion of all the four islands is that of the church of England.

The SCILLY ISLES, anciently the SILURES, are a cluster of dangerous rocks, to the number of $1 \mathrm{AO}$, lying about thirty miles from. the Land's End in Cornwall, of which county they were reckoned 2 part. By their situation between the English Channel and St. George's Channel, they have been the destruction of many ships and lives. Sir Cloudesley Shovel, returning from a fruitless expedition against Toulon, was lost here in October, 1707. St. Mary's is the largest of these islands, being about nine or ten miles in circumfer. ence, and containing as many houses and inhabitants as all the rest. The number of the latter is about 700 ; several of the other islands are well inhabited, and have large and secure harbours.

The ISLE OF MAN has been supposed to take its name from the Saxon word Mang (or among,) because lying in St. George's Channel. It is almost at an equal distance from England, Scotland, and Ireland. It is certain the Mona mentioned by Tacitus was not this island, but the Isle of Anglesey. Mona, indeed, seems to have been a generical name with the ancients for any detached island. Its length from north to south is rather more than thirty miles, its breadth from eight: to fifteen; and the latitude of the middle of the island is fifty-four degrees sixteen minutes north. It is said that on a clear day three Britannic kingdoms may be seen from this island. The air here is wholesome, and the climate, only making an allowance for the situation, nearly the same as that in the north of England, from which it does not differ much in other respects. The hilly parts are barren, and the champaign fruitful in wheat, barley, oats, rye, flax, hemp, roots, and pulse. The ridge of mountains, which, as it were, divide the island, both protects and fertilises the vallies, where there is good pasturage The better sort of inhabitants have good sizeable horses, and a small kind, which is swift and hardy; nor are they troubled with any noxious animals. The coasts abound with sea-fowl; and the puffins, which breed in rabbit-holes, are almost lumps of fat, and Vor. I. 
esteemed very delicious. It is said that this island abounds with iron; lead, and copper mines, though unwrought; as are the quarries of marble, slate, and stone.

The Isle of Man contains seventeen parishes, and four towns on the sea-coasts. Castle-town is the metropolis of the island, and the seat of its government; Peele of late years begins to flourish ; Douglas has the best market and best trade in the island, and is the richest and most populous town, on account of its excellent harbour, and its fine mole, extending into the sea. It contains about 900 houses, and is a neat pleasant town : the buildings are lofty, but the streets narrow and close. Ramsey has likewise a considerable commerce, on account of its spacious bay, in which ships may ride safe from all winds, excepting the north-east. This island is situated extremely convenient for being the store-house of smugglers, which it was till within these few years.

The established religion of Man is that of the church of England. The bishop of Sodor and Man enjoys all the spiritual rights and preeminences of the other bishops, but does not sit in the British house of peers; his see never laving leen erected into an English barony. One of the most excellent prelates who ever adorned the episcopal character, was Dr. Thomas Wilson, bishop of Man, who presided over the diocese upwards of fifty-seven years, and died in the year 1755, aged ninety-three. He was eminently distinguished for the piety and the excmplariness of his life, his benevolence and hospitality, and his unremitting attention to the happiress of the people intrusted to his care. He encouraged agriculture, established schools for the instruction of the children of the inhabitants of the island, translated some of his devotional pieces into the Manks' language, to render them more generally useful to them, and founded parochial libraries in every parish in his diocese. Some of his notions respecting government and church discipline were not of the most liberal kind : but his failings were so few, and his virtues so numerous and conspicuous, that he was a great blessing to the Isle of Man, and an ornament to human nature. Cardinal Fleury had so much veneration for his character, that, out of regard to him, he obtained an order from the court of France, that no privateer of that nation should ravage the Isle of Man.

The ecclesiastical government is well maintained in this island, and the livings are comfortable. The language, which is called the Manks, and is spoken by the common people, is radically Erse, or Irish, but with a mixture of other languages. The New Testament and the Common Prayer Book have been translated into the Manks' language. The natives, who amount to about 30,000 , are inoffensive, cliaritable, and hospitable. The better sort live in stone houses, and the poorer in thatched; and their ordinary bread is made of oatmeal. Their products for exportation consist of wool, hides, and tallow; which they exchange with foreign shipping for commodities they may have occasion for from other parts. Before the south promontory of Man is a little island, called the Calf of Man : it is about three miles in circuit, and separated. from Man by a channel about two furlongs broad.

This island affords some curiosities which may amuse an antiquary. They consist chiefly of Runic sepulchral inscriptions and monuments, of ancient brass daggers, and other weapons of that metal, 
and partly of pure gold, which are sometimes dug up, and seem to indicate the splendour of its ancient possessors.

With respect to the history of this island, it was the rendezvous of the Scandinavian rovers, and their chief force was here collected; and from hence they annoyed the Hebrides, Great Britain, and Ireland. The kings of Man are often mentioned in history ; and though we have no regular account of their succession, and know but few of their names, yet they undoubtedly were for some ages masters of those seas. About the year 1263, Alexander II, king of Scotland, a spirited prince, having defeated the Danes, laid claim to the superiority of Mian, and obliged Owen, or John, its king, to acknowledge him as lord paramount. It seems to have continued tributary to the kings of Scotland, till it was reduced by Edward I; and the kings of England, from that time, exercised the superiority over the island; though we find it still possessed by the posterity of its Danish princes, in the reign of Edward III, who dispossessed the last queen of the island, and bestowed it on his favourite, Montague, earl of Salisbury. His family honours and estate being forfeited, Henry IV, bestowed Man, and the patronage of the bishopric, first upon the Northumberland family, and, that being forfeited, upon sir John Stanley, whose posterity, the earls of Derby, enjoyed it, till, by failure of heirs male, it devolved upon the duke of Athol, who married the sister of the last lord Derby. - Reasons of state rendered it necessary for the crown of Great Britain to purchase the customs of the island from the Athol family: and the bargain was completed by $70,000 l_{\text {. }}$ being paid to the duke in 1765 . The duke, however, retains his territorial property in the island, though the form of its government is altered; and the king has now the same rights, nowers, and prerogatives, as the duke formerly enjoyed. The inhabitants also retain many of their ancient constitutions and customs. 


\section{SCOTLAND.}

EXTENT AND SITUATION.

$\left.\begin{array}{l}\text { Length } 270 \\ \text { Breadth } 160\end{array}\right\}$ between $\left\{\begin{array}{r}55^{\circ} \text { and } 59^{\circ} \text { North latitude. } \\ 1^{\circ} \text { and } 6^{\circ} \text { West longitude. }\end{array}\right.$

Containing 27,794 square miles, with 58 inhabitants to each.

NAME....Scotland was known to the Romans by the name of Cale. slonia, a name, according to some, derived from a Celtic word, signi. fying forests or mountains : or, perhaps, it is related to the word Gael, by which name the northern or Highland Scots still call themselves. After the expiration of the Roman power, Scotland became the coun Ery of the Picts or Peohts, who were either the Britons driven northwards, or, as some think, a new colony from the south of Norway. At length, in the eleventh century, the Scoti coming over from Ireland and establishing themselves in Scotland, the name of Scotia was transferred from Ireland to Scotland.

BoundarIES....Scotland is bounded on the south by England; and on the north, east, and west, by the Deucaledonian, German, and Irish Seas, or more properly, the Atlantic Ocean.

Division and SUBDIvisions....Scotland is divided into the counties south of the Firth of Forth, the capital of which, and of all the kingdom is Edinturgh ; and those to the north of the same river, of which the chef town is Aberdeen. This was the ancient national division; but some modern writers, with less accuracy, have divided it into

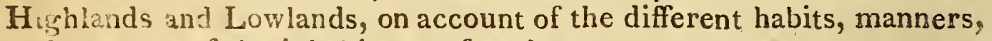
and custums of the inhabitants of each.

Eighteen counties, or shires, are allotted to the southern division, and fifteen to the nortiern : and those counties are subdivided into sheriffdoms, stewartries, and bailiwicks, according to the ancient, tenures and privileges of the landholders.

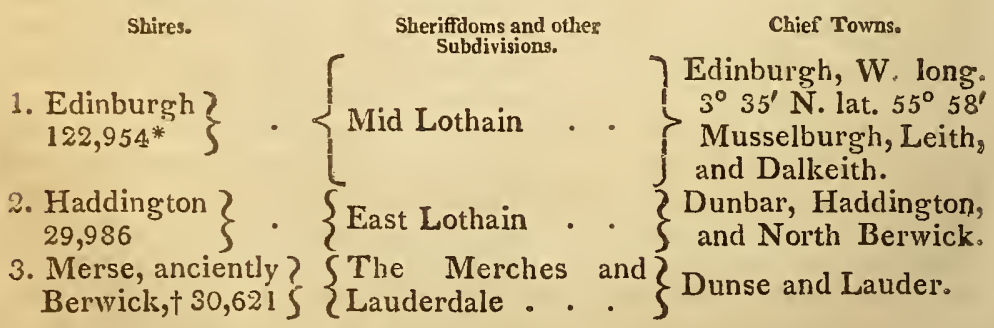

- The numbers show the population of each county, according to the returns under the act passed in 1801.

+ Berwick, on the north side of the Tweed, belonged formerly to Scotland, and gave name to a county in that kingdom; but it is now formed into a town and county of itself, in a political sense distinct from England and Scotland, having its own privileges. 
5elkirk 5070 - Ettrick Forest . Selkirk.

6. Peebles 8735 . Tweeddale . P Peebles.

. Lanark 146,699 \{Clydesdale $\} \begin{aligned} & \text { Glasgow, W. lon. } 4^{\circ} 15^{\circ} \\ & \text { N. Lat. } 55^{\circ} 52^{\prime} \text { Harnil- }\end{aligned}$

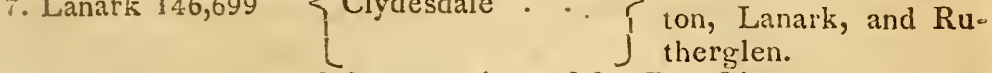

8. Dumfries 54,597 Nithsdale, Annandale Dumfries, Annan.

9. Wigtown 22,918 \{ Galloway, West part Wigtown, Stranraer, 10. Kircudbright $\left\{\begin{array}{l}\{\text { Galloway, East } \\ 29,211\end{array}\right\}$ part.... Kircudbright.

11. Ayr 84,306. $\{$ Kyle, Carrick, and Ayr, Kilmarnock, Ir-

12. Dumbarton 20,710 Lenox . . . Dumbarton.

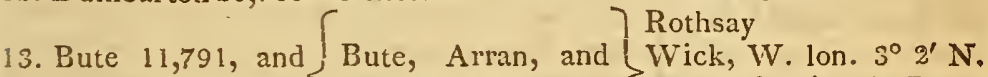
14. Caithness 22, 609 Caithness . $\left\{\begin{array}{l}\text { lat. } 58^{\circ} 40^{\prime} \text { and Thur- } \\ \text { so. }\end{array}\right.$

15. Renfrew 78,056 $\left\{\right.$ Renfrew ... $\left\{\begin{array}{l}\text { Renfrew, Paisley, } \\ \text { Greenock, and Port }\end{array}\right.$

16. Stirling 50,825 Stirling . . Stirling and Falkirk. 17. Linlithgow 17,844\{ West Lothain $\left\{\begin{array}{l}\text { Linlithgow, Burrough- } \\ \text { stonness, and Queen's } \\ \text { ferry. }\end{array}\right.$ Argyle, Cowal, 13. Argyle 71,859 \{ $\begin{aligned} & \text { and Lorn, with Inverary, Dunstaffnage, } \\ & \text { part of the Wes- }\end{aligned}$ Killonmer, and Camtern Isles, particu- beltown. larly Ila, Jura, Mull, Uist, Teri, Col, and Lismore. (Perth, Athol, Gowry, Broadalbin,

19. Perth 126,366. Monteith, Strath- Perth, Scone, Dumern, Stormont, 3 blane, Blair, and DunGlenshield, and keld. $\left.\begin{array}{l}\text { 20. Kincardine, or } \\ \text { Mearns 26,349 }\end{array}\right\}\left\{\begin{array}{l}\text { Raynock } \\ \text { Mearns ... }\end{array}\right.$ Bervie, Stonehive, and

$1^{\circ} 55^{\prime}$, N. lat, $57^{\circ} 7^{\prime}$. rioch, and Strath- $\rightarrow$ sersburgh, Peterhead, bogie $\quad$ Kintore, Strathbogie, Inverary, and OId Meldrum. 
Shires.

Sheriffioms and other

Chief Towns

22. Inverness 74,292 $\left\{\begin{array}{l}\text { Aird, Strathglass, } \\ \text { Sky, Harris, Bade- } \\ \text { noch, Lochaber, } \\ \text { and Glenmorison }\end{array}\right\} \begin{aligned} & \text { Fort Autess, Inverlochy, } \\ & \text { leau. }\end{aligned}$

23. Nairne 8257 and

24. Cromartie 3052

Western part of Murray and Cro- $\}$ Nairne, Cromartie.
martie

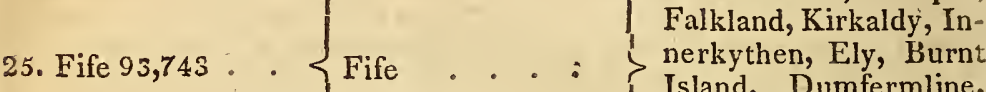

St. Andrew's, Cowper,

Island, Dumfermline,

Dysart, Anstruther \&

$\left.\begin{array}{l}\text { 26. Forfar or An- } \\ \text { gus } 99,127\end{array}\right\}\left\{\right.$ Forfar, Angus $\left\{\begin{array}{l}\text { Montrose, Forfar, Dun- } \\ \text { dee, Arbroth, and } \\ \text { Brechin. }\end{array}\right.$

7. Banff $35,807 .\left\{\begin{array}{l}\text { Banff, Boyne, Euzy, } \\ \text { vern, Boy, }\end{array}\right.$

27. Banff 35,807 • $\{$ Balveny, Stratha- $\}$ Banff and Cullen.

win, and part of Buchan . . .

88. Southerland23,117 $\left\{\begin{array}{c}\text { Strathnaver and Su- } \\ \text { therland ... }\end{array}\right\}$ Strathey and Dornoch.

29. Clacmannan 10,858 and

30. Kinros 6725

Fife part . Culross, Clacmannan, $\left\{\begin{array}{l}\text { Culross, Clacmannan } \\ \text { Alloa, and Kinross. }\end{array}\right.$

Easter and Wester Ross Isles of Lewis, Lochbroom,

31. Ross 52,291 * $\{$ Lochcarren, Ard-

Taine, Dingwall, Fortmeanach, Redcas. tle, Ferrintosh, rose, Rosemarkie, and New Kelso. Strathpeffer, and Ferrindonald
$\{$ Murray and Strath-

32. Elgin or Mur-?

ray 26,705$\}$

33. Orkney 46,844

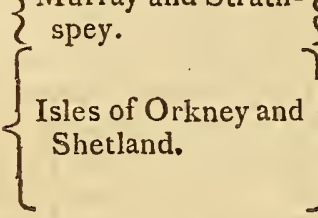

Elgin and Forres.

Kirkwall, W. lon. $3^{\circ} 8$, N. lat. $58^{\circ} 58^{\prime}$.

I.erwick, W. lon. $1^{\circ} 30^{\prime \prime}$ N. lat. $60^{\circ} 20^{\prime}$. Scalloway.

In all thirtyothree shires, which choose thirty representatives to sit in the parliament of Great Britain; Bute and Caithness choosing alternately, as do Nairne and Cromartie, and Clacmannan and Kinross.

The royal boroughs which choose representatives are,

Edinburgh

Kirkwall, Wick, Dornoch,

Dingwall, and Tayne.

Fortrose, Inverness, Nairne,

Forres

\section{1}

Elgin, Cullen, Banff, Inverary, and Kintore ... . Aberdeen, Bervie, Montrose, $\}$ Aberbrothe, and Brechin $\}$. 
Forfar, Perth, Dundee, Cow- $\}$ per, and St. Andrew's . $\}$ Crail, Kilrenny, Anstruther, East and WVest, and Pittenween

Dysart, Kirkaldy, Kinghorne, and Burnt Island

Innerkythen, Dumfermline, Queensferry, Culross, and Stirling .

Glasgow, Renfrew, Ruther-\{ glen, and Dumbarton . $\}$
Haddington, Dunbar, N. Berwick, Lauder, \& Jedburgh, Selkirk, Peebles, Linlithgow, and Lanark

Dumfries, Sanquehar, Annan, Lochmaban, and Kircud- $\} 1$ bright

Wigtown, New Galloway, Stranraer, and Whitehorn $\}$ I Ayr, Irvine, Rothsay, Cambel-\{ town, and Inverary .. $\}$

FACE OF THE COUNTRY....The appearance of the southern part of Scotland has a great resemblance to that of England; and, with respect both to the general aspect of the country, and to the progress of cultivation, exhibits every kind of rural variety : the northern part is chiefly an assemblage of vast dreary mountains, not however, without some fertile vallies on the northern and eastern coasts." The name of Highlands is properly given to Argyleshire, the western part of Perthshire, and the counties of Ross, Southerland, and Caitiness. The nudity of the country in many parts, in consequence of the want of wood, is generally observed by the traveller from the soutin; but the extensive plantations of trecs continualiy making by the nobility and gentry must, in a few years, greatly remedy, if not entirely remove, this defect. Scotland is in general diversified with a pleasing intermixture of natural objects. The vast inequalities of the ground, if unfavourable to the labours of the husbandman, are particularly pleasing to a traveller, and afford those delightful situations for country houses, of which many of the Scottish nobility and gentry have so judiciously availed themselves. It is their situation, more than any expensive magnificence, that occasions the seats of the dukes of Argyle and Athol, of lord Hopetoun, and many others, to fix the attention of every traveller.

Mountarns... The principal mountains in Scotland are the Gram. pian Hills, which run from east to west, from near Aberdeen to Cowal in Argyleshire, almost the whole breadth of the kingdom. Another chain of mountains, called the Pentland-hills, runs through Lothian, and joins those of Tweeddale. A third, called Lan mer-Muir, rises near the eastern coast, and runs westward through the Merse. Besides those continued chains, among which we may reckon the Cheviot or Tiviot Hills on the borders of England. Scotland con'tains many detached mountains, which, from their conical figure, are sometimes called by the Celtic name, Lazvs. One of the most remarkable of the Scottish mountains is Ben Fouaish, in the cast part of Ross-shire. It rises nearly in the form of a rick of hay to the height of $4200 \mathrm{feet}$, and ends in a flat summit or plain, three miles long, and half a mile broad. Ben Nevis, near Fort William, is reputed to be the highest mountain in Britain, being 4350 feet above the level of the sea. Its summit is covered with snow during the whole year.

Forests....The face of Scotland, even where it is most uninviting, presents us with the most incontrovertible evidences of its having formerly abounded with timber. The deepest mosses, or morasses, 
contain large logs of wood; and their waters being impregnated with. turpentine, have an antiseptic quality. The Syiva Caledonia, or Caledonian Forest, is supposed to have been Ettrick Forest, by which name the whole county of Selkirk was formerly called. Several parts of Scotland are still denominated forests; as Abernethy Forest In Aberdeenshire; Parff Forest, Reay Forest; and Broachiltive Forest in Argyleshire. Fir-trees grow in great perfection aimost all ovdr Scotland, and form beautiful plantations. The Scotch oak is excellent in the Highiands, where some woods reach 20 or 30 miles in length, and four or tive in breadin.

LAKE.... The lakes of Scotland (there called Lochs) are too many to be particularly described. Those called Loch-Tay, Loch-Loinond, Loch.Ness, Loch-Au, and one or two more, present us with such picturesque scenes as are scarcely equalled in any other country of Europe. Several of these lakes are beautifully fringed with woods, and contain great quantities of fresh water fish. The Scotch sometimes give the name of a loch to an arm of the sea; for example, Loch-Fyn, which is 60 miles long, and four broad, and is famous lor its excellent herrings. 'The loch of Spinie, near Elgin, is remarkable for swans and sygnets, which are there extremely numerous; owing, as some think, to the plant olorina, which grows in its waters. Near Loch-Ness is a high hill, on the top of which is a lake of cold fresh water about so fathoms in length, so deep that it has not yet becn fathomed, and which never freezes; whereas, but 17 miles from thence, the iake Lochanwyn, or Green take, is covered with ice all the year round. The ancient province of Lochaber receives that name from being the mouth of the lochs. The coasts of Scotland are in many parts indented with large, bold, navigable bays or arms of the sea, as the bay of Glenluce and Wigtown bay; sometimes they are called Firths, as the Solway Firth, which separates Scotland from England on the west; the Firth of Forth, Murray Firth, and those of Cromartie and Dornoch.

Rivers....The largest river in Scotland is the Forth, which rises in Monteith, near Callendar, and passing by Stirling, after a number of beautiful meanders, discharges itself near Edinburgh into that arm ot the German Sea to which it gives the name of Firth of Forth. Second to the Forth is the Tay, which issues out of Loch-Tay, in Broadalbin, and, running south-east, passes the town of Perth, and falls into the sea at Dundee. The Spcy, which is called the most rapid river in Scotland, issues from a lake of the same name in Badenoch, and, running from south-west to north-east, falls into the sea near Elgin; as do the rivers Dee and Don, which run from west to east, and disembogue themselves at Aberdeen. The Tweed rises on the borders of Lanarkshire, and, after many serpentine turnings, discharges itself into the sea at Berwick, where it serves as a boundary between Scotland and England, on the eastern side. The Clyde is a large river on the west of Scotland, has its rise in Annandale, runs north-west through the valiey of that name, and, after passing by Lanark, Hamilton, the city of Glasgow, Renfrew, Dumbarton, and Greenock, falls into the Firth of Clyde, opposite to the Isle of Bute. Besides these principal rivers, Scotland contains many of an inferior size, well provided with salmon, trout, and other fish, which equally enrich and beautify the country. Several of those rivers have the name of $E s k$, which is an old Celtic word for water. 
Casals....A canal forming a junction between the rivers Forth and Clyde, was begun in 1768, and finished in 1790 ; when, on the 28th of July a hogshead of the water of the forth was poured into the Clyde, as a symbol of their junction. This canal, in its dimensions, is much superior to any work of the same nature in Engrland. It is 35 miles in length; in the conrse of which navigation the ressels are raised by means of 20 locks, to the height of 155 feet above the level of the sea. Procecling afterwards on the summit of the country, for 18 miles, it thell descends by 19 other locks into the Clyde. It is ctrried over 36 rivers and rivulets, and two great roads, by 38 aqueducts of hewn stone. By one of these, 400 feet in lenyth, it passes the Kelvin, near Glasgow, at the height of 70 feet above the berl of the river in the valley below. It crosses the great road from Edinburgh to Glasgow, by a fine aqueduct bridge; and is carried orer the water of Logie by another aqueduct bridge, the arch of which is 90 feet broad. The great utility of this communication between the eastcrn and western scas to the tracle of Great Britain and Ireland must be evident, from the consideration that it shortens the distance between them by the shortest passage, that of the Pentland Firth, nearly 600 miles.

Oher canals are executing and projecting in Scotland. The canal of Crinan, which will save a circuitous and difficult navigation round, Cantire, is beyun, and in a considerable state of forwardness; and in Apri, 1804, a bill was brought into parliament for making an inland navigation from Inverness to Fort IVilliam, through Loch-Ness, and Loch-Lochie, to Loch-Linney.

NIFTALS AND MINERALS....Though Scotland does not at present boast of its gold mines, yet it former!y afforded a considerable quantity of that nuctal for its coinage. James $V$. and his father contracted with certain Germans for working the mines of Crawfori-Moor : and when the former married the Frencin king's daughter, a number of covered dishes, filled with coins of Scotch gold, were presented to the guests by way of desert. The civil wars and troubles which followed, urder his daughter, in the minolity of his grandson, drove those foreigners, the chief of whom was called Cornelius, from their works, which since that time have never been resumed. Some small pieces of goid have been found in those parts; washed down by the tloods. It likewise appears by the public records, that those beautiful coins, struck by James $V$, called bonnet pieces, were fabricated of gold found in Scotland, as were other medals of the same metal.

The lead mines of scotland are very productive and profitable, and, it is saia, contain greal quantities of silver; but there al'c no silver nimes that are worked at present. Some copper mines have been found near Ldinburghi; and many parts of Scotland, in the east, west and northern counties, produce exceilent coal of various kinds, large gututitics of which are exported. Lime-stone is fould here in great. pienty, as are also tree stone and several kinds of marble.

1.dpis azmi is dug up in Lanarkshire; alum mines have been found in Bantsine; crystal valiegated pebbles, and other transparent stones, which admit of the finest polish for seals, are found in various punts; as atre talc, potter's clay, airl finller's earth. The new earth of the nodern mineralogists and chemists, called strontian, is found in Argylesini e. No country produces greater plenty of aron ore, both in mines and stones, thail Scotlanil; of which the properictors now begin to reap the profits, in their founderics, at at Carron and other metalline manuluctures.

VOI 1. 
Climate, sorl, and agriculturf. The air of Scotland is mole. temperate than could be expected in so northerly a climate. This arises partly from the rariety of its hills, vallies, livers, and lakes; but still more, as in England, from the vicinity of the sea, which affords those warm breezes, that not only soften the luatural kecnness of the air, but, by keeping it in perpetual agitation, render it purc and healthful, and prevent those epidemic distempers that prevail in many other countries. In the neiglibourhood of some high mountains, however, which are generally covered with stuw, the air is kecn and piercing for about nine months in the year. The soil in general is not so fertile as that of England; and in many places less fitted for agriculture than for pasture. At the same time there are particular plains and vallies of the most luxuriant fertility; though experience has proved, that many vegetables and iortulane productions do not come so soon to maturity in this country as in England.

The soil of Scotland may be rendered, in many parts, nearly as fruitful as that of England. It is even said that some tracts of the low countries exceed in value English estates of the same cxtent, because they are less exhausted and worn out than those of the southern parts of the island: and agriculture is now perhaps as well understood, both in theory and practice, among many of the Scotch landLords and farmers, as it is in any part of Europe.

But the fruits of skill and industry are chiefly perceivable in the counties lying upon the river Forth, called the Lothains, where the farmers, as well as in Angus, generally rent from 3 to $500 l$. per ann. are well fed, well clothed, and comfortably lodged. The reverse, however, may be observed of a very considerable part of Scotand, where the landlords, ignorant of their real interest, refuse to grant such leases as would encourage the tenant to improve his own firm. In such places the husbandman barely exists upon the gleanings of a scanty farm, seldom exceeding 20 or $30 l$. per anu. the cattle are Jean and small, the houses mean beyond expression, and the face of the country exhibits the most deplowable marls of poveriy and oppression.

Vegetables....Scotland in general, produces wheat, rye, bayley, oats, hemp, flax, hay, and pasture. In the southern counties, the finest garden fruits, particularly apricots, ncctarines, and peaclies, are little, if at all inferior to those in England; and the same may be said of the common fruits. The uncultivated parts of the Highlands abound in various kinds of salubrious and pleasant-tasted berrics; though it must be owned that many extensive tracts are covered with a strong heath. The seacoast produces the alga-marina, dulse or dulish, a most wholesome nutritive weed, in great qualitities, and other marine plants, which are eaten for nourishment or pleasure.

ANmals... This country contains few or no kinds cither of wild or domestic animals that are not common with its neighbours. The red-rleer and roe-buck are found in the Highlands ; but their flesh is not comparable to English venison. Hares, and all other animals for grame, are here plentiful; as are the grouse and heath-cock, which is a most delicious bild, as likewise the capperkaily, and the ptarmigan, which is of the pheasant kind; but these birds are scarce cven in the Highlands, and, when discovered, are very shy. Eagles and beattiful falcons are not unfrequent here, and the shores abound in various kiuds of sea-fowl. The numbers of black cattle that cover the hills of Scotfand towards the Highlands, and sheep tiat are fed upun the beautiful 
mountains of Tweeddale, and other parts of the south, are almost incredible; and the black cattle, when fattened on the southern pastures, have been reckoned superior to English beef.

Formerly the kings of Scotland took great pains to mend the breed of the Scotch horses, by importing a large and more generous kind from the continent: but notwithstanding all the care that was taken, it was found that the climute and soil of Scotland were unfavourable to that noble aninial; for they diminished both in size and spirit; so that, about the tine of the union, few horses, natives of Scotland, were of much value. Great efforts have been made of late to introduce the Engrlish and foreign breeds, and such care has been taken to provide them with ploper food and management, that success has equalled the niost sanguine expectations.

NiTURAL ceriosiTifs.... Traces of ancient volcanoes are not un: frequent in Scotland. The hill of Finehaven is one instance; and the hill of Bergonium, near Dunstaffage castle, is another, yielding vast quantities of punnices, or scorie of different kinds, many of which are of the same species with those of the Icelandic volcanoes. Among other natural curiosities of this country, is a heap of white stone;, most of then clear like chrystal, together with great quantities of oyster and other sea-shells, found on the top of a mountain called Scorna-Lappich, in Ross-shire, tweaty miles distant from the sea. Slains, in Nberdecnshire, is said to be remarkable for a petrifying cave, called the Dropping Care, where water oozing through a spongy porous rock at the top, quickly consolidates after it drops to the b'ottum. Scotland, like other mountainous countries, abounds in wild and picturesque scenes, rocks, cataracts, and caverns. Of the latter there are some in Fifeshire, of extraordinary dimensions, in whick inhuman cruelties are said to have been perpetrated.

Populatrox.... The population of Scotland, according to the very accurate estimate given in sir John Sinclair's Statistical Account of Scotland, was, in $1798, \mathrm{i}, 526,492$ : in 1755 , it was only $1,265,380$; so that in 43 years it had increased $26:, 112$. By the returns made to the Population bill, passed in 1801, the present number of inhabitants in Scotland is $1,599,068$; to which if we add 8692 , the estimated number of inhabitants in the places from which no returns had been made, the total will be $1,607,760$.

Natrovat, character, maxers and gustoms.... The people of Scotland are generally raw-boned, and a kind of characteristical feature, that of high cheek-bones, prevails in their faces; they are lean, but clean-limbed, and can endure incredible fatigues. Their adventurous spirit was chiefly owing to their laws of succession, which irivested the elcler brother as head of the fumily, with the inheritance, and left but a very scanty portion for the other sons. This obliged the latter to seek their fortunes abroad, though no people have more. affection for their native soil than the Scotch have in general. It is true, this disparity of fortune among the sons of one family prevails in Lingland likewise ; but the resources which younger brothers hava in England are rumerous, compared to those of a country so narrow, and so little improved, either by commerce or agriculture, as Scotland was formerly.

An intelligent reader may easily perceive that the ridiculous family. pride, which is perhaps not yet entirely extinguished in Scotland, was owing to the feuclal institutions which prevailecl there longer than in England. The family differences, aspecially of the Highlimders, 
familiarized them to blond and slaughter; and the most ferocious passions were authorized and cherished by their chicftains. Their kings, excepting some of them who were endued with extraordinary virtues, were considered only as commanders of the army in time of war; for in time of peace their civil authority was so little, that every clan or family, even in the most civilized parts of Scotland, looked upon its own chieftain as its sovereign. These prejudices were confirmed even by the laws, which gave those petty tyrants a power of life and death upon their own estates; and they generally executed their hasty sentences in four-and-twenty hours after the party was apprehended. The pride which those chieftains had of outvying each other created perpetual animosities, which seldom or never ended without bloodshed; so that the common people, whose best qualification was a blind devotion to the will of their master, and the aggrandizement of his name, lived in a state of continual hostility. The late Archibald, duke of Argyle, was the first chieftain who had the patriotism to attempt to reform his dependents, and to banish from them those barbarous ideas. His example has been followed by other's ; and there can scar'cely be a doubt, but that a very few years will reconcile the Highlanders to all the milder habits of society.

The gentry of Scotland who reside upon their estates, differ little, at present, in their manners and style of living from their English neighbours of the like fortunes. The peasantry have their peculiarities; their ideas are confined, but no people can form their tempers better than they do to their stations. They are taught from their infancy to bridle their passions, to be have submissively to their superiors, and live within the bounds of the most rigid economy. Hence they save their money and their constitutions; and few instances of murder, perjury, robbery, and other atrocious vices, occur at present in Scotland. They seldom enter singly upon any daring enterprise; but when they act in concert, the secrecy, sagacity and resolution, with which they carry on any desperate undertaking, is not to be paralleled; and their fidelity to one another, under the strongest temptations arising from their poverty, is still more extraordinary. Their mobs are managed with all the caution of conspiracies; witness that which put Porteus to death in 1736, in open defiance of law and government, and in the midst of 20,000 people : and though the agents were well known, and some of them apprehended and put on their trial, with a reward of $500 l$. annexed to their conviction, yet no evidence could be found sufficient to bring them to punishment. The firlelity of the Highlanders of both sexes, under a still greater temptation, to the young pretender, after his defeat at Culloden, could scarcely be believed, were it not well attested.

They affect a fondness for the memory and language of their fore. fathers beyond perh ps any people in the world. They are fond of ancient Scotch cishes, such as the haggess, the sheep's head singed, the fish in sauce, the chicken broth, and minced collops. These dishes in their original dressing, were savoury and nutritive for $k \in e n$ appetites; but the modern improvements that have been made in the Scotch cookery have rendered them agreeable to the most delicate palates.

The inhabitants of most parts of Scotland, who live chiefly by pasture, have a natural vein for poetry; and the beautiful simplicity of the Scotch tunes is relished by all the true judges of nature. Those of a lively and merry strain have been introduced into the army by 
the fifes, an instrument for which they are remarkably well suited. It has been ridiculously supposed that Rizzio, the unhappy Italian. secretary of Mary queen of Scots, reformed the Scotch music. This. is a falsehood invented by his country, in envy to the Scots. Their finest tures existed in their church music, long before Rizzio's arrival; nor cloes it appear that Rizzio, who was chiefly employed by his mistress in foreign dispatches, ever componed an air during the short time he lived in Scotland: but were there no other evidences to confute this report, the original character of the music itsclf is sufficient.

The common people of Scotland retain the solemn decent manner of their ancestors at burials. When a relation dies in a town, the parish beicile is sent round with a passing-bell; but he stops at certain places, and with a slow melancholy tone announces the name of the party deceased, and the time of his interment, to which he invites all his fellow countrymen. At the hour appointed, if the deceased was beloved in the place, vast numbers attend. The procession is sometimes preceded by the magistrates and their officers, and the body is carried in a coffin, covercd by a velvet pall, with chair-poles, to the grave, where it is interred without any oration or address to the people, or prayers, or furthcr ceremony, than the nearest relation thanking the conpany for their attendance. The funerals of the nobility and gentry are performed in much the same manner as in England, but without any funeral service. The Highland funerals were generally preceded by bagpipes which played certain dirges, called coronachs, and were accompanied by the voices of the attendants of both sexes.

Dancing is a favourite amusement in this country; but little regard is puid to st or grucefuiness : the whole consists in agility, and in keeping time to their own tunes, which they do with great exactness.

One of the peculiur diversions practised by the gentlemen, is the Goff, which requires an equal degree of art and strength: it is played with a bat and a ball, and resembles that of the Mall, which was common in England in the middle of the seventeenth century. "The diversion of Curling is, perhaps, peculiar to the Scots. It is performed upon ice, with large flat stones, often flom twenty to two hundred jolinds weight each, which they hurl from a common stand towards a mark at a certain distance; and whoever is nearest the mark is the v.ctor. "I lhese two may be called the standing winter and summe: diversions in Scotland.

'The dress of the Highlanders is a kind of national characteristic, a description of wich must not be omitted. The Highland plaid is compresed of a woollen stuff, sometimes very fine, callcd tartan. This corsists of various colours, forming stripes which cross each other at right angles; and the natives value themselves on the judicious arrangement, or what they call sets of those stripes and colours, which, when skilfully managed, produce a pleasing effect to the eye. Above the shirt, the Highlander wears a waistcoat of the same composition with the plaid, which commonly consists of twelve yurds in width, and whicl they throw over the shoulder nearly in the form of a Roman toga, as represented in ancient statues; sometimes it is fastened round the middle with a leathern belt, so that part of the plaid hangs down before and behind like a petticoat, and supplies the want of, breeches. This they call being dressed in a phelig, but the Lowlanders call it a kilt, which is probably the same word with Celt. Sometimes they wear a kind of petticoat of the same variegated stuff, bnckled round the waist; and this they term the nhelibeg; which seems to 
be of Milesian extraction. Their stockings are likewise of tartan, tied below the knee with tartan garters formed into tasseis. 'The pourer people wear upon their feet brogues made of untanned or undressed leather; for their heats a blue that cap is used, called a bonnet, of a particular woollen manulacture. From the belt of the phelibeg hung generally their knives and a dagger, which they call a dirk, and an iron pistol, sometines of tine workmanship, and curiousiy in. laid with silver. The introduction of the broad sword of Andrea Ferrara, a Spaniard (which was always part of the Highland dress) seems to be no earlier than the reign of James III, who invited that excellent workman to Scotland. A large leathern purse, richly adorned with silver, hanging before, was always part of a Highland chicltain's dress.

The dress of the higrhland women consisted of a petticoat and jerkin, with strait sleeves, trimned or not trimmed according to the quality of the wearer. Over this they wore a plaid, which they either held close under their chins with the hand, or fastened with a buckle of a particular fashion. On the head they wore a kcrchief of fine linen of different forms. The womens' plaid has been but lately disused in Scotland by the ladies, who wore it in a graceful manner, the drapery falling towards the feet in large folds. A curious virtuoso may find a strong resemblance between the variegated and fimbriated draperies of the Scots, and those of the Tuscans (who wcre unquestionably of Celtic original) as they are to be seen in the monuments of antiquity.

The attachment of the Highlanders to this dress rendered it a bond of union, which often proved dangerous to the government. Many efforts had been made by the legrislature, after the rebellion in 1715 , to disarm them, and oblige then to conform to the Low-country dresses. The disarming scheme was the most successful; for when the rebellion in 174.5 broke out, the common people had scarcely any other arms than those which they took from the king's troops. 'Their overthrow at Culloden rendered it no difficult matter for the législature to force them into a total change of their dress. Its conveniency, however, for the purposes of the field, is so great, that the Highland regriments still retain it. Even the common people have of late resumed the use of it ; and, for its lightness and the fireedom it gives to the body, many of the Highland gentlemen wear it in the sunmer time. 'The dress of the higher and middle ranks of the Low-country differs little or nothing from the English; but many of the peasantry still retain the bonnet, for the cheapness and lightness of the wear.

Cities, CHIEF TOWNS, and EDIFlces.... Edinburgh, the capital of Scotland, naturally claims the first place under this head. The castle, befure the use of artillery, was deemed to be impregnable. It was probably built by the Saxon king Edwin, whose territory reached to the Firth of Forth, and who gave his name to Edinburgh, as it certainly did not fall into the hands of the Scots till the reign of Indulphus, who lived in the year 953. The town was built for the benefit of protection from the castle; and a more inconvenient situation for a capital can scarcely be conceired; the high-street, which is on the ridge of a hill, lying east and west; and the lanes ruming down its sides north and south. In former times the town was surrounded by water, excepting towards the east ; so that, when the French landed in Scotland during" the regency of Mary of Guise, they gave it the name of Lislebourg. This situation suggested the idea of building very lofty houses, divided into stories, each of which contains a suite of rooms, generally 
farge and commodious, for the use of a family; so that the high street of Eclinburgh, which is chicfly of hewn stone, broad, and well paved, makes a graud appearance, especially as it rises a full mile in a direct line and gradual ascent from the palace of Holyrood-house on the cast, and is terminated on the west by the rude majesty of its castle, built upon a lofty rock, inaccessible on all sices, except where it joins to the city. 'The castle not only orcrlooks the city, its envirous, gardens, the new town, and a fine rich neighbouring country, but commands a most extcnsive prospect of the river loorth, the shipping, the opposite coast of lifie, and eren some hills at the distance of 40 or 50 miles, which border tipon the llighlands. This crowded population, however, was so extrenely inconvenieut, that the English, who seldom went further into the country, returned with the deepest impression of Scotch nastiness, which became prorerbial. The castle has some good apartments, a tolerable train of artillery, and has not only a large magazine of arms and ammunition, but contaius the regalia, which were cleposited here under the most solemn legal instruments, engagring that tlacy should not be remored from thence. All that is known at present of those regalia, is contained in the instrument which was taken at the tine of their being deposited, where they are fully describud.

Ficing the castle, as has been alrcady observed, at a mile's distance, stancls the abbey, or rather palace of Holyrood-house. The inner quadrangle of this palace, begun by James $\mathrm{V}^{\top}$. and fuished by Charles 1. is of magnifoent modern architecture, built according to the plan arid under the direction of sir William Bruce, a Scotch gentleman of family, and one of the greatest architects of that age. Round the guadrangle runs an arcade, adorned with pilasters; and the inside contains magnificent apartments. Its long gallery contains figures, sontue of which are from portraits, but all of them painted by modern artists, of the kings of Scotland down to the time of the revolution. James VII. when duke of York, intended to have made great improvements about this palace; for at present nothing can be more unconfortable than its situation, at the bottom of bleak, unimproved crags and mountains, with scarcely a single tree in its neighbourhood.

'The hospital, founded by George Herriot, goldsmith to James VI. commonly called Herriot's WVork, stands to the south-west of the castle, in a noble situation. It is the finest and most regular specimen which Inigo Jones (who went to Scotland as architect to queen Aune, wile of king James VI.) has left us of his Gothic inanner, and far cxceoding any thing of that kind to be seen in England. One Balcanguhille, a divine, whon Herriot left his executor, is said to have prevailed upon Jones to admit some barbaruus devices into the building, particularly the windows, and to have insisted that the omaments of cach should be somewhat different from those of the others. It is, notwi:hstanding, upon the whole, a delightful fabric, and adorned with gardens not inelegantly laid out. It was built for the naintenance and education of poor children belonging to the citizens and tradesmen of Edinburgh, and is under the direction of the city magistrates.

Among the other public edifices of Edinburgh, before the Revolution, was the college, which claims the privileges of an university, founded by king Janes VI. and by him put under the direction of the nagistrates, who have the power of chancellor and vice-chancellor. Little can be said of its buildugs, which were calculated for the sober liefary mancrs, of those days; they are, however, improvable, and 
may be rendered elegant. What is of far more importance, it is supplied with excellent professors in the several branches of learning; and its schools for every part of the medical art are reckoned equal to any in Europe. This college is provided with a library, founded by one Clement Little, which has been of late greatly augmented; and a museum belonging to it was given by sir Andrew Balfour, a physician.

'The Parliament Square, ol, as it is there called, Close, was formerly the most ormamental part of this city : it is formed into a very noble quadrangle, part of which consists of lofty buildings; and in the middie is a fine equestrian statue of Charles II. The room built by Charies $I$. for the parliament-house, though not so large, is better proportioned than WVestminster-hall: and its roof, though executed in the same manner, has been by good judges heid to be superior. It is now converted into a court of law, where a single judge, called the lord-ordinary, presides by rotation : in a room near it sit the other judges; and adjoining are the public offices of the law, exchequer, chancery, shrievality, and magistracy of Edinburgh; and the valuable library of the lawyers. The latter equals any thing of the kind to be found in England, or perhaps in any part of Europe, and was at first entirely founded and furnished by lawyers. The number of printed books it contains is amazing; and the collection has been made with exquisite taste and judgment. It contains likewise the most valuable manuscript remains of the Scottish history, chartularities, and other papers of antiquity, with a series of medals.

The high churcl of Edinburgh, called that of St. Giles, is now divided into four churches, and a room where the general assembly sits. It is a large Gothic building, and its steeple is surmounted by arches, formed into an imperial clown, which has a good effect.

The modern edifices in and near Edin'urgh, such as the exchange, public oflices, its hospitals, bridges, in I the like, demonstrate the great improvement of the taste of tise Scots in their public works. Paraliel to the city of lidinburgh, on the north, the nobility, gentry, and others, have erected a new town. The streets and squares are laid out with the utmost regularity, and the houses are built with stone, in an elegant taste.

Between the old and the new town lies a narrow bottom or vale, which, agreeably to the original plan, was to have been formed into a slieet of water, bordered by a teriace-walk, and the ascent towards the new town corered with pleasure-gardens, shrubberies, \&c. This dosign, however, has not yet been carried into execution. At the west o" upper end of this vale, the castle, a solid rock, $n$ it less than uwenty stories high, looḱs down with awful magnificence. The eastern extremity is bouncled by a lofty bridge, the middle arch being ninety fect high, which joins the new buildings to the city, and renders the descent on each side the vaie (there being no water in this piace) mole commodious for carriares.

Edirburgh contains a playhouse, sanctioned by act of parliament; and concerts, assemblies, balis, music-meetings, and other polite amusements, are as frequent and brilliant here, as in any part of his majesty's dominious, London and Bath excepted. In the new town arc screral handsome and convenicnt hoteis, and the coifee-houses and taverns in the old town are much improved.

Edinburgh is governed by a lord provost, four bailies, a dean of guild, and a treasurer, annually chosen fron the common council. The lord provost is colonel of the town-guard, a military institution 
to be found in no part of his majesty's dominions but in Edinburgh; they serve for the city watch, and patrol the streets, are useful in suppressing small commotions, and attend the execution of criminals. Besides this guard, Edinburgh raises sixteen companies of trained bands, which serve as milita. The number of inhabitants in Edinburgh, according to the returns under the late act, is 82,560 . The revenues of the city consist chicfly of that tax which is now common in most of the bodies corporate in Scotland, of two Scotch pennies, amounting in the whole to two thirds of a farthing, laid on every Scotch pint of ale (containing two English quarts) consumed within the precincts of the city. Its product has been sufficient to defray the expence of supplying the city with excellent water, brought in leaden pipes from the distance of four miles; of erecting reservoirs, enlarging the harbour of Leith, and completing other public works, of great expence and utility.

Leith, though near two miles distant, may be properly called the harbour of Edinburgh, being under the same jurisdiction. It contains nothing re markable but the remains of two citadels (if they are not the same) which were fortified and bravely defended by the French, under Mary of Guise, against the English, and atterwards repaired by Cromwetl. The neighbourhood of Edinburgh is adorned with noble seats, which are daily increasing: some of them yield to few in England. About four niles from Edinburgh, is Roslin, noted for a stately Gothic chapel, esteemed one of the niost curious pieces of workmanship in Europe; founded in the year 1410, by William St. Clair; prince of Orkney, and duke of Oldenburgit.

Glasgow, in the shire of Lanark, situated on a gentle declivity, sloping towards the rirer Clyde, 44 miles west of Edinburgh, is, for population, commerce, and riches, the secoud city in Scotland, and, con: sidering its size, the first in great Britain, and perhaps in Europe, as to elegance, regularity, and the beautiful materials of its buildings. Thie streets cross each other at right angles, and are broad, straight, wellpaved, and consequently clean. The houses make a grand appearance, and are in general four or five stories high, and many of them, towards the centre of the city, are supported by arcades, which form piazzas, and give the whole an air of magnificence. Some of the modern built churches are in the first style of architecture; and the-cathedral is a stupendous Gothic building, hardly to be paralleled in that kind of architecture. It contains threc churches, one of which stands above another, and is furnished with a very fine spire springing from a tower; the whole being reckoned a masterly and matchless fabric. It was dedicated to St. Mungo, or Kentigern, who was bishop of Glasgow in the 6th century. The cathedral is upwards of 600 years old, and was preserved from the fury of the rigid reformers by the resolution of the citizens. The town-honse is a lofty building, and has very noble apartments for the magistrates. The university is esteemed the most spacious and best built of any in Scotland. In this city are several well endowed hospitals; and it is particularly well supplied with large and convenient inns, proper for the accoinmodation of strangers of any rarak. In Glasgow are seven churches, and eight or ten meeting houses for sectaries of various denominations. The number of its inhabitants is 17,385 .

Aberdeen may be consiclered as the third town in Scotland for im. provement and population. It is the capital of a shire,to which it gives. its name and contains two towns, New and Old Aberdeen. The former

VOI. 3 . 
is the shire town, and evidently built for the purpose of commerce. It is a large well-built city, and has a good quay, or tide-harbour: in it are three churches, and several episcopal meeting-houses. It has a considerable degree of foreign commerce and much shipping, a wellfrequented university, and about 20,000 inhabitants. Old Aberdeen, near a mile distant, though almost joined to the new by means of a long village, has no dependance on the other; it is a moderately large market town, but has no haven. In each of these two places there is a well-endowed college, both together being termed the university of Aberdeen, although quite independent of each other.

Perth, the capital town of Perthshire, lying on the river Tay, trades to Norway and the Baltic; is finely situated, has an improving linen manufactory, and lies in the neighbourhood of one of the most fertile spots in Great Britain, called the Carse of Gowry. Perth was once the capital of Scotland. Here the courts of justice sat, the parliament assembled, ar d the king resided : it was then defended by a strong castle, and is at present one of the most regular and handsome towns in Scotland: it contains about 15,000 inhabitants. Dundee contains about 26,000 inhabitants ; it lies near the mouth of the river 'Tay ; ${ }^{\prime}$ it is a town of considerable trade, exporting much linen, grain, herrings, and peltry, to sundry foreign parts ; and has three churches. Montreos, Aberbrothick, and Brechin, lic in the same county of Angus : the first has a great and flourishing foreign trade, and the manufactures of the other two are in an improving state.

Commerce, Manufactures... The trade and manufactures of Scotland are in most respects similar to those of England, though on a smaller scale, and for many years past have been rapidly improving. The chief exports are linen, grain, iron, lead, glass, woollen stuffs, soap, \&c. ; the imports are wines, brandy; and from the West Indies and America, rum, sugar, rice, cotton, and indigo. The total amount of the exports from Scotland in 1793 was computed at $1,024,742 l$. and the number of ships employed were 2234 .

The fisheries of Scotland have been greatly improved of late years, and send large supplies to the English and foreign markets. The busses, or vessels employed in the great herring fishery on the western coasts of Scotland, are fitted out from the north-west parts of England, the north of Ireland, as well as the numerous ports of the Clyde and neighbouring islands. The grand rendezvous is at Campbeltown, a commodious port of Argyleshire, facing the north of Ireland, where sometimes 300 vessels have been assembled. They clear out on the 12th of September, and must return to their different ports on the 13 th of January. They are also under certain regulations respecting the number of tons, men, nets, \&c. But though the political existence of Great Britain depends upon the number and bravery of her seamen, this fishery has hitherto laboured under many difficulties; the adventurers in it having frequently been losers, in consequence of the bounty of $50 \mathrm{~s}$. per ton (since recluced to 30s.) not having been regularly paid.

The chief manufacture of Scotland is that of linen of various kinds, of which several year's ago 400,000 yards were yearly whitened in one bleachery on the banks of the Tay, and the whole quantity stamped for sale in Scotland, beside what was made for private use, amounted to above seventeen millions of yards, in value nearly 900,000l. which quantity has been since increased. In the town of Paisley and its neighbourhood on the Clyde, the quantity of white sewing thread an- 
nually made was valued at $50,000 l$; and that of silk gauze, which is here afforded cheaper than in any other place, at 60,000l.; which manufactures, together with several others, have since considerably increased, above 15,000 persons being employed and maintained by them. Of the woollen manufactures of Scotland, that of carpets appears to be the most successful and productive.

The iron works at Carron, one mile from Falkirk, are said to be the largest in Europe; above a thousand men are employed in them, and all sorts of iron goods are made from the smallest article to the largest cannon, a great quantity of which are exported to Germany, Russia, and other foreign countries. The short peace of ordnance called a carronade was first made here, and hence received its name.

Constitution, GovernMent AND LAwS... The ancient constitution and government in Scosland have been highly applauded, as excellently adapted to the preservation of liberty; and it is certain that the power of the king was greatly limited, and that there were many checks in the constitution upon him, which were well calculated to prevent his assuming or exercising a despotic authority. But the Scottish constitution of government was too much of the aristocratic kind to afford to the common people that equal liberty which they had a right to expect. The king's authority was'sufficiently restrain. ed; but the nobles, chieftains, and great landholders, had it too much in their power to tyrannize over and oppress their tenants, and the common people.

The ancient kings of Scotland, at their coronation, took the following oath, containing three promises, viz.

"In the name of Christ, I promise these three things to the Christian people my subjects : First, that I shall give order, and employ my force and assistance, that the church of God, and the Christian people, may enjoy true peace during our time under our government. Secondly, I shall prohibit and hinder all persons, of whatever degree, from violence and injustice. Thirdly, in all judgments $I$ shall follow the prescriptions of justice and mercy, to the end that our clement and merciful God may show mercy unto me and to you."

The parliament of Scotland anciently consisted of all who held any portion of land, however small, of the crown, by military service. This parliament appointed the time of its own meetings and adjourn. ments, and comittees to superintend the administration during the intervals of parliament; it had a commanding power in all matters of government; it appropriated the public money, ordered the keeping of it, and called for the accounts; it armed the people, and appointed commanders; it named and commissioned ambassadors; it granted and limited pardons; it appointed judyes and courts of judicature : it named officers of state and privy-counsellors; it annexed and alienated the revenues of the crown, and restrained grants by the king. The king of Scotland had no negative voice in parliament; nor could he declare war, make peace, or conclude any other public business of importance, without the advice and approbation of parliament. The prerogative of the king was so bounded, that he was not even intrusted with the executive part of the government. And so late as the minority of James IV, who was contemporary with, and son-in-law to Ilenry VII, of England, the parliament pointed out to him his duty, as the first servant of his people; as appears by the act still extant, In short, the constitution was rather aristocratical than monarchical. 
The abuse of these aristocratical powers, by the chieftains and great landholders, gave the king, however, a very consideralale interest among the lower ranks; and a prince who had sense and address to retain the affections of his people, was generally able to humble the most overgrown of his subjects; but when, on the other hand, a king of Scotland, like James III, showed a disrespect to his parliament, the event was commonly fatal to the crown. The kings of Scotland, notwithstanding this paramount power in the parliament, found means to weaken and elude its force; and in this they were assisted by the clergy, whose revenues were immense, and who had very little dependence upon the pope, and were always jealous of the powerful nobility'. 'This was done by establishing a select body of members, who were called the lords of the articles. These were chosen men out of the clergy, nobility, knights, and burgesses. The bishops, for irstance, chose eight peers, and the peer's eight bishops ; and these sixteen jointly chose eight barons (or knights of the shire) and eight commissioners for burghs; and to all those were added eight great officer's of state, the chancellor being president of the whole.

Their business was to prepare all questions and bills, and other matters brought into parliament; so that in fact, though the king could give no negative, yet being, by his clergy, and the places he had to bestow, always sure of the lords of the articles, nothing could come into parliament that could call for his negative. It must be acknowledged that this institution seems to have prevailed by stealth; nol was it ever brought into any regular system; even its modes varied ; and the greatest lawyers are ignorant when it took place. The Scots, however, never lost sight of their original principles; and though Charles I, wished to form thèse lords of the articles into regular machines for his own despotic purposes, he found it impracticable ; and the melancholy consequences are well known. At the revolution, the Scots gave a fresh instance how well they understood the principles of liberty, by omitting all pedantic debates about abdicalion, and the like terms, and voting king James at unce to have forfeited his crown; which they gave to the prince and princess of Orange.

This spirit of resistance was the more remarkable, as the people of Scotland had groaned under the most insupportable ministerial tyranny ever since the Restoration. If it be asked, Why did they submit to that tyranny? the answer is, In order to preserve that independency of England, which Cromwell and his parliament endeavoured to destroy by uniting them with England. They therefore chose rather to submit to a temporary evil ; but they took the first opportunity to get rid of their oppressors.

Scotland, when it was a separate kingdom, cannot be said to have had any peers, in the English sense of the word. The nobility, who were dukes, marquises, earls, and lords, were by the king made hereditary members of parliament; but they formed no distinct house; for they sat in the same room with the commons, who had the same deliberative and decisive vote with them in all public matters. A baron, though not a baron of parliament, might sit upon a lord's assize in matters of life and death; nor was it necessary for the assizers, or jury, to be unanimous in their verdict. The feudal customs, even at the time of the Restoration, were so prevalent, and the rescue of the great criminal was commonly so much apprehended, that seldom above two days passed bctween the sentence and execution. 
Great uncertainey occurs in the Scottish history, by confounding parliaments with conventions; the difference was, that a parliament could enact laws as well as impose taxes; a convention, or meeting of the states, only met for the purpose of taxation. Before the Union, the kings of Scotland had four great and four lesser officers of state; the great were, the lord high chancellor, high treasurer, privy seal, and secretary ; the four lesser were, the lords register, advocate, treasurerdepute, and justice-clerk. Since the Union, none of these continue, excepting the lords privy-seal, register, advocate, and justice-clerk. A third secretary of state has occasionally been nominated by the king for Scottish affairs, but under the same denomination as the other two secretaries. The above officers of state sat in the Scotch parliament. by virtue of their officers.

The officers of the crown were, the high-chamberlain, constable, adniral, and marshal. The offices of constable and marshal were hereditary. A nobleman has still a pension as admiral ; and the office of marshal is exercised by a knight-marshal.

The office of chancellor of Scotland differed little from the same in England. The same may be saicl of the lords treasurer, privy-seal, and secretary. The lord-register was head-clerk.to the parliament, consention, treasury, exchequer, and session, and keeper of all public records. Though this office was only during the king's pleasure, yet it was very lucrative by the disposal of the deputation, which lasted during life. He acted as teller to the parliament; and it was dangerous for any member to dispute his report of the numbers upon division. The lord advocate's office resembles that of the attorney-general in England, only his powers are far more extensive ; because, by the Scottish laws, he is the prosecutor of all capital crimes before the justiciaary, and likewise concurs in all pursuits before sovereign courts, for breaches of the peace, and also in all matters civil, wherein the king or his donator hath interest. Two solicitors are named by his majesty, by way of assistants to the lord advocate. The office of justice-clerk entitles the possessor to preside in the criminal court of justice, while the justice-general, an office which will hereafter be mentioned, is absent.

The ancient constitution of Scotland admitted of many other officers both of the crown and state; but they are either now extinct, or too inconsiderable to be described here. That of lyon king at arms, or the rex frcialium, or grand herald of Scotland, is still in being; and it was formerly an office of great splendour and importance, insomuch that the science of heraldry was preserved there in greater purity than in any other country in Europe. This officer was even crowned solemnly in parliament with a golden circle; and his authority (which is not the case in England) in all armorial affairs, might be carried into execution by the civil law.

The privy council of Scotland, before the revolution, had, or assumed, inquisitorial powers, even that of torture ; but it is now sunk in the parliament and privy-council of Great Britain; and the civil and criminal causes in Scotland are chiefly cognizable by two courts of judicature.

'The first is that of the college of justice, which was instituted by James V, after the model of the French parliament, to supply an ambulatory committe $e$ of parliament, who took to themselves the names of the lords of council and session, which the present members of the 
college of justice still retain. This court consists of a president and fourteen ordinary members, besides extraordinary ones named by the king, who may sit and vote, but have no salaries and are not bound to attendance. This court may be called a standing jury in all matters of property that lie before them. The civil law is their directory in all matters that come not within the municipal lavs of the kingdom. It has been often matter of surprise, that the Scots were so tenacious of the forms of their court, and the essence of their laws, as to reserve them by the articles of the union. This however, may be easily accounted for, because those laws and forms were essential to the possession of estates and lands, which in Scotland are often held by modes incompatible with the laws of England. The lords of council and of session act likewise as a court of equity ; but their decress are (fortunately perhaps for the subject) reversible by the British house of lords, to which an appeal lies. The supreme criminal judge was named the Justiciar, and the court of justiciary succeeded to his power.

The justice-court is the highest criminal tribunal in Scotland; but in its present form it was instituted so late as the year 1672, when a lord-justice-general, removable at the king's pleasure, was appointed. This lucrative office still exists in the person of one of the chief nobility; but the ordinary members of the court are the justice-clerk and five other judges, who are always nominated from the lords of session. In this court the verdict of a jury condemns or acquits; but, as has been already hinted, without the necessity of their being unanimous.

Besides these two great courts of law, the Scots, by the articles of the Union, have a court of exchequer. This court has the same power, authority, privilege, and jurisdiction, over the revenue of Scotland, as the court of exchequer in England has over the revenue there; and all matters and things competent to the court of exchequer in England relating thereto, are likewise competent to the exchequer of Scotland. The judges of the exchequer in Scotland exercise certain powers which formerly belonged to the treasury, and are stil! vested in that of England.

- The court of admiralty in Scotland was, in the reign of Charles II, by act of parliament, declared to be a supreme court, in all causes competent to its own jurisdiction : and the lord high admiral is declared to be the king's lieutenant and justice-general upon the seas, and in all ports, harbours, and creeks of the same; and upon fresh waters and navigable rivers, below the first bridge, or within floed-mark; so that nothing competent to its jurisdiction can be meddled with, in the first instance, but by the lord high admiral and judges of his court. Sentences passed in all inferior courts of admiralty may be brought again before this court : but no appeal lies from it to the lords of the session, or any other judicatory, unless in cases not maritime. Causes are tried in this court by the civil law, which in some cases is likewise the common law of Scotland, as well as by the laws of Oleron, Wisby, and the Hanse-Towns, and other maritime practices and decisions common upon the continent. The place of lord-admiral of Scotland is little more than nominal : but the salary annexed to it is reckoned worth $1000 l$. a year; and the judge of the admiralty is commonly a lawyer of distinction, with considerable perquisites pertaining to his office. 
The college or faculty of advocates, which answers to the English inns of court, may be called the seminary of Scottish lawyers. They are within themselves an orderly court, and their forms require great precision and examination to qualify the candidates for admission. Subordinate to them is a body of inferior lawyers, or, as they may be called, attornies, who call themselves writers to the signet, because they alone can subscribe the writs that pass the signet; they likewise have a by-government for their own regulation. Such are the different law-courts that are held in the capital of Scotland: we shall pass to those that are inferior.

The government of the counties in Scotland was formerly vested in sheriffs and stewards, courts of regality, baron-courts, commissaries, justices of the peace, and coroners.

Formerly sheriffdoms were generally hereditable ; but by act of parliament, they are now all vested in the crown; it being enacted, that all high sheriffs, or stewards, shall, for the future, be nominated and appointed annually by his majesty, his heirs, and successors. In regard to the sheriff-deputies, and steward-deputies, it is enacted that there shall only be one in each county, or stewartry, who must be an advocate, of three years standing at least. For the space of seven years, these deputies are to be nominated by the king, with such continuance as his majesty shall think fit; after which they are to enjoy their office ad vitam aut culpam, that is, for life, unless guilty of some offence. Some other regulations have been likewise introduced, highly for the credit of the sheriff's courts.

Stewartries were formerly part of the ancicnt royal domain; and the stewards had much the same power in them as the sheriff had in his county.

Courts of regality of old were held by virtue of a royal jurisdiction vested in the lord, with particular immunities and privileges; but these were so dangerous and so extravagant, that all the Scotch regalities are now dissolved by act of parliament.

Baron courts belong to every person who holds a barony of the king. In civil matters they extend to causes not exceeding forty shillings sterling; and in criminal cases, to petty actions of assault and battery; but the punishment is not to exceed twenty shillings sterling, or setting the delinquent in the stocks for three hours in the day-time. These courts, however petty, were in former days invested with the power of life and death, which they have now lost.

The courts of commissaries in Scotland answer to those of the English cliocesan chancellors, the highest of which is kept at Edinburgh; wherein, before four judges, actions are pleaded concerning matters relating to wills and testaments, the right of patronage to ecclesiastical benefices, tithes, divorces, and causes of that nature; but in almost all other parts of the kingdom there sits but one judge on these causes.

According to the present institution, justices of the peace in Scotland exercise nearly the same powers as those in England. In former times their office, though of very old standing, was insignificant, being cramped by the powers of the great feudal tyrants, who obtainerl an act of parliament, that they were not to take cognizance of riots till fifteen days after the fact.

The institution of coroner is as old as the reign of Malcolm II, the sreat legislator of Scotland, who lived before the Norman invasion of 
England. They took cognizance of all breaches of the king's peace ; and they were required to have clerks to register depositions and matters of fact, as well as verdicts of jurors; the office, however, is at present, much disused in Scotland.

The legal punishments in Scotland are nearly the same as in England, only that of beheading is performed by an instrument called the maiden, which resembles the French guillotine; and of which the model was brought from Halifax in England, to Scotland, by the regent, earl Morton; where it was first used for the execution of himself.

From the above short view of the Scotch laws and institutions, it is plain that they were radically the same with those of the English. The latter allege, indeed, that the Scots borrowed the contents of their $R e$ giam Magestatem, their oldest law-book, from the work of Glanville, who was a judge under Henry II, of England. The Scots, on the other hand, say that Glanville's work was copied from their Regiam Magestatem, even with the peculiarities of the Tatter, which do not now, and never did, exist in the laws of England.

The royal burghs in Scotland form, as it were, a commercial parliament, which meets orice a year at Edinburgh, consisting of a representative from each burgh, to consult upon the common good of the whole. Their powers are extensive; and before the Union they made laws relating to shipping, to masters and owner's of ships, to mariners and merchants by whom they were freighted; to manufactures, such as plaiding, linen, and yarn; to the curing and packing of fish, salmon, and herrings, and to the importing and exporting several commodities. The trade between Scotland and the Netherlands was subject to their regulation; they fixed the staple port, which was formerly at Dort, and afterwards at Camprere. Their conservator is indeed nominated by the crown; but then their convention regulates his power, approves his deputies, and appoints his salary : so that in truth the whole staple trade is subjected to their management. Upon the whole, this is a very singular institution, and sufficiently proves the vast attention which the sovernment of Scotland formerly paid to trade. It took its present form in the reign of James III, 1487, and had excellent consequences for the benefit of commerce.

The conformity between the practice of the civil law of Scotland, and that in England, is remarkable. The English law leports are of the same nature with the Scotch practice; and their acts of sederunt answer to the English rules of court; the Scottish wadsetts and reversions, to the English mortgages and defeasances; their poinding of goods, after letters of horning, is much the same as the English executions upon outlawries; and an appeal against the king's pardon, in cases of murder, by the next of kin to the deceased, is admitted in Scotland as well as in England. Many other usages are the same in both kingdoms. There was in particular an ancient custom, which proves the similarity between the English and Scottish constitutions. In old times, all the freeholders in Scotland met together in presence of the king, who was seated on the top of a hillock, which, in the old Scottish constitution, was called the Moot, or Mute-hill; all national affairs were here transacted, judgments given, and difierences ended. This Moothill was probably of the same nature as the Saxon Folcmote, and sig. nified only the hill of meeting.

ORDER OF THE THISTLE... This is a military order instituted, as the Scotch writers assert, by their king Achaius, in the ninth century, ap- 
on his making an offensive and defensive league with Charlemagne, king of France; or, as others say, on account of his victory over Athelstan, king of England, when he vowed in the kirk of St. Andrew, that he and his posterity should ever beai in their ensigns the figure of the cross on which that saint suffered. It has been frequently ne. glected, and as often resumed. It consists of the sovereign and twelve companions, who are called Knights of the Thistle, and have on their ensigns this significant motto, Nemo me imfune lacesset, "None shall safely provoke me."

REL1Gion....Ancient Scottish historians, with Bede and other writers, generally agrree that Christianity was first taught in Scotland by some of the disciples of St. John the Apostle, who fled to this northern country to avoicl the persecution of Domitian, the Roman emperor; though it was not publicly professed till the beginning of the third century, when a prince, whom Scotch historians call Donald the First, his queen, and several of his noules, were solemnly baptised. It was farther confirmed by enigrations from South Britain, during the persecutions of Aurelius and Dioclesian, when it became the established religion of Scotland, under the management of certain learned and pious men, named Culdees, who seem to have been the first regular clergy in Scotland, and were governed by overseers or bishops chosen by themselves from among their own body, and who had no pre-eminence of rank over the rest of their brethren.

Thus, independent of the church of Rome, Christianity seems to have been taught, planted, and finally confirmed in Scotland, as a national church, where it flourished in its native simplicity, till the arrival of Palladius, a priest sent by the bishop of Rome in the fifth century, who found means to introduce the modes and ceremonies of the Romish church, which at length prevailed, and Scotland became in. volved in that darkness which for ages overspread Europe; though its dependence upon the pope was very slender, when compared to the blind subjection of many other nations.

The Culdees long maintained their origiral manners, and remained a distinct order, notwithstanding the oppression of the Romish clergy, till the age of Robert Bruce in the 14th century, when they disap. peared

Soon after the power of the pope in England was destroyed by Henry VIII, a similar reformation began in Scotland, in the reign of James $\mathrm{V}$ : it made great progress under that of his daughter Mary, and was completed through the preaching of John Krox, who had adopted the doctrines of Calvin, and was the chief reformer of Scotland.

The religion at present established by law in Scotland, differs chiefIy from that of the church of England, in having for its fundamental principle a parity of rank and authority among its clergy : all its ecclesiastics, or presbyters, being equal in dignity, and forming among themselves a kind of ecclesiastical commonwealth of the democratic species: It agrees with the reformed clurches abroad in its opposition to popery; but it is modelled principally after the Calvinistical plan established at Geneva. This establishment, at various periods, proved so tyrannical over the laity, by having the power of the great and lesser excommunication, which were attended by a forfeiture of estate, and sometimes of life, that the kirk sessions, and other bodies, have been abridged of all their dangerous powers over the laity, who were extremely jealous of thcir being revived. Even that relic of

VOI. I.

n 
popery, the obliging fornicators of both sexes to sit upon what they call a repenting stool, in the church, and in full view of the congregation, begins to wear out, it having been found that the Scotch wo. men, on account of that penance, were the greatest infanticides in the world. In short, the power of the Scotch clergy is at present very moderate, or at least very moderately exercised; nor are they accountable for the extravagancy of their predecessors. They have been, ever since the revolution, firm adherents to civil liberty, and the house of Hanover, and acted with remarkable intrepidity during the rebellion in 1745 They dress without clerical robes: but some of them appear in the pulpit in gowns, after the Geneva form, and bands They make no use of set forms in worship. The rents of the bishops, since the abolition of episcopacy, are paid to the king, who commonly appropriates them to pious purposes. A thousand pounds a year is always sent by his majesty for the use of protestant schools erected by act of parliament in North Britain, and the western isles; and the Scotch clergy, of late, have instituted funds for the support of their widows and orphans. The number of parishes in Scotland is 941 , of which 31 are collegiate churches, that is, where the cure is served by more than one minister.

The highest ecclesiastical authority.in Scotland is the general assembly, which we may call the ecclesiastical parliament of Scotland. It consists of commissioners, some of whom are laymen, under the title of ruling elders, from presbyteries, royal burghs, and universities. A presbytery, consisting of less than twelve ministers, sends two ministers and one ruling. elder; if it contain between twelve and eighteen minister's, it sends three, and one ruling elder; if it contain between eigh. teen and twenty-four ministers, it sends four ministers and two ruling elders; but if the presbytery have twenty-four ministers, it sends five ministers and two ruling elders. Every royal burgh sends one ruling elder, and Ediuburgh two; whose election must be attested by the respective kirk sessions of their own burghs. Every university sends one commissioner, usually a minister of their own body. These commissioners are chosen yearly, six weeks before tho meeting of the assembly. The ruling elders are often persons of the first quality of the country. The king presides by his commissioner (who is always a nobleman) in this assembly, which meets annually in. May; but he has no voice in their deliberations. "Ihis assembly chooses a clergyman for its moderator, or speaker. Appeals are brought from all the other ecclesiastical courts in Scotland to the genera! assembly; and no appeal lies from its determination in religious. matters.

Provincial synods are next in authority to the general assembly. They are complosed of a number of the adjacent presbyteries, over whom they have a power; and there are fifteen of them in Scotland; but their acts are reversible by the general assembiy

Subordinate to the synods, are presbyteries, of which there are sixtynine in Scotland, each consisting of a number of contiguous parishes. The ministers of these parishes, with one ruling elder chosen half yearly out of every session, compose a presbytery. These presbyteries meet in the head town of that division, but have no jurisdiction beyond their own bounds, though within these they have cognizance of all ecclesiastical causes and niaters. A chief part of their business is the ordination of candidates for livings, in which they are regular and 
solemn. The patron of a living is bound to nominate or present in six months after a vacancy; otherwise the presbytery fills the place jure devoluto; but that privilege does not hold in royal burghs.

A kirk session is the lowest ecclesiastical judicatory in Scotland, and its authority does not extend beyond its own parish. The members consist of the ministers, elders, and deacons. The deacons are laymen, and act nearly as churchwardens do in England, by having the superintendency of the poor, and taking care of other parochial affairs. The elder, or, as he is called, the ruling elder, is a place of great parochial trust, and he is generally a lay-person of quality or interest in the parish The elders are supposed to act in a kind of co-ordinacy with the minister, and to be assisting to him in many of his clerical duties, particularly in catechising, visiting the sick, and at the cammunion table

The office of ministers, or preaching presbyters, includes the offices teacons and ruling elders; they alone can preach, administer the sacrament, catechise, pronounce church censures, ordain deacons and ruling elders, assist at the imposition of hands upon other ministers, and moderate or preside in all ecclesiastical judicatories.

The established religion of cotland formerly partook of all the austerities of Calvinism. and of too much of the intolerance of popery: but at present it is mild and gentle; and the sermons and other theological writings of many of che modern Scotch divines are equally distinguished by good sense and moderation. In the Lowlands there are a great number of congregations who dissent from the presbyterian establishment and doctrines in several particulars, and are called Seceders. These are again subdivided into Burgher's and Antiburghers. They maintain their own preachers, though scarcely any two congregations agree either in principle or practice with each other.

The other dissenters in Scotland, consist of the episcopalians, a few quakers, many baptists, and other sectaries, who are denominated from their preaciers. Episcopacy, from the time of the restoration in 1660 , to that of the revolution in 1688 , was the established religion of Scotland; and would probably have continued so, had not the bishops, who were in general very weak men, and creatures of the duke of York, afterwards James VII and Il, refused to recognize king IVilliam's title, The partisans of that unhappy prince retained the episcopal religion: and king William's government was rendered so unpopular in Scotland, that in queen Anne's time, the episcopalians were more numerous in some parts than the presbyterians; and their meetings, which they held under the act of toleration, as well attended. $\Lambda$ Scotch episco. palian thus becoming another name for a jacobite, they received sonie checks after the rebellion in 1715: but they recovered themselves so well, that at the breaking out of the rebellion in 1745 , they become again numerous : after which the government found mcans to invalidate the acts of their clerical order. Their meetings, however, still subsist, but thinly; the decline of the nonjurors having suppressed episcopacy in Scotland. The English bishops supply them with clergy qualified according to law, whose chapels are chiefly filled by the English, and such Scotch hearers of that persuasion as have places under government

The defection of some great families from the cause of popery, and the distinction of others, have rendered its votaries inconsiderable in Scotland. 'They are chiefly confined to the northern parts, and the 
islands : and they appear to be as quiet and inoffensive as protestant subjects.

Scotland, during the time of episcopacy, contained two archbishoprics, St. Andrew's and Glasgow ; and twelve bishoprics, Edinburgh, Dunkeld, Aberdeen, Murray, Brechin, Dumblain, Roth, Caithness, Orkney, Galloway, Argyle, and the Isles.

Literature... For this article we may refer to the literary history of Europe for 1400 years past. The western parts and isles of Scotland produced St. Patrick, the celebrated apostle of Ireland. The writings of Adamnanus, and other authors who lived before, and at the time of the Norman invasion, which are still extant, are specimens of early Scotch learning Charles the Great, or Charlemagne, most unquestionably held a correspondence, by letters, with the king of Scotland, with whom he entered into a league; and employed Scots in planning, settling, and ruling his favourite universities, and other seminaries of learning, in France, It:aly, and Germany. It is an undoubted truth, though a seeming paradoxical fact, that Barbour, a Scottish poet, philosopher, and historian, though prior in time to Chauser, having flourished in the year 1368, wrote, according to the modern ideas, as pure English as that bard; and his versification is perhaps more harmonious. The destruction of the Scottish monuments of learning and antiquity has rendered their early annals lame, and often fabulous; but the Latin style of Buchanan's history is equal in classical purity to that of any modern productions. The letters of the Scottish kings to the neighbouring princes are incomparably the finest compositions of the times in which they were written, and are free from the barbarisms of those sent them in answer. This has been considered as a proof that classical learning was more cultivated at the court of Scotland than at any other in Europe.

The discovery of the logarithms, a discovery which in point of ingenuity and utility may vie with any that has been made in modern times, is the indisputable right of Napier of Merchistone. And since his time, the mathematical sciences have been cultivated in Scotland with great success. Keil, in his physico-mathematical works, to the clearness of his reasoning, has sometimes added the colouring of a poet. Of all writers on astronomy, Gregory is allowed to be one of the most perfect and elegant. Maclaurin, the companion and the friend of sir Isaac Newton, was endowed with all that precision and force of mind which rendered him peculiarly fitted for bringing down the ideas of that great man to the level of ordinary apprehensions, and for diffusing that light through the world which Newton had confined within the sphere of the learned $H$ is Treatise on Fluctions is regarded by the best judges in Europe as the clearest account of the most refined and subtile speculations on which the human mind ever exerted itself with success. While Maclaurin pursued this new career, a gometrician no Ies famous distinguished himself in the almost deserted track of antiquity. This was the late Dr. Simpson, so well known for his illustrations of the ancient geometry. His Elements of Euclid, and, above all, his Conic Sections, are sufficient of themselves to establish the scientific reputation of his native country.

In the department of history the highest celebrity has been acquired by Scottish writers. Hume was the first who, with any pretensions to classical elegance, wrote the history of England. Dr. Robertson began 
his literary career of glory with the history of his own country. This was followed by that of all Europe, in the reign of the emperor Charles V. The captivating account of the discovery of America was next presented to the world; and an historical disquisition concerning India was the last production of this philosophical historian. To Dr. Henry his country and the world are indebted for a history of Great Britain, on a plan entirely new, in which he has brought within one glance of the eye every thing interesting in the civil history, constitution, learning, arts, commerce, and manners of the people, from the earliest authenticity. The investigations of Dr. Adam Smith on the subject of national wealth and politics, have perhaps never been equalled; and the moral philosophy of Hutcheson will be allowed, even by its opponents, to be ingenious, and plausibly supported.

In medicine the names Pitcairn, Arbuthnot, Monro, Smellie, Whytt, Cullen, Brown, and Gregory, hold a distinguished place. Nor have the Scots been unsuccessful in cultivating the belles lettres. Foreigners who inhabit warmer climates, and conceive the northern nations incapable of tenderness and feeling, are astonished at the poetic genius and delicate sensibility of Thompson, and the various powers of Armstrong, Beattie, and Burns.

UNIVERsitres.. The universities of Scotland are four : that of St. Andrews, founded by bishop Wardlaw, in 1411; it consists of three colleges, two of which are united, and in which, some years ago, the number of students was said to be only 100 ; that of Glasgow, founded by bishop Turnbull, in 1453, containing between five and six hundred students ; that of Aberdeen, consisting of two colleges, in the old town, founded by bishop Elphinstone, in the year 1500, and one in the new town, founded by George Keith, fifth earl-marshal, in 1593; and that of Edinburgh, founded by James VI, in 1580 , which usually contains about 1000 students. The old buildings of this university having fallen to decay, the foundation of a new edifice, to which our most gracious sovereign has been a very liberal benefactor, was laid in 1789 , and may be expected soon to be completed on such an elegant and magnificent plan, as shall render it a noble monument of national munificence and taste.

LANGDAGE.... The Earse or Gaelic, a dialect of the Celtic, nearly the same with the Irish, is still spoken in the Highlands; but the language of the Low-countries, which is of the same origin with the English, is continually, extending. The English and Scotch are written in the same manner; and the pronunciation of the latter is scarcely more different from that of London than we find it in many of the northern and western English counties.

Antiquities....The Romam and other antiquities found in Scotland have of themselves furnished matter for large volumes. The stations of the Roman legions, their castella, the pretentures or walls reaching across the island, have been traced with grreat precision by antiquaries and historians; so that, without some new discoveries, an account of them could offord no instruction to the learned, and but little amusement to the ignorant; because at present they can be discovered only by critical eyes. Some mention of the clief, however, may be proper. The course of the Roman wall (or, as it is called by the country people, Graham's Duke, from a tradition that a Scottish warrior of that name 
first broke over it ) between the Clyde and Fortb, which was first mal, ked out by Agricola, and completed by Antoninus Pius, is still discernible, as are several Roman camps in the neighbourhood. Agricola's camp, at the bottom af the Grampian Hills, is a striking remain of Roman antiquity. It is situated at Ardoch, in Perthshire, and is generally thought to have been the camp occupied by Agrioola, before he fought the bloocly battle, recorded by Tacitus, with the Caleclonian king Galgacus, who was defeated. Some writers think that this remain of antiquity at Ardoch was, on account of the numerous Roman coins and inscriptions found near it, a Roman castellum or fort. Be that as it may, it certainly is the most entire and best preserved of any Roman antiquity of that kind in North Britain, having no less than five rows of ditches and six ramparts on the south side; and of the four gates which lead into the area, three are very distinct and plain, viz. the pratoria, decumana, and dextra.

The Roman temple, or building in the form of the pantheon at Rome, or of the dome of St. Paul's at London, stood upon the banks of the ziver Carron in Stirlingshire, but was barburously demolished by a neighbouring Goth, for the purpose of mending a mill-pond Its height was twenty-two feet, and its external circumference at the base was eighty-eight feet; so that upon the whole it was one of the most complete Roman antiquities in the world. It is thought to have been built by igricola, or some of his successors, as a temple to the god Termisus, as it stood near the pratenture which bounded the Roman empire in Britain to tire north. Near it are some artificial conical Frounds of earth, which stili letain the name of Duni-pace or Dunipacis; which serve to prove that there was a kind of solemn conspromise between the Romans and the Caledonians, that the former should not extend their empire farther to the northward.

Innumerable are the coins, urns, utensils, inscriptions, and other re. mains of the Romans, that have been found in different parts of Scotland: some of them to the north of the wall, where, however, it cloes not appear that they made any establishnent. By the inscriptions found near the wail, the names of the legions that built it, and how far they carried it on, may be learned The remins of Roman highways arc frequent in the southern parts.

Danish camps and fortifications are easily discernible in several northern counties, and are known by their square figures and difficult situitions. Dome houses or stupendous fabrics remain in Ross-shire; Dut whether they are Danish, Pictish, or Scottish, does not appear. 'They are, perhaps, Norwegian or Scandinavain structures, and built: about the fifth century, to favour the descents of that people upon those cousts.

Two Pictisls monuments, as they have been supposed to be, of a very extraordinary construction, were lately standing in Scotland; one of them at Abernethy in Perthshire, the other at Brechin in Angus; both of them are columns, hollow in the inside, and without the stair-case; that of Brechin is the most entire, being covered at the top with a spiral roof of stone, with three or four windows above the cornice; it consists of sirty regular courses of hewn free-stone, laid circularly, and regilarly tapering towards the top. If these columns are really Pictish, ihat people niust have had among them architcets who far exceeded those of any coeval monuments to be found in Europe, as they have all the appearance of an order; and the building is neat, and in the Roman 
style of architecture. It is, however, difficult to assign them to any but the Picts, as they stand in their dominions: and some sculptures upon that at Brcchin denote it to be of Christian origin. It is not indeed impossible that these sculptures are of a later date. Besides these two pillars, many other Pictish buildings are found in Scotland, but not in the same style.

The restiges of erections by the ancient Scots themselves are not only curious but instructive, as they regard many important events of their history. That people had amongst them a rude notion of sculpture, by which they transmitted the actions of their kings and heroes. At a place called Abcrlemno, near Brechin, four or five ancient obelisks are still to be seen, calied the Danish stones of Aberlemno. They are orected as commemorations of the Scotch rictories over that people; and are adorned with bas-reliefs of men on horseback, and many emblematical figures and hieroglyphics, not intelligible at this day. Many other historical monuments of the Scots have been discovered; but it must be acknowledged that the obscurity of their sculptures has opened a field of boundless and frivolous conjectures, so that the interpretations of many of them are often fanciful. Among these the stone near the town of Forress, or Fortrose, in Murray, far surpasses all the others in magnificence and grandeur, "and is," says Mr. Gordon, "perhaps, one of the most stately monuments of that kind in Europe." it rises about 23 feet in height above ground, and is, as I am credibly informed, no less than 12 or 15 fcet selow; so that the whole height is at least 35 feet, and its breadth near five. It is all one single and entire stone; great variety of figures in relievo are carved on it, and some of them are still distinct and visible; but the injury of the weather has obscured those towards the upper part. Though this monument has bcen generally considered as Danish, yet it is not improbable that it is Scuttish, and was erected in commemoration of the final expulsion of the Danes out of Murray, where they held their last settlement in Scotland, after the defeat they received from Malcolm, a few years bctore the Forman invasion.

At Sandwick, in Ross-shire, is a very splendid ancient obelisk, surrounded at the base with large, well-cut flag stones, formed like stcps. Both sides of the column are covered with various enrichments, in well-finished carved work. One facc prescnts a sumptuous cross, with a figure of St Andrew on each hanch and some uncouth animals and flowrings underneath. The central division, on the reverse, exhibits a variety of curious figures, burds and animals.

The ruins of the cathedral of Elgin are very striking; and many parts of that fine building have still the remains of much grandeur and dignity in them. The west cloor is highly ornamented; there is much elegance in the carvings, and the whole edifice displays very elaborate workmanship.

Among the remains of ancient castles, may be mentioned Kildrumy castle in the north of Scotland, which was formerly a place of great strength and magrificence, and often used as an asylum to noble families in times of civil war. Invcrugic castle, the ancient seat of the earl-mareschals of Scotland; is also a large and lofty pile, situated on a steep bank of the river; two very ligh towers bound the front, and, even in their rlecaying state, give the castle an air of much srandeur 
and antiquity. Long rows of venerable trees, inclosing the adjoin. ing garden, add to the effect of the decayed buildings. Near the town of Huntley are the ruins of Huntley castle. On the avenue that leads to it, are two large square towers, which had defended the gateway. The castle seems to be very old, and a great part of it is demolished : but there is a massy building of a more modern date, in which some of the apartments, and in particular, their curious ceilings, are still in tolerable preservation They are painted with a great variety of subjects, in small divisions, in which are contained many emblematical figures.

Besides these remains of Roman, Pictish, Danish, and-Scottish antiquities, many Druidical monuments and temples are discernible in the northern parts of Scotland, as well as in the isles, where we may suppose their paganism took its last refuge. They are easily perceived by their circular forms; but though they are equally regular, yet none of them are on so large a scale as the Druidical erections in South Britain. There is in Perthshire a barrow, which seems to be a British erection, and the most beautiful of the kind, perhaps, in the world. It exactly resembles the figure of a ship, with the keel uppermost. The common people call it Ternay, which some interpret to be terre navis, the ship of earth. It seems to be of the most remote antiquity, and, perhaps, was erected to the memory of some British prince, who acted as auxiliary to the Romans; for it is situate near Auchterarder, not many miles distant from the great scene of Agricola's operations.

Histony.... Tliough the writers of ancient Scottish history are too fond of fable, yet it is easy to collect from the Roman authors, and other evidences, that Scotland was formerly inhabited by different people. The Caledonians appear to have been the first inhabitants; the Picts probably were the Britons, who were forced northwards by the Belgic Gauls, about fourscore years before the descent of Julius Cæsar, and who settling in Scotland, were joined by great numbers of their countrymen, that were driven northwards by the Romans. The tract lying southward of the Forth appears to have been innabited by the Saxons, and by the Britons, who formed the kingdom of Alcuith, the capital of which was Dumbarton: but all these people, in process of time, were subdued by the Scots.

It does not appear that the Caledonians, the ancient Celtic inhabitants of Scotland, were attacked by any of the Roman generals before Agricola, anno 79. The name of the prince he fought with was Galdus, by Tacitus, named Galgacus; and the history of that war is not only transmitted with great precision, but corroborated by the remains of the Roman encampments and forts, raised by Agricola, in his march toward Dunkeld, the capital of the Caledonians. The brave stand made by Galdus against that great general, does honour to the valour of both people; and the sentiments of the Caledonian, concerning the freedom and independency of his country, appear to have warmed the noble historian with the same generous passion. It is evident, however, that Tacitus thought it for the honor of Agricola to conceal some parts of this war; for though he inakes his countrymen victorious, yet they certainly returned southward to the provinces of $\mathrm{Ho}$ resti; which was the county of Fife, without improving their advantage. 
Galdus, otherwise called Corbred, was, according to the Scottish historians, the twenty-first in a lineal descent from Fergus I, the founder of their monarchy; and though this-genealogy has been disputed, yet nothing can be more certain from the Roman histories, than that the Caledonians, or Scots, were governed by a succession of brave and wise princes, during the abode of the Romans in Britain. Their valiant resistance obliged Agricola himself, and, after him, the emperors Adrian and Severus, to build the two famous prætentures or walls, one between the Friths of Clyde and Forth, already mentioned, and the other between Tinmouth and the Solway-Frith, which is described in our account of England, to defend the Romans from she Caledonians and Scots; and which prove that the independence of the latter was never subdued.

Christianity was introduced into Scotland about the year 201 of the Christian æra, by Donald I. The Picts had at this time gained a footing in Scotland; and being often defeated by the ancient inhabitants, joined the Romans against the Scots and Caledonians, who were of the same original, and considered themselves as one people; so that the Scots monarchy suffered a short eclipse; but it broke out with more lustre than ever, under Fergus II, who recovered his crown; and his successors gave many severe overthrows to the Romans and Britons.

When the Romans left Britain in 448, the Scots, as appears by Gildas, a British historian, were a powerful nation, and, in conjunc= tion with the Picts, invaded the Britons; and having forced the Roman walls, drove them to the very sea; so that the Britons applied to the Romans for relief; and in the famous letter, which they called their groans, they tell them, that they had no choice left, but that of being swallowed up by the sea, or perishing by the sword of the barbarians : for so all nations were called who were not Romans, or under the Roman protection.

Dongard was then king of Scotland; and it appears from the oldest histories, and those that are least favourable to monarchy, that the succession to the crown of Scotland still continued in the family of Fergus, but generally descended collaterally; till the inconveniences of that mode of succession were so much felt, that by degrees it fell into disuse, and it was at last settled in the descending line.

About the year 796, the Scots were governed by Achaius, a prince so much respected, that his friendship was courted by Charlemagne, and a league was concluded between them, which continued inviolate while the monarchy of Scotland had an existence. No fact of equal antiquity is better attested than this league, together with the great service performed by the learned men of Scotland, in civilizing the vast clominions of that great conqueror, as has been already observed under the article Literature. The Picts still remained in Scotldud, as a separate nation, and were powerful enough to make war upon the Scots; who, about the year 843, when Kenneth Mac Alpin was king of Scotland, finally subdued them; but not in the savagc manner mentioned by some historians, by extermination; for he obliged them to incorporate themselves with their conquerors, by taking their names, and adopting their laws. The successors of Kenneth Mac Alpin maintained almost perpetual wars with the Sax * ons on the southward, and the Danes and other barbarous nations towards the east; who, being masters of the sea, harassed ihe Scots by powerful invasions. The latter, however, were more fortunate than

Vou. 1 .

$\mathrm{P} p$ 
the English : for while the Danes were erecting a monarchy in England, they were everywhere overthrown in Scotland by bloody battles, and at last driven out of the kingdom. The Saxon and Danish monarchs, who then governed England, were not more successtul against the Scots, who maintained their freedom and independency, not oniy against foreigners, but against their own kings, when they thought them endangered. The feudal law was introduced among them by Malcolm II.

Malcolm III, conmonly called Malcolm Canmore, from two Gaelic words which signify a large head, but most probably froin his great capacity, was the eighty-sixth king of Scotland, from Fergus I, the supposed founder of the monarcily; the forty-seventh from its restorer, Fergus II ; and the iwenty-second from Kenneth III, who conquered the kingdom of the Picts. Every reader who is acquainted with the tragedy of Macbeth, as written by the inimitable Siakspeare, who keeps close to the facts delivered by historians, can be no stranger to the fate of Malcoln's father, and his own history, previous to his mounting the throne in the year 1057. He was a wise and magnanimous prince, and in no respect inferior to his cotemporary the Norman conqueror, with whom he was often at war. He married Margaret, daughter to Edward, surnamed the Outlaw, son to Edimund Ironside, king of England. By the death of her brother, Eugar Atheling, the Saxon right to the crown of England devolved upon the posterity of that princess, who was one of the wisest and worthiest women of the age ; and her daughter Maud was accordingly married to Henry I, of England. Malcolm, after a glorious reign, was killed, with his son, treacherously, it is said, at the siege of Alnwick, by the besieged.

Malcolm III, was succeeded by his brother Donald VII, and he was dethroned by Duncan II, whose legitimacy was disputed. They were succeeded by Edgar, the son of Malcolm III, who was a wise and valiant prince; he was succeeded by Alexander I, and, upon his death, David I, mounted the throne.

David was one of the greatest princes of that age, whether we regard him as a man, a warrior, or a legislator. To him Henry II, the mightiest prince of his age, owed his crown; and his possessions in England, joined to the kingdom of Scotland, placed Davil's power nearly on an equality with that of England. The code of laws drawn up by him, do his memory immortal honour. They are said to have been compiled under his inspection, by learned men, whom he assembled from all parts of Europe, in his magnificent abbey of Melross. He was succeeded by his grandson, Malcolm IV, and he by William, surnamed from his valour, The Lion. William's son, Alexander II, was succeeded, in 1249 , by Alexander III, who was a good king. He married, first, Margaret, daughter to Henry III, of England, by whom he had Alexander, the prince who married the earl of Flanders's daughter; David; and Margaret, who married Hangowan, or, as some call him, Eric, son to Magnus IV, king of Norway, who bore to hin a daughter named Margaret, commonly called the Maiden of Norway : in whom king William's whole posterity failed; and the crown of Scotland returned to the descendants of David, earl of Huntingdon, brother to king Malcolm IV, and king William.

This detail has been given, because it is connected with great events. Upon the death of Alexander III, John Baliol, who was great grandson to David, earl of Huntingdon, by his eldest daughter Mar- 
garet; and Robert Bruce, grandfather to the great king Robert B uice, grahdson to the same earl of Huntingdon, by his youngest datignter, Isabel; became competitors for the crown of Scotland. The laws of succession, which were not so well established in Europe as they are at present, rendered the case very difficult. Both parties were almost equally matched in interest; but after a confused interregnum of some ycars, the great nobility agreed in referring the de. cision to E ward I, of England, the most politic and ambitious prince of his age $H e$ accepted the office of arbiter: but having long had an eye to the crown of Scotland, he revived some obsolete absurd claims of its dependency upon that of England; and, finding that Baliol was disposed to hold it by that disgraceful tenure, he awarded it to him; but afterwards dethroned him, and treated him as a slave, without Baliol's resenting it.

After this, Eciward used many endeavours to annex the crown of Scoiland to his own; which were often defeated; and though for a short time he made himself master of Scotland, yet the Scots were ready to revolt against him on every favourable opportunity. Those who were so zealously attached to the independency of their country, as to be resolved to hazard every thing for it, were indeed but few, compared to those in the interest of Edward and Baliol, which was the same: and for some time they were obliged to temporise. Edward avaiied himself of their weakness and his own power. $\mathrm{He}$ accepted of a formal surrender of the crown of Baliol, to whom he allowed a pension, hut detained him in England; and sent every no. bleman in Scotland, whom he in the least suspected, to different prisons in or near London. He then forced the Scots to sign instru. ments, acknowledging their subjection to him; and most barbarously carried off or destroyed all the monuments of their history, and the evidence of their independency : and particularly the famous fatidical or prophetic stone, which is still to be seen in Westminster Ab. bey.

These severe proceedings, while they rendered the Scots sensible of their slavery, revived in them the ideas of their freedom; and Edward, finding their spirits were not to be subdued, endeavoured to caress them, and affected to treat them on a footing of equality with his own subjects, by projecting a union, the clief articles of which have since taken place between the two kingdoms. The Scotch patriots treated this project with disdain, and united under the brave Willian IVallace to expel the English. Wallace performed actions that entitled him to eternal renown, in executing this scheme. Being, however, nu more than a private gentleman, and his popularity daily increasing, the Scotch nobility, among whom was Robert Bruce, the son of the first competitor, began to suspect that he had an eye upon the crown: especially after he had defeated the earl of Surry, Edward's viceroy of Scotland, in the battle of Stirling; had recluced the garrisons of Berwick and Roxburgh; and was declared by the states of scotland their protector. Their jealousy operated so far, that they formed violent cabals against the brave Wallace. Edward, upon this, once more invaded Scotland, at the head of the most numerous and best disciplined army England had ever seen; for it consisted of 80,000 foot, 3000 horsemen, completely armed, and 4000 light-armed; and was attended by a fleet to supply it with provisions. These, besides the troops who joined him in Scotland, formed an irresistible body; Edward, however, was obliged to divide it, reserw. 
ing the command of 40,000 of his best troops to himself. With these he attacked the Scotch army, under Wallace, at Falkirk, while their disputes ran so high, that the brave regent was deserted by Cumming, the most powerful nobleman in Scotland, and at the head of the best division of his countrymen. Wallace, whose troops did not exceed 50,000 , being thus betrayed, was defeated with vast loss, but made an orderly retreat; during which he found means to have a conference with Bruce, and to convince him of his error in joining with Edward. Wallace still continued in arms, and performed many gallant actions against the English; but was betrayed into the hands of Edward, who most ungenerously put him to death at London, as a traitor. Edward died as he was preparing to renew his invasion of Scotland, with a still more desolating spirit of ambition, after having destroyed 100,000 of her inhabitants.

Bruce died soon after the battle of Falkirk, but not before he had inspired his son, who was a prisoner at large about the English court, with the glorious resolution of vindicating his own rights, and the independence of his country." He escaped from London, and with his own laand killed Cumming, for his attachment to Edward; and after collecting a few patriots, among whom were his own four brothers, he assumed the crown, but was defeated by the English, who had a great army in Scotland, at the battle of Methven. After his defeat, he fled with one or two friends to the western isles'and parts of Scotland, where his fatigues and sufferings were as extreme, as the courage with which he and his few friends bore them, the lord Douglas, especially, was incredible. Though his wife and daughters were sent prisoners to England, where the best of his friends and two of his brothers were put to death, yet such was his persevering spirit, that he recovered all Scotland, excepting the castle of Stirling, and improved every advantage that was given him by the dissipated conduct of Edward II; who raised an army more numerous and better appointed than that of his father, to make a total conquest of Scotland. It is said that it consisted of 100,000 men, though this has been supposed to be an exaggerated computation: however, it is admitted, that the army of Bruce did not exceed 30,000 ; but all of them veterans, who had been bred up in a detestation of tyranny.

Edward, who was not deficient in courage, led his powerful army towards Stirling, then besieged by Bruce, who had chosen, with the greatest judgment, a camp near Bannockburn. The chief officers under Edward were, the earls of Gloucester, Hereford, Pembroke, and sir Giles Argenton. Those under Bruce were, his own brother sir Edward, who, next to himself, was reckoned to be the best knight in Scotland; his nephew, Randolph, earl of Murray; and the young lord Walter, high steward of Scotland. Edward's attuck of the Scotch army was exceedingly furious, and required all the courage and firm. ness of Bruce and his friends to resist it, whic! they did so effectual$1 y$, that they gained one of the most complete victories that is recorded in history. The great loss of the English fell upon the bravest part of their troops, who were led on by Edward in person against Bruce himself. The Scotch writers make the loss of the English amount to 50,000 men. There certainly never was a more total defeat, though the conquerors lost 4000 . The fower of the English nobility were either killed or taken prisoners. Their camp, which was immensely rich, and calculated for the purpose rather of a triumph than a campaign, fell into the hands of the Scots; and Edward him: 
self, with a few followers, was pursued by Douglas to the gates of Berwick, from whence he escaped in a fishing-boat. This great and decisive battle happened in the year 1314 .

The remainder of Robert's reign was a series of the most glolious successes; and so well did his nobility understand the principles of civil liberty, and so unfettered were they by religious considerations, that, in a letter they sent to the pope, they acknowledged that they had set aside Baliol for debasing the crown, by holding it of England; and that they would do the same by Robert, if he should make the like attempt. Robert, having thus delivered Scotland, sent his brother Edward to Ireland, at the head of an army, with which he conquered the greatest part of that kingdom, and was proclaimed its king; but by exposing himself too much, he was killed. Robert, before his death, made an advantageous peace with England; and died in 1328, with the character of being the greatest hero of the age.

The glory of the Scots may be said to have been in its zenith under Robert I, who was succeeded by his son David II. He was a virtuous prince; but his abilities, both in war and peace, were eclipsed by his brother-in-law and enemy, Edward III, of England, whose sister he married. Edward, who was as eager, as any of his predecessors to effect the conquest of Scotland, espoused the cause of Baliol, son to Baliol the original competitor. His progress at first was amazingly rapid, and he and Edward defeated the royal party in many bloody battles; but Baliol was at last driven out of his usurped kingdom by the Scottish patriots. David had the misfortune to be taken prisoner by the English at the battle of Durham; and, after continuing above eleven years in captivity, paid 100,000 marks for his ransom; and died in peace, without issue, in the year 1371.

The crown of Scotland then devolved upon the family of Stuart, by its head having been married to the daughter of Robert $I$. The first king of that name was Robert II, a wise and brave prince. He was succeeded by his son Robert III, whose age and infirmities disqualified him from reigning; so that he was forced to confide the government to his brother, the duke of Albany, an ambitious prince, who seems to have had an intention to procure the crown for his own family. Robert, upon this, attempted to send his second son to France; but he was most ungenerously intercepted by Henry IV, of England; and, after suffering a long captivity, he was obliged to pay an exorbitant ransom. During the imprisonment of James in England, the military glory of the Scots was carried to the greatest height in France; where they supported that tottering monarchy against England, and their generals obtained some of the first titles of the kingdom.

James, the first of that name, upon his return to Scotland, discovered great talents for government, enacted many wise laws, and was belored by the people. He had received an excellent education in England during the reigns of Henry IV, and V, where he saw the feudal system refined from many of the imperfections which still ad. hered to it in his own kingdom; he determined therefore to abridge the overgrown power of the nobles, and to recover such lands as hat been unjustly wrested from the crown during his minority and the preceding reigns : but the execution of these desigus cost him his life; he being murdered in his bed by some of the chief nobility in 1437, and the forty-fourth year of his age. 
A long minority succeeded; but James II, would probably have equalled the greatest of his ancestors both in warlike and civil virtues, had he not beeri suddenly killed by the accidental bursting of a cannon, in the thirtieth year of his age, as he was besieging the castle of Roxburgh, which was defended by the English.

Suspicion, indolence, immoderate attachment to females, and many of the errors of a feeble mind, are visible in the conduct of James III ; and his turbulent reign was closed by a rebellion of his subjects, beirig slain in battle in 1488, aged thirty-five.

His son, James IV, was the most accomplished prince of the age: he was naturally generous and brave : he loved magnificence, he delighted in war, and was eager to obtain fame. He encouraged and protected the commerce of his subjects, so that they greatly increased in riches; and the court of James, at the time of his marriage with the daughter of Henry VII, was splendid and respectable. Even this ailiance could not cure him of his family distemper, a predilection for the French; into whose cause he rashly entered, and was killed, with the flower of his nobility, by the English, in the battle of Flowden, anno 1513, and the fortieth of his age.

The minority of his son, James V, was long and turbulent : and when he grew up, he married two French ladies; the first being daughter to the king of France, and the latter of the house of Guise. He iustituted the court of session, enacted many salutary laws, and greatly promoted the trade of Scotland, particularly the working of the mines. At this time the balance of power was so equally poised between the contending princes of Europe, that James's friendship was courted by the pope, the emperor, the king of France, and his uncle Henry VIII, of England, from all of whom he received magnificent presents. But James took little share in foreign affairs; he seemed rather to imitate his predecessors in their attempts to humble the nobility: and the doctrines of the reformation beginning to be propagated in Scotland, he permitted, at the instigation of the cler$\mathbf{g y}$, a religious persecution; though it is generally believed, that, had he lived longer, he would have seized all the church revenues, in imitation of Henry. Having rather slighted some friendly overtures made to him by the king of England, and thereby given great um. brage to that prince, a war at length broke out between them. A large army, under the command of the duke of Norfolk, entered Scotland, and ravaged the country north of the Tweed. After this short expedition, the Finglish army retired to Berwick. Upon this the king of Scotland sent ten thousand men to the western borders, who entered England at Solway-Frith; and he himself followed them at a small distance, ready to join them upon occasion. He soon after gave great offence to the nobility and the army, by imprudently depriving their general, lord Maxwell, of his commission, and conferring the command on Oliver Sinclair, a private gentleman, who was his favourite. The army were so much disgusted with this alteration, that they were ready to clisband, when a small body of English horse appeared, not exceeding five hundred. A panic seized the Scots, who immediately took to flight, supposing themselves to be attacked by the whole body of the English army. The English horse, seeing them flee with such precipitation, closely pursued them, and slew great numbers; taking prisoners seven lords, two hundred gentlemen, and eight hundred soldiers, with twenty-four pieces of ordnance. This disaster so much affected ling James, that it threw 
him into a fit of illness, of which he soon after died, on the 14th of December, 1542 .

His daughter and successor, Mary, was but a few hours old at the lime of her father's death. Her beauty, her misconduct, and her misfortunes, are alike famous in history. It is sufficient here to say, that during her minority, and while she was wife to Francis II, of France, the reformation advanced in Scotland; that being called to the throne of her ancestors while a widow, she married her own cousin-german, the lord Darnley, whose untimely death has given rise to so much controversy. The consequence of her husband's death, and of her marriage with Bothwell, who was considered as his murderer, was an insurrection of her subjects, from whom she fled into England, where she was ungenerously detained a prisoner for eighteen years, and afterwards, on motives of state policy, beheaded, by queen Elizabeth, in 1587, in the forty-sixth year of her age.

Mary's son, James VI, of Scotland, succeeded, in right of his blood, from Henry VII, upon the death of queen Elizabeth, to the Euglish crown, after manifesting considerable abilities in the government of Scotland. This union of the two crowns, in fact, destroyed the independency, as it impoverished the people of Scotland: for, the seat of government being removed to England, their trade was checked, their agriculture neglected, and their gentry obliged to seek for, situations in other countries. James, after a splendid but troublesome reign over his three kingdoms, left them, in 1625, to his son, the unfortunate Charles I. That prince, by his despotic principles and conduct, induced both his Scottish and English subjects to take up arms against him; and, indeed, it was in Scotland that the sword was first drawn against Charles. But when the royal party was totally defeated in England, the king put himself into the power of the Scottish army; they at first treated him with respect, but afterwards delivered him up to the English pariiament, on condition of their paying 400,000 pounds to the Scots, which was said to be due to them for arrears. However, the Scots afterwards made several bloody but unsuccessful attempts to restore his son, Charles II. That prince was finally defeated by Cromwell, at the battle of Worcester, in 1651; after which, to the time of his restoration, the commonwealth of England and the protector gave law to Scotland.

The state of parties in England, at the accession of queen Anne, was such, that the Whigs once more had recourse to the Scots, and offered them their own terms, if they would agree to the incorporate union as it now stands. It was long before the majority of the Scotch parliament would listen to the proposal; but, at last, partiy from conviction, and partly through the effects of money distributed among the needy tiobility, it was agreed to; since which event, the history of Scotland becomes the same with that of England. 


\section{ISLES OF SCOTLAND.}

THE Isles of Scotland consist of three clusters; the Hebrides, or Western Islands, the Orkneys, and the Islands of Shetland.

The WESTERN ISLANDS, or HEBRIDES, are situate on the north-west coast of Scotland, between 35 and $59 \mathrm{deg}$. of north latitude, and are supposed to exceed 300 in number; but there are not more than thirty whose sizes render them deserving notice. Of these the principal are Arran, Ilay, Jura, Mull, Skye, Lewis, and Har. ris, which form one island; North Uist, and South Uist, Iona, os Icolm-kill, Staffa, and Hirta, or St. Kilda.

The isle of Arran is about twenty-four miles in length, and where widest about fourteen in breadth. It consists chiefly of a series of rough and broken mountains, from one of the highest summits of which, named Goatfell, in the centre of the island, the view extends at once to Ireland and the Isle of Man, and even into South Britain. There are several rivulets and four or five lakes of fresh water in this island. The number of inhabitants is about 7000 , and the chief place the village of Ranza. This island, with the island of Bute, which is about twelve miles long, and four broad, and some others of inconsiderable size, constitute the county or shire of Bute. The chief kown of Bute is Rothsay, which has a castle, and gave the title of duke to the eldest sons of the kings of Scotland, as it now does to the prince of Wales. Rothsay is likewise a royal burgh. The number of inhabitants in the island of Bute is about 4000 .

The island of Ilay is twenty-four miles long, and nearly eighteen broad. The soil is good, and might by industry be rendered extremely productive. The whole island is the property of Mr. Campbell of Shawfield. A lead mine was cliscovered here in 1763. The number of inhabitants is about 7000 .

Jura, about thirty miles long, and seven or eight broad, is separated from Ilay by a narrow sound, from one to four miles broad. It is one of the most rugged of the Western Islands, which are in general mountainous. The mountains called the Paps of Jura, which are a range of eminences of a conical form, present a singular appearance. One of them has been found to have an elevation of 850 yards, though it is greatly exceeded in height by the loftiest, named Ben-an-Oir. The number of inhabitants is supposed to be not more than 1000.

The isle of Mull is nearly thirty miles long, and in some places almost as broad. It is very rugged and mountainous, like the other Western Isles. It contains two parishes, but only one village, named Tobermory, near the northern part of the island, where a fishing sta. tion has lately been erected. There are several ruins of ancient cas-

* Anciently called the Hebudes. The origin of the modem name Hebrides is not known, except it be a corruption of Hebudes. 
tles in this island. The number of inhabitants is between five and six thousand.

The isle of Skye is the largest of the Hebrides, being about fifty miles in length, and in some places above twenty broad. It abounds, especially in the interior parts, in rocks, mountains, and bogs. The inhabitants are about 15,000 in number. This island forms a part of Inverness-shire.

Long island, to the westward of Skye, consists of two peninsulas, the northern of which is denominated Lewes, and the southern Harris. The extent of both these together is about ninety miles in length, and ten or twelve, and in some parts twenty miles in breadth. The isles of North Uist, South Uist, and Barra, continue this chain of islands to the south 110 miles more, including about sixteen miles of water. The number of inhabitants in them all is about 20,000; the only town is Stornoway, in the east part of Lewes, a considerable and flourishing place, with an excellent harbour, and containing above 2000 inhabitants. At the village of Classerness, in the southern part of the same peninsula, is a Druidical temple, as well preserved and perfect, though not of such large dimensions, as that of Stonehenge.

The celebrated island of Iona, or Hyona, called also $\mathrm{Hui}$, or $\mathrm{Hy}$, and I Coluim Kill, or the Isle of Columba's church, seems to have served as a sanctuary for St. Columba, and other holy men of learning, while Ireland, England, and Scotland, were desolated by barbarism. The church of St. Mary, which is built in the form of a cathedral, is a beautiful fabric. It contains the bodies of some Scotch, Irish, and Norwegian kings, with some Gaelic inscriptions. The tomb of Columba, who lies buried here, is uninscribed. The steeple is large, the cupola is twenty-one feet square, the doors and windows are curiously carved, and the altar is of the finest marble. Innumerable are the inscriptions of ancient customs and ceremonies that are discernible upon this island, and which give countenance to the well-known observation, that when learning was nearly extinct on the continent of Europe, it found a refuge in Scotland, or rather in these islands.

Staffa, situate ten miles to the north-east of Iona, is a small island, only one mile long, and half a mile broad, and inhabited by a single family. It is however, remarkable, for consisting of one entire pile of basaltic pillars, arranged in natural colonnades, wonderfully magnificent. Mr. Banks, now sir Joseph Banks, in relating his voyage through the Hebrides, in 1772, says: "We were no sooner arrived than we we: struck with a scene of magnificence which exceeded our expectations, thoufh founded, as we thought, upon the most sanguine foundations : the whole of that end of the island (Staffa) supported by ranges of natural pillars, mostly above fifty feet high, standing in natural colonnades, according as the bays or points of land formed themselves; upon a firm basis of solid unformed rock, above these, the stratum which reaches to the soil or surface of the island, varied in thickness as the island itself formed into hills or vallięs; each hill, which hung over the columns below, forming an ample pediment; some of these, above sixty feet in thickness from the base to the point, formed by the sloping of the hill on each side, almost in the shape of those used in architecture."

The cave of Fingal, a vast and magnificent cavern in this island, 371 feet long, 53 broad, and 117 high, composed of such pillars, is

Yoz.I. 
thus described by Mr. Banks. "We proceeded along the shore, treading upon another Giant's Causeway, every stone being regularly formed into a certain number of sides and angrles; till, in a short. time, we arrived at the mouth of a cave, the most magnificent, I suppose, that has ever been described by travellers. The mind can hardly form an iciea more magnificent, than such a space, supported on each side by ranges of columns, and roofed by the bottoms of those which have oeen broken off in order to form it, between the angles of which, a yellow stalagmatic matter has exuded, which serves to deñne the angles precisely, and at the same time vary the colour, with a great deal of elegance; and to render it still more agreeable, the whole is lighted from without; so that the farthest extremity is very plainly seen from without; and the air within, being agritated with the flux and reflux of the tide, is perfectly dry and wholesome, free entirely from the damp of vapours, with which natural caverns in general abound."

To the north-west of Mull are the islands, of Tirey and Col ; the former of which produces a beautiful marble of a rose colour. Tirey is level and fertile, but Col is rocky, or rather, as Dr Johnson has observed, one continued rock, covered with a thin layer of earth. This latter island is about thirteen miles long, and three broad, and contains about 800 inhabitants.

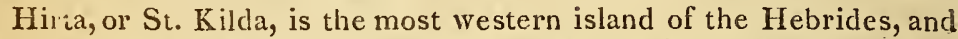
is three miles long, and two broad. The soil is fertile, but the arable land scarcely exceeds eighty acres, though by industry more might be added. The mountain or rock of Congara, in this island, is accounted the Teneriff of the British islands, its height above the level of the sea being 1800 yards. The whole island is surrounded with the most tremendous rocks, and has only one landing place, and even there it is impossible to land, except in calm weather. About twentyseven families reside here, in a small village on the castern side of the island. These people display the most astonishing courage and dexterity in climbing the dreadful precipices in quest of sea fowls and their eggs, which furnish them with food during a great part of the year. The multitudes of these bircis are prodigious, the rocks round the island being so covered with them that they appear like mountains covered with snow; yet they so entirely disappear in November, that from the middle of that month to the middle of February not one is to be seen. The people of the Hebrides are clothed and live like the Scotch Highlanders. They are similar in persons, constitutions, customs, and prejudices; but with this difference, that the more polished manners of the Lowlanders are every day gaining ground in the Highlands. Perhaps the descendants of the ancient Caledonians, in a few years, will be discernible only in the Hebrides.

Those islands alone retain the ancient usages of the Celts, as des. cribed by the oldest and best authors; but with a strong tincture of the feudal constitution. Their shanachies, or story tellers, supply the place of the ancient bards, so famous in history; and are the historians, or rather genealogists, as well as poets, of the nation and family. The chief is likewise attended, when he appears abroad, with his musician; who is generally a bagpiper, and dressed in the manner of the English minstrels of former times, but, as it is said, much more sumptuously. Notwithstanding the contempt into which that music is fallen, it is almost incredible with what care and attention it was cultivated among these islanders so late as the beginning 
of the last century. They had regular colleges and professors, and the students took degrees according to their proficiency. Many of the Celtic rites, some of which were too barbarous to be retained, or even mentioned, are now abolished. The inhabitants, however, still preserve the most profound respect and affection for their several chieftains, notwithstanding all the pains that have been taken by the British legislature to break those connexions, which experience has shown to be so dangerous to government. The common people are but little better lodged than the Norwegians and Laplanders : though they certainly fare better; for they have oatmeal, plenty of fish and fowl, cheese, butter, milk and whey ; and also mutton, beef, goat, kid, and renison. They indulge themselves, like their forefathers, in a romantic poetical turn; and the agility of both sexes in the exercises of the field, and in dancing to their farourite music, is remarkable.

The inhabitants of the Hebrides, particularly of the isle of Skye, formerly pretended, at least many of them, to the power of foreknowing future events by what was termed the second sight. 'This gift, which in the Erse language is called Taish, is supposed to be a supernatural faculty of seeing visions of events before they happen. Many extraordinary stories in support of this clelusion are related in these islands, and some of them have been vouched by persons of sense, character, and learning. The adepts of the second sight pretend that they have certain revelations, or rather presentations either really or typically to their eyes, of certain events that are to happen in the compass of twenty-four or forty-eight hours. We do not, however, from the best information, observe that any two of those adepts agree as to the manner and form of those revelations, or that they have any fixed method for interpreting their typical appearances. The truth seems to be, that those islanders, by indulging themselves in lazy habits, acquire visionary ideas, and overheat their imaginations, till they are presented with those phantasms, which they mistake for fatidical or prophetic manifestations. They instantly begin to prophesy; and it would be absurd to suppose, that, amidst many thousand predictions, some may not happen to be fulfilled; and these, being well attested, give a sanction to the whole.

Many learned men have been of opinion, that the Hebrides being the most westerly islands where the Celts settled, their language must remain there in its greatest purity. This opinion, though very plausible, has failecl in experience. Many Celtic words, it is true, as well as customs, are there found : but the vast intercourse which the Hebrides had with the Danes, the Norwegians, and other northern people, whose language has no affinity with the Celtic, has rendered. their language a compound; so that it approaches in no degree to the purity of the Celtic, commonly called Erse, which was spoken by their neighbours in Lochaber and the opposite coasts of Scotland, the undoubted descendents of the Celts, among whom their language remains more unmixed.

The religion professed in the Hebricles is chiefly presbyterian, as established in the church of Scotland: but popery and ignorance are still but too prevalent.

The ORKNEY ISLANDS, anciently the Orcades, lie to the north of Dungsby-liead, between $58^{\circ} 48^{\prime}$ and $59^{\circ} 20^{\prime}$ of north latitude; being separated from the most northern part of Scotland by a tempestuous strait called the Pentland Frith, twenty-four miles long and twelve broad. They are nearly eighty in number, but only twenty-six are 
inhabited, the rest consisting of what are called holms and skerries; the former of which are islands entirely consigned to pasturage, and the latter barren rocks.

The largest of the Orkney islands is Pomona, called also the Mainland. Its length is about twenty-four miles, and its breadth in some places nine, in others only two, as it is of an extremely irregular figure. It contains four excellent harbours, one of which is that of Kirkwall, the principal town in the island, and the capital of the Orkneys. This town extends nearly a mile in length, but contains only about three hundred houses. The cathedral of Kirkwall is a fine Gothic building, dedicated to St. Magnus, but now converted into a parish church. Its roof is supported by fourteen pillars on each side; and its steeple, in which is a good ring of bells, by four large piliars. The three gates of the church are chequered with red and white polished stone, embossed and elegantly flowered. The whole island is divided into nine parishes.

The other principal islands of this group are South Ronaldsha, Hoy, Sanda, Westra, and North Ronaldsha.

South Ronaldsha is one of the most fertile of the Orkneys : it is about seven miles long, and from two to five broad. Hoy is about ten miles in length, and four or five in breadth; and at high tide is. divided into two islands, the southern, named Waes or Walis, and the northern, Hoy. In this island is a mountain called Wart-hill, the height of which is estimated at 1620 feet, the summit of which, in the months of May, June, and July, shines and sparbles in an extraordinary manner when seen at a distance, though this brightness disappears on a nearer approach. The peasants on this account call it the enchanted carbuncle. The cause of this phenomenon has been suspected to be the reflection of the rays of the sun from some water; but no such water, when sought for, has been discovered. In a dark valley of Hoy is a kind of hermitage cut out of stone, called the dwarfie stone, thirty-eight feet long, eighteen broad, and nine thick; in which is a square hole, about two fect high, for an entrance, with a stone of the same size for a door. Within this entrance is the resemblance of a bed, with a pillow cut out of the stone, large enough for two men to lie on : at the other end is a couch, and in the middle a hearth, with a hole cut out above for a chimney. The island of Sanda is twelve miles long, from one to three broad, and of an extremely irregular form. Westra is eight miles long, and two broad. North Ronaldsha, the most northern of these islands, is only about three miles in length and one in breadth.

The number of inhabitants in the Orkneys is computed at 25,000. They consist of the mixed descendants of Norwegian colonists and Lowland Scots. The town of Kirkwall has so much trade, that in 1790 the exports werc estimated at 26,598l. and the imports at $20,803 l$. The exports consist of beef, pork, butter, tallow, hides, salted fish, linen yarn, coarse linen cloth, and kelp, of which the island of Sanda in particular produces great quantities; and the imports of coal, wood, sugar, spirits, wines, tobacco, snuff, hardware, printed linens and cottons, scc. The manufactures are linen yarn, coarse linen, and kelp. The language spoken here was formerly the Norse, or Norwegian; but this is now superseded by the English, or that of the Lowland Scots.

The SHETLAND ISLES are situate about twenty leagues to the 'north-east of the Orkneys, between lat. $59^{\circ} 45^{\prime}$ and $61 \% 10^{\prime}$ north. 
Tley are reckoned to be forty-six in number, besides about thirty holms and forty skerries. The principal of them is, as in the Orkneys, called the Mainland, which island is about 57 miles in length, and 10 or 12 in breadth; but is so broken by creeks and inlets, that scarcely any part of it is distant more than two miles from the sea. These inlets form at least 20 harbours, six of which are very spacious and commodious. The town of Lerwick, the only town of these islands, stands on the eastern side of Mainland, opposite the harbour called Brassa-sound, which is capable of containing above 2000 ships commodiously and safely. This town contains about 500 families. Skalloway, on the western side, which was once a town of some importance, is now dwindled into a very inconsiderable village, though the ruins of a castle are still to be seen there, and it is the seat of a presbytery. The other islands of this group present nothing which merits particular notice. Yell, situate to the north-east of Mainland, is 16 miles long, and five or six broad. It contains eight considerable harbours. Unst, at the northern extremity of this group, is eight miles long, and four broad, and has two excellent harbours.

The coasts of all these islands are in general rugged and precipitous, presenting in many places scenes truly grand and magnificent, and their interior is a rugged and bleak scene of barren rocks, with here and there a few scanty portions of cultivated ground. They are at present destitute of trees, though there is reason to believe they were not in former times. The air is keen and salubrious, and many of the natives live to a very great age. From their northern situation they enjoy, during two months in the middle of summer, almost perpetual day; there being sufficient light at midnight, in the months of June and July, for any person to see to read when the sky is clear. In the opposite season of the year the duration of the night is correspondent. Though there is little frost or snow, fogs, rain, storms, and a tempestuous sea, prevent the Shetlanders from having any communication, during the seven or eight winter months, either with the neighbouring islands or other countries. A remarkable instance of this is, that a Scottish fisherman was imprisoned in May, for publishing the account of the prince and princess of Orange being raised to the throne of England the preceding November; and he would probably have been hanged, had not the news been confirmed by the arrival of a ship.

The number of inhabitants in the Shetland islands was computed, in 1798 , at 20,186. Their chief food consists of fish, and variou's kinds of sea-fowl which cover the rocks, and in taking which they display extraordinary address and courage. Agriculture here is in a very low state, oats and bere being the only grain sown. The cattle are rather larger than those in the Orkneys. These islands are famous for a very small breed of horses, which are extremely active, strong, and hardy ; and are frequently employed to draw the carriages of the wealthy and curious of the capital, especially the ladies, on account of their diminutive size and beauty. The trade of the Shetland Isles consists principally in the export of fish, chielly herrings; cod, ling, and torsk or tusk. The Dutch, in time of peace, carry or a great fishery in the neighbourhood of these islands; three thousand busses, or fishing vessels, having been known to be employed by thein. in one season in the herring-fishery, besides those fitted out from Hamburg, Bremen, and other northern parts.

The natives of these islands differ litlle in their character and habits 
from the Lowland Scots, except that their manners are more simple, and their minds less cultivated. Their religion is the protestant, according to the discipline of the church of Scotland; and their civil iustitutions are much the same with those of the country to which they belong.

In some of the northern islands, the Norwegian, which is called the Norse language, is still spoken. Their great intercourse with the Dutch, during the fishing season, renders that language likewise common.

The islands both of Shetland and Orkney were anciently subject to Norway; and were sold in the thirteenth century, by Magnus of Norway, to Alexander, king of Scotland, by whom they were given as fiefs to a nobleman of the name of Speire. After this they were claimed by, and became subject to, the crown of Denmark. Christian I, in the reign of James III, conveyed them in property to the crown of Scotland, as a marriage portion with his daughter Margaret: and all future pretensions were entirely ceded on the marriage of James VI of Scotland with Anne of Denmark. The isles of Shetland and Orkney now form a stewartry, or shire, which sends a member to parliament. 


\section{IRELAND.}

SITUATION AND EXTENT.

Miles.

Length 280$\}$ between $\left\{51^{\circ} 30^{\prime}\right.$ and $55^{\circ} 20^{\prime}$ North latitude.

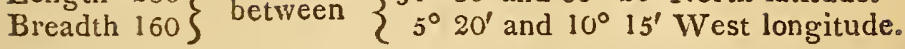

Ireland contains 27,457 square miles, with 145 inhabitants to each.

Name...It appears that Ireland was known to the Greeks by the name of Juverna. The Romans called it Hibernia. In the middle ages it frequently was termed Scotia, which name was transferred to Scotland when the Scuti from Ireland settled in the latter country. The native denomination is Erin, which, it is said, signifies the Land of the West; and from which both the ancient appellation Hibernia, and the modern name Ireland, are probably derived.

BoUNDARIES.... By the boundaries of an island we must be understood to mean the different names given to the sea by which it is surrounded in different parts. Thus Ireland has to the north, west, and south, the Atlantic Ocean: and to the east St. George's Channel, which separates it from WVales; the Irish Sea, which divides it from the English counties of Lancashire and Cumberland; and the North Channel, which separates it from Scotland. The distance from Dublin to Holyhead in North Wales, the usual passage from England, is about 60 miles; but from Donaghadee to the Mull of Galloway in Scotland, it is only about 20 miles.

Divisions....Ireland is divided into four provinces, Leinster, UIster, Connaught, and Munster; which are again subdivided into 32 counties:

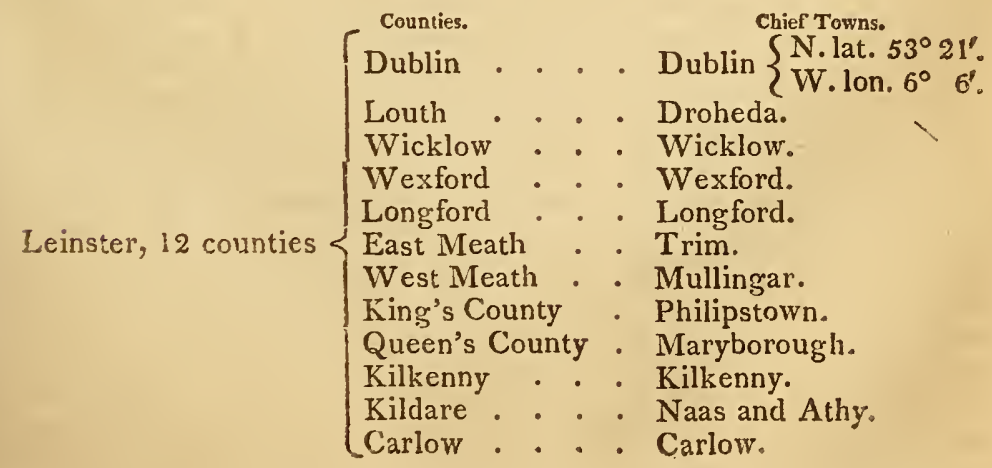




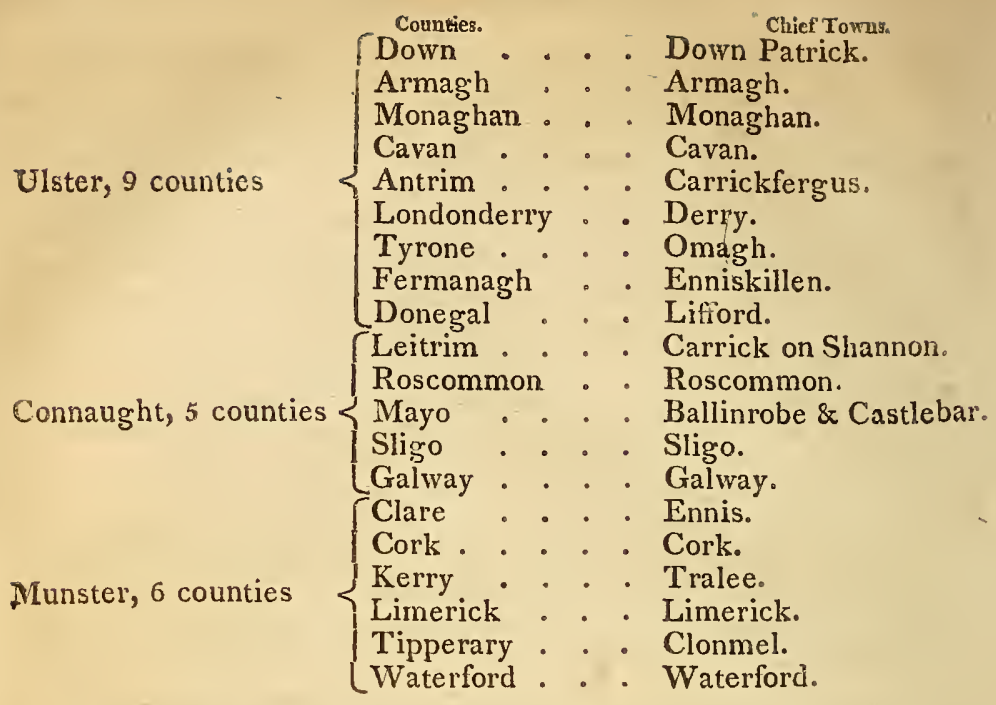

FACE OF THE country....Ireland is, in general, a level country, the tace of which is pleasingly diversified by nature with occasional hills and gentle undulations, and clothed by the mild temperature and humidity of the air with an unfacing verdure. Yet a great part of the island, from the scarcity of trees, and the want of improvement by the cultivation which it seems to invite, presents only a naked aspect.

Mountarss....Ireland, as has been above observed, cannot be considered as a mountainous country, though several chains of high hills are found in different parts. In the county of Down are ridges, called the mountains of Mourne and Iveagh, one of which, Slieve Donard, or Mount Donard, has been calculated at a perpendicular height of 1056 yards. Many other mountains are found in Ireland, which contain beds of minerals, coals, stone, slate, and marble, with veins of iron, lead, and copper.

The mountains Nephin and Croagh Patrick, in the county of Mayo, are 880 yards high. The latter is in the form of an immense cone, and discernible at the distance of 60 miles.

Forests....There were formerly extensive forests in the counties of Donegal, Tyrone, Fermanagh, and Antrim; and considerable woods in those of Wicklow, Wexford, Tipperary, and Cork. But these have now disappeared, or at least have been greatly diminished, partiy by the extension of tillage, and partly by the consumption of them in fuel for domestic uses, and for the iron manufactories. Ireland, however, affords excellent turf and moss, which are of great service for firing, where wood and coals are scarce.

Bocs.... The bogs of Ireland, or, as they are called by the northern Irish, mosses, form a principal feature of this country. They differ from the English morasses in being rarely level, but lising into hills. In Donegal there is a bog which presents a perfect scenery of hill and dale. Many of them are very extensive; that of Allen, notwithstanding it has been much diminished by the reclaiming a great portion of it, still extends seventy miles in length, and is computed to contain 260,000 acres. There are many others of great extent, and 
smaller ones are scattered over the whole island. Where they do not occupy too great a proportion of the land, they are of utility to the inhabitants, by the abundance of fuel which they furnish. The waters of these bogs, far from emitting putrid exhalations, like standing pools and marshes, are of an antiseptic and strongly astringent quality ; as appears from their preserving for ages, and even adding to the durability of, the timber which is found every where buried beneath their surfaces, and from their converting into a kind of leather the skins of men and animals who have had the misfortune of being lost, and remaining in them any length of time.

LAKES... There are in Ireland a great number of lakes, or, as they were formerly called, loughs, particularly in the provinces of Ulster and Connaught. 'The principal are that of Erne, in the county of Fermanagh, which is more than thirty English miles in length, and twelve in its greatest breadth, at its northern extremity; that of Corrib, in the county of Galway, about 20 miles in length, and from 2 to 5 wide; and the great lake Neagh, between the counties of Antrim, Down, and $A$ rmagh, above 18 miles in length, and nine in breadth, and occupying an area of nearly 60,000 Irish, or above 90,000 English acres. The water of the latter lake is said to have a petrifying quality. Some of the Irısh lakes afford the most beautiful and romantic prospects, particularly that of Killarney, which takes its name from a small town in the county of Korry. 'This lake, which may be divided into three, is entirely surroundes with mountains, rocks, and precipices, the immense declivities of which are covered with woods, intermixed with evergreens, from near tr.eir tops to the lakes themselves; among which are a number of sivulets tumbling over the precipices, some from heights of little less than 300 feet. On the top of one of the surrounding mountains is a small round lake, about a quarter of a mile in diameter, called the Devil's Punch Bowl. From the surface of the lake to the top of the cavity, or brim of the bowl, may be about 300 yards; and when viewed from the circular top, it has a most astonishing appearance. The depth of it is vastly great; but not unfathomable, as the natives pretend. The discharge of the superfluous waters of this bowl, through a chasm, into the middle lake, forms one of the finest cascades in the world, visible for 150 yards. The echoes among the hills surrounding the southern parts of the lake, which is mostly inclosed, are equally delightful and astonishing. The proprietor, the earl of Kenmore, has placed some cannon in the most proper places, for the amusement of travellers; and the discharge of these pieces is tremendous, resembling almost the rolling of a violent peal of thunder, which seems to travel the surrounding scenery, and die away among the distant mountains. Here also musical instruments, especially the horn and trumpet, afford the most delightful entertainment, and raise a concert superior to that of a hundred performers. Among the vast and craggy heights that surround the lake, is one stupendous and frightful rock, the front of which towards the water is a most horrid precipice, called the Eagle's Nest, from the number of those birds which have their nests in that place.

Rrvers.... The largest river in Ireland is the Shannon, which issues from Lough-Allen, in the county of Leitrim, serves as a boundary be. tween Connauglit and the three other provinces, and after a course of 350 miles, forming in its progress many beautiful lakes, falls into the Atlantic Ocean, between Kerry-point and Loop-head, where it is nine 
miles broad. The navigation of this river is interrupted by a ridge of rocks spreading quite across it, south of Killaloe; but this might be remedied by a short canal; and communication might also be made with other rivers. The Bann falls into the ocean near Coleraine; the Boyne falls into St. George's Channel at Droheda, as does the Liffey at the bay of Dublin, and is only remarkable for watering. that capital, where it forms a spacious harbour. The Barrow, the Nore, and the Suir, water the south part of the kingdom, and, after uniting their streams below Ross, fall into the channel at Waterford havell.

BAYS AND HARBOURs....But the bays, havens, harbours, and creeks, which every where indent the coast, form the chief glory of Ireland, and render that country, beyond any country in Europe, best fitted for foreign commerce. The nost considerable are those of Carrickfergus, Stangford, Dundrum, Carlingford, Dundalk, Dublin, Waterford, Dungarvan, Cork, Kinsale, Baltimore, Glandore, Dunmanus, Bantry, Kenmare, Dingle, Shannonmouth, Galway, Sligo, Donegal, Killebegs, Lough-Swilly, and Lough-Foyle.

Canals....The improvements of inland navigation have not been unattended to in Ireland. By the canal of Newry a communication is formed between the great lake Neagh and the bay of Carlingford, and by that of Lisburn a navigation is openor between the same lake and the bay of Carrickfergus. Two great canals called the Royal Canal and the Grand Canal, have bern-planied and begun at Dublin; on opposite sides of the river Lirrey. They were intended to form a navigation across the island, from the bay of Dublin to the Shannon. The latter has been carriea above forty miles to the river Barrow, while a branch proceeds in another direction towards the Shannon; but the former was stopped at the bog of Allen, and has long remained unfinished.

METALS aND MTNERALs.... Ireland contains mines of iron, copper, lead, silver, and gold. The latter has been cliscovered within these few years, in the county of Wicklow. It is now worked for government, and it is said that a new and very rich vein has been lately discovered. The silver and lead mine in the county of Antrim yields a pound of pure silver from thirty pounds of lead. There are also silver mines, though not equaliy productive, in the counties of Sligo and Limerick. There is a rich mine of copper at a place called Crone Bawn in the county of Wicklow, and another at Redhills in the county of Kildare. Extensive iron-ivorks have been established within these fcw years, at Arigna, in the county of Leitrim.

Some of the Irish marble quarries contain a kind of porphyry, which is red striped with white. Quarries of fue slate are found in most of the counties. Mines of coal are found in many parts of Ireland, particularly near Castlecomer in the county of Kiikenny; the coal from which being of a hard sort, and proper for the forging of iron, is conreyed, even by land carriage, to very distant parts of the island.

Climate, soIL, AND AGRICULTURE....The climate of Ireland differs net mucin from that of England, excepting that it is more moist, the seasons in general being much wetter. From the reports of various registers, it appears that the number of days on which rain had fallen in Ireland was much greater than in the same years in England. But, in many respects, the climate of Ireland is more agreeable than that of England; the summers being cooler, and the winters less severe 
The piercing frosts, the cleep snows, and the dreadful effects of thunder and lightning, which are so frequently observed in the latter country, are never experienced here.

The moisture abore alluded to, being peculiarly favourable to the growth of grass, has been urged as an argument why the inhabitants should confine their attention to the rearing of cattle, to the total de. sertion of tillage, and consequent injury to the growth of population; but the soil is so infinitely various, as to be capable of almost every species of cultivation suitable to such latitude, with a fertility equal to its variety. This is so conspicuous, that it has been observed by Mr. Young, that "natural fertility, acre for acre, over the two kingdoms, is certainly in favour of Ireland ; of this there can scarcely be a doubt entertained, when it is considered that some of the more beautiful, and even the best cultivated countics in England, owe almost every thing to the capital, art, and industry, of its inhabitints."

"The circumstance which strilses me as the greatest singularity of Ireland," adds the same respectable traveller, "is the rockiness of the soil, which should seem at first sight against that degree of fertility ; but the contrary is the fact. Stone is so general, that I have good reason to believe the whole island is one vast rock, of different strata and kinds, rising out of the sea. I have rarely heard of any great depths being sunk without meeting with it. In general it ap. pears on the surface in every part of the kingtiom : the flattest and most fertile parts, as Limerick, Tipperary, and Meath, have it at no great depth, almost as much as the more barren ones. May we not recognize in this the hand of bounteous Providence, which has given, perhaps, the most stony soil in Europe to the moistest climate in it? If as much rain fell upon the clays in England (a soil very rarely met with in Ireland, and never without much stone) as falls upon the rocks of her sister island, those lands could not be cultivated. But the rocks here are clothed with verdure; those of limestone, with only a thin covering of mould, have the softest and most beautiful turf imaginable."

Tillage in Ireland has been too much discountenanced, and is ill understood, even in the best corn counties. The farmers are oppressed by the persons called middle men, who rent farms of the landlords, and let them out to the real occupiers.

Ireland rears vast numbers of black cattle and sheep, and the Irish wool is excellent. The prodigious supplies of butter and salt provisions (fish excepted) shipped at Cork, and carried to all parts of the world, afford the strongest proofs of the natural fertility of the Irish soil.

VEGETABLES.... The vegetable productions of Ireland are nearly the same as those of England. Few countries yield better grain than what is produced in the parts of the island where the cultivation of it is attended to. Great quantities of hemp and flax are raised, especially in the northern counties, where the linen manufacture is principally carried on. Potatoes, as is well known, seem especially to suit the soil of the country, and are a particular object of cultivation in all parts of Ireland.

Axisals.... Wolves were formerly found in Ireland, and were not exterminated till near the end of the seventeenth century. The Irish wolf-dogs, a species of large grey-hounds, near four feet in heipht, are now very nearly extinct. In some parts of the country some herds of red deer are still found wild, particularly in the mountain- 
ous tract near the lake of Killarney. Whether it be owing to the soil or the climate, it is certain that in Ireland there are neither moles nor toads, nor any kind of serpents; and it is not more than eighty or nincty years since frogs, of which there are now abundance, were first imported from England. The magpye and the nightingale are strangers here; and it is said that the latter bird, if brought over in a cage, soon pines and dies. There are also some other birds and several kinds of fish, which abound in England, but are unknown in Ireland.

Natural curiosities... The greatest natural curiosity in Ireland is the Giant's Causeway, in the county of Antrim, about eight miles from Coleraine, which is thus described by Dr. Pococke, late bishop of Ossory, a celebrated traveller and antiquary. He says, "that he measured the most westerly point at ligh water, to the distance of 360 feet from the cliff; but he was told, that at low water, it extended 60 feet farther upon a descent, till it was lost in the sea. Upon measuring the eastern point, he found it 540 feet from the cliff; and saw as much more of it as of the other, where it winds to the east, and is, like that, lost in the water.

"The causeway is composed of pillars, all of angular shapes, from three sides to eight. The eastern point, where it joins the rock, terminates in a perpendicular cliff, formed by the upright sides of the pillars, some of which are 33 fect 4 inches high. Each pillar consịsts of several joints or stones, lying one upon another, from six inches to about one foot in thickness; and what is very surprising, some of these joints are so convex, that their prominences are nearly quarturs of splieres, round each of which is a ledge, which holds then together with the greatest firmuess, every stone being concave on the other side, and fitting in the exactest manner the convexity of the upper part of that beneath it. The pillars are from one to two feet in diameter, and generally consist of about forty joints, most of which separate very easily; and one may walk along upon the tops of the pillars, as far as to the edge of the water.

"But this is not the most singular part of this extraordinary curiosity, the cliffs themselves being still more surprising. From the bottom, which is of black stone, to the height of about sixty feet, they are divideci at equal distances, by stripes of a redidish stone, that resembles a cement, about four inches in thickness; upon this there is another stratum of the same black stone, with a stratum of five inches thick of the red. Over this is another stratum, ten feet thick, clivided in the same manner; then a stratum of the red stone, twenty feet deep, and above that a stratum of upright pillars; above these pillars lies another stratum of black stone, twenty feet high; and abore this again, another stratum of upright pillars, rising, in some places, to the tops of the cliffs; in others not so high, and in others again above it, where they are called the Chinnies. The face of these cliffs extends about three English miles."

Ireland abounds in cataracts, caverns, and romantic prospects. The scenery of the lake of Killarney has been already described. In the side of the mountain of Kishecorran, in the county of Sligo, are six caverns, which extend to the distance of 80 or 90 feet. The sides are covered with a smooth, white substance, like plaister. The largest has, at the entrance, a kind of hall, of a circular form, about 30 feet in diameter, and as many in height. Near the city of Cork there is a vast subterranean labyrinth, called the Oven, the extent of which 
has never been explored, though it has been advanced into to the dis tance of a quarter of a mile, or more. But the most celebrated cavern in Ireland is the cave of Dunuore, about three miles from Kilkenny. This has only been explbred as far as a subterranean river which runs through it about a quarter of a mile from the entrance, where is a difficult descent of about 100 feet. One part of this cavern resembles a grand Gothic structure in ruins; the other has the appearance of a magnificent temple, from the ceiling of which depend stalactic concretions, in the forms of inverted cones and pyramids, which, when strongly illuminated, shine with astonishing brilliance, and produce a most extraordinary effect.

The largest cataract in Ireland is that of Adragool, in Bantry-Bay. On the top of a rocky mountain, which rises almost perpendicularly, is a lake of considerable size, from which issues a sheet of water at first 30 feet wide, which expands as it descends, and dashing from rock to rock, forms a series of cataracts, till it is projected in the form of an arch, over a lower hill into the sea. It is visible at the town of Bantry, at the distance of 14 miles.

Population....At the commencement of the last century, the number of inhabitants in Ireland was thought to be about two millions; whereas, in 1672, there were, according to sir IVilliam Petty, no more than 1,100,000. But from the accounts laid before the house of commons in 1786, as returned by the hearth-money collectors, the number of houses in Ireland amounted to 474,234. If we add to this the probable increase since, and allow for the numbers intentionally or unavoidably overlooked in such returns, we may reasonably conclude that the present actual amount is 500,000 .

We are next to consider what average number of persons we should allow to each house. In the peasants' cottages in Ireland, perhaps the most populous in the world, Mr. Young, in some parts, found the average 6 and $6 \frac{1}{2}$; others have found it, in different places, to be 7 ; and Dr. Hamilton, in his account of the island of Raghery, enumerates the houses, and discovered the average therein to be 8 . In the cities and principal towns, the houses, particularly in the manufacturing parts, generally contain several families; and from different accounts the numbers in such are from 10 up so high as 70 .

From these data then, it will not, perhaps, be erroneous, if we fix the average for the whole island at 8 persons to each house; which, multiplied by the number of houses, makes the population of Ireland amount to four millions.

National character, MANNERs, AND customs....It is justly observed by $\mathrm{Dl}_{1}$. Leland, with regard to the manners of the ancient Irish, that if we make our inquiries on this subject in English writers, we find their representations odious and disgusting : if from writers of their own race, they frequently break out into the most animated encomiums of their great ancestors. The one can scarcely allow them any virtue : the other, in their enthusiastic ardour, can scarcely discover the least imperfection in their laws, grovernment, or manners. The historian of England sometimes regards them as the most detestable and contemptible of the human race. The antiquary of Ireland raises them to an illustrious eminence above all other European countries. Yet when we examine their records, without resard to legendary tales or poetic fictions, we find them, even in their most brilliant periods, advanced only to an imperfect civilization; 2 . 
state which exhibits the most striking instances both of the virtues and the vices of humanity.

With respect to the present descendants. of the old Irish, or, as they are termed by the protestants, the mere Irish, they are generally represented as an ignorant, uncivilized, and blundering sort of people. Impatient of abuse and injury, they are implacable and violent in all their affections : but quick of apprehension, courteous to strangers, and patient of hardship. Though in these respects there is, perhaps, little difference between them and the more uninformed part of their neighbours, yet their barbarisms are more easy to be accounted for, from accidental than natural causes. By far the greater number of them are papists; and it is the interest of their priests, who govern them with absolute sway, to keep them in the most profound ignorance. They have also laboured under many discouragements, which in their own country have prevented the exertion both of their mental and bodily facuities; but when employed in the service of foreign princes, they have been distinguished for intrepidity, courage, and fidelity. Many of their surnames have an O, or Mac, placed before them, which signify grandson and son. Formerly the O was used by their chiefs only, or such as piqued themselves on the antiquity of their families. Their music is the bagpipe, but their tupes are generally of a melancholy strain; though some of their latest airs are lively, and, when sung by an Irisiman, are extremely diverting. The old Irish is generally spoken in the interior parts of the kingdom, where some of the old uncouth customs still prevail, particularly their funeral howlings; but this custom may be traced in nany countries of the continent. Their custom of placing a dead corpse before their doors, laid out upon tables, having a plate upon the boiy to excite the charity of passengers, is practised even in the skirts of Dublin. Their convivial meetings on Sundar afternoon, with dancing to the bagpipe, and more often quarrelling arnong themselves, are offensive to every stranger. But, as we have already observed, these customs are chiefly confined to the more unpolished provinces of the kingdom, particularly Connaught; the common people there having the least sense of law and government of any in Ireland, while their tyrannical landlords or leaseholders squeeze the poor without mercy. "The common Irish, in their manner of living, seem to resemble the ancient Britons, as described by Roman authors, or the present Indian inhabitants of America. Mean huts or cabins built of clay and straw, partitioned in the middle by a wall of the same materials, serve the double purpose of accommodating the family, who live and sleep promiscuously, having their fires of turf in the middle of the floor, with an opening through the roof for a chimney; the other being occupied by a cow, or such pieces of furniture as are not in immediate use.

Their wealth consists of a cow, sometimes a horse, some poultry, and a spot for potatoes. Coarse bread, potatoes, eggs, milk, and sometimes fish, constitute their food; for, lowever plentifully the fields may be stocked with cattle, these poor natives seldom taste butchers' meat of any kind. Their children, plump, robust, and hearty, scarcely know the use of clothes, and are not ashamed to appear naked in the roads, and gaze upon strangers.

In this idle and deplorable state, many thousands have been lost to the community, and to themselves, who, if they had but an equal chance with their neighbours, of being instructed in the real princi- 
ples of Christianity, and being inured and encouraged to industry and labour, would have added considerable strength to government.

The descenclants of the English and Scots, since the conquest of Ireland by Henry II, though not the most numerous, form the wealthiest part of the nation. Of these are most of the nobility, gentry, and principal traders, who inhabit the eastern and northern coasts, where most of the trade of Ireland is carried on ; especially Belfast, Londonderry, and other parts of the province of Ulster, which, though the poorest soil, is, next to Dublin and its neighbourhood, by far the best cultirated and most flourishing part of the kingdom. Here a colony of Scots in the reign of James I, and other presbyterians who fled from persecution in that country in the succeeding rcigris, planted themselves, and established that great staple of Irish wealth, the linen manufacture, which they have since carried on and brought to the utmost perfection. From this short review it appears, that the present inhabitants are composed of three distinct clusses of people; the old Irish, poor, ignorant, and depressed, who inhabit, or rather exist upon, the interior and western parts; the descendants of the English, who inhabit Dublin, Waterford, and Cork, and who gave a new appearance to the whole coast facing England, by the introduction of arts, commerce, science, and more liberal ideas of religion; and, thirdly, emigrants from Scotland in the northcrn provinces, who, like the ochers, are so zealously attached to their own religion and manner of living, that it will require some ages before the inhabitants of Ireland are so thoroughly consolidated and blended as to become one people. The gentry, and better sort of the Irish nation in general, difier little in language, dress, manners, and customs, from those of the same rank in Great Britain, whom they imitate. Their hospitality is well known; but in this they are some. times suspected of more ostentation than real friendship.

Cities, Chief Towns, AND EDIfices....Dublin, the capital of Ire. land, is, in magnitude and number of inhabitants, the second city in the British cominions. It is about ten miles in circumference, being nearly two miles and a half in length, and as much in breadth; and is supposed to contain about 156,000 inhabitants. It stands about seven miles from the sea, at the bottom of a large and spacious bay, to which it gives name, upon the river Liffey, which divides it almost into two equal parts, and is banked in, through the whole length of the city, on both sides, which form spacious and noble quays, where vessels below the first bridge load and unload before the merchants" cloors and warchouses. To protect the harbour from the winds, a mole or huge wall has been constructed nearly four miles in length, with a lighthouse on its extremity, and another corresponding to it on the opposite promontory, called the hill of Howth. A stranger, on entering the bay of Dublin, which is about seven miles broad, and in stormy weather extremely dangerous, is agreeably surprised with the beautiful prospect on each side, and the distant view of Wicklow mountains; but the city itself, from its low situation, makes no great appearance. The increase of Dublin within these last thirty years is incredible. The number of houses in the year 1777 , was 17,151 , and they are now estimated at not less than 22,000. This city, in its appearance, bears a near resemblance to London. "The houses are of brick; the old streets are narrow and mean, but the new streets are as elegant as those of the metropolis of Great Britain. Sackville-street, which is sometimes called the MIall, is particularly 
noble. The houses are elegant, lofty, and uniformiy built, and a gravel-walk runs through the whole at an equal distance from the sides.

The river Liffey, though navigable for sea vessels as fal as the customhouse, or centre of the city, is but small, when compared with the Thames at London. It is crossed by six bridges, three of which, Essex-bridge, Queen's-bridge, and Sarah's-bridge, are elegant, especially the last, which has been finished but a few years. It consists of one arch, 106 feet in the span or width across the stream, and 28 feet high.

Many of the public edifices of Dublin are very magnificent ; among which may be enumerated the late parliament-house, the university, the courts of justice, the custom-house, the royal exchange, completed in 1779, and which is an elegant structure of white stone, with semicolumns of the Corinthian order, a cupola, and other ornaments. The castle, which is the residence of the viceroy stands on a rising ground, near the centre of the city, and consists of two courts, one of which is of an oblong rectangular form, the other a less regularly shaped quadrilateral.

St. Stephen's-green is a very spacious and beautiful square, round which there is a gravel walk, a mile in circuit. Many of the houses in this square are very elegant; but a want of uniformity is observable throughout. In this respect it is greatly exceeded by the new square near it, called Merrion-square; the houses of which being lofty and uniform, and built with stone as high as the first floor, give the whole an air of magnificence, not, perhaps, exceeded by any place in England.

The civil government of Dublin is by a lord-mayor, \&c. the same as in London. Every third year, the lord-mayor, and the twenty-four companies, by virtue of an old charter, are obliged to perambulate the city and its liberties, which they call Riding the Franchises. Upon this occasion the citizens vie with each other in show and ostentation, which is sometimes productive of disagreeable consequences to many of their families. In Dublin there are twenty parishes, a cathedral, eighteen parish churches, eight chapels, three churches for French, and one for Dutch protestants, seven presbyterian meeting houses, two for methodists, two for quakers, and sixteen Roman-catholic chapels. There are also two theatres; a royal hospital like that at Chelsea, for invalids; a lying-in hospital, with gardens, built and laid out in the finest taste; an hospital for lunatics, founded by the famous dean Swift, who himself died a lunatic; and sundry other hospitals for patients of every description. Some of the churches have been lately rebuilt in a more elegant manner. Indeed, whatever way a stranger turns himself in this city, he will perceive a spirit of elegance and magnificence; and if he extends his view over the whole kingdom, will be convinced that works of ornament and public utility are no where more encouraged than in Ireland.

Cork is deservedly reckoned the second city in Ireland, in magnitude, riches, and commerce. It lies 129 miles south-west of Dublin, and contains 8500 houses, and about 70,000 inhabitants. Its haven is deep, and well sheltered from all winds; but small vessels only can come up to the city, which stands about seven miles up the river Lee. This is the chief port of merchants in the kingdom; and there is, perhaps, more beef, tallow, and butter shipped off here, than in all the 
other ports of Ireland, taken together. Hence there is a great resort of ships to this port, particularly of those bound from Great Britain to Jamaica, Barbadoes, and all the Caribbee islands, which put in here to victual and complete their lading. It appears, that in the reign of Edward IV, there were eleven churches in Cork, though there are now only seren, and yet it lias ever since that time been esteemed a thriving city: but it must be observed, that besides the churches, there are at this time six mass-houses, two dissenting meeting-horses, another for quakers, and a chapel for French protestants. Kinsale is a populous and strong town, with an excellent harbour, and considerable commerce and shipping. Waterford is reckoned next to Cork tor riches and shipping; but it suffered greatly in the late rebellion, and cannot now be estimated to contain above 30,000 inhabitants. It is commanded by Duncannon Fort, and on the west side of the town is a citadel. . Lim:erick is a handsome, populous, commercial, strong city ; it lies on both sicies the Sliannon, and contains 5257 houscs, and about 45,000 inhabitants.

Belfast is a large, sea-port, and trading town, at the mouth of the Lagen VVater, where it falls into Carrickfergus Bay. Downpatrick has a flourishing linen manufacture. Carrickfergus, or Knockfergus, by some deemed the capital town of the province, has a good harbour and castle, but little commerce. Derry, or Londonderry, as it is most usually called, stands on Lough-Foyl, is a strong little city, having linen manufactures, with some shipping. Donegal, the county town of the same name, otherwise called the county of Tyrconnel, is a place of some trade, as is likervise Enniskilling.

Comerce aND MaNUFactures.... The exports of Ireland are linen cloth, yarn, lawns, and cambrics, horses and black cattle, beef, pork, green hides, tanned leather, calf-skins dried, tallow, butter, candles, clieese, ox and cow horns, ox hair, horse hair, lead, copper ore, herrings, dried fish, rabbit skins and fur, otter skins, goat skins, salmon, and some other commodities. In the year 1799, the exports from Ireland amounted to $4,575,25 \mathrm{ll}$. and her imports to $4,396,009 \mathrm{l}$. The manufacture of linen yields an exportation to the amount of nearly $2,000,000 l$. annually. The Irish have carried their inland manufactures, even those of luxury, to a considerable height ; and their lordlieutenants and their courts have of late enconraged them by their examples, and while they are in that government, make use of no other.

Government AND LAws.... Ireland formerly was only entitled the dominion or lordship of Ireland, and the king's style was no other than donirus Hibernix, lord of Ireland, till the $33 \mathrm{~d}$ year of king Henry VIII, when he assumed the title of king, which is recognised by act of parliament in the same reign

Before the union in 1801, Ireland was governed by its own parliament consisting of a house of commons, composed of 300 members, and a house of peers, while the king was represented by a lord. lientenant or viceroy. By the articles of union, which took place on the 1st of January, 1801, England, Scotland, and Ireland, have become one kingdom, by the name of the United Kingdom of Great Britain and Ireland. The office of lord-lieutenant is still continued. Of the peers of Ireland at the time of the union, four spiritual lords, by rotation of sessions, and twenty-eight temporal peers for life, sit and vote in the house of lords; and one hundred commoners, viz. two for each county of Ireland, two for the city of Dublin, two for 
the city of Cork, and one for each of the thirty-two most considerable cities, towns, and boroughs, are the number of representatives of Ireland in the house of commons of the parliament of the united kingdom.

It is also provided by these articles "that for the space of twenty years after the union shall take place, the contribution of Great Britain and Ireland respectively, towards the expenditure of the united kingdom in each year, shall be defrayed in the proportion of fifteen parte for Great Britain, and two parts for Ireland," this proportion, at the expiration of that time, to be subject to revision and regulation from other considerations.

The laws of Ireland differ very little from those of England; for, after the conquest of Ireland by king Henry II, the laws of England were received and sworn to by the Irish nation, assembled at the council of Lismore : and by subsequent particular acts made in Ireland, the statutes in force in England have been adopted, and decisions in common law have been taken as precedents; so that the laws of the two countries are nearly the same: there are however some minute variations.

For the regular distribution of justice, there are in Ireland four terms held annually for the decision of causes; and four courts of justice; the chancery, king's-bench, common-pleas, and exchequer. The high sheriffs of the several counties were formerly chosen by the people, but are now nominated by the lord-lieutenant.

REVENUE....In Ireland the public revenue arises from hereditary and temporary duties, of which the king is the trustee, for applying it to particular purposes : but there is, besides this, a private revenue arising from the ancient demesne lands, from forfeitures for treason and felony, prisage of wines, light-house duties, and a small part of the casual revenue, not granted by parliament; and in this the crown has the same unlimited property that a subject has in his own freehold.

The revenue of Ireland amounts at present to $2,800,000 \mathrm{l}$; but that the expenditure considerably exceeds that sum, is manifest from the magnitude of the public debt of that country; which, according to the statement of $\mathrm{Mr}$. Foster, the Irish member in the house of commons, amounted in 1800 to 25 millions sterling, and at present (1804) is 52 millions and a half. To pay the interest of this debt, several new taxes have lately been imposed.

MilitTARy fORCE.... In consequence of the late rebellion, and the threats of a French invasion, a very considerable military force is now kept up in Ireland ; consisting of regular troops and militia from England, Irish militia, and yeomanry. In the year 1800, the force maintained in Ireland consisted of 45,839 regulars, 27,104 militia, and 53,557 yeoman:y; making in the whole 126,500 men in arms.

OrDer of St. Patrick....This order was instituted Februly 5. and the installation of the first knights was performed on the 17 th of March, 1783. It consists of the sovereign and fifteen other knights' companions. The lord-lieutenants of Ireland for the time being officiate as grand masters of the order, and the archbishop of Armagh is the prelate, the archbishop of Dublin the chancellor, and the dean of St. Patrick the register of the order. The knights are installed in the cathedral of St. Patrick, Dublin. Their robes are splendid, and the badge is three crowns united together on a cross, with the 
motto round, Quis sefrarabit? 1783, fastened by an Irish harp to the crown imperial. A star of eight points encircles it on the coat.

ReLIGION.... The established religion "and ecclesiastical discipline of Ireland is the same with that of England. Among the bulk of the people in the most uncultivated parts, popery, and that too of the most absurd, illiberal kind is prevalent. The Irish papists still retain their nominal bishops and dignitaries, who subsist on the voluntary contributions of their votaries. But even the blind submission of the latter to their clergy, does not prevent protestantism from making a very rapid progress in the towns and communities. How far it may be the interest of England, that some kind of balance between the two religions should be kept up, we shall not here inquire.

Ireland contains at least as many sectaries as England, particularly presbyterians, baptists, quakers, and methodists, who are all of them colerated or connived at. Great efforts have been made, ever since the days of James $I$, in erecting free-schools for civilizing and converting the Irish papists to protestantism. The institution of the incorporated society for promoting English protestant workingschools, has been extremely successful, as have been many institutions of the same kind in introducing industry and knowledge among the Irish.

The archbishopricks are four ; Armagh, Dublin, Cashel, and Tuam.

The bishopricks are eighteen; viz. Clogher, Clonfert, Cloyne, Cork, Derry, Down, Dromore, Elphin, Kildare, Killala Kilmore, Killaloe, Leighlin, Limerick, Meath, Ossory, Rapho, and Waterford.

LITERATURE....Learning seems to have been cultivated in Ireland at a very early period. Mr. O'Halloran says, that the Irish " appear to have been, from the most remote antiquity, a polished people, and that with propriety they may be called the fathers of letters."

It is said, that when St. Patrick* landed in Ireland, he found many holy and learned Christian preachers there, whose votaries were pious and obedient. Camden observes, that "the Irish scholars of S.t. Patrick profited so notably in Christianity, that, in the succeeding age, Ireland was termed Sanctorum Patria. Their monks so greatly excelled in learning and piety, that they sent whole flocks of most learned men into all parts of Europe, who were the first founders of Lieu-Dieu-abbey, in Burgundy; of the abbey Bobie, in Italy; of Wirtzburg, in Franconia; St. Gall, in Switzerland; and of Malmesbury, Lindisfarran, and many other monasteries, in Britain." We have also the testimony of venerable Bede, that, about the middle of the seventh century, many nobles, and other orders of the Anglo. Saxons, retired from their own country, into Ireland, either for instruction, or for an opportunity of living in monasteries of stricter discipline; and that the Scots (as he styles the Irish) maintained them, taught them, and furnished them with books, without fee or rewald: "a most honourable testimony," says lord Lyttleton, " not only to the learning, but likewise to the hospitality and bounty of that nation." Dr. Leland remarks, that a conflux of foreigners to a retired island, at a time when Europe was in ignorance and confusion, gave peculiar listre to this seat of learning : nor is it improbable or

- It has been affirmed, that St. Patrick was a Scotchman; but Mr. O'Halloran Jenies this, and says, that " it appears from the most authentic records that $\mathrm{Pa}$. trick was from Wales." 
surprising, that seven thousand students studied at Armagh, agreeably to the accounts of Irish writers, though the seminary of Armagh was but one of the many colleges erected in Ireland.

In modern times, the Irish have also distinguished themselves in the republic of letters. Archbishop Usher does honour to literature itself. Dean Swift, who was a native of Ireland, has perhaps never been equalled in the walks of wit, humour, and satire. The sprightliness of Farquhar's wit is well known to all the lovers of clrama. And among the men of distinguished genius whom Ireland has produced, may also be particularly mentioned, sir Richard Steele, bishop Berkeley, Parnel, Sterne, Goldsmith, and the late celebrated Mr. Burke.

UNIVERSITY....Ireland contains but one university, which is denominated Trinity-college. It consists of two quadrangles, in the whole of which are thirty-three buildings, of eight rooms each. It has an excellent library, a great part of the books of which were collected by archbishop Usher.

This seminary was founded and endowed by queen Elizabeth ; but the original foundation consisted only of a provost, three fellows, and three scholars; which has from time to time been augmented to twenty-two fellows, seventy scholars, and thirty sizers. However, the whole number of students is at present about four hundred, who are of three classes-fellow-commoners, pensioners, and sizers, or servitors. Of the fellows, several are called seniors; and the annual income of each of these is about seven hundred pounds. There are thirteen professors of various sciences. The provostship is supposed to be worth three thousand pounds a year. Trinity-college has a power of conferring degrees of bachelor's; masters, and doctors, in all the arts or faculties. The visitors are, the chancellor, or vicechancellor, and the archbishop of Dublin.

LANGUAGE.... The language of the Irish is a dialect of the ancient Celtic, and nearly the same with that of the Scottish Highlanders opposite the Irish coast. The usage of the Irish language occasions among the common people, who speak both that and the English, a peculiar tone in speaking, which is general among the vulgar, and prevails even among the better sort, who do not understand Irish. It is probable that, a few ages hence, the latter will be accounted among the dead languages.

The Lord's prayer in Trish is as follows:

Ai nothairne ata ar neamh, naomhthar hairm; tigeadh do riogachd: deuntar do thoil, ar an ttalamh mar ata ar neamh; tabhair dhuirn a niu ar naran lethamhail; agus maithdhuirn ar bhfiaca amait mar maitkmidrne mar bhfeithcamhnuibb fein ; agus na leig sinn a cathughadh, achd saor sinn o olc: oir is leat fein an rioghachd, agus an cumhachd, agus an ghloir suffioruige. Amen.

Antrquities.....Among the principal antiquities of Ireland are the round towers, which are tall hollow pillars of stone and lime, of a nearly cylindrical form, but narrowing somerwhat upwards, with a conical roof. Fifty-six of these towers, from fifty to a liundred and fifty feet high, and from eight to twelve in diameter, are still standing in different parts of Ireland. Antiquaries da not appear to be agrees with respect to their origin and use ; some supposing that they were built by the Danes and Norwegians, in their piratical incursions, who made use of them as spy-towers, light-houses, or beacons; and others 
that they served as belfries to the monasteries; which, it is said, is agreeable to the import of their Irish name cloghad.

In Ireland are likewise found cairns, carnedhs, or piles of loose stones, heaped up on the tops of hills, for the celebration of some pagan rites; circles of stones; harrows, or artificial hillocks; cromlyeeaghs, or large flat stones raised from the ground, horizontal or inclined, intended, probably for the purposes of superstition; and rude fortresses, called raths, and diens; supposed to have been built by Scandinavian invaders. The ruins of stately castles, erected towards the end of the twelfth century, by the Anglo-Norman colonists, are found in almost every part of the country.

History.. The history of Ireland has been carried to a very remote antiquity, and may, with greater justice than that of almost any other country, be distinguished into the legendary and authentic. In the reign of Edward II, an Ulster prince boasted to the pope of an uninterrupted succession of one hundred and ninety-seven kings of Ireland, to the year 1170. Even the more moderate Irish antiquaries carry their history up to 500 years before the Christian æra, at which time they assert that a colony of Scythians, immediately from Spain, settled in Ireland, and introduced the Plonician language and letters into this country; and that however it might have been peopled still earlier from Gaul or Britain; yet Heber, Heremon, and Ith, the sons of Milesius, gave a race of kings to the Irish, distingruished from their days by the name of Gadelians, and Scuits, or Scots. But as our limits will not permit us to enlarge on the dark and contested parts of the Irish history, we shall only observe, that it was about the middle of the fifth century that the great apostle of Ireland, St. Patrick, was employed in the propagation of Christianity in this country, though there had been Christian missionaries here long before, by whose means it had made a considerable progress among the inhabitants of Ireland. After this period, Ireland was occasionally invaded by the Saxon kings of England; but in the years 795 and 798 , the Danes and Norwegians, or, as they were called, Easterlings, invaded the coast of Ireland; and were the first who erected stone edifices in that kingdom. The common habitations of the Irish, till that time, were hurdles, covered with straw and rushes, and but very few of solid timber. The natives defended themselves bravely against the Easterlings, who built Dublin, Waterford, Limerick, Wexford, and Cork; but they resided chiefly at Dublin, or in its neighbourhood, which, by the old Irish, was called Fingal, or the Land of Strangers. The natives, about the year 962, seem to have called to their assistance the Anglo-Saxon king Edgar, who had then a considerable maritime power; and this might have given occasion. for his clergy to call him king of great part of Ireland. It is certain that Dublin was about that time a flourishing city, and that the rative Irish gave the Easterlings several defeats, though supported by their countrymen from the continent, the Isle of Man, and the Hebrides.

In the twelfth century, Henry the Second of England formed a design of annexing Ireland to his dominions. He is said to have been induced to this by the provocation he had received from some of the Irish chieftains, who had afforied considerable assistance to his ene. mies. His design was patronised by the pope, and a fair pretext of attacking Ireland offered about the year 1168. Dermot Mac Murrough, king of Leinster, and an oppressive tyrant, quarrelled with 
all his neighbours, and carried off the wife of a petty prince, $O^{\prime}$ Roirk. A confederacy being formed against him, under Roderic $\mathrm{O}^{\prime}$ Connor, who, it seems, was the paramount king of Ireland, he was driven from his country, and took refuge in the court of Henry II, who promised to restore him, upon taking an oath of fidelity to the crown of England, for himself and all the petty kings depending on him, who were very numerous. Henry, who was then in France, recommended Mac Dermot's cause to the English barons, and particularly to Strongbow, earl of Pembroke, Robert Fitz-Stephen, and Maurice Fitzgerald. Those noblemen undertook the expedition upon much the same principles as the Norman and Breton lords did the conquest of England under William I; and Strongbow was to marry Mac Dermot's daughter, Eva. In 1169 the adventurers reduced the towns of Wexford and Waterford; and the next year, Strongbow arriving with a strong reinforcement, his marriage was celebrated.

The descendants of the Danes continued still possessed of Dublin, which, after some ineffectual opposition, made by the king $\mathrm{O}^{\prime} \mathrm{C}$ Connor, was taken and plundered by the English soldiers : but Mac Turkil, the Danish king, escaped to his shipping. Upon the death of Dermot, Henry II became jealous of earl Strongbow, seized upon his estates in England and Wales, and recalled his subjects from Ireland. The Irish about the same time, to the amount of 60,000 , besieged Dublin, under king O'Connor; but though all Strongbow's Irish friends and allies had now left him, and the city was reduced to great extremity, he forced the Irish to raise the siege with great loss; and going over to England, he appeased Henry, by swearing fealty to him and his heirs, and resigning into his hands all the Irish cities and forts he held. During Strongbow's absence, Mac Turkil returned with a great fleet, and attempted to retake the city of Dublin, but was killed at the siege; and in him ended the race of the Easterling princes in Ireland.

In 1172 , Henry II, attended by 400 knights, 4000 veteran soldiers, and the flower of his English nobility, landed near Waterford; and not only all the petty princes of Ireland, excepting the king of UIster, but the great king Roderic O'Connor, submitted to Henry, who pretended that O'Connor's submission included that of Ulster, and that consequently he was the paramount sovereign of Ireland. Be that as it will, he affected to keep a magnificent court, and held a parliament at Dublin, where he parcelled out the states of Ireland, as William the Conqueror had done in England, to his English nobility. He then settled a civil administration at Dublin, as nearly similar as possible to that of England, to which he returned in 1173, having first settled an English colony from Bristol in Dublin, with all the liberties, free customs, and charters, which the citizens of Bristol enjoyed. From that time Dublin began to flourish. Thus the conquest of Ireland was effected by the English almost with as much ease as that of Mexico was by the Spaniards, and for much the same reasons; the rude and unarmed state of the natives, and the differences that prevailed among their princes or leaders.

Henry gave the title of lord of Ireland to his son John, who, in 1185 , went over in person to Ireland; but John and his giddy Norman courtiers made a very ill use of their power, and rendered themselves hateful to the Irish, who were otherwise very well disposed towards the English. Richard I, was too much taken up with the crusades to pay any great regard to the affairs of Ireland; but king 
John, after his accession, made amends for his former behaviour to. wards the Irish. He enlarged his father's plan of introducing into Ireland English laws and officers, and he erected that part of the provinces of Leinster and Munster, which was within the English pale, into twelve counties. We find, however, that the descendants of the ancient princes in other places, paid him no more than a nominal subjection. They governed by their old Brehon laws, and exercised all acts of sovereignty within their own states; and indeed this was pretty much the case so late as the reign of James I. The unsettled reign of Henry III, his wars and captivity, gave the Irish a very mean opinion of the English government during his reign; but they seem to have continued quiet under his son Edward I. Gaveston, the famous favourite of Edward II, acquired great credit while he acted as lieutenant of Ireland; but the successes of the Scotch king, Robert Bruce, had almost proved fatal to the English interest in Ireland, and suggested to the Irish the idea of transferring their allegiance from the kings of England to Edward Bruce, king Robert's brother. That prince accordingly invaded Ireland, where he gave,repeated defeats to the English governors and armies; and being supported by his brother in person, he was actually crowned king at Dunkalk, and narrowly missed being master of Dublin. The younger Bruce seems to have been violent in the exercise of his sovereignty, and he was at last defeated and killed by Bermingham, the English general. After this, Edward II ruled Ireland with great moderation, and passed several excellent acts with regard to that country.

But during the minority of Edward III, commotions were again renewed in Ireland, and not suppressed without great loss and disgrace on the side of the English. In 1333 a rebellion broke out, in which the English inhabitants had no inconsiderable share. A succession of vigorous, brave governors at last quieted the insurgents; and about the year 1561, prince Lionel, son to Edward III, having married the heiress of Ulster, was sent over to govern Ireland, and, if possible, to reduce its inhabitants to an entire conformity with the laws of England. In this he made a great progress, but did not entirely accomplish it. It appears, at this time, that the Irish were in a very flourishing condition, and that one of the greatest grievances they complained of was, that the English sent over men of mean birth to govern them. In 1594, Richard II, finding that the execution of his despotic schemes in England must be abortive without further support, passed over to Ireland with an army of 34,000 men, well armed and appointed. As he made no use of force, the Irish looked upon his presence to be a high compliment to their nation, and admired the magnificence of his court. Richard, on the other hand, courted them by all the arts he could employ, and bestowed the honour of knightnood on their chiefs. In short, he behaved so as to entirely win their affections. But in 1399, after having acted in a very despotic manner in England, he undertook a fresh expedition to Ireland, to revenge the death of his lord-lieutenant, the earl of March, who had been killed by the wild Irish. His army again struck the natives with consternation, and they threw themselves upon his mercy. It was during this expedition that the duke of Lancaster landed in England; and Richard, upon his return, finding himself deserted by his English subjects on account of his tyranny, and that he could not depend upon the Irish, surrendered his crown to his Gival. 
The Irish, after Richard's death, still retained a warm affection for the house of York; and, upon the revival of that family's claim to the crown, embraced its cause. Edward IV made the earl of Desmond lord-lieutenant of Ireland for his 'services against the Ormond party and other adherents of the house of Lancaster, and, he was the first Irish chieftain that obtained this honour. Even the accession of Henry VII to the crown of England did not reconcile the Irish to his title as duke of Lancaster: they therefore readily joined Lambert Simnel, who pretended to be the eldest son of Edward IV; but for this they paid dear, being defeated in their attempt to invade England. This made them somewhat cautious at first of joining Perkin Warbeck, notwithstanding his plausible pretences to be the đuke of York, second son of Edward IV. He was, however, at last recognised as king by the Irish; and in the preceding pagres, under the history of England, the reader may learn the event of his pretensions. Henry behaved with moderation towards his favourers, and was contented with requiring the Irish nobility to take a fresh oath of allegiance to his govcrument. This lenity had the desired effect during the administration of the two earls of Kildare, the earl of Surry, and the earl of Ormond. Henry VIII governed Ireland by supporting its chiefs against each other: but the emperor Charles $\mathbf{V}$, endeavouring to gain them to his interest, Henry made his natural son, the duke of Richmond, his lord-lieutenaut. This did not prevent the Irish from breaking out into rebeliion in the year 1540 , under Fitzgerald, who had been lord-deputy, and was won over by the emperor, but was at last hanged at Tyburu. After this the house of Austria found their account, in their quarrels with England, to form a strong party among the Irish.

About the year 1542, James V, king of Scotland, formed some pretensions to the crown of Ireland, and was favoured by a strong party among the Irish themselves. It is hard to say, had he lived, what the consequence of his claim might have been. Henry understood that the Irish had a mean opinion of his dignity, as the kings of England had hitherto assumed no higher title than that of lords of Ireland. He therefore took that of king of Ireland; which had a great effect with the native Irish, who thought that allegiance was not due to a lord: and, to speak the truth, it is somewhat surprising that this expedient was not thought of before. It produced a more perfect submission of the native Irish to Henry's government than ever had been known; and even O'Neil, who pretended to be successor to the last paramount king of Ireland, swore allegiance to Henry, who created him earl of Tyrone.

The pope, however, and the princes of the house of Austria, by remitting money, and sometimes sending over troops to the Irish, still kept up their interest in that kingdom, and drew from them vast numbers of men to their armies, where they proved as good soldiers as any in Europe. This created inexpressible difficulties to the English government, even in the reign of Edward VI; but it is remarkable, that the reformation took place in the English part of Ireland, with little or no opposition. The Irish seem to have been very quiet during the reign of queen Mary; but they proved thorns in the side of queen Elizabeth. The perpetual disputes she had with the Roman-catholics, both at home and abroad, gave her great uneasiness; and the pope and the house of Austria always found new resources against her in Ireland. The Spaniards possessed 
themselves of Kinsale; and the rebellions of Tyrone, who baffled and outwitted her favourite general, the earl of Essex, are well known in English history:

The lord deputy Mountjoy, who succeeded Essex, was the first Englishman who gave a mortal blow to the practices of the Spaniards in Ireland, by defeating them, and the Irish before Kinsale, and bringing Tyrone prisoner to Eagland, where he was pardoned by queen Elizabeth, in 1602. This lenity, shown to such an offender, is a proof of the great apprehensions Elizabeth had from the popish interest in Ireland. James I confirmed the possessions of the Irish; bat such was the influence of the pope and the Spaniards, that the earls of Tyrone and Tyrconnel, and their party, planned a new rebellion, and attempted to seize the castle of Dublin ; but their plot being discovered, their chicfs fled beyond seas. They were not idle abroad; for in 1608 they instigated sir Calim O'Dogherty to a fresh rebellion, by promising him speedy supplies of men and money from Spain. Sir Calim was killed in the dispute, and his adherents were taken and executed. The attainders of the Irish rebels, which passed in the reigns of James and Elizabeth, vested in the crown 511,465 acres, in the several counties of Donegal, Tyrone, Colerain, Fermanagh, Cavan, and Armagh ; and enabled the king to make that protestant plantation in the north of Ireland, which, from the most rebellious province in the kingdom, became, for many years, the most quiet and industrious.

Those prodigious attainclers, however just and necessary they might be, operated fatally for the English in the reign of Charles I. The Irish Roman-catholics in general were influenced by their priests to hope not only to repossess the lands of their forefathers, but to restore the popish religion in Ireland. They therefore entered into a deep and detestable conspiracy for massacreing all the English protestants in that kingdom. In this they were encouraged by the unhappy dissensions that broke out between the king and his parliaments in England and Scotland. Their bloody plan being discovered by the English government at Dublin, prevented that city from falling in to their hands. They however, partly executed, in 1641, their horrid scheme of massacre; but authors have not agreed as to the numbers who were murdered; perhaps they have been exaggerated by warm protestant writers: some of the more moderate have estimated the numbers of the sufferers at 40,000 ; other accounts speak of 10,000 or 12,000 ; and some have diminished that number.* What followed in consequence of this rebellion, and the reduction of Ireland by Cromwell, who retaliated the cruelties of the Irish papists upon themselves, belongs to the history of England. It is certain that they suffered so severely, that they were quiet during the reign of Cliarles II. His popish successor, and brother, James II, even after the revolution took place, found an asylum in Ireland; and was encouraged to hope, that, by the assistance of the natives there, he might remount his throne : but he was deceived, and his own pusillanimity co-operated with his disappointment. He was

* Mr. Hume, after enumerating the various harbarities practised by the papists "upon the protestants, says, "By some computations, those who perished by all "those cruelties are made to amount to an hundred and fifty, or two hundred "thousand; by the most moderate, and probably the most reasonable account, "they must have been near 40,000." History of England, vol. vi. p. 317, edit. \&ิพ0. 1763.

Vol. I. 
driven out of Ireland by his son-in-law, after the battle of the Boyne, the only victory that king William ever gained in person; a victory, however, on which depended the safety of the protestant religion, and the liberties of the British empire. Had James been victorious, he probably would have been reinstated on the throne; and nothing else could be expected than that, being irritated by opposition, victorious over his enemies, and free from every restraint, he would have trampled upon all rights, civil and religious, and pursued more arbitrary designs than before. The army of William consisted of 36,000 men, that of James of 33,000 , but advantageously situated. James, it is true, fought at the head of an undisciplined rabble : but his French auxiliaries were far from behaving like heroes. It must be acknowledged, however, that he left both the field and the kingdom too soon for a brave man.

The forfeitures that fell to the crown on account of the Irish rebel. fions and the revolution, are almost incredible; and had the acts of parliament, which gave them away, been strictly enforced, Ireland must have been peopled with British inhabitants. But many political reasons occurred for not driving the Irish to despair. The friends of the revolution and the protestant religion were sufficiently gratifi. ed out of the forfeited estates. Too many of the Roman-catholics might have been forced abroad; and it was proper that a due balance should be preserved between the Roman-catholic and the protestant interest. It was therefore thought prudent to relax the reins of government, and not to put the forfeitures too rigorously into execution. The experience of half a century has confirmed the wisdom of the above considerations. The lenity of the measures pursued in regard to the Irish Roman-catholics, and the great pains taken for the instruction of their children, with the progress which knowledge and the arts have made in that country, have greatly diminished the popish interest. The spirit of industry has enabled the Irish to know their own strength and importance; to which some accidental circumstances have concurred. All her ports were opened for-the exportation of wool and woollen yarn to any part of Great Britain; and of late years, acts of parliament have been made occasionally, for permitting the importation of salt beef, pork, butter, cattle, and tallow, from Ireland to Great Britain.

But though some laws and regulations had occasionally taken place favourable to Ireland, it must be acknowledged, that the inhabitants of that country laboured under considerable grievances, in consequence of sundry unjust and injudicious restraints of the parliament of England, respecting their trade. These restraints had injured Ireland, without benefitting Great Britain. The Irish had been prohibited from manufacturing their own wool, in order to favour the woollen manufactory of England; the consequence of which was, that the Irish wool was smuggled over into France, and the people of that country were thereby enabled to rival us in our woollen manufacture, and to deprive us of a part of that trade. An embargo had also been laid on the exportation of provisions from Ireland, which had been extremely prejudicial to that kingdom. The distresses of the Irish manufacturers, as well as those of Great Britain, had likewise been nuch increased by the consequences of the American war. These circumstances occasioned great murmuring in Ireland and some attempts were made for the relief of the inhabitants of that kingdom, in the British parliament, but for some time without success; 
for a partiality in favour of the trade of England prevented justice from being done to Ireland. But several incidents which happened afterwards, at length operated strongly in favour of that kingdom. When a large body of the king's troops had been withdrawn from Ireland, in order to the employed in the American war, a considerable number of Irish gentlemen, farmers, trader's, and other persons, armed, and formed themselves into volunteer companies and associations, for the defence of Ireland against any foreign invaders. By degrees, these volunteer associations became numerous and welldisciplined; and it was soon discovered, that they were inclined to maintain their rights at home, as well as to defend themselves against: foreign enemies. When these armed associations became numerous and formidable, the Irish began to assume a higher tone than that to which they had before been accustomed; and it was soon manifest, that their remonstrances met with unusual attention, both from their own parliament, and from that of Great Britain. The latter, on the 11 th May, 1779, presented an address to the king, recommending to his majesty's most serious consideration the distressed and impover. ished state of the'loyal and well-deserving people of Ireland; and desiring him to direct that there should be prepared and laid before parliament, such particulars relative to the trade and manufactures of Great Britain and Ireland, as should enable the national wisdom to pursue effectual measures for promoting the common strength, wealth, and commerce of his majesty's subjects in both kingdorns: To this address the king returned a favourable answer; and in Oct. of the same year, both houses of the Irish parliament also presented addresses to his majesty, in which they declared, that nothing but granting Ireland a free trade could save it from ruin. Notwithstanding which, it being soon arter suspected, by many of the people of that kingdom, that the members of their parliament would not exert themselves with rigour in promoting the interests of the nation, a very claring and numerous mob assembled before the Parliamenthouse in Dublin, crying out for a free trade, and a short money bill. They assaulted the members, and endeavoured to compel them to swear that they would support the interest of their country, by roting for a short money bill; and they demolished the house of the attorney general. The tumult at length subsided: and two Irish money bills, for six months only, were sent over to England, where they passed the great seal, and were immediately returned, without any dissatisfaction being expressed by government at this limited grant.

In the mean time the members of the opposition in the English parliament very strongly represented the necessity of an immediate attention to the complaints of the people of Ireland, and of a compliance with their wishes. The arguments on this side of the question were also enforced by the accounts which came from Ireland; that the volunteer associations in that kingdom amounted to forty thousand men, unpaid, self-appointed, and independent of government, well armed and accoutred, daily improving in discipline, and which afterwards increased to eighty thousand. The British ministry appeared for some time to be undetermined what part they should act in this important business; but the rememisrance of the fatal effects of rigorous measures respecting America, and the very critical situation of Great Britain, at length induced the first lord of the treasury to bring in such bills as were calculated to afford effectual commersial relief to the people of Ireland. Laws were accordingly 
passed, by which all those acts were repealed which had prohibited the exportation of woollen manufactures from Ireland, and other acts by which the trade of that kingdom to foreign countries had been restrained; and it was likewise enacted, that a trade between Ireland and the British colonies in America and the West Indies, and the British settlements on the coast of Africa, should be allowed to be carried on, in the same manner, and subject tor similar regulations and restrictions with that carried on between Great Britain and the said colonies and settlements.

These laws in favour of Ireland were received with much joy and exultation in that kingdom : and the Irish nation being indulged in their requisitions respecting trade, now began also to aim at important constitutional reformations; and in various counties and cities of Ireland, the right of the British parliament to make laws which should bind that kingdom, was denied in public resolutions. By degrees, the spirit which had been manifested by the Irish parliament seemed a little to subside; and a remarkable instance of this was, their agreeing to a perpetual mutiny bill, for the regulation of the Irish army, though that of England had always been passed, with a true constitutional caution, only from year to year. This was much exclaimed against, by some of the Irish patriots; and it is, indeed, not easy to clear their parliament from the charge of inconsistency; but this bill was afterwards repealed, and the commercial advantages afforded them by several acts in their favour, greatly contributed to promote the prosperity of Ireland. As before observed, by the act repealing the statute of the 6th George I, they were fully and completely eman. cipated from the jurisdiction of the British parliament; and the appellant jurisdiction of the British house of peers in Irish causes was likewise given up.

In the year 1783, the government, the nobility, and the people of Ireland, vied with each other in countenancing and giving an asylum to many families of the Genevese, who were banished from their city, and to others, who voluntarily exiled themselves for the cause of liberty, not willing to submit to an aristocracy of their own citizens, supported by the swords of France and Sardinia. A large tract of land, in the county of WVaterford, was allotted for their reception, a town was marked out, entitled New Genera, and a sum of money granted for erecting the necessary buildings. These preparations. for their accommodation, were, haweyer, rendered ultimately uscless, by some misunderstanding (not fully comprehended) which arose between the parties; and the scheme accordingly fell to the glound.

Upon the occasion of the unhappy malady with which the king was afflicted in 1788, the lords and commons of Ireland came to a resolution to address the prince of Wales, requesting hirs to take upon him the government of that kingdom, during his majesty's indisposition, under the style and title of prince regent of Ireland; and to exercise and administer, according to the laws and the constitution of the realm, all the royal authorities, jurisdictions, and preragatives, to the crown and government thereof belonging. The marquis of Buckingham (being then lord lieutenant) having declined presenting the address, as contrary to his oath and the laws, the two houses resolved on appointing delegates from each; the lords appointed the duke of Leinster, and the earl of Charlemont; and tile commons, four of their members. The delegates proceeded to London, and, in February, 1789 , presented the address to his royal highness, by whom they. 
were most graciously received; but his majesty having, to the infnite joy of all his subjects, recovered from his severe indisposition, the pince returned them an answer fraught with the warmest sentiments of regard for the kingdom, and of gratitude to parliament, for the generous manner in which they proposed investing him with the regency, though the happy recovery of his royal father had now renclered his acceptance of it unnecessary.

The parliament of Ireland afterwards extended liberal indulgences to the Roman-catholics of that kingdom, by establishing the legality of interrarriage between them and the protestants, by admitting then: to tae profession of the law, and the benefit of education, and by r.moving all obstructions upon their inclustry in trade and manufactures; and in the year 1793, in consequence of the concessions of government, a bill passed the legislature, by which the Roman-catholics, being freeholders, were entilled to vote for members to serve in parliament.

But notwithstanding the catholics of Ireland had been restored, in some measure, to their civil rights, by the concession of the elective franchise; it does not appear that either their own leaders or their parliamentary adherents were satisfied with what had been granted, or were likely to be contented with less than a total repeal of all remıaining disqualifications; and when, in the beginning of the year 1795, earl Fitzwilliam was appointed lord-lieutenant of Ireland, after the accession of the Portland party to administration, they considered the point in dispute as absolutely conceded by the ministry. A committee was therefore appointed to bring forward a petition to parliament for a repeal of all remaining disqualifications. Notice of this his lordship transmitted to the minister, stating at the same time his own opinion of the absolute necessity of concession, as a measure not only wise, but essential to the public tranquillity. To this no answer was re'ceived, ard on the 12 th of February Mr. Grattan moved for leave to bring in a bill for the further relief of his majesty's subjects professing the Roman-catholic religion; and after a feeble opposition leave was given. By the intrigues, however, of another political party, at the head of which was a Mr. Beresford, a gentleman who had united in his own person, or in that of his son, the important and discordant offices of minister; commissioner of the treasury; of revenue; counsel to the commissioners; storekeeper, and banker; the measure was defeated, and lord Fitzwilliam suddenly recalled. His lordship left Dublin for England on the 25th of March, which day was observed in that city as a day of general mourning: the shops were shut; no business was transacted; and the citizens appeared in deep mourning. In College-green a number of respectable gentlemen, dressed in black, took the horses from his excellency's carriage, and drew it to the water's side. His lordship wished, as usual on such occasions, to distribute money; but, with the noblest enthusiasm, the offer was rejected, even by a mob." The military had been ordered out, in expectation of some disturbance; but nothing appeared among the populace but the serious emotions of sorrow, and the utmost order and clecorum.

Earl Camden, who was appointed to succeed his lordship, arrived in Dublin on the 31 st of March. The whole system of administration was now changed; all ideas of concession on the part of government were abandoned, and coercive measures alone employed to silence all complaints. Of this harsh and unyielding system, the fac- 
tious and disaffected took advantage to promote their designs, and increase the numbers of their adherents.

About the beginning of the year 1791, the society which has since become so notorious under the name of United Irishmen was instiruted; the ostensible principles of which were parliamentary reform, and what they chose to term catholic emancipation, or a full restoration of the catholics to all the privileges of Irish subjects. This society is said to have owed its origin to a person whose life has since paid the forfeit of his treasonable intrigues, Mr. Theobald Wolfe Tone, and its constitution certainly evinced much ability and political knowledge. The real views of the authors and leaders, which, Iatterly at least, appear to have been no less than to efiect a total separation of the country from Great Britain, and the erection of a republic, after the plan and under the protection of France, were probably scarcely mistrusted by the great body of the members. The first and principal article expressed that " the society was constituted for the purpose of forwarding a brotherhood of affection, a community of rights, and an union of power among Irishmen of every religious persuasion; and thereby to obtain a complete reform in the legislature, founded on the principles of civil, political, and religious liberty." For several years this society, from the secrecy and circumspection with which its affairs were conducted, attracted but litthe the attention of government. But the violence of party disputes which followed on the recal of earl Fitzwilliam, considerably increased the number of its adherents, and added to them several persons of abilities and influence, in particular Mr. Arthur O'Connor, who had distinguished himself by his able support of earl Fitzwilliam's administration in the house of commons; Dr. M'Nevin, who had been chairman of the committee for enforcing the claims set forth in the catholic petition; and Mr. Oliver Bond, an opulent citizen of Dublin, who had been an active supporter of the same principles. From the confession of these very persons, it appears, however, that when they joined this society, the views of its leader's were no longer confined to parliamentary or constitutional relief of any kind; since in the year 1795, through the medium of Mr. Tone, and other Irish refugees who had fled to France, a regular communication was opened between the French directory and the United Irishmen; and in the course of the summer of 1796, lord Edward Fitzgerald proceeded to Switzerland, and had an interview, near the French frontier, with general Hoche, when it is believed the whole plan of an invasion was finally adjusted. An attempt to carry it into execution wasmade in the December following, when the French fleet took the opportunity afforded by a thick fog to elude the vigilance of admiral Colpoys, by whom they had been for several months blocked up in Brest, and set sail for Ireland. But the fleet was dispersed by violent storms : a part of it, however, consisting of eight two-deckers, and nine other vessels of different classes, anchored, on the 24th, in Bantry bay. The violence of the weather preventing any attempt to effect a landing, they quitted the coast on the 27 th in the evening; but an officer and seven men were driven on shore in a boat belonging to one of the French ships. This officer, upon examination, stated that the fleet, when it left Brest, consisted of about fifty sail, and that it had on board twenty-five thousand men, commanded by general Hoche. A considerable degree of alarm was excited in Ireland by the appearance of this armament; but the people in general, in this part of the 
kingdom, evinced the most determined loyalty, and manifested the greatest readiness to meet and resist the enemy, wherever they might attempt a descent.

The failure of the expedition under Hoche, did not, however, discourage the members of the Irish Union; they, on the contrary, endeavoured more firmly-to cement their alliance with France, and established a regular communication and correspondence with that country. New arrangements were made for an invasion; and Dr. M'Nevin, about this time, transmitted to the French government a memorial, in which he stated that 150,000 United Irishmen were enrolled and organized in the province of Ulster. During the summer of 1797 great preparations were therefore made for a second attempt, both at Brest and in the Texel; it having been determined that the Dutch should supply a fleet and land forces to co-operate in this desisn. But this plan was rendered abortive by the memorable victory of lord Duncan over the Dutch fleet, on the 1 lth of October of that year.

In the beginning of the year 1798, Mr. O'Connor came to England, with an intention, as it afterwards appeared, of going over to France, in conjunction with John Binns, an active member of the London Corresponding Society, James Coigley, an Irish priest, and a person of the name of Allen. Being however suspected, they were apprehended, and tried at Maidstone, where they were all acquitted, except Coigley, on whom had been found a treasonable, though extremely absurd paper, purporting to be an address from the "Secret Committee of England to the Executive Directory of France." $\mathrm{He}$ was therefore convicted, and executed. O'Connor, after his acquittal, was detained, on another charge of treason preferred against him, and sent back to Ireland.

In the course of these different negociations with the enemy, the violence of some of the disaffected party in Ireland, could scarcely be restrained from breaking out into open insurrection, without waiting for the promised assistance from the Gallic republic; but they were overruled by those who had more coolness and caution. The government of Ireland, in the mean time, received only obscure and perplexed intelligence of these proceedings, which appear to have been conducted with so much art and secrecy as to prevent adminis. tration from discovering, for a considerable time, the real views and conduct of the society. But at length they received information that a' seditious meeting was to be held at the house of a person of the name of Alexander, ai Belfast, on the 14th of April, 1797; and, in consequence, colonel Barber, with a detachment of soldiers, proceeded on that day to the place of meeting, where he found two societies or committees actually sitting, and seized their papers and minutes, among which were the printed declaration and constitution of the United Irishmen, various reports from provincial and county committees, and several other important documents, which no longer left a doubt respecting the extent and views of this formidable conspiracy. About the same time, likewise, the magistrates in other parts of the kinglom discovered other papers that were circulated by the society, and which served to confirm the discoveries already made, and to throw additional light on the proceedings of the conspirators.

The most active and vigorous measures were now adopted by government. A very considerable addition was made to the military force of the kingdom; a bill was passed prohibiting seditious meet- 
ings; the habeas corpus act was suspended; whole counties were procla med out of the king's peace, and seizures made of great quantities of concealed arms. In the enforcement of these measures, many acts of rigour, and even of cruelty, appear to have been committed by the agents of government; but it should be at the same time remembered, that numerous acts of atrocious barbarity were likewise committed by the rebels. The loyalists knew that if the schemes of their enemies proved successful, the plunder and confiscation of their property was the least evil they had to fear. The concealment and obscurity of the danger, which they knew to be imminent, might well excite a dread, which rendered them incapable of listening to the dictates of moderation, or even in some cases to those of justice.

These rigorous measures were, likewise, in some degree, still further justified by the more complete discovery which government soon after made of the traitorous designs and proceedings of the society. Among other members of it was a Mr. Reynolds, who had formerly been a silk manufacturer of some note in the city of Dublin. He had been sworn a United Irishman in February, 1797, and in the winter following appointed treasurer for the county of Kildare, in which he resicled, and also a colonel in the rebel army. This per. son, whether moved by remorse, and returning love for his country, or by other motives, it is not necessary to inquire, disclosed to government, about the latter end of February, 1798, the nature and extent of the conspiracy ; and a meeting of delegates being summoned for the 12th of March, at the house of Mr. Oliver Bond, he gave information of it ; in consequence of which fourteen of the delegates were apprehended, with their secretary, $\mathbf{M}^{\prime} \mathrm{Can}$; and at the same time Dr. M'Nevin, counscllor Emmet, and some other active members of the societies were taken into custody. A warrant had been issued against lord Edward Fitzgerald, but he cscaped; he was afterwards, howcver, discovered in the place of his concealment, when, on the police officers entering the room, the unhappy nobleman made a clesperate defence : he wounded two of the principal of them, $\mathrm{Mr}$. justice Swan, and captain Ryan, dangerously; and was himself so severely wounded, that he languished a few days only before he expired.

The seizure of the delegates gave a fatal blow to all the plans of the United Irishmen. A new directory was chosen ; but their proceedings were soon disclosed by another informer, a captain Armstrong, who had pretended to enter into the conspiracy with the inten. tion of discovering their schemes, and betraying them to government. The confusion and alarm into which the rebels were thrown by the discovery of their plots, and the apprehending of their leaders, determined them to make a desperate effort: and a general insurrection was resolved on by the military committee, to take place on the $23 \mathrm{~d}$ of March. But government being perfectly informed of the intentions of the conspirators, caused several of the principal of them to be apprehended; on the 19 th and 21 st the city and county of Dublin were proclaimed, by the lord-lieutenant and council, in a state of insurrection; the guards of the castle and of all the principal objects of attack were trebled, and the whole city in fact converted into a garrison. The infatuated multitude, however, implicitly obedient to the directions they had received from their leaders, rose at the time appointed in various parts of the country, and, on the 25th, appeared 
in great force, their number amounting to not less than 15,000 , in the neighbourhood of Wexford and Enniscorthy, and attacked and cut in pieces the whole of a party of the North Cork militia, except colonel Foote, and two privates. They then made an attack, on the $28 \mathrm{th}$, on the town of Enniscorthy, which they carried sword in hand; and on the 30th made themselves masters of Wexford, where they liberated from prison Mr. Beauchamp Bagenal Harvey, who was afterwards nominated to the chief command of their army. Under him, as their general, they attacked the town of New Ross, but were repulsed with great slaughter. They were likewise repulsed in their attacks on some other places. The royal forces, however, suffered a check on the 4 th of June, when the strong post of the rebels being attacked by colonel IValpole, he was unfortunately killed in the beginning of the action, and his corps being in a situation in which it was unable to act, was forced to retire to Arklow. Encouraged by this success, the rebel army, on the 9 th, presented itself before Arlklow, where general Needham commanded a considerable body of the king's troops; but the position that general had taken, and the dispositions he made, were such that they were defeated with great loss.

On the 2 lst of June, general Lake made his grand attack on the strong position of the rebels on Vinegar-hill, near Enniscorthy, having gradually collected troops from every part till he had almost surrounded them. They maintained their ground obstinately for an hour and a half, but at length fled with precipitation, leaving behind them $\mathbf{2}$ great number of killed and wounded; and thirteen small pieces of ordnance of different calibres.

Immediately after this action, a large body of the king's forces advanced to IVexford, which general Moore entered so opportunely, as to prevent the town from being laid in ashes. The rebels, before they evacuated the town, offered to treat; but general Lake refused to sign any terms with rebels with arms in their hands; though to the deluded multitude he promised pardon, on condition of delivering up their leaders and returning to their allegiance. The rebel troops immediately evacuated the town. Their general, Bagenal Harvey, had quitted them soon after the battle of New Ross; but being discovered and taken with some others in a cave, he was tried by a court-martial, and executed on the bridge of Wexford.

In the beginning of June alarming commotions likewise took place in the north of Ireland, and the insurrection soon became almost general in the counties of Down and Antrim; but on the 12th the rebels received a complete defeat at Ballynahinch, were they lost upwards of four hundred men. They fought with great obstinacy, and their leader Munro was taken prisoner, and afterwards executed.

The Fnglish government, in the mean time, though not dissatisfied with the conduct of lord Camden, resolved to give Ireland a military lord-lieutenant; and the marquis Cornwallis arrived at Dublin in that capacity on the 20th of June, and immediately assumed the reins of government. The conduct of his lordship was temperate and jucicious. On the 17 th of July he sent a message to the house of commons by lord Castlereagh, intimating that he had received his majesty's coinmands to acquaint them, "that he had signified his gracious intention of granting a general pardon for all offences committed on or before a certain day, upon such conditions, and with such exceptions, as might be compatible with the general safety,"

TOL. I.

$\mathrm{U} u$ 
But "these offers of mercy to the repentant were not to preclude measures of vigour against the obstinate."

A special commission was now opened in Dublin for the trial of the principal delinquents; several of whom were tried and executed. Among them Mr. Oliver Bond was tried, convicted, and condemned; and in his fate the other conspirators began to foresee their own. The rebellion appeared to be completely crushed; the fugitive rebels were every where returning to their allegiance, and delivering up their arms, and no bope remained of any effectual assistance from France. In this situation a negotiation was opened between the Irish government and the state prisoners; the issue of which was, that government consented to pardon Mr. Bond, and desist from any further prosecution of the other leaders of the conspiracy, who, on their parts engaged to make a full confession of all the proceedings and plans of the society; after which they were to be permitted to transport themselves to any country not at war with his majesty. The information they communicated was laid before the Irish house of commons, and has furnished materials for the brief account here given. Mr. Oliver Bond survived his pardon only a few days; and Mr. Arthur O'Connor, Dr. M'Nevin, and the rest, after having been a considerable time confined in Ireland, were removed to prisons in Scotland; whence, after the conclusion of the late peace, they were permitted to transport themselves to France, where they still remain.

After the failure of the expedition under general Hoche, France, fortunately for Great Britain, made no attempt to assist the Irish insurgents till it was too late; and the aid then sent was very feeble, and inadequate to the end proposed. On the 22d of August, some frigates and transports from France appeared in Killala bay, and landed about a thousand men, with a quantity of arms and ammunition. The number of insurgents who joined the invaders was not considerable; but the French general Humbert, by his conduct, proved himself an officer of ability, and worthy of command where there was a fairer prospect of success. He advanced without loss of time to Castlebar, where general Lake was collecting his forces, attacked, and compelled him to retreat with the loss of six pieces of camnon and a few men; after which he advanced towards Tuam: but on the 7 th of September the marquis Cornwallis came up with the French in the vicinity of Castlebar, when they retreated, and the next morning, after a slight resistance, surrendered at discretion. The rebels who had joined them were dispersed, and a great number of them killed or taken. Another effort was afterwards made by the French to support, or rather to rekindle the flames of rebellion in Ireland. On the 17 th of Séptember a fleet sailed from France, consisting of one ship of the line (the Hoche) and eight frigates, with troops and ammunition on board, destined for Ireland; but this armament was completely defeated by the squadron under the command of sir John Borlase VVarren, as has been already related in our summary of the affairs of England.

The few remaining troops of rebels, who were dispersed among the woods and mountains, now successively laid down their arms. A chief of the name of Holt, at the head of a number of banditti, continued for some time to commit depredations in the mountainous parts of the county of Wicklow: but at last it was believed that he made terms with government, and was permitted to save his life by relin quishing for ever his native country. 
Every estimate of the number of those who lost their lives in this deplorable contest must necessarily be vague and uncertain. Some have stated it at thirty thousand, while others have swelled it to a hundred thousand, of whom they say nine-tenths were of the insurgents ; the loss of the royalists being about ten thousand men. Slaughter and desolation at length procured a kind of peace; but the great problem was, to discover by what means the flames of discord night be prevented from bursting out afresh. As the most effectual preventative of a repetition of these calamities, government recommended a legislative union of the two kingdoms. A proposition for such an union was submitted to the parliaments of England and Ireland on the same day, January 22, 1799, and in both houses of the English parliament, the address, which is considered as an approbation of the measure, passed without division. A similar address was carried in the Irish house of lords by a majority of thirty-three, but rejected in the commons by a majority of two, which the next day increased to six against the measure, which was therefore laid aside for that time. Government, however, by no means lotally abandoned it; for, in the beginning of the next session, on the 15 th of January, 1800, the proposition was again submitted to the parliament of Ireland; when the address in the house of lords passed without a debate; and, after an animated discussion in the commons, which lasted till the noon of the following day, was approved by a majority of forty-two. The aet of union afterwards passed the British parliament, received the royal assent on the $2 \mathrm{~d}$ of July, 1800, and took place on the 1st of January, 1801 .

How far this union will prove a remedy for the distressed condition and discontents of the poor, time must discover. At first view it seems difficult to say how a legislative union can remove the cause of the civil commotions which have lately distracted that unfortunate kingdom; how it can lessen religious prejudices, or prevent, what it seems rather calculated to increase, the expenditure of Irish property at a clistance from the country whence it is derived. Yet it must not be denied, that unity in government has many advantages, and is indeed essentially necessary ; and that a close connexion and firm consolidation of the three kingdoms, with an impartial and equal distribution of protection and rights, fairly granted and faithfully maintained, must tend to infuse new life into every part of the united nation, while it adds to the prosperity, the wealth, and the power of the whole.

Notwithstanding the union, however, a spirit of discontent and disaffection still manifests itself among the lower orders in many parts of Ireland. The agents of the leaders in the last rebellion, who, after the late peace, were permitted to transport themselves to France, soon renewed their attempts to excite an insurrection similar to the former: but, fearing that their designs were discovered, in consequence of the blowing up of a house in which they had concealed a quantity of gunpowder and arms, they were induced to rise before their plans were matured. On the 2sd of July, 1803, great numbers of persons of the lower classes suddenly flocked to Dublin from different parts of the country; and a riotous mob assembled with a view to surprise the castle. Meeting in Thomas-street with lord Kilwarden, the chief justice of Ireland, who had conducted the prosecutions after the last rebellion, as attorney-general, they forced him and his nephew, who was with him, out of his carriage, and barbar. 
ously murdered them with their pikes. The delay which the perpetration of this atrocious act occasioned, lias been supposed (so little were government apprised of their designs) to have saved the castle, by affording time for the Liberty Pangers, and some regular troops, to collect, who attacked and cispersed them, but not till lieutenantcolonel Brown, of the 21 st regiment, and six or seven others of the military had unfortunately lost their lives. Many persons were apprehencled and tried, and several suffered death, for this feeble and frantic attempt at rebellion. Among those executed was Emmet, the son of the counsellor of that name, who, it is probable, was the principal director and leader of the misguided rabble. Government has since taken the necessary precautions to guard against the danger of any similar attempts, and the country now appears to be in a tolerable state of tranquillity. 


\section{FRANCE.}

\section{EXTENT AND SITUATION.}

\section{Miles. $\left.\begin{array}{l}\text { Length } 610 \\ \text { Breadth } 560\end{array}\right\}$ between $\left\{\begin{array}{r}42^{\circ} \text { and } 51^{\circ} \text { North latitude. } \\ 5^{\circ} \text { West and } 8^{\circ} \text { East longitude. }\end{array}\right.$}

France, before the revolution, contained, 161,810 square miles, with 172 inhabitants to each.

Under Bonaparte, including all the conquered countries annexed to its territories, it contained 244,270 square miles, with 178 inhabitants to each.

After the restoration it was again reduced to nearly its ancient limits.

NAME....France took its name from the Francs, or Freemen, a German nation, restless and enterprising, who conquered the Gauls, the ancient inhabitants : and the Roman force not being able to repress them, they were permitted to settle in the country by treaty.

Boundaries....It is bounded by the English channel and Holland on the north ; by Italy, Switzerland, and Germany, from which it is separated by the Rhine, on the east; by the Mediterranean and the Pyrenean mountains, which divide it from Spain, on the south; and by the bay of Biscay on the west.

Divisions.... The ancient provinces of France were divided by the first national assembly into 8.3 departments, whicn were increased by new acquisitions to 108 , including the six departments into which Piedmont afterwards was divided. The situation, names, extent in square miles, and population of these departments, according to the accounts lately published by the French government, are as follows:

Ancient Provinces.

Departments. Chief Towns.

Square Population.

French Flanders

Nord . . Lille . . . 1758

Artois . . Pas de Calais

Picardy . . Somme

Normandy . $\left\{\begin{array}{l}\text { Lower Seine } \\ \text { Calvados . } \\ \text { Manche . }\end{array}\right.$

Arras . . . 2054

Amiens . . 1900

Pouen . . . 1858

Caen . . . 1645

Coutances . 2009

839,833

570,836

465,034

642,773

480,317

Orne . .

Alençon . . 1859

566,826

Eure .

Evreux.

425,920

415,574

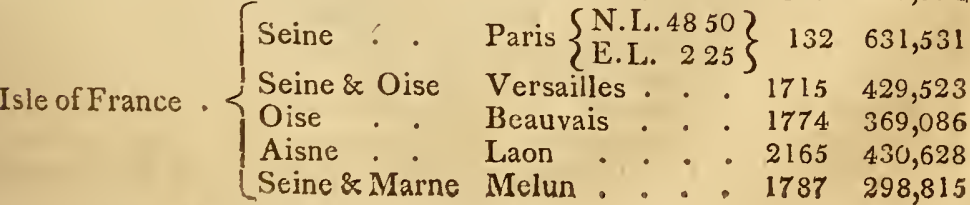


Ancient Provinces.

Departments.

Chief Towns.

Square Populs.
Miles.

Marne . Rheims . . $2473 \quad 310,493$

Champagne . $\left\{\begin{array}{l}\text { Ardennes . Sedan . . . } 1820 \quad 264,036 \\ \text { Udper }\end{array}\right.$

Aube . . Troyes . . . 1820240,661

U Upper Marne Chaumont . . $1907 \quad 237,785$

$\left\{\begin{array}{l}\text { Meuse }: \text { Bar sur Ornain }: 1830284,703 \\ \text { Moselle }: \text { Metz . } 1910371,957\end{array}\right.$

Lorraine . \{ Meurthe.. Nancy ... . 1875 342,107

Vosges : Epinal : : $1902 \quad 334,169$

Alsace. $\quad\left\{\begin{array}{llll}\text { Lower Rhine } & \text { Strasburg: : } & 1661 & 488,350 \\ \text { Upper Rhine Colmar. . } & 1758 & 404,018\end{array}\right.$

Isle and Vilaine Rennes . . . $2087 \quad 501,528$

Lower Loire Nantes . . . . $2232 \quad 368,506$

Bretagne . . Cotes du Nord St. Brieux .. . 2207510,456

Finisterre . Brest . . . $2226 \quad 474,349$

Morbihan . Vannes • . 2061 425,485

Maine \& Perche $\left\{\begin{array}{l}\text { Sarthe } \\ \text { Mayenne : : Le Mans : : : } 1886410,380\end{array}\right.$

Anjou . . $\left\{\begin{array}{c}\text { Mayenne and } \\ \text { Loire .. }\end{array}\right\}$ Angers .. $2227 \quad 376,033$

Touraine . . Indre and Loire Tours . . . $1882 \quad 278,758$

$\left\{\begin{array}{l}\text { Loiret . O Orleans • . } 2055289,728 \\ \text { Luren }\end{array}\right.$

Orleannois . $\left\{\begin{array}{l}\text { Eure and Loire Chartres . . } 1794259,967 \\ \text { Loire an Chis }\end{array}\right.$

Berry . . Sher ... Bourges . . 2154218,297

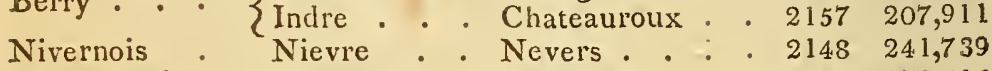

Bourbonnois . Allier . . Moulins . . 2165272,616

' Yonne . . Auxerre . . $2257 \quad 333,278$

Burgundy.$\left\{\begin{array}{l}\text { Cote d'Or Dijon . . . } 2681347,842 \\ \text { Sand }\end{array}\right.$

Saone \& Loire Macon . . . . 26004447,565
U Upper Saone Vesoul . . 1628294,936

Franche Comté $\left\{\begin{array}{l}\text { Doubs .. . Besançon . . } 1557227,075 \\ \text { Duras }\end{array}\right.$

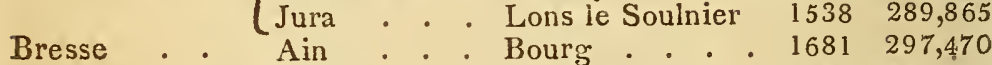

$\left\{\begin{array}{l}\text { Vienne . Poitiers . . } 21412250,807 \\ \text { Vendee }\end{array}\right.$

Poitou . . $\{$ Deux Sevres Niort . . . 1848 242,658

Vendee . Fontenay le Comte 2112 270,271

$\left.\begin{array}{c}\text { Saintonge and } \\ \text { Aunis . . }\end{array} \begin{array}{c}\text { Lower Cha- } \\ \text { rente }\end{array}\right\}$ Saintes . . . $2114 \quad 402,105$

Angoumois . Charente . - Angouleme . . 1840 321,477

Marche . C Creuse . . Gueret . . 1721 226,224

Limosin . SUpper V:ienne Limoges . . 1750 259,795

\{orreze.. Tulles . . . 1708 243,654

Auvergne . SPuy de Dome Clermont . . 2464 508,444

Shhone : Lyons . . 856345,644

Lyonnois . \{ $\begin{aligned} & \text { Roire . . Montbrison : . } 1498 \text { 292,588 } \\ & \text { Lois }\end{aligned}$

Dauphine
Guyenne.
Perigord. 
Ancient Provinces.

Departments. Chief Towns,

Snuare

Miles.

Popula.

tion.

Quercy . .

Lot . . Cahors

383,683

Rovergue and Marche.

\{Aveyron : Rodes . . . 2764

328,195

Landes . Mont de Marson 2763

Gers . . Auch . . . 2055

236,039

291,845

Gascony . Arriege . Tarascon . . 1473

191,693

Upper Pyre-? nees $\cdot\}$

Tarbes . . . 1440

206,680

Bearn . . $\left\{\begin{array}{c}\text { Lower Pyre- } \\ \text { nees }\end{array}\right\}$

Pau . . . . 2354

384,030

Rousillon .

Languedoc Eastern $\dot{\mathrm{P}} \mathrm{y}-\{$

Perpignan

126,626 Upper Ga-

Toulouse . . 2356

432,263

Tarn . . Castres . . 1774

272,163

Aucle . . Carcassone . . 1908

Herault . . Montpellier . . 1982

Gard . . . Nismes . . 1832

226,198

301,099

322,144

Cevennes. $\left\{\begin{array}{l}\text { Lozcre } \cdot \text { Mende }: \text { : }: 1572 \\ \text { Ardeche }: \text { Privas } 1665\end{array}\right.$

155,936

290,833

Upper Loire Le Puy . . . 1540 261,512

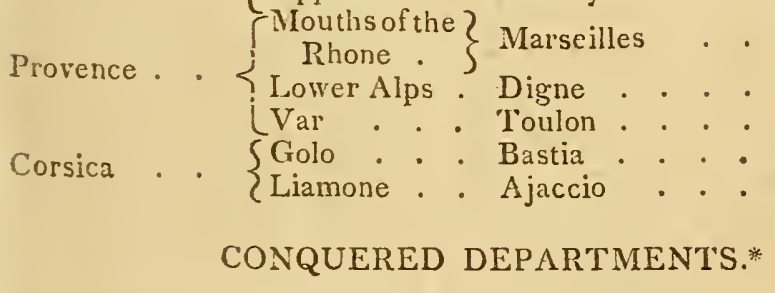

Ancient Sames.

Departments. Chief Towns.

Square Popula:
Miles.

Territory of A-

vignon and

County of Ve- $\{$ Vaucluse . Avignon . . 1079 190,180 naissin .

Savoy .

Mont Blanc.

Chambery . . 664

296,336

County of Nice Maritime Alps Nice . . . 1008 128,814

City and territo -\{

ry of Geneva Leman

Geneva . . . 1140

215,884

\section{NETHERLANDS.}

Ancient Names.

Departments. Chief Towns.

Square Popula
Miles.

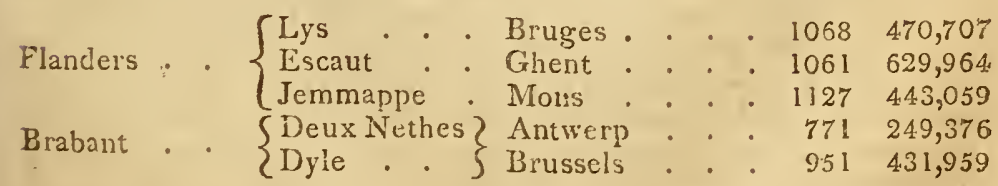

* These departments are given to show the extent of the late empire, although they no longer form a part of the French territory. 


\begin{tabular}{|c|c|c|c|c|c|c|}
\hline Ancient Names. & Departments. & Chief Towng. & & & $\begin{array}{l}\text { Square } \\
\text { Miles. }\end{array}$ & $\begin{array}{c}\text { Popula: } \\
\text { tion. }\end{array}$ \\
\hline $\begin{array}{l}\text { Duchy of Guel } \\
\text { derland }\end{array}$ & Lower Meuse & Maestricht & & & 2056 & 267,249 \\
\hline $\begin{array}{l}\text { Liege \& Duch } \\
\text { of Limbourg }\end{array}$ & Ourthe . & Liege . & - & $\cdots \quad \bullet$ & 2167 & 313,876 \\
\hline $\begin{array}{l}\text { County of } \mathrm{Na} \\
\text { mur }\end{array}$ & $\left.\begin{array}{c}\text { Sambre and } \\
\text { Meuse }\end{array}\right\}$ & Namur . & - & - & 1343 & 180,655 \\
\hline $\begin{array}{l}\text { Duchy of Lux } \\
\text { emburg }\end{array}$ & Forets . . & Luxembur & & - & 2065 & 225,549 \\
\hline GERMAN 'I' & $\begin{array}{r}\text { RITORY ON } \\
\text { RH }\end{array}$ & $\begin{array}{l}\text { THE LEF } \\
\text { INE. }\end{array}$ & & BANI & & THE \\
\hline Ancient Names. & Departments. & Chief Towns. & & & $\begin{array}{l}\text { Square } \\
\text { Miles. }\end{array}$ & \\
\hline $\begin{array}{l}\text { Archbishopric } \\
\text { of Cologne }\end{array}$ & Roer . . & Cologne & • & - & 1953 & 616,287 \\
\hline $\begin{array}{l}\text { Archbishopric } \\
\text { of Treves }\end{array}$ & $\left.\begin{array}{c}\text { Rhine \& Mo- } \\
\text { selle }\end{array}\right\}$ & Coblentz & • & $\cdot \cdot$ & 1415 & 248,814 \\
\hline $\begin{array}{l}\text { Duchy of Deux } \\
\text { Ponts }\end{array}$ & Sarre . . & Treves. & - & $\cdot \cdot$ & 1878 & 259,522 \\
\hline $\begin{array}{l}\text { Archbishopric } \\
\text { of Mentz . }\end{array}$ & Mont Tonnere & Mentz . & d & - 1 & 1779 & 342,316 \\
\hline
\end{tabular}

\section{PIEDMONT.}

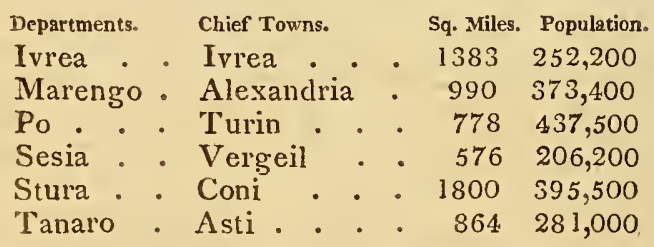

Holland, which was added to France in 1810, contains 12,662 square miles, and 2,001,416 inhabitants.

Each department is divided into three, four, or five districts, called communal arrondissements. These districts are again subdivided into cantons, which are composed of a certain number of communes. A commune is sometimes a single town, and sometimes a union of several villages, possessing a mayor and communal municipality. All the considerable cities are divided into several communes.

FACE OF THE country.... France is in general a plain country, and its appearance is very various in different parts. The departments of Upper Vienne and Correze, and others in the south, afford many rich and beautiful landscapes; while those of the old provinces of Bretagne, Anjou, and Maine, present extensive wastes of heath, and have almost the appearance of a desert.

Mountarns... The chief mountains in France, or its borders, are the Alps, which divide France from Italy; the Pyrenees, which divide France from Spain; the Vosges, which separate the department of that name from the departments of Upper Saone and Upper Rhine; Mount Jura, which divides France from Switzerland; the Cevennes, in the late province of Languedoc; and Mount d'Or, in Puy de Dome.

Forests... The chief forests of France are those of Orleans, which contain 14,000 acres of wood of various kinds, oak, elm, ash, \&c. and 
the forest of Fontainebleau, near as large; and near Morchismoir is a torest of tall, straight timber, of 4000 trees. Besides these, there are numbers of woods, some of them deserving the name of forests, in different departments; but too remote from sea-carriage to be of much national utility.

LAKES....Few lakes are found in this country. There is one at the top of a hill near Alegre, which is so deep that the vulgar report it to be bottomless. There is another at Issoire, in Puy de Dome : and one at la Besse, into which if a stone be thrown, it causes a noise like thunder,

RIVERs....The principal rivers in France are the Loire, the Rhone, the Garonne, and the Seine. The Loire takes its course north and north-west, being, with all its windings from its source to the sea, computed to run about 500 miles. The Rhone flows on the southwest to Lyons, and then runs on due south, till it falls into the Mediterranean.' The Garonne rises in the Pyrenean mountains, takes its course first north-east, and has a communication with the Mediterranean, by means of a canal, the work of Lewis XIV. The Seine, soon after its rise, runs to the north-west, visiting Troyes, Paris, and Rouen, in its way, and falls into the English Channel at Havre. 'To these we may add the Saone, which falls into the Rhope at Lyons; the Charente, which rises near Havre de Grace, and discharges itself in the bay of Biscay at Rochefort; the Rhine, which rises in Switzeriand, is the eastern boundary between France and Grermany, and receives the Moselle and the Sarte in its passage; the Somme, which rises in the department of Aisne, and passing by St. Quentin, Peronne, and Amiens, falls into the English Channel below Abbeville; the Var, which rises in the Alps, and runs south, dividing France from Italy, and falling into the Mediterranean, west of Nice; and the Adour, which rises in the department of the Upper Pyrenees, and running from east to west by Tarbes and Dax, falls into the bay of Biscay, below Bayonne.

Canals....The vast advantage, both in commerce and conveniency; which arises to France from those rivers, is wonderfully improved by the artificial rivers and canals which form the chief glory of the reign of Lewis XIV. That of Languedoc was begun in the year 1666 , and completed in 1680; it was intended for a communication between the ocean and the Mediterranean, for the speedier passage of the French fleet : but though it was carried on at an immense expense for 100 miles, over hills and vallies, and even through a mountain in one place, it has not answered that purpose. By the canal of Paris, travellers easily pass by water from thence to St. Omer, Gra. veline, Dunkirk, Ypres, and other places. The canal of Orleans is another noble work, and runs a course of eighteen leagues, to the im= mense benefit of the public and the royal revenue. France abounds with other canals of the like kind, which render her inland navigation inexpressibly commodious and beneficial.

Mineral wateis, and remarkable springs.... The waters of Barrege, which lie near the borders of Spain, under the Pyrenean mountains, have been preferred to all the others of France, for the recovery of health : but probably the cures performed by them are more owing to their acciciental success with some great persons, and the salubrity of the air and soil, than to the virtues of the waters. The waters of Sultzbach, in the department of the Upper Phine, are said to ${ }^{\circ}$ cure the palsy, weak nerves, and the stone. At Bagneres, not 
far from Barrege, are celebrated mineral waters and baths, to which people resort as to the English baths, at spring and autumn. Forges, in the department of the Lower Seine, is celebrated for its mineral waters; and those of St. Amand cure the gravel and obstructions. It would be endless to enumerate all the other real or pretended mineral wells in France, as well as many remarkable springs; but there is one near Aigne, in Puy de Dome, which boils violently, and makes a noise like water thrown upon lime; it has little or no taste, but has a poisonous quality, and the birds that drink of it, it is said, die instantly.

Metals and Minerals....France has many unworked mines, which would be very productive, if duly attended to; but at present do not yield minerals sufficient for consumption. The value of the iron, copper, tin, and other metals, imported from abroad, in a raw state, amounted, in the year 1787 , to $900,000 \mathrm{l}$. and that of manufactured steel to above 250,000l. Exertions have, however, since been made to work the native mines of iron, with which the northern departments especially abound; and, in 1798, it was computed that there were 2000 furnaces and forges for the working of iron and steel. The late province of Languedoc is said to contain veins of gold and silver. Alsace has mines of silver and copper, but they are too expensive to be wrought. Alabaster, black marble, jasper, and coal, are found in many parts of the kingdom. Bretagne abounds in mines of iron, copper, tin, and lead. Saltpetre is made in every part of the kingdom, and sea-salt is now procured free from oppressive duty, but not remarkable for its purity. At Laverdau, in Cominges, there is a mine of chalk. At Berry there is a mine of ochre; which serves for melting of metals, and for dyeing, particularly the best drab cloth: and in the province of Anjou are several quarries of fine white stone. Some excellent turquoises (the only gem that France produces) are found in Languedoc; and great care is taken to keep the mines of marble and free stone open all over the kingdom.

Climate, soll, and Agriculture....The air, particularly that of the interior parts of the country, is in general mild and wholesome; but some authors think it is not nearly so salubrious as is pretended; and it must be acknowledged, that the French have been but too successful in giving the inhabitants of Great Britain false prepossessions in favour of their own country. It must indeed be owned, that their weather is more clear and settled than in England. In the northern provinces, however, the winters are more intensely cold, and the inhabitants not so well supplied with firing, which in France is chiefily of wood. The soil is excellent, and produces corn, wine, oil, and almost every luxury of life. Some of the fruits have a higher flavour than those of England; but neither the pasturage nor tillage are comparable to ours. The heats, in many parts, burn up the ground, so that it has no verdure; and the soil barely produces as much rye and chesnuts as serve to subsist the poor inhabitants.

Notwithstanding the great efforts made in agriculture, much of the land remains uncultivated; and although some provinces, as $\mathrm{Al}$ sace and Languedoc, yield an exuberance of corn, it is frequently im. ported.

Vegetables.... Oak, elm, ash, and other timber, common in Eng. land, is found in France; but it is said, that the internal parts of the kingdom begin to feel the want of fuel. France abounds in esculent roots, in all kinds of sallads, and in excellent fruits, particularly 
grapes, figs, prunes, chesnuts, apples in the northern provinces, and capers in the southern. It produces annually, though not enough for consumption, above twelve million pounds of tobacco, besides hemp, flax, manna, saffron, and many drugs. Alsace, Burgundy, Lorrain, and especially the Pyrenean mountains, supply it plentifully. with timber and other wood. Silk is so abundantly produced, besides what is imported, as to afford a considerable trade. The province of Gatinois produces great quantities of saffron. The wines of Champagne, Burgundy, Bourdeaux, Gascony, and other provinces of France; are so well known, that they need only to be mentioned. It is sufficient to observe, that though they differ very sensibly in their taste and properties, yet all of them are excellent, particularly those of Champagne, Burgundy, Bourdeaux, Pontacke, Hermitage, and Frontiniac : and there are few constitutions, be they ever so valetudinary to which some one or other of them is not adapted.

Wine, the staple, is made to the value of $15,000,000 l$. annually, more than an eighth part of which, besides brandy and vinegar, was exported. Olive oil is made in large quantities, particularly in the provinces next the Mediterranean; but the consumption is so great that much of it is imported from Italy; the inferior sort supplies the soap manufactories of Marseilles. Languedoc produces an herb called kali, which, when burnt, makes excellent barilla, or pot-ashes. 'The French formerly were famous for horticulture, but they are at present far inferior to the English both in the management and clisposition. of their gardens. Prunes and capers are produced at Bourdeaux, and near Toulon.

France contains ferw animals, either wild or tame, that are not to be found in England, excepting wolves and wild boars. Their horses, black cattle, and sheep, are far inferior to the English; nor is the wool of their sheep so fine. The hair and skin of the chamois, or mountain goats, are more valuable than those of England. We know of no difference between the marine productions of France and those of England, but that the former is not so well served, even on the seacoast, with saltwater fish.

Natural curiosities.... The natural curiosities of 'France consist chiefly in subterraneous caverns and remarkable springs. Near Salins, in the department of Jura, are several remarkable caves, the extent of which, taken together, is about 400 feet in length, and 60 in breadth. The descent into them is by 40 stone steps, and 20 of wood. At the bottom, by the aid of lighted torches, may be seen six springs of salt water, and two of fresh, gushing out and running with great rapidity. The streams are kept separate by proper trenches, which conduct them into other vaults, supported by large pillars; wherein are placed reservoirs for the reception of the salt water, which is afterwards conveyed to the top by proper engines, and, being put into pans, great quantities of salt are extracted from it. At Baulme, 12 miles from Bescancon, is a cavern above 300 feet urider ground, full of icicles, and at the bottom a little river, which, it is said, flows in the winter, and is frozen in the summer. In the neighbourhood of Nismes is a subterraneous cavern, which, the vulgar pretend, reaches to Arles, passing under the Rhone a distance of 20 rniles.

Among the natural curiosities of this country may likewise be reckoned the plain of $\mathrm{La} \mathrm{Crau}$, in Provence, near the mouth of the Rhone, which is the most singular stony desert perhaps in Europe. 
It it about five leagues in diameter, and contains between 20 and 25 square leagues, or about 150,000 English acres. It is entirely composed of shingle, or round gravel; some of the stones are as large as the head of a man.

Populatron....The population of France, before the revolution, was estimated at about 26,000,0no; but the number of inhabitants in the original territory of France is now found to amount, according to the enumeration lately published by the French government, to 28,700,000. To which if we add the population of the lately united departments, or the countries which the ambition of that government had violently annexed to its own territory, the whole will be swelled to the prodigious amount of 43,425,000.

National character, manners, and customs...The French, in their persons, are rather lower than their neighbours; but they are well proportioned and active, and more free than other nations, in general, from bodily deformities. The ladies are celebrated more for their sprightly wit than personal beauty : the peasantry in general are remarkably ordinary, and are best described by being contrasted , with women of the same rank in England. The upper classes accomplish themselves in the exercises of dancing, fencing, and riding; in the practice of which they excel all their neighbours in skill and gracefulness. They are fond of hunting; and the gentry, before the revolution, had left off their heavy jack-boots, their huge war-saddle, and monstrous curb bridle, in that exercise, and accommodated themselves to the English manners.

The genius and manners of the French are well known, and have been the subject of many able pens. A national vanity is their predominant character : and they are perhaps the only people ever heard of, who have derived great utility from a national weakness. It supports them under misfortunes, and impels them to açtions to which true courage inspires other nations. This character has been conspicuous both in the higher and middling ranks, where it produces excellent officers; and in the common soldiers of France, who, it must be confessed, in the late war against the allied powers, exhibited prodigies of valour. But it cannot be denied that excessive cruelty has marked every step of the revolution, both at home and abroad.

The French affect freedom and wit; but fashionable dresses and diversions engross too much of their conversation. Their diversions are much the same with those of the English; but their gallantry is of a very different complexion. Their altention to the fair degenerates into gross foppery in the men, and in the ladies it is kept up by admitting of indecent freedoms; but the seeming levities of both sexes are seldom attended with that criminality, which, to people not ușed to their manners, they seem to inclicate; nor are the husbands so indifferent as we are apt to imagine about the conduct of their wives. The French are excessively credulous and litigious : but of all people in the world they bear adversity and reduction of cilcumstances with the best grace; though in prosperity many of them are apt to be insolent, vain, arbitrary, and imperious.

The French have been much censured for insincerity; but this charge has been carried too far, and the imputation is generally owing to their excess of civility, which renders their candour suspicious: in private life, they lage certainly many amiable qualities; and a 
great number of instances of generosity and disinterestedness may be tound amongst them.

It is doing the French no more than justice to acknowledge, that, as they are themselves polite, so they have given a polish to the ferocious manners, and even virtues, of other nations. Before the revolution, they were disposed to think very favourably of the Engiish. They both imitate and admire our writers: the names of Bacon, Locke, Newton, Milton, Pope, Addison, Hume, Robertson, Richardson, and many others, are sacred among the French of any education.

With many defects, the French have some good qualities; politeness of manners, attention to strangers, and a general taste for literature among those in the better ranks of life.

The French dress of both sexes is so well known, that it is needless to expatiate upon it here ; but, indeed, their dress in cities and towns is so variable, that it is next to impossible to describe it. They certainly have more invention in that particular than any of their neighbours, and their constantly changing their fashions is of service to their manufactures.

Cities AND chIEF rowns....Paris, the capital of France, is divided into three parts ; the city, the university, and that which was formerly called the town. The city is old Paris; the university and the town are the new. Paris contains more works of public magnificence than utility. Its palaces are showy, and some of its streets, squares, hotels, hospitals, and churches, superbly decorated with a profusion of paintings, tapestry, images, and statues; but Paris, notwithstanding its boasted police, is greatly inferior to London in many of the conveniences of life, and the solid enjoyments of society. Without entering into more minute disquisitions, Paris, it must be owned, is the paradise of splendour and dissipation. The tapestry of the Gobelins* is unequalled for beauty and richness. The Louvre is a building that does honour to architecture itself; it was adorned by many excellent institutions for the arts and sciences, particularly the three academies, and ennobled by the residence of the learned. The Thuilleries, the palace of Luxemburg, where a valuable collection of paintings are shown, the royal palace and library, the guild-hall, and the hospital for invalids, are superb to the highest degree. The city of Paris is said to be fifteen miles in circumference. The streets are very narrow, ancl the houses very high, many of them seven stories. The houses are built of stone, and often contain a different family on every floor. The river Seine, which runs through the centre of the city, is not half so large as the Thames at London; it is too far distant from the sea for the purposes of navigation, and is not furnished, as the Thames, with vessels or boats of any sort; over it are many stone and wooden bridges, which have nothing to recommend them. The streets of Paris are generally crowded, particularly with coaches, which gives that capital the appearance of wealth and grandeur; though, in reality, there is more show than substance. The glittering carriages that dazzle the eyes of strangers are mostly common hacks, hired by the day or week to the numerous foreigners

- One Goblei, a noted dyer at Rheims, was the first who settled in this place, in the reign of Francis $I$, and the house has retained his name ever since: and here the great Colbert, about the year 1667, established that valuable manu. tactory. 
who visit that city; and, in truth, the greatest part of the trade of Paris arises from the constant succession of strangers that arrive daily from every nation and quarter of the globe. This ascendency is undoubtedly owing to the reputation of their language, their public buildings, their libraries, and collections of paintings, that are open to the public; the cheapness of provisions, excellency of the French wines, and, above all, the purity of the air and climate in France. With all these advantages, Paris, in general, will not bear a comparison with London, in the more essential circumstances of a thriving foreign and domestic trade, the cleanliness of their streets, neatness of their houses, especially within; the plenty of water, and that of a better quality than the Seine, which, it is said, disagrees with strangers, as do likewise their small wines. In the houses of Paris most of the floors are of brick, and have no other kind of cleaning than that of being sprinkled with water, and swept once a day. These brick floors, the stone stairs, the want of wainscoting in the rooms, and the thick party-ivalls of stone, are, however, good preservatives against fire, which seldom does any damage in this city. Instead of wainscoting the walls are covered with tapestry or damask. The beds in general are very good, and well ornamented with tester and curtains. Their shops are but poorly stored with soods; and the shop-keepers and tradesmen are an indolent, loitering people. There is a remarkable contrast between this class of persons and those of the same rank in London. In Paris, the women pack up parcels, enter the orders, and do most of the drudgery business of the shop, while the husband loiter's about, talks of the great, of fastions and diversions, and the invincible force of their armies. The Parisians, howevex, as well as the natives of France in general, are remarkably temperate in their living; and to be intoxicated with liquor is considered as infamous. Bread, and all manner of butcher's meat and poultry, are extremely good in Paris; the beef is excellent ; the wine they gererally drink is a very thin kind of Burgundy. The common people, in the summer season, live chiefly on bread, butter, grapes, and strall wine. 'The Parisians, till lately, scarcely knew the use of tea; but they have coffee in plenty. The population of this city has been greatly exaggerated both by the Parisians and by travellers: the number of inhabitants, according to the official statements of the sovernment, is 547,576 .

The environs of Paris are very pleasant, and contain a number of fine seats, small towns, and villages; some of them, being scattered on the edges of hills rising from the Seine, are remarkably delightful.

The palace of Versailles, which stands twelve miles from Paris, though magnificent and expensive beyond conception, and adorned with all that art can furnish, is a collection of buildings, each of exquisite architecture, but not forming a whole, ag reeable to the grand and sublime of that art. The gardens, and water-works (which are supplied by mcans of prodigious engines, across the Seine at Marli, about three miles distance) are astonishing proofs of the fertile genius of man, and highly worthy of a stranger's attention. Trianon, Marli, St. Germain en Laye, Meudon, and other royal palaces, are laid out with taste and judgment; each has its peculiar beauties for the entertainment and amusement of that luxurious court which lately occupied them.

Bourdeaux and Marseilles were formerly cities of extensive com- 
merce and opulence. They still rank next to Paris in population, the -former containing 112,844 , and the latter 111,130 inhabitants.

Lyons, a rich manufacturing city, suffered greatly in the civil wars of the revolution, but is stated still to contain 109,500 inhabitants.

The ancient city of Orleans stands on the Loire, in the department of Loiret, about sixty miles to the south of Paris. It has a noble cathedral, which commands a view of the Loire for an extent of thirty miles, and a stately bridge of nine elliptic arches, nearly a quarter of a mile in length, and forty-five feet broad. The centre arch is above a hundred feet wide. The population of this city is, however, only 36,175 .

Strasburg is a strongly fortified city, and has a Gothic cathedral, the spire of which is 574 feet high.

Brest is a small but very strong town upon the English channel, with a most spacious and finely fortified road and harbour, the best and safest in all the kinglom; yet its entrance is difficult, by reason of many rocks lying under water. At Brest there are docks, magazines for all kinds of naval stores, rope-yards, store-houses, \&c.

Lewis XIV rendered Toulon, from a pitiful village, a sea-port of 'great importance. He fortified both the town and harbour for the reception and protection of the navy. Its old and its new harbour lie contiguous; and, by means of a canal, ships pass from the one to the other, both of them having an outlet into the spacious outer-harbour. Its arsenal, established also by that king, has a particular store-house for each ship of war; its guns, cordage, \&xc. being separately laid up. Here are spacious workshops, for blacksmiths, joiners, carpenters, lock-smiths, carvers, \&c. Its rope-walk, of stone, is 520 toises or fathoms in length, with three-arched walks. Its general magazine supplies whatever may be wanting in the particular store-houses, and contains an immense quantity of all kinds of stores, disposed in the greatest order.

Commerce and Manufactures.....Next to Henry IV, justly styled the Great, the famous Colbert, minister to Lewis XIV, may be called the father of the French commerce and manufactures, Under him there was a great appearance that France would make as illustrious a figure, as a trading, as she did then as a warlike people; but the truth is, the French do not naturally possess that undaunted perseverance which is necessary for commerce and colonization; though no people, in theory, understand them better. It is to be considered at the same time, that France, by her situation, by the turn of her inhabitants for certain manufactures, and the happiness of her soil, must be always possessed of great inland and neighbouring trade.

The silk manufacture was introduced into France so late as the reign of Henry IV; and in the age of his grandson, Lewis XIV, the city of Tours alone employed 8000 looms and 800 mills. The city of Lyons then employed 18,000 looms; but after the impolitic and unjust revocation of the edict of Nantes, the expulsion of the protestants, and the ruinous wars maintained by France, they decreased to 4000; and their silk manufacture is now rivalled by that of England, where the French protestants took refuge, and were happily encouraged. Next to Tours and Lyons, Paris, Chatillon, and Nismes, are most celebrated for silk manufactures. France, before the revolution, contaired 1500 silk mills, 21,000 looms for stuffs, 12,000 for ribbands and lace, 20,000 for silk stockings, all of which employed two mil- 
lions of people. They also manufacture gloves and stockings from spider-silk. On the other hand, the French woollen cloths and stuffs, more especially at Abbeville, Amiens, and Paris, are said now to be little inferior to those of England, and have greatly injured them, particularly in the Turkish market, assisted by the clandestine im. portation of English and Irish wool, and workmen.

In manufactures, the French have always been distinguished for their invention, and the English for their superior improvement. Abbeville is famous for cloth, linen, sail-cloth, and soap; Auvergne for fine thread, lace, stuffs, and paper; Nismes for fine serges; Cambray for cambrics; St. Quentin for lawns; and Picardy for plate glass.

Mr. Anderson gives the following account of the trade of France before the revolution: "Her land trade to Switzerland and Italy is by way of Lyons; to Germany, through Metz and Strasburg; to the Necheriands, through Lisle; to Spain (a most profitable one) through Bayonne and Perpignan. As for her naval commerce, her ports in the Channel, and on the Western Ocean, are frequented by all the trading nations in Europe, to the great advantage of France, more especially respecting what is carried on with England, Holland, and Italy. The trade from her Mediterranean ports (more particularly from Marseilles) with Turkey and Africa, has long been very considerable. The negro trade from Guinea supplies her sugar colonies, besides the gold, ivory, and drugs, got from thence."

- The exports are wine, vinegar, brandy, oil, silks, satins, linens, woollen cloth, tàpestries, laces, gold and silver embroideries, toys, trinkets, perfumery, paper, prints, books, drugs, dyes, \&c. The im. ports are hardware, earthen-ware, cottons, metals, hemp, flax, silk, wool, horses, East and West India goods, \&x. Before the revolution France employed one million tons of shipping, with near 50,000 sea= men; the imports were valued at $9,583,333 l$. the exports at $12,500,000 l$. and the nation had a balance of trade of more than two million in its favour; but its manufactures have since greatly declined, and its fo. reign commerce was totally annihilated during the last war with Fngland, the superiority of the British navy scarcely suffering a French vessel to appear on the ocean. The restoration of her colonies, and her present friendly understanding with England, will no doubt revive the commerce of France.

Constitution and government....France, by the revolution in 1789 , founded a new constitution, upon the principle that all men are free, and equal in their rights. After the death of the king, in the year 1793, another constitution was framed, and adopted, which was again succeeded by another, usually called the constitution of the third year. By this constitution the government was vested in a directory of five members; and a legislative body composed of a council of ancients, of two hundred and fifty members, and a council of five hundred.

But in November, 1799, this constitution was likewise overthrown, and a new form of government erected, consisting of what is called a conservative senate of eighty members; a tribunate of one hundred; a legislative body of three hundred; and three consuls, nominated for ten years and indefinitely re-eligible. The first consul, which office was held by general Bonaparte, possessed all the real powers of government. Bonaparte soon procured himself to be declared consul for life; and afterwards assumed the title and authority. 
of emperor, which he exercised in the most arbitrary manner. The present constitution adopted at the restoration is as follows :

The French people are equal in the eye of the law, whatever otherwise are their titles and ranks. They contribute without distinction in proportion to their fortune to the expenses of the state. They are all equally admissable to civil and military employments. Their ind.vidual liberty is equally guaranteed; no person can be prosecuted and arrested, but in cases provided by the law, and in the forms which that prescribes. Every one professes his religion with equal liberty, and enjoys the same protection in his worship. In the mean time the Catholic, Apostolic, and Romish Religion, is the religion of the state. The ministers of the Catholic, Apostolic, and Romish religion, and those of other modes of Christian worship, receive support from the royal treasury alone. The French people have the right to publish and print their opinions in conformity to the laws which ought to repress the abuse of this liberty. All property is inviolable, with out any exception of that which is called national, the law making no distinction. The state can demand the sacrifice of individual property for the public benefit legally proved; but with a previous indemnity.

The person of the king is inviolable and sacred. His ministers are responsible. To the king alone belongs the executive power. The king is the supreme chief of the state, commands the forces by land and sea and declares war, makes treaties of peace, alliance, and commerce, appoints to all employments of public administration, and makes the regulations and decrees for the execution of the laws and the safety of the state. The legislative power is exercised collectively by the king, the house of peers, and the house of deputies of departments. The king proposes the law. The proposition of a law is carried at the will of the king, to the house of peers, or to that of deputies, except laws for raising revenue, which must be first addressed to the house of deputies. Every law must be freely discussed and voted for by a majority of each of the two houses. The houses have the right to supplicate the king to propose a law upon any subject, and to point out what it appears to them proper the laws should contain. This request may be made by each of the two houses, but after having been discussed in secret committee, it shall not be sent to the other house by that which proposed it, until after a delay of ten days. If the proposition is aciopted by the other house, it shall be submitted to the eyes of the king; if he rejects it, it shall not be again brought forward the same session. The king alone sanctions and promulgates the laws. The civil list is fixed for the whole duration of the reign by the first legislature assembled after the acces= sion of the king.

The house of peers is an essential part of the legislative body. It is convoked by the king, at the same time with the house of deputies of departments. Every assembly of the house of peers which shall be hoiden out of the time of the session of the house of deputies, ol which shall not be convened by a clecree of the king, is unlawful and entirely null. The nomination of peers of France belongs to the king. Their number is unlimited. He may vary their dignities, name them for life, or make them hereditary according to his pleasure. The peers have admittance into the house at 25 years of age, but have not a deliberative voice until 30 . The chancellor of France presicles in the house of peers, and in his absence a peer named by 
the king. 'The members of the royal family and the princes of the blood are peers by right of birth. They take their seats immeciately after the president: but have no deliberative voice until they are 25 years of age. The princes cannot take their seats in the nouse, but on the order of the king, expressed at each session by a mes. sage, on penalty of rendering void every thing that shall be cone in their presence. All the deliberations of the house of peers are secret. The house of peers takes cognizance of the crimes of high treason, and attempts against the safety of the state, which are disfined by law. No peer can be arrested but by an authority of the house, and judged by it in criminal matters.

The house of deputies is composed of deputies elected by the clectoral colleges, the organization of which is determined by law. The deputies are elected for tive years, and in such manner that the house is renewed for one fifth part every year. No deputy can be admitted into the house unless he is 40 years of age, and unless he pays a direct contribution of 1000 francs. If, however, there are not found in the department 50 persons of the age mentioned, paying at least 1000 francs direct concribution, their number is computed by those who are highest taxed below 1000 francs, and these cannot be elected concurrently with the first. The elcctors who concur in the nomination of deputies, camnot have the right of suffragc, unless they pay a direct contribution of 300 francs, or if they are under thirty years of age. The presidents of the electoral collegges are appointed by the king, and of right members of the collegc. A half, at least, of the deputies must be chosen among candidates who have their political domicil with the department. The president of the house of deputies is appointed by the king from a list of five members presented by the house. The sittings of the house are public; but the request of five members is sufficient to require them to sit in secret committee. The house resolves itself into a board to discuss projects which have been presented to it by the king. No amendment can be made to a law, unless it is proposed in committee by the king, and unless it has been sent and discussed at the board. The house of deputies receives all propositions for imposts, and it is not till after these propositions have been acceded to, that they can be carried to the house of peers. No impost can be established or levied that has not been consented to by the two houses and sanctioned by the king. A land tax can be consented to for but one year.-Indirect taxes may be for many years. The king convenes the two houses every year - He prorogues them, and may dissolve that of the deputies of the departments; but in that case he must convolie a new one in the cour'se of three months. No constraint upon the body of any member of the house, can be exercised during the session, or within six weeks which precede or follow it. No member of the house can, during the continuance of the session, be prosccuted or arrested in: a criminal matter, except in case of a flagrant offence, and after the house has permitted the prosecution. No petition to either of the houses can be made and presented, except in writing. The law forbids presenting them in person and at the bar.

The ministers may be members of the house of pecrs or of the house of deputies. - They have besides admission into either house, and are to be heard whenever they demand it. The house of deputies has the right of accusing the ministers, and of arraigning them 
before the house of pecrs, which alone has the power of trying them. They can be prosecuted only for treason or extortion.

Ail justice cissanates from the king. It is administered in his name, by judyes whom heappoints and establishes. The judges appointed by the king are irremoveable. The justices of the peace, although appointed by the king, are not irrenoveable. No one can be withdrawn fron his natural judges. There cannot, of consequence, be created commissions and extraordinary tribunals. The jurisdiction of provost marshal is not comprised under this denomination, if the establishment of them be judged necessary. The discussions are public in criminal matters, at least when that publicity is not dangtrous to order and good morals, and in this case the tribunal declares it by a decree. The institution of juries is preserved. The king has the right of granting pardons, and of commuting penalties.

LAws....With respect to the judicial administration of the country, the laws are grounded on the Roman, or civil and particular local customs. Each district has a primary judicial tribunal, and each de. partment a criminal tribunal. Every three departments possess a tribunal of appeal, which takes cognizance by appeal of all the causes determined by the tribunals of the districts under its jurisdiction. Each canton has a justice of the peace. All the tribunals of appeal acknowledge a superior tribunal, called the court of cassation, possessing the power of annulling the sentences of the tribunals of appeal which appear to it illegal, and of referring the examination of the cause to any other tribunal it shall please to appoint.

Revenue.... The revenue in the year 1788 , before the revolution, was 20 millions and a half sterling; and its ordinary expenditure exceeded the revenue five millions and a half.

The extraordinary expenses of the war carried on by the republic were principally defrayed by the seizure of church lands, confiscations, requisitions and contributions imposed on the conquered countries, which are very different from permanent revenue.

In the ycar 1797, Gilbert, a member of the council of five hundred, stated the revenue for the 6 th year at $479,593,579$ livies, or 19,980,000l. sterling.

On the 13 th of October, 1799 , the executive directory sent a message to the council of five hundred, stating the amount of the receipts of the 7 th year of the republic at $476,000,000$ livres, or somewhat above 19,800,000l. sterling. The expenses of the year they stated, at the same time, at $726,000,000$ livres, or $30,250,000 l$. sterling.

The annual contributions charged on the one hundred and two de= partments, for land tax, tax on moveables and sumptuary, houses and windows, additional hundredths, \& c. amounted, according to the last official statements, to $351,438,997$ livres, or $14,643,291 l$.

ARMY AND NavY.... The peace establishment of the army, for the year 1792, was 111,000 infantry, 30,000 cavally, and 11,000 artillery; in the whole 152,000 men. But when the allied powers marle war on the French, the number of forces the latter brought into the field almost erceeds belief. In the year 1798 , they had 780,000 men in arms, 'The military establishment of France, in the beginning of the year 1802, was, 
84 Regiments of cavalry, amounting to : : : : :- 46,350

110 Regiments of infantry .......... 341,000

10 Demi brigades of veterans . . . . . . . 13,960 Artillery, foot and horse . . . . . . . 26,600

Total

427,910

The army with which Bonaparte invaded Russia in 1812, was, ac cording to the French statement, as follows :

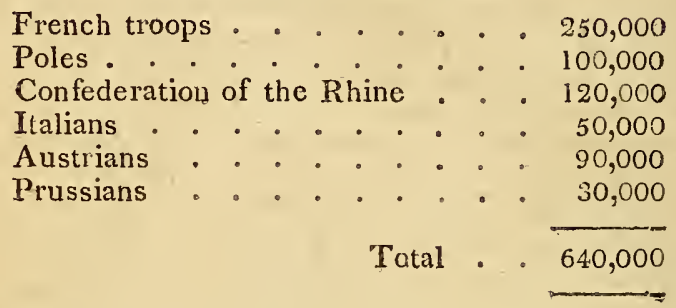

The number of troops in France, and in garrison in other places, at the restoration, were said to amount to nearly $500,000 \mathrm{men}$.

The repeated victories of the English by sea, in the course of the Iate war, had extremely reduced, and, indeed, nearly annihilated, the navy of France. Bonaparte was nevertheless making continued exertions for the formation of a navy. In 1813 the minister stated the number of ships of the line as 100, 65 of which were completely equipped and ready for sea: When the British entered Antwerp in April, 1814, there were on the stocks 17 sail of the line, 4 of which were of 110 guns, the others of 80 , three frigates, and as many brigs. There were also in the Scheldt, fit for sea, 21 sail of the line, 10, frigates, \&c.

Titues, \&c....'The first national assembly abolished all nobility, hereditary distinctions, difference of orders, titles, denominations, and prerogatives. Even the appellation of Monsieur was disused, and that of Citizen substituted in its stead. Since, however, the accession of Bonaparte to sovereigr. power, the term citizen is laid aside, and that of Monsieur revived. He himself took the title of His Imperial Majesty, and his brothers were styled Their Imperial Highnesses. He appointed marshals of the empire, grand dignitaries, an arch-elector, arch-chancellor, \&cc. He likewise instituted what is called a legion of honour, the commanders and members of which were nominated by himself, and which was perhaps intended as an introduction to orders of nobility and hereditary distinctions to be derived from the imperial fountain of honour.

The title of the king is simply, king of France and Navarre, and by way of compliment he is called His most Christian Majesty.

RELIGION.... By the laws of the constitution framed by the first national assembly, no man was to be molested for his opinions, or interrupted in the exercise of his religion. The territorial possessions of the Gallician church were claimed as national property, and disposed of through the medium of a paper money, called assignats, for the creditors of the state : and the clergy made dependent upon pensionary establishments, paid out of the national treasury; put of which 
were also paid the expenses of worship, the religious and the poor. All monastic establishments were suppressed; but the friars and nuns were allowed to observe their vows, and nuns optionally to remain in their convents, or retire upon pensions. By subsequent constitutions, it was declared that there is no predominant religion in France, and that none is patronized or paid by the state; but that all sects and modes of worship shall enjoy equal toleration.

But since the administration of the government has been vested in Bonaparte, he has concluded a concordat or convention with the pope, by which the catholic religion is declared the religion of the great majority of the French citizens, and the government engages to make a suitable provision for the bishops and ministers. No bull or brief, however, of the court of Rome can have any effect in France without the consent of the government; and none of the clergy are to give the nuptial benediction, except to those who have been married by the civil officers. The concordat bears date, Sept. 10, 1801 .

The protestant religion, as professed by the different reformed churches, is also tolerated, and the maintenance of the ministers, when necessary, provicled for in like manner by the state.

Before the revolution there were in France nineteen archbishoprics, and 118 bishoprics : by the concordat there are 10-archbishoprics: Paris, Maines, Besançon, Lyons, Aix, Toulouse, Bourdeaux, Bourges, Tours, and Rouen; and 50 bishoprics.

LiteratUre.... The French, like the other nations of Europe, were for many centuries immersed in barbarity. The first learning they hegan to acquire, was not of that kind which improves the understanding, corrects the taste, or regulates the affections. It consisted in a subtle and quibbling logic, which was more adapted to pervert: than to improve the faculties. But the study of the Greek and Roman writers, which first arose in Italy, diffused itself among the French, and gave a new turn to their literary pursuits. This, together with the encouragement which the polite and learned Francis I, gave to all men of merit, was extremely beneficial to French literature. During this reign, many learned men appeared in France, who greatly distinguished themselves by their writings; among whom were Budæus, Clement Marot, Peter du Chatel, Rabelais, and Peter Ramus. The names of Henry and Robert Stephens are also mentioned by every real scholar with respect. It was not, however, till the seventeenth century, that the French began to write with elegance in their own language. The Académie Françoise was formed for this purpose; and though their labours, considered as a body, were not so successful as might have been expected, some particular academicians have done great service to letters. In fact, literary copartnerships are seldom very successful. Of this we have a remarkable example in the present case. The academy published a dictionary for improving the French language, which was universally despised; Furetieres, a single academician, published another, that met witl universal approbation.

Lewis XIV was the Augustus of France. The protection he gave to letters, and the pensions he bestowed on learned men, both at home and abroad, which, by calculation, did not amount to above 12,000l. per annum, have gained him more glory than all the military enterprises upon which he expended so many millions. The learned men who appeared in France during this reign are ton numerous to be mentioned. The tragic poets, Racine and Corncille, have.desev- 
vedly obained a very high reputation; the first was distinguished for skill in moving the passions ; the second, for majesty; and both, for the strength and justness of their painting, the elegance of their taste, and their strict adherence to the rules of the drama. Moliere would have exhausted the subjects of comedy, were they not every where inexhaustible, and particularly in France. In works of satire and criticism, Boileau, who was a close imitator of the ancients, possessed uncommon merit. But France has not yet produced an epic poem that can be mentioned with Milton's; nor a genius of the same extensive and universal kind with Siakspeare, equally fitted for the gay and the serious, the humorous and the sublime. In the eloquence of the pulpit and of the bar, the Frenci are greatly our superiors; Bossuet, Bourdaloue, Fletcher, and Masillon, have carried pulpir eloquence to a degree of perfection which we may approach to, but can hardly be expected ever to surpass. The genius, however, of their religion and government was extremely unfavourable to all improvements in the most useful branches of philosophy. All the cstablishments of Lewis XIV, for the advancement of science, were not able to counterbalance the influence of the clergy, whose interest it was to keep mankind ignorant in matters of religion and morality ; and the influence of the court and ministry, who had an equal in. terest in concealing the natural rights of mankind, and every sound principle of government. The French have not therefore so many good writers on moral, religious, or political subjects, as have appeared in Great Britain. But France has produced some great nen, who do honour to humanity; whose career no obstacle could stop; whose freedom no government, however despotic, no religion, however superstitious, could curb or restrain. As an historian, De Thou is entitled to the highest praise ; and who is ignorant of Pascal, or of the archbishop of Cambray? Few men have done more service to religion, either by their writings or their lives. As for Montesquieu, the is the legislator of nations : his works are read in every country and language; and wherever they are read, they enlighten and invigorate the human mind. And indeed the distinguished literary productions of the reign of Lewis XV, universally breathe sentiments incompatible with superstition or despotism; but too many of them incur the opposite reproach of irreligion and licentiousness.

In the belles lettres, the lighter kinds of poetry, and lively essays, no nation ever produced more agreeable writers : anong whom we may place Montaigne, D'Argens, and Voltaire, as the most considerable.

Before the immortal Newton appeared in England, Descartes was the greatest philosopher in modern times. He was the first who applied algebra to the solution of geometrical problems; which naturally prepared the way for the analytical discoveries of Newton. Many eminent mathematicians have flourished in the present age, particularly Clairaut, Bezout, and D'Alembert ; the latter of whom, to the precision of a geometer, has united the talents of a fine writer.

Since the beginning of the last century, the French have almost vied with the English in natural philosophy. Buffon would deserve to be reckoned among men of science, were he not still more remarkable for his eloquence than for his philosophy. He is to be regarded as a philosophical painter of nature; and, under this view, his natural history is the first work of its kind.

Their painters, Poussin, Le Brun, and, above all, Le Sueur, did 
lyonour to the age of Lewis XIV. They have none at present to compare with them in the more noble kind of painting: but $\mathbf{M}$. Greuse, for portraits and conversation pieces, never perhaps was excelled.

Sculpture is in general better understood in France than in most other countries of Europe. Their engravings on copper-plates have been universally and justly celebraied; but such a liberal patronage has been afforded to English artists, that they are now thought to excel their ingenious neighbours, and have rivalled them also in the manufacture of paper proper for such impressions. Their treatises on ship-building and engineering stand unrivalled; but in the practice of Бoth they are outdone by the English. No genius has hitherto equalled Vauban in the theory or practice of fortification. The French were long our superiors in architecture; though we now are their equals in this art.

Universities, PUBLIC COLLEges, AND ACADrMies....Before the revolution, there were in France twenty-eight universities or public colleges, as follow : Aix, Angers, Arles, Avignon, Besançon, Bourdeaux, Bourges, Caen, Cahor's, Dol, Douay, La Fleche, Montauban, Montpelier, Nantes, Orange, Orléans, Paris, Perpignan, Poitiers, Pont-a-Mousson, Richlieu, Pheims, Soissons, Strasburg, Toulouse, Tournon, and Valence. Among these, the Sorbonne at Paris was the most celebrated.

The following literary establishments were supported out of the national treasury : the French Acadeny, Academy of Belles Lettres, Academy of Sciences, Royal Society of Medicine, King's Library, Observatory, and the Free School of Design. Under the republic, - primary, central, and special schools have been established; a priinary school for each canton; a central school for each department; and special schools for the higher sciences, such as astronomy, and for those arts which require a particular education for the public service, such as medicine and surgery. Education in these establishments is at the public expence, but the scholars are maintained by their parents or friends.

An academy called the National Institute has likewise been founded, the installation of which took place in the hall of the former Academy of Sciences, in the palace of the National Museum, formerly the Louvre. It is composed of a hundred and forty-four members; among the first of whom were found the names of La Lande, La Place, Fourcroy, Reynel, Marmontel, Volney, Berthollet, Bittaube, \&c. This national academy holds a public meeting on the 15 th of every month; its conferences point out and promote the progress of the arts and sciences; but it has no authority whatever over the schools.

LAXGUAGE.... The French language is chiefly composed of words radically Latin, with many German derivatives introduced by the Franks. It is now rather on the decay : its corner-stones, fixed under Lewis XIV, are, as it were, loosened; and, in the present mode of writing and expressing themselves, the modern French too often disregard that purity of expression which alone can render a language classical and permanent. One of the wisest measures of Lewis XIV, was his encouragement of cvery proposal that tended to the purity and perfection of the French language. He succeeded so far as to render it the most universal of all the living tongues; a circumstance 
that tended equally to his greatness and his glory; for his court and nation thereby became the school of arts, sciences and politeness.

As to the properties of the language, they are, undoubtedly greatly inferior to the English: but they are well adapted to subjects void of elevation or passion; and well accommodated to dalliance, compliments, and common conversation.

The Lord's Prayer in French is as follows:-Nôtre Père, qui es aux cieux, ton nom soit sanctifié; ton regne vienne; ta volonté soit faii en la terre comme au ciel; donne nous aujourd hui nôtre pain quotidien; hardonne nous nos offenses, comme nous frardonnons à ceux qui nous ont offensés; et ne nous indui point en tentation, mais nous delivre du mal: car à toi est le regne, la funissance, et la gloire, aux siècles des siècles. Amen.

Antrquities....Few countries, if we except Italy, can boast of more valuable remains of antiquity than France. Some of the French anfiquities belong to the time of the Celis ; and consequently, compared to them, those of Rome are modern. Father Mabillon has given us a most curious account of the sepulchres of their kings, which have been discovered so far back as Pharamond; and some of which, when broken open, were found to contain ornaments and jewels of value. At Rheims, and other parts of France, are to be seen triumphal arches : but the most entire is at Orange, erected on account of the victory obtained over the Cimbri and the Teutones by Caius. Marius and Luctatius Catulus. After Gaul was reduced to a Roman province, the Romans took delight in adorning it with magnificent edifices, both civil and sacred; some of which are more entire than any to be met with in Italy itself. The $y^{\prime} u$ ins of an amphitheatre are to be found in Chalons, and likewise at Vienna. Nismes, however, exhibits the most valuable remains of ancient architecture of any place in France. The famous Pont du Garde was raised in the Augustan age, by the Roman colony of Nismes, to convey a stream of water between two mountains for the use of that city ; it consists of three bridges, or tier's of arches, one above another; the height is 174. feet, and the length extends to 723. Many other ruins of antiquity are found at Nismes; but the chief are the temple of Diana, and the amphitheatre, which is thought to be the finest and most entire of the kind of any in Europe; but, above all, the house erected by the emperor Adrian, called the Maison Carrée. The architecture and sculpture of this building are so exquisitely beautiful, that it enchants even the most ignorant : and it is still entire, being very little affected either by the ravages of time or the havoc of war. At Paris, in la Rue de la Harpe, may be seen the remains of the Therma, supposed to have been built by the emperor Julian, surnamed the Apostate, about the year 356, after the same model as the baths of Dioclesian. The remains of this ancient edifice are many arches, and within them a large saloon. It is fabricated of a kind of mastic, the composition of which is not now known, intermixed with small square pieces of frec-stone and bricks. But the most extraordinary of all artificial curiosities is the subterraneous cavern at Paris. For the first building of that city, it was necessary to get the stone in the environs. As Paris was enlarged, the streets and suburbs extended to, and were built on, the ancient quarries from which the stone had been taken; and hence proceed the caverns or frightful cavities which are found under the houses in several quarters of the city. Eight persons some years since perished in one of them, a gulf of 150 feet 
deep, which excited the police and government to cause the buildings of several quarter's to be prixately propped up. All the suburbs of St. James's, Harpe-street, and cren the street of Tournon, stand upon the ancient quarries; and pillars have been erected to support tise weight of the houses; but as the lofty buildings, towers, and steeples, now tell the eye that what is seen in the air is wanting under the feet, so it would not require a very violent shock to throw back the stones to the places from whence they were raised.

At Arles in Provence is an obelisk of oriental granite, 52 feet high, and seven feet diameter at the base, and all but one stone. Roman temples and aqueducts are frequent in France. The most remarkable are in Burgundy and Guienne; the passage cut through the middle of a rook near Briançon in Dauphiné is thought to be a Roman work, if not of greater antiquity. The round buckler of massy silver, taken out of the Rhone in 1665 , being twenty inches in diameter, and weighing twenty-one pounds, contalning the-story of Scipio's continence, is thought to be coeval with that great general.

History.... The history of no country is better authenticated than that of France, and it is particularly interesting to an Einglish reader. This country, which was by the Romans called Transalpine Graul, or Gaul beyond the Alps, to distinguish it from Cisalpine Gaul on the Italian side of the Alps, was probably peopled from Italy, to which it lies contiguous. Like other European nations, it soon became a desirable object to the ambitious Romans; and, after a brave resistance, was annexed to their empire, by the invincible arms of Julius Cæsar, about forty-eight years before Christ. Graul continued in the possession of the Romans, till the downfal of that empire in the fifth century; when it became a prey to the Goths, the Burgundians, and the Franks, who subdued, but did not extirpate, the ancient natives. The Franks, themselves, who gave it the name of France, or Frankenland, were a collection of several people inhabiting Germany; and particularly the Salli, who lived on the banks of the river Sale, and. who cultivated the principles of jurisprudence bettei' than their neighbours. These Salli had a rule, which the rest of the Franks are said to have adopted, and has been by the modern Franks applied to the succession of the throne, excluding all females from the inheritance of sovereignty, and is well known by the name of the Salic Law.

The Franks and Burgundians, after establishing their porver, and reducing the original natives to a state of slavery, parcelled cut the lands among their principal leaders; and succeeding kings found it necessary to confirm their privileges, allowing them to exercise sovereign authority in their respective governments, until they at length assumed an independency, only acknowledging the king as their head. This gave rise to those numerous principalities that were form merly in France, and to the several parliaments; for every province became, in its policy and government, an epitome of the whole kingdom; and no laws were made, or taxes raised, without the concurrence of the grand council, consisting of the clergy and of the nobility.

Thus, as in other European nations, immediately after the dissolu= tion of the Roman empire, the first government in France seems to have been a kind of mixed monarchy, and the power of their kings extremely circumscribed and limited by the feudal barons.

The first Christian monarch of the Franks (according to Daniel, one of the best French historians) was Clovis, who began his reign

VOL. I. 
anno 481 ; and was baptized, and introduced Christianity, in the year 496. The mind of Clovis had been affected by the pathetic tale of the passion and the death of Christ; and, insensible of the beneficial consequences of the mysterious sacrifice, he exclaimed, with religious fervour, "Had I been present with my valiant Franks, I would have revenged his injuries "' But though he publicly professed to acknowledge the truth of the gospel, its divine precepts were but little respected. From this period the French history exhibits a series of great events; and we find them generally engaged in domestic broils, or foreign wars. The first race of their kings, prior to Charlemagne, found a cruel enemy in the Saracens, who then overran Europe, and retaliated the barbarities of the Goths and Vandals upon their posterity. In the year 800, Charlemagne, king of France, the glory of those dark ages, became master of Germany, Spain, and part of Italy, and was crowned king of the Romans by the pope. He divided his empire, by will, among his sons; which proved fatal to his family and posterity. Soon after this, the Normans, a fierce warlike people from Norway, Denmark, and other parts of Scandinavia, ravaged the kingdom of France; and, about the year 900 , obliged the French to yield Normandy and Bretagne to Rollo, their leader, who married the king's daughter, and was persuaded to profess himself a Christian. This laid the foundation of the Norman power in France, which afterwards grave a king to England, in the person of William duke of Normandy, who subdued Harold, the last Saxon king, in the year 1066 . This event proved unfortunate and ruinous to France, as it engaged that nation in almost perpetual wars with England, for which it was not an equal match, notwithstanding its numbers, and the assistance it received from Scotland.

The rage of crusading, which broke out at this time, was of infinite service to the French crown, in two respects: in the first place, it carried off many thousands of its turbulent subjects, and their leaders, who were almost independent of the king; in the next, the king succeeded to the estates of many of the nobility, who died abroad without heirs.

But passing over the dark ages of the crusades, the expedition to the Holy Land, and war with England, which have already been mentioned, we shall proceed to that period when the French began to extend their influence over Europe, in the reign of Francis I, contemporary with Henry VIII, of England. This prince, though he was brave to excess in his own person, and had defeated the Swiss, who till then were deemed invincible, was an unfortunate warrior. He had great abilities and great defects. He was a candidate for the empire of Germany, but lost the imperial crown; Charles V, of the house of Austria, and king of Spain, being chosen. In the year 1520, Francis having invited Henry VIII, of England, to an inter view, the two kings met in an open plain, near Calais; where they and their attendants displayed their magnificence, with such emula. tion and profuse expense, as gave it the name of the Field of the Cloth of Gold. Feats of chivalry, parties of gallantry, together with such exercises and pastimes as were in that age reckoned manly or elegant, rather than serious business, occupied both courts during eighteen days that they continued together.* Francis made some

- The French and English historians describe the pomp of this interview, and the various spectacles, with great minuteness. One circumstance mentioned by 
successful expeditions against Spain, but suffered his mother, of whom he was very fond, to abuse his power: by which he disobliged the constable of Bourbon, the greatest of his subjects, who joined in a confederacy against him with the emperor and Henry VIII, of England. In his adventurous expedition into Italy, he was taken prison. $\mathrm{er}$ at the battle of Pavia, in the year 1524, and obliged to agree to dishonourable terms, which he never meant to perform, to regain his liberty. His non-performance of those conditions was afterwards the source of many wars between him and the emperor; and he died in 1547 .

France, at the time of his death, notwithstanding the variety of disagreeable events during the late reign, was in a flourishing condition. Francis I, was succeeded by his son Henry II, who, upon the whole, was an excellent and fortunate prince. He continued the war with the emperor of Germany to great advantage for his own dominions; and was so well served by the duke of Guise, that, though he lost the battle of St. Quentin against the Spaniards and the English, he retook Calais from the latter, who never since had any footing in France. He married his son the dauphin to Mary queen of Scots, in hopes of uniting that kingdom to his crown; but in this scheme, he, or rather his country, was unfortunate, as may be seen in the history of Scotland. He was killed in the year 1559, at an unhappy tiltingmatch, by the count of Montgomery.

He was succeeded by his son, Francis II, a weak, sickly, inactive prince, and only thirteen years of age, whose power was entirely engrossed by a prince of the house of Guise, uncle to his wife, the beautiful queen of Scotland. This engrossment of power encouraged the Bourbon, the Montmorenci, and other great families, to form a strong opposition against the government. Antony, king of $\mathrm{Na}$ varre, was at the head of the Bourbon family; but the queen-mother, the famous Catharine of Merlicis, being obliged to take part with the Guises, the confederacy, which had adopted the cause of Huguenotism, was broken in pieces, when the sudden death of Francis happened, in the year 1560 .

This event took place while the prince of Condé, brother to the king of Navarre, was under sentence of death for a conspiracy against the court; but the queen-mother saved him, to balance the interest of the Guises; so that the sole clirection of affairs fell into her hands, during the minority of her second son, Charles IX. Her regency was a continued series of dissimulation, treachery, and murder. The duke of Guise, who was the scourge of the protestants, was assassinated by one Poltrot, at the siege of Orleans; and the murderer was unjustly thought to have been instigated by the famous

the mareschal de Fleuranges, who was present, and which appears singular in the present age, is commonly omitted. "After the tournament," says he, "the French and English wrestlers made their appearance, and wrestled in presence of the kings and the ladies; and as there were many stout wrestlers there, it af. forded excellent pastime; but as the king of France had neglected to bring any wrestlers out of Bretagne, the English gained the prize. After this the kings of France and England retired to a tent, where they drank together; and the king of England seizing the king of France by the collar, said, "s My brother, I must wrestle with you," and endeavoured, once or twice, to trip up his heels ; but the king of France, who was a dexterous wrestler, twisted him round, and threw him on the earth with prodigious violence. The king of England wanted to re. new the combat, but was prevented." Memoirs de Fleuranges, 12mo. Paris 1753, p. 329. 
Coligni, admiral of France, who was then at the head of the protestant party. Three civil wars succeeded. At length the court pretended to grant the Huguenots a very advantageous peace; and a match was concluded between Henry, the young king of Navarre, a protestant, and the French king's sister. The heads of the protestants were invited to celebrate the nuptials at Paris, with the infernal view of butchering them all, if possible, in one night. The project proved but too successful, though it was not completely executed, on St. Bartholomew's day, 1572. The king himself assisted in the massacre, in which the admiral Coligni fell. The signal for the inhuman slaughter of so many thousands was to be made by striking the great bell of the palace. At that dreadful knell, the work of death was begun, and humanity recoils from the horrors of the fatal night of St. Bartholomew; yet the reader may expect, amidst the general carnage, that some few moments should be devoted to the fate of Coligni. He had long retired to rest, when he was aroused by the noise of the assassins, who had surrounded his house. A German, named Besme, entered his chamber; and the admiral, apprehending his intentions, prepared to meet death with that fortitude which had ever distinguished him. Incapable of resistance, from the wounds he had received by two balls, in a late attempt to assassinate him, with an undismayed countenance, he had scarce uttered the words-" "Young man, respect these grey hairs, nor stain them with blood," when Besme plunged his sword into his bosom, and, with his barbarous associates, threw the body into the court. The young duke of Guise contemplated it in silence; but Henry, the count d'Angoulême, natural brother to Charles, spurned it with his foot, exclaiming-"Courage, my friends! we have begun well; let us finish in the same manner." It is said that about 30,000 protestants were murdered at Paris, and other parts of France; and this brought on a fourth civil war. Though a fresh peace was concluded in 1573 with the protestants, yet a fifth civil war broke out the next year, when the bloody Charles IX died without heirs.

His third brother, the duke of Anjou, had some time before been chosen king of Poland; and hearing of his brother's death, he with some dificulty escaped to France, where he took quiet possession of that crown by the name of Henry III.

Religion at that time supplied to the reformed nobility of France the feudal powers they had lost. The heads of the protestants could raise armies of Huguenots. The governors of provinces behaved in them as if they had been independent of the crown; and the parties were so equally balanced, that the name of the king alone turned the scale. A holy league was formed for the defence of the catholic religion, at the head of which was the duke of Guise. The protestants, under the prince of Condé, and the duke of Alençon, the king's brother, called the German princes to their assistance; and a sixth civil war broke out in 1577 , in which the king of Spain took the part of the league, in revenge of the duke of Alençon declaring himself lord of the Netherlands. The civil war was finished within the year, by another pretended peace. The king, from his first accession to the crown, had plunged himself into a course of infamous debauchery and religious extravagancies. He was entirely governed by his profigate favourites, but he possessed natural good sense. He began to suspect that the proscriptions of the protestants, and the setting aside from the succession the king of Navarre, on account of his religion, 
which was aimed at by the holy league, was with a view to place the duke of Guise, the idol of the Roman catholics, on the throne; to which that duke had some distant pretensions. To secure himself on the throne, a seventh civil war broke out in 1579, and another in the year 1585, both of them to the disadvantage of the protestants, through the abilities of the duke of Guise. The king thought him now so dangerous, that, after inviting him in a friendly manner to court, both he, and his brother the cardinal, were, by his majesty's orders, and in a manner under his eyes, basely assassinated in 1588 . The leaguers, upon this, declared that Henry had forfeited his crown, and was an enemy to religion. This obliged him to throw himself into the arms of the protestants; but while he was besieging Paris, where the leaguers had their greatest force, he was in his turn assassinated by one Clement, a young enthusiastic monk, in 1589. 'In Henry III, ended the line of Valois.

The readers of history are well acquainted with the difficulties, on account of his religion, which Henry IV, king of Navarre,* head of the house of Bourbon, and the next heir by the Salic law, had to encounter before he mounted the throne. The leaguers were headed by the duke of Maine, brother to the late duke of Guise; and they drew from his cell the decrepit cardinal of Bourbon, uncle of the king of Navarre, to proclaim him king of France. Their party being strongly supported by the power of Spain and Rome, all the glorious actions performed by Henry, his courage and magnanimity, seemed only to make him more illustriously unfortunate : for he and his little court were sometimes without common necessaries. He was, however, personally beloved; and no objection lay against him but that of religion. The leaguers, on the other hand, split among themselves; and the French nation in general were jealous of the Spaniards. Henry, after experiencing a variety of good and bad fortune, came secretly to a resolution of declaring himself a Roman catholic. This was called a measure of prudence, if not of necessity; as the king of Spain had offered his daughter Isabella Clara Eugenia to be queen of France, and would have married her to the young duke of Guise.

In 1593, Henry went publicly to mass, as a mark of his conversion. This complaisance wrought wonders in his favour; and having with great difficulty obtained absolution from the pope, all France submitted to his authority, and he had only the crown of Spain to contend with; which he did for several years with various fortune. In 1598, he published the famous edict of Nantes, which secured to his old friends, the protestants, the free exercise of their religion; and next year the treaty of Vervins was concluded with Spain. Henry next chastised the duke of Savoy, who had taken advantage of the late troubles in his kingdom; and applied himself with wonderful attention and success (assisted in all his undertakings by his minister, the great Sully) to cultivate the happiness of his people, by encourag. ing manufactures, particularly that of silk, the benefit of which France experiences at this day. Having re-established the tranquillity, and in a great measure secured the happiness, of his people, he formed connexions with the neighbouring powers, for reducing the ambition

* A small kingdom lying upon the Pyrenean mountains, of the greatest part of which, Upper Navarre, Henry's predecessors had been unjustiy dispossessed by Ferdinand king of Spain, about the year 1512. 
of the house of Austria; for which purpose, it is said, he had formed great schemes, and collected a formidable army; others say (for his intention does not clearly. appear), that he designed to have formed Christendom into a great republic, of which France was to be the head, and to drive the Turks out of Europe; while others attribute his preparations to more ignoble motives, that of a criminal passion for a favourite princess, whose husband had carried her for protection into the Austrian dominions. Whatever may be in these conjectures, it is certain, that, while he was making preparations for the coronation of his queen, Mary of Medicis, and was ready to enter upon his grand expedition, he was assassinated in his coach, in the streets of Paris, by one Ravaillac, another young enthusiast like Clement, in 1610 .

Lewis XIII. son to Henry IV., was but nine years of age at the time of his father's death. As he grew up, he discarded his mother and her favourites; and chose for his minister the famous cardinal Riehelieu, who put a period, by his resolute and bloody measures, to the remaining liberties of France, and to the religious establisiment of the protestants there, by taking from them Rochelle; though Charles I. of England, who had married the French king's sister, made some weak efforts, by his fleet and armies, to prevent it. This put an end to the civil wars on account of religion in France. Historians say, that in these wars above a million of men lost their lives; that 150,000,000 livres were spent in carrying them on; and that nine cities, four hundred villages, two thousand churches, two thousand monasteries, and ten thousand houses, were burnt or otherwise des. troyed during their continuance.

Richelieu, by a masterly train of politics, though himself bigoted to popery, supported the protestants of Germany, and Gustavus Adolphus against the house of Austria. After quelling all the rebellions and conspiracies which had been formed against him in France, he died some months before Lewis XIII.; who, in 1643, left his son, afterwards the famous Lewis XIV., to inherit his kingdom.

During that prince's non-age, the kingdom was torn in pieces under the administration of his mother, Anne of Austria, by the factions of the great, and the divisions between the court and parliament, for the most trifing causes, and upon the most despicable principles. The prince of Condé flamed like a blazing star; sometimes a patriot, sometimes a courtier, and sometimes a rebel. He was opposed by the celebrated Turenne, who from a protestant had turned papist. The nation of France was involved at once in civil wars and domestic dissentions. But the queen-mother having made choice of cardinal Mazarin for her first minister, he found means to turn the arms even of Cromwell against the Spaniards; and to divide the domestic enemies of the court so effectually among themselves, that when Lewis assumed the reins of government in his own hands, he found himself the most absolute monarch that had ever sat upon the throne of France. He had the good fortune, on the death of Mazarin, to put the domestic administration of his affairs into the hands of Colbert; who formed new systems for the glory, commerce, and manufactures of France, in all of which he was extremely successful.

To write the history of this reign, would be to write that of all Europe. Ignorance and ambition were the only enemies of Lewis; through the former, he was blind to every patriotic duty of a king, and promoted the interest of his subjects only that they might the 
better answer the purposes of his greatness : by the latter he embroiled himself with all his neighbours, and wantonly rendered Germany a dismal scene of devastation. By his impolitic and unjust revocation of the edict of Nantes in the year 1685, and his persecutions of the protestants, he obliged them to take shelter in England, Holland, and different parts of Germany, where they established the silk manufaclure, to the great prejudice of their own country. He was so blinded by flattery, that he arrogated to himself the divine honours paid to the pagan emperors of Rome. He made and broke treaties for his own conveniency, and at last raised against himself a confederacy of almost all the other princes of Europe; at the head of which was king IVilliam III. of England. He was so well served, that he made head for some years against this alliance ; but having proroked the English by his repeated infidelities, their arms under the duke of Marlborough, and the Austrians under the prince Eugene, rendered the latter part of his life as miserable as the beginning of it had been splendid. His reign, from the year 1702 to 1712 , was one continued series of defeats and calamities; and he had the mortification of seeing those places taken from him, which, in the former part of his reign, were acquired at the expense of many thousand lives. Just as he was reduced, old as he was, to the desperate resolution of collecting his people, and dying at their head, he was saved, by the English tory ministry deserting the cause, withdrawing from their allies, and concluding the peace of Utrecht in 1713 . He survived his deliverance but two years; anch in his last hours, displayed a greatness of mind worthy of his elevated situation: "Why do you weep ?" said he to his domestics; "did you think me immortal ?" He died on the first of September, 1715, and was succeeded by his great grandson, Lewis XV.

The partiality of Lewis XIV. to his natural children might have involved France in a civil war, had not the regency been seized upon by the duke of Orléans, a man of sense and spirit, and the next legitimate prince of the blood; who having embroiled himself with Spain, the king was declared of age in 1722 , and the regent, on the 5 th of December, 1723, was carried off by an apoplexy.

Among the first acts of the government of Lewis XV. was his nominating his preceptor, afterwards cardinal Fleury, to be his first minister. Though his system was entirely pacific, yet the situation of affairs in Europe, upon the death of the king of Poland in 1734, more than once embroiled him with the house of Austria. The intention of the French king was to replace his father-in-law, Stanislaus, on the throne of Poland. In this he failed, through the interposition of the Russians and Austrians; but Stanislaus enjoyed the title of king, and the revenues of Lorraine, during the remainder of his life. The connexion between France and Spain forced the former to become principals in a war against Great Britain, which was terminated by the peace of Aix-la-Chapelle in 1748 .

In the year 1757, Francis Damien, an unhappy wretch, whose sullen mind, naturally unsettled, was inflamed by the disputes between the king and his parliament relative to religion, embraced the desperate resolution of attempting the life of his sovereign. In the dusk of the evening, as the king prepared to enter his coach, he was suddenly wounded, though slightly, with a penknife, between the fourth and fifth ribs, in the presence of his son, and in the midst of his guards. The daring assassin had mingled with the crowd of 
courtiers, but was instantly betrayed by his distracted countenance, He declared it was never his intention to kill the king; but that he only meant to wound him, that God might touch his heart, and incline hin to restore the tranquillity of his dominions by re-establishing the parliament, and banishing the archbishop of Paris, whom he regarded as the source of the present commotions. In these frantic and incoherent declarations he persisted, amidst the most exquisite tortures; and after human ingenuity had been exhausted in devising new modes of torment, his judges, tired out with his obstinacy, consigned him to a death, the inhumanity of which is increased by the evident madness that stimulated him to the desperate attempt, and which might fill the hearts of savages with horror; he was conducted to the common place of execution, amidst a vast concourse of the populace; stripped naked, and fastened to the scaffold by iron gyves. One of his hands was then burnt in liquid faming sulphur; his thighs, legs, and arms, were torn with red hot pincers; boiling oil, melted lead, resin, and sulphur, were poured into the wounds; and, to con!plete the horrid catastrophe, he was torn to pieces by horses.

The Jesuits, having rendered themselves universally odious by their share in the conspiracy against the late king of Portugal, fell in France under the lash of the civil power, for certain fraudulent mercantile transactions. They refused to discharge the debts of one of their body, who had become bankrupt for a large sum, and who was supposed to act for the benefit of the whole society. As a monk, indeed, he must necessarily do so. The parliaments eagerly seized an opportunity of humbling their spiritual enemies. The Jesuits were every where cited before those high tribunals in 1761, and ordered to do justice to their creditors. They seemed to acquiesce in the decision, but delayed payment under various pretences. New suits were commenced against them in 1762 , on account of the pernicious tendency of their writings. In the course of these proceedings, which the king endeavoured in vain to prevent, they were compelled to produce their Institute, or the rules of their order, hitherto studiously concealed. That mysterious volume, which was found to contain maxims subversive of all civil government, and even of the fundamental principles of morals, completed their ruin. All their colleges were seized, all their effects confiscated; and the king, ashamed or afraid to protect them, not only resigned them to their fate, but finally expelled them the kingdom by a solemn edict, and utterly abolished the order of Jesus in France.

Elated with this victory over ecclesiastical tyranny, the French parliaments attempted to set bounds to the absolute power of the crown, and seemed determined to confine it within the limits of the law. Not satisfied with refusing, as usual, to register certain oppressive edicts, or with remonstrating against them, they ordered criminal prosecutions to be commenced against the governors of several provinces, acting in the king's name, who had enforced the registration of those edicts. The magnanimity of these assemblies had awakened new ideass in the bosoms of the French; they were taught by the late remonstrances to consider their inherent rights; and this flame, in the succeeding reign, burst forth with accumulated force, and over. whelmed the throne of despotism.

As to the war with Great Britain, which was ended by the peace of Fontainebleau in 1763 , the chief events attending it, so humiliating to 
France, have been already mentioned in the history of England, and therefore need not be recapitulated here.

Corsica, a small island in the Mediterranean, had long resisted with manly firmness the oppressive councils of the Genoese, who claimed the sovereignty over it by right of conquest. But, unable to support those pretensions, Genoa transferred them to France; on condition that Lewis should put her in full possession of the adjacent island of Capraia, which the Corsicans had lately invaded had reduced. To execute his engagements, powverful armaments were fitted out by Lervis, at Antibes and Toulon; twenty battalions of French were landed in Corsica; and the natives, whose free suffrages had summoned Paoli, one of their principal chiefs, to the supreme government of the island, determined to defend their liberties to the utmost.

A sharp and bloody war, such as suited the inferior numbers of the inhabitants and the nature of the country, was carried on in all the fastnesses and mountainous parts of the island; and it was not till after the French had fatally experienced, in two successive campaigns, the enthusiastic courage which animates the champions of freedom, that they overwhelmed, by their superior numbers, this unfortunate people; nor liad Lewis much reasort to triumph in an acquisition, to attain which he had sacrificed several thousand of his bravest troops, and only extended his dominion over a rugged and unproductive island.

The late unfortunate king, Lewis XVI., succeeded his grandfather, Lewis XV. on the 10th of May, 1774. Several regulations were made after his accession, highly favourable to the general interests of the nation; particularly the suppression of the Mousquetaires, and some other corps, which, being aclapted more to the parade of guarding the royal person than any real military sérvice, were supported at a great expense, without an adequate return of benefit to the state. One remarkable circumstance which attended this reign, was the placing of M. Necker, a protestant and a native of Switzerland, at the head of the French finances, in 1766. Possessed of distinguished and acknowledged abilities, his appointment would have excited no surprise, had it not been contrary to the constant policy of France; which had carefully excluded the aliens of her country and faith from the controul of the revenue. Under the direction of Necker, a general reform took place in France, through every department of the revenue. When hostilities commenced, in 1777, between France and. Great Britain, in consequence of the assistance afforded by the former to the revolted British colonies in America, the people of France were not burdened with new taxes for carrying on the war ; but the public revenue was augmented by the economy, improvements, and reformation, that were introduced into the management of the finances. In consequence of this national economy, the navy of France was.also raised to so great a height as to become truly formidable to Great Britain.

In the beginning of the year 1780, in consequence of the repre. sentations of Mr. Necker, a variety of unnecessary offices in the houschold of the queen were abolished; and sundry other important regulations aciopted for the ease of the subject, and the general be nefit of the kingclom. Could we implicitly credit his memorial, he changed the excess of the disbursements (at least one million sterling) of the year 1776, into an excess of revenue in the year 1780, to the amount of $4.45,000 \mathrm{l}$. But the measures of Mr. Necker were not calculated to procure him frienfo at rourt; the interested and the 
ambitious naturally became his enemies; and the king appears not to have possessed sufficient firmness of mind to support an upright and able minister. He was therefore displaced, and is said to have been particularly opposed by the queen's party.

The dismemberment of the British empire had been the grand object of France ; and the independence of the United States having been acknowledged in the fullest and most express terms by Great Britain, the preliminary articles of peace were signed at Paris on the 20 th of January, 1783; but the immense expenses incurred were found at last to be much more than the revenues of the kingdom could by any means support; and the miserable exigencies to which government was reduced contributed to increase the public discontents. These, with the popular sentiments of Liberty which the French arny imbibed in America, and carried home with them, prepared the way for the late disastrous revolution.

The ambition of the French government made its subjects acquainted with liberty, by assisting the insurgents in America and Holland; and cxcited a spirit among the people, which could not well admit of the continuance of arbitrary power at home. Mr. Necker having been dismissed from the direction of public affairs, and succeeding ministers being endowed neither with his integrity nor abilities, the finances of the nation were on the point of being. nearly ruined. When the edict for registering the loan at the conclusion of 1785 , which amounted to the sum of three millions three hundred and thirty thousand pounds, was presented to the parliament of Paris, the murnurs of the people, and the remonstrances of that assembly, assumed a more legal and formidable appearance. The king, however, signified to the select deputations that were commissioned to convey to him their remonstrances, that he expected to be obeyed without farther delay. The ceremony of registering took place on the next day, but was accompanied with a resolution, importing, that public economy was the only genuine source of abundant revenue, the only means of providing for the necessity of the state, and restoring that credit which borrowing had reduced to the brink of ruin.

This proceeding was no sooner known, than the king required the attendance of the grand deputation of parliament; he erased from their records the resolution that had been adopted; and declared himself satisfied with the conduct of monsieur de Calonne, his comptroller-general.

However gratified by the support of his sovereign, monsieur de Calonne could not fail of feeling himself deeply mortified by the opposition of the parliament. An anxious inquiry into the state of the public finances hald convinced him that the expenditure had far exceeded the revenues; in the present situation, to impose new taxes was impossible, to continue the method of borrowing was ruinous, and to have recourse only to economical reforms would be found wholly inadequate; and he hesitated not to cleclare, that it would be impossible to place the finances on a solid basis, but by the reformation of whatever was vicious in the constitution of the state. To give weight to this reform, the minister was sensible that something more was necessary than royal authority; he perceived that the parliament was neither a fit instrument for introducing a new order into public affairs, nor would submit to be a passive machine for sanctioning the plans of a minister, even if those plans were the emanations of perfect wisdom. 
Under these circumstances, the only alternative that seemed to remain was to have recourse to some other assembly, more dignified and solemn in its character; and that should consist, in a great degree, of members from the various orders of the state, and the different provinces of the kingdom. But the true and legitimate assembly of the nation, the states-general, had not met since the year 1614 . Another assembly had occasionally been substituted in the room of the states-general; - this was distinguished by the title of the notables, or men of note, and consisted of a number of persons from all parts of the kingdom, chiefly selected from the higher orders of the state, and nominated by the king himself. This assembly had been convened by Henry the IVth, and again by Lewis the XIIIth; and was now once more summoned by the authority of the present monarch; and the 29 th of January, 1787, was the period appointed for their opening.

It was under great difficulties that monsieur de Calonne first met the assembly of the notables, and opened his long-expected plan. He began by stating, that the public expenditure liad for centuries past exceeded the revenues; that a very considerable deficiency had of course existed; and that, at his own accession to office, it was three millions three hundred and thirty thousand pounds.

To remedy this evil, the comptroller-general recommended a territorial impost, in the nature of the English land-tax, from which no rank or order of men were to be exempted; and an inquiry into the possessions of the clergy, which hitherto had been exempted from bearing a proportion of the public burdens. The various branches of internal taxation were also to undergo a strict examination; and a considerable resource was presented in mortgaging the demesne lands of the crown.

Before monsieur Necker retired from the management of the finances, he had published his "Compte rendu au Roi," in which France was represented as possessing a clear surplus of four hundred and twenty-five thousand pounds sterling. This performance had been read with avidity, and had been considered as an æra in the history of France. The credit of this statement was ably vindicated by monsieur de Brienne, archbishop of Toulouse, and by the count de Mirabeau, a still more formidable enemy to Calonne. His eloquence, however, might have successfully vindicated his system and reputation against the calculations of Brienne, and invectives of Mirabeau, but the genius of the comptroller-general sunk under the influence of the three great bodies of the nation. The grand and essential object of reform was to equalize the public burdens, and, by rendering the taxes general, to diminish the load of the lower and most useful classes of the people. The ancient nobility and the clergy had ever been free from all public assessment; the crowds of new noblesse, who had purchased their patents, were by that shameful custom exempted, both themselves and their posterity, from contributing proportionably to the expenses of the state: the magistracies likervise throughout the kingdom enjoyed their share of exemptions: so that the whole weight of the taxes fell on those who were least able to bear them. Thus the nobility, the clergy, and the magistracy, were united against the minister; and the event was such as might be expected. The intrigues of those three bodies raised against him so loud a clamour, that, finding it impossible to stem the torrent, mon- 
sieur de Calonne not only resigned his place on the 12 th of April, but soon after retired to England from the storm of persecution.

The notables proceeded in their inquiries; and it was now suggested that an assembly of the states should be called, as the notables were not competent to impose a new tax. As the deliberations of the notables were not carried on in secret, this proposal was instantly circulated through the capital, and supposed to be a new discovery. The notables were soon after dissolved, without having accomplished any thing except the justification of monsieur Necker.

The stamp-act, however, was established, and a bed of justice was held by the king on the 5th of August, 1787, at which the parliament of Paris was obliged to attend, and the edict was registered, notwithstanding their protest to the contrary. But the parliament, though defeated, were far from subdued: on the day after the king had held his bed of justice, they entered a formal protest against the concession that had been extorted from them.

Painful as every appearance of violence must have proved to the mild disposition of Lewis, he could not consent to surrender, without a struggle, that authority which had been so long exercised by his predecessors. Since the commencement of the present discontents, the capital had been gradually filled with considerable bodies of troops; and about a week after the parliament had entered the protest, an officer of the French guards, with a party of soldiers, went at break of day to the house of each individual member, to signify to him the king's command, that he should immediately. get into his carriage and proceed to 'Troyes, a city of Champagne, about seventy miles from Paris, without writing or speaking to any person out of his own house before his departure. These orders were served at the same instant; and before the citizens of Paris were acquainted with the transaction, the parliament were already on the road to the scene of their banishment.

So great was the resentment of the whole nation on account of the banishment of the parliament, that after a month's exile it was recalled. This was scarcely done, when they were desired to register a loan; at which they hesitated, notwithstanding all the manœuvres of the ministers. At last the king came to the house, and held what is called a royal session. The edicts were now registered; but the duke of Orleans protested, in the presence of the king, against the legality of the proceeding. The parliament protested against the legality of the session itself, but to no purpose. The duke of Orléens, with four others, were banished; the king called for the journals of the house, destroyed the protest, and forbade it to be inserted again. Great clamours were raised by the banishment of the duke of Orléans, and the other members of parliament; remonstrances were presented by the parliaments of Paris, Bordeaux, and Rennes; but the exiles were not recalled till the spring of $178 \mathrm{~s}$.

No alternative remained now to Lewis, but to plunge his country into all the calamity of civil war, or to comply with the wishes of his people, and re-establish the states-general. In the first case, he must have expected to encounter the majority of the people, animated by the exhortations and examples of their magistrates : the peers of the realm had expressed the strongest disapprobation of his measures, nor could he even depend any longer on the princes of his blood; but what afforded the most serious matter of alarm, was the spirit hately displayed among the military, who, during the disturbances in 
the provinces, had reluctantly been brought to draw their swords against their countrymen; and many of those officers, who had recently served in America, publicly proclaimed their abhorrence of despotism.

It was under these impressions, in the beginning of August, an arrét was published, which fixed the meeting of the states-general to the first of May in the ensuing year, viz. 1789 ; at the same time every step was taken to secure the favourable opinion of the public. New arrangements took place in the administration; and monsieur Necker, whom the confidence of the people had long followed, was again introduced into the management of the finances; the torture, which by a former edict had been restricted in part, was entirely abolished; every person accused was allowed the assistance of counsel, and permitted to avail himself of any point of law ; and it was decreed, that, in future, sentence of death should not be passed on any person, unless the party accused should be pronounced guilty by 2 majority at least of three judges.

The eyes of all Europe were now turned on the states-general, or national assembly, whose re-establishment, in the month of May, 1789, presented a new æra in the government of France. But the moment of this meeting was far from auspicious to the court, but greatly so to the interests of the nation. The minds of the French had long been agitated by various rumours; the unanimity that hac? been expected from the different orders of the states was extinguish. ed by the jarring pretensions of each; and their mutual jealousies were attributed by the suspicions of the people to the intrigues of the court, who were supposed already to repent of the hasty assent that had been extorted. A dearth that pervaded the kingdom increased the general gloom and discontent; and the people, pressed by hunger and inflamed by resentment, were ripe for revolt. The sovereign also, equally impatient of the obstacles he incessantly encountered, could not conceal his chagrin; the influence of the queen in the cabinet was again established, and was attended by the immediate removal of monsieur Necker. This step, which evinced a total change of resolutions, and which, from the popularity of the minister, was likely to produce a violent fermentation in every order of men, was followed by other's equally injudicious. The states-general were driven into the Salle des Etats, where they held their meetings, by detachments of the guards, who surrounded them, and who waited only the orders of the court to proceed to greater extremities against the obnoxious representatives of the nation.

Had these mánifestations of vigoür been only sustained by instantly attacking and entering Paris, it is not to be doubted, that, unprepared as it still was, and unwilling to expose to the licence of an incensed soldiery the lives and properties of its citizens, the capital would have been without difficulty reduced to obedience. But the delay whicls succeeded gave the inhabitants time to recover from their first emotions of surprise and apprehension. They say the timidity and imbecility of the government, which, having soutcled the charge? dared not advance to the attack. They profited by this want of exertion; and passing from one extreme rapidly to another, they almos: unanimously took up arms against their rulers. Joined by the French guards, who, from a long residence in the capital, had been peculiarly exposed to seduction, and who at this decisive moment aban. doned their sovereign, the Parisians broke through every obstacis 
by which they had hitherto been restrained. The supplies of arms and ammunition which had been provided for their subjugation, were curned against the crown; and the Hôtel des Invalicles, the great repository of military stores, after a faint resistance, surrendered.

The prince de Lambesc, who alone, of all the officers commanding the royal troops in the vicinity of Paris, attempted to carry into execution the plan for disarming the capital, was repulsed in a premature and injudicious attack, which he made at the head of his dragoons, near the entrance of the garden of the Thuille:ies. Already the Prevôt des Marchands, monsieur de Flesselles, convicted of entertaining a correspondence with the court, and detected in sending private intelligence to monsieur de Launay, governor of the Bastile, had been seized by the people, and fallen the first victim to general indignation. His head, borne on a lance, exhibited an alarming spectacle of the danger to which adherence to the sovereign must expose in a time of anarchy and insurrection.

The Bastile alone remained : and while it continued in the power of the crown, Paris could not be regarded as secure from the severest chastisement. It was instantly invested, on the 14th of July, 1789, by a mixed multitude, composed of citizens and soldiers who had joined the popular banner. De Launay, who commanded in the castle, by an act of perfidy unjustifiable under any circumstances, and which rendered his fate less regretted, rather accelerated than delayed the capture of that important fortress. He displayed a flag of truce, and demanded a parley; but abusing the confidence which these signals inspired, he discharged a heavy fire from the cannon and musketry of the place upon the besiegers, and made considerable carnage. Far from intinidating he only augmented, by so treacherous a breach of faith, the rage of an incensed populace. They renewed their exertions with a valour raised to phrenzy, and were crowned with success. The Bastile, that awful engine of despotism, whose name alone diffused terror, and which for many ages had been sacred to silence and despair, was entered by the victorious assailants. De Launay, seized and draggzed to the Place de Grêve, was instantly dispatched, and his head carried in triumph through the streets of Paris.

In this prison were found the most horrible engines for putting to the severest tortures those unhappy persons whom the cruelty or jealousy of despotism had deternined to destroy. An iron cage, about twelve tons in weight, was found with the skeleton of a man in it, who had probably lingered out a great part of his days in that horrid mansion. Among the prisoners released by its destruction, were major White a Scotsman, earl Massarene an Irish nobleman, and the count de Lorges. The former appeared to have his intelleczual faculties almost totally impaired by the long confinement and miseries he had endured; and, by being unaccustomed to converse with any human creature, had forgotten the use of speech. Earl Massarene, at his arrival on the British shore, eagerly jumped out of the boat, fell down on his knees, and, kissing the ground thrice, exclaimed, "God bless this land of liberty !" The count de Lorges, at a very advanced period of life, was also liberated, and exhibited to, the public curiosity in the Palais Royal. His squalid appearance, his white beard which descended to his waist, and, above all, his imbecility, resulting probably from the effect of an imprisonment of thirty-two years, were objects highly calculated to operate upon the 
senses and passions of every beholder. It is indeed impossible not to participate in the exultation which a capital and a country, so long. oppressed, must have experienced at the extinction of this detestable and justly-dreaded prison of state.

With the Bastile expired the despotism of the French princes, which long prescription, submission, and military strength, seemed to render equally sacred and unassailable; which neither the calamities of the close of Lewis XIV.'s reign, the profligacy and enormities of the succeeding regency, nor the state of degradation into which the monarchy sunk under Lewis XV., had ever shaken : that power which appeared to clerive its support almost as much from the loyalty and veneration as from the dread and terrors of the subject, fell prostrate in the dust, and never betrayed any symptom of returning life.

The next morning after the capture of the Bastile, the monarch appeared in the national assembly, but without the pomp and parade of despotism. His address was affectionate and consolatory. He lamented the disturbances at Paris; disavowed all consciousness of any meditated attack on the persons of the deputies; and added, that he had issued orders for the immediate removal of the troops from the vicinity of the nietropolis. The tear of sympathy started into almost every eye. An expressive silence first pervaded the assembly, which presently was succeeded by a burst of applause and acclamation. On the 16 th, the king having intimated to the national assembly his intention of visiting Paris the following day, he accordingly, on the morning of the 17th, left Versailles in a plain dress, and with no other equipage than two carriages with eight horses each, in the first of which he rode nimself. A part of the national assembly in in their robes accompanied him on foot; and the militia of Versailles composed his only guard till the procession arrived at the Seve, where they were relieved by the Paris militia, with the marquis de la Fayette at their head : and from this place the suite of the monarch amounted to about 20,000 men. 'Their progress was remarkably slow; and no shout was to be heard lut rive la nation! Mr. Bailly, on presenting the keys of the city, addressed his majesty in a short speech, the exordium of which was. - "These, sir, are the keys which were presented to Henry IV. He came to reconquer his people; it is our happiness to hare re-conquered our ling." On receiving the com. plimentary address of the mayor, \&c. the king exclaimed, with an air of pathetic emotion which scarcely allowed him utterance, " $\mathrm{My}$ people may always rely upon my affection." He received from the hands of the mayor the national cockade; and when he showed himself at the window with this badge of patriotism, the joy of the people could no longer be restrained; the shout of Vive le Roi! which had scarcely been heard in the former part of the day, filled the whole atmosphere, and resounded from one extremity of the city to the other. The return of the king to Versailles was a real triumph. The citizens, almost intoxicated with joy, surrounded his carriage : his countenance, which in the morning bore the aspect of melanctoly, was now cheerful and smiling; and he appeared sincerely to partake in the general satisfaction.

The events which followed, are, by the candid of all parties, allowed to be enveloped in an almost impenetrable veil of obscurity. An incident which occurred at Versailles contributed to excite a most unliappy commotion. On the Ist of October an entertainment was 
given by the gardes-du-corhs, or king's body guards, to the officers of a regiment of Flanders, who had just joined them in the service of guarding the monarch. Several of the officers of the national guard, with others of the military, were invited. At the second course four toasts were given-"The king, the queen, the dauphin, and the royal family." "The nation" was proposed, but, according to a number of witnesses, expressly rejected by the gardes-du-corps. After this, the queen, having been informed of the gaiety of the scene, persuaded his majesty, who was just returned from hunting, to accompany her, with the heir apparent, to the saloon. She appeared with the dauphin in her arms, affectionate as she was lovely, and carzied the royal infant through the saloon, anidst the acclamations and murmurs of the spectators. Fired with enthusiasm, the soldiers drank the health of the king, the queen, and the dauphin, with their swords drawn; and the royal guests bowed respectfully and retired.

The entertainment, which had hitherto been conducted with some degree of order, now became a scene of entire confusion. Nothing was omitted, to inflame the passions of the military. The music played the fayourite air-" $O$ Richard, $O$ my king, the world abandons thee !" the ladies of the court distributed white cockades, the antipatriot ensign; and even some of the national guard, it is said, did not refuse to accept them.

During these transactions, the city of Paris was afficted with alt the evils of famine. At this juncture the news arrived of the fatal banquet at Versailles, with evcry circumstance greatly magnified, Early on the morning of the memurable 5th of October, a woman sallied out from the quarter of St. Fustache, and entering the corps de-garde, and seizing a drum, paraded the adjacent streets beating an alarm, and exciting the people by clamours respecting the scarcity of bread. She was soon joined by a very numerous mob, chiefly of women, to the amount of 800 , who proceeded to Versailles; where the king, upon hearing their complaints, signed an order for bringing corn from Senlis and Lagni, and for removing every obstacle which impeded the supply of Paris. This order was reported to the women, and they retired with gratitude and joy.

This band of Amazons was no sooner dispersed, than it was succeeded by another. The national assembly continued sitting; but the session was tumultuous, and interrupted by the shouts and harangues of the Parisian fish-women, who filled the galleries; their applause was mingled with affecting murmurs and complaints-the multitude crying out that they were actually starving, and that the majority of them had eaten nothing for upwards of twenty-four hours. The president therefore humanely ordered that provisions should be sought for in every part of the town; and the hall of the assembly was the scene of a miserable, scanty, and tumultuous banquet. Indeed, such was the dreadful famine, that the horse of one of the gardes-ducor/s being killeci in a tumult, it was immediately roasted, and greedily devoured by the mot.

Darkness and a deluge of rain added to the horrors of the night. The wretched multitudes who had travelled from Paris, were exposed, almost famished, to the inclemencies of the weather, in the open streets : within the castle all was trepidation; nothing was to be heard from without but imprecations, and the voices of enraged multitudes demanding the life of the queen and the gardes-du-corhs. Toward 
midnight, however, all appeared tolerably still and peaceable; when the beating of drums, and the light of innumerable torches, announced the approach of the Parisian army.

The day began to break at about haif past five; and at this period crowds of women, and other desperate persons, breathing veugeance, and thirsting for blood, advanced to the castle, which, in an hour of fatal security, was left unguarded in several places. An immense crowd found its way into every part. The queen had been awakened a quarter of an hour before by the clamours of the women who assembled upon the terrace; but her waiting woman had satisfied her, by saying "that they were only the women of Paris, who, she supposed, not being able to find a lodging, were walking about." But the tumult approaching, and becoming apparently more serious, she rose, dressed herself in haste, and ran to the king's apartment by a private passage. In her way she heard the noise of a pistol and a musquet, which redoubled her terror. "Mr friend," said she to every person she met, "sare me and my children!" In the king's chamber she found the dauphin, who had been brought thither by one of her women; but the king was gone. Awakeved by the tumult, he had seen from a window the multitude pressing towards the staircase ; and alarmed for the queen, he hastened to her apartment, and entered it at one door at the moment she had quitted it by the other. He returned without loss of time; and having with the queen brought the princess-royal into the chamber, they prepared to face the multitude.

In the mean time the noise and tumult increased, and appeared at the very door of the chamber. Nothing was to be heard but the most dreadful exclamations, with violent and repeated blows against the outer door; a pannel of which was broken, and instant death was expected by the royal company. Suddenly, however, the tumult seemed to cease-every thing was quiet, and a moment after a gentle rap was heard at the door. The dool was opened, and in an instant the apartments were filled with the Parisian guard. The officer who conducted them ordered them to ground their arms. "IVe come," said he, "to save the king;" and turning to such of the sardes-du-corhs as were in the apartments, "We will save you also, gentlemen ; let us from this moment be united."

The royal family now ventured to show themselves at the balcony, and received the most lively acclamations of respect from the soldiers and the people. A single voice, or a few voices, exclaimed-" The king to Paris !" and this was instantly followed by an universal acclamation enforcing the same demand. The king addressed them :$\because$ You wish me to go to Paris:-I will go, on the condition that I am to be accompanied by my wife and children."-He was answered by reiteraterl acclamations of "Vive le Roi !" It was two in the afternoon before the procession set out. During the progress all was gaiety and joy among the soldiers and spectators : and such was the respect in which the French nation still held the name and person of their king; that the multitude were superstitiously persuaded that the royal presence would actually put an end to the famine. On his arrival, the king was congratulated by the municipality, and declared his approbation of the loyalty which the city of Paris manifested.

The spirit of the nation was so entirely averse from the principles of the high aristocratic party, that numbers of them, particularly the Vor. I. 
lsing's two brothers, and some of the first rank and fortune, took refuge in foreign countries, where they applied themselves indefatigably to the purpose of exciting war against their country.

Great preparations were made for the celebration of a grand confederation; in which the representatives of the nation, the king, the soldiery, and all who were in ostensible situations, should solemnly, and in the face of the whole nation, renew their oaths of fidelity to the new constitution; and this confederation was decreed to take place on the 14th of July, 1790, in honour of the taking of the Bastile, and of the first establishment of Gallic liberty. The Champ de Mars, so famous for having been the rendezvous of the troops which in the preceding year were intended to over-awe the capital, was chosen for this solemnity. This piece of ground, which is about 400 toises (or 800 yards) in diametcr, is bounded on the right and left by lofty trees, and commands at the further extremity a view of the Military Academy. In the middle of this vast plain an altar was erected for the purpose of administering the civil oath; and round it an immense amphitheatre was thrown up, of a league in circumference, and capable of containing 400,000 spectators. The entrance was through triumphal arches. The king's throne was placed under an elegant pavilion in the middie, and on each side of it were seats for the member's' of the national assembly.

The important 14 th of July at length arrived. The national guards of the departments, distinguished by their respective standards, the battailions of infantry, and the different troops of cavalry, the marine of France, and the foreigners who served under its banners, being arranged in military order, the king and the national assembly took a solemis oath to maintain the constitution; the armed citizens repeated it amongst the applauses of innumerable spectators. They swore to live free, or clie; and this oath was taken on the same day through the whole extent of the kingdom.

The escape of the king and queen with their infant children, and monsieur and madame, on the 20th of June, 1791, menaced France with the convulsions of anarchy and the horrors of civil war. The route of the royal fugitives, which had been expected to have been towards the Austrian Netherlands, the nearest frontier of the kingdom, was in fact directed towards Metz; from the presence of so gallant and accomplished a royalist as M. de Bouillé in that quarter, from its vicinity to the prince of Condé's army in Germany, and from the probable reluctance of Leopold to hazard the tranquillity of his Netherlands by permitting any incursion from them into France.They reached St. Menehould, a small town about 150 miles from Paris. The king was there recognised by the postillion, who said to him, "Mon roi, je vous cannais, mais je ne vous trahirai has." "I know you, my king, but I will not betray you." But the post-master, M. Drouet, less full of monarchic prejudice, adlopted a different conduct. He avoided, with great dexterity and presence of mind, betraying his knowledge of the rank of the royal travellers, being much struck with the resemblance which his majesty's countenance bore to his effigy on an assignat of fifty livres. The carriages taking the road to Varennes, he went a cross road to rejoin them; and arriving before them at Varennes, he alarmed the town and assembled the national guards, who, notwithstanding the detachment of hussars by which they were escorted, disarmed them, and the King was then made a frisoner; and at six o'clock in the afternoon of the 25 th of 
June, their majesties, with the dauphin and madame royale, arrived at the Thuilleries.

The new constitution was presented to the king on the $3 \mathrm{~d}$ of September, 1791 : who, on the $13 \mathrm{th}$, signified his acceptance of it in writing; and the following day appeared in the assembly, introduced by a deputation of sixty members, and solemnly consecrated the assent which he had already given, and concluded with an oath "to be faithful to the nation and to the law, and to employ the powers vested in him for the maintenance of the constitution, and the due execution of the law." Soon after this, the second national council assembled, with abilities far inferior to the first.

The clubious and undecided conduct of the emperor, and the refuge and protection found in the German empire by the emigrant princes, excited France to vigorous resolutions; and a manifesto, addressed to all states and nations, made its appearance. The forcible measures pursued, had the effect of intimidating the German princes; and the emigrants were constrained to an ignominious dispersion from the frontiers. But the protection of the emperor and the Prussian king afforded them asylums more remote and less obtrusive. Irresolution seemed to preside in the councils of the emperor; a monarch more eminent for the mild virtues of peace, than for the exertions of war. He had acknowledged the national flas; he had declared that he regarded the king of the French as absolutely free; - while the league of Pilnitz (which, as was avowed by the court of Vienna, was not only intended to secure Germany from such a revolution as France had experienced, but even to extinguish the dreaded scurce), and the protection afforded to the emigrants, were infallible proofs that the emperor. could not be regarded as a friend. His sudden death, on the 1st of March, 1792, excited great consternation among the aristocrats, and afforded joy and exultation to the supporters of the constitution. Another event, no less unexpected, happened in the death of the Sivedish monarch, on the 29th of the same month; and the superstitious vulgar imagined that they beheld the peculiar protection of heaven in the removal of the two chief foes of France in so short a time.

In the progress of the negotiations between the national assembly and the court of Vienna, the young king of Hungary, excited by the influence of Prussia, began to exhibit more enmity, and to use severer language. At length, on the 5th of April, M. de Noailles, in his dispatches to the French minister for foreign affairs, explained the propositions of the Imperial court-that satisfaction should be given to the German princes, proprietors of Alsace; that Avignon, which had been appropriated by France, should be restored to the pope; and that the internal government of France should be invested with sufficient efficiency, that the other powers might have no apprehensions of being troubled by France. These terms produced a declaration of war against Francis 1 ., king of Hungary and Bohemia; decreed by the assembly, and ratified by the French king, on the 24th of April.

The first movement of the French was stained with defeat; and with the unpropitious murder of Theobald Dillon, their leader, who fell a prey to the suspicious and savage ferocity of some of his solcliers, who fled from the énemy, but attacked their general. The court of Vienna had, in the beginning of July, published a declaration, cxplaining the cause of the war, and retorting on the French 
nation some of the heavy charges contained in its declaration of wat against the king of Hungary and Bohemia, now emperor of Germany. On the 26 th day of the same month, the Prussian monarch issued a concise exposition of the reasons which determined him to take up arms against France. He pleaded his alliance with the emperor; and that, as sovereign of a German state, he was bound to interfere to prevent the violation of the rights of the German princes of Alsace and Lorrain, and the invasion of the territories of others: and he colicluded by honestly avowing that it was his intention to repress the too great liberty of France, which might afford a danger ous example to neighbouring countries. At the same time the duke of Brunswick, general of the combined armies of Austria and Prussia, published, at Coblentz, a declaration to the inhabitants of France, conceived in the most haughty and presumptuous terms : he declared his intention of putting a stop to the anarchy which prevailed in France, and of restoring the king to his power; and yet he afterwards says his design was not to interfere in the internal government. It is unnecessary to dwell on the other parts of this insolent memorial; in which France was already regarded as a conquered country, and directions were given to the magistrates, national guards, and inhabitants at large : but the threat that the city of Paris should be given up to military execution, in case the least outrage should be offered to the king, queen, or royal family, is worthy of a Hun.

The excesses of the night between the 9th and 10th of August we relate with pain. At midnight the alarm-bell sounded in every quar.ter of Paris, the générale was beat, and the citizens flew to arms. The palace of the Thuilleries was attacked by the multitude; and the king; queen, and royal family, were forced to take refuge in the national assembly. At first the Swiss guards (who were obnoxious to the people, and had been ineffectually proscribed by repeated decrees of the assembly, the king not being allowed to have a foreign guard) repelled the populace; but these being reinforced by the Marseillois, and federates from Brest, (bodies which the Jacobins seem to have brought to Paris to balance the Swiss) and by national guards, the gates of the palace were burst open. The artillery joined the assailants. The consequences were, that, after a slaughter of about four hundred on each side, the Swiss guards were exterminated, and the palace ransacked.

The month of September seemed pregnant with the total ruin of French freedom; while the three following months reversed the scene, and exhibited a tide of success on the part of France, perhaps unexampled in modern history. It is with infinite concern that we direct the attention of our readers to the prison scene, which occurred on the $2 \mathrm{~d}$ and $3 \mathrm{~d}$ of September. The horrid massacre of the defenceless prisoner's, and other aristocrats, which took place at that period, is an eternal disgrace to the Parisian populace; who, in their fury, spared not even that gentle sex which all civilized nations hold in the highest respect. The number of the slain has doubtless been exaggerated, as usual; yet supposing that, by the most moderate account, only two thousand perished, the enormity of the deed remains the same. Some extenuation might be offered for the affair of the 10th of August in which a people, who supposed themselves betrayed to slavery and all its evils, so recently experienced and shaken off, assumed their revenge and their cause into their own hands; but no defence can be offered for this unnecessary crime. Had 
the combined armies besieged Paris, it is difficult to conceive what aid tney could have found from two or three thousand aristocrats, and many of these secured in chains.

A national convention had been called, to determine on the charges brought against the king. They met on the 24th of September : and, on the fir'st day of the meeting, the abolition of royalty in France was decreed by acclamation; and the following day it was ordered that all public acts should be dated "the first year of the French republic." But hardly was this convention constituted, when a violent faction appeared, headed by Marat,* Robespierre, and others, who repeatedly degraded its transactions by their fanaticism; and, being supported by the Jacobins and Parisian populace, proved too powerful for the convention to punish them as it wished. Repeated instances have proved that the convention was not free, but must vote as the mob of Paris dictated; the moderation of the members being often obliged to yield to the indecent applauses and hisses of the galleries.

So rapid was the progress of the French arms; and so great were the distresses in the combined armies, arising from a scarcity of provisions, from a long rainy season, and from a considerable mortality' among the Prussians (by the French accounts, estimated at one half) that the Prussians retreated from the dominions of France : which example the Austrians soon followed.

Even at the very time when Paris was in the greatest danger, the invasion of Savoy was ordered. On the 2 ist of September general Montesquieu entered the Savoyard territories, seized on the frontier posts and castles without resistance, and two days after took Montmelian. Chamberry and all Savoy soon followed; but the conquest, not being resisted, was productive of no military glory. The imprudence of the national convention, in permitting Savoy to incorporate itself with France, has excited wonder. After frequent declarations that the French would enter into no war with any view to conquest, their conduct in this respect was absurd and impolitic. It subjected them to the merited reproach that, under the pretence of liberty, they maintained the destructive maxims of their ancient government; and that their wishes to increase their territory, perhaps to subjugate Europe, remained the same. Admiral Triguet, commanding a squadron in the Mediterranean, captured Nice, Villa Franca, and the fortress of Montalban, belonging to the king of Sardinia.

The conquest of Saroy was regarded as a trifle; but when Custine began his acquisitions in Germany, every eye was turned to the rapidity and importance of his progress, till diverted by the wonders of Dumouriez. Spires yielded to the French arms on the 30th of September, and Worms soon after followed : ample supplies of provisions and ammunition were found in these cities. Custine, pursuing his course along the left bank of the Rhine, next captured Mentz, and

* Marat fell by the hands of female vengeance. Marie Anne Charlotte Cordey, strongly impressed with the calamities which he had brought upon her country, took a journey to Paris, in July, 1793, on purpose to put a period to his existence. Meeting Marat as he was coming from the bath, and entering into conversation with him (the more certainly to identify his person) she plunged a dagger into his breast; upon which he fell, and soon expired. Glorying in having exterminated a monster, she delivered herself up to the officers of justice; and with the utmost firmness submitted to her fate, in laving her head severed by the guillotine, in the 25 th year of ber age. 
afterwards Frankfort. He was eager to proceed to Coblentz, that noted seat of the counter-revolutionists ; but the Prussians and Austrians at length indicated a renewal of hostilities by garrisoning that town, and encamping in the adjacent country.

The conquest of the Austrian Netherlands forms the next grand object. Dumouriez had promised to pass his Christmas at Brussels ; and what was regarded as an idle vaunt proved very modest, for that city was in his hands by the 14 th of November. That able general, having entered the Netherlands on the 1st or $2 \mathrm{~d}$ of that month, with an army of forty thousand men, and with a most formidable train of artillery, occupied the first five days in repeated engagements with the Austrian army, commanded by the duke of Saxe-Feschen, governor of the Austrian Netherlands, and by general Beaulieu; which, however, exceeded not twenty thousand. At length, on the 6th of November, a decisive battle was fought at Jemappe, which decided the fate of the Netherlands. The contest was very general : all the points of the enemy's flanks and lines were attacked at once; all the bodies of the French were in action, and almost every individual fought personally. The cannonade began at seven in the morning. Dumouriez ordered the village of Carignon to be attacked, because he could not attempt the heights of Jemappe till he had taken that village. At noon the French infantry formed in columus, and rapidly advanced to decide the affair by the bayonet. After an obstinate defence, the Austrians at two o'clock retired in the utmost disorder.

Dumouriez immediately advanced, and took possession of the neighbouring town of Mons, where the French were received as brethren. The tidings arriving at Brussels, the court was struck with an indescribable panic, and instantly fled to Ruremond; whence it was again to be driven by the arms of Miranda. Tournay surrendered to a detachment on the 8 th of November. Dumouriez, having refreshed his troops at Mons, advanced to Brussels; where, after an indecisive engrgement between his van and the Austrian rear, he was received with acclamations on the 14th of that month Ghent, Charleroi, Antwerp, Malines (or Mechlin) Louvain, Ostend, N mur, in short, all the Austrian Netherlands except Luxemboury, successively followed the example of the capital; and the conquests of Lewis XIV were not more rapid.

Many of the priests, who were banished, came to England, and were received with great benevolence; this was followed by the decree of the national convention against the emigrants; by which they were declared clead in law, their effects confiscated, and themselves adjudged to immediate death if they appeared in France.

Another decree, of the $19 \mathrm{th}$ of November, attracted the attention of every nation in Europe. It is in the following terms : "The nacional convention declare, in the name of the French nation, that they will grant fraternity and assistance to all those people who wish to procure liberty; and they charge the executive power to send orders to the generals to give assistance to such people, and to defend citizens who have suffered, or are now suffering, in the cause of liberty." This decree, and others of a similar tendency, seemed to instisute a political crusade against all the powers of Europe.

No sooner had Antwerp yielded to the French arms, than, in order to conciliate the Belgians, the opening of the navigation of the Scheldt (shut up by the treaty of Munster, in 1648) was projected and ordered; notwithstanding this treaty, so far as respects the shutting up 
of the navigation of this river, had been confirmed to the Dutch in succeeding treaties, guaranteed both by the courts of Versailles and London. The Dutch regarded this nieasure as injurious to their trade; for Antwerp might prove a dangerous rival to Ansterdam. The infraction of this treaty was one of the reasons which induced the parliament of Great Britain to oppose the unwarrantable pretensions of the French.

The memorable trial of the king commenced on the 11 th of $\mathrm{De}$ cember. The issue is too well known. The firmness of this unfortunate monarch during his trial, and at the place of execution, (on the 21 st of January, 1793,) increased the commiseration of every indifferent spectator; and callous indeed must be the person who does not partake of the sympathy which was felt through all Europe upon this transaction.

It would be a tedious and disagreeable undertaking to trace minutely and gradually the progress of the dispute between France and England. IVithout affixing any degree of credit to the reports that Great Britain had early but secretly acceded to the concert of princes, and the treaty of Pilnitz, it is natural to believe that the British ministry had long viewed with a jealous eye the progress of the French revolution towards a turbulent democracy. IVe must, however, do the French nation the justice to confess, that the unanimous voice of that people was clamorous from the first for peace and alliance with England. A series of events changed this inclination. A bill for forcibly transporting aliens out of the kinglom was introduced into parliament. The ports of Great Britain were shut against the exportation of corn to France, while it was permitted to her enemies. In the eud, the ambassador of the republic, M. Chauvelin, was ordered, under the authority of the alien bill, at a short notice, out of the kingdom: immediately after which dismission, the convention declared that the French republic was at war with the king of England, and the stadtholder of the United Provinces.

In consequence of these measures, general Dumouriez proceeded with a large body of troops to invade Holland; exhorting the Batavians, in a violent manifesto, to reject the tyrannic aristocracy of the stadtholder and his army, and to become a free republic. The Dutch made preparations for defending themselves; and the English cabinet seconded their efforts, by an immediate embarkation of troops, to the command of which the duke of York was appointed.

The subjugation of Holland was the first project of general Dr. mouriez: and when the ease with which he had effected the conquest of the Netherlands, and the courage and ability displayed by him and his army at the famous battle of Jemappe, were considered, there seemed reason to apprehend that he would soon make an impression on these provinces; and the easy surrender of Breda and Gertruydenberg encouraged him to boast that he would terminate the contest by a speedy approach to Amsterdam. Certain events, however, ensued, which effectually prevented the performance of this promise.

General Mirancla, who had besieged the city of Maestricht, and summoned the governor to surrender, was attacked by prince Frederic of Brunswick, and defeated with considerable loss. The Austrians, after this, divided themselves into three columns; two of which marched towards Maestricht, and the siege of that place was immediately raised. The third pursued the advanced guard of the republic; and the absence of several commanding officers was supposed to 
have greatly facilitated the success of the Prussians in these rell. counters.

On the 14th of March, the Imperialists advanced from Tongres towards Tirlemont, by St. Tron; and were attacked by general Dumouriez successively on the 15 th and following days. The first attempts were attended with success: the Austrian advanced posts were obliged to retire to St. Tron, through Tirlemont, which they had already passed. On the 18th, a general engagement took place at Neerwinden; the French army being covered on the left by Dormael, and on the right by Landen. The action continued, with great obstinacy on both sides, from seven in the morning till five in the afternoon, when the French were obliged to fall back; and the $\mathrm{Au}$. strian cavalry, coming up, put them entirely to flight. The loss in each army was great. The French displayed considerable courage. and address; but were overpowered by the superior numbers, and perhaps by the more regular discipline, of their enemies.

Dumouriez was now suspected of treachery; and general Miranda intimated his suspicions, in a confidential letter to Petion, dated the 21 st of March. Four commissioners were immediately sent from Paris, with powers to suspend and arrest all generals and military officers whom they should suspect, and bring them to the bar of the convention. 'These commissioners, on the ist of April, proceeded to St. Amand, the head-quarters of Dumouriez; and, being admitted to his presence, explained to him the object of their mission. After a conference of some hours, the general, finding that he could not persuade them to favour his intentions, gave the signal for a body of soldiers who were in waiting; and ordered the minister of war, Bournonville (who was sent to supersede him) and the commissioners $\mathrm{Ca}$ mus, Blancal, La Marque, and Quinette, to be immediately convered to general Clairfait's head-quarters at Tournay, as hostages for the safety of the royal family.

Dumouriez, notwithstanding his splendid talents, found himself grossly mistaken with respect to the disposition of his army. They had resented the affront so imprudently offered to their general : but when he came to explain to them his plan, and propose the restoration of royalty in the person of the prince, they all forsook him; and he was obliged to fly with a very few attendants, making his escape through a dreadful discharge of musketry, which the whole column poured upon him and his associates.

The latter end of June, and the beginning of July, were chiefly distinguished, in the north, by some petty skirmishes between the two grand armies. In the latter part of July, the Austrians obtained some successes of more importance. The garrison of Condé, after sustaining a blockade of three months, surrendered on the 10th, by capitulation, to the prince of Cobourg : and Valenciennes, on the 20 th of the same month, to the duke of York, not without some suspicions of treachery in both cases.

Encouraged by these successes, a large detachment from the combined army, under the command of the duke of York, proeeeded, without loss of time, to attack the port and town of Dunkirk. On the 22d of August, the duke of York marched from Furnes to attack the French camp at Ghivelde; which was abandoned at his approach, and he was almost immediately enabled to take the ground which it was his intention to occupy during the siege. On the 24th, he attacked the outposts of the French; 
who, with some loss, were driven into the town. In this action, the famous Austrian general Dalton, and some other officers of note, were killed. The succeeding day, the siege might be said regularly to commence. A considerable naval armament from Great Britain was to have co-operated in the siege; but, by some neglect, admiral Nacbride was notable to sail so early as was expected. In the mean time, the hostile army was extremely harassed by the gun-boats of the French: a successful sortie was effected by the garrison on the 6 th of September; and the French collecting in superior force, the duke of York, on the 7 th, after several severe actions, in which the allied forces suffered very considerably, was compelled to raise the siege, and leave behind him his numerous train of artillery. General Houchard was afterwards impeached by the convention, and beheaded, for not having improved his success to the best advantage; as it was asserted that he had it in his power to capture almost the whole of the duke of York's army.

The disaffection of the southern provinces of France was at this time productive of serious dangers to the new republic. It is well known that the deputies and people of these provinces were among: the most active to promote the dethroning of the king on the 10th of August, 1792. It is therefore somewhat extraordinary, that the same men should be among the first to rebel against the authority of the convention. The formidable union which took place, under the name of federate refublicanism, between the cities of Marseilles, Lyons, and Toulon, in the course of the months of June and July, seemed to threaten almost the dissolution of the existing authorities. A considerable aimy was, however, dispatched against Lyons, and the city closely besicged. The Marseillois, in the mean time, opened their gates on the approach of the republican army, and submitted: but the people of Toulon entered into a negociation with the English admiral, lord Hood, who was then cruising in the Mediterranean; and he took possession both of the town and slipping, in the name of Lewis XVII, and under the positive stipulation that he should assist in restoring the constitution of 1789 .

Among the victims of popular resentment who fell about this period, was the celebrated general Custine; whose former services, whatever might have been his subsequent demerits, ought to have secured him more lenient treatment. He was recalled to Paris, from the command of the northern army, in the beginning of July; and on the $22 d$ committed, under a decree of the convention, a prisoner to the Abbey. He was tried by the revolutionary tribunal; and accused of having maintained an improper correspondence with the Prussians while he commanded on the Rhine, and of having neglected various opportunities of throwing reinforcements into Valenciennes, It is needless to say that he was found guilty; to be suspected was then to be condemned : and the populace of Paris, now accustomed to such scenes, beheld the sacrifice of their former defender with calm indifference, or with blind exultation.

The trial and condemnation of the queen immediately followed that of general Custine. She had been removed, on the nigit of the 1st of August, from the Temple, to a small and miserable apartment in the prison of the Conciergerie; where she remained till she was brought before the revolutionary tribunal, on the 15 th of October. The act of accusation consisted of several charges, many of which

Vor. I. 
were frivolous and incredible, and few of them appeared to be suffciently substantiated by evidence; but had the conduct of Marie Antoinette been more unexceptionable than there is reason to believe it was, it is not very probable that she would have escaped. After an hour's consultation, therefore, the jury brought in their verdict"Guilty of all the charges."

The queen heard the sanguinary sentence with dignity and resignation; perhaps, indeed, it might be considered by her less as a punishment than as a release. On the 16 th of October, at about eleven o'clock in the forenoon, she was conducted in a coach, from the prison of the Conciergerie, to a scaffold prepared in the Place de la Revolution, where her unfortunate husband had previously suffered. The people, who crowded the streets as she passed, exhibited no signs of pity or compunction. Her behaviour, as her last sufferings approached, was decent and composed. She met her fate in the thirty * eighth year of her age.

Soon after the convention had brought the queen to the scaffold, they entered upon the trial of Brissot, and his supposed accomplices. Brissot was charged with having said and written, at the commencement of the revolution, that Fayette's retiring from the public service was a national misfortune; with having distinguished himself three times in the Jacobin club by speeches, of which one provoked the ruin of the colonies, another the massacre of the patriots in the Champ de Mars, and the third the war against Austria.

Upon these and other vague accusations, Brissot, and twenty-one more of the convention, were brought to trial before the revolutionary tribunal, on the 24th of October; a few days afterwards the jury declared all the accused members to be accomplices in a conspiracy which had existed against the unity and indivisibility of the French republic; and the tribunal immediately condemned them all to the punishment of death. Valazé, after he had heard his sentence, stabbed himself; and the remaining twenty-one were executed on the soth of October.

The wretched and intriguing Egalité, late duke of Orléans, was soon after brought to the block. He was accused of having aspired to the sovereignty from the commencement of the revolution; but how well founded the charge was, it is not easy to determine. $\mathrm{He}$ was conveyed in a cart, on the evening of the 6th of November, to the place of execution; and suffered with great firmness amidst the insults and reproaches of the populace.

In the south of France, neither the exertions of the allies, nor the surrender of the Toulonese, were sufficient to produce the expected consequence of establishing a monarchical government. On the 30th of November, the garrison of Toulon made a vigorous sortie, in order to destroy some batteries which the French were erecting on certain heights within cannon-shot of the city. The detachment sent for this purpose accomplished it; and the French troops were surprised, and fled. The allies, too much elated with their success, pursued the fugitives till they unexpectedly encountered a considerable force which had been sent to cover their retreat. At this moment, general O'Hara, commander in chief at Toulon, came up; and, while he was exerting himself to bring off his troops with regularity, received a wound in his arm, and was made prisoner by the republicans. Near a thousand of the British and allied forces were killed, wounded, or taken prisoners, on this occasion. 
Soon after the capture of the British general O'THara, the city of Toulon was evacuated by the allies. On the morning of the 19 th of December, the attack began before all the republican forces had time to come up. It was chiefly directed against an English redoubt (Fort Mulgrave) defended by more than three thousand men, twenty pieces of cannon, and several mortars. This formidable post was attacked. about five o'clock in the morning, and at six the republican flag was flying upon it.

The town was then bombarded from noon till ten o'clock the same night; when the allies and part of the inhabitants, having first set fire to the town and shipping, precipitated their flight. Two chaloupes, filled with the fugitives, were sunk by the batteries. The precipitation with which the evacuation was effected, caused a great part of the ships and property to fall into the hands of the French, and was attended with the most melancholy consequences to the wretched inhabitants-who, as soon as they observed the preparations for flight, crowded to the shores, and demanded the protection which had been promised them on the faith of the British crown. A scene of confusion, riot, and plunder, ensued; and though great efforts were made to convey as many as possible of the people into the ships, thousands were left to all the horrors of falling into the hands of their enraged countrymen. Many of them plunged into the sea, and made a rain attempt to swim on board the ships; others' were seen to shoot themselves on the beach, that they might not endure the greater tortures they might expect from the republicans. During: all this, the flames were spreading in every direction; and the ships that had been set on fire were threatening every instant to explode, and blow all around them into the air. This is but a faint description of the scene on shore, and it was scarcely less dreadful on board the ships-loaded with the lieterogeneous mixture of nations; with aged men and infants, as well as women; with the sick from all the hospitals, and with the mangled soldiers from the posts just deserted, their wounds scill undrest. Nothing could equal the horrors of the sight; except the still more appalling cries of distraction and agony, that filled the ear, for husbands, fathers, and children, left on shore.

In the latter end of March, the party called the Hebertists, consisting of Hebert, Momero, Vincent, and some others, were arrested, brought to trial before the revolutionary tribunal, and twenty of them executed. A few days after, the celebrated Danton, Fabre d'Eglan. tine, Bazire, Chabot, and others, were arrested as conspirators against the republic, tried in a very summary way, and sentenced to death; which sentence was executed on the 5th of April, 1794 .

In consequence of these executions, the government of France, however nominally republican, became almost entirely vested in one man, the usurper Robespierre-a name which will probably be transmitted, with infamy, to late posterity. Under his sanguinary admin. istration, the prisons of Paris, at one time, contained between seven and eight thousand persons. Of the number of those tried and executed, we have no precise account; but they in general appeared rather to be sacrificed in multitudes to a jealous and cowardly cruelty, than condemned with even the shadow of justice. In one of these barbarous slaughters, the princess Elizabeth, the sister of the late unfortunate monarch, having been condemned on the most frivol. 
ous pretexts, was executed the last of twenty-six persons who were carried to the scaffold on the same day.

But, after the death oi Danton, the fall of this tyrannical demagogus rapidiy approached. A strong party was secretly formed against him in the convention; headed by Tallien, Legendre, and some others. Finding themselves sufficiently strong, Tallien moved the arrest of Robespierre and his creatures; which decree was passed with applauses from every quarter. The presiclent then ordered one of the ushurs of the hall to take Robespierre into custody: but such was the awe which the presence of this man was accustorned to inspire, that the officer hesitated to perform his duty; till Robespierre himself muce a sign of obedience, and followed the usher out of the hall. The prisoners were conducted by a few peace-officers to the prison of the Luxembourg: but the administrator of the police on duty there, who was one of their creatures, refused to receive them; and they were then led, rather in triumph than as prisoners, to the Hotel de Ville.

In the mean time, Henriot, another leader of the party, had also been arrested, but found means to escape and raise his partisans; who took post with him and Robespierre in the Hotel de Ville, where they pretended to form themselves into a new convention, and declared the other representatives traitors to their country. The people, however, did not espouse their cause ; the national guard, who had at first obeyed their orders with reluctance, forsook them; and the deputies who had been dispatched for that purpose, attacked them in the Hotel de Ville. Bourdon de l'Oise, after having read the proclamation of the convention, rushed into the hall of the commune, with a sabre and pistols; the insurgents were completely de. serted, and now endeavoured to turn their arms against themselves. Robespierre the elder discharged a pistol in his mouth; which, how ever, failed of its effect, and only wounded him in the jaw, while. he received another wound from a gensdarme in the side. The younge: Robespierre threw himself out of a window, and broke a leg and an arm; Le Bas shot himself upon the spot; Couthon stabbed himself twice with a knife; and Henriot was thrown out of a window.

The prisoners were immediately conveyed before the revolutionary tribunal ; and their persons being identified, they were condemned to suffer death in the Place de la Revolution: where the two Robespierres, and nineteen others, were executed at seven in the evening of the 28th of July, 1794.

In the campaign of this year, the arms of the new republic were successful on every side against the allies. In Flanders, general Jourdan gained the battle of Fleurus; and Charleroi, Ypres, Bruges, and Courtray, surrendered to the French: Ostend was evacuated; general Clairfait defeated near Mons, which immediately surrendered; and the prince of Cobourg compelled to abandon the whole of the Netherlands, while the victors, without opposition, entered Brussels and Antwerp. Landrecy, Quesnoi, Valenciennes, and Conde, were successively retaken; and the French armies, pursuing their success, took Aix-la-Chapelle, defeated Clairfait near Juliers, and made themselves masters of Cologne and Bonn. Maestricht and Nimeguen were likewise taken.

The United Provinces began now to be seriously alarmed. The states of Friesland were the first to feel their danger; and, in the month of October, these states determined to acknowledge the French 
republic, to break their alliance with England, and to enter into a treaty of peace and alliance with France. In some of the other provinces, resolutions hostile to the stadtholder and his government were likewise passed; and such appeared to be the temper of the people, even at $\Lambda$ msterdam, that on the 17 th of October, the government of Holland published a proclamation, prohibiting the presenting of any petition or memorial upon public or political subjects, and all popular meetings or assemblies of the people upon any occasion.

On the 7 th of December, the French made a feeble attempt to cross the IVaal, but were repulsed with loss; but on the 15 th the frost set in with unusual rigour, and opened a new road to the French armies. In the course of a week, the Maes and the Waal were both frozen over; and on the 27 th a strong column of French crossed the Maes, near the village of Driel. They attacked the allied army for an extent of above twelve leagues; and, accorling to the report of general Pichegru, "were as usual victorious in every quarter." The army of the allies retreated before them; and, in its retreat, endured incredible hardships from the severity of the weather and the want of necessaries. On the 10th of January, 1795, general Pichegru, hava ing completed his arrangements, made his grand movement. The French crossed the Waal at different points; with a force, according to some accourits, of 70,000 men. A general attack was made upon Walmoden's position between Nimeguen and Arnheim. The allies were defeated in erery quarter; and, utterly unprepared either for resistance or for flight, suffered equally from the elements and the enemy.

It was in vain that the stadtholder issued manifestoes, proclamations, and exhortations to the Dutch peasantry, conjuring them to rise in a mass for the defence of the country. The French continued to advance, and the allies to fly before them, till Utrecht surrendered to them on the 16th of January, Rotterdam on the 18th, and Dort on the succeeding day. The utmost consternation now prevailed among the partisans of the stadtholder. The princess of Orange, with the younger and female part of the family, and with all the plate, jeirels, and moveables, that could be packed up, escaped on the 15th. The stadtholder and the hereditary prince did not leave Holland till the 19th. His serene highness embarked at Scheveling, in an open boat, with only three men to navigate her; and arrived safe at Harwich. In England, the palace of Hampton-court was assigned him for his residence.

On the 20th of January, general Pichegru entered Amsterdam in triumph, at the head of 5000 men; and was received by the inhabitants with the loudest acclamations. The whole of the United Provinces either submitted to, or was reduced by the French, in a few weeks. An assembly of the provisional representatives of the people met on the 27th of January; and the whole government was changed, and modelled nearly after the French plan.

In the mean time, the king of Prussia, finding he could derive no advantage from the war, began to relax, his efforts. The Prussian and Austrian forces, as well as their leaders, were on bad terms with each other; but it was not suspected that any defection was about to take place on the part of the Prussians, till they began to retreat rowards the Rhine, which they soon after passed. A negotiation between Prussia and France followed; which ended in a treaty of 
peace signed at Basle, on the 5th of April, 1795, by which his. Prisie sian majesty entirely abandoned the coalition.

The Prussian negotiation was followed by the treaty made between the French republic and Spain, in which country the arms of France had made a progress equally successful and rapid. Fontarabia, which guards the entrance of Spain, and which had cost the duke of Berwick 8000 men, had been taken, almost immediately, by a detachment from the French army; Rosas was likewise taken; and the troops of the republic had made themselves masters of the greater part of the rich provinces of Biscay and Catalonia, and were, in fact, in full march for the capital of the kingdom. Orders were therefore clispatched to M. D'Yriarte, at Basle, immediately to conclude a treaty; which ivas accordingly signed by the Spanish minister and M. Barthelemi, at Basle, on the $22 \mathrm{~d}$ of July.

About the middle of this year, died the infant son of the unfortunate Lewis XVI. An unjust and close imprisonment, if it did not produce, at least, it is probable, hastened his fate. He had always been an unhealthy child, and subject to a scrofulous complaint; a disorder in which confinement and inactivity are frequentiy fatal. For some time previous to his decease, he had been afficted with a swelling in his knee, and another in his wrist. His appetite failed, and he was at length attacked with a fever. It does not appear that medical aid was denied him, or neglected. The disease, however, continued to increase; and on the morning of the 9 th of June, he expired in the prison of the Temple, where he had been confined from the fatal autumn of 1792 .

Moved perhaps by this event, orinfluenced by the general sympathy of the people of France, the committee of public safety, in the beginning of July, proposed the exchange of the princess, sister of the dauphin (who was likewise a prisoner in the temple) for the deputies delivered up to Austria by the treachery of Dumouriez; and for the two ambassadors Semonville and Maret, who had been seized contrary to the law of nations, on a neutral territory, by an Austrian corps. The emperor, after some hesitation, acceded to the proposal; and before the conclusion of the year, the princess was delivered to the Austrian envoy, at Basle in Switzerland, and the deputies were restored to their country.

In the course of this year, an expedition was planned by the English ministry, to invade the coast of France, in that part where the royalists (known by the name of Chouans) were in arms against the republicans. The force employed consisted chiefly of emigrants; under the command of M. Puisaye, M. d'Hervilly, and the count de Sombreuil. They landed in the bay of Quiberon, and took the fort of the same name; but soon after experienced a sad reverse : the fort being surprised by the republican troops, under the command of general Hoche; who killed or made prisoners the gireater part of the emigrants, Chouans, and English, in the fort, amounting nearly to 10,000 men. The count de Sombreuil, the bishop of Dol, (with his clergy who accompanied him,) and most of the emigrant officers, who were made prisoners, were tried by a military tribunal, and put to death. Before the month of April, in the ensuing year (1796) the force of the insurgents in this part of France was entirely broken; and their chiefs, Charette and Stofflet, taken prisoners and put to death.

In Germany, the French army had crossed the Rhine near Man- 
heim, and blockaded Mentz, to which they had already laid siege for sereral months. In this attempt, however, they were unsuccessful : they suffered a defeat from the Austrians, and were compelled to repass the river. A suspension of arms, for three months, was soon after agreed to by the generals of the contending armies, which was ratified by the respective powers.

In the succeeding year (1796) the campaign opened in the south, on the 9th of April; when the rapid and signal victories of the republican troops, under the command of the then obscure and little known, but now celebrated Buonaparte (which name he has since chosen to write Bonaparte) ended, in little more than a month, the war with, Sardinia. The battles of Millessimo, Dego, Mondovi, Monte Lermo, and Monte Notte, compelled his Sardinian majesty to accept such terms as the conquerors thought proper to offer ; and a treaty of peace, by which he ceded Savoy and Nice to France, was signed on the 17 th of May.

Bonaparte pursued his success; and, again defeating Beaulieu, the Austrian general, at the battle of the bridge of Lodi, forced the shattered remains of the Austrian army to retire towards Mantua, pursued by one part of the republican forces: while the remainder entered Milan on the 18th of May without further resistance, and the French armies gained possession of the whole of Lombardy.

The armistice which had been concluded on the Rhine, was afterwards prolonged, but at length declared to be at an end on the 31 st of May: when the army of the Sambre and Meuse, under general Jourdan, gaining considerable advantages over the Austrians, advanced into the heart of the empire; while another army, under general Moreau, passed the Rhine at Strasbourg, took the fort of Kehl (a post of great importance on the opposite bank) and penetrating through Bavaria nearly to Ratisbon, endeavoured to form a junction with the army of Jourdan. This attempt, however, did not succeed; both armies experienced a reverse of fortune, and were obliged to retreat till they recrossed the Rhine. The situation of general Moreari was highly critical ; and his retreat is acknowledged, on all sides, to have been conducted with great military skill. The archduke Charles, who commanded the Austrian army, followed Moreau in his retreat; and laid siege to the fort of Kehl, which he retook after a most obstinate resistance on the part of the French.

To restore the affairs of Italy, the emperor assembled a new army, composed of the flower of the German troops serving on the Rhine; and gave the command of it to general Wurmser, one of the oldest and ablest of the imperial generals. This force, on its first arrival, was successful : the French were repulsed, defeated, and compelled to raise the siege of Mantua. Bonaparte, however, soon returned to the charge ; and, after a series of hotly-contested actions, the army of Wurmser was so reduced and harassed, that he was obliged to shut himself up in Mantua; where he was closely besieged by the victors, who at the same time made incursions into the Tyrol; and, by the battle of Rovereclo, and the possession of Trent, became masters of the passes that led to Vienna. The Austrians, at the same time, made a great effort, under general Alvinzy, to rescue the gallant IVurmser and his besieged army; but the battle of Arcole compietely defeated their design, and Mantua was soon after obliged to surrender.

The victories of Bonaparte compelled the pope, the king of $\mathrm{Na}$ - 
ples, and the inferior princes of Italy, to conclude such treaties as the French thought proper to dictate. The victors likewise founded a new republic in Italy, at first called the Cispadane, but afterwards the Cisalpine republic, to which they annexed such parts of the papal territory as they judger convenient.

After the taking of Mantua, the victorious Bonaparte penetrated into the Tyrol, and directed his course towards the Imperial capital. The archduke Charles was opposed to him, but was unable to check his progress. The/republican armies had at length advanced so near to Vienna, that the utmost alarm and confusion prevailed in that city. The bank suspended its payments; and the emperor was preparing to forsake his capital, and renove to Oimutz. In this criticai situa. tion of his affairs, his imperial majesty opened a negociation with Bonaparte; a short armistice was agreed to; and the preliminaries of peace between the emperor and king of Hungary, and the French republic, were signed at Leoben, in the month of April, 1797.

In the mean time, a tumult having taken place at Venice, in which a number of the French soldiers were murdered in the hospitals of that city, the French armies, on their return, abolished the ancient government of Venice, planted the tree of liberty in St. Mark's Place, established a municipality, and proposed to annex the city and territory to the new Cisalpine republic. But the conclusion of the definitive treaty of peace with the emperor being protracted on account of the French refusing to restore Mantua, as it is alledged it was stipulated they should in the preliminaries, they at length agreed to cede to him the city and a part of the territory of Venice, in compensation for Mantua.

The definitive treaty of peace between France and the emperor was signed at Campo Formio, on the 17 th of October, 1797. By this treaty the emperor ceded to France the whole of the Netherlands, and all his former territory in Italy. He received in return the city of Venice, Istra, and Dalmatia, and the Venetian Islands in the Adriatic: the French were to possess the other Venetian islands.

While the negociations which terminated in this treaty was carrying on, the disputes of two contending parties were producing a new revolution in France. On the 5th of March, the two councils drew the lots, which deprived one third of their members of their seats in the legislature, and the new deputies elected in their room took their seats on the 20th of the same month. It soon appeared that the antidirectorial party had received a considerable accession of strength. The conduct of the directory was very freely canvassed; retrenchment of expense in both civil and military offices was proposed; the laws relative to polygamy were ordered to be revised; and the severity of those against priests and emigrants was greatly relaxed. The proceedings of the directory, with respect to the Venetian, Genoese, and Helvetic republics, were severely censured, and it was evident that an open rupture between the directory and the councils was inevitable. Unfortunately for the party in opposition to the directory, the armies took part with the latter. The army of Italy transmitted to the directory a most violent address relative to these disputes, and its example was followed by the other armies of the republic. The opposition party were slow and irresolute in the measures they took for their defence : they probably relied with too much confidence on their supposed strength, as they had a decisive majority in the council of five hundred, and two out of the five directors, Carnot and Bar- 
thelemi, were in their interests. Barras, however, and his party, supported by the armies, resolved on a prompt and violent measure, which effectually decided the conquest.

On the morning of the 4 th of September, at the carly hour of three o'clock, Barras, and the two directors who acted with him, ordered the alarm-guns to be fired, and the halls of the councils to be surrounded with a military force. General Augereau, who was charged with the execution of these orcers, repaired to the barracks, and addressed the guard of the legislative body, assuring thern that he came only to preserve the republic from the conspiracy of royalists. The soldiers declared, with shouts of approbation, that he had only to command, and they were ready to obey. Thus reinforced by the very men to whom alone the councils could look for deferice, Augereau entered the hall of the five hundred, and seized Pichegru, the president, with his own hands, and ordered about eightecn others of the most conspicuous characters to be arrested and committed to the temple. The halls were shut up, and the members of both councils appointed to meet in other places which were pointed out to them. Carnot and Barthelemi were implicated in the fate of their friends in the councils. The former took advantage of the tumult, and fled; the latter calmly awaited the storm, and was put under arrest. Barthelemi, Pichegru, and a number of the deputies who were seized by Augereau, were transported to Cayenne, whence the two former, and some others, afterwards found means to return to Europe.

The power of the directory, or rather of the party of Barras, being now rendered complete by this decisive victory over the councils, they projected new schemes of ambition and conquest, in order to give employment to the armies, and afford them an opportunity of enriching themselves by plunder. A tumult having taken place, at Rome, in which a French general was killed, they subverted the government of that city, deposed the pope, and erected a new republic, which they called the Roman republic. They likewise found a pretext to invade and levy heavy contributions on Switzerland, which they endearoured to transform into a new republic, under the title of the Helvetic republic; the government of which would, in consequence, be delivered into the hands of their own officers and partisans. Of these invasions the reader will find a further arcount under the heads of Italy and Switzerland.

In the beginning of the year 1798, a congress of deputies from the states of the German empire met at Rastadt, to negociate a peace between France and the empire, on the basis of the treaty of Campo Formio: Bonaparte repaired thither, met the assembled plenipotentiaries, and exchanged with count Meerfeldt the ratification of the treaty of peace with the court of Vienna; after which he returned to Paris, leaving the commissioners, Trielhard and Bonnier, to conduct the negociations, which were protracted to a great length.

After the conclusion of peace with the emperor, the army became a burthen which it was found difficult to support; and though a part of it had been employed in the plundering of Rome, and the oppression of Switzcrland, there still remained a large body of troops in a state of inaztivity that might ultimately prove dangerous to the government. An immediate invasion of England was therefore announced to be resolved on, and an army collected along the coast of France opposite to Great Britain, to which was given the pompous title of the Army of England. Convinced, however, of the impracticability

VOL. I. s D 
of such an invasion, if ever it were really intended, the project was changed for another likewise sufficiently absurd, which was an expedition to Egypt, under the command of Bonaparte ; and the uitimate object of which, it is believed, was to penetrate, either by the Isthmus of Suez, or by the Red Sea, to the Indian Ocean, embark the troops, and, by a co-operation with Tippoo Sultan, endeavour to effect the overthrow of the British empire in the East. While preparations were secretly making for this expedition, the public were amused with strange and monstrous stories of rafts to be constructed for the invasion of England, and troops were collected on the northern coast of France, while the navy of the republic were secretly repairing to Toulon. At length the preparations being completed, Bonaparte embarked on board the fleet, under the command of admiral Brueys, with about 40,000 men, chiefly the veterans of the Italian army, and sailed from Toulon in the latter end of May. On the 9th of June he arrived off the island of Malta, where he demanded leave to water the fleet, which was refused by the grand-master, in consequence of which the French on the following day landed a body of troops. The little island of Gozzo was taken by one detachment, while the southern parts of Malta were reduced by another. The greater part of the inhabitants took refuge in the garrison, which, howevel, made but a feeble resistance, the grand-master on the 11 th agreeing to a capitulation, by which the whole island and its dependencies were surrendered to the French republic.

After leaving a garrison of 4000 men in Malta, Bonaparte proceeded on his royage, about the 21 st of June, and arrived at Alexandria on the Ist of July, having escaped the British squadron which was detached in pursuit of him under the commant of admiral Nelson. His usual good fortune appeared to attend him in all his first attempts. The town of Alexandria was taken by assault, on the night of the 5 th, with the loss of between two and three hundred men, and on the 21 st the French army appeared before Cairo, which was defended by Morad Bey with a considerable body of the Mamalukes; but on the $23 \mathrm{~d}$ it was attacked and carried. The beys, however, attempted to rally, and collected a formidable force in the neighbourhood of Cairo; but the battle of the pyramids, which was fought on the $26 \mathrm{th}$, rendered the French masters of the greater part of the country. In that engagement, twenty-three beys, with all the forces they could bring into the field, were completely defeated. Two thousand of the Mamalukes were slain, and four hundred camels with their baggage, and fifty pieces of cannon, were taken, with a very trifling loss on the part of the French.

The conquest of Egypt now appeared to be complete; but on the 1st of August the expecition received a terrible blow in the defeat and destruction of the fleet, by admiral Nelson, of which an account has already been given in our historical summary of the affairs of Lingland. The French land-forces, however, remained in possession of Egypt; and, to secure his conquest, Bonaparte advanced into Syria, where, after gaining some advantages, he received a decisive check before St. John d'Acre. The English squadron, under sir Sydney Smith, intercepted a flotilla which was bringing his battering artillery and ammunition from Egypt; and, sir Sydney acting in concert with the Turks, he was completely repulsed in every assault, and obliged to raise the siege, and retreat back to Egypt with the shattered remains of his army. From Egypt, Bonaparte soon after took an opportunity 
to make his escape to France ; where, as we shall presently see, he became the author of a new and extraordinary revolution in the constitution and government.

The unprincipled attack on Egypt, contrary to the faith of treaties, so incensed the Turks, that they inmediately declared war against the French republic; and the emperor of Russia, having accepted a subsidy from Great Britain, entered into a treaty of alliance with the Ottoman Porte and with England, and gave orders for a large body of troops to be raised to act against France. Austria likewise appeared disposed to avail itself of the assistance of this new ally; and the French directory having applied to the emperor for an explanation on this subject, and received none which they deemed satisfactory, sent orders to general Jourdan to pass the Rhine, with the avowed intention of forcing the diet of Ratisbon to declare against the march of the Russian troops. He executed these orders on the 1st of March, 1799; and nearly about the same time, general Bernadotte, at the head of an army of observation, passed the Rhine at Waldeck, invested Philipsburg, and summoned that fortress to surrender, while general Ney sent a similar summons to Manheim which immediately opened its gates to him. Yet, notwithstanding these proceedings, the French ambassador declared to the congress of Rastadt, which, though it had sat solong, had as yet come to no conclusion, that these hostile movements were undertaken solely to prevent the interference of the court of Petersburg, and accelerate a general peace. The congress soon after was broken up, and two of the three French plenipotentiaries basely and inhumanly murdered, as they were leaving the town, by some Austrian hussars, or persons who had assumed that disguise.

The cabinet of Vienna being now certain of the aid of Russia, the Austrian army, under the command of the archduke Charles, passed the Lech, on tire 4th of March; and the war, which had so long desolated Europe, was renewed. Fortune, at first, appeared to declare in favour of the French. A body of troops of that nation, advancing through Schaffhausen towards Suabia, were opposed by a detachment of Aurtrians whom they defeated, taking the general and three thousand men prisoners. They were also successful for a short time in Italy. Their troops occupied the whole of Tuscany ; and the king of Sarcinia was reduced in the month of January, to the cruel necessity of formally renouncing the sovereignty of Piedmont, and retiring with his family and adherents to the island whence he derived his title. The king of Naples likewise having taken up arms and invaded the Roman republic, after being at first so successful as to obtain possession of Rome, was totally defeated and obliged to take refuge in the island of Sicily.

But soon after the commencement of hostilities with Austria, the French arms experienced a fatal reverse. On the 25 th of March, general Jourdan attacked the Austrians near Stockach, but was defeated, and obliged to retire in disorder; and on the $26 \mathrm{th}$ of the same month general Kray beat the French on the Adige near Verona, and again defeated them on the 30th. On the 14th of April, marshal Suwarrow arrived with the first column of the Russian troops, and the successes of the allies became rapid and uninterrupted. On the 24th of the same month, the Austrians and Russians passed the Oglio, and drove the French before them. They then crossed the Adda, and Suwarrow, on the 27 th, défeated Moreau at Cassano: and. 
so decisive was his victory, that general Serruier and three thousand men were taken prisoners, and Milan opened its gates to the conquerors on the 30h. Peschiera was talsen on the 6th of May, and, on the 10th, Pizzigethone surrendered to general Kray: on the 12 th the Austrians entered Bologna, and took twelve hundred prisoners; and on the $23 \mathrm{dl}$ they took possession of Ferrara. In Picdmont, the French, rotwithstanding the efforts of Moreau, Macdonald, and Joubert, beheld themselves successively deprived of all their strong holds. The Austrians entered Turin on the 27th of May, and the citadel surrendered on the 20th of June. Mantua, after a short siege for so strong a place, surrendered on the 30th of July; the city of Alessandria on the same day ; and such was the success of the campaign, that the French were obliged to abandon the whole of Italy; Genoa, and a small portion of the adjoining territory, only excepted. On the 25th of August a desperate battle was fought between the French and the Austrians and Russians at Novi, to the territory of Genoa, in which the French are supposed to have lost not less than ten thousand men; but this viciory was purchased with a loss nearly as great on the part of the allies.

On the side of Switzerland, the affairs of the republic at first wore a less disastrous aspect; Massena having obtained some slight advantages. These, however, were soon counterbalanced by events more favourable to the allies; the French general being obliged to abandon Zurich, which was immediately occupied. by the Austrian troops under Hotze.

Italy being now rescued from the power of the French, it was resolved that Suwarrow should proceed with his army to Switzerland, to drive the French back into their own territories, and enter France: where he was to endeavour to re-establish the fallen monarchy. The directory were now convinced of their danger, and made every exertion to reinforce their armies in Switzerland, and the most active preparations for a vigorous defence. General Massena, who commanded the republican army in that country, displayed great military genius, and evinced uncommon abilities in all his enterprises. Knowing that if Suwarrow effected a junction with the troops already acting against him, he must. be inevitably overpowered, he determined to attack the latter; and in a variety of actions, during four whole days between the 14th and 20th of September, repeatedly defeated the Austrian and Russian armies; many thousands being killed and taken prisoners, among the former of which was the brave Austrian general Hotze.

Suwarrow, in consequence, on his arrival in Switzerland, found it impossible to join his defeated and dispirited allies; his plans were all rendered abortive; he was under the necessity of immediately withdrawing into Germany ; and during his retreat over mountains covered with snow, and through roads nearly impassable, he suffered as much loss as could have ensued after a signal defeat.

On the 13th of October, Bonaparte, having found means to escape from Egypt, and elude the vigilance of the British cruisers, arrived in France, accompanicd by general Berthier and some other officers. The recent losses which the republic had sustained, and the imminent danger which threatened its very existence, had greatly weakened the authority of the directory, and prepared the way for the total alteration of the constitution and government which had probably been projected by the abbé Sieyes, and which the popularity 
and enterprising spirit of Bonaparte enabled him to carry into execution.

The first step towards this revolution was taken by the council of ancients; which, on the 9th of November, passed a decree consisting of five articles, the chief of which were, that the legislative body should, on the next day, be removed to St. Cloud; that Bonaparte should be commissioned to carry into execution this decree; and, for this purpose, should be appointed commandant of all the troops in Paris or its neighbourhood, of the guard, of the legislative body, of that of the directory, and of the stationary national guard; that this decree shouid be communicated by message to the council of five hundred, and to the executive directory, and transmitted to all the communes of the republic by extraordinary couriers. After this decree had been passed, the council of ancients proceeded to publish an address to the French nation, justificatory of their own conduct, and asserting, "that the common safety, and common prosperity, were the objects of this constitutional measure : the inhabitants of Paris were desired to remain tranquil, since the presence of the legislative body would soon be restored to them, and the result would show whether the legislative body was worthy and capable of preparing the means of happiness." General Bonaparte soon after appeared at the bar, accompanied by several officers of his staff, and addressed the council in a short speech, in which he represented that the republic was perishing, and they knew it, but that the decree they had just passed had saved it:- "Yes," said he, "we will have a republic founded on true liberty, and national representation. I swear it in my name, and that of my companions in arms." Most of the members present received these exclamations with applauses : and the assembly broke up with shouts of "Live the republic!"

On the same day the council of five hundred, having been informed, by a message from the council of ancients, of the decree passed by the latter, adjourned, in consequence, to the following day, when they were to nieet at St. Cloud. In the sitting which was held there on the 10th, they appointed a committee of seven members, commissioned to make a report on the situation of affairs. The sitting was very tumultuous, many members exclaiming-" No dictator! No dictatorship!" The secretary read a letter from the director Barras, stating that "the glory which accompanied the return of the illustrious warrior, to whom he hac had the happiness to open the career of renown, the distinguished marks of confidence shown him by the legislative body, and the decree of the national representation, had convinced him that the perils of liberty were then surmounted, and the interest of the armies secured; and that he returned with joy to the rank of a simple citizen, happy to transfer, complete, and render more respectable than ever, the destinies of the republic, of which he had been one of the depositaries."

While some of the members were urging the propriety of choosing another director in the room of Barras, general Bonaparte entered the hall, attended by some officers and grenadiers, and walked up towards the president. A violent agitation immediately ensued among the members, some of whom rushed precipitately from their seats, and endeavoured to seize him by the collar; others cried, "Outlaw him !" and one attempted to stab him with a dagger, but the blow was warded off by a grenadier. The tumult increased to a most violent degree. All the members quitted their seats; the president, 
Lucien Bonaparte, laid down his badge of office on the table, and resigned; upon which the doors of the hall were opened, and an officer entered with à guard, exclaiming, "General Bonaparte orders the hall to be cleared." The order was carried into effect in a few minutes.

The sittings were resumed in the evening, and Lucien Bonaparte took the president's chair. A decree was passed, abolishing the - directory, and appointing a consular government of three, namely, Sieyes, Bonaparte, and Roger Ducos, who all appeared, and took the oath to be faithful to the republic; after which, the council adjourned its sittings till the 20th of February. On the same day, the council of ancients met also at St. Cloud, the proceedings of which day were almost a copy of those of the council of five hundred. They likewise voted the abolishing of the directory, the appointment of a consular executive of three persons, and then adjourned till the 20th of February. By the same decrees, sixty-one members were expelled from the legislative body; and thus was the national representation, and the vaunted constitution of the third year, overturned by one man, and the bayonets of a few soldiers.

A new constitution was then formed, which was accepted by the armies, anc, apparently at least, by the people. By this constitution, the whole of the executive, and indeed all other power, was vested in the first consul, general Bonaparte, who entered on the administration of his government by making propositions for commencing negotiations for peace. His applications to the government of Great Britain on that subject have been already mentioned in our account of the affairs of England. He afterwards made similar applications to the court of Vienna, but his overtures, which indeed appear to have been sufficiently vague, being rejected by both those powers, the most active preparations were made on all sides for the prosecution of the war.

The last campaign had closed with the taking of Coni, and the retreat of the French army into the territory of Genoa, which was now the only important place in Italy that remained in its possession. 'The Austrians took the field on the 6th of April 1800 ; and Massena, who commanded the French army, was attacked by general Melas, and forced to retire to Savona and Vado, whence he was compelled to fall back to Genoa, with the remainder of his army, which consisted of 18,000 men. In Genoa he defended himself during two months with the most determined obstinacy, and did not surrender till every hope of succour had vanished; till every kind of provision had been exhausted; till 15,000 of the inhabitants of the city had perished by the famine, and his army was reduced to only $8000 \mathrm{men}$. Genoa was given up to the Austrians on the 5th of June.

In the mean time Bonaparte, having assembled an army at Dijon, put himself at the nead of it on the 6th of May, passed the mountains St. Gothard and St. Bernard, and surmounting apparently insuperable obstacles, entered Italy, where he inmediately made himself master of Milan, Pavia, Piacenza, Cremona, and the whole course of the Po. The Austrian general Melas appears to have been so confident that it was impossible for an army to enter Italy by the route the French had taken, that he took no measures to oppose the passage of Bonaparte till it was too late. At length he dispatched geneyal Otto with thirty battalions, to stop the progress of the French army which was marching towards Piedmont; but that general was 
defeated at Casteggio, with the loss of 3000 men kilied, and 6000 taken prisoners.

This victory was the prelude to the great and decisive battle of Marengo, fought five days afterwards, and which fixed the fate of Italy. Melas having assembled the whole of his forces, marched to meet his enemy, and took post in the village Marengo. In the battle which ensued, victory appeared at first to have declared decidedly for the Austrians. The centre of the French was compelled to retreat with great slaughter ; but the body of reserve, under general Desaix, impetuously charging the Austrians, who were thrown into some confusion by the eagerness of pursuit, and their confidence that the battle was gained, turned the fortune of the day; and though Desaix himself fell in the attack, gave the French a complete victory. The Austrians lost, by the French accounts, in killed, wounded, and prisoners, 15,000 men; and the loss of the French could not be much less. Yet so important was this hattle in its consequences, that the next day, general Melas, finding his situation no longer tenable, proposed an armistice, which was accepted by Bonaparte, and by which Genoa was immediately surrendered to the French, together with all the strong places of Lombardy and Piedmont.

In Germany the French had opened the campaign with similar success. They crossed the Rhine in three divisions, at Kehl, Brisac, and Basle, and forced the Austrian army to fall back on the line of Stockach, where a battle took place on the 4 th of May, in which the French were victorious, and which in a great degree decided the fate of the campaign, as the Austrians were not able afterwards to make any effectual resistance, but continued to retreat and suffer successive defeats.

When the armistice was concluded in Italy, the Austrian general of the army in Germany endeavoured to avail himself of it, to put an end to the progress of the troops under Moreau, but the French general would not listen to such a proposition : on the contrary, being in possession of Munich, and the greater part of Bavaria, he detach ed Lecourbe towards the Tyrol to seize upon the Vorarlberg and the Grisons, and form a junction with the army of Italy. The offer of a suspension of arms however having been repeated, and count St. Julien having arrived at Paris, with proposals for peace, an armistice was at length concluded for the armies in Germany, leaving each in possession of the posts it occupied at the time it was signed.

In the negotiations now carried on at Paris, the court of Vienna intimated that it was bound in honour only to treat for peace in concert with Great Britain. The first consul signified his consent that the negotiations should include a peace with England, but required a naval armistice as a preliminary. This demand, under certain conclitions, the British ministry did not reject; but they would not permit the Brest fleet to be supplicd with stores, or succours to be sent to the French army in Egypt. This proposal therefore not being accepted, Ponaparte refused tn negotiate with England, and the emperor refused to ratify the preliminaries of peace which had been signed by his envoy count $\mathrm{St}$. Julien at Paris.

The rupture of these negotiations was followed by that of the armistice in Germany, which had been renewed by the emperor, at the expence of surrendering the important fortresses of Ulm, Ingolstadt, and Plilipsburg, into the hands of the French, as a pledge of 
his sincere desire of peace. The campaign recommenced on the 24th of November, and in the beginning of December the Austrians were defeated by Moreau in the decisive battle of Hohenlinden, in which the French took 10,000 prisoners, with 80 pieces of cannon: the archduke Charles was likewise defeated, with the loss of 8000 men ; and the emperor was convinced that he had no resource but in a peace.

Another armistice was therefore concluded on the 27 th of December, and negotiations for peace were opened at Luneville, and carried on with such dispatch, that the preliminary treaty was signed on the 3d of February, 180 I, by count Cobentzel and Joseph Bonaparte, and soon after ratified by the emperor. By this treaty, the cession of the Belgic provinces to France, as stipulated by the treaty of Campo Formio, was ratified in a more formal manner; and the whole of the country on the left side of the Rhine, the cession of which had been assented to at the congress of Rastacit, was likewise given up to France. The boundaries of the Cisalpine, now called the Italian republic, were enlarged, and the dukes of Tuscany and Modena were compelled to renounce their territories, and accept such indemnities as should be provicled for them in Germany.

Of the conclusion of the peace of Amiens between France and England, and the causes of its rupture, a concise account has already been given in our history of England.

As soon as the preliminaries of the latter peace were signed, and the cessation of hostilities with England had left the seas open to the French marine, Bonaparte fitted out a great expedition for St. Domingo, to restore, as he said, the French West India colonies to tranquillity and order. On board the fleet and the transports which accompanied it, an army of 25,000 men, the flower of the French soldiery, and completely equipped, was embarked. The famous negro chief, Toussaint l'Ouverture, who was at the head of a formidable body of negroes, was successively defeated, and at length concluded a capitulation with the French generals; who afterwards seized him, pretending they had discovered that he was engaged in a plot against them, and sent him to France, where he soon ended his days in the dungeon in which he was confined. The recommencement of the war with Great Britain having deprived the first consul of the means of sending any reinforcements to his troops in St. Domingo, the French, after suffering still more from the climate than from the enemy, have been at length entirely driven out of the island.

The unbounded ambition of Bonaparte now began to display itself in its true colours. He had assumed the title of president of the Italian republic, with, in reality, the same unlimited authority which he exercised in France; and not contented with holding the title and power of first consul, according to the constitution he had introduced, he procured himself to be appointed consul for life, with the power of nominating his successor. These new assumptions were, however, only steps to the throne to which he aspired.

In the beginning of the year 1804 , a conspiracy was formed against him, in which the late general Pichegru and Georges, formerly a leader of the insurgents in La Vandée, were engaged. They had endeavoured to induce general Moreau, who lived in retirement, and had never condescended servilely to flatter Bonaparte, to join them; but this he seems to have refused, probably disapproving some part 
of their plan. Before they could determine whether they should proceed or abandon their designs, they were discovered and apprehencled by the spies and agents of Bonaparte. Pichegru was found clead in his bed, in prison, before his trial, having died, as was said, by his own hands; Georges and eleven others suffered death by the guillotine ; and Moreau, who was condemned to two years imprisonment, was afterwards permitted, by the despot, to take his departure for America.

In consequence of this conspiracy, the abject and venal senate of Bonaparte, at the suggestion of his creatures, solicited him to take on himself the imperial dignity, and declare it hereditary in his family, under pretence that the government of the republic would thus become permanently established, and secure from the attacks of all its enemies. This application was made by the senate, in a body, on the 20th of May, 1804; and the first consul was graciously pleased, for the good of his country, to comply with their request, and accordingly assumed the title of Emperor of the French; and appointed his imperial highness prince Joseph Bonaparte, grand elector; and his imperial highness prince Louis Bonaparte, constable of the empire. His two colleagues, the second and third consuls, having proved their fidelity to him by not interfering in the smallest degree in the affairs of government, except as directed by him, were gratified with the high-sounding titles of arch-chancellor and arch-treasurer of the empire.

Bonaparte's elevation to the throne of France, added to several other circumstances, aroused anew the jealousy of Russia, and a coalition between that power, Sweden, Austria, and Great Britain, was formed. The events of this war have been noticed in our account of Russia. In 1805 Bonaparte was crowned king of Italy.

The good understanding subsisting between the court of Naples and that of England, had long given offence to the emperor of France. $\mathrm{He}$ had determined, if possible, to exclude the British altogether from the trade of the continent, and this was one of the principal objects of dispute between him and the northern powers. They had been compelled to submit, and the like terms must be exacted from Naples. The king, however, persisted in refusing to give up his British connexions, and Bonaparte accordingly declared that he had forfeited his crown. He appointed his brother Joseph Bonaparte king of Naples, and sent a powerful army under Massena, Regnier, and Lacy, to assist in placing him upon the throne. The government of Naples, not having troops sufficient to resist so formidable a force, retired under the protection of the English to Sicily, and soon after Capua, Peschari, and Naples, surrendered to the French. The peasantry of Calabria resisted their invaders with the most desperate bravery, and the fortress of Gaeta sustained a long and obstinate siege. About this time a British force of about 5000 men, commanded by general Stuart, landed at St. Euphemia. Regnier immediately advanced with 7000 men to attack them, and on the 4th of July, 1806, a severe action was fought, in which the French were completely routed. This splendid affair was however attended with but little advantage; as general Stuart soon after re-embarked for Sicily. The Calabrians were overpowered; Gaeta was finally obliged to surrender; and king Joseph obtained complete possession of his new dominions.

Prussia, who, during the late war, had viewed the disasters of her VOL. I. 
neighbours with indifference, and had expected by remaining neutral to secure the favour of France, was now too late convinced of her error. In some negociations which had taken place with England, Bonaparte had promised to restore Hanover. This he had done without consulting Prussia, who was actually in possession of that territory. The formation of the Rhinish confederation, and the keeping up of French armies on the Prussian lines, were also objects of complaint. The French government was very willing to engage in a contest, from which it might derive great advantages, and in which success was almost certain. See Prussia.

The nomination of Joseph Bonaparte to the throne of Naples was soon followed by that of Louis to the throne of Holland. In 1808 the power of Bonaparte was at its acme. All the governments of Europe, England and Sweden alone excepted, appeared to act under his command. He had enticed the king of Spain into France, and had compelled him to resign his crown into his hands. Spain was overrun with French troops, and her means of resistance were small. This war will be noticed under the article Sparn. Bonaparte declared his brother Joseph king of Spain, and Murat filled his place at Naples. The different powers of Europe were called upon to acknowledge the sorereignty of Joseph. This acknowledgment was refused by the emperor of Austria, who seemed disposed to make another attempt to assert the independence of his empire. The impoverished state in which Austria was left after the treaty of Presburg, obliged her to have recourse to extraordinary means for recruiting her strength. Her army was almost annihilated, while those of the surrounding nations were well-organized and numerous; and yet every attempt which she made to place her military upon a footing with that of her ncighbours, was complained of by Bonaparte as arising from a hostile disposition towarcls France. Thus the emperor Francis was compelled, either to leave his defenceless territories for a high way to all the armies of Europe, or to involve himself in fresh difficulties with France. A diplomatic controversy had been carried on ever since the signing of the treaty of Presburg, the conditions of which, on the part of France, had never been fulfilled, and in March, 1809, active hostilities recommenced. See GERMANY. The issue of the war was a fresh triumph to France, and by the terms of peace Austria was rendered for ever incapable of renewing the contest. Her seaports were annexed to France, and Russia, Bavaria, and Saxony, each received part of her territory. These terms would probably have been much vorse, had it not been for the sacrifice which the emperor Francis made in giving his daughter to Bonaparte in marriage. On the 16 th of December, a decree passed the French senate, divorcing Bonaparte and the empress Josephine; and on the 1st of April, 1810, he was married to Maria Louisa, daughter of the empeior of Austria. In this year Louis Bonaparte was removed from the throne of Holland, on account, it was stated, of the mildness of his government, and that province was declared a part of the French empire.

The impatience of Bonaparte to compel the adoption of his continental system, excited him to make extraordinary and imperative demands of Russia; and as early as the year 1810, only three years after the conclusion of the treaty of Tilsit, symptoms of resistance were exhibited by the Russian court. The whole of 1811 was spent by the two powers, in making the most formidable preparations. The 
object of Russia being merely defensive, her armies were assembled altogether with in her own territories. The troops of France and her allies were marched towards the north, from all directions. The events of the first campaign, and its unfortunate result to the cause of Bonaparte, have been detailed in the history of Russia. Bonaparte seems to have been fearful that the news of his disasters would excite something serious against him in France; at least this is the best reason which can be given for his abanclonment of his army, and hasty return to Paris, in which capital he arrived on the 18 th of December, 1812, eleven days after he left IVilna. He immediately assembled the senate, and in his speech, told them that he had been every where victorious in Russia, and that his losses were altogether owing to the severity of the climate.

In the mean time the Russian armies continued to advance. On the 18th of December, the Prussian general York, with 30,000 men, deserted from the French standard. Sweden also openly avowed her disposition, by issuing a manifesto against France, dated January 7 th. On the 27 th of December the Russians entered Memel, whence they immediately proceeded towards Konigsiburg, where they arrived on the 6th of January. Warsaw was surrendered on the 8 th of February, by the Austrians, to general Miloradovitch. The Russians met with little or no opposition in their march. The Austrians did not seem disposed to engage them, but continued to retire towards their own lines. The French army was totally destroyed; and the Prussians every where received them with juy. On the 4th of March, they were in possession of Berlin, the capital of Prussia. Pillau and Thorn had been previously captured, and on the 10th they entered Hamburg. On the 17th, the king of Prussia, from Breslau, issued a declaration of war against France, and immediately joined the Russians with all his forces. On the 17 th of April, Bonaparte left $\mathrm{Pa}$ ris for the head-quarters of his army, having previously appointed the empress, regent. His new raised conscripts, added to the troops of his German allies, made his army amount to near 300,000 men. On the 5th of April, the advance of the French army under Beauharnois, was met near Magdeburg by a superior Russian and Prussian force, commanded by Wigtenstein, by whom he was defeated and compelled to retreat. Bonaparte continued advancing with his main army towards the Saale; on the 30th he passed through Weimar. The Russians and Prussians occupied a position nearly parallel with the French; the latter on the Saale, the former on a line descending from Dessau, through Leipzic, to Altenburg. Bonaparte crossed the Saale at Naumburg, and advanced with a view of forcing the allied lines. This, however, was prevented by the allies, who, perceiving his intention, attacked him with great impetuosity at Lutzen on the 1st of May. The action commenced at twelve at noon, and continued till night. Both sides claimed the victory, and both maintained their positions. They each acknowledged 10,000 killed. But the Russians, although they had a decided superiority of numbers, thought it prudent, soon after the battle, to retire behind the Elbe. The French advanced as the allies retreated, and on the 12 th Bonaparte, in company with the king of Saxony, entered Dresden. He left that capital on the $18 \mathrm{th}$, and arrived the next morning before Bautzen, where the allies under Wigtenstein had determined to make a stand. Having united all their forces, the French commencod the attack at day-break on the 21 st. The ground was warmly 
contested all day; but in the evening the allies retired from the field, and commenced their retreat towards Silesia. Fortune seemed now to have taken a decided turn in fayour of Bonaparte. Bernadotte, the crown-prince of Sweden, landed at Stralsund on the 12th of May, and immediately proceeded towards Hamburg, which was threatened by general Vandamme. But he was too late; and that city was taken by storm on the 30 th.

Austria, during the campaign in Russia, had taken an active part on the side of France; but when the contending armies approached her frontiers, she declared her intention of becoming neutral. She, however, continued to augment her forces, which, at the opening of the second campaign, amounted to upwards of 200,000 men. Availing herself of her neutrality, she now came forward as a mediator between the belligerent courts. The allies, confident that her views could not be materially different from their own, gladly listened to the proposal; and Bonaparte, fearful of offending the emperor Francis, and also wishing time to bring up his reinforcements, agreed to an armistice, previous to entering into negociations for peace. The terms which the allies proposed as the basis of the negociations, were; the dissolution of the confederation of the Rhine; the restoration of the empire of Germany, and of the Austrian dominions in Italy; the integrity of the house of Bourbon in Spain, and of that of Orange in Holland, and the reduction of France within her ancient limits. With these demands, so highly favourable to her, Austria of course united. As soon as these terms were made known, Bonaparte determined not to accede to them; but, sensible that his refusal would involve him in immediate hostilities with Austria, and wishing to gain as much time as possible, he agreed to the assembling of a congress at Prague. To allow the congress time, the armistice was extended to the 10th of August, and when that time expired, Bonaparte declared his intention of prosecuting the war, to mairtain the integrity of his empire. As soon as Austria was informed of this determination, she issued a declaration of war against France ; and hostilities recommenced. On the 22d of August, the allied army began its operations, passed into Saxony, and on the 25th encamped near Dresden. On the 26th, Bonaparte entered Dresden from Silesia, and on that day the whole allied army attempted to carry the city by assault. The French fought without the city. The action lasted till night; when the allies returned to their encampment, and the French retired within the walls. On the $27 \mathrm{th}$, the French became the assailants, and towards evening obliged the allies to recommence their retreat into Bohemia. On the 3oth, the French corps d'armee, under general Vandamme, approached the Bohemian frontier. The allies immediately attacked them with a greatly superior force, and drove them back with slaughter. Vandamme was taken prisoner.

General Blucher, who commanded the allies in Silesia, met with a force much stronger than his own, commanded by marshal Ney. With these he maintained six or eight engagements in rapid succession, and eventually was compelled to retire to the vicinity of Janer. On the 24th, the emperor Napoleon, with Ney, left Silesia, and the former returned to Dresden. Ney passed through Lusatia, to attack the crown prince. Upon this, Blucher immediately recommenced offensive operations. On the 25 th, he made a general attack upon the French lines; the result of which was the precipitate retreat of the French into Lusatia. This disaster called Napoleon a second 
time fiom Dresden. He joined his army on the 4th of September, and immediately attacked Blucher, whom he defeated, and compeiled again to retreat. Bonaparte then returned to Dresden, and Blucher advanced to Rechinbach. On the 5 th, the grand combined army issued again from the passes of Bohemia, and took the road to Dresden. Bernadotte, having twice beaten Oudinot, had advanced into Saxony, and was in communication with the right wing of Blucher, who had been reinforced by 50,000 men under prince Swartzenburg. Another Austrian force was sent in the direction of Leipzic, to cut off Bonaparte's communications. The allies also received a considerable addition to their cause in the king of Bavaria, who concluded a treaty with the emperor of Austria, and engaged to furnish him with 20,000 men. Bonaparte several times advanced and offered battle to the grand allied army. But they always retired on his approach, while Blucher and Bernadotte continued advancing on the other side of Dresden. Finding himself likely to be compietely surrounded, Bonaparte at length concluded to retreat. He left Dresden on the 23d, and his army followed on the 26th, taking the road to Leipzic. The crown prince and Blucher immediately left the Elbe, and took post on the 11th of October behind the Saale. This army Bonaparte determined to attack, in order to keep open his communication with France, but was frustrated by the unexpected march of the grand army in his rear. On the 15 th, he concentrated his army in the vicinity of Leipzic. On that day the crown prince and Blucher marched on Halle, while the grand army advanced from the south. On the succeeding day the opposing armies came into fierce contact along the whole of their line. The battle was long and bloody, but by no means decisive. At the close of the day the parties occupied the same positions as when battle commenced. On the 17th, there was no fighting. On the $18 \mathrm{th}$, the contest was renewed, and victory declared for the allies. The French disasters commenced by the desertion of a large body of Saxon troops, whose example was afterwards followed by the Bavarians and Wurtemburgers. Besides this they lost 40,000 men in killed, wounded, and prisoners. On the 19 th, Leipzic was stormed by the crown prince, and carried after a short but violent conflict. Bonaparte, with the remains of his army, quitted it about nine o'clock, retreating on the road to Erfurt, where they arrived on the $23 \mathrm{~d}$. He continued the retreat without halting till he reached the Rhine, where he left his army, and returned to Paris on the 9 th of November. The senate immediately ordered 300,000 additional conscripts to be raised. The French were closely pursued by the allies. On the 5th, their head-quarters were at Frankfort. The crown prince marched through Hanover towards Holland. The Dutch, however, rose, without any foreign assistance, upon the French authorities, and declared for the house of Orange. On the 11 th, the garrison of Dresden, 16,000 strong, under St. Cyr, surrendered to the Russians. From Frankfort the allies offered Bonaparte the -same terms as they did during the armistice. He told them he agreed to the basis, but delayed under various excuses appointing negociators; evidently with a view to gain time. All this while he was making the greatest exertions to renew his army. The allies crossed the Rhine on the 20th of December, marched rapidly through Switzerland, and entered Geneva on the 30th. On the 16th of January, the head-quarters of prince Swartzenburg were at Langres. He continued advancing without meeting with much opposition, and on the $3 d$ 
of February encamped near Troyes. That part of his army which took Geneva, was before Lyons on the 19th of January. General Blucher crossed the Rhine at Mayence on the 1st of January. Wigtenstein entered France near Strasburgh on the 21 st. On the 29th, marshal Blucher reached Brienne, where he was met by Bonaparte. After much hard fighting, the French were obliged to retreat. Bonaparte fell back on Troyes and Arcis, and the next day on Nogent. On the 6th of February, prince Swartzenburg was at Bar-sur-Seine, and marshal Blucher at Plancey, 25 miles from Nogent. Marmont having approached with a considerable force from the Netherlands, Blucher was now obliged to move with caution. On the 13th, his head-quarters were at Champaubert. On the 14th, Marmont and Bonaparte, having effected a junction, attacked him with great impetuosity in front and rear, and obliged him to retreat to Chalons, with considerable loss. The advance of Swartzenburg and Wigtenstein prevented the French from pursuing this advantage, and obliged them to retire across the Seine. This river was passed by Wigtenstein at Pont-sur-seine. On the $16 \mathrm{th}$, his advance was driven in by the French; after which he recrossed the Seine, and Bonaparte established his head-quarters at Troyes. This city was attacked on the $3 \mathrm{~d}$ and 4th of March by the grand allied army, and taken, after an obstinate defence. The movements of Blucher now indicated an intention of uniting his army with that of prince Swartzenburg. To prevent this, it was necessary for Bonaparte to exert all his power. Driven from Troyes, he attacked the marshal at Laon on the 9 th, but was repulsed. After this, Bonaparte suddenly pushed upon Rheims, which place he occupied, after defeating the corps of general St. Priest, which defended it. Swartzenburg advanced his head-quarters to Port-sur-seine on the 15 th, with an intention of crossing the Seine there. But the defeat of St. Priest incluced him to carry his head-quarters upon his right to Arcis-sur-aube. After the occupation of Rheims, Bonaparte returned to the Marne, which he crossed at Epernay on the 16th. On the 17th, prince Swartzenburg crossed the Aube with part of his army, and Bonaparte pushed on to Arcis surAube, which he occupied on the 20th. Here his army was attacked by the allies, and, after an obstinate resistance, the place was taken by the prince of Wurtemburg. While these events were taking place, general Blucher, reinforced by the corps of St. Priest, advanced on the $18 \mathrm{th}$ to Rheims, and retook that place on the $19 \mathrm{th}$. Bonaparte having retreated towards Vitry on the Marne, the two allied armies pere now enabled to unite. They were now 200,000 strong. With this immense force they came up with the French under Marmont, Morlien, Oudinot, and Macdonald, on the 25th, and defeated them, takirg 10.000 prisoners. They then took up their march upon Paris, losing Bonaparte in their rear, and driving before them the scatterci lemains of the French army. On the 28 th, Blucher arrived at Mezux, and Swartzenburg at Legny. On the 29 th, the allied army appeared before Paris, and on the soth that city capitulated. On the 31 st, the emperor of Russia and king of Prussia entered Paris. The people hailed them as deliverer's, and immediately declared for Louis XVIII.

During the greater part of the time that these important military operations were transacting, negociations were carrying on between the different allied, and the French ministers, at Chattilon-sur-Seine. They met on the 4th of February. The restoration of the Bourbons 
to the throne of France, had always been a favourite idea with the people and government of England, and their minister at the congress, lord Castlereagh, used all his influence to prevent their treating with Bonaparte upon any terms. The views of the emperor of Austria were different. His fanily alliance made him disposed to uphold the Bonaparte dynasty; and he had prevailed upon the other continental allies, to offer the French emperor the same terms which had been twice before rejected. The English minister was, howerer, resolute; and soon gained over to his side Russia, Prussia, and most of the German states. The matter was at length compromised, and it was determined to leave the thing altogether to the French nation; the allies giving them a fair opportunity of expressing their sentiments. The negociations at Chattilon, with Bonaparte's ministers, were accordingly dropped on the 18th of March. As soon as he had entered Paris, the emperor Alexander issued a proclamation, declaring, "that the allies would treat no more with Napoleon Bonaparte, or any of his family ;" and negociations with the French senate were immediately commenced. This body passed a decree on the $2 \mathrm{~d}$ of April, declaring, that Napoleon Bonaparte had forfeited the throne. On the 6th, they passed another, declaring, that " the French people call freely to the throne of France, Louis Stanislaus Xavier de France, brother of the late king, and after him the other members of the house of Bourbon, in the ancient order." On the 12 th, the count d'Artois, brother of Louis, arrived in Paris; and was immediately placed at the head of the provisional government. On the $3 \mathrm{~d}$ of Nay, the king himself arrived from England, and took peaceable possession of the throne of his ancestors, amidst the acclamations of his people. Bonaparte having resigned his pretensions to the throne, was banished by the senate to the island of Elba.

Small as were the whole forces of Bonaparte, in comparison with those of the allies, he was obliged, during all the campaign, to keep his best troops in the south, to oppose the progress of lord Wellington.

This general having driven marshal Soult to his intrenched camp before Bayonne, entered the French territory early in November. He did not deem it prudent to attack Soult in his present strong position, but determined by advancing to draw him from it. Two divisions of his army under general Hill and marshal Beresford crossed the Nive on the 9 th of December. On the morning of the 11 th, marshal Soult marched his whole army out of the intrenched camp, and attacked the corps of generals Hill and Hope. He was repulsed with loss. On the 12th, the attack was recommenced on lord VVellington's left, and was continued till afternoon, when the French marshal withdrew his troops entirely within his intrenched camp. During the night he passed a large force through Bayonne, with which, on the morning of the $13 \mathrm{th}$, he made a most desperate assault upon sir Rowland Hill, and was again repulsed. For the remainder of the month of December, the armies remained quietly in their positions. On the $3 \mathrm{~d}$ of January, the French havines collected a considerable force on the Gave, obtained some slight advantages over the advance posts of the allies. On the 6 th, the allied army advanced on the Gave. The French retreated without contesting the positions. While the right wing of his army was advancing on the east of Bayonne, lord Wellington pushed his left across the Adlour between Bayonne and the sea. On the 25 th, the French army was assembled at Or. 
thes, where they seemed disposed to make a stand. On the 27 th, they were attacked by the allies, who were at first partially repulsed, but at length obtained the victory, which was complete, the French retreating in the greatest disorder. The advance of lord Wellington was now opposed much more by the badness of the weather and roads, than by the enemy. On the 12 th of March, sir William Beresford approached Bordeaux, and was met by the mayor and citizens, who hailed his approach with acclamations; and taking off the eagles, and other badges of their servitude to Napoleon, substituted the white cockade. The department of Landes was one of the last in abandoning, and was the first in again proclaiming the house of Bourbon. The duke d'Angouleme, nephew of the king, entered Bordeaux with the allies. On the 20 th, Soult, having rallied part of his flying army, and received some reinforcements, assembled his troop at Tarbes. Lord Wellington attacked them on the same day, and dispersed them with considerable loss. Large bodies of the French troops deserted. After the battle, lord Wellington marched towards Toulouse; on the $25 \mathrm{th}$, he was within six miles of that city. Soult took a strong position on the $24 \mathrm{th}$, in the suburbs of Toulouse; where he seemed disposed to make another stand. Marshal Beresford being on his march from Bordeaux, to join the allied army, lord Wellington determined to wait his arrival before he attacked the French positions. Beresford having arrived, the attack was made on the 10th of April. The battle was warmly contested, and the Spaniards were at first repulsed with considerable loss. But marshal Beresford having driven in the left of the French, the Spaniards returned to the charge, and the positions were carried. On the night of the $11 \mathrm{th}$, the French evacuated Toulouse, which was immediately entered by the allies. On the $12 \mathrm{th}$, information was received of the change of government at Paris. On the 16 th, Soult acknowledged the provisional government, and hostilities ceased.

On the 4th of June, the king appeared before the two houses, and submitted the constitution, which was adopted. On the 30th of May, treaties of peace were signed between France and England, Russia, Austria, and Prussia. These treaties leave France in the possession of more territory than ever she possessed under her former kings. Most of her foreign possessions, which had been captured by England, are also restored.

Louis XVIII was born November 17th, 1755; married May 14, 1771, Maria-Josepha-Louisa, daughter of the king of Sardinia, born September 2d, 1753; died at Hartwell, England, in 1811. They had no children.

Brother of the king,

Charles-Philip, count d'Artois, (monsieur) born October 9, 1757 ; married November 6, 1773, to Maria-Theresa, daughter of the duke of Savoy. His children are,

1. Louis-Anthony, duke of Angouleme, born August 6, 1775; married June 10, 1793, to Maria-Theresa-Charlotte, daughter of Louis XVI. He is without issue.

2. Charles-Ferdinand, duke of Berri, born January 24, 1778. 


\section{NETHERLANDS, OR BELGIUM.}

THOUGH the provinces of the Netherlands, which were formerly subject to the house of Austria, and afterwards were annexed to France, have now become part of the dominions of the house of Orange, yet as that event is so recent, and as they are still distinguished by the name of Belgium, as well as by the natural characteristics of the country and its inhabitants, we shall here describe them in a separate article.

EXTENT AND SITUATION.

$\left.\begin{array}{l}\text { Miles. } \\ \text { Breadth } 180 \\ \text { Breadth }\end{array}\right\}$ between $\left\{\begin{aligned} & 49^{\circ} 20 \text { and } 51^{\circ} \text { so North latitude. } \\ & 2^{\circ} 30 \text { and } 6^{\circ} 30 \text { East longitude. }\end{aligned}\right.$

Containing 10,572 square miles, with 285 inhabitants to each.

NAME....The country formerly divided into seventeen provinces, and known by the name of the Netherlands, was formerly part of Gallia Belgica, and afterwards of the circle of Belgium, or Burgundy, in the German empire. They obtained the general name of the Netherlands, or Low Countries, from their low situation with respect to Germany.

Boundaries... That part of these provinces, which is now usually called the Netherlands or Belgium, is bounded on the north by Holland; on the east by Germany, on the south by the French departments of the Moselle, Arclennes and the North; and on the west by the North or English sea.

Division....The Netherlands, in the full extent of the term, anciently consisted of seventeen provinces, of which seven constituted the seven united provinces, usually known by the name of Holland. The remaining ten, till they were ceded by Austria to France, were divided between the Dutch, the Austrians, and the French. Austria possessed the whole of the provinces of Antwerp, Malines, and $\mathrm{Na}$ mur; and the French the whole of those of Artois and Cambresis. Brabant and Limburg were possessed partly by Austria and partly by Holland; and'Hainault and Luxemburg were in like manner divided between Austria and France. The province of Flanders was shared between all these three powers, under the names of Austrian, Dutch, and French Flanders. The whole of these ten provinces is now in. corporated with Holland.

FAcE of THE COUNTRY....The Netherlands are a flat country, containing no roountains, and but few hills. "The rural scene," says Mr. Shaw, " presents here pleasing prospects on all sides : fields crowned with fruitful crops, meadows covered with numerous herds, neat and commodious farm-houses set singly or in groups, cheerful and extended villages embowered among trees, and divided from

VoL, I. 
each other by small intervals; while through such fair landscapes wind the rivers, and extend the clear canals of Flanders and Brabant." In the duchy of Luxemburg, or the department of the Foresis, the country is less cultivated, and presents a less lively scene.

ForEsts....In the department of Jemappe is the forest of Soignes; and in that of the Forests, are ample remains of the ancient forest of Ardennes, which formerly extended from the Moselle to the sea.

Rivers, canals....The chief rivers are the Maese or Meuse, Sambre, Demer, Dyle, Nethe, Geet, Sanne, Ruppel, Scheldt, Lis, Scarpe, Deule, and Dender.... The principal canals are those of Brussels, Ghent, and Ostend.

Metals, minerals.....Mines of iron, copper, lead, and sulphur, are found in Luxemburg and Limburg, at present the departments of the Forests and of Ourthe, as are some marble quarries ; and in the province of Namur, or the department of the Sambre and Meuse, there are coal-pits, and a species of bituminous fat earth, proper for fuel, with great plenty of fossile nitre.

Climate, soir, Agriculture....The air of Brabant, and upon the coast of Flanders, is bad; that in the interior parts is more healthful, and the seasons more settled, both in winter and summer, than they are in England. The soil and its produce are rich, especially in corn and fruits. They have abundance of pasture; and Flander's itself has been reckoned the granary of France and Germany, and sometimes of England. The most barren parts for corn rear far more profitable crops of flax, which is here cultivated to great perfection. The state of agriculture in the Netherlands has received the highest praise from those well qualified to judge of it; and has, incleed, been celebrated for these 600 years past. Upon the whole, the late Austrian Netherlands, by the culture, commerce, and industry of the inhabitants, was formerly the richest and most beautiful spot in Europe, whether we regard the variety of its manufactures, the magnificence and riches of its cities, the pleasantness of its roads and villages, or the fertility of its land. If it has fallen off in latter times, it is owing partly to the neglect of its government, but chiefly to its vicinity to England and Holland; but it is still a most desirable and agreeable country.

VEGETABLES, ANimaLs....Great quantities of corn, flax, and maclder, are grown in the Netherlands, and the pasturage is particularly abundant. The cattle, which are purchased lean in the more northern countries, soon fatten and grow to a large size. The animals are in general the same as in the neighbouring countries of France and Holland.

Natural curiosities..... No precipices, cataracts, nor any grand and romantic natural scenery can be expected in this flat and low country. A stone quarry, under a hill near Maestricht, which is worked into a kind of subterranean palace, supported by pillars twenty feet high, may be mentioned under this head, though it may seem rather an artificial than a natural curiesity.

Population... The number of inhabitants in this country has usually been estimated at about two Millions; but according to the enumeration published by the French government, the nine departments of Belgium contain $3,018,70$ s inhabitants. See Table of the DePartMENTS Of FRANCE.

National character, Manners.o.The Flemings, by which name 
the natives of the Low Countries were usually called, though the appellation was strictly applicable only to those of Flanders, have been generally esteemed a heavy, blunt, honest people, but their manners are somewhat indelicate. They are ignorant, and fond of religious ceremonies and exhibitions. Their diversions are the same with those of the peasants of the neighbouring countries. In the part of the Netherlands which has been long in possession of the French, the inhabitants are become entirely French in their dress, language, and manners; but in the other parts the peasants diess like the Dutch boors, though the upper classes have long since adopted the French fashions. The French language, manner's, and intrigues, which prevailed in all the principal towns, rendered the final reduction of the country an easy task.

Cities, chief Towns, edifices....Brussels, the former residence of the governor or vice-roy of the Austrian Netherlands, is an elegant city, adorned with a noble square, one side of which is occupied by a spacious town-house. The late palace of the Austrian governor is a magnificent structure. The city stands on the small river Senne, and contained in its flourishing state above 100,000 inhabitants : at present the number is 66,000 .

The walls of Ghent, formerly the capital of Flanders, and celebrated for its linen and woollen manufactures, contain the circuit of ten miles; but now unoccupied, and great part of it in a manner void : the number of inhabitants, however, is still 56,000 . Bruges, formerly so noted for its trade and manufactures, but above all for its fine canals, is now dwindled into an inconsiderable place. Antwerp, once the emporium of the European continent, is now reduced to be a tapestry and thread-lace shop, with the houses of some bankers, jewellers, and painters, adjoining. One of the first acts of the Dutch, soon after they threw off the Spanish yoke, was to ruin at once the commerce of Antwerp, by sinking vessels, loaded with stone, in the mouth of the Scheldt; thus shutting up the entrance of that river to ships of large burden. This was the more cruel, as the people of Antwerp had been their friends and fellow-sufferers in the cause of liberty ; but they foresaw that the prosperity of their own commerce was at stake. In 1568 , when its tracle is supposed to have been at its greatest height, it was computed to contain above 200,000 inhabitants: at present the number is only 61,800 .

The other principal cities of the Netherlands, are Mons, containing 18,000 inhabitants; Maestricht 17,000; Malines or Mechlin 16,000; Namur 16,000; Bruges 15,000; and Luxemburg 10,000.

Commerce and Manufactures.... The chief manufactures of the Netherlands, are their beautiful linens and laces; in which, notwithstanding the boasted improvements of their neighbours, they are yet unrivalled; particularly in that species called cambrics, from Cambray, the chief place of its manufacture. These manufactures form the principal article of their commerce.

Government.... These provinces being now incorporated with Holland are under the inmediate government and laws of that country.

ReLigion.... The prevailing religion of this country is Roman Catholic; but all religions are tolerated.

'The archbishopric of Malines or Mechlin was the former metropolitan sce; Cambray was also an archbishopric. The bishoprics 
were Ghent, Bruges, Antwerp, Arras, Ypres, Tournay, St. Omers Namur, and Ruremonde.

LITERATURE AND THE ARTS....The societies of Jesuits formerly produced the most learned men in the Austrian Low Countries, in which they had many eligible settlements. Works of theology, and the civil and cannon law, Latin poems and plays were their chief productions. Strada is an elegant historian and poet. The French historians Froissart and Philip de Comines were natives of Flanders; the learned Lipsius was born near Brussels.

The Flemish painters and sculptors have great merit, and form a. school by themselves. The works of Reubens and Vandyke cannot be sufficiently admired. The models for heads of Firamingo, or the Fleming, particularly those of children, have never yet been equalled; and the Flemings formerly engrossed tapestry-weaving to themselves.

Universities....These are Louvain, Douay, Tournay, and St. Omers. The first was founded in 1426, by John IV, duke of Brabant, and enjoys great privileges. By a grant of pope Sixtus IV, this university had the privilege of presenting to all the livings in the Netherlands, except in Holland.

LANGUAGE..... The vernacular language of this country is the Flemish, a dialect of the Dutch; but it is nearly superseded, except among the peasantry, by the French.

Antiquities.... Some Roman temples and other buildings, and the remains of Roman roads are found in the Netherlands. There are also many churches and convents, venerable for their antiquity; and. the magnificent old edifices of every kind, in all the cities, give evidence of their former grandeur. In 1607, some labourers found 1600 gold coins, and ancient medals, of Antoninus Pius, Aurelius, and Lucius Verus.

History....The seventeen provinces, and that part of Germany which lies west of the Rhine, were called Gallia Belgica by the Romans. About a century before the Christian æra, the Battæ removed from Hesse to the narshy country bounded by the Rhine and the Maese. They gave the name of Batavia to their new country. Generous and brave, the Batavians were treated by the Romans with great respect, being exempted from tribute, governed by their own laws, and obliged only to perform military services. Upon the decline of that empire, the Groths, and other northern people, possessed themselves of these provinces first, as they passed through them in their way to France, and other parts of the Roman empire; and afterwards being erected into small governments, the heads of which were despotic within their own dominions, Batavia and Holland became inde= pendent of Germany, to which it had been united under one of the grandsons of Charlemagne, in the beginning of the 10th century, when the supreme authority was lodged in the three united powers, of a count, the nobles, and the towns. At last, they were swallowed up by the house of Burgundy, anno 1433.

The emperor Charles V, the heir of that family, transferred them, in the year 14.77, to the house of Austria, and ranked them as part of the empire, under the title of the Circle of Burgundy. The tyranny of his son Philip II, who succeeded to the throne of Spain, made the inhabitants attempt to throw off his yoke, which occasioned a general insurrection, the counts Hoorn and Egmont, and the prince of Orange, 
appearing at the head of it ; and Luther's reformation gaining srounct about the same time in the Netherlands, his disciples were forced by persecution to join the malcontents. Philip II, in consequence introduced a kind of inquisition, which, from the inhumanity of its proceedings, was called the "Council of Blood," in order to suppress them; and many thousands were put to death by that court, besides those that perished by the sword. Count Hooln and count Egmont were taken and beheaded; but the prince of Orange, whom they elected to be their stadtholder, retiring into Holland, that and the adjacent provinces entered into a treaty for their mutual defence, at Utrec_st, in the year 1579. And though these revolters at first were thought so despicable as to be termed beggars by their tyrants, their perseverance and courage were such, under the prince of Orange, and with the assistance afforded them by queen Elizabeth, both in troops and money, that they forced the crown of Spain to declare them a free people, in the year 1609; and afterwards they were acknowledged by all Europe to be an independent state, under the title of THE UNITED Provinces.

After the independency of the Seven United Provinces was acknowledged, the Spaniards remained possessed of the other ten provinces, ur, as they are termed, the Low Countries, until the duke of Marlborough, as general of the allies, gained the memorable victory of Ramillies, in the year 1706; after which, Brussels, the capital, and great part of these provinces, acknowledged Charles VI, afterwards emperor of Germany, for their sovereign; and his daughter, Maria Theresa, remained possessed of them until the war of 1741, when the French reduced them, except part of the province of Luxemburg; and would have retained them from that time, but for the exertions of the Dutch, and chiefly of the English, in favour of the House of Austria, which continued in undisturbed possession of the part of the Netherlands secured to it by the peace of 1748 , till the disputes which took place between these provinces and the emperor Josenh, in the years 1788 and 1789 .

The quarrel originated, like those in other countries, concerning the prerogatives assumed by the emperor, which were more extensive than his subjects wished to allow; and the emperor making use of force to assert his claims, the territories of the United States be. came a refuge for the discontented Brabanters.

On the part of his imperial majesty, the insurgents were not treated with lenity. A proclamation was issued by count . Trautmandsdorff, governor of Brussels, intimating, that no quarter should be given them, and that the villages in which they concealed themselves should be set on fire. General Dalton marched with 7000 men to retake the forts, proclaiming that he meant to become master of them by assault, and would put every soul he found in them to the sword.

In opposition to this sanguinary proclamation, the patriots issued a manifesto, in which they declared the emperor to have forfeited his authority, by his various oppressions and cruelties, his annulling his oath, and infringing the constitution. Banishment was threatened to such as took part with him; and all were exhorted to take up arms in defence of their country, though strict orders were given that no crowds or mobs should be allowed to pillage ; and whoever was found doing so, should be treated as an enemy to his country. 
This was dated at Hoogstraten, in Brabant, October the 24th, 1789. Almost every town in Austrian Flanders showed its determination to oppose the emperor, and the most enthusiastic attachment to military affairs displayed itself in all ranks of men. Even the ecclesiastics manifested their valour on this occasion; which perhaps was naturally to be expected, as the emperor had been very active in depriving them of their revenues. A formidable army was soon raised, which after some successful skirmishes, made themselves masters of Ghent, Bruges, Tournay, Malines, and Ostend; so that general Dalton was obliged to retire to Brussels. A battle was fought before the city of Ghent, in which the patriots were victorious, though with the loss of 1000 men, besicles women and children. It reflects indelible disgrace on the emperor, as well as on the commanders of his troops, that they committed the most dreadful acts of cruelty on the unhappy objects who fell into their hands. Orders were given to plunder and destroy wherever they could obtain any booty; while the merciless savages not only destroyed the men, but killed women and sucking: infants. Some of them plunged their bayonets into the bodies of children in the cradle, or pinned them against the walls of the houses. By these monstrous cruelties, they insured success to their adversaries; for the whole countries of Brabant, Flanders, and Malines, almost instantly declared in their favour. They published a memorial for their justification, in which they gave, as reasons for their conduct, the many oppressive edicts with which they had been halassed since the death of the empress-queen; the unwarrantable extension of the imperial prerogatives, contrary to the coronation-oath of the emperor, and which could not be done without perjury on his part; the violence committed on his subjects, by forcibly entering their houses at midnight, and sending them prisoners to Vienna, to perish in a dungeon, or on the banks of the Danube. Not content with this, he had openly massacred his subjects; he had consigned towns and villages to the flames, and entered into a design of exterminating people who contended only for their rights. These things, they owned, might be terrible at the time, and easily impose upon weak minds, but " the natural courage of a nation, roused by repeated injuries, and animated by despair, would rise superior to those last efforts of vindictive tyranny, and render them as impotent and abortive, as they were wicked and unexampled." For all which reasons they declared themselves independent, and for ever released from the nouse of Austria.

The emperor, now perceiving the bad effects of his cruelty, published proclamations of indemnity, \&c. but they were treated with the utmost contempt. The patriots made the most rapid conquests; insomuch, that, before the end of the year, they were masters of every place in the Netherlands, except Antwerp and Luxemburg.

Notwithstanding they thus appeared for ever separated from the house of Austria, yet the death of Joseph, happening soon after, produced such a change in the conduct of government, as gave a very unexpected turn to the situation of affairs; and the mild and pacific disposition of Leopold, who succeeded his brother, the conciliatory measures he adopted, together with the mediation of Great Britain, Prussia and Holland, made a material alteration in the affairs of these provinces; and a convention, which was signed at Reichenbach, on the 27 th of July 1790 , by the abovementioned high contracting 
powers, had for its object the re-establishment of peace and good order in the Belgic provinces of his imperial majesty.

Their majesties of Great Britain and Prussia, and the states-general of Holland, became in the most solemn manner, guarantees to the emperor and his successors for the sovereignty of the Belgic provinces, now reunited under his dominion.

The ratification of this convention was exchanged between the contracting parties, within two months from the date of signing, which was executed at the Hague, on the 10th of December 1790.

The incursion of the French into these provinces, their complete conquest, the cession of them to France by the treaty of Campo Formio, and the confirmation of that cession by the peace of Luneville, have already been related in our history of the late transactions of that people.

By the arrangements of the late peace, they have been united to Holland; and are governed by the Prince of Orange, under the title of the Sovereign Prince of the United Netherlands. 


\title{
THE SEVEN UNITED PROVINCES, OR HOLLAND.
}

\author{
EXTENT AND SITUATION.
}

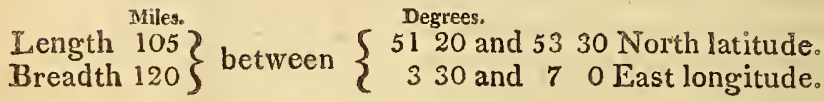

Containing 9400 square miles, with 280 inhabitants to each.

NAme... This country was a part of that inhabited by the ancient Batavi : it is usually called Holland, from the name of the chief province; which is formed from the German words hohl and land, and signifies a hollow or low country. Since the revolution occasioned by the incursion of the French in 1795, it has taken the name of the Batavian Republic.

Boundaries....It is bounded on the north and west by the German ocean, and the Zuyder sea; on the east by Germany; and on the south by the Netherlands, or Belgium.

Divisions... The United Provinces were, properly speaking, eight, viz. Holland, Overyssel, Zealand, Friesland, Utrecht, Groeningen, Guelderland, and Zutphen; but the two latter forming only one sovereignty, they generally are termed the Seven United Provinces. Besides these, the Dutch republic contained the county of Drenthe, a kind of separate province in Overyssel, which had no share in the government; and what was called the Land of the Generality, or Dutch Brabant, Dutch Flanders, and the part of Limburg which belonged to the republic. When the government was changed into a monarchy in 1806, it received the addition of Fast Friesland on the N. E. and Holland was divided into Amstetland and Maasland.

The extent and population of these provinces in 1809 are stated as follows in Hassel's Tables :

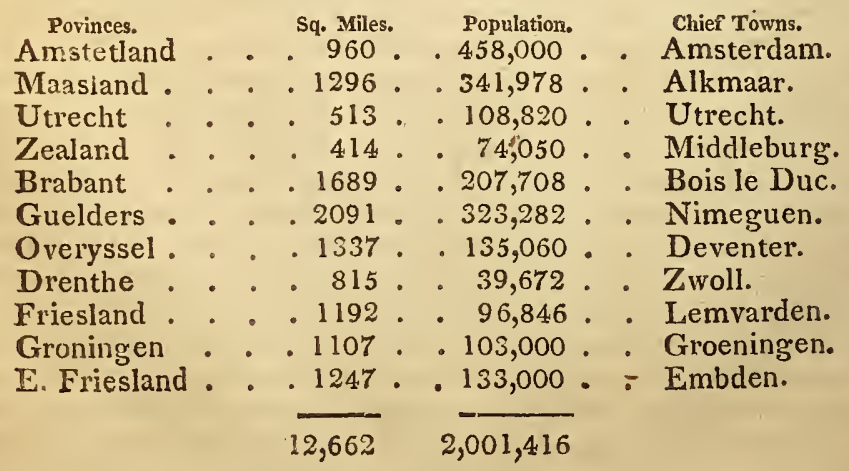


After the expulsion of the stadtholder, and the introduction of a new form of government under the influence of the French, the $\mathrm{Ba}$ tavian republic was divided into eight departments, as follows:

Ancient Provinces,

Departments.

Chief Towns.

Groeningen and Friesland Ems.

Leuwarden.

Oreryssel, and part of Guelder-? land and Zutphen

Remainder of Guelderland and Zutphen, and part of Utrecht

Part of Holland

Old Yessel.

Rhine.

Amstel.

North part of Holland, and south? part of Leyden inclusive. $\}$

Remainder of south part of Hol- $\}$ land and remainder of Utrecht $\}$

Eastern part of Dutch Brabant. Dommel.

Western part of Dutch Brabant, and Zealand
Texel.

\author{
Delft.
}

Zwoll.

Arnheim.

Amsterdam.

Alkmaar.

Utrecht.

Bois le Duc.

Each of these departments was divided into seven circles or disericts.

FAce of the country.... Holland is situate opposite to England, at the distance of 90 miles, from the east side of the English Channel; and is only a narrow slip of low swampy land, lying between the mouths of several great rivers; and what the industry of the inhabitants have gained from the sea by means of dykes, which they have raised, and still support with increctible labour and expense. Here are no mountains, nor rising grounds, no plantations, purling streams, or cataracts. The whole face of the country, when viewed from a tower or steeple, has the appearance of a continued marsh or bog, drained, at certain distances, by innumerable ditches: and many of the canals, which in that country serve as high roads, are in the summer months highly offensive to the smell.

Rivers, LaKes, canals... The chief rivers of Holland are the Rhine, (one of the largest rivers in Europe,) the Maese or Meuse, the Dommel, the IVaal, the Issel, the Scheldt, and the Vecht. There are many other small rivers that fall into these.

The principal lake of Holland is the sea of Haerlem; there are also some small lakes in the north of the province of Holland, and in Friesland and Groeningen.

The canals of these provinces are almost innumerable. The usual way of passing from town to town is by covered boats, called treckscuits, which are dragged along the canals by horses on a slow uniform trot, so that passengers reach the different towns where they are to stop precisely at the appointed instant of time. This method of travelling, though to strangers rather dull, is extremely convenient to the inhabitants, and very cheap. By means of these canals an extensive inland commerce is not only carried on through the whole country, but, as they communicate with the Rhine and other large rivers, the productions of every country are conveyed at a small expense into various parts of Germany and Flanders. A treckscuit is divided into two different apartments, called the roof and the ruim; the first for gentlemen, and the other for common people. Near Amsterdam and other large cities, a traveller is astonished when he beholds the effects of an extensive and flourishing commerce. Hero

Vor. I. 
the canals are lined for miles together with elegant neat country houses, seated in the midst of gardens and pleasure grounds, intermixed with figures, busts, statues, temples, \&c. to the very water's edge.

Metals, minerals....Holland produces neither metals nor minerals, except a little iron; nor any mineral waters.

Climate, soll, agriculture....The air of the United Provinces is foggy and gross, until it is purified by the frost in winter, when the east wind usually sets in for about four months, and their harbours are frozen up. The moisture of the air causes metals to rust, and wood to mould, more than in any other country, which is the reason of their perpetually rubbing and scouring, and of the brightness and cleanliness in their houses, so much taken notice of. The soil is unfavourable to vegetation; but, by the industry of the inhabitants in making canals, it is rendered fit for pasture, and in many places for tillage.

VEGETABLES, ANIMALs.... The quantity of grain produced here is not sufficient for home consumption; but, by draining the bogs and marshes, the Dutch have many excellent meadows, which fatten lean German and Danish cattle to a vast size; and they make prodigious quantities of the best butter and cheese in Europe. Their country produces turf, madder, tobacco, some fruit and iron; but all the pitcoal and timber used there, and, indeed, most of the comforts and even the necessaries of life, are imported. They have a good breed of sheep, whose wool is highly valued : and their horses and horned cattle are of a larger size than in any other nation in Europe. It is said that there are some wild bears and wolves here. Storks build and hatch on their chimnies; but being birds of passage, they leave the country about the middle of August, with their young, and return the February following. Their river-fish are much the same as ours; but their sea-fish are generally larger, owing perhaps to their fishing in deep water. No herrings visit thcir coasts; but they have many cxcellent oyster-beds about the islands of the Texel, producing very large and weli-tasted oysters. Notwithstanding all the inconveniences, the inclustry of the Hollanders furnishes as great a plenty of the necessaries and commodities of life, and upon as easy terms, except to travellers and strangers, as can be met with in any part of Europe.

Curiosities....Holland, like the Netherlands, presents none of the vast and grand scenery of nature. The numerous canals with which the country is intersected, may be considered as interesting to the curiosity of the traveller; and the prodigious dyles (some of which are said to be seventeen ells in thickness) mounds, and canals, constructed by the Dutch, to preserve their country from those dreadful inundations by which it formerly suffered so much, are works equally stupendous and singular. The Stadthouse of Amsterdam is perhaps the best building of that kind in the world: it stands upon 13,659 large piles, driven into the ground; and the inside is equally convenient and magnificent. Sevęral museums, containing antiquities and curiosities, artificial and natural, are to be found in Holland and the other provinces, particularly in the university of Leyden.

Popuration....The Seven United Provinces are perhaps the best peopled of any spot of the same extent in the world. They contained in 1785 , according to a public account then given, 113 cities and towns, 1400 villages, and $2,758,632$ inhabitants; besides the twenty- 
five towns, and the people in what are called the Lands of the Generality, or conquered countries' and towns of other parts of the $\mathrm{Ne}$ therlands. The population of 1809 is given in the table of divisions. Since then the destruction of commerce has continued very much to reduce the number of inhabitants. In 1811 they had decreased to $1,881,880$.

National character, NANners, custons....The manners, habits, and even the minds of the Dutch (for so the inhabitants of the United Provinces are in general called) seem to be formed by their situation, and to arise from their natural wants. Their country, which is preserved by mounds and dykes, is a perpetual incentive to labour; and the artificial drains, with which it is every where intersected, must be kept in perpetual repair. Even what may be called their natural commodities, their butter and cheese, are produced by a constant attention to the laborious parts of life. Their principal food they earn out of the sea, by their herring fisheries; for they dispose of most of their valuable fish to the English, and other nations, for the sake of gain. The air and temperature of their climate incline them to phlegmatic, slow dispositions, both of body and mind; and yet they are irascible, especially if heated with liquor. Even their virtues are orving to their coldness with regard to every object that does not immediately concern their own interests; for, in all other respects, they are quiet neighbours and peaceable subjects.

The valour of the Dutch becomes warm and active, when they believe their interests at stake; witness their sea-wars with England and France. Their boors, though slow of understanding, are manageable by fair means. Their seamen are plain, blunt, but rough, surly, and an ill-natured sort of people, and appear to be insensible of public spirit and affection for each other. Their tradesmen in general are reckoned honest in their dealings, and very sparing of their words. Smoking tobacco is practised by the old and young, of both sexes; and as they are generally plodding upon ways and means of getting money, no people are so unsociable. A Dutchman of low rank, when drunk, is guilty of every species of brutality. The Dutch have also been known to exercise the most dreadful inhumanities for interest abroad, where they thought themselves free from discovery; but they are in general quiet and inoffensive in their own country, which exhibits but few instances of murcler, rapine, or violence. As to the habitual tippling and drinking charged upon both sexes, it is owing, in a great measure, to the nature of their soil and climate. In general, all appetites and passions seem to run lower and cooler here than in most other countries, that of avarice excepted. Their tempers are not airy enough for joy, or any unusual strains of pleasant humour; nor warm. enough for love; so that the softer passions seem no natives of this country; and love itself is little better than a mechanical affection, arising from interest, convenience, or habit; it is talked of sometimes among the young men, but as a thing they have heard of, rather than felt, and as a discourse that becomes them, rather than affects them.

In whatever relates to the management of pecuniary affairs, the Dutch are certainly the most expert of any people; as, to the knowledge of acquiring wealth, they unite the no less necessary science of preserving it. It is a kind of general rule for every man to spend less than his income, be that what it will; nor does it often enter into the heads of this sagacious people, that the common course of ex- 
pense should equal the revenue; and when this happens, they think; at least, they have lived that year to no purpose ; and the report of it used to discredit a man among them, as much as any vicious or prodigal extravagance does in other countries. But this rigid frugality is not so universal among the Dutch as it was formerly; for a greater degree of luxury and extravagance has been introduced among them, as well as the other nations of Europe. Gaming is likewise practised by many of their fashionable ladies, and some of them discover more propensity to gallantry than was known there in former times. No country can vie with Holland in the number of those inhabitants whose lot, if not riches, is at ieast a comfortable sufficiency; and no where fewer failures or bankruptcies occur. Hence, in the midst of a world of taxes and contributions, they flourish and grow rich. From this systematic spirit of regularity and moderation, joined to the most obstinate perseverance, they succeeded in the stupendous works of draining their country of those immense deluges of water, that had overflowed so large a part of it during many ages, while, at the same time, they brought under their subjection and command the rivers and seas that surround them, by dykes of incredible thickness and strength, and made them the principal bulwarks on which they rely for the protection and safety of their territories against the danger of an enemy. This they have done by covering their frontiers and cities with innumerable sluices; by means of which, at the shortest notice, the most rapid inundations are let in, and they become, in a few hours, inaccessible. From that frugality and perseverance by which they have been so much characterised, they were enabled, though labouring under the greatest difficulties, not only to throw off the Spanisis yoke, but to attack that powerful nation in the most tender parts, by seizing her rich galleons, and forming new establishments in Africa, and the East and West Indies, at the expense of Spain, and thereby becoming, from a despicable province, a most powerful and formidable enemy. Equally wonderful was the rise of their military and marine establishments ; maintaining, during their celebrated contention with Lewis XIV, and Charles II, of England, not less than 150,000 men, and upwards of eighty ships of the line. But a spirit of frugality being now less universal among them, the rich traders and mechanics begin to approximate to the luxuries of the English and French; and their nobility and high magistrates, who have retired from trade, rival those of any other part of Europe in their table, buildings, furniture, and equipages.

The diversions of the Dutch differ not much from those of the English, who seem to have borrowed from them the neatness of their drinking booths, skittle and other grounds, and small pieces of water, which form the amusements of the middling ranks; not to mention their hand-organs, and other musical inventions. They are the best skaters upon the ice in the world. It is amazing to see the crowds in a hard frost upon the ice, and the great dexterity both of men and women in darting along, or rather flying, with inconceivable velocity.

The dress of the Dutch formerly was noted for the large breeches of the men, and the jerkins, plain mobs, short petticoats, and other oddities of the women; all which, added to the natural thickness and clumsiness of their persons, gave them a very grotesque appear- 
ince. These dresses now prevail only among the lower ranks, and more particularly among the sea-faring people.

CitIES, CHIEF TOWNS, EDIFICES....Amsterdam, which is built upon piles of wood, is thought to contain 212,000 people, and to be, next to London, the most commercial city in the world. It stands on the river Amstel. Its conveniences for commerce, and the grandeur of its public works, are almost beyond description. In this and all other cities of the United Provinces, -the beauty of the canals, and walks under trees planted on their borders, is admirable; but above all we are struck with the neatness and cleanlines's that is every where observed within cloors. This city, however, labours under two great disadvantages--bad air, and the want of fresh wholesome water, which obliges the inhabitants to proserve the rain-water in reservoirs. Rotterdam is next to Amsterdam for commerce and wealth; its inhabitants are computed at 48,000 . The Hague, though but a village, is the seat of government in the United Provinces, and is celebrated for the magnificence and beauty of its buidings, the resort of foreign ambassadors and strangers of all distinctions who live in it, the abundance and cheapness of its provisions, and the politeness of its inhabitants, who are computed to be about forty thousand; it is no place of trade, but it has been for many years noted as an emporium of pleasure and politics. Middleburg in Zealand has a large town hall, and was the seat of the provincial states, and of the council of Flanders. Leyden and Utrecht are fine cities, as well as famous for their unirersities. Delft, Dort, and Groeningen. are likewise considerable towns, containing cach about 20,000 inbabitants. In Saardam, a wealthy trading place, Peter the Great of Moscovy, in person, served his apprenticeship to ship-building, and laboured as a common handicraft. The upper part of Guelderland is subject to Prussia, and the capital city is Guelder.

Commerce, Manufactures....An account of the Dutch commerce, previous to the late revolutions, would have comprehended that of almost all Europe. There is scarcely a manufacture that they did not carry on, or a state to which they did not trade. In this they are assisted by the populousness of their country, the cheapness of their labour, and above all, by their water-carriage, which, by means of their canals, gives them advantages beyond all other nations. The United Provinces were the grand magazine of Europe : and goods might be purchased here sometimes cheaper than in the countries where they grow. The East India company had the monopoly of the most valuable spices for more than a hundred years, and, till the late wars with England, was extremely opulent and powerful. Their capital city in India is Batavia, which is said to exceed in magnificence, opulence, and commerce, all the cities of Asia. Here the riceroys appear in greater splendour than the stadtholder; and some of the Dutch subjects in Batavia scarcely acknowledge any dependence on the mother country. They have other settlements in India; but all their colonies, at the termination of the late war, were in the possession of the English. Not to mention their herring and whale fisheries, which they have carried off from the native proprietors, they are distinguished for their pottery, tobacco-pipes, Delft-ware, finely refined salt; their oil mills, and starch manufactures; their hemp and fine paper manufactures; their fine linen and table damasks; their saw mills for timber, either for shipping or houses, in immense quantities; their great sugar baking; their vast woollen, 
cotton, and silk manufactures; wax bleaching; leather dressing; the great quantity of coin and specie, assisted by their banks, especially by that of Amsterdam; their East India trade; and their general industry and frugality. Their commerce, however, suffered greatly during the late wars, and was totally destroyed by Bonaparte, when he took possession of the country.

Public trading companies..... Of these, the principal is the EastIndia company, incorporated in 1602 , by which formerly the Dutch acquired immense wealth, divided forty per cent. and sometimes sixty, about the year 1660; at present the dividends are much reduced; but in a hundred and twenty-four years, the proprietors, on an average, one year with another, divided somewhat above twenty-four per cent. So late as the year 1760 , they divided fifteen per cent.; but the Dutch West India company the same year divided no more than two and a half per cent. This company was incorporated in 1621. The bank of Amsterdam was thought to be inexhaustibly rich, and was under an excellent direction; it is said, by sir Willian 'Temple, to contain the greatest treasure, either real or imaginary, that is known any where in the world. What may seem a paradox is, that this bank was so far from paying any interest, that the money in it was worth somewhat more than the current cash is in common payments. Mr. Anderson supposes that the cash, bullion, and pawned jewels in this bank, which were kept in the vaults of the Stadthouse, amounted to thirty-six (though others say only to thirty) millions sterling.

Constitution, Government, Laws....Before the French entered Holland, in January, 1795, the United Provinces formed a common confederacy; yet each province had an internal government or constitution independent of the others; this government was called the states of that province; and the delegates from them formed the states-general, in whom the sovereignty of the whole confederacy was vested; but though a province should send two or more delegates; yet such province had no more than one voice in every resolution; and before that resolution could have the force of a law, it must be approved of by every province, and by every city and republic in that province. This formality, in times of great danger and emergency has been set aside. Every resolution of the states of a particular province must be carried unanimously.

The council of state consisted likewise of deputies from the several provinces, but its constitution was different from that of the statesgeneral; it was composed of twelve persons, whereof Guelderland sent tivo; Holland three; Zealand two; Utrecht two; Friesland one; Overyssel one; and Groeningen one. These deputies, however, did not vote provincially, but personally. Their business was to prepare estimates, and ways and means for raising the revenue, as well as other matters that were to be laid before the states-general. The states of the provinces were styled "Noble and Mighty Lords," but those of Holland, "Noble and Most Mighty Lords;" and the statesgeneral, "High and Mighty Lords," or, "The Lords the Statesgeneral of the United Netherlands ;" or, "Their High Mightinesses." Subordinate to these two bodies, was the chamber of accompts, which was likewise composed of provincial deputies, who audited all public accompts. The admiralty formed a separate board, and the executive part of it was committed to five.colleges, in the three maritime provinces of Holland, Zealand, and Friesland. In Holland the people 
had nothing to do either in choosing their representatives or their magistrates. In Amsterdam, which took the lead in all public deliberations, the magistracy was lodged in thirty-six senators, who were chosen for life, and every vacancy among them was filled up by the survivors. The same senate also elected the deputies to represent the cities in the province of Holland.

The above particulars are mentioned, because, without a knowledge of them it is impossible to understand the history of the United Provinces from the death of king IVilliam to the year 1647, when the stadtholdership was made hereditary in the male and female representatives of the family of Orange. This office in a manner superseded the constitution already described. The stadtholder was president of the states of every province; and such was his power and influence, that he could change the deputies, magistrates, and officers, in every province and city. By this he held the moulding of the assembly of the states-general, though he had no voice in it: in short, though he had not the title, he had more real power and authority than some kings; for besides the influence and revenue he derived from the stadtholdership, he had several principalities and large estates of his own. The late stadtholder, who was expelled by the French, was William V, prince of Orange and Nassau, son of the stadtholder William Charles, who married Anne, princess royal of Great Britain, and died in 1751 .

Though Holland under this constitution was called a republic, yet its grovernment was far from being of the popular kind : nor did the people enjoy that degree of liberty which might at first view be apprehended. It was indeed rather an oligarchy than a commonwealth; for the bulk of the people were not suffered to have the least share in any part of the government, not even in the choice of the depucies. It may also be observed that very few persons in this state dared speak their real sentiments freely; and they were generally educated in principles so extremely cautious, that they could not relinquish them when they entered more into public life.

After the departure of the stadtholder, on the conquest of Holland by the French, in 1795, a convention was assembled to administer the government, and frame a constitution for the new Batavian republic. 'The first plan they presented was rejected by the people in the primary assemblies; but another was afterwards drawn up, which was accepted. This constitution was again changed in several particulars in 1,793 ; and the Batavian republic is now governed by a directory of twelve members, the president of which is changed every three months, and of which one member goes out annually; and a legislative body of 35 members, which assembles twice, and if necessary oftener, in the year, and appoints a committee of twelve of its members to examine and report on the laws and regulations proposed by the directory. But the Batavian republic was annihilated, in 1806, and the constitution suffered another revolution, Louis Bonaparte being created king of Holland.

In 1810, when this country was united to France, it received the Napoleon Code; with which it continued to be governed, till the new revolution of 1814, when the Prince of Orange was recalled; who is now styled the Sovereign Prince of the United Netherlands. The government since the restoration has undergone several alterations, approaching nearly in form and spirit to that of Great Britian. 
With respect to the administration of justice in this country, every province has its tribunal, to which, except in criminal causes, appeal lies from the petty and county courts; and it is said that justice is no where distributed with more impartiality.

Revenue....The republican government of the United Provinces proportioned their taxes according to the abilities of each province $\mathrm{or}^{2}$ city. Those taxes consisted of an almost general excise, a landtax, poil-tax, and hearth money; so that the public revenue amounted annually to about three millions and a half sterling. The province of Holland paid nearly half of this revenue. The following is the rate at which each of the Seven United Provinces contributed towards the public expence.

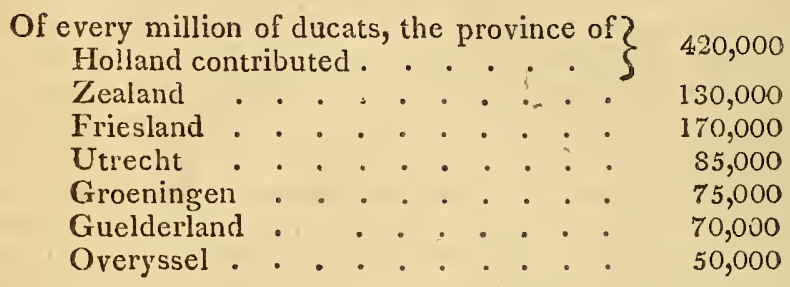

Of the 420,000 ducats paid by the province of Holland, the city of Amsterdam furnished upivards of 320,000 . The taxs in these provinces are so heavy, and so many, that it is not without reason a certain author asserts, that the only thing which has escaped taxation there is the air they breathe. But for the encouragement of trade, the duties on goods and merchandise are exceedingly low. In the year 1797 , after the defeat of the Dutch fleet by admiral Duncan, a tax of eight per cent. on all income was imposed for the re-establishment of their navy. A forced loan of three per cent. on all capital and property, and a tax of seven per cent. besides, on all income, were likewise decreed; and additional taxes of the same kind have since been imposed.

The public debt of the United Proyinces is stated by Boetticher at one hundred and thirty millions sterling; but an estimate lately published, which appears to be from authority, it amounts only to one thousand millions of florins, or about one hundred millions sterling.

Army, NAvr....The number of land forces in the United Provinces, in time of peace, commonly amounted to about forty thousand. At present, they have not more than twenty thousand. The marine force of the United Provinces used to be very great, and they formerly fitted out very formidable fleets; but their navy has for many years been much neglected. Their late war with Great Britain obliged them to increase it; but it was soon reduced to a very feeble and shattered state, in consequence of the surrender of admiral Lucas's squadron at the Cape of Good Hope, the victory gained by admiral Duncan, and especially the surrender of the fleet in the Texel to admiral Mitchel. Their naval force, however, still amounts to fifteen ships of the line, and as many frigates.

ReLigion....After the irruption of the French into Holland, the new government of the Batavian republic declared that no religion is established or paid by the state; but prior to that event the estab- 
lished religion here was the presbyterian and Calvinism; none but presbyterians were admitted to any office or post in the government, excepting in the army; yet all religions and sects were tolerated, and had their respective meetings or assemblies for public worship, among which the papists and Jews were very numerous. And, indeed, this country may be considered as a striking instance of the benefits arising to a nation from universal toleration. As every man is allowed to worship God according to the dictates of his own conscience, persons of the most opposite opinions live together in the most perfect harmony and peace. No man in this republic has any reason to complain of being oppressed on account of his religious principles; nor any hopes, by advancing his religion, to form a party, or to break in upon the government; and therefore, in Holland, men live together as citizens of the world; their differences in opinion make none in affection, and they are associated together by the common ties of humanity and bonds of peace, under the protection of the laws of the state, with equal encouragements to arts and industry, and equal freedom of speculation and inquiry.

Literature....Erasmus and Grotius, who were both natives of this country, stand almost at the head of modern learning. Haarlem disputes the invention of printing with the Germans, and the magistrates keep two copies of a book entitled Shreculum Salvationis, print$\epsilon d$ by Koster in 1440; and the inost elegant editions of the classics came from the Dutch presses of Amsterdam, Rotterdam, Utrecht, Leyden, and other towns. The Dutch have excelled in controversial divinity, which insinuated itself so much into the state, that, before principles of universal toleration prevailed, it had almost proved fatal to the government; witness the violent disputes about Arminianism, freewill, predestination, and the like. Besides Boerhaave, they have produced excellent writers in all branches of medicine. Grævius, Gronovius, father and son, and Burman, are ranked among the principal of their numerous commentators upon the classics. In the other departments of literature, the Dutch publications are mechanical, and arise chiefly from their employments, in universities, church, or state.

Uxiversities....These are Leyden, Utrecht, Groeningen, Harderwicke, and Franker.

The university of Leyden, which was founded in 1575, is the largest and most ancient in all the United Netherlands. Its library, besides a number of printed books, contains above two thousand oriental manuscripts, Here is also a physic-garden, and an anatomical theatre.

The university of Utrecht was changed from a school into an university in 1636; but it has not all the privileges of the other universities, being entirely subject to the magistrates of the city. The physic-garden here is very curious; and for the recreation of the students, on the east side of the city, just without the gate, is a beautiful mall, consisting of seven straight walks, two thousand paces in length, regularly planted with limes; but that in the middle is properly the mall.

There are abundance of youth, of the principal nobility and gentry from most countries in Europe, at these seminaries of literature; and as every one may live as he pleases, without being obliged to be profuse in his expences, or so much as quitting his night-gown for either weeks or months together, foreigners of all ranks and corr-

Vorm I. $3 \mathrm{H}$ 
ditions are to be seen here. The force of example is strikingly exhibited at these universities; for frugality in expence, order, a composed behaviour, attention to study, and assiduity in all things, being the characteristics of the natives, strangers who continue amongst them soon aciopt their manners and form of living. And though the students live as they please, and study as much or as little as they think fit, yet they are in general remarkable for their sobriety and good manners, and the asșiduity and success with which they apply themselves to their studies. No oaths are imposed, nor any religious tests; so that Roman-catholic parents, and even Jews, send their children here with as little scruple as protestants.

Language... The language of the United Provinces is Low Dutch, which is a corrupted dialect of the German; but the people of fashion speak English and French. The Lord's Prayer runs thus: Onse Vader, die in de hemelin zyn, urven naam worde seheylight: uqvekoningkryk kome : uve rville geschiede gelyck in den hemel zoo ook on den arden, ons dagelicks broot geef ons heeden, ende vergeeft onse schulden gelyk ook wy vergeeven onse schuldenaaren: ende enlaat ons niet in versoeckinge, maer vertast ons van der boosen. Amen.

Antrquities.... Holland contains few antiquitics. Near Catwyk is a ruinous Roman tower; and in the middle of Leyden an artificial mount, on which is a round tower built, according to traditional report, by Hengist the leader of the Saxons who invaded England.

History....After the Seven United Provinces had obtained their independence, as related in the preceding summary of the history of the Netherlands, they soon became distinguished as a commercial and maritime state; and by their sea wars with England, under the commonwealth, Cromwell, and Charles II, justly acquired the reputation of a formidable naval power. When the house of Austria, which for some ages ruled over Germany, Spain, and part of Italy, with which they afterwards continued to carry on bloody wars, was become no longer formidabie; and when the public jealousy was directed against that of Bourbon; which was favoured by the government of Holland, who had dispossessed the prince of Orange of the stadtholdership; the spirit of the people was such, that they revived it in the person of the prince, who was afterwards William III, king of Great Britain ; and during his reign and that of queen Anne, they were principals in the grand confederacy against Lewis XIV, king of France.

Their conduct towards England in the wars of 1742 and 1756 has been mentioned in the history of that country, as also the occurrences which led to a rupture between them and the English in the year 1780. As it was urged that they refused to fulfil the treaties which subsisted between them and Great Britain, so all the treaties which bound Great Britain to them were declared null and void, as if none had ever existed. By this war, their trade suffered considerably; but Negapatnam, in the East Indies, was the only place not restored to them by the peace of 1783 .

Probably to their separation from Great Britain may be attributed the differences between the states-general and the emperor Joseph II, who, from the exhausted state of several of the European powers, seemed to have a favourable opportunity of accomplishing his designs. In the year 1781 he had been allowed to demolish the Dutch barrier in his dominions, for which they had contended so despe- 
rately in the time of queen Anne; and he now seemed willing to encroach upon their territories. A conference concerning the boundaries of their respective nations was proposed to the states; but before this could take place, he began to commit some acts of hostlity, and extended his dominions a little by way of preliminary. Two small forts, St. Donat and St. Paul, were seized upon, as well as sonie part of the marshes in the neighbourhood of Sluys. As a prelude to the negotiations, he also demanded that the Dutch guardship should be rernoved from before Lillo, in acknowledgment that one of the prerogatives of his imperial majesty was the free navigation of the Scheldt. This being complied with, the negotiations were opened at Brussels, on the 24th of April, 1784, when several other demands of small portions of territory, and little sums of money were made; the most material requisition being the town of Maestricht and its territory. For some time the conferences were carried on in that dry and tedious manner which generally marks the proceedings of the Dutch; but the emperor urged on his demands with great vigour, and matters seemed fast tending towards an open rupture. On the $23 \mathrm{~d}$ of August he delivered in his ultimatum to the commissioners at Brussels, in which he offered to give up his demand on Maestricht, in consideration of having the free and unlimited navigation of the Scheldt, in both its branches, to the sea; and, in token of his confidence of the good intentions of the states, he determined to consider the river as open from the date of that paper. Any insult on his flags in the execution of these purposes, he would conclude to be a direct act of hostility, and a formal declaration of war on the part of the republic. To prevent all injuries contrary to the incontestible rights of his imperial majesty, and to leave no doubts of his unalterable resolution to adhere to the propositions contained in the ultimatum, his majesty could not forbear determining to send to sea, from Antwerp, a ship under his flag, after having declared long enough before in what manner he should consider all violent opposition that might be made to the free passage of the said ship.

The ship was stopped in its passage, as was another, ordered to sail from Ostend up the Scheldt to Antwerp. But the Dutch offered to dismiss the vessels, if the captains would engage to return to their respective places, and not continue their voyage on the river; which they refused to do. 'This the emperor called insulting his flag, and declared to all foreign courts, he could not look on this fact but as "an effective declaration of war on the part of the republic". In answer to their conduct in stopping the imperial ships, which the emperor styled an insult to his flag, and by which he declared them to have begun hostilities, the Dutch ministers at Brussels, in a paper delivered to that court, protested "that as their sole aim was to support their incontrovertible right, they could not, with any appearance of justice, be considered as guilty of a hostile aggression.".

Great preparations were made for immediate hostilities against the Dutch; and several hundred of the Imperialists, with some fieldpieces, advancing towards the counterscarp of Lillo, the commanding officer of that place ordered the sluices to be opened, November 7, 1784, which effected an inundation that laid under water many miles of the flat country around the forts on the Scheldt, to preserve them from an attack. Both parties exerted themselves in case they should be called forth to open a campaign in the next spring; but 
France and Prussia interposed as negotiators and meciators, and succeeded in bringing about a reconciliation. However, from the conduct of the emperor in the partition of Poiand, and in demolishing the fortifications of the barrier places in the Netherlands, and demanding a free navigation of the Scheldt and to the East Indies; advancing from one pretension to another; it is apparent that the most solemn treaties will be no longer observed, by some courts and statesmen, than till they have an opportunity, with ability, to break them.

During the progress of their contentions with the emperor, this country was greatly distressed by intestine animosities, which it may be proper in this piace briefly to state. The continued series of losses which they had sustained in the late war with Great Britain was peculiarly disgraceful to the republic. All their settlements in the West Indies fell into the hands of the British, without resistance; their ships were captured, and trade ruined; while the disasters of the war excited the animosity of the two factions against each other to the highest degree. The partriots, or aristocratic party, attributed their defeats to the stadtholder, who had openly expressed his predilection for the English at the beginning of the American quarrel. 'To this conduct the patriots now very artfully reverted. They accused him of having advised the aggression of the English, and of contributing to their success by treachery. The evident inequality of the struggle, the notorious deficiency of all warlike articles in the dock-yaids and arsenals of the republic, the frequent and public reclamations made by the prince and by the council of state on the subject of that deficiency, were forgotten; and the wilful misconduct of the stadtholder was boldly alleged by the patriots as the sole cause of that miserable succession of defeat and disgrace which immediately followed the commencement of hostilities. Whilst these were the recriminations of the patriots, the monarchical or Orange party accused their antagonists of having involved the country in a dangerous war, at a time when it was entirely unprepar. ed for it.

This produced various accusations and vindications between the two parties, until at last, in the month of May, 1786, the stadtholder gave orders to seize on Vreeswick, a post of importance to the city of Utrecht, on account of its situation on the canal between that city and the tcrritories of South Holland; containing also the sluices by which both these provinces might be overflowed. This brought on a skirmish between the troops of the stadtholder and the burghers of Utrecht, in which the latter proved victorious. Some other unimportant hostilities took place; but while the military operations were carried on in such a languid manner, a violent tumult happened at Amsterdam, in which several persons were killed. This was followed by a revolt of most of the regular troops of Holland, who went over to the stadtholder; but notwithstanding this apparent advantage, and some others which afterwards took place, the disputes still contined with extreme violence, insomuch that the princess of Orange herself was seized, and detained prisoner a night by the patriots.

These turbulent commotions were, however, at last settled by the king of Prussia, who for this purpose marched an army into the territories of the United Provinces, and took possession of the city of Rotterdam, and some other places without resistance. This so 
much overawed both parties, that they quickly came to an accommodation, and a treaty was concluded between that monarch and the states of Holland. By this, the two contending parties were formally reconciled, and the courts of London and Berlin guaranteed the stadtholdership, as well as the hereditary government of each province, in the House of Orange, with all the rights and prerogatives settled in the years 1747 and 1748 ; by which all attempts to disturb the domestic tranquillity of the republic, by means of any foreign interference, appeared to be effectually guarded against by the close union that subsisted between those two important powers.

The late revolution in Holland, in consequence of the irruption of the French, and the expulsion of the stadtholder from that country, has already been briefly narrated in our history of France, to which we must refer the reader. We shall therefore only add, that the Batavian republic, which was instituted soon after the expulsion of the Orange family, lasted but a short time. Not being sufficiently trained to the will of the conqueror, the Dutch were compelied to surrender even that shadow of self-government; a monarchy superseded the republican form, and regal power was conferred on Louis, one of the brothers of Napoleon, with the title of King of Holland, and Constable of France.

Bonaparte soon found that even this measure did not place Holland sufficiently under his controul. The government of Louis was too mild, and occasional infractions of the continental system, were permitted. Bonaparte commanded his brother to enforce that system in the severest manner; and Louis, not willing to witness that ruin of the country, which it was out of his power to avert, resigned his crown. Bonaparte now took the administration into his own hands, and in 1810 Holland was declared a part of the French empire. Holland remained in this degraded and debased situation, till the victories of the northern allies, in 1813, revived the spirit of liberty, in the German states. The flame soon reached Holland. It began in Amsterdam, and spread from city to city with electrical rapidity. Deputies were immediately despatched to England, to recall the Prince of Orange. The people, sensible that many of their misfortunes, were owing to the weakness of their former government, conferred, on the Prince, the title and office of Sovereign, and the government has now become, in effect, a limited monarchy. By the terms of the late peace, Hoiland has acquired, by the accession of the Netherlands, a greater extent of continental territory, than she ever before possessed. The principal part of her colonial possessions, have also been restored. The title of the prince, is now, WVilliam Frederick, by the grace of God, Prince of Orange and Nassau, Sorereign Prince of the United Netherlands, Sxc. 


\section{GERMANY.}

EXTENT AND SITUATION.

$\left.\begin{array}{l}\text { Length } \begin{array}{c}\text { Miles. } \\ 620\end{array} \\ \text { Breadth } 530\end{array}\right\}$ between $\left\{\begin{array}{rr}45^{\circ} 30^{\prime} \text { and } 55^{\circ} 30^{\prime} \text { North lat. } \\ 6^{\circ} 0^{\prime} \text { and } 19^{\circ} 0^{\prime} \text { East long. }\end{array}\right.$

Containing 180,000 square miles, with 128 inhabitants to each.

Name....Great part of modern Germany lay in ancient Gaul, as has been already mentioned: and the word Germany itself may be considered as modern. Many fanciful derivations have been given of the word ; the most probable is, that it is compounded of Ger or Gar, and Man, which in the ancient Teutonic signifies a warlike man. The Germans were called by various other names, such as Allemanni, Teutones : which last appears to have been their most ancient designation; and the Germans themselves call their country Teutschland.

Boundaries....Germany is bounded on the north by the German Occan, Denmark, and the Baltic ; on the east by Prussia, Gallicia, and Hungary; on the south by the Adriatic sea, Italy, and Switzerland; and on the west by France, from which it is separated by the Rhine, Holland, and the North sea.

Divisions... Germany formerly was divided into the Upper, or Southern, and the Lower, or Northern. The emperor Maximilian, predecessor and grandfather to the emperor Charles V, divided it into ten great circles; and the division was confirmed in the diet of Nuremberg, in 1552 ; but the circle of Burgundy, or the seventeen provinces of the Low Countries, being afterwards detached from the empire, we are to confine ourselves to nine of those divisions as they now subsist.

Of these, three are in the north, three in the middle, and three in the south.

$$
\begin{aligned}
& \text { The northern circles } . ~\left\{\begin{array}{l}
\text { Upper Saxony. } \\
\text { Lower Saxony. } \\
\text { Westphalia. }
\end{array}\right. \\
& \text { The circles in the middle } \cdot\left\{\begin{array}{l}
\text { Upper Rhine. } \\
\text { Lower Rhine. } \\
\text { Franconia. }
\end{array}\right. \\
& \text { The southern circles } \cdot \cdot,\left\{\begin{array}{l}
\text { Swabia. } \\
\text { Bavaria. } \\
\text { Austria. }
\end{array}\right.
\end{aligned}
$$


1. CIRCLE OF UPPLR SAXONY.

Containing 31,200 square miles.

Divisions.

Subdivisions.

Sq. Miles. Population.

Chief Towns,

Pomerania, Prus. Pomerania 7200 sia and Sweden.

Swed. Pomerania 1200

Electorate of
Brandenburg,
subject to its
elector, the king
of Prussia.

Old Mark

Middle Mark

Priegnitz

Ucker Mark<smiles>CCC(C)C</smiles>

New Mark

Electorate of Saxony, subject $j$ to its elector.*

Principality of the house of Saxony, subject< 10 their respective princes.

with part of Altenburg

Saxe Coburg Saalfield Saxe Coburgs Meinungen Saxe Coburg Hildburghaus'n

Principality of Anhalt, subject Anhalt Dessau Anh. Bernburg $54,0,000\{$ Stettin, lat. 53 $32, \mathrm{~N}$. long.

110,000 Stralsund Stendal Berlin, lat. 52
31, N. long. $1,200,000\{1321, \mathrm{E}$. Perleberg: Prentzlow Custria

Dresden, lat. $510, \mathrm{~N}$. lon. 13 50, E. Wittenberg Langensalza Leipsic Leipsic Erzebirge 10,170 Voigtland

Freyberg: 600,000 Plauen Neustadt Merseburg Naumburg Querfurt $106,000\left\{\begin{array}{l}\text { Weimar } \\ \text { Eisenach }\end{array}\right.$ $165,000\{$ Gotha $70,000\left\{\begin{array}{l}\text { Coburg } \\ \text { Sonnenburg } \\ \text { Hildburghaus'n }\end{array}\right.$

800 to its princes.

Principality of Schwarzburg. County of

Stolberg. Anhalt Cothen Schwarzburg $\{$ Sonderhausen Sch. Rudolstadt

721 Stolberg Stolberg

County of Hohenstein, subject? $\left.\begin{array}{l}\text { partly to Prussia, and partly to } \\ \text { the counts of Stolberg }\end{array}\right\}$ 80 192

* The whole of the territories of the elector of Saxony comprehend 11,776 square miles, with $2,100,000$ inhabitants. 


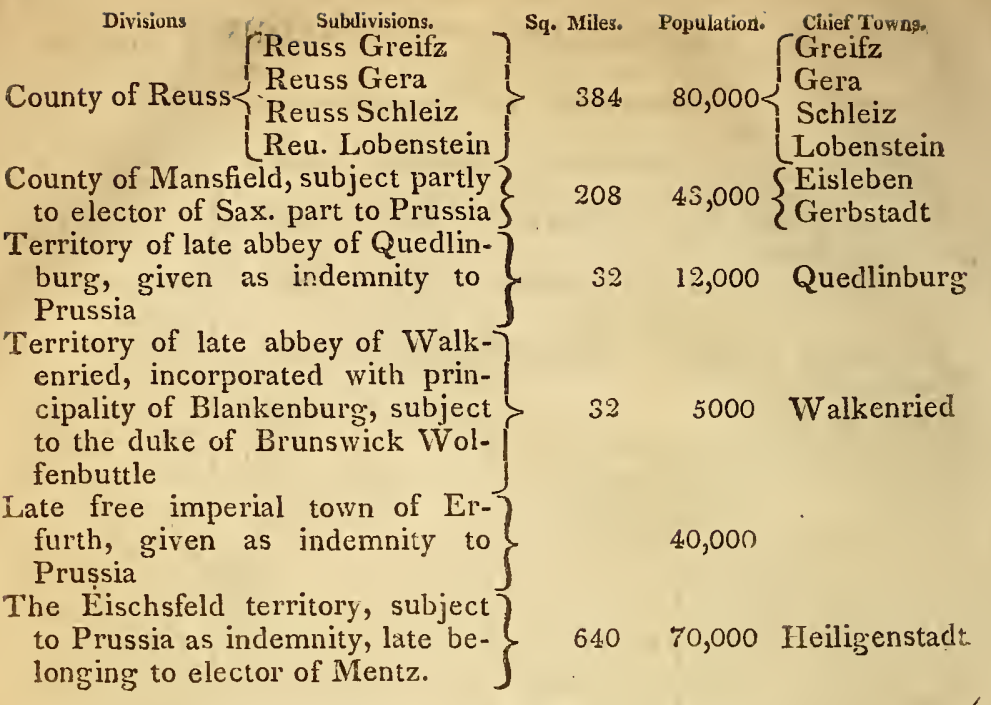

\section{CIRCLE OF LOWER SAXONY.}

Containing 17,600 square miles.

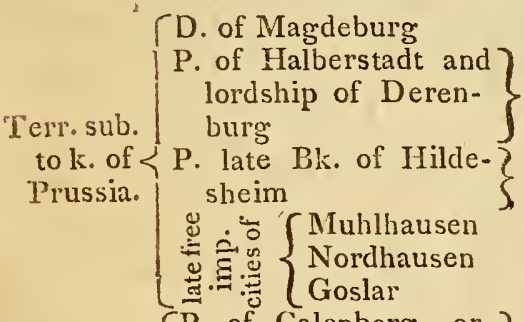

Elect. of

P. of Calenberg, or ? Hanover, P. of Luneburg, or \{ sub.to its Celle. elect. the Duchy of Saxe Lauking of G. enburg, with terBritain. ritory of Hadan.

Duchy of Bremen.

T. of duke of P. of Wolfen-? Brunswick $\left\{\begin{array}{l}\text { buttle. } \\ \text { S }\end{array}\right.$ Wolfenbuttle. (P. of Blankenb.

$\left.\begin{array}{l}\begin{array}{c}\text { Duchy of } \\ \text { Mecklen- } \\ \text { burg. }\end{array} \\ \begin{array}{c}\text { Lordship of } \\ \text { of Sweden. } \\ \text { Schwerin } \\ \text { Meck. Strelitz. }\end{array}\end{array}\right\}$

D. of Holstein, with lordship of Pinneberg and county of Ranzau, sub. to king of Denmark.

T. of d. of Holstein Ol- $\}$ Part of Bk. denburg, as indemn. $\}$ of Lubec. $\}$

\section{290,000 Magdeburs}

$480 \quad 100,000$ Halberstadt

64090,000 Hildesheim

9000

10,000

6000

124.8

$200,000\left\{\begin{array}{l}\text { Hanover } \\ \text { Goettingen }\end{array}\right.$

$230,000\left\{\begin{array}{l}\text { Luneburg } \\ \text { Celle or Zelle }\end{array}\right.$

51270,000 Lauenburg:

1600200,000 Stade

$960190,000\left\{\begin{array}{l}\text { Brunswick- } \\ \text { Wolfenbuttle }\end{array}\right.$

104. 12,000 Blankenburg

$4800400,000\left\{\begin{array}{l}\text { Schwerin } \\ \text { Gustrow }\end{array}\right.$

New Strelitz

$6000 W^{\text {Wismar }}$

2304

$350,000\left\{\begin{array}{l}\text { Kiel } \\ \text { Altona }\end{array}\right.$

16020,000 Eutin 
Divisions.

The flee Imperial Sublivisions.

The free Imperial Hambur's

their territories. $\mathrm{Bremen}$
S, Miles

96

80

64. 50,000

Chief Towns.

\section{CIRCLE OF WESTPHALIA.}

Containing 20,000 square miles.

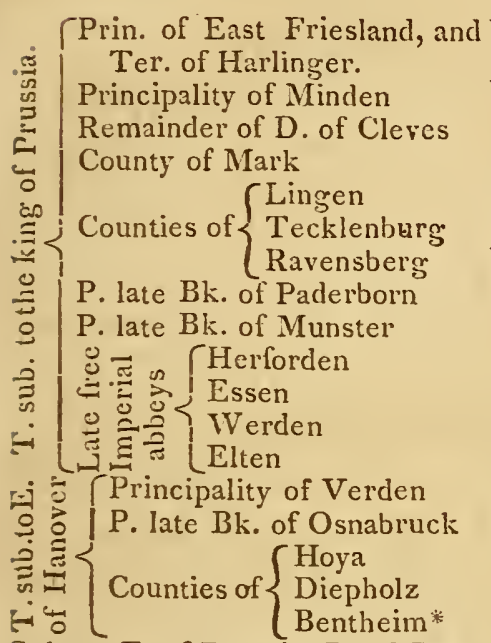

Sub. to its Duchy of Oldenburg? ownduke. $\{$ with indemnity Territ. of P. of Dillenburg house of P. of Nassau Siegen

Orange- P. of Dietz

Nassau, $\{$ P. of Hadamar or Nass. C. of Spielberg Abbey of Corvey

C. of Lippe, sub. \{Lippe Detmold to its counts L.Schauenberg C. of Schauenberg, sub. partly to

Lippe Schauenberg; partly to Hesse Cassel.

C. of Wied. $\left\{\begin{array}{l}\text { Wiedrunkel } \\ \text { Wied Neuwied }\end{array}\right.$

Counties $\left\{\begin{array}{l}\text { Sayn } \\ \text { Pyrmont }\end{array}\right.$

Rietberg, sub. to Hesse-Cassel
Sub. to E. of Bavaria. D. of Berg

Dietz† Town of Dortmund

\begin{tabular}{|c|c|c|}
\hline 864 & 100,000 & Embden \\
\hline 496 & 60,000 & Minden \\
\hline & 55,000 & Wesel \\
\hline 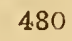 & 124,000 & Hamm \\
\hline 208 & 30,000 & $\left\{\begin{array}{l}\text { Lingen } \\
\text { Teclklenburg }\end{array}\right.$ \\
\hline 72 & 35,000 & Ravenșburg \\
\hline 328 & 120,000 & Paderborn \\
\hline 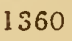 & 200,000 & Munster \\
\hline 32 & 2000 & Herforden \\
\hline 40 & 5500 & Essen \\
\hline 40 & 5000 & Werden \\
\hline 32 & 4.000 & Elten \\
\hline 192 & 30,000 & Verden \\
\hline 896 & 125,000 & Osnabruck \\
\hline 650 & 50,000 & Hoya \\
\hline 128 & 10,000 & Diepholz \\
\hline 342 & 25,000 & Bentheim \\
\hline 040 & 230,000 & Dusseldorf \\
\hline 4 & 135,000 & $\begin{array}{l}\text { Oldenburg } \\
\text { Delmenhorst }\end{array}$ \\
\hline & 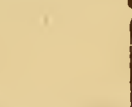 & $\begin{array}{l}\text { Dillenburg } \\
\text { Siegen } \\
\text { Dietz }\end{array}$ \\
\hline 800 & 180,00 & $\begin{array}{l}\text { Hadamar } \\
\text { Coppenbruge } \\
\text { Dortmund }\end{array}$ \\
\hline 60 & 70,000 & $\begin{array}{l}\text { Colvey } \\
\text { Detmold } \\
\text { Blomberg }\end{array}$ \\
\hline 584 & 50,000 & $\begin{array}{l}\text { Rinteln } \\
\text { Stadthagen }\end{array}$ \\
\hline 64 & 26,00 & $\begin{array}{l}\text { Runkel } \\
\text { Neuwied }\end{array}$ \\
\hline & 4.500 & $\begin{array}{l}\text { Altenkirchen } \\
\text { Pyrmont }\end{array}$ \\
\hline$c$ & 10,000 & Rietberg \\
\hline
\end{tabular}

- This country was held in pledge by the elector of Hanover since 1753; but since the seizure of the electorate by the French, the count of Bentheim-Steinfurt has entered into possession.

The whole territory of the house of Orange Nassau, including the late in. demnities, contains about 1600 square miles, with 300,000 inhabitants.

VOL.I. 


\begin{tabular}{|c|c|c|}
\hline $\begin{array}{l}\text { Divisionis. } \\
\text { Sublivisions. } \\
\text { Duke of Arembel'g }\end{array}$ & $\begin{array}{l}\text { s. Miles, } \\
528\end{array}$ & $\begin{array}{l}\text { Populat. } \\
36,000\end{array}$ \\
\hline Duke of Croy & 88 & -9000 \\
\hline Duke of Lors and Corswaren & 48 & 4500 \\
\hline $\begin{array}{l}\text { Prince of Salm Kyburg } \\
\text { Prince of Salm Salm }\end{array}$ & 304 & 27,000 \\
\hline ounties of $\left\{\begin{array}{l}\text { Gehmen } \\
\text { Holzapfel }\end{array}\right.$ & - & \\
\hline
\end{tabular}

\section{CIRCLE OF THE UPPER RHINE。}

Containing 7800 square miles.

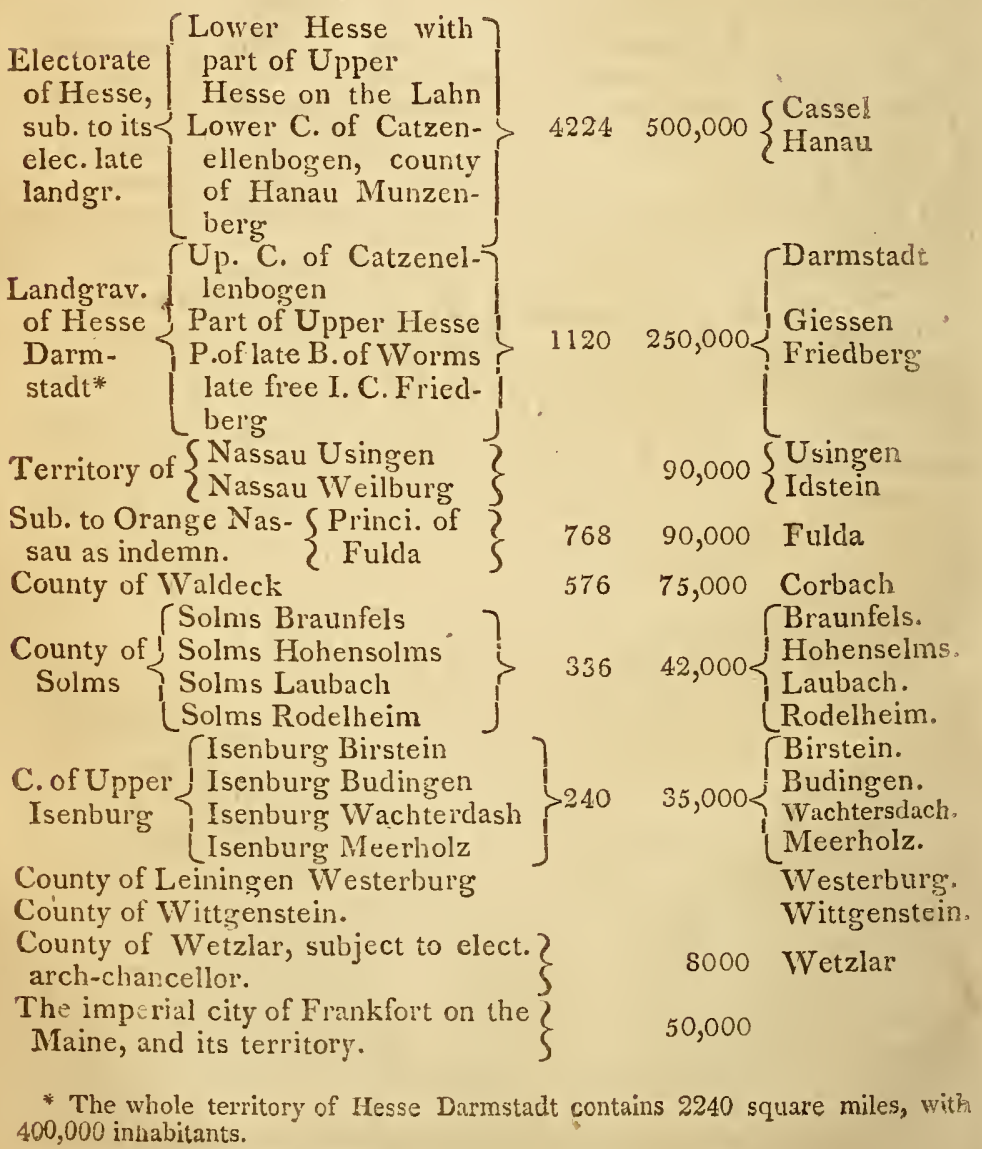




\section{CIRCLE OF THE LOWER RHINE.}

Containing, 6848 square miles.

Divisions. Subdivisions.

Sq. Miles.

Pop.

Chief Towns.

272

45,000 Aschaffenburg.

chancellor* chaffenburg.

T. of elect. [Part of palatinateof the

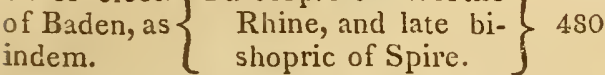

T. of elect. (Duchy of Westphalia 1120

of Hesse, as

Part of elect. of Mentz 208

indem.

Part of palatinat.

56

T. of Nas- $\{$ Part of late clectorates

sau Usingen

as indem.

of Mentz and Co- $\} 540$

T. of Nas-

logne.

10,000 Lindenfels. $\left.\begin{array}{l}\text { sau Weil- } \begin{array}{l}\text { Part of late electorate } \\ \text { of Treves. }\end{array} \\ \text { of }\end{array}\right\}$

240

$100,000\left\{\begin{array}{l}\text { Rudesheim. } \\ \text { Linz. }\end{array}\right.$

Heidelberg.

130,000 Manheim.

Philipsburg.

100,000 Brilon.

37,000 Gernsheim.

burg, as

36,000 Ehrenbreitstein

indem.

T. of C. of $\{$ Part of the late electo- $\}$

as indem.

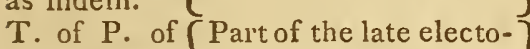

Wiedrun- $\{$ rates of Cologne and

kel as indem

Treves.

T. of P. of $\}$

Salm Rei-

ferscheid

Part of the electorate

Bedburg, as

indem.

T. of duke (County of Recklingsof Arem. $\{$ hausen, part of the

berg, as

indem.

$\left\{\begin{array}{l}\text { late electorate of } \\ \text { Cologne. }\end{array}\right.$

336

$40,000\left\{\begin{array}{l}\text { Amorbach. } \\ \text { Bischoffsheim } \\ \text { Mosbach. }\end{array}\right.$

6200 Altenwied

T. of P. of )

Nassau

Orange, as

Lordship of Bielstein

\section{Krautheim}

indem.

Divided be--

tween Nas-

sau, WVeil- County of I.ower Isen-

burg, and

IViedrun-

kel.

burs.

Isenburg

Bielstein

* The elector arch-chancellor likewise possesses the principality of Ratisbon, the county of Wetzler, and the abbey of Compostella at Frankfort. His whole territory contains 480 square miles, and 100,000 inhabitants. 


\section{CIRCLE OF FRANCONIA.}

Containing 7880 square miles.

\begin{tabular}{|c|c|c|}
\hline Divisions. & Subd & ivisions. \\
\hline & Cul & nbach \\
\hline the king 0 & Prin. $c$ & f Anspach o \\
\hline Prussia & & 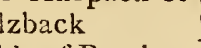 \\
\hline & P.late & bk. of Bam \\
\hline & $\begin{array}{l}\text { P. late } \\
\text { burs }\end{array}$ & bk. of Wurz \\
\hline Territ. of & $\dot{\overrightarrow{0}} \dot{0}$ & Rothenburg \\
\hline elector o & & Schweinfurt \\
\hline Bavaria & $\ddot{D}$ & Weissenburg \\
\hline & & Windsheim \\
\hline & 吾 & $\begin{array}{l}\text { Gochsheir } \\
\text { Sennfeld }\end{array}$ \\
\hline
\end{tabular}

Sq. Miles, Pop.

Chief Towns.

1200 220,000 Bayreuth

1120275,000 Anspach

1056200,000 Bamberg

1392240,000 Wurzburg

9624,000 Rothenburg

166000 Schweinfurt

166000 Weissenburg

4500 Windsheim

Gochsheim

Sennfe!d

Sub. partly

to E. of

Salzburg, Prin. late bishopric and part $\}$ of Eichstadt, or to E. of Aichstadt

70,000 Aichstadt

Bavaria

T. of Teu-

tonicorder $\}$ Dist. of Mergentheim

Sub. to E.

and other

branclies

of the $\mathrm{H}$.

County of Henneberg

of Saxony J

(Hohenlohe Oeringen $\mathrm{Neu}$ -

$\left\{\begin{array}{l}\text { enstein } \\ \text { Hohenlohe Langenburg } \\ \text { Hohenlohe Ingelfingen } \\ \text { Hohenlohe Kirchberg } \\ \text { Hohenlohe Bartenstein } \\ \text { Hohenlohe Schillingsfurst }\end{array}\right\}$

County of Wertheim

County of Schwarzenberg

County of Castell

County of Erbach

County of Limpurg

County of Wiesentheid

County of Rieneck

Free imperial city of Nuremberg

and territory

80 12,000 Mergentheim

$640 \quad 100,000\left\{\begin{array}{l}\text { Schleusingen } \\ \text { Meiningen }\end{array}\right.$

416100,000 Ingelfingen

Kirchberg

Bartenstein

Schillingsfur.

Wertheim

224. 25,000 Schwarzenb.

Castell

240 25,000 Erbach

11216,000 Gaildorf

Wiesentheid Rieneck

38650,000 Nuremberg

7. CIRCLE OF SWABIA.

Containing 11,200 square miles.

Electo, of
Wurtem- $\left\{\begin{array}{l}\text { D. of Wurtemberg } \\ \text { berg }\end{array} \begin{array}{c}\text { New territ. given } \\ \text { as indemn. }\end{array}\right\} \begin{array}{llll}608 & 140,000\end{array}\left\{\begin{array}{l}\text { Ellwangen. } \\ \text { Heilbron. } \\ \text { Rottweil.v }\end{array}\right.$




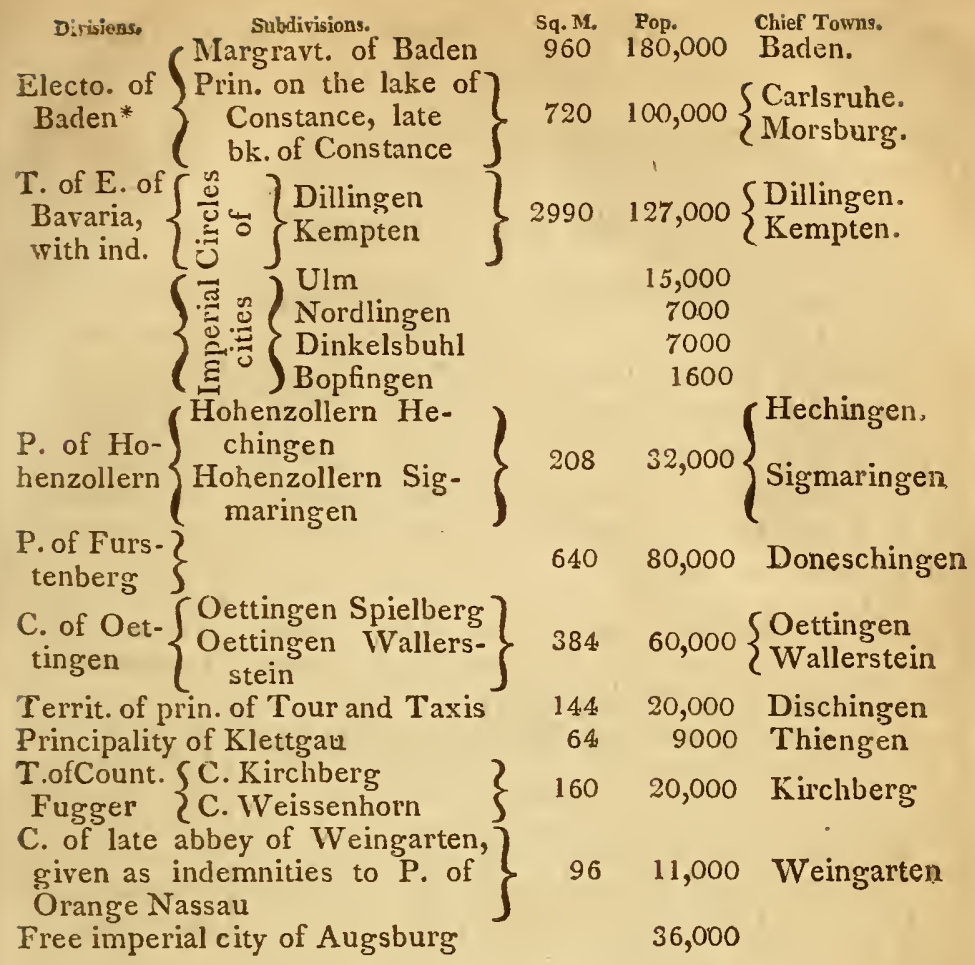

This circle likewise contains several other small baronies and secularized abbeys with their territories, given as indemnities to different princes.

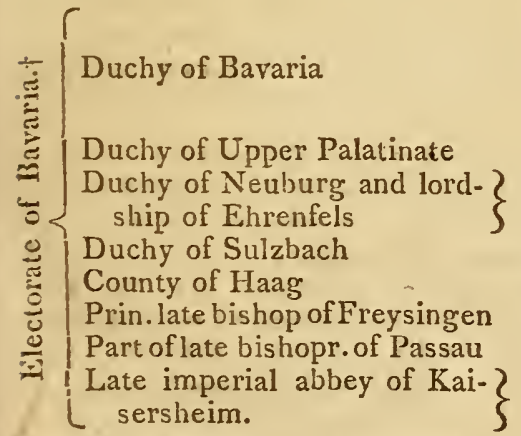

Prin. of Ratisbon, indemnity to clector arch-chancellor.

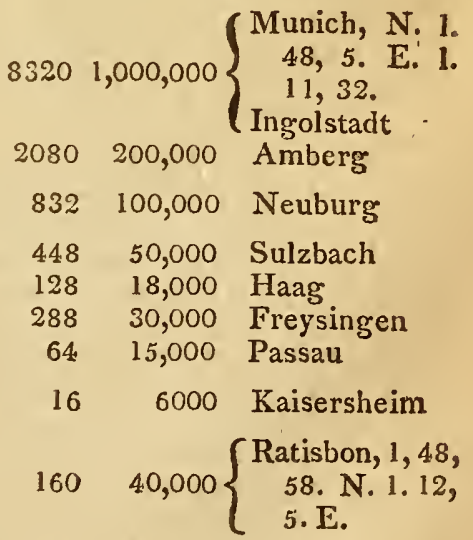

- The whole territory of the electorate of Baden, including the country in the circle of the Lower Rhine, is estimated to contain 2080 square miles, with 420,000 inliabitants.

$t$ The whole territory of the elector of Bavaria, including his possessions in Swabia, Franconia, and Westphalia, contains 18,912 square miles, with 2,517,000 inhabitante. 
Divisions, Subdivisions. Sq. Miles。 Pop. Chief Torms,

County of Ortenburg, subject to its own count

3000 Ortenbug

County of Sternstein, territory of \{

P. Labkowitz.

Neustadt

\section{CIRCLE OF AUSTRIA.}

Containing 44,528 square miles.

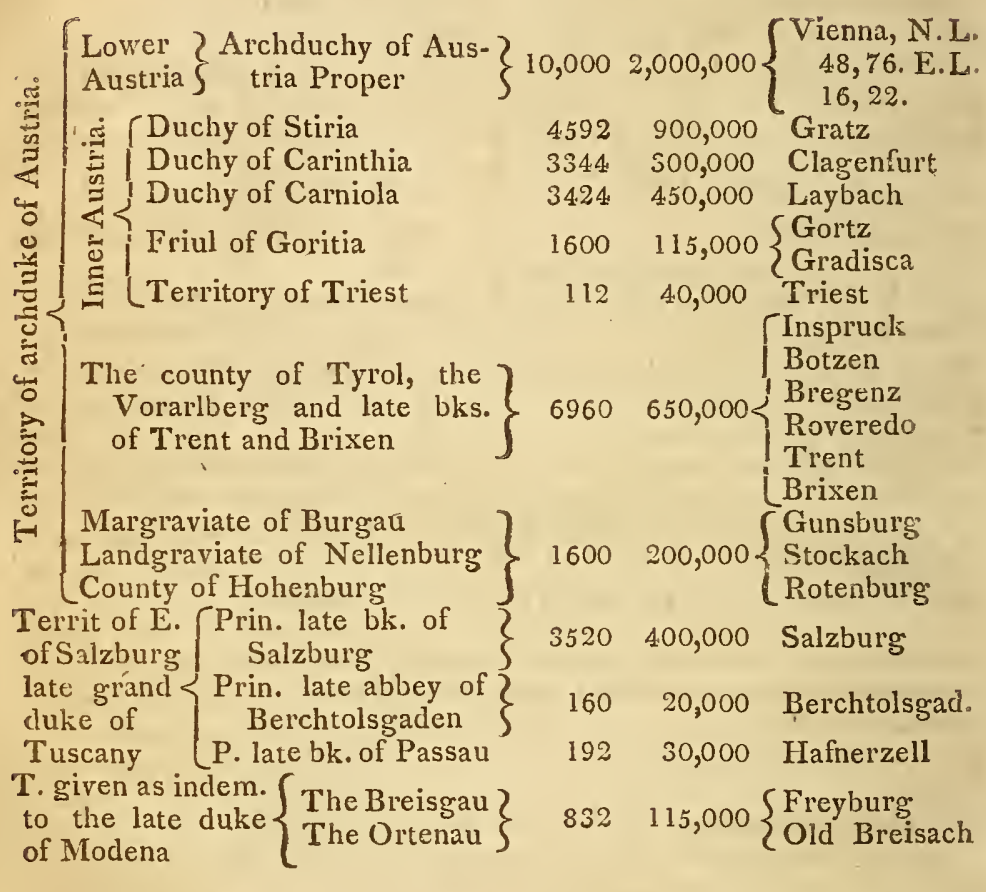

Face of THE country....The southern part of Germany is mountainous and hilly ; the northern presents wide sandy plains, with scarcely the appearance of a hill. On the eastern side are the most extended plains, and the greatest chains of mountains.

Mountains....The chief mountains of Germany are the Alps, which divide it from Italy, and those which separate Saxony, Bavaria, and Moravia, from Bohemia, called the Erzgebirge and the Sudettes. In the north are the mountains of the Harz which extend about fifty miles through part of Lower and Upper Saxony. Many other large tracts of mountains are found in different parts of the empire.

Forests....The great passion which the Germans have for hunting the wild boar is the reason why, perhaps, there are more woods and chases yet standing in Germany than in many other countries. The Hercynian forest, which in Cæsar's time was nine days journey in length, and six in breadth, is now cut down in many places, or parcelled out into woods, which go by particular names. Most of the woods are pine, fir, oak, and beech. There is a vast number of forests of less note in every part of this country; almost every count, 
baron, or gertleman, having a chase or park, adorned with pleasurehouses, and weli-stocked with game, viz. deer, of which there are seren or eight sorts, as roebucks, stags, \&c. of all sizes and colours, and many of a vast growth; plenty of hares, coneys, foxes, and boars. They abound so much also with wild fowl, that in many places the peasants have them, as well as venison, for their ordinary food.

LAKES.... The chief lakes of Germany, not to montion many inferior ones, are those of Constance (called the Boden-see) and Bregentz. Besides these, are the Chiem-see, or the lake of Bavaria; and the Zirnitzer-see, in the duchy of Carniola, whose waters often run off, and return agrain, in an extraordinary manner.

RiverS AND LAEES.... No country can boast a greater variety of noble large rivers than Germany. At their head stands the Danube or Donau, so called from the swiftness of the current, and the course of which, without reckoning its windings, is computed to be 1620 miles. The other principal rivers are the Rhine, the length of the course of which is above 600 miles, the Elbe, Oder, Weser, and Necher.

Mineral waters and Baths....Germany is said to contain more of these than all Europe besicles. The Spa waters, and those of Seitzer and Pyrmont, are well known. Those of Aix-la-Chapelle are still more noted. They are divided into the Emperor's Bath, and the Little Bath; and the springs of both arc so hot, that they let them cool ten or twelve hours before they use them. The baths and medicinal waters of Embs, WVisbaden, Schwalbach, and Wildungen, arc reported to be extremely efficacious in almost all diseases. The mineral springs at the last mentioned place are said to intoxicate as soon as wine, and therefore they are inclosed. Carlsbad and Baden baths have been described and recommended by many great physicians, and uscd with grcat success by many royal personages. It is, however, not improbable, that great part of the salutary virtues ascribed to these waters is owing to the exercises and amusements of the patients, and numbers of the company which crowd to them from all parts of the world ; many of whom do not repair thither for health, but for amusement and conversation.

Mietals and MrNerals....Germany abounds in both. Many places in the circlc of Austria, and other parts of Germany, contain mines of silver, quicksilver, copper, tin, iron, lead, sulphur, nitre, and vitriol. Saltpetre, salt mines, and salt pits, are found in Austria, Bavaria, Silesia, and the Lower Saxony ; as are carbuncles, amethysts, jasper, sapphire, agate, alabastcr, several sorts of pearl, turquois stones, and the finest of rubies, which adorn the cabinets of the greatcst princes and virtuosi. In Bavaria and Tyrol, are quarries of curious marble, slate, chalk, ochre, red lcad, alum, and bitumen; besides other fossils. Several of the $G \in$ rman circles furnish coal-pits : and the terra sigillata of Mentz, with whitc, yellow, and red vcins, has been pretended to be an antidote against poison.

Climate, soil, Agriculture... The climate of Gcrmany, as in all extensive countries, differs greatly, not only on account of the situation to the north, or south, or east, or west, but according to the insprovement of the soil, which has a great effect on the climate. The most mild and settled weather is found in the middle of the country, at an equal distance from the sea and the Alps. In the rorth it is sharp; towarls the south it is more temperate. The seasons vary as mucli as the soil : in the south and western parts they are 
more regular than in those that lie near the sca, or that abound in lakes and rivers.

The soil of Germany is not improved to the full by culture ; and therefore in many places it is bare and steril; though in others it is extremely fertile. A greater attention, however, is now given to agriculture in this country, and many improvements have been made of late years.

VEGETABLES....Among the vegetable productions of Germany are all kinds of grain, flax, hemp, hops, saffron, tobacco, and excellent orchard fruits. The vine is found to flourish throughout more than the half of Germany, but the most esteemed wines are produced in the circles of Swabia and the Rhine. The wines of these countries are commonly called Rhenish and Moselle, and differ from those of other countries in a peculiar lightness, and detersive qualities, more sovereign in some diseases than any medicine.

Antmals....Germany yields abundance of excellent heavy horses : but their horses, oxen, and sheep, are not comparable to those of England, probably owing to want of skill in feeding and rearing them.

The German wild boars differ in colour from our common hogs, and are four times as large. Their flesh, and the hams made of it, are preferred by many even to those of Westmoreland, for flavour and grain. The glutton of Germany is said to be the most voracious of all animals. Its prey is almost every thing that has life, which it can manage, especially birds, hares, rabbits, goats, and fawns; which it surprises artfully and devours greedily. On these the glutton feeds so ravenously, that it falls into a kind of a torpid state, and not being able to move, he is killed by the huntsmen; but though both boars and wolves will kill him in that condition, they will not eat him. His colour is a beautifui brown, with a faint tinge of red.

Some parts of Germany are remarkable for fine larks and great variety of singing birds, which are sent to all parts of Europe.

Curiosities, NATURAL AND ARTIFICIAl....In describing the mineral and other springs, a great part of this article, which is very copious, has been already anticipated.

Next to the lakes and waters, the caves and rocks are the chief natural curiosities of Germany. There is said to be a cave, near Blackenburg, in Hartz-forest, of which no person has yet found the end, though many have advanced into it for twenty miles. But the most remarkable curiosity of that kind is near Hamelen, about thirty miles from Hanover, where, at the mouth of a cave, stands a monument which commemorates the loss of 130 children, who were there swallowed up in 1284. This fact, however, though it is very strongly attested, has been disputed by some critics. Frequent mention is made of two rocks near Blackenburg, exactly representing two monks in their proper habits; and of many stones which seem to be petrifac. tions of fishes, frogs, trees, and leaves.

With respect to artificial curiosities, the Germans have always accounted as orie of the principal, the tun at Heidelberg, which holds 800 hogsheads, and, though now empty, was formerly full of the best Rhenish wine, from which strangers were seldom suffered to retire sober. Every cour't of Germany produces a cabinet of curiosiLies, artificial and natural, ancient and modern.

Vienna itself is a curiosity; for here may be seen the greatest variety of inhabitants to be met with any where, as Greeks, Transylvanians, Sclavonians, Turks, Tartars, Hungarians, Croats, Ge'- 
mans, Poles, Spaniards, French, and Italians, in their proper habits. The imperial liurary at Vienna is a great literary rarity, on account of its ancient manuscripts. It contains upwards of 80,000 volumes, among which are many valuable manuscripts in Hebrew, Syriac, Arabic, Turkish, Armenian, Coptic, and Chinese; but the antiquity of some of them is questionable, particularly a New Testament in Greek, said to have been written 1500 years ago, in gold letters, upon purple. Here are likewise many thousand Greek, Roman, and Gothic coins and medals; with a vast collection of other curiosities of art and nature.

Population....The population of the German empire, is estimated at between 26 and 27 millions. The particular population of most of the different states of the empire has already been given in the Table of the Circles.

National character, manners, customs....The Germans in their persons are tall, fair, and strong built. The ladies have generally fine complexions; and some of them, especially in Saxony, have all the delicacy of features and shape that are so bewitching in some other countries.

Both men and women affect rich dresses, which in fashion are the same as in France and England : but the better sort of men are excese sively fond of gold and silver lace, especially if they are in the army. The ladies at the principal courts differ not much in their dress from the French and English, and at Vienna are said to be as fond of paint as the former. At some courts they appear in rich furs; and all of them are loaded with jewels, if they can obtain them. 'The female part of the burghers' families, in many. of the German towns, dress in a very different manner, and some of them inconceivably fantastic ; but in this respect they are gradually reforming, and many of them. make quite a different appearance in their dress from what they did thirty or forty years ago. As to the peasantry and labourers, they dress, as in other parts of Europe, according to their employments, converience, and circumstances. The stoves made use of in Germany are the same with those already mentioned in our account of other northern nations, and are sometimes made portable, so that the. ladies carry them to church. In Westphalia, and many other parts of Germany, they sleep between two feather-beds, with sheets stitched to them, which, by use, becomes a very comfortable practice. The most unhappy part of the Germans are the tenants of little needy princes, who oppress them to keep up their own grandeur; but, in general, the circumstances of the common people are more comfortable than those of their neighbours.

The Germans are naturally a frank, honest, hospitable people, free from artifice and disguise. The higher orders are ridiculously proud of titles, ancestry, and show. The Germans in general are thought to want animation, as their persons promise more vigour and activity than they commonly exert, even in the field of battle. But when commanded by able crenerals, they have achieved great things both against the Turks and the French ; and in the late war the Austrians exhibited prodigies of military valour and genius.

Industry, application, and perseverance, are the great characteristics of the German nation, especially the mechanical part of it. Their works of art would be incredible, were they not well known; especially in watch and clock making, jewellery, turnery, sculpture, drawing, painting, and certain kinds of architecture. The Germans have been

VOL. I.

$3 \mathrm{~K}$ 
charged with intemperance in eating and drinking, and perhaps not unjustly, in consequence of the vast plenty of their country in wine and provisions of every kind; but such excesses are now less common. At the greatest tables, though the guests drink pretty fieely at dinner, yet the repast is commonly finished by coffee, after three or four public toasts have been given. But no people have more feasting at marriages, funerals, and on birth-days.

The German nobility are generally men of so much honour, that a sharper, in other countries, especially in England, frequently succeeds better by assuming the character of a German, than in any other way. All the sons of noblemen inherit their fathers' titles; which greatly perplexes the heralds and genealogists of that country. The German husbands are not quite so complaisant as those of some other countries to their ladies, who are not entitled to any pre-eminence at the table; nor indeed do they seem to affect it, being far from either ambition or loquacity, though they are said to be somewhat too fond of gaming. Many of the German nobility, having no other hereditary estate than a high-sounding title, easily enter into their armies, and those of other sovcreigns. Their fondness for title is attended with many other inconveniences; their gentlemen of property think the cultivation of their lands, though it might treble their revenue, below their attention, and that they should degrade themselves by being concerned in the improvement of their grounds.

The domestic diversions of the Germans are the same as in England; billiards, cards, dice, fencing, dancing, and the like. In summer, people of fashion repair to places of public resort, and drink the waters. As to their field diversions, besides their favourite one of hunting, they have bull and bear baiting, and the like. The inhabitants of Vienna live luxuriously, a great part of their time being spent in feasting and carousing; and in winter, when the several branches of the Danube are frozen over, and the ground covered with snow, the ladies taken their recreation in sleclges of different shapes, such as griffins, tigers, swans, scallop-shells, \&xc. Here the lady sits, dressed in velvet lined with rich furs, and adorned with laces and jewels, having on her head a velvet cap; and the sledge is drawn by one horse, stag, or other creature, set off with plumes of feathers, ribbands, and bells. As this diversion is taken chiefly in the nighttime, servants ride before the sledges with torches; and a gentleman, standing on the sledge behind, guides the horse.

Cities, chlef towns, rorts, And adfices. This is a copious head in all countries, but more particularly so in Germany, on account of the numerous independent states it contains.

Vienna is the capital of the circle of Austria, and being the residence of the emperor, is generally considered as the capital of Germany. It is a noble and a strong city, and the princes of the house of Austria have omitted nothing that could contribute to its grandeur and riches. Vienna contains an excellent university, a bank, which is in the manacement of its own magistrates, and a court of commerce, immediately subject to the aulic council. Its religious buildings, with the walks and gardens, occupy a sixth part of the town; but the suburbs are larger than the city. It would be endless to enumerate the many palaces of this capital, two of which are imperial ; its squares, academies, libraries ; and the imperial cabinets of curiosities. Among its rich convents, is one of the Scotch nation, built in honour of their countryman St. Colman, the patron of Austria; 
and one of the six gates of this city is called the Scots" gate, in remembrance of some notable expioit performed there by the troops of that nation. The inhabitants of Vienna, including the suburbs, amounted in the year 1812 to 250,000 : and the encouragement given by the sovereign has rendered this city the rendezvous of foreigners.

The streets, except those in the suburbs, are narrow and dirty. The houses of this city are generally of sione, five or six stories high, and flat roofed. They have three or four cellars under one another, with an open space in the middle of each arched roof, for the communication of air; and from the lowermost of all there is a tube to the top, to let in air from the streets. The winds often blow so strong, that it is troublesome to walk the streets. A remarkable prerogative of the sovereign here is, that the second floor of every house belongs to him, and is assigned to whomsoever he thinks proper: and hence there is no part of Germany where lodging is so dear as at Vienna. An odd custom prevails here of putting iron bars to all the windows, up to the rery tops of the houses; which makes them all look like so many prisons. The houses and furniture of the citizens are greatly disproportioned to the magnificence of the palaces, squares, and other public buildings; but the excessive imposts laid by the house of Austria upon every commodity in its dominions, must always keep the manufacturing part of its subjects poor.

Berlin, the capital of the electorate of Brandenburg, and of the dominions of the king of Prussia, is situate on the river Spree, and, besides the royal palace, has many other superb edifices; it contains fourteen I.utheran and eleven Calvinist churches, besides a Catholic one. Its streets and squares are spacious, and built in a very regular manner; but the houses, though neat without, are ill finished, and ill furnished within, and very indifferently provided with inhabitants. The king's palace here, and that of prince Henry, are very magnificent buildings. The opera house is also a beautiful structure : and the arsenal, which is handsomely built, in the form of a square, contains arms for 200,000 men. There are sundry manufactures in Berlin, and several schools, libraries, and charitable foundations. The number of its inhabitants, according to Busching, in 1755, was 126,661, including the garrison. In the same year, and according to the same author, there were no fewer than 443 silk looms, 14.9 of half silks, 2858 for woollen stuffs, 4.53 for cotton, 248 for linen, 454 for lace-work, 39 frames for silk stockings, and 310 for worsted ones. In the year 1804 , the number of inhabitants was 156,664 , exclusive of the soldiers of the garrison, and their wives and children. They have here manufactures of tapestry, gold and silver lace, and mirrors.

Dresden, the capital of the elector of Saxony, is remarkable for its fortifications, palaces, public buildings, churches, and charitable foundations; it is beautifully situated on both sides of the Elbe, and is the school of Germony for statuary, painting, enamelling and carving; not to mention its mirrors, and founderies for bells and cannon, and its foreign commerce carried on by means of the Elbe. The inhabitants of Dresden, by the latest accounts, are computed to amount to about 60,000 .

The electorate of Saxony is by nature the richest country in Germany, if not in Europe ; it contains 210 walled towns, 61 market towns, and about 3000 villages, according to the latest accounts of the Ger: mans themselves (to which, however, we are not to give an implicit 
belief;) and the revenue, amounts to $\$ 5,000,000$. This sum is so moderate, when compared to the richness of the soil and the variety of splendid manufactures, that the Saxon princes appear to have been the most moderate and patriotic of any in Germany.

The city of Leipsic in Upper Saxony, 46 miles distant from Dresden, is situated in a pleasant and fertile plain on the Pleisse, and the inhabitants are said to amount to about 50,000. There are also large and well built suburbs, with handsome gardens. Between these suburbs and the town is a fine walk of lime trees, which was laid out in the year 1702, and encompasses the city. Mulberry-trees are also planted in the town-ditches: but the fortifications seem rather calculated for the use of the inhabitants to walk on, than for defence. The streets are clean, commodious, and agreeable, and are lighted in the night with seven hundred laimps. They reckon 436 merchant houses, and 192 manufactories of different articles, as brocades, paper, cards, \&c. Leipsic has long been distinguished, for the liberty of conscience allowed here to persons of different sentiments in religion. Here is a university, which is still very considerable; with eight churches for the Lutherans (theirs being the established religion) one for the Calvinists, and a chapel in the castle for those of the Romish church. The university library consists of about 26,000 volumes, 6000 of which are folios. Here is also a library for the magistrates, which consists of about 36,000 volumes and near 2000 manuscripts, and contains' cabinets of urns, antiques, and medals, with many curiosities of art and nature. The exchange is an elegant building. Three annual fairs are held here; which are particularly famous for the number of literary productions, brought to them from all parts of Germany.

The city of Hanover, the capital of that electorate, stands on the river Leine, and is a neat, thriving, and agreeable city. It contains about twelve hundred houses, among which there is an electoral palace. It carries on some manufactures; and in its neighbourhood are the palace and elegant gardens of Herenhausen. The dominions of the electorate of Hanover contain about seven hundred and fifty thousand people, who live in fifty-eight cities, and sixty markettowns, besides villages. The city and suburbs of Bremen, which duchy belongs, by purchase, to the said elector, contain about fifty thousand inhabitants, who have a considerable trade by the Weser. The other towns belonging to this electorate have trade and manufactures : but, in general, it must be remarked, that the electorate has suffered greatly by the accession of the Hanover family to the crown of Great Britain. The secularised bishopric of Osnaburg, lies between the rivers WVeser and Ems. The chief city, Osnaburg, has been long famous all over Europe for the manufacture known by the name of the duchy, and for the manufacture of the best Westphalia hamis. The whole revenue of the bishopric amounted to about $50,000 l$.

Munich, the capital of the electorate of Bavaria, is a very populous and beautiful city, situate on the Iser. The houses are high, and the streets spacious, with canals in several of them. It is esteemed the most elegant city in Germany, and contains about 2300 houses, and 48,740 inhabitants. 'The electoral palace is a very sumptuous edifice; besides which there are two other electoral palaces at a little distance from the city; that of Nymphenburg, admired for its gardens, and that of Schlesheim.

Ratisbon, or Regensburg, where the diet of the empire assembles, 
is of considerable size, but of a dark and dull appearance, and contains 22,000 inhabitants. It is remarkable for an ancient bridge of fifteen arches over the Danube, in length 350 yards. It was lately a free imperial city, but is now the capital of the principality of Ratis. bon, part of the territory of the new elector arch-chancellor.

Augsburg is still a free imperial city, and the largest and most ancient in Swabia. It is situate between the rivers Lech and Wertach, which unite in its environs, and flow to the Danube. It was once a place of considerable trade, and is said to be nine miles in circuit : at present it coritains only about 36,000 inhabitants.

Frankfort on the Maine, so called to distinguish it from another of the same name on the Oder, is situated in a healthy, fertile, and delightful country on the river just mentioned, by which it is divided in to two parts, distinguislied by the names of Frankfort and Saxenhausen. The former of these, being the largest, is divided into twelve wards, and the latter into two; and both are computed to contain about three thousand houses. The fortifications; which are both regular and solid, form a decagon, or figure consisting of ten bastions, faced with hewn stone; the ditches are deep, and filled with fresh water; and all the out-works are placed before the gates. Frankfort is the usual place of the election and coronation of the kings of the Romans, and is also a free and imperial city. It is of a circular form, without any suburbs; but the streets are generally narrow, and the houses are mostly built of timber and plaister, and covered with slate; though there are some handsome private structures, of a kind of red marble, that deserve the name of palaces; as the buildings called the Compestel and Fronhof, the Triershof, the Cullenhof, the German-house, an august edifice, situated near the bridge over the Maine, the Hesse Darmstadthof, the palace of the prince de la Tour, and the houses of the counts of Solms, Schauenburg, and Schonborn. There are likewise three principal squares.

The imperial city of Hamburg is situate on the Elbe at the conflux of the rivers Alster and Bille. The houses are in general high; the streets irregular and narrow. There are many canals which run through the city, and there are 84 bridges over them. The fortifications are strong, in the old Dutch style, with great ditches, and walls of such thickness, that several carriages can drive abreast on the ramparts, which are planted with rows of trees. Though the city is nearly 70 miles from the sea, the Elbe is here between four and five miles broad. Hamburg contains above 120,000 inlabitants. It has long been the most commercial city in Germany.

CoMARERE AND MANUFACTUREs...Germany has vast advantages in point of commerce, from its situation in the heart of Europe, and being intersected, as it were, with great rivers. Its native materials for commerce, besides mines and minerals, are hemp, hops, flax, anise, cumin, tobacco, saffron, madder, truffles, variety of excellent roots and potherbs, and fine fruits, equal to those of France and Italy. (iermany cxports to other countries, corn, tobacco, horses, lean, catflle, butter, cheese, honey, wax, wines, linen and woollen yarn, ribbands, silk and cotton stuffs, toys, turnery wares in wood, metals, and ivory, goat-skins, wool, timber both for ship building and houses, cannon and bullets, hombs and bomb shells, iron plates and stoves, tinned plates, steel work, copper, brass wire, porcelain, the finest upon Earth, earthen ware, glasses, mirrors, hogs' bristles, mum, beer, tartar, smalt, zaffer, Prussian blue, printers' ink, and many other articles. 
The revocation of the edict of Nantes, by Lewis XIV, which obliged the French protestants to settle in different parts of Europe, was of infinite service to the German manufactures. They now make velvets, silks, stuffs of all kinds, fine and coarse linen and thread, and every thing necessary for wear, in great perfection. The porcelain of Meissen, in the electorate of Saxony, and its paintings, have been long in great repute.

Constitution, GOVERnMENT, AND LAWS....Almost every prince in Germany (and there are nearly 500 of them) is arbitrary with regard to the government of his own estates; but the whole of them form a great confederacy, governed by political laws, at the head of which is the emperor, whose power in the collective body, or the diet, is not directorial, but executive : but even that gives him vast influence. The supreme power in Germany is the diet, which is composed of the emperor, or, in his absence, of his commissary, and of the three colleges of the empire. The first of these is the electoral college; the second is the college of princes; and the third, the college of imperial towns.

The empire was hereditary under the race of Charlemagne, but after that, became elective ; and in the beginning, all the princes, nobility, and deputies of cities, enjoyed the privilege of voting. In the reign of Henry $V$, the chief officers of the empire altered the mode of election in their own favour. In the year 1239, the number of electors was reduced to seven. One elector was added in 1649, and another in 1792. In consequence of the late secularisations, and other alterations made in the constitution of the empire, under the influence of France and Russia, they are now ten in number, viz. one ecclesiastical and nine secular electors.

The dignity of the empire, though elective, has for some centuries belonged to the house of Austria, as being the most powerful of the German princes; but, by French management, upon the death of Charles VI, grandfather, by the mother's side, to the emperor Joseph II, the elector of Bavaria was chosen to that dignity, and died, as it is supposed, heart-broken, after a short uncomfortable reign. The power of the emperor is regulated by the capitulation he signs at his election; and the person, who in his life time is chosen king of the Romans, succeeds, without a new election, to the empire. He can confer titles and enfranchisements upon cities and towns; but as emperor, he can levy no taxes, nor make war or peace, without the consent of the diet. When that consent is obtained, every prince must contribute his quota of men and money, as valued in the matriculation roll, though, perhaps, as an elector or prince, he may espouse a different side from that of the diet. This forms the intricacy of the German constitution; for George II, of England, as elector of Hanover, was obliged to furnish his quota against the house of Austria, and also against the king of Prussia, while he was fighting for them both. The emperor claims a precedency for his ambassadors in all Christian courts.

The ten electors of the empire, who have the sole election of the emperor, are in order as follow :

The elector of Ratisbon (or Aschaffenburg) arch-chancellor of the empire.

The elector and king of Bohemia (the present emperor) who is grand cup-bearer: 
The elector of Bavaria, who is grand sewer, or officer who serves out the feasts.

The elector of Saxony, who is great marshal of the empire.

The elector of Brandenburg (king of Prussia) who is arch-cham. berlain.

The elector of Brunswick-Lunenburg (Hanover; the king of Great Britain) who is arch-treasurer.

The elector of Salzburg (late grand duke of Tuscany.)

The elector of Wurtemberg, who is arch-pantler.

The elector of Baden.

The elector of Hesse.

It is necessary for the emperor, before he calls a diet, to have the advice of those members: and during the vacancy of the imperial throne the electors of Saxony and Bavaria have jurisdictions, the for mer over the northern, and the latter over the southern circles.

The diet is composed of the electoral college, the college of princes, and the college of imperial torwns.

The electoral college consists of the ten electors above enumerated, each of whom has a personal vote, termed by the German lawyers votam virile. The college of princes is divided into two classes; the proper princes of the empire, as dukes, margravines, landgraves, princes and princely counts, who have each a personal vote, and the counts and lords of the empire, who are arranged in four colleges or benches, viz. the Wetteravian, Swabian, Franconian, and Westphalian, each of which has but one vote, styled voinm curiatum. In this college Austria and Salzburg have the directory by turns. The college of imperial cities consists of deputies from the Hans towns, Hamburg, Bremen, and Lubeck, and the imperial cities Frankfort on the Maine, Nuremberg, and Augsburg. The imperial cities are free republics under no particular sovereign, but immediately under the emperor and the empire.

The imperial chamber, and that of Vienna, which is better known by the name of the Aulic council, are the two supreme courts for determining the great causes of the empire, arising between its respective members. The imperial council consists of fifty judges or assessors. The president, and four of them, are appointed by the emperor, and each of the electors chooses one, and the other princes and states the rest. This court is at present held at Wetzler, but formerly resided at Spire : and causes may be brought before it by appeal. The Aulic council was originally only a revenue court of the dominions of the houses of Austria. As that family's power increased, the jurisdiction of the Aulic council was extended upon the powers of the imperial chamber, and even of the diet. It consists of a president, a vice-chancellor, a vice-president, and a certain number of Aulic counsellors, of whom six are protestants, besides other officers; but the emperor, in fact, is master of the court. These courts follow the ancient laws of the empire for their guides, the golden bull, the pacification of Passau, and the civil law.

Besides these courts of justice, each of the nine circles has a director to take care of the peace and order of the circle. This director is in general one of the most powerful princes of the circle.

In case of great public offences, after the votes of the diet are collected, and sentence pronounced, the emperor, by his prerogative, commits the execution of it ta a particular prince or princess, whose 
troops live at free quarter upon the estates of the delinquent, and he is obliged to make good all expences.

Every state which acts directly or indirectly against the fundamental laws of the empire, is subject to the punishment of the ban, or proscription of the empire. The ban is of two kinds : the one is privatory, the other provisionary. The first consists in depriving a prince or state of the empire, of all their rights, privileges, dignities, \&c. : the second consists in taking away the actual government of the states, and committing them to the care of some other, until it be otherwise ordered. But this sentence of proscription is difficult to obtain, because it is difficult to unite all the orders of the empire in the same measure. The execution of it belongs to the director of the circle where the prince resides, and every feudal state of the empire is subject to it.

The constitution of the Germanic body is a study of no small difficulty. However plausibly invented, the several checks upon the imperial power may be, it is certain that the house of Austria has more than once endangered the liberties of the empire, and that they have been saved by France. The house of Austria, indeed, met with a powerful opposition from the house of Brandenbur?, in consequence of the activity and abilities of the king of Prussia. It may here be proper to inform the reader of the meaning of a term which frequently appears in the German history ; that of the Pragmatic Sanc. tion. This is no other than a provision made by the emperor Charles VI, for preserving the indivisibility of the Austrian dominions in the person of the next descendant of the last possessor, whether male or female. This provision has been often disputed by other branches of the house of Austria, who have been occasionally supported by France from political views, though the pragmatic sanction is strongly guaranteed by almost all the power's of Europe. The emperor Charles VII, elector of Bavaria, and Augustus, king of Poland, attempted to overthrow it, as being descended from the daughters of the emperor Joseph, elder brother to Charles VI. It has likewise been repeatedly opposed by the court of Spain.

Few of the territories of the German princes are so large as to be assigned to viceroys, to be oppressed and fleeced at pleasure ; nor are they entirely without redress when they suffer any grievance; as they may appeal to the general diet, or great council of the empire, for relief. The subjects of the petty princes in Germany are generally the most unhappy ; for these princes, affecting the grandeur and splendor of the more powerful, in the number and appearance of their officers and clomestics, in their palaces, gardens, pictures, curiosities, guards, bands of music, tables, dress, and furniture, are obliged to support all this vain pomp and parade at the expence of their vassals and dependents. With respect to the burghers and peasants of Germany, the former in many places enjoy great privileges: the latter also, in some parts, as in Franconia, Swabia, and on the Rhine, are generally a free people, or perform only certain selvices to their superiors, and pay the taxes ; whereas, in the marquisate of Brandenburg, Pomerania, Lusatia, Moravia, Bohemia, Austria, Stc. their condition is various, indeed, but universally very servile.

The judicial courts throughout Germany follow in their decisions the Roman or civil law, except where that law is altered or superseded by the statutes of the several states; which are very various, as the states themselves are extremely numerous. 
Revenues AND MilitaRy FORCE.... Both the military force and revenue of the emperor, merely as the head of the Germanic league or Ruman empire, are very inconsiderable. He has only an annual income of about 5000 or $6000 l$. sterling, arising from some inconsiderable fiefs in the Black Forest, and some trifling contributions from the imperial cities, of which, it is said, scarcely $2000 l$. come into the imperial treasury. The extraordinary revenues levied on the different states are called Roman months, because they were formerly raised by monthly assessments, for the maintenance of the troops who escorted the emperor to Rome, when that was the place of his coronation. A Roman month is about 5000l. and a certain number of these sums is paid by each state, according to the proportions for the different princes and states registered in what is called the matricula. tion-book, kept by the arch-chancellor of the empire.

In tine same book are registered the contingents or number of troops to be raised by each state, when war is decreed by the diet. These together would compose an army of about 30,000 men; but the whole force of the empire, were it exerted in one effort, would amount, exclusive of those countries which, though subject to German princes, are not a part of Germany, to 400,000 men : and the revenues of the different princes and states of the empire, with the same limitation, have been estimated at above sixteen millions sterling.

The revenues of the electorates and principal states of the empire, and the military force usually maintained by them, according to the latest and most authentic accounts, are as follow:

Princes.

Elector of Saxony

Elector of Bavaria

Elector of Hanover

Elector of Wurtembers

Elector of Baden

Elector of Hesse

Elector of Salzburg

Elector arch-chancellor

Duke of Brunswick Wolfenbuttle

Dukes of the house of Saxony

Dukes of Mecklenburg

Princes of Hohenlohe

$\begin{array}{cr}\text { Revenue. } & \text { Military Force. } \\ 1,250,000 l . & 32,000 \\ 1,200,000 & 28,000 \\ 960,000 & 18,000 \\ 600,000 & 7000 \\ 400,000 & 4000 \\ 300,000 & 12,000 \\ 300,000 & 2500 \\ 100,000 & \\ 280,000 & 3500 \\ 277,000 & 1300 \\ 230,000 & 15.00 \\ 150,000 & \end{array}$

The electors of Brandenburg and Bohemia (the king of Prussia and head of the house of Austria) are not included in this list, as theil pevenues and armies are raised from the whole of the Prussian and Austrian dominions.

IMPERIAL, ROYAL, AND OTHER TITLES, ARMS, AND ORDERS... The emperor of Germany pretends to be successor to the emperors of Rome, and has long, on that account, been admitted to a tacit precedency on all public occasions among the powers of Europe. Austria is but an archdukedom; nor has he, as the head of that house, a vote in the election of emperor, which is limited to Bohemia. Innumerable are the titles of principalities, dukedoms, baronies, and the like, with which he is vested as archduke; and he by a patent bearing date the 10th of August, 1804, assumed the title of hereditary emperor of Austria. The arms of the empire are a black eagle with two heads hovering with expanded wings in a field of gold; and over the heads

VOL. I. 
of the eagle is seen the imperial crown. On the breast of the eagle is an escutcheon quarterly of eight, for Hungary, Naples, Jerusalem, Arragon, Anjou, Guelders, Brabant, and Barr. It would be as useless as difficult to enumerate all the different quarterings and armorial bearings of the archlucal family. Every elector, and indeed every independent prince of any importance in Germany, claims a right of instituting orders; but the emperors pretend that they are not admissible unless confirmed by them. The emperors of Germany, as well as the kings of Spain, confer the order of the Golden Fleece, as descended from the house of Burgundy. The empress dowager, Eleonora, in 1662 and 1666, created two orders of ladies, or female knights; and the late empress queen instituted the order of St. Theresa.

The "Order of the Golden Fleece" was instituted at Bruges, in Flanders, on the 10th of January, 1429, by Philip, duke of Burgundy, on the day of his marriage with his third wife. It is supposed that he chose the badge, as being the chief of the staple manufactures of his country. It at first consisted of thirty knights; including the sovereign, who were of the first families in the Low Countries; and it still continues to be classed with the most illustrious orders of knighthood in Europe. At present there are two branches of it; of the one the emperor is sovereign, and the king of Spain of the other; all must prove their noble descent from the twelfth century. The motto of the order is "Pretium non vile laborum." The "Teutonic Order" owed its origin to some religious Germans in Jerusalem during the crusades, who assumed the title of "Teutonic knights, or brethren of the hospital of our Lady of the Germans at Jerusalem." Conrade, duke of Swabia, invited them into Prussia, about the year 1230 ; soon after they conquered Prussia for themselves, and became one of the most powerful orders in Europe. By their internal quarrels, they afterwards lost their power and possessions : and Albert, marquis of Brandenburg, grand master of the order, on his abjuring popery, abdicated the grand mastership, subdued Prussia, and expelled all the papists who would not follow his example. The order is now divided into two branches : the protestant branch, which had a house at Utrecht; and that for papists, which has a house at Mergentheim, in Germany, and of which the members must take the oath of celibacy. The ensign distinguishing this branch is worn round the neck, pendent to a gold chain.

The time of the institution of the "Order" of the Red Eagle" is uncertain. The margrave of Bareith is sovereign of it, and it is generally bestowed on military officers. In the year 1690 , John George, elector of Saxony, and Frederic III, elector of Brandenburg, on terminating their disputes, established the "Order of Sincerity," as a confirmation and security hereafter of their amity. The knights of this order wear a bracelet of gold; on one side are the names of the two princes, with this device, "Amitie sincère ;" on the other side are two armed hands, joined together, and placed on two swords, with two palm branches crossed, with this motto, "Unis hour jamais."

John George, duke of Saxe Weissenfels, instituted the "Order of the Noble Passion," in the year 1704, of which the duke is the sovereign. Each knight of the order is to contribute to the mainrenance of the maimed or decayed soldiers in the service of the sovereign. In the year 1709, Lonisa Elizabeth, widow of Philip duke of Saxe Merseburg, revived the "Order of the Death's Head," first instituted in 1652, by her father, the dulse of Wurtemberg. A prin - 
cess of that house alone can be sovereign of it, and none but women of virtue and merit (birth and fortune not regarded) be received into it. They are to avoid gaming, theatrical amusements, and luxuries of all kinds. The badge of the order is a Death's head enamelled white, surmounted with a cross pattée, black; above the cross pattée, another cross, composed of five jewels, by which it hangs to a black ribband edged with white, and on the ribband these words, "Memento mori" worn at the breast.

The great order of Vurtemberg is that "of the Chase." instituted in the year 1702 by the then duke, and improved in the year 1719 . On the left side of the coat is a silver star enbroidered, of the same figure as the badge, in the middle of a green circle, with the motto "Amicitiæ Virtutisque Fœdus." The festival of this order is on St. Hubert's day, he being the patron of sportsmen.

In the year 1709, the elector Palatine revived the "Order of St. Hubert," first instituted by a duke of Juliers and Cleves, in memory of a victory gained by him on St. Hubert's day, in 14.47. All the knights have either military employments or pensions. The archbishop of Salzburg, in 1701, instituted the "Order of St. Rupert," in honour of the founder and patron of the see he held, and as the apostle of his country. As the archbishop was the richest and most powerful prince of Bavaria, next to the elector, his order is in good esteem. In the year 1729, Albert, elector of Bavaria, instituted the "Order of St. George, the Defender of the Immaculate Conception," the knights of which are obliged to prove their nobility by father and mother for five generations.

The "Order of the Golden Lion," instituted by the late landgrave of Hesse-Cassel, is equally a military and civil order, but mostly conferred on general officers. The landgrave also instituted the military "Order of Merit," the badge of which is a gold cross, of eight points, enamelled white, and in the centre this motto, "Pro Virtute et Ficlelitate :" it is worn at the coat button-hole, pendent to a blue ribband edged with silver.

Religron....Before the reformation introduced by Luther, the German bishops were possessed (as indeed many of them continued to be till the late secularisations) of prodigious power and revenues, and were the tyrants of the emperors as well as of the people. Their ignorance was only equalled by their superstition. The Bohemians were the first who had an idea of reformation, and made so glorious a stand, for many years, against the errors of Rome, that they were indulged in the liberty of taking the sacrament in both kinds, and other freedoms not tolerated in the Romish church. This was in a great measure owing to the celebrated Englishman John Wickliffe, who went much further in reforming the real errors of popery than Luther himself, though he lived about a century and a half before him. Wickliffe was seconded by John Huss and Jerome of Prague, who, notwithstanding the emperor's safe-conduct, were infamously burntat the council of Constance.

The reformation introduced afterwards by Luther, ${ }^{*}$ of which we have spoken in the Introduction, though it struck at the chief abuses in the church of Rome, was thought in some points (particularly that of consubstantiation, by which the real body of Christ, as well as the

* Born in Saxony, in the year 1483; began to dispute the doctrines of the Romish. church 1517 ; and died 1546, in the 63d year of lis age. 
elements of bread and wine, is supposed to be taken in the sacrament) to be imperfect. Calvinism,* therefore, or the religion of Geneva (as now practised in the church of Scotland) was introduced into Germany, and is the religion professed in the territories of the king of Prussia, the landgrave of Hesse, and some other princes, who maintain a parity of orders in the church. Some even assert, that the numbers of protestants and papists in the empire are now almost equal. Germany, particularly Moravia and the Palatinate, as also Bohemia, is overrun with sectaries of all kinds; and Jews abound in the empire. At present, the rnodes of worship and forms of church government are, by the protestant German princes, considered in a civil rather than a religious light.

The elector archchancellor (the late elector and archbishop of Mentz) is primate and metropolitan of all Germany ; and the see of Mentz has been transferred to Ratisbon. Germany formelly contained six archbishoprics and thirty-eight bishoprics.

LITERATURE... No country has produced a greater variety of authors than Germany, and there is no where a more general taste for reading, especially in the protestant countries. Printing is encouraged to a fault; almost every man of letters is an author: they multiply books without number in every department of literature; and thousands of theses and disputations are annually published; for no man can be a graduate in their universities who has not published one disputation at least.

Many of the Germans have greatly distinguished themselves in various branches of learning and science. They have written largely upon the Roman and canon laws. Stahl, Van Swieten, Stork, Hoffman and Haller, have contributed greatly to the improvement of physic ; Ruvinus and Dillenius, of botany; Heister, of anatomy and surgery : and Neumann, Zimmermann, Pott, and Margraff of chemistry. In astronomy, Kepler deservedly obtained a great reputation; and Puffendorf is one of the first writers on the law of nature and nations, and has also merit as an historian. But at the end of the last century, and the beginning of the present, Germany, by her clivines, and by her religious sects, was so much involved in disputes about systematic theology, that fer comparatively paid any attention to other parts of learning or to polite literature. The language also, and the style of writing in German books, which at the time of the Reformation was pure and original, became ridiculous, by a continual intermixture of Latin and French words; which, though they were not understood by the people in general, were thought to give an air of superiority to the writers, and therefore much affected : for an opinion prevailed among the learned in Germany, and many have not yet divested themselves of it, that compiling huge volumes, and larding them with numberless quotations from all sorts of authors, and from all languages, was the true test of great erudition. Their productions, therefore, became heavy and pedantic, and were in consequence, disregarded by other nations.

It was about the year 1730 that the prospects of literature in Ger-

* John Calvin was born in the province of Picardy, in the north of France, anno 1506. Being obliged to fly from that kingdom, he settled at Geneva, in 1539, where he established a new form of church discipline, which was soon after embraced by several nations and states, who are now denominated Presbyterians, and, from their doctrinal articles, Calvinists. He died at Geneva, in the year 1564; and his writings make nine volumes in folio. 
many began to brighten. Leibnitz and Wolff opened the way to a better philosophy than had hitherto prevailed. Gottsched, an author and professor at Leipsic, who was greatly honoured by Frederick II, king of Prussia, introduced a better taste of writing, by publishing a German grammar, and by instituting a literary society for publishing and restoring to its purity the German language, and by promoting the study of the belles lettres. We may consider this as the epocha from which the Gernans began to write with elegance in their own language upon learned subjects, and to free themselves, in a considerable degree, from that verboseness and pedantry by which they had been characterised. About this time, several young men in the unirersity of Leipsic, and other parts of Lower Germany, united in publishing some periodical works, calculated for the general entertainment of persons of literary taste. Some of these gentlemen after. wards became eminent authors; and their works are held in Germany in high estimation.

The style of preaching among the German divines also now underwent a considerable change. They began to translate the best English and French sermons, particularly those of Tillotson, Sherlock, Saurin, Bourdaloue, and others. They improved by these models; and Mosheim, Spalding, Zollikofer, and others, have published sermons which would do credit to any country; although they still retain too much of that prolixity for which German divines and commentators have been so much censured. Nor can it be denied, that great numbers of the German preachers, even in large and opulent towns, are still too much distinguished by vulgar language, absurd opinions, and an inattention to the dictates of reason and good sense.

Some of the English periodical writings, such as the Spectator, Tatler, and Guardian, being translated into the German language, excited great emulation among the writers of that country, and a number of periodical papers appeared, of various merit. One of the first and best was published at Hamburg, under the title of "The Patriot ;" in which Dr. 'Thomas, the late bishop of Salisbury, was concerned; he being at that time chaplain to the British factory at Hamburg, and a considerable master of the German language. The late professor Gillert, who is one of the most elegant of the German authors, and one of the most esteemed, has greatly contributed to the improvement of their taste. His way of writing is particularly adaptecl to touch the heart, and to inspire sentiments of morality and piety. I Iis fables and narrations, written in German verse, his letters, and his moral romances, are so much read in Germany, that even many of the ladies have them all by heart. His comedies are also very popular; though they are rather too sentimental, and better adapted for the closet than for the stage.

Haller the famous physician, Hagedorn, Uz, Croneigh, Lessing; Gleim, Gerstenberger, Kleist, Klopstock, Ramler, Zacarie, Weiland, and others, have excelled in poetry. Schlegel, Cronegh, Lessing, Weiland, Weise, Schiller, and Kotzebue, have acquired fame by their dramatic writings. Rabener has by his satirical works, immortalised his name among the Germans; though some of his picces are of too local a naturc, and too much confined to German customs, manners, and characters, to be read with any high degree of pleasure by persons of other nations. Gesner, whose Idyls and Death of Abel have been translated into the English language, and favourably received, is better known to an English reader. 
In chemistry and in medicine, the merit of the Germans is very conspicuous; and Reimaraus, Zimmermann, Abt, Kæstner, Segner, Lambert, Mayer, Kruger, and Sulger, have acquired fame by their philosophical writings. Busching is an excellent geographical writer; and Mascoe, Bunau, Putter, Gatterer, Gebaur, and Schmidt, have excelled in historical works. But it cannot be denied that the Germans, in their romances, are a century behind us. Most of their publications of this kind are imitations of ours, or else very dry and uninteresting; which perhaps is owing to education, to false delio cacy, or to a certain taste of knight errantry which is still predominant among some of their novel writers.

In works relating to antiquity, and the arts known among the ancients, the names of Winckelman, Klog, and Lessing, are familiar with those who are skilled in this branch of literature. In ecclesiastical, philosophical and literary history, the names of Albertus Fabricius, Mosheim, Semler, and Brucker, are well known among us. Raphelius, Michaëlis, and Walch, are famous in sacred literature. Cellarius, Burman, Taubman, Reiske, Ernesti, Reimarus, Havercamp, and Heyne, have published some of the best editions of Greek and Latin classics.

It is an unfavourable circumstance for German literature, that the French language should be so fashionable in the German courts instead of the German, and that so many of their princes should give it so decided a preference. Frederic II, king of Prussia, had ordered the Philosophical Transactions of his royal society at Berlin, from the beginning of its institution, to be published in the French tongue ; by which, some of the Germans think his majesty cast a very undeserved reproach upon his native language.

With respect to the fine arts, the Germans have acquitted themselves very well. Germany has produced some good painters, architects, sculptors, and engravers. They even pretend to have been the first inventors of engraving, etching, and mezzotinto. Printing, if first invented in Holland, was soon after greatly improved in Germany. The Germans are generally allowed to have been the first inventors of great guns, as also of gunpowder, in Europe, about the year 1320. Germany has likewise produced some excellent musicians; Handel, Bach, Hasse, and Haydn, of whom Handel stands at the head, having arrived at the sublime of music.

UNIVERSITIES....There are at present in Germany thirty-one universities, of which fourteen, viz. those of Leipsic, Rostock, Greifswalde, Wittenberg, Tubingen, Iena, Helmstadt, Giessen, Rinteln, Altorf, Kiel, Halle, Goettingen, and Erlangen, are Lutheran ; three, viz. Frankfort on the Oder, Marburg, and Duisburg, of the reformed or Calvinistic religion; twelve, viz. Prague, Vienna, Wurzburg, Freyburg, Landshut, Dillingen, Ollmutz, Gratz, Paderborn, Salzburg, Fulda, and Bamberg, catholic ; and two, Heidelberg and Erfurt, mixed, or both catholic and protestant. There are also a number of colleges, gymnasia, pedagogies, and Latin schools. There are also many academies and societies for promoting the study of natural philosophy, the belles lettres, antiquities, painting, sculpture, architecture, \&x. as the Imperial Leopoldine Academy of the Naturæ Curiosi : the Academy of Sciences at Vienna, at Berlin, at Goettingen, at Erfurt, at Leipsic, at Duisburg, at Giesen, and at Hamburg. At Dresden and-Nuremberg are academies for painting: at Berlin a royal military academy; and at Augsburg is the Imperial 
Franciscan Academy of Fine Arts; to which we may add the Latin Society at Iena. Of the public libraries the most celebrated are those of Vienna, Berlin, Halle, Wolfenbuttle, Hanover, Goettingen, Weimar, and Leipsic.

Language.... The German language is derived from the old Teutonic and Gothic. It varies considerably in its dialects as spoken in different parts of the country, and is purest in Saxony and Hanover, and in the southern and eastcrn provinces most corrupted and uncouth. Latin and French are the most useful languages in Germany, when a traveller is ignorant of High Dutch.

The German Paternoster is as follows :-Unser Vater, der du bist im himmel, geheiliget werde dein name. Zukomme dein reich. Dein zville greschehe, wie im himmel also auch auf erden. Unser taglich brodt gib uns heute. Und vergib uns unsere schulden, als quir vergeben unsern schuldigern. Und fuehre uns nicht in versuchung. Sondern erlase uns von dem basen. Den clein ist das reich, und clie krafft, und die herrlichkeit, in ewigkeit. Amen.

Avtrquitres....A few remains of Roman edifices and other antiquities are found in Germany. The vast Gothic palaces, cathedrals, castles, and, above all, town-houses, in Germany, are very curious, and impress the beholder with their rude magnificence : many castles have the same appearance, probably, as they had 400 years ago; and their fortifications generally consist of a brick wall, trenches filled with water, and bastions or half-moons.

History....The manners of the ancient Germans are well described by the elegant and manly pencil of Tacitus, the Roman historian. They were a brave and independent race of men, and peculiarly distinguished by their love of liberty and arms. They opposed the force of the Roman empire, not in its origin or in its decline, but after it had arrived at maturity, and still continued in its full vigour. The country was divided into a number of principalities, independent of each other, though occasionally connected by a military union for defending themselves against such enemies as threatened the liber. ties of them all. At length, the Roman power, supported by art and policy, prevailed over a great part of Germany, and it was reduced to the condition of a province. When the Roman empire was shattered by the northern barbarians, Germany was overrun by the Franks, about the year 480 , and a considerable part of it long remained in subjection to earls and marquises of that nation. In this situation Ger.many continued, notwithstanding the efforts of particular chieftains or princes to reduce the rest into subjection, until the beginning of the ninth century; then it was that Charlemagne, one of those eccentric and superior geniuses who sometimes start up in a barbarous age, first extended his military power, and afterwards his civil authority, over the whole of this empire. The posterity of Charlemagne inherited the empire of Germany until the death of Lewis III, in the year 911 ; at which time the different princes, assuming their original independence, rejected the Carlovingian line, and placed Conrade, duke of Franconia, on the throne. Since this time, Germany has ever been considered as an elective monarchy. Princes of different families, according to the prevalence of their interest and. arms, have mounted the throne. Of these, the most considerable, until the Austrian line acquired the imperial power, were the houses of Saxony, Franconia, and Swabia. The reigns of these emperors contain nothing more remarkable than the contests between them 
and the popes. From these, in the beginning of the thirteenth century, arose the factions of the Guelphs and Ghibelines, of which the foriner was attached to the pope, and the latter to the emperor; and both, by their violence and inveteracy, tended to disquiet the empire for several ages. The emperors too were often at war with the Turks; and sometimes the German princes, as happens in all elective kingdoms, with one another about the succession. But what more deserves the attention of a judicious reader than all those noisy but uninteresting disputes, is the progress of goverument in Germany, which was, in some measure, opposice to that of the other kingdoms of Europe. When the empire raised by Charlemagne fell asunder, all the different independent princes assumed the right of election; and those now distinguished by the name of electors had no peculiar or legal influence in appointing a successor to the imperial throne; they were only the officers of the king's household, his secretary, his steward, chaplain, marshal, or master of his horse, \&c. By degrees, as they lived near the king's person, and, like all other princes, had independent territories belonging to them, they increased their influence and authority; and in the reign of Otho III, of the house of Saxony, in the year 984, acquired the sole right of electing the emperor.* Thus, while, in other kingdoms of Europe, the dignity of the great lords, who were all originally allodial or independent barons, was diminished by the power of the king, as in France, and by the influence of the people, as in Great Britain; in Germany, on the other hand, the power of the electors was raised upon the ruins of the emperor's supremacy, and of the jurisdiction of the people. Otho I, having, in the year 962, united Italy to the empire of Germany, procured a decree from the clergy, that he and his successors should have the power of nominating the pope, and of granting investitures to bishops. Henry V, a weak and wicked prince, in the year 1122 surrenclered up the right of investiture and other powers, to the disgrace of the imperial dignity; but pope Benedict XII, refusing absolution to Louis V, of Bavaria, in 1338, it was declared, in the diet of the empire, that the majority of suffrages of the electoral college should confer the empire without the consent of the pope, and that he had no superiority over the emperor, nor any right to reject or to approve of elections. In 1438, Albert II, archduke of Austria, was elected emperor, and the imperial dignity continued in the male line of that family for three hundred years. One of his successors, Maximilian, married the heiress of Charles duke of Burgundy, whereby Burgundy, and the seventeen provinces of the Netherlands, were annexed to the house of Austria. Charles V, grandson of Maximilian, and heir to the kingdom of Spain in right of his mother, was elected emperor in the year 1519. Under him Mexico and Peru were conquered by the Spaniards: and in his reign happened the reformation of religion in several parts of Germany; which, however, was not confirmed by public authority till the year 1648 , by the treaty of Westphalia, and in the reign of Ferdinand III. The reign of Charles V, was continually disturbed by his wars with the German princes, and the French king, Francis I. Though successful in the beginning of his reign, his good fortune toward the conclusion of it began to forsake

- Wiquefort says, that nothing was settled as to the number of electors, or the electoral dignity, till Charles IV, who was chosen emperor in 1347, and made that famous constitution for the election of emperors called the Golden Bull. 
lim; which, with other reasons, occasioned his abdication of the crown.

His brother, Ferdinand I, who in 1558 succeeded to the throne, proved a moderate prince with regard to religion. He had the address to procure his son, Maximilian, to be declared king of the Romans, in his own life time, and died in 1564. By his last will he ordered, that, if either his own male issue or that of his brother Charles, should fail, his Austrian estates should revert to his second daughter Anne, wife to the elector of Bavaria, and her issue.

This destination is noticed, as it gave rise to the opposition made by the house of Bavaria to the pragmatic sanction in favour of the late empress-queen of Hungary, on the death of her father, Charles VI. The reign of Maximilian II, was disturbed with internal commotions, and an invasion from the Turks; but he died in peace in 1576. He was succeeded by lis son Rodolph, who was involved in wars with the Hungarians, and in differences with his brother Matthias, to whom he ceded Hungary and Austria in his life time. To him succeeded in the empire, Matthias, under whom the reformers, who went by the names of Lutherans and Calvinists, were so much divided among themselves as to threaten the empire with a civil war. The ambition of Matthias at last reconciled them ; but the Bohemians revolted, and threw the imperial commissaries out of a window at Prague. This gave rise to a ruinous war, which lasted thirty years. Matthias thought to have exterminated both parties; but they,formed a confederacy, called the Evangelic League, which was counterbalanced by a Catholic League.

Matthias dying in 1618, was succeeded by his cousin, Ferdinand II ; but the Bohemians offered their crown to Frederic, the elector palatine, the most powerful protestant prince in Germany, and son-inlaw to his Britannic majesty, James I. That prince was incautious enough to accept of the crown; but he lost it, being entirely defeated by the duke of Bavaria and the imperial generals, at the battle of Prague : and he was also deprived of his own electorate, the best part of which was given to the duke of Bavaria. The protestant princes of Germany, however, had among them at this time many able commanders, who were at the head of armies, and continued the war with great firmness and intrepidity: among them were the margrave of Baden Dourlach, Christian duke of Brunswick, and count Mansfield; the last was one of the ablest generals of the age. Christian IV, king of Denmark, declared for them; and Richelieu, the French minister, did not wish to see the house of Austria aggrandised. The emperor, on the other hand, had excellent generals; and Christian, having put himself at the head of the evangelic league, was defeated by Tilly, an imperialist of great reputation in war. Ferdinand so grossly abused the advantages obtained over the protestants, that they formed a fresh confederacy at Leipsic, of which the celebrated Gustavus Adolphus, king of Sweden, was the head. His victories and progress, till he was killed at the battle of Lutzen, in 1632 , have already been related. But the protestant cause clid not tie with him. He had brought up a set of heroes, such as the duke of Saxe Weimar, Torstenson, Banier, and others, who shook the Austrian power, sill, under the mediation of Sweden, a general peace "vas concluded among all the powers at war, at Munster, in the year 1648; which forms the basis of the present political system of Europe.

VoL. I,

s M 
Ferdinand II died in 1637, and was succeeded by his son, Ferdinand III, who died in 1657 , and was succeeded by the emperor Leopold, a severe, unamiable, and not very fortunate prince. He had two great powers to contend with; France on the one side, and the Turks on the other; and was a loser in his war with both. France took from him Alsace, and many other frontier places of the empire; and the Turks would have taken Vienna, had not the siege been raised by John Sobieski, king of Poland. Prince Eugene, of Savoy, was a young adventurer in arms, about the year 1697 ; and, being one of the imperial generals, gave the Turks the first checks they received in Hungary; and by the peace of Carlowitz, in 1699, Transyivania was ceded to the emperor. The empire, however, could not have withstood the power of France, had not the prince of Orange, after. wards king William III, of England, laid the foundation of the grand confederacy against the French power, the consequences of which have been already described. The Hungarians, secretly encouraged by the French, and exasperated by the unfeeling tyranny of Leopold, were still in arms, under the protection of the Porte, when that prince died, in 1705.

He was succeeded by his son Joseph, who put the electors of Cologne and Bavaria to the ban of the empire : but being very ill served by prince Lcwis, of Baden, the general of the empire, the French partly recovered their affairs, notwithstanding their repeated defeats. The duke of Marlborough, though he obtained very splendid. victories, had not all the success he expected or deserved. Joseph himself was suspected of a design to subvert the Germanic liberties; and it was evident, by his conduct, that he expected England should lake the principal part in the war, which was chiefly carried on for his benefit. The English were disgusted at his slowness and selfishness; but he died in 1711 , before he had reduced the Hungarians; and, leaving no male issue, was succeeded in the empire by his brother Charles VI, whom the allies we re endeavouring to place on the throne of Spain, in opposition to Philip, duke of Anjou, grandson to Lewis XIV.

When the peace of Utrecht took place, in 1713, Charles at first made a show as if he would continue the war; but found himself unable, now that he was forsaken by the English. He therefore was obliged to conclude a peace with France, at Baden, in 1714, that he might oppose the progress of the 'Turks in Hungary, where he received a total defeat from prince Eugene, at the battle of Peterwaradin. They received another, of equal importance, from the same general, in 1717, before Belgrade, which fell into the hands of the imperialists; and the following year the peace of Passarowitz, between them and the Turks, was concluded. Charles was continually eimployed in making arrangements for increasing and preserving lils hereditary clominions in Italy and the Mediterranean. Happily for him, the crown of Britain devolved to the house of Hanover; an event which gave him a very decisive weight in Europe, by the connexions of George I and II with the empire. Charles was sensible of this, and carried matters with so high a hand, that, about the year 1724 and 1725 , a breach ensued between him and George I ; and so unsteady was the system of affairs all over Europe at that time, that the principal powers often changed their old alliances, and concluded new 
ones, contrary to their interest. Without entering into particulars; it is sufficient to observe, that the safety of Hanover, and its aggrandisement, was the main object of the British court; as that of the emperor was the establishment of the pragmatic sanction, in favour of his daughter, the late empress-queen, he having no male issue. Mutual concessions upon those great points restored a good understanding between George II and the emperor Charles; and the elector of Saxony, being prevailed upon by the prospect of gaining the throne of Poland, relinquished the claims he had upon the Austrian. succession.

The emperor, after this, had very ill success in a war he entered into with the Turks, which he had undertaken chiefly to indemnify himself for the great sacrifices he had made in Italy to the princes of the house of Bourbon. Prince Eugene was then dead, and he had no general to supply his place. The system of France, under cardinal Fleury, happened at that time to be pacific; and she obtained for him, from the Turks, a better peace than he had reason to expect. Charles, to pacify the German and other European powers, had, before his death, given his eldest daughter, Maria Theresa, in marriage to the duke of Lorraine, a prince who could bring no accession of power to the Austrian family. Charles died in 1740 .

He was no sooner in the grave, then all he had so long laboured for must have been overthrown, had it not been for the firmness of George II. The pragmatic sanction was attacked on all sides. The young: king of Prussia with a powerful army, entered and conquered Silesia, which he said had been wrongfully dismembered from his family. The king of Spain and the elector of Bavaria set up claims directly incompatible with the pragmatic sanction; and in this they were joined by France; though all those powers had solemnly guaranteed it. The imperial throne, after a considerable vacancy; was filled by the elector of Bavaria, who took the title of Charles VII, in January 1742. The French poured their armies into Bohemia, where they took Prague : and the queen of Hungary, to take off the weight of Prussia, was forced to cede to that prince the most valuable part of the duchy of Silesia, by a formal treaty.

Her youth, her beauty and sufferings, and the noble fortitude with which she bore thenl, touched the hearts of the Hungarians, under whose protection she threw herself and her infant son; and though they had always been remarkable for their disaffection to the house of Austria, they declared unanimously in her favour. Her generals drove the French out of Bohemia; and George II, at the head of an English and Hanoverian army, gained the battle of Dettingen, in 174.3. Charles VII was at this time distressed on the imperial throne, and driven out of his elecţoral Dominions (as had been his ancestor, in queen Anne's reign, for siding with France) and would have given the queen of Hungary almost her own terms; but slic haughtily and impoliticly rejected all accommodation, though advised to it by his Britannic majesty, her best and indeed only friend. T'his obstinacy gave a colour for the king of Prussia to invade Bobemia, under pretence of supporting the imperial dignity; but though he took Prague, and subdued the greatest part of the kingdom, he was not supported by the French; upon which he abandoned all his conquests, and retired to Silesia. This event confirmed the obstinacy of the queen of Hungary, who came to an accommodation with the 
emperor, that she might recover Silesia. Soon after, his imperial majesty, in the beginning of the year 1745, died; and the duke of Lorraine, then grand duke of Tuscany, consort to her Hungarian majesty, after surmounting some difficulties, was chosen emperor, by the title of Francis $I$.

The bad success of the allies against the French and Bavarians in the Low Countries, and the loss of the battle of Fontenoy, retarded the operations of the empress-queen against his Prussian majesty. The latter defeated the emperor's brother, prince Charles of Lorraine, who had before driven the Prussians out of Bohemia; and the conduct of the empress-queen was such, that his Britannic majesty thought proper to guarantee to him the possession of Silesia as ceded by treaty. Soon after, his Prussian majesty pretended that he had discovered a secret convention which had been entered into between the empress-queen, the empress of Russia, and the king of Poland as elector of Saxony to strip him of his dominions, and to divide them among themselves. Upon this he suddenly attacked the king of Poland, drove him out of Saxony, defeated his troops, and took posses-ion of Dresden, which he held till a treaty was made under the mediation of his Britannic majesty, by which the king of Prussia acknowledged the duke of Lorraine, now become great duke of Tuscany, for emperor. The war continued in the Low Countries, not only to the disadvantage but to the discredit of the Austrians and Dutch, till it was finished by the treaty of Aix-la-Chapelle, in April 1748. By that treaty, Silesia was once more guaranteed to the king of Prussia. It was not long before that monarch's jealousies were renewed and verified; and the empress of Russia's views falling in with those of the empress-queen and the king of Poland, who were unnaturally supported by France in their new schemes, a fresh war was kindled in the empire, in the year 1756. The king of Prussia declared against the admission of the Russians into Germany, and his Britannic majesty against that of the French. Upon those two principles, all former differences between these monarchs were forgotten, and the British parliament agreed to pay an annual subsidy of $670,000 l$ to his Prussian majesty during the continuance of the war, the flames of which were now rekindled with more fury than ever.

His Prussian majesty once more broke into Saxony, defeated the imperial general Brown at the battle of Lowositz, forced the Saxons to lay down their arms though almost impregnably fortified at Pirna; and the elector of Saxony again fled to his regal dominions in Poland. After this, his Prussian majesty was put to the ban of the empire; and the French poured, by one quarter, their armies, as the Russians did by another, into Germany. The conduct of his Prussian majesty on this occasion is scarcely to be paralleled in history. He broke once more into Bohemia with inconceivable rapidity, and defeated an army of 100,000 Austrians, under general Brown, who was killed, as the brave marshal Schwerin was on the side of the Prussians. He then besieged Prague, and plied it with a most tremendous artillery; but, just as he was beginning to imagine that his troops were invincible, they were defeated at Colin, by the Austrian general Daun, obliged to raise the siege, and to fall back upon Fisenach. The operations of the war now multiplied every day. The emperialists, under count Daun, were formed into excellent troops; but they were beaten at the battle of Lissa, and the Prussians took Breslau, and obtained many 
cther great advantages. The Russians, after entering Germany, gave a new turn to the aspect of the war; and the cautious yet enterprising genius of count Daun aid his Prussian majesty under infinite difficulties, notwithstanding all his great victories. At first he defeated the Russians at Zorndorf; but an atiack made upon his army, in the night time, by count Daun, at Hockirchen, had nearly proved tatal to his affairs, though he retrieved them with admirable presence of mind. He was obliged, however, to sacrifice Saxony, for the safety of Silesia ; and it has been observed, that few periods of history afford such room for reflection as this campaign did : six sieges were raised almost at the same time; that of Colberg, by the Russians; that of Leipsic, by the duke of Deux Ponts, who commanded the army of the empire; that of Dresden, by count Daun; and those of Neiss. Cosel, and Torgau, also by the Austrians.

Many important events which passed at the same time in Germany, between the French, who were driven out of Hanover, and the English, or their allies, must be omitted on account of the brevity necessary to be observed in this compendium. The operations on both sides are of little importance in history, because nothing was done that was decisive, though the war was extremely bloody and burdensome to Great Britain. Great was the ingratitude of the empress-queen to his Britannic majesty and his allies, who were now daily threatened with the ban of the empire. The Russians had taken possession of the kingdom of Prussia, and laid siege to Colberg, the only port of his Prussian majesty in the Baltic. Till then, he had entertained too mean an opinion of the Russians; but he soon found them by far the most formidable enemies he had to encounter. They advanced, under count Soltikoff, in a body of $100,000 \mathrm{men}$, to Silesia. In this distress he acted with a courage and resolution that bordered upon despair ; but was, at last, totally defeated by the Russians, with the loss of 20,000 of his best troops, in a battle near Frankfort on the Oder. He became now the tennis-ball of fortune. Succeeding defeats seemed to announce his ruin, and all avenues towards peace were shut up. He had lost, since the first of October 1756, the brave marshal Keith, and forty brave generals, besides those who were wounded and made prisoners. At Landschut, the imperial general Laudohn defeated his army under Fouquet, on which he had great dependence, and thereby opened to the Austrians an easy passage into Silesia. None but Frederic II would have thought of continuing the war under such repeated losses; but every defeat he received seemed to give him fresh spirits. It is not, perhaps, very easy to account for the inactivity of his enemies after his defeat near Frankfort, but by the jealousy which the imperial generals entertained of their Russian allies. They had taken Berlin, and laid the inhabitants under pecuniary contributions; but towards the end of the campaign he defeated the imperialists in the battle of Torgau, in which count Daun was wounded. This was the best fought action the king: of Prussia had ever been engaged in; but it cost him 10,000 of his best troops, and was attended with no great consequences in his favour. New reirforcements which arrived every day from Russia, the taking of Colberg by the Russians, and of Schweidnitz by the Austrians, seemed almost to have completed his ruin; when his most formidable enemy, the empress of Russia, died, January 5,1762. George II had. died on the 25 th of October 1760. 
The deaths of those illustrious personages were followed by great consequences. The British ministry of George III were solicitous to put an end to the war, and the new emperor of Russia recalled his armies. His Prussian majesty was, notwithstanding, so very much reduced by his losses, that the empress-queen, probably, would have completed his destruction, had it not been for the prudent reluc. tance of the other German princes to annihilate the house of Brandenburg. At first the empress-queen rejected all terms proposed to her, and ordered 30,000 men to be added to her armies. The visible unwillingness of her generals to execute her orders, and the suc. cesses obtained by his Prussian majesty, at last prevailed upon her to agree to an armistice, which was soon followed by the treaty of Hubertsberg, February 15, 1763, which again secured to his Prussian majesty the possession of Silesia.

Upon the death of the emperor, the husband of Maria Theresa, in 1765 , her son Joseph, who had been crowned king of the Romans in $\mathbf{3 7 6 4}$, succeeded him in the empire. Soon after his accession, he dis. covered great activity and ambition. He joined in the dismemberment of Poland, with Russia and Prussia. He paid a visit incognito, and with moderate attendants, to Rome, and the principal courts of Italy; and had a personal interview with his Prussian majesty, though this did not prevent hostilities from being commenced between Aus. tria and Prussia, on account of the succession to the electorate of Bavaria. The Austrian claims on this occasion were very unjust; but, in the support of them, while the contest continued, the emperor displayed great military skill. Though vast armies were brought into the field on both sides, no action happened of much importance and an accommodation at length took place. The enperor afterwards demanded of the Dutch the free navigation of the Scheldt, but in this he likewise failed. He endeavoured, however, to promote the happiness of his subjects; granted a most liberal religious toleration, and suppressed mest of the religious orders of both sexes, as being utterly useless, and even pernicious to society; and in 1783, by an edict, abolished the remains of servitude and villainage, and fixed also the fees of the lawyers at a moderate amount, granting them a pension in lieu. He also abolished the use of torture in his hereditary dominions, and removed many of the grievances under which the peasants and common people laboured. He was a prince who mixed with his subjects with an ease and affability which are very uncommon in persons of his rank. He loved the conversation of ingenious men, and appeared solicitous to cultivate knowledge.

Peter-Leopold, grand duke of Tuscany, succeeded his-brother Joseph II, and engaged the public praise by repeated instances of moderation and solid principles. His former management of his Italian sovereignty, which was prudent and beneficent, showed that he aspired to more just reputation than can be acquired by the mere splendors of royalty. One of the bishops of Hungary having refused his license to a catholic subject to marry a protestant woman, the emperor dismissed him from his see but pardoned him afterwards, upon concession, and desired the bishop to exhort his brethren to comply with the imperial ordonnances, else no favour should be shown.

The French revolution now attracted the attention of the powers of Europe. A conference was held at Pilnitz, between the emperor, 
the king of Prussia, and the elector of Saxony, at which the plan of attacking France was proposed and discussed. Leopold for some time was very irresolute, but at last seemed to be resolved on war, when he died of a pleuritic fever, on the 1st of March 1792, after an illness of four days.

His son Francis was raised to the imperial throne in the middle of July following. He embarked with zeal in the confederacy formed against France. The disastrous consequences of this war to the house of Austria, till its conclusion, or rather suspension, by the treaty of Campo Formio; and the transient success, but final failure, which attended its renewal, till its termination by the peace of Luneville in 1801; have been related in our account of the affairs of France. The war which afterwards broke out between Russia and Austria on the one part, and France on the other, has been noticed in our account of Russia.

Austria seemed inclined to submit to France, for no greater a length of time, than was sufficient, to renew her resources. For the immediate causes of the war of 1809 , we must refer to France. On the 10th of April, the archduke Charles entered Bavaria; but was not enabled to proceed far, being met by the French army. A corps of Austrians, under the archduke Louis, had been left without support. Bonaparte, perceiving this, attacked them with a superior force, and defeated them, taking 18,000 prisoners. While Bonaparte was pursuing this advantage, the archduke Charles, by a sudden movement, occupied the same spot where his brother had been defeated. Bonaparte immediately retraced his steps, attacked the archduke on the $22 \mathrm{~d}$ of April, at Eckmuhl, and completely overthrew him. The Austrians fled to Ratisbon, where they were again attacked, and driven across the Danube. Bonaparte now marched directly for Vienna. He appeared before that city on the 10th of May, and entered it, after meeting with a slight resistance. The archduke Charles, now posted his army on the north bank of the Danube, behind Vienna. His line extended from Krems to Presburg. Bonaparte determined to cross the river, and attack him. The passage not being disputed, the French crossed on the 20th, and occupied the villages of Aspern and Esling These positions were suddenly attacked on the 2 ! st, and a dreadful slaughter ensued. The battie was only terminated by night. The advantages of the day, were decidedly on the side of Austria. The French were driven from Aspern, and their general position was much nearer the Danube, than on the preceding day. The next day the contest was renewed, and Bonaparte was completely discomfited. In the night he retired to the island of Lidau, in the river. From that time, to the 5 th of July, both armies occupied themselves in preparing for another battle. The Austrian general erected strong fortifications opposite the French army. But Bonaparte crossed on the 5th at some distance below, and thus rendered the Austrians batteries useless. On the 6th the grand engagement took place, which decided the fate of the campaign. The Austrians were driven from all their positions, and pursued to Znaim. Here the empcror Francis proposed an armistice, which was signed on the 12th, and negociations for a definitive treaty were immediately entered into. Among other mortify ing concessions, the emperor Francis was obliged to relinquish his title, of emperor of Germany, which had, for a considerable time, been merely nominal. 
For want of power to do otherwise, Austria was now obliged to act, as one of the vassals of Bonaparte, until the victorious armies of Russia, advancing from the north, gave her an opportunity of once more asserting her independence. The part which Austria now assumed, and the happy consequences of that coalition, in restoring the balance of Europe, have been related in our historical notices of France.

Francis II, emperor of Germany, was born February 3, 1768 ; married, January 6, 1788, Elizabeth, princess of Wurtemberg, who died 1790. He married 2dly, September 1790, Maria-Theresa, of Naples, his cousin.

On the death of his father Peter-Leopold, late emperor, March 1st, 1792, he succeeded to the crown of Hungary and Bohemia; and July 15, 1792, was elected emperor of Germany.

He had no issue by his first marriage. By the latter he has.

Maria-Louisa, born December 12, 1791; married to Bonaparte in 1810.

Ferdinand-Charles, born April 19, 1793.

Leopoldina-Carolina-Josepha, born, January 22, 1797.

Maria-Clementina-Frances-Josepha, born March 1, 1798.

Joseph-Francis-Leopold, born April 9, 1799.

Caroline-Ferdinanda-Josepha-Demetria, born April 8, 1801.

Brothers and Sisters of the Emperor.

Ferdinand-Joseph, elector of Salzburg (late grand duke of Tuscany) born May 6, 1769 ; married, September 19, 1790, Louisa-Amelia. Theresa, daughter of Ferdinand IV, king of Naples.

Charles-Lewis, born September 5, 1771 .

Joseph-Anthony, born March 9, 1776, palatine of Hungary.

Anthony-Victor-Joseph, born August 31, 1779.

John-Baptist-Joseph, born January 20, 1782 .

Regnier-Joseph, born September 30, 1783.

Louis-Joseph, born December 14, 1784.

Rodolph-John-Joseph-Regnier, born January 8, 1788.

Maria-Theresa-Josepha-Charlotta, born January 14, 1767 ; married, October 18, 1787, to Anthony, brother to the elector of Saxony.

Maria-Anna-Ferdinanda, born April 21, 1770; elected princess abbess of the chapter of Prague, 1791.

Electors of the Empire.

Charles-Theodore, elector of Ratisbon, archchancellor of the holy Roman empire, primate and metropolitan of Germany, born February 8,1744 ; elected coadjutor of the archbishopric of Mentz, June 5, 1787 ; succeeded to the archbishopric July 26,1802 ; elector of Ratisbon, 1802 .

Francis-Joseph-Charles, emperor of Germany, and king of Hungary, elector of Bohemia, born February 12, 1768.

Frederic-Augustus IV, elector and duke of Saxony, born December 23, 1750; succeeded his father December 17, 1763; married, January 29, 1769, to the princess Amelia-Augusta, of Deux-Ponts.

Frederic-William III, king of Prussia, elector of Brandenburg, born August 3, 1770 . 


\section{GERMANY.}

George III, king of Great Britain, elector of Brunswick-Lunenburg, born June 4, 1738.

Ferdinand-Joseph (late grand duke of Tuscany) elector of Salzburg, born May 6, 1769.

Frederic II, duke and elector of Wurtemberg, born November 6, 1754 ; married, in second marriage, to the princess royal of England, Charlotta-Augusta-Matilda, May 18, 1797; succeeded his father, duke Frederic-Eugene, December, 23, 1797 ; elector 1802.

Charles-Frederic, elector of Baden, born November 22, 1728 ; succeeded the margrave, his grand-father, May 12, 1738, and to the estates of the branch of Baden-Baden, October 21, 1771 ; married, in second marriage, November 24, 1787, to Louisa-Caroline, countess of Hochberg; elector 1802.

William IX, elector of Hesse, born June 3,1743 ; married, September 1, 1764, to Wilhelmina-Caroline, daughter of Frederic V, king of Denmark; succeeded his father as lándgrave of Hesse-Cassel, October 31, 1785; elector 1802. 


\section{GENELAL VLEW}

OF THE

\section{AUSTRIAN DOMINIONS.}

THE extensive and powerful monarchy of Austria is composed of the following provinces and countries, which form the hereditary dominions of the present emperor of Germany, who has lately assumed the hereditary title of emperor of Austria.

Provinces and Countries.

Archduchy of Austria Proper

Duchies of $\left\{\begin{array}{l}\text { Stiria } \\ \text { Carinthia } \\ \text { Carniola }\end{array}\right.$

Territory of Triest

County of Tyrol

Principality of Swabia

Kingdom of Bohemia

Marquisate of Moravia

Austrian Silesia

Kingdom of Gallicia and Lodomeria

Kingdom of Hungary

Transylvania

The Buckowine

Illyria, of Sclavonia and Croatia

Hungarian and Venetian Dalmatia

The Venetian Territory

\begin{tabular}{rr} 
Sq. Miles. & \multicolumn{1}{c}{ Population. } \\
10,080 & $1,820,000$ \\
6592 & 800,000 \\
3100 & 300,000 \\
3424 & 400,000 \\
120 & 40,000 \\
6960 & 610,000 \\
1600 & 200,000 \\
14,400 & $2,810,000$ \\
6400 & $1,260,000$ \\
1296 & 250,000 \\
37,000 & $3,900,000$ \\
59,500 & $6,300,000$ \\
16,400 & $1,500,000$ \\
2900 & 130,000 \\
12,080 & 900,000 \\
4640 & 300,000 \\
8000 & $2,000,000$ \\
\hline 195,212 & $23,520,000$
\end{tabular}

The population of Austria has since been stated at $26,970,030$.

The Austrian dominions are situated between 45 and 52 degrees of north latitude, and between 12 and 27 degrees of east longitude. Titeir length, from the frontiers of Switzerland to the utmost limits of Transylvania, may be estimated at about 760 miles; and their breadth, from the river Bug, which fornss a boundary between Austria and Prussian Poland, to the Save, which divides Austria from Turkey, at about 520. The number of inhabitants to the square mile is, as appears from the preceding table of the extent and population of the countries of which they are composed, nearly 110 .

The name of Austria has been formed by the Italian and French pronunciation of the German words Oster Reich, the eastern kingdom, which name this territory received on account of its situation with respect to the western empire established by Charlemagne.

The archduchy of Austria Proper exceeds all the other provinces of Germany in the fertility of its soil (productive especially in corn, 
fruits, and wine) the abundance of its pastures, and the salubrity of the air. It is divided by the river Ens into Upper and Lower Austria; the capital of the former of which is Vienua, already described : besides which it contains 35 cities and 256 market towns. The capital of the latter is Lintz, a strong town, defended by two castles, and containing about 15,000 inhabitants : besides which it has 13 other cities and 88 market towns:

The duchy of Stiria, situate to the south of the archduchy of Austria, with Hungary on the east and Carniola to the south, is about 125 miles long, and 17 broad. Though a mountainous country, it is well cultivated, and produces every kind of grain. The mountains contain silver, lead, copper and particularly iron. The Muehr and the Ens are the principal rivers. The iron mines have been worked above 1000 years, yet still continue extremely productive; and the Stirian steel is in great estimation. In the whole duchy there are nearly 120 towns, and 500 citadels, many of the latter built on the summits of rocks. The capital is Gratz, situate on the Muehr; a regularly fortified city, with a strong citadel. It has a university, and contains about 30,000 inhabitants.

The duchy of Carinthia, situate to the south-west of Stiria, is likewise a mountainous and woody country, and contains mines of iron and lead; but there are many fertile vallies which yicld wheat and other grain, though not sufficient to supply the wants of the inhabitants. It contains 31 towns; the principal of which is Clagenfurt, on the river Glan, surrounded by a strong wall, and containing six churches, three convents, and 10,000 inhabitants.

The duchy of Carniola, to the south of Stiria, is 120 miles long and 100 broad. It is in general mountainous; but many parts yield not only good pasturage, but excellent corn, hemp, flax, and millet. In the mountains are mines of iron, leat and copper. The quicksilver mines of Idria, in this duchy, may be considered as a natural curiosity. They were discovered in 1499, and yield annually 300,000 pounds weight of mercury. 'The descent into them is by stone stairs and ladders, and the length of the galleries is computed at 1580 feet. The principal rivers are the Sare, the Laybach, the Gurk, and the Culpa. Various kinds of fruits, as chesnuts, walnuts, olives, oranges, citrons, lemons, pomegranates, almonds, and figs, abound here; and black cattle and horses are bred in great numbers. This duchy is estimated to contain 56 towns, 200 citadels, and 4000 villages. The capital is Laybach, situate, on the river of the same name, and containing a cathedral, and about 20,000 inhabitants.

Austrian Friuli is situate between Carinthia, Carniola, the duchy of Venice, and the territory of Triest. It is divided into the two counties of Gorz, or Goriz, and Gradisca. It is principally mountainous, but has large and fertile vallies, which produce corn, fruits, wine, and silk. The chief town is Gorz, or Goritz, containing a castle, and about 10,000 inhabitants.

The small territory of 'Triest, sitnate between Carniola, Friuli, and the Adriatic Sea, produces wine, excellent fruits and sea salt, procured from the salt works at Zaula and Servola. The capital Triest, stands on the Adriatic: it is a free port, with a considerable and increasing trade; from six to eight thousand ships annually arriving there from the different countries of Europe. It is likewise a bishop's see; contains a cathedral and 30,000 inhalitants.

The duchies of Stiria, Carinthia, and Carniola, and the territories 
of Friuli and Triest, are comprehended under the denomination of Inner Austria, and, together with the county of Tyrol, are included, as a part of Germany, in the circle of Austria.

The county of Tyrol, situate to the east of Carinthia, is 150 miles long and 120 broad. It is extremely mountainous, the chain of the Noric or Rhætian Alps running through its whole length, and rivalling the Alps of Switzerland in numerous glaciers. It contains mines of silver, copper, and lead, and produces corn and wine, very fine flax, and silk. The wild animals are bears, wolves, and foxes; and the domestic, horses, black cattle, and sheep. Great numbers of canary birds are bred here, and carried, for sale, to almost every part of Europe. The manufactures are those of silk, velvet, and leather, as also of iron and steel. The principal town is Inspruck on the Inn; formeriy the residence of the archdukes of Austria. It contains a university with a considerable library, and has a strong castle. The number of inhabitants is 12,000 . 'Tyrol, in the more extensive sense of the denomination, likewise comprehends the bishoprics of Trent and Brixen, formerly subject to their respective bishops, but lately secularised, and given as indemnities to the house of Austria. The former of these cities, rendered celebrated by the great council of Trent, held here from 1545 to 1563 , contains about 8000 inhabitants, and the latter about 4000 .

The religion of all these provinces is the Roman-catholic, attended indeed with a considerable degree of toleration in the archduchy of Austria, at least at Vienna; but in Stiria no other doctrine or worship is permitted but the Roman-catholic.

The language, in general, is the German, though somewhat impure; but in some parts the Wendish is spoken by the common people; and in the southern provinces, the Italian, at least a dialect of that language, prevails.

The other countries which compose the Austrian monarchy, and lie without Germany, will be treated of separately in order.

Revenue.... The revenues of the Austrian monarchy are estimated at 48,244,009 dollars, of which the archduchy of Austria contributes nearly one third. The portions of this revenue which Hungary, and the other countries, subject to the house of Austria, contribute, will be found in the accounts of those countries. The revenue formerly exceeded the expences; but the different wars in which the house of Austria has engaged in modern times, especially in the late arduous struggle with France, have accumulated a debt, which is now estimated at above 70 millions sterling.

Army....The arny of Austria, on the peace establishment, in the year 1801 , was stated, from official returns, at $328,600 \mathrm{men}$. The different armies brought into the field, by Austria, in 1813, amounted to about $500,000 \mathrm{men}$.

Austria being almost altogether an inland country, has no navy, and her commerce is very insignificant.

TrTtE....The title of the sovereign of Austria, since the assumption of the hereditary imperial clignity, is as follows: Francis II, by the frace of God, elected emperor of the Romans, al ways august, hereditary emperor of Austria, king of Germany, Hungary, Bohemia, \&xc, archduke of Austria, duke of Lorraine, Venice, Salzburg, \&cc. 


\title{
BOHEMIA AND MORAVIA.
}

\author{
SITUATION AND EXTENT OF BOHEMIA.
}

$\left.\begin{array}{l}\text { Mriles. } \\ \text { Bength } 210 \\ \text { Breadth } 175\end{array}\right\}$ between $\left\{\begin{array}{c}\text { Degrees. } \\ 12 \text { and } 1630 \text { East long. } \\ 4830 \text { and } 51 \text { north latitude. }\end{array}\right.$

Containing 14,400 square miles, with 195 inhabitants to each.

SITUATION AND EXTENT OF MORAVIA.

$\left.\begin{array}{lr}\text { Liles. } \\ \text { Breadth } 140\end{array}\right\}$ between $\left\{\begin{array}{c}\text { Degrees. } \\ 15 \text { 30 and } 1830 \text { East longitude. } \\ 4840 \text { and } 50 \text { North latitude. }\end{array}\right.$

Containing 64.00 square miles, with 196 inhabitants to each.

Names....Bohemia, or Boheim, or Bojenheim, signifies the home or residence of the Boii, a Celtic nation, who removed into that country from Gaul, before the expedition of Julius Cresar. The present inhabitants call themselves Czechy, or, as the Germans generally write the name, Tschechs, from Czech, or Tschech, the name of one of their ancient chiefs. They are of Slavonic origin.

Moravia derives its name from the river Morawa, which runs through it.

Bouxdaries.... Bohemia is bounded on the north by Misnia and Lusatia, in Upper Saxony ; on the east by Silesia and Moravia; on the south by the archduchy of Austria; and on the west by Franconia, and the palatinate of Bavaria.

Moravia is bounded on the north by Silesia; on the east by Hungary; on the south by the archduchy of Austria; and on the west by Bohemia.

Divisions....Bohemia is divided into the sixteen circles of Bunzlat, Koningingrats, Chrudim, Kaurzim, Beraun, Rakonitz, Saas, Leutmeritz, Biczow, Czaslau, Tabor, Budweis, Prachin, Klattau, Pilsen, and Elbogen. The city of Prague is not included in either of these circles, but forms a kind of circle, or district, of itself.

Moraria is divided into the six circles of Olmutz, Brunn, Znaim, Iglau, Hradisch, and Prerau; which are the names of their respective chief towns.

Mountaiss and Forests....Bohemia is surrounded with mountains and woods. On the north-west it is divided from Upper Saxony by the Erzgebirge, a word signifying mountains containing mines; and to the north-east from Silesia by the Sudetic chain and the Giant Mountain; on the south-east and south it is separated from Moravia and the archduchy of Austria by the Moravian mountains; and on the west it has for its boundary the Fichtel mountains and the lohemian forest.

Rivers and Lakes.... The chief rivers of Bohemia are the Elbe, 
the Muldau, and the Egra; those of Moravia are the Morawa, which gives name to the country, and the Oder, which rises in the circle of Olmutz, and falls into the Baltic at Siettin, in Pomerania. In Boliemia are a few small lakes, but which have nothing to merit notice. "

Metals and minerals....Bohemia contains rich mines of silver, quicksiver, iron, copper, lead, and especially tin; as also sulphur and saitpetre. Above' a hundred towns and places might be named where mine-works have been etablished. Various species of marble and almost every kind of precious stones are found here; but, in general, they are deficient in hardness. In Moravia, in the circle of Brunn, are iron mines, and quarries of marble; and in the circle of Znaim were formerly gold mines : at present there are mines of iron, sulphur, saltpetre, and vitriol.

Climate, soll, AND PRoduce....The climate of Bohemia is warm, pleasant, and wholesome; the soil is in general rich, but in some places sandy. It is very fertile in corn, considerable quantities of which are exported, as also in pasturage, garden and orchard fruits, and excelleni hops. Moravia resembles Bohemia in its climate, soil, and produce; but agriculture, according to Mr. Marshall, is somewhat better understood and conducted in the latter country.

Animals....The wild animals of Bohemia are bears, lynxes, wolves, foxes, martens, badgers, beavers ; the tame, black cattle, sheep, and an excellent breed of horses. The woods abound in game and wild fowl. In Moravia is found a species of leopards, of the size of $\operatorname{dog} s$, but thicker, called, by the inhabitants, rysowe.

Population, national character, Manners, and customs...The population of Bohemia was estimated in 1803 , at $3,111,472$, and that of Moravia at $1,363,817$. The Bohemians, in their persons, habits, and mauners, resemble the Germans. There is among them no moddie state of people; for every lord is a sovereign, and every tenant a slave. But the emperor Joseph II, generously discharged the Bohemian peasants, on the imperial demesnes, from the state of villanage in which they have been so long and so unjustly retained; and it will be happy if his example should be followed by the Bohemian nobility, and the $y$ be thereby induced no longer to deprive their vassals of the rights of human nature. Although the Bohemians, at present, are not remarkable either for arts or arms, yet they formeriy distinguished themselves as the most intrepid assertors of civil and religious lilerty in Europe; witness the early introduction of the reformed religion into their country, when it was scarcely known in any other; the many glorious defeats they gave to the Austrian power; and their generous struggles for independence. Their virtues may' be considered as the causes of their decay, as no means were left unemployed by their despotic masters for breaking their spirit: though it is certain their internal jealousies and dissensions greatiy contributed to their subjection. Their customs and diversions are the same as in Germany.

Cities, chief towns....The capital of Bohemia is Prague, situate -almost in the centre of the kingdom, on both sides of the river Muldau. It is three German, or more than twelve English, miles in circumference; contains a cathedral, ninety-two churches and chapels, about forty convents, and 80,000 inhabitants, of whom about 10,000 are Jews. Here is a noble bridge of eishteen arches ovcr the Muldau, which separates what is called the old town from the new. It is a place of little or no trade, and therefore the middling inhabitants are 
not wealthy; but the Jews are said to carry on a large commerce in jewels.

Reichenberg, in the circle of Bunzlau, is the next city to Prague for importance and population, containing about 10,000 inhabitants, and having considerable linen manufactures.

Olmutz, an ancient and strongly fortified city, was formerly the capital of Moravia; but Brum is now considered as such, being the seat of the administration of the Austrian government. Brunn is likewise a strong city, containing about 16,000 inhabitants, and having manufactures of cloth, velvets, and plush.

Manufactures, commerce.... The manufactures of Bohemia are numerous and flourishing. The linen manufacture it is computed employs above 300,000 persons, the woollen 60,000 , and the cotton 50,000. Bohemia is likewise celebrated for beautiful glass and paper. The manufactures of Moravia are nearly the same. The exports of these from both countries are very considerable.

Constitution and Governarent....The forms, and only the forms, of the old Bohemian constitution still subsist; but the government under the emperor is despotic. The states are composed of the clergy, nobility, gentry, and representatives of towns. Their sovereigns of late have not been fond of provoking them by ill usage, as they have a general aversion towards the Austrians. This kingdom is frequently described as part of Germany, but with little reason; for it is not in any of the nine circles, nor does it contribute any thing towards the forces or revenues of the empire, nor is it subject to any of its laws. What gives some colour to this mistake, is, that the king of Bohenia is the first secular elector of the empire, and their kings have been elected emperors of Germany for many years.

The government of Moravia, which since the year 1526 has been subject to the house of Austria, is administered by a council and president appointed by the emperor. The states, however, which are similar in their composition to those of Bohemia, meet annually on a celtain day, as a matter of form.

Arms.... The arms of Bohemia, are, argent, a lion gules, the tail moved, and passed in saltier, crowned, langued, and armed, Or. The arms of Moravia are a crowned eagle in a field azure.

Revenue.... Bohemia contributes to the revenue of Austria about $8,900,000$ rix dollars (or nearly 1,400,000l. sterling) and Moravia about $2.660,000$ or $440,000 l$. sterling.

ReLigion....The cstablished religion of Bohemia is the Romancatholic, yet there are many protestants among the inhabitants, who are now tolerated in the free exercise of their religion. The religion of Moravia is in like manner catholicism: but there are many Lutherans; and some of the Moravians have embraced a visionary unintelligible protestantism, if it deserves that name, which they have propagated by their zealous missionaries in several parts of the globe. They have a meeting-house in London, an establishment at Bedford, and are found in various parts of the American states.

Prague is an archbishopric, and Koningingrats a bishopric. In Moravia, Olmutz is a bishopric, under the archbishopric of Prague.

Universities. .. The only university in Bohemia is that of Prague, founded in 1347 : it once could boast 30,000 students, but now has not more than 200. In Moravia is the university of Olmutz, founded in 1567.

LANGUAGE...The language of Bohemia is a dialect of the Slavonic; 
that of Moravia differs very little from it; but German is very com: moniy spoken in boin countries.

History.... The Boil, from whom, as mentioned above, the country derived its name, were driven out by the Marcomanni. Bohemia becane afterwards a province of the Ostrogoths, Lombards, Thuringians, and Franks, till in 534 it was overrun by the Slavi. Charlemagne, and some of his successors, made these new inliabitants tributary; but they soon regained their independence, though they still preserved a certain connexion with the German empire. The Bohemian nobility however elected their own princes, though the emperors of Germany sometimes imposed a king upon them, and at length usurped that throne themselves. In the year 14.38, Albert II, of Austria received three crowns : Hungary, the Empire, and Bohemia.

In 1414, John Huss, and Jerome of Prague, two of the first reformers, and Bohemians, were burnt at the council of Constance, though the emperor of Germany had given them his protection. This occasioned an insurrection in Bohemia : the people of Prague threw the emperor's officers out of the windows of the council chamber; and the famous Zisca, assembling an army of 40,000 Bohemians, defeated the emperor's forces in several engagements, and drove the imperialists out of the kingdom. The divisions of the Hussites among themselves enabled the emperor to regain and keep possession of Bohemia, though an attempt was made to throw off the imperial yoke, by electing, in the year 1618, a protestant king in the person of the prince palatine, son-in-law to James I, of England. The misfortunes of this prince are well known. He was driven from Bohemia by the emperor's generals, and, being stripped of his other dominions, was forced to depend on the court of England for a subsistence. Since the war of thirty years, which desolated the whole empire, the Bohemians have remained subject to the house of Austria.

Moravia was anciently inhabited by the Quadi, who were driven out by the Siavi. From the beginning of the eighth to the end of the ninth century, it was a powerful independent kingdom; in the eleventh it was subdued by the German enperors; and in the twelfth made a margravàte; is the fiftecnth century it came into the possession of the house of Austria, to wlich it has ever since remained subject. 


\title{
GALLICIA AND LODOMERIA.
}

\author{
EXTENT AND SITUATION.
}

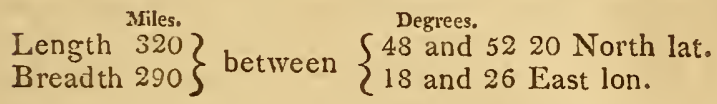

Containing 37,000 square miles, witl 105 inhabitants to eacl.

Bouxdaries....Gallicia is bounded on the nortl and east by Prussian and Russian Poland; on the south by Hungary, Transylvania, and Silesia; and on the west by Silesia.

Divisions.... This country, which is composed entirely of the provinces of dismembered Poland, is divided into East and WVest Gallicia, the former consiscing of the territory assigned to Austria, in the first division of Poland in 1772: and the latter of the part added on the final division and extirction of that kingdom in 1795 .

Eas: Gallicia is divided into eighteen cilcles or districts; viz those of Misiowitz, Ducla, Rseszow, Sanok, Sambor, Lemberg, Tomaschow, Zamosk, Bilz. Brody Zloczow, Mariampol, Stanislow, Zaleszik Lublin, Cheım, Bial, and Siedlitz.

Vest Gallicia is divided into the following twelve circles : Bochnia, Sandez, Przemislaw, Tornow, Cracow, Kielz, Konsk, Olkusch, Radomir, Insul. Radom, and Linow.

FACE OF THE coUntry, moUntaINs, Forests....Gallicia is in general a level country, except towards the south, on which side it is separated from Hungary by the Carpathian mountains. In some parts there are wide sandy plains, and extensive forests and morasses.

Pivers... The principal rivers are the Vistula, which, rising in the Carpathian mountains, traverses the country, and falls into the Baltic sea rear Dantzic, after a course of about 4.50 miles; the Bug, which. divides Gallicia from Russian and Prussian Poland; the Dneister, and the Pruth.

Metals, miserals....This country contains mines of iron, lead, and copper, and quarries of marble. Near Olkusch are mines of silver and lead. The salt mines of Weliczka near Cracow are the rich-. and most productive in Europe, affording a rom.... ling annually; though it is cristrustria. Out of some mines at Itza,
ed since theys riorth-east of Cracow, are dug several kinds of earth, ahich are excellently adapted to the potter's use, and supply all the country with earthern-ware.

Climate, SOIL, PRODUCE....Gallicia is that part of the late kinglom of Poland, which is situater in the mildest climate, and of which the soil is most productive. Except a few sandy tracts, it is extremely fertile both in corn and pasturage. It produces, plentifully, grain of

Vol. I. 
every kind, as also hemp, flax, and tobacco, and would be better ctil, tivated, were there sufficient means of disposing of its produce. Honey and wax are obtained here in great abundance. The manna of this and the other parts of Poland is produced by an herb that grows in the mearlows and marshy grounds: in the months of June and July the inhabitants gather it by sweeping it into sieves, with the dew. It is esteemed a great delicacy by the Poles, who dress it in a variety of ways. The woods abound in oak, beech, pine, and fur trees.

Animals....The forests in the northern parts of Gallicia, and those of Warsovia or Masovia in Prussian Poland, contain great numbers of uri, or buffaloes, whose flesh the Poles powder, and esteem it an excellent dish. Wolves, boars, the glutton, lynx, elks, and deer, all of them wild, are common in the Polish forests; there are also wild horses and asses, and wild oxen. A kind of wolf, resembling a hart, with spots on his belly and legs, is found here, and affords the best fur in the country. The elk, which is common in the northern parts of this country, is a very extraordinary animal. The flesh of the Polish elk forms the most delicious part of their greatest feasts. His body is of the deer make, but much thicker and longer; the legs high, the feet broad, like a wild goat's. Naturalists have observed, that, upon clissecting an elk, there are frcquently found in his head some large flies, and the brain almost eaten away; and it is an observation sufficiently attested, that in the large woods and wildernesses of the north, this poor animal is attacked, towards the winter chiefly, by a larger sort of flies, that, through its ears, attempt to take up their winter quarters in its head. This persecution is thought to affect the elk with the falling sickness, by which means it is frequently taken more easily than it would be otherwise.

Poland produces a creature called bohac, which resembles a guineapig, but seems to be of the beaver kind. They are noted for digging holes in the ground, which they enter in October, and do not come out, except, occasionally for food, till April : they have separate apartments for their provisions, lodgings, and their dead; they live together by ten or twelve in a herd. In the northern parts of this country, and in Lithuania, are found eagles and vultures. The quails, it is said, have green legs, and their flesh is reckoned to be unwholesome. The remiz, or little species of titmouse, is frequently found in these parts : it is remarkable for the wondrous structure of its pendent nest, formed in the shape of a long purse, with amazing art.

The domestic animals are numerous; black cattle, horses of a good breed, and sheep, the wool of which is said to be very fine.

Natural curiosities.... The principal natural curiosity of this country is the salt mines of Wieliczka, which have been mentioned. They consist of wonderful caverns, several hundred yards deep, at the bottom of which are many intricate windings and labyrinths. Out thes a gre lug four different kinds of salts; one extremely hard, these are all brack $10.1, \ldots . .$. hit clearer; a third white, but brittle; four kinds are dug in different mines, near wrat fresher. These one side of them is a stream of salt water, and on the othepw.iz on fresh. The descent into these mines is by pits of great depth; and the galleries and chambers are of immense size, commonly supported by timber, or by vast pillars of salt, out of which material even subterraneous chapels are formed : but the splendour and extent of these saline apartments have been exaggerated by travellers. 
The virtues of a spring in the vicinity of Cracow, which increases and decreases with the moon, are said to be wonderful for the preservation of life : and it is reported that the neighbouring inhabitants commonly live to 100 , and some of them to 150 years of age. This spring is inflanmable, and, by applying a torch to it, it flames like the subtlest spirit of wine. The flame, however, dances on the surface without heating the water : and if neglected to be extinguished, which it may easily be, it communicates itself, by subterraneous conduits, to the roots of trees in a neighbouring wood, which it consumes; and about seventy years ago the flames are said to have lasted for three years before they could be entirely extinguished.

Population, National Character, manners, and customs...The number of innabitants in Eastern Gallicia is estimated at 3,563,816, and in Western Gallicia at $1,281,037$, amounting together to $4,844,853$. The population of the whole of Poland, before its first dismemberment in 1772 , was estimated at $13,404,000$.

The Poles, in their persons, make a noble appearance ; their complexion is fair, and their shapes are well proportioned. They are brave, honest, and hospitable; and their women sprightly, yet modest, and submissive to their husbands. Their mode of salute is to incline their heads, and to strike their breasts with one of their hands, while they stretch the other towards the ground; but when a common person meets a superior, he bows lis head near to the earth, and with his head touches the leg near to the heel of the person to whom he pars obeisance. Their diversions are warlike and manly : vaulting, dancing, and riding the great horse, hunting, skaiting, bull and bear baiting. They usually travel on horseback; a Polish gentleman will not travel a stone's throw without his horse; and they are so hardy, that they will sleep upon the ground, without any bed or covering, in frost and snow. 'The Poles never live above stairs, and their apartments are not united : the kitchen is on one side, the stable on another, the dwelling house on the third, and the gate in the front. They content themselves with a few small beds; and if any lodge at their houses, they must carry their bedding with them. When they sit down to dinner or supper, they have trumpets and other nusic playing, and a number of gentlemen to wait on them at table, all serving with the most profound respect; for the nobles who are poor, frequently find themselves under the necessity of serving those that are sich : but their patron usually treats them with civility, and permits the eldest to eat with him at his table, with his cap off; and every one of them has his peasant-boy to wait on him, maintained by the master of the family. At an entertainment, the Poles lay neither knives, forks, nor spoons, but every guest brings thern with him; and they no sooner sit down to table, than all the doors are shut, and not opened till the company return home. It is usual for a nobleman to give his servant part of his meat, which he eats as he stands behind him, and to let him drink out of the same cup with himself; but this is the less extraordinary, if it be considered that these servants are esteemed his equals. Bumpers are much in fashion, both here and in Russia; nor will they easily excuse any person from pledging them. It would exceed the bounds of this work to describe the grandeur and equipages of the Polish nobility; and the reader must figure to himself an idea of all that is fastidious, ceremonious, expensive, and showy in life, to have any conception of their way of living. They sarry the pomp of their attendance, when they appcar abroad, even 
to ridicule; for it is not unusual to see the lady of a Polish grandec, besides a coach and six, with a great number of servants, attended by an oid gentleman-usher, an old gentlewoman for her governante, and a dwart of each sex to hold up her train; and if it be night, her coach is surrounded by a great number of flambeaux.

The Poles are divided into nobles, clergy, citizens or burghers, and peasants : the peasants were of two sorts; those of the crown, and those belonging to individuals. Though Poland had its princes, counts, and barons, yet the whole body of the nobility were naturally on a level, except the difference that arose from the public posts they enjoyed. Hence all who were of noble birth called one another brothers. They did not value titles of honour, but thought a gentleman of Poland the highest appellation they could enjoy. They had many considerable privileges; and, indeed, the boasted Polish liberty was properly limited to them alone, partly by the indulgence of former kings, but more generally from ancient custom and prescription. Under their ancient constitution, before the last partition of the country, they had a power of life and death over their tenants and vassals; paid no taxes; were subject to none but the king; might choose whom they would for their king; and none but they, and the burghers of some particular towns, could purchase lands. In short, they were almost entirely independent, enjoying many other privileges entirely incompatible with a well regulated state; but if they engaged in trade, they forfeited their nobility. These great privileges made the Polish geniry powerful; many of them had large territories, with $a$ despotic power over their tenants, whom they called their subjects, and transferred or assigned over with the lands, cattle, and furniture. Until Casimir the Great, the lord could put his peasant to death with impunity; and, when the latter had no children, considered himself as the heir, and seized all his effects. In 1347, Casimir prescribed a fine for the murder of a peasant; and enacted that, in case of his decease without issue, his next heir should inherit. But these and other regulations proved ineffectual against the power and tyranny of the nobles, and were either abrogated or eluded. Some of them had estates from five to thirty leagues in extent, and were also hereditary sovereigns of cities, with whicl the king had no concern. One of their nobles sometimes possessed above 4000 towns and villages. Some of them could raise $S$ or 10,000 men. The house of a nobleman was a secure asylum for persons who had committed any crime; for none might presume to take them from thence by force. They had their horse and foot guards, which were upon duty day and night before their palaces and in their ante-chambers, and marched before them when they went abroad. They made an extraordinary figure when they came to the diet, some of them having 5000 guards and attendants; and their debates in the senate were often determined by the sword. When great men had suits at law, the diet or other tribunals decided them; yet the execution of the sentence must be left to the longest sword; for the justice of the kingdom was commonly too weak for the grandees. Sometimes they would raise 6000 men of a side, plunder and burn one another's cities, and besiege castles and forts; for they thought it below them to submit to the sentence of judges, without a field-battle. As to the peasants, they were born slaves, and had no idea of liberty. If one lord killed the peasant of anotler, he was not capitally convicted, but only obliged to make reparation by another peasant equal in value. 
The peasants were at the absolute disposal of their master, and all their acquisitions served only to enrich him. They were indispensably obliged to cultivate the earth; they were incapable of entering upon any condition of life that might procure them freedom, without the permission of their lords : and they were exposed to the dismal and frequently fatal effects of the caprice, cruelty, and barbarity of their tyrannical masters. In modern times, indeed, a few nobles of enlightened understandings ventured to give liberty to their vassals. The first who granted this freedom was Zemoiski, formerly great chancellor, who in 1760 enfranchised six villages in the palatinate of Masovia, and afterwards on all his estaies. The event showed the project to be no less judicious than humane, equally conducive to the interests of the nobles and the happiness of the peasants; for it appeared that, in the districts in which the new arrangements had been introduced, the population of the villages considerably increas. ed, and the revenues of their estates were augmented in a triple proportion. Prince Stanislaus, nephew of the late king of Poland, likewise enfranchised four viliages near Warsaw; and not only emancipated his peasants from slavery, but condescended to direct their affairs.

Whether the same liberal policy will be adopted by the governments which have seized and divided Poland, time must show; but in their dominions, especially in Russia, many of the peasants do not appear to be in a much better condition.

The inns in this country are long stables, built with boards, and covered with straw, without furniture or windows; there are chambers at one end; but none can lodge there, because of flies and other vermin; so that strangers generally choose rather to lodge among the horses. Travellers are obliged to carry provisions with them; and when foreigners want a supply, they apply to the lord of the village, who forthwith provides them with necessaries.

Dress.... The dress of the Poles is rather singular. 'They shave their heads, leaving only a circle of hair upon the crown, and men of all ranks generally wear large whiskers. They wear a vest which reaches down to the middle of the leg, and a kind of gown over it lined with fur, and girded with a sash; but the sleeves fit as close to their arms as a waistcoat. Their breeches are wide, and make but one piece with their stockings. They wear a fur cap or bonnet; their shirts are without collar or wristbands, and they wear neither stock nor neckcloth. Instead of shoes, they wear Turkey leather boots; with thin soles, and deep iron heels bent like a half moon. They carry a pole-axe, and a sabre, or cutlass, by their sides. When they appear on horseback, they wear over all a short cloak, which is commonly covered with furs both within and without. The people of the best quality wear sables, and others the skins of tigers, leopards, \&rc. Some of them have fifty suits of clothes, all as rich as possible, and which descend from father to son. Were it not for our own partiality to short dresses, we must acknowledge that of the Poles to be picturesque and majestic. Charles II, of England thought of introducing the Polish dress into his court, and, after his restoration, wore it for two years, chiefly for the encouragement of the English brcad-cloth; but discontinued it through his connections with the French.

The habit of the women very much resembles that of the men; a simple Polonaise, or long robe edged with fur; but some people of 
fashion, of both sexes, affect the French or English modes. As to the peasants, in winter they wear a sheep's-skin with the wool inwards, and in summer a thick coarse cloth ; but as to linen, they wear none. Their boots are the rinds of trees wrapped about their legs, with the thicker parts to guard the soles of their feet.

Citres, chief Towns...Lemberg, or Leopol, is the capital of Gallicia, and the seat of the Austrian government of East Gallicia. It is a large and opulent city, situate on the Peltew, which soon after falls into the Bug. It is the see of a Roman-catholic archbishop, and also of a Greek bishop and an Armenian bishop. It is defended by two castles, has a cathedral, and contained in 1808 about 50,000 inhabitants. Brody is a commercial town, with a fortified castle, and 21,000 inhabitants, one-third of whom are Jews. Lublin carries on a considerable trade in clotn, corn, and Hungarian wines. Three annual fairs are held here, which are frequented by Russian, Turkish, Greek, and Armenian merchants. Chelm, and Luckow, both bishops' sees, are likewise among the principal towns of East Gallicia.

Cracow is the seat of the Austrian government of West Gallicia ; and was anciently the capital of the kingdom of Poland. The city and suburbs are of great extent, but do not now contain more than 25,000 inhabitants. It is the see of a bishop, and a university. Here is a magnificent cathedral, in which the kings of Poland were crowned, and an ancient and strongly fortified castle, which was the residence of those sovereigns before they removed their court to Warsaw. Sendomir, situate on an eminence near the Vistula, is another considerable town of West Gallicia. It is well fortified both by nature and art, and its delightful situation rendered it the favourite residence of Casimir the Great, and other kings of Poland.

Warsaw, the late capital of Poland, will be described in our account of Prussia, to which monarchy it now appertains.

Manufactures, commerce.... The manufactures of Gallicia are not very considerable, and are confined to articles of immediate necessity. They are however greatly favoured by the Austrian government, and are increasing and improving. The commerce of this country is principally carried on by the Jews. Salt is the most important article of the exports, which consist besides of corn, tobacco, cattle, wool, skins, tallow, bristles, honey, and wax.

Government, and ancient constitution of poland...Gallicia, as making a part of the Austrian dominions, is now necessarily under an absolute monarchical government. The old constitution of Poland differed little from aristocracy : hence it has been called a kingdom and commonwealth. The king was head of the republic, and was elected by the nobility and clergy in the plains of Warsaw. They elected him on horseback; and in case there should be a refractory minority, the majority had no control over them but to cut them in pieces with their sabres; but if the minority were sufficiently strong, a civil war ensued. Immediately after his election, he signed the jacta conventa of the kinglom, by which he engaged that the crown should be elective; that his successor should be appointed during his life; that the diets should be assembled every two years; that every noble or gentleman in the realm should have a vote in the diet of election; and that, in case the king should infringe the laws and privileges of the nation, his subjects should be absolved from their allegiance. In fact, the king was no more than president of the senate, which was composed of the primate, the archbishop of Lem. 
berg, fifteen bishops, and 130 laymen, consisting of the great officers of state, the palatines, and castellans. The palatines were the gover. nor's of the piovinces, who held their offices for life. The offices of tire castellans in time of peace were almost nominal; but when the military or feudal services were required, they were the lieutenants of the palatines, and commanded the troops of their several districts.

The diets of Poland were ordinary and extruordinary : the former met once in two, and somerimes three years; the latter was summoned by the king, upon critical emergencies, and continued no longer than a fortnight; but one dissenting voice rendered all their deliberations ineffectual. Previous to a general diet, either ordinary or extraordinary, which could sit but six weeks, there were dietines, or provincial diets, held in different districts. The king, with the advice of the permanent council, sent them letters, containing the heads of the business that was to be treated of in the general diet. The gentry of each palatinate might sit in the dietine, and choose nuncios or deputies to carry their resolutions to the grand diet. The great diet consisted of the king, senators, and deputies from provinces and towns, viz. 178 for Poland and Lithuania, and 70 for Prussia : it met twice at Warsaw, and once at Grodno, by turns, for the convenience of the Lithuanians, who made it one of the articles of their union with Poland; but in the late reign they were always summoned to Warsaw.

Revenue...A Austria derives from Gallicia a revenue of from ten to twelve millions of florins, or about $1,200,000 l$. sterling. The whole revenue of the late kingdom of Poland was estimated at only $440,000 l$. sterling.

Polish ORDERS OF KNighthood...The "Order of the White Eagle" was first instituted by Uladislaus, in the year 1325, but revived by Augustus I, in the year 1705 , to attach to him some of the Polish nobles, who, he feared, were inclined to Stanislaus, his competitor: it was conferred also on the czar, Peter the Great, of Russia. Its ensign is a cross of gold enamelled with red, and appendant to a blue ribband: the motto, Pro fide, rege et lege. The late king instituted the "Order of St. Stanislaus," soon after his election to the crown in 1765. The badge is a gold cross enamelled red, and on the centre of it is a medallion, with the image of St. Stanislaus, enamelled in proper colours. It is worn pendent to a red ribband edged with white. The star of the order is silve?, and in the centre is a cypher of S. A. R. (Stanislaus Augustus Rex) encircled with the motto "Premiando incitat."

PEIIGrox....The established religion of this country is the Romancatholic : but Lutherans, Calvinists and Greeks are tolerated; and the Jews, who are very numerous, enjoy considerable privileges, as they do in the rest of the Austrian states.

The principles of Socinianism made a very early and considerable progress in Poland. A translation of the bible into the Polish language was published in 1572 ; and two years after, under the direction of the same persons, the catechism, or confession, of the Unitarians was published at Cracow. The abilities and writings of Socinus greatly contributed to the extensive propagation of his opinions; but though the Socinians in Poland have been very numerous, wey have at different times been greatly persecuted. At present a morc liberal toleration prevails. 
Lemberg, as mentioned above, is an archbishopric; the bishoprics are Cracow, Chelm, and Luckow.

In the late kingdom of Poland were two archbishoprics, Gnesna and Lemberg. The archbishop of the former was primate, and always a cardinal. During an interregnum he acted as regent of the kingdom. Gnesna is now in the territory of Prussia.

Literature... Though Copernicus, the great restorer of the true astronomical system, Vorstius, and some other learned men, were natives of Poland, yet many circumstances in this country are far from being favourable to learning. Latin is spoken, though incorrectly, by the common people in some parts. But the contempt which the nobility, who place their chief importance in the privileges of their rank, have ever shown for learning; the servitude of the lower people; and the universal superstition among all ranks of them, have wonderfully retarded, and, notwithstanding the liberal efforts of his late majesty, still continue to retard, the progress of letters in this kingdom. However, of late, a taste for science has spread itself among the nobles, and begins to be regarded as an accomplisiment.

UN1versities...The university of Cracow was founded in 1364. It consists of eleven colleges, and had the superintendance of 14. grammar schools dispersed through the city. The number of students in 1778 amounted to 600 . Of the other two universities of Poland, Wilna, and Posna or Posen; the former has become subject to Russia, and the latter to Prussia.

Language... The native language of this country is the Polish: the German, however, is understood in many parts of it; and, as above observed, an impure and incorrect Latin is also in use. The Polish language is a dialect of the Slavonic; it is harsh and unharmonious, from the great number of consonants it employs.

The Lord's prayer in Polish is as follows:

Oycze nass ktory na niebiesiech iestes; niech sie swieci imie twoie; niech frzyidzic ono krolestwo twoie, niech sie stanie ona qvola twoia iako u niebie tak y na ziemi. Chleba nassego onego porvssedniego day nam $d z i s i a, y$ odfuse nam nasse winy, iako y my od hussczamy zvinoqvaycom nassym; y nie u rodz nas u pokussenie; ale rvyrwi nas od onego slego: iz twoie iest krolestruo, y moc, y chrvala na wieki. Amen.

History....As the whole of this country was a part of the late kingdom of Poland, its history will necessarily be included in the history of Poland, a summary of which we shall here give.

Poland, in ancient times, was possessed by the Vandals, who were afterwards partly expelled by the Russ and Tartars. It was divided into many small states or principalities, each almost independent of the other, though they generally had some prince who was paramount over the rest. In the year 700, the people, through the oppression of their petty chiefs, gave the supreme command, under the title of duke, to Cracus, the founder of the city of Cracow. His posterity failing, in the year 830 , a peasant, named Piastus, was elected to the ducal dignity. He lived to the age of 120 years; and his reign was so long and auspicious, that every native Pole who has since Been elected king is called a Piast. From this period till the accession of Micislaus II, in 964, we have no very certain records of the history of Poland. The title of duke was retained till the year 999, when Boleslaus assumed the title of king, and conquered Moravia, Prussia, and Bohemia, making them tributary to Poland. Boleslars's II, added Red Russia to Poland, by marrying the heiress of that 
Juchy, anno 1059. Jagello, who in 1384 mounted the throne, was grand duke of Lithuania, and a pagan; but on his being elected king of Poland, he not only become a Christian, but used every endeavour to bring over his subjects to that religion. He united his hereditary dominions to those of Poland; which gave such influence to his poster. ity orer the hearts of the Poles, that the crown was preserved in his family, until the male line became extinct in Sigismund Augustus, in 1572 , who admitted the reformerl, with Greeks and all other sects, to a seat in the diet, and to all the honours and privileges before confined to the catholics He gave such evident marks of favour to the protestant confession, that he was suspected of being inclined to change his religion. At this time two powerful competitors appeared for the crown of Poland; these were, Henry, duke of Anjou, brother to Charles IX, king of France, and Maximilian of Justria. The Frencls interest prevailed, by private bribes to the nobles, and a stipulation to pay an innual pension to the republic from the revenues of France; but Henry had not been four months on the throne of Poland when his brother died, and he returned privately to France, which kingdom he governed by the name of Henry Iif. The party who had espoused the interest of Mlaximilian, endeavoured once more to revive his pretensions; but the majority of the Poles being desirous to choose a prince who night reside among them, made choice of Stephen Batori, prince of Transylvania, who, in the beginning of his reign, meeting with same opposition from the Austrian faction, took the wisest method to establish himself on the throne, by marrying Anne, the sister of Sigismund Iugustus, and of the royal house of the Jagellons. Stephen produced a great change in the military affairs of the Poles, by establishing a new militia, composed of Cossacs, a rough and barbarous l'ace of mell, on whom he bestowed the Uklaine, or frontiers of his kingdom. Upon his death, in 1586, the Poles chose sigismund, son of John, king of Swerlen, by Catharine, sister of Sigismund II, for their king

Sigismund was crowned king of Sweden after his father's 'death; but being expelled, as we have seen in the history of Sweden, by the Swedes, a long war ensued between them and the Poles, but terminated in favour of the latter. Sigismund being secured in the throne of Poland aspired to that of Russia as well as Sweden; but after long wars he was defeated in both views He was afterwards engaged in a variety of unsuccessful wars with the Turks and Swedes. At last a truce was concluded under the mediation of France and England : but the Poles were forced to agree that the Swedes should keep Elbing, Memel, Braunsberg, and Pillau, together with all they had taken in Livonia. In 1623, Sigismund died, and Uladislaus, his son succeeded. This prince was successful both against the Turks and the Russians, and obliged the Swedes to restore all the Polish dominions they had taken in Prussia. His reign, however, was unfortunate, by his being instigated, through the avarice of his nobles and generals, to encroach upon the privileges of the Cossacs in the Ukraine. As the war whicin followed was carried on against the Cossacs upon ambitious and perfid ous principles, the Cossacs, naturally a bave people, became desperate; and on the succession of John II, brother to Uladislaus, the Cossac general Schmielenski deleated the Poles in two great battles, and forced them to a dishonourable peace. It appears that, during the course of this war, the Polish nobility behaved as the worst of ruflians, and their conduct was highly condemnetl by John; while his nobility 
disapproved of the peace he had concluded with them. As the jealousy hereby occasioned continued, the Russians came to a rupture with the Poles; and being joined by many of the Cossacs, they, in 1654 , took Smolensko. This was followed by the taking of Wilna and other places; and they coinmitted most horrid ravages in Lithuania. Next year Charles X, of Sweden, after overrunning Great and Little Poland, entered into Polish Prussia, all the towns of which received him, except Dantzic. The resistance made by that city gave the Poles time to reassemble; and their king, John Cassimir, who had fled into Silesia, was joined by the Tartars as well as the Poles: so that the Swedes, who were dispersed through the country, were every where cut in pieces. The Lithuanians, at the same time disowned the allegiance they had beell forced to yield to Charles, who returned to Sweden with no more than a handful of his army. It was during this expedition that the Dutch and English protected Dantzic, and the elector of Brandenburg acquired the sovereignty of Ducal Prussia, which had submitted to Charles. Thus the latter lost Poland, of which he had made an almost complete conquest. The treaty of Oliva was begun after the Swedes had been driven out of Cracow and Thorn, by which Royal Prussia was restored to the Poies. They were, however, forced to quit all pretensions to Livonia, and to cede Smolensko, Kiow, and the duchy of Siveria, to the Russians.

During these transactions, the Polish nobility grew dissatisfied with the concessions their king had made to the Cossacs, many of whom had thrown off the Polish yoke; others charged him with want of capacity ; and some, with an intention to rule by a mercenary army of Crermans. Casimir, who very possibly had no such intentions, and was fond of retirement and study, finding that cabals and factions increased every day, and that he himself might fall a sacrifice to the public discontent, abdicated his throne, and died abbot of St. Germain in France, employing the remainder of his days in Latin poetical compositions, which are far from being despicable.

The most remote descendants of the ancient kings ending in John Casimir, many foreign candidates presented themselves for the crown of Poland; but the Poles chose for their king a private gentleman, of little interest and less capacity, one Michael Wiesnowiski, because he was descended from a Piast. His reign was disgraceful to Poland. Large bodies of Cossacs had put themselves under the protection of the Turks, who conquered all the provinces of Podolia, and took Kaminieck, till then thought impregnable. The greatest part of Poland was then ravaged, and the Poles were obliged to pay an annual tribute to the Sultan. Notwithstanding those disgraceful events, the credit of the Polish arnis was in some measure maintained by John Sobieski, the crown general, a brave and active commander, who had given the Turks several defeats. Michacl dying in 1673 , Sobieski was chosen king; and in 1676 he was so successful against the infidels, that he forced them to remit the tribute they had imposed upou Poland; but they kept possession of Kaminieck. In 1683 , Sobieski, though he had not been well treated by the house of Austria, was so public spirited as to enter into the league that was formed for the defence of Christendom against the infidels, and acquired immortal lonour, by obliging the Turks to raise the siege of Vienna, and making a terrible slaughter of the enemy; for all which glorious services, and driving the Turks out of Hungary, he was ungratefully requited by the emperor Leopold.

Sobieski returning to Poland continued the war against the Turks, 
but unfortunately quarrelled with the senate, who suspected that he wanted to make the crown hereditary in his family. He died, after a glorious reign, in 1696.

After the death of Sobieski, Poland fell into great distractions. Many confederacies were formed, but all parties seemed inclined to exclude the Sobieski family. In the mean time Poland was insulted by the Tartars, and the crown in a mianner put up to sale. The prince of Conti, of the blood royal of France, was the most liberal bidder; but while he thought the election almost sure, he was disappointed by the intrigues of the queen dowager, in favour of her younger son, prince Alexander Sobieski, for which she was driven from Warsaw to Dantzic. Suddenly Augustus, elector of Saxony, started up as a candidate; and after a sham election, being proclaimed by the bishop of Cujavia, he took possession of Cracow with a Saxon army, and actually was crown. ed in that city in 3697 . The prince of Conti made several unsuccessful efforts to re-establish his interest, and pretended that he had been actually chosen; but he was afterwards obliged to return to France, and the other powers of Europe seemed to acquiesce in the election of Augustus. The manner in which the latter was driven from the throne, by Charles XII, of Sweden (who procured the advancement of Stanislaus) and afterwards restored by the czar, Peter the Great, has been already related in the history of Sweden. It was not till the year 1712 that Augustus was fully confirmed on the throne, which he held upon precarious and disagreeable terms. The Poles were naturally attached to Stanislaus, and were perpetually forming conspiracies and plots against Augustus, who was obliged to maintain his authority by means of his Saxon guards and regiments. In 1725, his natural son, prince Maurice, afterwards the famous count Saxe, was chosen duke of Courland; but Augustus was not able to maintain him in that dignity against the power of Russia and the jealousy of the Poles. Augustus died, after an unquiet reign, in $173 \mathrm{~s}$, having done all he could to instire the succession of Poland to his son Augustus II (or, as he is called by some, III.) This occasioned a war, in which the French king maintained the interest of his father-in-law, Stanislaus, who was actually reelected to the throne by aconsiderable party, of which the prince primate was the head. But Augustus, entering Poland with a powerful army of Saxons and Russians, compelled his rival to retreat to Dantzic, whence he escaped with great difficulty into France. In the history of Germany, the war between Augustus IY, as elector of Saxony, or rather as the ally of Russia and Austria, and Frederic il, king of Prussia, has been already noticed. It is sufficient to say, that though Augrustus was a mild and moderate prince, and did every thing to satisfy the Poles, he never could gain their hearts; and all he obtained from them was merely shelter, when the king of Prussia drove him from his capital and electorate. Augustus died at Dresden in 1763, upon which count Stanislaus Poniatowski was chosen king, by the name of Stanislaus Augustus; though it is said that the election was conducted irregularly, and that he ostained the crown chiefly through the influence of the empress of Russia. He was a man of abilities and address; but from various concurring causes, he had the unhappiness to see Poland, during his reign, a scene of desolation and calamity. In 1766 a petition was presented to the king, in the name of all the protestant nobility, and in behalf also of the nembers of the Greek cliurch, conjointly called the dissidents, in which they demanded to be re-instated in their ancient righis and privileges, and to be placed upon the same footing 
in every respect as the Roman-catholic subjects of the kingdom. The king gave no answer to the petition of the dissidents; but the matter was referred to the diet, which was held the following year, when the minister's of the courts of Russia, London, Berlin, and Cupenhagen, supported their pretensions. The diet appeared to receive the complaints of the dissidents with great moderation, as to the free exercise of their worship; which gave some flattering expectations that the affair would be happily terminated. But the intrigues of the king of Prussia appear to have prevented this: for, though lie openly professed to be a zealous defender of the cause of the dissidents, it was manifest, from the event, that his great aim was to promote the views of his own ambition. The intervention of the Russians in the affairs of Poland also gave great clisgust to all parties in the kingdom. The whole nation ran into confederacies formed in distinct provinces; the popish clergy were active in opposing the cause of the dissidents ; and this unfortunate country became the theatre of the most cruel and complicated of all war's, partly civil, partig religions, and partly foreign. The confusion, devastation, and civil war, continued in Poland during the years 176,1770 , and 1771 , whereby the whole face of the country was almost destroyed; many of the principd popish families retired into foreign states with their effects ; and had it not been for a body of Russian troops, whicn acted as guards to the king at Varsaw, that city had likewise exhibited a scene of plunder and massacre. To those complicated evils were added, in the year 1770, that most dreadful scourge the pestilence, which spread from the frontiers of Turkey to the adjoining provinces of Podolia, Volhynia, and the Ukraine; and in these provinces, it is said, swept off 250,000 people. Meanwhile some of the Polish confederates interceded with the Turks to assist them ayain t their powerful oppressors; and a war ensued between the Russians and the Turks on account of Poland. The conduct of the grand seignior, and of the Ottoman Porte, towards the distressed Poles, was just and honourable, and the vory reverse of that of their Christian, catholic, and apostolic neighbours.*

* In 1764 , the empress of liussia transmitted to the court of Warsaw an act of renunciation, signed with her own hand, and sealed with the seal of the empire : in which she declares, "That she did by no means arrogate either to lierself, he? heirs and successors, or to her empire, any right or claim to the districts or terri. tories which are actually in possession, or subject to the authority, of the kingrom of Poland, or great duchy of Lithuania ; but that, on the contrary, her said majesty would guarantee to the said kingdom of Poland and duchy of Lithuania all the immmities, lands, territories, and districts, which the said kingdom and duchy ought by right to possess, or did now actually possess; and would at all times, and for ever, maintain them in the full and free enjorment thereof, against the attempts of all and every one who should, at any time, or on any pretext, endeav our, to dispossess them of the same." In the same year clid the king of Prussia sign, with his own hand, an act, wherein he declared, "That he had no claims, formed no pretensions on P'oland, or any part thereof: that he renounced all claims on that kingdom, either as king of Prussia, elector of Brandenburg, or cluke of Pomerania" in the same instrument he guarantees, in the most solemn manner, the territories and rights of Polaind against every power whatever. The entpress queen of Hingary, so late as the month of January 1771 , wrote a letter with her own hand to the king of Poland, in which she gave him the strongest assurances, "That her friendship for him and the republic was firm and unaltera. ble; that the motions of her troops ought not to alarm him; that she had never entertained a thought of seizing any part of his dominions, not would even suffer any other power to do it." From which, according to the political creed of princes, we may infer, that to guarantee the rights, liberties, and revenues of a state, means to anuihilate those liberties, seize upon those rights, and appropriate those revenues to their own use. Such is the faith of princes! 
In the year 1772, it appeared that the king of Prussia, the emperor and empress-queen, and empress of Russia, had entered into an alliance to divide and dismember the kingdom of Poland ; though Prussia was formerly in a state of vassalage to Poland, and the title of king of Prussia was never acknowledged by the Poles till 1764. Russia also in the beginning of the 17 th century, saw its capital and throne possessed by the Poles; while Austria, in 1683, was indehted to a king of Poland for the preservation of its metropolis, and almost for its very existence. These three allied powers, acting in concert, set up their formal pretensions to the respective districts which they had allotted for and guaranteed to each other; Polish or Western Prussia, and some districts bordering upon Brandenburg, for the king of Prussia; almost all the south-east parts of the kingdom bordering upon Hungary, together with the rich salt-ivorks of the crown, for the empress-queen of Hungury and Bohemia; and a large district of country about Mohilow upon the banks of the Dmeper, for the empress of Russia. But though each of these powers pretended to hate a legal title to the territories which were allotted them respectively, and published manifestoes in justitication of the measures which they had taken, yet as they were conscious that the fallacies by which they supported thcir pretensions were too gross to impose upon mankiud, they forced the Poles to call a new diet, and threatened them, that ii they did not consent unanimous. ly to sign a treaty for the ceding of those provinces to them respectively, the whole kingdom should be laid under a military execution, and treated as a conquered state. In this extremity of distress, several of the Polish nobility protested against this violant act of tyranny, and retired into foreign states, choosing rather to live in exilc, and to have all their landed property confiscated, than to be instruments of bringing their country to utter ruin: but the king, under the threatening of deposition and imprisonment, was prevailed upon to sign this act, and his example was followed by many of his subjects.

The conduct of the king of Prussia in Poland was the most tyrannical that can be conceived an the year 1771, his troops entered into Great Poland, and carried off from that province and its neighbourhood, at a moderate computation, 12,000 families. On the 29 th of October, in the same year, he published an edict, commanding every person, under the severest penalties, and even corporal punishment, to take is payment, for for'are, provisions, corn, horses, \&xc. the money offered by his troops and commissaries. This money was either silver, bearing the impression of Poland, and exactly worth one-third of its nominal value, or ducats struck in imitation of Dutch ducats, seventeen per cent. inferior to the real ducats of Holland. With this base money he bought up corn and forage enough, tut only to suppiy his army for two whole years, but to stock magrazines in the country itself, where the inhabitants were forced to come and re-purchase corn for their daily subsistence, at an advanced price, and with good money, his commissaries refusing to take the same coin they had paid. At the lowest calculation, he gained, by this honest manceuvre, seven millions of dollars. Having stripped the country of money and provisions, his next attempt was to thin it still more of its inhabitants. To people his own dominions at the expense of Poland had been his great aim : for this purpose, he devised a new contribution; every town and village was obliged to furnish a certain number of murriageable girls; the parents to give, as a portion, a feather-bed, four pillows, a cow, two hogs, and three ducats in gold. Some were bound hand and foot, and carried of as 
criminals. His exactions from the abbeys, convents, cathedrals, and nobles, were so heavy, and exceeded at last their abilities so much, that the priests abaudoned their churches, and the nobles their lands. These exactions continued with unabated rigour, from the year 1771 to the time the treaty of partition was declared, and possession taken of the provinces usurped. From these proceedings, it would appear that his Prussian majesty knew of no rights but his own; no pretensions but those of the house of Brandenburg; no other rule of justice but his own pride and ambition.

In the year 1788, the Poles made some endeavours to assert their independence. The diet met, and the king proposed a confederation, which was agreed to, and the army ordered to be reinforced to 100,000 men. As the evils of an elective monarchy had been the chief cause that Poland had almost ceased to be considered as a nation, a new constitution was framed, and approved by the diet and the king, on the $3 \mathrm{~d}$ of May 1791. By this constitution the line of the future kings of Poland was to commence in Frederic-Augustus, elector of Saxony; and, in case he should have no male issue, a husband chosen by him for his daughter was to commence the dynasty. But this constitution was opposed by the partitioning powers; and, after a short and unequal struggle with Russia, this unhappy country was forced to abandon it. The manifesto of the Russian Empress, rephete with sentiments disgraceful to humanity, was followed by some skirmishes; but it is said that a letter, written with her own hand to the Polish king, in which she declared her resolution to double or triple her troops, rather than abandon her pretensions, induced that benignant monarch to prevent the further effusion of blood

On the 6th of January 1793, the king of Prussia issued a declaration respecting the march of his troops into Poland, and soon after the Prussian army advanced, and one of its detachments appeared under the walls of Thorn. The inhabitants refusing entrance to the troops, the gates were forced, the municipal guard dislodged from their post, and the Prussian regiments entered the defenceless city, as if it had been a place taken by assault. At the same time different Polish detachments, dispersed throughout Great Poland, were attacked and driven from their posts by superior force.

On the 2d of April the Prussian troops took possession of Dantzic ; and, about the same time, the empress of Russia commanded the king of Poland to remove to Grodno, under the escort of Russian troops, for the express purpose of sanctioning the alienation and partition of his kingdom.

The means employed to effect the mock ratification of the partition of this unfortunate country were entirely characteristic of the baseness of the cause. The diet in the month of September, was assailed for three successive days with official notes from the Russian ambassador and the Prussian minister, full of threats, pressing the signature of the treaty. The states, however, persisted in their refusal. At last $\mathbf{M}$. de Sievers, the Russian ambassador, sent his ultimatum in a note, which ended with the following remarkable expressions: "The underwritten must besides inform the states of the republic assembled in the confederate diet, that he thought it of absolute necessity, in order to prevent every disorder, to order two battalions of grenadiers, with four pieces of cannon, to surround the castle, to secure the tranquility of their deliberations The underwritten expects that the sitting will not terminate until the demanded signature of the treaty is 
decided." Conformably to this threat, the Russian soldiers so closeIr surrounded the castle, that no person was suffered to go out : some of the officers took their station in the senate, pretending to guard his majesty's person against conspirators. The king, however, sent a delegation to the Russian ambassador declaring that he would not open the session in the presence of the Russian officers. In consequence, they were ordered to retire, except the general, who declared publicly, that no member should be permitted to quit the senate before consent to the treaty was given. 'The debates were long and violent; and it Was not until three o'clock the next morning, after three successive divisions, that the diet came to a resolution, in which they declare, before all Europe, to whom they had frequently appealed, that " Contrary to the faith of treaties most sacredly observed on their part, as well as to that of the treaty recently entered into with his majesty the king of Prussia, and at his own desire, in the year 1790, whereby the independence and the integrity of Poland were guaranteed in the most solemn manner; that, being deprived of free-will, surrounded at the moment of the present act by an armed foreign force, and threatened with a further invasion of the Prussian troops, they are forced to commission and authorise a deputation appointed to treat with the said king, to sign the treaty, such as it was planned and amended under the mediation of the Russian ambassador."

On the 7th of February 1794, the baron d'Ingelstrohm, who had succeeded the count de Sievers as ambassador at Warsaw, demanded a public annulling of the acts of the diets of 1788 and 1791 , together with the form of the constitution then established, and the-surrender of every paper, whether in public records or private cabinets, respecting that transaction The court of Russia soon afterwards issued its mandate for the reduction of the military force to $16,000 \mathrm{men}$. This was opposed by several regiments, particularly in South Prussia, where the insurgents, headed by the gallant Madalinski, a Polish nobleman, and brigadier of the national troops, peremptorily refused to disband. The spirit of resistance was widely diffused, and the capital assumed a military aspect. In this situation fifteen thousand Russian troops were sent into Poland, the ambassador was instructed to deliver to the permanent council an official document representing the danger that threatened the king, and requesting the commissioners of war to dispatch an army to oppose Madalinski; and the permanent council was desired to take into custody every suspected person. Both these requisitions were, however, refused; and it was pointedly replied to the latter. that, according to the laws of the republic, no Polish nobleman could be arrested, without being legally convicted.

The imperious conduct of the Russians drove the oppressed Poles to desperation. The peasants were compelled to lodge and board the Russian soldiers, and transport them from place to place, without receiving the least remuneration, or any other reward than brutality and insolence. It could not be expected that a gallant and high-spirited people would long tamely submit to such insult and injury. Their patriotic spirit, though latent, was not extinguished. It was roused into action by incessant sufferings, and by continued efforts of the intrepid Kosciusko, who early in February appeared at the hearl of a considerable body of Polish insurgents, attacked the Prussians who had taken possession of their country, forced them to retreat, and pursued them to a considerable distance. The Russian troops having evacuased Crasons on the 23d of March, Kosciusko entered that town on the 
night of the 24th, and next morning ordered the gates to be shut, and declared bimself commander in chief of all the Polish forces. He then imposed an oath of fidelity on all the military in the city, took possession of the public treasure, and proceecled to measures of military sequestration. On the day on which he entered Cracow, he issucd a proclamation, couched in the most energetic tcrms, inviting the nation to shake off their disgraceful fetters, and to unite in forming a new confederation. The proclamation was received with unanimous applausc; and "Long live Kosciusko!" resounded from every quarter. He was conducted to the town-house, and presented to the principal nobility, who had assembled there to receive him; and by them he was formally invested with the title of gencral. Every article for the support of his army was abundantly supplied. On the 26th, the different corporations assembled under their respective banners bcfore the town-house, whence the magistrates led them in proccssion to the church of the Holy Virgin, where the constitution of the 3d of May 1791, was publicly read with great soiemnity. and an oath taken to defenct it.

The Polish nobles had no sooner taken the oaths in the presence of Kosciusku, than thcy departed for their respective estates, in order to arm and assemble their vassals. Baron d'Ingelstrohm, about the same time, surrounded the dict at Warsaw with a military force, and demanded the surrender of the arsenal. This demand was spiritedly resisted; and notice of it having been sent to Kosciusko, he about the end of March, took the route to Warsaw with his army, and a reinforcement of 4000 peasants, armed with pikes, \&xc. On the 4th of Aprif he was met by a cletachment of 6000 Russians, with a park of heavy artillery, on their march to reduce Cracow. A fierce encountcr ensued. The Polish peasants bcing driven to desperation, made a dreadful slaugliter of the Russian plundercrs. General Woronzow was taken prisoner, and above 1000 Russians killed on the spot; while the Poles lost only sixty men, and took elcren pieces of cannon and all the ammunition. After the battle, Kosciusko fell back with his army towards Cracow, where he was joined by a very corsiderable body of disaffected Polish troops

On the 16th of April, baron d'ingelstrohm dcmanded the surrender of the arsenal, the disarming of the military, and that twenty pcrsons of the first consequcnce should be arrested, and, if found guilty, punished with death. This occasioned a general commotion, in which the citizens, having procured arms from the arsenal, after an incessant combat of thirty-six hours, drove the Russians out of the city with great slaughter. A deputation had been sent to inform the king of the attempt of the Russians to seize the arsenal; when the monarch replied, "Go, and defend your honour." The situation of the king after the contest became very critical, and the people were extremely jealous of every movement he made. They compelled him to promisc repeatedly that he would not quit Warsaw; and, not satisfied with his assurances, insisted upon placing two municipal officers as a guard upon him; and he was desired fiequently to exhibit himself to the people.

Forty thousand Russians were now put in motion towards Poland from the Ukraine, and 16,000 from Livonia. About the end of May, the corps of Kiosciusko amounted to nearly 23,000 men; that of general Kochowsli to 18,000 ; that of Jaffinski to 6000 ; a corps of 12,000 was stationed at Wilna, and another at Warsaw which consisted of 8000. The peasants were not included in this calculation. 
About the end of June a manifesto was published by the emperor, on the occasion of his troops entering Poland. On the 12th of July, the head-quarters of the king and prince of Prussia were only three or four leagues from Warsaw, whence they issued a placard, stating that the enemy had flet before them in their progress. In the mean time, however, Kosciusko (who had eluded the Prussian troops, by a brave attack. had clefeated the forces which opposed him, and had thrown himself into WVarsaw. On the 3 lst of June, the Prussians began to attack the city by a heavy cannonade, and severai hundred bombs were in the course of the day thrown into WVarsaw; a dreadful fire was kept up on the besieger's by night and by day, and an incredible num. ber of lives were lost. The king and the prince-royal are both said to have been in imminent danger at this time. On the $2 \mathrm{~d}$ of August; his Prussian majesty, whose hopes of success had probably been a little damped, attempted to open a negociation with the king of Poland for the surrender of the capital, which was rejected. About the middle of this month, accounts were transmitted to the Prussian camp, of insurrections having arisen in South Prussia (formerly Great Poland) of which his Prussian majesty had taken possession the preceding year; and on the night of the 5 th of September, the Prussian and Russian forces abandoned the siege of Warsaw, after a fruitless attack of two months, much wcakened by the diseases and desertions which prevailed in their camps, and disabled from the want of provisions and am. munition.

In the course of the same month, the Russian grand army, consisting of 20,000 men, arrived in Poland, and on the 18 th a severe engagement took place near Brzese, in which the Poles lost very considerable numbers, and were compelled to retreat across the Bog. On the 10th of October anothel battle was fought between the Russians, under general Ferfen, and the troops under Kosciusko. The Russians advanced twice to the attack, but were repulsed by the Poles, who, however, unfortunately, not contented with the advantages they had gained, aballdoned their favourable position on the heights, and pressed on to the attack in their turn. This movement threw the troops into some con. fusion; and the Russians forming themselves anew, the rout soon became general. The battle, which began at seven in the morning, did not end till noon. Kosciusko flew from rank to rank, and was continual$1 y$ in the hottest part of the engagement. At length he fell, and a Cossack, who did not know him in the peasant's dress which he constantly wore, wounded him from behind with a lance. He recovered, and advanced a few steps, but was again knocked down by another Cossack, who was preparins to give him a mortal blow, when his arm was stopped by a Russian officer, who is said to have been general Chrnozazow, to whose wife Kosciusko had a short time before politely given leare of cleparture from Warsaw to join her husband. The unfortunate Kusciusko implored the officer, if he wished to render him a service, to allow the soldier to put an end to his existence; but the latter chose rather to make him a prisoner. The Polish infantry defended themselves with a blavery proportioned to that of their general, and faught with a degree of valour almost approaching to fury.

The Russians under general Ferfen soon afterwards summoned Warsaw to surrender; and on being refused, after the junction of the different corps under Ferfen, Dernfeldt, Dernifow, and Suwarrow, procceded on the 4 th of November to attack the suburb of Praga, or Prague, separated from Warsaw by the Vistula, which was defended by 
more than an hundred pieces of cannon disposed upon thirty-three batteries. The Russians succeeded in their assault, and the Polish generals found themselves unable to oppose, with 10,000 soldiers, which was the whole of their force, the united attack of 50,000 men. After a severe conflict of eight hours, the resistance on the part of the Poles ceased; but the massacre of the sanguinary Suwarrow continued for two hours longer; and the pillage lasted tifl noon on the following day. Five thousand Poles were computed to have been slain in the assault; the remainder were either imprisoned or dispersed. The citizens were compelled to lay down their arms ; and their houses were plundered by the merciless Russians, who, after the battle had ceased nearly ten hours, about nine o'clock at night set fire to the town, and again began to massacre the inhabitants. Nine thousand persons, unarmed men, defenceless women, and harmless infants, perished either in the flames or by the sword, and nearly the whole of the suburb was reduced to ashes. In the whole of this seige it is computed that not less than 30,000 Poles lost their lives.

The city being thus reduced under the power of the Russians, the lking was for a short time restored to a kind of mock authority, by the supreme council remitting into his hands that which it had exercised. On the 9th of November, the Russian general made his triumphal entry into $\mathrm{W}$ arsaw, in which the streets were lined with his troops, and the inhabitants, shut up in their houses, observed a melancholy silence. The chief magistrate delivered him the keys of the bridge of the suburb, after which be received the compliments of the king; and, on the 10th, went with much pomp to the castle, to pay his respects to his majesty. To complete the whole of this execrable scene, the first of December was set apart for a day of solemn thanksgiving, and Te Deum was sung for the triumph of barbarous oppression.

In the mean time Kosciusko was under surgical care at Nozcylack, where the utmost attention was paid to his recovery. He was afterwards sent to Petersburg, under a very powerful military escort, and was confined in the fortress there, till the death of Catherine II, when the late emperor, who on several occasions showed great liberality towards the persecuted Poles, set him at liberty, assigned him a pension, and allowed him his choice, either to return to his own country, or go to America Kosciusko preferred the latter, and arrived safely in the asylum which he chose. On his way thither he passed through England, and was received with the warmest welcome and congratulation. by all the friends of freedom.

On the 20th of December, 1794, a courier arrived from the enıpress, demanding the arrestation of count Ignatius Potocki, and several of the other patriots, whom she ordered to be sent to Petersburg. The same messenger brought a command from the empress to the unhappy monarch of Poland to repair to Grodno, who, in obedience to the summons, set off from his capital on the 7 th of January, 1795.

The unfortunate king was afterwards removed to Petersburg, where he had a palace and a suitable pension assigned him, and where he clied, February 11, 1798. With him ended the kingdom of Poland. 


\title{
HUNGARY.
}

\section{SITUATION AND EITENT.}

\author{
Miles. Degrees. \\ I.ength 320$\}$ between $\{16$ and.35 East longitude. \\ Breadth 210$\}$ between $\left\{46\right.$ and $4930^{\prime}$ North latitude.
}

Containing 59,500 square miles, with 105 inhabitants to each.

NAME.....The name of Hungary has been usually derived from the Huns, who anciently possessed this country; but Mr. Gibbon finds its origin in that of the Ugri, or Uger, a Tartarian tribe who migrated from the confines of China, and, after overrunning almost the whole of Germany, established themselves in this country in the tenth century.

Bounsarifs....Hungary Proper (for it formerly included Transylvania, Sclaronia, Croatia, Morlachia, Servia, Wallachia, and other countries) is bounded on the north by Gallicia; on the east by the Buckowine and Transylvania: on the south by Sclavonia; and on the west by the circle of Austria and Moravia.

Divisions... .Hungary is divided into Upper and Lower Hungary, situate on opposite sides of the Danube. These are again each divided into two circles, which are subdivided into gespann schafts, or counties, in number 52. Presburg is the metropolis of Lower', and Caschau of Upper Hungary.

The province of Temestvar has been considered as distinct from Hungary, because it was formerly governed by an independent king; aid it has several times been in possession of the Turks; but the Austrians gaining possession of it, it was incorporated into the kingdom of Hungary in 1778. The province of Temeswar is ninety-four miles long, and sixty-seven broarl, containing about 3850 square miles. It has been divided into four districts, Csanad, Temeswar, Wer'schez, and Lugos. Temeswar, the principal town, is situate in E. long. $22^{\circ}$ $15^{\prime}$, N. lat. $45^{\circ} 54^{\prime}$.

Movntaixs.....The Carpathian mountains, which divide Hungary from Poland on the nortl, are the principal; though many detached mountains are found in the country. Their tops are generally covered with wood, and on their sides grow the richest grapes in the world.

Rivers..... These are the Danube, the Drave, the Sau, or Save, the Theisse, the Raab, and the IVaag.

LAKES, AND MINERAL WATERS....Hungary contains several lakes, particularly the Platten, or the Platten Sea, about forty-six. miles long and eight broad, and abounding with fish. The Hungarian baths and mineral waters are estemed the most sovereign of any in Europe; but their magnificent buildings, laised by the Turks when in possession of the country, particularly those of Buda, are suffered to go to decay. 
Metals and Minerals.....Hungary ccntains mines of gold, silver, copper, very rich antimony, coal, salt, and alum. The gold mines are at Cremnitz, about 4.0 miles to the south of the Carpathian mountains; and the silver at Shenanitz, about 20 miles further to the south. Scvcral kinds of precious stones are found in Hungary, particularly that beatitiful gem the opal, which has hitherto been discovered in no other country in the world.

Climate, soll, ANd Ppoduce...The climate of the southern parts of Hungary is found to be unhealthful, owing to its numerous lakcs, stagnated waters, and marshes; but the northern part being mountainous and barren, the air is pure and wholesome. No country in the world can boast a richer soil than that plain which extends 300 milcs, from Presburg to Belgrade, and produces corn, grass, tobacco, saffren, asparagus, melons, hops, pulse, millet, buck-wheat, delicious grapes, and fruits of various kinds.

VEGETABLES.....Besides those already enumerated, the fincs of Hungary deserve particular attention for the exccllent wine afforded by their grapes, particularly the celebrated Tokay, which has receiyed its name from a town in the north of Hungary, in the vicinity of which it is made in the greatest perfection.

Animals.....Hungary is remarkable for a fine breed of horses, generally mouse-coloured and highly esteenicd by military ufficers, so that great numbers of them are exported. There is a remarkable brced of large rams in the neighbourhood of Presburg. The other aninals of Hungary, are in general, the same with those of Germany and the neighbouring countries.

Natural coliosities..... Ncar Szadello, about 30 milcs from Caschau, is an extraordinary cavcrn, of such prodigious extcnt that it is reported by the ratives to reach several miles under the hills, and has never been completely explored. It includes within it, diffierent caves and passages, which contain numerous stalactites of various sizes. "It is such a labyrinth," says Dr. Townson, a late intclligent traveller in Hungary, " that I firmly believe that a man, oncc lost in it, though he have lights and food enough to last him a month, would not be able to find his way out." And Mr. Korabinsky, a Gcrmon writer, says that it is of such astonishing dimensions in length, that two membcrs of the Royal Society of London, who were scnt some years ago inio Hungary, by the society, to examine this and other curiosities, after remaining in it three days, could ncver get to the end of it, nor find an opening.

Near Szilitze is another celcbrated cavern, about 100 feet broad, 150 deep or long, and 20 or 30 high From the roof, at the further end, hangs an immense icicle, or rather a congeries of icicles; and in one corner is a great mass of ice. This ice, it is said, thaws in the winter, when the ground without is covered with snow, and frcezes again amid the heats of summer. But this is no doubt an exaggeration, in consequence of the observer's depending too much on their feelings; the cave, probably, always preserving the same temperature, which has been found to be that of the freezing point.

Near Demanovo, about 16 milcs from Rosenburg, is a cavern full of bones, of animals no doubt which have made it their haunt; but among which the crcdulous pretend the complete skcleton of a dragon has been found, which is preserved in the museum of the elector of Saxony, at Dresden. 
Population.....Before the Turks obtained possession of Constantinople, Hungary was one of the most populous and flourishing kingdoms in Europe: and if the house of Austria should give the proper encouragement to the inhabitants to repair their works, and clear their fens, it inigbt become so again. The population of Hungary, exclusive of Transylvania, Sclavonia, and Dalmatia, was estimated, in 1776 , by the celebrated Busching, to be 3,170,000; and Mr. Windish, an Hungarian, in his Geography of Hungary, published in 1780, says, " the population, according to a new accurate examination, is $3,170,000$, excluding Transylvania, Sclavonia, and Dalmatia." But the committee appointed by the diet of 1791 , to inquire into things of this nature, "somie of whose notes," says Dr. "Townson, "I have had in my hands, estimate the population of Hungary in its greatest extent, but always excluding Transylvania, at about $8,000,000$, which, they add, is 1777 souls per square mile. In No. 61, of Mr. Slotzer's Stats Anzeigen, there is a detailed account, which mak'es the total population 7,4.17,4.15." Hoeck states ihe population of Hungary and Illyria at 7,350,000; whence the number of inhabitants for Hungary alone may, perhaps, be justly takeIr at about $6,300,000$.

National character, maners, and customs.... The Hungarians are a brave, generous, and hardy race of men; their manners are peculiar to themselves; and they pique themselves on being descend. ed from those heroes who formed the bulwark of Christendom against the infidels. In their persons they are well made. Their fur caps; their close-bodied coats, girded by a sash, and their cloke or mantle, which is so contrived as to buckle under the arm, so that the right hand may be always at liberty; give them an air of military dignity. The men shave their beards, but preserve their whiskers on their upper lips. Their usual arms are the broad-sword, and a kind of pole-axe, besides their fire-arms. The ladies are reckoned handsomer than those of Austria; and their sable dress, with sleeves straight to their arms, and their stays fastened before with little gold, pearl, or diamond buttons, are well known to the French and English ladies. Both men. and women, in what they call the mine towns, wear fur and even sheepskin dresses. The inns upon the roads are most miserable hovels, and even those seldom to be met with. The hogs, which yield the chief animal food for the peasants, and the poultry, live in the same apartment with their owners. The gout and fever, owing to the unwholesomeness of the air, are the predominant diseases in Hungary. The natives in general are indolent, and leave trade and manufactures to the Greeks and other strangers settled in their country, the flatness of which renders travelling commodious, either by land or water. The diversions of the irhabitants are of the warlike and athletic kind. They are in general a brave and magnanimous people. Their ancestors, even since the beginning of the present century, were so jealous of their liberties, that, rather than be tyrannized over by the house of $\mathrm{Au}$ stria, they often put themselves under the protection of the Ottoman court; but their fidelity to the late empress-queen, notwithstanding the provocations they received from her house, will be always remembered to their honour.

The inhabitants of Temeswar are computed at 450,000. There are in this country many faraons, zigeuners, or gypsies, supposed to be real descendants of the ancient Egyptians. They are said to resemble the ancient Egyptians in their features, in their propensity to melancholy, and in many of their manners and custems; and it has been as: 
serted that the lascivious dances of Isis, the religious vencration of onions, many famous Egyptian superstitions and specifics, and the Egyptian method of hatching eges by means of dung; are still in use arnong the female gypsies in Temeswar.

Citres, CHIEF Towns, $\Lambda$ ND EDIFICEs....Buda, by the Germans called Offen, the metropolis of Hungary, has neither fortifications nor: gates; it is three or four miles long, but very narrow. The cities of Buda and Pest may be considered as one, for they are only separated by the Danube; over which there is a bridge of boats half a mile in length. Buda contains 22,00n inhabitants, and Pest 16,000. The finest public and private buildings are in Pest, and within the fortress. The royal palace is a vast and stately pile of building; and the hospital for invalids, now used as barracks, is fine and spacious. At Buda, the Hungarian regalia, formerly deposited at Pest, are now kept. The crown, in the year 1784 , was removed to Vienna by order of the emperor Joseph II. But this nreasure gave so great offence, and excited such violent discontents, that it was sent back to Bucla in 1790 , where it was received with the most extraragant testimonies of joy, the whole city and suburbs being illuminated. This crown was sent, in the year 1000, by pópe Sylvester II, to Stephen, king of Hungary, and was made after that of the Greek emperors : it is of solid gold, weighing nine marks and three ounces, ornamented with fifty-three sapphires, fifty rubies, one large emerald, and three hundred and thirty-eight pearls. Besides these stones, are the images of the apostles and patriarchs. The pope added to this crown a silver patriarchal cross, which was afterwards inserted in the arms of Hungary. At the ceremony of the coronation a bishop carries it before the king. From the cross is clerived the title of apostolic king; the use of which was renewed nnder the reign of the empress-queen Maria-Theresa. The sceptre and the globe of the kingdom are of Arabian gold ; the mantle, which is of fine linen, is said to be the work of Gisele, spouse of St. Stephen, who, they say, embroidered in gold the image of Jesus Christ crucified, and many other images of the patriarchsand apostles, with a number of inscriptions. The sword is two-erlged, and rounded at the point. Presburg, the capital of Lower Hungary, has a claim to be ccnsidered as the metropolis of the kingdom; for Puda has been so often, and for so long a time in the power of the Turks, that this city has generally been the seat of government and the place where the diets have been held, and the coronation ceremonies performed. It is well built, aud stands on a fine situation on the banks of the Danube, which is here 350 yards broad. It contains about 28,000 inhabitants, of whom one-fourth are Lutherans, and great numbers Jews. Caschau, the capital of Upper Hungary, contains about 6000 inlrabitants. The principal church here is a fine building, in the Gothic taste, and in good preservation. Tyrnau is a handsome town, containing about 7000 inhabitants, and so many churches and convents that it has been called the Litile Rome. It was also the seat of a university; but that has been renoved to Pest. Raab, Gran, and Comorn, are fortified towns of considerable strength. The small town of Kitzee, about two or three miles from Presburg, claims the first fabrication of coaches; which, it is asserted, derive their name, in the different languages of Europe, from the name of that place. Tokay has been already mentioned for the excellency of its wines.

MANUFACTURES AND COMMERCE.... The manufactures of Hungary are few and of little importance: there are some, however, of leather, linen cloth, and different kinds of hard-ware. The exports consist of 
hor'ses, cattle, swine (to the amount of several hundred thousand pounds annually) corn, wine, tobacco, the productions of the mines, linen, raw and manufactured skins, tallow, saffron, honey, wax, and oil. In the year 1787, the exports amounted to $17,800,000$ florins (about $1,800,000 l$. sterling) and the imports to $13,800,000$ florins $(1,4.00,000 l$. $)$ learing a balance to the country of $4,000,000$ of florins, or $4,00,000 l$. sterling.

Constitution and government.....The Fungarians have preserved the remains of many checks upon the regal power: They have a diet or parliament: which assembly consists of two tables or houses; the first composed of magnates, or the great officers of the crown, princes, counts, barons, archbishops, ; and the second, of the abbots, prelates, and deputies from the chapters and each of the two-and-fifty gespannschafts, or counties, into which the kingdom is divided. These houses, however, form but one body, as their rotes are taken together. The diet, besides being convened on all great national events, should meet at stated times. Under Matthias Corvinus, and Ferdinand I, it was decreed, they shoald be annual; and under Leopold I, that they should be triennial; which was confirmed by Charles VI, and is still considered as the constitutional period. But sovereigns and their ministers often wisls to get rid of these incumirances; and from 1764 to 1790 , no diet was held; though many important affiars had happened within that period. It ought not to sit more than two months. There is likewise a Hungary-office, which resembles our chancery, and which resides at Vienna; as the palatine's council, which nearly resembles the British privy-council, but has a municipal jurisdiction, does at Presburg. Every royal town has its senate; and the grespannschafts have magistrates, who act as our justices of the peace. Besides these, there is an exchequer, nine chambers, and other subordinate courts.

REveNUE.... The revenue which the emperor derives from Hungary amounts to about two millions sterling.

ARMY ...The emperor can bring into the field, at any time, seventy or eighty thousand Hungarians in their own country, but seldom draws out of it above ten thousand: these are generally light-horse, and well known in modern times by the name of Hussar's. They are not near? so large as the German horse; and therefore the hussars stand up on their short stirrups when they strike. Their expedition and alertness have been found so serviceable in war, that the greatest powers in Europe have troops that go by the same name. Their foot are called Heydukes, and wear feathers in their caps, according to the number of enemies they pretend to have killed: both horse and foot are an excellent militia, very good at a pursuit, or ravaging and plundering a country, but not equal to regular troops in a pitched battle. The sovereign may summon the Hungarian nobility to take the field and defend their country. This service is called an insurrectio, and from it the high clergy are not exempt. In the frequent wars in which Hungary was formerly engaged, principally against the Turks, this service was rather a severe obligation. The number of combatants each broughtit into the field was in proportion to his estate. The archbishop of Gran and the bishop of Erlau, brought each two stands of colours, and under each stand a thousand men; the archbishop of Colocza, and several bishops, a thousand each. In the fatal battle of Mohatch, seven bishops were left on the field.

The standing military force of Hungary, in the year 1794, consisted, according to Dr. Townson, of nine regiments of infantry, of $3000 \mathrm{men}$ 
each, thirteen regiments of frontier militia, of 4000 each, and seven re. giments of hussars, of 1200 each; amounting, in the whole, to 87,400 men.

An ms.....The arms of Hungary are a shield divided perpendicularly into three parts : the first division, or, contains seven Hungarian towers; the second, gules, the Szekler eagle; and in the third, gules, are the sun and moon of Saxony.

ORDER OF KNIGHTHOOD.....The Hungarian order of knighthood is that of St. Stephen; the badge of which is an Hungarian cross, worn suspended by a green edged ribband.

RELIGION.... The established religion of Hangary is the Roman-catholic; but the protestants, who are generally believed to be as numerous as the catholics, and who, two centuries ago, were more numerous, enjoy complete toleration. They have entire freedom of public worship, with churches and bells, and their own schools and seminaries of learning, and are admitted to fill all the public offices, and to a seat in the legislative councils.

There are two archbishoprics in Hungary-Gran and Colocza. The bishoprics are those of Erlau; Nitra, Raab, Waitzen, Funf-kirchen (or Five Churches) Vesprim, Gross, Wardein, (or Great Waradin) Osanad Stuhlweissenberg, Neusohl, and Rosenau. The last three were founded in 1777 .

The archbishop of Gran, as archbishop, is lord lieutenant of the county, primate and chancellor of Hungary; has the exclusive right of crowning the king, and can create nobility upon the archiepiscopal dominions. His levenue is about $36,000 l$. sterling per ann. while that of the archbishop of Colocza is not more than $5000 \ell$.

UnIVERSITIES..... The principal university of Hungary is that of Buda, which has an annual income of $20,000 \%$. sterling, of which $4000 l$. is allotted to pay the salarics of the professors. Here is a large library and an obscrvatory. Raab and Caschau are likewise styled universities, but they are rather acadamies founded by the Jesuits. The university of Tyrnau, as mentioned above, has within these few years been removed to Pest.

LANGUAGE.....As the Hungarians are mixed with Germans, Slavonians, and Wallachians, they have a variety of dialects. The Hungarian Proper appears to be radically different from the Slavonian, and has been supposed to be a branch of the Finnic. The upper and middling classes of people speak German and Latin, though with the latter they continually mix words that can only be understood by those who are acquainted with the Hungarian, Slavonian, or German languages.

The Lord's Prayer in Hungarian is as follows: Mi atyank ki vagy a mennyekben, zentelssek meg a te neved; jojjon el a te orzagod: Legyen. meg a te akaratod, minr a menyben, ugy itt e foldonnis. A mi mindennafii kenyerunket ad meg nekunkma: es botsasd meg a mi vetkeinket, mikenfin, miis megbotsatunk azkonak a kik mi ellenunc vetkeztenek; es ne vigy minket a kesertetbe : de zabadits meg minket a gonosstol: mert tied az orssag, a hatalom, es a dirsoseg mind orokke. Amen.

Antrquities.....Many Roman antiquities, such as militaly roads, zuins, and coins, have been found in Hungary and other parts of the ancient province of Dacia. About 20 miles from Belgrade are the remains of a most magnificent Roman bridge. Hungary was formerly remarkable for its coinage; and there are still extant, in the cabinets of the curious, a complete series of coins of their former kings. More Greek and Roman medals have been discovered in this country, that, perhaps, in any other in Europe. 
History.... The Huns, after subduing this country in the middle of the third century, communicated their name to it, being then part of the ancient Pannonia. They were succeeded by the Goths; the Goths were expelled by the Lombards; they by the Avari; who were followed by the Slavi in the beginning of the 9th century. At the close of it, the Ugri or Ugurs, emigrated from the banks of the Volga, and took possession of the country. Hungary was formerly an assemblage of different states; and the first who assumed the title of king was Stephen, in the year 997, when he embraced Christianity. In his reign the form of government was established, and the crown rendered elective. About the year 1310, king Charles Robert ascended the throne, and subdued Bulgaria, Servia, Croatia, Dalmatia, Slavonia, and many other provinces; but many of those conquests were afterwards reduced by the Venetians, Turks, and other powers. In the 15th century, Huniades, who was guardian to the infant king Ladislaus, bravely repulsed the Turks when they invaded Hungary ; and, upon the death of Ladislaus, the Hungarians, in 1438, raised Matthias Corvinus, son of Huniades, to their throne. Lewis, king of Hungary, in 1526, was killed in a battle, fighting against Solyman, emperor of the Turks. This battle proved almost fatal to Hungary: but the archduke Ferdinand, brother to the emperor Charles V, hav ing marriea the sister of Lewis, claimed the title of Hungary, in which he succeeded with some difficulty; and that kingdom has ever since belonged to the house of Austria, though, by its constitution, its crown ought to be elective. For the rest of the Hungarian his:tory, see Geramany. 


\section{TRANSYLVANIA, SLAVONIA, 'HHE BUCK- OWINE, CROATIA, AND DALMA'TIA.}

'THESE countries appear under one division, for several reasons, and particularly because we have no very exact account of their extent and boundaries. The most authentic is as follows: TransyuvaNIA is bounded on the north by the Carpathian mountains, which divide it from Gallicia; on the east by Moldavia and Wallachia; on the south by Wallachia; and on the west by Hungary. It lies between 22 and 26 degrees of east longitude, and 45 and 48 of north latitude. Its length is about 180, and its breadth 120 miles; contains nearly 14,000 square miles, and is surrounded on all sides by high mountains. Its produce, vegetables, and animals are almost the same with those of Hungary. The air is wholesome and temperate; but the wine of this country, though good, is not equal to the Iungarian. Its interior goverrment still partakes greatly of the ancient feudal system, being composed of many independent states and princes, who are little more than nominally subject to the Austrians. Papists, Lutherans, Calvinists, Socinians, Arians, Greeks, Mahometans, and other sectaries, here enjoy their several religions. Transylvania is thought to add but little to the Austrian revenue, though it exports some metals and salt to Hungary. All sorts of provisions are very cheap, and excellent in their kinds. Hermanstadt, the capital, contains about 16,000 inhabitants, and is a large, strong, and well built city ; as are Clausenburg and Weissenburg. The seat of government is at Hermanstadt, and the governor is assisted by a council made up of Roman-catholics, Calvinists and Lutherans. The diet, or parliament, meets by summons, and receives the commands of the sovereign, to whom of late they have been more devoted than formerly. They have a liberty of making remonstrances and representations in case of grievances.

Transylvania is part of ancient Dacia, the inhabitants of which long cmployed the Roman arms before they could be subdued. It was overrun by the Goths on the decline of the Roman empire, and then by the Huns. Their descendants retain the same military character. The population of the country is estimated at $1,500,000$. The military force is at present reduced to six regiments of 1500 each; but it is well known, that, during the last two wars in which the house of Austria was engaged, the Transylvanians did great services. Hermanstadt is the only bishopric ; and the Transylvanians at present seem to trouble themselves little either about learning or religion, though the Roman-catholic is the sstablished church. Stephen I, king of Hungary, introduced Christianity there about the year 1000; and it was afterwards governed $b_{y}$ an Hungarian vaivod or viceroy. The various rcvolutions in their government prove their impatience under slavery; and though the treaty of Carlowitz, in 1699, gave the sovereignty of 
Transylvania, as also of Slavonia, to the house of Austria, yet the natives enjoy what we may call a loyal aristocracy, which their sovereigns do not think proper to invade. In October, 1784, on account of the real or feigned oppressions of the nobility, near 16,000 assembled, and committed great depredations on those whose conduct had been obnoxious to them. Several had their palaces burnt, and were glad to escape with their lives. The revolters were disappointed in their attempt on Clausenburg; and afterwards offered to separate, and go home in peace, on the terms of a general pardon, better treatment from the nobility', and a freedom from vassallage. Lenient terms were granted to them; and, with the punishment of a few, the insurrection was suppressed.

The Bucrowine was formerly a part of Transylvania, and afterwards of Moldavia, but was ceded to the Austrians by the Turks in 1771. It is situate between Moldavia and Gallicia, is about 90 miles long and 50 broad, and contains nearly 3000 square miles and about, 130,000 inhabitants. The country is full of woods, and produces but little corn. The people derive their support from the cattle they rear, and the wax and honey afforded them by their bees. The inhabitants consist of various nations, as IVallachians, Germans, Hungarians, Armenians, Jews, and a great number of Gypsies. The language is the WVallachian, tut the German becomes continually nore prevalent. This country has been united by the Austrian government in Gallicia, and is under the same administration. The capital is Tzernowitz, situate on the Pruth, the see of a Greek archbishop, and containing about 6000 inhabitants.

Slavonia lies between the 17 th and 21 st degrees of east longitude; and the $45 \mathrm{th}$ and $46 \mathrm{th}$ of north latitude. It is estimated to be about 200 miles in length, and 60 in breadth and contaius about $10,0 \% 0$ square miles. It is bounded by the Drave on the north, by the Datuube on the east, by the Save on the south, and by Stiria in Austria on the west. The reason why Hungary, Transylvania, Slavonia, and the other nations subject to the house of Austria in those parts, contain a surprising variety of people, differing in name, language, and manners, is because liberty here made its last stand against the Roman arms, which by degrees forced the remains of the different nations they had conquered into those quarters. The thickness of the woods, the rapidity of the rivers, and the strength of the country, favoured their resistance; and their descendants, notwithstanding the power of the Turks, the Austrians, the Hungarians, and the Poles, still retain the same spirit of independency. IVithout regarding the arrangements made by the sovereigns of Europe, they are quiet under the government that leaves them most at liberty. That they are generous as well as brave appears from their attachment to the house of Austria, since it is well known that they preserved the pragmatic sanction, and kept the imperial crown in that family. The Slavonians formerly so much employed the Roman arms, that it is thought the word slave took its original from them, on account of the great numbers of them who were carried into bondage, so late as the reign of Charlemagne. Though Slavonia yields neither in beauty nor fertility to Hungary and Transylvania, yet the ravages of war are still visible in the face of the country, which lies in a great measure unimproved. The Slavonians are zealous Roman-catholics, though Greeks and Jews are tolerated. Here are two bishoprics; that of Posega, which-is the capital of the country, and Zagrab, which lies on the Drave; but we know of no uni- 
versities. Esseck is a large and strong town, remarkable for a wooden bridge, over the Drave and adjoining marshes, five miles long and fifteen paces broad, built by the Turks. Waradin and Peterwaradin are places noted in the wars between the Austrians and Turks. The inhabitants are composed of Servians, Radzians, Croats, Wallachians, Germans, Hungarians, and various other nations. In 1746 Siavonia was united to Hungary, and the states send representatives to the diet of Hungary.

Croatia is situate between the 15 th and 17 th degrees of east longitude, and the $45 \mathrm{th}$ and 47 th of north latitude. It is 80 miles in length, and 70 in breadth, and contains about 2800 square rales. The manners, government, religion, language, and customs, of the Croats are similar to those of the Slavonians and Transylvanians, who are their neighbours. They are excelient irregular troops, and, as such, are famed in modern history, under the name of Pandours, and various other designations. Carolstadt is a place of sone note, bui Ziggrab, or Agram, is the capital of Croatia. All the sovereignty exercised over them by the Austrians seems to consist in the military arrangements for bringing them occasionally into the field. A viceroy presides over Croatia, jointly with Slavonia, and

Hungarian Dalmatia. This lies in the upper part of the Adriatic Sea, and consists of five districts, in which the most remarkable places are the two following: Segna, which is a royal free town, fortified both by nature and art, and situated near the sea, in a bleak, mouniainous, and barren soil. The bishop of this place is a suffragan to the archbishop of Spalatro. Here are twelve churches, and two convents. The governor resides in the old palace, called the Royal Castle. 2. Ottoschatz, a frontier fortification on the river Gatzka. That part of the fortress where the governor and the greatest part of the garrison reside, is surrounded with a wall and some towers; but the rest of the buildings, which are mean, are erected on piles in the water; so that one neighbour cannot visit another without a boat.

The part of Dalmatia formerly cailed Venetian Dalmatia, is now likewise subject to Austria, and together with Hungarian Dalmatia, is estimated to contain about 4640 square miles, and above 300,000 inhabitants. The country is mountainous, but fruitful. The capital is Spalatro, which has a fine harbour, and is the see of an archbishop. Zara is ancther large town, with 7000 inhabitants, and so strongly fortified that it is deemed almost impregnable. Sebenico is likewise a strong town. The natives of this part of Dalmatia carry on a considerable trade, and are esteemed the best mariners of any on the coasts of the Adriatic or any part of Italy. The Dalmatians resemble the Slavonians in their manners, and speak the same language. They profess the Roman.catholic religion.

In Venetian Dalmatia is the small aristocratic free state of Poglissa, formerly under the protection of Venice, but now under that of the Austrian government. This state contains about 20,000 inhabitants, and its chief magistrate bears the title of ruelike cnes, or great lord, and is chosen annually from some noble Hungarian families which arc settled there.

A small part of Dalmatia belongs to the Turks, and another part to the republic of Ragusa, the territory of which contains about 270 square miles, and 80,000 inhabitants. Ragusa is an aristocratical state, formed nearly after the model of that of Venice. The government is in the hands of the nobility; and the chief of the republic, who is 
styled rector, is changed every month, and elected by scrutiny or lot. During his short administration, he lives in the palace, and wears a ducal habit. As the Ragusans are unable to protect themselves, they make use of their wealth to procure them protectors, the chief of whom, for many years, was the grand seignor. They endeavour also to keep upon good terms with the Venetians, and other neighbouring states. But in the year 1783 , a dispute arose between them and the king of Naples, respecting a claim of right to his appointing a commander of the Ragusan troops. It was terminated by the republic's putting itself under that king's protection. The city of Ragusa is not above two miles in circumference, but it is well built, and contains some handsome edifices. The ancient Epidaurus was situated not far from this city. The Ragusans profess the Romish religion; but Greeks, Armenians, and Turks, are tolerated. Almost all the citizens are traders: and they keep so watchful an eye over their freedom, that the gates of the city of Ragusa are allowed to be open only a few hours in the day. The language chiefly in use among the Ragusans is the Slavonian, but the greatest part of them speak the Italian. They have many trading vessels, and are great carriers in the Mediterranean, like the Dutch, being constantly at peace with the piratical states of Barbary. The towns of Gravosa and Stagno, 50 miles N. E. of Ragusa, are within the territories of this republic: and there are also five small islands belonging to it, the principal of which is Melida. 


\title{
PRUSSIA.
}

EXTENT AND SITUATION OF THE KINGDOM OF PRUSSIA PROPER

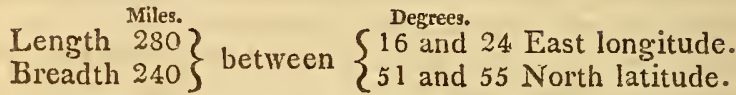

NANE...The name of Prussia is derived from its ancient inhabitants, the Borussi, or Porussi : so called from the Slavonic word 10 , near, and Russi; signifying the people who lived adjacent to, or near, the Russians.

Boundaries....The kingdom of Prussia is bounded on the north by the Baltic sea and Russia (Samogitia) on the east by Russia (Lithuania) on the south by Gallicia and Silesia, and on the west by Brandenburg and Pomerania.

Divisions....The general divisions of Prussia, with their extent and - population, were in 1809 as follows :

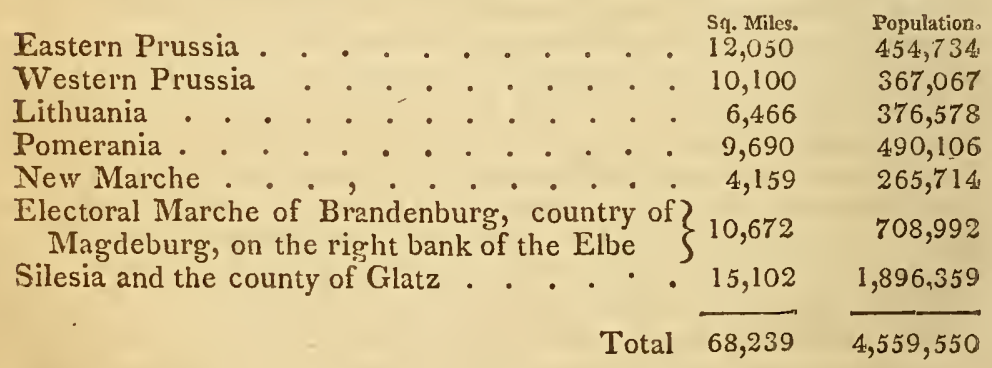

West Prussia consists principally of the territory wrested from Poland in the year 1772; and Lithuania and New Marche, of the portion of the same country allotted to Prussia at its final division in 1795.

Face of the country, Forests, Lakes....The kingdom of Prussia is in general a level country : there are no mountains; but extensive forests and woods, especially in the parts acquired from Poland.

Prussia abounds in lakes; the principal of which are the Sperling See, the Mauer See and the Gneserich Lake. The first of these is 20 miles long and as many broad. In East Prussia, it is reckoned, there are 300 small lakes; and 160 in West Prussia.

Rivers, canals....The chief rivers are the Vistula, the Pregel, the Memel, the Netze, the Bro, and the Warte. The two canals called Frederic's canals, and the Bromberg canal, unite the Netze with the Vistula.

At the mouths of the rivers Vistula and Memely singular havens, called by the Germans haffs, are formed by long narrow tracts of land. This tongue of land in the Frisch-haff, at the mouth of the 
Vistula, is 70 miles in length, and from three to ten broad. It is saici to have been thrown up by tempests about the year 1190 .

Metals, mrerals....Prussia yields no metals, except a little iron ore: its peculiar and valuable mineral is amber, which is usually found at about the depth of 100 feet, and is often washed on shore by tempests. It is now generally supposed to be a vegetable production, mineralised by some unknown operation of nature.

Climate, soil, PROducE....The climate of Prussia is more damp and raw, and the cold more lasting than in Germany ; but the air is salubrious, and the natives frequently attain to a considerable age. The soil is tolerable; and produces corn, flax, hemp, hops, tobacco, various kinds of fruits, and timber in abundance.

Anrmals... The uri or bison, a kind of wild ox, and a species of beaver, are found here, as are also lynxes, bears, and foxes. The horses, cattle, and sheep, resemble those of the northern parts of Germany.

Cities, chief towss....Berlin the capital of the Prussian dominions, being situated in the electorate of Brandenburg, has been described as a city of Germany.

Konigsberg the former seat of government, and capital of old Prussia, is situated on an island formed by the river Pregel, over which it has seven bridges. This city is seren miles in circumference, and contains 4480 houses, and above 50,000 inhabitants. It carries on an extensive trade, the river being navigable for ships of considerable burden. Besides its college or university, which contains 38 professors, it has magnificent palaces, a town house, and exchange; as also a good harbour, and a citadel, which is called Fredericksburg, and is a regular square.

Warsaw, the late capital of Poland, is situate on the Vistula, partly in a plain and partly on a gentle ascent rising from the river. It contains many magnificent palaces and other buildings, besides churches and convents. The streets are spacious, but ill paved; and the greatest part of the houses, particularly in the suburbs, are mean wooden hovels. The city exhibits a strong contrast of wealth and poverty, and has little or no commerce.

The number of inhabitants in 1787 was nearly 90,000, including the suburb of Praga. At present, after what the city, and especially that suburb, suffered from the siege and massacre by the Russian army in 1794 , they are estimated at about 65,000 .

Dantzic formerly the capital of Polish Prussia, is famous in history on many accounts, particularly for being at the head of the Hanseatic association, commonly called the Hanse-towns. It is situate on the Vistula, rear five miles from the Baltic, and is a large, beautiful, populous city : its houses generally are five stories high; and many of the streets are planted with chesnut-trees. It has a fine harbour, and is still a very commercial city, although it is now on the decline in that respect. It formerly contained 80,000 inhabitants, but in the year 1793 they were diminished to 30,000. Dr Busching affirms, that it appears from ancient records, that as early as the year 997 Dantzic was a large commercial city, and not a village or inconsiderable town, as some pretend.

Prussian Poland was in 1807 taken from Prussia by the French and given to Saxony. Warsaw is now the capital of the Dutchy of Warsaw, which was restored by Bonaparte to a kind of mock independence. 
Marienwerder, the seat of the government of West Prussia, stands on the Vistula. The cathedral is the largest church in the kingdom of Prussia, being 320 feet long. It seems by its strong breastworks to have formerly served as a fortress. Here is also a castle and a spacious palace, built in the old Gothic style.

Elbing and Thorn are cities of considerable trade, and contain, the former about 16,000, and the latter 9,000 inhabitants. Posen, late a Polish city, the seat of the government of South Prussia, is the see of a catholic bishop, has a university, and contains 13 convents and 15,000 inhabitants.

National character, manners, custons....The character, manners, and customs of the inhabitants of the old kingdom of Prussia, are nearly the same with those of their neighbours in the north of Germany. Those of the Poles have been already described in our account of Gailicia.

Commerce and manufactures....The Prussian manufactures are not inconsiderable : they consist of glass, iron-work; paper, gunpowder, copper, and brass mills; manufactures of cloth, camlet, linen, silk-stockings, and other articles. The inhabitants export a variety of naval stores, amber, linseed, and hemp-seed, oatmeal, fish, mead, tallow, and caviare; and it is said that 500 ships are loaded every year with those commodities, chiefly from Konigsberg.

Redigion.... The religion of Prussia is very tolerant. The establish. ed religions are those of the Lutherans and Calvinists, but chiefly the former ; but papists, antipaedobaptists, and almost all other sects, are here tolerated.

UNIVERSITIES, LITERATURE, LANGUAGE....The university of Konigsberg was founded in 1544; that of Franisfort on the Oder in 1516, by Joachim, elector of Brandenburg. To these are to be added the Polish university of Posen, which has now become subject to Prussia. There are many schools and seminaries of education in the kingdom of Prussia, but it has produced few men of eminent literary abilities.

The language of Prussia is the German; but in the territory lately acquired from Poland, the Polish, as may be expected, prevails.

Constitution and government.... His Prussian majesty is absom lute through all his dominions. The government of this kingdom is by a regency of four chancellors of state : viz. 1. The great master; 2. The great burgrave; 3 . The great chancellor; and, 4. The great marshal. There are also some other councils, and 37 bailiwicks. The states consist, 1 . Of counsellors of state; 2. Of deputies from the nobility; and, 3. From the commons. Besides these institutions, Frederic II, erected a board for commerce and navigation.

Revenue... The revenue of the Prussian monarchy, before the additions made to it by the last division of Poland, and the changes occasioned by carrying into effect the plan of indemnities, was estimated at $3,879,000 l$. sterling, of which

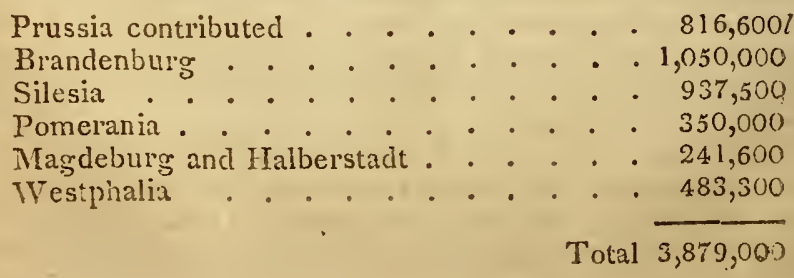


After the last division of Poland, and before the treaty of Tilsit, the revenue was annually about $30,000,000$ of dollars. In 1808 it amounta ed to but $13,150,000$ dollars.

'This revenue arises from the contributions, domains, salt-works, excise, posts, tolls, and various taxes and duties. The duty on amber alone is said to produce above 26,000 dollars annually.

Notwithstanding his numerous army, and other state expenses, Frederic II had no national debt, but on the contrary in the last years of his reign, expended annually, in the improvement of his dominions, to the amount of $\$ 2,330,000$; and between the years 1763 and 1784 $15,555,000$ dollars.

In 1809 the national debt amounted to $25,920,000$ dollars.

ARMY....The Prussian army, even in time of peace, consisted formerly of about 220,000 , including 40,000 cavalry, of the best disciplined troops in the world; and during the seven year's war, that force was augmented to 300,000 men. But so great a military force, however it may aggrandise the power and importance of the king, is utterly inconsistent with the interest of the people. The army is chiefly composed of provincial regiments; the whole Prussian dominions iveing divided into circles or cantons; in each of which, one or more regiments, in proportion to the size and population of the division, have been originally raised, and from it the recruits continue to be taken : and each particular regiment is always quartered, in time of peace, near the canton from which its recruits are drawn. Whatever number of sons a peasant may have, they are all liable to be taken into the service, except one, who is left to assist in the management of the farm. The rest wear badges from their childhood: to mark that they are destined to be soldiers, and obliged to enter into the service whenever they are called upon. The maintaining so large an army, in a country naturally so little equal to it occasioned, however, such a drain from population, and such a withdrawing of strength from the labours of the earth, that Frederic II, endeavoured in some degree to save his own peasantry, by drawing as. many recruits as he could from other countries. These foreign recruits remain continually with the regiments in which they are placed; but the native Prussians have every year some months of furlough, during which they return to the houses of their fathers of brothers, and work at the business of the farm, or in any other way they please.

The Prussian army was, after the treaty of Tilsit, very much recluced; not consisting, in 1808 , of more than 80,000 men. When Prussia joined the coalition against France, in 1813, she was not able to bring above 70,000 troops into the field, until her treasury had been replenished by Great Britain. At the close of the war her army consisted of 100,000 men.

Arms....The royal arms of Prussia are, argent, an eagle displayed sable, crowned or, for Prussia. Azure, the imperial sceptre or, for Courland. Argent, an eagle displayed gules, with semicircular wreaths, for the marquisate of Frandenburg. To these are added. the respective arms of the several provinces subject to the Prussian erown.

ORDERS OF KNIGHTHOOD...There are six orders of knighthood: the "Order of Concord," was instituted by Christian Ernest, margrave of Brandenburg, in the year 1660 , to distinguish the part he had acted in restoring peace to many of the princes of Europe. Frederic III.

Vor. I. 3. S- 
clector of Brandenburg, and afterwards king of Prussia, instituted, in 1685, the "Order of Generoslty." The knights wear a cross of eight points, enamelled blue, having in the centre this motto, " $L$ cs Générosité." pendent to a blue ribband. The same prince instituted the "Order of the Black Eagle," on the day of his coronation at Konigsberg, in the year 1700: the sovereign is always grand-master: and the number of kniglits, exclusive of the royal family, is limited to thirty, who must also be admitted into the "Order of Generosity," previous to their receiving this, unless they be sovereign princes. The badge is an eight-cornered golden blue enamelled cross, in the middle of which is the name of the sovereign, and on the edges are four black spread-eagles. It is worn suspended from a broad orange-coloured ribband which passes from the left to the right. The knights wear on the left side of their coats a silver star, in the middle of which is a black eagle, with the motto Suum Cuique. The "Order of Merit" was instituted by Frederic II, in the year 1740, to reward the merit of persons either in arms or arts, without distinction of birth, religion, or country. The king is sovereign, and the number of knights unlinited. Frederic II, likewise instituted the orders of "St. Stephen" and "St. John ;" the former in 1754, the latter in 1756.

History... The ancient history of Prussia, like that of other kingdoms, is lost in the clouds of fiction and romance. The early inhabitants, a brave and warlike people, descended from the Siavonians, refused to submit to the neighbouring princes, who, on pretence of converting them to Christianity, endeavoured to subject them to slavery. They made a noble stand against the kings of Poland; ore of whom, Boleslaus IV, was by them defeated and killed in 1163. They contintied independent, and pagans, till the time of the crusades, when the German knights of the Teutonic order, about the year 1227 , undertiok their conversion by the edge of the sword, but upon condition of having, as a reward, the property of the country when conquered. A long scries of wars followed, in which the inhabitants of Prussia were almost extirpated by the religious knights, who, in the thirtcentl century, after conmitting the most incredible barbarities, peopled the country with Germans. After a vast waste of blood, in 1466 a peace was concluded between the knights of the Teutonic order and Casimir IV, king of Poland, who had undertaken the cause of the oppressed people; by which it was agreed, that the part now called Polish Prussia should continue a free province, under the king's protection; and that the knights and the grand-master should possess the other part, acknowledging themselves vassals of Poland. This gave rise to fresh wars, in which the knights endeavoured, but unsuccessfully, to throw off their vassallage to Poland. In 1525, Albert, margrave of Brandenburg, and the last grand-master of the Teutonic order, laid aside the habit of his order, embraced Lutheranism, and concluded a peace at Cracow, by which the margrave was acknowledged duke of the east part of Prussia (formerly called, for that reason, Ducal Prussia) but to be held as a fief of Poland, and to descend to his male heirs; and upon failure of his male issue, to his brother and his male heirs. Thus ended the sovereignty of the Teutonic order in Prussia, after it had subsisted nearly 300 years. In 1657, the elector Frederic-William of Brandenburg, deservedly called the Great, had Ducal Prussia confirmed to him; and, by the conventions of Welau and Bromberg, it was freed, by John Casimir 
king of Poland, from vassallage; and he and his descendants were declared independent and sovereign lords of this part of Prussia.

As the protestant reigion had been introduced into this country by the margrave Albert, and the electors of Brandenburg were now of that persuasion, the protestant interest favoured them so much, that Frederic, the son of Frederic-IVilliam the Great, was raised to the dignity of king of Prussia, in a solemn assembly of the states, proclamed January 18, 1701, and soon after acknowledged as such by all the powers of Cnristendom. His grandson, Frederic II, in the memoirs of his family, gives us no high idea of this first king's talents for government, but expatiates on those of his own father, Frederic-IVilliam, who succeeded in 1713 . He certainly was a prince of strong natural abilities, and considerably increased the revenues of his country, but too often at the expence of humanity. At his death, which happened in 174.0 , he is said to have left seven millions steriing in his treasury, which enabled his son, by his wonderful victories, and the more wonderful resources by which he repaired his defeats, to become the admiration of the age. He improved the arts of peace as well as of war, and distinguished himself as a poet, philosopier, and legislator. Some of the principal transactions of his reign have alieady becn related in our account of the history of Germany. In the year 1783 he published a rescript signifying his pleasure that no kneeling should in future be practised in honour of his person, assigning for his reason, that this act of humiliation was not due but to the Divinity; and near 2,000,000 of crowns were expended by him, in 1782, in draining marshes, establishing factories, settling colonies, relieving distress, and in other purposes of philanthropy and policy.

Frecieric-William II, who succeeded his uncle, August 17, 1786, made many salutary regulations for his subjects, and established a court of honour to prevent the diabolical practice of duelling in his dominions.

The exertions of Prussia against France, till the treaty of peace concluded between those two powers on the 5th of April 1795, have been.already related in our account of France.

Frederic-IVilliam II,* died at Berlin, of a dropsy, November 16, 1797 , and was succeeded by his son, Frederic-William III, the present sovereign. With an amiable and unwarlike disposition, ill suited to the turbulent spirit of the times, Frederic-Wiiliam's chief endeavour, was to preserve his kingdom in peacc and quiet. He disliked war, and therefore in 1799 declined an alliance with Russia against France, and determined to abide by his system of neutrality. But this system, at such a period, served only to show his want of energy. By attempting conciliation with all, he became contemptible to all. The attempts of Russia and Austria, to engage him in the war of 1805, were equally unavailing. The king was almost the last person in Prussia, to open his eyes to the real designs of Bonaparte. When at length the representations of his queen, and ministers, dispelled the delusion; the policy he adopted, was as rash, as before it had

- In enumerating the kings of Prussia, we liave thought it most proper to fol. low the method used in Prussia, and throughout Germany, where the Frederics are distinguished from the Frederic-Witliams : thus the uncle of the late king, and the late king, frequently here styled Frederic III, and Frederic IV, are always called, on the continent, Frederic II, and Frederic-William II; the father of the former not being styled Frederic II, but Fredcric-William I. 
been blind. Prussia, totally unprepared, was suddenly engaged in a war with France, while the latter, at peace with all the other powers of tine continent, was enabled to direct the whole of her immense resources to the same point. The event of the war was as every one expected. The battle of Jena, which was fought on the 11 th of Oc. tober 1806, was one of the most decisive victories Bonaparte evel gained. It had been preceded by several slight affairs, all of which terminated in favour of the French. The battle of Auerstadt was fought, by a different army, on the same day with that of Jena; and was equally disgraceful to the Prussian arms. The few troops that were railied, fled to Prenzlau, whither the French pursueci them, and obliged them to surrender. The king fled to Memel, where he remained, till invited to Tilsit, by the emperor of Russia and Bonaparte. By the treaty then concluded, Prussia lost all her Polish possessions, the important city of Dantzic, and all her territory on the left of the Elbe. The former were given to Saxony, and the latter formed part of the new kingtom of Westphalia.

These accumulated misfortunes, determined the king to submit to any thing, rather than again resort to arms. The subsequent demands of Bonaparte, were quietly acquiesced in, and Prussia became little more than a province of France. Even when, after the repeated disasters of the French, in 1812, the Russians had advanced into the heart of Germany; and when the greater part of the Prussian people had taken up arms against the French; this timid monarch, was so fearful of ultimate success, as to delay for some time a declaration of war. Vhen, however, he had once joined his fortunes with those of Russia, he entered into all her measures with spirit, and Prussia, by the result, has regained her importance as a nation.

Frederic-William III, born August 3, 1770, married December 24, 1793, to Louisa-Augusta-IVilhelmina-Amelia, daughter of CharlesLouis-Frederic, duke of Mecklenburg Strelitz, by whom he has issue;

Frederic-William, born October 15, 1795.

Frederic-IVilliam-Louis, born March 22, 1797.

Frederica-Louisa-Charlotte-IVilhelmina, born July 1s, 1798 .

Charles-Frederic-Alexander, born June 29, 1801.

Queen Dowager, Frederica-Louisa, daughter of the landgrave Louis IX, of Hesse Darmstadt ; born Oct. 16, 1751 . 


\section{SILESIA.}

SILESIA is situate between $49^{\circ} 30^{\prime}$ and $52^{\circ} 20^{\prime}$ of north latitudies, and 15 and 19 degrees of east longitude. It is bounded on the north by the Mark of Brandenburg and Lusatia, on the east by Gallicia and South Prussia, on the south by Hungary and Moravia, and on- the west by Moravia, Bohemia, and Lusatia. It belongs to Prussia, except a small part of Upper or Southern Silesia. The Prussian part contains 10,960 square miles and 1,896,359 inhabitants. Since the division of Poland in 1795, a part of that country, in extent about 656 square miles, has been incorporated with it, and placed under the same government. The Austrian part contains 1296 square miles and 320,000 inhabitants.

Silesia is divided into Lower and Upper Silesia. The former is agrain subdivided into the seven principalities of Breslau, Brieg, Schwiednitz, Jauer, Leignitz, Wohlau, and Glogau, immediately subject to the Prussian mosarch, besides some oiher principalities and lordships not immediately subject; and the latter, into the istee immediate principalitics of Munsterberg, Oppeln, and Ratibor, besides some mediate principalities and inferior lordships. The Austrian part of Silesia, at the extremity of Upper Silesia, is divided into the two circles of Jagerndorf and Teschen.

The Sudetic chain of mountains, a part of which is called the Riesengebirge, or Giant-mountain, divide this country from Bohemia. The Elbe and the Oder have their sources among these mountains; the latter of which flows through the country, dividing it nearly into two equal parts. Besides these, the principal rivers are the Vistula, the Niesse, the Boner, the Oppa, the Quies, and the Elsa. In the northern parts are several small lakes ard morasses. The mountainous parts contain mines of gold and silver, but they are not worked ; they also produce copper, lead, and iron, sulphur, salt-petre, alum, and vitriol. The soil in the vicinity of South Prussia and Lusatia is sandy, and not very productive; tut this deficiency is com= pensated by the fertility of the other and larger part of Silesia, which produces wheat, rye, barley, oats, maize, bick-wheat, linseed, peas, beans, hops, and madder. In the mountains of Upper Silesia, tar, pitch, and resin, are made from the pine and fir; and the larch-trees yield turpentine. The breed of sheep here is said to be very profitable on account of the excellency of their wool. The wild animals of this country are lynxes, which frequent only the mountainous parts; a few bears and wolves; and foxes, weasels, otters, and beavers; but the latter in no great number. In the Oder are caught salmon and sturgeon, the latter of which are sometimes extremely large; as also skate and lampreys. The other rivers, but especially the lakes and ponds, abound in various kinds of fish.

Silesia is said to contain 180 cities and towns, and 4,000 villages. The capital is Breslau, situate at the confluence of the Oder and the small river Ohlau, which last runs through several of the streets. It is a large well-built fortified city, containing 3,200 houses and upwards 
of 60,000 inhabitants' one third of whom are catholics, and nine-tenths of the other two-thirds Lutierans; yet the protestants have only nine churches, while the catholics have twenty-six; many of which are, however, cloisters. Breslau is the see of a catholic bishop, whose ecclesiastical jurisdiction extends over the whole of Silesia. The ca thedral was founded about the year 1150 , and contains several magnificent chapels, which have been added to the body of the church by different former bishops. The principal of the protestant churches is the Lutheran church of St. Elizabeth. In the library belonging to this church is what may be considered as a curious manuscript : to the naked eye it appears to be a drawing with a pen of the Venus de Medicis, upon a half-sheet of folio paper; but on examining it with a magnifying-glass, it is found to be a copy of Ovid's Art of Love, perfectly legible, and the whole five books within a compass of ten inches in length and three in width. Breslau las a university, which was founcled in 1702 by the emperor Leopold.

Schweidnitz is a large and handsomely built town, which, since it has become subject to Prussia, has been rendered a very strong place. It contains upwards of 6,000 inhabitants, about one fourth of whom are cathoiics, and claims the intolerant and disgraceful privilege of suffering no Jews within its walls. Brieg is likewise a large well-built town and nearly as populous as Schweidnitz.

Trappau, considered as the capital of Austrian or Bohemian Silesia, because it is the seat of the Austrian administration of that province, is situate on the Oppa : it has a castle, and contains about 3,000 inhabitants. Teschen, the other principal town in the Austrian part, situate on the Elsa, contains about 5,000 iphabitants.

The principal manufactures of Silesia are those of thread, twine, linen, flax, and damask : the chief exports are madder, mill-stones, thread, yarn, linen and woollen cloth. Since Silesia has fallen under the dominion of the kings of Prussia, commerce has been considerably improved, and many excellent regulations have been made for that purpose.

The German language is generally spoken in Silesia, and the speaking of French is considered as an affectation.

Silesia was anciently inhabited by the Suevi, a Teutonic nation. In the seventh century the Slavonians made themselves masters of the country. They enibraced Christianity in the ninth century. Silesia was afterwards united with Poland, and acknowledged the Polish dukes and kings as its sovereigns. In the fourteenth century the Silesian princes rendered themselves independent of Poland, and the whole of the ducluy became subject to the kings of Bohemia. On the death of the emperor Charles VI, in the year 1740, Frederic II, king of Prussia laid claim to certain principalities of Silesia, and supported his claim so powerfully by his arms, that Lower and the greater part of Upper Silesia, with the county of Glatz, were ceded to him by the treaty of Breslau, and have ever since remained subject to Prussia.

The county of Glatz is situate between Bohemia, Moravia, and Silesia, and is about 40 miles in length and 25 in breadth. It is surrounded on all sides by mountains, which contain mines of coal, copper, and iron, and quarries of stone and marble. It has excellent pastures, which feed great numbers of cattle. Glatz, the principal town, is a strongly fortified place, containing within the walls about 400 houses, and as many more in four suburbs. The number of inhabi$\tan t s$ is about 8,000 . The town carries on a considerable trade. 


\title{
SWITZERLAND。
}

\author{
SITUATION AND EXTENT.
}

$\left.\begin{array}{l}\text { Length } 230 \\ \text { Breadth } 120\end{array}\right\}$ between $\left\{\begin{array}{r}6 \text { and } 11 \text { East longitude. } \\ 46 \text { and } 48 \text { North latitude. }\end{array}\right.$

Containing 14,960 square miles, with 150 inhabitants to each.

NAME.... Switzerland was considered by the Romans as a part of Gaul, and inhabited by the Helvetii on the west, and the Rhæti on the east. The modern name of Switzerland, or Swisserland, seems to be derived from that of the canton of Schweitz, one of the earliest in forming the league by which the liberty of the country was asserted against the dukes of Austria. After the revolution in its government, effected by the influence and arms of France, it took the name of the Helvetic Republic.

Bouvd ARIEs....It is bounded on the north by the circle of Swabia in Germany, on the east by Tyrol, on the south by the Italian republic and by France, and on the west by France, from which it is separated by Mount Jura.

Divisions....Switzerland, before the year 1798, was divided into thirteen cantons, which stood, in point of precedency, as follows : 1 . Zurich; 2. Bern; 3. Lucern ; 4. Uri ; 5. Schweitz ; 6. Unterwalden; 7. Zug ; 8. Glaris; 9. Basil; 10. Freyburg; 11. Soleure, or Solothurn; 12. Schaffinausen; 13. Appenzel.

Besides these there were certain districts and towns which were the subjects of the cantons, and some small states who were their allies. The extent and population of the cantons, and of their subjects and allies, were as follows :

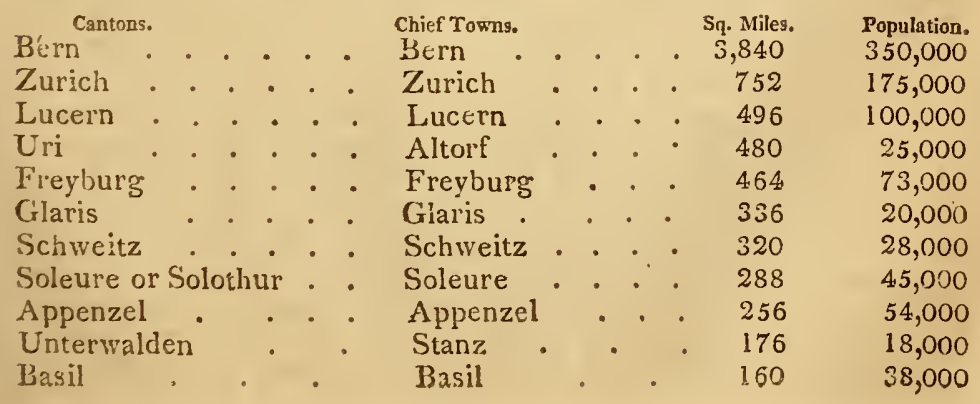




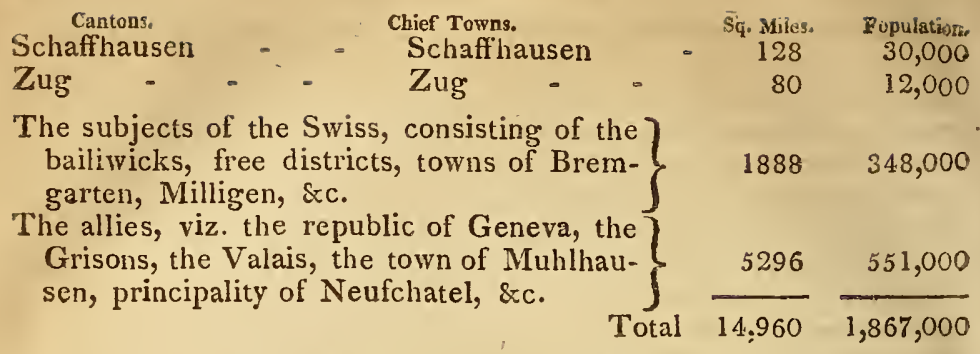

Under the present constitution and government of Switzerland, the country, exclusive of the republic of Valais, and the territory of Neufchatel, is divided into 20 cantons, the extent and population of which are estimated as follows:

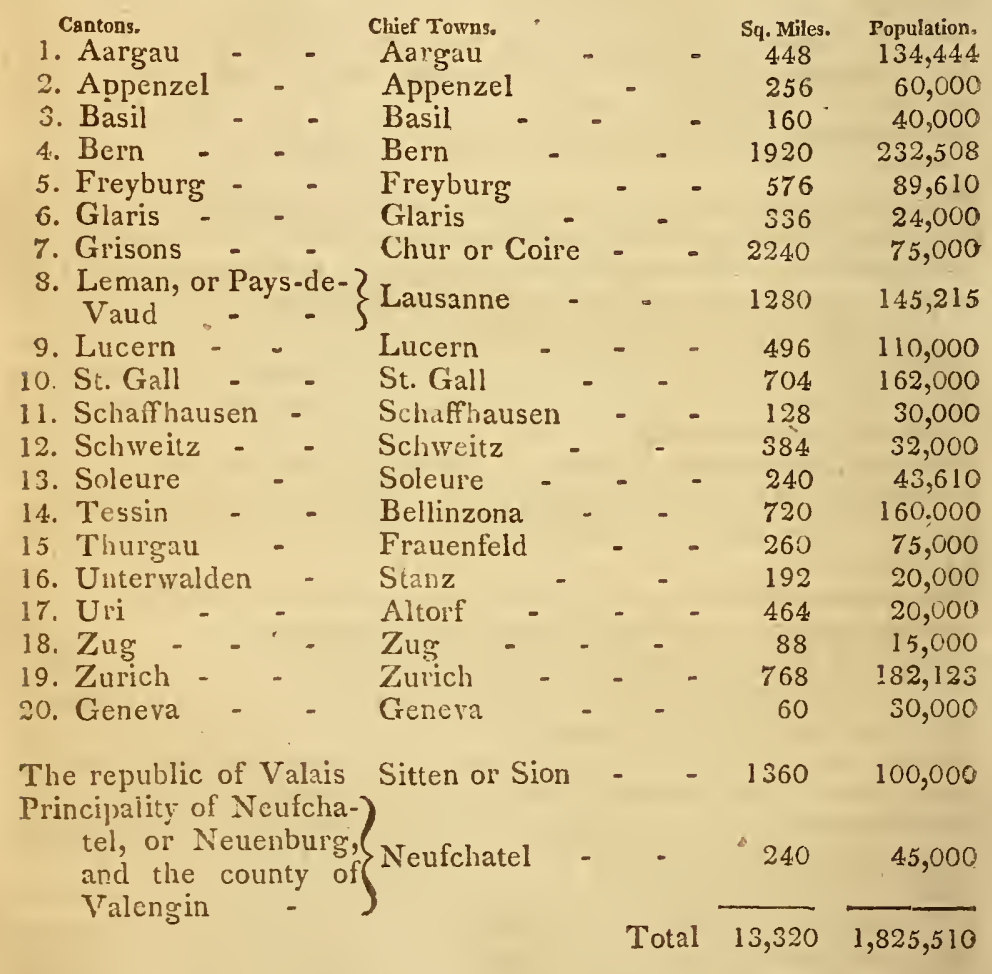

Face of the country, Mountans.... The face of Switzerland is in general so mountainous, that even the parts of it accounted level abound with eminences that in other countries would be called mountains. Nature seems here to have formed every thing on her grandest scale. The summits of the Alps, Mount St. Bernard, St. Gothard, the Jungfrau, or Virgin, and the Schreckenhorn, or Peak of Terror, present the most sublime and stupendous scenes: but Mont Blanc, the highest mountain of the old continent, is particularly distinguishecl from the other mountains, by having its summits and sides cloth- 
ed to a considerable depth with a mantle of snow, almost without the intervention of the least rock to break the glare of the white appearance. According to the calculation of M. de Luc (by whose improvement of the barometer elevations are taken with a degree of accurricy before unattainable) the height of this mountain above the level of the sea is $2391 \frac{1}{3}$ French toises, or 15,304 English feet; or according to sir George Shuckborough, 15,662 feet, which gives a difference of only 558 feet. The peaks of Teneriffe and the summit of Etra have been frequently supposed to be the highest points of the globe : but from the most accurate observations it will be found that Mont Blanc is of much more elevation, and that there are no mountains (except those in America, particularly Chiniboraco, the highest point of the Cordilleras, the elevation of which, according to Condamine, surpasses 3000 toises, or 19,200 feet, but according to others, $20,608 \mathrm{feet}$ ) which are equal in altitude to Mont Blanc.

LAEES....The principal lakes of Switzerland are, the lake of Constance, called by the Germans the Boden See, which is about 45 miles in length and 15 in breadth; and the lake of Geneva, about 40 miles long and nine at its greatest breadth. The other lakes are those of Lucern, Zurich, Thun, Bienne, or Biel, and Brentz.

Rrvers....The chief rivers are the Rhine (which rises in the chain of mountains bordering on St. Gothard) the Rhone, the Aar, the Reuss, the Tesin, the Oglio, and the Limmat.

Metals axd Minerals....The mountains contain mines of iron, crystal, virgin sulphur, and springs of mineral waters.

CliMATE, soil, AND AGRICULTURE....From the mountainous nature of this country, around which the Alps form an amphitheatre of more than 100 miles, the frosts are severe in winter, the eminences being covered with snow sometimes all the year long. In summer the inequality of the soil renders the same province very unequal in its seasons: on one side of the mountains the inhabitants are often reaping, while they are sowing on another. The vallies, however, are warm and fruitful, and well cultivated; and nothing can be more delightful than the summer months in this charming country It is subject to rains and tempests; for which reason public granaries are every where erected, to supply the failure of the crops.

There is perhaps, no country in the world where the advantageous effects of unwearied and persevering industry are more remarkably conspicuous than in Sivitzerland. In passing over the mountainous parts, the traveller is struck with admiration, to observe rocks that were formerly barren now planted with vines, or abounding with rich pasture; and to mark the traces of the plough alung tie osides of precipices so steep, that a horse could not even mount them without great difficulty. In short, the inhabitants seem to have surmounted. every obstruction which soil, situation, and climate, have thrown in their way, and to have spread fertility over various spots of the country, which nature seemed to have consigned to everlasting barrenness. The feet of the mountains, and sometimes also the very summets, are covered with vineyards, corn-ficlds, meaclows, and pasture-grounds. Other parts of this country are more dreary, consisting almosi entirely of barren and inaccessible rocks, some of which are continually covered with snow or ice. The vallies between these icy and snowy mountains appear like so many smooth frozen lakes, and from the latter vast fragments of ice frequently fall down into the more fruitful

Vox. I. $3 \mathrm{~T}$ 
spots beneath. In some parts there is a regular gradation from cx treme wildness to high cultivation;-in others, the transitions are very abrupt, and very striking. Sometimes a continued chain of cultivated mountains, richly clothed with woods, and studded all over with hamlets, cottages above the clouds, pasturages which appear suspended in the air, exhibit the most delightful landscapes that call be conceived; and in other places appear rugged rocks, cataracts, and mountains of a prodigious height covered with ice and snow.

VEGETABLES AxD ANIMALS.... Switzerland produces wheat, barley, oats, rye, flax, and hemp; plenty of apples, pears, grapes, which afford an excellent wine, nuts, cherries, plums, and chesnuts; the parts towarcls Italy abound in peaches, almonds, figs, citrons, and ponegranates; and most of the cantons abound in timber. Besides game, fish, and fowl, are also found, in some of the higher and more inaccessible parts of the Alps, the bouquetin and the chemois, whose activity in scouring along the steep and craggy rocks, and in leaping over the precipices, is hardly conceivable. The blood of both of these animals is of so hot a nature, that the inhabitants of some of these mountains, who are subject to pleurisies, take a few drops of it, mixed with water, as a remedy for that disorder. 'The flesh of the chamois is esteemed very delicious. Among the Alps is likewise found a species of hares, which in summer are said perfectly to resemble other hares, but in winter become all over white, so that they are scarcely distinguishable among the snow. But this idea has been lately exploded, nor is it certain whether the two species ever couple together. The white hare seldom quits his rocky residence. Here are also yellow and white foxes, which in winter sometimes come down into the vallies.

Curiosities, NATURAL AND ARTificial...Every part of Switzer. land abounds in natural curiositics; continually presenting precipices, glaciers, torrents, and cataracts. The glaciers are immense fields of ice, which usually rest on an inclined plane: being pushed forwards by the pressure of thcir own weight, and but weakly supported by the rugged rocks beneath, they are intersected by large transverse crevi. ces, and present the appearance of walls, pyramids, and other fantas(ic shapes, observed at all heights and in all situations, wherever the declivity is beyond thirty or forty degrees.

Mr. Coxe thus describes the method of travelling over these glaciers. "TVe had each of us a long pole spiked with iron; and in order to secure us as much as possible from slipping, the guides fastened to our shoes crampons, or small bars of iron, provided with four small spikes of the same metal. At other times, instead of crampons, we had large rails in our shoes, which more effectually answered our purpose. The difficulty of crossing the vallies of ice arises from the immense chasns. IVe rolled down large stones into several of them; and the great length of time before they reached the bottom gave us some conception of their depth; our suicles assured us, that in some places they are not less than five hundred feet clcep. I can no otherwise convey to you an image of this body of ice brokcu into irregular ridges and deep chasms, than by comparing it to a lake instantaneously frozen in the midst of a violent storm." In speaking of an unsuccessful attempt of some gentlemen to reach the summit of Mont Blanc, he presents to his readers a most horrid image of the danger of these chasms. "As 
they were returning in great haste (owing to the day being far advanced) one of the party slipped, in attempting to leap over a chasm of ice. He held in his hand a long pole, spiked with iron, which he struck into the ice; and upon this he hung, dreadfully suspended for a few moments, until he was released by his companions."

Near Schaff hausen is a tremendous cataract, or rather three unequal cataracts, down whicl the Rhine dashes headlong upon the rock below. Near Rosiniere is a famous spring, which rises in the midst of a natural basin of twelve square feet. The force that acts upon it must be prodigious; after a great shower of rain it carries up a column of water as thick as a man's thigh, nearly a foot above its surface. Its temperature nerer varies : it is clear as crystal, and its depth is unfathomable; probably the end of some subterraneous lake, that has never found an issue for its waters.

Among the artificial curiosities may be mentioned an extraordinary hermitage two leagues from Freyburg, formed by the hands of a single hermit, who, about a century ago, laboured on it for twentyfive year's. It is the greatest curiosity of the kind perhaps in the world, as it contains a chapel; a parlour twenty-eight paces in length, twelve in breadth, and twenty feet in height; a cabinet, a kitchen, a cellar, and other apartments ; with the altar, benches, flooring, ceiling, all cut out of the rock.

At Schaff hausen was a very extraordinary bridge over the Rhine, justly admired for the singularity of its architecture. The river is extremely rapid, and had already destroyed several stone bridges of the strongest construction, when a carpenter of Appenzel offered to throw a wooden bridge of a single arch across the river, which is near 400 feet wide. The magistrates, however, required that it should consist of two arches, and that he should for that purpose, employ the middle pier of the old bridge. Accordingly the architect was obliged to obey; but he contrived to leave it a matter of doubt, whether the bridge was supported by the middle pier, and whether it would not have been equally as safe if formed solely of one arch. The sides and top were covered, and the road which was almost level, was not carried as usual over the top of the arch, but, if the expression may be allowed, let into the middle of it, and therefore suspended. A man of the slightest weight felt it tremble under him; though waggons, heavily laden, might pass over without danzer. Considering the boldness of the plan and construction, it must appear extraordinary that the architect was only, as was said before, a carpenter, without the least tincture of literature, totally ignorant of mathematics, and not versed in the theory of mechanics. His name was Ulric Grubenman. The bridge was finished in less than three years, and cost ajout 8000 . sterling. It was burnt by the French when they evacuated Schafi hausen, after being defeated by the Austrians, April 15 th, 1799.

At the famous pass of Pierre Pertuis, the road is carried through a solid rock near fifty feet thick, the height of the arch twenty-six, and its breadth twenty-five.

At Lucein (says Mr. Coxe) is to be scen a topographical representation of the most mountainous parts of Switzerland, by general Pfiffer, a native of this town, and an officer in the French service. It is a model in relief, and well cleserves the attention of the curious traveller. What was finished in 1776 , compriserl about sixty square leagues, in the cantons of Lucern, Zug, Barn W: Schweitz, and 
Unterwalden.* The model was twelve leet long, and nine and a half broad. The composition is principally a mastic of charcóal, lime, clay, a little pitch, with a thin coat of wax : and is so hard as to be trod upon without receiving the least damage. The whole is painted with different colours, representing the objects as they appear in nature. It is worthy of particular observation, that not only the woods of oak, beech, pine, and other trees, are distinguished, but also that the strata of the several rocks are marked, each being shaped upon the spot, and formed with granite, gravel, calcareous stone, or such other natural substances as compose the original mountains. The plan is indeed so minutely exact, that it comprises not only all the mountains, lakes, towns, villages, and forests; but every cottage, every torrent, every road, and even every path, is distinctly and accurately represented. The general takes his elevation from the level of the lake of Lucern, which, according to $\mathbf{M}$. de Saussure, is about fourteen hundred and eight feet above the Mediterranean. This model, exhibiting the most mountainous parts of Switzerland, conveys a sublime picture of immense Alps piled one upon another; as if the story of the Titans were realised, and they had succeeded (at least in one spot of the globe) in heaping Ossa upon Pelion, and Olympus upon Ossa. From the account of this officer, it appears, that there are continued chains of mountains of the same elevation, rising in progression to the highest range, and from thence gradually descending in the same proportion to Italy.

Population, national chakacter, manners, customs..... The population of this country has already been given, according to the latest estinates, under the article Divisions. The Swiss are a brave, hardy, industrious people, remarkable for their fidelity, and their zealous attachment to the liberties of their country. Like the old Romans, they are equally inured to arms and agriculture. A general simplicity of manners, and open and unaffected frankness, together with an invincible spirit of freedom, are the most distinguishing characteristics of the inhabitants of Switzerland. A very striking proof of the simplicity and openness of manners of this people, and of astonishing confidence, is mentioned by Mr. Coxe, who says, upon the authority of general Pfiffer, that, on each side of the road that runs through the valley of Muotta, in the canton of Schweitz, there are several ranges of small shops uninhabited, yet filled with various goods, of which the prices are marked : any passengers who wish to become purchasers, enter the shops, take away the merchandise, and deposit the price, which the owners call for in the evening. They are in general a very enlightened nation; their common people are far more intelligent than the same rank of men in most other countries; a taste for literature is very prevalent among those who are in better circumstances, and even among many of the lowest rank; and a genuine and unartful good breeding is extremely conspicuous in the Swiss gentry. On the first entrance into this country, the traveller cannot but observe the air of content and satisfaction which appears in the countenances of the inhabitants. The cleanliness of the houses, and of the people, is peculiarly striking; and in all their manners, behaviour, and dress, some strong outlines may be traced, which distinguish this happy people from the neighbouring nations, who labour under the

* Count Stolberg, who saw this model in 1791, says of it: "This model, the size of which is vast, contains 220 square leagues." 
eppression of despotic government. Even the Swiss cottages convey the liveliest image of cleanliness, ease, and simplicity, and cannot but strongly impress upon the observer a most pleasing conviction of the peasant's happiness. In sonie of the canions, each cottage has its little territory, consisting generally of a field or two of fine pasture ground, and frequently skirted with trees, and well supplied with water. Sumptuary laws are in force in most parts of Switzerland: and no dancing is aliowed; except upon particular occasiuns. Silk, lace, and several other articles of luxury, are cotally pronibited in some of the cantons : and even the head dresses of the ladies are regulated. All games of hazard are also strictly prohibited; and in other games, the party who loses above six florins, which is about nine shillings of our money, incurs a considerable fine. Their diversions, therefore, are chiefly of the active and warlike kind; and as their time is not wasted in games of chance, many of them employ part of their leisure hours in reading, to the great improvement of their understandings. The youth are diligently trained to all the martial exercises, such as running, wrestling, throwing the hammar, and shooting, both with the cross-bow and the musket.

Gortres and IDIOTs.... The inhabitants in one part of this country, particularly in the republic of Valais, are very much subject to goitres, or large excrescences of flesh that grow from the throat, and often increase to a most enormous size; but what is more extraordinary, idiotism also remarkably abounds amongst them. "I saw," says $\mathrm{Mr}$. Coxe, "many instances of both kinds; as I passed through Sion, some idlots were basking in the sun, with their tongues out, and their heads hanging down, exhibiting the most affecting spectacle of intellectual imbecility that can possibly be conceived." The causes which produce a frequency of these phænomena in this country form a very curious question.

The notion that snow water occasions these excrescences is totally void of foundation. For, on that supposition, why are the natives of those places that lie most contiguous to the glaciers, and who drink no other water than what descends from those immense reservoirs of ice and snow, free from this malady? And why are the inhabitants of those countries in which there is no snow, afflicted with it? For these guttural turnours are to be found in the environs of Naples, in the island of Sumatra, and at Patna and Pernea in the East Indies, where snow is unknown.

The springs that supply drink to the natives are impregnated with a calcareous matter, called in Switzerland tuf, nearly similar to the incrustations of Matlock in Derbyshire, so minutely dissolved as not in the least to affect the transparency of the water. It is not improbable that the impalpable particles of this substance, thus dissolved, should introduce themselves into the glands of the throat, and produce goitres, for the following reasons : because $t u f$, or this calcareous deposition, abounds in all those districts where goitres are common. There are goitrous persons and much tuf in Derbyshire, in various parts of the Valais, in the Valteline, at Lucern, Freyburg, and Bern, near Aigle and Bex, in several places of the Pays-de-Vaud, near Dresden, in the vallies of Savoy and Piedmont, near Turin and Milan. But the strongest proof in favour of this opinion, says our author, is derived from the following facts. A surgeon whom I met at the baths of Leuk informed me, that he had not unfrequently extracted concresions of $t u f$-stone from several goitres; and that from one in particu- 
Iar, which suppurated, he had taken several flat pieces, each about half an inch long. He added, that the same substance is found in the stomach of cows, and in the goitrous tumours to which even the dogs of the country are subject. He had diminished and cured the goitres of many young persons by emmolient liquors, and external applications; and prevented them in future, by removing his patients from the place where the springs are impregnated with $t u f$ : and if that could not be contrived, by forbidding the use of water which was not purified.

Children are occasionally born with guttural swellings, but this may arise from the aliment of the mother. It is to be presumed that people accustomed to these excrescences will not be shocked at their deformity; but it does not appear, as some writers assert, that they consider them as beauties. To judge from the accounts of many travellers, it might be supposed that the natives, without exception, were either idiots or goitres; whereas, in fact, the Valaisans, in general, are a robust race : and all that with truth can be affirmed is, that goitrous persons and icliots are more abundant in some districts of the Valais than perhaps in any other part of the globe. It has been asserted that the people very much respect these idiots, and even consider them as blessings from heaven. The common people, it is certain, esteem them so, for they call them "souls of God without sin ;" and many parents prefer these idiot children to those whose understandings are perfect, because, as they are incapable of intentional criminality, they consider them as certain of happiness in a future state. Nor is this opinion entirely without its good effect, as it disposes the parents to pay greater attention to such helpless beings. These idiots are suffered to marry, as well among themselves as with others.*

Cities, chief Towns, EDifrces.... Of the se the most considerable is the city of Bern, standing on the river Aar. It is extremely neat and handsome, the streets being wide and long, and including, within it, several streams and fountains. It contains about 13,000 inhabitants. Basil is accounted, by some the capital of all Switzerland. It is situate in a fertile and delightful country, on the banks of the Rhine, and the confines of Alsace and the empire. It contains two hundred and twenty streets, and six market-places. The town-house, which stands on the river Birsec, is supported by very large pillars, and its great hall is finely painted by the celebrated Hans Holbein, who was a native of this city. The situation of Basil is pleasing: the Rhine divides it into the upper and lower town; and it is considered as one of the keys of Switzerland. Baden is famous for its antiquity and baths. Zurich is far less consicierable than Bern; but in the arsenal is shown the bow of the famous William Tell ; and in the library is a manuscript of excellent letters, written by the unfortunate lady Jane Grey to the judicious reformer Bullinger, in elegant Latin and German.

The city of Geneva, which, before it was annexed to France, was an associate of Switzerland, and under the protection of the Helvetic body, but within itself an independent state and republic, is well built, and well fortified; and contains 26,000 inhabitants, most of whom are Calvinists. It is situate at the efflux of the Rhone from the lake of Geneva.

* Coxe's Travels through Switzerland, rol, i. p. 385, \&c. 
Manufactures, commerce....The productions of the loom, linen, dimity, lace, stockings, handkerchiefs, ribbands, silk, painted cottons, and gloves, are common in Switzerland; and the inhabitants, notwithstanding their sumptuary laws, fabricate silks, velvets, and woollen manufactures. The Swiss export horned cattle, horses, sheep, cheese, butter, leather, linen, lace, wrought cotton and silk, and watches. They import corn, flax, silk, cotton, spices, and salt. The situation of Switzerland, and its numerous liavigable lakes and rivers, would be very favourable to commerce, were the inhabitants more intent and assiduous to avail themselves of those advantages.

Constitution and government.... The old constitution and government of Switzerland were very complicated, from the cantons, though belonging to the same body, being partly aristocratical, and partly democratical. Every canton was absolute in its own jurisdiction; but those of Bern, Zurich, and Lucern, with other dependencies, were aristocratical, with a certain mixture of democracy, Bern excepted. Those of Uri, Schweitz, Unterwalden, Zug, Glaris, and Appenzel, were democratical. Basil, though it had the appearance of an aristocracy, rather inclined to a democracy. But even these aristocracies and democracies differed in their particular modes of government. However, in all of them the real interests of the people appear to have been much attended to; and they enjoyed a degrree of happiness not. to be expected in despotic governments. Eacli canton prudently reconciled itself to the errors of its neighbour, and cemented, on the basis of affection, a system of mutual defence.

The confederacy, considered as a republic, comprehended three divisions. The first were the Swiss, properly so called; the second the Grisons, or the states confederated with the Swiss for their common protection; the third, those præfectures which, though subject to the other two, by purchase or otherwise, preserved each its own particular magistrates. Every canton formed within itself a little republic; but when any controversy arose that might affect the whole confederacy, it was referred to the general diet, which sat at Baden, where, each canton having a vote, every question was decided by the majority. The general diet consisted of two deputies from each canton, besides a deputy from the abbot of St. Gall, and the citics of St. Gall and Bienne. It is observed by Mr. Coxe, to whom the public have been indebted for the best account of Switzerland that has appeared, that there is no country in which happiness and content more universally prevail among the people. For whether the grovernment be aristocratical, democratical, or mixed, a general spirit of liberty pervades and actuates the several constitutions; so that even the oligarchical states (which, of all others, are usually the most tyrannical) are here peculiarly mild; and the property of the subject is securely guarded against every kind of violation. A harmony is maintained by the concurrence of their nutual felicity; and their sumptuary laws, and equal division of their fortunes among their children, secm to insure its continuance. There is no part of Europe which contains, within the same extent of region, so many independent commonwcalths, and such a variety of different governments, as are coliected together in this remarkable and delightful country; and yet, with such wislom was the Helvetic union composed, and so little have the Siviss, of late years, been actuated by the spirit of conquest, that, since the firm and complete establishment of their general confederacy, and till the unproroked invasion of their country by the French, they have 
scarcely ever had occasion to employ their arms against a foreign enemy ; and have had no hostile commotions among themselves, that were not very soon happily terminated.

In the year 1798, Switzerland, obliged to yield to the intrigues and arms of France, abolished the old constitution, and framed another on the French model; by which the whole country was declared a republic one and indivisible, and the government vested in two councils and a directory. But in the year 1802 this constitution was likewise abolished, by the authority of the first consul of France, and another presented to them for their acceptance; but which the great majority of them rejected, as still more repugnant to their political principles and habits than the former. Their opposition was so determined that they had recourse to arms; and the first consul thought proper to withdraw his constitution, and offer them a new one, which they consented to accept. By this, as under the original constitution of Switzerand, eacis of the cantons has its distinct internal government, which, in seven of them, Schweitz; Appenzel, Glaris, Unterwalden, Uri, Z'ig, and the Grisons, is of the democratic kind, all the male inhabitants above twenty years of age having voices in the landesgemeine, or assembly, in which all laws and regulations proposed by the magistrates and public officers are discussed. The government of seven others, Bern, Zurich, Soleure, Freyburg, Lucern, Basil, and Schaffhausen, is of the aristocratic form, being administered by a great and little council, the composition and privileges of which are clifferent in the difierent states 'The five new cantons, Aargau, Leman, Thurgau, St. Gall, and Tesino (or Ticino) are likewise aristocratic, and governed by two councils. The general government of the country, is administered by a diet, to which each of the cantons sends a member, and which assembles annually at Freyburg, Bern, Soleure, Basil, Zurich, and Lucern, in rotation. The president of the dict is a kind of chief magistrate, and is styled landamman of Switzerland. The nineteen deputies, of which the diet consists, have, in the whole, twenty-five voices; the deputies of those cantons, the population of which exceeds 100,000, viz. Bern, Zurich, Leman, Aargau, St. Gall, and the Grisons, having two voices; those of the other cantons tave only one. The diet assembles on the first Monday in June, and, in the ordinary course of affairs, continues its sittings during one month. It decides on war and peace, and concludes treaties of alliance and commerce; but, on these subjects, there must be a concurrence of three-fourths of the cantons.

REvenue.... The revenue of Switzerland, before that country was oppressed and plundered by the French, was estimated at 1,050,000l. sterling. It was derived from, 1. The profits of the demesne land; 2 . The tenth of the produce of all the lands in the country; 3 . Customs and duties on merchandise; 4. The revenues arising from the sale of salt, and some casual taxes.

The finances of Bern and Zurich were in a very flourishing state, and those cantons were saicl to be possessed of great wealth, which no doubt, fell a prey to Frenck rapacity and extortion. In the smalier cantons the revenues scarcely defrayed the expences. The revenue in 1809 was stuted by Hassel at 550,000 dollars.

Mimitary force.... The internal strength of the Swiss cantons, independent of the militia, consists of 13.400 men. raised according to the population and abilities of each. Every burgher, pcasant, and subject, $\mathrm{n}$ as obliged to exercise himself in the use of arms; appeal 
tn the stated days for shooting at the mark; furnish himself with proper clothing, accoutrements, powder and ball; and to be always ready for the defence of his country. The Swiss engaged in the service of foreign princes and states, either merely as guards, or as marching regiments; in the latter case the government permitted the enlisting of volunteers, though only for such states as they were in alliance with, or with whom they had entered into a previous agreement on that article. But no subject was to be forced into foreign service, or even to be enlisted without the concurrence of the magistracy.

By the new constitution, no canton is to have more than 200 troops that receive pay, nor to embody more than 500 militia, without the consent of the landamman. In 1809 the army consisted of 15,000 men, besides near 30,000 in foreign service.

RELIGION.... Though all the Swiss cantons form but one political re* public, yet they are not united in religion. The cantons of Lucern, Uri, Schweitz, Unterwalden, Zug, Freyburg, and Soleure, are catholics; those of Bern, Zurich, Basil, and Schaffhausen, Calvinists; and. those of Appenzel and Glairs, of both religions. Of the six new cantons, Leman and Tesino, are catholics; and the Grisons, Aargau St. Gall, and Thurgau, of both religions. The catholics are under the jurisdiction, in ecclesiastical matters, of the bishops of Basil, Lausanne, Sion, and Coire, and the abbots of St. Gall and Einsidlen. The republic of Valais, though formerly the scene of cruel persecutions on account of its affection to protestantism, is catholic. The inhabitants of the principality of Neufchatel are chiefly Calvinists; but all sects of religion are tolerated These differences in religion formerly created many public commotions, which seem now to have subsided. Ulric Zwingli, or Zwinglius, born at Wildhausen, was the apostle of protestantism in Switzerland. He was a moderate reformer, and differed from Luther and Calvin only in a few speculative points; so that Calvinism may be said to be the religion of the protestant Swiss. But this must be understood chiefly with respect to the mode of church government; for in some doctrinal points, they are far from being universally Calvinistical. There is, however, too much religious bigotry prevalent among them; and, though they are ardently attached to the interest of civil liberty, their sentiments on the subject of religious toleration are, in general, much less liberal.

Literature....Calvin, whose name is so well known in all protes tant countries, instituted laws for the city of Geneva, which are held in high esteem by the most learned of that country. The ingenious and eloquent Rousseau, whose works the present age has received with so much approbation, was a citizen of Geneva. Rousseau gave a force to the French Ianguage, which it was thought incapable of re. ceiving. In England he is generally known as a prose writer only, but the French admire him as a poet. His opera of the Devin de Villase, in particular, is much esteemed. M. Bonnet, and Mess. de Saussure and de Luc, also deserve to be mentioned with applause. Haller, a native of Bern, deserves the highest eulogy, as a poet, phy. siologist, and a philosopher. Lavater, so celebrated for his essays on physiognomy, and some other works, was likewise of this country.

UNIVERSITIES... The university of Basil, founded in 1459, has a very curious physic-garden, which contains the choicest exotics; and adjoining to the library, which possesses some valuable manuscripts, is a museum well furnished with natural and artificial curiosities, and Vor.. I. 
with a great number of medals and paintings. In the cabinets of Erasmus and Amerbach, which also belong to this university, there are no less than twenty original pieces of Holbein; for one of which, representing a dead Christ, a thousand ducats have been offered. The other universities, which indeed are commonly only styled colleges, are those of Bern, Lausanne, and Zurich.

LANGUAGE.... Several languages prevail in Switzerland; but the most common is German. The Swiss who border upon France speak an impure French, as those near Italy do a corrupt Italian.

Antriqurties....Some Roman antiquities are found in this country, but they are not numerous. The ruins of Cæsar's wall, which extended eighteen miles in length, from mount Jura to the banks of lake Leman, are still discernible. Many monuments of antiquity, have been discovered near the baths of Baden, which were known to the Romans in the time of Tacitus. Switzerland boasts of many noble religious buildings, particularly a coilege of Jesuits; and many cabinets of valuable manuscripts, antiques, and curiosities of all kinds.

History.... The present Swiss and Grisons, as has been already mentioned, are the descendants of the ancient Helvetii, subdued by Julius Cæesar. Their mountainous uninviting situation formed a better security for their liberties than their forts or armies. They continued long under little more than a nominal subjection to the Burgundians and Germans, till about the year 1300, when the emperor, Albert I, treated them with so much rigour, that they petitioned against the cruelty of their governors. This served only to double the hardships of the people; and one of Albert's Austrian governors, Gresler, in the wantonness of tyranny, set up a hat upon a pole, to which he ordered the natives to pay as much respect as to himself. The famous IVilliam Tell being observed to pass frequently without taking notice of the hat, and being an excellent marksman, the tyrant condenned him to be hanged, unless, he cleft an apple upon his son's head, at a certain distance, with an arrow. Tell cleft the apple; and Gresler asking him the meaning of another arrow he saw stuck in his belt, he bluntly answered, that it was intended for his (Gresler's) leart, if he had killed his son. Tell was condemned to prison upon this; but, making his escape, he watched his opportunity, and shot the tyrant, and thereby laid the foundation of the Helvetic liberty.

It appear's, however, that, before this event, the revolt of the Swiss from the Austrian tyranny had been planned by some noble patriots among them. Their measures were so just, and their course so intrepid, that they soon effected a union of several cantons.

Zurich, driven by oppression, sought first an alliance with Lucern, Uri, Schweitz, and Unterwalden, on the principles of mutual defence; and the frequent successes of their arms against Albert, duke of Austria, insensibly formed the grand Helvetic union. They first conquered Glaris and Zug, and admitied them to an equal participation of their rights. Bern united itself in 1353; Freyburg and Soleure 130 years after; Basil and Schaffhausen in 1501; and Appenzel, in 1513, completed the confederacy, which repeatedly defeated the united powers of France and Germany; till, by the treaty of Westphalia, in 1648 , their confederacy was declared to be a free and incle pendent state.

Neufchatel, since the year 1707 , has been under the dominion of the king of Prussia; but the inhabitants are free to serve any prince 
whatever, and by no means bound to take an active part in his wars. The king has the power of recruiting among them, and of naming a governor; but the revenue he derives is not above $5000 l$. yearly, great part of which is laid out on the roads and other public works of the country.

Towards the close of the year 1797, Switzerland fell a prey to the rapacity and ambition of France; the emissaries and partisans of which republic had prepared the way for the subjugation of the country, by exciting anong the people a spirit of discontent against the guvernment, especially in the aristocratic republics. That the aristocracies of Switzerland were not entirely blameless, either in their conduct towards their subjects or towards the French, may, perhaps, be true : but if the power of the state, and its very moderate emoluments, were in some, or perhaps the majority, of the cantons, monupolised by a few families, it must still be remembered that their authority was exercised with the utmost moderation, and that the people were contented and happy. The real views of the French directory, in their attack on Switzerland, however they might endeavour to colour them by pretending that they were invited by the people, and that their sole aim was to assert the cause of general liberty, no doubt were to give employment to, and procure pay and plunder for, their armies; as also to secure the command of a country, the possession of the important posts of which, in case of a renewal of hostilities with the empire, would both secure their frontier, and enable them to attack with much greater advalitage.

The first act of hostility on the part of the French was the seizing of the Helvetic part of the bishopric of Basle, of which they took possession under some frivolous pretext, and contrary to an express treaty concluded with the Swiss in the year 1792. The Helvetic body, knowing they were too weak to resist, submitted patiently to this usurpaiion; but soon after an insurrection which took place in the Pays-de-Vaud, and which, it is not improbable, was produced by the instigation of the agents of France, afforded an opportunity for an interference which soon cerminated in the subjugation of almost the whole of Switzerland to the French yoke, and almost the entire overthrow of its form of government. In the month of December, the French directory took upon them to demand of the government of Bern, what they termed the restoration of the rights of that people, and the assembling of the states of the Pays-de-Vaud. This demand they immediately prepared to enforce by arms, and general Meynard was ordered to march with a body of 15,000 men, to support the claims of the discontented in that country. The supreme council of Bern, fearful of entering into a contest with the powerful armies of France, on the 5th of January, 1798, issued a proclamation enjoining the citizens of the Pays-de-Vaud to assemble in arms, to renew the oath of allegiance, to proceed to reform the abuses of the government, and to assert and re-establish all their ancient rights. The malcontents, however, encouraged by the protection of the French army, proceeded to open hostilities, and seized on the castle of Chignon. The government of Bern now had recourse to arms, and ordered a body of 20,000 troops, under the command of colonel Weiss; to disperse the insurgents. But the contest was soon decided by the French "army under general Meynard, which immediately advanced, while the Swiss retreated, and, by the beginning of February, had taken possession of the whole of the Pays-de.Vaud. 
The council of Bern still atiempted to negotiate with the Frenchi directory; but, at the same time, assembled an ar'my of about 2u,000 men, the command of which they gave to M. d'Etach, formerly a field-marshal in the service of France. This torce was joined by the quotas of the other Swiss caltons, amouning to about 5500 men. The directory, however, required that the dilcient magistrates of Bern should be dismissud from their offices, anci the constitution of the state changed to one more agreeable to democratic principles and the new system of liberty and equality. These c nditions the government of Bern absolutely refused to submit to, and sent orders to break off ail further negotiations. The curectory, alarmed at this appiarance of firmness and resistance, and fearing they were not sufficiently prepared, sent general Brune to take the command of their army in the Pays-de-Vaud, with orders to conclude an armistice until he should receive a sufficient reinforcement. Brune, immediately upon his arrival, announced to the senate of Bern, that he came prepared to adjust all differences amicably, and requested that they would send cornmissioners to treat with him. These were accordingly sent, and an armistice concluded for eight days. But, on the $2 \mathrm{~d}$ of March, two days, it is affirmed, before the truce agreed on had expired, the castle of Domach, at the northern extremity of the canton of Soleure, was attacked and carried by the French; and, at the same time, 13,000 men were marched under the walls of Soleure, which capitulated to general Schawenbourg on the first summons. Freyburg was immediately after reduced by general Brune, and the Swiss army was forced to retreat.

The French generals immediately advanced towards Bern, where all was confusion, both in the city and in the army, the left division of which had mutinied, deserted their posts, and put to death some of their officers. The Swiss army was reduced by desertion to 14,000 men, exclusive of a rabble of undisciplined peasants, raised by the landsturm, or levy of the country en masse. About 8000 of the regular forces were stationed at Neweneg, and 6400 held the position of Frauenbrun, against which general Schawenbourg advanced from Soleure, at the head of 18,000 men. On the morning of the 5 th of March, both posts were attacked by the French. The troops of Neweneg repulsed the enemy; but those at Frauenbrun, after a vigorous resistance, were compelled to retreat. M. d'Erlach rallied. his men at Uteren, where a second engagement took place; but with no better success on the part of the Swiss. They afterwards, however, made a stand at Gravholtz, about a league and a half from Bern; but were thence driven to the gates of the capital, where, after another severe battle, they were entirely defeated; and, on the evening of the 5 th, general Brune entered the city of Bern, by capitulation. The divisions of the Swiss army stationed at Neweneg and Guminen retreated, and the soldiers of the latter column, in a fit of rage and despair, murdered their officers, and, among others, their unfortunate general d'Erlach.

The defeat of the Bernese was followed by the submission of nearly. the whole of Switzerland; though the democratic republics still made a stand, defeated general Schawenbourg, and forced him to retire with the loss of $\$ 000$ men, after he had consented to a treaty by which he engaged not to enter the smaller cantons.

After this revolution the Swiss confederacy changed its constitution, and even its name. Provincial governments, under the direc. 
tion of the French generais, were established in the different dis tricts, and the whole assumed the name of the Helvetic republic. Contributions and requisitions were levied, as usual, by the French commissioners; and the most shocking enormities perpetrated. During the campaign of 1799 , the northern part of Switzerland became. the seat of war between the Austrians and the French, and the cantons of Schaffhausen and Zurich, especialiy the latter, suffered the severest distress from the ravages of the contending armies.

When the country, how ever, was no longer exposed to the horrors of war, and especially after the conclusion of the peace of Luneville, Switzerland became gradually more reconciled to its new form of government; but this form not perfectly according with the views of Bonaparte, when he had become sovereign dictator in France, he proposed a new constitution to the Swiss, which was accepted by the senate, but gave such offence to the people in general that they flew to arms, appointed commanders, formed magazines, and took the field. under several leaders, particularly Aloys Reding, who had distinguished himself in defending his country against the first invasion of the French. They defeated the French troops in several skirmishes, and, after an obstinate conflict under the walls of Bern, obliged that city to capitulate, and forced the members of the government in the interest of the French, to retire to Lausanne. These abject creatures of France applied to the first consul, who immediately in answer, signified his resolution of acting as mediator, assuring them that his mediation should be efficacious ; requiring, at the same time, that deputies from the senate and from each of the cantons, should meet at Paris to assist in forming a government that might appear less objectionable to the people. The Swiss, fearing the consequences of further resistance, reluctantly acquiesced in the proposal : the deputies met at Paris, the new constitution already des. cribed was framed and accepted, Aloys Reding was appointed land. amman of Switzerland, and on these terms tranquillity was restored to the country. 


\section{SPAIN.}

\section{SITUATION AND EXTENT。}

$\left.\begin{array}{l}\text { Length } 620 \\ \text { Breadth } 510\end{array}\right\}$ between $\left\{\begin{array}{r}9 \text { Degrees. } \\ 36 \text { and } 4.4 \text {. North latitude. }\end{array}\right.$

Containing 144,616 square miles, with 70 inhabitants to eacis.

Names....Spain formerly included Portugal, and was known to the ancients by the name of Iberia, and Hesperia, as well as Hispania. It was, about the time of the Punic wars, divicled into Citerior and Ulterior: the Citerior contained the provinces lying north of the river Iherus, or Ebro; and the ulterior, which was the largest part, comprehended all that lay beyond that river. The name of Hispania, from which this country has received its different denominations in the modern languages, has been supposed to be derived from Hispan, one of its ancient kings, or from the town of Hispulis, the modern Seville. Bochart derives it from the Phœnician word shanjah, a rabbit; those animals having been formerly very numerous here.

Boundaries.... It is bounded on the west by Portugal, and the Atlantic Ocean; by the Mediterranean on the east; by the Bay of Biscay, and the Pyrenean mountains, which separate it from France, on the north; and by the strait of the sea at Gibraltar on the south.

Divrsions....Spain is divided into fourteen provinces, or districts (almost all of which are styled kingloms by the Spaniards) besides islands in the Mediterranean.

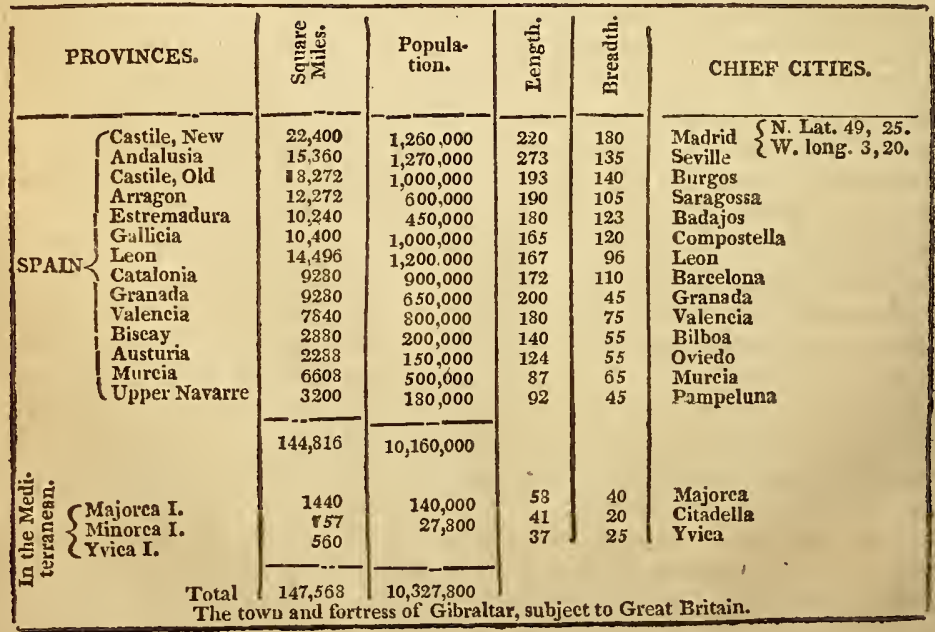


Face of the country....Spain in general presents abundant pase tures, vineyards, groves of orange trees, and hills covered with aromatic plants. In some parts are extensire plains, almost destitute of trees and verdure, bounded by ridges of lofty mountains, the summits of which are covered with snow during the greater part of the year.

Mountains....It is next to impossible to specify these, they are so numerous; the chief and the highest, are the Pyrenees, near 200 miles in length, which extend from the Bay of Biscay to the Mediterranean, and divide Spain from France. Over these mountains there are only five narrow passages to France; and the road through the pass that separates Roussillon from Catalonia reflects great honour on the engineer who planned it. It formerly required the strength of thirty men to support, and nearly as many oxen to drag up, a carriage, which four horses now do with ease. The Cantabrian mountains (as they are called) are a kind of continuance of the Pyrenees, and reach to the Atlantic Ocean, south of Cape Finisterre. No Englishman ought to be unacquainted with Mount Calpe, now called the Hill of Gibraltar, and in former times one of the Pillars of Hercules; the other, Mount Abyla, lying opposite to it in Africa.

Among the mountains of Spain, Montserrat is particularly worthy the attention of the curious traveller, being one of the most singular in the world, for situation, shape, and composition. It stands in a vast plain, about thirty miles from Barcelona, and neariy in the centre of the principality of Catalonia. It is called by the Catalonians Monte Sorrado, or the sawed mountain; and is so named from its singular and extraordinary form; for it is broken and divided, and crowned with an infinite number of spiring cones, or pine heads, so that it has the appearance, when seen at a distance, of the work of man; but, upon nearer approach, is seen to be evidently the production of nature. It is a spot so admirably adapted for retirement and contemplation, that it has, for many ages, ieen inhabited only by monks and hermits, whose first vow is never to forsalse it. When the mountain is first perceived at a distance, it has the appearance of an infinite number of rocks cut into conical forms, and built one upon another to a prodigious height, and seems like a pile of grotto work, or Gothic spires. Upon a nearer view, each cone appears of itself a mountain: and the whole composes an enormous mass about 14 miles in circumference. The Spaniards compute it to be two leagues in height.* As it is like no other mountain, so it stands quite unconnected with ariy, though not far distant from some that are very lofty. A convent is erected on the mountain, dedicated to our lady of Montserrat, to which pilgrims resort from the furthest parts of Europe. All the poor who come here are fed gratis for three days, and all the sick reccived into the lospital. Sometimes, on particular fes. tivals, seven thousand persons arrive in one day; but people of condition pay a reasonable price for what they eat. On different parts of the mountain are a number of hermitages, all of which have their little chapels, ornaments for saying mass, water cisterns, and most of them little gardens. The inhabitant of one of these liermitages, which is dedicated to St. Benito, has the privilege of making an

* Mr. Swinburne estimates its height at only 3300 feet; and observes that the arms of the convent are the Virgin Mary sitting at the foot of a rock half cut through by a saw. 
annual entertainment on a certain day, on which day all the other hermits are invicd, winen they receive the sacrament from the hands of the mountan vicar, and, after divine service, dine together. They meet also at this hermitage on the days of the saints to whom their severai hermitages are dedicated, to say mass, and commune with. each other. But at other times they live in a very solitary and recluse manner, perform various penances, and adhere to very rigid rules of abstinence. They never eat flesh; nor are they allowed to keep within their walls either dog, cat, bird, or any living thing, lest their attention should be withdrawn from heavenly to earthly affections. The number of professed monks there, is 76, of lay brothers 28 , and of singing boys 25 ; besides physician, surgeon, and servants. $\mathrm{Mr}$ Thicknesse, who has published a very particular description of this extraordinary mountain, was informed by one of the hermits, that he often saw from his habitation the islands of Minorca, Majorca, and Yvica, and the kingdoms of Valencia and Murcia.

Filabres is another remarkable detached mountain, situate about three leagues from Almeria, in the province of Granada. It consists entirely of a single stone, or solid block, of white marble, a league in circuit, and near 700 yards in perpendicular height.

Forests....Spain contains many forests, partly in consequence of the neglect of cultivation, and partly because they had heen reserved by the sovereign for the amusement of the chase. That called Pardo is nearly thirty miles in length.

Rivers, LAKEs.... The principal rivers of Spain are the Douro, formerly Durus, which falls into the Atlantic Ocean below Oporto in Portugal; the Tajo or Tagus, which falls into the Atlantic Ocean below Lisbon; the Gaudiana, which falls into the same ocean near Cape Finisterre; as does the Guadalquiver at St. Lucar; and the Ebro, the ancient Iberus, which flows into the Mediterranean Sea below Tortosa.

The river Tinto, the qualities of which are very extraordinary, rises in Sierra Mornea, and empties itself into the Mediterranean near Huleva. The name of Tinto has been given to it from the tinge of its waters, which are as yellow as a topaz, hardening the sand, and petrifying it in a most surprising manner. If a stone happen to fall in, and rest upon another, they both become, in a year's time perfect ly united and conglutinated. This river withers all the plants on its banks, as well as the roots of trees, which it dyes of the same hue as its waters. No kind of verdure will grow where it reaches, nor any fish live in its stream. It kills worms in cattle when given them to drink; but in general no animals will drink out of this river, excepting goats, whose flesh nevertheless has an excellent flavour. These singular properties continue till other rivulets run into it and alter its nature; for when it passes by Niebla, it is not different from other rivers. It falls into the Mediterranean six leagues lower down.

Several lakes in Spain, particularly that of Beneventa, abound with fish, especially excellent trout. The water of a lake near Antiquera is made into salt by the beat of the sun.

The medical waters of Spain are little known; but many salutiferous springs are found in Granada, Seville, and Cordova. Throughout Spain the water's are found to have such healing qualities, that they are excelled by those of no country in Europe; and they are continually more and more resorted to, especially at Alhamar, in Granada. 
Caxals.... Several canals have, of late years, been begun in Spain, but most of them are still in an unfinished state. That of Arragron is intended to form a communication, through the Ebro, from the Bay of Biscay to the Mediterranean. The canal of Castile is to begin at Segovia, about 40 miles to the north of Madrid, and extend to the Bay of Biscay. Other canals have been projected from the Escurial, and from the capital, to the Tagus; the former, it is said, is completed.

Metals and Minerals...Spain abounds in both, and in as great variety, and of the same kinds, as the other countries of Europe. Cornelian, agate, loadstones, hyacinths, turquois stones, quicksilver, copper, lead, sulphur, alum, calamine, crystal, marbles of several kinds, porphyry, the finest jasper, and even diamonds, emeralds, and amethysts, are found here. At Almaden in La Mancha is a mine of quicksiiver, the most ancient known in the world, which produces annually 250 tons of that mineral, and has produced 900. Near Cardona in Catalonia is a mountain of fossil salt, a league in circuit, neariy $5: 00$ feet high, and extending downwards to an unknown depth. The Spanish iron, next to that of Dumascus, furnishes the best arms in the world, and, in former times, brought in a vast revenue to the crown; the art of working it being here brought to great perfection. Spanish gun-. barrels, and sivords of Toledo, are still highly valued. Among the ancients, Spain was celcbrated for gold and silver mines; and silver was in such plenty, that Strabo, who was contemporary with Augustus Cæsar, informs us, that when the Carthaginians took possession of Spain, their domestic and agricultural utensils were of that metal. These mines have now disappeared; but whether by their being exhausted, or through the indolence of the inhabitants in not working them, we cannot say; though the latter cause seems to be the most probable.

Climate, soll, produce...Except during the equinoctial rains, the air of Spain is dry and serene, but excessively hot in the southern provinces in June, July, and August. The vast mountains that run through the country, are, however, very beneficial to the inhabitants, by the refreshing breezes that come from them in the southernmost parts; though those towards the north and north-east are in the winter very cold.

Such is the moisture of the hills, bounded on the north by the Bay of Biscay, and to the south by snowy mountains, that the utmost care is not sufficient to preserve their fruits, their grain, their instruments of iron, from mould, from rot, and from rust. Both the acetous and the putrid fermentation here make a rapid progress. Besides the relaxing humidity of the climate, the common food of the inhabitants contributes much to the prevalence of most diseases which infect the principality of Austuria. Yet, although subject to such a variety of endemical diseases, few countries can prorluce more instances of longevity; many live to the age of a hundred, some to a hundred and ten, and others much longer. The same observation may be extended to Gallicia, where, in the parish of St. Juan de Poyo, A. D 1724, the curate administered the sacrament to thirteen persons whose ages together made one thousand four hundred and ninety-nine, the young est of these being one hundred and ten, and the oldest one hundred and twenty-seven. But in Villa de Fofinanes, one Juan de Outeyro, a poor labourer, died in the year 1726, aged more than one hunclred and forty-six years.

VOL. I. 
The soil of Spain was formerly very fruitful in corn, but the natives have lately found some scarcity of it, by their disuse of tillage, through their indolence; the causes of which will be afterwards explained. It produces in many places, almost spontaneously, the richest and most delicious fruits that are to be found in France and Italy; oranges, lemons, prunes, citrons, almonds, raisins, and figs. The wines of Spain, especially sack and sherry, are in high request among foreigners: There are in the district of Malaga (according to Mr. Townsend) fourteen thousand wine-presses, chiefly employed in making the rich wine, which, if white, from the nature of the country, is called Mountain; if red, from the colour, vino tinto, known in England by the name of Tent. Good mountain is sold from thirteen to sixteen pounds the butt, of one hundred and thirty-five gallons, according to quality and age. It is reckoned that from eight hundred to a thousand vessels enter this port every year, of which about one-tenth are Spanish; and. the exports in wine, fruit, oil, and fish, are computed at about $375,000 l$. per annum; but they have been considerably more.

Spain indeed offers to the traveller large tracts of unpromising, because uncultivated, ground; but no couniry perhaps maintains such a number of inhabitants who neither toil ner work for their food; such are the generous qualities of the soil. Even sugar-canes thrive in Spain; and it yields saffron, honey, and silk in great abundance. A late writer, Ustariz, a Spaniard, computes the number of shepherds in Spain to be 4.0,000; and has given us a most curious detail of their cocoliomy, their changes of pasture at certain times of the year, and many other pirticulars unknown till lately to the public. Those sheep walks afford the finest of wool, and are a treasure in themselves. Some of the mountains in Spain are clothed with rich trees, fruits, and herbage, to the tops; and Seville oranges are noted all over the world. No country produces a greater variety of aromatic herbs, which render the taste of their kids and sheep so exquisitely delicious. The kingdom of Murcia abounds so much with mulberry-trees, that the product of its silk amounts to $200,000 l$. a year. Upon the whole, few countries in the world owe more than Spain does to nature and less to industry.

VEGETAries.... Besides the vegetable productions already mentioned, Spain produces excellent wheat, rice, tobacco, and saffron. Thyme, lavender, rosemary, and other aromatic herbs, grow in prodigious abundance both on the mountains and in the vallies. A kind of grass or rush called esfarto, which is very plentiful in the southern provinces, is made into mats and ropes, and even into fine linen.

Animals....The Spanish horses, especially those of Andalusia, are thought to be the handsomest of any in Europe, and at the same time are very swift and serviceable. The king endeavours to monopolise the finest breeds for his own stable and service. Spain furnishes likewise mules and black cattle; and the wild bulls have so much ferocity, that the bull-feasts were the most magnificent spectacle the court of Spain could exhibit; nor are they yet disused. Wolves are the chief beasts of prey in Spain, which is well stored with all the game and wild-fowl that are to be found in the neighbouring countries al:eady described. The Spanish seas afford excellent fish of all kinds, especially anchovies, which are here cured in great perfection. This country is much infested with locusts; and Mr. Dillon observes, that in 1754. La Mancha was covered with them, and the horrors of famine assailed the fruitful provinces of Andalusia, Murcia, and Valen- 
tia. They have sometimes appeared in the air in such numbers as to darken the sky; the clear atmosphere of Spain has become gloomy, and the finest summer day in Estremadura been rendered more dismal than the winter of Holland. Their sense of smelling is so delicate, that they can discover a cornfield or a garden at a considerable distance; which they will ravage almost in an instant. $\mathbf{M r}$. Dillon is of an opinion, that the country people, by timely attention and observation, might destroy the eggs of these formidable insects, and thereby totally extirpate them.

Natural curiosities....Among the natural curiosities, the medicinal springs, and some lakes where extraordinary noises are heard, form a principal part. The river Guadiana, like the Mole in Engiand, runs under yround, and then rises again. It disappears near Alcazar de San Juan, in the country of La Mancha, and, running under ground nearly eight leagues, emerges again at some lakes called the Eyes of the Guadiana. The royal cabinet of natural history, at Madrid, was opened to the public, by his majesty's orders, in 1775. Every thing in this collection is ranged with neatness and elegance, and the apartments are opened twice a week for the public, besides being shown privately to strangers of rank. The minerai part of the cabinet, containing precious stones, marbles, ores, \&c. is very perfect; but the collection of birds and beasts at present is not large, though it may be expected to improve rapidly, if care be taken to obtain the productions of the Spanish American colonies. Here is also a curious collection of vases, basins, ewers, cups, plates, and ornamental pieces, of the finest agates, amethysts, rock crystals, \&c. mounted in gold and enamel, set with cameos, entaglios, \&c. in elegant taste, and of very fine workmanship, said to have been brought from France by Philip V. The cabinet also contains specimens of Mexican and Peruvian vases and utensils.

In blowing up the rock of Gibraltar, many pieces of bones and teeth have been found incorporated with the stone, some of which have been brought to England, and deposited in the British Museum. On the west side of the mountain is the cave called St. Michael's, eleven hundred and ten feet above the horizon. Many pillars, of various sizes, some of them two feet in diameter, have been formed in it by the droppings of water, which have petrified in falling. The water perpetually drops from the roof, and forms an infinite number of stalactites, of a whitish colour, composed of several coats or crusts, and which, as well as the pillars, continually increase in bulk, and may probably in time fill the whole cavern. From the summit of the rock, in clcar weather, not only the town of Gibraltar may be seen, but the bay, the straits, the towns of St. Roque and Algesiras, and the Alpuxara mountains; mount Abyla, on the African shore, with its snowy top; the cities of Ceuta, Tangier, and great part of the Barbary coast.

Population....Spain, formerly the most populous kingdom in Europe, is now but thinly inhabited. This is owing partly to the numerous emigrations to America, and partly to the indolence of the natives, who will not labour to raise food for their families. Another cause may be assigned, and that is, the vast numbers of ecclesiastics, who lead a iffe of celibacy. Some writers have assigned several other causes, such as the wars with the Moors, and the final expulsion of that people. The present inhabitants of this kingdom have been computed, by some authors; at 13 millions, and by others at 11 . Feyjoo, a 
Spanish writer, estimates them at only 9,250,000. According to an enumeration, arranged in classes, given by $\mathrm{Mr}$. Townsend, they amounted, in 1787 , to $10,268,250$; which corresponds with sufficient accuracy to the total of the population of the different provinces before given from the statistical tables of Bœtticher. England is therefore much more than twice as populous as Spain considering its extent.

National character, manners, customs....The persons of the Spaniards are generally tall, especially the Castilians; their hair and complexions swarthy, but their countenances are very expressive. The court of Madrid has of late been at great pains to clear their upper lips of mustaches, and to introduce among them the French dress, instead of their black cloaks, their short jerkins, strait breeches, and long 'Toledo swords, which dress is now chiefly confined to the lower ranks. The Spaniards, before the accession of the house of Bourbon to their throne, affected that antiquated dress, in hatred and contempt of the French; and the government probably will find some difficulty in abolishing it entirely, as the sane spirit is far from being extinguished. An old Castilian, or Spaniard, who sees none above him, thinks himself the most important being in nature ; and the same pride is commonly communicated to his descendants. This is the true reason why many of them are so fond of removing to America, where they can retain all their native importance, without the danger of seeing a superior.

Ridiculous, however, as this pride is, it is productive of the most exalted qualities. It inspires the nation with generous, humane, and virtuous sentiments; it being seldom found that a Spanish nobleman, gentleman, or even trader, is guilty of a mean action. During the most embittered wars they have had with England, for nearly 100 years past, we know of no instance of their taking advantage (as they might easily have done) of confiscating the British property on board their galleons and Plate fleet, which was equally secure in time of war as peace. This is the more surprising, as Philip V, was often needy, and his ministers were far from being scrupulous of breaking their good faith with Great Britain.

From the best and most credible accounts of the late wars, it appears, that the Spaniards in America gave the most humane and noblc relief to all British subjects who were in distress and fell into their hands, not only by supplying them with necessaries, but money; and treating them in the most hospitable manner while they remained among them.

Having said thus much, we are carefully to distinguish the Spanish nobility, gentry, and traders, from the lower ranks of Spaniards, who are as mean and rapacious as those of any other country. The kings of Spain, of the house of Bourbon, have seldom ventured to employ native Spaniards of great families, as their ministers. These are generally French or Italians, but most commonly the latter, who rise into power by the most infamous arts, and of late times from the most abject stations. Hence it is, that the French kings of Spain, since their accession to that monarchy, have been but very indifferently served in the cabinet. Alberoni, who had the greatest genius among them, embroiled his master with all Europe, till he was driven into exile and disgrace ; and Grimaldi, the last of their Italian ministers, hazarded a rebellion in the capital, by his oppressive and unpopular measures. 
The common people who live on the coasts partake of all the bad qualities that are to be found in other nations. They are an assemblage of Jews, French, Russians, Irish adventurers, and English smugglers, who being unable to live in their own country, mingle with the Spaniards. In time of war they follow privateering with great success; and when peace returns, they engage in all illicit practices, and often enter into the Irish and Walloon guards in the Spanish service. There are about 40,000 gypsies, who, besides their trade of fortune-telling, are inn-keepers in the small towns and villages. The character of the Spaniards is thus drawn by Mr. Swinburne. "The Catalans appear to be the most active stirring set of men, the best calculated for business, travelling, and manufactures. The Valencians are a more sullen seclate race, better adapted to the occupations of husbandmen, less eager to change place, and of a much more timid, suspicious cast of mind than the former. The Andalusians seem to be the greatest talkers and rhodomontaders of Spain. The Castilians have a manly frankness, and less appearance of cunning and deceit. The New Castilians are, perhaps, the least industrious of the whole nation; the Old Castilians are laborious, and retain more of the ancient simplicity of manners; Loth are of a firm cletermined spirit. The Arragonese are a mixture of the Castilian and Catalan, rather inclining to the former. The Biscayners are acute and diligent, fiery and impatient of controul, more resembling a colony of republicans than a province of an absolute monarchy: and the Gallicians are a plodding pains-taking race of mortals, that roam over Spain in search of a hardly-earned subsistence."

The beauty of the Spanish ladies reigns mostly in their novels and romances; for though it must be acknowledged that Spain produces as fine women as any country in the world, yet beauty is far from forming their general character. In their persons, they are mostly small and slender; but they are said to employ great art in supplying the defects of nature. If we were to hazard a conjecture, we might reasonably suppose that those artifices rather diminish than increase beauty, especially when they are turned of twenty-five. Their indiscriminate use of paint, not only upon their faces, but their necks, arms, and hands, undoubtedly disfigures their complexions and shrivels their skin. It is at the same time universally allowed, that they have great wit and vivacity.

Among the many good qualities possessed by the Spaniards, their sobriety in eating and drinking is remarkable. They frequently breakfast, as well as sup, in bed. Their breakfast is usually chocolate, tea being very seldlom drank. Their dinner is generally beef, mutton, veal, pork, and bacon, greens, \&c. all boiled together. They live much upon garlic, chives, sallad, and radishes; which, according to one of their proverbs, are food for a gentleman. The men drink very little wine; and the women use water or chocolate. Both sexes usually sleep after dinner, and take the air in the cool of the evening. This is the common practice in warm countries, such as Italy, Spain, and Portugal, where, generally speaking, the weather is clear, and the inhabitants are mostly in the habit of rising much earlier than in England. The human body cannot furnish spirits sufficient to resist the effects of the violent heat; through the whole day, without some such refreshment; it is, therefore, the universal practice to $\mathrm{g}$ o to sleep for some hours after dinner, which in those countrics 
is over early; and this time of repose, which lasts for two or three hours, is in Spain called the Siesta, and in Portugal the Sesta. Dancing is so much their favourite entertainment, that you may see a grandmother, mother, and daughter, all in the same country dance. Many of their theatrical exhibitions are insipid and ridiculous bombast. 'The prompter's head sometimes appears through a trap-door, above the level of the stage, and he reads the play loud enough to be heard by the audience. Gallantry is a ruling passion.in Spain. Jealousy, since the accession of the louse of Bourbon, has siept in peace. The nightly musical serenades of mistresses by their lovers are still in use. The fights of the cavaliers, or bull feasts, are almost peculiar to this country, and make a capital figure in painting the genius and manners of the Spaniards. On these occasions, young gentlemen have an opportunity of showing their courage and activity before their mistresses; and the valour of the cavalier is proclaimed, hon. oured, and rewarded, according to the number and fierceness of the bulls he has killed in these encounters. Great pains are used in settling the form and weapons of the combat, so as to give a relief to the gallantry of the cavalier. The diversion itself, which is attended with circumstances of great barbarity, is undoubtedly of Moorish original, and was adopted by the Spaniards when upon good terms with that nation, partly through complaisance, and partiy through rivalship.

There is not a town in Spain but what has a large square for the purpose of exhibiting bull-fights; and it is said, that even the poorest inhabitants of the smallest villages will often club together, in order to procure a cow or an ox, and fight them, riding upon asses for want of horses.

Cities, chief towns, edifices....Madrid, though unfortified, it being only surrounded by a mud wall, is the capital of Spain, and contains about 180,000 inhabitants. It is surrounded with very lofty mountains, whose summits are frequently covered with snow. It is well paved and lighted, and some of the streets are spacious and handsome. The houses of Madrid are of brick, and are laid out chiefly for show, convenience being little considered; thus you will usually pass through two or three large apartments of no use, in order to come at a small room at the end where the family sit. The houses in general look more like prisons than the habitations of people at their liberty; the windows, besides having a balcony, being: grated with iron bars, particularly the lower range, and sometimes all the rest. Separate families generally inhabit the same house, as in Paris and Edinburgh. Foreigners are very much distressed for lodgings at Madrid, as the Spaniards are not fond of taking strangers into their houses, especially if they are not catholics. Its greatest excellency is the cheapness of its provisions; but neither tavern, coffee-house, nor newspaper, excepting the Madrid Gazette, is to be found in the whole city. The royal palace stands on an eminence, on the west side of the city; it is a spacious magnificent structure, consisting of three courts, and commands a very fine prospect. Each of the fronts is 4.70 feet in length, and 100 high, and there is no palace in Europe fitted up with greater magnificence; the great audience chamber especially, which is 120 feet long, and hung with crimson velvet richly embroidered with gold: it is ornamented also with 12 looking-glasses made at St. Ildefonso, each ten fect high, and. with 12 tables of the finest Spanish marble. The other royal 
palaces round it are designed for hunting seats, or houses of retirement for their kings. Some of them contain fine paintings and good statues. The chief of those palaces are the Buen Retiro (now stript of all its best pictures and furniture) Casa del Campo, Aranjeuz, and St. Iidefonso.

A late traveller has represented the palace of Aranjeuz, and its gardens, as extremely delightful. Here is also a park many leagues round, intersected, in different parts, by alleys of two, three, and ever four miles extent. Each of those alleys is formed by two double rows of elmirees; one double row on the right, and one on the left, which renders the shade thicker. The alleys are wide enough to admit four coaches abreast, and betwixt each double row there is a narrow channel, through which runs a stream of water. Between these alleys there are thick groves of smaller trees of various kinds; and thousands of deer and wild boars wander there at large, besides numberless hares, rabbits, pheasants, partridges, and several other kinds of birds. The river Tagus runs through this place, and divides it into two unequ.l parts. The central point of this great park is the king's palace, which is partly surrounded by the garden, and is exceedingly pleasant, adorned with fountains and statues; and it also contains a vast variety of the most beautiful flowers, both American and European. As to the palace of Aranjuez itself, it is rather an elegant than a magnificent building.

The palace of St. Ildefonso is built of brick, plaistered and painted, but no part of the architecture is agreeable. It is two stories high, and the garden front has thirty-one windows, and twelve rooms in a suit. The gardens are on a slope, on the top of which is a great reservoir of water, called here El MIar (the sea) which supplies the fountains : this reservoir is furnished from the torrents which pour down the mountains. The water works are excellent, and far surpass those of Versailles. The great entry of the palace is somewhat similar to that of Versailles, and with a large iron palisade. In the gardens are twenty-seven fountains; the basins are of white marble, and the statues, many of which are excellent, are of lead, bronzed and gilt. These gardens are in the formal French style, but ornamented with sixty-one very fine marble statues, as large as the life, with twenty-eight marble vases, and twenty leaden vases gilt. The upper part of the palace contains many valuable paintings, and the lower part antique statues, busts, and basso-relievos.

The pride of Spain, however, is the Escurial; and the natives say, perhaps with justice, that the building of it cost more than that of any other palace in Europe. The description of this palace forms a sizeable quarto volume; and it is said that Philip II, who was its founder, expended upon it six millions of ducats. It is situate about i wenty miles from Madrid, in a deep recess at the foot of the Guadarama mountains. It contains a prodigious number of windows, 200 in the west front, and in the east 366 ; and the apartments are clecorated with an astonishing variety of paintings, sculpture, tapestry, ornaments of gold and silver, marble, jasper, gems, and other curions stones. This building, besides its palace, contains a church, large, and richly ornamented; a mausoleum, cloisters, a convent, a college, and a library containing about thirty thousand volumes; but it is more particularly valuable for the Arabic and Greck manuscripts with which it is enriched. Above the shelves are paintings in fresco, by Parthelemi Carducho, the subjects of which are taken from sacred 
or profane history, or have relation to the sciences of which the shelves below present to us the elements. Thus, the council of Nice is represented above the books which treat of theology; the deatis of Archimedes, at the siege of Syracuse, indicates those which relate to the mathematics; and Cicero promouncing his oration in favour of Rabirius, the works relative to eloquence and the bar. A very singular circumstance in this library may be agreeable to the curious reader to know, which is, that, on viewing the books, he will find them placed the contrary way, so that the edges of the leaves are outwards, and contain their titles written on them. The reason for, this custom is, that Arius Montanus, a learned Spaniard of the sixteenth century, whose library had served as a foundation for that of the Escurial, had all his books placed and inscribed in that manner, which no doubt appeared to hin to be the most commodious method of a rranging them. He introduced his own method into the Escurial; and since his time, and for the sake of uniformity, it has been follow: ed with respect to the books afterwards added. Here are also large apartments for all kinds of artists and mechanics. The fathers that live in the convent are in number 200, and they have an annual revenue of 100,000 dollars. The mausoleum, or burying place of the kings and queens of Spain, is called the Pantheon, because it is built upon the plan of that temple at Rome, as the church to which it belongs is upon the model of St. Peter's. It is thirty-six feet in diameter, and incrusted with fine marbles.

Allowing to the Spaniards their full estimate of the incredible sums bestowed on this palace, and on its furniture, statues, paintings, columns, vases, and the like decorations, which are most anazingly rich and beautiful, yet we hazard nothing in saying, that the fabric itself discovers a bad taste upon the whole. The conceit of building it in the form of a gridiron, because St. Lawrence, to whom it was dedicated, was broiled on such an utensil, and multiplying the same figure through its principal ornaments upon the doors, windows, altars, rituals, and sacerdotal habits, could have been formed only in the brain of a tasteless bigot, such as Philip II, who erected it to commemorate the victory he obtained over the French (but by the assistance of the English forces) at St. Quentin, on St. Lawrence's day, in the year 1557. The apartment where the king resides, forms the handle of the gridiron. The building is a long square of 640 feet by 580 . The height of the roof is 60 feet. It has been enriched and adorned by his successors, but its outside has a gloomy appearance, and the inside is composed of different structures, some of which are master pieces of architecture, but forming a disagreeable whole. It must, however, be confessed, that the pictures and statues that have found admission here, are excellent in their kind, and some of them not to be equalled even in. Italy itself.

Cadiz is the great emporium of Spanish commerce. It stands on an island separated from the continent of Andalusia, without the Straits of Gibraltar, by a very narrow arm of the sea, over which a fortified bridge is thrown, and joins it to the main land. The entrance into the bay is about 500 fathoms wide, and guarded by two forts, called the Puntals. The entrance has never been of late years attempted by the English in their wars with Spain, because of the vast interest our merchants have in their treasures there, which they could not reclaim from the captors. The streets are narrow, ill paved and filthy, and full of rats in the night; the houses lofty, with flat roofs, and few are 
without a turret for a view of the sea. The population has been reck oned at 60,000 inhabitants, many of whom are foreigners. The cathedral has been already 50 year's building, and the roof is not yet finish. ed. The environ's are beautifully rural.

Cordova is now an inconsiderable place; the streets are crooked and dirty, and but few of the public or private buildings conspicuous for their architecture. The palaccs of the inquisition and of the bishop are extensive and well situated. The cathedral was formerly a mosque divided into seventeen aisles by rows of columns of various marbles, and is very rich in plate; four of the silver candlesticks cost $85 l$. a piece. The revenue of the see amounts to $3500 l$. per annum, but as the bishops cannot devise by will, all they die possessed of escheats to the king.

Seville, the Julia of the Romans, is, next to Madrid, the largest city in Spain, but is greatly decayed both in riches and population. The number of inhabitants, however, is still estimated at 80,000 .' The shape is circular, and the walls seem of Moorish construction; its circumference is five miles and a half. The suburb of Triana is as large as many towns, and remarkable for its gloomy Gothic castle, where, in 1481, the inquisition was first established in Spain. Its manufactures in wool and silk, which formerly amounted to 16,000 , are now reduced to 400 ; and its great office of commerce to Spanish America, is removed to Cadiz. 'The cathedral of Seville is a fine Gothic building, with a curious steeple or tower, having a moveable figure of a woman at the top, called La Giralda, which turns round with the wind, and which is referred to in Don Quixote. This steeple is reckoned one of the greatest curiosities in Spain, and is higher than St. Paul's in London; but the cathedral, in Mr. Swinburte's opinion, is by no means equal to York-minster for lightness, elegance, or Gothic delicacy. The first clock made in the kingdom was set up in this cathedral, in the year 1400, in the presence of king Henry III. The prospect of the country round this city, beheld from the steeple of the cathedral, is extremely delightful.

Barcelona, formerly Barcino, said to be founded by Hamilcar Bar. cas, is a large circular trading city, containing 15,00 n houses, situated on the Mediterranean, facing Minorca, and is said to be the handsomest place in Spain; the houses are lofty and plain, and the streets well lighted and paved. The citadel is strong, and the place and inhabitants famous for the siege they sustained, in 1714, against a formidable army, when deserted both by England and the emperor, for whom they had taken up arms. The number of inhabitants is supposed to be about 111,00 n, and they supply Spain with most of the clothing and arms for the troops. A singular custom prevails among them: on the lst of November, the eve of All Souls, they run about from house to house to eat chesnuts, believing that for every chesnut they swallow, with proper faith and unction, they shall deliver a soul out of pur * gatory.

Valencia is a large and almost circular city, with lofty walls. The streets are crooked and narrow, and not paved; the houses ill built and filthy, and most of the churches tawdry. Priests, nuns, and friars, of every dress, swarm in this city, whose inhabitants are computed at 100,000. Its archbishopric is one of the best in Spain; its revenue amounting to about 170,000 dollars a year.

Carthagena is a large city, but has few good streets, and fewer remarkable buildings. The port is very complete, formed by nature in

VoL. I. 
the figure of a hart, and the arsenal is a spacious square south-west of the town, with 40 pieces of cannon to defend it towards the sea. When Mr. Swinburne visited it in 1775 , there were 800 Spanish criminals, and 600 Barbary slaves, working at the pumps, to ketp the docks dry, \&xc. and treated with great inhumanity. The crimes for which the Spaniards were sent there deserved, indeed, exemplary punishment. The population amounts to near 50,000.

Granada stands on two hills, and the ancient palace of the Alhambra crowns the double summit between two rivers, the Douro, and the Xenil. The former glories of this city are passed away with its old inhabitants; the streets are now filthy, the aqueducts crumbled to dust, and its trade lost. Of 50,000 inhabitants, only 18,000 are reckoned useful; the surplus is made up of clergy, lawyers, children, and beggars. The amphitheatre for buli-feasts is built of stone, and one of the best in Spain. The environs of the city are still pleasing and healthful.

Bilboa is situate on the banks of the river Ybaizabal, and is about two leagues from the sea. It contains about 800 houses, with a large square by the water side, well shaded with pleasant walks, which extend to the outlets on the banks of the river, where there are great numbers of houses and gardens, which form a most pleasing prospect, particularly in sailing up the river; for, besides the beautiful verdure, 'numerous objects open gradually to the eye, and the town appears as an amphitheatre, which enlivens the landscape, and completes the scenery. The houses are solid and lofty, the streets well paved and level, and the water is so conveyed into the streets, that they may be washed at pleasure, which renders Bilboa one of the neatest towns in Europe. Population 13,000.

Malaga is an ancient city, and not less remarkable for its oppulence and extensive commerce, than for the luxuriance of its soil, yielding in great abundance the most delicious fruits; whilst its rugged mountains afford those luscious grapes which give such reputation to the Malaga wine, known in England by the name of Mountain. The city is large and populous, and of a circular form, surrounded with a douUle wall, strengthened by stately towers, and has nine gates. A Moorish castle, on the point of a rock, commands every part of it. The streets are narrow : and the most remarkable building in it is a stupendous cathedral, begun by Philip II, said to be as large as that of St. Paul's, in London. The bishops income is 70,000 dollars. The number of inhabitants is about 42,000 .

The city of Salamanca is of a circular form, built on three hills and two vallies, and on every side surrounded with prospects of fine houses, noble seats, gardens, orchards, fields, and distant villages; and is ancient, large, rich, and populous. There are ten gates to this city, and it contains twenty-five churches, twenty-five convents of friars, and the same number of nunneries. The most beautiful part of this city is the great square, built about forty years ago. The houses are of three stories, and all of equal height and exact symmetry, with iron balconies, and a stone balustrade on the top of them : the lower part is arched, and forms a piazza all round the square, which extends two liundred and ninety-three feet on each side. Over some of the arches are medallions, with busts of the kings of Spain, and several eminent men, in stone basso relievo, among which are those of Ferdinando Cortez, Francis Pizarro, Davilla, and Cid Ruy. In this square the bull fights are exhibited, for three days only, in the month of June. 
The River Tormes runs by this city, and has a bridge orer it of 25 arclses, built by the Rumans, and yct entire. The population is about 15,000 .

Toledo is one of the most ancient cities in Spain, and during several centuries it held the rank of its metropolis. But the neighbourhood of Madrid has by degrees stripped it of its numerous inhabitants, and it would have been almost entirely deserted but for its cathedral, the income of which being in great part spent here, concributes chiefly to the maintenance of the few thousands that are left, and assists, in some degree, those small manufactures of sword-blades and silk stuffs that are established in this city. It is now exceedingly ill built, poor, and mean. This city is said to have formerly contained 200,000 inhabitants; they now do not exceed 25,000 .

Burgos was the ancient capital of the kingdom of Castile, but is now in obscurity. The cathedral is one of the most magnificent structures, of the Gothic kind, now in Europe. Its form is exactly the same as that of York-minster, and on the east end is an octagron building, exactly like the chapter-house at York. Number of inhabitants 10,000 .

Gibraltar, once a celebrated town and fortress of Andalusia, is at present in possession of Great Britain. Till the arrival of the Saracens in Spain, which took place in 711 , or 712 , the rock of Gibraitar went by the name of Mons C'alne. On their arrival, a fortress was built upon it, and it obtained the name of Gibel Tariff, or Mount Tariff, from the name of their general, and thence Gibraltar. It was in the possession of the Spaniards and Moors by turns, till it was taken from the former by a combined fleet of English and Dutch ships, under the command of sir George Rooke, in 1704, and this rather through accident than any thing else. The prince of Hesse, with 1800 inen, landed on the isthmus ; but an attack on that side was found to be impracticable, on account of the steepness of the rock. The fleet fired 15,000 shot, without making any impression on the works; so that the fortress seems to be equally impregnable both to the British and Spaniards, except by famine. At last, a party of sailors, having got merry with grog, rowed close under the New Mole in their boats; and as they saw that the garrison, which consisted only of 100 men, did not mind them, they were encouraged to attenipt a landing; and having mounted the mole, hoisted a red jacket as signal of possession. This being immediately observed from the fleet, more boats and sailors were sent out, who, in like manner, having ascended the works, sot possession of a battery, and soon obliged the town to surrender. Aficr many fruitless attempts to recover it, jt was confirmed to the English by the treaty of Utrecht, in 1713. Repeated attempts have since been made to wrest it from England, but without success; the war preceding the last rendered it more famous than ever, when it underwent a long siege against the united forces of Spain and France, by land and sea, and was gallantly defended by general Elliot and his garrison, to the great loss and disgrace of the assailants; though it must be granted the place is by nature almost impregnable. Near 300 pieces of cannon of different bores, and chiefly brass, which were sunk before the port in the floating batteries, were raised and sold, for the use of the garrison. It is a commodious port, and formed naturally for commanding the passage of the Straits, or, in other words, the entrance into the Mediterranean and Levant seas. But the road is neither safe against an enemy nor storms: the bay is about twenty 
leagues in circumference. The straits are 34 miles long, and 15 broat, througn which sets a current from the Atlantic Occall into the Mediterraicean, and for the stemming of it a brisk gale is required. The town was neither large nor beautiful, and in the last siege was totally destroyed by the enemies bombs; but on account of its fortifications is esteemed the key of Spain, and is always furnished with a garrison well provider for its defence. The harbour is formed by a mole, which is well fortified and planted with guns. Gibraltar is accessible on the land side only by a narrow passage between the rock and the sea; but that is wailed and fortified both by art and nature, and so enclosed by high steep hills, as to be almost inaccessible. It has but two gates on that side, and as many towards the sea. Across this isthmus the Spaniards have drawn a fortified line, chiefly with a view to hinder the garrison of Gibraltar from having any intercourse with the country behind them; notwithstanding which they carry on a clandestine trade, particularly in tobacco, of which the Spaniards are exceedingly fond. The garrison is, however, confined within very narrow limits : and, as the ground produces scarcely any thing, all their provisions are brought them either from England, or from Centa on the opposite coast of Barbary. Formerly Gibraltar was entirely under military government; but that power producing those abuses which are naturally attendant on it, the parliament thought proper to erect it into a body corporate, and the civil power is now lodged in its magistrates.

The other towns of importance are, Murcia, on the Segura, containing 44,000 inhabitants ; Sarragossa, on the Ebro, with 42,000 inhabitants; Ferrol, on the Bay of Corunna, 30,000; Ecija, in Andalusia, 28,000 ; Jaen, in Andalusia, 27,000; Valladolid, in Leon, 24,000; Lorca, in Murcia, 22,000 ; St. Jago di Compostella, the chief town of Gallicia, 21,000; Orihuela, in Valencia, on the Segura, 21,000; Alicant, in Valencia, on the Mediterranean, 17,000; Elche, 20 miles south-west of Alicant, 17,000; Lerida, in Catalonia, 16,000; Pampeluna, in Upper Navarre, 14,000; St. Sebastian, on the Bay of Biscay, 12,000; Oviedo, the capital of Asturias, 10,000; Badajoz, on the Guadiana, in Estremadura, 10,000; and Leon, the capital of Leon, 10,000 .

The Chief islands belonging to Spain in Europe are Minorca, Ma jorca, and Yvica, pronounced Eviza. Minorca which was taken by the English, in 1780, under general Stanhope, and confirmed to Great Britain by the treaty of Utrecht in 1713, was retaken by the Spaniards, February 15, 1782, and is now a Spanish island again, containing about 27,000 inhabitants.

Commerce and manufactures....The Spaniards, unhappily for themselves, make gold and silver the chief branches both of their exports and imports. They import these metals from America, and afterwards export them to other countries of Europe. Cadiz is the chief emporium of this commerce. "Hither," says Mr. Anderson, in his history of Commerce, "other European nations send their merchandise to be shipped off in Spanish bottoms for America, sheltered (or, as our old English phrase has it, coloured) under the name of the Spanish factors. Those foreign nations have here their agents and correspondents, and the consuls of those nations make a considerable figure. Cadiz has been said to have the finest store-houses and magazines for commerce of any city in Europe ; and to it the flota and galleons regularly import the treasures of Spanish America. The proper Spanish merchandises exported from Cadiz to America, are 
of no great value; but the duty on the foreign merchandise sent thither would yield a great revenue (and consequently the profits of merchants and their agents would sink) were it not for the many frauclulent practices for eluding those duties."

At St. Ildefonso the glass manufacture is carried on to a degree of perfection unknown in England. The largest mirrors are made in a brass frame, 162 inches long, 93 wide, and six deep, weighing near nine tons. These are designed wholly for the royal palaces, and for presents from the king. Yet even for such purposes it is ill placed, and proves a devouring monster in a country where provisions are dear, fuel scarce, and carriage exceedingly expensive. Here is also a royal manufacture of linen, employing about fifteen looms; by which it is said the king is a considerable loser.

In the city of Valencia there is a very respectable silk manufacture in which five thousand looms, and three hundred stocking frames, give employment to upwards of 20,000 of the inhabitants, without enumerating those who exercise professions relative to the manufacture, such as persons who prepare the wood and iron work of so great a number of machines, or spin, wind, or dye the silk. At Alcora, in the neighbourhood of Valencia, a manufacture of porcelain has been successfully established; and they very much excel in painted tiles. In Valencia, their best apartments are floored with these, and are remarkable for neatness, for coolness, and for elegance. They are stronger and much more beautiful than those of Holland.

At Carthagena they make great quantities of the esparta ropes and cables, some of them spun like hemp, and others plaited. Both operations are performed with singular rapidity. These cables are excellent, because they float on the surface of the water, and are not therefore liable to be cut by the rocks on a foul coast. The esparto rush makes good mats for houses, alpargates, or short trousers, and bus kins for peasants, and latterly it has been spun into fine thread for the purpose of maling cloth. If properly encouraged, there is no doubt that the manufacture may be brought to such perfection as to make this once useless rush a source of abundant wealth to the southern provinces of Spain, for it is the peculiar and natural production of all the high and uncultivated mountains of the south.

As to the hempen cordage which is made in Spain for the use of the royal navy, $\mathbf{M}$. de Bourgoanne observes, that it is better and more durable than that of the principal dock-yards and magazines in E rope : because in combing the hemp, all the towy part we leave in it is taken out, and made use of in calking; whence results the double advantage of more solid cordage, and the better calking of vessels. Another custom in our rope-yards which the Spaniards have avoided adopting, is the tarring the cordage, and keeping it a long time piled up. In this state the tar ferments, and eats the hemp, and the cordage is extremely apt to break after being used but a short space of time.

The Spaniards formerly obtained their hemp from the north; at present they are able to do without the assistance, in this article, of any other nation. 'The kingdom of Granada already furnishes them with the greatest part of the hemp they use; and in case of need, they may have recourse to Arragon and Navarre. All the sail-cloth and cordage in the magazines at Cadiz are made with Spanish hemp, the texture of which is even, close, and solid.

The most important production of this country, and the most valu 
able article of commerce, is barilla, a species of pot-ash, procured by burning a great variety of plants almost peculiar to the kingdoms of Valencia and Murcia, such as soza, algazal, suzon, sayennes, salicornin, with barilla. It is used for making soap, for bleaching, and for glass. All the nations in Europe, by the combustion of various vegetable substances, make some kind of pot-ash ; but the superior excellence of the barilla has hitherto secured the preference. The country producing it is about sixty leagues in length, and eight in breadth, on the borders of the Mediterranean. The quantity exported annually from Spain (according to the testimonies of both Mr. Townsend and M. de Bourgoanne) is about a hundred and fifty quintals, most of which are sent to France and England, and a small quantity to Genoa and Venice.

Spain is one of the richest countries in Europe in salt-petre, a most important article of commerce. The account of this surprising manufacture we shall abridge from $\mathrm{Mr}$. Townsend: "I observed," says he, "a large enclosure, with a number of mounts of about twenty feet high, at regular distances from each other. These were collected from the rubbish of the city of Madrid, and the scrapings of the highways. They had remained all the winter piled up in the manner in which I found them. At this time men were employed in wheeling them away, and spreading abroad the earth to the thickness of about one foot, whilst others were turning what had been previously exposed to the influence of the sun and air. The preceding summer these heaps had been washed, and being thus exposed, would yield the same quantity of salt again : and, as far as appears, the produce would never fail : but, after having been washed, no salt-petre can be obtained without a subsequent exposure. Some of this earth they can lixiviate once a year, some they have washed twenty times in the last seven years, and some they have subjected to this operation fifteen times in one year, judging always by their eye when they may wash it to advantage, and by their taste, if it has yielded a lixivium of a proper strength ; from which, by evaporating the water in boiling, they obtain the salt-petre."

There are flourishing manufactures of coarse linens at Escary, in Biscay; at Grazalema in Andalusia, and at several places in Valencia. The manufactures of lace have of late arrived at such perfection, that there is scarcely any distinction observable between the laces of France and Spain.

The other manufactures of Spain are chiefly wool, copper, and hardware. Great efforts have been made by the government, to prevent the other European nations from reaping the chief advantage of the American commerce; but these never can be successful, till a spirit of industry is awakened among the natives, so as to enable them to supply their American possessions with their own commodities and merchandise. Meanwhile, the good faith and facility with which the English, French, Dutch, and other nations, carry on this contraband trade, render them greater gainers by it than the Spaniards themselves are, the clear profits seldom amounting to less than twenty per cent. This evidently makes it an important concern, that those inımense riches should belong to the Spaniards, rather than any active European nation: but of this subject there will be occasion to speak in the account of America.

Constitution and Government....Spain, from being the most free, is now the most despotic kingdom in Europe; and the poverty 
which is so visible in most parts of the country is in a great degree the result of its government, in the administration of which no proper attention is paid to the interests and welfare of the people. The monarchy is hereditary, and females are capable of succession. It has even been questioned, whether his catholic majesty may not bequeath his crown, upon his demise, to any branch of the royal fanily he pleases. It is at least certain, that the house of Bourtion mounted the throne of Spain in virtue of the last will of Charles II.

The cortes, or parliaments of the kingdom, which formerly, especially in Castile, had greater power and privileges than those of England, are now abolished; but some faint remains of their constitution are still discernible in the government, though all of them are ineffectual, and under the controul of the king.

The privy council, which is composed of a number of noblemen, or grandees, nominated by the king, sits only to prepare matters, and to digest papers for the cabinet council, or junto, which consists of the first secretary of state, and three or four more named by the king; and in them resides the direction of all the executive part of government. The council of war takes cognizance of military affairs only. The council of Castile is the highest law tribunal of the kingdom. The several courts of the royal audicnces are those of Gallicia, Sevilla, Majorca, the Canaries, Saragossa, Valencia, and Barcelona. These judge primarily in all causes within fifteen miles of their respective cities or capitals, and receive appeals from inferior jurisdictions. Besides these there are many subordinate tribunals, for the poiice, the finances, and other branches of the administration.

The government of Spanish America forms a system of itself, and is delegated to viceroys, and other magistrates, who are in their respective districts almost absolute. A council for the Indies is established in Old Spain, and consists of a governor, four secretaries, and twenty-two counsellors, besides officers. Their decision is final in matters relating to America. The members are generally chosen from the viceroys and magistrates who have served in that country. The two great viceroyalties of Peru and Mexico are so considerable, that they are seldom trusted to one person for more than three years; and their emoluments are sufficient to make his fortune in that time.

While the royal family were prisoners in France, the people took the government into their own hands, and elected a cortes, who, through a provisional administration of their own appointment, conducted the affairs of the nation. This cortes framed a constitution, by which the power of the king was considerably restricted, and the rights of the ptople insured. But the king, upon his return, refused to sign the constitution, denounced the cortes, and resumed his former absolute prerogatives; and the Spanish nation, after enduring for the cause of liberty, the most bloody scourges of civil war, for six years, welcomed with joyful acclamations the return of their tyrant.

The foreign possessions of the crown of Spain, besides those in America, are the towns of Ceuta, Oran, and Masulquiver, on the coast of Parbary, in Africa; and the islands of St. Lazaro, the Philippines, and Ladrones, in Asia.

Revenues.. The revenues arising to the king yearly amount to about $30,000,000$ dollars; and they form the surest support of his government. Il is American income, is immense; but it is generally, in a manner, embezzled, or anticipated, before it arrives in Old Spain. The king has a fifth of all the silver mines that are worked, but little of it 
comes into his coffers. He finds means, however, in case of a war, or public emergency, to.sequester into his own hands great part of the American treasures belonging to his subjects; who never complain, because they are always punctually repaid with interest. The finances of his present catholic majesty are in better order, both for himself and his people, than those of the greater part of his predecessors.

As to the taxes whence the internal revenues arise, they are various, arbitrary, and so much suited to conveniency, that we cannot. state them with any certainty. They are laid upon all kinds of goods, houses, Iands, timber, and provisions; the clergy and military orders are likewise taxed.

The national debt amounted in 1783 to $81,364,000$ dollars; in 1790 to $123,200,000$; in $1800,203,000,000$, and in 1809 to $311,000,000$. This debt has been principally created, by the govertument issuing notes called vales reales, redeemable at the pleasure of the king, and bearing but a moderate interest. Their value varies, but they are always under par, and sometimes as low as 30 per cent. discount.

Military and Marine strength.... The land forces of the crown of Spain, in time of peace, are never fewer than 70,000; but in case of war they amount to a much more considerable force. In 1807 at the commencement of the war with France, it consisted of the following corps: royal guards 650 ; guards 3000 ; the kings carbiniers 73,000 ; infantry of the line 92,240 , inclusive of six Swiss regiments; light infantry 7000 ; artillery 6000 ; corps of engineers 1396 ; cavalry 18,000. Total 201,286, besides 50,000 trained militia. As these troops were however, badly cloathed, badly armed and worse officered, the effective force, fit for service, must have been much less. The great dependence of the king, is upon his Walloon or foreign guards. His present catholic majesty has been at great care and expence to raise a poiverful marine. The Spanish fleet in Europe and America, consisted in 1808, of 218 sail; 42 of which were ships of the lire, 30 frigates, 20 corvettes, 4 zebecks, 40 brigantines, 15 bomb-ships and 67 smaller vessels. All along the coast of Spain are watch-towers firom mile to mile, with lights and guards at night: so that from Cadiz to Barcelona, and from Bilboa to Ferrol, the whole kingdom may be soon alarmed in case of an invasion.

ROYAL ARMS, TITLES, NOBILITY, AND ORDERS....Spain formerly comprehended twelve kingdoms, all of which, with several others, were, by name, entered into the royal titles, so that they amounted in all to about thirty-two. This absurd custom is still occasionally continued, but the king is now generally contented with the title of IIis Catholic Majesty. The kings of Spain are inaugurated by the delivery of a sword, without being crowned. Their signature never mentions their name, but I THE KING. Their eldest son is called prince of Austurias, and their younger children of both sexes are, by way of distinction, called infants, or infantas, that is, children.

The armorial bearing of the kings of Spain, like their title, is loaded-with the arms of all their kingdoms. It is now a shieldg divided into four quarters, of-which the uppermost on the right hand, and the lowest on the left, contain a castle or, with three lowers, for Castile; and in the uppermost on the left, and the lowest on the right, are three lions gules, for Leon; with three lilies in the centre for Anjou.

The general name for those Spanish nobility and gentry who are unmixed with the Moorish blood, is Hidalgo. They are divided into 
princes, dukes, marquises, counts, viscounts, and other inferior titles. Such as are created grandees may stand covered before the king, and are treated with princely distinctions. A grandee cannot be apprehended without the king's order; and cardinals, archbishops, a anbassadors, knights of the golden fleece, and certain other great dignitaries, both in church and state, have the privilege, as well as the grandees, to appear covered before the king.

The "Order of the Golden Fleece," particularly described before in the orders of Germany, is generally conferred on princes and sovereign dukes : but the Spanish branch of it has many French and Italian nobility; there are no commands or revenues annexed to it.

The "Order of St. James," or St. Jago de Compostella, is the richest of all the orders of Spain. It was divided into two branches, each under a grand master; but the office of both was given, by pope Alexander VI, to the kings of Spain and Portugal as grand masters in their respective dominions. The order is highly esteemed in Spain, and only conferred on persons of noble families. The same may be said of the "Order of Calatrava," first instituted by Sanchio, king of Toledo : it took its name from the castle of Calatrava, which was taken from the Moors, and here began the order, which became very powerful. Their number, influence, and possessions, were so considerable as to excite the jealousy of the crown, to which, at length, their revenues, and the office of grand master, were annexed by pope Innocent VIII. The celebrated "Order of Alcantara," derived its origin from the order of St. Julian, or of the Pear-tree; but after Alcantara was taken from the Moors, and made the chief residence of the order, they assumed the name of knights of the order of Alcantara, and laid aside the old device of the pear-tree. This order is highly esteemed, and conferred only on persons of ancient and illustrious families. The "Order of the Lady of Mercy" is said" to have been instituted by James I, king of Arragon about the year 1218 , on account of a vow made by him to the Virgin Mary, during his captivity in France, and was designed for the redemption of captives from the Moors, in which were expended large sums of money. It was first confined to men, but a lady of Barcelona afterwards got women included in it. This order possesses considerable revenues in Spain. The "Order of Montesa" was instituted at Valencia, as the close of the thirteenth century, in the place of the Templars, and enjoyed their possessions. Their chief seat being the town of Montesa, the order from thence derived its name, and chose St. George for their patron. In the year 1771, the late king instituted, after his own name, the "Order of Charles III," in commemoration of the birth of the infant. The badge is a star of eight points, enamelled white, and edged with gold ; in the centre of the cross is the image of the Virgin Mary : vestments, white and blue. On the reverse, the letters C. C. with the number III, in the centre, and this motto, Virtuti et Merito: None but persons of noble descent can belorg to this order.

Peligron....The Romish religion is the only one tolerated in Spain. The inquisition, a tribunal disgraceful to human nature, was, to the honour of the cortes, abolishied by them, during the absence of the king in France, and to the disgrace of the latter, re-established by him upon his return. The Spaniards embrace and practise the Roman-catholic religion with all its absurdities; and in this they have been so steacly that their kiıg is distinguished by the spithet of Most Catholic. It appears, however, that the burning zeal which distinVoL.I. 
guished their ancestors above the rest of the catholic world, has lost. much of its activity, and seems nearly extinguished; and the power of the clergy has been much reduced of late years. A royal edic has also been issued, to prevent the admission of novices into the different convents, without special permission, which has a great tendency to reduce the monastic orders. It is computed that there are now, in the kingdom of Spain; 54,000 friars, 34,000 nuns, and 20,000 secular clergy, but as little true moral religion as in any country under heaven.

In Catalonia, the confidence of the people in the intercession of saints, has at all periods been a source of consolation to them, but upon some occasions has betrayed them into mischief. Every company of artisans, and every ship that sails, is under the immediate protection of some patron. Besides folio volumes, which testify the innumerable miracles performed by our Lady in Montserrat, every subordinate shrine is loaded with votive tablets. This has been the parent of pre. sumption, and among the merchants has brought many families to want. The companies of insurance in the American war, having each of them its favourite saint, such as San Ramon de Penaforte, la Virgen de la Merced, and others, associated in form by the articles of partnership, and named in every policy of insurance ; and having with the most scrupulous exactness allotted to them their correspondent dividend, the same as to any oiher partner, they concluded that with such powerful associates it was not possible for them to suffer loss. Under this persuasion, they ventured, about the year 1779 , to insure the French West-India-men at fifty per cent, when the English and Dutch had refused to do it at any premium, and indeed when most of the ships were already in English ports. By this fatal stroke, all the insuring companies, except two were ruined.

ArchBishoprics AND BISHOPRics.... In Spain there are eight arch. bishoprics, and forty-six bishoprics. The archbishop of Toledo is styled the primate of Spain; he is great-chancellor of Castile, and has a revenue of nearly 440,000 dollars per annum; but the Spanish court has now many ways of lessening the revenues of the church, as by pensions, rionatious to hospitals, \& $\mathrm{c}$. and premiums to the societies of agriculture. This archbishopric pays annually 15,000 ducats to the monks of the Escurial, besides other pensions; and it is assertm ed that there is not a bishopric in Spain but has somebody or other quartered upon it : and the second-rate benefices are believed to be in the same predicament. Out of the rich canonries and prebends, are taken the pensions of the new order of knights of Charles III. The riches of the Spanish churches and convents are the unvarying objects of admiration to all travellers as well as natives; but there is a sameness in them all, excepting that they differ in the degrees of treasure and jewels they contain.

Literature....Spain has not produced learned men in proportion to the excellent capacities of its natives. This defect may, in some measure, be attributed to the indolence and bigotry of the Spaniards, which prevent them from making that progress in the polite arts which they otherwise would: but the greatest impediment to literature in Spain, is the despotic nature of its government.' Several of the ancient fathers of the church were Spaniards; and learnirfy owes much to Isidore, bishop of Seville, and cardinal Ximenes. Spain has likewise produced some excellent physicians. Such was the gloom of the Austrian government that took place with the emperor Charies 
F, that the inimitable Cervantes, the author of Don Quixote, born at Madrid in 1549 , entered into the army in a station little superior to that of a common soldier, and died neglected, after fighting bravely for his country at the battle of Lepanto, in which he lost his left hand. His satire upon knight-errantry, in his adventures of Don Quixote, did as much service to his countrymen, by curing them of that ridiculous spirit, as it now does honour to his own memory. He was in prison for debt when he composed the first part of his history, and is perhaps to be placed at the head of moral and humorous satirists.

The Visions of Quevedo, and some other's of his humorous and satirical pieces, having been translated into the English language, have rendered that author well known in this country. He was born at Madrid in the ytar 1570, and was one of the best writers of his age, excelling equally in verse and prose. Besides his merit as a poet, he was well versed in the Oriental languages, and possessed great erudition. His works are compriseri in three volumes quarto, two. of which consist of poetry, and the thild of pieces in prose. As a poet, he excelled both in the serious and burlesque style, and was happy in a turn of hunour similar to that which we admire in Butler and swift.

Poetry was cultivated in Spain at an early period. The most distinguished dramatic poet of this nation was Lopez de Vega, who was contemporary with our Shakspeare. He possessed an imagination astonishingly fertile, and wrote with great facility; but in his dramatic works he disregarded the unities, and adapted his plays more to the taste of the age, than to the rules of criticism. His lyric compositions, and fugitive pieces, with his prose essays, form a collection of fifty volumes, besides his dramatic works, which make twenty-six volumes more; exclusive of four hundred scriptural dramatic pieces, called in Spain Autos Sacramentales. Chalderon was also a dramatic writer of considerable note, but many of his plays are very licentious in their tendancy.

Tostatus, a divine, the most voluminous perhaps that ever wrote, was a Spaniard; but his works have been long distinguished only by their bulk. Herrera, and some other historians, particularly De Solis, have shown great abilities in history, by investigating the antiquities of America, and writing the history of its conquest by their countrymen. Among the writers who have appeared in Spain in modern times, father Feyjoo has been one of the most distinguished. His performances display great ingenuity, very extensive reading, and uncommon liberality of sentiment, especially when his situation and country are considered. Many of his pieces have been translated into English, and published in four volumes, 8vo. Don Francisco Perez Bayer, archdeacon of Valencia, and author of a Dissertation on the Phonician language, may be placed in the first rank of Spanish literati. Spain has likewise produced many travellers and voyagers to both the Indies, who are equally amusing and instructive.

Some of the Spaniards have distinguished themselves in the polite arts; and not only the cities, but the palaces, especially the Escurial, discover many striking specimens of their abilities as sculptors and architects; Palomino, in an elaborate treatise on the art of painting, in two volumes folio, has inserted the lives of two hundred and thirty-three painters and sculptors, who flourished in Spain from the time of Ferdinand the Catholic, to the conclusion of the reign of Philip IV. Amongst the most eminent Spanish painters, were. Velasques; Murillo, who is commonly called the Spanish Vandyke; 
Ribeira; and Claudio Coello, whose style of painting was very simiIar to that of Paul Veronese.

UNIVERSITIES....In Spain are reckoned 24 universities, the chief of which is Salamanca, founded by Alphonsus, ninth king of Leon, in the year 1200 . It contains 21 colleges, some of which are very magnificent. Most of the nobility of Spain send their sons to be educated here. The others are Seville, Granada, Compostella, Toledo, Valladolid, Alcala, Siguenza, Valencia, Lerida, Huesca, Saragossa, Tortoso, Ossuna, Onata, Candia, Barcelona, Murcia, Taragona, Baeza, Avila, Oriuela, Oviedo, and Palencia.

LANGUAGE.... The Spanish language like the Italian, is derived from the Latin ; and it might properly be called a corrupted Latin, were it not for the terminations, and the exotic words introduced into it by the Moors and Goths, especially the former. It is a majestic and expressive language ; and foreigners, who understand it best, esteem it mos:; for the Spanish works of genius appear to disadvantage even in the best translations : and Cervantes speaks almost as aukward English, as Shakspeare does French. It may, however, be considered as a standard tongue, having nearly retained its purity for upwards of 200 years. The Lords Prayer in Spanish is as follows:-Padre nuestro, que estas én el cielo, sanctificado se el tu nombre; venga a nos el tu reyno; kagase ta voluntad, assi en la tierra comoen el cielo; el han nuestro de cada dia da nos de oy; y fardona nos nuestras deudas assi como nos otros herdonamos a neustros deudores; no nos dexes cair en la tentacion, mas libra nos de mal; porque tao es el reyno, y la potencia, y la gloria, her los siglos. Amen.

Antrquities....These consist chiefly of Roman and Moorish. NearSegovia, a grand aqueduct, erected by Trajan, extends over a deep valley between two hills, and is supported by a double row of 159 arches. Other Roman aqueducts, theatres, and circi, are to be found at Tarragona, and in different parts of Spain. A ruinous watch-tower near Cadiz, is vulgarly, but erroneously, thought to be one of the pillars of Hercules. Near the city of Salamanca are the remains of a Roman way, paved with large flat stones; it was continued to Merida, and from thence to Seville. At Toledo are the remains of an old Roman theatre, which is now converted into a church, said to be one of the most curious remains of antiquity. It is 600 feet in length, 500 in breadth, and of a proportionable height; the roof, which is amazingly bold and lofty, is supported by 350 pillars of fine marble, in ten rows, forming eleven aisles, in which are 366 altars, and 24 gates ; every part being enriched and adorned with the most noble and costly ornaments. At Martorel, a la ge town where much black lace is manufactured, is a very high bridge, built in 1768 , out of the ruins of a decayed one that had existed 1985 years from its erection by Hannibal. At the north end is a triumphal arch or gateway, said to have been raised by that general in honour of his father Hamilcar. It is almost entire, well proportioned and simple without any kind of ornament, except a rim or two of hewn stone. Near Morviedro (once the faithful Saguntum, destroyed by Hannibal) are some Roman remains-as the ruins of the theatre, an exact semicircle about 82 yards diameter; some of the galleries are cut out of the rock, and 9000 persons might attend the exhibitions without inconvenience.

The Moorish antiquities are rich and magnificent. Among the most distinguished of these is the royal palace of the Alhambra, at Granada, which is one of the most entire as well as the most stately of 
wny of the edifices which the Moors erected in Spain. It was built in 1280 by the second Moorish king of Granada; and, in 1492, in the reign of their eighteenth king, was taken by the Spaniards. It is situate on a hill, which is ascended by a road bordered with hedges of double or imperial myrtles, and rows of elms. On this hill, within the walls of the Alhambra, the emperor Charles V, began a new palace in 1568 , which was never finished, though the shell of it remains. It is built of yellow stone : the outside forms a square of one hundred and ninety feet. The inside is a grand circular court, with a portico of the Tuscan and a gallery of the Doric order, each supported by thirty-two columns, made of as many single pieces of marble. The grand entrance is ornamented with columns of jasper, on the pedes. tais of which are representations of battles, in marble basso-relievo. The Aihambra itself is a mass of many houses and towers, walled round, and built of large stones of different dimensions. Almost all the rooms have stucco walls and ceilings, sorne carved, some painted, and some gilt, and covered with various Arabic sentences. Here are several baths, the walls, floors, and ceilings of which are of white marble. The gardens abound with orange and lemon trees, pomegratuates, and myrtles. At the end of the gardens is another palace called Ginaraliph, situate on a more elevated station than the Aihambra. From the balconies of this palace is one of the finest prospects in Europe, over the whole fertile plain of Granada, bounded by snowy mountains. The Moors to this day regret the loss of Granada, and still offer up prayers to God for the recovery of the city. Many other noble monuments, erected in the Moorish times, remain in Spain, some of them in tolerable preservation, and others exhibiting superb ruins.

History... Spain was probably first peopled by the Celtæ, from Gaul, to which it lies contiguous; or from Africa, from which it is only separated by the narrow strait of Gibraltar. The Phœnicians sent colonies thither, and built Cadiz and Malaga. Afterwards, upon the rise of Rome and Carthage, the possession of this kingdom became an object of contention between those powerful republics; but at length the Roman arms prevailed, and Spain remained in their possession until the fall of that empire, when it became a prey to the Goths. In the beginning of the fifth century; the Suevi, the Vandals, and the Alani, divided this kingdom among them : but in the year 584, the Goths again became its masters.

These, in their turn, were invaded by the Saracens, who, about the end of the seventh century, had possessed themselves of the finest kingdoms of Asia and Africa; and, not content with the immense regions that formerly composed great part of the Assyrian, Greek, and Roman empires, crossed the Mediterranean, ravaged Spain, and established themselves in the southerly provinces of that kingdom.

Don Pelao is mentioned as the first old Spanish prince who distinguished himself against these infidels (who were afterwards known by the name of Moors, the greater part of them having come from Mlauritania), and he took the title of the king of Austuria about the year 720 . His successes animated other christian princes to take arms likewise, and the two kingdoms of Spain and Portugal for many ages were perpetually embroiled in bloody wars.

The Moors in Spain were superior to all their contemporaries i11 arts and arms, and the Abdoulrahman line retained possession of the throne nearly three hundred years. Learning flourished in Spain, 
while the rest of Europe was buried in ignorance and barbarity. But the Moorish princes by degrees became weak and effeminate, and their chief ministers proud and insolent. A series of civil wars ensued, which at last overturned the throne of Cordova, and the race of Abdoulrahman. Several petty principalities were formed on the ruins of this empire, and many cities of Spain had each an independent sovereign. Every Adventurer was then entitled to the conquests he made from the Moors, till Spain at last was divided into weive or thirteen kingdoms; and about the year 1095, Henry of Burgundy, was declared by the king of Leon, count of Portugal; but his sin, Alfonso, threw off his dependence on Leon, and declared himself king. A series of brave princes gave the Moors repeated overthrows in Spain, till about the year 1492, when all the kingdoms in Spain, Portugal excepted, were united by the marriage of Ferdinand, king of Arragon, and Isabella, the heiress and afterwards queen of Castile, who took Gra. nada, and expelled out of Spain the Moors and Jews who would not be converts to the Christian faith, to the number of 170,000 families.

The expulsion of the Moors and Jews in a manner depopulated Spain of artists, labourers, and manufacturers; and the discovery of America not only added to that calamity, but rendered the remaining Spaniards most deplorably indolent. 'To complete their misfortunes, Ferdinand and Isabella introduced the popish inquisition, with all its horrors, into their dominions, as a safeguard against the return of the Moors and Jews.

Charles V, of the house of Austria, and emperor of Germany, succeeded to the throne of Spain, in right of his mother, who was the daughter of Ferdinand and Isabella, in the year 1516. The extensive possessions of the house of Austria in Europe, Africa, and, above all, America, from whence it drew immense treasures, began to alarm the jealousy of neighbouring princes, but could not satisfy tie ambition of Charles; and we find him constantly engaged in foreign wars, or with his own protestant subjects, whom he in vain attempted to bring back to the catholic church. He also reduced the power of the nobles in Spain, abridged the privileges of the commons, and greatly extended the regal prerogative. At last, after a long and turbulent reign, he came to a resolution that filled all Europe with astonishment, withdrawing himself entirely from any concern in the affairs of this world, in order that he might spend the remainder of his days in retirement and solitude.*

* Charles, of all his vast possessions, reserved nothing for himself but an annual pension of 100,000 crowns; and chose, for the place of his retreat, a vale in Spain, of un great extent, watered by a small brook, and surrounded by rising grounds, covered with lofty trees. He gave strict orders that the style of the building which he erected there should be such as suited his present situation, rather than his former dignity. It consisted only of six rooms; four of them in the form of friar's cells, with naked walls ; and the other two, each twenty feet square, were lung with brown cloth, and furnished in the most simple manner. Here be buried in solitude and silence his grandeur, his ambition, together with all those vast projects which, during half a century, had alarmed and agitated Europe, filling every kingdom in it, by turns, with the terror of his arms, and the dread of being sub. jected to his power. Here he employed himself in studying the principles and in forming curious works of mechanism, of which he had always been remarkably fond. He was particularly curious with regard to the construction of clocks and watches : and laving found, after repeated trials, that he could not bring any two of them to go exactly alike, he reflected, it is said, with a mixture of surprise and regret, on his own folly, in having bestowed so mucls time and labour on the more 
Agreeably to this determination, he resigned Spain and the Netherlands, with great formality, in the presence of his principal nobility, to his son, Philip II ; but could not prevail on the princes of Germany to elect him emperor, which dignity they conferred on Ferdinand, the brother of Charles, thereby dividing the dangerous power of the house of Austria into two branches; Spain, with all its possessions in Africa and the New World, the Netherlands, and some Italian states, remained with the elder branch; whilst the empire, Hungary, and Bohemia, fell to the lot of the younger, which they still possess.

Philip II inherited all his father's vices, with few of his good qualities. He was austere, haughty, immoderately ambitious, and, through his whole life, a cruel bigot in the cause of popery. His marriage with queen Mary of England, an unfeeling bigot like himself, his unsuccessful addresses to her sister Elizabeth, his resentment and fruitless war's with that princess, his tyranny and persecutions in the Low Countries, the revolt and loss of the United Provinces, with other particulars of his reigin, have been already mentioned in the history of those countries.

In Portugal he was more successful. That kingdom, after being: gorerned by a race of wise and brave princes, fell to Sebastian, about the year 1557. Sebastian lost his life and a fine army, in a headstrong, unjust, and ill-concerted expedition against the Moors, in Africa; and in the year 1580, Philip united Portugal to his own dominions, though the Braganza family, of Portugal, asserted a prior right. By this acquisition, Spain became possessed of the Portuguese settlements in India, some of which she still holds.

The descendants of Philip proved to be very weak princes; but Philip and his father had so totally ruined the ancient liberties of Spain, that they reigned almost unmolested in their own dominions. Their viceroys, however, were at once so tyrannical and insolent over the Portuguese, that, in the reign of Philip IV, in the year 1640, the nobility of that nation, by a well conducted conspiracy, expelled their tyrants, and placed the duke of Braganza, by the title of John IV, upon their throne; and ever since, Portugal has been a distinct kingdom from Spain

The kings of Spain, of the Austrian line, failing in the person of Charles II, who left no issue, Philip duke of Anjou, second son to the dauphin of France, and grandson to Lewis XIV, mounted that throne, in virtue of his predecessor's will, by the name of Philip V, anno 1701. After a long and tloody struggle with the German branch of the house of Austria, supported by England, he was confirmed in his dignity, at the conclusion of the war, by the shameful peace of Utrecht, in 1713. And thus Lewis XIV, through a masterly train of politics (for, in his wars to support his grandson, as we have already observed, he was almost ruined) accomplished his favourite project of transferring the kingdom of Spain, with all its rich possessions in America and the Indies, from the house of Austria, to that of his own family of Bourbon. In 1734, Philip invaded Naples, and got that kingdom for his son Don Carlos, the Sicilians

vain attempt of bringing mankind to a precise uniformity of sentiment concerning the intricate and mysterious doctrines of religion. And here, after two year's retirement, he was seized with a fever which carried him off, in the 59 th year of his age. 
readily acknowledging him for their sovereign, through the oppression of the imperialists.

After a long and turbulent reign, which was disturbed by the ambition of his wife, Elizabeth of Parma, Philip died in 1746, and was succeeded by his son Ferdiriand VI, a mild and peaceable prince, who reformed many abuses, and endeavoured to promote the commerce and prosperity of his kingdom. In 1759 he died, without issue, through melancholy for the loss of his wife. Ferdinand was succeeded by his bro:her, Charles III, then king of Naples and the Two Sicilies, son to Philip V, by his wife the princess of Parma.

He was so warmly attached to the family compact of the house of Bourbon, that two years after his accession, he even hazarded his American dominions to support it. War being declared between him and England, the latter took from him the famous port and city of Havanna in the island of Cuba, and thereby rendered herself entirely mistress of the navigation of the Spanish plate fleets. Notwithstanding the success of the English, their ministry thought proper, hastily, to conclude a peace in corsequence of which Havanna was restored to Spain. In 1775, an expedition was concerted against Algiers by the Spanish ministry, which had a most unsuccessfui termination. The troops, which amounted to upwards of 24,000 , and who were commanded by lieutenant-general conte de O'Reily, landed about a league and a half to the eastward of the city of Algiers; but were disg racefully beaten back, and obliged to take shelter on board their ships, having 27 officers killed, and 191 wounded; and 501 rank and file killed, and 2088 wounded. In the years 1783 and 1784, they also renewed their attacks against Algiers by sea, but after spending much ammunition, and losing many lives, were forced to retire without doing much injury.

When the war with Great Britain and her American colonies had subsisted for some time, and France had taken part with the latter, the court of Spain was also prevailed upon to commence hostilities against Great Britain. The Spaniards closely besieged Gibraltar, both by sea and land; it having been always a great mortification to them, that this fortress should be possessed by the English. The grand attack was on the 13th of September, 1782, under the command of the duke de Crillon, by ten battering ships, from 600 to 1400 tons burden, carrying in all 212 brass guns, entirely new, and discharging shot of 26 pounds weight. The showers of shot and shells which were directed from them, from their land-batteries, and on the other hand from the various works of the garrison, exhibited a scene of which perhaps neither the pen nor the pencil can furnish a competent idea. It is sufficient to say, that four hundred pieces of the heaviest artillery were playing at the same moment: an instance which has scarcely occurred in any siege since the invention of those wonderful engines of destruction.

The irresistible impression of the numerous red-hot balls from the garrison was soon conspicuous; for in the afternoon, smoke was perscived to issue from the admiral's ship and another, and by one in the morning several were in flames, and numbers of rockets were thrown up from each of their ships as signals of distress; and thus ended all the hopes of the Spaniards of reducing the fortress of Gibraltar. Some trifling operations continued on the side of the Spaniards till the restoration of peace in 1783 .

In other enterprises, however, the Spaniards proved more success 
fil. The island of Minorca was surrendered to them on the 6th of February, 1782, after having been besieged for 171 days. The garrison consisted of no more than $2692 \mathrm{men}$, while the forces of the enemy amounted to 16,000 , under the command of the duke de Crillon. The Spanish commander at first attempted to corrupt the governor (general Mur:ay) but this being rejected with indignation, the siege was commenced in form; and the garrison would have showed themselves equally invincible with those of Gibraltar, had it been possible to relieve them in the same manner.

His late catholic majesty attempted to oblige his subjects to desise from their ancient dress and manners, and carried his endeavours so far that it occasioned such a dangerous insurrection at Madrid as obliged him to part with his minister, the marquis of Squillace; thereby affording an instance of the necessity that even despotic princes are under of paying some attention to the inclinations of their subjects.

The sudden dismission of count Florida Blanca from the office of prime minister originated in causes not disclosed. It is imlagined that the court found this step necessary to appease the public murmurs at some measures, particulariy the edict concerning strangers, which contributed to impose further fetters upon commerce, and which has since been repealed. On the 28 th of February, 1792, the minister was removed, and count d'Aranda, an old statesman, a warm friend of the queen and nobility of France, succeeded to his employments, till some other arrangement could be formed. It is said, he abolished the superintendant tribunal of police, a kind of civil inquisition; and in other liberal measures appeared to see the real interests of monarchs, and which is certainly to concede with grace, in order to prevent the despair of the people from recurring to force. His influence, however, was but short; and he was succeeded by the duke d'Alcudia.

The irregularities committed in France, the indecent reception of the humane interference of the court of Spain in favour of the king, and the representations of the confederated sovereigns, induced the court of Spain to declare war against France, on the 23d of March, 1793. The issue of this war, the treaty of peace concluded by Spain with the French republic on the 23d of July, 1795, and the subsequent hostilities with England till the conclusion of the peace of Amiens, have already been mentioned in our historical accounts of those countries.

No sooner was the treaty of Tilsit concluded, than Bonaparte, not content with having the resources of Spain at his command, resolved to place some of his own family upon her throne. Under pretence of preserving tranquillity, he poured large bodies of troops into Spain, who obtained possession of all the important fortresses. He then informed the royal family, that he was about paying a visit to Madrid in person, and invited them to meet him at Bayonne. When there, he compelled the king formally to renounce the crown of Spain, in favour of his brother Joseph Bonaparte.

The Spanish nation was not, however, to be gulled so easily. They saw through the designs of Bonaparte. They established provincial juntas, which were soon resolved into one supreme central junta, which declared Joseph Bonaparte to be an usurper. A like disposiaion showed itself in Portugal; and a treaty offensive and defensive,

Vor.

4. $\Lambda$ 
was formed between the two nations of the peninsula, and the govern: ment of Great Britain. In Andalusia, the battle of Baylen, and the surrender of the French army under Dupont, gave great spirit to the patriotic cause, and the French armies were repulsed by almost unarmed citizens in every quarter. General Moncey was driven from. Valencia ; at Sarragossa the very women acquired military renown, and at Gerona even the monks took up arms. These events,so alarmed king Joseph for his personal safety, tha: he fled precipitately from Madrid towards France. On the 20th of July 1803, 10,000 men un= der Sir Arthur Wellesley, arrived at Colunna, from England. The Spaniards, however' informing him that they considered their forces in that quarter sufficient for their own defence, he proceeded to Lisbon. The British forces landed in Mondego Bay on the first of August. On the' 2 Ist they defeated general Junot, at Vimiera, and obliged him to retreat towards Lisbon. On the $22 \mathrm{~d}$ Sir $\mathrm{Hew}$ Dalrymple arrived from England, and took the command of the Britisi army, and on the 30th a convention was concluded, by which the French were to leave Por. tugaj and be conveyed to France. Early in November, marshal Ney defeated general Blake at Espinosa, and again on the 11 th at Reynosa. Bifore the 21 st, the armies of the north of Spain, and that of Estre. madura, had been dispersed, and the French turned their wbole force against Castanos; who was brought to action at Tudela, on the $23 \mathrm{~d}_{\text {p }}$ and completely defeated. On the 4 th of December, the French en tered Madrid (xeneral Wellesley having returned to England, and Dalrymple having been recalled, the command of the British army devolved upon Sir John Moore, who left Lisbon on the 27th of Octo ber, to join the Spanish forces in Gallicia. On the 13th of November, he arrived with his advaliced guard at Salamanca, where he was surprised to hear, that the French were only 20 leagues distant, at Vallaclolid, and that their main armies were approaching. Having a very inferior force, and not receiving any support from the Spaniards, whom he found totally discomfited, general Moore was obliged to retreat. On the 16 th of January lie was overtaken and attacked by the French near Corunna. General Moore was killed, but the French were completely repulsed, and the next day the British troops embarked at Corunna, unmolested. Sir Arthur Wellesley, having rezurned to Lisbon, now resumed the command of the British troops in Portugal Having expelled Soult from that kingdom, he effected a junction with the Spanish general Cuesta at Oropesa on the 20th of July. Cuesta having advanced, his out-posts were attacked and driven in by the French; upon which he fell back upon the British at Talavera. The French, emboldened by this slight success, advanced, and on the 28 th the battle of T'alavera was fought, which resulted in a complete victory to the combined army. The French, however, being much the most numerous, and the British being but badly supported by the Spaniards, lord Wellington was not able to pursue his victory, and was finally obliged to retreat towards Lisbon. 'The French now turned their arms towards the south, which they soon overrun, capturing Seville, Granada, Malaga, and other places, and driving the Supreme Junta to Cadiz. On the 20th of February 1810, general O'Donnell was defeated by marshal Augereau in Catalonia. On the 15t: of June, marshal TVassena arrived from France to take the command of the French armies. He immediately commenced the siege of Ciudad Rodrigo, which fell on the 10th of July. On the 27 th Alneida shared the same fate. On the 27th of August, lord Wellington, 
llaving concentrated his whole force, amounting to near 50,000 British and Portuguese, on the heights of Busaco, was attacked by Massena swith upwards of 100,000 wien. The French were repulsed with loss. On the 14th of November, Massena commenced his retreat, in which he was vigorously pursued by the allied army. The French halted at Santarem, and the allies at Cartaxo, in which positions the two armies remained for some time.

On the $2 d$ of January 1811 , Suchet entered Tortosa, and on the 29 th Soult took possession of Oivenza. On the 5 th of March Massena left Santar'em, and the British again pursued. Continued skirmishes now took place, in which the French suffered severely. On the 4 th of April they crossed the boundary line, and Portugal was once more freed from her invaders. On the 2d of May the French attempted to drive the British from the village of Fuente d'Honor, but were repulsed; they renewed the attack on the 5 th, but with no better success. They now continued tieir retreat. On the 15 th marshal Beresiord, in conjunction with the Spanish troops under generals Blake and Castanos, repulsed marshal Soult at Albuera with considerable loss. About the middle of Junt, Missena having been reinforced, again advanced, and obliged lord Wellington to relinquish the sieges of Badajoz and Ciudad Rodrigo, and retire to the neighbourhood of Soito.

Early in 1812 Valencia surrendered to the French, and general Blake and his whole army ware taken prisoners : lord Wellington was more successful; on the 8th of January he took Ciudad Rodrigo by assault. Badajoz was stormed and carried on the 6th of April. About this time also, the Spanish guerilla corps were very active, harassing the French in all their movements. On the 17tin of Jute the British advance drove the French from Salamanca, towards which place, Marmont returned however, with reinforcements, and on the 22d the battle of Stlamanca was fought: the contest was severe, but the Brit ish were again victorious. Marmont fled towards Valladolid and was closely pursued. On the 30 th of July lord Wellington entered Valladolid, whence he iminediately proceeded for Madrid On the 12th of August the British army took possession of that city; Joseph Bonaparte having retired towards Toledo.

On the 13th of August a body of Spanish troops attacked Bilboa, whence the French were driven with loss. On the same day, was proclaimed at Madrid, by order of lord Wellington, as duke of Ciudad Rodrigo, the constitution formed by the general cortes of the kingdom. It was received with joy by the people, and the next day all the officers of government were sivorn to observe it. On the 19th of August, Astorga surrendered to the Spaniards. About the 24th, intelligence was received at Madrid, that Valencia, Tarragona and Lerida, were in the hands of the allies. After a blockarle of thirty-one months, the siege of Cadiz was raised on the 25 th. Thus the cause of Spain, began at length to assume the appearance of eventual suc. cess, of which many had previously despaired. Lord Wellington left Madrid on the first of September, and pursued his flying enemy, through Valladolid to Burgos. The siege of Burgos was commenced on the 19th, and continued until the 20th of October, when it was raised by the approach of Soult from the south, and the allies retired upon the Douro. The French having now a superiority of numbers, the allies were obliged to retreat. Soult pursued them closely. General Hill abandoned Madrid, and it was again occupied by the French 
on the 1st of November. They however left it on the 4th, and a Spst nish force took possession. About this time the Spanish cortes appointed lord Wellington generalissimo, and commander in chief, of the armies of Spain. The affairs of the north, now compelled Bonaparte to recall Soult, with the best of his troops, into France, and the army, thus weakened, again resumed a defensive posture. The allied army advanced upon them, and Suchet retreated rapidly, but in good order, to Burgos. He destroyed the works in that citadel, and passed on. Having united with Joseph Bonaparte, he made a stand at Vittoria on the 19 th of June 1813 . On the 2 Ist the battle of Vittoria was fought, and the French were driven from all their positions, and pursued by the British into France. On the 13th of July Soult arrived at Bayonne, having been reappointed to the command. The line of the allied army, stationed in the passes of the Pyrenees, was forced on the 24th, and the French again entered Spain. On the 27th and 28th, Soult attacked lord Wellington's right, and after various success, was repulsed with loss. On the 30 th he attacked the left, under sir Rowland Hill, which he succeeded in turning, and established himself in their position. On the slst, lord Wellington attacked in his turn, and regained the lost position. The French were driven beyond the $\mathrm{Pu}$ erto. On the $2 \mathrm{~d}$ of August they were again attacked, and on the 4th were once more in France. On the 30th San Sebastian was taken by storm. On the 7 th of October, the allies commenced crossing the Bidassoa, and storming the French works on that river. These operations occupied several days, but were finally successful. The French now occupied a strong position in front of St Jean de Luz. Here they were again attacked on the 10th, and pursued to their entrenched camp before Bayonne. The surrender of Pampeluna on the 31 st, put an end to the French invasion of Spain, and the remaining hostile operations were transacted within the territory of France.

Bonaparte, seeing all his projects of family aggrandizement thus dissipated, and feeling his own throne to tremble beneath him, resolved, if possible, to convert the hostile Spaniards into friends. With this view, he formed a treaty with Ferdinand, in which he guaranteed to the latter his kingdom, upon condition of his sending the English and Portuguese out of Spain, and withdrawing the Spaniards from France. Ferdinand despatched a copy of this treaty to the cortes for ratification; but they immediately passed a decree, by which all the acts of the king were made nugatory, not only while he remained in the power of Bonaparte, but until he had taken the oaths prescribed by the new constitution. They appointed persons to receive him, and forbid his being accompanied by any Frenchmen, or partisans of Bonaparte, on his entrance into Spain. All their precautions were however in vain. Ferdinand was received by the people with enthusiasm; and confident of their support, he adopted the most violent measures. He refused to sign the constitution. He declared all the acts of the cortes null and illegal, and themselves to be a band of traitors; and worst of all, he re-established the inquisition. Many of the leaders of the cortes, with the editors of the constitutional papers, were imprisoned, and some of them even condemned to death. Whether these tyrannical measures will be tamely submitted to, or whether they will be productive of another revolution, remains yet to be decided. 
Ferdinand VII, king of Spain, was born October 14, 1784.

\section{Father to the King.}

Charles IV, the late king, born November 11, 1748, married September 4, 1765, to Louisa-Maria-Theresa, princess of Parma, by whom he has issue, besides Ferdinand

1. Charlotte-Jochima, born April 25, 1775.

2. Maria-Louisa-Josephine, born July 9, 1777.

3. Philip, born August 10, 1783.

4. Charles-Maria-Isidor, born March 29, 1788.

5. Maria-Isabella, born July 6, 1789.

6. Francis-de-Paula-Anthony, born March 10, 1794.

\section{Brothers to Charles IV.}

1. Ferdinand, the present king of Sicily, born January 12, 1731 married May 12, 1768, to the ar'chduchess Mary-Charlotte-Louisa, sister to Joseph II, late emperor of Germany.

2. Anthony-Pascal, born December 31, 1755. 


\section{PORTUGAL.}

SITUATION AND EXTENT:

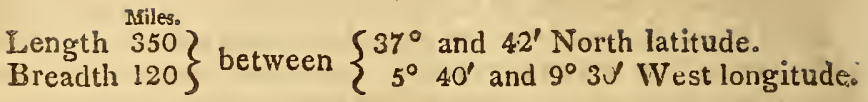

Containing 27,071 square miles, with 70 inhabitants to each.

Names....Portugal was known to the ancients by the name of Lusi. tania, derived by the mythologists from Lysas, the son of Bacchus, who is said to have settled a colony here. Tue modern name of Por tugal is supposed to be derived from Calle, the ancient name of Oporto, with the addition of Porta, or port, on account of the excelIence of its harbour. In the eleventh century this name was extended to the whole kingdom.

BOUNDARIES....It is bounded by Spain on the north and east, and on the south and west by the Atlantic Ocean, being the most westerly kingdom on the continent of Europe.

Drvisions.... By the form of the country, it is naturally divided into three parts; the northern, middle, and southern provinces. The provinces are six in number.

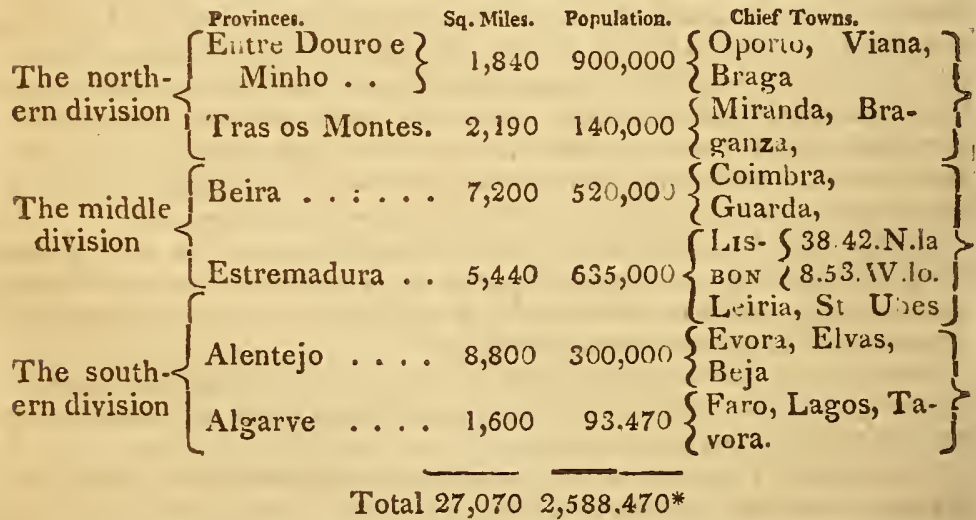

* The above numbers are those given by Mr. Murphy in his General View of the State of Portugal, 1798. The population of these provinces is thus stated in Boetticher's tables :

\begin{tabular}{lr|rr} 
Entre Douro e Minho & 430,300 & Estremadura & $35 \cap, 000$ \\
Tras os Montes & $\mathbf{1 8 0 , 8 0 0}$ & Alentejo & 265,223 \\
Beira & $\mathbf{5 5 0 , 8 5 6}$ & Algarve & 63,700 \\
& & & \\
& & Total $\mathbf{1 , 8 4 0 , 8 7 9}$
\end{tabular}

As Mr. Murphy followed Portuguese authors, his statement may perhaps be exaggerated; but it seems more probable that the population of Portugal exceeds, than that it falls short of two millions. 
Face of the country, Mountains....The face of Portugal is mountaiıous, or rather rocky, for the mountains are generally barren: the chief are those which divide Algarve from Alentejo; those of Tras os Montes; Arrabida and Montejunto in Estremadura; Estrella in Beira; Ossa in Alentejo; and Cintra about five leagues southwest of Lisuon, well known to navigators as being the most westerly part of a:i Europe. The cape coniguous to it, at the mouth of the Tajo, is cailed the rock of Cintra, or the rock of Lisbon.

Rivers, Lakes, Mineral waters....Though every brook in Portu. gal is reckoned a river, yet the chief Portuguese rivers are mentioned in Spain, all of them falling into the Atlantic Ocean. The Tagus or 'Tajo was anciently celebrated for its golden sand. It has its source in the mountains of Molina, at the extremity of Castile, neal Arragon; whence it runs for the most part due west, till it reaches Lisbon, and falls into the Atlantic Ocean, after traversing, in the whole of its course, 450 miles, of which 150 are in Portuyal, and the remainder in Spain. This river annually overflows its banks as regularly as the Nile, and inundates the Champagne lands, particularly about Villa Franca and Santerem, which renders the soil exceedingly fertile. The Minho and Douro are the bcundaries of the province Entre Douro e Minho. Portugal contains several small lakes and springs; some of them are absorbent even of the lightest substances, such as wood, cork, and feathers. The baths called Caldas da Rainha, about 45 miles fronı Lisbon, are medicinal and sanalive; and some hot baths are found in the little kingdom, or rather province, of Algarve.

Metals, merals....This country appears to have been as celebrated iu ancient times for its gold and silver mines as South America is at present, but no mines of these metals are now worked. There are lead mines which yield silver at Mursa and Lamego, and there is a mine of copper at Elvas The iron mines are well known, but are neglected for want of fuel, though coal has been found in different parts. Portugal produces beautiful marbles, almost every kind of precious stones, and indeed minerals of every description.

Climate, soil, agriculture....Though Portugal is one of the smalicst countries in Europe, its climate is very various in different paris; in the northern provinces it is cold, in the middle and near the sea temperate, and in the southern hot.

The air, especially about Lisbon, is reckoned soft and beneficial to corsumptive patients; it is not so scorching as that of Spain, being refreshed from the sea-breezes.

The soil of Portugal is not in general equal to that of Spain for fertility, especially in corn, which is imported from other countries. Agriculture, at the same time is greatly neglected. According to the best information, two-thirds of the kingdom are at present left untilled, and the portion that is under vines, olives, corn, pulse, wood, S.c. is not in general in that state of improvement of which it is susceptible.

VEGETABEE PRODUCTIONS....Fruits of every kind known in Europe, and particularly oranges, lemons, citrons, figs, grapes, apricots, peaches, almonds, and melons, grow here in many places almost spontaneously. In general, however, the fruits are not esteemed to be so highly flavoured as in Spain. The Portuguese wines, when old and 
genuine, are esteemed to be very friendly to the human constitution, and safe to drink.*

Anrmals....These are nearly the same as in Spain. The horses are few and of an inferior breed; but the mules are strong, hardy and sure footed. The sheep are not very numerous. Large herds of swine are found in various parts of the country, the flesh of which, as they feed chiefly on grass and acorns, has an excellent flavour, whence the preference given to Portuguese hams in most parts of Europe, particularly in England.

Natural curiosities.... These consist principally of the lakes already mentioned, and some extraordinary caverns In the province of Tras os Montes, at a place called St. Miguel das tres Minhas are three immense mines, generally supposed to have been worked by the Romans. The mouth of the largest, which has been cut through the solid rock, is a mile and a half in circumference, and upwards of 500 feet deep. At the bottom it is 2400 feet in length, and 1400 ins breadth. Near this is another of great dimensions, and a third in an elevated situation called Covas, the length of which is 2600 feet, the breadth 1500, and the depth 500. The lake of Escura, on the summit of the mountain of Estrella, in the province of Beira, is of a depth litherto unascertained; its water is of a dark green colour, and it has never been known to yield fish of any kind. Fragments of the masts of ships, it is said, have been found in it, whence it has been supposed to have a subterranean communication with the sea, notwithstanding it is so far inland. It is added, as an additional proof of this conjecture, that it is smooth or agitated according as the sea is tranquil or rough, and that in stormy weather it makes a rumbling noise, that may be heard at the distance of several miles.

Population....According to the statements before given, it appears that Portugal contains about two millions or two millons and a half, of inhabitants. The number of Portuguese in all the colonies appertaining to the crown, are estimated at about nine hundred thousand. By a survey made in the year 1780, there were in that kingdom 4,262 parishes, and $1,742,250$ lay persons (which is but 522 laity to each parish on a medium) besides above 300,000 ecclesiastics of both sexes.

National character, manners, customs...The moderate Portuguese retain nothing of that adventurous enterprising spirit that rendered their forefathers so illustrious 300 years ago. They have, ever since the house of Braganza mounted the throne, degenerated in all their virtues; though some noble exceptions are still remaining among them, and no people are so little obliged as the Portuguese are to the reports of historians and travellers. Their degeneracy is evidently owing to the weakness of their monarchy, which renders them inactive for fear of disobliging their powerful neighbours; and that inactivity has proved the source of pride, and other unmanly vices. Treachery has been laid to their charge, as well as ingratitude, and, above all, an intemperate passion for revenge. They are, if possible, more superstitious, and both in high and common life, affect more state, than the Spaniards themselves. Among the lower people, thieving is commonly practised; and all ranks are accused of being

* The Port wines are made in the districts round Oporto, whicl do not produce one half the quantity that is consumed, under that name, in the British dominions only. The merchants in this city have very spacious wine-vaults, capable of holding 6 or 7000 pipes, and it is said that 20,000 are yearly exported from Oporto. 
unfair in their dealings, especially with strangers. It is hard, however, to say what alteration may be made in the character of the Portuguese, by the expulsion of the Jesuits, and diminution of the papal influence among them; by that spirit of independence, with regard to commercial affairs, which, to the interest of their country, is now so much encouraged by their court and ministry; but above all, to the events of the late war, which has served so much to rouse the spirit of the nation.

The Portuguese are neither so tall nor so well made as the SpaDiards, whose habits and customs they initate; only the quality affect to be more gaily and richly dressed. The Portuguese ladies are thin, and small of stature. Their complexion is olive, their eyes black and expressive, and their features generally regular. They are es. teemed to be generous, modest, and witty. They dress like the Spanish ladies, with much aukwardness and affected gravity, but in general more masnificently; and they are taught by their husbands to exact from their servants a homage, that in other countries is paid only to royal personages. The furniture of the houses, especialiy of their grandees, is rich and superb to excess; and they maintain an incredible number of domestics, as they never discharge any who survive after serving their ancestors. The poorer sort have scarcely any furniture at all, for they, in imitation of the Moors, sit always cross-legged on the ground. The Portuguese peasant has never reaped any advantage from the benefits of foreign trade, and of the fine and vast countries the kings of Portuga! possessed in Africa or in the East; or of those still remaining to them in South America. The only fureign luxury he is yet acquainted with is tobacco; and when his feeble purse can rcach it, he purchases a dried Newfoundland corl-fish : but this is a regale he dare seldom aspire to. A piece of bread made of Indian corn, and a salted pilchard, or a head of garlic, to give that bread a flavour, compose his standing dish; and if he can get a bit of the hog, the ox, or the calf he himself fattens, to regale his wretched family at Christmas or Easter, he has reached the pinnacle of happiness in this world; and indeed whatever he pose sessed beyond this habitual penury, according to the present state and exertions of his intellects, would quickly be taken from him, or rather he would willingly part with it, being taught by his number. less ghostly comforters, with which his country swarms, to look forward for ease and happiness to another state of existence, to which they are themsclves the infallible guides and conductors.

To these remarks we shall subjoin those of Mi. Murphy, a late traveller in Portugal. "The common people of Lisbon and its environs are a laborious and hardy race. It is painful to see the trou. ble they are obliged to take for want of proper implements to carry on their work. Their cars have the rude appearance of the earliest ages; these vehicles are slowly drawn by two stout oxen. The corn is shelled by the treading of the same animals. They have many other customs which to us appear very singular: for example, women sit with the left sicle towards the horse's head when they ride. A postillion rides on the left horse. A tailor sits at his work like a shoemaker. A hair-dresser appears on Sundays with a sword, a cockade, and two watches, or at least two watch-chains. A tavern is known by a vine-bush, a house to be let by a piece of blank paper, the door of an accoucheur by a white cross, and a Jew by his extra. catholic devotion, A Portuguese peasant will not walk with a supe:

VoL. I. 
rior, an aged person, or a stranger, without giving him the righthand side, as a mark of respect. He never passes by a human being without taking off his hat, and saluting him with these words, The Lord preserve you for many years! In speaking of an absent friend he always says; I die with impatience to see him." They all imagine their country is the blessed Elysium, and that Lisbon is the greatest city in the world."

Cities, chief towns, edifices....There are in Portugal, 22 cities, anci 54.1 towns. Lisbon, the capital of the kingdom, is situated on the north side of the mouth of the Tagus. It stands on seven hills, and contains many grand edifices, among which one of the principal is the patriarchal church. The treasures of sacred relics, gold, silver, precious stones and costly furniture of this venerable edifice, are imsnense. The new square called Praçado Comercio, is 615 feet long, and 550 broad; in the centre is a noble equestrian statue of bronze of Joseph I. The new church, built by her present majesty, is the largest and most magnificent edifice erected in Lisbon since the earth. quale in 1755 , the fatal effects of which are still visible in many parts of the city, and never fail to impress every spectator with an awful remembrance of that disaster; according to the most accurate accounts, there were not less than 24,000 victims to it. The Portuguese have, however, availed themselves of this misfortune and, like the English after the destructive fire of 1666, have turned the temporal evil into a permanent good. All the new streets erected in Lisbon, in the piace of the old, are capacious, regular, and well paved, with convenient foot-paths for passengers, as in the streets of London. In point of cleanliness, Lisbon is no longer a subject of so much animad. version to strangers as formerly; but all is not yet done, as it still wants common-sewers, pipe-waters, and privies. Lisbon is deservedly accounted the greatest port in Europe, next to London and Amsterdam. The harbour is spacious and secure, and the city itself is guarded from any sudden attack towards the sea by forts, though they would make but a poor defence against ships of war.

Of the population of this city no exact account has been recently published; and the rapid increase of its inhabitants of late years, must render any calculation of that kind very uncertain. In the year 1774, the forty parishes into which Lisbon is divided, were found to contain 33,764 houses; and in the year 1790 , they amounted to 38,102 . In the latter year the population was supposed to exceed 240,000. Later accounts state the number of houses at 44,057 , and the population at 350,000 . From the magnitucle of the city, indeed, we should be induced to suppose that its population was considerably more than above stated; for it is computed to be four miles long, by one and a half broad; but many of the houses have large gardens, and such as have not are, in general, laid out upon a large scale, on account of the heat of the climate.

The church and monastery near Lisbon, where the kings of Portugal are buried, are inexpressibly magnificent, and several monasteries in Portugal are dug out of the hard rock. The chapel of St. Roch is probably one of the finest and richest in the world; the paintings are mosaic work, so curiously wrought with stones of all colours, as to astonish the beholders.

The second city in this kingdom is Oporto, which is computed to contain 70,000 inhabitants. The number of houses exceeds 15,000, including 10 churches, 12 convents and 9 hospitals. The chief article 
of commerce in this city is wine; and the inhabitants of half the shops in the city are coopers. The merchants assemble daily in the chief street, to transact business; and are protected from the sun by sail-cloths hung across from the opposite houses. About thirty English families reside here, who are chiefly concerned in the wine trade.

Coimbra, in the province of Beira, is a large and ancient city. It is built on both sides of the river Mondego, and contains near 12,000 inhabitants, who are principally occupied in the manufactures of earthen ware, linen and woollen.

Evovra, in Alentejo, is a fortified town, situated in a plain, surrounded on all sides by mountains. It contains 14,000 inhabitants and 3100 houses.

St. Ubes or Setuval, in Fstremadura, has a good harbour, which is defended by fort St. Jago. It is built on the ruins of the ancient Setobriga, at the head of a bay, near the mouth of the Zadaen. It has a fine fishery, and a very good trade, particularly in salt. It contains 12,000 inhabitants and 3000 houses.

Elvas, is a strong frontier town, the capital of Alentejo, with a eastle and bishop's see. Here is a remarkable aqueduct, four miles in length, and supported by three arches, one over the other. The number of inhabitants is $12,5 \cup 0$.

Braga, the capital of Entre Minho è Douero, is seated in a plain, near the river Cavado. The trade of this town is considerable. Hats are the principal article of manufacture. The number of inhabitants is 12,300 , and of houses 3000 .

Manufactures, commerce...The Portuguese exchange their wine, salt, and fruit, and most of their own materials, for foreign manufactures. They make a little linen, and some coarse silk and woollen, with a variety of straw-work, and are excellent in preserving and candying fruit. The commerce of Portugal, though seemingly extensive, proves of little solid benefit to her, as the European nations trading with her, engross all the productions of her colonies, as well as her own native commodities, as her gold, diamonds, pearls, sugars, cocoa-nuts, fine red wood, tobacco, hides, and the drugs of Brasil, her ivory, ebony, spices, and drugs of Africa and East-India, in exchange for the almost numberless manufactures, and the vast quantity of corn and salt fish, supplied by those European nations, by the United States of America, and by the English North American colonies.

The Portuguese foreign settlements are, however, not only of immense value, but vastly improveable. These are Brasil, the isles of Cape Verd, Madeira, and the Azores. They bring gold from their plantations on the east and west coast of Africa, and likewise slaves for manufacturing their sugars and tobacco in Brasil, and their South American settlements. The slave trade, is, however, declining fast, having been discouraged by the government.

What the value of these colonies may be, is unknown perhaps to themselves; but they certainly abound in all the precious stones, and rich mines of gold and silver, and other commodities that are produced in the Spanish dominions there. It is computed that the king's fifth of gold sent from Brazil, amounts annually to 300,000 . sterling, notwithstanding the vast contraband trade. The little shipping the Portuguese have, is chiefly employed in carrying on the slave-trade, 
and a correspondence with Goa, their chief settlement in the East Indies. and inelr other posscssions there, as Diu, Daman, Macao, \&c.

Constitution, government, and laws.... Phe crowu of Portugal is absolute; but the natuon stril preserves an appearance of its ancient free constitution, in the meeting of the cortes, or statis, consisting, of clergy, nobility, and commons. Tney pretend to a right of being consulted upon the imposition of new taxes; but the only real power they have, is, that their assent is necessary in every new reguiation with regard to the succession. In this they are induged, to prevent all fuiure disputes on that account.

This government was, not long since, the most despotic in Europe. The established law was generaily a dead lettcr, excepring where its decrees were carried into exccution by the supplementary mandates of the sovereign, which were generaliy employed in defcating tine purposes of safety and protection, wnich law is calculated to extend equally over all the subjects.

The people had no more share in the direction of goverriment, in enacting of laws, and in the regulating of agriculture aisd comnerce, than they have in the government of Russia, or China The far greater part knew nothing of what was done in that respect. Every man had no other alternative but to yield a biind and ready obedience, in whatever concerned himself, to the decrees and laws of the king, as promulgated from time to time by his secretaries of state. The preamble of every new law published run thus: " $I$, the king, in virtue of my ozen certain knowledge, of my royal quill and hleasure, and of my full, sufireme, and arbitrary hower, which I hold only of God, and for which I an accountable to no man on earth, I do, in conseguence, order and command," Ec. Ec.

The absence of the royal family, in Brasil, and the intercourse which has bcen so closely maintained with the English, for several years past, has given the Portuguese a taste for political liberty, of which it will be difficult again to deprive them.

All great preferments, both spiritual and temporal, are disposed of in the council of state, which is composed of an equal number of the clergy and nobility, with the secretary of state. A council of war regulates all military affairs, as the treasury courts do the finances. The council of the palace is the highest tribunal that can receive appeals, but the Casa da Supplicaçao is a tribunal from which no appeal can be brought. The laws of Portugal are contained in three duodecimo volumes, and have the civil law for their foundation.

Revenues.... The revenues of the crown amount to about $16,000,000$ of dollars annually. The customs and duties on goods exported and imported are excessive, and farmed out. Foreign merchandise pays twenty-three per cent. on importation, and fish from Newfoundland twenty-five per cent. Fish taken in the neighbouring seas and rivers pays twenty-seven per cent. and the tax upon lands, and cattle that are sold, is ten per cent. The king derives a considerable revenue from the several orders of knighthood of which he is grand-master. The pope, in consideration of the large sums he draws out of Portugal, gives the king the money arising from indulgences, and licences to eat flesh at times prohibited, \&c. The national debt is upwards of $20,000,000$ of dollar's.

ARMY, NAvY....In the late reign, though they received the most effectual assistance from Fngland, when invaded by the French and Spaniards, his most faithful majesty judged it expedient to raise a 
considerable body of troops, who were chiely disciplined by foreign officers; but afier that period the army was again neglected, no proper encouragement being given to foreign officers, and little attention paid to the discipline of the troops, until the fresh invasion by France in 1807. The army was then re-organized by the British, and under their yuidance, acquired great credit in the course of the war. In $180 \mathrm{j}$ the regular army consisted of $50,000 \mathrm{men}$, the militia of 30,000 . At the commencement of the last war, the army did not, however, excted 25,000. At present, the Portuguese troops are so intermixed with those of England and Spain, that it is impossible to ascertain their number. The naval force of this kingdom consists of 13 ships of the line, of from 74 to $8 u \mathrm{~g} u n s ; 14$ frigrates, of from 36 to 40 guns; 10 sloops of war and 2 schouners; manned by 12,000 seamen and marines.

Royal titues.. .The king's titles are, King of Portugal and the Algarves, on this and on the other side of the sea in Africa. Lord of Guinea, and of the conquest, navigation, and commerce of Echiopia, Arabia, Persia, and Brasil. John V, was complimented by the pope, with the title of his Most Faithful Majesty. The title of the heir ap. parent is Prince of Brasil : and that of his eldest son, Prince of Beira. The rest of the princes of the blood-royal are called Infante.

Arars....The arms of Portugal are, argent, five escutcheons, azure, placed cross-wise, each charged with as many besants as the first, placed saltier-wise, and pointed, sable, for Portugal. The shield bordered, gules, charged with seven towers, or, three in chief, and two in each flanch. The supporters are two winged dragons, and the crest a dragon, or, under the two flanches, and the base of the shield appears at the end of it; two crosses, the first flcur-de-iis, vert, which is for the order of Aviez, and the second patee, gules, for the order of Christ; the motto is changeable, each king assuming a new one; but is frequently these words, fro Rege et Grege, "For the King and the P. ople."

NoBILITY AND ORDERS... The titles and distinctions of the nobility are much the sume as those of Spain. The orders of knighthood are three; 1. That of Avis or Aviez, first instituted by Aiphonsus Henrique $z$ king of Portugal, in the year 1147 , as a military and religious. order, on account of his taking Evora from the Moors. In 1213 it was subject to the order of Calatrava, in Spain; but when Don John of Portugral seized the crown, he made it again independent. 2. The "Order of St. James," instituted by Dennis I, king of Portugal, in the year 1310, supposing that under that saint's protection he became victorious over the Moors; and he endowed it with great privileges. The knights profess chastity, hospitality, and obedience, and none are admitted till they prove the gentility of their blood. Their ensign is a red sword, the habit white, and their principal convent is at Dalmela. 3. The "Order of Christ" was instituted in the year 1317, by Dennis I, of Porlugal, to en rage the nobility to assist him more powerfully against the Moors. The knights obtained great possessions, and elected their grandmaster, till 1522, when pope Adrian VI, conferred that office on John III, and his successors to the crown of Portugal. These orders have small commanderies and revenues annexed to them, but are in little esteem. The "Qrder of Malta" has likewise twenty-two commanderies in Portugal.

ReLigion.... The established religion of Portugal is popery, in the strictest sense. The Portuguese have a patriarch; but formerly he 
depended entirely upon the pope, unless when a quarrel subsisted. between the courts of Rome and Lisbon. The power of his hoiness in Portugal has been of iate so much curta led, that it is difficult to describe the reiigious state of that country : all we know is, that the royal revenues are greatiy increased, at the expence of the religious institutions in the kingdom. The inquisition, so long the dread of the people, and the greatest instrumen of oppression, in the hands of the king and clergy, has been lately abolished.

The archbishoprics are two, Braga and Evora, and there are ten bishoprics. The patriarch of Lisbon takes precedence of all the bishops and archbiśnops in the kingdom, is first chaplain to the king, and a cardinal of the consistory at Rome. His revenue amounts to 2bout $30,000 l$. sterling per annum, and the revenue of the patriarchal church is above 114,000l. per annum.

Literature... The men of learning which this country has produced are so few that they are mentioned with indignation, even by those of the Portuguese themselves who have the smallest tincture of literature. Some efforts, though very weak, have of late been made by a few, to draw their countrymen from this deplorable state of ignorance. It is universally allowed, that the defect is not owing to the want of genius, but of a proper education. The ancestors of the present Portuguese were certainly possessed of more true knowledge, with regard to astronomy, geography, and navigation, than perhaps any other European nation, about the middle of the 16 th century, and for some time after. Camoens, who himself was a great. adventurer and voyager, was possessed of a true, but neglected, poetical genius.

Universities....These are Coimbra, founded in 1291, by king Dennis; and which had fifty professors : but it has lately been put under some new regulations; Evora, founded in 1559; and the college of the nobles at Lisbon. All the books that belonged to the banished Jesuits, which compose a very large library, are kept in this college. The English language is likewise taught here. There is also a military and marine academy, where young gentlemen are educated in the science of engineering and naval tactics.

Language. ..The Portuguese language differs but little from that of Spari, and that provincially, many of the words being derived from the Limosin, and other dialects of the south of France, The Lord's Prayer is as follows: Padre nosso que estas nos ceos, sanctificado scio - tu nome; venha a nos tuo reyno, seia feita a tua votade, assi nos ceas, como na terra. O pao nosso de codidia, dano lo oci nestro dia. E herdoa nos as nossas dexes cahir om tentacao, mas doamos a os nossos deve. dores. E nao nos devidas, assi como nos herlibra nos do mal. Amen.

Antrquities....The Roman bridge and aqueduct at Coimbra are almost entice, and deservedly admired. The walls of Santarem are said to be of Roman work likewise. At Evora are the ruins of a temple of Diana, and an aqueduct ascribed to the celebrated Quintus Sertorius. Near Braga are the remains of a temple supposed to have been declicated to Esculapius. At Chaves have been discovered, not long since, the ruins of a magnificent aqueduct, baths, cisterns, seve ral fragments of columns, and capitals, and cornices of jasper exquisitely worked. There are also remains of Moorish castles and other edifices.

History....This kingdom comprehends the greate.st part of the ancient Lusitanja, and shared the same fate with the other Spanish 
provinces, in the contest between the Carthaginians and Romans, and in the decline and fall of the Roman empire, and was successively in subjection to the Suevi, Alans, Visigoths, and Moors. In the eleventh century, Alfonso VI, king of Castile and Leon, rewarded Henry, grandson of Robert, king of France, for his bravery and as= sistance against the Moors, with his daughter, and that part of Portu= gal then in the hands of the Christians. Henry was succeeded by his son Alfonso Henry, in the year 1095, who gained a decisive victory over five Moorish kings in July 1139. This victory proved the origin of the monarchy of Portugal, for Alfonso was then proclaimed king by his soldiers. He reigned forty-six years, and was esteemed for his courage and love of learning. His descendants maintained themselves on the throne for some centuries; indeed Sancho II, was expelled from his dominions for cowardice, in the year 1240.

Dennis I, or Dionysius, was called the Father of his country: he built and rebuilt forty-four cities and towns in Portugal, founded the military order of Christ, and was a very fortunate prince. He reigned forty-six years. Under his successor, Alfonso IV, happened several earthquakes at Lisbon, which threw down part of the city, and destroyed many lives. John I, was illustrious for his courage, prudence, and conquests in Africa; under him Madeira was first discovered, in 1420, and the Canaries; he took Ceuta, and, after a reign of forty-nine years, died in the year 1433. In the reign of Alfonso V, about 1480 , the Portuguese discovered the coast of Guinea; and in the reign of his successor, John II, they discovered the Cape of Good Hope, settled colonies, and built forts in Africa, Guinea, and the East Indies. Emranuel, surnamed the Great, succeeded him in 1495; atid adopted the plan of his predecessors, fitting out fleets for new discoveries. Vasco de Gama, under him cruised along the coast of Africa and Ethiopia, and landed in Hindoostan; and in the year 1500, Alvarez discovered Brasil.

Juhn III, succeeded in 1521, and, while he lost some of his African setterments, made new acquisitions in the Indies. He sent the famous Xavier as a missionary to Japan, and, in the height of his zeal, established that infernal tribunal, the inquisition, in Portugal, anno 1520, against the entreaties and remonstrances of his people. Sebastian, his grandson, succeeded him in 1557, and undertook a crusade against the Moors in Africa. In 1578, in a battle with the king of Fez aud Morocco, on the banks of the river Lucco, he was defeated, and either slain or drowned. Henry, a carclinal, and uncle to the unfortunate Sebastian, being the son of Emanuel, succeeded, but died without issue in the year 1580: on which, Antony, prior of Crato, wys chosen king, by the states of the kingdom; but Philip II, of Spain, as has been observed in our history of that country, pretended that the crown belonged to him; because his mother was the eldest. daughter of Emanuel, and sent the duke of Alva with a powerful force, who subdued the country, and proclaimed his master king of Portu. gal the 12 th of September, 1580.

The viceroys under Philip and his two successors, Philip III, and Philip IV, behaved towards the Portuguese with great rapacity and violence. The Spanish ministers treated them as vassals of Spain, and, by their repeated acts of oppression and tyranny, so excited the hatred and courage of the Portuguese, as to produce a revolt at Lisbon, the first of December, 1640 The peuple obliged John, duke of Braganza, the legitimate heir to the crown, to accept it, and he sac- 
ceeded to the throne by the title of John IV, almost without bloode shed; and the foreign 'settlements also acknowledged hin as their sovereign. A fierce war subsisted for many years between the two kingdoms, and all the efforts of the Spaniards to re-unite them proved vain; so that a treaty was concluded in February, 1668, by which Portugal was declared to be free and independent.

The Portuguese couid not have supported themselves under their revolt from Spain, hacl not the latter power been engaged in wars with England and Holland; and, upon the restoration of Charles II, of England, that prince having married a princess of Portugal, prevailed with the crown of Spain to give up all pretensions to that kingdom. Alfonso, son to John IV, was then king of Portugal. He had the misfortune to disagree at once with his wife and his brother Peter; and they, uniting their interests, not only forced Alfonso to resign his crown, but obtained a dispensation from the pope for their marriage, which was actually consummated. They had a daughter ; but Peter, by a second marriage, had sons, the eldest of whom was John, his successor, and father to the late king of Portugal. John, like his father, joined the grand confederacy formed by king William; but neither of them were of much service in humbling the power of France. On the contrary, he almost ruined the allies, by occasioning the loss of the battic of Alnmanza, in 1707. John died in 1750, and was succeeded by his son Joseph, whose reign was neither happy to himself, nor fortunate for his people. The fatal earthquake, in 1755 , overwhelmed his capital, and shook his kingdom to the centre. His succeeding administration was not distinguished by the affection that it required at home, or the reputation which it had sustained abroad. It was deeply stained with domestic blood, and rendered odious by excessive and horrible cruelty. In September, 1758, the king was attacked by assassins, and narrowly escaped with his life, in a solitary place near his country palace of Belem. The families of Aveira and Tavora were destroyed by torture, in consequence of an accusation being exhibited against them of having conspired against the king's life. But they were condemned without propor evidence, and their innocence has since been authentically declared. From this supposed conspiracy is dated the expulsion of the Jesuits (who were conjectured to have been at the bottom of the plot) from all parts of the Portuguese dominions The marquis de Pombal, who was at this time the prime minister of Portugal, governed the kingdom for many years with a most unbounded authority, and which appears to have been sometimes directed to the most cruel and arbitrary purposes.

In 1762, when a war broke out between Spain and England, the Spaniards, and their allies, the French, attempted to force his faithful majesty into their alliance, and offered to garrison his sea-towns against the English with their troops. The king of Portugal rejected this proposal, and deciared war against the Spaniards, who, without resistance, entered Portugal with a considcrable army, while a body of French threatened it from another quarter. Some have doubted whether any of these courts, were in earnest upon this occasion, and whether the whole of the pretended war was not concerted to force England into a peace with France and Spain, in consideration of the apparent danger of Portugal. It is certain, that both the French and Spaniards carried on the war in a very dilatory manner, and that, had they been in earnest, they might have been masters of Lisbon long before the arrival of the English troops to the assistance of the Por- 
tuguese. However, a few English battalions put an effectual stop, by their courage and conduct, to the progress of the invasion. Portugal was saver, and a peace was concluded at Foutainblea:, in 1763.

His Portuguese majesty having no son, his cldest daughter was marived, by dispensation from the pope, to don Pedro, her own uncle, to prevent the crown from falling into a foreign family. The late king dicu on the 24th of February, 1777, and was succeeded by his daughter, the present queen. One of the first acts of her majesty's reign was the renoval trom power of the marquis de Pomba!; an event which excited general joy throughout the kingdom, as might naturally be expected from the arbitrary and oppressive nature of his administration: though it lias been alleged in his favour, that he adopted sundry puolic measures which were calculated to promote the real interests of Portugal.

On the loth of March, 1792, the prince of Brasil, as presumptive heir to the crown, published an edict, declaring, that as his mother, from her unhappy situation, was incapable of malraging the affairs of government, he would place his signature to public papers, till the returu of her health; and that no other change should be made in the forms.

Portugal, as the ally of England, took a feeble part in the war against France; but her exertions were confined to furnishing Spain with a few auxiliary troops, and sending a small squadron to join the English flet. Atter Spain had made peace with France, a war took place between the former country and Portugal, but which was not productive of any very important events. In August, 1797, a negotiation for a treaty of peace between France and Portugal was entered into, and the treaty actually concluded; but the French directory refused to ratify it, alleging that the queen of Portugal, so far from showing a disposition to abide by its articles, had put her forts and principal ports into the possession of the English. After the failure of this attempt at negotiation, Portugal continued a member of the alliance against France; though her aid was very unimportant, consisting only of a small squadron, which cruised in the Mediterranean, and assisted in the blockade of Malta. At length, a short time previous to the signing of the prelininaries of the peace of Amiens, Portugal concluded a peace with Spain, the latter power restoring some places that had been taken from Partugal; which in return ceded in perpetuity to Spain the fortress of Olivenza, with its territory and inhabitants, from the Guadiana, which river, by the same treaty, was made the boundary of the two kingdoms in that part. This treaty was signed at Badajoz, June 6,1801 ; and on the 20th of September, of the same year, Portugal likewise concluded a treaty of peace with France, the principal article of which made some alterations in the limits of Portuguese and French Guiana, considerably to the advantage of the latter power.

The queen is disordered by .religious melancholy; Dr. Willis at the request of the prince, some years since, made a voyage to Lisbon, to attempt her cure; but her recovery remaining hopeless, the gavernment of the country rests with the prince of Brasil. After the renewal of hostilities between England and France, in 1803, Bonaparte invited the court of Lisbon to join in the war against England, and to exclude English vessels from all the harbours of Portugal. With this requisition the prince of Brasil refused to comply, as dishonourable to himself, as well as extremely injurious to his suljects : but he was ohliged to purchase a compromise by paying a considerable tri-

Voz. 3 . $4 \mathrm{C}$ 
bute in money. This submission however served only to increase the tyrants demands, as well as to swell the insolence of his ministers. The conquest of Portugal was determined on, as a prelude to that of Spain, and a French army under general Junot, was ordered to march into the country. Rather than attempt to resist an invader so powelful, the Prince wisely resolved to evacuate Portugal, in order to save his foreign territories, which were much more imporcant; for had he waited the arrival of Junot, he would have lost his liberty, or his life, and been compelled to surrender all his dominions, at home and abroad. In executing this new and hazardous undertaking, he received great assistance from the British navy; himself, the royal family, and many of the nobility, being safely conveyed to Brasil in South America, where the court now resides.

The events of the war, have been already related in our account of Spain.

Maria-Frances-Isabella, queen of Portugal, born December 17, 1734; married, June 6, 1760, to her uncle, cion Pedro Clement, F. R. S. born Juiy 5, 1717, who died May 25, 1786; began to reign February $24,1777$.

Their issue.

John-Maria-Joseph-Louis, born May 13,1767 ; married, January 9, 1790, to Maria-Louisa, of Spain, born July 9, 1777.

Their issue.

1. Maria-Theresa, princess of Beira, born April 29th, 1793.

2. Isabella-Maria-Francisca, born May 19, 1797.

3. A prince of Beira, born August 12, 1798.

Sisters to the queen.

1. Anna-Frances-Antoinetta, born October 8, 1736.

2. Maria-Francisca-Benedicta. boru July 24, 1746; married in 1764, to her nephew the prince of Brasil, who died September 11, 1788. 


\section{ITALY.}

\section{SITUATION AND EXTENT.}

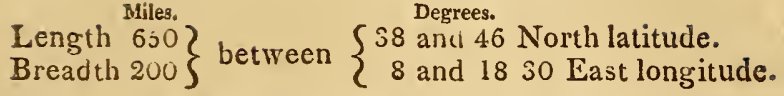

Containing, after deducting the territory lately annexed to France, and including the islands of Sicily and Sardinia, 71,050 square miles, with 220 inhabitants to each.

NAmE... The name of Italy, Italia, is usually derived from Italus, the leader of an ancient colony from Arcadia. Sir Walter Raleigh has supposed, with equal ingenuity aid probability, that it is the same with: \&iolia, and received from a colony of Greeks from that country.

BOUNDARIES...Italy is bounded on the nortin by Switzerland and the circle of Austria; on the east by the Adriatic Sea, on the south by the Mediterranean, on the west by Switzerland and France.

Dirisions.... Italy, at present, contains the following states and kingo doms.

States.

Kingdom of Italy,

Ligurian Republic,

Duchy of Venice,

Duchy of Parma

and Placentia, $\}$

Republic of Lucca,

Ki: gison of Etruria,

Repub. of San Marino

The Ecclesiastical State,

Kingriom of Naples,

Isiand and kingd. of Sicily,

Isld. and kingd. of Sardinia,
S. Miles.

9,280

1,760

8,000

1,440

368

7,360

32

10.080

20.500

7,300

6,930

Total, 71,050

$\begin{aligned} \text { Population. } & \text { Chief Towns. } \\ 3,555.500 & \text { Muidi. } \\ 60,000 & \text { Genoa. } \\ 2,0,0,000 & \text { Venice. } \\ 250,000 & \text { Parma. } \\ 120,000 & \text { Lucca. } \\ 1,050,000 & \text { Florence. } \\ 5,000 & \text { San Marino. } \\ 1,50,000 & \text { Rome. } \\ 4,700,000 & \text { Naples. } \\ 1,300,000 & \text { Palermo. } \\ 423,500 & \text { Cagliari. }\end{aligned}$

$15,504,000$

Considerable changes are expected to take place, in the political divisions of Italy, in consequence of the late revolution in France, but to what extent, is not yet known.

FACE OF THE COUNTRY.... The beautiful prospects and scenery of Italy have been the theme of almost all travellers in this delightful country. In some parts, indeed, there are extensive plains which have rather a naked, though not a barren appearance, and in others marshes and standing waters, which render the air unwholesome; but the general aspect of the country presents rich groves of olive, orange, citron, almonds, and other fruit-trees, intermingled with corn fields, inclosed by rows of tall poplars, elms, and mulberry trees, which support the luxuriant branches of the vine; while transparent streams descend the eminences, and meander through the vallies, exhibiting at once the image of the most exuberant fertility, and forming the most va. ried and enchanting landscapes. 
Mourtains....The principal mountains are the Alps on the borders of Francy, Swltzerland; and Germany, and the Apennines, which run along the coast of Genoa, and then pass through the whole length of Italy, generally approaching nearer to the Adriatic than the Mediterranean. Tha celcbrated volcanoes of Vesuvius and $\mathbb{E}$ tna are situate, the former in the vicinity of Naples, and the latter in the island of Sicily; but we shall reserve the description of these for the head of Natural Curiosities.

LaIES, Rivers, Mineral waters....The most considerable lakes in Italy are the Lago Magggiore, or the Greater Lake, called also the Luke of Locarno, about 27 miles in length and three in breadth: the lake of Como, about 32 miles in length and two and a half in breadth; the lake of Garda, about 30 miles long and eight broad, and the lakes of Lugano, Perugia, Terni and Celano.

The principal rivers are the Po, the Adige, the Tiber, and the Arno. The two former rise in the Alps, the first in Savoy, the sccond in Tyrol, and both flow into the Gulf of Venice, the former after a course of about 360 miles, the latter after having run about 200 The Tiber and the Arno rise in the Apennities and fall into the sea of Tuscany, the former near Rome, after having flowed through that city, and the latter near Pisa.

Mineral springs are found in various parts of Italy. The baths of Baia, near Naples, were celebrated in the time of the Romans. At Pisa are medicinal springs, one of which is said exactiy to resemble in taste the Cheltenham water in England.

Metals, minerals.... The mountains of Italy abound in mines that produce emeralds, jasper, agate, porphyry, lapis lazuli, and other valuable stones. Iron and copper mines are found in a few places; and a mill for forging and fabricating these metals is erected near Tivoli, in Naples. Sardinia is said to contain mines of gold, silver, lead, iron, sulphur, and alum, though they are now neglected. Beautiful marble of all kinds is one of the chief productions of Italy.

Chimate, soll, produc f....The climate of Italy is various, and some parts of this country exhibit melancholy proofs of the alterations that accidental causes make on the face of nature; for the Campagna di Roma, where the ancient Romans enjoyed the most salubrious air of any place perhaps on the globe, is now almost pestilential through the decrease of inhabitants, which has occasioned a stagnation of waters, and putrid exhalations. The air of the northern parts, which lie among the Alps, or in their neighbourhood, is keen and piercing, the ground being in many places covered with snow in winter. The Apennines, which are a ridge of mountains that longitudinally almost divide Italy, hase great effects on its climate; the countries on the south being warm, those on the north mild and temperate. The sea breczes refresh the kingdom of Naples so much, that no remarkable inconveniency of air is found there, notwithstanding its southern situation. In general, the air of Italy may be said to be dry and pure.

The happy soil of Italy produces the comforts and luxuries of life in great abundance; each district has its peculiar excellency and commodity; wines, the most delicious fruits, and oil, are the most general productions. As much coin grows here as serves the inhabitants; and, were the ground properly cultivated, the Italians might export it to their neighbours. In Lombardy, a crop of corn, another of silk, and another of wine, are obtained every year from the same land; the vines being planted in rows, with mulberry-trees For their support, and the intervals solya with corn. 
In the abundance, variety, and flavour of its fruits, no country in Europe can vie with Italy; which, besides oranges, lemons, citrons, and figs, produces such quantities of chesnuts, cherries, and plums, that they are of little value to the proprietors.

Aximals.... There is little difference between the animals of Italy, and those of France and Germany already mentioned.

Natural currosities....Among the natural curiosities of Italy the most conspicuous are its volcanoes. Mount Vesuvius, is five Italian miles distant from the city of Naples. The declivity of this mountain towarcis the sea is every where planted with vines and fruit-trees, and it is equally fertile towards the bottom. The circumjacent plain affords a delightful prospect, and the air is clear and wholesome. The south and west sides of the mountain form very different views, being, like the top, covered with black cinders and stones. The height of Mounc Vesurius has been computed to be 3,900 feet above the surface of the sea; and it has been a volcano beyond the reacli of history or tradition. An animated clescription of its ravages in the year 79 , is given by the younger Pliny, who was a witness to what he wrote. From that time to the year 1631 , its eruptions were but small and moderate; thell, however, it broke out with accumulated fury, and desolated miles around. In 1694, was a great eruption, which continued near a month, when burning matter was thrown out with so much force, that some of it fell at thirty miles distance, and a vast quantity of liquid lava ran down like a river for three miles distance, carrying every thing before it which lay in its way. In 1707, when their was another eruption, such quantities of cinders and ashes were thrown out, that it was dark at Naples at noon-day. In 1767, a violent eruption happened, which is reckoned to be the 27 th from that which destroyed Herculaneum, in the time of Titus. In this eruption, the ashes, or rather snuall cinders, slıowered down so fast at Napies, that the people in the streets were obliged to use umbrellas, or adopt sorne other expedient, to guard themselves against them. The tops of the houses and the balconies were covered with these cinders; and ships at sea, twenty leagues from Naples, were covered with them, to the great astonishment of the sailors. An eruption happened also 1766 , another in 1779, which have been particularly described by sir William Hanilton in the Philosophical Transactions; and another in June, 1794, which laid waste a considerable tract of country, and destroyed several villages, and a great number of habitations. It has been observed by a modern traveller, that though Mount Vesuvius often fills the neighbouring country with terror, yet, as few things in nature are so absolutely noxious as not to produce some good, even this raging volcano, by its sulphureous and nitrous manure, and the heat of its subterraneous fires, contributes not a litthe to the uncommon fertility of the country about it, and to the profusion of fruits and herbage with which it is every where covered. Besides, it is supposed that, while open and active, the mountain is less hostile to Naples, than it would be, if its eruptions were to cease, and its struggles confined to its own bowels, for then might ensue the most fatal shocks to the unstable foundation of the whole district of Terra di Lavoro.

Mount $\mathbb{E}$ tna is 10,954 feet in height, and has been computed to be 180 miles in circumference at its base; while Vesuvius is only about 30. It stands separate from all other mountains, its figure is circular, and it terminates in a cone. The lower parts of it are very fruitful 
in corn and sugar-canes; the midille abounds with woods, olive-trees, and vines; and the upper part is almost the whole year covered with snow. Its fiery eruptions have always rendered it famous; in one of these which happened in 1669 , fourteen towns and villages were destroyed, and there have been several terrible eruptions since that time. There is generally an earthquake before any great eruption. In 1693, the port town of Catania was overturned, and 18,000 people perished.

Near the lake Agnano and Pozzuolo, there is a valley called Solfatara, because vast quantities of sulphur are continuaily forced out of the clefts by subterranean fires. The grotto del Cane is remarkable for tts poisonous steams, and is so called from its kiiling dogs that enter it, if forced to remain there. Scorpions, vipers, and serpents, are said to be common in Apulia.

Savoy may likewise be enumerated among the curiosities of Italy. Tnose vast bodies of snow and ice, which are called tie glaciers of Savoy, deserve to be paricularly mentioned. There are five glaciers which extend almost to the plain of the vale of Cinamouny, and are separated by wild forests, corn fields, and rich meadows; so that immense tracts of ice are blended with the highest cultivation, an! perpetually succeed to each other, in the most singular and striking vicissitudes. All these several vallies of ice which lie chiefly in the holows of the mountains, and are some leagues in length, unite together at the foot of Mont Blanc; the higbest mountain in Europe, and probably of the ancient world. According to the calculations of M. de Luc, the height of this munntain above the level of the sea, is $2391 \frac{1}{4}$ French toises, or 15,303 English feet. "I am convinced," says Mr. Coxe, "from the situation of Mont Blanc, from the height of the mountains around it, from its superior elevation above them, and its being seen at a great distance from all sicles, that it is higher than any mountain in Sivitzerland; which, beyond a doubt, is next to Mont Blanc, the highest ground in Europe."

The cascade of Terni, about four miles from the town of that name, is perhaps the most beautiful cataract in the world. The river Velino, at a short distance from its junction with the Nar, falls suddenly down a precipice, nearly 300 fect in height, and dashes with such violence on the rocks below, that a great part of its stream lises in vapour. It afterwards fails down two other precipices, almost as high as the first; its waters each time rising in a kind of mist. The aggregati height of the three falis is supposed to be about 800 feet. Near Tivoli is another beautifu! cascade, the river Teverone, the ancient Anio. fallin:r about 50 feet.

Population, national character, manners, customs... The whole popuiation of Italy, according to Has sel, amounts to $16,117,000$.

The Itali :ns are generally well-proportioned, and have such meaning in their looks, that they have greatly assisted the ideas of their painters. The women are well-shaped, and very amorous. The marriage ties, especially of the better soit, are said to be of very little value in Italy. Every wife has been represented to have her gallant or cicisbeo, with whom she keeps company, and sometimes cohanits, with very little cercmony, and no offence on either side. But this practice is chiefly remarkable at Venice; and indeed the representations which have been made of this kind by travellers, app ar to have been much exaggerated. With regard to the morles of life, the best quality of a modern Italian is sobriety, and they submit very patiently to 
the public government. With great taciturnity, they discover but litcle reflection. They are ratiner vindictive than brave, and more supsertitious than devout. The midding ranks are attached to their native customs, and seem to have no ideas of improvement. Tineir fondness for greens, fruits, and vegetables of ali kinds, contributes to their contentment and satisfaction; and an Italian gentiernan or peasant can be luxurious at a very small expense. Though perhaps all Italy does not contain many descendants of the ancient Romans, yet the present inhabitants speak of themselves as successors of the conquerors of the world, and look upon the rest of mankind with contempt.

The dress of the Italians is little different from that of the neighbouring countries, and they affect a medium between the Frencls volatility and the solemnity of the Spaniards. The Neapolitans are commonty dressed in black, in compliment to the Spaniards. It cannot be clenied that the Italians excel in the fine arts : though they make at present but a very inconsiderable figure in the sciences. They cultivate and enjoy vocal music at a very dear rate, by emasculating their males when young; to which their mercenary parents agree without remorse.

The Italians, the Venetians especially, have very little or no notion of the impropriety of many customs that are considered as criminal in other countries. Parents, rather than their sons should throw themselres away by unsuitable marriages, or contract diseases by promiscuous amours, hire mistresses for them, for a month, or a year, or some determined time ; and concubinage, in many places of Italy, is an avowed licensed trade. The Italian courtesans, or bona. robas, as they are called, make a kind of profession in all their cities. Masquerading and gaming, horse-races without riders, and conversations or assemblies, are the chief diversons of the Italians, excepting religious exhibitions, in which they are pompous beyond all other nations.

A modern writer, describing his journey through Italy, gives us a very unfavourable picture of the Italians and their manner of living. "Give what scope you please to your fancy," says he, "you will never imagine half the disagreeableness that Italian beds, Italian cooks, and Italian nastiness, offer to an Englishman. At Turin, Milan, Venice, Rome, and perhaps two or three other towns, you meet with good accommodations; but no words can express the wretchedness of the other inns. No other beds than those of straw, with a mattress of straw, and next to that a dirty sheet, sprinkled with water, and consequently damp : for a covering, you have another sheet as coarse as the first, like one of our kitchen jack-towels, with a dirty coverlid. The bedstead consists of four wooden forms or benches. An English peer and peeress must lie in this manner, unless they carry an upholsterer's shop with them. There are, by the bye, no such things as curtains; and in all their inns the walls are bare, and the floor has never yet been washed since it was first laicl. One of the most indelicate customs here is, that men, and not women, make the ládies beds, and would do every office of à maid-servant, if suffered. They never scour their pewter; their knives are of the same colour. In these inns they make you pay largely, and send up ten times as much as you can eat. The soup, like wash, with pieces of liver swimming in it; a plate full of brains fried in the shape of fritters; a dish of livers and gizzards; a couple of forvls (always .killed after 
your arrival) boiled to rags, without any the least kind of sauce os herbage; another fowl, just killed, stewed as they call it; then two more fowls, or a turkey, roasted to rags. All over Italy, on the roads, the chickens and fow is are so stringy, you may divide the breast into as many filaments as you can a halfpenny-worth of thread. Now and then we get a little piece of mutton or veal; and generally speaking, it is the only eatable morsel that falis in our way. The bread all the way is exceedingly uad; and the butter so rancid, that it cannot be touched, or even borne within the reach of your smell. But what is a greater evil to travellers than any of the above recited, are the infinite numbers of gnats, bugs, fleas, and lice, which infest us by day and night."

RELIGION....The religion of the Italians is the Roman-catholic. The inquisition here is little more than a name; and persons of all religions live unmolested in Italy, provided no gross insuit is offered to their worship. In the Introduction, we have given an account of the rise and establishment of popery in Italy, from whence it spread over ali Europe; likewise of the causes and symptoms of its decline. The ecclesiastical government of the papacy has employed many volumes in describing it. The cardinals, who are next in dignity to his holiness, are seventy; but that number is seldom or never complete : they are appointed by the pope, who takes care to have a majority of Italian cardinals, that the chair may not be removed from Roine, as it was once to Avignon in France, the then pope being a Frenchman. In promoting foreign prelates to the cardinalship, the pope regulates himself according to the nomination of the princes who profess that religion. His chief minister is the cardinal patron, generally his nephew, or near relation, who improves the time of the pope's reign by amassing what he can. When met in a consistory, the cardinals pretend to controul the pope, in matters both spiritual and temporal, and have been sometimes known to prevail. The reign of a pope is seldom of long duration, being generally old men at the time of their election. The conclave is a scene where the cardinals: principally endeavour to display their abilities, and where many transactions pass very inconsistent with their pretended inspiration by the Holy Ghost. During the election of a pope, in 1721 , the animosities ran so high, that they came to blows with both their hands and feet, and threw the ink-standishes at each other. We shall here give an extract from the creed of pope Pius IV, (1560) before his elevation to the chair, which contains the prircipal points wherein the church of Rome differs from the protestant churches. After declaring his belief in one God, and other heads wherein Christians in general are agreed, he proceeds as follows :

"I most firmly admit and embrace the apostolical and ecclesiastical traditions, and all other constitutions of the church of Rome.

"I do admit the Holy Scriptures in the same sense that holy mother-church doth, whose business it is to judge of the true sense and interpretation of them; and I will interpret them according to the unanimous consent of the fathers.

"I do profess and believe that there are seven sacraments of the law, truly and properly so calied, instituted by Jesus Christ our Lord, and necessary to the salvation of mankind, though not all of them to every one; namely, baptism, confirmation, eucharist, penance, extreme unction, orders, and marriage, and that they do confer grace; and that of these, baptism, confirmation, and orders, may not be 
wepeated without sacrilege. I do also receive and admit the received and approved rites of the catholic church in her solemn administration of the above said sacraments.

"I do embrace and receive all and every thing that hath been defined and declared by the holy council of 'Trent* concerning original sin and justification.

"I do also profess that in the mass there is offered unto God a true, proper, and propitiatory sacrifice for the quick and the dead; and that in the most holy sacrament of the eucharist there is truly, really, and substantially, the body and blood, together with the soul and divinity, of our Lord Jesus Christ; and that there is a conversion made of the whole substance of the bread into the body, and of the whole substance of the wine into the blood; which conversion the catholic church calls Transubstantiation. I confess that under one kind only, whole and entire, Christ and a true sacrament is taken and received

"I do firmly believe that there is a purgatory; and that the souls kept prisoners there do receive help by the suffrages of the faithiful.

"I do likewise believe that the saints reigning together with Christ are to be worshipped and prayed unto; and that they do offer up prayers unto God for us, and that their relics are to be had in veneration.

"I do most firmly assert that the images of Christ, of the blessed Virgin the mother of God, and of other saints, ought to be had and retained, and that due honour and veneration ought to be given unto them. $\dagger$

"I do likewise affirm, that the power of indulgences was left by Christ to the church, and that the use of them is very beneficial to christian people.

"I do acknowledge the holy catholic and apostolical Roman church to be the mother and mistress of all churches: and I do promise and swear true obedience to the bisiop of Rorne, the successor of St. Peter, the prince of the apostles, and vicar of Jesus Christ.

"I do undoubtedly receive and profess all other things which have been delivered, defined, and declared by the sacred cannons and œcumenical councils, and especially by the holy synod of Trent. And all other things contrary thereto, and all heresies condemned, rejected, and anathematised by the church; I do likewise condemn, reject, and anathematise."

- A convocation of Roman-catholic cardinals, archbishops, bishops, and divines, who assembled at Trent, by virtue of a bull from the pope, anno 1546, and devoted to him, to determine upon certain points of faith, and to suppress what they were pleased to term the rising heresies in the cluurch.

† An English traveller, speaking of a religious procession some years ago at Florence, in Italy, describes it as follows : "I had occasion," says he, "to see a procession where all the noblesse of the city attended in their coaches. It was the an niversary of a charitable institution in favour of poor maidens, a certain number of whom are portioned every year. About two hundred of these virgins walked in procession, two and two together. They were preceded and followed by an irregular mob of penitents, in sackcloth, with lighted tapers, and monks currying crucifixes, bawling and bellowing the litanies; but the greatest object was the figure of the Virgin Mary, as big as the life, standing within a gilt frame, dressed in a gold stuff, with a large hoop, a great quantity of false jewels, her face painted and patched, and her hair frizzled and curled in the very extremity of the fa. shion. Very little regard had been paid to the image of our Saviour on the cross; but when the Lady Mother appeared on the shoulders of three or four lusty friars, the whole populace fell upon their knees in the dirt."

VOL. I.

$\& D$ 
ArchisновrIcs....There are forty-one archbishoprics in Italy, but the suffragans annexed to them are too indefinite and arbitrary for the reader to depend upon; the pope creating or suppressing them as he pleases.

LEARNING AND LEARNED MEN, PAINTERS, STATURAIES, ARCHITECTS, AND ARTISTS....In the Introciuction we have particularised some of the great men which ancient Italy has produced. In modern times, that is, since the revival of learning, sone Italians have shone in controversial learning, but they are chiefly celebrated by bigots of their own persuasion. The mathematics and natural philosophy owe much to Galileo, Torricelli, Malpighi, Borelli, and several other Italians. Strada is an excellent historian: and the history of the council of Trent, by the celebrated father Paul, is a standard work. Guicciardini, Bentivoglio, and Davila, have been much condemned as historians by their several admirers. Machiavel is equally famous as an historian and as a political writer. His comedies have much merit: and the liberality of his sentiments, for the age in which he lived, is amazing. Among the prose writers in the Italian languagge, Boccacio has been thought one of the most pure and correct in point of style : he was a very natural painter of life and manners, but his productions are two licentious. Petrarcha, who wrote both in Latin and Italian, revived among the moderns the spirit and genius of ancient literature: but among the Italian poets, Dante, Ariosto, and Tasso, are the most distinguished. There are said to be upwards of a thousand comedies in the Italian language, though not many that are excellent : but Metastasio has acquired a great reputation by writing dramatic pieces set to music. Sannazarius, Fracastorius, Bembo, Vida, and other natives of Italy, have distinguished themselves by the elegance, correctness, and spirit of their Latin poetry, many of their compositions not yielding to the classics themselves. Socinus, who was so much distinguished by his opposition to the doctrine of the Trinity, was a na. tive of Italy.

The Italian painters, sculptors, architects, and musicians, are unrivalled, not only in their number, but their excellence. The revival of learning, after the sack of Constantinople by the Turks, revived taste likewise, and gave mankind a relish for truth and beauty in design and colouring. Raphael, from his own ideas, assisted by the ancients, struck out a new creation with his pencil, and still stands at the head of the art of painting. Michael Angelo Buonarotti, united in his own person painting, sculpture, and architecture. The colouring of Titian has perhaps never yet teen equalled. Bramante, Bernini, and many other Italians, carried sculpture and architecture to an amazing height. Julio Romano, Correggio, Caracci, Veronese, and others, are, as painters, unequalled in their several manners. The same may be said of Corelli, and other Italians, in music. At present Italy cannot justly boast of any extraordinary genius in the fine arts.

Universities.... Those of Italy are, Rome, Venice, Florence, Mantua, Padua, Parma, Verona, Milan, Pavia, Bologna, Ferrara, Pisa,* Naples, Salerno, and Perusia.

LANGUAGE....The Italian language is remarkable for its smoothness, and the facility with which it enters into musical compositions. The ground-work of it is Latin, and it is easily acquired by a good classical sc!ıolar. Almost every state in Italy has a different dialect; and 
the prodigious pains taken by the literary societies there, may at last fix the Italian into a standard language. At present, the Tuscan style and writing is most in request.

The Lord's prayer run thus : Padre nostro che sei nel cielo, sia sanctificato il tuo nome; il tuo regno venga; la tua volontà sia fatta siccome. in cielo cosi anche in terra: dacci oggi il nostro hane cotidiano; e remettici i nostri debita, siccome noi ancora rimettiamo à nostri debitori: - non inducici in tentatione, ma liberaci dal maligno; herciocche tuo è il regno, e la hotenza, e la gloria in semfiterno. Amen.

ANriquities... Among the antiquities of Italy, the amphitheatres claim the first rank, as exhibiting the most wonderful specimeus of ancient magnificence. There are at Rome considerable remains of that which was erected by Vespasian, and finished by Domitian, called the Coliseo. Twelve thousand Jewish captives were eniployed by Vespasian in this building; and it is said to have been capable of containing eighty-seven thousand spectators seated, and twenty thousand standing. The architecture of this amphitheatre is perfectly light, and its proportions are so just, that it does not appear so large as it really is. But it has been stripped of all its magnificent pillars and ornaments, at various times, and by various enemies. The Goths, and other barbarians, began its destruction, and popes and cardinals have endeavoured to complete its ruin. Cardinal Farnese, in particular, robbed it of some fine remains of its marble cornices, friezes, \&c. and, with infinite pains and labour, took away what was practicable of the outside casing of marble, which he employed in building the palace of Farnese. The amphitheatre of Verona, erected by the consul Flaminius, is thought to be the most entire of any in Italy. There are forty-five rows of steps carried all round, formed of fine blocks of marble about a foot and a half high each, and above two feet broad. Twenty-two thousand persons may be seated here at their ease, allowing one foot and a half for each person. This amphi. theatre is quite perfect, and has been repaired with the greatest care, at the expence of the inhabitants. They frequently give public spectacles in it, such as horse-races, combats of wild beasts, \&c. The ruins of theatres and amphitheatres are likewise visible in other pla. ces. The triumphal arches of Vespasian, Septimius Severus, and Constantine the Great, are still standing, though decayed. The ruins of the baths, palaces, and temples, answer all the ideas we can form of the Roman grandeur. The Pantheon, which is at present converted into a modern church, and which from its circular figure is commonly called the Rotunda, is more entire than any other Roman temple which is now remaining. There are still left several of the niches which anciently contained the statues of the heathen deities. The outside of the building is of Tivoli free-stone, and within it is in. crusted with marble. The roof of the Pantheon is a round dome, without pillars, the diameter of which is a hundred and forty -four feet ; and though it has no windows, but only a round aperture in the centre of this dome, it is very light in every part. The pavement consists of large square stones and porpliyry, sloping round towards the centre, where the rain-water, falling down through the aperture on the top of the dome, is conveyed away by a proper drain covered with a stone full of holes. The collonade in the front, which consists of sixteen columns of granite, thirty-seven feet high, exclusive of the pedestals, and capitals, each cut out of a single block, and which are of the Corinthian order, can hardly be viewed without astonishment. 
The entrance of the church is adorued with columns forty-eight feet high, and the architrave is formed of a singie piece of sranite. On the left hand, on elutering the portico, is a large antique vase of $\mathrm{Nu}$ midian marble; and in the area before the church is a fountain with an antique of porphyry. The pillars of Trajan and Autonine, the former 175 feet high, and the latter covered with instructive sculptures, are still remaining. A traveller forgets the devasiations of the northern barbarians, when he sees the rostrated column erected by Duilius in commemoration of the first naval victory the Romans gained over the Carthaginians; the statue of the wolf yiving suck to Roinulus and Remus, with visible maiks of the strokes of lightning, mentioned by Cicero; and the original brass plates containing tie laws of the twelve tables; and a thousand other indentical antiquities, some of them transmitted unhurt to the present times; not to mention medals, and the infinte variety of seals and engraved stones which abound in the cabinets of the curious. Many palaces, throughout Italy, are furnished with busts and statues fabricated in the times of the republic and the higher enpire.

The Appian, Flaminian, and Emilian roads, the first 200 miles, the second 130, and the third 50 miles in length, are in mariy places still entire; and magnificent ruins of villas, reservoirs, bridges, and the like, present themselves in every part of Italy.

The subterraneous constructions of Italy are as stupendous as those above ground : such are the cloacæ, and the catacombs, or repositories for dead bodies, in the neighbourhood of Rome and Naples. It is not above 50 years since a painter's apprentice discovered the ancient city of Pæstum or Posidonia, in the kingdom of Naples, still standing; for so indifferent are the country people of Italy about objects of antiquity, that it was a new discovery to the learned. An inexhaustible mine of curiosities exists in the ruins of Herculaneum, a city lying between Naples and Vesuvius, which in the reign of Nero, was almost destroyed by an earthquake, and afterwards, in the first year of the reign of 'Titus, overwhelmed by a stream of the lava of Vesuvius. The melted lava in its course filled up the streets and houses in some places to the height of sixty-eight feet above the tops of the latter, and in others one liundred and ten feet. This lava is now of a consistency which renders it extremely difficult to be removed or cleared away : it is composed of bituminous particles, mixed with cinders, minerals, metallic and vitrified sandy substances, which altogether form a close and heavy mass. In the revolution of so many ages, the spot it stood upon was entirely forgotten; but in the year 1713 , upon digging into these parts, some remains of this unfortunate city were discovered, and many antiquities were dug out; but the search was afterwards discontinued, till the year 1736, when the king of Naples employed men to dig perpendicularly eighty feet deep, whereupon not only the city made its appearance, but also the bed of the river which ran through it. The temple of Jupiter was then disclosed, and the whole of the theatre. In the temple was found a statue of gold, and the inscription that decorated the great doors of entrance. In the theatre, the fragments of a gilt chariot of bronze, with horses of the same metal, likewise gilt; this had been placed over the principal door of entrance. There were likewise found among the ruins of this city, multitudes of statues, busts, pillars, paintings, manuscripts, furniture, and various utensils. 'The streets of the town appear to have been quite straight and regular, the houses 
well built, and much alike; sone of the rooms paved with Mosaic, others with fine marbles, others again with bricks three feet long and six inches thick. It appears that the town was not filled up so unexpectedly with the melted lava, as to prevent the greatest part of the inhabitants from escaping with many of the richest effects : for when the excavations were made, there was not more than a dozen skeletons tuund, and but little gold, silver, or precious stones.

Tise town of Poinpeii was destroyed by the same erup:ion of Mount Vesuvius which occasioned the destruction of Herculaneum; but it was not discuvered till near forty years after the discovery of $\mathrm{H} t \mathrm{rcu}^{\mathrm{c}}$ laneum. One street, and a few detached buildings of this town, have been cleared; the street is well paved witl the same kind of stone of which the ancient roads are mude, and narrow causeways are raised a foot and a half on each side for conveniency of foot passengers. Dr. Hloore oi erves, that $t$ e street itself is not so broad as the narrowest part of the Strand, and is supposed to have been inhabited by tradespeople. The traces of wheels of carriages are to be seen on the pavement. The houses are smali, but give an idea of neatness and conveniency. The stucco on the walls is smooth and beautiful, and as hard as marbie. Some of the rooms are ornamented with paintings, mostly siugle figur:s, representing some animal. They are tolerably well executed, and a little water being thrown on them, the colours appear surprisingly fresh. Most of the houses are built on the same plan, anch have one small room from the passage, which is conjectured to have been the shop, with a window to the street, and a place which. seems to have been contrived for showing the goods to the greatest advantage. In another part of the town is a rectangular building, with a colonnade towards the court, something in the stile of the Royal Exchange at Londen, but smaller. At a considerable distance from this, is a temple of the goddess Ises, the pillars of which are of brick, stuccoed like those of the guard-room; but there is nothing very magnificent in the appearance of this edifice. The best paintings hitherto fourd at Pompeii, are those of this temple; they have been cut out of the walls and removed to Portici. Few skeletons were found in the streets of this town, but a considerable number in the houses. In one apartment (says Mr. Sutherland) we saw the skeletons of 17 poor wretches who were confined by the ancles in an iron machine. Many other bodies were found, some of them in circumstances which plainly shewed that they were endeavouring to escape when the eruption overtook them.

States of Italy, governments, cities, chief towns....Thus far, of Italy in general; but as the Italian states are not, like the republic of Switzerland, or the empire of Germany, cemented by a political confederacy, to which every member is accountable (for every Italian state has a distinct form of government, trade, and interests) it will be necessary to take a separate view of each, to assist the reader in forming an idea of the whole.

The first and principal state which presents itself in the northern part of Italy is the new kingdom of Italy, founded in the year 1797 by Borsaparte, under the name of the Cisalpine Republic. In the year 1799 it was for a time abolished, by the success of the Austrian and Russian arms ; but restored again after the battle of Marengo, in 1800, and acknowledged, on the part of Austria, by the treaty of Luneville. It consists of the Austrian duchies of Milan and Mantua, the duchy of Modena, the principalities of Massa and Carrara; the Venetian 
provinces of Cremasco, Bergamasco, Bresciano, and a part of the $\mathrm{Ve}$. ronese, as far as the Adige; the three legations of the ecclesiastical state, Bologna, Ferara, and Romagna, and the late subjecis of the Grisons, Bormio, the Valteline, and Claevers. It is bounded on the north by Switzerland and the county of Tyrol; on the east by the duchy of Venice and the Adriatic Sea; on the south by the kingdom of Etruria, Lucca, and the ecclesiastical state ; and on the west by Piedmont. It is divided into thirteen departments, viz. Agogna, Lario, Milan, Serio, Mella, Upper Po, Mencia, Crostolo, Panaro, Lower Po, Reno, Rubicon, Verono. The country is in gencral extremely fertile and productive. Milan, the capital and seat of government, is situate in a plain between the rivers Adda and Tesino. It is a strong city, with a citadel, and a magnificent cathedral in the Gothic taste, adorned, it is said, with 4000 statues. It contains about 130,000 inhabitants. The other principal cities are Mantua, one of the strongest fortresses in Europe, and containing about 20,000 inhabitants, who boast that Virgil was a native of their country ; Pavia, celebrated for its ancient university, founded by Charlemagne ; Bologna, containing 63,000 inhabitants; Modena, with about 26,000, and 100 churches; Ferrara, a bishop's see and university; Ruvenna, the capital of the papal legation of Romagna; and Verona; of which latter city, how. ever, a small part on the left bank of the Adige appertains to the Austrian Venetian territory. This kingdom rose and fell with Bonaparte. Austria has resumed her portion, and the other sections, have mostly reverted to their former owners.

When under the government of its own dukes, the duchy of Milan', gave law to all Italy. The revenue of this duchy was above $300,000 l$. annually, which it was supposed might maintain an army of 30,000 men. Mantua was also a rich duchy, which brought to its own dukes an annual revenue of 500,000 crowns. The duchy of Modena (formerly Mutina) before the late revolutions excited by the French in Italy, was governed by its own duke, the head of the house of Este, from whom the family of Brunswick descended. The duke was absolute within his own dominions $\mathrm{He}$ was under the protection of the house of Austria, and a vassal of the empire. He received, as an indemnity for his duchy, the territories of the Brisgau and the Ortenau in Germany.

The republic of Genoa, or the Ligurian republic, is greatly degenerated from its ancient power and opulence. The territory is divided into three circles, or districts, called la Riviera di Levante, or eastern coast; la Riviera di Ponente, or western coast; and $i l$ Centro, the centre or midland district. Genoa is a most superb city, and contains some very magnificent palaces, particularly those of Doria* and Durazzo. The inhabitants of distinction dress in black, in a plain, if not an uncouth manner. Their chief manufactures are velvets, damasks, gold and silver tissues, and p?per. The city of Genoa contains about 100,000 inhabitants; among whom were many rich trading individuals. Its maritime power is dwindled down to a few galleys. The common people are wretched beyond expression, as is the soil of its territory. Near the sea some parts are tolerably well cultivated. The

* Andrew Doria, the head of this family, famous for his military exploits, and the deliverer of Genoa, was born in the territory of Genoa, in the year 1468; he was offered the sovereignty of the state, but refused it, and gave to the people that republican form of government which subsisted till the late revolution; he lived to the age of ninety-three, the refuge and friend to the unfortunate. 
old government of Genoa was aristocratical, being vested in the nobility; the chief person was called the doge, or duke; to which dignity no person was promoted till he was fitty years of age. Every two years a new doge was closen, and the former became incapable, during five years, of holding the same post again. The doge grave audience to ambassadors; all orders of groverument were issued in his name, and he was allowed a body-guard of two hundred Germans.

By the new constitution of the Ligurian republic, framed at Paris in the year 1801, the government is vested in a doge and senate of thirty, and a legislative body of seventy members; of which onefifth go out annually. The revenue is said to amount to above $600,000 l$. but there are great public debts.

VENICE, now a part of the Austrian territory, was one of the most celebrated republics in the world, on account both of its constitution and former power. The duchy consists at present of the seven provinces of Venice, or the Dogeat, Treviso, Padua, Vicenza, Verona, and Belluno; which latter is divided into the three districts of Belluno, Feldre, and Carode. The city of Venice is seated on seventy-two islands at the bottom of the north end of the Adriatic Sea, and is separated fiom the continent by a marshy lake of five Italian miles in breadth, too shaliow for large ships to navigate, which forms its prin cipal strength. Venice preserves the vestiges of its ancient magnificerice, but is in every respect degenerated, except in the passion. which its inhabitants still retain for nusic and mummery during their carnivals. They seem to have lost their ancient taste for painting and architecture, and to be returning to Gothicism. They had, however, lately some spirited differences with the court of Rome, and seemed to be disposed to throw off their obedience to its head. As to the constitution of the late republic, it was originally democratical, the magistrates being chosen by a general assembly of the people, and so continued for ore hundred and filty years; but various changes afterwards took place: doges, or dukes, were appointed, who were invested with great power, which they often grossly abused, and some of them were assassinated by the peopie. By degrees a body of hereditary nobility was formed; continued and progressive encroachments were made on the riglits of the people; and a complete aristocracy was at length established upon the ruins of the ancient popular governmert. The nobility were divided into six classes, amounting in the whole to 2500 , each of whom, when twenty-five years of age, had a right to be a member of the grand council. Before the late revolution, these elected a doge, or chief magistrate, in a peculiar manner by ballot, which was managed by gold and silver balls. The doge was invested with great state, and with emblems of supreme autho. rity, but had very little power, and was not permitted to go out of the city without the permission of the grand council. The government anc laws were administered by different councils of the nobles.

The college, otherwise called the signory, was the supreme cabinet council of the state, and also the representative of the republic. This court gave audience, and delivered answers, in the name of the republic, to foreign ambassadors, to the deputies of towns and provinces, and to the generals of the arny. It also received all requests and me. morials on state affairs, summoned the senate at pleasure, and arranged the business to be discussed in that assembly. The council often took cognizance of state crimes, and had the power of seizing accused persons, examining them in prison, and taking thoir answers 
in writing, with the evidence against them. But the tribunal of state inquisitors, which consisted only of three members, and which was in the highest degree despotic in its manner of proceeding, had the power of deciding, without appeal, on the life of every citizen beionging to the Venetian state....the highest of the nobility, even the doge hiniself, not being excepted. To these three inquisitors was given the right of employing spies, considering secret intelligence, issuing orders to seize all persons whose words or actions they might think reprenensible, and afterwards trying them, and ordering them to be executed, when they thought proper. They had keys to every apartment of the ducal palace; and could, whenever they pleased, penetrate into the very bed-chamber of the doge, open his cabinet, and examine his paper ; and, of course, might command access to the house of every individual in the state. They continued in office only one year, but were not responsible afterwards for their conduct whilst they were in authority. So much distrust and jealousy were displayed by this goverument, that the noble Venetians were afraid of having any intercourse with foreign ambassadors, or with foreigners of any kind, and were even cauticus of visiting at each other's houses.

All the orders of Venetian nobility are dressed in black gowns, large wigs, and caps which they hold in their hands. The ceremony of the doge's marrying the Adriatic once a year, by dropping into it a ring from his bucentaur, or state barge, attended by those of all the nobility, was intermitted, for the first time for several centuries, on Ascension-day 1797; and the bucentaur has since been taken away from Venice by the French. The inhabitants of Venice amount to about 140,000 . The grandeur and convenience of the city, particularly the public palaces, the treasury, and the arsenal, are beyond expression. Over the several canals of Venice are laid near 500 bridges, the greatest part of which are of stone. The Venctians still have some manufactures in scarlet cloth, gold and silver stuffs, and, above all, fine looking-glasses, all which bring in a considerable revenue to the owners; that of the state, annually, is said to have amounted to $8,050,000$ of Italian ducats, each valued at $38 \frac{1}{4}$ cents of our money. Out of this were defrayed the expences of the state, and the pay of the army, which, in the time of peace, consisted of 16,000 regular troops (always commanded by a foreign general) and 10,000 militia. They kept up at small fleet for curbing the insolence of the piratical states of Barbary. The French, however, pressed into their services the ships they found here; and likewise carried away immense quantities of arms and military stores from the arsenal.

The Venetians have some orders of knighthood, the chief of which are those of the Stola d'Oro, so called from the robe they wear, which is conferred only on the first quality; and the military order of St. Mark, of which in the proper place.

In ecclesiastical matters, the Venetians have two patriarchs; the authority of one reaches over all the provinces, but neither of them has much power: all religious sects, even the Mahomedan and pagan, are here tolerated in the free exercise of their religion.

The Ventians are a lively, ingenious people, extravagantly fond of public amusements, with an uncommon relish for humour. They are in general tall and well made; and many fine manly countenances are met with in the streets of Venice, resembling those transmitted to us by the pencils of Paul Veronese and Titian. The women are of a fine style of countenance, with expressive features, and are of an easy ad- 
dress. The common people are remarkably sober, obliging to stran. gers, and gentie in their intercourse with each other. As it is very much the custom to go about in masks at Venice, and great liberies are taken during the time of the carnival, an idea has prevailed, that there is much more licentiousness of manners here than in other places : but this opinion seems to have been carried too far. Great numbers of stangers visit Venice during the time of the carnival, and there are eight or nine theatres here, including the opera-houses.

Tine duchy and city of Parma, together with the duchies of Placentia and Guastalla, furm one of the most flourishing states in Italy, of its extent. The soils of Parma and Placentia are fertile, and produce the richest fruits and pasturages, and contain considerable manutaco tures of silk. The city of Parma is the seat of a bishop's see and a university ; and some of its magnificent churches are painted by the famous Correggio. It contains about 55,000 inhabitants, and Placentia about 25,000 . Both are embellished with magnificent edifices. The late duke of Parma was a prince of the house of 'Bourbon, and son to Don Philip, the king of Spain's younger brother. His court was thought to be the politest of any in Italy; and it is said that his revenues amounted to $175.000 l$. sterling a year. After his death, in 1803, the French took possession of the duchy of Parma. The duchies of Parma and Placentia, are now settled upon Maria Louisa, daughter of the emperor of Austria, and wife of Bonaparte, and after her, upon her son, styled by his father, the king of Rome.

The inhabitants of LuccA, which is a small free commonwealth, lying on the Tuscan sea, in a delightful plain, are the most indus trious of the Italians. They have improved their country into a beautiful garden, so that, though they do not exceed 120,000, their annual revenue, amounts to $80,000 l$. sterling. Their capital is Lucca, which contains about 40,000 inhabitants, who deal in mercery goods, wines, and fruits, especially olives. The vicinity of the grand-duchy of Tuscany kept the people of Lucca constantly on their guard, in order to preserve their freedom; for, in such a situation, a universal concord and harmony can alone enable them to transmit to posterity the blessings of their darling liberty, whose name they bear on their arms, and whose image is not only impressed on their coin, but also on the city gates, and all their public buildings. It is also observable, that the inhabitants of this little republic, being in possession of freedom, appear with an air of cheerfulness and plenty, seldom to be found among those of the neighbouring countries.

The kingdom of Etruria is composed of the late grand duchy of Tuscany, the small stato degli Presidi, and the principality of Piombino. It is almost surrounded by the papal territory and the Mediterranean sea. It is extremely fruitful, and well cultivated, producing great quantities of corn, wine, and oil. The capital is Florence, which, during the reigns of the illustrious house of Medici, was the cabinet of all that is valuable, rich, and masterly, in architecture, literature, and the arts, especially those of painting and sculpture. It contains above 70,000 inbabitants. The beauties and riches of the grand-duke's palaces have been often described; but, before they were plundered by the French, all description fell short of their contents; so that, in every respect, this city was reckoned, after Rome, the second in Italy. The celebrated Venus de Medici, which is considered as the standard of taste in female beauty and proportion, stoori in a room called the Tribunal; but has been carried away by 
the French, and is now at Paris. From the inscription on its base, it appears to have been made by Cleomenes, an Athenian, the son of Aponodorus. It is of white marble, and was surrounded by other master-pieces of sculpture, some of which are said to be the works of Praxiteles, and other Greek masters. Every corner of this beautiful city, which stands between mountains covered with olive-trees, vineyards, and delightful villas, and divided by the Ano, is full of wonders, in the arts of painting, statuary, and architecture. It is a plece of some strength, and contains an archbishop's see and a univursity. The inlabitants boast of the improvements they have made in the I a alian tongue, by means of their Academia della Crusca; and severai other academies are now established at Florence. Though the Florentines affect great state, ye: their nobility and gentry carry on a retail trade in wine, which they sell from their cellar windows; and sometimes they even hang out a broken flask, as a sign where it may be bought. 'They deal, besides wine and fruits, in' gold and silver stuffs. U'pon the accession of the archduke Peter Leopold, afterwards emperor of Germany, to this duchy, a great reformation was introduced, both into the grovernment and manufactures, to the great benefit of the finances. It is thought that the great-duchy of Tuscany could bring into the ficld, upon occasion, 30,000 fighting men, and that its revenues were above $500,000 l$. a year. The other principal towns of Tuscany are Pisa, Leghorn, and Sienna: the first and last are much decayed; but Leghorn is a very handsome city, built in the modern taste, and with such regularity, that both gates are seen from the market-place. It is well fortified, having two forts towards the sea, besides the citadel. The ramparts afford a very agreeable prospect of the sea, and of many villas on the land side. Here all nations; and even the Mahommedans, have free access, and many settle. The number of inhabitants is 58,000 , among whom are said to be 20,000 Jews, who live in a particular quarter of the city, have a handsome synagogue, and, though subject to very heavy imposts, are in a thriving condition, the greatest part of the commerce of this city going through their hands.

When the French erected Tuscany into a kingdom, by the name of the kingdom of Etruria, they gave the sovereignty to Louis the son of the duke of Parma, to whom the grand-duchy of Tuscany was formerly ceded by the treaty of Luneville. Since his cleath, in 1803, the government has been administered in the name of his infant son Louis, born December 23, 1799, by the queen-dowager, Maria-Louisa, daughter of the present king of Spain.

The republic of St. Marino is here mentioned as a geographical curiosity. Its territories consist of a high craggy mountain, with a few tminences at the bottom, and the inhabitants boast of having: preserved their liberties as a republic for 1300 years. It is under the protection of the pope ; and the inoffensive manners of the inhabitants, whose number is not more than 10,000, with the small value of their territory, have preserved its constitution.

The Ecclesiastical State, which contains Rome, formerly the capital of the worid, is situated about the middle of Italy. The ill effects of popish tyranny, superstition, and oppression, are here seen in the highest perfection. Those spots, which under the masters of the world were formed into so many terrestrial paradises, surrounding their magnificent villas, and enriched with all the luxuries that art and nature could produce, are now converted into noxious pestilen- 
sial marshes and quagmires; and the Campagna di Roma, that formerly contained a milion of inhabitants, would afford, at present, of itself, but a miserable subsistence to about tive bundred. Noiwithstanding this, the pope is a considerable tempora. prince ; and it is supposed that his annual revenue, notwithstanding the great diminution it has suffered of late years, may be still estimated at about 1,300,000 dollars.

Modern Rome, which stands on the Campus Martius, \&c. is thirteen miles in circumference; and contained in 1797, 163,000 inhabitants. Within its circuit there is a vast number of gardens and vineyards. It stands upon the Tiber, an incunsiderable river when compared to the Thames, and navigated by small boats, barges, and lighiters. The castle of Si. Angelo, though its chief fortress, would be found to be of small strength, were it regularly besieged. The city, standing upon the ruins of ancient Rome, lies much higher, so that it is difficult to distinguish the seven hills on which it was originaliy built: When we consider Rome as it now stands, there is the strongest reason to believe that it exceeds ancient Rome itself in the magnificence of its structure. Nothing in the old city, when mistress of the worid, could come in competition with St. Peter's church; and periaps many other churches in Rome exceed, in beauty of architecture, and value of materials, utensils, and furniture, her ancient temples; tnough it must be acknowledged that the Pantheon must have been an amazing structure. No city, however, in its general appearance, can unite more magnificence and poverty than this, as adjoining the most superb palaces we see the meanest habitations: and temples, the boasted ornaments of antiquity, choked up by sheds and cottages. From the drawings of this city Mr. Watkins expected to see the streets at least as broad as in London, but was disappointed. Il Corso, the principal and most admired, is but little wider than St. Martin's lane ; but this mode of building their streets so narrow, is done with a view of intercepting, as much as possible, the sun's heat. The inhabitants of Rome, in 1714, amounted to 143,000.

The cities of Bologna, Ferrara, Ravenna, and Rimini, formerly a part of the papal territory, are included in the kingdom of Italy. Ancona, situate on the Adriatic, is a place of considerable trade, and contains about 20,000 inhabitants. It was made a free port by Clemest XII, who formed a mole on the ruins of the ancient one, raised by the emperor Trajan, above 2000 feet in length, 100 in breadth, and about 60 in depth, from the surface of the sea. Near this stands the triumphal arch of Trajan, which, next to the Maison Quarrée, at Nismes, is the most entire monument of Roman magnificence existing. Urbino, the capital of the legation of that name, is famous for being the native city of the celebrated painter Raphael. Sinigaglia, in the same legation, has about 12,000 inhabilants. The rest of the ecciesiastical state contains many towns cclebrated in ancient history, and even now exhibiting the most striking vestiges of their flourishing state about the beginning of the 16th century; but they are at present little better than desolate, though here and there a luxurious magnificent church and convent may be found, which is supported by the toil and sweat of the ineighbouring peasants. Loretto, in the mean time, an obscure spot, never thought or heard of in times of antiquity, became the admiration of the world, for the riches it contained, and the prodigious resort to it of pilgrims, and other devotees, from a notion industriously propagated by the Romish clergy, that the house 
in which the Virgin Mary is said to have dwelt at Nazareth, was carried thither through the air by angels, attended with many other miraculous circumstances, such as that all the trees, on the arrival of the sacred mansion, bowed with the profoundest reverence; and great care was taken to prevent any bits of the materials of this house from being carried to other places and exposed as relics, to the prejudice of Loretto. The image of the Virgin Mary, and of the divine intant, are of cedar, placed in a small apartment, separated from the others by a silver balustrade, which had a gate of the same metal. It is impossible to describe the gold chains, the rings and jewels, emeralds, pearls, and rubies, wherewith this image was loaded; and the angels of solid gold, who were here placed on every side, were equally enriched with the most precious diamonds. To the superstition of the Roman-catholic princes Loretto was indebted for this mass of trtasure. But on the approach of the French army, after the invasion of the papal state, this treasure was privately witidrawn, and invaders found little to gratify their rapacity : indeed it was before very generally supposed that the real gold and jeweis had long since been carried away, and metals and stones of less value substituted in their place.

There is nothing very particular in the pope's temporal government at Rome. Like other princes, he has guards, or sbirri, who take care of the peace of the city, under proper magistrates, both ecclesiastical and civil. The Campagna di Roma, which contains Rome, is under the inspection of his holiness. In the other provinces he governs by legates and vice-legates. He monopolises all the corn in his territories, and has always a sufficient number of troops on foot, under proper officers, to keep the provinces in awe.*

The king of Naples and Sicily, tor, as he was more properly called, the king of the 'Two Sicilies (the name of Sicily being common to both) was formerly possessed of the largest dominions of any prince in Italy, as they comprehended the ancient countries of Samnium, Campania, Apulia, Magna-Græcia, and the island of Sicily, containing in all, about 32,000 square miles. They are bounded on all sides by the Mediterranean and the Adriatic, except on the north-east, where Naples terminates on the Ecclesiastical State. The Apennine runs through it from north to south; and its surface is estimated at 35,000 square leagues. The air is hot, and the soil fruitful of every thing produced in Italy. The wines called Vino Greco, and Lacryma Christi, are excellent. The city of Naples, its capital, which is extremely superb, and adorned with all the profusion of art and riches, and its neighbourhood, would be one of the most delightful places in Europe to live in, were it not for their vicinity to the volcano of Vesuvius, which sometimes threatens the city with destruction, and the soil being pestered with insects and reptiles, some of which are venomous. The houses in Naples are inadequate to the population, but in general are five or six stories in height, and flat at the top; 'on which are placed numbers of flower vases, or fruit-trees in boxes

- Gregory Barnabas Chiaramonti, the present pope, who has assumed the name of Pins Vil, was born at Cesena, August 14, 1742, and elected pope at Venice, March 13, 1800.

f Ferdinand IV, king of the Two Sicilies, third son of his late catholic majesty, the kir: $\mathrm{g}$ of Spain, born January 12, 1751, ascended the throne October 5, 1759; and married, April 7,1768 , to the archduchess Maria-Carolina.Louisa, sister to the late emperor. 
of earti, producing a very gay and agreeable effect. Some of the streets are very irandsome: no street in Ronie equals in beauty the Surada di Toledo, at Naples; and still less can any of them be compared with those beautiful streets that lie open to the bay. The richest and most commodious convents in Europe, both for male and femalc rotaries, are in this city; the most fertile and beautiful hills of the environs are covered with them : and a sma!l part of their revenue is spent in feeding the poor, the monks distriuuting bread and soup to a certain number every day before the doors of the convents.

This country now forms two separate kingdoms; Ferdinand IV, having been driven to Sicily by the French in 1805, and Joseph Bona. parte placed on the throne of Naples. In 1808, Bonaparte ordered his brother from Naples to Spain, and gave the former to Murat, one of his tavourite generals. Murat, by timely deserting the cause of his master, made his peace with the allies, and thus secured his kingdom. The king of Sicily still, however, asserts his claim to Napies.

Though above two-thirds of the property of the kingdom of $\mathrm{Na}$ ples are in the hands of the ecclesiastics, the protestants live here with great freedom. The present revenues of the king amount to about 10,000,000 dollars a year. The exports of the kingdom are le. gumes, hemp, aniseeds, wool, oil, wine, cheese, fish, honey, wax, manna, saffron, gums, capers, macaroni, salt, pot-ash, flax, cotton, silk, and divers manufactures. The king has a numerous but generally poor nobility, consisting of princes, clukes, marquises, and other high-sounding titles; and his capital, by far the most populous in Italy, contains 412,000 inhabitants. Among these there are 40,000 lazaroni, the greater part of whom have no dwelling-houses, but sleep every night in summer under porticoes, piazzas, or any kind of shelter they can find, and in the winter, or rainy time of the year, which lasts several weeks, the rain falling in torrents, they resort to the caverns under Capo di Monte, where they sleep in crowds like sheep in a penfold. Those of them who have wives and children, live in the suburbs of Naples, near Posilippo, in huts, or in caverns, or chambers dug out of that mountain. Some gain a livelihood by fishing, others by carrying burdens to and from the shipping; many waik about the streets ready to run on errands, or to perform any labour in their power for a very small recompence. As they do not meet with constant employment, their wages are not sufficient for their maintenance : but the deficiency is in some degree supplied by the soup and bread which are distributed at the doors of the convents.

But though there is so much poverty among the lower people, there is a great appearance of wealth among some of the great. The Neapolitan nobility are excessively fond of show and splendor. This ap. pears in the brilliancy of their equipages, the number of their attenc. ants, the richness of their dress, and the grandeur of their titles. According to a late traveller ( $\mathrm{Mr}$. Swinburne) luxury of late has advanced with gigantic strides in Naples. Forty years ago the Neapolitan ladies wore nets and ribbons on their heads, as the Spanish wo. men do to this day, and not twenty of them were possessed of a cap : but hair plainly drest is a mode now confined to the lowest order of inhabitants, and all distinction of dress between the wife of a noble. man and that of a citizen is entirely laid aside. Expence and extra. vagance are here in the extreme. 
Through every spot of the kingdom of Naples the traveller may be said to tread on classic ground, and no country presents the eye with more beautiful prospects. There are still traces of the mediorable town of Cannæ, as tragments of altars, corn ces, grates, walls, vaults, and under ground granaries; and the scene of action between Hannibal and the Romans is still marked out to posterity, by the name of nezzo di sangue, "fieid of biood." Taranto, a city that was once the rival of Rome, is now remarkable for little else than its fisheries. Sorento is a town placed on the brink of steep rocks, that overhang the bay, and, of all the places in the kingdom, has the most delightful climate. Nola, once famous for its ampinitieatre, and as the place where Augustus Cæsar died, is now hardly worth observaion.

Brundusium, now Brindisi, was the great supplier of oysters for the Roman tables. It has a fine port, but the buidings are poor and ruinous; and the fall of the Grecian empire untor the Turks leduced it to a state of inactivity and poverty, from which it has not yet emerged. Except Rome, no city can boast of so maily remains of ancient sculpture as Benevento: here the arch of Trajan, one of the most magnificent remains of Roman grandeur, out of Rome, erected in the year 114, is still in tolerable preservation. Reggio contains nothing remarkable but a Gothic cathedral. It was destroyed by an earthquake before the Morsian war, and rebuilt by Julius Cæsar: part of the wall still remairs, and was much damaged by the carthquake in 1783, but uot destroyed : only 126 persons lost their lives, out of 16,000 inhabitants. The ancient city of Oppido was ensirely ruined by that earthquake, the greatest force of which seerns to have been exerted near that spot, and at Casal Nuova, and To $\mathbf{T}$ ra Nuova. From 'Trupea to Squillace, most of the towus and villayes were either totally or in part overthrown, and many of the inhabitants buried in the ruins.

Sicily, once the granary of the world for corn, still continues to supply Naples, and other parts, with that commodity ; but its cultivation, and consequently, fertility, is greatly diminished. Its vegetable, mineral, and animal productions, are pretty much the same with those of Italy.

Both the ancients and moderns have maintained that Sicily was originally joined to the continent of Italy, but gradually separaterl from it by the encroachments of the sea, and the shocks of earthquakes, so as to become a perfect island. The climate of Sicily is so hot, that even in the beginning of January the shade is refreshing: and chilling winds are only felt a few days in March, and then a small fire is sufficient to banish the cold. The only appearance of winter is found towards the summit of Mount $\mathbb{E}$ tna, where snow falls, which the inhabitants have a contrivance for preserving. Churches, convents, and religious foundations are extremely numerous here: the buildings are handsome, and the revenues considerable. If this island were better cultivated, it would, in many respects, be a delightful place of residence. There are a great number of fine remains of antiquity here. Some parts of this island are remarkable for the beauty of the female inhabitants. Palermo, the capital of Sicily, is computed to contain 120,000 inhabitants. The two principal streets, and which cross each other, are very fine. This is said to be the only town in all Italy which is lighted at night at the public expence. It carries on - a considerable trade; as also did Messina, which, before the earth. 
quake in 1783, was a large and well-built city, containing many churches and convents, generally elegant structures. By that earthquake a great part of the iower district of the city and of the port was destroyed, and consiclerable damage clone to the lofty uniform build. ings called the Palazzata, in the shape of a crescent; but the force of the eartinquake, though violent, was nothing at Messina or Rcgeio, to what it was in the plain; for of 30,000 , the supposed population of the city, only 700 are said to have perishcd. "The greatest mortality fell upon those towns and countries situated in the plain of Calabria Uiteriore, on the western side of the mountains Dejo, Sacro, and Caulone. At Casal Nuova, the princess Gerace, and upwards of 4000 of the inhabitants, lost their lives; at Bagnara, the number of dead amounted to 3017 : Paclicina and Palmi count their loss at about 3000 each; Terra Nuova about 1400; Seminari still more. The sum total of the mortality in both Calabrias and in Sicily, by the earthquakes alone, according to the returns in the secretary of state's office at Naples, was 32,367 ;" but sir William Hamilton says, he has good reason to believe, that, including strangers, the number of lives lost must have becn considerably greater; 40,000 at least may be allowed, he believes, without exaggeration.

The inhabitants of Sicily, under the auspicies of Great Britain, have lately changed their form of government, from an absolute, to a limited monarchy. Thc executive powcr is vcsted in the king and his ministers; and the legislative in two houses of parliament, the lords and conımons. The clergy have a seat in the former.

The island of SARDinia, which gives a royal title to the duke of $\mathrm{Sa}$ voy, lies about 150 miles south by west of Leghorn, and has seven cities or towns. Its capital, Cagliari, is a university, an archbishopric, and the seat of the viceroy, containing about 50,000 inhabitants. His Sardinian majesty's revenues, from this island, are estimated at about 8100,000 a year. It yields plenty of corn and wine, and has a coral fishery. Its air is bad, from its marshes and high mountains on the north, and therefore was a place of exile for the Romans. It was formerly annexed to the crown of Spain, but at the peace of Utrecht was given to the emperor, and in 1719 to the house of Savoy.*

The island of Corsica lies opposite to the Genoese continent, between the gulf of Genoa and the island of Sardinia, and is bette: known by the noble stand which the inhabitants made for their liberty against their Genoese tyrants, and afterwards against the base and ungenerous efforts of the French, to enslave them, than from any advantages they enjoy from nature or situation. Though mountainous and woody, it produces corn, wine, figs, almonds, chesnuts, olives, and other fruits. It has also some cattle and horses, and is plentifully supplied, both by sea and rivers, with fish. The inhabitants amount to above 18\%,000. Bastia, the capital is a place of some strength; though other towns of the island that were in possession of the malcontents appear to have been but poorly fortified.

In the year 1794 it was taken by the English, and annexed to the crown of England. A constitution was framed for it, a viceroy appointed, and a parliament assembled. But it has since been retaken by, and still remains in the possession of, the French.

* Emanuel V, king of Sardinia, born July 24, 1759; married April 21, 1789, to Maria-Theresa, daughter of Ferdinand, archduke of Austria; succeeded his brother (Emanuel IV, born May 24, 1751) by cession July 4, 1802: 
Capri, the ancient CAPREA, is an island to which Augustus Cass? often came for his healthi and recreation, and which Tiberius made a scene of the most infamous pieasures. It lies tin ree Italian miles from that part of the main land winich projects farthest into the sca. It éx sends four miles in length from east to west, and about one in breadth. The western part is, for about two miles, a continued rock, very high, and inaccessible next the sea; yet Ano Capri, the largest town of the island, is situated here; and in this part are several places covered with a very fruitful soil. The eastern end of the island also rises up in precipices that are nearly as high, though not quite so long, as the western. Between the rocky mountains, at each end, is a slip of lowor ground that runs across the island, and is one of the pleasantest spots that can easily be conceived. It is covered with myrties, olives, almonds, oranges, figs, vineyards, and corn fields, which look extremely fresh and beautiful, and afford a most delightful little lanciscape, when viewed from the tops of the neighbouring mountains. Here is situated the town of Caprea, two or three convents, and the bishop's palace. In the midst of the fertile tract rises a hill, which in the reign of Tiberius was probably covered with buildings, some remains of which are still to be seen. But the most considerable ruins are at the extremity of the eastern promontory.

From this place there is a very noble prospect; on one side of it the sea extends further than the eye can reach; just opposite is the green promontory of Sarentum, and on the other sicie the bay of Naples.

IschrA, and some other islands on the coasts of Naples and Italy, have nothing to distinguish them but the ruins of their antiquities, and their being now beautiful summer retreats for their owners. Eiba has been renowned for its mines from a period beyond the reach of history. Virgil and Aristotle mention it. Its situation is about ten miles south-west from Tuscany, and it is 80 miles in circumference, containing near 7000 inhabitants. It was divided between the king of Naples, to whom Porto Longone belongs, the great duke of Tuscany, who was master of Porto Ferraio, and the prince of Piombino. The fruits and wine of the island are very good, and the tunnery, fisheries, and salt, produce a good revenue. It is now the residence of Napoleon Bonaparte, late emperor of France and king of Italy, and is all that remains to one, who was, but lately, the most powerful monarch of the world.

LIPARI IsLands.... These islands lie to the north of Sicily, and were anciently called the Eolian islands. They are twelve in number, viz. Lipari, Stromboli, Vulcano, Saline, Felicuda, Alicuda, Panaria, Vulcanello, Basiluzzo, Lisca Bianca, Dattolo, and Fila Navi. They are subject to the king of Sicily, and produce great quantities of alum, sulphur, nitre, cinnabar, and most kinds of fruits, particularly raisins, currants, and figs, in great perfection. Some of their wines are much esteemed, especially the Malvasia or Malmsey. Great quantities of pumice are exported from Lipari. All these islands are of volcanic origin, and Stromboli has a considerable volcano, which is remarkable for being continually in a state of eruption. The number of inhabitants in Eipari amounts to between 9 and 10,000, and those of Stromboli to about 1000; but Vulcano is uninhabited, and several of the other. islands are little more than barren rocks.

We shall here mention the isle of MALTA, though it is not properly sanked with the Italian islands. It was formerly called Melita, and is situated in 15 degrees E. long. and 36 degrees $N$. lat. 60 miles south 
of Cape Passaro in Sicily. It is of an oval figure, 20 miles long, and 12 broad. The air is clear, but excessively hot: the whole island seems to be a white rock, covered with a thin surface of earth, which is however amazingly productive of excellent fruits and vegetables. This island, or rather rock, was given to the knights of St. John of Jerusalem, in 1530, by the emperor Charles V, when the Turks drove them out of Rhodes, under the tender of one falcon yearly to the viceroy of Sicily, and to acknowledge the kings of Spain and Sicily for their protectors. They are under vows of celibacy, chastity, and perpetual war with the infidels, and are governed by a grand-master who is elected for life. The knights were required to be of noble birth, both in the paternal and maternal line, for four descents. They are divided into what are called languages according to the countries from which they come. These languages are eight in number, viz. those of Provence, Auvergne, France, Italy, Arragon, Germany, Castile, and England, succeeded by the Anglo-Bavarian language. The number of knights is unlimited. The badge of the order is a white cross, with eight points, worn on the left side.

The principal city of Malta is Valetta; founded by the grand-master, La Valette, in 1566, after the raising of the siege of Malta by the Turks. It is perhaps one of the strongest fortresses in the world, and the whole island is strongly fortified wherever a landing is practicable. The former residence of the knights was called II Borgo, the Burgh, and after its súccessful resistance of the Turks, Citta Vittoriosa (the victorious city.) The ancient capital was Citta Vecchia, or the Old City, called likewise Citta Notabile, built on the highest ground and nearly in the centre of the island. A cliannel about five miles in width, in the middle of which is the small island of Comirio, separates Malta from the island of Goza or Gozza, which is about twelve miles long and six broad. Malta is divided into 24 casals or districts, and Goza into six. The population of these two islands is greater, in proportion to their extent, than that of any country in Europe; Malta, containing 75,000 inhabitants, Gozza 12,000, and Comino 600.-Total 87,600 .

The island of Malta was surprised and seized by the French under Bonaparte, in his way to Egypt, in the year 1798, and after a long blockade, taken by the English in 1800, by whom it is still retained. The knights have left the island, and a number of them have established the seat of the order in Calabria, under the grand-master Tomasi, elected principally by the French interest.

ARMS AND ORDERS.... The pope, as sovereign prince over the territory of the church, bears for his escutcheon, gules, consisting of a long head cape, or, surmounted with a cross, pearled and garnished with three royal crowns, together with the two keys of St. Peter, placed in saltier. The arms of 'Tuscany, or, five roundles, gules, two two, and one, and one in chief, azure, charged with three fleurs-de-lis, or. Those of Venice, azure, a lion winged, sejant, 'or, holding under one of his paws a book covered, argent. Tilose of Genoa, argent, a cross, gules, with a crown closed for the island of Corsica; and for supporters two griffins, or. The arms of Naples are, azure, semée of feur-de-lis, or, with a label of five points, gules.

The " order of St. Januarius" was instituted by the late king of Spsin when king of Naples, in July, 1738. The number of knights is limited to thirty, and the sovereignty of the order is possessed by

Vol. I. $4 \mathrm{~F}$ 
the king of Naples. All the knights must prove the nobility of their descent for four centuries, and are to be addressed by the title of excellency. St. Januarius, the celebrated patron of Naples, is the patron of this order. The "order of Annunciation" was instituted in the year 1355, by Amadeus V, count of Savoy, in memory of Amadeus I, who bravely defended Rriodes against the Turks, and won those arms which are now borne by the dukes of Savoy: " gules, a cross argent." It is counted among the most respectable orders in Europe: the knight must be of a noble family, but also a catholic. In the year 1572, Emanuel Philibert, duke of Savoy, instituted the "order of St. Lazarus," and revived and united to it the obsolete order of St. Maurice; which was confirmed by the pope, on condition of maintaining Ewo gallies against the Turks.

In the year 828, it is pretended that the body of St. Mark was removed from Alexandria, in Egypt, to Venice. Accordingly, this saint was taken for their tutelar saint and guardian, and his picture was formerly painted on their ensigns and banners. When the "order of St. Mark" was first instituted is uncertain, but it was an honour conferred by the doge or duke of Venice and the senate, on persons of eminent quality, or who had done some signal service to the republic. The knights, when made, if present, were dubbed with a sword on their shoulders, the duke saying "Esto miles fidelis" (be a faithful soldier.) Absent persons were invested by letters patent; but their title, "Knights of St. Mark," is merely honorary : they have no revenue, nor are they under any obligations by vows as other orders. About the year 1460, Frederick III, emperor of Germany, instituted the " order of St. George," and dedicated it to St. George, tutelar saint and patron of Genoa. The doge was perpetual grand-master. The badge, a plain cross enamelled, gules, pendent to a gold chain, and worn about their necks. The cross is also embroidered on their cloaks. In the year 1561, Casimir of Medicis, first grand duke of Tuscany, instituted the " order of St. Stephen," in memory of a victory which secured to him the sovereignty of that province. He and his successors were to be grand-masters. The knights are allowed to marry, and their two principal conventual houses are at Pisa. It is a religious as well as military order, but the knights of justice and the ecclesiastics are obliged to make proof of nobility of four descents. They wear a red cross with right angles, orled or, on the left side of their habit, and on their mantle.

The " order of the Holy Ghost" was founded with their chief seat, the hospital of that name in Rome, by pope Innocent III, about the year 1198. They have a grand-master, and profess obedience, chastity, and poverty. Their revenue is estimated at 24,000 ducats daily, with which they entertain strangers, relieve the poor, and train up deserted children, \&xc. Their ensign is a white patriarchal cross with twelve points, sewed on their breast on the left side of a black mantle. The "order of Jesus Christ," instituted by pope John XXII, was reformed and improved by pope Paul $\mathrm{V}$. The reigning pope was to be always sovereign of it, and it was designed as a mark of distinction for the pope's Italian nobility; but on account of its frequent prostitution, it has fallen into discredit. The " order of the Golden Spur" is said to have been instituted by pope Pius IV, 1559, and to have been connected with the "order of Pius," instituted a year afterwards; but the badges were different. The knights of Pius are suppressed, and all that the knights of the Golden Spur have preserved to themselves, 
is the title of counts of the sacred palace of the Lateran. The badge is a star of eight points, white, and between the two bottom points a spur, gold.

Histor y....Italy was probably first peopled from Greece, as has been mentioned in the Introduction; to which we refer the reader for the ancient history of this country, which, for many ages, gave law to the then known world, under the Romans.

The empire of Charlemagne, who died in 814 , soon experienced the same fate with that of Alexander. Under his successors it was in a short time entirely dismembered. His son, Louis the Dobonair, succeeded to his dominions in France and Germany, while Bernard, the grandson of Charlemagne, reigned over Italy and the adjacent Islands. But Bernard having lost his life by the cruelty of his uncle, against whom he had levied war, and Louis himself dying in 840 , his dominions were divided among his sons Lothario, Louis, and Charles. Lothario, with the title of emperor, retained Italy, Provence, and the fertile countries situated between the Saone and the Rhine; Louis had Germany; and France fell to the share of Charles, the youngest of the three brothers. Shortly after this, Italy was ravaged by different contending tyrants; but, in 964 , Otho the Great re-united Italy to the imperial dominions. Italy afterwards suffered much by the contests between the popes and the emperors; it was harassed by wars and internal divisons, and at length various principalities and states were erected under different heads.

Savoy and Piedmont, in time, fell to the lots of the counts of Maurienne, the ancestors of his present Sardinian majesty, Victor Amadeus II, becoming king of Sardinia in virtue of the quadruple alliance concluded in 1718 .

The great duchy of Tuscany belonged to the emperor of Germany, who governed it by deputies to the year 1240 , when the famous distinctions of the Guelphs, who were the partisans of the pope, and the Gibellines, who were in the emperor's interest, took place. The popes then persuaded the imperial governors in Tuscany to put themselves under the protection of the church; but the Florentines in a short time formed themselves into a free commonwealth, and bravely defended their liberties against both parties by turns. Faction at last shook their freedom; and the family of Medici, long before they were declared either princes or dukes, in fact governed Florence, though the rights and privileges of the people seemed still to exist. The Medici, particularly Cosmo, who was deservedly called the Father of his country, being in the secret, shared with the Venetians in the immense profits of the East-India trade, before the discoveries made by the Portuguese. His revenue in ready money, which exceeded that of any sovereign prince in Europe, enabled his successors to rise to sovereign power; and pope Pius V, gave one of his descendants (Cosmo, the great patron of the arts) the title of great-duke of Tuscany in 1570 , which continued in his family to the death of Gaston de Medicis, in 1757, without issue. The great duchy was then claimed by the emperor Charles VI, as a fief of the empire, and given to his son-in-law, the duke of Lorrain (afterwards emperor, and father of Joseph II,) in lieu of the duchy of Lorrain, which was ceded to France by treaty. Leopold, his second son (brother and successor to the emperor Joseph II, ) upon the death of his father, became grand duke. When he succeeded to the imperial crown, his son Ferdinand entered upon the sopereignty of the grand duchy of 
Tuscany, which the French afterwards gave under the title of the kinguon of Eiruria, to the sun of the duke of Parma. As an indemnification the grand-auke recenved the tiectorate of Salzburg.

No country has undergone greater vicissitudes of goverument than Naples or Sicily, chiefly owing to the inconstancy of the natives. Chris:ians and Saracens by turns con juered it. The Normans under Tancred drove out the Saracens, and, by their connexions with the Greeks, established there, while the rest of Europe was plunged in monkish ignorance, a most respectable mollarchy, flourishing in arts and arms. About the year 1166, the popes being then all-powerful in Europe, their intrigues broke into tise succession of the line of Tancred, and Naples and Sicily at last came into the possession of the French; and the house of Anjou, with some interruptions and tragical revolutions, held it till the Spaniards arove them out in 1504, when it was annexed to the crown of Spain.

The government of the Spaniards under the Austrian line was so oppressive, that it gave rise to the famous revolt, headed by Massanicllo, a youing fisherman, in the year 1647 . His success was so surprising, that he obliged the haughty Spaniards to abolish the oppressive taxes, and to confirm the liberties of the people. Before these could be re-established perfectly, he became delirious, through his continual agitations of body and mind, and he was put to death at the head of his own mob. Naples and Sicily continued with the Spaniards till the year 17v0, when the extinction of the Austrian line opened a new scene of litigation. In 1706, the archduke Charles, alterwards emperor, took possession of the kingdom. By virtue of various treaties, which had introduced Don Carlos, the king of Spain's son, to the possession of Parma and Placentia, a new war broke out in 1733, between the houses of Austria and Bourbon, about the possession of Naples; and Don Carlos was received into the capital, where he was proclaimed king of both Sicilies : this was followed by a very bloody campaign; but the farther effusion of blood was stopt by a peace between France and the emperor, to which the courts of Madrid and Naples at first demurred, but afterwards acceded in 1736 , and Don Carlos remained king of Naples. Upon his accession to the throne of Spain, in 1759 , it being founcl, by the inspection of physicians and other trials, that his eldest son was by nature incapacitated for reigning, and his second being heir-apparent to the Spanish monarch, he resigned the crown of Naples to his third son, Ferdinand IV, the present sovereign of Sicily, who married an archduchess of Austria. The present king of Naples is Joachim Murat, brother-in-law to Bonaparte. He is a man of low extraction, but of considerable military talents.

The Milanese, the fairest portion of Italy, went through several hands: the Vicontis were succeeded by the Galeazzos and the Sforzas; but fell at last under the power of the emperor Charles V, about the year 1527, who gave it to his son, Philip II, king of Spain. It remained with that crown till the French were driven out of Italy, in 170s, by the imperialists. They were clispossessed of it in 1745 ; but by the emperor's cession of Naples and Sicily to the present king of Spain, it returned to the house of Austria, who governed it by a viceroy, till the conquest of it by the French, and the establishment of the new kingdom of Italy, of which it formed the principal part. It has now again reverted to Austria.

The duchy of Mantua was formerly governed by the family of 
Gonzaga, who, adhering to France, the territory was forfeited, as a fiel of the empire, to the house of Austria. Guastalia was separated from it in 1748 , and made part of the duchy of Parma.

The firsi duke of Parna was natural son to pope Paul III, the duchy having been annexed to the holy see in 1545, by pope Julius I1. The descendants of the house of Farnese terminated in the late queen-dowayer of Spain, whose son, Cnarles IV, obtained the duchy, and his nepuew neld it, witu the duchy of Placentia, till his death in 18u3, wreu it was occupied by the French. It is now, with Placentia, in ine possessıon of Maria-Louisa, archduchess of Austria, and late enupress of France.

The Venetians were formerly the most formidable marine power in Europe. In 1194 they conquered Constantinople itself, and held it: for some time, together with great part of the continent of Europe and Asia They were more than once brought to the brink of destruction by the confederacies formed against them among the other powurs ot Europe, especiaily by the league of Cambray in 1509, but were as often saved by the disunion of the confederates. The discovery of a passage to India, by the Cape of Good Hope, gave the first blow to tieir greatness, as it lost them the Indian trade. By degrees the Turks took from them their most valuable possessions on the cultinent; and so late as the year 1715 they lost the Morea. In 1797 the French seized upon the city of Venice, abolished its government, and soon after ceded it by treaty to the emperur, with a considerable part of its continental territory.

The Genoese for some time disputed the empire of the Mediterranean sea with the Venetians, but were seldom or never able to maintain their own indeperdency by land, being generally protected, and sometimes subjected, by the French and imperialists. Their doge, or first magistrate, used to be crowned king of Corsica, though it does not clearly appear by what title. The successful effort they made in driving the victorious Austrians out of their capital, during the war, which was terminated by the peace of Aix-la-Chapelle, in 1718 , has few parallels in history, and serves to show the effect of despair under oppression.

'The history of the papacy is connected with that of Christendom itself. The most solid foundations for its temporal power were laid by the famous Matilda, countess of 'Tuscany, and heiress of the greatest part of Italy, who bequeathed a large portion of her dominions to the famous pope Gregory VII, (who, before his accession in 1073 , was so well known by the name of Hildebrand.) It would be too tedious here to enter into a detail of the ignorance of the laity, and the other causes that operated to the aggrandisement of the papacy, previous to the reformation. Even since that æra, the state of Europe has been such, that the popes liave had mole than once great weight in its public affairs, chiefly through.the weakness and bigotry of temporal princes.

The papal power is evidently now nearly extinct. Even before the present times, when innovation and revolution have made such rapid strices, the pope was treated by Roman-catholic princes with very little more ceremony than is due to him as bishop of Rome, and possessed of a temporal principality. The late pope Pius VI, though he acted with considerable caution and moderation, co-operated with the allied powersagainst France: in consequence of which, the French made an incursion into his territories, where they met with 
little resistance, and compelled him to sign a peace on such terms as they thought proper to dictate. He paid a considerable contribu. tion in money; and consented that such of the most valuable statues and pictures in Rome, as commissioners appointed for that purpose should select, should be carried away, and conveyed to Paris. But about the latter end of December, 1797, a riot happening at Rome, in which the French general Duphot was killed, the French army under general Berthier, marched against that city, entered it without resistance, and, on the 15th of February, 1798, the tree of liberty was planted, the papal government abolished, and the Roman people declared by the French commander to have entered on the rights of sovereignty, and to constitute what was termed the Roman republic. On the 20th of March the new constitution was published, and the government declared to be vested in five consuls, composing a directory under the direction of the French general as commander in chief, 32 senators, corresponding to the council of ancients in France, and 72 tribunes, called the representatives of the people.

The pope remained in Rome when the French entered it, and suffered himself to be made a prisoner by them. They confined him to his own rooms, and put the seal of confiscation on every thing he had; but in a few days they resolved that he should be sent from Rome, and on the morning of the 20th of February he left that city, accompanied by a body of French cavalry, who escorted him to Sienna in Tuscany; whence, on the 26th of May, he was removed to a Carthusian convent within two miles of Florence ; from which, after the recommencement of hostilities with the allies, he was again removed to Grenoble and Valence in France, at which latter town he died on the 19th of August, 1799. In the beginning of December a conclave was held at Venice, and, on the 13th of March following, cardinal Chiaramonti was elected to the papal chair.

In November, 1798, the king of Naples commenced hostilities against the French, attacked the new Roman republic, and entered Rome in triumph. But this success was quickly followed by a fatal reverse. The French collecting their forces, not only soon regained Rome, but totally defeated the Neapolitan army, made themselves masters of the city of Naples, and compelled its sovereign to take refuge in the island of Sicily. The successes which attended the arms of the Austrians and Russians in the campaign of 1799, aided by the powerful co-operation of the English fleet under lord Nelson, however, again expelled the French both from Naples, and Rome, and the king of the two Sicilies returned to his capital. But the victory of Bonaparte at Marengo, and the conditions of the peace of Zuneville, which the emperor of Germany was compelled to conclude, again gave the French a power in Italy, against which neither the pope nor the king of Naples were able to contend. The former having been sent for by the new emperor of France, solemnly crowned him at Paris; and in the kingdom of Naples 15,000 French troops were stationed.

The pope has now, by the general treaty of Paris, been restored to Bis temporal dominions, but his power is there limited, and he is no Donger dreaded or courted, by the surrounding nations. 


\section{TURKEX.}

THR GRAND SEIONOR'S DOMLAIONS ARE DIVIDRD INTA

1. TURKEY IN EUROPE.

$\left.\begin{array}{l}\text { 3. TURKEY IN ASIA. } \\ \text { 3. TURKEY IN AFRICA. }\end{array}\right\} 790,560$ Square Miless.

\section{TURKEY IN EUROPE.}

\section{SITUATION AND EXTENT.}

$\left.\begin{array}{l}\text { Miles. } \\ \text { Bength } 910 \\ \text { Breadth } 760\end{array}\right\}$ between $\left\{\begin{array}{l}\text { Degrees. } \\ 36 \text { and } 49 \text { North latitude, } \\ 16 \text { and } 32 \text { East longitude. }\end{array}\right.$

Containing 182,560 square miles, with 45 inhabitants to each.

NAME....This extensive empire derives its name from that of its conquerors and possessors, the Turks, or Turkmans, which word, 2ccording to some writers, signifies quanderers. The Turkish historio ans, derive this name from that of Turk, who they say was their ancestor, and the son of Yafis or Japhet.

Bocndaries....Turkey in Europe is bounded by Russia, the Buckovina, Traissylvania, and Sclavonia, on the north ; by Circassia, the Biack Se', the Propontis, Hellespont, and Archipelago, on the East; by the Mediterranean on the South; by the same sea, and the Aus. trian terriories, on the West.

Divisrows.... The following are the provinces into which it is divided.

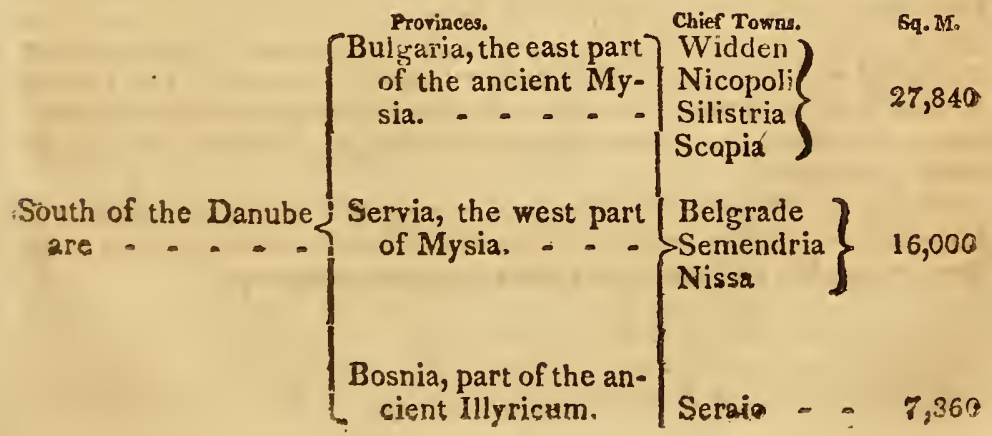




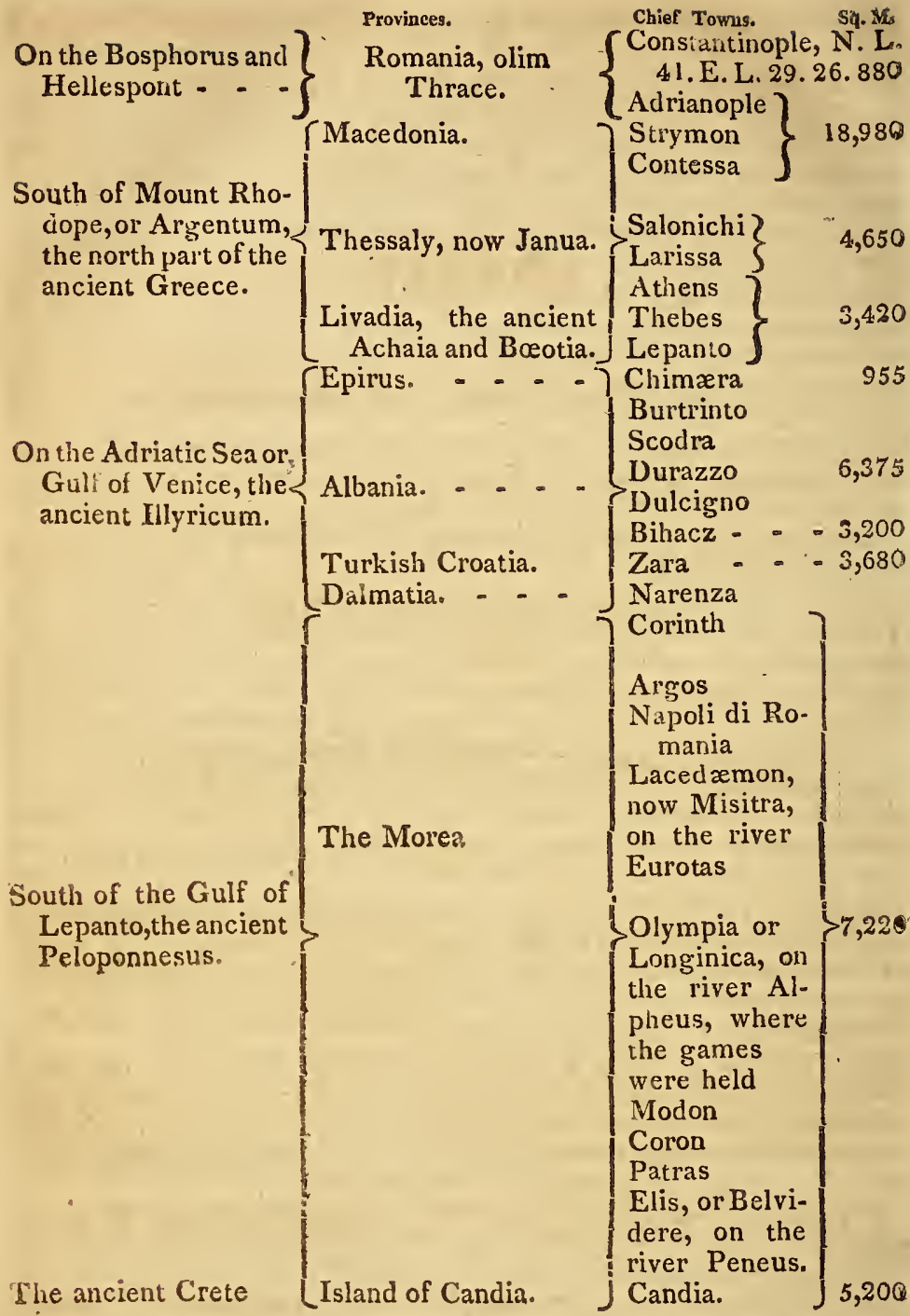

Seas and straits....The Euxine, or Black Sea; the Palus Mæötis, or Sea of Asoph; the Sea of Marmora, which separates Europe from Asia; the Archipelago; the Iönean Sea, and the Levant, would, were they properly improved, give to Turkey in Europe, particularly that part of it where Constantinople stands, every advantage both for trade and dominion. The straits of the Hellespont or Dardanelles, and the Bosphorus, or canal of Constantinople, which connect the Sea of Marmora with the Archipelago on the one side, and the Black Sea on the other, are remarkable in modern as well as in ancient history. The former, viz. the Hellespont, or Dardanelles, is only two miles and a half in breadth, and is famous for the passage of Xerxes over it, when 
about to invade Greece, and of Alexander in his expedition against Asia. The former for the more easy transportation of his numerous forces, laid a bridge of boits over it. It is also celebrated by the poets in the story of two lovers, Hero and Leander, of whom, the latter swam across it to his mistress, but one night was unhappily drowned. The Bosphorus is about the same breadth, but has not been so much celcbrated by historians and poets.

Mountarns... The principal mountains of Turkey in Europe, are the chain of the ancient Hæmus, now called Emineh; Mount Athos, which stands on a peninsula, projecting into the Archipelago or Egean Sea; Olympus and Pindus, the latter now called Mezzo No. vo, which separates Thessaly from Epirus, and Parnassus in Achaia, so celebrated for being consecrated to the Muses, which still retains its ancient denomination.

LAKES... This country affords no lakes of considerahle extent; but in Albania and the Morea, are found some small ones of classical ces lebrity.

Rivers....The chief rivers of European Turkey, are the Danube, which enters the Black Sea by several channels, after having traversed the Turkish territory the extent of 400 miles; the Save; the Dncister; the Maritz or ancient Hebrus; the Vardari or ancient Axius; the Aspro Potamo, or White River, anciently the Achelous; and, in the Morea, the Rophia, the ancient Alpheus.

Metals, minerals.... Mines of iron, lead, and copper, are found in several parts of Turkey in Europe; but they are entirely neglected, from the ignorance and indolence of the Turks. In Macedonia were anciently gold-mines, which produced to Philip, the father of Alex* ancler the Great, 1000 talents, or nearly three millions sterling annually. The ancient Phrygia, and the Troad, is likewise said to be abundant in silver. Alum and sulphur, perfectly pure, are found in Greece; where also are quarries of the most, beautiful marble. The island of Paros has been in all ages celebrated for its marble of an exquisite whiteness.

Clmate, soil, AGriculture....The climate of this part of Turlscy is saluibrious. The seasons are regular and pleasant, and have been celebrated from the remotest times of antiquity. The soll, though unimproved, is luxuriant beyond description; and it is necessary that it should be so for the subsistence of the inhabitants; for of agriculture: very little is known or practised by the Turks.

VEgetable PRODUCtions....These are excellent all over the Eurapean Turkey, especrally when assisted by the smallest degree of industry. Besides pot and garden herbs of almost every kind, this country prodiuces, in great abundance and perfection, oranges, lemons, citrons, pomegranates, grapes of an uncommon sweetness, excellent figs, almonds, olives, and cotton. Besides these, many drugs, not common in other parts of Europe, are produced here.

Aximsts....The Thessalian or Turkish horses are excellent both for their beauty and service. The black cattle are large, especially in Greece. The goats are a most valuable part of the animal creation to the inhabitants, for the nutrition they afford both of milk and flesh. The large eagles which abound in the neighbourhood of Badadagi furnish the best feathers for arrows for the Turkish archers, and they sell at an uncommon price. Partridges are very plentiful in Greece; 25 are all other kirds of fowls and quadrupeds all oper Turkey in Eu-

Vก.. I. $4 \mathrm{G}$ 
rope: but the Turks and Mahometans in general are not very fond of animal food.

Natural curiosities... Among these are generally classed Mount. Athos, already mentioned, now called Monte Santo, from the numerous convents erected on it. It is situate on a peninsula which extends into the $\mathbb{E}$ gean Sea, and is indeed a chain of mountains, reaching the whole length of the peninsula, seven Turkish miles in length, and three in breadth; but it is only a single mountain that is properly called Athos. This is so lofty, that on the top, as the ancients relate, the sun-rising was beheld four hours sooner than by the inhabitants of the coast : and, at the solstice, its shade reached into the Agora, or market-place of Myrina, a town in Lemnos, which island was distant eighty-seven miles eastward. There are twenty-two convents on Mount Athos, besides a gireat number of celis and grottos, with the habitations of no less than six thousand monks and hermits; though the proper hermits, who live in grottos, are not above twenty: the other monks are anchorites, or such as live in cells. These Greek monks, who call themselves the inhabitants of the holy mountains, are so far from being a set of slothful people, that, besides their daily offices of religion, they cultivate the olive and vineyards, are carpenters, masons, stone-cutters, cloth-workers, tailors, \&c. They also live a very austere life; their usual food, instead of hesh, being vegetables, dried olives, figs, and other fruit; onions, cheese, and, on certain days (Lent excepted) fish. Their fasts are many and severe, which, with the healthfulness of the air, renders longevity so common there, that many of them live above a hundred years. It appears from Elian, that anciently the mountain in general, and particularly the sumnit, was accounted very healthy, and conducive to long life; whence the inhabitants were called Macrobii, or long-lived. IVe are farther informed by Philostratus, in the life of Apollonius, that numbers of philosophers used to retire to this mountain, for the better contemplation of the heavens and of nature ; and after their example the monks doubtless built their cells.

The cavern or grotto in the island of Antiparos, is one of the greatest natural curiosities in this country or perhaps in the world. It is above 80 yards high, and 100 wide. From the roof hang a variety of marble stalactites, of the most elegant and picturesque forms; and on the floor are large masses of stalagmite, one of which, in the centre, resembles a beautiful marble pyramid.

The famous cave of Trophonius is still a natural curiosity in Lividia, the ancient Bœotia. It is a square cavern, with a bench on each side of it, hewn out of the rock, and a round hole at one end, scarcely large enough for a man to pass through.

Population....The population of this great empire is by no means equal, either to its extent or fertility, nor is it possible to ascertain it with any great accuracy. It certainly is not so great as it was before the Christian æra, under the emperors, or even a century ago, owing to various causes, and, above all, to the tyranny under which the natives live; and their polygamy, which is undoubtedly very unfavourable to population, as may be evinced from many reasons; and particularly, because the Greeks and Armenians, among whom it is not practised, are incomparably more prolific than the Turks, notwithstanding the rigid subjection in which they are kept by the latter. The plague is another cause of depopulation. According, however, to the latest and most probable estimates, European Turkey contains 
about nine millions of inhabitants; Turkey in Asia, ten millions: and Egypt, if that country may still be considered as a part of the Turkish empire, about two millions and a half: so that the whole number of the subjects of the Ottoman sultan, is little more than twenty millions.

National character, Manners, customs... The Turks are gene. rally well made and robust men : in youth, their complexions are fair, and their faces handsome : their hair and eyes are black, or dark brown. The women, when young are commonly handsome, but they generally look old at thirty. In their demeanour, the Turks are rather hypochondriac, grave, sedate, and passive; but when agitated by passion, furious, raging, ungovernable; big with dissimulation, jealous, suspicious, and vindictive beyond conception : in matters of religion, tenacious, superstitious, and morose: Though the generality seem hardly capable of much benevolence, or even humanity, with regard to Jews, Christians, or any who differ from them in religious matters, yet they are far from being devoid of social affections for those of their own religion. But interest is there supreme god; and when that comes in competition, all ties of religion, consanguinity, or friendship, are with the generality, speedily dissolved. The morals of the Asiatic Turks are far preferable to those of the European. They are hospitable to strangers, and the vices of avarice and inhumanity reign chiefly among their great men. They are likewise said to be charitable to one another, and punctual in their dealings. Their charity and public spirit is most conspicuous in their building caravanseras, or places of entertainment, on roads that are destitute of accommodations, for the refreshment of poor pilgrims or travellers. With the same laudable view they search out the best springs, and dig wells, which in those countries are a luxury to weary travellers. The Turks sit cross-legged upon mats, not only at their meals, but in company. Their ideas are simple and confined, seldom reaching beyond the walls of their own houses, where they sit conversing with their women, drinking coffee, smoking tobacco, or chewing opium. They have little curiosity to be informed of the state of their own, or any other country. If a vizier, pasha, or other officer, be turned out, or strangled, they say no more on the occasion than that there will be a new vizier or governor, seldom inquiring into the reason of the disgrace of the former minister. They are perfect strangers to wit and agreeable conversation. They have few printed books, and seldom read any other than the Koran, and the comments upon it. Nothing is negotiated in Turkey without presents, and here justice may commonly be bought and sold.

The Turks dine about eleven o'clock in the forenoon, and sup at five in the winter, and six in the summer, and this is their principal meal. Among the great people, their dishes are served up one by one; but they have neither knife nor fork, and they are not permitted by their religion to use gold or silver spoons. Their victuals are always highly seasoned. Rice is the common food of the lower sort, and sometimes it is boiled up with gravy; but their chief dish is pilau, which is mutton and fowl boiled to rags; and the rice being boiled quite dry, the soup is high seasoned, and poured upon it. They drink water, sherbet, and coffee ; and the only debauch they know is in opium, which gives them sensations resembling those of intoxication. Guests of high rank sometimes have their beards perfumed by a female slave of the family. They are temperate and sober from a. 
principle of their religion, which forbids them the use of wine; though in private many of them indulge themselves in strong liquors. Their common salutation is by an inclination of the head, and laying their right hand on their breast. 'They sleep in linen waistcoats and drawers, upon mattresses, and cover themselves with a quilt. Few or none of the considerable inhabitants of this vast empire have any notion of walking or riding either for health or diversion. The most religious among them find, however, sufficient exercise when they conform. themselves to the frequent ablutions, prayers, and rites, prescribed. them by Mahomet.

Their active diversions consist in shooting at a mark, or tilting it with darts, at which they are very expert. Some of their great men: are fond of hunting, and take the field with numerous equipages, which are joined by their inferiors; but this is often done for political purposes, that they may know the strength of their dependents. With. in doors the chess or draught-boards are their usual amusements; and if they play at chance games, they never bet money, that being prohibited by the Koran.

Dress.... The men shave their heads, leaving a lock on the crown, and wear their beards long. They cover their heads with a turban, and never put it off but when they sleep. Their shirts are without collar or wristband, and over them they throw a long vest, which they tie with a sash, and over the vest they wear a loose gown somewhat shorter. Their breeches, or drawers, are of a piece with their stockings; and instead of shoes they wear slippers, which they put off when they enter a temple or house. They suffer no Christians, or others who are not Turks, to wear white turbans. The dress of the women difiers little from that of the men, only they wear stiffened caps upon their heads, with horns something like a mitre, and wear their hair down. When they appear abroad, they are so muffled up as not to be known by their nearest relation. Such of the women as are virtuous, make no use of paints to heighten their beauty, or to dis. grise their complexion; but they often tinge their hands and feet with benna, which gives them a deep yellow. The men make use of the same expedient to colour their beards.

Marriages....Marliages in this country are chiefly negotiated by the ladies. When the terms are agreed on, the bridegroom pays down a sum of money, a license is taken out from the cadi, or proper magistrate, and the parties are married. The bargain is celebrated, as in other nations, with mirth and jolity; and the money is generally employed in furnishing the house of the young couple. They are not allowed by their law more than four wives, but they may have as many concubines as they can maintain. The wealthy Turks, therefore, besides their wives, keep a number of women in their harams, or, as they are improperly called in Europe, their seraglios. But all these indulgences are sometimes insufficient to restrain their unnatural desires.

Funerazs...The burials of the Turks are decent. The corpse is attended by the relations, chanting passages from the Koran; and after being deposited in a mosque (for so they call their temples) it is buried in a freld by the iman, or priest, who pronounces a funeral sermon at the time of the interment. The male relations express their sorrow by alms and prayers; the women by decking the tomb en certain days with flowers and green leaves; and, in mourning for 
a husband they wear a particular head dress, and leave off all finery for cwelve months.

Tine Greeks, who compose a large portion of the inhabitants of Turkey in Europe, are gay, witty, and cunning. They exercise various trades, and appiy themselves to maritime affairs. They delight: in music and ciancmg. The rich are well informed, supple, and very intriguing. They study languages, and make evcry exertion to be $\mathrm{cm}$ pioyed as physicians, drogniaus, or interpreters, or as agents by the Turks who hold the first places of the empire. The ancient families court the honour of furnishing the first drogman to the Porte, and of being appointed hospodars, or sovereigns, of Wallachia or Moldavia, notwithstanding the danger attached to those eminent places. 'They are at the sume time in general, timid, superstitious, and exact obser: vers of fasts and lents. Their priests are very numerous, and affect austerity of manners. The superior clersy are well informed, and tolerably rich: the other ecclesiastics are poor, and very ignorant.

Cities, chief Towss, Edifices....Constantinople, the capital of this yreat empire, is situated on the European side of the Bosphorus: It was built upon the ruins of the ancient Byzantium, by the Roman emperor Constantine the Great, as a more inviting situation than Rome, for the seat of empire. It became afterwards the capital of the Greek empire; and having escaped the destructive rage of the barbarous nations, it was the greatest as well as the most beautiful. city in Europe; and the only one, during the Gothic ages, in which there remained any traces of the ancient clegance in manners and arts. While it remained in the possession of the Greek emperors, it was the only mart in Europe for the commodities of the East Indies. It derived great advantages from its being the rendezvous of the crusaders: and being then in the meridian of its glory, the European writers in the ages of the crusades, speak of it with astonishment. Constantinople is at this day one of the finest cities in the world, by its situation and its port. The prospect from it is noble. The most regular part is the Besestin, inclosed with walls and gates, where the merchants have their shops excellently ranged. In another part of the city is the Hippodrome, an oblong square of 4.00 paces by 100 , where they exercise on horsebuck. The Meidan, or parade, is a large spacious square, the general resort of all ranks. On the opposite side of the port are four towns, but considered as a part of the suburbs, their distance being so small, a person may easily be heard on the other side. They are namied Pera, Galata, Scutari, and Tophana. In Pera the foreign ambassadors and all the Franks or strangers reside, not being permitted to live in the city. Galata, also, is mostly inhabited by Franks or Jews, and is a place of great trade. The scraglio abounds with antiquities The tomb of Constantine the Great is still preserved. The mosque of St. Sophia, once a Christian church, is thought in some respects to exceed, in grandeur and architecture, St. Peter's at Rome. The city is built in a triangular form, with the seraglio standing on a point of one of the angles, from whence there is a prospect of the delightful coast of Lesser Asia, which is not to be equalled. When we speak of the seraglio, we do not mean the apartments in which the grand seignor's women are confined, as is commonly imagined, but the whole inclosure of the Ottoman palace, which might well suffice for a moderate town. The wall which surrounds the seragrlio is thirty feet high, having battlements, embrasures, ard towers, in the style of ancient fortifications. There are in 
it nine gates, but only two of them magnificent; and from one of these the Baba Hoomajun, or 'sublime gate, the Ottoman court takes the name of the Porte, or the Sublime Porte, in all public transactions and records. Both the magnitude and population of Constantinople have been greatly exaggerated by credulous travellers. It is surrounded by a high and thick wall, with battlements after the Oriental manner, and towers, defended by a lined but shallow ditch, the works of which are double on the land side. Some authors have estimated it to contain above 800,000 inhabitants, and others 600,000 ; but, according to Mr. Dallaway, they do not exceed 400,000 , including the suburbs of Galata, Pera, Tophana, and Scutari. Of these, 200,000 are Turks, 100,000 Greeks, and the remainder Jews, Armenians, and Franks of all the European nations. The city has frequently suffered great damage by fires, either owing to the narrowness of the streets and the structure of the houses, or the practices of the Janisaries, who, it is said, fire the city as often as they are discontented with the government. In $1633,70,000$ houses were burned; in 1784 a fire consumed 10,000 ; and in 1788 , there was so extensive a conflagration as to threaten the entire destruction of the city.

The seraglio, or palace of the emperor, is so extensive that it is said to occupy the whole of the ground on which the ancient city of Byzantium stood. The treasures contained within this imperial residence, are prodigious; and its furniture is distinguished not by its variety, but the richness of the materials of which it is composed: silk and cloth of gold are substituted for cotton and woollen stuffs: fringes are strung with pearl and inferior jewels, and the walls are wainscotted with jasper, mother-of-pearl, and veneered ivory. In the audience-chamber, where the ambassadors are received by the sultan in person, is a throne as resplenclant as the mines of the east can make it, with a canopy of velvet fringed with jewels, under which he sits in state for a few minutes, to hear the compliments of the sovereign who solicits his friendship.

The ladis of the seraglio are a collection of beautiful young women, chicfly sent as presents from the provinces and the Greek is. lands, most of them the children of Christian parents. The brave prince Heraclius, some years since, abolished the infamous tribute of childiren of both sexes, which Georgia formerly paid every year to the porte. The number of women in the haram depends on the taste of the reigning monarch, Sultan Selim had two thousand; Achmet had but three hundred; and the present sultan has nearly 1600 .

On their admission, they are committed to the care of old ladies, taught to sew and embroider, music, dancing, and other accomplishments, and furnished with the richest clothes and ornaments. They all sleep in separate beds, and between every fifth there is a preceptress. Their chief governess is called katon kiaja, or governess of the noble young ladies. These ladies are scarcely ever suffered to go abroad, except when the grand seignor removes from one place to another, when a troop of black eunuchs convey them to the boats, which are enclosed with lattices and linen curtains; and when they go by land, they are put into close chariots, and signals are made at certain distances, to give notice that none may approach the roads through which they march. Among the emperor's attendants are a number of mutes, who act and converse by signs with great quickness; and some dwarfs, who are exhibited for the diversion of his majesty. 
Opposite to the seraglio, on the Asiatic side, and about a mile and 2 half distant across the water, is Scutari, adorned with a royal mosque, and a pleasant house of the grand-seignor. On the brow of an adjacent hill is a grand prospect, embracing in one view the city of Constantinople, the suburbs Galata and Pera, the small seas of the Bosphorus alid Propontis, with the adjacent countries on each shore. Adrianople, the second city of European Turkey, is situate on the Mariza, or ancient Hebrus, about 140 miles north-west of Constantinople. It is of a circular form, and surrounded by a wall and towers: it contains several splended mosques. The seraglio, or palace, is pleasantly situated, being separated from the city by the small river Ar$\mathrm{da}$, and commanding an extensive view of the country, which is fertile, and celebrated for its excellent vines. The number of inhabitants in Adrianople is about 80,000 : The other principal cities are Silistria, in Bulgaria, with about 60,000 inhabitants ; Philippi, on the river Maritz, with 120,000 inhabitants ; Saloniki, in Macedonia, 62,000; Serajo, the capital of Bosnia, 48,000 ; Janna, in Thessaly, 30,000 ; Seres, in Macedonia, 30,000; Larissa, in Thessaly, 20,000, and Belgrade, the capital of Servia, which has been repeatedly taken and re-taken by the Austrians and Turks, and contains about 25,000 inhabitants.

Commerce and manufactures.... These objects are little attended to in the Turkish dominions. The nature of the government destroys that happy security which is the mother of arts, industry, and commerce, and such is the debasement of the human mind, when boine down by tyranny and oppression, that all the great advantages of commerce, which nature has, as it were, thrown under the feet of the inhabitants by their situation, are here totally neglected. The ad. vantages of Tyre, Sidon, and Alexandria, and all those countries which carried on the commerce of the ancient world, are overlooked. The Turks command the navigation of the Red Sea, which opens a communication with the Southern Ocean, and presents them with all the riches of the Indies. Whoever looks on a map of Turkey, must admire the situation of their capital, upon a narrow strait that separates Europe from Asia, and communicates on the south with the Mediterrancan Sea, thereby opening a passage to all the European nations, as well as the coast of Africa. The same strait, communicating northwards with the Black Sea, opens a passage, by means of the Danube, and other great rivers, into the interior parts of Germany, Poland, and Russia.

In this extensive empire, where all the commodities necessary for the largest plan of industry and commerce are produced, the Turks content themselves with manufacturing cottons, carpeis, leather, and soap. The most valuable of their commodities, such as silk, a variety of drugs, and dyeing stuffs, they generally export without giving them much additional value by their own labour. The internal commerce of the empire is extremely small, and managed only by Jews and Armenians. In their traffic with Europe, the Turks are altogether pas sive. The Euglish, French, Dutch, and other Europeans, resort hither with their commodities, and bring back those of Turkey in the same bottoms. They seldom attempt any distant voyages, and are possessed only of a few coasting vessels in the Asiatic Turkey, their chief royal navy lying on the side of Europe. The inattention of the Turks to objects of commerce, is perhaps the best security to their government. The balance of power established among the princes of Europe, and their jealousies of one another, secrie to the Turks the 
possession of countries, which, in the hands of Russians, or any active state, might endanger the commerce of their neighbours, especially their tracle with India.

Constitution, government, Laws....The Turkish government is commonly exhibitcd as a picture of all that is shocking anci unisatural in arbitrary power. But from the accounts of sir James Porter, who resided at the Porte, in quality of ambassador from his Britannic majesty, it appears that the riguurs of that despotic government are considerably moderated by the power of religion. For though in this cmpire there is no hereditary succession to property, the rights of individuals may be rendered fixed and secure, by being annexed to the church, which is done at an inconsiderable expence. Even Jews and Christians may in this manner secure the enjoyment of their lands to the latest posterity; and so sacred and inviolable has this law been held, that there is no instance of an attempt on the side of the prince to trespass or reverse it. Neither does the observance of this institution altogether depend on the superstition of the sultan : he knows that any attempt to violate it would shake the foundations of his throne, which is solely supported by the laws of religion. Were he to transgress these laws, he would become an infidel, and cease to be the lawful sovereign. The same observation extends to all the rules laid down in the Koran, which was designed by Mahommed both as a political code and as a religious system. The laws there enacted, having all the force of religious prejuciices to support them, are inviola. ble; and by them the civil rights of the Mahommedans are regulated. Even the comments on this book, which explain the law where it is obscure, or extend and complete what Mahommed had left imperfect, are conceived to be of equal validity with the first institutions of the prophet; and no member of the society, however powerful, can trans. sress them without censure, or violate them without punishment.

The Asiatic Turks, or rather subjects of the Turkish empire, who hold their possessions by a kind of military tenure, on condition of their serving in the field with a particular number of men, think themselves, while they perform that agreement, almost independent of the emperor, who seldom calls for the head or the estate of a subject who is not an immediate servant of the court. The most unhappy subjects of the Turkish government are those who approach the highest dignities of state, and whose fortunes are constantly exposed to sudden alterations, and depend on the breath of their master. There is a gradation of great officers in Turkey, of whom the vizier, or prime minister ; the kiaja, second in power to the vizier; the reis-effendi, or secretary of state; and the aga of the janisaries, are the most considerable. These, as well as the mufti, or high priest; the pashas, or governor's of provinces; the civil judges ; and many others, are commonly raised, by their application and assiduity, from the meanest stations in life, and are often the children of Tartar or Christian slaves taken in war. Tutored in the school of adversity and arriving at preeminence through a thousand difficulties and dangers, these men are generally as distinguished for abilities as deficient in virtue. They possess all the dissimulation, intrigue, and corruption, which often accompanies ambition in a humble rank; and they have a further reason for plundering the people, because they are uncertain how long they may possess the dignities to which they have attained, The adminiseration of justice, therefore, is extremely corrupt over the whole empire: but this proceeds from the manners of the judges, and not from 
the laws of the kingdom, which are founded upon very equitable principles.

Revenues....The riches drawn from the various provinces of this empire must be immense. The revenues arise from the customs, and a variety of taxes which fall chiefly on the Christians, and other subjects, not of the Mahommedan religion. The rich pay a capitation tax of thirty shillings a year; tradesmen, fifteen shillings; and common labourers, six shillings and ten pence haltpenny. Another branch of the revenue arises from the annual tribute paid by the Tartars, and other nations bordering upon Turkey, but governed by their own princes and laws. These form what are called the miri, and amount to about four millions and a half sterling. All these, however, are trifling, when compared with the vast sums extorted from the governors of provinces, and officers of state, under the name of fresents. These harpies, to indemnify themselves, as we have already observed, exercise every species of oppression that their avarice can suggest, till, becoming wealthy from the vitals of the countries and people they are sent to govern, their riches frequently give rise to a pretended suspicion of disloyalty or misconduct, and the whole fortune of the offender devolves to the crown. The devoted victim is seldom acquainted with the nature of the offence, or the names of his accusers; but, without giving him the least opportunity of making a defence, an officer is dispatched with the imperial decree to take off his head. The unhappy pasha receives it with the highest respect, putting it on his head, and after he has read it, says, "The quill of God and the emperor be done!" or some such expression, testifying his entire resignation to the will of his prince. Then he takes the silken cord, which the officer has ready in his bosom, and having tied it round his own neck, and said a short prayer, the officer's servants throw him on the floor, and, drawing the cord tight, soon dispatch him; after which his head is cut off, and carried to court.

The revenue of the whole Turkish empire is estimated at about $40,000,000$ of dollars, while the expences do not usually exceed twenty. This revenue has lately been considerably augmented by improvements in the administration of the different branches, and particularly the farms.

ARMY, NAVY....The Militia of the Turkish empire is of two sorts : the first have certain lands appointed for their maintenance, and the other is paid out of the treasury. Those that have certain lands amount to about 268,000 effective men. Besides these, there are also certain auxiliary forces raised by the tributary countries of this empire. The khan of the Crim Tartars, before his country was subjected to Russia, was obliged to furnish $100,000 \mathrm{men}$, and to serve in person, when the grand-seignor took the field In every war, besides the above forces, there are great numbers of volunteers, who live at their own charge, in expectation of succeeding the officers. These adventurers do not only promise themselves an estate if they survive, but are taught, that if they die in war against the Christians, they shall go immediately to Paradise. The forces which receive their pay from the treasury are called the spahis, or horse guards, and are in number about 12,000; and the janisaries, or foot guards, who are esteemed the best soldiers in the Turkish armies, and on whom they principally depend in an engagement. These amount to about $25,000 \mathrm{men}$, who are quartered in and near Constantinople. They frequently grow mutinous, and have proceeded so far sometimes as to depose the sultan. They are

VoL. I. $4 \mathrm{H}$ 
educated in the seraglio, and trained up to the exercise of arms from their infancy; and there are not less than 100,000 foot soldier's scattered over every province of the empire, who procure themselves to be registered in this body, to enjoy the privilege of janisaries, which are very great, being subject to no jurisdiction but that of their aga, or chief commander. Mr. Eton states the number of janisaries at 113,400 ; the whole of the Turkish infantry at 207,400 , and the cavalry at 181,000; making a total of 388,400 . But, deducting from these the leventis, who belong to the fleet, and can only be employed near the coast where the fleet is; the garrisons of Constantinople, and the fortresses and frontiers in Europe and Asia; the bostangees, who only march when the grand-seignor takes the field; the miklagis, and such as serve the vizier, the beglerbegs, and pashas, and never go into the battle; the remainder of effective men will amount only to 186,400 . Yet the Porte (adds he) has often found it difficult to assemble 100,000 men; and in 1774, with its utmost efforts, could only bring into the field 142,000 . The constant wars in which he has been lately engaged with Russia, has obliged the grand seignor to pay more attention to the raising and disciplining of his armies. In 1804 he had an army of 190,000 infantry, and 107,000 cavalry, from which, however, the foregoing deductions should be made.

The naval force of the Turks is very inconsiderable. In 1806 it consisted of 20 ships of the line, 15 frigates, and 32 smaller vessels. Their galleys now are of no use as ships of war; but there are about twenty large vessels called caravellas, which belong to merchants, and in time of war are frequently taken into the service of the Porte, and carry 40 guns.

Titues And ARMs.... The emperor's titles are swelled with all the pomp of eastcrn magnificence. He is styled by his subjects, the Shadazu of God, a God on earth, Brother to the Sun and Moon, Disfloser of all carthly Crozuns, Ecc. The grand-seignor's arms are, vert, a crescent, argent, crested with a turban, charged with three black plumes of heron's quills, with this motto, Donec totum imfleat orbem.

RELIGION.... The established religion is the Mahommedan, so called from Mahommed, the author of it, some account of whom the reader will find in the following history of Arabia, the native country of that impostor. The Turks profess to be of the sect of Omar; but these are split into as many sectaries as their neighbours the Christians. The mufti or sheik islam is the supreme chief of the religion of $\mathrm{Ma}$ hommed in Turkey, the oracle who is consulted, and who solves all the questions which are put to him: his decisions are called fetfas. The sultan has recourse to him in all difficult and intricate cases, and he promulgates no law, makes no declaration of war, establishes no impost, without having obtained a fetfa. It is the mufti who girds on the sultan's sword on his accession to the throne, at the same time reminding him of the obligation of defending the religion of the prophet, and of propagating its creed. The ulemas, or doctors of religion and the laws, constitute a powerful body, sometimes formidable to the throne itself. They possess the most lucrative employments, are secure from the extortions of pashas and great men, and cannot legally be put to death without the consent of their chief, the mufti. Their property, after their decease, passes as a right to their heirs, and cannot be appropriated by the imperial treasury, unless they have accepted some office under the government. The imauns, who serve the mosques, and the muezins, whose employment is to ascend the 
minarets five times a day to call the people to prayers, do not belong to this body; they may be dismissed from their office, or voluntarily resign it, and return into the class of simple private persons.

The toleration of the Turks has been much extolled, but they make this toleration a source of revenue. The Christians are tolerated where they are most profitable ; but the hardships imposed upon the Greek church are such as must always dispose that people to favour any revolution of government. Constantinople, Jerusalem, Alexandria, and Antioch, are patriarchates; and their heads are indulged, according as they pay for their privilege, with a civil as well as an ecclesiastical authority over their votaries. The same may be said. of the Nestorian and Armenian patriarchs; and every great city that can pay for the privilege, has its archbishop or bishop.' All male Christians pay a:so a capitation tax from seventeen years old to sixty, according to their stations.

The insulting distinction of Christian and Mahommedan (says $\mathbf{M r}$. Eton) is carried to so great a length, that even the minutiæ of dress are rendered subjects of restriction. A Christian must wear only clothes and head-dresses of dark colours, and such as Turks never wear, with slippers of black leather, and must paint his house black, or dark brown. 'The least violation of these frivolous and disgusting regulations is punished with death. Nor is it at all uncommon for a Christian to have his head struck off in the street, for indulging in a little more foppery of dress than the sultan or vizier, whom he may meet incognito, approves. If a Christian strikes a Mahommedan, he is most commonly put to death on the spot, or at least ruined by fines and severely bastinadoed; and if he strikes, though by accident, a sherif, or descendant of Mahommed, who wears the green turban, of whom there are thousands in some cities, it is death without remission.

Literature....The Turks till of late professed a sovereign contempt for our learning. Greece, which was the native country of genius, arts, and sciences, produces at present, besides Turks, numerous bands of Christian bishops, priests, and monks, who in general are as ignorant as the Turks themselves, and are divided into various absurd sects of what they call Christianity. The education of the Turks seldom extends further than reading the Turkish language and the Koran, and writing a common letter. Their jurisprudence and theology consist only of commentaries on the Koran; their astronomy is astrology, and their chemistry alchemy; of the history and geography of other countries they are perfectly ignorant. Some of them understand astronomy, so far as to calculate the time of an eclipse; but the number of these being very small, they are looked upon as extraordinary persons.

LANGUAgE... The Turkish language is derived from the Zagatai, a dialect of the Tartarian. It is the easiest of any we are acquainted with, because it is the most regular. It has only one conjugation of verbs, one declension of nouns, and no gender. There is no cxcep. tion nor any irregular verb or noun in the language. It is not very copious, yet it is manly, energetic, and sonorous. To supply the want of words, their writers freqtently mix with it the Arabic and Persian. The Lord's Prayer in Turkish is as follows :

Bahamuz hanghe guiglesson, chuduss olssum ssenungh adum; gelson ssenung memlechetnn; olssum ssenungh istegung ni esse gugthaule gyrde; echame gumozi loergunon vere bize begun, zem bassa bize bo 
slygomozi; nyeze hizde basiaruz borsetiglero mosi; hem yedma hize ge. heneme; de churtule bizyjaramuzdan. Amen.

The Greeks speak a modernised Greek, and in the Asiatic pro. vinces the Arabic and a dialect of the Syriac is spoken. A speci. men of the modern Greek follows in their Paternoster:

Pater hemas, onios iso ces tos ouranous : hagiasthito to onoma sou: na erti he basilia sou: to thelema sou na genetez itzon eu to ge, os is ton ouranon : to htsomi hemas doze hemas semoren : $k$ a sichorase hemos ta crimata hemon itzone, $k \mathfrak{a}$ hemas sichorasomen ekinous opou hemas adikoun: ke meu ternes hemas is to hirasmo, alla soson hemas apo to kaxo. Amen.

Antiquities....Almost every spot of ground, every river, and every fountain in Greece, presents the traveller with the ruins of a celebrat ed antiquity. On the isthmus of Corinth, the ruins of Neptune's temple, and the theatre where the Isthmian games were celebrated, are still visible. Athens, which contains at present above 10,000 inhabitants, is a fruiful source of the most magnificent and celebrated antiquities in the world; a minute account of which would exceed the limits of this work; but it will be proper to mention some of the most considerable. Among the antiquities of this once superb city, are the remains of the temple of Minerva, built of white marble, and eucompassed with for $y$-six fluted columns of the Doric order, fortytwo feet high, and seven feet and a half in circumference : the architrave is aclorned with basso relievos, admirably executed, representing the wars of the Athenians. To the south-east of the Acropolis, a citadel which defends the town, are seventeen beautiful columns of the Corinthian order, thought to be the remains of the emperor Ailrian's palace. They are of fine white marble, about fifty feet high, including the capitals and bases. Just without the city stands the temple of Theseus, surrounded with fluted columns of the Doric order; the portico at the west end is adorned with the battle of the Contaurs, in basso-rclievo; that at the east appears to be a continuation of the same history : and on the outside of the porticoes, in the spaces between the triglyphs, are represented the exploits of Theseus. On the south-west of Athens is a beautiful structure, commonly called the Lantern of Demosthenes : this is a small round edifice of white marble, the roof of which is supported by six fluted columns of the Corinthian order, nine feet and a half high; in the space between the columns are pannels of marble; and the whole is covered with a cupola, carved with the resemblance of scales: and on the frieze are beautifully represented, in relievo, the labours of Hercules. Here are also to be seen the temple of the Winds, the remains of the theatre of Bacchus, of the magnificent aqueduct of the emperor Adrian, and of the temples of Jupiter Olympius and Augustus. The remains of the temple of the oracle of Apollo are still visible at Castri, on the south side of Mount Parnassus; and the marble steps that descend to a pleasing running water, supposed to be the renowned Castalian spring, with the niches for statues in the rock, are still discernible.

The history of the Turks will be given at the end of our account of Turkey in Asia, from whicts country they derive their origin and extended their conquests into Europe. 


\section{ISLANDS BELONGING TO TURKEY IN EUROPE,}

\section{BEING PART OF ANCIENT GREECE.}

The principal of these islands, so celebrated in the Grecian history, is Cindia, the ancient Crete, famous in remote antiquity, for being the birth-place of Jupiter, the kingdom of Minos the legislator, and for its hundred cities. This island is situate between 35 and 36 degrees of north latitude, being 180 miles long, and 40 broad, almost equally distant from Europe, Asia, and Africa, and contains 5220 square miles. The famous Mount Ida stands in the middle of the island, and is no better than a barren rock; and Lethe, the river of oblivion, is a torpid stream. Some of the vallies of this island produce witie, trusts, and corn; all of them remarkably excellent in their kind. The siege of Candia, the capital of the island, in modern times, was of nuch longer ciuration and more bloody than that of Troy. The Turks invested it in the beginning of the year 164.5; and its Venetian garrison, after bravely defending itself against fifty-six assaults, tili the latter end of September, 1669, made at last, an honourable capitulation The siege cost the Turks $180,000 \mathrm{men}$, and the Venctias,s 80, 00 .

Negropont, the ancient Euboea, stretches from the south-east to the north-west, and on the eastern coast of Achaia or Livadia. It is ninety miles long and twenty-five broad, and contains about 13,000 square miles. Here the Turkish gallies lie. The tides on its coasts are irregular; and the island itself is very fertile, producing corn, wine, fruit, and cattle, in such abundance, that all kinds of provisions are extremely cheap. The chief towns in the island are, Negropont, calied by the Greeks Egripo, situated on the south-west coast of the island, on the narrowest part of the strdit; and Castel Rosso, the ancient Carystus.

Lemas, or Stalimene, lies on the north part of the Egean Sea or Archipelago, and is almost a square of twenty-five miles in length and breadth. Though it produces corn and wine, yet its principal riches arise from its mineral earth, much used in medicine, sometimes called terra Lemnia, or terra sigillata, because it is sealed up by the Turks, who derive from it a considerable revenue.

Scyros is about sixty miles in circumference, and is remarkable chiefly for the remains of antiquity which it contains; about three. hundred Greek families inhabit it.

The CyCLADEs islands lie like a circle round Delos, now called Dilli, the chief of them, which is south of the islands Mycone and Tirse, and almost mid-way between the continents of Asia and Europe. Though Delos is not above six miles in circumference, it is one of the most celebrated of all the Grecian islands, as being the birth-place of A pollo and Diana, the magnificent ruins of whose tem. ples are still visible. This island is almost destitute of inhabitants. 
Paros lies between the islands of Luxia and Melos. Like all the other Greek islands, it contains the most striking and magnificent. ruins of antiquity; but it is chiefly renowned for the beauty and whiteness of its marble.

SANTORIN is one of the southernmost islands in the Archipelago, and was tormerly called Calista, and afterwards Thera. Though seemingly covered with pumice-stones, yet, through the industry of the inhabitants, who are about 10,000, it produces barley and wine, with some wheat. One-third of the people are of the Latin church, and subject to a popish bishop. Near this island another arose of the sane name, from the bottom of the sea, in 1707. At the time of its birth there was an earthquake, attended with most dreadful lightsings and thunders, and bollings of the sea for several days, so that, when it arose out of the sea, it was a mere volcano; but the burning soon ceased. It is about 200 feet above the sea; and at the time of its first emerging, it was about a mile broad, and five miles in circumference, but it has since increased. Several other islands of the Archipelago appear to have had the like original; but the sea in their neighbourhood is so deep as not to be fathomed.

The islands is the Ionian Sea, on the other side of Greece, belonged to Venice till the late revolution, and the cession by the French of the greater part of the Venetian dominions to Austria. They were tirst occupied by the French, but were taken from them by the Russians and Turks, who, in 1800 , formed them into an aristocratical republic, by the name of the REPUBLIC of the SEVEN ÍsLANDS, which was recognised by the treaty of Amiens. This republic is under the protection of Russia and Turkey, to the latter of which it pays a certain tribute every three years. But Russia appears to take the greatest interest in these islands; and seems to treat them as a distant posscssion appertaining to its empire. There are now nearly 10,006 Russian troops in Corfu and some others of these islands; which are nomually governed by a legrislative body and a president, but in reality by the Russian general and troops. The seven islands which compose this republic, are Corfu, Paxo, Santa Maura, Cefalonia, Theaki, Zante, and Cerigo.

Corfu, the ancient Corcyra, and the Phaecia of Homer, who places here his gardens of Alcinous, is about 45 miles long and 20 broad. It is situate opposite Albania, near the continent, between 39 and 40 degrees of north latitude, and 19 and 20 of east longitude. The air is healthy, the soil fertile, particularly in the northern part; and the fruits of every kind excellent, especially a delicious species of figs, there called Fracazzoni. Its other principal produce is salt, oil, and honey.. The number of inhabitants is about 70,000 . The town of Corfu, the capitai, has an excellent harbour, is a place of considerable strength, and the seat of government for this republic.

PAxo, or PAxu, situate at a little distance to the south of Corfu, is about 15 miles in circumference : it produces wine, oil, and almonds; but has but few inhabitants. The town is called San Nicolo, and has a good harbour. Opposite to it is a small island called Antipaxo.

Santa MaURA, the ancient LeUcadia, is about fifty miles in circumference : it was anciently joined to the continent, but the isthmus was cut through by the Carthaginians, or, as others say, the Corinthians : the channel between the island and the continent is at present, it is said, not more than 50 paces broad. It produces corn, wine, oil, eitrons, pomegranates, almonds, and other fruits, and has fine pastures. 
The principal article of its trade is salt. The town of St. Maura contains about 6000 inhabitants, and is well fortified. Port Drepano in this island is an excellent harbour.

Cefalonia, the ancient Cephallenia, is situate opposite the Gulf of Lepanto, anciently the Sea of Crissa, and is about 40 miles in length, and from 10 to 20 in breadth. The climate is extremely mild; flowers bloom in the season which corresponds to winter, and the trees bear ripe fruits twice in the year, in April and November, but those of the latter month are smaller than the others. The number of inhabitants in this island is between 60 and 70,000. The chief articles of commerce are oil, muscadine wine, and the species of grapes called currants.* The principal town is of the same name.

'Theaki, or Little Cefalonia, a small island opposite Cefalonia, claims particular notice, because it was the ancient ItHACA, the birth-place and kingdom of Ulyssis. It contains only about 3000 inhabitants. The name of the principal town is Valthi, which has a spacious harbour.

$Z_{\text {ANTE, }}$, the ancient $Z_{\text {ACYNThus, }}$ is situate opposite the western coast of the Morea, and is about 14 miles long and 8 broad. The climate and produce is similar to those of the other islands. Its principal riches consists in currants, which are cultivated in a large plain under the shelter of mountains, which gives the sun greater power to bring them to maturity. Here are also the finest peaches in the world, each weighing eight or ten ounces. The number of inhabitants in this island is about 30,000 . The principal town is Zante, which is fortified and has a good harbour.

Cerigo, the ancient Cythera, according to the mythologists the favourite residence of Venus, is situate to the south-east of the Morea, and is about 50 miles in circumference. The greater part of it is mountainous and rocky, but the rest produces corn, and excellent grapes. The town of San Nicolo in this island has a fort and a good road for ships.

* So called from a corruption of Corinth, whence the vines were originall brought.

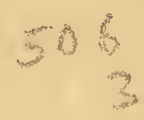

THE END OF VOLUMT I. 




Solat

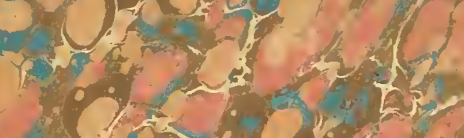
crovent ien.

$57,2+2=$

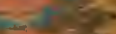

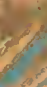

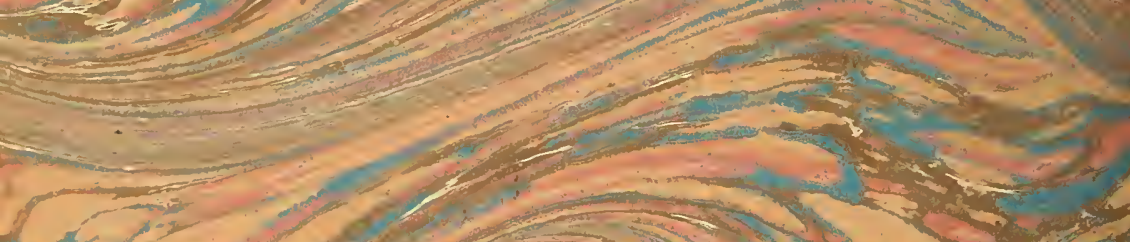

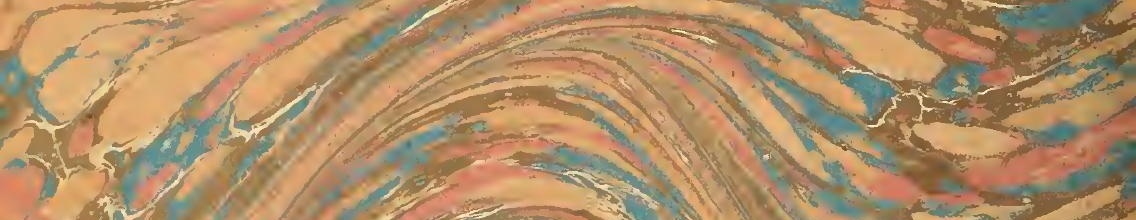
$2 \frac{12}{6}$

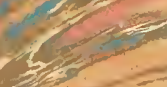

$-3$

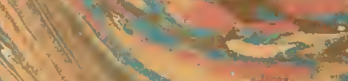

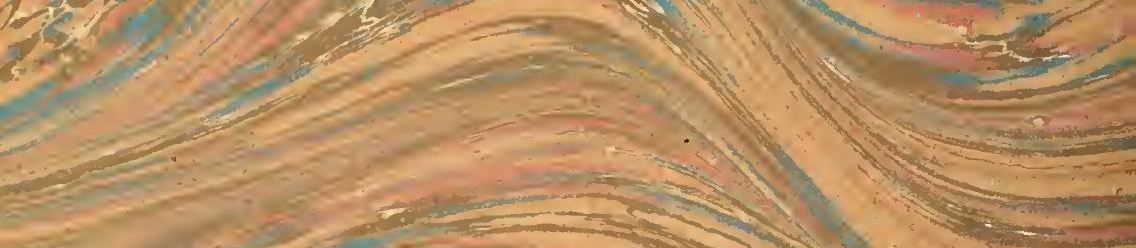

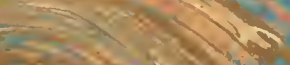

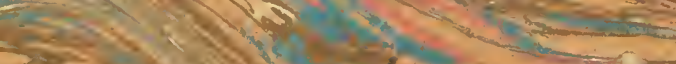

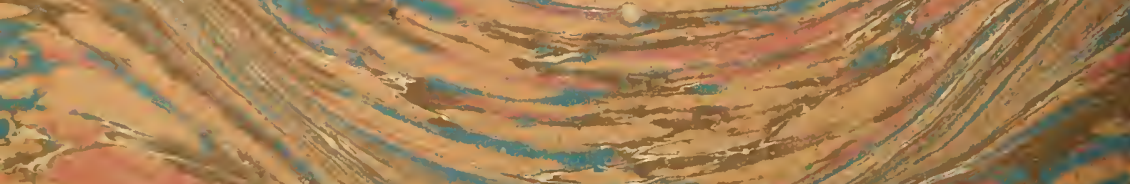

$\operatorname{lat}^{2}$

Nitis

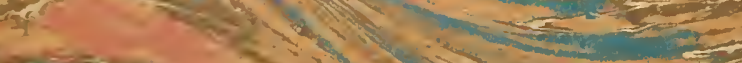
and

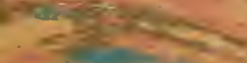




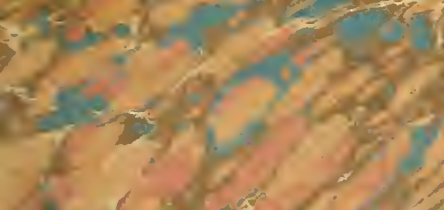

Q

,

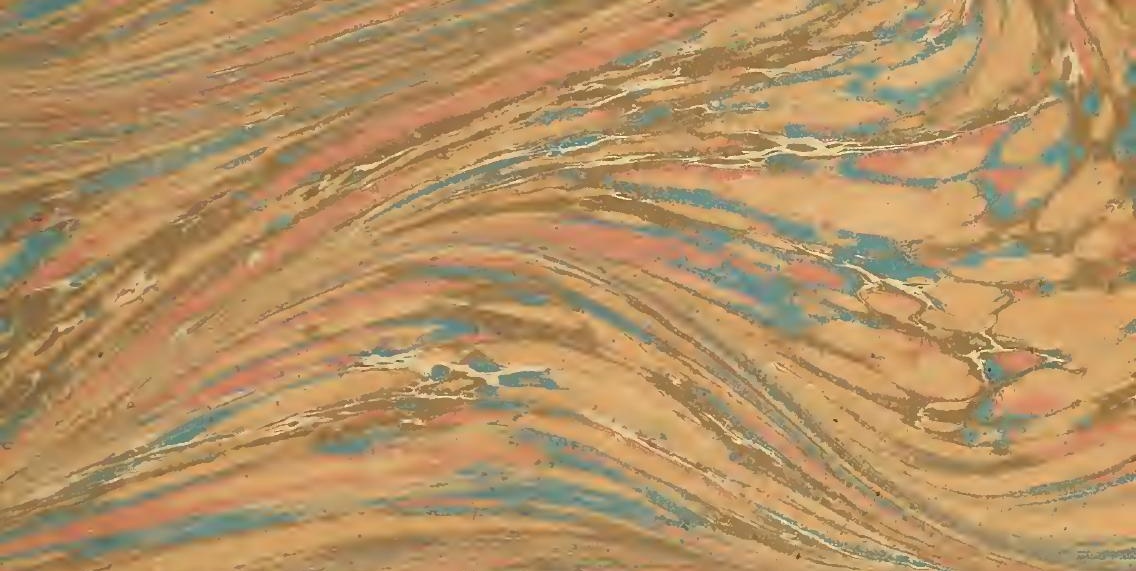

>

$2+\frac{1}{20}$

=

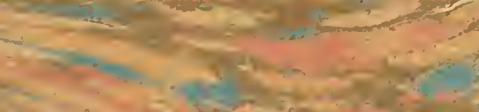

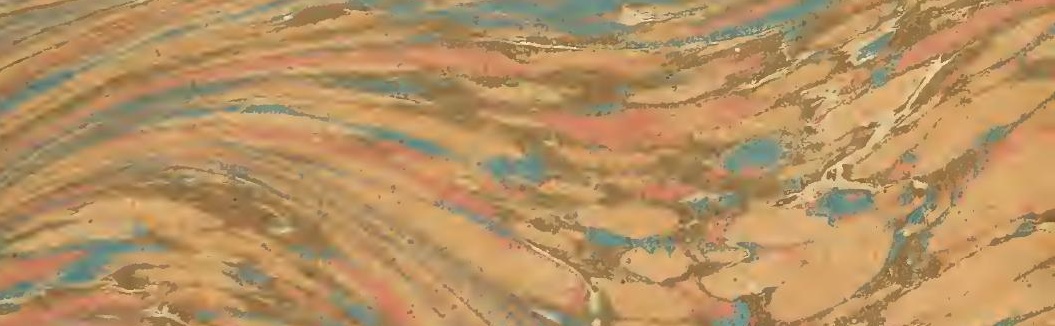

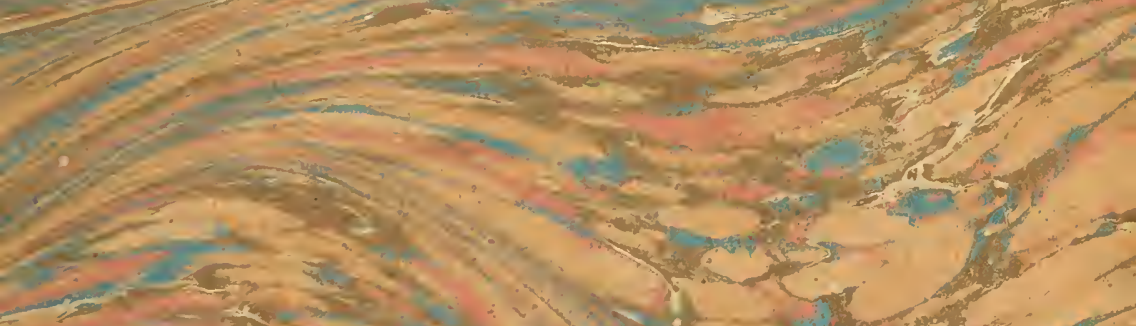

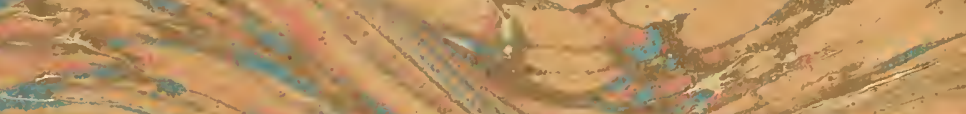

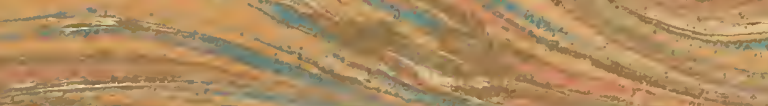

(1)

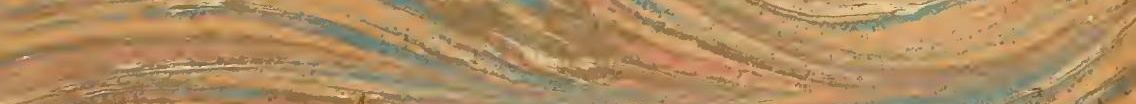

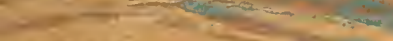

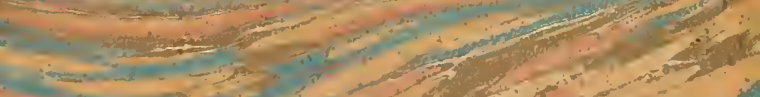

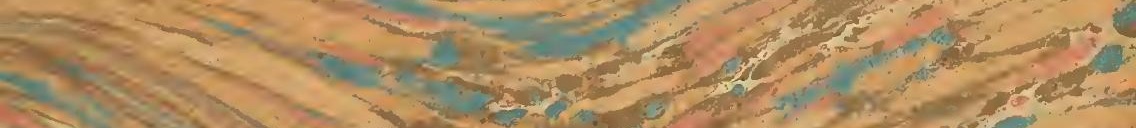

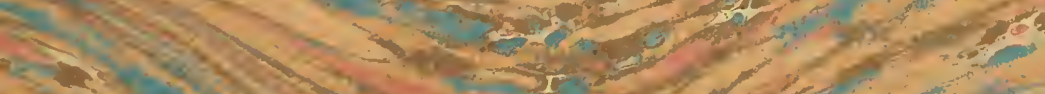

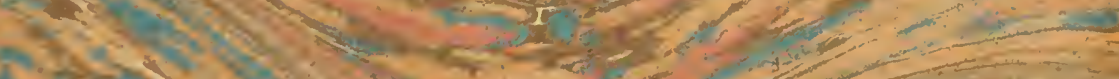

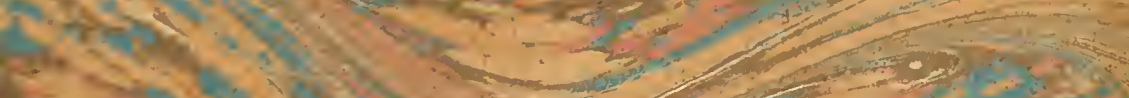

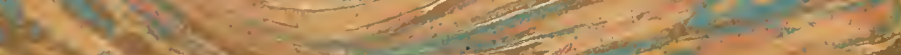

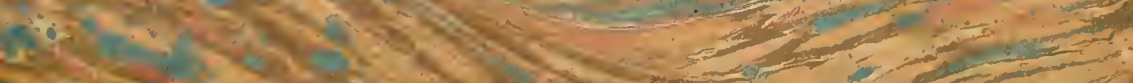




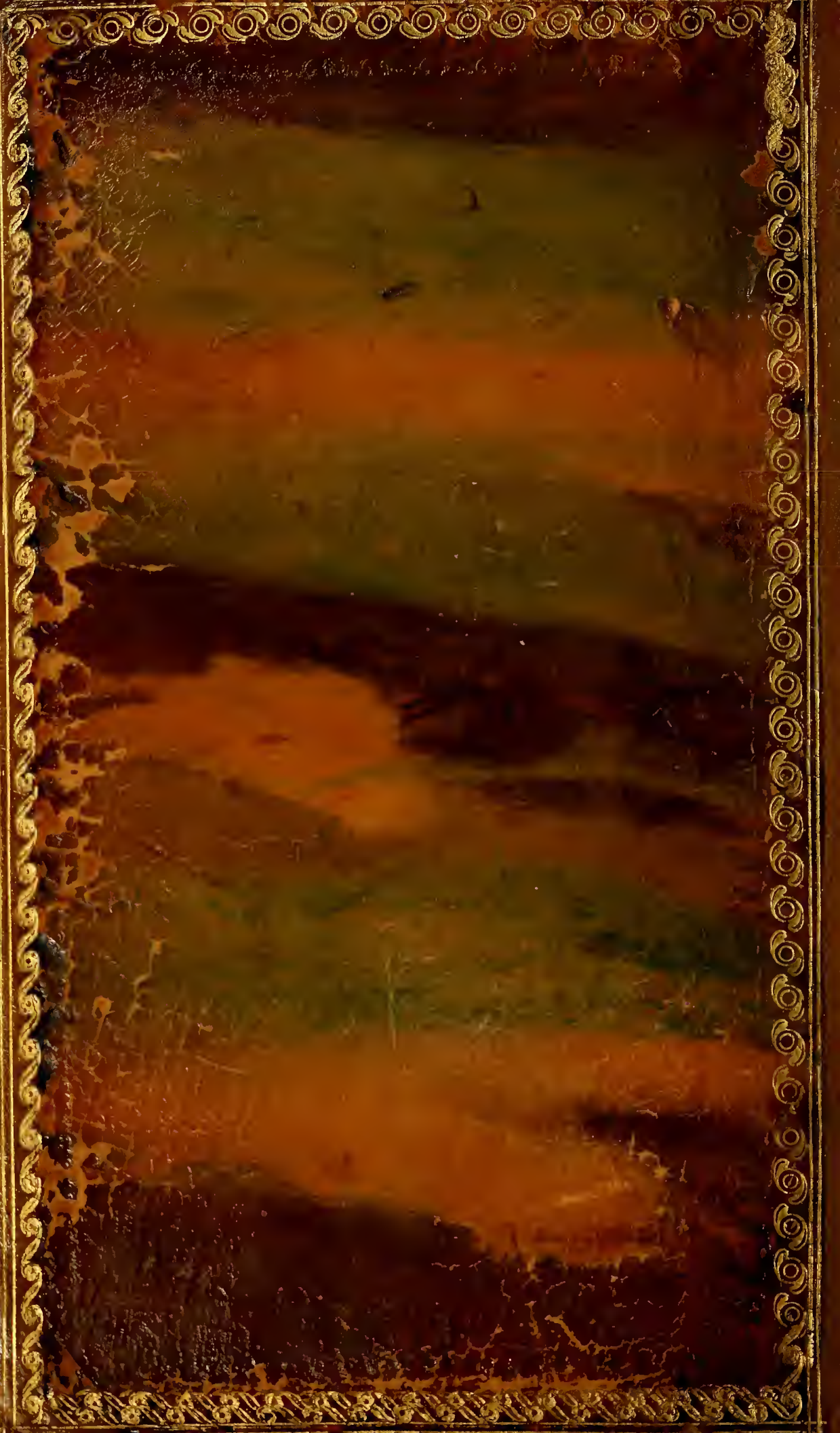

